Andrews University

Digital Commons @ Andrews University

\title{
The Theological Significance of the Relations of Freedom and Time in the Sciences and Humanities: An Evaluation of the Contributions of David Bohm and Pauli Pylkko
}

Michael F. Younker

Andrews University, myounker@andrews.edu

Follow this and additional works at: https://digitalcommons.andrews.edu/dissertations

Part of the Religious Thought, Theology and Philosophy of Religion Commons

\section{Recommended Citation}

Younker, Michael F., "The Theological Significance of the Relations of Freedom and Time in the Sciences and Humanities: An Evaluation of the Contributions of David Bohm and Pauli Pylkko" (2019).

Dissertations. 1694.

https://digitalcommons.andrews.edu/dissertations/1694

https://dx.doi.org/10.32597/dissertations/1694

This Dissertation is brought to you for free and open access by the Graduate Research at Digital Commons @ Andrews University. It has been accepted for inclusion in Dissertations by an authorized administrator of Digital Commons@ Andrews University. For more information, please contact repository@andrews.edu. 


\begin{abstract}
THE THEOLOGICAL SIGNIFICANCE OF THE RELATIONS OF FREEDOM AND TIME IN THE SCIENCES AND HUMANITIES: AN EVALUATION OF THE CONTRIBUTIONS OF DAVID BOHM AND PAULI PYLKKÖ
\end{abstract}

by

Michael F. Younker

Adviser: Martin Hanna 


\title{
ABSTRACT OF GRADUATE STUDENT RESEARCH
}

\author{
Dissertation
}

Andrews University

Seventh-day Adventist Theological Seminary

\section{Title: THE THEOLOGICAL SIGNIFICANCE OF THE RELATIONS OF FREEDOM AND TIME IN THE SCIENCES AND HUMANITIES: AN EVALUATION OF THE CONTRIBUTIONS OF DAVID BOHM AND PAULI PYLKKÖ}

Name of researcher: Michael F. Younker

Name and degree of faculty adviser: Martin Hanna, Ph.D.

Date Completed: May 2019

The concepts of freedom and time underlay all other philosophical and theological questions. This dissertation addresses the natures and relations of freedom and time and their impact upon theological reflection, primarily through the works of the philosopher of science, David Bohm and the philosopher of the humanities, Pauli Pylkkö. These two representatives come from the two competing cultures of the sciences and humanities, which illustrate the deep philosophical conflict that has emerged between these cultures concerning the natures of freedom and time. Specifically, the paradigmatic contributions of Albert Einstein's four-dimensional 'timeless space-time' (with timeless freedom) alongside Bohm, on the one hand, and Martin Heidegger's four-dimensional 'temporal time-space' (with temporal freedom) alongside Pylkkö, on the other hand, clearly illustrate the contrasting ideas which contemporary reflection has generated concerning the natures and relations of freedom and time, as well as their functions within theology.

Within the study, chapter 1 introduces the background, problem, and methodology employed in the investigation, as well as describing the role that the most perplexing area of natural science, quantum physics, has played in recent reflection on the natures of freedom and time. Chapter 2 
surveys the contemporary extent and context of the conflicting understandings of freedom and time, tracing both their interrelationship as well as influence upon broader discussions between science and religion, as well as various "third culture" disciplines, such as psychology and psychiatry, economics, and the socio-political sciences, and the role religion and theological reflection have within these third cultures. It was demonstrated that the basic philosophical impulses driving Einstein and Bohm, on the one hand, and Heidegger and Pylkkö, on the other hand, are in fact traceably related to many of the widespread polarizations occurring throughout the socio-political disciplines. Chapters 3 and 4, in turn, examine the concepts of freedom and time within the work of Bohm, who is building off of Einstein's theories, and Pylkkö, who is building off of Heidegger's ideas. Chapter 5 compares and evaluates Bohm and Pylkkö's concepts of freedom and time, both for the sciences and humanities, and demonstrates how their contributions fit within the contemporary dialogue concerning science and religion, as well as projects how they may contribute to future developments within the sciences, humanities, and a variety of issues within theology. This was done with specific regard to the differing and incompatible trajectories encouraged by the two cultures of the sciences and humanities.

The findings of this study indicate that although the conflict over the concepts of freedom and time is now generally well recognized by close observers of the developments in philosophy and society, and its effects are virtually omnipresent, it is still widely neglected by many specialist practitioners within the two cultures, which, as 'cultures,' do indeed often operate within isolated 'bubbles.' This has only led philosophy and society unwittingly down a path into a widespread implicit contradiction, the consequences of which are just now beginning to reach an explicit or critical stage throughout societies at large. Thus, the need was discovered for a reconceptualization of the concepts of freedom and time to 'reconcile,' or redefine, the differing cultures and their conflict.

One of the more promising avenues for finding conceptual replacements for freedom and time, and the reconceptualization of the two cultures themselves, is found in the perplexing and mysterious realm of quantum physics. Unfortunately, the quantum phenomena can be interpreted in at least four contradictory ways. First, as simply a continuation of the classical world, pending just a bit more information (that may or may not be forthcoming-in harmony with the early Bohm). 
Second, as providing a possible support for the traditional dualism concerning the mental and physical world (the standard Copenhagen view). Third, as opening up the possibility of a new way of seeing physical reality, one oriented towards an infinite depth of interwoven yet differentiated layers which retain, in many core respects, the classical image of science-David Bohm's later view, building off Einstein. And fourth, as indicative of the need to break down the reign of classical science altogether, not merely for the study of nature, but dissolving its very methodology as applied even in the social sciences-Pauli Pylkkö's view, building off Heidegger.

For the purposes of true conceptual replacement, and through a review of the potential of the first two options to actually aid in resolving the conflict, it was determined that Bohm's and Pylkkö's proposals do offer the most potential for progress beyond the impasse between the two cultures. First, Bohm's views of freedom and time are indeed distinct from previous concepts that have dominated throughout history. He believes that there are many different layers with differing orders within reality that are all interconnected, in contrast to the atomistic view which dominates classical science. What distinguishes his view from others is that the different layers may necessarily involve the appearance of disorder from the perspective of a higher or lower order. Because of the infinite complexity of reality, it is impossible to actually perceive any absolute determinism in nature which grants one meaningful freedom. Correspondingly, the meaning of time is transformed into one of relative degrees of temporal and timeless vertical orders in various relationships to each other throughout an overall 'timeless' holomovement. Critically, the social spheres are also included within the various posited layers.

Second, Pylkkö's views of freedom and time are also distinct from most concepts that have dominated history. Pylkkö also believes that all of reality is fundamentally interconnected. However, he also believes that the relationship between order and disorder is itself one of the key fundamental features exhibited in nature, and that randomness plays a critical role. He also dismisses the idea of any residual 'timeless' platonic realm. Freedom and time are fundamentally constituted by their relationship to the interconnected or nonlocal yet locally manifested random events of nature, creating an aconceptual experiential flow. Because this basic feature is common to all reality, including the social spheres, the concepts of freedom and time Pylkkö articulates are operative at 
every level, guiding the meaning of social and cultural movements, as well as those in physics. As such, rather than freedom being an exceptional case within a deterministic world, determinism is rather the 'illusion' within a more fundamentally free world, noting that freedom here is tied to random temporally and nonlocally extended events. Laws, including natural ones, can only exist within an underlying framework that possesses freedom of some sort-and this freedom should be considered foundational, rather than the laws, though this is not to dismiss the existence of laws nor their necessity, either in nature or at the social level.

Bohm's and Pylkkö's theories, while in some ways similar and parallel efforts to resolve a common problem, are nevertheless very different and incompatible in other ways. The most important feature of their incompatibility is found in the opposite terminology they use, which in some ways perpetuates one of the most fundamental conflicts between the two cultures. Bohm retains and endorses the language of timelessness, whereas Pylkkö retains and endorses the language of temporality. As such, in some ways, while indeed moving beyond the precise characteristics of the broader conflict between the two cultures, they too perpetuate it. If nothing else, this illustrates clearly that, indeed, freedom and time are the fundamental concepts both creating and dividing the two cultures. Furthermore, because of the close relationship freedom and time have in relation to the idea of God, divergent theologies are inevitable so long as this crisis persists.

Within the dialogue between science and religion and within the sphere of theology, Bohm's and Pylkkö's ideas contribute to problems created by the two cultures. Within the sciences, it appears unlikely that either the dogmatic classical view or the neoplatonic Copenhagen view will welcome the insights of Bohm and Pylkkö. In part, this is because of the powerful dominance of the scientific culture, which controls so many sectors of society and the academy. Bohm and Pylkkö will likely remain outsiders to this dominance for some time, if not permanently. Theologies that embrace the sciences 'as they are' will only be open to limited aspects of the work of Bohm, and less so, Pylkkö. Ironically, tenets of each of their ideas are also present in the most advanced interpretations of physics. Specifically, overall determinism within the realm of 'science,' which is in harmony with the earlier Bohm, and the acceptance of genuine randomness 'in some manner' within nature, which is in harmony with Pylkkö. Both of these are accepted by many mainstream theologians supportive of the 
scientific community. However, the synthetic work that Bohm and Pylkkö have each attempted challenges the status quo in ways which the scientific community overall, as a culture, will likely find unpalatable. The same would be true for the many theologians who show great deference to science today.

Conversely, within the realm of the humanities, the work of both Bohm and Pylkkö is likely to find much greater resonance, or, at the same time, elicit even sharper disagreement. The concepts of freedom and time play a central role in several major issues intersecting the humanities with theology, including religious pluralism, politics and social justice, soteriology alongside the Sanctuary and atonement, the reality of biblical prophecy, the Sabbath and rest, and the biblical concept of the Remnant and the philosophical significance of a minority holding the truth. In all of these areas, Bohm's and Pylkkö's conceptions of freedom and time could profoundly transform these socio-religious, theological, and biblical issues by modifying our views of how freedom and time intersect with hermeneutics and thus theology itself. However, in most cases, the trajectories their ideas would encourage concerning these areas would be in opposite directions. Thus, the theoretical continuation of the two cultures' impasse may endure. Nevertheless, theologians are far more likely to find Bohm's and Pylkkö's ideas attractive, and the integration of their thinking, especially Bohm's, has already begun to take place.

Overall, the study offers the following specific conclusions. First, the contrasting descriptions of freedom and time given by Einstein and Heidegger do fundamentally conflict, and their differences have had a profound impact on philosophy, science, and theological reflection. Second, essentially all further sub-disciplines, particularly the third culture disciplines that most directly impact human societies and the earth, are also profoundly affected by the contradictory tension. Third, the more classic 'science and religion' debate, as well as a host of other related issues, such as the nature of hermeneutics, are also profoundly affected by this conflict. Fourth, potential avenues toward ameliorating the conflict are present in the contributions of Bohm and Pylkkö. However, fifth, the conceptions of freedom and time presented in Bohm and Pylkkö also conflict, leaving philosophy and theology with a primordial choice between timeless time and determinism or, perhaps, its accompanying timeless freedom or temporal time and temporal nondeterminate freedom. It is not 
one that need be left merely theoretical, however, as the impact and consequences of their ideas can be traceably worked out in both a variety of disciplines as well as within theology. This allows one to a posteriori explore the issue, rather than leaving it merely an abstract hypothetical question. This does not mean a resolution is simple to achieve, but that there is more research that can be undertaken to obtain more knowledge about the concepts.

Lastly, sixth, this study brings to clearer light several issues pertaining to freedom and time that some theologians and theistic scientists are simply unaware of or passively ignoring. Many do operate, consciously or unconsciously, within a 'bubble.' This state of things cannot continue, or their respective contributions will slide into irrelevancy on one side or contribute unknowingly or unnecessarily toward a deepening of the polarization. The reality is, many biblical interpreters simply ignore the debates between science and religion, but if the philosophical issues undergirding both disciplines and discussions are in fact rooted in common concepts, then greater interdisciplinary efforts should be pursued to fully appreciate and critique the impact philosophy has upon both theology and science. Biblical exegesis is directly impacted by the clash of the two philosophical cultures, yet many theologians remain unaware of the depth and significance of this reality. Our ability, as theologians, to navigate the issues and questions facing the 21st century requires we engage this conflict intelligently, and in this we can learn from both Bohm and Pylkkö. This may alter how we relate to many past paradigms, especially in science, the arena which Bohm and Pylkkö have exposed as far more vibrant and open for philosophical reflection than has generally been previously realized. Obviously, given the attention to the subject matter in the present study, it would seem that there is value to critically engaging the more dominant culture, particularly in the academy, which is that of the sciences. The dominance of 'science' as such must always be critically addressed, especially by those from within the discipline of theology. Yet, at the same time, the 'science' of today is immensely complex, and the work of physicists and philosophers like Bohm and Pylkkö make this abundantly clear. 
Andrews University

Seventh-day Adventist Theological Seminary

THE THEOLOGICAL SIGNIFICANCE OF THE RELATIONS OF FREEDOM AND TIME IN THE SCIENCES AND HUMANITIES: AN EVALUATION OF THE CONTRIBUTIONS OF DAVID BOHM AND PAULI PYLKKÖ

\author{
A Dissertation \\ Presented in Partial Fulfillment \\ of the Requirements for the Degree \\ Doctor of Philosophy
}

by

Michael F. Younker

May, 2019 
(C) Copyright by Michael F. Younker 2019

All Rights Reserved 


\section{THE THEOLOGICAL SIGNIFICANCE OF THE RELATIONS OF FREEDOM AND TIME IN THE SCIENCES AND HUMANITIES: AN EVALUATION OF THE CONTRIBUTIONS OF DAVID BOHM AND PAULI PYLKKÖ}

A dissertation presented in partial fulfillment of the requirements for the degree Doctor of Philosophy

by

Michael F. Younker

APPROVAL BY THE COMMITTEE:

Faculty Adviser, Martin Hanna

Associate Professor of Systematic Theology

John C. Peckham

Professor of Systematic Theology

Jay Brand

Professor of Leadership and

Higher Education

Gary Burdick

Professor of Physics

Nicholas P. Miller

Professor of Church History
Director of Ph.D./Th.D. Program John W. Reeve Assistant Professor of Church History

Dean, SDA Theological Seminary Jiř́ Moskala

Professor of Old Testament Exegesis 
TABLE OF CONTENTS

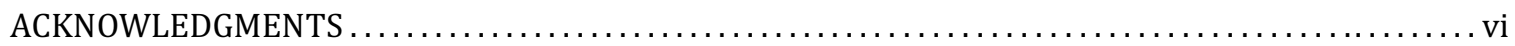

Chapter

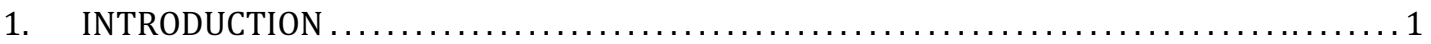

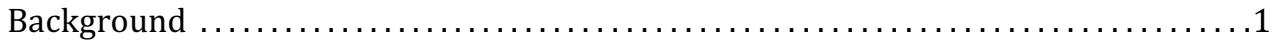

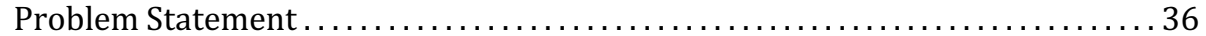

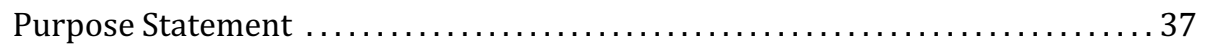

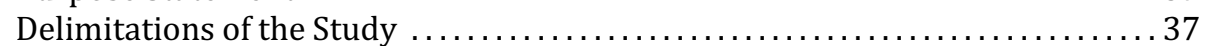

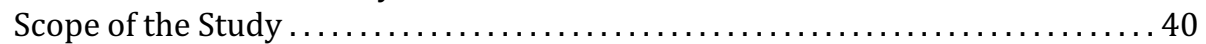

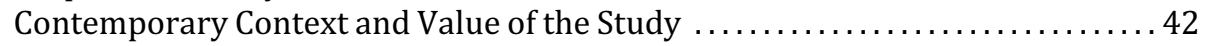

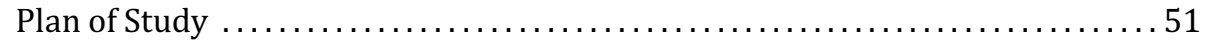

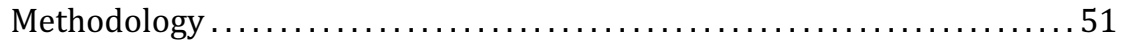

Prolegomenon to Freedom and Time: Understanding the Two Cultures of the

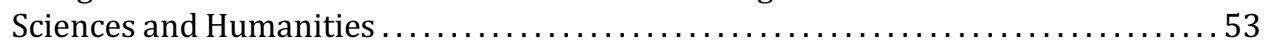

Where Do Theology and Religious Studies Belong? ..................... 58

The Challenge of "Cultures" and "Concepts" .......................... 64

The Revolutionary Implications of Quantum Physics and Its Impact Upon

Freedom and Time, the Two Cultures, and the Necessity of a Third Culture ....69

2. THE CONTEXT OF FREEDOM AND TIME WITHIN THE “TWO CULTURES” MILIEU:

THE THIRD CULTURE AND THE PLACE OF RELIGION $\ldots \ldots \ldots \ldots \ldots \ldots \ldots \ldots \ldots \ldots$

The Conflict Between the Two Cultures Concerning Freedom and Time ............ 95

The Two Cultures and Religion: Where is the Real Debate? ................... 108

The Science and Religion Dialogue: A Dead End? ......................... 115

The Emergence of the Real Conflict and the Ongoing Crisis in the

Third Culture: An Opportunity for Religion to Find a Place? ...............118

The Divide Within the "Mediatory" Third Culture Disciplines Concerning

Freedom and Time and the Place of Religion ............................ 147

Freedom and Time within the Third Culture Disciplines of

Psychology and Psychiatry ........................................ 148

The Place of Religion within Psychology and Psychiatry .............. 158

Freedom and Time within the Third Culture Discipline of Economics ............164

The Place of Religion within Economics ....................... 172

Freedom and Time within the Third Culture Disciplines of the

Socio-Political Sciences ......................................... 178

The Place of Religion within the Socio-Political Sciences ............... 195

Summary on the Third Culture Crisis and the Failure to Find a Place for Religion ..... 198

3. DAVID BOHM'S VIEW ON THE RELATIONS OF FREEDOM AND TIME

202 


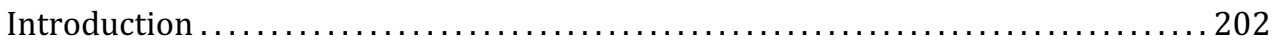

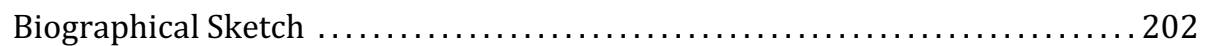

Bohm's Contribution Within the Context of the Two Cultures ................ 211

Einstein's Contribution: Space-Time ............................... 214

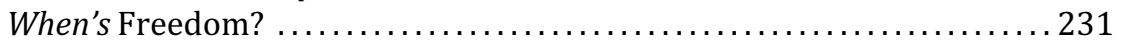

Einstein's Influence Upon Theology ........................... 237

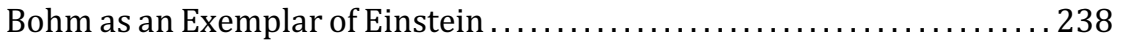

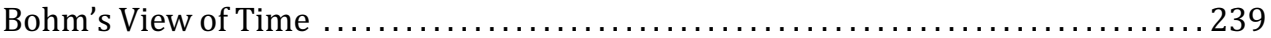

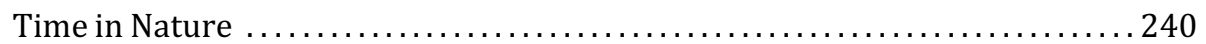

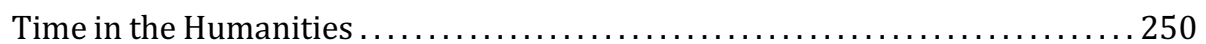

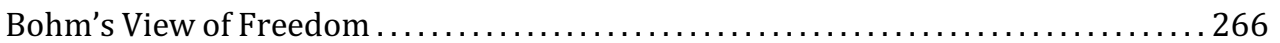

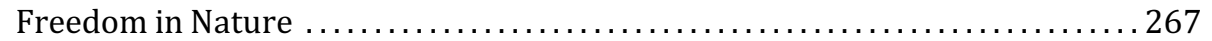

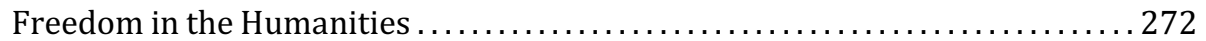

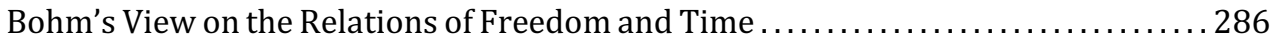

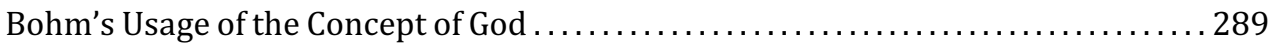

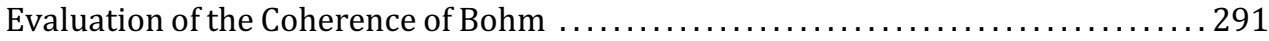

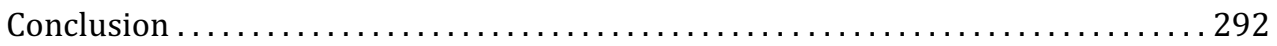

4. PAULI PYLKKÖ'S VIEW ON THE RELATIONS OF FREEDOM AND TIME $\ldots \ldots \ldots \ldots \ldots \ldots . \ldots 294$

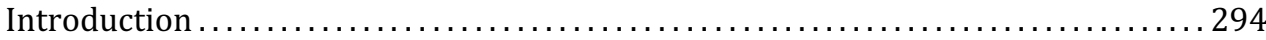

Biographical Sketch ............................................ 294

Pylkkö's Contribution Within the Context of the Two Cultures .............. 296

Heidegger's Contribution: Time-Space ............................. 302

Where's Freedom? ........................................ 334

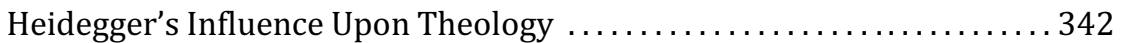

Pylkkö as an Exemplar of Heidegger ........................... 350

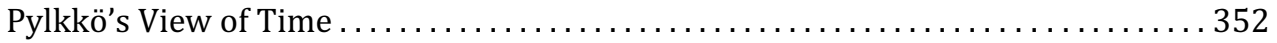

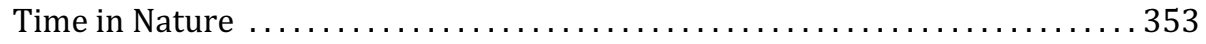

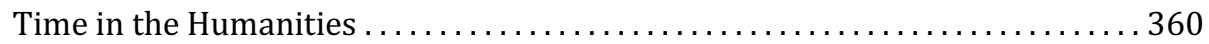

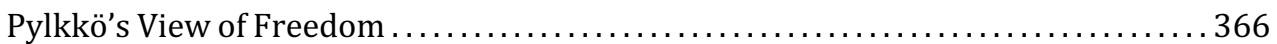

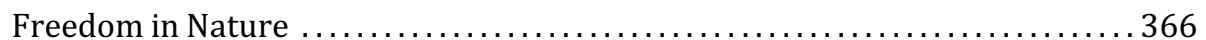

Freedom in the Humanities ....................................... 367

Pylkkö's View on the Relations of Freedom and Time ......................... 374

Pylkkö's Usage of the Concept of God ..................................... 376

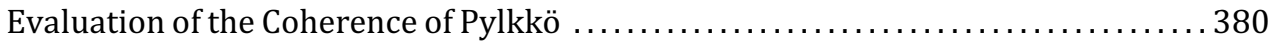

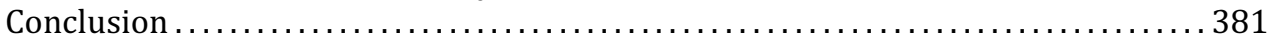

5. COMPARATIVE ANALYSIS OF BOHM'S AND PYLKKÖ'S VIEWS ON THE RELATIONS OF FREEDOM AND TIME WITH A VIEW TOWARD THEIR THEOLOGICAL SIGNIFICANCE .....383

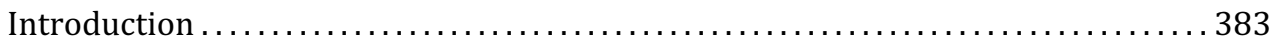

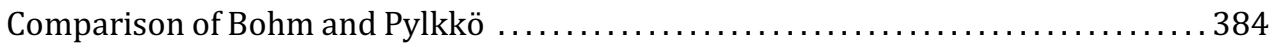

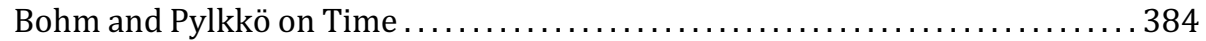

Bohm and Pylkkö on Freedom .................................... 387

Bohm and Pylkkö on the Relations of Freedom and Time .................... 389

Bohm and Pylkkö on God ....................................... 391

Summary of the Comparative Analysis of Bohm's and Pylkkö's Views ........... 394

The Projected Reception of Bohm's and Pylkkö's Insights Within the Crisis of the

Two Cultures and Theological Reflection ................................ 395

God, Freedom, and Time in the Natural Sciences ....................... 397

The Dogma of Classical Science ................................ 397

The Dogma of the Neoplatonic Copenhagen Science .................. 401 


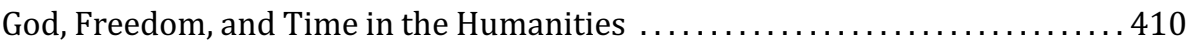

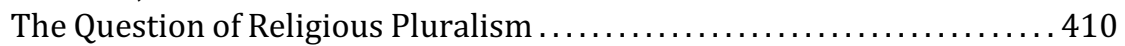

Political and Social Justice .................................. 413

The Atonement, the Biblical Sanctuary, Sacramentalism, and Salvation ....415

The Reality of Biblical Prophecy .............................. 424

The Biblical Sabbath, Rest, and Morality as a Science ................. 426

The Biblical Concept of the 'Remnant' and the Protection of the

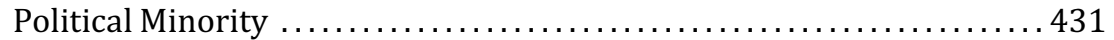

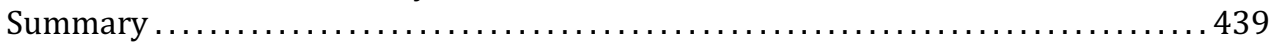

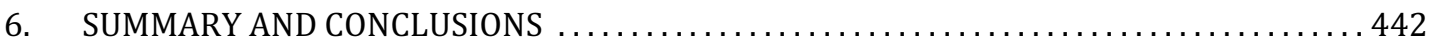

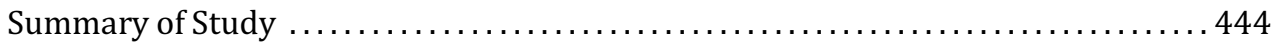

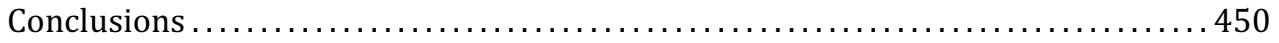

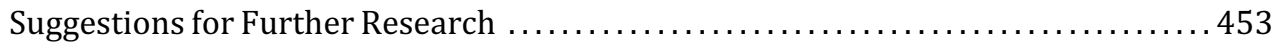

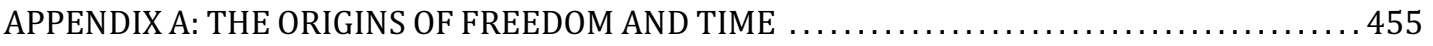

The Origins of the Concepts of Freedom and Time $\ldots \ldots \ldots \ldots \ldots \ldots \ldots \ldots \ldots \ldots+\ldots \ldots \ldots$

The Origin of Time in Western Philosophy and Theology ................ 457

The Origin of the Concept of Time in Ancient Greece and the West .........460

Summary on the Origin of Time in Ancient Greece and the West .......... 491

The Origin of Freedom in Western Philosophy and Theology ............... 491

The Origin of the Concept of Freedom in Ancient Greece and the West .....494

Summary on the Origin of Freedom in Ancient Greece and the West........526

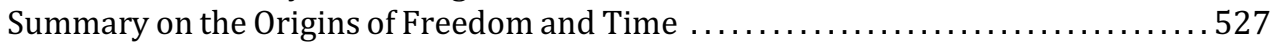

BIBLIOGRAPHY

.532 


\section{ACKNOWLEDGMENTS}

On several occasions, this dissertation impinged upon my freedom and time to pursue many other things I felt inspired to enjoy. Yet, at the end of it, I can assert that this dissertation has made me value the realities of freedom and time in ways I had never before imagined. So first, I wish to thank the Lord of freedom and time for the joy of existence, and the thrill of resting in Him alone! There is no thing or place that is the equal of free time with my Creator (Mark 2:27-28; 2 Cor. 3:17).

Beyond God, I would like to think my family for their support for me during the many years that graduate education requires. My father (Randall), my mother (April), and my sisters (Rebecca, Elizabeth, and Sarah), as well as my many other extended family members. Their support has been immense and immeasurable. Few can say that their parents aided their academic journey in a tangible way, but both my father (with his professional interest in science and religion) and mother (editorial as well as another pair of listening ears) have aided and encouraged my educational pursuits, including the very topic of this dissertation project, and so I wish to especially thank them for that assistance and encouragement.

Within my academic program, many individuals have also inspired and encouraged me, especially the late Chair of the Theology department, Miroslav Kiš, who accepted me into the Ph.D program. Additionally noteworthy among them are my professors John T. Baldwin, for his passion for

Scripture and the sciences, Fernando Canale, whose work in biblical hermeneutics and philosophy lies most directly at the foundation of this dissertation, and my classmates and fellow scholars, Tiago Arrais and Kenneth Bergland, whose work has greatly inspired me. Of course, the patience and open mind of my adviser Martin Hanna, whose flexibility and encouragement for this ambitious project must also be noted, along with the thoughtful comments, opportunities for dialogue, and overall support and friendship, as well as critiques, of John C. Peckham and Jay Brand, whose diverse 
specialties greatly improved the final product. Whatever shortcomings remain are the author's alone, and none of the above. 


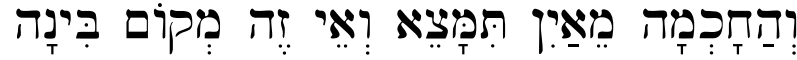

"But where can wisdom be found? And where is the place of understanding?"

Job 28:12 


\section{CHAPTER 1}

\section{INTRODUCTION}

\section{Background}

Amongst the most perplexing concepts with which humankind has ever wrestled are the consanguineously parallel mysteries of freedom and time. ${ }^{1}$ Concerning freedom in particular, it has been aptly remarked that "the mystery of freedom is ... a well of immeasurable depth-its bottom is the final mystery." In a similar manner for time, it has been mused that "it is possible to philosophize endlessly on the 'nature' of time."3 The philosopher Immanuel Kant recognized the centrality of both of them for metaphysical inquiry, in his oft cited quote that the foundational questions concerning metaphysics relate to "God, freedom, and immortality [or existence in relation to time]."4

\footnotetext{
${ }^{1}$ Without being exhaustive, the most widely acknowledged and particularly mysterious and foundational concepts philosophers have long discussed would include God, life, consciousness, love, space, matter, language, good, evil, humanity, and, last but not least, the focus of this study, freedom and time. It is surely no accident that freedom and time are often discussed in relationship to all of the previously listed concepts-indeed, they all draw their meanings from their relationships to freedom and time. In respect to this shared foundational status, it appears freedom and time share a particularly 'consanguineous' connection-which will also be revealed through their parallel conceptions, as described below.

${ }^{2}$ Richard E. Johnson, Existential Man: The Challenge of Psychotherapy (Elmsford, NY: Pergamon Press, 1971), 4.

${ }^{3}$ Edward T. Hall, The Dance of Life: The Other Dimension of Time (New York, NY: Anchor Books, 1983), 13.

${ }^{4}$ Immanuel Kant, Critique of Pure Reason, $2^{\text {nd }}$ ed. tr. Friedrich Max Müller (Macmillan \& Co., 1920), 792; $640,602,3$ (addition mine). There is a layer of subtlety and misdirection in Kant's statement, however. As Walter Stace correctly perceives of Kant's view, "the world which we have been describing, the world of things which are in space and time, and to which the categories apply, is one of Kant's two worlds. It may be called the space-time world. It is the world to which science applies, and in which science is one hundred per cent true, without any exceptions whatever.... God, freedom and immortality cannot be found in it.... God is not in space or in time at all. It is at this point that we come in sight of the central thought of Kant's system. The spacetime world, to which science applies, is not 'reality'; it is only 'appearance.'... Space and time cannot be real, because the thoughts of them are self-contradictory.... Kant's view is that space, time, and the categories, are not what he calls 'things in themselves.' They are not the real things which exist outside us and apart from our minds.... They are our ways of perceiving and thinking about things, which we cannot avoid because our minds are so made," Walter Terence Stace, Religion and the Modern Mind (New York, NY: J. B. Lippincott, 1952), 193-194. In what will be the first of many ironic twists in unraveling an interpretation of freedom and time, however, is that Kant's postulation that our space-time world (as conceived in his pre-relativity and prequantum era) doesn't fully define 'real' time may be correct in light of relativity and quantum physical
} 
The complexity of the mysterious natures of both freedom ${ }^{5}$ and time ${ }^{6}$ magnify, and their

meanings multiply, the more one delves into their function in the discourses present in, foremost,

interpretations; whether the objects of metaphysics are real, however, remains another question.

${ }^{5}$ Not only are the natures of both freedom and time generally conceded to be underdetermined, if not ultimately indeterminable, by many scholars, but whether either of them meaningfully exists remains controversial in itself. For example, the always relevant question of whether human freedom, in particular, even exists at all remains today a matter of significant dispute. Recent work indicates that there is a strong perception by some scholars that, by and large, "academic philosophers, psychologists, and neuroscientists teach their students to believe that their actions may be determined and beyond their control, that free will is an illusion," Bob Doyle, Free Will: The Scandal in Philosophy (Cambridge, MA: I-Phi Press, 2011), iii. The subject of freedom has received considerable attention lately. For example, see Nicholas Rescher, Free Will: An Extensive Bibliography (Piscataway, NJ: Rutgers University Press, 2010). Much of its increasing relevance is explained by Thomas Nadelhoffer and Daniela Tocchetto, who observe, "while the free will debate has traditionally been the fairly cloistered haunt of philosophers and theologians, a growing number of scientists have recently become increasingly vocal about their skepticism concerning free will. With articles appearing in The New York Times, The Economist, Forbes Magazine, WIRED, and USA Today, the debate about free will has finally hit the mainstream. One common theme in the way free will has been discussed in the popular press is that recent scientific advances (especially in neuroscience) threaten or undermine our traditional picture of agency and responsibility," Thomas Nadelhoffer and Daniela Goya Tocchetto, "The Potential Dark Side of Believing in Free Will (and Related Concepts)," in Exploring the Illusion of Free Will and Moral Responsibility, ed. Gregg D. Caruso (Lanham, MD: Lexington Books, 2013), 121-122. Within such a context, "everyone wants to discover whether human freedom really exists, and we can no longer be satisfied with philosophical strategies that place this question forever beyond our reach.... The existence of God and the fate of the soul, the struggle between good and evil, remain the most important philosophical questions for the majority of humankind, yet these very questions now strike most intellectuals as deeply naive, or at best as exiled to the no man's land of faith. While such metaphysical problems are not ignored entirely, they continue to strike most observers as lying beyond the pale of rigorous technical philosophy-a view now even more widespread in continental circles than among the analytics, some of whom are taking a renewed crack at these problems.... We have been trained, in other words, not to wonder in public about the most overpowering cosmological mysteries, even as some of us continue to wonder about them in private. We are now penned up safely in a narrow range of verifiable and technically precise medications on human access, ranging from stylish to dry. The present book has urged another attitude toward the world. The term 'guerilla metaphysics' is meant to signal both this attitude and my full awareness that the traditional cathedrals of metaphysics lie in ruins," Graham Harman, Guerrilla Metaphysics: Phenomenology and the Carpentry of Things (Peru, IL: Open Court Publishing, 2005), 255-256. Doyle concurs, believing that all too often those who do believe in freedom "accept the faulty reasoning that freedom exists only on some metaphysical plane" that makes freedom "a mystery beyond explanation" or "a gift of God beyond understanding by our finite minds," leaving philosophers and theologians pragmatically helpless in the face of scholars, especially scientists, who deny human freedom, Doyle, Free Will: The Scandal in Philosophy, iii.

${ }^{6}$ Similarly to freedom, time is also a very divisive subject today. Many respected physicists believe reality to be ultimately timeless; i.e., lacking time. See, for example, Julian Barbour, The End of Time: The Next Revolution in Physics (Oxford, UK: Oxford University Press, 1999); and Victor J. Stenger, Timeless Reality: Symmetry, Simplicity, and Multiple Universes (Amherst, NY: Prometheus Books, 2000). As Clayton Crockett observes, "many contemporary physicists follow [Carlo] Rovelli in dispensing with time, including Julian Barbour and Roger Penrose," Clayton Crockett, Deleuze Beyond Badiou: Ontology, Multiplicity, and Event (Chichester, West Sussex: Columbia University Press, 2013), 150. See Carlo Rovelli, The Order of Time (New York, NY: Riverhead Books, 2018). Other physicists disagree, such as Lee Smolin, Time Reborn: From the Crisis in Physics to the Future of the Universe (New York, NY: Houghton Mifflin, 2013). Smolin attempts to climb "back up from timelessness to establish time in its rightful place at the core of our conception of the world," ibid., 240. In any case, the "tension between what physics, philosophy, and everyday experience say about time is something that needs to be addressed," Levi Bryant, Nick Srnicek, and Graham Harman, "Towards a Speculative Philosophy," in The Speculative Turn: Continental Materialism and Realism, ed. Levi Bryant, Nick Srnicek, and Graham Harman (Melbourne, Australia: RE Press, 2011), 17. 
theology ${ }^{7}$ (including in particular the biblical issues concerning the Sabbath, ${ }^{8}$ prophecy, ${ }^{9}$ and

eschatology ${ }^{10}$ ), but also every area of philosophy, ethics, psychology and psychiatry, economics,

sociology, politics, and the natural sciences. It appears that in every discipline of study, diverse and

\begin{abstract}
${ }^{7}$ My interest in theology originates from a western Judeo-Christian background and accordingly this study will primarily engage theology from within this tradition except where applicable. From the Christian perspective, specifically, it is the Holy Spirit (amongst the divine trio, that is, the Father, Son, and Holy Spirit) that is most frequently explicitly associated with the concept of freedom through time, although the significance of this will not be explored in this study, nor do I suggest freedom is not associated with the other members of the divine trio. For example, see Paul D. Molnar, Faith, Freedom and the Spirit: The Economic Trinity in Barth, Torrance, and Contemporary Theology (Downers Grove, IL: InterVarsity Press, 2015); Wilson Varkey, Role of the Holy Spirit in Protestant Systematic Theology: A Comparative Study of Karl Barth, Jürgen Moltmann, and Wolfhart Pannenberg (Langham Monographs, 2011); and José Comblin, The Holy Spirit and Liberation (Eugene, OR: Wipf and Stock, 1989). As a popular Protestant theologian, Ellen White, expressed it, "the Holy Spirit is a free, working, independent agency. The God of heaven uses His Spirit as it pleases Him; and human minds, human judgment, and human methods can no more set boundaries to its working, or prescribe the channel through which it shall operate, than they can say to the wind, 'I bid you to blow in a certain direction, and to conduct yourself in such and such a manner.' As the wind moves in its force, bending and breaking the lofty trees in its path, so the Holy Spirit influences human hearts, and no finite man can circumscribe its work," Ellen G. White, "The Work of the Holy Spirit in Conversion," in The Signs of the Times March 8 (1910), par. 2.

${ }^{8}$ The special worship of God on Sabbath and later also Sunday has received important attention throughout biblical and Christian history. See, for example, Christopher John Donato, ed. Perspectives on the Sabbath: Four Views (Nashville, TN: B\&H Academic, 2011); Walter Brueggemann, Sabbath as Resistance; Saying No to the Culture of Now (Louisville, KT: Westminster John Knox Press, 2014); A. M. Simataa, The Seventh-day Sabbath and the Christian Doctrine of Redemption (Bloomington, IN: Xlibris, 2015); Terrence D. O'Hare, The Sabbath Complete: And the Ascendency of First-Day Worship (Eugene, OR: Wipf \& Stock, 2015); Lynne M. Baab, Sabbath Keeping: Finding Freedom in the Rhythms of Rest (Downers Grove, IL: InterVarsity Press, 2005); Isidor Grunfeld, The Sabbath: A Guide to Its Understanding and Observance $4^{\text {th }}$ ed. (Jerusalem, Israel: Feldheim Publishers, 2003), 20; A. J. Swoboda, Subversive Sabbath: The Surprising Power of Rest in a Nonstop World (Grand Rapids, MI: Brazos Press, 2018); Sigve Tonstad, The Lost Meaning of the Seventh Day (Berrien Springs, MI: Andrews University Press, 2009); George R. Knight, A Brief History of the Seventh-day Adventists $2^{\text {nd }}$ ed. (Hagerstown, MD: Review and Herald, 2004); Richard M. Davidson, A Love Song for the Sabbath (Hagerstown, MD: Review and Herald, 1988); Skip MacCarty, In Granite Or Ingrained?: What the Old and New Covenants Reveal about the Gospel, the Law, and the Sabbath (Berrien Springs, MI: Andrews University Press, 2007); Samuele Bacchiocchi, Divine Rest for Human Restlessness: A Theological Investigation of the Good News of the Sabbath (Berrien Springs, MI: Biblical Perspectives, 1997); Samuele Bacchiocchi, From Sabbath to Sunday: A Historical Investigation of the Rise of Sunday Observance in Early Christianity (Vatican City: Pontifical Gregorian University, 1977); Contrastingly, Muslims do not see Friday as a day of 'rest' for Islam. See S. S. Kapoor, Islam (New Delhi: Hemkunt, 2004), 37.

${ }^{9}$ See, for example, Paul Boyer, When Time Shall Be No More: Prophecy Belief in Modern American Culture (Cambridge, MA: The Belknap Press, 1992). Note also, Uriah Smith, The Prophecies of Daniel and the Revelation (Literary Licensing LLC, 2014); C. Mervyn Maxwell, God Cares: The Message of Daniel (Nampa, ID: Pacific Press, 1998); C. Mervyn Maxwell, God Cares: The Message of Revelation (Nampa, ID: Pacific Press, 1998); William H. Shea, Daniel: A Reader's Guide (Nampa, ID: Pacific Press, 2005); and Tim Roosenberg, Islam \& Christianity in Prophecy revised ed. (Emmett, ID: Islam and Christianity in Prophecy Seminars, 2016).

${ }^{10}$ See, for example, the recent publications by David Wilkinson, Christian Eschatology and the Physical Universe (New York, NY: T\&T Clark, 2010); Jonathan Martin, Biblical Eschatology (Eugene, OR: Wipf and Stock, 2013); George F. R. Ellis, ed. The Far-Future Universe: Eschatology from a Cosmic Perspective (Radnor, PA: Templeton Foundation Press, 2002); and Neal DeRoo and John Panteleimon Manoussakis, ed. Phenomenology and Eschatology: Not Yet in the Now (Burlington, VT: Ashgate, 2009).
\end{abstract}


often conflicting understandings of freedom ${ }^{11}$ and time ${ }^{12}$ are either explicitly or implicitly present, and this has been so throughout all of recorded history. ${ }^{13}$ Everyone has some conception of freedom and time, but their understandings of them are different.

Importantly, recently it has been suggested that there is an underappreciated yet intricate "interconnection of freedom and time," such that "the problem of the relation of freedom and time" appears to reveal "a difficult birth and a slow development" that "has still not been fully worked out, even today." ${ }^{14}$ Christophe Bouton pinpoints the interrelated problem by observing that recent key figures in philosophy to have addressed freedom "have this in common, that they were one and all confronted with the problem of the temporality of human freedom and, in order to resolve this problem, felt obliged to think [about] the plasticity of time, that is, its capacity to be modified and

\footnotetext{
${ }^{11}$ Given that "there are many problems in defining freedom," I will forego listing any definitions until later in the study as relevant. The difficulties in part originate from the fact that "not only are there many meanings of freedom, but the same definition may be accepted by many groups who will interpret it differently according to their own ... beliefs and culture... [such that] it tends to lose some of its value in meaningful communication," John Richard Thackrah, Politics Made Simple (London, UK: William Heinemann Ltd., 1987), 53.

${ }^{12}$ Similarly to freedom, "time has many meanings. Time is an important measure of how things relate to each other. Time is also a scientific measure, [as well as] a benchmark to measure how society and culture interact," Frederick Kile, Escape from Time: Disconnecting from Culture (Lincoln, NE: iUniverse, 2000), 10. Further definitions for time will also be given later where appropriate. What is important is that "the cultural meanings of time vary widely, just as the individual perceptions of time do, which themselves are culturally influenced," Jon L. Berquist, Controlling Corporeality: The Body and the Household in Ancient Israel (Piscataway, NJ: Rutgers, 2002), 107. See also, P. J. N. Baert, ed. Time in Contemporary Intellectual Thought (Amsterdam, The Netherlands: Elsevier Science, 2000); and Jon E. Roeckelein, The Concept of Time in Psychology: A Resource Book and Annotated Bibliography (Westport, CT: Greenwood Press, 2000). Roeckelein observes that "of all the great abstractions of science, it is omnipresent time (not space, force, or matter) that comes most often to human lips. However, oddly enough, it is difficult to define time. To the psychologist, time is a dimension of consciousness, the way by which we give order to our experiences. To the physicist, time is one of the three basic quantities (the others are distance and mass) by which the universe is described in physical terms. To the philosopher, time is a diversity of many other things. Yet, among all these scholarly 'speakers-of-truth,' none of them are able to define it in a way satisfactory to one another-or even to themselves," ibid., 1.

${ }^{13}$ For comprehensive reviews of the concept of freedom from an historical perspective, see Mortimer J. Adler, The Idea of Freedom Volumes 1 \& 2 (Westport, CT: Greenwood Press, 1976); Illham Dilman, Free Will: An Historical and Philosophical Introduction (New York, NY: Routledge, 1999); and Orlando Patterson, Freedom in the Making of Western Culture Vol. 1 (New York, NY: BasicBooks, 1991). Concerning the concept of time from an historical perspective, see Adrian Bardon, A Brief History of the Philosophy of Time (New York, NY: Oxford University Press, 2013); Dan Falk, In Search of Time: The History, Physics, and Philosophy of Time (New York, NY: St. Martin's Press, 2008); J. T. Fraser et al., ed. Time, Science, and Society in China and the West: The Study of Time $V$ (Amherst, MA: The University of Massachusetts Press, 1986); and Charles M. Sherover, ed. The Human Experience of Time: The Development of Its Philosophic Meaning (Evanston, IL: Northwestern University Press, 2001).

${ }^{14}$ Christophe Bouton, Time and Freedom, tr. Christopher Macaan (Evanston, IL: Northwestern University Press, 2014), 14-15.
} 
configured by freedom."15 Such resolutions, however, should not be understood to have successfully integrated the domains of science and human free will. The contemporary free-will conundrum demonstrates the current impasse clearly, ${ }^{16}$ intertwining the contemporary science of nature and its functionally presumed causal determinism ${ }^{17}$ into the problem of how to understand both freedom

${ }^{15}$ Bouton, Time and Freedom, 15 (emphasis original).

${ }^{16}$ Doyle suggests that all too often it seems as though "humans are seen as cogs in a vast biological machine," but he insists that "physical and biological science can produce no such evidence," Doyle, Free Will: The Scandal in Philosophy, iii. As an advocate of free will, part of Doyle's proposed theory importantly posits that "free will is [part of] ... a temporal sequence," directly linking freedom with a certain conception of time, ibid., 196.

The classic Enlightenment expression of the tension between freedom and the natural sciences' conclusions on the determinacy of nature, and its implications for time, can be seen from the French mathematician and astronomer Pierre Simon de Laplace (1749-1827), as he comments, "We ought to regard the present state of the universe as the effect of its antecedent state and as the cause of the state that is to follow. An intelligence knowing all the forces acting in nature at a given instant, as well as the momentary positions of all things in the universe, would be able to comprehend in one single formula the motions of the largest bodies as well as of the lightest atoms in the world, provided that its intellect were sufficiently powerful to subject all data to analysis; to it nothing would be uncertain, the future as well as the past would be present to its eyes," leaving in essence a 'timeless present reality' to a 'God's Eye' perspective, in Pierre Simon de Laplace, Théorie Analytique (1820), Introduction, VI-VII; as cited in Ernest Nagel, The Structure of Science: Problems in the Logic of Scientific Explanation (Harcourt, Brace \& World, 1961), 281-282. Note also, Ludwig von Bertalanffy, Problems of Life: An Evaluation of Modern Biological Thought (London: Watts \& Co., 1952), 162; and Milič Čapek, "The Unreality and Indeterminacy of the Future in the Light of Contemporary Physics," in Physics and the Ultimate Significance of Time: Bohm, Prigogine, and Process Philosophy, ed. David Ray Griffin (Albany, NY: State University of New York Press, 1986), 297-308. Čapek comments that “[Laplace's] view of causality culminated in Laplace's frequently quoted passage, according to which the [temporal] impersonal world order became a timeless implicative pattern in which the distinctions between the past, present, and future disappear. Spinoza as well as Parmenides would have been delighted. Note the conceptual evolution; Galileo still spoke of God; Spinoza provided a substitute, speaking of 'God or nature' (Deus sive natura); finally, Laplace, in his famous answer to Napoleon, dropped even the word. ('Sir, je n'ai pas besoin de cette hypothese.') But Laplace's 'omniscient mind' was really nothing but a secularized and depersonalized version of the omniscient God of traditional theology, equally changeless, equally timeless. How much this mode of thinking is alive today is shown in Einstein's words, pronounced at the very end of his life when he heard about the death of his close friend: 'the distinction between past, present and future is only an illusion, even if a stubborn one,"' ibid., 303.

${ }^{17}$ That natural science is integrally part of the historical problem of both freedom and time and the human being is explained, in addition to the comments in the preceding footnote above, thus: "Ever since [René] Descartes and [Isaac] Newton, since the very beginning of modern physics, defenders of human freedom have tended to concede the rest of nature to determinism, arguing that only man is free, while everything else in the universe is governed by causal laws. Indeed, this is one of the primary motives for the long dominance of Western thought by the dualistic opposition between mind and body. The body was thought to be governed by the laws of physics, like all other material things. But human beings could still be free because the human mind was conceived to be an immaterial substance and therefore exempt from the laws of physics. This dualistic doctrine was carried to such absurd lengths that French physiologists defended the vivisection of animals on the ground that animals are merely intricate but mindless machines and therefore incapable of feeling any pain," J. Melvin Woody, Freedom's Embrace (University Park, PA: The Pennsylvania State University Press, 1998), 253254. Accordingly, "the fundamental Western question of freedom and determinism is transformed into a modern problem that is to be played out in the emergent and developing histories of modern philosophy and the social sciences .... [Since the] modern problem of freedom can now be located originally in nature, the principle of determinism becomes the source of a fundamental metaphysical tension in modern thought on the question of freedom. That tension is found, as [Thomas] Hobbes has shown, in the radical fact that the principle of determinism is being taken as ruling the material world, of which the physical and the human are thus to be understood as but two complementary material parts," in Charles Varela, Science for Humanism: The Recovery of 
and time as they intersect within the physical human being. ${ }^{18}$ Notably the prominence of the physical problem of freedom has become especially acute today in part because of its entanglement with the discipline of physics, which is widely considered the domain where time is most directly examined.

While definitions of freedom and time vary widely across the vast spectrum of specialized disciplines that exist today, since the middle of the $20^{\text {th }}$ century, most contemporary discussions about both freedom and time have taken place within the tensions between the broad academic umbrellas of the "two cultures" formally distinguished by the chemist and novelist Charles P. Snow in 1959. ${ }^{19}$ Snow understood the two cultures as representing those more interested in either the sciences ("scientists") or the humanities ("literary/artistic intellectuals"). ${ }^{20}$ Although the division

Human Agency (New York, NY: Routledge, 2009), 69.

18 "It is no secret that the traditional problem of free will emerged in ancient times with the suspicion that conflicts existed between human freedom and determinism in one or more variant forms of determinism-physical, psychological, theological or fatalistic. If these conflicts between freedom and determinism are not real, the central 'free will' problem would be solved-or better, it would be 'dissolved,' since the worries that generated it would be unfounded. Such a 'dissolutionist' strategy regarding free will is a prevalent theme of modern philosophy: the ancient quarrels about free will and determinism can finally be put to rest because there is no genuine conflict between the two.... In its prevalent 'modernist' form, dissolutionism leads to 'compatibilism'-the view that freedom in every significant sense (free will included) is compatible with determinism. Compatibilism is surely the dominant view on free will among philosophers today.... But there is also a 'postmodernist' form of dissolutionism according to which there is no single, coherent, intelligible concept of free will that could be incompatible or compatible with determinism. On this view, both incompatibilism and compatibilism fall short of what we want because what we want-free will-is no coherent thing at all," in Robert Kane, "Free Will: The Elusive Ideal," in First Philosophy: Fundamental Problems and Readings in Philosophy: Vol. III: God, Mind, and Freedom, ed. Andrew Bailey (Broadview Press, 2004), 269293, 273.

${ }^{19}$ After discussing the theme in his classroom lectures at Christ's College in England, Charles Percy Snow first published an article on the "two cultures" in 1956, then delivered it as a talk (as part of the "Rede" lecture series) with some additions in 1959, which was then published as a short book. Widespread interest in his book led him to publish it a second time with yet more additions in 1963 as The Two Cultures: And a Second Look: An Expanded Version of The Two Cultures and the Scientific Revolution. For a recent published version, see Charles P. Snow, The Two Cultures (New York, NY: Cambridge University Press, 1998). "Snow defined culture in two ways, as 'intellectual development (development of the mind) and in an anthropological sense (common attitudes, common standards and patterns of behavior, common approach),"' Dorothy F. Chappell and E. David Cook, Not Just Science: Questions Where Christian Faith and Natural Science Intersect (Grand Rapids, MI:

Zondervan, 2005), 89. Snow's "analysis was vigorously attacked by the literary critic F. R. Leavis. As a broadbrush description, most scientists think Snow's distinction is close to the truth. In any case, Snow could claim some knowledge of both cultures, since he was also a successful novelist," Garrett Hardin, Living within Limits: Ecology, Economics, and Population Taboos (Oxford, UK: Oxford University Press, 1993), 317 n. 4. See also, Christine Charyton, "Art, Creativity, and Culture: How Art Intersects with Science in the Expression of Artistic Creativity," in Creativity and Innovation Among Science and Art: A Discussion of the Two Cultures, ed. Christine Charyton (Dordrecht, The Netherlands: Springer, 2015), 179.

${ }^{20}$ In Albert Levi's analysis, "Snow described the dissimilarities between these two cultures in terms of the dominant ethical disposition of each and concluded that, on the whole, scientists more than humanists possess the necessary intellectual equipment and the moral resolve to tackle global problems," Albert William Levi and Ralph A. Smith, Art Education: A Critical Necessity (Chicago, IL: Illini Books, 1991), 170. See also Gerard Lum, Vocational and Professional Capability: An Epistemological and Ontological Study of Occupational Expertise 
between the two cultures, merely formally articulated by Snow, ${ }^{21}$ developed over many years and through a wide variety of historical circumstances, ${ }^{22}$ its manifestation and ensuing crisis, in not just the academy but also the mainstream world, occurred relatively suddenly. Furthermore, the crisis between the two cultures has had longstanding and continuing consequences.

The division was not only between science laboratories and departments, which were making new discoveries with astonishing frequency, and humanities departments, even as the animosity between them remains vociferous, ${ }^{23}$ but the division also emerged within philosophy departments. Within many universities, if not also within individual philosophy departments, a rather spirited competition ensued, which continues today, between the "Analytic" versus "Continental" schools of

(New York, NY: Continuum, 2009); and Snow, The Two Cultures, 11.

21 "The idea that there are two cultures, two modes of intellectual inquiry, or more fundamentally two modes of thought and practice that belong to human existence, did not originate in $1959 \ldots$ The roots of such divisions go very deep into our heritage, receiving many different formulations and precipitating many attempts at reconciliation. These divides and reconciliations permeate our view not only of academic and intellectual inquiry, but also our very conception of what it means to be a thinking being," Tom Greaves, Starting with Heidegger (New York, NY: Continuum, 2010), 139.

${ }^{22}$ As is often the case, a complicated confluence of historical factors helped create the contemporary crisis of the "two cultures," beyond simply developments in the academy (i.e., within the relevant disciplines themselves). Steve Fuller suggests that "in the two decades following World War II," "the logical positivists had reduced political discourse to ideological differences that could not be resolved by strictly empirical means, as they involved appeals to the fears and hopes of the audiences to whom they were directed. From the standpoint of the Cold War, such [non-empirical political] discourse was therefore best 'contained', since the only foreseeable alternative was violent conflict. Politics left philosophy when it was no longer seen as something that could be reasoned about. Moreover, many postwar societies instantiated this depoliticized sensibility by shifting the job requirements of their civil servants, encouraging those trained in the 'technocratic' sciences of engineering and economics, while discouraging those trained in the more traditional humanistic fields. Just this shift enabled C. P. Snow's lecture on the 'two cultures' to acquire the iconic status it has held over the past halfcentury," Steve Fuller, The Sociology of Intellectual Life: The Career of the Mind in and Around the Academy (London, UK: SAGE Publications, 2009), 75-76. See also, Stephen Toulmin, Cosmopolis: The Hidden Agenda of Modernity (Chicago, IL: The University of Chicago Press, 1990), 43; and Michael Mack, Philosophy and Literature in Times of Crisis: Challenging our Infatuation with Numbers (New York, NY: Bloomsbury Academic, 2014), 1920.

${ }^{23}$ Note, for example, a couple recent popular articles clearly demonstrating the contemporary animosity between the sciences and the humanities. Compare Michael White, "The Humanities Are In Crisis Science Is Not," at http://www.science20.com/adaptive_complexity/humanities_are_crisis_science_not (accessed April 27, 2009); and Maria Konnikova, "Humanities Aren't a Science, Stop Treating Them like One," at http://blogs.scientificamerican.com/literally-psyched/2012/08/10/humanities-arent-a-science-stoptreating-them-like-one/ (accessed August 10, 2012). For more, see Robin Ian MacDonald Dunbar, The Trouble with Science (Harvard, MA: Faber and Faber, 1995), 2; and Robert M. Young, "Science and the Humanities in the Understanding of Human Nature," Inaugural Lecture as Professor of Psychotherapy and Psychoanalytic Studies, Centre for Psychotherapeutic Studies, University of Sheffield, May 25, 2000, available at http://human-nature. com/rmyoung/papers/pap131h.html (accessed January 30, 2013). 
thought. ${ }^{24}$ From a broader perspective, the consequences of this are seen in the fact that the situation has led some observers to believe that the competition between the two is indicative of a "contradiction between science and humanism [that] has [still] not been recognized by most intellectuals, a contradiction that has undermined the vitality of Western culture." ${ }^{25}$ Some have also suggested this is reflected in the way the two cultures are related to the wide-ranging division and parallel tensions between modernists and postmodernists, ${ }^{26}$ whose ongoing conflict today may be the true heir of Snow's concerns. ${ }^{27}$

For the immediate purposes of this study, however, what is noteworthy is that the emergence of the two cultures in the academy would coincide with and influence developments concerning how

\footnotetext{
24 "Opposition ... between a scientific and a literary culture ... also emerged in philosophy.... [Such a] distinction between two attitudes or cultures in philosophy enables us to make sense of the analytic/continental divide," Frederiek Depoortere and Magdalen Lambkin, "Editors' Introduction," in The Question of Theological Truth: Philosophical and Interreligious Perspectives, eds. Frederiek Depoortere and Magdalen Lambkin (Amsterdam, The Netherlands: Rodopi, 2012), 4. Note also, Simon Critchley, Continental Philosophy: A Very Short Introduction (Oxford, UK: Oxford University Press, 2001), 49; Hans-Johann Glock, What is Analytic Philosophy? (Cambridge, UK: Cambridge University Press, 2008), 70; and Asher Seidel, Inhuman Thoughts: Philosophical Explorations of Posthumanity (Lanham, MD: Lexington Books, 2008), 79. Seidel observes, "Continental philosophers, for example, are typically regarded as humanistic in their subject matter and methods. Analytic philosophers, such as those inheriting the concerns, if not the methods, of the logical positivists, at times appear either scientific, or aspiring to be scientific, at least in the loose, intuitive sense of the term," ibid. See also, Andreas Vrahimis, "Philosophy and Humanistic Education: J. S. Mill's Catastrophic Pedagogy," in Pedagogies of Disaster, ed. Vincent W. J. Van Gerven Oei, Adam Staley Groves, and Nico Jenkins (Brooklyn, NY: Punctum Books, 2013), 311; and Michael A. Peters, Education, Philosophy and Politics: The Selected Works of Michael A. Peters (New York, NY: Routledge, 2012), 210-211.

${ }^{25}$ Shlomit C. Schuster, Philosophy Practice: An Alternative to Counseling and Psychotherapy (Westport, CT: Praeger Publishers, 1999), 79.

${ }^{26}$ For example, Gregg Henriques comments: "An interesting debate between modernists and postmodernists emerged in the 1990's. Called the science wars, the debate highlighted the fact that-as has been popularized at least since C. P. Snow's famous characterization of the two cultures of the sciences and humanities in 1959-the academy has failed to produce a consensually agreed-upon vision of the human condition and nature of knowledge," Gregg Henriques, A New Unified Theory of Psychology (London, UK: Springer, 2011), 249. See also the notable works by Alan Sokal and Jean Bricmont, Fashionable Nonsense: Postmodern Intellectuals' Abuse of Science (New York, NY: Picador, 1998); Chris Horrocks, "Between Relativism and Truth: Jean Baudrillard, the Sokal Affair and the Use of Scientific Terminology Across Cultural Boundaries," in Relative Points of View: Linguistic Representations of Culture, ed. Magda Stroinska (Oxford, UK: Berghahn Books, 2001), 101-118; and Patricia Waugh, "Thinking in Literature: Modernism and Contemporary Neuroscience," in The Legacies of Modernism: Historicising Postwar and Contemporary Fiction, ed. David James (Cambridge, UK: Cambridge University Press, 2012), 75-95.

${ }^{27}$ Some claim that "the gulf between C. P. Snow's cultures has not proven to be as unbridgeable as he had worried. Certainly, the gulf did not become debilitating; the two cultures never went to war. However," today we have found ourselves with "another two cultures: the modern and the postmodern. There is the same lack of understanding, but now there is hostility and often debilitating conflict," George Fallis, Multiversities, Ideas, and Democracy (Toronto, Canada: University of Toronto Press, 2007), 257.
} 
freedom and time are described and understood that would be in tension. ${ }^{28}$ Furthermore, as history has continued to unfold, this tension has become more entrenched, especially as it has spread into the general populace. Indeed, another manifestation, in some respects, of the 'two cultures' would be that of the academy and the general population. Here the risk of scientists becoming a cultic priesthood of experts $^{29}$ ruling the 'ignorant' masses creates another more pragmatic actualization of the 'two cultures' that remains a sensitive issue to navigate, ${ }^{30}$ especially when this is replicated within religious contexts between theologian-scientists and the laity. Of course, it could be similarly argued

\footnotetext{
${ }^{28}$ Concerning freedom, "the story of the two cultures," is, "namely," the story of "the realm of necessity and the realm of freedom, [that is respectively] the natural and the moral world," and it is this which "distinguishes science from the humanities and makes any philosophy of science insufficient which is not able to point up this difference," Johannes Roggenhofer, "From Science Wars to Science Worries: Some Reflections on the Scientific Conquest of Reality," in Knowledge and the World: Challenges Beyond the Science Wars, eds. Martin Carrier, Johannes Roggenhofer, Günter Küppers, and Philippe Blanchard, (New York, NY: Springer, 2004 ), 302. As it pertains to the tension the cultures have generated regarding time, the philosopher David Ray Griffin explains the perspective of the physicist Ilya Prigogine: 'the problem of the 'two cultures' has not been that scientists have not read enough humanities and humanists enough science, but that there has been nothing in common between the two thought worlds. At the root of the cleavage has been the fact that, while the humanities and social sciences are necessarily time-oriented, classical science has been nontemporal," David Ray Griffin, "Introduction," in Physics and the Ultimate Significance of Time: Bohm, Prigogine, and Process Philosophy, 16. Or, as Paul Harris positions it within the discussion succinctly: "Time stands at a complex, ambivalent nexus between literature and science. The division between the two cultures of the humanities and sciences is replicated in the mutual exclusion between aesthetic or philosophical interpretations of time and scientific analyses of time," Paul A. Harris, "Time," in Encyclopedia of Literature and Science, ed. Pamela Gossin (Westport, CT: Greenwood Publishing Group, 2002), 469. Harris further illuminates the problem by noting that "a similar subdivision occurs with each culture: The formalist strand of literary aesthetics emphasizes the power of art to arrest time and hold it fixed, while several other approaches rather view literature as an expression of cultural process. Scientific analysis of time runs up against the 'irreversibility paradox,' which stems from the fact that many 'fundamental laws' of physics are time-reversible, whereas entropy and observed experience point to an irreversible 'arrow of time,' ibid.

${ }^{29}$ Such an aristocratic-technocratic priesthood can take many forms, but as guardians of 'difficult' knowledge that nevertheless has a great impact on society, this scenario is already unfolding in many parts of the world. But beyond more social concerns, the priesthood of scientists can take on more metaphysical forms. See Beverly H. Burris, Technocracy at Work (Albany, NY: State University of New York Press, 1993), esp. 22-25; and Anthony Van Den Beukel, The Physicists and God: The New Priests of Religion? (North Andover, MA: Genesis Publishing, 1995).

${ }^{30}$ For a recent example of this one may turn toward the field of medicine, which operates as a mediating culture between the masses and experts. Marlowe Hood shares that recent studies suggest "a rising tide of suspicion amplified by social networks has eroded public trust in modern medicine, leaving scientists and health officials scrambling for ways to shore up its credibility," in Marlowe Hood, "Modern Medicine Infected by the Virus of Mistrust," at https://medicalxpress.com/news/2018-01-modern-medicine-infectedvirus-mistrust.html (accessed January 26, 2018). That this is occurring in the medical field, a "third culture" which mediates between the sciences and humanities, is significant, as will be noted below.
} 
that the development of differences in how freedom and time are understood is what helped create the contemporary phenomena of the two cultures in the first place. ${ }^{31}$

In either case, the competition that developed between the two cultures concerning their understandings of freedom and time is clearly illustrated in the work of the widely lauded modernist physicist Albert Einstein ${ }^{32}$ and the postmodernist philosopher Martin Heidegger. ${ }^{33}$ These two

${ }^{31}$ In seeking after a clue that might unveil the origin of the conflict between the two cultures, it must be remembered that, even in this specific context of academic cultures, "all cultures consist of concepts," Alexandre Kimenyi, "Anatomy of Culture," at http://kimenyi.com/anatomy-of-culture.php (accessed May 21 2014). Furthermore, meaningful "communication requires common concepts," Marion Ledwig, "Folk Psychology and Proverb Knowledge as Common Knowledge in Decision-Making," in Cultures: Conflict, Analysis, Dialogue, ed. Christian Kanzian and Edmund Runggaldier (Piscataway, NJ: Transaction Books, 2007), 193-200, 195. See also, Marion Ledwig, Common Sense: Its History, Method, and Applicability (New York, NY: Peter Lang, 2007), 136. Therefore, given that different cultures sometimes have different concepts, and "common knowledge is restricted to the culture one lives in," if different conceptualizations of seemingly common concepts emerged gradually, then it might be possible to explain the emergence of the two cultures from a primordial culture that struggled over differing conceptualizations of the primordial concepts of freedom and time, Ledwig, "Folk Psychology and Proverb Knowledge as Common Knowledge in Decision-Making," 195.

${ }^{32}$ Einstein is frequently acknowledged "as the world's (and perhaps history's) most renowned scientist," standing without peer as "the iconic scientific figure of the twentieth century," Todd Timmons, Makers of Western Science: The Works and Words of 24 Visionaries From Copernicus to Watson and Crick (McFarland, 2012), 174. See also, Dennis R. Hall and Susan Grove Hall, ed. American Icons: An Encyclopedia of the People, Places, and Things that have Shaped Our Culture (Westport, CT: Greenwood Press, 2006), 222; Abraham Pais, Subtle is the Lord: The Science and Life of Albert Einstein (New York, NY: Oxford University Press, 1982); and Donald Goldsmith and Marcia Bartusiak, eds. E = Einstein: His Life, His Thought, and His Influence on Our Culture (New York, NY: Sterling Publishing Co., 2006). Concerning science itself and Einstein's relationship to it, historically, "it was not until science emerged in the $16^{\text {th }}$ century that rationalism and empiricism were wed and sensory information provided that which was reasoned about. Science therefore minimized the extremes of both rationalism and empiricism," B. R. Hergenhahn, An Introduction to the History of Psychology (Belmont, CA: Wadsworth, 2009), 34. Thus, as Richard Milton, a challenger of modern science's grip, nevertheless states it, "Einstein's general theory of relativity, published in 1915, is often taken as a flawless example of the scientific method in operation. The theory was universally accepted so quickly and decisively because Einstein was able to make several predications from the theory that were empirically confirmed within only eight years," essentially, despite certain complexities, making Einstein an "ideal follower of the scientific method," which "is the centrepiece of western analytical thought. It is the golden untarnishable truth at the heart of the West's rational philosophy. Centred on the concept of proof, of concrete empirical evidence and repeatability, the scientific method is the closest that human minds have ever approached to eternal truth by rational means," a "paradigm" to be followed. Richard Milton, Alternative Science: Challenging the Myths of the Scientific Establishment (Rochester, VT: Park Street Press, 1996), 185. The well known philosopher of science Karl Popper concurred, "what impressed me most was Einstein's own clear statement that he would regard his theory as untenable if it should fail certain tests.... Here was an attitude utterly different from the dogmatism of Marx, Freud, Adler and even more so that of their followers. Einstein was looking for crucial experiments whose agreement with his predictions would by no means establish his theory; while a disagreement, as he was the first to stress, would show his theory to be untenable," Karl Popper, Conjectures and Refutations (London, UK: Routledge \& Kegan Paul, 1963), 34.

33 Although some may trace the origins of postmodernism further back, to figures such as Friedrich Schleiermacher, "Heidegger's influence on twentieth century thought has been profound and many of the writers who see themselves, or have been plausibly seen, as postmoderns have been influenced by him," Nicholas J. Rengger, Retreat from the Modern: Humanism, Postmodernism, and the Flight from Modernist Culture (London, UK: Bowerdean Publishing, 1996), 35. Note also, Bernhard E. Bürdek, Design: History, Theory and Practice of Product Design rev. ed. (Basel, Switzerland: Birkhäuser, 2015), 102. Martin Woessner asserts, "Heidegger was a polarizing philosopher in the twentieth century. His legacy divided his profession into two 
represent the most iconic representatives of the two cultures, the sciences and humanities, during the

past century. Einstein and Heidegger represent the quintessential masters of exploring the concept of

time, as represented in their best known contributions, namely Einstein's special and general theories

of relativity ${ }^{34}$ and Heidegger's lifelong reflections on human existence in his magnum opus Being and

antagonistic camps-so-called analytic and continental philosophies, respectively.... If Heidegger cannot be seen as the cause of the continental/analytic split, he certainly served as its most frequent point of contention. . . Such disputes show no sign of abating," Martin Woessner, Heidegger in America (New York, NY: Cambridge University Press, 2011), 181. Woessner furthermore contends that "without Heidegger, postmodern theology simply would not exist," ibid., 125. Heidegger has also alternately been described as an anti-modernist by David J. Rosner, Conservatism and Crisis: The Anti-modernist Perspective in Twentieth Century German Philosophy (Lanham, MD: Lexington Books, 2012), xii. Various individuals have expressed sentiments along the lines of Friedrich Kittler, who notes that his friend, Terry Winograd, a computer programmer, "familiarized himself with Martin Heidegger in order to gain an initial understanding of what the humanities, and humans in their language-bound everyday existence, are all about," Friedrich Kittler, "Thinking Colours and/or Machines," in Theory, Culture \& Society \#23 (2006), 40. "Heidegger took a very strong stance and maintained that the humanities should not imitate the methods of the natural sciences at all," and that although "rigorousness is indeed a great advantage of mathematics and the natural sciences," "this advantage indeed has its price, namely, their confinement upon a much limited domain of natural or technical objectivity. With respect to the various existential situations confronted by man, they indeed appear too narrow," Kwan Tze-wan, "The Human Sciences and Historicality: Heidegger and the Self-positioning of the Western Humanistic Tradition," in Space, Time and Culture, eds. David Carr and Chan-Fai Cheung (Dordrecht, The Netherlands: Kluwer Academic, 2004), 39. See also, Barbara Bolt, Heidegger Reframed: Interpreting Key Thinkers for the Arts (New York, NY: I. B. Tauris \& Co., 2011), 6; Iain D. Thomson, Heidegger, Art, and Postmodernity (Cambridge, UK: Cambridge University Press, 2011); Michael A. Peters, ed. Heidegger, Education, and Modernity (Lanham, MD: Rowman \& Littlefield, 2002), 4; Timothy Clark, Martin Heidegger (London, UK: Routledge, 2002); and David Inglis and Christopher Thorpe, An Invitation to Social Theory (Malden, MA: Polity Press, 2012), 189-207; Ulrich Horstmann, "The Aphorist as GoBetween," in Literature and Philosophy, ed. Herbert Grabes (Tübingen, Germany: Gunter Narr Verlag, 1997), 150; and Pauline Marie Rosenau, Post-Modernism and the Social Sciences: Insights, Inroads, and Intrusions (Princeton, NJ: Princeton University Press, 1992).

${ }^{34}$ For an introduction to relativity, see Rafael Ferraro, Einstein's Space-Time: An Introduction to Special and General Relativity (New York, NY: Springer, 2007); and Albert Einstein, Relativity: The Special and the General Theory, tr. Robert W. Lawson (New York, NY: Three Rivers Press, 1961, 1916). Put concisely, these two theories state that all motion must be defined relative to a frame of reference and that space and time are relative, rather than absolute concepts: they consist of two principal parts. The theory dealing with uniform motion (special theory of relativity or special relativity) is based on the two postulates that physical laws have the same mathematical form when expressed in any inertial system, and the velocity of light is independent of the motion of its source and will have the same value when measured by observers moving with constant velocity with respect to each other. Derivable from these postulates are the conclusions that there can be no motion at a speed greater than that of light in a vacuum, mass increases as velocity increases, mass and energy are equivalent, and time is therefore dependent on the relative motion of an observer measuring the time. The theory dealing with gravity (general theory of relativity or general relativity) is based on the postulate that the local effects of a gravitational field and the acceleration of an inertial system are identical. What is critical to grasp here is that because Einstein's equations generate motion over time as part of the symmetry of his theory, physicists realize that there is no true evolution of time in relativity. Furthermore, because the speed of light (c) is considered to be the fastest known form of physical motion (rather, the only pure physical motion), the speed of causality is associated with it, bringing the issue of temporal-causality into the theory of relativity in a distinct manner. For more on this, see David Bohm, The Special Theory of Relativity (New York, NY: Routledge, 1996), $118,156$. 
Time and elsewhere. ${ }^{35}$ The way these two intellectuals viewed time, with Einstein capturing time 'objectively' within a series of ingenious mathematico-physical equations, ${ }^{36}$ and Heidegger making time the 'subjective' lynchpin for hermeneutics (the 'art of interpretation') to become the philosophical key to understanding what it means to be human, and the subsequent influence they have had on others who have continued along their conceptual trajectories, has been significant. ${ }^{37}$ Importantly, however, and illustrative of the division between the two cultures, by and large "Heidegger's name is very rarely mentioned in the mainstream philosophy of science literature," where "there is virtually no serious consideration of his thought." ${ }^{38}$ Of course, as one might expect

${ }^{35}$ For a recent translation of his most famous work, see Martin Heidegger, Being and Time, tr. Joan Stambaugh with Dennis J. Schmidt (Albany, NY: State University of New York Press, 2010). “Considering himself conversant enough in mathematics and physics to discuss the nature of time with [Albert] Einstein, Heidegger believed that what was missing from the scientific account was the human dimension. He thought that because of this absent 'spiritual' perspective, most people today feel 'lost' in their world," Eva Hauel Cadwallader, "Guest Preface," in William Henry Werkmeister, Martin Heidegger on the Way, ed. Richard T. Hull (Atlanta, GA: Rodopi, 1996), xviii. Cadwallader notably adds, however, that "it is important not to confuse the term 'spiritual [geistlich] as Heidegger used it with either 'moral' or 'religious.' He went out of his way to deny such connotations," ibid. Accordingly, Heidegger was especially interested in the human dimension, not the religious one per se that includes God, emphasizing the humanities as a distinct area of study apart from theology or religion, at least as Heidegger understood those disciplines during his time. Accordingly, Heidegger "offered his 'ontological' (philosophical) account of 'Being' as opposed to the 'ontic' or 'factical' one posed by science and the unthinking ordinary mentality stemming from it in a technological era. He saw the 'ontological' viewpoint as necessary for the possibility of living a genuinely human life as opposed to the mere biological and physical existence of a sapient humanoid among a world of things," ibid. As Tom Greaves explains of the original context that motivated Heidegger, "when Heidegger was a student and young academic philosopher in early twentiethcentury Germany, there was a deep-seated sense that there were two cultures of thought, or two kinds of 'science'. On the one hand, there are the natural sciences (Naturwissenshaften) that try to find universal laws of nature and generally applicable explanations for natural phenomena. On the other hand, there are the 'spiritual sciences' (Geisteswissenshaften), which in English are usually called humanities, that seem to be concerned with phenomena that cannot be easily brought under such laws and general explanations, but rather are concerned with the particularities of texts, actions, works and so forth. How was philosophy to situate itself with regard to these two cultures? Does philosophy belong to one or the other? Are they really irreconcilable, or is there actually a way of finding what is common between them?" Greaves continues, "These were the kind of questions that were felt to be philosophically pressing. There were two schools of thought that tried to engage with them. On the whole, the neo-Kantians saw philosophy as principally engaged in giving a conceptual grounding to the natural sciences. The historical and hermeneutic school, on the other hand, thought that we must ultimately grasp the significance of natural science within an understanding of the history and development of human knowledge and life as such," Greaves, Starting with Heidegger, 140.

${ }^{36}$ For a review of Einstein's equation, see John C. Baez and Emory F. Bunn, “The Meaning of Einstein's Equation," available at http://math.ucr.edu/home/baez/einstein/einstein.pdf (accessed July 1, 2014). See also, Hans Reichenbach, From Copernicus to Einstein (Read Books Ltd., 2013).

${ }^{37}$ Einstein and Heidegger are frequently featured in general works discussing time. For example, see Lawrence W. Fagg, The Becoming of Time: Integrating Physical and Religious Time (Atlanta, GA: Scholars Press, 1995), 21-26, 29-56; and Mike Sandbothe, The Temporalization of Time: Basic Tendencies in Modern Debate on Time in Philosophy and Science, tr. Andrew Inkpin (Lanham, MD: Rowman \& Littlefield, 2001), 42-43, 61-108.

${ }^{38}$ Hans Pedersen, "Approaching the Debate over Tensed and Tenseless Theories of Time from a Heideggerian Perspective," in Being Amongst Others: Phenomenological Reflections on the Life-World, ed. Eric Chelstrom (Angerton Gardens, UK: Cambridge Scholars Press, 2006), 12-23, 17. 
within the "two cultures" milieu, the same holds true for most postmoderns and Heideggerians concerning Einstein's theories, ${ }^{39}$ which are blithely dismissed as being not ultimately meaningful for understanding the essence of existence or the human condition. As Richard Polt explains, "Einstein's theories are meaningful only to someone trained to approach nature in a certain way, the way of Western modernity. Science, while it may reveal certain facts, nevertheless still requires a special mood and a special use of language" that may be too constraining for philosophy and even the philosophy of science itself, and thus science discourages "other approaches that may someday prove to be more illuminating" for understanding reality, even those portions of it which may appear amenable to scientific approaches. ${ }^{40}$ The irony in the above situation is that both Einstein and Heidegger could, themselves, be considered more interested in engaging the other side of the still developing two cultures schism than their followers generally appear to be today.

Overall, what is clear is that Einstein's and Heidegger's works have had a continuing and profound impact upon both scholars and popular culture concerning how to "describe" time. More specifically, the influence of their differing descriptions of how time relates to or is manifest within

\footnotetext{
39 “The widespread adoption, around 1919, of Einstein's Theory of General Relativity ... contributed to a bifurcation between the arts and sciences. Different 'dialects,' or jargon, developed for the different disciplines making communication very difficult between scientists and artists," Janelle Robyn Humphreys, Shadows of Another Dimension: A Bridge Between Mathematician and Artist (University of Wollongong Thesis Collections, 2009), 15-16.

${ }^{40}$ Richard Polt, Heidegger: An Introduction (London, UK: Routledge, 1999), 125. Polt adds, “Heidegger is not a radical relativist who would say that Einstein's theories are on par with astrology. Einstein's theories are true: that is, they do unconceal things, and much more so than astrology. However, this unconcealment is made possible for us by a historical context which, like all historical contexts, is limited and is open to innovation," ibid. Polt also observes, however, that "we may have explained the controversy; we have not resolved it." For Heidegger's dismissal of science and its "logic, as a theory of propositional truth," as holding less "importance for philosophy" carries significant consequences. "As we are about to see, [Heidegger's] thinking about" a more "primordial truth calls for an investigation of the mysteries of human freedom-and here, logic is no help to us," ibid., 126. Similarly, Heideggerian scholar Theodore Schatzki in one of his recent works openly "disregards debates about the proper analysis of objective [Newtonian or Einsteinian] time and space. Eschewing these debates is inconsequential for [my] present purposes" as "their resolution is more or less irrelevant to social analysis," Theodore R. Schatzki, The Timespace of Human Activity: On Performance, Society, and History as Indeterminate Teleological Events (Plymouth, UK: Lexington Books, 2010), 4. As such, Heideggerians like Polt and Schatzki feel free to disregard Einstein and his scientific method whenever they feel it necessary or advantageous. The attitude of these Heideggerians follows directly from that of one of Heidegger's best known students, Hans-Georg Gadamer, who wrote that "science" is "no longer the quintessence of knowledge and of what is worth knowing, but [merely] a way" of knowing amongst others, Hans-Georg Gadamer, Reason in the Age of Science, tr. Frederick G. Lawrence (Cambridge, MA: The MIT Press, 1982), 69-70 (addition mine).
} 
humans is evident through their respective introductions of a timeless four-dimensional space-time ${ }^{41}$

and a temporal four-dimensional time-space. ${ }^{42}$ It is generally acknowledged that these opposed

\begin{abstract}
${ }^{41}$ Einstein, with notable help from the mathematician Hermann Minkowski, famously construed reality as a "four-dimensional whole, or 'block-universe'." In such a universe, "temporal development and coming-intobeing would not be something that occurs but rather something that is implicit in that fixed, unchangeable fourdimensional whole." Einstein combined space and time into a new "three-dimensional space and onedimensional time," wherein "time is here block-time, the whole of time timelessly laid out," J. J. A. Mooij, "The Flow and the Map: On the Dynamic and Static Views of Time," in The Two Cultures: Shared Problems, eds. Ernesto Carafoli, Gian Antonio Danieli, Giuseppe 0. Longo (Milano, Italy: Springer-Verlag, 2009), 17. It is important to note that, while Einstein himself did not bother pursuing an explicit mathematical proof for timelessness, his friend and mathematician Kurt Gödel did do so. "By 1949, Gödel had produced a remarkable proof: In any universe described by the Theory of Relativity, time cannot exist. Einstein endorsed this result reluctantly, but he could find no way to refute it, and in the half-century since then, neither has anyone else," Palle Yourgrau, A World Without Time: The Forgotten Legacy of Gödel and Einstein (Cambridge, MA: Basic Books, 2005), back cover.
\end{abstract}

Very importantly, it must be pointed out that there are is an alternative interpretation of Relativity that does not require a four-dimensional 'block-universe,' and is somewhat more compatible with a Newtonian view of absolute space and time, though is still incompatible with a Heideggerian understanding. For the purposes of my study it merely must be noted that many physicists hold the above views. In any case, the alternative interpretation is based upon the Lorentz Transformations, described by Hendrik Lorentz. For multiple explanations of their role in Relativity, see William Lane Craig, Time and the Metaphysics of Relativity (Dordrecht, the Netherlands: Springer, 2001); William Lane Craig and Quentin Smith, eds. Einstein, Relativity and Absolute Simultaneity (New York, NY: Routledge, 2008); Craig Bourne, A Future for Presentism (Oxford, UK: Oxford University Press, 2006); Marc Lange, Because Without Cause: Non-Causal Explanations in Science and Mathematics (Oxford, UK: Oxford University Press, 2017); and Peter Forrest, "Relativity, the Passage of Time and the Cosmic Clock," in The Ontology of Spacetime II, ed. Dennis Dieks (Amsterdam, The Netherlands: Elsevier, 2008), 245-254. This interpretation will be briefly addressed below in chapter three.

${ }^{42}$ It should be stated as clearly as possible that the meaning of 'temporality' in Heidegger's time-space is in contradistinction to not only Einstein's space-time, but also the colloquial use of 'temporality' within a Newtonian worldview. This distinction is not well understood by many scientists and theologians. The evolution of Heidegger's thinking from Being and Time in 1927 to his later development of time-space cannot be detailed here. For more on Heidegger's concept of time-space, see, for example, Rufus A. Duits, Raising the Question of Being: A Unification and Critique of the Philosophy of Martin Heidegger (Boca Raton, FL:

Dissertation.com Publishers, 2009), 108-110. Duits observes, Heidegger's "time-space is in essence fourdimensional; but in contrast to four dimensional space-time, time-space has three temporal dimensions and one spatial dimension," ibid., 109. The concept of time-space is introduced in Martin Heidegger, Contributions to Philosophy (of the Event), tr. Richard Rojcewicz and Daniela Vallega-Neu (Bloomington, IN: Indiana University Press, 2012), 293-306; and Martin Heidegger, What is a Thing?, tr. W. B. Barton, Jr., and Vera Deutsch (Chicago, IL: Henry Regnery, 1967), 16-17. Heidegger's 'time-space has nothing to do with the physicists' sense of spacetime; it is not a four-dimensional container. Nor is it something like a span of time. The idea of time-space also completely supersedes any attempt to elevate subjective time over objective time." Rather, "time-space, for Heidegger, is a way of articulating the primordial dimensionality of Being," a "way of talking about a site of preobjective opening or 'constitution,' a site that radically precedes such distinctions as space and time," David Wood, The Deconstruction of Time (Evanston, IL: Northwestern University Press, 2001), xxi. Thus, "Dimensionality, Heidegger writes, "belongs to true time and to it alone,"” Claude Cernuschi, Barnett Newman and Heideggerian Philosophy (Lanham, MD: Fairleigh Dickinson University Press, 2012), 210. Heidegger's views are in direct contrast to many analytical philosophers of time, wherein "since time is one-dimensional, it is hard to see how there could be interesting 'geometrical' questions about time," Peter van Inwagen, Metaphysics $2^{\text {nd }}$ ed. (Boulder, CO: Westview Press, 2002), 70 n. 3. For many Heideggerians, however, time is not only considered to be multi-dimensional, but it also has geometrically analogous components. See, for example, Steven M. Rosen, Topologies of the Flesh: A Multidimensional Exploration of the Lifeworld (Athens, OH: Ohio University Press, 2006), 23-49; and Diego Lucio Rapoport, "Hyper Klein Bottle Logophysics Ontopoiesis of the Cosmos and Life," in Phenomenology of Space and Time: The Forces of the Cosmos and the Ontopoietic Genesis of Life: Book Two, ed. Anna-Teresa Tymieniecka (London, UK: Springer, 2014), 283. "Einstein's purport of vanishing subjectivity from physics, is maintained by denying self-reference as an essential ontological and geometrical locus," ibid. See 
mirror-like descriptions, to all appearances, do indeed offer contradictory explanations ${ }^{43}$ of the ultimate nature of time. ${ }^{44}$

also, John Llewelyn, The Rigor of a Certain Inhumanity: Toward a Wider Suffrage (Bloomington, IN: Indiana University Press, 2012), 69. "The denial of temporal overlap is undermined once it is granted that the view of time as a straight line is an abstraction from our concrete lived experience of the geometry of time and therefore the experience of language is [better described as] that of a circle or, better, a spiral. This may be a spiral upward or a spiral downward, depending on whether the interpretation of a term is imaginative or unimaginative.... To imagine is at least to ask What if? And that question can be asked of the past, of the present, or of the future," ibid.

${ }^{43}$ There is evidently a "contradiction between [Einstein's] special relativity and [Heideggerian] temporality" if one takes them "both seriously," which is "amplifie[d] . . . by claiming that nature is at the same time the unmediated background of practice, and irrelevant for the temporality of practice," Niels Viggo Hansen, "Spacetime and Becoming: Overcoming the Contradiction Between Special Relativity and the Passage of Time," in Physics and Whitehead: Quantum, Process, and Experience, ed. Timothy E. Eastman and Hank Keeton (Albany, NY: State University of New York Press, 2003), 148-149. Hansen adds that "in Heidegger's view, any construction of physical time is bound to be so much of an externalization and hypostatization of a certain aspect of the temporality of practice that contradiction should be expected rather than avoided. Hence, a genuine coherent understanding of the relation would only be possible by reducing any physical notion of time to the role of a practical bookkeeping device, so derivative as to have no ontological significance beyond that revealed by a hermeneutics of its underlying practice entirely independent of its technical details. On the face of it, this denial is all that Heidegger has to offer us as an answer to the contradiction," ibid., 148. Hansen's own "solution" is to highlight the speculative work of Whitehead, who, siding very much with Heidegger on one key point, shares that temporal facts are not global, but local, which he admits may not be tenable or thinkable-and such a notion would not be acceptable to most scientists anyway. Again, as Hansen explains, "the gentle tone of voice which should be heard in the process metaphysical suggestion" here "is proposed as a conceptual structure which may make coherent sense of vastly different and apparently contradicting fields of language and practice, which is exactly what experienced temporality and scientific time are. And it seeks legitimacy not by pointing to aprioristic authority from some unquestionable fundamentals somewhere else, but rather from turning out to be richer and more useful than other schemes in this kind of situation. So in looking to Whitehead's systematic development of the concept of process, we find not so much authority as instead a particularly rich, radical and flexible structure" to try out, ibid., 159 (italics mine). Noteworthy, however, is that Whitehead's project controversially depends upon 'timeless' "eternal objects." See Jon Mills and Janusz A. Polanowski, The Ontology of Prejudice (Atlanta, GA: Rodopi, 1997), 161; and for a critique of them, see Everett W. Hall, "Of What Use Are Whitehead's Eternal Objects?," in Alfred North Whitehead: Essays on His Philosophy, ed. George L. Kline (Lanham, MD: University Press of America, 1989), 101-116. Hall's suggestions and 'solutions', however, only seem to highlight the paradoxical ambiguity of Whitehead's suggested philosophy, ibid., 114-115. See also, Kent D. Palmer, The Fragmentation of Being and the Path Beyond the Void: Speculations in an Emergent Onto-Mythology (Orange, CA: Apeiron Press, 2007), 134-139.

Furthermore, the significance of Einstein and Heidegger's differences on freedom and time for the culture wars is explained, in part, by Otto Pöggeler, when he observed, "Heidegger wanted to be able to enter into dialogue with ... Einstein." However, "Einstein argued that the concept of lived time," with which Heidegger and the similarly thinking philosopher Henri Bergson depended, came from "a metaphysical illusion . .. based upon an unscientific intuition," Otto Pöggeler, "Heidegger, Nietzsche, and Politics," in The Heidegger Case: On Philosophy and Politics, eds. Tom Rockmore \& Joseph Margolis (Philadelphia, PA: Temple University Press, 1992), 127. See also, Jimena Canales, The Physicist \& the Philosopher: Einstein, Bergson, and the Debate That Changed Our Understanding of Time (Princeton, NJ: Princeton University Press, 2015), esp. 139-152, 252264. Canales explains that Heidegger went even further than Bergson, to "tackle aspects of time in a way that was not limited by the dual perspective of 'clock' versus 'lived' time," ibid., 148.

${ }^{44}$ In contrast to Newtonian time, "we might assume that contemporary relativistic space-time is closer to the time-space that Heidegger is trying to help us to think, but that concept takes time as another calculable element (the $t$ of the equations), as a fourth parameter that, with the three spatial parameters, constitutes the four-dimensional space of physics. However, as Heidegger points out, this is essentially a very elaborate development from out of the original metaphysical flattening, abstracting, and grasping that create parametric space and time," Gail Stenstad, Transformations: Thinking After Heidegger (Madison, WI: The University of Wisconsin Press, 2006), 105. 
The tension resulting from Einstein's and Heidegger's descriptions of the nature of time and its potential relationship to the human being interestingly further manifests itself in tensions concerning how freedom should be described, particularly for humans, establishing a distinct interrelationship between specific conceptions of freedom and distinct understandings of time. ${ }^{45}$ Although neither Einstein nor Heidegger emphasized the issue of freedom extensively relative to their other pursuits, ${ }^{46}$ interpreters of their respective contributions realized that both Einstein's and Heidegger's views of time required freedom to be located outside of the traditional understandings of nature and natural science which have predominated since Isaac Newton, René Descartes, and Immanuel Kant.

${ }^{45}$ Of course, as the thesis of the current study posits, freedom intricately related to discussions on time. This is because "metaphysical issues about freedom also involve time" if "whether we have free will ... depends on how present time is related to future time," which in turn depends on how time itself is defined, Quentin Smith, Time, Change, and Freedom: An Introduction to Metaphysics, eds. Quentin Smith and L. Nathan Oaklander (New York, NY: Routledge, 1995), ix. Of course, the questions concerning what a "moment" of time is at which an act of freedom may occur, and what distinguishes a willed, free, or contingent act from a necessary one, remain highly controversial in philosophy and the natural sciences. Note also, Richard Double, Metaphilosophy and Free Will (New York, NY: Oxford University Press, 1996), 10. Many believe that "as an empirical issue, the interplay between contingency and necessity in the history of life will remain unsettled for some time," Evan Thompson, Mind in Life: Biology, Phenomenology, and the Sciences of the Mind (Cambridge, MA: The Belknap Press of Harvard University Press, 2007), 217.

${ }^{46}$ Notably, Einstein himself did not believe in human freedom or free will, as is explained by Walter Isaacson, Einstein: His Life and Universe (New York, NY: Simon \& Schuster, 2007), 391-392. Furthermore, despite certain quotes to the contrary, he struggled with the concept that God is personal, preferring deism. See the discussion by W. Russell Ogden, The Freedom Book: Choosing Your Future (Bloomington, IN: WestBow Press, 2011), 19-20. Einstein also wrote, concerning God, that "If this being is omnipotent, then every occurrence, including every human action, every human thought, and every human feeling and aspiration also is His work; how is it possible to think of holding men responsible for their deeds and thoughts before such an almighty Being? In giving out punishment and rewards He would to a certain extent be passing judgment on Himself. How can this be combined with the goodness and righteousness ascribed to Him?," Albert Einstein, Out of My Later Years (New York, NY: Philosophical Library, 1950), 27.

Conversely, although Heidegger discusses freedom with less specificity and frequency in his lifetime corpus than his many other concerns, it has nevertheless been suggested to be "a possible and fruitful endeavor 'to read the philosophy of Heidegger as a whole as a philosophy of freedom,'” Bret W. Davis, Heidegger and the Will: On the Way to Gelassenheit (Northwestern University Press, 2007), 71. Davis approvingly cites the opinion of Günter Figal, Martin Heidegger: Phänomenologie der Freiheit, $3^{\text {rd }}$ ed. (Weinheim: Beltz Athenäum, 2000 ), 23. In fact, Heidegger did address the topic of freedom at length in such works as Martin Heidegger, The Essence of Human Freedom, tr. Ted Sadler (New York, NY: Continuum, 2002); and Martin Heidegger, Schelling's Treatise on the Essence of Human Freedom, tr. Joan Stambaugh (Athens, OH: Ohio University Press, 1985). In a somewhat surprising quote, given his strong emphasis on "time" and "Being," Heidegger once even asserted: "the question concerning the essence of human freedom is the fundamental question of philosophy, in which is rooted even the question of Being," thus "the question concerning the essence of freedom is the fundamental problem of philosophy, even if the leading question thereof consists in the question of Being." In the same work, Heidegger explained that "the essence of freedom only comes into view if we seek it as the ground of the possibility of Dasein, as something prior even to being and time," Heidegger, The Essence of Human Freedom, 203, 205, 93 (emphasis original). 
Einstein's philosophy, which actually denied the existence of free will ${ }^{47}$ in favor of an absolute determinism throughout nature, banished any concept of freedom to a Kantian timeless-idealistic metaphysical ${ }^{48}$ (the meaning of the 'meta' within 'metaphysics' has generated complex discussions,

\begin{abstract}
${ }^{47}$ For more, see Denis Brian, Einstein: A Life (New York, NY: J. Wiley, 1996), 233. See also, Lewis Tagliaferre, Theofatalism: Theology for Agnostics and Atheists (Bloomington, IN: iUniverse, 2013), 123-124; and V. Alexander Stefan, Thus Spoke Einstein on Life and Living: Wisdom of Albert Einstein (La Jolla, CA: The Stefan University Press, 2011), 345-346. For the original German by Einstein, written in 1932, see Albert Einstein, http://www. einstein-website.de/z_biography/credo.html (accessed September 24, 2017). "Ich glaube nicht an die Freiheit des Willens," ibid.

${ }^{48}$ Overall, of course, depending on one's own background or the time period one is studying, the meaning, content, purpose, and necessity of metaphysics may seem optional or even undesirable. This is because the precise meaning of metaphysics itself depends greatly on the context of what exactly metaphysics is described as doing or studying. In particular, note the extended discussion in the Stanford Encyclopedia of Philosophy, Peter van Inwagen, "Metaphysics," at http://plato.stanford.edu/entries/metaphysics/ (accessed June 7, 2011). Additionally important is the relationship of metaphysics to science. For example, prior to the modern development of the "history of science, scientific questions were addressed as a part of metaphysics known as natural philosophy. The term science itself meant 'knowledge' of, originating from its use with epistemology. The scientific method, however, transformed natural philosophy into an empirical activity deriving from experiment unlike the rest of philosophy. By the end of the $18^{\text {th }}$ century, it had begun to be called
\end{abstract} 'science' to distinguish it from philosophy. Thereafter, metaphysics denoted philosophical enquiry of a nonempirical character into the nature of existence. Some philosophers of science, such as the neo-positivists, say that natural science rejects the study of metaphysics, while other philosophers of science strongly disagree," in Peter Gay, The Enlightenment: The Rise of Modern Paganism (New York NY: W. W. Norton \& Company, 1966), 132-141. Importantly, some believe that "the only way that metaphysics and science can be compatible is if metaphysics-'that which comes after physics'-is in fact mathematics. Science without mathematics is nothing." Indeed, within such a view, "it's not the scientific method" that one should refer to, "but the mathematical method that gives science all of its power. It's mathematical rationalism, not experimental empiricism, that defines science. To see the truth of that, simply remove mathematical rationalism from science and see what's left." Brother Cato suggests that "due to empiricist ideology, [some] scientists dogmatically reject the ontology of mathematics. This makes them people of faith, not reason. It makes them worshipers of the religion of scientism." "Everything falls into rational and logical place as soon as you ground science in mathematics rather than in sensory experiments. ..". "science [must] at last" switch "from empiricism to rationalism," Brother Cato, Illuminism Contra Discordianism (Raleigh, NC: Lulu Press, 2016), np (additions mine). See also, Brother Abaris, The Illuminist Army (Raleigh, NC: Lulu Press, 2016). There is, interestingly, at first glance a similarity to the views of metaphysics as mathematics and metaphysics as theology. "The nature of the reality of mathematical objects and the objectivity of mathematical statements constitute two of the deepest problems in the philosophy of mathematics. Objectivity would imply a fundamental harmony between the structure of the human mind and the intelligibility of the universe; it would imply that knowledge arrived at through mathematical theories accurately represents the nature of the world and that there is an intrinsic harmony between the nonempirical, logical worlds of the mind and the empirical worlds of experience. But there are huge difficulties with such a view, and some have even suggested that logic itself is empirical.... It is possible, in other words, to construct an internally coherent mathematical theory without supposing that any reality exhibiting the properties corresponding to that theory can be found in the physical universe. Indeed, mathematics seldom regards the physical universe as an appropriate criterion to employ in deciding upon the intrinsic interest of its theories, and once the question is asked it is not easy to say why the physical universe should be the final arbiter of 'reality' except under one particular preference.... This description [given above] shows a prima facie similarity between the mathematical and theological enterprises. It is possible to construct countless internally consistent theologies without supposing that there is an objective reality, a god or gods, to whom they refer. To the numerous major world religions can be added a large number of variants, each with its distinctive way of speaking about a god or some kind of ultimate reality. The nature of the reality of theological objects and the objectivity of theological statements constitute two of the deepest problems in the philosophy of religion," John Puddefoot and Irène Fernandez, "Mathematics and Theology," in the Encyclopedia of Christian Theology: Vol. 1 (A-F), ed. Jean-Yves Lacoste (New York, NY: Routledge, 2005), 1010-1013, 1010. 
with at least three prominent and sometimes conflicting interpretations aiding the confusion many

have about it which affects how freedom and time are described ${ }^{49}$ ) existence beyond both natural

\begin{abstract}
${ }^{49}$ With reference to the footnote immediately preceding this one, 'metaphysics,' as I use it here and will use throughout this study, has at least three distinct meanings that at times become interrelated. Historically, it must be noted that the phrase itself originated with Aristotle, as an inquiry into the "science which investigates being qua being [ôv î̉ ôv] and the properties inherent in it in virtue of its own nature." Whereas the other branches of human enquiry (the modern branches of the sciences) or regional ontologies tend to "cut off a part of being and investigate the attributes of this part," metaphysics enquires into the nature of being itself, or general or 'fundamental ontology,' Aristotle, The Metaphysics: Books I-IX, tr. Hug Tredennick (Cambridge, MA: Harvard University Press, 1980), 147. As such, 'metaphysics' also seeks to understand the 'One and the Many,' a classic problem of ancient philosophy that endures to this day, and when used as such and in relation to the above, metaphysics is sometimes called 'general metaphysics.' Aristotle's use of the term constitutes the first or original meaning. See also, Timothy Stanley, Protestant Metaphysics after Karl Barth and Martin Heidegger (Eugene, OR: Cascade Books, 2010), 16-17.

Second, 'metaphysics' can refer to our inquiries into, as Kant put it in his frequently cited quote, "God,
\end{abstract} freedom, and immortality [or existence in relation to time]," Kant, Critique of Pure Reason, 792; 3, 602, 640 (addition mine). Generally throughout this study it will be used in this Kantian way in reference to any discussion that seeks to describe the relationship of God, freedom, and time, which is sometimes referred to as 'special metaphysics.' Noteworthy is that to a great degree, what motivates Heidegger's departures from Kant concern directly these issues. See, for example, Martin Heidegger, Phenomenological Interpretation of Kant's Critique of Pure Reason, tr. Parvis Emad and Kenneth Maly (Bloomington, IN: Indiana University Press, 1997), 10-11, 41; and for a reformulation of the fundamental questions of philosophy: "What can I know? What should I do? What may I hope for? These three questions belong to the domain of special metaphysics (knowledge of things: to cosmology; human action and freedom: to psychology; the hope of immortality as union with God: to theology); they determine the nature of man and constitute the field of philosophy. The three questions can be reduced to (summarized in) a forth, single question: What is man?" George Kovacs, The Question of God in Heidegger's Phenomenology (Evanston, IL: Northwestern University Press, 1990), 124. The interrelationship of nature (cosmology), psychology, and immortality, constitute the nexus within which freedom and time appear and interact.

Thirdly, it can refer to, as Lord Kelvin evidently quipped, "mathematics," which he considered to be "the only good metaphysics," E. T. Bell, Men of Mathematics, (New York, NY: Simon \& Schuster, 2014), xvii. Kelvin's point, which is one supported through the anti-metaphysical period that dominated the scientific community in the 20th century, is that metaphysics refers most properly to that which is "after," "beyond," or "not" "physics" or "nature," but usually somehow applicable to or explains principles of nature, as with mathematics. It is in this sense that 'metaphysics' is used directly above in the text, with an emphasis on the beyond or "not" in relation to mathematized nature or mathematized natural science, which has an integral relationship with Einstein's theory of relativity.

The relationship between metaphysics, rationalism, empiricism, and mathematics is explained well by Ian Mueller, "Geometry and Scepticism," in Science and Speculation, eds. Jonathan Barnes, Jacques Brunschwig, Myles Burnyeat, and Malcolm Schofield (Cambridge, UK: Cambridge University Press, 1982), 70. Mueller shares, "As a rule mathematics has not sorted well with empiricism.... The very characteristics which make mathematics a problem for the empiricist make it a paradigm of knowledge for the rationalist," ibid., 70. Of course, modern science would change this relationship. R. Hooykaas insightfully observes that the scientific thinkers Johannes "Kepler and Galileo, in contrast to Plato, put forward a mathematical empiricism," thus combining the basic insights of Plato with his more empiricist minded student, Aristotle, R. Hooykaas, Religion and the Rise of Modern Science (Edinburgh, Scotland: Scottish Academic Press, 1972), 35-36. The mathematized empiricism of Kepler and Galileo brought the 'metaphysical mathematics' into materialism and physicalism, thus allowing the latter two to gain the prominence they have held lately as a complete postulate of reality. Of course, this is precisely the issue that is contended against by some, such as Thomas Nagel, Mind and Cosmos: Why the Materialist Neo-Darwinian Conception of Nature is Almost Certainly False (Oxford, UK: Oxford University Press, 2012), 18. Nagel questions, "how much of the world's intelligibility consists in its subsumability under universal, mathematically formulable laws governing the spatiotemporal order. If there are limits to the reach of science in this form, are there other forms of understanding that can render intelligible what physical science does not explain?," ibid. 
science and world-time. ${ }^{50}$ For most Heideggerians, freedom also appears outside of natural science as commonly understood (whether it is located within man as a physical being is a separate question); however freedom flows within some sort of temporal-idealistic ${ }^{51}$ metaphysical time, ${ }^{52}$ in a way that conflicts with both Einstein's space-time and Newton's absolute cosmic time. ${ }^{53}$ In other words,

${ }^{50}$ As explained by Roy D. Morrison II, “Tillich, Einstein, and Kant: Method, Epistemology, and the Personal God," in Theonomy and Autonomy: Studies in Paul Tillich's Engagement with Modern Culture, ed. John Jesse Carey (Macon, GA: Mercer University Press, 1984), 49-51; and Martin Gardner, The Whys of a Philosophical Scrivener (New York, NY: St. Martin's Press, 1999), 413, n. 8. Gardner states, “Kant's view can be compressed as follows: In the space-time world of your experience, the world investigated by science, causal determinism must be assumed; in this sense the will is not free. But morality is meaningless unless the will is somehow free. For practical reasons, therefore, we must assume that the human soul, considered as a noumenon, a thing in itself, belongs to a transcendent, timeless realm, and in this realm it is truly free. How empirical determinism and noumenal freedom can be reconciled, however, is a mystery utterly beyond our finite minds," ibid. Considering the influence of both Einstein and Kant's perspectives today, Morrison comments that, for those who have tried, "any attempt to overcome Kant must necessarily have involved an attempt to overcome Einstein because the latter carried Kant's theoretical attitude to its logical conclusion and, hence, provides no encouragement whatsoever for speculative metaphysics or for an ontology on the other side of the transcendental horizon," Morrison, "Tillich, Einstein, and Kant," 49. Alternately explained, those adhering to the philosophical commitments of Einstein (including Newtonian science, notwithstanding Einstein's significant revisions of Newton's contributions) and his descriptive analysis of reality typically depict human freedom as timeless or supratemporal-an atemporal flash in time. The reason for this is that Einsteinian thinking, which constitutes the operative model of scientific thinking, understands time as defined by the space-time continuum, which necessarily implies that freedom (if there is any freedom and reality is not completely determined) be located outside of time, hence, in a timeless realm. See, for example, the physicist Vesselin Petkov, Relativity and the Nature of Spacetime (Berlin, Germany: Springer-Verlag, 2009), 172; and Antoine Suarez, "Quantum Randomness, Free Will and Evolution," Powerpoint Presentation online at www.quantumphil.org (accessed 2010). This is an inheritance of the classical Kantian epistemology, which is reflected aptly by Slavoj Žižek's description of Shelling's inquiry into the problem of freedom, where "freedom is atemporal: a flash of eternity in time," Slavoj Žižek, with F. W. J. Von Schelling, The Abyss of Freedom: Ages of the World: An Essay, tr. Judith Norman (Grand Rapids, MI: The University of Michigan Press, 1997), 33. Here freedom is outside of the temporal-deterministic natural world and its closed continuum of causal laws which imply ontological timelessness. Stated otherwise-if ontological timelessness (the temporal-deterministic world of nature) defines space-time, and is considered the true realm of "time," then any other "location" must be "timeless" by definition, or so it seems.

${ }^{51}$ That Heidegger can be interpreted as a temporal idealist is argued forcefully by William D. Blattner, Heidegger's Temporal Idealism (Cambridge, UK: Cambridge University Press, 1999).

${ }^{52}$ As the Heideggerian philosopher Melvin Woody puts it, "freedom is necessarily temporal precisely because it must determine itself independently of the world. Freedom is not in [world] time, and therefore temporal; it is temporally. Its being is such as to require temporality of itself," Woody, Freedom's Embrace, 146 (addition mine). See also, Charles M. Sherover, Are We In Time? And Other Essays on Time and Temporality (Evanston, IL: Northwestern University Press, 2003), 170, 177; Frank Schalow, Departures: At the Crossroads Between Heidegger and Kant (Germany: Walter de Gruyter, 2013), 119-124, 131, 136-139; and Bouton, Time and Freedom, 141. Note also, Greg Shirley, Heidegger and Logic: The Place of Lógos in 'Being and Time' (New York, NY: Continuum, 2010), 103.

${ }^{53}$ Isaac Newton's "absolute time... does not depend on any physical object, but flows independently and without reference to external objects," Richard A. Holland, God, Time, and the Incarnation (Eugene, OR: Wipf \& Stock, 2012), 26. Holland also insightfully comments, "unlike the ancient Greek philosophers, and unlike later theologians, Newton does not anywhere describe eternity as timeless. Rather, God's eternity is the source or fountainhead of duration," ibid. However, as Julian Barbour observes, for many scientists, "Newton's absolute time was completely overthrown by the revolution of the special theory of relativity," Julian B. Barbour, Absolute or Relative Motion?: The Discovery of Dynamics Vol. 1 (New York, NY: Cambridge University Press, 1989), 633. See also, Milton K. Munitz, Cosmic Understanding: Philosophy and Science of the Universe (Princeton, NJ: 
interpreters of Einstein's and Heidegger's works agree that according to both their respective views, freedom should be separated from natural science or nature through the study of physics. ${ }^{54}$ However, they also generally concur that Einstein and Heidegger disagreed about the nature of metaphysics itself, including, in particular, how metaphysics should relate to both freedom and time.

Critically, the above tense situation concerning freedom and time has been inherited and replicated within the disciplines of theology and religious studies, both historically, as well as in the

Princeton University Press, 1986), 96; and Friedel Weinert, The Scientist as Philosopher: Philosophical Consequences of Great Scientific Discoveries (Berlin, Germany: Springer-Verlag, 2005), 113. It should also be noted, however, as Henry Stapp observes, "before Newton the history of the world could have been regarded as a growing body of facts, with the factual content of the region $t<T$ representing what is fixed and settled at time $T$, and the region $t>T$ representing the realm of the unfixed possibilities. However, Newton's laws altered this picture: they fixed the complete space-time story, once the initial conditions were fixed. Hence the idea of process was effectively banished.

This banishment of process made way for Einstein's theory of relativity. For if the entire space-time story is fixed, then choices of coordinates become purely matters of scientific convenience: there is no need for a scientist to worry about the questions of 'what exists now' or 'what has already taken place.' In a deterministic world the whole notion of 'becoming' becomes so nebulous and shadowy that it drops completely out of the physicist's stock of operative ideas." However, "the non-deterministic character of quantum theory reopens the whole question of the connection of space and time to the ontological categories of existence, being, becoming, etc.," Henry P. Stapp, "Light as a Foundation of Being," in Quantum Implications: Essays in Honour of David Bohm, eds. B. J. Hiley and F. David Peat (London, UK: Routledge, 1987), 259. In any case, from a Heideggerian perspective, "Newton's absolute time," which was cast aside by the standard interpretation of Einstein's relativity, was merely "an inert container that doesn't interact with its contents and never changes. Each nowpoint is sealed off from the future and past, making time a row of self-sufficient moments like a string of pearls.

"Although this sounds innocent enough, Heidegger sees an inauthentic fleeing concealed in this ordinary conception of time. Seeing it as a sequence of nows that are closed off from each other places death as an actual event safely in the future. Since the future strictly speaking doesn't exist yet and since the present now exists entirely on its own, I don't have to worry about my death. That's a thought for another day, for when it becomes actual. As long as it is a mere future possibility it has nothing to do with me now so I can and even should ignore it and live in the moment. It is only on the basis of authentic ecstatic time, where my now is formed and informed by the future, that I can live my death as a possibility which is always relevant. Thus, the inauthentic suppression of morbid thoughts is enabled by the ordinary conception of time whereas the authentic anticipation of death and living as a mortal takes place on the more primordial form of ecstatic time," Lee Braver, Heidegger: Thinking of Being (Cambridge, UK: Polity Press, 2014), 124. Or, as Pierre Keller explains, according to Heidegger, the "vulgar" notion of time "has dominated the philosophical tradition and the natural sciences. It is based on the assumption that time, regardless of whether it is identified with tense or not, is something that is essentially measurable by clocks. From Heidegger's point of view, the vulgar notion of time is a distortion of temporality," Pierre Keller, Husserl and Heidegger on Human Experience (Cambridge, UK: Cambridge University Press, 2004), 184.

${ }^{54}$ Although "physics" and "metaphysics" have already been referred to in several footnotes, at this point, it should be stated plainly that "spatial and mechanical descriptions and explanations predominate in physics-the paradigm science (and our [contemporary] culture's paradigm for all knowledge)," Christian de Quincey, Radical Nature: Rediscovering the Soul of Matter (Montpelier, VT: Invisible Cities Press, 2002), 54. The mechanical description of nature (physics) comes from the static (timeless) character of mathematics, the foundation of calculativeness in nature, and thus the true metaphysics of the natural sciences and scientists. The significance of this cannot be overestimated throughout this study. In any case, for physics, space is the locus in which time is discussed, and mechanical descriptions of the bodies that move through space constitute the venue within which time is meaningful. 
present, especially in connection with the problem of divine omniscience and human freedom. ${ }^{55}$

Theology at large has historically relied upon philosophical or scientific analyses of time ${ }^{56}$ and

freedom ${ }^{57}$ (including even with the more nuanced concept of moral or ethical freedom, that is, the

issue of making certain "good" kinds of choices, which is often viewed as a derivative of existential

freedom, that is, the power to make choices of any kind-this point is of considerable significance ${ }^{58}$ );

${ }^{55}$ This point cannot be overemphasized-the primary reason thinkers in the Western-Christian tradition have had problems with God's relationship to freedom and time concern his foreknowledge of free choices, and evil, without preventing it or being culpable in some way of comprehensively causing the future. Relatedly, but conversely, if God's foreknowledge is to be preserved, then He must be, somehow, timeless. See the overviews of the problem in, for example, John S. Feinberg, No One Like Him: The Doctrine of God (Wheaton, IL: Crossway Books, 2001), 375-436, 735-776. See also, Nelson Pike, God and Timelessness (London, UK: Routledge \& K. Paul, 1970); William Hasker, God, Time, and Knowledge (Ithaca, NY: Cornell University, 1989); Brian Leftow, Time and Eternity (Ithaca, NY: Cornell University, 1991); Robert John Russell, Time in Eternity: Pannenberg, Physics, and Eschatology in Creative Mutual Interaction (South Bend, IN: University of Notre Dame Press, 2012); Philip Clayton, Adventures in the Spirit: God, World, Divine Action (Minneapolis, MN: Augsburg Fortress, 2008); William Lane Craig, God, Time, and Eternity: The Coherence of Theism II: Eternity (Dordrecht, The Netherlands: Kluwer Academic, 2001); William Lane Craig, The Problem of Divine Foreknowledge and Future Contingents from Aristotle to Suarez (Leiden, The Netherlands: E. J. Brill, 1988); and John Martin Fischer, ed. God, Foreknowledge, and Freedom (Stanford, CA: Stanford University Press, 1989).

${ }^{56}$ Notably, "time" has predominantly been understood in relationship to the patterns and cycles evident in nature and abstract philosophical reasoning, such as mathematical sequentiality, rather than upon any "revealed" theological understanding. The point here, however, also concerns the divide between so-called popular theology and academic theology. More than ever before, as the sophistication of discourse on time has intensified in both philosophy, physics, and theology, popular theology suffers in its accuracy concerning what the philosophers and physicists are actually saying, creating untold confusion, and lessening the relevance of academic theology. This is not necessarily a bad thing in itself, in the sense of inhibiting academic progress, but merely the cause of much confusion, and creates "two cultures" of a different sort between the popular and scholarly worlds. Such divisions did not exist in the past, at least in the same way, prior to the advent of postmodernism. Accordingly, as various specialists weigh in from many disciplines on matters such as freedom and time, such as psychology, the differences multiply concerning how science, philosophy, and theology interact or should interact.

${ }^{57}$ Representing a common position, Lydia Jaeger represents a Christian free-will compatibilist who places freedom into a mysterious metaphysical realm. See my discussion on Lydia Jaeger in Michael F. Younker, "A Dialogue Between Contemporary Perspectives and Ellen White on Divine Action and Quantum Physics," in the Journal of the Adventist Theological Society Vol. 23 \#1 (2012), 120-154, 136-137. The postmodernist challenge predominantly comes from the notion that all the above forms of determinism are founded upon a common view of science, and that this form of "science does not think," and is thus fundamentally inadequate to address the human existential situation, as pointed out by Martin Heidegger, What is Called Thinking?, tr. Fred D. Wieck and J. Glenn Gray (New York, NY: Harper \& Row, 1968), 8, 135. Such a phrase, of course, risks "catapult[ing] philosophy [and freedom] to a certain source of a higher truth which is not understandable for non-philosophers. That is, it is necessary to make a perfect separation of philosophy from a theoretical treatment of the reality that surrounds us," Andrzej Przyłębski, "Gadamer's Critique of the Instrumental Philosophy of Language," in Gadamer's Hermeneutics and the Art of Conversation, ed. Andrzej Wierciński, (New Brunswick, NJ: Transaction Publishers, 2011), 240. The two options, compatibilism and incompatibilism, dominate the Christian landscape.

${ }^{58}$ Of course, when God or the Holy Spirit are invoked as an influence within human behavior, an inevitably more complex situation ensues. Nevertheless, the contours of how moral freedom has thus far been described emphasize its relationship to existential and other freedoms in a derivative manner-it is secondary, not primary, and in either case still depends upon certain conceptions of freedom and time. I.e., being morally free allows us to enjoy and experience the "neutral" aspects of existential freedom and time, which are often presumed to be "value free" somehow. In either case, however, even moral freedom can be interpreted as a 
theology by itself, as an historic academic discipline, has never originated any popular or meaningfully distinct understandings of the concepts of time, freedom, and their interrelationship that have influenced scientists or philosophers. ${ }^{59}$ Rather, theology, in the academy, has always needed its "handmaiden," philosophy, which has become all the more evident in the $21^{\text {st }}$ century, and some are quite blunt about their debt to and enthusiasm for it.

To illustrate the above point, the contributions of Einstein and Heidegger have both been used by theologians and scholars of religion to support and create arguments for two of the more popular but incompatible positions in recent times concerning God's relationship to freedom and time. In Einstein's case, his ideas have encouraged and reenforced divine timelessness ${ }^{60}$ and its accompanying conception of foreknowledge and varying limitations on if not outright banishments of human freedom, which associates Einstein's ideas with previous generations of Christian thinkers and their correspondent schools of thought. As Linda Zagzebski proclaims, "the doctrine of timelessness does have a certain advantage worth noting. It is simply more metaphysically exciting than the view that God is temporal. ${ }^{\prime 11}$ In particular, this would include most contemporary Calvinists, ${ }^{62}$ but also

subset of scientific freedom-that is, moral freedom can be interpreted as synonymous with natural theology.

${ }^{59}$ This is especially true of American analytical philosophers, such as William Lane Craig, one of the preeminent philosophers of time today in analytic Christian philosophical circles. Throughout his career, Craig has extensively endeavored to reconcile his views of time and freedom with physics and logic, but has spilled relatively little ink engaging Scripture or, particularly in his case, Heideggerian philosophy. As Garrett DeWeese, another American analytic philosopher, concurs as he dismisses Heidegger, "certainly there is much more that could be said about the Continental tradition in philosophy of time marked by the trajectory from Nietzsche through Husserl and Heidegger to Derrida, but I shall leave it aside. It is not that phenomenology has no important insights into our experience of time, or that deconstructionism has nothing interesting to say about our reading of the history of the philosophy of time. It is, rather, a judgment that the Anglo-American tradition of analytical philosophy is better equipped to develop an understanding of time that is consistent with the best theories of the natural sciences. This analytical approach will be metaphysical in nature, in marked contrast to the decidedly anti-metaphysical nature of the Continental tradition," Garrett J. DeWeese, God and the Nature of Time (Burlington, VT: Ashgate, 2004), 22. The same neglect of Heidegger holds true within the works of other notable analytic scholars such as Alvin Plantinga, Tim Maudlin, and Peter van Inwagen, despite the fact that they discuss time and freedom in numerous places.

${ }^{60}$ Einstein's future influence upon theology was evident quickly even in the 1920's, as seen through William Anthony Granville, The Fourth Dimension and the Bible (Boston, MA: The Gorham Press, 1922), iv-v, 73.

${ }^{61}$ Linda Trinkaus Zagzebski, The Dilemma of Freedom and Foreknowledge (Oxford, UK: Oxford University Press, 1991), 65.

62 "God's transcendent position over time can be seen to be implicit in the biblical assertion that 'God is light' (John 1:5). For if we take this statement to be a physical metaphor of God's true relationship to the temporal sphere, we find that He must be timeless after all, since according to Einstein, anything that travels at the speed of light is inherently timeless by definition. This metaphor contains the physical analogue to God's omnipresence as well, because anything that travels at the speed of light must also have infinite mass according to Einstein's relativity theory, and this is the very same thing that an infinite and omnipresent being would have 
arguably all mainstream Christian thought from Augustine through Aquinas, and beyond. ${ }^{63}$ This

if it were physical in nature! The insuperable nature of the Godhead is also cleverly concealed within this metaphor, because the speed of light ... is widely acknowledged to be the cosmic speed limit throughout the universe. But insofar as God is light, then nothing can surmount Him because absolutely nothing can move faster than Him. However, the Bible doesn't simply tell us that God travels at the speed of light. It tells us that He is light. This can be understood to mean that He is the very essence of timelessness and insuperable omnipresence. Hence, even Einstein's theory of relativity is able to give us important scientific information about the likely nature of the Godhead," Michael Anthony Corey, The God Hypothesis: Discovering Design in Our "Just Right" Goldilocks Universe (Lanham, MD: Rowman \& Littlefield Publishers, 2007), 239 (emphasis original). Robert Lefavi remarks that "it is fascinating that Einstein's theory of relativity opens up the possibility that in the $16^{\text {th }}$ century John Calvin grasped hold of a tiny bit of truth... when he outlined his highly unpopular Doctrine of Predestination (saying all sinners are condemned before they're born, but through mercy, God has already chosen some of them to be redeemed). Calvin, most scholars would argue and I would agree, was wrong in his insistence that God chose those certain souls to be redeemed prior to their actions and expressions of free will on Earth.

"Yet Einstein showed us that past, present and future have already occurred depending upon a person's reference frame. Perhaps, as God dwells outside all reference frames (though God's eternal, all-encompassing vantage point contains the totality of all parts of the universe and their reference frames), God sees future events in creation prior to their occurrence; maybe, as God sees all time from a vantage point external to it, God already knows who on Earth will be redeemed and who will not.

"Thus, we encounter the notion that the book may have already been written, just not yet read-at least not here in our reference frame. In this small way, we may see some semblance of accuracy with one aspect of Calvin's doctrine," Robert Lefavi, Reasons to Believe: A Journey of Spiritual Awareness in the Modern World (Pasadena, CA: Hope Publishing, 1999), 55-56. See also, Jitse M. Van der Meer, "European Calvinists and the Study of Nature: Some Historical Patterns and Problems," in Calvinism and the Making of the European Mind, eds. Gijsbert van den Brink and Harro Höpfl (Leiden, The Netherlands: Koninklijke Brill, 2014), 103-130, 122-123. Van der Meer comments that Einstein and Calvin both shared a similar philosophical heritage concerning the "unitary modes of thinking about physical reality," ibid., 123. See also, Tony Campolo, Speaking My Mind: The Radical Evangelical Prophet Tackles the Tough Issues Christians are Afraid to Face (Nashville, TN: Thomas Nelson, 2004), 113-117.

63 "In the official line from Augustine through Thomas Aquinas and Calvin, the doctrine of election became a matter of the predestination of individuals for their salvation, and this all happened in an eternal forum with little reference to history. Along this line the holiness of the church refers to the sum total of saints who have been chosen in a timeless eternity." Although Luther helps initiate, but does not yet escape from, "another line which begins to stand out in the light of history and eschatology," Carl E. Braaten, Principles of Lutheran Theology (Philadelphia, PA: Fortress Press, 1983), 56. It must be noted there is a careful distinction between the Platonic or absolute timelessness advocated by Augustine and the eternal timelessness (or "eternal present") of Boethius. As Tom Greggs explains, Plato's "approach makes eternity timeless: the eternity of ideas and the deity in its changelessness are the opposite of the changing nature of the temporal as it is subjected to change and flow. Plato, it seems, has generally won the day within classical dogmatics. Augustine, for example, tended to follow the Platonic opposition of time and eternity: time is a creation of God and thus must be entirely separated from divine eternity; there is no time in the divine life, since eternity does not include time, is not present to time and is not the condition of the unity of time. Augustine related time to movement and, for him, there was, thus, no movement before the movement of bodies in creation. Time is, for him, therefore, the antithesis of eternity: God's eternity is timeless." Alternately, "Boethius ... does not oppose time and eternity, but he does compare time and eternity. Compared to eternity, time moves for Boethius: we pass through from past to future, through changing passing moments. But, the key distinctive between time and eternity for Boethius is that time does not embrace the whole simultaneously as eternity does.... Time fails to imitate eternity precisely because it moves," which is later picked up by Aquinas, Tom Greggs, "The Order and Movement of Eternity: Karl Barth on the Eternity of God and Creaturely Time," in Eternal God, Eternal Life: Theological Investigations into the Concept of Immortality, ed. Philip G. Ziegler (New York, NY: T\&T Clark, 2016), 3-4. However, the question of the 'moment' or the nature of the movement of time's flow remains unaddressed, and thus implicitly timeless, for Boethius. See also, Ellen White, Manuscript Releases Vol. 14 (1990), 21-22; and DeWeese, God and the Nature of Time, 134-145. 
would include later Protestant movements like Lutheranism ${ }^{64}$ and even Arminianism, despite the latter's emphasis on human free-will ${ }^{65}$ in a manner resembling Kant's. ${ }^{66}$ Notably, Einstein's ideas have also been invoked in recent history by advocates of Eastern religions, such as Hinduism, in support of the idea of Ajna or the third-eye chakra and the role of time in meditation in connection with alignment to the cosmic or divine whole. ${ }^{67}$ Heidegger, on the other hand, while agnostic himself in his writings, has also been cited as an influence and support for Eastern philosophies, ${ }^{68}$ as well as

\footnotetext{
${ }^{64}$ Martin Luther's own view, at times, of predestination and the bondage of the will, appears to also locate God's knowledge and presence in a timeless realm, and he struggled with the concept of free-will in relation to sinful nature. See, for example, Richard Marius, Martin Luther: The Christian Between God and Death (Cambridge, MA: The Belknap Press of Harvard University Press, 1999), 325; Randy Alcorn, If God is Good: Faith in the Midst of Suffering and Evil (Colorado Springs, CO: Multnomah Books, 2009), 240-241; and Martin Luther, The Bondage of the Will: Written in Answer to the Diatribe of Erasmus on Free-Will, tr. Henry Cole (Fort Worth, TX: RDMc Publishing, 2005). More specifically, however, Luther clearly still embraced a view of Christ's presence in a timeless manner in relationship to the Eucharist and soteriology. As Nancy Van Deusen points out, "Luther's view still presupposes the container-concept of space, and it reduces the salvific presence of Christ to the vanishing-point of the timeless sacramental moment," maintaining a very specific ontology revealing God's presence in a timeless realm, Nancy Elizabeth Van Deusen, The Medieval West Meets the Rest of the World (Institute of Mediaeval Music, 1995), 43. See also the excellent article describing Luther's philosophical heritage by Silvia Canale Bacchiocchi, "Luther in the Eucharistic Debates: Sola Scripture or Divination of Man?," in Scripture and Philosophy: Essays Honoring the Work and Vision of Fernando Luis Canale, eds. Tiago Arrais, Kenneth Bergland, and Michael F. Younker (Berrien Springs, MI: Adventist Theological Society Publications, 2016), 355-381; and Fernando Canale, Scripture Replacing Tradition (Berrien Springs, MI: Andrews University Lithotech, 2005), 137-139.

${ }^{65}$ The key issue here is that Arminius viewed time in an uncritical, "vulgar," or somewhat Newtonian way, which Heidegger rejects. As far as God is concerned, Jacob (James) Arminius arguably viewed God's relationship to time ultimately similarly to Calvin, even though he emphasized human freedom. See Canale, Scripture Replacing Tradition, 139-140; Roger E. Olson, Arminian Theology: Myths and Realities (Downers Grove, IL: InterVarsity Press, 2006), 89; R. T. Mullins, The End of the Timeless God (Oxford, UK: Oxford University Press, 2016), 53-57; and Steven C. Roy, How Much Does God Foreknow?: A Comprehensive Biblical Study (Downers Grove, IL: InterVarsity Press, 2006), 14 n. 7. Arminius shared, in what appears an endorsement of a temporally eternal God of sorts with timeless knowledge, that "I am thoroughly persuaded that God's knowledge is eternal, unchangeable, and infinite, and that it extends to all things as well necessary as contingent, to all things which He himself does mediately or immediately and which He permits to be done by others. But the mode in which He knows certainly future contingencies, and especially those which appertain to creatures of free will, and which He has decreed to permit, not Himself to do-this I do not comprehend," James Arminius, The Works of James Arminius, tr. James Nichols and William Nichols (Grand Rapids, MI: Baker Books, 1991), 64. Arminius's admittance of such a fundamental mystery only raises the problem of God's relationship to human freedom and time yet again.

${ }^{66}$ Ric Machuga, Three Theological Mistakes: How to Correct Enlightenment Assumptions about God, Miracles, and Free Will (Eugene, OR: Cascade Books, 2015), 253.

${ }^{67}$ Margaret Stephenson Meere, The Child Within the Lotus (Dulwich Hill, Australia: Rockpool Publishing, 2009), 209-210. See also, Sai Grafio, Mysteries: Ancient and Modern (New Delhi: Sterling Publishers, 1999), 52.

${ }^{68}$ Graham Parkes, "Introduction," in Heidegger and Asian Thought, ed. Graham Parkes (Honolulu, HI: University of Hawaii Press, 1987), 1-14.
} 
supporting both a more robust view of human freedom and free-will, ${ }^{69}$ in addition to implicit support for process and open theism, where God's knowledge of the future is limited owing to the future freewill decisions of humans. ${ }^{70}$

Indeed, arguably every prominent conception of God's relationship to time and human freedom depends upon a conception of time or freedom that originated outside (certainly the mainstream interpretations of westernized Judeo-Christian or biblical) theology. ${ }^{71}$ This is neatly illustrated in the

\footnotetext{
${ }^{69}$ This is the irony contained within Heidegger's response to Nietzsche's 'death of god.' For Heidegger, the timeless god of Greek metaphysics prevented any freedom (as in Calvinism), and hence the death of god was the opening of a liberation of human freedom to encounter, perhaps, the real God. See Duane Armitage, Heidegger and the Death of God: Between Plato and Nietzsche (Cham, Switzerland: Palgrave Macmillan, 2017), 66-67; Davis, Heidegger and the Will: On the Way to Gelassenheit, 301; and Christopher Rickey, Revolutionary Saints: Heidegger, National Socialism, and Antinomian Politics (University Park, PA: The Pennsylvania State University Press, 2002), 98-99. Rickey observes that "Heidegger's 'mystical' understanding of freedom quite clearly distinguishes him from either Aristotelian or modern thought." Rather, Heidegger possesses what one might call a "religious understanding of human freedom," and "Heidegger's own radical politics grew out of his understanding of freedom," ibid., 98-99.

${ }^{70}$ This does not mean, however, as will be seen below, that Heidegger has been correctly understood by such advocates of his name or ideas in some cases. In any case, "Heidegger and others have been suspicious of the role that nontemporal deity and atemporal metaphysics has played, and have called for a conception of reality within the context of temporality. Process theism may offer a conception of God as appearing within the horizon of temporality," Lewis S. Ford, Transforming Process Theism, (Albany, NY: State University of New York Press, 2000), 179. Similarly, see John Davenport, "A New Existential Model of God: A Synthesis of Themes from Kierkegaard, Buber, Levinas, and Open Theism," in Models of God and Alternative Ultimate Realities, eds. Jeanine Diller and Asa Kasher (London, UK: Springer, 2013), 568; and Eugene Thomas Long, "Philosophy of Religion after Postmodernism," in Nature, Truth, and Value: Exploring the Thinking of Frederick Ferré, eds. George Allan and Merle F. Allshouse (Lanham, MD: Lexington Books, 2005), 90. Also, for example, divine temporality is interpreted by David Pensgard to mean essentially one thing and one thing only, a lack of foreknowledge. Thus, whatever omniscience may be granted to a temporal God, it, by the use and definition of the very word 'temporal', means God cannot know the future, nor even anticipate it. David Pensgard, Existential Temporality as Fore-Ignorance: Implications for Divine Foreknowledge (MARS Thesis, Liberty University B. R. Lakin School of Religion, 2008). Pensgard concludes, "the theist is left to choose between theological determinism on the one hand, and the open view on the other. It seems that the fore-ignorance account of existential temporality has greater jurisdiction to force this choice upon philosophers like [Alvin] Plantinga, [William Lane] Craig, and [Thomas P.] Flint than does any metaphysical theory. Moreover, the option of retreating into 'Socratic ignorance' has also been removed because fore-ignorance, by strongly ruling out middle positions, demands that one make a choice between one of the two strong options. Full appreciation of fore-ignorance, therefore, within the Philosophy of Religion, must result in polarization," ibid., 110-111. Again, according to Pensgard, a proper understanding of the two options "renders untenable those views that would attribute to God complete foreknowledge and existential temporality," ibid., 110.

${ }^{71}$ The constraints of this study do not permit me to explore this at length, but it is one that appears to be the case in works such as Terrance L. Tiessen, Providence and Prayer; How Does God Work in the World? (Downers Grove, IL: InterVarsity Press, 2000). Tiessen discusses eleven different models of divine providence (namely, the semi-Deist, Process, Openness, Church Dominion, Redemptive Intervention, Molinist, Thomist, Barthian, Calvinist, and Fatalist models, and his own, a Middle Knowledge Calvinist model), all of which include understandings of freedom and time in relation to God and humans that are inherited from philosophy.
} 
recent work of the biblical theologians John Peckham ${ }^{72}$ and Tiago Arrais, ${ }^{73}$ who both address issues

related to divine ontology and the nature of God and the God-world relationship, which presume the

problem of the relationship between the divine and freedom and time, and the work of the

philosophical theologian, Cameron Freeman, who similarly sees the issues of freedom and time at the

center of the "paradoxical" metaphysics implicit within the biblical narratives and teachings of

Jesus. $^{74}$

${ }^{72}$ See John C. Peckham, The Love of God: A Canonical Model (Downers Grove, IL: InterVarsity Press, 2015), 15. Peckham presents a technical exposition of perhaps the two most popular but conflicting models of divine love, the transcendent-voluntarist model, and the immanent-experientialist model, with "the former being a descendant of classic theism and the latter representing process panentheism," ibid. In reality, then, Peckham is not so much exploring love as much as he is implicitly exploring freedom and time, which both undergird any interpretation of love. Notably, both of these models fit within the problematic of the two cultures, especially insofar as determinations on the nature of freedom and time are essential for any proper understanding of love-love is either timeless or temporal, determined or free-willed, on the part of God and creatures. Here, the former models, respectively, represent a scientific approach, and the latter approaches are more influenced by the humanities, with some complicated qualifications (I'd suggest both are ultimately more influenced by a scientific approach, and neither is properly oriented toward an acknowledgment of a potential Heideggerian understanding of temporality. Concerning why this may be, I would suggest, alongside the recent work of Irene McMullin, Time and the Shared World: Heidegger on Social Relations (Evanston, IL: Northwestern University Press, 2013), that the potential usefulness of a Heideggerian view of sociality has been mostly neglected and underdeveloped). Very importantly, Peckham suggests neither of these two popular models may be adequate within his Scriptural "final-form canonical approach to systematic theology," ibid., 17. This is not to say certain passages from Scripture can't be read to support either of the two proposed views, but that altogether Scripture presents them in some tension, requiring a view that takes this into account, ibid., 277-278. For more on his hermeneutical methodology concerning Scripture, see also John C. Peckham, Canonical Theology: The Biblical Canon, Sola Scriptura, and Theological Method (Grand Rapids, MI: Eerdmans, 2016).

${ }^{73}$ See Tiago Arrais, A Study on the Influence of Philosophical Presuppositions Relating to the Notion of the God-human Relation Upon the Interpretation of Exodus (Andrews University, Berrien Springs, MI: Doctoral Dissertation, 2015). Arrais suggests that Being has been interpreted in two ways, as temporal/historical or timeless, and each of these corresponds to two predominant conflicting interpretations of God's relationship to humans and the world, particularly as manifested in the book of Exodus, ibid., 25-107, esp. 88-91. Arrais observes that there is a "division between historical-critical approaches to the text and the biblical theology movement," which, "as two disciplines, revolved around the limits of what historians were able to do," ibid., 91. Arrais continues, observing that for some scholars "Old Testament theology could not be a historical inquiry 'because it is concerned with what is timelessly or abidingly true,"' citing Ben C. Ollenburger, "From Timeless Ideas to the Essence of Religion: Method in Old Testament Theology Before 1939," in The Flowering of Old Testament Theology: A Reader in Twentieth-Century Old Testament Theology, 1930-1990, eds. Ben C. Ollenburger, Elmer A. Martens, and Gerhard F. Hasel (Winona Lake, IN: Eisenbrauns, 1992), 3-19, 18. See also, James K. Hoffmeier and Dennis R. Magary, eds. Do Historical Matters Matter to Faith?: A Critical Appraisal of Modern and Postmodern Approaches to Scripture (Wheaton, IL: Crossway, 2012).

${ }^{74}$ Cameron Freeman, Post-metaphysics and the Paradoxical Teachings of Jesus: The Structure of the Real (New York, NY: Peter Lang, 2010), 27-33 73, 85, 101, 224-225. Freeman observes that "Greek metaphysical assumptions have been widely used not only in the Western philosophical tradition, but also in the historical unfolding of the Christian religion. This point was confirmed by Heidegger, who argued that the theological enterprise in the Christian tradition eventually misunderstood the specific nature of its task and rather than taking up the interpretation of Biblical revelation, it adopted Greek forms of discourse and purported to give rational grounds for the Being of God," ibid., 28. Freeman advocates a return to Scripture with an awareness of the deconstruction of Greek metaphysics accomplished by Heidegger in mind. Freeman makes reference to the fact that many of "Jesus' enigmatic teachings are deeply concerned with free-will and our capacity to decide with passion for ourselves how to respond to his message. So rather than providing a pre-given program of 
It is also noteworthy that from within Christianity, the strongest advocates of divine timeless

foreknowledge and deniers of libertarian human freedom, Calvinists, share an aversion toward existentialists similar to Heidegger ${ }^{75}$ that is only matched by the strongest deniers of meaningful human freedom within the secularized and atheistic scientific world. ${ }^{76}$ This again represents a replication of Snow's competing "two cultures" taken to their extremes within Christianity and scientistic atheism. In summary, the way freedom and time have been discussed in religious circles and elsewhere has always been, thus far, consciously or unconsciously, constrained by the historical

rules and procedures for admission into the Kingdom, the paradoxical language of Jesus disrupts the quest for cognitive certainty about the question of God by setting up the necessary conditions for the decision of faith with an 'aporetic anxiety' that interrupts any ruling discourse of preestablished certainties," ibid., 259. For example, Freeman suggests the "irreducible tension between grace and free-will means that we never exercise more humanity-i.e. personal freedom, autonomy, etc than when we are fully divine-i.e. utterly dependent on the grace of God. In other words, we are truly free only when we can (1) take personal responsibility for all our words and actions, and (2) ascribe all our good works to God," ibid., 85. See also, Larry J. Waters, "Paradoxes in the Pauline Epistles," in Bibliotheca Sacra 167 (October-December 2010), 423-441.

${ }^{75}$ As the accusation is common by his opponents that Heidegger is an "existentialist," I will occasionally include quotes that consider him as such. However, Heidegger explicitly rejected the label, and was uncomfortable with the label "humanism" as well, making his relationship to the "humanities" a rather complex issue owing to what it was the humanities were considered to be in the academy previous to him. Note, Martin Heidegger, “Letter on 'Humanism,'” tr. Frank A. Capuzzi, in Pathmarks, ed. William McNeill (Cambridge, UK: Cambridge University Press, 1998), 239-276.

${ }^{76}$ See, for example, Jens Zimmermann, Incarnational Humanism: A Philosophy of Culture for the Church in the World (Downers Grove, IL: InterVarsity Press, 2012), 41-42; Sam Harris, Free Will (New York, NY: Free Press, 2012); Tom Butler-Bowdon, The Literature of Possibility (Nicholas Brealey Publishing, 2013), 6; and R. K. McGregor Wright, No Place for Sovereignty: What's Wrong with Freewill Theism (Downers Grove, IL: InterVarsity Press, 1996), 68-69. What is clear is that Heideggerianism is more sympathetic to Barthian and Lutheran tendencies, rather than Calvinism. See Stanley, Protestant Metaphysics after Karl Barth and Martin Heidegger; Michael E. Zimmerman, Heidegger's Confrontation with Modernity: Technology, Politics, and Art (Bloomington, IN: Indiana University Press, 1990), 178-180; and Heidegger's own interest in Luther over Calvin, as seen in Martin Heidegger, The Phenomenology of Religious Life, tr. Matthias Fritsch and Jennifer Anna Gosetti-Ferencei (Bloomington, IN: Indiana University Press, 2004), 47, 67, 87, 115, 212-213. Regardless of their own precise views on freedom, it is not uncommon for scientifically minded atheists to suggest that Heidegger's "addition of Being to being seems just as fallacious as the burdening of the natural with the supernatural. There simply is no reality other than reality, suggesting that being is being and Being is Mumbo-Jumbo. Further, perhaps, Heideggerian violations of Occam's razor have their own specific, unfortunate consequences. This is because, just as ancient and medieval Hermeses gossiped about the supernatural at the expense of knowing the natural, so Heidegger interpreted Being at the expense of being," Stephen P. Reyna, Connections: Brain, Mind, and Culture in a Social Anthropology (New York, NY: Routledge, 2002), 90. Reyna also stated, "this dualism [between the positive sciences and Being] further ties Heidegger with premodern seers, because it recreates their belief in two realms that need to be known about; only this time these are not the natural and the supernatural. They are being and Being," ibid, 88. Such accusations, as Paul Kurtz similarly observes, connect Heidegger with spiritualists providing a justification for why scientifically minded atheists should dismiss Heideggerians. "The two cultures do not live side by side in peaceful coexistence any longer; in recent decades there have been overt radical attacks on science that threaten its position in society." In particular, a strong "philosophical attack comes from the disciples of Heidegger" who "argue that science is only one mythic system or narrative among many others." As such, they claim that "there are 'two truths,"” and that "there exists, along with cognitive scientific knowledge, a mystical and spiritual realm and/or æsthetic and subjective aspects of experience," Paul Kurtz, Skepticism and Humanism: The New Paradigm (Piscataway, NJ: Transaction Publishers, 2001), 30. 
developments within philosophy which have culminated in the development of the two cultures and their foundational schism over the two concepts of freedom and time.

As such, given the above, neither a Christian view that retains a conflated unitary or dualistic position regarding the relationship between metaphysics and natural science, nor an atheistic science that denies metaphysics and God altogether, are at present serving as a source of possible solutions to the differing and incompatible views of freedom and time advanced in the sciences and humanities, but are, rather, a consequence and further replicator of them. The question, then, of whether theology or religion can unify or surpass the competing "two cultures" concerning how best to understand freedom and time appears, presently, to have an inconclusive or negative answer.

This suggests one possible reason for the lack of influence, or consistency of influence, of Christianity, as well as other religions, within either the general populace or academic circles. The lack of concord within religion, concerning precisely the same issues that historic philosophy and the academy today are in general divided over concerning freedom and time, testifies to the fact that currently religion, and theology, are functionally inert to resolve philosophical problems. It would seem we are in need of generating a "third culture" to mediate and resolve the conflict through new conceptual discovery, rediscovery, and/or creation. Noteworthy is that Snow himself intimated as much-while maintaining his favoritism toward the sciences. ${ }^{77}$ The debate today, then, is who should

\footnotetext{
77 "While C. P. Snow contrasted the cultures of science and the arts in The Two Cultures, one of the points on which he was most criticised was the implication that there were only two cultures. He pointed out in the 1964 revision of The Two Cultures, that the only word in the title which was not attacked was 'the'. As he says, the implication was that the title Two Thousand and Two Cultures would have been better. Snow insisted that the number of significant cultures really is very small. He was, however, prepared to accept that there would be soon, if there were not already, a third culture-that of the social sciences. Snow himself here included social history, sociology, demography, political science, economics, government (in the American academic sense), psychology, medicine, and social arts such as architecture. Though recognising that it was a 'mixed bag', he saw 'an inner consistency. All of them are concerned with how human beings are living or have lived.'” Hague himself believed, circa 1984, that "the social sciences still have a long way to go before they can be recognised alongside the natural sciences, not least because one cannot easily carry out valid experiments. Nevertheless, the outlook and the approach to problems which the social sciences have given me over the years provides a distinctive approach to problems which is that of neither the scientist nor of the mainstream arts man," Douglas Hague, "The Fourth Industrial Revolution," in New Scientist 26 (April 1984), 25. See also, Gunnar Myrdal, "How Scientific Are the Social Sciences?," in Bulletin of the Atomic Scientists (Jan. 1973), 31-37.
} 
take the lead in guiding what form such a third culture might assume ${ }^{78}$ and what role religion might find or have within it. ${ }^{79}$

The entirety of the above conflict concerning the interrelationship of freedom and time in the sciences and humanities has been continued through the work of successors to the Einsteinian and Heideggerian conceptual trajectories. From the culture of science, David Bohm (1917-1992), an early protégé of Einstein's, and a respected physicist early in his career, and later a philosopher in his own right, articulated an admirably elegant but controversial ontological theory ${ }^{80}$ to explain some of the

\footnotetext{
${ }^{78}$ The concept of the "third culture" can be interpreted in at least two (sometimes incompatible) ways. First, as an actual pragmatic culture of those scholars inhabiting the social or humane sciences in the academy; a "social group belonging to delineated disciplines." Second, it can refer to new fundamental concepts that define the way an individual or group of scholars think, and are thus related to an attempt to actually philosophically unify the broader "two cultures." Of course, one might surmise that an effective third culture of the first kind could function as the second kind, a unifying culture, in itself. Snow, evidently thinking of the third culture in this latter way, having apparently failed to identify the philosophical source of the problem, noted that there was the need for a "third culture" consisting initially or primarily of social scientists, that is, scholars of the humane sciences, that should help mediate between the two cultures. See Snow, The Two Cultures, 53-100; 66, 70; and Sanford A. Lakoff, "The Nth Culture Problem," in Bulletin of the Atomic Scientists (May, 1964), 21-23. Lakoff explains that for Snow, the third culture would "argue about the effects, the uses, and the direction of scientific research, instead of arguing about the two cultures," ibid, 22. As such, Snow was "in effect urging an effort to close the division between the sciences and the humanities through a kind of mutual education or perhaps through the creation of a new intellectual universalism" that could be manifested through those "third culture" disciplines closest to society at large, ibid. Snow's hopes, however, for an effective third culture never properly materialized. See, for example, John H. Cartwright and Brian Baker, Literature and Science: Social Impact and Interaction (Santa Barbara, CA: ABC-CLIO, 2005), 300-302; and John Brockman, ed. The Third Culture: Beyond the Scientific Revolution (New York, NY: Simon \& Schuster, 1995), 17-18, where it is suggested that because literary intellectuals and most social scientists have refused to communicate productively with traditional scientists to create a useful mediatorial "third culture," the task has fallen to the scientists themselves to communicate "directly with the general public.... Today, [scientists as] third-culture thinkers tend to avoid the middleman and endeavor to express their deepest thoughts in a manner accessible to the intelligent reading public," ibid, 18. Such an approach, of course, maintains the conflict with scholars in the humanities.

${ }^{79}$ The problem is a subtle one, and penetrates into the relationship of rational-empirical "science" and metaphysics, which is a key part of understanding the dispute between Einstein and Heidegger. In brief, and summarizing the entirety of the problematic, secularists and Christians are each divided between the two cultures; being an atheist or a theist is not a significant factor, in itself, for determinating whether one is more inclined toward the sciences or humanities, respectively. Note Henry F. Schaefer, Science and Christianity: Conflict Or Coherence? (Watkinsville, GA: Apollos Trust, 2003), 10-11.

${ }^{80}$ For an analysis of his most notable theory, which influenced his later philosophy but is distinct from it, see Peter R. Holland, The Quantum Theory of Motion: An Account of the de Broglie-Bohm Causal Interpretation of Quantum Mechanics (Cambridge, UK: Cambridge University Press, 1993); and Detlef Dürr and Stefan Teufel, Bohmian Mechanics: The Physics and Mathematics of Quantum Theory (London, UK: Springer, 2009). For Bohm's own final version, see David Bohm and B. J. Hiley, The Undivided Universe: An Ontological Interpretation of Quantum Theory (London, UK: Routledge, 1993). Bohm's motivation arises from the fact that "quantum mechanics can say little or nothing about reality itself. In philosophical terminology, it does not give what can be called an ontology for a quantum system. Ontology is concerned primarily with that which is and only secondarily with how we obtain our knowledge about this (in the sense, for example, that the process of observation would be treated as an interaction between the observed system and the observing apparatus regarded as existing together in a way that does not depend significantly on whether these are known or not)," ibid., 2. For updated appraisals, see Lee Smolin, Einstein's Unfinished Revolution: The Search for What Lies Beyond the Quantum (Toronto, Canada: Alfred A. Knopf, 2019); and Jan Walleczek, Gerhard Grössing, Paavo
} 
apparent contradictions Einstein encountered but never resolved in quantum physics, ${ }^{81}$ which remains the most puzzling area of contemporary natural science. ${ }^{82}$ After he developed his theories in physics, the need for creating new understandable descriptions of freedom, time, and their interrelationship became central to Bohm's more philosophical depictions of how physical nature relates to mental/conscious (or human) reality, at both the individual (or psychological) and the socio-political levels. ${ }^{83}$ Although as a physicist Bohm was apparently not aware of Heidegger, he was keenly aware of the general conflict between the two cultures, and sought to reconcile them. ${ }^{84}$

Pylkkänen, and Basil Hiley, eds. Emergent Quantum Mechanics: David Bohm Centennial Perspectives (Basel, Switzerland: MDPI, 2019).

${ }^{81}$ For overviews of David Bohm's work that includes both a biographical and philosophical analysis, see Mathew Chandrankunnel, Philosophy of Quantum Mechanics: Quantum Holism to Cosmic Holism: The Physics and Metaphysics of Bohm (New Delhi, India: Global Vision Publishing, 2008); and F. David Peat, Infinite Potential: The Life and Times of David Bohm (Jackson, TN: Perseus Books, 1997).

82 "The quantum measurement problem is arguably the most difficult conceptual problem in the foundations of physics. It is an indication of its difficulty that attempts to solve it have led physicist and philosophers of physics to speculate concerning the relationship between physical and mental states," Jeffrey A. Barrett, "Quantum Mechanics and Dualism," in Quantum Physics Meets the Philosophy of Mind: New Essays on the Mind-Body Relation in Quantum-Theoretical Perspective, eds. Antonella Corradini and Uwe Meixner (Berlin, Germany: Walter de Gruyter, 2014), 65. Of course, the mind and consciousness, viewed as originating within a "three-and-a-bit-pound physico-chemical blob inside our skulls," turns out to be "arguably, the most difficult and pressing problem in all of philosophy," Andrew Bailey, ed. First Philosophy III: God, Mind, and Freedom: Fundamental Problems and Readings in Philosophy (Orchard Park, NY: Broadview Press, 2004), 136. "The reason why the interpretation of quantum mechanics has been one of the most fundamental conceptual problems of modern science and practically all the best physicists, philosophers of science and mathematicians of the past century confronted themselves with this problem, is probably the uneasy feeling that there might be a deeply rooted contradiction between two of the basic pillars of contemporary physics: quantum theory and relativity theory," in Luigi Accardi, Kentaro Imafuku and Massimo Regoli, "An Introduction to the EPRChameleon Experiment," in Fundamental Aspects of Quantum Physics: Proceedings of the Japan-Italy Joint Workshop on Quantum Open Systems, Quantum Chaos and Quantum Measurement, ed. Luigi Accardi and Shuichi Tasaki (Singapore: World Scientific Publishing, 2003), 307. The philosopher of science Tim Maudlin affirms the same thought: "We cannot simply accept the pronouncements of our best theories, no matter how strange, if those pronouncements contradict each other. The two foundation stones of modern physics, Relativity and quantum theory, appear to be telling us quite different things about the world," Tim Maudlin, Quantum NonLocality and Relativity: Metaphysical Intimations of Modern Physics $3^{\text {rd }}$ ed. (Chichester, UK: John Wiley \& Sons, 2011), 23. They all follow one of the esteemed fathers of quantum theory, John Bell, who commented: "We have an apparent incompatibility, at the deepest level, between two fundamental pillars of contemporary theory .... It may be that a real synthesis of quantum and relativity theories requires not just technical developments but radical conceptual renewal," that is, new concepts, John S. Bell, "Speakable and Unspeakable in Quantum Mechanics," in J. S. Bell, Collected Papers on Quantum Philosophy: Speakable and Unspeakable in Quantum Mechanics, ed. Simon Capelin (Cambridge, UK: Cambridge University Press, 1987), 169-172. See also, Lee Smolin, Three Roads to Quantum Gravity (New York, NY: Basic Books, 2001), 3-5.

${ }^{83}$ For example, David Bohm, "Freedom and the Value of the Individual," in The Essential David Bohm, ed. Lee Nichol (New York, NY: Routledge, 2005), 253-260; and “The Super-Implicate Order," ibid., 139-157.

${ }^{84}$ Bohm was known to correspond at length with artists about the nature of reality, such as Charles Biederman, and much of their correspondence is now published. See David Bohm with Charles Biederman, Bohm-Biederman Correspondence: Creativity and Science, ed. Paavo Pylkkänen (London, UK: Routledge, 1999). Others in the humanities with whom Bohm communicated with at length would include the Indian mystic Jiddu Krishnamurti. See Jiddu Krishnamurti and David Bohm, The Future of Humanity: Two Dialogues between J. 
Representing this desire, and highlighting the interest by contemporary scholars navigating between

the two cultures and probing the deepest questions of philosophy and natural science, Bohm's and Heidegger's views have been favorably compared on several recent occasions ${ }^{85}$ Additionally, the implications of Bohm's basic ideas for theology have been sympathetically considered by several theologians, including those from such diverse backgrounds as New Age religions, ${ }^{86}$ Islamic (Sufi) mysticism, ${ }^{87}$ Roman Catholicism, ${ }^{88}$ and various other Protestant Christians, ${ }^{89}$ including some of the

Krishnamurti and David Bohm (The Netherlands: Krishnamurti Foundation, 1986). In summary, in some of his books, such as On Creativity, "Bohm's own contact with artists caused him to take a fresh look at the structures of reality as comprehended directly with the senses. 'Vice versa,' he continues saliently, 'new scientific notions of structure may be significant to the artist, not so much because they suggest particular ideas to be translated into artistic form, but, rather, because if they are understood at a deep level they will change one's way of thinking about everything, including art,"' John Aloysius McCarthy, Remapping Reality: Chaos and Creativity in Science and Literature-Goethe, Nietzsche, Grass (Amsterdam, The Netherlands: Rodopi, 2006), 76, citing David Bohm, On Creativity, ed. Lee Nichol (London, UK: Routledge, 2003), 39. McCarthy, in particular, optimistically believes that, "thanks to people like ... David Bohm, ... [t] he chasm that once seemed to separate the two cultures of science and the humanities has diminished, if not disappeared. The methodologies still differ and the way we formulate our questions is still divergent, but the role of imagination and metaphor is common to both our endeavors," Remapping Reality, 334.

85 "There is a fascinating similarity between the ontology proposed by Heidegger and [Maurice] Merleau-Ponty and the ontological interpretation of quantum theory proposed by the theoretical physicist, David Bohm," Rupert Wegerif, "From Dialectic to Dialogic," in Theories of Learning and Studies of Instructional Practice, ed. Timothy Koschmann (New York, NY: Springer Science, 2011), 210. See also, for example, Paul Scott Derrick, Thinking for a Change: Gravity's Rainbow and Symptoms of the Paradigm Shift in Occidental Culture (València, Spain: Universitat de València, 1994), 202-222; Paul Scott Derrick, We Stand Before the Secret of the World: Traces Along the Pathway of American Romanticism (Spain: Universitat de València, 2003), 32-33; Wim Wenders and Mary Zournazi, Inventing Peace: A Dialogue on Perception (New York, NY: Palgrave Macmillan, 2013), 134-135; and Mihai I. Spariosu, Dionysus Reborn: Play and the Aesthetic Dimension in Modern Philosophical and Scientific Discourse (Ithaca, NY: Cornell University, 1986), 286. Spariosu comments that Bohm's "concept of the flowing totality of being" "bears a remarkable family resemblance to Heidegger's ... Weltspiel," ibid. Derrick similarly observes that Bohm's "'holomovement' . . corresponds with Heidegger's Being," Derrick, We Stand Before the Secret of the World, 32.

${ }^{86}$ Wouter J. Hanegraaff, New Age Religion and Western Culture: Esotericism in the Mirror of Secular Thought (Albany, NY: State University of New York Press, 1998), 70-71.

${ }^{87}$ For example, see the favorable opinions of Ahmed Hulusi, Up to Date Understanding of Islam, tr. Ahmed Baki (Istanbul, Turkey: Kitsan, 1996), 23; Graham Smetham, The Grand Designer: Discovering the Quantum Mind Matrix of the Universe (Brighton, UK: Shunyata Press, 2011), 340-341; Hazrat Inayat Khan, The Heart of Sufism: Essential Writings of Hazrat Inayat Khan (Boston, MA: Shambhala Publications, 1999), 2; Hendrikus Johannes Witteveen, Universal Sufism (Dorset, UK: Element, 1997), 62-63; and Yousef Daoud (Joe Martin), The Rose and the Lotus: Sufism and Buddhism (Bloomington, IN: Xlibris, 2009), 15.

88 "One of the most interesting of modern physicists from a Catholic point of view was David Bohm," Stratford Caldecott, "Catholicism and the New Age Movement," in The Catholic Church and World Religions: A Theological and Phenomenological Account, ed. Gavin D’Costa (New York, NY: T\&T Clark, 2011), 212 n. 20. Note also the highly respected Catholic theologian from the Communio movement, David L. Schindler, Ordering Love: Liberal Societies and the Memory of God (Grand Rapids, MI: Eerdmans, 2011), 355-356; Heidi Ann Russell, The Source of All Love: Catholicity and the Trinity (Maryknoll, NY: Orbis Books, 2017); and Ilia Delio, The Emergent Christ: Exploring the Meaning of Catholic in an Evolutionary Universe (Maryknoll, NY: Orbis Books, 2011).

${ }^{89}$ For example, see the Lutheran theologian Ted Peters, "David Bohm, Postmodernism and the Divine," in Zygon $20 \# 2$ (June 1985), 193-217. 
most prominent American evangelicals, ${ }^{90}$ for not only descriptions of God, but also relationality and the Trinity. ${ }^{91}$ Lastly, although Bohm himself resisted applying his ideas to theology, ${ }^{92}$ he did not hesitate to engage in conversations with theists who were interested in his work and was aware his ideas might influence their theology.

Conversely, Pauli Pylkkö, a philosopher from the culture of the humanities, ${ }^{93}$ has expanded upon Heidegger's ideas toward a conclusion Heidegger seemed intent on avoiding-the unity of philosophy with physics. Utilizing the latest research in quantum physics, Pylkkö initiated an effort to unify Heidegger's understanding of the temporality of human existence (Dasein) and freedom with science and nature, ${ }^{94}$ a unity Heidegger did not achieve or, perhaps, even consider possible. ${ }^{95}$ Pylkkö disagrees with Heidegger concerning the significance of quantum phenomena ${ }^{96}$ for science and

${ }^{90}$ In particular, William Lane Craig, Time and the Metaphysics of Relativity, 227-229, 233-234. Craig utilizes the younger Bohm's proposal for understanding how determinism in nature contributes to a singular cosmic time, which he relates to God's metaphysical time.

${ }^{91}$ Kirk Wegter-McNelly, The Entangled God: Divine Relationality and Quantum Physics (New York, NY: Routledge, 2011), 28, 59-83, 107-166.

${ }^{92}$ Kevin J. Sharpe, David Bohm's World: New Physics and New Religion (Cranbury, NJ: Associated University Presses, 1993), 93. Bohm himself wrote that "the word 'God' means many different things to different people, and it becomes hard to know exactly what is implied.... [Nevertheless, to] suggest that there is a creative intelligence underlying the whole [of reality], which might have as one of the essentials that which was meant by the word 'God,"' is possible. In any case, "I think it is essential not to limit God, if you believe in God," Bohm, On Creativity, 107.

${ }^{93}$ Pylkkö has written at length on several influential thinkers from the humanities, such as the $19^{\text {th }}$ century German music composer and theater director Richard Wagner, as well as the German writer and novelist Ernst Jünger, a World War I veteran, who wrote about his war experiences. See Pauli Pylkkö, Richard Wagner Ajattelijana: Antimodernisti, Luonnonmystikko, Gnostikko (Kiel, Finland: Uuni Verlag GbR, 2005); Pauli Pylkkö, "Lemuurien Yö - Ernst Jünger ja Kansallissosialismi," 155-198; and Pauli Pylkkö with Leena Pylkkö, "Huomautuksia Romaanin Kasveista ja Eläimistä," 199-203, in Ernst Jünger, Marmorijyrkänteillä, tr. Pauli Pylkkö (Kustavi, Finland: Uuni, 2006). Additionally, Pylkkö’s own philosophical work has been cited within novels reflecting upon the world of art, such as with Siri Hustvedt, The Blazing World (New York, NY: Simon \& Schuster, 2014), 255.

${ }^{94}$ For a brief analysis of Pauli Pylkkö's primary contributions, see Louis S. Berger, The Unboundaried Self: Putting the Person Back Into the View from Nowhere (Victoria, BC: Trafford Publishing, 2005), 98-115; and Gordon G. Globus, Quantum Closures and Disclosures: Thinking-Together Postphenomenology (Amsterdam, The Netherlands: John Benjamins Publishing, 2003), 96-111. In brief, Pylkkö's work represents the logical extension and naturalization of Heidegger's work, as noted by Sami Pihlström, Naturalizing the Transcendental: A

Pragmatic View (Amherst, NY: Humanity Books, 2003), 230, 265 n. 6. Like anyone inclined toward any form of pragmatism, Pylkkö, as Pihlström observes, attacks “well-established dichotomies," ibid., 161.

95 "While Heidegger takes important steps beyond the traditional Western metaphysics of time in his characterization of existential temporality, he reduces nature to the role of that which is encountered in the fallen/vulgar mode of this temporality," Hansen, "Spacetime and Becoming: Overcoming the Contradiction Between Special Relativity and the Passage of Time," 148.

${ }^{96}$ As Pylkkö explains, in contrast to what Heidegger evidently believed, "it is far from obvious that quantum physics, the greatest upheaval in the twentieth century science, perhaps of all modern science so far, actually continues or smoothly extends the classical picture of nature and man," Pauli Pylkkö, The Aconceptual 
philosophy, and as such wishes to engage scientists with the concerns of those in the humanities.

Pylkkö is also specifically interested in how freedom and time relate and should be described, ${ }^{97}$ at

both the individual or psychological and socio-political levels. ${ }^{98}$ Although Pylkkö's direct engagement

with the concept of God remains limited, his appropriation of Heidegger's own complex thoughts on

the concept of God retain a place for meaningful discussion about the concept of God within Pylkkö's

own works and as an extension of Heidegger's thought pathway. ${ }^{99}$ Pylkkö is also aware that his ideas

Mind: Heideggerian Themes in Holistic Naturalism (Amsterdam, The Netherlands: John Benjamins Publishing, 1998), 58. In harmony with Pylkkö, James Watson observes that "Heidegger seems to understand all of modern science in the mode of classical physics, and he also seems to imply that quantum theory is nothing but an extension of classical physics," James R. Watson, "Beyond Ontic-Ontological Relations," in Heidegger on Science, ed. Trish Glazebrook (Albany, NY: State University of New York, 2012), 52. Thus, as Andrew Haas points out, also in harmony with Pylkkö, "if quantum theory demonstrates that the sciences stand between the natural and human world in such a way that they form a part of everything they investigate, the usual distinction between subject and object, inner and outer world, body and soul-like the Cartesian difference between res extensa and res cogitans that Heidegger 'destructures' in Being and Time-cannot be maintained," Andrew Haas, The Irony of Heidegger (New York, NY: Continuum, 2007), 151-152. “One might say that Heidegger's epistemology was realistic but his metaphysics were idealistic. The Cartesian belief in the reality of extended substance was a generalization from a very limited region of being; natural sciences and mathematics could not be the road to ontology, but rather the hermeneutical sciences pointed the way. Thus Heidegger's existentialism reinforced the split between scientific and humanistic thought," David F. Lindenfeld, The Transformation of Positivism: Alexius Meinong and European Thought, 1880-1920 (Berkeley, CA: University of California Press, 1980), 262263. Of course, whether any resolution to the tension between Einstein and Heidegger on time and freedom appears possible through quantum physics remains uncertain, as both classical Einsteinian time-space or relativity theory and quantum mechanics have been invoked for the concept of timelessness. To determine why this is so is central to the purpose of this study. For an example of the tensions concerning the use of language about time in science, see for example, Dag Landvik, "At the Speed of Light," in Aspects of Consciousness: Essays on Physics, Death and the Mind, ed. Ingrid Fredriksson (Jefferson, NC: McFarland \& Company, 2012), 76-92.

${ }^{97}$ For example, note especially Pauli Pylkkö, "Indeterminacy and Experience," in Current Trends in Connectionism: Proceedings of the 1995 Swedish Conference on Connectionism, ed. Lars F. Niklasson and Mikael B. Bodén (Hillsdale, NJ: Lawrence Erlbaum, 1995), 321-329.

${ }^{98}$ Amongst other concerns, in particular, as Tere Vadén explains, Pylkkö "tries to cure the antidemocracy [sentiments] of [Heidegger's] Dasein philosophy by a strong dose of non-classical natural science. The project is promising, but very few philosophers steeped in so-called continental philosophy or critical theory care enough about the natural sciences in order to follow," Tere Vadén, Heidegger, Žižek and Revolution (Rotterdam, The Netherlands: Sense Publishers, 2014), 3 n. 2.

${ }^{99}$ Although Pylkkö, not a theologian, occasionally mentions the role of the concept of God throughout his writings, what is noteworthy of particular focus is the way in which he utilizes Heidegger's concept of "ontotheo-logy," a description by Heidegger of all metaphysical reflection since the ancient Greeks, wherein ontology and theology were always combined, to critique our view of science and nature. Originally, Heidegger's intent was to note that our reflections about ourselves, other beings, and the ultimate or highest being were conflated into one mode of inquiry. See especially, Pylkkö, The Aconceptual Mind, 27-76. Note Heidegger's claim that "Western metaphysics ... since its beginning with the Greeks has eminently been both ontology and theology.... Metaphysics is onto-theo-logy," Martin Heidegger, Identity and Difference, tr. Joan Stambaugh (University of Chicago Press, 2002), 54; 121. 
could influence the ongoing debates in the contemporary academy between science, religion, and the humanities, and has briefly addressed the issue. ${ }^{100}$

Bohm's and Pylkkö's contributions ${ }^{101}$ clearly represent the trajectories or thought-pathways of both Einstein and Heidegger, respectively. However, they also take the insights of their ideological mentors in directions they could not have clearly anticipated by following their ideas to fresh possible conclusions in light of later developments in philosophy and empirical natural science, exploring the boundaries of the emerging era of post-humanism ${ }^{102}$ and the problems within critical realism, ${ }^{103}$ which is important for many theologians as well. ${ }^{104}$ Additionally, their explicit concern for issues

${ }^{100}$ Pauli Pylkkö, "Fysiikkaviikari Filosofian Ihmemaassa: Eli Olisiko Tiedeuskovaisuutta Hoidettava Lääkkeillä Ja Kirurgialla? Kari Enqvistin Kuoleman ja unohtamisen aikakirjat ja muita hänen kirjoituksiaan," at http://www.uunikustannus.fi/fysiikkaviikari.pdf (accessed June 10, 2015).

${ }^{101}$ It should be observed that their overall views have also been very briefly compared and considered to be parallel in some ways. See, for example, Paavo Pylkkänen, "Can Quantum Analogies Help Us to Understand the Process of Thought?," in Brain and Being: At the Boundary Between Science, Philosophy, Language and Arts, eds. Gordon G. Globus, Karl H. Pribram, and Giuseppe Vitiello (Philadelphia, PA: John Benjamins, 2004), 190. See also, Paavo Pylkkänen, Mind, Matter and the Implicate Order (Berlin, Germany: Springer-Verlag, 2007), 133 n. 8.

${ }^{102}$ One of the most important new movements in philosophy is post-humanism, which integrates into its purview the realities of our technological world merging with humanity, and the necessary reenvisioning of both human nature and the rest of nature that goes alongside this thought pathway. A few of the individuals exploring this frontier include Floyd Merrell, Sensing Corporeally: Toward a Posthuman Understanding (Toronto, Canada: 2003); Cary Wolfe, What is Posthumanism? (Minneapolis, MN: University of Minnesota Press, 2010); Pramod K. Nayar, Posthumanism (New York, NY: John Wiley \& Sons, 2014); Peter Mahon, Posthumanism: A Guide for the Perplexed (New York, NY: Bloomsbury, 2017); William S. Haney II, Globalization and the Posthuman (Newcastle upon Tyne, UK: Cambridge Scholars Press, 2009); Alan Smart and Josephine Smart, Posthumanism: Anthropological Insights (Toronto, Canada: University of Toronto Press, 2017); Stefan Herbrechter, Posthumanism: A Critical Analysis (New York, NY: Bloomsbury Academic, 2013); Sam Mickey, Coexistentialism and the Unbearable Intimacy of Ecological Emergency (Lanham, MD: Lexington Books, 2016); and Robert Pepperell, The Posthuman Condition: Consciousness Beyond the Brain (Bristol, UK: Intellect Books, 2003).

${ }^{103}$ Another major movement in philosophy has been toward "critical realism," which seeks to hold together 1) ontological realism, 2) epistemic relativism, 3) judgmental rationality, and 4) methodological pluralism. See the recent work by Roy Bhaskar, as introduced in Roy Bhaskar and Mervyn Hartwig, ed. Enlightened Common Sense: The Philosophy of Critical Realism (New York, NY: Routledge, 2016). Bhaskar credits David Bohm as an influence and ally. See Roy Bhaskar and Mervyn Hartwig, The Formation of Critical Realism: A Personal Perspective (New York, NY: Routledge, 2010), 175. Indeed, some of Bhaskar's work very much mirrors the work of Bohm, as explained by Colin Wight, "Realism, Science and Emancipation," in Realism, Philosophy and Social Science, eds. Kathryn Dean, Jonathan Joseph, John Michael Roberts, and Colin Wight (New York, NY: Palgrave Macmillan, 2006), 32-64, and according to Wight, Bhaskar's later work also represents a rejection of many Critical Realist tenets in a manner that may parallel Bohm's own trajectory. Of course, Bhaskar is also interested in human freedom or emancipation. See Andrew Collier, Critical Realism: An Introduction to Roy Bhaskar's Philosophy (New York, NY: Verso, 1994), 169-204.

${ }^{104}$ As Andrew Moore explains, it is possible that "the case for the truth of realism in Christian faith is separable in principle from that of scientific realism." Rather, "one can be a realist concerning one class of entity (macroscopic objects in the physical world, for example) and an anti-realist concerning others (say those of mathematics) without presuming" that choosing an anti-realist view in one instance will demand the adoption of such a view in other domains, Andrew Moore, Realism and Christian Faith: God, Grammar and Meaning 
pertaining to the two cultures, and detailed, though self-admittedly embryonic, inquiries into how freedom and time should be understood, both in their interrelationship with each other and in how they are applied to the individual and society, establish them as distinct forerunners of some of the deepest and most important questions philosophers have and will continue to discuss into the $21^{\text {st }}$ century, ${ }^{105}$ alongside future theologians exploring the ramifications and challenges of posthumanism ${ }^{106}$ and its corollary transhumanism, and the varieties of pantheism and panentheism that often accompany them. ${ }^{107}$

In summary thus far, the situation is as follows. The problem of freedom concerns its apparent coexistence with determinism, particularly in nature. This problem is reduplicated and magnified in the mystery of the localized physical human being. Tradition has separated freedom from nature,

(Cambridge, UK: Cambridge University Press, 2003), 185. See also, Howard Robinson, "Idealism and Perception: Why Berkeleyan Idealism is Not as Counterintuitive as It Seems," in Idealism and Christian Philosophy: Idealism and Christianity Vol 2, eds. Steven B. Cowan and James S. Spiegel (New York, NY: Bloomsbury, 2016), 84-86.

${ }^{105}$ Inasmuch as both Bohm and Pylkkö are relatively unknown to many philosophers and theologians, residing as they do on the edges of these disciplines and riding the fence between the "two cultures," it is worth reiterating that they both have a growing influence in certain segments of the academy in the $21^{\text {st }}$ century, although Pylkkö is by far the less well known of the two. For his part, Bohm represents a key figure in the debates surrounding the proper interpretation of quantum physics, and even if his more innovative ideas were mostly scorned by his contemporary fellow physicists, Bohm's influence after his death in philosophy, psychology, sociology, education, theology (not just Western Christianity), and even overt science fiction have been significant, and today some younger physicists are reconsidering his ideas. Note J. B. Kennedy, Space, Time and Einstein: An Introduction (New York, NY: Routledge, 2003), 181. See also, Emily Horton, Contemporary Crisis Fictions: Affect and Ethics in the Modern British Novel (New York, NY: Palgrave Macmillan, 2014), 119-120; Gérard Gouesbet with Jean Bricmont, Hidden Worlds in Quantum Physics (Mineola, NY: Dover Publications, 2013), 240; Anja Skaar Jacobsen, Léon Rosenfield: Physics, Philosophy, and Politics in the Twentieth Century (Toh Tuck Link, Singapore: World Scientific Publishing, 2012), 275-306, note especially, 304 n. 7. Concerning Pylkkö, the lesser known of the two, the Bohmian scholar Paavo Pylkkänen considers Pylkkö "one of the most interesting and original [philosophers] to have appeared in recent years." Pylkkänen continues, "Pylkkö underlines the fundamentally aconceptual nature of the mind, and his views have some interesting similarities to Bohm's views ..., although there are also important differences," Pylkkänen, Mind, Matter and the Implicate Order, 133 n. 8.

${ }^{106}$ For a few examples of theologians exploring the issues in post-humanism, see David Albertson and Cabell King, eds. Without Nature?: A New Condition for Theology (New York, NY: Fordham University Press, 2010); Jennifer L. Koosed, ed. The Bible and Posthumanism (Atlanta, GA: Society of Biblical Literature, 2014); Ilia Delio, Making All Things New: Catholicity, Cosmology, Consciousness (Maryknoll, NY: Orbis Books, 2015); and Ilia Delio, The Unbearable Wholeness of Being: God, Evolution, and the Power of Love (Maryknoll, NY: Orbis Books, 2013).

${ }^{107}$ For example, see Elaine Graham, "Manifestations of the Posthuman in the Postsecular Imagination," in Perfecting Human Futures: Transhuman Visions and Technological Imaginations, eds. J. Benjamin Hurlbut, and Hava Tirosh-Samuelson (New York, NY: Springer VS, 2016), 68; Adam Pryor, Body of Christ Incarnate for You: Conceptualizing God's Desire for the Flesh (Lanham, MD: Lexington Books, 2016), xv, 119, 151, 163, 171; and Brent Waters, From Human to Posthuman: Christian Theology and Technology in a Postmodern World (New York, NY: Routledge, 2006), 80, 85. Much of this movement builds off of the work of the Catholic philosopher Pierre Teilhard de Chardin, The Phenomenon of Man (New York, NY: HarperCollins, 1976). 
leaving it in some sort of 'timeless' metaphysical realm outside any natural cause and effect temporal sequence, but today this is widely recognized as encouraging a contradiction.

The problem of freedom finds a close parallel in how time is understood today. Alongside prior presuppositions about temporal determinism and continuity in combination with nature, time has now come to be understood as merely an additional spatial dimension in physics, and localized in such a way as to be relativized and as determined as the rest of nature. This would mean there is no real 'becoming' in the world. Thus, any notion of a cosmically objective or experientially subjective human time which brings new things into existence is as elusive or metaphysically nonexistent as the idea of freedom.

The problem of freedom and the problem of time thus merge together as part of a broader problem concerning the natures of metaphysics and physics. Logically enough, the concept of God also inherits the preceding problems of freedom and time, bringing the entirety of Kant's metaphysical issues together as one problem. The consequence of the situation just described has, it appears, generated the 'two cultures' that have engaged society's concerns and interests, including in the religious world. Both cultures have had marked successes in influencing various historical and contemporary societies and ideas, but, at heart, they contain contradictory interpretations about freedom, time, and their interrelationship.

\section{Problem Statement}

The problem this dissertation will address is that the mid 20th century rise of the two academic cultures of the sciences and humanities, exemplified through the contributions of Albert Einstein and Martin Heidegger, illustrate that although freedom and time have historically been recognized as related, competing developments in the philosophical foundations of the sciences and humanities have encouraged their interrelationship to become articulated in incompatible ways. Significantly, and not surprisingly, such tension has also been reflected in recent research on the relationship of freedom and time within theology. All together, then, the traditional subject matters of metaphysics (God, freedom, and time) have been cast into a confused disarray. 
The above problem is manifested within the work of David Bohm and Pauli Pylkkö. Respectively building upon Einstein and Heidegger, Bohm and Pylkkö have furthered discussions on how to understand the interrelationship of freedom and time. However, their views on freedom and time have not yet been subjected to an appropriate comparative analyses to determine if there is any possibility of a resolution to the conflicting and incomplete conclusions of their predecessors, nor been applied to questions concerning the inevitable tensions between interpretations of freedom and time within theology, let alone a specifically biblical theology. If Bohm's and Pylkkö’s works could shed light on how any resolution could be accomplished, the hope of meaningfully reintroducing an appropriate metaphysics concerning God, freedom, and time into a place at the table of intellectual discourse might again be possible.

\section{Purpose Statement}

The purpose of this study is to outline the significance of the conflict between the two cultures concerning freedom and time, and then describe, compare, and contrast Bohm's and Pylkkö's positions on the interrelationship of freedom and time to evaluate their tentative significance for theological reflection and the constitution of an appropriate metaphysics concerning God, freedom, and time.

\section{Delimitations of the Study}

A comprehensive investigation of both the historical, and even contemporary, perspectives on the interrelationship of freedom and time are obviously beyond the purview of this dissertation. Furthermore, this study is not focusing on the concepts of freedom or time separately-each does have several nuanced meanings within different socio-political contexts and cultures that this study can only touch upon or allude to in places. As such, explaining or resolving any given aspect of the many problems that remain unresolved by common consensus in understanding the viability of, or nature of, the concepts of freedom (including free-will) and time, are obviously beyond the aspirations of a study such as this one. Furthermore, this is not a study evaluating the viability, utility, or accuracy of the latest advances in psychology, neuroscience, micro-biology, and laboratory or theoretical physics, 
even if some of the latest studies about them are cited and discussed for their potential philosophical and theological relevance.

In addition to the above considerations, it should be specifically noted that beyond brief explanations, the detailed engagement of Bohm and Pylkkö with quantum empirical phenomena and their more technical scientific work are beyond the scope of this study. It must be emphasized that the unresolved mysteries of quantum physics and related areas (the scope of Relativity's domain, gravitation, etc.), such as within cosmology and cosmogony, have spawned numerous schools of thought amongst physicists, philosophers, and theologians attempting to make sense of it all, with or without being aided by special revelation such as Scripture. This study does not portend to resolve or clarify such issues; however, it may aid in positioning the rationale behind some of the different positions taken in the aforementioned areas. Thus, although in many respects Bohm's and Pylkkö's technical work, in particular Bohm's as a physicist, contributed to the development of their thinking on freedom and time, the descriptions they offer for freedom and time have already been mostly separated from their more technical work within their own respective writings. Pylkkö himself, for example, heavily relies upon the reports of quantum physicists, yet he is himself no physicist. As such, the proposed research will focus on the tentative trajectories of how their ideas on freedom and time may potentially contribute to future theological reflection, leaving any detailed discussion or review of their technical work unnecessary and a distraction from the present research. Nevertheless, although I will not engage the detailed interpretations of quantum physics, given the attention that quantum physics has attracted in recent years, I will introduce the field and general situation of quantum physics in a special section concerning some preliminary considerations below within the prolegomenon of this introductory chapter.

The complex breadth and depth of the subjects to be focused upon in this study require some additional specific delimitations. (1) This study is primarily descriptive, not polemical, aiming for clarifying issues, while only tentatively advancing implications and potential trajectories for any new understandings of freedom and time and their relationship to theology through the works of the selected individuals. (2) Concerning the specific focus of the study-the perspectives of Bohm and 
Pylkkö concerning freedom and time-it must be noted that the study will not deliver any detailed or definitive presentation of other aspects of their work (which extend very widely), except where necessary for the sake of clarifying their positions on freedom and time. (3) Concerning the various interrelated issues that intersect with freedom, time, and God, the specific focus of this study will necessarily be limited to the selected authors and a limited survey of pertinent secondary literature that reflects directly upon the context of Bohm's and Pylkkö's contributions.

(4) Lastly, it must be emphasized that when describing the delimitations, and also scope, of a study such as this, the severity of the divide between the two cultures cannot be overestimated. This is especially so when figures like Einstein and Heidegger are mentioned, and their followers are featured, in today's multi- and trans-disciplinary contexts, which are all in one way or another subsumed under the two cultures' phenomena. ${ }^{108}$ Although this study will not review the complete historical details relating to the development of the two cultures, the original historical context that initiated the two cultures nevertheless represents an unavoidable topic which must be addressed (see Appendix) to provide some explanatory rationale for how the contemporary context today shapes the issues and contours of the study itself. ${ }^{109}$ This must be done, insofar as both the original and contemporary contexts impact upon the potential value of this study, given that the two cultures have significantly affected how the concepts of freedom and time have been approached and applied to any disciplines beyond philosophy and physics, including both theology and historical theology, where religionists are often caught, unawares, within the academic vortex of the "two cultures" battleground. Indeed, whether theology and the study of religion should be a science, or a humanity,

\footnotetext{
108 The subjects introduced in this study, from quantum physics to postmodernism and theology, are intimidating with expansive bibliographies addressing them. As such, there are obvious limits to what any single study can undertake when it addresses these subjects. What is of most interest to this study is the relationship between Einstein's and Bohm's ideas, on the one hand, and Heidegger's and Pylkkö's ideas, on the other hand, which has too often been ignored within the two culture's context, as noted above.

${ }^{109}$ On this point, it is important to observe that Heidegger himself suggested that "at the root of these controversies concerning the distinction between [the] two modes of inquiry is a repetition of what had already been articulated in antiquity" with the Greeks, Greaves, Starting with Heidegger, 142.
} 
or a unique third culture remains a matter of some dispute that this study will and must also address. ${ }^{110}$

\section{Scope of the Study}

To clarify the scope of the problem of the study also requires a few additional explanatory comments. The nature of the problem requires examining some additional adjacent issues pertaining to the context of the discussions surrounding the sciences, the humanities, and religion to accurately represent how the problem is actually understood by many people. Specifically, in this introductory chapter below, and in introducing the current dynamics surrounding the current manifestation of the third culture in chapter two, I will expand upon a key point regarding the impact of this debate between the two cultures and theology-that presently theology is a replicator of the conflict within the two cultures concerning its understanding of the concepts of freedom and time. In order to do this, it will be necessary to include an overview of the major contours of the continuing popular and academic debate over whether science and religion are compatible, and what role the humanities, as the often ignored component of this debate, have in such a discussion.

Because of the confusion and ambiguity surrounding the above situation between science, religion, and the humanities, the question of "how" religion should tackle the issues of freedom and time, as a unique or third culture, becomes an issue in itself that must be clarified. The relations of

\footnotetext{
${ }^{110}$ To illustrate the problem within the context of the contemporary secular western academy, not only is religion now frequently considered a humanity by the broader public academy, particularly with the scientific community, but also part of a discipline long in decline. For example, Brian Fraser observes of the situation in British Columbia in Canada between 1945-1965, the very time when Snow's two cultures assessment was made, "when religious studies was classified as one of the humanities, it was identified with the part of the curriculum that was shrinking rather than expanding." This situation came about as the "social sciences began to replace the humanities as the dominant disciplines in the Faculty of Arts." Furthermore, corresponding with the rise of the hard and softer social sciences, which are both part of the sciences, the traditional humanities, outside of English, "either remained stationary or went into a period of decline, Brian John Fraser, The Study of Religion in British Columbia: A State-of-the-Art Review (Waterloo, Ontario: Wilfrid Laurier University Press, 1995), 43. For more on the controversy concerning the methods of science and the humanities over the subject matter of religion, and whether religious studies should be a part of the sciences or humanities, see, for example, William J. Wainwright, "Introduction," in God, Philosophy, and Academic Culture: A Discussion between Scholars in the AAR and the APA, ed. William J. Wainwright (Oxford, UK: Oxford University Press, 1996), 3-12; and Robert J. Henle, "Science and the Humanities," in Philosophy and Science as Modes of Knowing: Selected Essays, ed. Alden L. Fisher and George B. Murray (New York, NY: Appleton-Century-Crofts, 1969), 3-4. Henle expresses concern, from a time closer to Snow's original lecture, that "science would, in this new [emerging third] culture, [displace and] play all the knowledge roles played by philosophy, theology and the humanities in pre-scientific culture," ibid., 5.
} 
freedom and time in the sciences and the humanities will be shown to be reflected back upon theology as a de facto third culture-that is, religion may already be a "third culture" of some sort, but it isn't helping at present to resolve the problems related to freedom and time. Through exposing the historical and contextual backdrop of the above discussions, a more fruitful pathway forward may be articulated that correctly positions the contributions of Bohm and Pylkkö.

The process by which I will explore the efforts of the existing third culture to engage the problem of freedom and time requires the exposure of the key element that divides the two cultures in the academy. This will be clarified by exploring how freedom and time are the key concepts dividing the critical cross-cultural disciplines of (1) psychology and psychiatry, (2) economics, and the (3) socio-political sciences. ${ }^{111}$ Like theology and religion, these three disciplines are singled out because they have been particularly affected by the conflict between the two cultures, residing distinctly "between" them and thus heavily impacted by the controversy surrounding them. And again, like theology and religion, they are also disciplines that are clearly divided over the function and role that freedom and time should take within them. Thus they demonstrate the challenge such divided disciplines have influencing the broader academy today in productive ways. Some have already suggested, including Snow himself, that these three disciplines collectively constitute a third culture which should mediate the two cultures, wherein the meanings and ethical and moral (and therefore theological) implications of the two cultures can be applied and most directly studied. ${ }^{112}$ That is, the third culture disciplines demonstrate the natural link between theology, religion, and the two cultures. However, as will be shown, they are not succeeding in resolving the conflict.

\footnotetext{
${ }^{111}$ Such an overview is not ancillary to the present study's focus on Bohm and Pylkkö, as they also address issues beyond the narrow umbrella of the "two cultures" and theology, including, in particular, the disciplines of psychology and psychiatry, economics, and the social and political sciences.

112 "Many now loosely consider Snow's third culture as including economics, political science, and indeed psychiatry," Michael Robertson and Garry Walter, Ethics and Mental Health: The Patient, Profession and Community (Boca Raton, FL: CRC Press, 2014), 180. Importantly, however, Robertson and Walter also point out that psychiatrists (their area of study) in particular experience the tension created by the two cultures, knowing full well that "profound moral questions arise from this epistemic quandary," ibid. Others operating in the health sciences concur. See Warren T. Reich, "A Corrective for Bioethical Malaise: Revisiting the Cultural Influences that Shaped the Identity of Bioethics," in The Development of Bioethics in the United States, eds. Jeremy R. Garrett, Fabrice Jotterand, and D. Christopher Ralston (New York, NY: Springer, 2013), 86.
} 
A contemporary review of the situation is, I believe, necessary for properly and fully illustrating just why and how the sometimes apparently esoteric and obscure approaches toward freedom and time in contemporary philosophy and physics impact the many practical fields of discourse, particularly those constituting Snow's third culture. Even cursorily tracing such influences may prove illuminative for understanding how many believe theology and religion should relate to the third culture disciplines of psychology and psychiatry, economics, and the socio-political sciences, ${ }^{113}$ which have all received extensive and explicit recent interest by religionists and theologians and all of which utilize concepts of freedom and time inherited from the broader context of the two cultures of the sciences and humanities. ${ }^{114}$ As all suggestions for further research at the end of the study will presume the necessity of such an explanatory introduction, it should be provided early in the study for the benefit of the reader throughout the study.

\section{Contemporary Context and Value of the Study}

This study represents both a multi-, inter-, and cross-disciplinary (perhaps cross-cultural) study. As such, it may be helpful to offer a few additional words concerning the somewhat unique context behind the study, with an aim toward pointing out its value. Indeed, with all of the prior introductory comments in mind, one of the most important tasks of a more abstract, even esoteric study such as this one is to highlight its practical implications and applications. Toward this end, I will briefly provide some additional contemporary context surrounding the complexities of this particular project, which happen to be directly relevant to the contributions of Bohm and Pylkkö.

Perhaps a contemporary and historical comment may be apropos to illustrate the poignant animosity between the two cultures. The fact is, Heidegger has often been criticized by contemporary

\footnotetext{
${ }^{113}$ It is a common sentiment today by advocates of religion that "theology can-and should-inform law, medical ethics, economic policy, and just about every other practical consideration," Casey Chalk, "The Glorious Mission of Theology," in The Catholic Thing at https://www.thecatholicthing.org/2018/02/01/the-gloriousmission-of-theology/ (accessed February 1, 2018).

${ }^{114}$ Again, the three disciplines of psychology and psychiatry, the socio-political sciences, and economics, are specifically included as they have attracted an increasing interest from theologians and religionists in recent times. This is reflected in many contemporary authors, such as Anthony B. Bradley, Something Seems Strange: Critical Essays on Christianity, Public Policy, and Contemporary Culture (Eugene, OR: Wipf \& Stock, 2016), xi.
} 
philosophy professors and others for his brief but seemingly unrepentant support of the National Socialist Nazi movement and Adolf Hitler ${ }^{115}$ ("the Nazi pope to Hitler's emperor"116) in Germany prior to World War II. It has, more specifically, been suggested that Heidegger's alleged "irrationalism"117 contributed to his sympathies for fascist Nazism on the Right, ${ }^{118}$ which some have seen echoed in more contemporary socio-cultural movements in politics. ${ }^{119}$ All this, in very complex ways, is

${ }^{115}$ For example, Emmanuel Faye has argued that Nazism did in fact have connections with Heidegger's philosophy. Emmanuel Faye, Heidegger, l'introduction du Nazisme dans la Philosophie (Paris, France: Albin Michel S. A., 2005); now translated as Emmanuel Faye, Heidegger, The Introduction of Nazism into Philosophy in Light of the Unpublished Seminars of 1933-1935, tr. Michael B. Smith with a foreword by Tom Rockmore (London, UK: Yale University Press, 2009). See also, Víctor Farías, Heidegger and Nazism (Philadelphia, PA: Temple University Press, 1989); and Rüdiger Safranski, Heidegger: Between Good and Evil, tr. Ewald Osers (Cambridge, MA: Harvard University Press, 1999).

${ }^{116}$ It has been claimed by one recent commentator that Heidegger aspired "to become, in effect the Nazi pope to Hitler's emperor," which only failed because of the "collapse of the whole Nazi project," Anthony E. Mansueto and Maggie Mansueto, Spirituality and Dialectics (Lanham, MD: Lexington Books, 2005), 102.

${ }^{117}$ This is a frequent criticism of Heidegger. For an overview and defense of Heidegger against the claims of his "irrationalism," see Shirley, Heidegger and Logic: The Place of Lógos in 'Being and Time', 141-147;

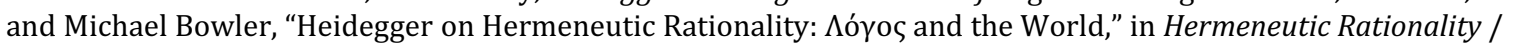
La rationalité herméneutique, eds. Maria Luísa Portocarrero, Luis António Umbelino and Andrzej Wierciński (Berlin, Germany: Lit Verlag, 2012), 220.

${ }^{118}$ See the discussions in Lawrence Vogel, The Fragile "We": Ethical Implications of Heidegger's Being and Time (Evanston, IL: Northwestern University Press, 1994), 62-63; and Mark Basil Tanzer, Heidegger: The Freedom of Dasein in the Early Heidegger (Amherst, NY: Humanity Books, 2002), esp. 12-21.

${ }^{119}$ Mark Thompson, "Trump and the Dark History of Straight Talk," at https://www.nytimes.com/ 2016/08/28/opinion/sunday/trump-and-the-dark-history-of-straight-talk.html (accessed February 9, 2017). Thompson notes that Trump, in many ways a 'cultural-literary' intellectual' of the 'humanities' for his communicatory resonance with his followers, and Heidegger, both promoted, in essence, being 'true to yourself', that is, authentic. Thompson is worth quoting at length: "Modern authenticism began as a reaction to the Enlightenment program to recast language to conform to the notion of Reason. Immanuel Kant's friend Johann Georg Hamann was one of the first to make the case that, if you take ideas and words out of their behavioral and cultural context, they lose meaning and relevance. A purely rationalist language would no longer be able to express community or faith. Hamann's contemporary, the philosopher Johann Gottfried Herder, made the critical link between language, culture and nationhood, and soon authenticity of language became associated with another product of Enlightenment thought: nationalism.

"These ideas entered European thought through a chain of influence that stretched from Hegel to Kierkegaard to Nietzsche. By the early 20th century, Martin Heidegger was distinguishing not just between authentic and inauthentic modes of being, but between authentic and inauthentic language.

"Once you heard the voice of a man, and that voice knocked at your hearts, it wakened you, and you followed that voice." That was Adolf Hitler, the man whom Heidegger would praise for helping the German people rediscover their authentic essence, addressing government and Nazi party leaders in September 1936. According to Hitler, the miraculous appearance of the 'voice'-by which he meant the profound bond between himself and his audience that let him express their deepest feelings-allowed ordinary men and women, who were 'wavering, discouraged, fearful,' to unite as a Volk, or national community. It was at once a political and a personal 'voice' that, thanks to the invention of radio, could reach out not just to audiences at political rallies, but into any living room.

"Authenticism was banished to the fringes of politics after World War II and the defeat of European fascism. Technocratic policy-making delivered relative prosperity and security for the majority, and many voters found the rationalist rhetoric of mainstream politicians credible. Authenticism does not even rate a mention in George Orwell's landmark 1946 essay 'Politics and the English Language.' But the uncertainty and division that have followed the global crash, mass migration and the West's unhappy wars in the Middle East 
unavoidably entangled within contemporary Christianity as certain prominent conservative Religious

Right American theologians engage in these arenas, ${ }^{120}$ while at the same time the Roman Catholic

leader as of 2013, Pope Francis, is regarded by some as the Leftist "flag-bearer of the global" anti-

Right resistance ${ }^{121}$ (Francis' leftism is notably in contrast to his more Right leaning predecessor

have given it a new opportunity.

Today's authenticists come in many different guises, from pure anti-politicians like Mr. Trump and Italy's Beppe Grillo to mainstream mavericks as diverse as Britain's Boris Johnson and Ted Cruz. None of them are Hitlerian in intent, but nationalism typically looms large ('Make America Great Again!'), as does the explicit or implicit contrast between the chosen community and a dangerous or unacceptable 'other,' which in 2016 almost always means elites and foreign immigrants," ibid. For a more sympathetic philosophical analysis of a Heideggerian nature against totalitarianism, of either the Right or Left, see Hannah Arendt, and her critique of modern society, as described by Mike Cosper, "Grinding Through the Pleasure Factory: Reading Arendt at Disney World," at https://www.cardus.ca/comment/article/4285/grinding-through-the-pleasure-factoryreading-arendt-at-disney-world/ (accessed May 3, 2017). For an insightful work discussing the role of Heideggerian ontology in leadership, see Donna Ladkin, Rethinking Leadership: A New Look at Old Leadership Questions (Cheltenham, UK: Edward Elgar, 2010), esp. 34, 107-109, 159-160.

${ }^{120}$ For an article describing the situation, see Ken Shepherd, "Theologian Wayne Grudem, Who Briefly Recanted His Endorsement, Back on the Trump Train," at http://www.washingtontimes.com/news/2016/oct /20/theologian-wayne-grudem-who-briefly-recanted-his-e/ (accessed March 2, 2017). See also, Wayne Grudem, Politics According to the Bible: A Comprehensive Resource for Understanding Modern Political Issues in Light of Scripture (Grand Rapids, MI: Zondervan, 2010); and, for the irony of it, Hemant Mehta, "Christian Theologian: I Still Support Donald Trump Because Hillary Clinton is Worse Than Hitler," at http://www.patheos. com/blogs/friendlyatheist/2016/10/11/christian-theologian-i-still-support-donald-trump-because-hillary-clin ton-is-worse-than-hitler/ (accessed March 2, 2017). Note also, that opposite Trump, earlier in the campaign, was the open socialist Bernie Sanders representing the Democratic Party. His own views have recently received attention relative to the issue of religious freedom. Emma Green, "Bernie Sanders's Religious Test for Christians in Public Office," at https://www.theatlantic.com/politics/archive/2017/06/bernie-sanders-chris-van-hollenrussell-vought/529614/ (accessed June 8, 2017).

${ }^{121}$ Austen Ivereigh, "Is the Pope the Anti-Trump?" at https://www.nytimes.com/2017/03/04/ opinion/sunday/is-the-pope-the-anti-trump.html (accessed March 4, 2017). Ivereigh describes Trump and Francis as "the world's two most compelling populists," despite the fact that their positions often express "the diametrical opposition of their visions," ibid. They represent, in other words, 'two cultures', and their relevance to the "two cultures" of the sciences and humanities which drives my study is apropos, as Trump supporters are often accused of decrying the overreach of "Leftist scientists" into society, whereas Francis appears, by and large, to support the greater reach and impact of "science" in society (e.g., climate change science). See also, George Neumayr, The Political Pope: How Pope Francis is Delighting the Liberal Left and Abandoning Conservatives (New York, NY: Hachette Book Group, 2017). Also noteworthy is that many campaign slogans from the past decade of U.S. Presidential elections show that Republican candidates favor slogans referring to the past and its role in defining the future, whereas Democrats focus on the future more than the past. For a collection of recent campaign slogans, see https://en.wikipedia.org/wiki/List_of_U.S._presidential_campaign_ slogans (accessed May 12, 2017). The point is that both recognize the role of "time" in their political visions, but the way they emphasize it reveals certain biases and presuppositions. The very words "conservative" and "progressive," as associated with the Republican Right and Democratic Left, respectively, demonstrate an attitude toward "time." Of course, the issues are more complicated than this simple illustration, even as the illustration is informative. See also, Tobias Becker, "Chronopolitics: Time of Politics, Politics of Time, Politicized Time," at https://www.hsozkult.de/event/id/termine-39537 (accessed February 26, 2019). As Becker observes, "recently, Brexit and Trump have both been portrayed in terms of a temporal politics, as indicative of 'being stuck in the past' or the nostalgic yearning for a Golden Age," ibid. 
Benedict XVI ${ }^{122}$ ). Conversely, while Einstein has suffered no character attacks comparable to that which Heidegger and his ideas have endured, it is nevertheless true that Einstein himself, and his ideas, offer support to the idea that humans do not have free-will, a legacy that connects him with a number of notorious figures and political movements throughout history that provide his theories with dubious company and cast a shadow upon the auspices of the scientific community which embraces them. Such movements include several variants of communism and Marxism (both Soviet, Chinese, and South American), ${ }^{123}$ controversial movements which also have passionate advocates within Christianity, particularly through the controverted and ironically, yet intriguingly, named

\footnotetext{
${ }^{122}$ For a recent critique of Pope Francis, see Gerald McDermott, "Is Pope Francis a Liberal Protestant?," at https://www.firstthings.com/web-exclusives/2017/11/is-pope-francis-a-liberal-protestant (accessed November 15, 2017). For further insight into the current dynamics of higher education within the Catholic church in the United States, see Anne Hendershott, "Taking the Catholic Out of Catholic Universities," at https://www.city-journal.org/html/taking-catholic-out-catholic-universities-15495.html (accessed November 27, 2017). Also, for an interesting study on the complexities of the Roman Catholic church worldwide, see Arno Tausch, "Global Catholicism in the Age of Mass Immigration and the Rise of Populism: Comparative Analyses, Based on Recent 'World Values Survey' and 'European Social Survey Data,'” at https://www.academia.edu/ 30068865/Global_Catholicism_in_the_age_of_mass_migration_and_the_rise_of_populism_comparative_analyses_ based_on_recent_World_Values_Survey_and_European_Social_Survey_data (accessed January 17, 2018). See also, John Cornwell, "Pope vs. Pope: How Francis and Benedict's Simmering Conflict Could Split the Catholic Church," at https://www.vanityfair.com/news/2018/10/pope-francis-benedict-conflict-catholic-church (accessed November 2, 2018).

It should be noted here that secular politics is very much part of the discussion about science and religion, as notable politicians and religionists have clearly stated their opinions about the matter. For example, the conservative and former Alaskan Governor and U.S. Vice-Presidential candidate Sarah Palin has advocated openness toward creationism and Intelligent Design in schools, whereas the progressives former U.S. President Barack and his Vice-President Joe Biden have spoken against them. See Ronald L. Numbers, "Scientific Creationism and Intelligent Design," in The Cambridge Companion to Science and Religion, ed. Peter Harrison (Cambridge, UK: Cambridge University Press, 2010), 143.

${ }^{123}$ For example, a number of Leftist Chinese communists, such as Zhang Songnian and Zhou Enlai, praised Einstein's theories, and connected them with their theories concerning communism, Danian Hu, China and Albert Einstein: The Reception of the Physicist and His Theory in China, 1917-1979 (Cambridge, MA: Harvard University Press, 2005), 61. Similarly, many Russian Soviet Marxists saw a "fundamental compatibility" with a "substantial number of Einstein's ideas with the Marxist philosophy of science. Einstein's belief in causality as the supreme law of scientific explanation was firmly upheld by Soviet philosophers, as was his solid attachment to the idea of continuity both in natural processes and in the growth of scientific thought," Alexander Vucinich, Einstein and Soviet Ideology (Stanford, CA: Stanford University Press, 2001), 1, 4. Furthermore, many have questioned the presence of free-will within Marxist philosophy, though this has been debated. See the discussion in J. J. O'Rourke, The Problem of Freedom in Marxist Thought: An Analysis of the Treatment of Human Freedom by Marx, Engels, Lenin and Contemporary Soviet Philosophy (Dordrecht, Holland: D. Reidel Publishing, 1974), esp., 43; Paul Blackledge, Marxism and Ethics: Freedom, Desire, and Revolution (Albany, NY: State University of New York Press, 2012), 4, 19-20; and David W. Lovell, From Marx to Lenin: An Evaluation of Marx's Responsibility for Soviet Authoritarianism (Cambridge, UK: Cambridge University Press, 1984), xi, 16-20, 56, 60, 193. Proponents of Marxism would argue that "Marx believed that the concept of the state was the 'realization of rational freedom', ibid., 193. See also, Herbert Aptheker, The Nature of Human Democracy, Freedom and Revolution (New York, NY: International Publishers, 1967), 71.
} 
movement known as Liberation Theology, ${ }^{124}$ which originated with leftist Catholics who have consistently received accusations of Marxist sympathies. ${ }^{125}$ The paradoxes here are readily apparent-Heidegger, the philosopher of freedom, was connected with Nazism, while Einstein, who denied free-will, was a communist sympathizer tangentially linked with "liberation theology."

Overall, the reality of this public socio-political situation reaffirms that the "two cultures" can, at times, be manifested or replicated within varying popular ideologies in society, whether in Christianity or merely throughout the broader western society. More specifically, the two cultures can also be manifested in varying representations of populism and elitism in given socio-political circumstances, and either side, the so-called Right or Left, can be associated with populism (the 'humanities') or elitism (the 'sciences') in differing contexts. That is, some populist figures may be classified as representatives of the Right, while other populist figures are known socialists with communist or Marxist sympathies, and some polls suggest either variant of populist would have had the better chance of defeating the elitist candidates. ${ }^{126}$ Similarly, it is noteworthy that some populists

\footnotetext{
${ }^{124}$ See, for example, Craig L. Nessan, The Vitality of Liberation Theology (Eugene, OR: Pickwick Publications, 2012), 108; Christian Smith, The Emergence of Liberation Theology: Radical Religion and Social Movement Theory (Chicago, IL: The University of Chicago Press, 1991), 29-30; John R. Pottenger, The Political Theory of Liberation Theology: Toward a Reconvergence of Social Values and Social Science (Albany, NY: State University of New York Press, 1989), 64-98; Arthur F. McGovern, Liberation Theology and Its Critics: Toward an Assessment (Eugene, OR: Wipf \& Stock, 2009); Dennis McCann, Realism \& Liberation Theology: Practical Theologies in Creative Conflict (Eugene, OR: Wipf \& Stock, 2001); Bernard V. Brady, Essential Catholic Social Thought (Maryknoll, NY: Orbis Books, 2008), 161; and Leonardo Boff, Introducing Liberation Theology (Tunbridge Wells, Kent, UK: Burns \& Oates, 1987).

${ }^{125}$ For example, see Randall W. Reed, A Clash of Ideologies: Marxism, Liberation Theology, and Apocalypticism in New Testament Studies (Eugene, OR: Pickwick, 2010), 27; Paul E. Sigmund, Liberation Theology at the Crossroads: Democracy or Revolution (New York, NY: Oxford University Press, 1990), 4; and Phillip Berryman, Liberation Theology: The Essential Facts About the Revolutionary Movement in Latin America-and Beyond (New York, NY: Pantheon Books, 1987).

${ }^{126}$ Thus, it seems, the extremes dominate. See "2016 General Election: Trump vs. Sanders," at http://elections.huffingtonpost.com/pollster /2016-general-election-trump-vs-sanders (accessed October 23, 2017). Note also, Jesse Yomtov, "Would Bernie Sanders have Defeated Donald Trump?," at https://www.usatoday.com/story/news/politics/onpolitics/2016/11/09/bernie-sanders-donald-trump/9353 0352/ (accessed November 9, 2016); “General Election: Trump vs. Sanders," at https://www.realclear politics.com/epolls/2016/president/us/general_election_trump_vs_sanders -5565.html (accessed October 23, 2017); Julia Glum, “Election 2020: Poll Shows Joe Biden and Bernie Sanders Would Beat Donald Trump," at http://www.newsweek.com/bernie-sanders-joe-biden-trump-reelection-poll- 638432 (Accessed July 18, 2017); Paul Sperry, "Don't be Fooled by Bernie Sanders-He's a Diehard Communist," at http://nypost.com/2016/01/16/don't-be-fooled-by-bernie-sanders-hes-a-diehard-communist/ (accessed January 16, 2016); and Joseph Betz, “Commentary: Understanding Bernie Sanders' Brand of Socialism," at http://www.chicagotribune.com/news/opinion/commentary/ct-bernie-sanders-democratic-socialism-201602 23-story.html (accessed February 23, 2016). The purpose of this note is to make the point that both Trump, on the Right, and Sanders, on the Left, were both roughly equally popular in the 2016 election cycle, and both
} 
on the Right defy many of the stereotypes of the Right and Left, exposing some of the fault lines ${ }^{127}$ separating the elites on the Right and Left and the populist tendencies of the Right and Left. ${ }^{128}$

In brief, yes, this study does dig toward unearthing the roots of some of the hot issues of the day not only in the academic world, but also in the contemporary public, political, and Christian world concerning, however tangentially or directly, freedom and time, and yes, both Bohm and Pylkkö's writings make these connections directly relevant as they both address politics. Perhaps, then, while this dissertation may not resolve the contentious discussions that one may have experienced at holiday dinner tables with extended family members or friends, it may, in some way, help one to understand just why such contentions arise in the first place. No matter how "insane" or irrational the other side's argumentation may appear, their arguments just don't "go away." This study is, in a roundabout way, asking "why" this is so. Indeed, in contrast to the simplistic bifurcation that exists in the minds of some between the highly popularized "Left" and "Right" on socio-politico-theological issues in Western circles, I trust the study will demonstrate that the issues are considerably more complicated than many presume, even as these broader labels do have some meaning within discussions about the natures of freedom and time.

represented "populist" tendencies of the Right and Left, respectively.

${ }^{127}$ David Azerrad, “America Divided: Trumpism Emerges Where Left and Right Fall Short," at http://www.heritage.org/conservatism/commentary/the-clash-ideologies-america-divided-trumpism-emerges -where-left-and-right (accessed October 23, 2017). Azerrad claims that "Trumpist populism offers a clearer view of the fault lines of American politics than any of the competing worldviews on the Left and the Right," ibid. In this sense, Trump has proven a helpful aid in clarifying the situation in society that may help us move beyond the stagnation of the Left and Right, if society chooses to learn from what Trump brings to light. For more on the complexities driving the crisis in the United States, see Charles Murray, Coming Apart: The State of White America, 1960-2010 (New York, NY: Random House, 2013). Murray focuses on the "rich" vs. the "poor," which could also be described loosely as the 'rich beneficiaries of science' vs. the 'poor victims of rural-humanities decline.'

${ }^{128}$ The \#NeverTrump movement is actually spearheaded by many more traditional conservative intellectuals such as Jonah Goldberg, Bill Kristol, Ben Shapiro, Bret Stephens, and George Will, demonstrating there is a genuine discussion taking place amongst conservative intellectuals about the true meaning of "conservatism" in the broad sense as it is used in the United States. Note in particular, Jonah Goldberg, "Sorry, I Still Won't Ever Vote for Trump," at http://www.nationalreview.com/article/435686/donald-trump-republican -nomination-I-still-wont-vote-him (accessed May 21, 2016). Popular amongst this broader group is the thesis that Nazism is, contra the leftist opinion, actually a product of leftist thinking, not the Right and Trump. See Dinesh D'Souza, The Big Lie: Exposing the Nazi Roots of the American Left (Washington, D. C.: Regnery Publishing, 2017). Furthermore, while Trump is not known for his personal kindness and decorum, many conservatives lament this, such as Arthur C. Brooks, Love Your Enemies: How Decent People Can Save America from the Culture of Contempt (New York, NY: Broadside Books, 2019). 
The above colorful and controversial anecdote may help further illustrate the value of why this study is seeking to address the mysteries of freedom and time within the broader two cultures' milieu. Rather than address the issues yet again from a limited technical perspective buried within the confines of the academy in either theological, philosophical, or physics circles, it may be best to explicitly bring into the background of this study the potential consequences of the divergence of interpretations on the two critical concepts of freedom and time. Yet, of course, beyond the above considerations at the more popular or social level, the study also seeks to uncover and explain more about the fundamental philosophical mysteries of freedom and time in their own right, and how one's interpretation of them creates such a significant impact upon theology, which then, as I've just explained, has the potential to influence the entirety of society. In short, no, this is not merely a sociological study, but a philosophical and theological study with a sensitivity to the appropriate historical and sociological contexts that have defined how freedom and time are discussed.

Indeed, having shared the above, were one to wonder if the colorfully heated animosity that we sometimes find in mainstream political rhetoric in the United States is actually relevant within philosophical, theological, and physics discussions, it appears that it is indeed. However, the animosity between academic cultures is complicated by the fact that, for example, when physicists or philosophers write about freedom or time, they usually do so only with those from their own discipline as their dialogue partners. This has created a "split field" of academic and popular literature on the subjects of freedom and time, which is often reflected in the relevant bibliographies. Furthermore, of course, when the two camps aren't simply ignoring or neglecting each other, their limited interactions have often demonstrated pointed animosity. This has proven especially true for 
self-proclaimed Heideggerians ${ }^{129}$ and Bohmians, ${ }^{130}$ in particular, whenever respective advocates of either group engage the "mainstream" academy.

It appears the closer one gets to the actual source of the conflict between the two cultures-that of freedom and time-the more heated the conflict becomes, provided the opposition isn't ignored or blackballed altogether! In other words, the situation between Heideggerians, Bohmians, and their respective opponents seems, upon forced interaction, to mirror the situation between, for example, the "mainstream media" and various populist figures, as alluded to above, ${ }^{131}$ and some of the

\footnotetext{
${ }^{129}$ To support my point, according to Iain Thompson, "on hearing the [Heideggerian] expression 'ontotheology,' many philosophers start looking for the door" to exit the room because they believe the presentation to be irrelevant nonsense, Iain Thomson, Heidegger on Ontotheology: Technology and the Politics of Education (New York, NY: Cambridge University Press, 2005), 7. Besides applying to many analytically trained philosophers, Thomson's observation would most certainly include almost all practicing physicists, as well as many theologians. Thomson's pun has been picked up by others, such as J. Aaron Simmons and Bruce Ellis Benson, The New Phenomenology: A Philosophical Introduction (New York, NY: Bloomsbury Academic, 2013), 246 n. 5; and Louis S. Berger, Human Development, Language and the Future of Mankind: The Madness of Culture (New York, NY: Palgrave Macmillan, 2014), 25, reflecting the sometimes unspoken disdain by either side of the debates between the "two cultures" within philosophy, as well as theology.

${ }^{130}$ Within the physics community, although Bohm was universally respected as a promising physicist early in his career, once he broached some of the more philosophical issues behind the interpretation of quantum physics, many began to ignore him and his challenging theories which appeared empirically unprovable. Additionally, "[Bohm] associated himself in ways that wasn't worthy of him with all kinds of talk of parallels between quantum mechanics and Buddhism and became a New Age icon. It's a sad story. Bohm expected and had every right to expect that his theory was just going to change the whole landscape and instead it was completely ignored," David Z. Albert, as cited in Martha Nochimson, David Lynch Swerves: Uncertainty from Lost Highway to Inland Empire (Austin, TX: University of Texas Press, 2013), 196. M. López Corredoira affirms that Bohm's "work has largely been ignored by the scientific community. This behavior is indeed consistent with ... [the eminent physicist J. Robert] Oppenheimer's famous words against David Bohm: 'If we cannot disprove David Bohm, we must choose to ignore him,"' M. López Corredoira, "Is Ethics in Science an Oxymoron?" in Against the Tide: A Critical Review by Scientists of How Physics \& Astronomy Get Done, eds. Martín López Corredoira and Carlos Castro Perelman (Boca Raton, FL: Universal Publishers, 2008), 261. See also, Peat, Infinite Potential: The Life and Times of David Bohm, 133; Kent A. Peacock, The Quantum Revolution: A Historical Perspective (Westport, CT: Greenwood Press, 2008), 135; Philip A. Stahl, Beyond Atheism, Beyond God: The Quest for Transcendent Being (Bloomington, IN: iUniverse, 2013), 146-147; and Neil Kramer, The Unfoldment: The Organic Path to Clarity, Power, and Transformation (Pompton Plains, NJ: The Career Press, 2012), 42.

${ }^{131}$ Heidegger's association with Nazism has forced his readers and advocates to defend, not just Heidegger, but even themselves from accusations of ethnic, religious, and cultural bigotry. See, for example, Michael Marder, "A Fight for the Right to Read Heidegger," at https://opinionator.blogs.nytimes.com/2014/07 /20/a-fight-for-the-right-to-read-heidegger/ (accessed July 20, 2014). Marder complains: "Of course, none of the recent revelations about Heidegger should be suppressed or dismissed. But neither should they turn into mantras and formulas, meant to discredit one of the most original philosophical frameworks of the past century. At issue are not only concepts (such as 'being-in-the-world') or methodologies (such as 'hermeneutical ontology') but the ever fresh way of thinking that holds in store countless possibilities that are not sanctioned by the prevalent techno-scientific rationality, which governs much of philosophy within the walls of the academia. It is, in fact, these possibilities that are the true targets of Heidegger's detractors, who are determined to smear the entirety of his thought and work with the double charge of Nazism and anti-Semitism.

"Now, if canonical philosophers were blacklisted based on their prejudices and political engagements, then there wouldn't be all that many left in the Western tradition. Plato and Aristotle would be out as defenders of slavery and chauvinism; St. Augustine would be expelled for his intolerance toward heretics and 'heathens'; Hegel would be banned for his unconditional admiration for Napoleon Bonaparte, in whom he saw 'world spirit
} 
philosophical reasons for the divide actually appear related to the above analogy and the context of this study. All too often, the general populace within each side ignores the 'Other' in their day-to-day lives, but when forced to confront the 'Other,' the exchanges often become toxic, with neither side persuading the other, resulting in polarization. ${ }^{132}$ This is manifested clearly through the popular news and mainstream culture as well, especially for politicized and polarized issues like climate change or global warming, ${ }^{133}$ which happens to be directly relevant to discussions about the role of the sciences and humanities in society. The very idea of "settled science" is anathema to some Heideggerians, whereas, conversely, opposition to the idea that academic philosophy is legitimately "stories of interpretation" is part and parcel of the scientific worldview.

on horseback.'

"As for Heidegger himself, those minimally versed in his thought will know-whether they admit it or not-that his anti-Semitism contradicts both the spirit and the letter of his texts, regardless of the ontological or metaphysical mantle he bestows upon anti-Semitic discourse. Perhaps the German thinker did not sense this contradiction, but this does not mean that it was not there," ibid. Similarly, Donald Trump and his followers have faced accusations of ethnic, religious, and cultural bigotry that may belie his broader political philosophy. See, for example, Lydia O'Connor and Daniel Marans, "Here Are 16 Examples of Donald Trump Being Racist," at http://www.huffingtonpost.com/entry/president-donald-trump-racist-examples_us_584f2ccae4b0bd9c3dfe55 66 (accessed December 13, 2016). For more on the general political divide in the contemporary United States, see also, Charles Lipson, "Why America's Political Crisis is so Profound," at https://www.realclearpolitics.com /articles/2017/05/30/why_americas_political_crisis_is_so_profound_134037.html (accessed May 30, 2017).

${ }^{132}$ For three of the better recent academic discussions about the broader phenomena of polarization, see Kevin Arceneaux and Martin Johnson, Changing Minds or Changing Channels?: Partisan News in an Age of Choice (Chicago, IL: The University of Chicago Press, 2013); Matthew Levendusky, How Partisan Media Polarize America (Chicago, IL: The University of Chicago Press, 2013); and Natalie Jomini Stroud, Niche News: The Politics of News Choice (Oxford, UK: Oxford University Press, 2011). In relation to the problem of polarization in the news and political world, the cult of expertise has created yet another problem that is related to the "two cultures," though, in this case, it can become the culture of elites (experts) and the culture of the common person. It, too, has no easy resolutions. For more, and conflicting perspectives, see Tom Nichols, The Death of Expertise: The Campaign Against Established Knowledge and Why it Matters (Oxford, UK: Oxford University Press, 2017); Patrick M. Wood, Technocracy Rising: The Trojan Horse of Global Transformation (Mesa, AZ: Coherent Publishing, 2015); and Philip E. Tetlock, Expert Political Judgement: How Good Is It? How Can We Know? (Princeton, NJ: Princeton University Press, 2005). See also, Jonah Goldberg, "The Center Does Not Hold" (August 17, 2018), in National Review, at https://www.nationalreview.com/2018/08/trump-and-obama-ignore-political -center-amp-up-base/ (accessed August 17, 2018).

${ }^{133} \mathrm{~A}$ clear, and controversial, example of this phenomena can also be found in the idea that the conclusions of those advocating climate change or global warming represents "settled science." A Heideggerian would suggest that the very idea of "settled science" is oxymoronic, as science can never be settled when applied to the real world of human interpretation and activity. For interesting overviews on this, see David J. Stump, Conceptual Change and the Philosophy of Science: Alternative Interpretations of the A Priori (New York, NY: Routledge, 2015), 1-2; for a couple conservatives, see Roger L. Simon, I Know Best: How Moral Narcissism is Destroying Our Republic, If It Hasn't Already (New York, NY: Encounter Books, 2016); and Michael Hart, Hubris: The Troubling Science, Economics, and Politics of Climate Change (Ottawa, Canada: Compleat Desktops Publishing, 2015), 25-70. For a more scientific progressive perspective, see Chris Mooney, The Republican Brain: The Science of Why They Deny Science-and Reality (Hoboken, NJ: John Wiley \& Sons, 2012); and Chris Mooney, The Republican War on Science, revised (New York, NY: Basic Books, 2007). 


\section{Plan of Study}

\section{Methodology}

The first goal of this study is to provide some additional background information in this introductory chapter to address some important preliminary considerations concerning the challenges of a study focusing on freedom and time within the "two cultures" milieu. In doing so the study will also examine how the idea of a third culture, and its current manifestation, as well as the debates between science and religion, and the humanities and religion, fit into discussions about the concepts of freedom and time. Such an overview will also help illustrate the significance and implications of this study, given that the "two cultures" context overshadows most of the contemporary discussions concerning freedom and time, limiting, either explicitly or implicitly, the ways in which many scholars are able to advance possible solutions to the problems concerning freedom and time throughout the various sub-disciplines beneath the sciences and humanities. ${ }^{134}$ One final preliminary issue that will be addressed below in this introductory chapter is why quantum physics in particular has been such an inspiration to so many contemporary philosophers. This includes why it, uniquely, in the most forceful manner yet in history, has created so many intuitive problems for those discussing the concepts of freedom and time, and has inspired the need for a true third culture.

The second goal, undertaken in chapter 2 , will be to briefly review the scope and contemporary impact of the "two cultures" upon the academic community, both within the conflict between science and religion (thus expanding upon the preliminary issues exposed below in this chapter), and also directly in the third culture disciplines of psychology and psychiatry, economics, and the sociopolitical sciences, exploring each of them in turn with a brief comparative contrast, focusing in particular upon the concepts of freedom and time as they appear within these disciplines. This will be done to aid in clearly identifying the breadth and depth of the conflict between the two cultures'

\footnotetext{
${ }^{134}$ Unfortunately, no matter the sub-discipline, most contemporary studies that discuss either freedom or time are conducted exclusively within one overarching culture, either the sciences or humanities, and often adherents promoting the dominance of one culture struggle to see the relevance of the scholarship generated from those working from the other culture.
} 
interpretations of freedom and time. Such a survey will also open up the different forms that the idea of a third culture has taken, thus far, ${ }^{135}$ to mediate the two cultures, which has lately become popular in the scholarly and popular literature. ${ }^{136}$

For the third and forth goals, this dissertation will systematically examine, in turn, Bohm and Pylkkö's views on freedom, time, and their interrelationship in chapters 3 and 4, demonstrating that they are indeed at the forefront of the question from the disciplines of physics and philosophy and sensitive to the conflicting two cultures. As I introduce their work, I will also explain how the previous foundations provided by Einstein and Heidegger influenced their own respective contributions. Additionally, it will be shown that their efforts are indeed in many ways parallel, illustrating that the "two cultures" tensions concerning freedom and time are in fact well grounded in some of the latest contemporary reflections and developments in physics and philosophy.

The final and fifth goal, undertaken in chapter 5, will be to evaluate Bohm's and Pylkkö's collective potential role in resolving the conflicting "two cultures" contributions to the problem of

\footnotetext{
${ }^{135}$ Celina Raffl suggests "there exists no unifying perspective of the notion of the Third Culture. According to my understanding of the term, a Third Culture should be a new emerging culture based on a new way of thinking. I see the Third Culture as a new principle or paradigm that emerges from interaction of researches of various disciplines as well as with other parts of our social system, such as polity, economy, and culture, with stakeholders from outside academia, such as decision-makers, politicians, businessmen, activists, or non-governmental organizations," Celina E. Raffl, "The Two Cultures: A Third Look," in Cybernetics and Systems, ed. R. Trappl (Vienna, Austria: Austrian Society for Cybernetic Studies, 2006), 321.

${ }^{136}$ The issues become more complex and philosophical the further one reads into the literature. The call for a "third culture" has already been made, as noted above, and by necessity it will probably continue to emerge on its own in both the popular or mainstream world and the academic world. The only real question is, what form will the third culture take? And who will define it? As Søren Brier observes, "we are moving into a Third Culture: using all our knowledge and creative powers, we might be able to create a Third Culture in which art and science work together to create knowledge, a culture beyond the dichotomy separating Snow's cultures of science, technology, power and money, on the one hand, and the humanities, the arts, the social sciences, ethics, and aesthetics on the other." Importantly, Brier notes that "we have discovered that science, philosophy, and religion cannot eliminate metaphysics and that neither can Protestant Christianity. Today we must work with metaphysics in a reflective way," Søren Brier, Cybersemiotics: Why Information Is Not Enough (Toronto, Canada: University of Toronto Press, 2008), 142. Brier does not consider the pragmatic existence of psychology, the socio-political sciences, and economics as adequate to address what a true "third culture" should resolve, seeing deeper philosophical or metaphysical issues at play. Brier, rather, hopes himself to help "create a third culture, one that transcends the incommensurability between C. P. Snow's two cultures: science-technology, and the humanities and social sciences. I am trying to draw a map onto which a multitude of viewpoints can be plotted and their subject areas characterized and compared with other approaches. By erecting this framework I hope to expand the dialogue between sciences, the humanities, the social sciences, philosophy, and the existential quest to broaden our concept of reason in accordance with my stance toward making common frames for the open and systematic pursuits of knowledge and meaning," ibid., 13. Such a framework or model would describe "the functional relationships among traditional science, philosophy, religion, and politics" and, as such, constitute a "Third Culture" where "Snow's two cultures of the sciences and the humanities" were finally united, ibid., 135. Brier's project remains incomplete yet ongoing, and will face competition.
} 
understanding the relationship of God to freedom and time, and thus, in turn, generate new theological reflections concerning how the concept of God might better relate to freedom and time in the various disciplines. This will include, but not explore in detail, popular interpretations of Scriptural subjects, in an effort to position the contribution of this study to show the potential of Scripture to resolve the conflict ${ }^{137}$ in dialogue with philosophical developments. Chapter 6 will summarize the findings of the study and offer suggestions for further research.

\section{Prolegomenon to Freedom and Time: Understanding the Two Cultures of the Sciences and Humanities}

As I trust the extensive introduction thus far has demonstrated, when one steps back from the situation to take a glance at the big picture, the magnitude of the problem becomes more clear. If the concepts of freedom and time are understood in conflicting ways by the two cultures, ${ }^{138}$ and advocates of religion likewise fall into this same trap, then this demonstrates that religion as a discipline is not presently a mediator of the conflict between the two cultures nor an effective third culture discipline in itself. As such, the question then becomes, in what direction should one look for resolving the quagmire, especially for the honest aspirant advocate of a meaningful theology in today's complex world?

To fully appreciate the challenging nature of the previous question, it is important to remember that traditional (analytic) philosophy prior to Heidegger, at least in his view, functioned as "theology"

\footnotetext{
${ }^{137}$ In the process of undertaking some tentative steps to explaining how Scripture might, in the end, provide some original data to break the impasse that it itself seems to have encouraged in the use of Scripture to support the two cultures, I would point toward John Peckham's Canonical Theology: The Biblical Canon, Sola Scriptura, and Theological Method. The purpose in doing so will be to explain just what kinds of conceptual data within Scripture should have explanatory priority over and against traditional concepts with which the two cultures have operated and with which most religionists have also previously worked.

${ }^{138}$ The core problem is that the two cultures do not share a conceptual system, yet, at the same time, employ the same words, freedom and time, which ground many other key concepts within the two cultures, with different meanings. Such a situation creates a difficult situation to analyze 'objectively,' as there is no agreed upon system of concepts to offer such an evaluation. Rather, as the physicist Wolfgang Pauli once reportedly remarked of a paper he read and disagreed with, "it is not right. It is not even wrong!" The point is, "to claim that a scholarly or scientific paper is 'not even wrong' suggests that the author and the critic do not share the same conceptual system so that a judgment is not even possible," Arnold H. Modell, "Metaphor, Meaning, and the Mind," in Metaphor and Fields: Common Ground, Common Language, and the Future of Psychoanalysis, ed. S. Montana Katz (New York, NY: Routledge, 2013), 59.
} 
in its pursuit of metaphysics, ${ }^{139}$ and historically saw itself as "science." ${ }^{140}$ Although seemingly distant from the 'mathematical natural sciences' we are familiar with today, during the time of the early Greek philosophers, what was then known as the "humanities" soon became conjoined with the mathematically inspired neo-Platonic metaphysical-theology, ${ }^{141}$ which carried an air of objective certitude about itself in the minds of most leading thinkers at that time that later secularized science would usurp from both theology and the so-called humanities. ${ }^{142}$

${ }^{139}$ Heidegger, Identity and Difference, 54.

${ }^{140}$ Moreover, as explained by Richard Rorty, Philosophy and the Mirror of Nature: Thirtieth-Anniversary Edition, with Michael Williams and David Bromwich (Princeton, NJ: Princeton University Press, 2009), 131, the modern philosophers saw their own task as one to preserve the scientific side of philosophy from oppressive theological constructions and socio-political edifices. Rorty explains that "looking backward we see [René] Descartes and [Thomas] Hobbes as 'beginning modern philosophy, but they thought of their own cultural role in terms of what [William Edward Hartpole] Lecky was to call 'the warfare between science and theology' [in History of the Rise and Influence of the Spirit of Rationalism in Europe]. They were fighting (albeit discreetly) to make the intellectual world safe for Copernicus and Galileo.... [Hobbes] had no wish to distinguish what he was doing from something else called 'science.' It was not until after Kant that our modern philosophy-science distinction took hold," ibid.

${ }^{141}$ Plato identified "the 'one' in mathematics with the 'One' in metaphysics (God)" and made "all knowledge and all reality dependant upon the 'One' and 'Good' secundum se, which is contemplated in the divine science of metaphysics," James A. Weisheipl, "The Nature, Scope, and Classification of the Sciences," in Science in the Middle Ages, ed. David C. Lindberg (Chicago, IL: The University of Chicago Press, 1978), 477. See also, Jean Grondin, Introduction to Metaphysics: From Parmenides to Levinas (New York, NY: Columbia University Press, 2012), 35. As Karl Smith explains from a contemporary platonic perspective: "Mathematics is the foundation and lifeblood of nearly all human endeavors." Thus, the "ambiguity" surrounding mathematics "should be consoling. It suggests that mathematics has so many mansions that there is room for everyone," meaning mathematics has a role in "the natural sciences, in the social sciences, and in the humanities," Karl Smith, The Nature of Mathematics $11^{\text {th }}$ ed. (Belmont, CA: Thomson Higher Education, 2007), 955-e2. As such, "the case of mathematics and that of the arts require special attention. Applied mathematics certainly belongs with the sciences, but pure mathematics has always been touchy about being ascribed direct empirical relevance. As part of the old culture, it could easily claim a place among the humanities" and the heritage of Platonic rationalism, Abraham Edel, Interpreting Education, Vol. 3 (New Brunswick, NJ: Transaction Publishers, 1985), 268. See also, Stephen Toulmin, Return to Reason (Cambridge, MA: Harvard University Press, 2003), 31-32; and Jean Grondin, Sources of Hermeneutics (Albany, NY: State University of New York Press, 1995), 131-133.

${ }^{142}$ Jan Faye, "Neo-modernisn: A New Approach to the Humanities," in The Object of Study in the Humanities, ed. Julio Jensen (Gylling, Denmark: Narayana Press, 2004), 49. Faye observes that the Roman philosopher "Cicero saw Studio humanitatis, the reading of the classical texts, as a means to becoming a perfect human being. The attempt to give the Humanities a professional content was of secondary importance until the Humanities acquired certain characteristics of being science during the Enlightenment.

"In the two hundred years that followed, the Humanities matured and transformed into the human sciences, an era sometimes known as modernism. But since the 1960's strong reactions against what people saw as the scientism of the Humanities have haunted many intellectual groups," leading to the formal division between the new Heideggerian humanities and the Snow-inspired empirical sciences, ibid. Today, then, the situation has been ironically reversed in some postmodern circles, wherein it is claimed that mathematics is a human invention. For a brief review and critique of this position, see Lynn Gamwell, Mathematics and Art: A Cultural History (Princeton, NJ: Princeton University Press, 2016), 509-510. 
It is no mere coincidence that both mathematics (the foundation of Pythagorean-Platonic metaphysics ${ }^{143}$ and later modern natural science ${ }^{144}$ ) and Christian theology (influenced historically by Augustine's mathematical ${ }^{145}$ and neo-platonic reflections) have shared the appellation, at different times, of the "queen of the sciences,"146 and that the relationship and connections between theology, mathematics, and science, or what would become natural science (astronomy, physics, chemistry, biology), has been frequently revisited. ${ }^{147}$ Lately, many have lamented this relationship primarily

${ }^{143}$ Bertrand Russell, History of Western Philosophy (New York, NY: Simon \& Schuster, 1945), 37.

${ }^{144}$ Stephen Prickett makes reference to "E. A. Burtt's now widely accepted thesis that the foundations of modern science lie not in the Aristotelian tradition of observation and experiment, but in Platonic mysticism," Stephen Prickett, Narrative, Religion and Science: Fundamentalism Versus Irony, 1700-1999 (New York, NY: Cambridge University Press, 2002), 185. See also, E. A. Burtt, The Metaphysical Foundations of Modern Science (Mineola, NY: Dover, 2003).

${ }^{145}$ Reuben Hersh, What is Mathematics, Really? (Oxford, UK: Oxford University Press, 1997), 103-106.

${ }^{146}$ Richard Lennan, An Introduction to Catholic Theology (Mahwah, NJ: Paulist Press, 1998), 119; Hugh Duffy, Queen of the Sciences: The Special Relationship Between Catholic Theology and Liberal Education (Cork Hill Press, 2004); Amir Alexander, Infinitesimal: How a Dangerous Mathematical Theory Shaped the Modern World (London, UK: Oneworld Publications, 2014); and Timothy Gowers, June Barrow-Green, and Imre Leader, eds. The Princeton Companion to Mathematics (Princeton, NJ: Princeton University Press, 2008), 756. For more on the longstanding mystery of mathematics and its relationship to philosophy and Christian theology, see Nancy R. Pearcey and Charles B. Thaxton, The Soul of Science: Christian Faith and Natural Philosophy (Wheaton, IL: Crossway Books, 1994), 123-161. Essentially, Platonic inspired philosophers arrived at the same conclusions for both mathematics and spiritual realities, leading toward a sort of "timelessness" for ultimate reality, which included the human soul and God-timelessness was what they shared in common. As Roman Murawski explains, Plato "claimed that the subject of mathematics are mathematical (arithmetical and geometrical) ideas (or forms). They are real entities conceived as being independent of perception and being apprehended, as being capable of absolutely precise definition and as being absolutely permanent, that is to say timeless or eternal. Hence a mathematician does not create mathematical objects and their properties but does discover them.... Mathematics is very close to Plato's ideal of knowledge because it abstracts from changeable phenomena and concentrates on unchangeable, timeless, mind-independent and definite objects and relations between them.... Hence mathematics is a science whose aim is the description of timeless, mind-independent and definite mathematical objects (ideas) and their mutual relations," Roman Murawski, "Did Leibniz and Newton Discover or Create the Calculus?," in Topics in Logic, Philosophy and Foundations of Mathematics and Computer Science, eds. S. Krajewski et al. (Amsterdam, The Netherlands: IOS Press, 2007), 250. Of course, many other theological conclusions can be drawn from the mathematically dominated platonic philosophy. For example, Craig Eisendrath contends that "this timeless world, which the soul can understand, is curiously much like the soul. Plato writes, 'The soul is most like that which is divine, immortal, intelligible, uniform, indissoluble, and ever self-consistent and invariable. ... The soul has within itself the entire timeless world of ideas, which is God, so that God is immanent in each of us," Craig Eisendrath, Beyond Permanence (Bloomington, IN: Xlibris, 2011), 59.

${ }^{147}$ For a history of the relationship between mathematics and science, see Loren Graham and JeanMichel Kantor, Naming Infinity: A True Story of Religious Mysticism and Mathematical Creativity (Belknap Press, 2009); and Rudolf Steiner, The Origins of Natural Science (London, UK: Rudolf Steiner Press, 1985). For a review of the integral relationship mathematics has had with theology, see T. Koetsier and L. Bergmans, eds. Mathematics and the Divine: A Historical Study (Amsterdam, The Netherlands: Elsevier, 2005); Andrew Fletcher, Quantum God, Fractal Jesus: How Isaac Newton Redefined God Without Really Meaning To, And Why We Really Don't Get God (Monument, CO: TOK Seminars, 2012); and Daniel J. Cohen, Equations from God: Pure Mathematics and Victorian Faith (Baltimore, MD: John Hopkins University Press, 2008). Note that many questions are frequently raised concerning the freedom of the human mind and the foundation of objectivity in all forms of 'science', mathematics: "If the subject matter of mathematics is as these [ontological] realists say it is, then the 
because of how mathematics is, or became, so intricately related to calculative/computative

determinism, especially in nature, as well as dominating the very essence of 'science ${ }^{\prime 148}$ (one famous

definition of science is the "art of the soluble"149 ). This situation has raised a number of questions

about freedom from scholars and specialists in a variety of disciplines while generally determining

truths of mathematics are independent of anything contingent about the physical universe and anything contingent about the human mind, the community of mathematicians, and so on. What of apriority? The connection with Plato might suggest the existence of a quasi-mystical connection between humans and the abstract and detached mathematical realm.... Without this quasi-mystical connection to the mathematical realm, the ontological realist is left with a deep epistemic problem," Stewart Shapiro, ed. The Oxford Handbook of Philosophy of Mathematics and Logic (New York, NY: Oxford University Press, 2005), 6.

${ }^{148}$ The origin of the word "science" as we use it today is relatively recent, from the $17^{\text {th }}$ century, although the concept can be found in ancient Greece and elsewhere. See, for example, Muin-ud-Din Ahmad Khan, A Challenging Encounter with the West: Origin and Development of Experimental Science (Dhaka, Bangladesh: Bangladesh Institute of Islamic Thought, 1997), 1-78; and Gerald Holton and Stephen G. Brush, Physics-The Human Adventure: From Copernicus to Einstein and Beyond (New Brunswick, NJ: Rutgers University Press, 2004), 158. In a critically insightful paragraph, Robert Rosen explains his "contention that mathematics took a disastrous wrong turn some time in the sixth century B.C. This wrong turn can be expressed as an ongoing attempt, since then, to identify effectiveness with computability. That identification is nowadays associated with the name of Alonzo Church and is embodied in Church's Thesis. But Church was only among the latest in a long line going back to the original culprit. And that was no less than Pythagoras himself.... The impact of that wrong turn, made so long ago, has spread far beyond mathematics. It has entangled itself into our most basic notions of what science is. It might seem a far cry from the ultimately empirical concerns of contemporary science to the remote inner world of mathematics, but at root it is not; they both, in their different ways, rest on processes of measuring things, and on searching for relations ("laws") between what it is that they measure. From this common concern with measurement, concepts pertaining to mathematics have seeped into epistemology, becoming so basic a part of the adjective scientific that most people are quite unaware they are even there," Robert Rosen, Essays on Life Itself (New York, NY: Columbia University Press, 2000 ), 63. Similarly, Philip Regal believes that "scientific and mathematical thinking enter our values and behavior in many both conspicuous and subtle ways; they should be understood.... When a complex subject matter is reduced to numbers and structure, we have not necessarily made it scientific, though that is where the quest for scientific respectability has sent some disciplines. Critics call this 'math envy' or 'physics envy.' But a thirst for social status is not necessarily the same as useful progress.... It can be that a discipline is actually heading off into a mediocre or even sterile direction by reducing its subject matter largely to items that can be quantified, schematized, or experimented with easily," Philip J. Regal, The Anatomy of Judgement (Minneapolis, MN: University of Minnesota Press, 1990), 308.

For a direct application of this to theology, note the perspective of the practical theologian Ellen White: "Were the men for whom Christ has died devoid of moral nature, or were the gospel to be submitted to the understanding, to be decided by the intellect alone, men might approach it as they approach a mathematical problem. But this is not the case. The great truths of salvation are to be planted in the heart. The science of redemption is as high as heaven, and its value is infinite," at https://egwwritings.org/?ref=en_Ms69-1897.56\& para=6793.66 (accessed January 10, 2017); and "The gospel does not address the understanding alone. If it did, we might approach it as we approach the study of a book dealing with mathematical formulas, which relate to the intellect alone.... The Word of God is what it claims to be in the sixth chapter of John - the bread of life-for it represents the body and blood of the Son of God. Its aim is the heart. It addresses our moral nature, and takes possession of the will," at https://egwwritings.org/?ref= en_Lt5-1898.13\&para=5043.19 (accessed January 10, 2017). Thus, "while logic may fail to move, and argument be powerless to convince, the love of Christ, revealed in personal ministry, may soften the stony heart, so that the seed of truth can take root," Ellen White, Christ's Object Lessons (Oakland, CA: Pacific Press, 1900), 57. Her views directly express and illustrate a tacit awareness of the "two cultures" phenomenon within Christianity.

${ }^{149}$ P. B. Medawar, The Art of the Soluble (London, UK: Methuen, 1967). Meaning, here, "solvable." 
the concept of time, for both humans, ${ }^{150}$ the ecosystem, and nature in general, which has long been dominated ${ }^{151}$ by a mathematical or 'scientific' approach as the only viable mode of apprehension about itself. ${ }^{152}$

However, as noted above, since the onset of the latter half of the $20^{\text {th }}$ century and continuing into the $21^{\text {st }}$ century, many scholars have no longer seen philosophy as a science, especially when it is combined with religious studies or theology. Rather, most secular and some religious intellectuals

\footnotetext{
${ }^{150}$ Heidegger, in particular, sees the Cartesian "res corporea ... [as describing] a world of mathematical determinism. All things, in their thinghood, are determined by quantifiable measurements," Stephen Hancock, The Romantic Sublime and Middle-Class Subjectivity (New York, NY: Routledge, 2005), 37. See also, Wei-Bin Zhang, American Civilization Portrayed in Ancient Confucianism (New York, NY: Algora Publishing, 2003), 16-17; and Peter Gould, "Allowing, Forbidding, but not Requiring: A Mathematic for a Human World," in Complexity, Language, and Life: Mathematical Approaches, eds. John L. Casti and Anders Karlqvist (Berlin, Germany: Springer-Verlag, 1986), 5.

151 "Heidegger's analysis of the mathematical in modern science shows how Galileo's claim that 'the universe is a book written in the language of mathematics' lays nature bare in mathematical projection such that it is ripe for capitalist exploitation. For without the mathematical projection of nature in modern science, technological exploitation would have no basis for its reckoning of nature as exploitable resource. Accordingly, there is embedded in Heidegger an account of the function of science and technology in [the] capitalist exploitation of global peoples and resources," Trish Glazebrook and Matt Story, "Heidegger and International Development," in Heidegger in the Twenty-First Century, ed. Tziovanis Georgakis and Paul J. Ennis (New York, NY: Springer, 2015), 132. Importantly, to complete the Heideggerian picture, it must be noted that "Heidegger makes the inference that since the patterns found in the biological and human sciences-the sciences of 'living things-do not have a mathematical form that permits 'exactitude', therefore they are different in kind from the physical sciences." Of course, many believe "this is clearly wrong," and "equally wrong is his condescending inference that because they are not mathematical the sciences of living things are harder," Fred Wilson, "Placing Bergmann," in Ontology and Analysis: Essays and Recollections about Gustav Bergmann, eds. Laird Addis, Greg Jesson, and Erwin Tegtmeier (Piscataway, NJ: Rutgers University, 2007), 240. Wilson also importantly observes, for Heidegger, "science seeks objectivity [through patterns].... The pattern explored is one of change, yet it is a general pattern, universal, and therefore timeless change brought to a standstill," ibid., 238. Heidegger indeed consistently critiqued this viewpoint. Thus, "Heidegger has challenged any philosophy that uses the system of 'mathematical logic' as a tool in ontology," ibid., 236. See also, Dennis Skocz, "Environmental Management in the 'Age of the World Picture,"' in Heidegger and the Earth: Essays in Environmental Philosophy, eds. Ladelle McWhorter and Gail Stenstad (Toronto, Canada: University of Toronto Press, 2009), 130.

152 "We are accustomed by the dominant tradition of physics, established as the supreme model of successful science, to regard historical explanation as ancillary to structural explanation [through mathematics]. On the view that we here defend, this hierarchy must be reversed: structure results from history. Historical explanation is, thus, more fundamental than structural explanation. Cosmology affirms the ambition to be the most comprehensive natural science when it understands itself as a historical science first, and as a structural [mathematical] science only second," Roberto Mangabeira Unger and Lee Smolin, The Singular Universe and the Reality of Time (Cambridge, UK: Cambridge University Press, 2015), 42, as cited in Arran Gare, The Philosophical Foundations of Ecological Civilization: A Manifesto for the Future (New York, NY: Routledge, 2017), 129 (additions by Gare). See also, W. J. T. Mitchell, What Do Pictures Want?: The Lives and Loves of Images (Chicago, IL: The University of Chicago Press, 2005), xiv. "Heidegger proposed, famously, that we live in 'the age of the world picture,' by which he meant the modern age in which the world has become a picture-that is, has become a systematized, representable [timeless] object of technoscientific rationality," ibid. "Heidegger pinned his philosophical hopes on an epoch beyond modernity and beyond the world-as-picture. He thought the pathway to this epoch lay not in a return to prepictorial ages or a willed destruction of the modern world picture but in poetry-the kind of poetry that opens us up to Being," ibid. Mitchell himself disagrees, however, believing that "there is no getting beyond pictures, much less world pictures, to a more authentic relationship with Being, with the Real, or with the World," ibid.
} 
pragmatically consider philosophy and theology as a part of the humanities, often subsumed under the disciplines of literary criticism, history, and sociology. This divide has led adherents of the sciences and the humanities to hurl accusations at each other that they each promote a type of knowledge that is only accessible to their own respective culture, whether God is explicitly involved or not. Critically, however, and justifying their dispute, the knowledge derived from their respective sources is increasingly seen to be in conflict, over an ever growing range of issues, including the natures of freedom and time and the issues with which they are integrally related throughout the third culture disciplines.

\section{Where Do Theology and Religious Studies Belong?}

Importantly, as has now been revealed, adherents of religion, caught within this maelstrom, have become a divided camp themselves, torn between the sciences and humanities, or modernism and variant versions of postmodernism, rather than serving as effective mediators or offering true solutions. ${ }^{153}$ Indeed, it may be appropriate to note at this juncture that defining postmodernism is not

\footnotetext{
${ }^{153}$ Martin Woessner shares that "despite ... Heidegger's place in the canon of postmodern theology," his influence as such "remains a point of contention," Woessner, Heidegger in America, 126. See also, Frank Schalow, Heidegger and the Quest for the Sacred: From Thought to the Sanctuary of Faith (Dordrecht, The Netherlands: Kluwer, 2001), 131. Of course, many religionists lament the usage of Heideggerian "thinking" in religion. As Donald Bloesch shares, "theology could not say with the existentialist philosopher Martin Heidegger that 'thinking only begins at the point where we have come to know that Reason, glorified for centuries, is the most obstinate adversary of thinking.' Against philosophical irrationalism theology contends that it is sin, not reason, that constitutes the major obstacle to true understanding," Donald G. Bloesch, A Theology of Word \& Spirit: Authority \& Method in Theology (Downers Grove, IL: InterVarsity Press, 1992), 59. See also, Joseph Gerard Trabbic, Aquinas, God, and Ontotheology (Ann Arbor, MI: ProQuest, 2008), 28-30. Conversely, Carl Raschke asserts that "according to Heidegger, the [modernistic] Cartesian insurgency in thought occasions a usurping of the throne of the infinite God and his replacement with the human subject. Cartesianism is the beginning of what [Friedrich] Nietzsche terms 'the death of God.' ... Modern evangelical thought has unwittingly bought into the Cartesian assumption about the nature of truth. Foundationalism is simply a less tendentious term for modernism. Even a minimal foundationalism, however, does not mitigate the idolatrous predisposition of all modernism.... Contemporary evangelical theologians have not realized that, although they rhetorically maintain God's unshakable power and presence, they do so by following modern philosophy to midnight worship on the high places," Carl Raschke, The Next Reformation: Why Evangelicals Must Embrace Postmodernity (Grand Rapids, MI: Baker Academic, 2004), 24. Note also, William F. Vallicella, A Paradigm Theory of Existence: Onto-Theology Vindicated (New York, NY: Kluwer Academic Publishers, 2002); and theologian Jeffrey W. Robbins, Between Faith and Thought: An Essay on the Ontotheological Condition (Charlottesville, VA: University of Virginia Press, 2003). Overall, then, as Robert Greer observes, in religious circles, "on one extreme are those who still embrace modernism, regarding its death notices as highly exaggerated. On the other extreme are those heartily in favor of postmodernism," with various efforts to map out a middle path, mixing elements of each, but such efforts never appear to overcome the central problems. Robert C. Greer, Mapping Postmodernism: A Survey of Christian Options (Downers Grove, IL: InterVarsity Press, 2003), 206. See also, Fritz Guy, Thinking Theologically: Adventist Christianity and the Interpretation of Faith (Berrien Springs, MI: Andrews University Press, 1999), 106-107.
} 
easy, ${ }^{154}$ especially as it has developed at least two conflicting interpretations. The first perspective sees postmodernism as a 'positive' extension of modernism, ${ }^{155}$ and thus in many respects a logical

\footnotetext{
${ }^{154}$ Comments are often made to the effect that "postmodernism is an exceptionally difficult phenomenon to pin down, so much so that some have even suggested that it does not have a determinate meaning," Colin Campbell, "Postmodernism," in The Blackwell Companion to the Study of Religion, ed. Robert A. Segal (Malden, MA: Blackwell Publishing, 2006), 311.

${ }^{155}$ Joseph Conte believes the first definition, or what I call the 'positive' view of postmodernism, is revealed through the transition from modernity to postmodernity understood as the natural consequence of the increasing disciplinary specialization owing to the application of the scientific method both outside and within literary disciplines, and not about qualitatively new developments within the sciences or humanities themselves. Conte explains, "in the early twentieth century the fields of knowledge-the physical sciences, the humanities, the social sciences-underwent a rapid specialization. It became increasingly difficult for a well-educated individual to attain a professional level of knowledge outside of a single concentration of studies.... The instigation of
} what C. P. Snow would call the 'two cultures,' the literary and the scientific, in his 1959 Rede Lecture provides a platform for the specialization of disciplines that further divides the fields of knowledge," Joseph Conte, Design and Debris: A Chaotics of Postmodern American Fiction (Tuscaloosa, AL: The University of Alabama Press, 2002), 13. Conte continues, "the arborescence of disciplines, the formalization of modes of inquiry and the jargon that attends them, the inevitable hierarchizing that granted privilege to the sciences (and those disciplines that aspired to scientific status) constitutes a pronounced fragmentation at the last turn of the century-the division of ... inquiry into fields of specialization.... [The result was that] each field generates a terminology whose assigned meanings are specific and exclusive to its discipline-of-origin.... [As a consequence of this,] the specialization of the intellectual project in modernism results in a loss of shared terminology between disciplines. Literary modernism follows the trend in science toward reductionism, the analysis of systems in terms of their constituent parts. Physicists smash atoms into ever smaller elementary particles, to which they give the names quarks, leptons, and mesons. Neurologists examine the most complex organ, the brain, in terms of its circuitry of neurons. Literary critics of the mid-century outline the pathetic fallacy, symbolic logic, and the function of metonymy. In pursuit of specialization, modernist writers emulated various aspects of scientific disciplines in their own methodology.... The penchant in modern music, art and literature for 'difficulty' is itself a sign of the demand to specialization. [The poet T. S.] Eliot-whom Snow brands as the 'archetypal figure' of the literary intellectual for his enervated view that the world was suffering an entropic decline"-"argued that difficult poetry was necessitated by the 'variety and complexity' of modern civilization. But in their 'difficulty' literature and the arts were expressing their desire to be treated as specialized modes of knowledge comparable to the physical sciences," ibid., 14. As such, the lack of communication and the defensive obstinacy of specialists within each of the two cultures would increase, as the complexity within their respective fields of discourse multiplied. "Modernist literature sought to bring its argument to the ground of scientific discipline rather than marginalize itself as an entertaining conundrum or pleasant pastime," ibid., 15.

Conte proposes an interesting comparison to help explain the relationship of the complex modernism described above to postmodernism: “Let us imagine for the moment that Snow's 'two cultures' were those of the male and female genders.... In this dichotomy it is not difficult to associate a gender [male?] with the 'heroic' age of modern physics. The orientation in postmodernism, however, has shifted [past the feminine of relativity in its receptiveness to the modern?] to the 'Polymorphous/Androgynous' [of quantum uncertainty?]. Rather than propose a consummated union of literature and science that would leave them always a dissatisfied 'other,' postmodernism has achieved a 'perverse' multidirectionality in its attentions-a polymathy-that is constantly shifting in form and indiscriminately appropriative in manner. The polymathic postmodern does not make a dilettantish inquiry into a few favored terms, but aspires to an interdisciplinarity that presumes a shared discourse, the diffusion of theoretical concepts into all quadrants of society, and the sense of an integrated feedback loop among the disciplines. Whereas modernism exerted itself in the naming of parts, postmodernism aspires to a curriculum of the whole," ibid., 15 (additions mine). Furthermore, [within this context, the] 'crosstalk' ... between the disciplines of the sciences and the humanities makes chaos theory [(wherein small differences in initial conditions yield widely diverging outcomes for a given dynamical system, rendering long-term prediction impossible in general. This happens even though these systems are deterministic, meaning that their future behavior is fully determined by their initial conditions, with no random elements involved. In other words, notwithstanding the deterministic nature of these systems they are still not predictable)] exemplary of a postmodern turn toward interdisciplinary knowledge and polymathy. Ancillary to the shift in attitude toward disorder, the interdisciplinarity of postmodernism represents a paradigm shift from 
continuation of modernism, and this is seen through the varying labels and developments found in

the following post-postmodern movements, such as metamodernism, ${ }^{156}$ automodernism, ${ }^{157}$ and

the intensive specialization that governed discourse in modernism," ibid., 13 (additions mine).

Conte thus believes that postmodernism can perform the role of a globalizing agent (ibid., 26-27),

wherein "the development of an information society coincides with the political elevation of multiculturalism with its equanimity toward ethics and values regardless of origin. One can no longer speak of a 'two-cultures quarrel' when there are now so many cultures for which the exchange of values and ideas is inherently acceptable.... Postmodern resistance to the autoteleology of modernist texts, in which literature closes itself off from historical, biographical, and cultural interpretation, leaves the way open to the ideas and discourse of other-than-literary disciplines. No longer constrained by an ideal of textual autonomy espoused by modernist criticism, postmodern literature engages in a heightened degree of textual interactivity-between the 'two cultures' of literature and science, and between author and reader-culminating in the infinite connectivity of hypertext ...," ibid., 15-16. For a critique of Conte's views, see Stephen H. Kellert, Borrowed Knowledge: Chaos Theory and the Challenge of Learning Across Disciplines (St. Paul, MN: The University of Chicago Press, 2008), 205-208. For a concurring opinion similar to Conte's, see Ugo Pagallo, "Aliquid Est Sine Ratione: On Some Philosophical Consequences of Chaitin's Quest for $\Omega$," in Randomness and Complexity: From Leibniz to Chaitin, eds. Cristian S. Calude and Gregory J. Chaitin (Toh Tuk Link, Singapore: World Scientific Publishing, 2007), 287300, esp. 295-297.

${ }^{156}$ Important to observe is that many believe postmodernism is over because of "material events like climate change, financial crises, terror attacks, and digital revolutions," that serve to force society in certain directions, Timotheus Vermeulen and Robin van den Akker, "Notes on Metamodernism," in Journal of Aesthetics \& Culture Vol. 2\#1, 5677 (2010), 2. They add that another label that has been given to post-postmodernism is "hypermodern," ibid., 3. Additionally, they helpfully explain that if "epistemologically, the modern and the postmodern are linked to Hegel's 'positive' idealism, then metamodern aligns itself with Kant's 'negative' idealism. Kant's philosophy of history after all, can also be most appropriately summarized as 'as-if' thinking. As Curtis Peters explains, according to Kant, 'we may view human history as if mankind had a life narrative which describes its self-movement toward its full rational/social potential ... to view history as if it were the story of mankind's development,"' ibid., 5, citing Curtis Peters, Kant's Philosophy of Hope (New York, NT: Peter Lang, 1993), 117. Of course, Hegel's "positive" idealism suggested that history was "dialectically progressing toward some predetermined Telos," Vermeulen and van den Akker, 5. However, some believed that "this Telos had been achieved" with the universalization of Western liberal democracy, but "others suggested that it had come to a conclusion because people realized its purpose could never be fulfilled-indeed, because it does not exist. The current, metamodern discourse also acknowledges that history's purpose will never be fulfilled because it does not exist. Critically, however, it nevertheless takes [steps] toward it as if it does exist. Inspired by a modern naïveté yet informed by postmodern skepticism, the metamodern discourse consciously commits itself to an impossible possibility." "Humankind, a people, are not really going toward a natural but unknown goal, but they pretend they do so that they progress morally as well as politically. Metamodernism moves for the sake of moving, attempts in spite of its inevitable failure; it seeks forever for a truth that it never expects to find," ibid., 5. "Ontologically, metamodernism oscillates between the modern and the postmodern. It oscillates between a modern enthusiasm and a postmodern irony, between hope and melancholy, between naïveté and knowingness, empathy and apathy, unity and plurality, totality and fragmentation, purity and ambiguity. Indeed, by oscillating to and fro or back and forth, the metamodern negotiates between the modern and the postmodern. One should be careful not to think of this oscillation as a balance however; rather, it is a pendulum swinging between 2, 3, 5, 10, innumerable poles," ibid., 6 (addition mine). "Both the metamodern epistemology (as if) and its ontology (between) should thus be conceived of as a 'both-neither' dynamic. They are each at once modern and postmodern and neither of them," ibid., 6.

${ }^{157}$ Robert Samuels, "Auto-Modernity after Postmodernism: Autonomy and Automation in Culture, Technology, and Education," in Digital Youth, Innovation, and the Unexpected, ed. Tara McPherson (Cambridge, MA: Massachusetts Institute of Technology, 2008), 225-228. 
pseudomodernism or digimodernism. ${ }^{158}$ Conversely, the second more anti-modern ${ }^{159}$ or

hypermodern ${ }^{160}$ perspective sees postmodernism 'negatively' as a signal of modernism's innate and

terminable failures, ${ }^{161}$ and thus would reject any of the previous post-postmodernisms as 'progress' in

\footnotetext{
${ }^{158}$ Both of these latter two are proposed by Alan Kirby, Digimodernism: How New Technologies Dismantle the Postmodern and Reconfigure Our Culture (New York, NY: Continuum, 2009).

159 This is a complex term, and not always used consistently, though typically in a manner supportive of Heidegger. For a primer on its relevance to Christianity, see John Wesley Taylor V, "A Christian Critique of the Antimodern Quest: Challenge and Opportunity," in Journal of the Adventist Theological Society Vol. 25 \#2 (2014), 88-103.

${ }^{160}$ See, for example, Gilles Lipovetsky, Hypermodern Times (Cambridge, UK: Polity Press, 2005). In an
} insightful article, Gili S. Drori argues that "scientization, occurring primarily through education, permeates all spheres of hypermodern life and, by changing modes of thinking and consciousness, also changes modes of organization, social engagement and thus connectivity," Gili S. Drori, "Rationalizing Global Consciousness: Scientized Education as the Foundation of Organization, Citizenship, and Personhood," in Global Culture: Consciousness and Connectivity, eds. Roland Robertson and Didem Buhari-Gulmez (New York, NY: Routledge, 2016), 93. Drori adds that "scientized education ... has become a global institution, or a sacred cultural element of contemporary society, and legitimates global forms of both connectivity and consciousness," ibid., 93. Such a reality, however, brings mixed appraisals.

${ }^{161}$ An example of such a 'negative' evaluation of postmodernism would come from Michael Mack, who sees the shortcomings of modernism and postmodernism as interrelated. He thus describes the second, or negative, definition of postmodernism as follows: "Strikingly, the divide between two cultures, between nature and society, between science and politics is constitutive of modernity's consciousness.... We have never been modern for the reason that the modern purification project-premised as it is on the radical separation between nature and society-has actually never been put to practice nor could it have ever been realized ... because these nominally separated spheres are actually similarly constituted and in need of mediation. The project of modernity obfuscates or even denies the existence of subjectivity and the invisible.... Modernity could be defined as the unconscious of the invisible, as the unconscious of affect [which is ignored in 'positive' postmodernism].

"['Negative'] postmodernism recognizes that there is something wrong with the modern insistence on objectivity and visibility, but it abstains from further commitments that would investigate modernity's unconsciousness.... [Thus, 'negative'] 'postmodernism is a symptom [of modernism's failures], not a fresh solution. It lives under the modern Constitution, but it no longer believes in the guarantees the Constitution offers,'” meaning some other yet unarticulated solution for mediation between the two cultures is needed that will allow authentic postmodernism to become fully conscious of the invisible, Mack, Philosophy and Literature in Times of Crisis: Challenging our Infatuation with Numbers, 19-20. See also, James N. Rosenau, Distant Proximities: Dynamics Beyond Globalization (Princeton, NJ: Princeton University Press, 2003), 12. Rosenau similarly comments, "['negative' postmodernism's] globalizing and centralizing processes may not be the equivalent of those that serve to integrate.... If ['negative' postmodern globalization] is viewed as an indicator of complexity, and if the dangers of [modernistic] oversimplification are recognized, the ['negative' postmodernistic] fragmegration label has the virtue of sensitizing us to the contradictory tensions wherein the world is simultaneously moving in opposite directions," ibid.

Put another way, the transition from Newtonian to Einsteinian physics represents a complexly or seemingly 'paradoxical' yet still logical continuation of modernism, or the positive view of postmodernism-but not yet the truly 'contradictory' quantum physics, which introduces the negative side of postmodernism. In either case, postmodernism typically rejects "the two pillars of the mechanical worldview," namely "Newtonian atomism and Cartesian dualism," Ayssar Arida, Quantum City (New York, NY: Routledge, 2002), 108; 92-93. See also, Matthew Wickman, "Alba Newton and Alasdair Gray," in Scotland as Science Fiction, ed. Caroline McCracken-Flesher (Lanham, MD: Bucknell University Press, 2012), 175; Floyd Merrell, Semiosis in the Postmodern Age (West Lafayette, IN: Purdue University Press, 1995), 267; and Gerhard Hoffmann, From Modernism to Postmodernism: Concepts and Strategies of Postmodern American Fiction (Amsterdam, The Netherlands: Rodopi, 2005), 168-170. "It is easy to see that the revolutionary discoveries in the natural sciences are fundamental for both modernism and postmodernism," ibid., 168. Note also, Simon de Bourcier, Pynchon and Relativity: Narrative Time in Thomas Pynchon's Later Novels (New York, NY: Continuum, 2012), 26. 
any meaningful way, as they are all leading in one way or another to a dead end. Such post-

postmodernisms inevitably merely 'kick the can down the road. ${ }^{162}$

In any case, as such, the "culture" of religion has merely inherited the philosophical and

theoretical conflict within the broader two cultures and reproduced the conflict among self-professed believers, leaving religion as a (sometimes ignored) derivative third culture to the two cultures of the sciences and humanities in the $21^{\text {st }}$ century academy and its primary third culture disciplines of psychology and psychiatry, economics, and the socio-political sciences. The situation, then, becomes the following: If the two cultures were harmonized without the aid of traditional religion and theology in its derivative role, ironically the resulting new third culture of harmonization might be what would constitute a true religious culture. Only then could theology be philosophical ${ }^{163}$ in the truest sense. Thus, the ambiguity of the status of religion as a culture ${ }^{164}$ becomes an issue in itself, until or unless the natures of freedom and time attain more clarity.

"A strong case [can be made] for understanding [the seemingly separate] developments in literature and science as part of the same broad cultural-historical shift," but we must not fall into the trap of conflating "modernism and postmodernism into a single post-Einsteinian cultural moment" beyond the classical Newtonian culture, ibid. Indeed, "while Einstein's theories of relativity seemed to upset the stable reality of Newtonian physics (a challenge congruent to modernist experiments with new artistic perspectives on reality), it was quantum mechanics that heralded the real departure, after which the physical world could no longer be understood as a stable reality subject to a single set of identifiable laws.... Such a paradigm shift in science provides a plausible interpretive framework for literature," Inger H. Dalsgaard, "Science and Technology," in The Cambridge Companion to Thomas Pynchon, eds. Inger H. Dalsgaard, Luc Herman, Brian McHale (Cambridge, UK: Cambridge University Press, 2012), 157.

${ }^{162}$ Note the interesting study on how modernistic society's understanding of "innovation" is coming to an end owing to certain recent developments precipitated by post-postmodern scientific realities, including quantum physics. Greg Satell, Mapping Innovation: A Playbook for Navigating a Disruptive Age (New York, NY: McGraw-Hill, 2017), 179-186.

${ }^{163}$ Grondin, Sources of Hermenuetics, 93. Grondin explains, from within a Heideggerian context, that philosophy, for it to succeed, must "project for itself completely different goals" than what has traditionally been attempted, ibid. This insight can be, I think, successfully appropriated for a truly philosophical theology. For my own initial efforts to explain what this might mean as a biblicist Christian, see Michael F. Younker, "From Metaphysics to Templephysics: Situating the Significance of Fernando Canale's Contributions for the 'Christian Philosopher,'” in Scripture and Philosophy: Essays Honoring the Work and Vision of Fernando Luis Canale, eds. Tiago Arrais, Kenneth Bergland, and Michael F. Younker (Berrien Springs, MI: Adventist Theological Society Publications, 2016), 194-259. The present study is an elaboration upon the foundations for the incomplete project initiated above.

${ }^{164}$ The joke that theology is "the one discipline that studies an object that doesn't exist" remains popular amongst atheists. In any case, there is no doubt that theology, as the highest area of study within religion, possesses a number of challenges to establish its legitimacy and nature. See, for example, James G. Murphy, "Carnap's Distinction and the God-Question," in Philosophical Thinking and the Religious Context, ed. Brendan Sweetman (New York, NY: Bloomsbury, 2013), 148. 
Presently, therefore, given its derivative status, the question of religion's relevance is raised anew. ${ }^{165}$ How can the existing culture of religion reinsert itself into either the popular or academic arenas in a serious way that will meaningfully contribute to the conflict between the two cultures whose epistemological foundations the present religious culture has merely replicated? A search for the root of the conflict between the two cultures may prove helpful in seeking after the legitimacy or necessity of religion, and provide clues to how advocates of religion can avoid being 'played by the game' of the two cultures and their generated definitions. Alternately, if a way for religion to actually contribute to the academic discussion is to be found, then the culture of religion must readdress the foundation of the conflict between the broader two cultures; it must preemptively seek to become the true third culture in its own right by defining the concepts of freedom and time in an original way. ${ }^{166}$ The issues surrounding the problem of the cultures of the sciences, humanities, and religion, and their relationship to the idea of a third culture and the concepts of freedom and time, will be further developed below in chapter two.

\footnotetext{
${ }^{165}$ The three most interesting Western socio-demographic trends in recent times that reflect the changing status of the "culture" of religion are these-first, the rise of non-denominational Christians, alongside, second, the logically consequent collapse of denominational membership, and thirdly, the rise of agnostics and atheists as a total share of the population. Note Ed Stetzer, "The Rapid Rise of Nondenominational Christianity: My Most Recent Piece at CNN," at http://www.christianitytoday.com/edstetzer/2015/june/rapid-rise-of-nondenominational-christianity-my-most-recen.html (accessed June 30, 2015); and Kate Shellnutt, "The Rise of the Nons: Protestants Keep Ditching Denominations: Nondenominational Identity has Doubled in the US Since 2000, Gallup Finds," at http://www.christianitytoday.com/news/2017/july/rise-of-nons-protestants-denominationsnondenominational.html (accessed July 20, 2017). See also, Rich Schapiro and Erica Pearson, "Americans are Less Christian, More Atheist and Agnostic: Pew Survey," at http://www.nydailynews.com/news/national/ americans-christian-atheist-agnostic-survey-article-1.2219229 (accessed May 12, 2015); Philip Perry, "Study Contends There Are Twice as Many Atheists in America as Polls Show," at http://bigthink.com/philip-perry/ is-atheism-growing-in-america (accessed April 30, 2017); and "Atheism Doubles Among Generation Z," at https://www.barna.com/research/atheism-doubles-among-generation-z/ (accessed January 24, 2018). From a global perspective, the three most interesting trends are the overall decline of Christianity as a share of the population, and the corresponding rise of agnosticism, atheism, and Islam as shares of the total population. Note Michael Lipka and Conrad Hackett, "Why Muslims are the World's Fastest-growing Religious Group," at http://www.pewresearch.org/fact-tank/2017/04/06/why-muslims-are-the-worlds-fastest-growing-religious-g roup/ (accessed April 6, 2017).

${ }^{166}$ To illustrate the problem: "Psychology develops in a baby to the extent that he or she participates in activities, utilizes artifacts, and acquires cultural concepts.... The baby can participate in family activities only if he or she acquires shared concepts; utilizes artifacts such as spoons, chairs, napkins, clothing, and tables," Carl Ratner, Cultural Psychology: Theory and Methods (New York, NY: Springer, 2002), 58. Similarly, yet contrastingly, religion must be "born again" into a new creature to escape the conflicting parental (prenatal?) influences it has been raised with concerning the concepts of freedom and time. For religion to develop or mature and participate as a contributor to the fundamental concepts underlying the two cultures; religion must discover original ways of approaching the concepts of freedom, time, and their interrelationship, not merely inherit the concepts from two parents (the sciences and humanities) that are contradicting each other.
} 


\section{The Challenge of "Cultures" and "Concepts"}

"Culture" remains one of the most complex, ambiguous, and yet omnipresent features of human

existence. Our language, art styles, and innumerable other factors contribute to the identity of individuals and the groups within which they belong. Importantly, cultures exert many subtle or unconscious influences upon the concepts humans employ in their lives. ${ }^{167}$ In seeking after a clue addressing the origin of the conflict between the two cultures, it must be remembered and plainly stated that, even in this specific context of academic cultures, "all cultures consist of concepts."168 Furthermore, meaningful "communication requires common concepts." ${ }^{169}$ This means some sort of pragmatic approach must be utilized to attain any mutual understanding between cultural groups. Therefore, given that different cultures often possess unique and distinct concepts, and "common

\footnotetext{
${ }^{167}$ John Bargh, Before You Know It: The Unconscious Reasons We Do What We Do (New York, NY: Touchstone, 2017).

${ }^{168}$ Kimenyi, "Anatomy of Culture." Kimenyi explains that "Concepts have to do with how we conceive and perceive both physical and metaphysical phenomena. Depending on our cultural background the same 'reality' may be perceived or conceived differently or may not be perceived and conceived at all. For instance, even though death is universal, there are societies in which it is viewed as the end of life but there are others where it is seen as the beginning of life. The concept of beauty not only varies from culture to culture but also shifts from generation to generation. Natural gaps between teeth and black gum are signs of beauty in Rwanda but in the US gaps have to be filled. Fat is seen today as a sign of poverty and bad eating habits and slimness as a symbol of wealth and aristocracy, but it used to be the opposite. Time also has been found to be conceived differently. Among Anglo-Saxons, time is objective, unidirectional and seen as a commodity, hence the saying 'Time is money.' It has very much affected their lives. Among the Latins (French, Italians, Portuguese, Spaniards) time can be subjective as demonstrated by their languages: thus morning is either le matin or la matinée, day is le jour or la journée, evening le soir or la soirée, year l'an or l'année. The masculine form shown by the article le is objective whereas the feminine form marked by the article la is subjective. Among Rwandans, however, and some other Bantu groups, time is both phenomenological and cyclical. It is phenomenological because it is produced by events and activities. If the events that produce it such as change of seasons, sunset, sunrise, moonlight, etc., fail to materialize, time doesn't take place either. This is seen in the language use, thus hour is 'watch' isáahá, month is 'moon' ukwéezi, year 'crop' umwáaka and a political regime 'drum' ingoma. These temporal expressions are metonymically related to the meanings of the primary plane of expression. A watch is used to show the time, a new month is shown by a new moon in the sky, crops are planted once a year and traditionally before colonialism the symbol of authority was the drum during the monarchy. Time is also elastic. It can be short or long depending on the length of the event. Among the Bantu time is also cyclical. It comes back. For instance, 'soon' is seen as 'recently,' 'tomorrow' as 'yesterday' and 'distant future' as 'far past.' The expression for 'soon' and 'recently' is the same in Kinyarwanda vuba, for 'tomorrow' and 'yesterday' it is ejo, whereas 'the distant future' and 'the far past' it is kera," ibid. See also, Tim Ingold, Being Alive: Essays on Movement, Knowledge and Description (New York, NY: Routledge, 2011); and Peter B. Smith, Ronald Fischer, Vivian L. Vignoles, and Michael Harris Bond, Understanding Social Psychology Across Cultures: Engaging Others in a Changing World (London, UK: SAGE, 2013).

${ }^{169}$ Ledwig, "Folk Psychology and Proverb Knowledge as Common Knowledge in Decision-Making," 195; and Ledwig, Common Sense: Its History, Method, and Applicability, 136.
} 
knowledge is restricted to the culture one lives in," ${ }^{170}$ what is required at present is the initiation of a renewed dialogue between the two cultures for the purpose of locating concepts at the foundational level that they both share in common, but that are interpreted and understood differently. ${ }^{171}$

Within the context of this study it must also be noted, for example, that many concepts in theology, such as the atonement, ${ }^{172}$ cannot serve the present purpose of identifying the source of the conflict between the two cultures. This is because concepts such as the atonement are distinct to the culture of theology or religion, and, as part of religion's replication of the conflict between the two cultures, is itself understood in competing ways over the nature of time. ${ }^{173}$ Therefore, the necessity of

\footnotetext{
${ }^{170}$ Ledwig, “Folk Psychology and Proverb Knowledge as Common Knowledge in Decision-Making," 195.

${ }^{171}$ In such an endeavor, of course, one must be prepared to see the definition of 'concept' itself revised.
} This is how deep, or obvious, the problem can be. That is, a culture consists of a collection of concepts common to a social group, yet unfortunately common concepts can be interpreted differently generating competing cultures-and part of this is due to the very way concepts themselves are defined. As Thomas Højrup explains, it is unfortunate "that contemporary epistemology is dominated by the [scientific] extensional perspective" of concepts, making the [Heideggerian] "intensional perspective on concepts ... seem somewhat cryptic. The idea that concepts ultimately consist of concepts whose content derives from each other may seem strange. We have become accustomed to considering concepts as things, as labels or words with definitions, as terms which stand for things external to the concepts, i.e. as object-concepts. One entity can in principle be distinguished from other entities, defined and labeled individually, and followed continually over time and space or through various changes in its form. Nevertheless, we have learned from theoretical physics-or from deconstruction for that matter-that it is precisely when one imagines that there are entities 'out there', for which the electron concept is a label, that quantum leaps and co-ordination among particles at a random distance from each other must seem mystical while causality appears inevitable. It is necessary to 'de-substantialise' the concepts in order to eliminate the causality explanations. In the cultural sciences ... we meet the same type of problem when cultural concepts (are considered as things which) stand for external entities, i.e. as object-concepts," Thomas Højrup, State, Culture and Life-Modes: The Foundations of Life-Mode Analysis (Burlington, VT: Ashgate Publishing, 2003), 77. As Nigel Rapport and Joanna Overing helpfully add, "culture, as a conceptual structure made up of representations of reality" orients, directs and organizes actions "in systems by providing each with its own logic," Nigel Rapport and Joanna Overing, Social and Cultural Anthropology (New York, NY: Routledge, 2002), 95. As such, when differing cultures meet, mystifying misunderstandings can occur.

${ }^{172}$ For introductions to this theological concept, see, for example, James Beilby and Paul R. Eddy, eds. The Nature of the Atonement: Four Views (Downers Grove, IL: InterVarsity Press, 2006); Roy Gane, Altar Call (Berrien Springs, MI: DIADEM, 1999); and Ángel M. Rodríguez, Spanning the Abyss: How the Atonement Brings Humanity and God Together (Hagerstown, MD: Review and Herald, 2008).

${ }^{173}$ Notably, if the Atonement represents some sort of "justice," then it must be pointed out that traditional philosophy will provide competing definitions of justice because of differing concepts of how justice relates to freedom and time. For example, many see justice in a platonic "timeless" way and not related to a temporal act here on earth. See the discussions in Colin E. Gunton, The Promise of Trinitarian Theology $2^{\text {nd }}$ ed. (New York, NY: T\&T Clark, 1997), 137-139; and N. T. Wright, Evil and the Justice of God (Downers Grove, IL: InterVarsity Press, 2006), 96. Conversely, as Wright explains, correctly in my view, "what is achieved on the cross is not a timeless, abstract accomplishment located, if anywhere, among Plato's forms, well away from the reality of space-time history," ibid. See also, Robert Paterson, The Philosophy of the Atonement (Glasgow: David Bryce and Son, 1892), 46-49. The point is that uncritical theology, on its own, will find many of its distinct concepts predetermined by philosophical presuppositions. Theology is forced to remain attentive to the issues and concepts that philosophers debate, such as freedom and time. 
such a concept is seen as both unnecessary and special pleading in contemporary society and philosophy, whether from those philosophers oriented more toward the secularized sciences, or the secularized humanities, and, owing to the conflicted testimony such a concept offers concerning its relationship to freedom and time, irrelevant. Put simply, at heart, the atonement is a theological concept, not a philosophical concept, because it presupposes the existence of, and likely a certain conception of, the concepts of freedom and time within the concept of God and any God-man relationship.

However, if concepts could be identified that relate to theological concepts that are also critical but divisive within the two cultures, then the possibility of reintroducing the relevance of theology may be possible as a genuine third culture discipline. Indeed, if this were finally done, modifying or clarifying the significance or necessity of even foundational theological concepts, like the atonement, may become possible-it so happens that the atonement, as a prime example, happens to rely upon the foundational concepts of freedom and time. ${ }^{174}$ Indeed, implicit or explicit understandings of freedom and time are at the core of all legal theories, whether theological or socio-political, as will be seen below in chapter 2 , which helps establish a link between the theological and the socio-political spheres.

${ }^{174}$ Of primary significance in this regard would be the proposal by Fernando Canale that the biblical sanctuary, where the atonement proceedings take place, is founded upon a certain historical view of God's actions, both in heaven and on earth. See Fernando Canale, "Philosophical Foundations and the Biblical Sanctuary," in Andrews University Seminary Studies Vol. 36 No. 2 (Autumn 1998), 183-206. For more on the significance of the atonement relative to time, both theologically and for earth history, see the essays in John T. Baldwin, ed. Creation, Catastrophe, \& Calvary: Why a Global Flood is Vital to the Doctrine of Atonement (Hagerstown, MD: Review and Herald, 2000), especially Baldwin, "The Geologic Column and Calvary: The Rainbow Connection-Implications for an Evangelical Understanding of the Atonement," 108-123. Additionally, see, for example, Michael J. Murray, Nature Red in Tooth and Claw: Theism and the Problem of Animal Suffering (New York, NY: Oxford University Press, 2008), 76; Ronald E. Osborn, Death Before the Fall: Biblical Literalism and the Problem of Animal Suffering (Downers Grove, IL: InterVarsity Press, 2014); Oscar Cullmann, Christ and Time: The Primitive Christian Conception of Time and History, tr. Floyd V. Filson (London, UK: SCM Press, 1951); Mark I. Miravalle, Introduction to Mary: The Heart of Marian Doctrine and Devotion (Goleta, CA: Queenship Publishing, 2006), 145; Edward A. Jarvis, The Conception of God in the Later Royce (The Hague, Netherlands: Martinus Nijhoff, 1975), 80-81; Nathan D. Hieb, Christ Crucified in a Suffering World: The Unity of the Atonement and Liberation (Minneapolis, MN: Fortress Press, 2013), 92; Vernon White, Atonement and Incarnation: An Essay in Universalism and Particularity (Cambridge, UK: Cambridge University Press, 1991), 62-64; Stewart A.

McDowall, Evolution and the Need of Atonement (Cambridge, UK: Cambridge University Press, 1912, 2011), 166; Irpeel Ebenezer, Understanding the Gift of Salvation: And a Concise History of How the Church Through Ignorance and Unbelief Lost the Power of the Holy Spirit (Bloomington, IN: AuthorHouse, 2012), 177-178; Stewart Goetz, Freedom, Teleology, and Evil (New York, NY: T\&T Clark, 2008), 150-151; and Patrick R. Frierson, Freedom and Anthropology in Kant's Moral Philosophy (Cambridge, UK: Cambridge University Press, 2003), 118-119. 
The concepts of freedom and time have indeed been identified as critical concepts-they are central to the two cultures, and also for theology. If they are to effectively serve a mediatorial role, they must, therefore, be directly explored together from within both cultures simultaneously as one problem, through the most significant figures to have addressed and defined the concepts-in this case, Einstein and Heidegger and their followers, Bohm and Pylkkö. The reason being, if not explored together, from which culture could one claim any transcendent perspective ${ }^{175}$ If there are any other presuppositional concepts such as God inherent within the two cultures that encourage their tensions concerning freedom and time, only together, as a study on the two cultures in conjunction with a study on freedom, time, and their interrelationship, can any real hope for clarity be sought. In other words, one must analogically use both a telescope and microscope simultaneously to see freedom and time from afar as components of a complex cultural problem as well as up close as a philosophical problem in itself (i.e., the forest and the tree) to detect why the two cultures have thus far continued down divergent pathways. ${ }^{176}$ Only then might one seriously expect the possibility of the creation of a

\footnotetext{
175 The situation appears to devolve to the straightforward problem of all philosophers: "To ask questions about how much language and culture affect our understanding of the world is not to reject any possibility of our knowing the truth.... It is to make us more sensitive to the limitations of our knowledge and the need to support our beliefs on more solid footing than the fact that we, personally, find them to be 'obvious,'” Robert Solomon and Kathleen Higgins, The Big Questions: A Short Introduction to Philosophy (Belmont, CA: Wadsworth, 2010), 163. In this instance, particularly, my point of departure on what constitutes a 'transcendental perspective' is, hopefully, both philosophical in itself (reflecting the work of leading philosophers), as well as generated out of the conflict within the community of philosophers (reflecting the reality of the conflict), and, also, more sociologically (reflecting the broader tensions beyond the hallways and lecture rooms of philosophy departments to observe the effects of philosophy upon the masses; that is, the power of philosophy to actually affect social reality).

${ }^{176}$ To illustrate the necessity of this as concisely as possible, the philosopher J. M. E. McTaggart distinguished two theories of time at the beginning of the $20^{\text {th }}$ century called the A-theory (where events are ordered in terms of past, present, and future and the present can be understood to emphasize the role of the flowing "subjective present"-this is often associated with Heraclitus, Augustine, Newton, and "presentism" today) and B-theory (pairs of events are ordered in terms of either member of the pairs preceding the other or being simultaneous with it; this is also called the tenseless theory, and emphasizes an objective perspective-this is often associated with Parmenides and Einstein). For a review of them, see Simon Prosser, Experiencing Time (Oxford, UK: Oxford University Press, 2016), 1-21; and Brian Garrett, What is this Thing Called Metaphysics? (New York, NY: Routledge, 2006), 94. Students of the theologian Fernando Canale, and Canale himself, see Fernando Canale, The Cognitive Principle of Christian Theology: A Hermeneutical Study of the Revelation and Inspiration of the Bible (Berrien Springs, MI: Andrews University Lithotech, 2005), 93, 104-109, $123,230-231,251-253,270-271$, who have utilized Heidegger's ideas of time, have incorrectly assumed that Heidegger utilized the A-theory of time. For example, Canale states, time "is an overall quality shared by everything we find in reality. Time is the quality by which real things exist within a past-present-future flow," ibid., 251. Once more, "a timeless reality does not experience the flow from past to present and future, and therefore never changes or experiences anything new," ibid., 93. Again, "if 'temporality' means being within a past-present-future flow, to say that God is temporal does not automatically imply that He is transient," ibid., 252. Lastly, Canale repeatedly credits Heidegger with introducing temporality and time into philosophical
} 
true third culture with its own concepts that could displace the two cultures and be considered a serious and viable academic culture with practical or "real" world applications.

Overall, then, the approach of the rest of this study to the issues of freedom, time, and their interrelationship, alongside their role within religion and the two cultures, can, I think, be helpfully compared analogously to the scientist's use of a telescope and a microscope as just mentioned above. The root of the foundational problem in philosophy appears to concern freedom, time, and their interrelationship, inviting the use of a microscope to focus on these two concepts. However, it appears that how freedom and time are discussed today is so overwhelmingly dominated and controlled by the overarching two cultures that it is impossible to discuss freedom and time, in either

discourse in a fresh way, ibid., 230, 233. Note also one of Canale's students, Sven Fockner, Reason in Theology: A Comparison of Fernando Canale and Wolfhart Pannenberg, (MA Thesis, Andrews University, Berrien Springs, MI, 2008), 24-28, 35-36. The key point to be made is that Fockner is correct to associate Canale with Heidegger, and Canale with the A-theory, but incorrect about associating Heidegger himself with the A-theory. For an explanation and affirmation of this, see Taylor Carman, Heidegger's Analytic: Interpretation, Discourse and Authenticity in Being and Time (Cambridge, UK: Cambridge University Press, 2003), 173. The Heideggerian scholar Carman concurs with his fellow Heideggerian scholar William Blattner when he contends, "Blattner is right when he says that McTaggart's distinction between an ' $A$ series' (past-present-future) and a ' $B$ series' (earlier and later), between a tensed and a tenseless view of time, does not capture Heidegger's own notions of originary temporality, world-time, and the ordinary conception," ibid., 173. Unfortunately, such misconceptions and confusion are frequent in the literature. In Blattner's words: "Some readers of Heidegger have thought of his originary temporality as some kind of primordial flow of time. For example, some interpret Heidegger's originary temporality as 'dynamic.' By 'dynamic' these interpreters seem to mean either that time flows continuously (dynamic as opposed to static), or that it is an A-series rather than a B-series (tensed rather than untensed). Neither of these views captures Heidegger's arguments," Blattner, Heidegger's Temporal Idealism, 125. The point is, too many religionists have assumed things about freedom or time in philosophy when doing their theology that are not accurate. And, often, it is a scientific predisposition or presupposition that dominates. Note also Keller, Husserl and Heidegger on Human Experience, 184. Pierre comments that according to Heidegger, the "vulgar" notion of time "has dominated the philosophical tradition and the natural sciences. It is based on the assumption that time, regardless of whether it is identified with tense or not, is something that is essentially measurable by clocks. From Heidegger's point of view, the vulgar notion of time is a distortion of temporality," ibid. The significance of the above is that "the question [often] arises if there is a certain connection between the two main conceptions of time on the one hand, and the two cultures on the other hand. In particular, it seems probable that most people who opt for the static view belong to the scientific culture. Moreover, it might also be the case that most people who opt for the dynamic view belong to the literary culture," even if the connection is "rather weak," J. J. A. Mooij, "The Flow and the Map: On the Dynamic and Static Views of Time," 19. Notwithstanding its weakness, given the predisposition of scientists to view the A-theory and B-theory (technically most scientists favor the B-theory) as constitutive of the options available to the two cultures and the sentiments expressed above that this is, in fact, an inadequate interpretation for one of the key originators of one of the two cultures, the problem then becomes apparent in that if a deeper understanding of additional options are to be articulated we must return to the source of how time is understood (Heideggerianism) once more. In addition to recognizing that the limitations and predispositions of the two cultures must be kept in mind and clarified in relation to any alternative view, the possibility of reclassifying the old options must also remain open if additional concepts are unearthed. Finally, of course, the insufficiencies of both the A-theory and B-theory in relation to Heideggerian thought may prove significant when freedom is introduced into the problem of the concept of time. 
physics, philosophy, or theology functioning as a derivative of the former two, without simultaneously being made aware of and treating how the historical and conceptual baggage of the two cultures influences the descriptions of the latest developments in physics and philosophy and their interrelationship. Unfortunately, individuals typically emerge from one of the two cultures whenever they approach the concepts of freedom and time. As such, a telescope is necessary alongside a microscope to simultaneously view freedom, time, and their interrelationship from both afar and up close. Freedom and time must be addressed together in conjunction with the two cultures and any third culture, including one such as theology or religion. This way, it may be easier to see if there is any debris blocking our vison's access to the desired clarity on the concepts of freedom, time, and their interrelationship that is presently hindering the sciences and humanities from reaching harmony.

In the following section, I will provide an overview addressing the revolution that has occurred in the wake of the discovery of quantum physics. The purpose of doing this is to introduce just why quantum physics forces us to re-think about the concepts of freedom and time in ways that the previous eras of physics did not encourage, to see if new conceptions of freedom and time can be found that are more detailed or accurate. Quantum physics has revolutionized the thinking of many of those deeply reflecting about the world of science, and, at the same time, it has opened up the possibility of a more serious dialogue between science and the humanities, which is why both Bohm and Pylkkö utilize quantum physics within their philosophies. Correspondingly, quantum physics opens up the possibility of discussing the potential of a new third culture, which means the possibility of religion becoming a serious harmonizing influence between the two cultures remains open.

The Revolutionary Implications of Quantum Physics and Its Impact Upon Freedom and Time, the Two Cultures, and the Necessity of a Third Culture

Just over one hundred years ago, when gazing up at the moon at night, no reputable scientist would have dared to question whether or not the moon would still be there while his/her eyes glanced downward to shake the pebble out of their shoe. Such scepticism, they thought, might only occur with the scientist's lesser associate, the armchair nihilistic philosopher who only philosophized 
with his eyes closed. Yet, perhaps with only a little facetiousness, that was the essence of Albert Einstein's complaint against the advocates of the prevailing Copenhagen interpretation of quantum mechanics that was developing in the 1930's when he inquired of them, "is the moon still there when you are not looking at it?"177 Einstein was not the only witticist amongst the physicist community.

The confusion surrounding the theories of recent physics have inspired many creative uses of language, including the oft-quoted purported puns of Wolfgang Pauli, who remarked of various theories, "that is not only not right; it is not even wrong," and "what you said was so confused that one could not tell whether it was nonsense or not."178 The physicists' community has remained divided into two major camps ever since, consisting of Einstein, Louis de Broglie, Erwin Schrödinger, and Bohm on the one side (however different Bohm's views might later develop in contrast to Einstein's), and the majority or orthodox Copenhagen view represented by Niels Bohr, Werner Heisenberg, Wolfgang Pauli, and Max Born on the other side. ${ }^{179}$

${ }^{177}$ Albert Einstein, as quoted in Dipankar Home and Andrew Whitaker, Einstein's Struggles with Quantum Theory: A Reappraisal (New York, NY: Springer-Science, 2007), 175. Einstein's question probed one of the more troubling aspects of the developing quantum mechanics, that physical reality was in some way dependent upon an observer. Certain attributes of quantum-physical matter apparently, literally, didn't exist in a given location until an observer "decided" to measure them. If no one decided to measure these attributes, empirical evidence indicated their location only existed as a probability. A decision to search for them "created" their ontic existence. For more on Einstein's quote, see Françios Lurçat, "Understanding Quantum Mechanics with Bohr and Husserl," in Rediscovering Phenomenology: Phenomenological Essays on Mathematical Beings, Physical Reality, Perception and Consciousness, eds. Luciano Boi, Pierre Kerszberg, Frédéric Patras (Dordrecht, The Netherlands: Springer, 2007), 255; see also, N. David Mermin, "Is the Moon There when Nobody Looks? Reality and the Quantum Theory," in Philosophy of Science: An Anthology, ed. Marc Lange (Malden, MA: Blackwell Publishers, 2007), 619; Arkady Plotnitsky, Epistemology and Probability: Bohr, Heisenberg, Schrödinger, and the Nature of Quantum-Theoretical Thinking (New York, NY: Springer, 2010), 7; Amit Goswami, Richard E. Reed, and Maggie Goswami, The Self-Aware Universe: How Consciousness Creates the Material World (New York, NY: Penguin Putnam, 1995); R. Mirman, Quantum Mechanics, Quantum Field Theory: Geometry, Language, Logic (Lincoln, NE: iUniverse, 2004), 185; and Yemima Ben-Menahem, "Realism and Quantum Mechanics," in Microphysical Reality and Quantum Formalism, Vol. 2, eds. A. Van der Merwe, F. Selleri, and G. Tarozzi (Dordrecht, The Netherlands: Kluwer Academic Publishers, 1987), 111. Einstein voiced his complaint against the Copenhagen view many times and in many ways. Einstein was noted to remark that "the theory reminds me ... of the system of delusions of an exceedingly intelligent paranoiac," a "tranquilizing philosophy-or religion" that provides a "soft pillow to the true believer" but one that "has so damned little effect on me." It was merely an "epistemology-soaked orgy," as cited in Adam Becker, What Is Real?: The Unfinished Quest for the Meaning of Quantum Physics (New York, NY: Basic Books, 2018), 14.

${ }^{178}$ As cited in "Not Even Wrong," in Wikipedia: The Free Encyclopedia at https://en.wikipedia.org/ wiki/Not_even_ wrong (accessed October 14, 2017).

${ }^{179}$ Karl Popper, Quantum Theory and the Schism in Physics: From the Postscript to the Logic of Scientific Discovery (New York, NY: Routledge, 2000), 174-175. Popper explains that the three fundamental issues which divided the two camps were 1) determinism versus indeterminism, 2) realism versus instrumentalism, and 3) objectivism versus subjectivism. Einstein and his camp would occupy the first position of the preceding three issues, whereas Bohr would belong to the second position for each of the three issues. 
As astounding as it may seem for those uninitiated with the evolution from Newtonian particle theory to James Maxwell's mathematization of wave field mechanics, and their eventual extension into relativity and the quantum revolution, the dominant position concerning physical reality today indicates that when you look down at your shoe, the moon isn't there anymore. That is to say, not the moon, but certainly that tiny electron particle-ball that scientists thought was a microscopic "moon" they were staring at through their equipment. When such a particle is not being measured, it simply “doesn't exist" anymore with a specific location and velocity. For most scientists, this incongruity indicated that reality was seemingly and irreconcilably inconsistent. The principles and laws that appeared to govern the "macro" world simply didn't apply at the subatomic "micro" level. The microscopic level of nature did not appear to behave the same as at the macroscopic level. And still, almost 90 years after this was first empirically observed, no one knows why. ${ }^{180}$ Furthermore, since the 1980's and Alain Aspect's empirical confirmation of the quantum strangeness, ${ }^{181}$ progress toward a fundamental theory of everything in physics has slowed to a snail's pace if not ceased outright, ${ }^{182}$ even as new discoveries, or new applications of older discoveries, are applied in various technological areas. Additionally, however often philosophers may have teased us with such paradoxes in the past, such paradoxes never achieved the universal validity, controllability, verifiability, and most

\footnotetext{
${ }^{180}$ For the relationship of electromagnetic wave field mechanics and space-time, see Jonathan Allday, Space-time: An Introduction to Einstein's Theory of Relativity (Boca Raton, FL: CRC Press, 2019), 40-45. For historical and conceptual overviews of quantum physics, see Jim Baggott, The Quantum Story: A History in 40 Moments (Oxford, UK: Oxford University Press, 2011); Heinz R. Pagels, The Cosmic Code: Quantum Physics as the Language of Nature (Mineola, NY: Dover Publications, 1982); and Jagdish Mehra and Helmut Rechenberg, The Historical Development of Quantum Theory: 6 Vols. (New York, NY: Springer-Verlag, 1982-2000). For more detailed accounts on the conceptual issues, see Travis Norsen, Foundations of Quantum Mechanics: An Exploration of the Physical Meaning of Quantum Theory (Cham, Switzerland: Springer, 2017); Manjit Kumar, Quantum: Einstein, Bohr, and the Great Debate about the Nature of Reality (New York, NY: W. W. Norton \& Company, 2010); and John Gribbin, In Search of the Multiverse: Parallel Worlds, Hidden Dimensions, and the Ultimate Quest for the Frontiers of Reality (London, UK: Penguin Books, 2009). For one of the earliest works exploring the connection between physics and metaphysics see the doctoral dissertation of Charles Weiss, The Metaphysical Implications of Modern Physics (New York, NY: New York University, 1931).

${ }^{181}$ Alain Aspect, Philippe Grangier, Gérard Roger, "Experimental Realization of Einstein-PodolskyRosen-Bohm Gedankenexperiment: A New Violation of Bell's Inequalities," in Phys. Rev. Lett. $49 \# 2$ (1982), 91-94.

182 Steven Weinberg, "Changing Attitudes and the Standard Model," in The Rise of the Standard Model: Particle Physics in the 1960s and 1970s, eds. Lillian Hoddeson, Laurie Brown, Michael Riordan, and Max Dresden (Cambridge, UK: Cambridge University Press, 1997), 36-44. "Progress toward" "a fundamental theory that would be entirely satisfying in its completeness and simplicity" "seems to have come nearly to a stop. We are paying the price of our own success; the Standard Model has done so well that we cannot easily see how to go beyond it," ibid., 43.
} 
importantly, empirical accessability as with quantum phenomena. What's different about the quantum world is that virtually everyone working in quantum physics is forced to see and at least acknowledge the problems that the quantum world raises. ${ }^{183}$ And, nestled within the above challenges is the fact that the entire scope and nature of science itself as an enterprise is placed in question, including its classical formulation concerning the roles of the 'subject' and 'object' as a priori presuppositions, ${ }^{184}$ which influences not only our reading of the history of science and philosophy, but also the history of the arts and distinctly human disciplines. ${ }^{185}$

\footnotetext{
183 "Quantum physics forces us to start thinking about what understanding actually means, and how limited our human imagination is. Quantum physics, like no other scientific theory ever devised, pushes us to the point where we have to accept that we cannot find any kind of visualization of what happens in nature anymore. We can devise models for one phenomenon or another, but these models will certainly fail in different circumstances," Dirk Eidemüller, "Quantum Physics, Philosophy, and Understanding Our World," at http://www.chemistryviews.org/details/ezine/10054971/Quantum_Physics_Philosophy_and_Understanding_0 ur_World.html (accessed December 6, 2016).

${ }^{184}$ Perhaps one of the clearest articulations of this is by Steven M. Rosen, Dimensions of Apeiron: $A$ Topological Phenomenology of Space, Time, and Individuation (Amsterdam, The Netherlands: Rodopi, 2004), 342; and Steven M. Rosen, The Self-Evolving Cosmos: A Phenomenological Approach to Nature's Unity-in-Diversity (Toh Tuck Link, Singapore: World Scientific Publishing, 2008), 1-41. Essentially, within the realm of quantum phenomena, it is not clear what is meant by a subject or object. There are no 'clear' objects that are apprehended by 'clear' subjects-objects don't exist independently of subjects, and subjects seem dependent in some way upon objects, which are themselves unclearly defined. This had never before occurred within scientific discourse; only in philosophy had such ideas been suggested. It should be noted that this development builds off the establishment of wave field mechanics, Rosen, Dimensions of Apeiron: A Topological Phenomenology of Space, Time, and Individuation, 17-18.

${ }^{185}$ Steven M. Rosen, Science, Paradox, and the Moebius Principle: The Evolution of a 'Transcultural' Approach to Wholeness (Albany, NY: State University of New York Press, 1994), 127-198; Steven M. Rosen, Dreams, Death, Rebirth: A Topological Odyssey into Alchemy's Hidden Dimensions (Asheville, NC: Chiron Publications, 2014), 13-40; and Rosen, Dimensions of Apeiron: A Topological Phenomenology of Space, Time, and Individuation, 43-66. See also the wide ranging works by Floyd Merrell, Semiosis in the Postmodern Age; and Merrell, Sensing Corporeally: Toward a Posthuman Understanding, 265-295.
} 
Importantly, the natures of freedom ${ }^{186}$ and $\operatorname{time}^{187}\left(\right.$ and $\mathrm{God}^{188}$ ) are also critical problems that emerge from a study of the quantum realm, including the theoretical possibility of retrocausality, or the ability for the future to affect the past ${ }^{189}$ which introduces the question whether time has any arrow in its 'flow' at all. ${ }^{190}$ To observe some of the basic quantum paradoxes requires no specially trained philosophical mind or an awareness of specialized vocabulary; "universal" fundamental common sense demands the conflict in such a way as to be inconsistent with other common sense demands. Thus, a genuine conflict or tension appears to exist, one that never required the kind of attention that previous problems in modern science did in such an accessible and universal way. Therefore, unsurprisingly, perhaps the nature of the reality of time lies at the core of the quantum paradoxes, especially its central mystery, quantum gravity. ${ }^{191}$

Although in some respects it is true that there is nothing new under the sun when it comes to the world of philosophy, it also goes without saying that the scientific world today is markedly different from the one the ancient Greek philosophers Parmenides and Pythagoras or the modernist philosopher Kant lived in and about which they observed and philosophized. The world that Bohm and Pylkkö have reflectively engaged provides us with some new very challenging questions that

\footnotetext{
${ }^{186}$ By no means would I wish to suggest that current interpretations of quantum physical phenomena demand that we possess free will, as has been pointed out by several scholars; see, for example, Harris, Free Will, 28-30; and John R. Searle, Freedom \& Neurobiology: Reflections on Free Will, Language, and Political Power (New York, NY: Columbia University Press, 2007), 75. Nevertheless, despite the above detractors, quantum physics forces us to re-ask questions about free-will and time, as noted by William R. Klemm, Making a Scientific Case for Conscious Agency and Free Will (Cambridge, MA: Elsevier, 2016), 5; Steven Horst, Laws, Mind, and Free Will (Cambridge, MA: The MIT Press, 2011), 102-118; Paul Davies, God and the New Physics (New York, NY: Simon \& Schuster, 1983), 119-143; and Doyle, Free Will: The Scandal in Philosophy, 222-233.

${ }^{187}$ See the essays in Christophe Bouton and Philippe Huneman, eds. Time of Nature and the Nature of Time: Philosophical Perspectives of Time in Natural Sciences (Cham, Switzerland: Springer International Publishing, 2017).

${ }^{188}$ Quantum physics has forced us to also think about divine agency in nature and humanity in fresh ways. See, for example, Alvin Plantinga, Where the Conflict Really Lies: Science, Religion, \& Naturalism (Oxford, UK: Oxford University Press, 2011), 65-125; and Anna Case-Winters, "Rethinking Divine Presence and Activity in World Process," in Creation Made Free: Open Theology Engaging Science, ed. Thomas Jay Oord (Eugene, OR: Pickwick Publications, 2009), 74.

${ }^{189}$ See Huw Price, Time's Arrow and Archimedes' Point: New Directions for the Physics of Time (Oxford, UK: Oxford University Press, 1997).

${ }^{190}$ Henry Mehlberg, Time, Causality, and the Quantum Theory: Studies in the Philosophy of Science Vol. 2: Time in a Quantized Universe, ed. Robert S. Cohen (London, UK: D. Reidel, 1980), 157.

${ }^{191}$ For a penetrating discussion of the problems surrounding quantum gravity and time, see Steven M. Rosen, "Quantum Gravity and Phenomenological Philosophy," in Foundations of Physics Vol. 38 Issue 6 (June 2008), 556-582.
} 
inspire us think about the moon and tiny particles today in a very different way than in prior eras of history, much to the chagrin of Einstein and many other traditional physicists like him, some of whom are finally realizing the apparent futility of even attempting the traditional methods. ${ }^{192}$ Given the centrality of these differences, and their relationship to the contexts within which Bohm and Pylkkö developed and articulated their ideas alongside Heidegger's distinct distaste for the role of the positive sciences in philosophy, a concise review of the issues in quantum physics is pertinent. ${ }^{193}$ The notions that we have about reality, especially freedom and time, have remained under continual discussion in philosophical discourse throughout every period of history, which should come as no surprise, given their obvious universal interest and importance. Aside from freedom and time, some of the primary questions include understanding and describing the relationship between our thoughts, nature, and the existence of other minds or people. Perhaps it is obvious that the nature of reality concerning these issues and others are undoubtedly perplexing, encompassing many different facets. Although traditional discussions about reality cover the full range from basic metaphysical questions about the essences of things and the relationship between things to

\footnotetext{
192 Marcelo Gleiser, “We Have Pushed Physics Too Far,”at http://cosmos.nautil.us/short/90/we-have -pushed-physics-too-far (accessed January 7, 2017). Gleiser admits that "those who pursue a final theory, a theory that would weave together the many layers of physical reality into one mathematical wholeness," "we can call this the ultimate Platonic dream, the quest for a single simple and broad-ranging theory of physics. Indeed, during the past four decades, the search for such a theory has inspired many of the brightest physicists in the world. But today we are seeing the limits of this Platonic thrust to mathematize nature, due to a lack of experimental validation and several theoretical obstacles," ibid. Gleiser continues, opining within the current situation that "it's okay to live with the seeming arbitrariness of our present laws of physics, moving beyond the aesthetic dogma that simple is beautiful and beauty is truth. If physics is understood as a descriptive mode of explanation, free of the unifying quest, the angst of not knowing it all is exorcised. Maybe our current dilemma is a symptom of something bigger, a deep change in the methodological nature of physical theories. We may have to see them historically, tossing aside First Cause explanations and timeless truths as fruitless pursuits. Quite possibly, the nature of physical theories mirrors their own narrative construction, piecewise and gradual, creations of our imperfect and incomplete grasp on physical reality. And there's nothing wrong with that," ibid.

${ }^{193}$ As Heidegger stated, "All a priori Temporal-all philosophical-concept formation is fundamentally opposed to that of the positive sciences," Martin Heidegger, The Basic Problems of Phenomenology, tr. Albert Hofstadter (Bloomington, IN: Indiana University Press, 1982), 327. Note also, Martin Heidegger, Basic Questions of Philosophy: Selected "Problems" of "Logic", tr. Richard Rojcewicz and André Schuwer (Bloomington, IN: Indiana University Press, 1994), 4. "The essence of beings, however, is always the most worthy of questioning. Insofar as philosophy, in its incessant questioning, merely struggles to appreciate what is most worthy of questioning and apparently never yields results, it will always and necessarily seem strange to a thinking preoccupied with calculation, use, and ease of learning. The sciences, and indeed not only the natural sciences, must strive increasingly and, it seems, irresistibly for a complete 'technologizing' in order to proceed to the end of their course, laid down for them so long ago. At the same time, the sciences appear to possess genuine knowledge. For these reasons, the sharpest possible alienation with regard to philosophy and at the same time a presumed convincing proof of the futility of philosophy occur in and through the sciences," ibid.
} 
operational approaches and methods concerning the appropriation and utilization of knowledge, during no period in history have these issues received as much new data and rapid changes in how we might approach these challenges as during the past century. This is particularly true because of the discovery of quantum physics, alongside numerous technological advances. Furthermore, the controversies spawned by the advent of the quantum era can hardly be overstated. The definition of science and our best understanding of reality depended and still depends on its outcome, for which widely divergent perspectives have emerged.

Niels Bohr, the most prominent founder of the Copenhagen interpretation of quantum physics, which remains dominant today, represents one side of the debate when he declared, "it is wrong to think that the task of physics is to find out how nature is. Physics concerns what we can say about nature."194 However, Einstein, along with others, disagreed with Bohr, believing that it is the task of science to find out about nature itself. ${ }^{195}$ This attitudinal difference about the epistemic and ontic aspects of the issues, which reached such a sharp apex at the dawn of the quantum era in the 1930's, has dominated all discussion concerning the aim of science ever since, ${ }^{196}$ and can be analogously compared to the same question in philosophy-are we describing only what we can say about some aspect of reality, or reality itself? Are we seeing an ontic reality, that is, the way "things are," or an epistemic limitation, that is, what we can know "about things" when we observe quantum phenomena ${ }^{197}$ The current status quo of a Kantian/Cartesian/Platonic idealism coexisting with the (1963), 12.

${ }^{194}$ As explained by A. Petersen, “The Philosophy of Niels Bohr," in Bulletin of the Atomic Scientist 19\#7

${ }^{195}$ Harald Atmanspacher and Hans Primas, "Introduction," in Recasting Reality: Wolfgang Pauli's Philosophical Ideas and Contemporary Science (Germany, Berlin: Springer-Verlag, 2009), 1.

${ }^{196}$ Including strongly influencing landmark figures such as Thomas S. Kuhn, The Structure of Scientific Revolutions (Chicago, IL: University of Chicago Press, 1962), 12, 48, 49, 67, 88, 108.

197 "The most fundamental aspect of the Western intellectual tradition is the assumption that there is a fundamental division between the material and the immaterial world or between the realm of matter and the realm of pure mind or spirit. The metaphysical framework based on this assumption is known as ontological dualism. As the word implies, the framework is predicated on an ontology, or a conception of the nature of God or Being, that assumes reality has two distinct and separable dimensions. The concept of Being as continuous, immutable, and having a prior or separate existence from the world of change dates from the ancient Greek philosopher Parmenides. The same qualities were associated with the God of the Judeo-Christian tradition, and they were considerably amplified by the role played in theology by Platonic and Neoplatonic philosophy.

"Nicolas Copernicus, Galileo [Galilei], Johannes Kepler, and Isaac Newton were all inheritors of a cultural tradition in which ontological dualism was a primary article of faith. Hence the idealization of the mathematical ideal as a source of communion with God, which dates from Pythagoras, provided a metaphysical 
paradoxical "complementarity" Copenhagen interpretation, represents a very uneasy truce. ${ }^{198}$ In

what is surely an ironic twist, the paradoxical complementarity of Bohr's widely accepted

Copenhagen theory amongst quantum physicists has cemented into the 'hardest' of the hard sciences

the paradoxical residue of the need of the humanities. ${ }^{199}$ At the same time, many in the humanities

foundation for the emerging natural sciences. This explains why ... the creators of classical physics believed that doing physics was a form of communion with the geometrical and mathematical forms resident in the perfect mind of God. This view would survive in a modified form in what is now known as Einsteinian epistemology and accounts in no small part for the reluctance of many physicists to accept the epistemology associated with the Copenhagen Interpretation" which associates quantum mechanics with paradoxes and probabilities, not certainties, Robert Nadeau and Menas Kafatos, The Non-local Universe: The New Physics and Matters of the Mind (Oxford, UK: Oxford University Press, 1999), 83-84.

198 "It therefore appears evident that a radical emancipation from the negative philosophy of the Copenhagen school and from its irrationalistic aspects is a necessary precondition if one is to look for a real solution, i.e., for something completely different from their legitimation, of the main quantum paradoxes," Gino Tarozzi and Alwyn van der Merwe, "Epilogue," in Open Questions in Quantum Physics: Invited Papers on the Foundations of Microphysics, eds. G. Tarozzi and A. van der Merwe (Dordrecht, The Netherlands: D. Reidel Publishing, 1983), 391. See also, Peter E. Hodgson, Theology and Modern Physics (Burlington, VT: Ashgate, 2005), 150-151; and William J. Mullin, Quantum Weirdness (Oxford, UK: Oxford University Press, 2017 ), 31. Mullin explains that "a basic assumption from the early days of quantum research was that there was a dividing line between classical objects and quantum objects.... This division was the basis of the Copenhagen interpretation of quantum mechanics and was developed mostly by Niels Bohr.... But we no longer really believe in this view. In principle, every object obeys quantum mechanics rules, but seeing the wave like behavior of a baseball is very difficult ...., and too many external influences are present that destroy its quantum behavior," ibid. Thus the neat, clean ontological dualism referred to in the preceding era has become a muddier dualistic monism.

${ }^{199}$ As the architect of the Copenhagen view, "Niels Bohr challenged the ability of science and the human mind to proceed further. He almost seemed to be suggesting that science as we knew it had finally reached a limit and could go no further as a means of enquiry into the nature of reality," leaving room for the speculative humanities exploring freedom and language on the other side of the limit, F. David Peat, From Certainty to Uncertainty: The Story of Science and Ideas in the Twentieth Century (Washington, D.C.: Joseph Henry Press, 2002), 24. A number of thinkers have thus considered the Copenhagen position a premature surrender, and the dogmatism of its advocates the protectors of a 'conspiracy.' See, for example, David Ferry, The Copenhagen Conspiracy (Singapore: Pan Stanford Publishing, 2019). This is where Bohm fits into the story-his original aim for a unified, causal, deterministic or ontological theory of quantum mechanics, contra the Copenhagen view, represents his and Einstein's initial shared goal, even if they disagreed about how to get there concerning the issue of locality, with Bohm more open to nonlocality. Bohm's later ideas moved beyond the mere goal of a causal theory, but his work remains the catalyst in motivating others to seek one. For a defense of Bohmian mechanics as superior to the Copenhagen interpretation of quantum physics, see Xavier Oriols and Jordi Mompart, eds. Applied Bohmian Mechanics: From Nanoscale Systems to Cosmology (Singapore: Pan Stanford Publishing, 2012); and F. Borondo, "Dynamical Systems Approach to Bohmian Mechanics," in Quantum Trajectories: Atoms, Molecules, and Clusters-Structure, Reactivity, and Dynamics, ed. Patrim Kumar Chattaraj (Boca Raton, FL: CRC Press, 2011), 381-388. For more on how and why the Copenhagen view of quantum mechanics represents the residue of the humanities and its place in the conflict of the "two cultures," see Ragnar Fjelland, "The 'Copenhagen Interpretation' of Quantum Mechanics and Phenomenology," in Hermeneutic Philosophy of Science, Van Gogh's Eyes, and God: Essays in Honor of Patrick A. Heelan, S. J., ed. Babette E. Babich (New York, NY: Springer Science, 2002), 53-66. Fjelland summarizes by explaining that "both phenomenology and (the Copenhagen interpretation of) quantum mechanics are regarded as 'subjectivist' [by the monistic and reductionistic mainstream interpretation of classical science] and therefore anti-science [or humanistic]. Hence it is no accident that they are both under fire in the 'science wars,'” ibid., 63-64 (additions mine). 
assume paradoxical dualisms of their own, even Heidegger himself, ${ }^{200}$ as Pylkkö has pointed out, ${ }^{201}$ creating an unexpected connection between the Copenhagen view and Heidegger. Against the dualist position, and also against both of these groups of paradoxical positions, is the Bohmian view. ${ }^{202}$ Yet, what is truly remarkable in all this is that the basic phenomenal puzzle of the quantum world has remained essentially unchanged since its initial discovery and basic formulation.

The unsettled state of quantum interpretation parallels in a remarkable manner the other philosophical disciplines beyond natural science during this time, such as with linguistics. This is well illustrated by Richard Rorty who, following Ludwig Wittgenstein, helped deliver the "linguistic turn" in philosophy, insisting that we should give up on asking how the world is but rather concentrate on how it is described. ${ }^{203}$ Not surprisingly, the relationship between linguistics and quantum theory has received considerable attention and several have located direct links in the work of prominent linguists, such as Hillary Putnam, whose work in linguistics was evidently inspired by the problems in quantum physics. ${ }^{204}$

\footnotetext{
200 "It appears that Heidegger's antiepistemological notions [contra Descartes] had a great impact on ontological interpretations in quantum physics. Heidegger also had a great influence on the [Heideggerian] reconciliation of the 'two cultures (C. P. Snow) by introducing the necessity of hermeneutics into the field of natural science.... According to Heidegger's solution there is a refusal to express the ontology and epistemology of reality in terms of realism and idealism.... [However,] it is widely recognized that the terminology of Heidegger is chosen so as to avoid the connotation of traditional philosophical concepts, such as subject, object, consciousness and mind. Heidegger's philosophical system is an attempt to destroy the history of ontology, since Being, according to Heidegger, has been confused with beings. In order to understand Heidegger we are obliged to follow him in his terminological construction, which easily leads to difficulties if we step outside his system," Stefan Djupsjöbacka, Dialogue in the Crisis of Representation: Realism and Antirealism in the Context of the Conversation between Theologians and Quantum Physicists in Göttingen 1949-1961 (Tavastg, Finland: Åbo Akademi University Press, 2005), 71.

${ }^{201}$ Pylkkö, The Aconceptual Mind, 59-60. See also, Stefanos Geroulanos, An Atheism That Is Not Humanist Emerges in French Thought (Stanford, CA: Stanford University Press, 2010), 59; and Watson, "Beyond Ontic-Ontological Relations," 51-52.

${ }^{202}$ Jean Bricmont, Making Sense of Quantum Mechanics (New York, NY: Springer, 2016), 290. Bohm does, however, embrace the language of paradox on occasion.

Science, 1.

${ }^{203}$ Atmanspacher and Primas, Recasting Reality: Wolfgang Pauli's Philosophical Ideas and Contemporary

${ }^{204}$ Christopher Norris, for one, attributes quantum physics as an influence in the work of linguists like Hilary Putnam, who connected his readings of quantum theory to his work in language theory. See Christopher Norris, Quantum Theory and the Flight from Realism (New York, NY: Routledge, 2000), 205. "In Putnam's case . . .there is evidence that this shift of views [from an ontic to epistemic focus in linguistics] came about at least partly as a result of his prolonged engagement with issues in the philosophy of quantum mechanics," ibid.
} 
Turning to the quantum phenomena, itself, it's worth noting that it has variably been called something that "I think I can safely say that nobody understands," 205 and "makes absolutely no sense," ${ }^{206}$ yet remains resilient as "the most battle-tested theory in all of science-it has no competitors," ${ }^{207}$ all the while establishing itself as "incontestably the intellectual scandal of the century!"208 "Quantum mechanics ... laid waste to the earlier inductivist, generalizing, dogmatic science program. This latter was ... 'in its day ... extremely useful; and now that it is dead, it is stonedead, an archaeological curiosity ... turned into an obstructive agency." ${ }^{209}$ As Euan Squires put it, "in an endeavor to understand the quantum world, we are led beyond physics, certainly into philosophy and maybe even into cosmology, psychology and theology." Squires continues, "quantum phenomena challenge our primitive understanding of reality; they force us to re-examine what the concept of existence means." ${ }^{210}$

So what, exactly, is all the excitement about? Although a detailed examination of the quantum physical experiments is not possible here, it may prove helpful to summarize the key points. Put concisely, it has been claimed that "quantum physical" reality presents a paradoxically dualistic waveparticle description of matter, as well as appearing to exhibit an entangled nature that demonstrates non-local ${ }^{211}$ "spooky action"212 at a distance. Furthermore, quantum particles demonstrate

${ }^{205}$ Richard Feynman, The Character of Physical Law (Cambridge, MA: MIT Press, 1965), 129.

${ }^{206}$ Roger Penrose in Roger Penrose and C. J. Isham, ed. Quantum Concepts in Space and Time (Oxford, UK: Clarendon Press, 1986), 139.

${ }^{207}$ Bruce Rosenblum and Fred Kuttner, Quantum Enigma: Physics Encounters Consciousness (Oxford, UK: Oxford University Press, 2006), 51-52.

${ }^{208}$ René Thom, Prédire n'est pas Expliquer (Paris, France: Flammarion, 1993), 86. Translation mine from "incontestablement le scandale intellectuel du siècle!"

${ }^{209}$ Alfred North Whitehead, as cited by David Hakken, The Knowledge Landscapes of Cyberspace (New York, NY: Routledge, 2003), 91.

${ }^{210}$ Euan J. Squires, The Mystery of the Quantum World (New York, NY: Taylor \& Francis, 1994), preface.

${ }^{211}$ Notably, at least according to some, "one of the gross misinterpretations of the results of [the experiments demonstrating non-locality] in the popular press was that they showed that information traveled between the detectors at speeds greater than light. This was not the case, and relativity theory, along with the rule that light speed is the speed limit in the universe, was not violated. The proper way to view these correlations is that they occurred instantly or in 'no time' in spite of the vast distance between the detectors [in the experiment]," Nadeau and Kafatos, The Non-local Universe: The New Physics and Matters of the Mind, 79.

212 Einstein's famous words. For some conflicting descriptions of the problem of "spooky action" at a distance and the controversy surrounding it, see Jürgen Audretsch, Entangled Systems: New Directions In Quantum Physics (Weinheim, Germany: Verlag, 2007), 130-131; and Lily Splane, Quantum Consciousness: A Philosophy of the Self's Potential Through Quantum Cosmology (San Diego, CA: Anaphase II Publishing, 2004), 
discontinuous probabilistic jumps of motion that are unpredictable or random (free?) at the individual level, ${ }^{213}$ yet still fulfil mathematically consistent probabilities in large statistical quantities. ${ }^{214}$ Quantum phenomena also appear to be observer or consciousness dependent, and thus mixing mind and matter, ${ }^{215}$ or simultaneously mixes together the ontic ${ }^{216}$ and epistemic aspects of reality when researchers interact with it experimentally. ${ }^{217}$ As such, it appears to require redefining the relationship between the 'one and the many. ${ }^{, 218}$ As Bohr himself described some of the central mysteries of the quantum world, "unless you're shocked by quantum mechanics, you have not understood it." ${ }^{219}$

Contemporary scholars agree that "the development of quantum mechanics in the first decades of the twentieth century came as a shock to many physicists. Today, despite the great successes of quantum mechanics, arguments continue about its meaning, and its future." ${ }^{220}$ Indeed, it is widely

130-131. At the end of the day, however, as Jim Baggot concludes his remarks, "so, where does all this leave local reality? Physicists who have commented on these results (including those who disagreed with the principle) ... have largely accepted that these experimental tests create great difficulties for theories which feature a local reality. The message seems to be this: reality is non-local, so get used to it. We are obliged to give up local reality and accept that there can be some kind of 'spooky action at a distance,' perhaps involving some kind of strange communication between distant parts of the universe at speeds faster than that of light," Jim Baggott, Beyond Measure: Modern Physics, Philosophy, and the Meaning of Quantum Theory (Oxford, UK: Oxford University Press, 2004), 180.

${ }^{213}$ For an account of the various aspects of uncertainty or randomness in quantum physics, see Jared Hendricks, Quantum Physics $2^{\text {nd }}$ ed. (Morrisville, NC: Lulu Press, 2015), 39.

${ }^{214}$ Baggott, Beyond Measure: Modern Physics, Philosophy, and the Meaning of Quantum Theory, 76. This greatly frustrated Einstein, who insisted that "the Lord God does not play dice," as quoted in Doyle, Free Will: The Scandal in Philosophy, 228.

${ }^{215}$ Rosenblum and Kuttner, Quantum Enigma: Physics Encounters Consciousness, 52.

216 "In quantum theory, reality at its most basic level is understood in terms of possibility," not actuality or existence, Thomas E. Hosinski, The Image of the Unseen God: Catholicity, Science, and Our Evolving Understanding of God (Maryknoll, NY: Orbis Books, 2017), np. See also, Anton Zeilinger, "Quantum Physics: Ontology or Epistemology?," in The Trinity and an Entangled World: Relationality in Physical Science and Theology, ed. John C. Polkinghorne (Grand Rapids, MI: Eerdmans, 2010), 35-36.

${ }^{217}$ Quantum "entanglement (also called the EPR paradox or nonlocality) is not an epistemological issue (one about our knowledge of the situation). It is an ontological issue, which means that the effect has to do with the reality of the situation or the very 'being' (ontos) of the particles involved," Heidi Ann Russell, Quantum Shift: Theological and Pastoral Implications of Contemporary Developments in Science (Collegeville, MN: Liturgical Press, 2015), 62-63.

${ }^{218}$ Nadeau and Kafatos, The Non-local Universe: The New Physics and Matters of the Mind, 3-4, 13. Quantum physics appears to "demonstrate" a new kind of "relationship between parts and wholes in physical reality," ibid., 13.

${ }^{219}$ As cited in Rosenblum and Kuttner, Quantum Enigma: Physics Encounters Consciousness, 52.

${ }^{220}$ Steven Weinberg, "The Trouble with Quantum Mechanics," at http://www.nybooks.com/ articles/2017/01/19/trouble-with-quantum-mechanics/ (accessed January 19, 2017). 
acknowledged that physicists do not agree on what the quantum world is actually like-there is no consensus about what the physical world really is or looks like. ${ }^{221}$ This has led some to resort to a certain level of open skepticism about the future prospects of science, not just for the quantum realm, but in general. ${ }^{222}$

All this, of course, represents precisely the opposite attitude that defined Newtonian and even Einsteinian science for centuries, and which, it must be noted, continues to dominate mainstream science today in both general physics, technology, and standard cognitive science and linguistics. In a nutshell, the problem is not so much that either method of description, the classical, relativistic, or quantum, works or not, but rather the issue is how to reconcile or best make sense of and appreciate their contradictory approaches. ${ }^{223}$ This is because it seems each of the approaches applies to certain problems, but not for others, and the 'line of demarcation' between them is fuzzy. How can such a situation coexist in the same physical reality? As Robert Nadeau and Menas Kafatos explain the consequences of the situation, "when C. P. Snow recognized the growing gap between ... the two cultures," "his primary concern was that the culture of humanists-social scientists might become so scientifically illiterate that it would not be able to meaningfully evaluate the uses of new technologies. What he did not anticipate was that the two-culture gap would become a two-culture chasm and that the culture of scientists-engineers would become just as responsible for the failure to unify human

\footnotetext{
${ }^{221}$ Sophia Chen, "Physicists Can't Agree on What the Quantum World Looks Like," at https://www .newscientist.com/article/mg23331074-600-physicists-cant-agree-on-what-the-quantum-world-looks-like/ (accessed January 4, 2017).

${ }^{222}$ Stuart Firestein, "Certainly Not! Good Science Requires Cultivating Doubt and Finding Pleasure in Mystery," at http://nautil.us/issue/2/uncertainty/certainly-not (accessed January 4, 2017).

${ }^{223}$ There are, in fact, three approaches to physics-the classical Newtonian, the relativistic, and the quantum, though the former two are more 'intuitively' aligned from a scientific point of view. Heidi Ann Russell explains clearly the main point of contention between all three, namely that "the irreconcilable nature of quantum mechanics and general relativity has to do with the way each disagrees with Newtonian physics. While Newtonian physics explains the world we can observe and in which we interact with a great deal of success, general relativity describes the world of the very large on a cosmic scale, and quantum theory describes the world of the small on an atomic level. In doing so, general relativity accepts the assumptions that Newton made about the relationship between observers and the system they observe but altered Newton's understanding of time and space. Quantum mechanics alternatively accepted Newton's understanding of time and space as an unchanging background but altered Newton's understanding of the relationship between the observer and the observed. Consequently, one of the great issues that faces science today is the fact that these two theories which have been so successful in describing and explaining the way things work on their respective levels do not agree with one another," Russell, Quantum Shift: Theological and Pastoral Implications of Contemporary Developments in Science, 163.
} 
knowledge as the culture of humanists-social scientists," ${ }^{224}$ because their bedrock of authority, the classical scientific method and its epistemic-ontic tradition, would itself collapse under the weight of empirical evidence. Amazingly the methodology of natural science would eventually appear to undercut its own universal authority.

The above assertions, which would still be challenged by some scientists, may be difficult to fully apprehend or appreciate, especially by those with backgrounds lacking any training in advanced science. Yet, the acceptance of the idea that physical science has entered into, and even in a limited sense displaced philosophy, is controversial. Many oppose such an intrusion, from either side-both disgruntled traditional philosophers and a majority of scientists operating outside quantum physics. Thus, that physics and philosophy have met can only be regarded as the state of the discipline if philosophers, physicists, and theologians are examined who have duly considered the data, which is evidenced by the rapidly exploding number of books and articles addressing quantum physics by members of all three groups-the age of trans-disciplinarity has arrived. ${ }^{225}$ "The verificationist, antimetaphysical view of physics which dominated the first two-thirds of the twentieth century is simply outmoded in light of contemporary theoretical physics," states William Lane Craig. ${ }^{226}$ In discussing the results of quantum phenomena, Tim Maudlin remarks, "have we not left the precincts of physics for the unconstrained fantasies of speculative metaphysics?"227 As Philip Clayton, one familiar with and sympathetic to aspects of Heideggerian thought, observes, "what scientists and philosophers of science discovered in the late twentieth century, though they should have known it from centuries

\footnotetext{
${ }^{224}$ Nadeau and Kafatos, The Non-local Universe: The New Physics and Matters of the Mind,13-14.

${ }^{225}$ Piero Scaruffi, Thinking about Thought: A Primer on the New Science of Mind (Bloomington, IN:
} iUniverse, 2003). "Interest on the subjects of mind, consciousness and life is growing exponentially, and is affecting a growing number of disciplines. What used to be the exclusive domain of philosophical speculation is now part of scientific research conducted by neurologists, biologists, physicists, mathematicians, computer scientists, archeologists, anthropologists and psychologists," ibid., back cover. It is a given that theologians are also included amongst those disciplines mentioned above.

${ }^{226}$ William Lane Craig, Time and Eternity: Exploring God's Relationship to Time (Wheaton, IL: Crossway Books, 2001), 50. I would suggest that even beyond the first two thirds of the $20^{\text {th }}$ century, ever since Newton and his mathematical view of nature the same general perspective concerning nature had prevailed. This would include several hundred years of natural science within an anti-metaphysical prism.

${ }^{227}$ Maudlin, Quantum Non-Locality and Relativity: Metaphysical Intimations of Modern Physics, 119. The quote is in the context of discussing the appearance of counterfactual mathematical results and their relationship to observed quantum experiments-that is, unperformed experiments have no results. 
past, is that the spheres of the empirical and the metaphysical are not autonomous." He continues, "knowledge in one is incomplete unless one also understands the contribution of the other. Empirical results raise urgent metaphysical questions, and metaphysical positions frame empirical research.

Only those who know both sides can sort out the confusions that arise in each."228

The minimally inevitable conclusion for philosophers seeking to unravel reality's mysteries within the current situation is well grasped by Garrett DeWeese, one admittedly sympathetic to classical metaphysics,

Contrary to some philosophers who conceive of metaphysics as secondary to the empirical sciences, or perhaps as rendered obsolete by them, I believe that metaphysics is an independent enterprise. But independent does not mean isolated, and the deliverances of the empirical science[s] constitute some of the evidence that metaphysical theories must explain. Conversely, since data will always underdetermine theory, purely metaphysical considerations should be brought to bear in the process of theory adjudication. A successful theory will result from respectful interaction between the scientist and the philosopher... [This includes] acceptable interpretations of the theories of modern physics, notably the Special and General Theories of Relativity and Quantum Mechanics.... Greater explanatory power is one of the virtues by which competing theories have generally been judged. ${ }^{229}$

DeWeese, and others, see the implications clearly. To more fully understand the traditional empirical sciences of psychology, cosmology, theology and even philosophy as a whole, quantum physics must be understood and integrated to the best degree possible, acknowledging the limits intelligently of its ongoing revolution, but not dismissing its potential influence from ignorant or ill-informed perspectives on all the available data, which now includes quantum physics.

Today, all must recognize that quantum physics has introduced tremendous puzzles, challenges, and new possibilities for the philosopher and scientist alike. Quantum physics impacts upon many divergent disciplines and issues, including work relating to the relation of mind and matter, physical time, psychological time, determinism, indeterminism, free-will, causality, and many others, such as

\footnotetext{
${ }^{228}$ Clayton, Adventures in the Spirit: God, World, Divine Action, 37. For Clayton's use of and appraisal of Heidegger, see 40-41, 245-254.

${ }^{229}$ DeWeese, God and the Nature of Time, 6-7. Note also that many philosophers who are not physicists or who have but dabbled little in physics acknowledge and discuss the relevance of quantum phenomena. See, for example, Inwagen, Metaphysics, 119-132, 160, 210.
} 
economics ${ }^{230}$ and the social sciences, ${ }^{231}$ disciplines within the third culture referred to by Snow. The longstanding dualisms located in Plato, Descartes, and Kant must be reevaluated in light of quantum phenomena, and tentatively either rejected or reaffirmed in philosophically significant ways. One such affirmation is attempted through the work of respected physicist Bernard d'Espagnat, who tries to philosophically rebuild, in support of the Copenhagen view, a neo-Kantian/Platonic "soft" dualism through his proposal that reality is divided between the mathematical-scientific-empirical world and the "veiled" independent and inaccessible reality. That is, standard science rules successfully in the empirical world up to an arbitrary limit, which is the quantum domain. Beyond this is a veiled reality, d'Espagnat claims, that lies beyond the confines of standard contemporary science, ${ }^{232}$ and which is somehow "timeless," where some sort of ultimate "Being" is located, and furthermore, where love is somehow hidden. ${ }^{233}$

\footnotetext{
${ }^{230}$ Startling as it may be, some of the mysterious aspects of quantum physics are being invoked in economic works, such as Laurence J. Brahm, Fusion Economics: How Pragmatism is Changing the World (New York, NY: Springer, 2014); and Laurie Z. Hyland, Toward a New Money Reality and a Quantum Economy: A Visionary Look at How Money and the Economy Can Become Connecting Forces for a New World (Indianapolis, IN: Xlibris, 2013). For a more general 'social' speculative application of quantum physics, see Kunal K. Das, The Quantum Guide to Life: How the Laws of Physics Explain Our Lives from Laziness to Love (New York, NY: Skyhorse Publishing, 2013).

${ }^{231}$ Emmanuel Haven and Andrei Khrennikov, Quantum Social Science (Cambridge, UK: Cambridge University Press, 2013); and George Gilder, Microcosm: The Quantum Revolution in Economics and Technology (New York, NY: Touchstone, 1990). Gilder explains, a "key reason that quantum theory is so difficult to understand, so apparently riddled with paradox, is this continued use of the vocabulary of materialism to discuss phenomena that in the usual sense lack all material qualities, such as solidity, location, continuity, and inertia.... Separating the old and new sciences is a nearly unbridgeable gulf" of linguistic and conceptual ambiguity, ibid., 20.

232 The fullest exposition of his views are in Bernard d'Espagnat, On Physics and Philosophy (Princeton, NJ: Princeton University Press, 2006), esp. 376-381. His critical conclusion is that "what science deals with is, to repeat, empirical reality, to which the notion of a 'veil' does not apply," ibid., 378. See also, Bernard d'Espagnat, Veiled Reality: An Analysis of Present-day Quantum Mechanical Concepts (Boulder, CO: Westview Press, 2003); Bernard d'Espagnat, In Search of Reality (New York, NY: Springer, 1983); Juleon M. Schins, "Quantum Theory: A Pointer to an Independent Reality-A Discussion of Bernard d'Espagnat's 'Veiled Reality,'” in Mathematical Undecidability, Quantum Nonlocality and the Question of the Existence of God, eds. Alfred Driessen and Antoine Suarez (Dordrecht, The Netherlands: Springer, 1997), 179; and Joseph E. Brenner, Logic in Reality (Dordrecht, The Netherlands: Springer, 2008), 6-7.

${ }^{233}$ D’Espagnat, On Physics and Philosophy, 463 n. 31. D’Espagnat suggests that “Being is somehow prior to the mind-matter splitting" and that our minds "may vaguely 'recall' something of Being," ibid., 463. He continues that it is possible that the "human mind keeps some sort of a remembrance (a timeless one of course; language, here, is deficient) of this Being prior to splitting," ibid., 463 n. 31. D’Espagnat defines Being by suggesting that it cannot be reduced "to material components," and thus it is "impossible to believe consciousness to be just a product of matter, that is, of empirical reality." Importantly, he also suggests that "Being" is where "the archetypes of some of our feelings, great longing, love, etc.," are located, that is, they are "hidden there," ibid., 463.
} 
That is not to say the above appraisal is wholly universal. Einstein's incredulous remark about the moon represents the dogma of many stubborn resistors, perhaps most notably represented today by standout individuals like Roger Penrose ${ }^{234}$ and John Searle, who has, in his own words, "repeated to the point of tedium" ${ }^{235}$ that a standard scientific explanation must exist for the current problems. Furthermore, while both Penrose and Searle have more recently acknowledged some openness to the role of probabilistic laws or deterministic randomness, for both of them, the universe essentially remains, although exceedingly complex, ultimately nothing but a machine, with all events "determined" ${ }^{236}$ by their prior events in a tremendous non-calculable ${ }^{237}$ yet still space-time machinelike web. For them this would certainly include the quantum realm, whatever it may ultimately prove to be. Nevertheless, some prominent resistors to the bizarre phenomena found in quantum physics are quite honest and transparent about the situation, like Richard Dawkins echoing his colleague

\footnotetext{
${ }^{234}$ Roger Penrose, The Road to Reality: A Complete Guide to the Laws of the Universe (New York, NY: Random House, 2011); and Roger Penrose, The Emperor's New Mind: Concerning Computers, Minds, and the Laws of Physics (Oxford, UK: Oxford University Press, 1999). See also the explanation and critique of his work in Margaret A. Boden, Mind as Machine: A History of Cognitive Science Volume 1 \& 2 (Oxford, UK: Clarendon Press, 2006), 1232-1234.

${ }^{235}$ Searle, Freedom \& Neurobiology: Reflections on Free Will, Language, and Political Power, 76. See also, Boden, Mind as Machine: A History of Cognitive Science Volume 1 \& 2, 1234.

${ }^{236}$ Boden, Mind as Machine: A History of Cognitive Science Volume 1 \& 2,1235 . Yet, as Boden observes, Searle still insisted that "the problem of consciousness is a scientific problem, and encouraged the scientists to get on with it," ibid. The status of consciousness as a scientific problem cements into place the "hard problem" of consciousness, as observed by David J. Chalmers, "The Hard Problem: Facing Up to the Problem of Consciousness," in Explaining Consciousness: The 'Hard Problem,' ed. Jonathan Shear (Cambridge, MA: The MIT Press, 1997), 9-32.

${ }^{237}$ Penrose, The Emperor's New Mind: Concerning Computers, Minds, and the Laws of Physics, 220. "The vexed question of 'free will' hovers at the background, throughout this book-though for most of what I shall have to say, it will remain only in the background. It will have one specific, but minor, role to play later in this chapter (in relation to the issue of faster-than-light signalling in relativity). The question of free will is addressed directly in Chapter 10, and there the reader will doubtless be disappointed by what I have to contribute. I do indeed believe that there is a real issue here, rather than an imagined one, but it is profound and hard to formulate adequately. The issue of determinism is physical theory is important, but I believe that it is only part of the story. The world might, for example, be deterministic but non-computable. Thus, the future might be determined by the present in a way that is in principle non-calculable. In Chapter 20, I shall try to present arguments to show that the action of our conscious minds is indeed non-algorithmic (i.e. noncomputable). Accordingly, the free will that we believe ourselves to be capable of would have to be intimately tied in with some non-computable ingredient in the laws that govern the world in which we actually live. It is an interesting question-whether or not one accepts this viewpoint with regard to free will-whether a given physical theory (such as Newton's) is indeed computable, not just whether it is deterministic. Computability is a different question from determinism-and the fact that it is a different question is something that I am trying to emphasize in this book," ibid., 220.
} 
Steve Pinker in the field of neuroscience, who admitted that regarding where certain aspects of consciousness and language come from, it "beats the heck out of me." ${ }^{238}$ Clearly, he is not alone.

Perhaps the situation surrounding quantum physics can best be summed up by the insightful observations by Harald Atmanspacher and Frederick Kronz, who explain that the whole quantum crisis, and the reason it has become a crisis, is precisely because ontic and epistemic issues have been confused and addressed together but as if separately, or separately but as if together, rather than truly separately or simultaneously. ${ }^{239}$ Contrary to millennia of strict separation, it appears possible that ontic and epistemic concerns (the existences of matter and mind in themselves) must be unified and addressed simultaneously (unifying ontology and epistemology) in ways they have not been before, possibly along with all other traditional questions in physics and metaphysics. If addressed separately, it's possible that our best explanations and descriptions of either of them will be misinformed and inadequate. How, or if, such a unification can be done, and the consequences of doing so, are the focus of Bohm's and Pylkkö's work along with other post-phenomenologists, ${ }^{240}$ many

\footnotetext{
${ }^{238}$ As cited in Antony Flew and Roy Abraham Varghese, There is a God: How the World's Most Notorious Atheist Changed His Mind (New York, NY: HarperCollins, 2007), 176. See also, Philip Higgs and Jane Smith, Rethinking Our World (Cape Town, South Africa: Juta \& Co., 2007), 110. See also, Richard Dawkins and Steven Pinker, "Is Science Killing the Soul?," in The Guardian-Dillons Debate, Edge 53 (April 8, 1999).

${ }^{239}$ Harald Atmanspacher and Frederick Kronz, "Many Realisms" in Acta Polytechnica Scandinavica Ma91, (1998), 31-43. They share that "if ontic and epistemic elements must be considered at the same level of description," then what is interpreted "epistemically at one level may be interpreted ontically at another," in relation to standard versus quantum descriptions. Thus, "it may be speculated that at some very basic level of onticity the distinction of mental and material domains of reality becomes irrelevant. The question remains to be clarified whether this level is already addressed by contemporary quantum theory," ibid., 31. See also, ibid., 33.

${ }^{240}$ Although, it must be noted Bohm and Pylkkö are more radical than most post-phenomenologists. They, to some respects, deconstruct post-phenomenology. Originally stemming from the work of Edmund Husserl, the founder of phenomenology and teacher of Heidegger, post-phenomenology refers to both a philosophical movement as well as the efforts of several individuals to unite philosophy and science, specifically quantum physics with cognitive neuroscience. The inspiration of post-phenomenology is frequently traced to both the early though especially later writings of Heidegger, Maurice Merleau-Ponty, Jan Patocka, and Georges Bataille. The first to use and own the label would be Don Ihde, Postphenomenology: Essays in the Postmodern Context (Evanston, IL: Northwestern University Press, 1995), and his followers, philosophers of science and technology who work primarily on addressing the meaning and role of technology in society. See also, PeterPaul Verbeek, "Artifacts and Attachment: A Post-Script Philosophy of Mediation," in Hans Harbers, ed. Inside the Politics of Technology: Agency and Normativity in the Co-Production of Technology and Society (Amsterdam, The Netherlands: Amsterdam University Press, 2005), 125-146; 137, 140-141; and Peter-Paul Verbeek, What Things Do: Philosophical Reflections on Technology, Agency, and Design (State College, PA: Pennsylvania State University Press, 2005), particularly "Postphenomenology," 99-120, especially the definitions given on 113. For more on phenomenology in general, see Anna-Teresa Tymieniecka, ed. Phenomenology World-Wide: Foundations, Expanding Dynamics, Life-Engagements: A Guide for Research and Study (Dordrecht, The Netherlands: Kluwer Academic Publishers, 2002).
} 
of whom utilize quantum physical phenomena within their explanatory efforts, and who hope to create a more unified understanding of reality as a whole. ${ }^{241}$

This task of the unification of historically disparate disciplines, such as postmodern philosophy and physics (the "two cultures") is undoubtedly a difficult one to achieve, if it is possible at all (if not formally or definitionally, then particularly conceptually), ${ }^{242}$ however, given the longstanding prejudices on both sides, between scientists and philosophers, that have been mentioned above. Indeed, to comment on a typical philosopher's understanding of the differences between philosophy and science, one could look to none other than Heidegger himself, who wrote, "the task of philosophy differs from that of science, for, unlike science, philosophy examines not our conclusions but the basic conceptual models we employ-the kind of concepts and ordering patterns we use." Heidegger continues, "philosophy concerns not the explanation of this or that but questions such as 'what, really, is an explanation?"'243

\footnotetext{
${ }^{241}$ Concerning the interest in connecting quantum physics to the sciences of the mind and cognitive science, although often operating outside the mainstream, there has nevertheless been a consistent interest in quantum cognitive neuroscience that is acknowledged by mainline academic circles, despite the especial focus on it by postphenomenologists. Starting with Wolfgang Pauli and Carl Jung in the 1940's, Eugene Wigner in the 1960 's, with Henry Stapp, Roger Penrose and several others ushering in the idea again in force in the 1990's, quantum neuroscience has a lively if limited history. For a sample of key recent works integrating quantum physics into cognitive studies and neuropsychology, see the Bohmian scholar Pylkkänen, Mind, Matter and the Implicate Order; Max Velmans, Understanding Consciousness (New York, NY: Routledge, 2009); Henry P. Stapp, Mindful Universe: Quantum Mechanics and the Participating Observer (Berlin, Germany: Springer, 2007); Susan Blackmore, Conversations on Consciousness: What the Best Minds Think About the Brain, Free Will, and What It Means to Be Human (Oxford, UK: Oxford University Press, 2006); J. A. Tuszynski, ed. The Emerging Physics of Consciousness (Berlin, Germany: Springer-Verlag, 2006); Dean Radin, Minds: Extrasensory Experiences in a Quantum Reality (New York, NY: Pocket Books with Simon \& Schuster, 2006); Suzanne Gieser, The Innermost Kernel: Depth Psychology and Quantum Physics: Wolfgang Pauli's Dialogue with C. G. Jung (Berlin, Germany: Springer, 2005); Kunio Yasue, Mari Jibu, Tarcisio Della Senta, ed. No Matter, Never Mind (Amsterdam, The Netherlands: John Benjamins, 2002); Giuseppe Vitiello, My Double Unveiled (Amsterdam, The Netherlands: John Benjamins, 2001); Philip Van Loocke, ed. The Physical Nature of Consciousness (Amsterdam, The Netherlands: John Benjamins, 2000); Roger Penrose, Shadows of the Mind: A Search for the Missing Science of Consciousness (Oxford, UK: Oxford University Press, 1994); and Arthur Koestler, The Ghost in the Machine (London, UK: Arkana, 1989).

${ }^{242}$ Yair Neuman acknowledges that "multidisciplinarity might have a bad reputation due to the work of some charlatans who flutter between disciplines while providing no interesting ideas, hypotheses, or insights," but the increasing amount of knowledge available to us makes this necessary, as there are "complex" problems "in which different systems interact. In many cases we encounter problems that result from the interactions between these systems and when this happens our expertise [of a single reductionistic domain] might be an obstacle rather than advantage," Yair Neuman, Reviving the Living: Meaning Making in Living Systems (Amsterdam, The Netherlands: Elsevier, 2008), xvii, xviii (addition mine).

${ }^{243}$ Heidegger, What is a Thing?, 248. Heidegger would concur with Ohad Nachtomy and Justin Smith as they opine: "When philosophers and historians think of the conceptual innovations in early modern science that played an important role in the shaping of the modern world, it is generally mechanical physics that first comes to mind: the newly mathematized study of the motion of projectiles, planets, and billiard balls. The reason for
} 
Whether Heidegger may be correct or not about his understanding of "things" and the meaning of a valid explanation, what he and many other contemporary philosophers and scientists failed and continue to fail in properly recognizing or realizing is that what an explanation is was precisely what some physicists were asking about as they formulated their wild "conclusions" concerning the quantum phenomena. Physicists like Bohm, and philosophers like Pylkkö, now see things similarly to Heidegger, ${ }^{244}$ yet not exclusively from any 'careful thinking,' but from experimental empirical evidence alone, evidence that contradicts centuries of previous science. As Werner Heisenberg, one of the principle discoverers of quantum phenomena wrote, "when we get beyond this range of the classical theory, we must realize that our words [and the concepts they refer to] don't fit. They don't really get a hold in the physical reality." ${ }^{245}$ In the world of classical physics and mathematics, this

this focus is that there were real, incontestable advances in the understanding of how the physical world works, and this improved understanding had plainly tangible effects on the history of technology and applied science. However, it is a rather narrow understanding of history that concerns itself only with those domains of human endeavor that are enjoying a phase of rapid progress. For indeed, very often it is precisely the domains of inquiry that are lagging behind that also present the most difficult and interesting conceptual problems, and that weigh most heavily on the minds of the thinkers and experimenters who are simultaneously enjoying the fruits of their progress elsewhere. If in early modern Europe planetary motion was coming to be seen as more tractable than animal motion, this does not at all mean that planets were held to be in more urgent need of explanation than animals. Quite the contrary, one might say that what happened was this: The planets, as it turned out, lent themselves more easily to explanation. They were, one might provocatively suggest, the easier part of the scientific revolution. The harder part, the part that would not emerge as a full-fledged, independent domain of science until the $19^{\text {th }}$ century, concerned that great part of nature that appears resistant to explanation in the same terms as planets and billiard balls: the part of nature that does things that billiard balls do not do; the part that replicates itself, producing nearly identical copies of itself in many different ways; the part that has the capacity for self-motion; the part that eats and breathes.... Now there was, in the early modern period, a great diversity of views as to what exactly the relationship was between this latter domain of nature and the one described by mechanical physics. Arguably the most significant attempt to deal with the gap between these domains (living versus nonliving) was to assimilate the one into the other, that is, to understand the living world in mechanical terms. Many philosophers (a label that includes what are today called 'scientists'), such as René Descartes, supposed that the success of their own programs of mechanical physics depended upon their ability to explain the generation, structure, and motion of living beings, as Descartes put it, 'in the same manner as the rest,' which is to say Descartes hoped to make living nature comprehensible by appealing to the same principles and laws that were lately helping to make so much sense of the rest of nature. Others, such as the 'vitalist' philosopher Henry More, supposed that the motion and generation of living beings could not possibly be explained 'in the same manner as the rest,'” Ohad Nachtomy and Justin E. H. Smith, "Introduction," in The Life Sciences in Early Modern Philosophy, eds. Ohad Nachtomy and Justin E. H. Smith (Oxford, UK: Oxford University Press, 2014), 1-2.

${ }^{244}$ Paavo Pylkkänen, “The Quantum Epoché," in Progress in Biophysics and Molecular Biology Vol. 119, Issue 3 (December 2015), 332-340. "The empirical phenomena encountered in quantum and relativity physics have given rise to a new philosophical situation that poses a challenge to not only 'philosophy' in a Heideggerian sense, but also to phenomenology broadly understood," ibid., 335.

${ }^{245}$ Sandro Petruccioli, Atoms, Metaphors and Paradoxes: Niels Bohr and the Construction of a New Physics (Cambridge, UK: Cambridge University Press, 1993), 153 (emphasis and addition mine). See also, Abraham Pais, "The Image of Physics," in The Changing Image of the Sciences, eds. Ida H. Stamhuis, Teun Koetsier, Cornelis de Pater and Albert van Helden (Dordrecht, The Netherlands: Kluwer Academic Publishers, 
testimony is a shock, as there was only one way to describe the relationships between objects in physics for centuries, and our basic scientific words worked just fine to describe everything they saw. Though it shouldn't need to be mentioned, science works! It just "works." As you are reading this thesis, the laws of science are likely functioning properly and deterministically, just like Einstein thought they did. The letters I typed have preserved their identities from the depressed keyboard to the outputted PDF file, and not randomly reorganized themselves (I hope!).

The inability to express the results or conclusions of a scientific study in words (which includes numbers in the ordinary sense; that is, mathematical language) or images baffled Heisenberg. He was left stammering upon seeing quantum phenomena at work. No words fit. ${ }^{246}$ He attempted to use mathematical symbols to approximate what he saw happening, and which, in their own way worked quite well given a particular focus on the ontic or epistemic aim of a given experiment, but even more than falling short of the reality he appeared to be observing, his words appeared to contradict the phenomena when considered altogether. Were the "objects" his instruments observed particles or waves? To answer a "wavicle," "lave," or "eventity"247 is a semantic, patchwork, band-aid answer-an incomplete description and not an explanation, at least in the minds of most, and certainly not for those not well acquainted with just how those labels were chosen. The mystery of the physical world had reached a new layer or level of complexity, one that engaged the conceptual realm, a realm where

2002), 85-104; 99; David Lindley, Uncertainty: Einstein, Heisenberg, Bohr, and the Struggle for the Soul of Science (New York, NY: Random House, 2007), 150. For Heisenberg's quote and its implications to the philosophy of time and language, see Suzanne Guerlac, Thinking in Time: An Introduction to Henri Bergson (Ithaca, NY: Cornell University Press, 2006), 41; Henry J. Folse, The Philosophy of Niels Bohr: The Framework of Complementarity (North-Holland: The Netherlands, 1985), 95; Françios Lurçat, "Understanding Quantum Mechanics with Bohr and Husserl," 243; Manjit Kumar, Quantum: Einstein, Bohr, and the Great Debate about the Nature of Reality, 244; Robert M. Pirsig, "Subjects, Objects, Data and Values," in Quantum Structures and the Nature of Reality: The Indigo Book of Einstein Meets Magritte: An Interdisciplinary Reflection, eds. Diederik Aerts and Jaroslaw Pykacz (Dordrecht, the Netherlands: Kluwer Academic Publishers, 1999), 79-98; 83. Pirsig provides an excellent synopsis of the issues confronting the dawn of quantum physics.

${ }^{246}$ At one of the early points in the development of quantum theory, Heisenberg, when writing of his fellow physicist Erwin Schrödinger's mathematical formula which for complex reasons undermined his own theory, wrote, "the more I think about the physical portion of the Schrödinger theory, the more repulsive I find it .... What Schrödinger writes about the visualizability of his theory 'is [paraphrasing Bohr] probably not quite right,' in other words, it's crap," as cited in Baggott, The Quantum Story: A History in 40 Moments, 67.

247 The pragmatic names given to the mysterious wave aspect of a particle. For more on this, see B. R. Frieden, Probability, Statistical Optics, and Data Testing: A Problem Solving Approach (New York, NY: Springer, 2001), 450; and Palmer, The Fragmentation of Being and the Path Beyond the Void: Speculations in an Emergent Onto-Mythology, 134. 
words (or at least the scientific words Heisenberg had available), which had previously expressed all of nature with conceptual adequacy, no longer fit. He was forced to enter the domain of concepts rather than explanatory descriptions, or else his research wouldn't make sense according to the rules of scientific discourse. In many ways he needed a new language, not merely new words. ${ }^{248}$ Contrary to Heidegger's claim that the positive sciences only sought raw data and conclusions while philosophy alone was privileged with uncovering explanations, concepts, and patterns, in quantum physics the possibility of adjusting that situation is raised-physicists are now forced to think 'philosophically,' meaning the subject matter of physics is now philosophical in Heidegger's sense of forcing us to reconsider our fundamental concepts. And this conceptuality problem challenges our best ideas, in fresh ways for the first time in eons, in philosophy and science as traditionally understood, including what we believe about consciousness, time, causality, language, freedom, and ultimately, "the nature of reality."249

Given the above, however, one may ask, why has this situation not had a much greater impact upon society at large? Well, in some ways, one could say it has, especially in regards to the rise of pluralism and certain aspects of post-modernism. "Quantum thinking is new paradigm thinking," and "this new science focuses" us to see the broader shifts "in general culture" as "a move away from absolute truth and absolute perspective toward contextualism; a move away from certainty, toward an appreciation for pluralism and diversity, toward an acceptance of ambiguity and paradox, of complexity rather than simplicity." It points the way forward toward "new concepts, new language, and new images that new paradigm thinking requires." ${ }^{250}$ Such a collection of new concepts and words constitutes, in many ways, a new or third culture. This is reflected in the opinions of others,

\footnotetext{
${ }^{248}$ Pylkkö, The Aconceptual Mind, xx-xxi; and David Bohm, Wholeness and the Implicate Order (London, UK: Routledge, 1980), 34-60. "Quantum theory is weird not only because of its concepts, such as those related to the abandonment of determinism and local realism, but also for its place in the history of physics. It is so strange that 80 years after its creation, its recasting process-where the notions of a theory are clarified and its terms improved-remains unfinished. Although its mathematical machine is well established and its predictive power successful, the conceptual foundations of QT are still in debate," M. Greca and Olival Freire, "Meeting the Challenge: Quantum Physics in Introductory Physics Courses," in International Handbook of Research in History, Philosophy and Science Teaching, ed. Michael R. Matthews (New York, NY: Springer, 2014), 192.

${ }^{249}$ Audretsch, Entangled World: The Fascination of Quantum Information and Computation, xii.

${ }^{250}$ Nigel Thrift, Knowing Capitalism (London, UK: SAGE Publications, 2005), 63.
} 
such as Frank Wilczek, who have asserted that "the relatively small band of illuminati who have been initiated into the quantum culture view the world in a new and richer way." Unfortunately, "because of [the conceptual] difficulties, the quantum revolution has not yet had the deep impact on literary and, ultimately, common culture that its power and novelty merit." Nevertheless, "many more thinking people may like to be initiated into this third culture, to experience a real vision of its perspective. Certainly any aspiring philosopher (lover of insight) or theologian (interpreter of ultimate reality), or anyone who wants to imagine the technology and economy of the not-so-distant future, must become so initiated."251

On the other hand, however, the overall situation of the natural sciences illustrates the inertia of old paradigms and methods in many parts of the intelligencia and academy. While "the limits of Newtonian physics have been realized since the advent of relativity theory and quantum mechanics," “the Newtonian paradigm is still used to make accurate predictions and 'works'-we can get rockets to the moon by using it."252 In other words, the classical paradigm still functions adequately for most 'practical purposes,' or so it seems, and so it is still heavily relied upon even in cases where it may not be accurate or ideal. Thus, the situation today is that both sides acknowledge the need for a third culture that integrates the cultures of the sciences and humanities, but the fight over who exactly will guide this third culture remains open. ${ }^{253}$ In many cases it seems scientists, with their greater access to wealth and power, are forcing their way into the lead position to control this third culture-the risk inherent in this is that the true concerns of the humanities may not be met by such scientists. ${ }^{254}$

\footnotetext{
${ }^{251}$ Frank Wilczek, "The Third Culture: Is Quantum Physics, like Science and Literature, in a World of Its Own?," in Nature 424 (August 2003), 997-998 (addition mine).

${ }^{252}$ Rohnn B. Sanderson and Marc A. Pugliese, Beyond Nä̈veté: Ethics, Economics, and Values (Lanham, MD: University Press of America, 2012), 280 n. 3.

${ }^{253}$ A tension described by Victoria Vesna, "Towards a Third Culture or Working in Between," at http://vv.arts.ucla.edu/publications/publications/00-01/ThirdCulture/ThirdCulture.htm (accessed February 15, 2018); and Elizabeth Leane, Reading Popular Physics: Disciplinary Skirmishes and Textual Strategies (New York, NY: Routledge, 2016), 163-165.

${ }^{254}$ This is certainly the logical goal of many scientists-see, for example, Zev Naveh, Transdisciplinary Challenges in Landscape Ecology and Restoration Ecology-An Anthology (Dordrecht, The Netherlands: Springer, 2007), 394; and Bernhard Poerksen, The Certainty of Uncertainty: Dialogues Introducing Constructivism (Exeter, UK: Imprint Academic, 2004), 131. For some concerns about a third culture guided by scientists, see Herbrechter, Posthumanism: A Critical Analysis, 17-19.
} 
Accordingly, so long as science and mathematical logic represent the firmest basis upon which conclusivity may be grounded and hoped for even in a 'post-modern' world, it still exerts a great influence, even amongst the many competing interest groups in society. However, this is not to deny the influences of the 'new paradigm' which exist and also exert influence precisely because the classical paradigm hasn't and isn't solving critical problems, especially those relating to freedom and time, which lie at the heart of the third cultures. All together, then, competing paradigms appear to be operative in various parts of society, which is likely the real cause of our confusing post-postmodern condition today, and integrally related to the fragmegration of global society ${ }^{255}$ which is producing the conflicting and contradictory trends plaguing any global harmony or unity. The innate or intrinsic conformitarian tendencies of the classical paradigm can't harmonize the conceptual conflicts the new paradigm has generated in response to it, leaving disunity widely present and operative in society.

Yet, it is precisely the point shared just above that matters here. Quantum physics does, intuitively and forcefully, challenge long held traditional understandings about freedom and time, and thus it cannot be ignored forever as we wrestle with our deepest philosophical questions. This is not to say current understandings of the quantum world requires any specific understanding of freedom or time-it merely forcefully challenges us all to think about them more deeply-a condition that may itself be the telltale sign of post-postmodernism. A condition that itself forces thoughtful reflection. It is now more obvious than ever that a genuine third culture is needed, but making overtures toward the utility of the quantum world to tell us this doesn't tell us exactly what it will or should be like.

Without such a true third culture, our insolvent fragmegration will remain a problem for the world into the foreseeable future. Indeed, illustrative of just how deeply the conflict of the two cultures impact our interpretation of empirical data, quantum physics has been interpreted to support Heideggerian temporality and Einsteinian timelessness, essentially because one's prior definitional presuppositions come into play as one describes what they're seeing! Illustrating this clearly, Foutini Markopoulou asserts that "there are two kinds of people in quantum gravity. Those

\footnotetext{
${ }^{255}$ Rosenau, Distant Proximities: Dynamics Beyond Globalization, 12. See also, Louis E. Wolcher, The Ethics of Justice Without Illusions (New York, NY: Routledge, 2016), 78-79.
} 
who think that timelessness is the most beautiful and deepest insight in general relativity, if not modern science, and those who simply cannot comprehend what timelessness can mean and see evidence for time in everything in nature. What sets this split of opinions apart from any other disagreement in science is that almost no one ever changes their mind, there is practically no crossing camps on the issue of time." Such a situation, however, leads Markopoulou to muse that "on some days, this makes me wonder if the split is truly on scientific grounds or something deeper."256 In any case, philosophers and physicists continue to grapple with the challenges it raises as we move into the $21^{\text {st }}$ century. Recent times have seen a significant escalation of interest in these issues within the current post-postmodern milieu of multi/trans/interdisciplinary research, ${ }^{257}$ which

\footnotetext{
${ }^{256}$ Fotini Markopoulou, “Space Does Not Exist, So Time Can,” at http://fqxi.org/data/essay-contestfiles/Markopoulou_SpaceDNE.pdf?phpMyAdmin=0c371ccdae9b5ff3071bae814fb4f9e9 (accessed July 16, 2017), 1. Markopoulou continues, "I will argue that time exists and that the problem of time in quantum gravity should be seen as a paradox. Paradoxes are usually resolved when we realize that a certain unstated assumption is lurking in the background which, under closer inspection we see is false," which in the case of Markopoulou, the false assumption is that space exists, ibid. See also, George Musser, Spooky Action at a Distance: The Phenomenon That Reimagines Space and Time-and What It Means for Black Holes, the Big Bang, and Theories of Everything (New York, NY: Scientific American, 2015), esp. 167-202.

257 Steven Best and Douglas Kellner explain the multi-, trans-, and interdisciplinary complexity as follows: "Postmodern philosophical positions follow from relativity theory, quantum mechanics, and the undecidability principles of mathematics, suggesting connections between major conceptual shifts in the fields of philosophy and science [and theology]." As such, it could be proposed that "the postmodern paradigm shift suggests that the gulf between the 'two cultures' of science and the humanities is in some ways being bridged. The shared emphasis that truth is conditioned by language and culture in general and the incorporation of temporality and historical methods into science, as well as into literature and philosophy, dissolve rigid methodological boundaries among various fields while still allowing science to be characterized as a unique enterprise with its own distinctive methods and results. The transdisciplinary turn does not imply that scientists know their Plato or Shakespeare better today, any more than it implies that people rooted in the humanities know their quantum physics or chaos theory; rather it implies that a conscious use of postmodern concepts and methods may provide some common ground of discussion and that science, technology, and culture are becoming increasingly imbricated with one another. Of course, as the recent science wars show, postmodern concepts and critiques are passionately debated and contested and often dogmatically renounced, and a future 'postmodern consensus,' or a shared postmodern paradigm, is unlikely. At least for now, conflict between modern and postmodern paradigms, and over the postmodern itself, is intensifying, and the extent and passion of this conflict suggests that the postmodern debates will be with us for some time," Steven Best and Douglas Kellner, The Postmodern Turn (New York, NY: Guilford Press, 1997), 261 (addition mine). As evidence of the continuing conflict, some maintain that classical "Western science will likely outlive postmodernism. It may already have," Howard V. Hendrix, "Fighting Out of Context: Culture Wars Within and Without Science Fiction, from Snow to Sokal," in Science Fiction and the Two Cultures: Essays on Bridging the Gap Between the Sciences and the Humanities, ed. Gary Westfahl and George Edgar Slusser (Jefferson, NC: McFarland \& Company, 2009), 46. Evidence of this 'outliving' may be seen in the overall decline of significance of the humanities owing to the rise of the post-postmodernisms, particularly digimodernism. Yet for the practical situation, see, for example, Stacey Patton, "MLA President Offers a Sobering Critique of Graduate Education in the Humanities," at http://www.chronicle.com/article/A-Stark-Appraisal-of-Graduate/136171/ (accessed December 6, 2012). As Patton cites Michael F. Bérubé, one from the humanities: "When we look at the academic-job market for humanists, we can't avoid the conclusion that the value of the work we do ... simply isn't valued by very many people, on campus or off," ibid. Indeed, concerning the overall situation of the prospects of contemporary
} 
includes the efforts of Bohm and Pylkkö. It is within this rising multi-disciplinary societal milieu that the pressures of the conflict between the two cultures now press the hardest, and the need of a true mediatorial third culture appears greatest. In the following chapter, I will explore the role that freedom and time are serving within the third culture at present, to demonstrate the current nature and reach of the two cultures' crisis, which has cast religion and theology into an unsettled and uncertain place in society when and where it remains explicitly present, as pointed out by religious cultural philosophers such as the Catholic Charles Taylor. ${ }^{258}$

graduate education in the humanities, as Bérubé observes, "it is like a seamless garment of crisis, in which, if you pull on any one thread, the entire thing unravels. It is therefore exceptionally difficult to address any one aspect of graduate education in [the humanities in] isolation," ibid. Of course, given that religion and theology are generally regarded as a part of the humanities, one can see how and why religion's role in society is unsettled and uncertain and prone to extreme movements-if anything goes wrong and that "thread" is pulled, religion could morph in any direction, including being scientized.

${ }^{258}$ The product of this uncertainty encourages the critique of Charles Taylor, A Secular Age (Cambridge, MA: The Belknap Press of Harvard University Press, 2007). Taylor argues that the secular world lives in an immanent frame, one which focuses on the here and now (the older and still colloquial concept of the temporal, but for Heidegger another subservient timeless order). In contrast, the transcendent (traditionally conceived of as timeless, but for Heidegger, temporal) world of divine and religious realities is where we ought to have our focus. Freedom factors into his discussion in that, the immanent world sees only freedoms that can be attained in the here and now, while those conscious of the transcendent purpose of religion focus on the freedoms that eternal life will yield. See especially, ibid., 721-722. As Patrice Haynes explains, "a defining characteristic of western modernity is the eclipse of transcendence-or what, after Nietzsche, is called the 'death of God.' Modern society is an 'immanent order,' Taylor observes, one capable of understanding itself entirely in terms of natural laws, thus without reference to a transcendent principle, namely God. Furthermore, not only is transcendence considered to be metaphysically untenable, given the idea of self-sustaining nature, it is also viewed as problematic on ethical and political grounds. In the words of one commentator, 'Immanence means relevance.' Whereas, it may be said, longings for the heavens of transcendence results in political quietism, the turn to immanence focuses attention on this world, motivating social transformation in order to maximize human flourishing. Indeed, such optimistic expectations would inspire much Marxist thinking up until the collapse of communism in the 1980's," Patrice Haynes, Immanent Transcendence: Reconfiguring Materialism in Continental Philosophy (New York, NY: Bloomsbury Academic, 2012), 2. For a critique of the context of Taylor's contributions, see Kristien Justaert, Theology After Deleuze (New York, NY: Continuum, 2012), 33. 


\section{CHAPTER 2}

\section{THE CONTEXT OF FREEDOM AND TIME WITHIN THE “TWO CULTURES” MILIEU: THE THIRD CULTURE AND THE PLACE OF RELIGION}

The purpose of this chapter is to introduce the breadth of the impact of the divide between the two cultures concerning the problems of freedom, time, religion, and their interrelationship. Prior to outlining their basic conflict, however, this study will also demonstrate how the widespread "science and religion" and "the humanities and religion" debates are also intrinsically affected by both the two cultures' conflict and any mediatorial third culture disciplines. This will help position the place of theology and religion in relationship to the third culture. Having done the above, the study will proceed to provide a brief overview of select disciplines or sub-cultures that constitute the third culture, including representative scholars who work primarily from either scientific or humanistic orientations. Following Snow's own suggestion which has been affirmed by numerous others, these disciplines or sub-cultures are often collectively referred to as the third culture, or the humane sciences, and specifically include psychology and psychiatry, economics, and the socio-political sciences, amongst other closely related fields. An illustrative review of how the foundational philosophical issues of freedom and time impact upon these third culture disciplines will both demonstrate the underlying philosophical interconnectedness of the disciplines as well as prepare the way for explaining why both Bohm and Pylkkö strive for an all-encompassing philosophical perspective that unites the disciplines and surpasses the foundational two cultures' divide which has become so prominent today, dividing contemporary society in many ways.

Thus, what will be established below is whether or not the currently existing third culture is adequately addressing the concepts of freedom and time, and whether religion is performing any useful role in providing a better understanding of them. If it is not, the reasons for this may prove 
illuminative, and demonstrate why Bohm and Pylkkö are seeking a deeper conceptual renewal of freedom and time to move beyond the current impasse. Therefore, after the review of the currently existing third culture below, in the following chapters exploring Bohm and Pylkkö, the study will review the recent historical development of the concepts of freedom and time, noting in particular the roles that Albert Einstein and Martin Heidegger have assumed in defining the concepts of freedom and time, and the relationship that Bohm's and Pylkkö's works have toward them. This will include some comments elaborating upon some of the problems that relativity and quantum phenomena have assumed in relationship to science and philosophy, including the concepts of freedom and time.

\section{The Conflict Between the Two Cultures Concerning Freedom and Time}

A number of dyadic poles characterizing contemporary academic discourse can be subsumed within Snow's discussion of the two cultures of the sciences and the humanities. The psychologist Louis Berger helpfully lists many of them. For example, such frequently opposing pairs include: subjective vs. objective, deterministic vs. contingent, rational-calculative vs. irrational-mystical, science vs. culture, nature vs. nurture, technological progress vs. cultural heritage, atomistic vs. holistic, mathematics vs. language, and timeless vs. temporal, etc. ${ }^{259}$ Another couple of useful dyads, drawn from the introduction, might be modern vs. postmodern, and analytic vs. continental. ${ }^{260}$ What's noteworthy here is that in each of the preceding dyads the first term represents an emphasis of the culture of science, and the second emphasizes the culture of the humanities.

Berger and others have noted the thinkers most associated with these two labels, namely the tradition of Pythagoras, Parmenides, Plato, and Aristotle, through to Isaac Newton, Immanuel Kant,

\footnotetext{
${ }^{259}$ Louis S. Berger, Psychotherapy as Praxis: Abandoning Misapplied Science (Victoria, B.C.: Trafford Publishing, 2002), 1-2.

${ }^{260}$ Of course, many wish to avoid "being forced into the 'either/or' ... of choosing: analytic or continental, science or the humanities," Keith Robinson, "Mediating the Divide: Process Philosophy between the Two Cultures," in Applied Process Thought I: Initial Explorations in Theory and Research, eds. Mark Dibben and Thomas Kelly (Piscataway, NJ: Rutgers, 2008), 138. Nevertheless, Robinson continues, "continental philosophy as it has been generally understood in the $20^{\text {th }}$ century, in its (Heideggerian) tendency to refuse to engage the sciences as anything other than calculative thinking or as 'scientistic' maintains a simple bifurcation of the real that appeals to the 'essence', 'authenticity' or primordiality of the pretheoretical. In response to the alleged reduction of the 'life-world' to a mechanistic system the approach of continental philosophers is to recoil to a position of more or less absolute opposition, approaching the sciences merely as a source of metaphoricity that unworks its own conceptualizing impulse," ibid.
} 
and René Descartes for modernism, and Heraclitus and Protagoras through to Martin Heidegger for postmodernism. ${ }^{261}$ Gary Madison elucidates the problem the dyads above present to the halls of the academy and society: "The greatest problem we face is ... that of reconciling ... the demands of science with other, more traditional, values. This has been labeled the problem of the 'Two Cultures.' What is the relation between so-called scientific facts on the one hand and humanistic, religious, and other, nonscientific values on the other hand?" Madison believes we must "deliberately confront the problem of the Two Cultures and determine for ourselves the proper place of science within human life as a whole, within, that is, the wider realm of creative, cultural values" ${ }^{262}$ or we will find society ever more deeply mired within a swamp of competitive confusion.

The complex tension within the contemporary world referenced above holds true both within the academy (through the two cultures of the sciences and humanities) as well as society at large (through the reality of the uneasy coexistence of modernism and postmodernism). Understandings of freedom and time effectively serve to highlight the complexity. For example, the differences concerning freedom and time in the contemporary world have led for the passage of time to be loosely associated with the positive words "forward" and "upward," a progressive building up upon the foundation of the past which is "beneath" and "behind" us through the use of more efficient methods (faster computers, for example) ${ }^{263}$ Correspondingly, our freedom increases relative to the adscititious objective possibilities science and technology provides for us (e.g., in new medical technologies made available through a technologized healthcare system that works "quickly"),

\footnotetext{
${ }^{261}$ Berger, Psychotherapy as Praxis, 7, 90; and Gary Brent Madison, Understanding: A Phenomenological-Pragmatic Analysis (Westport, CT: Greenwood Press, 1982), 13.

${ }^{262}$ Madison, Understanding: A Phenomenological-Pragmatic Analysis, 10.

${ }^{263}$ We often "picture progress as indicating that the characteristics of something are proceeding forward or upward over time," Dennis Knight Heffner, Unlimited Progress: The Grand Delusion of the Modern World (Bloomington, IN: iUniverse, 2010), 16. Furthermore, "modernity projects an illusion of always moving forward and rendering the past irrelevant," Arthur Asseraf, "What's So New about News? The Interesting Thing about News Has Never Been its Truth or Falsehood but How it Explodes Our Sense of Onrushing Time," at https://aeon.co/essays/news-has-never-been-pristine-always-entangled-in-time (accessed May 23, 2017). See also, Irun R. Cohen, Tending Adam's Garden: Evolving the Cognitive Immune Self (London, UK: Academic Press, 2000), 47-49. "The primacy in Western science of the push has emerged from the idea of progress.... [T]he concept of progress assumes that things are heading to new vistas .... The idea of progress," or "that time progresses in one direction, as a fleeting arrow rather than as a cycling wheel, is a revolution in human thought that first appeared along with a monotheistic concept of history," which, when "married [to] the concept of ... Greek logic," "Western science was born of that union," ibid., 48-49.
} 
through the efficiency that speed provides, relative to the passage of time on the clock or calender. ${ }^{264}$ The ability to do "more" quickly represents an increase of freedom to do more in general, or more of what one wishes to do-freedom is, in part, the ability to do more. To illustrate this point through a common device such as a computer, an increase in speed, ever striving toward that instantaneous "timeless" speed, demonstrates greater freedom to use the computer to do more of what one wishes to do, rather than be constrained by "slowness" to experience boredom, ${ }^{265}$ which is perceived as a denial of our freedom. In other words, the contemporary world promotes the idea that progress is some sort of 'forward movement' toward 'the timeless instant' (instantaneousness) of action, or some sort of timeless objective ideals that exist 'beyond' time.

Indeed, our world today, dominated as it is by science and technology in the public sphere, celebrates more and more the growth of an instantaneous or "timeless time," ${ }^{266}$ where even "social time has" taken "the appearance of timeless time," where the "traditional arrangement of different

\footnotetext{
264 "As technologies, science and progress developed within a narrow horizon of function and comfort," Volney Gay, Progress and Values in the Humanities: Comparing Culture and Science (New York, NY: Colombia University Press, 2010), 59.

${ }^{265}$ As Heidegger observes, there appears to be an intimate relation between boredom and time. Martin Heidegger, The Fundamental Concepts of Metaphysics: World, Finitude, Solitude, tr. William McNeill and Nicholas Walker (Bloomington, IN: Indiana University Press, 1995), 80. “Boredom, Langeweile-whatever its ultimate essence may be-shows, particularly in our German word, an almost obvious relation to time, a way in which we stand with respect to time, a feeling of time. Boredom and the question of boredom thus lead us to the problem of time," ibid. In an ironic twist, however, Heidegger also asserts that if achieved, timeless time or the attainment of instantaneous immediacy in what we seek would also lead to boredom. See Heidegger, Contributions to Philosophy (Of the Event), 122-123. "'Science' pursues the securing of a state of knowledge entirely free of need, and it thereby also always remains, in the era of a complete lack of questioning, what is 'most modern.' All purposes and gains are fixed, all means are at hand, all benefits can be consummated; the only task is to overcome differences in the degree of refinement and to procure for the results the greatest possible scope of their easiest utilization. The hidden goal, to which all this and other things are hastening without surmising-or being able to surmise-the smallest part of it, is the state of complete boredom in the domain of the most proper achievements," ibid., 122-123. In other words, in the current context, what it appears Heidegger is suggesting is that if time passes too slowly, we become bored, yet, conversely, were time accelerated to an instantaneous timeless time, then boredom would also ensue because we would have everything instantly with no time for appreciation. The key here is understanding time in a human way.

${ }^{266}$ Nicholas Gane and David Beer, New Media: The Key Concepts (New York, NY: Berg Publishers, 2008), 20-21. Gane and Beer explain that "timeless time is an accelerated time that is unique to the new media age. It is a computerized time created by machines that operate and communicate with each other at speeds far beyond the sensory perceptions of their users. In more general terms, timeless time refers to a regime of instant communication and information exchange in which there is little time for reflection and perhaps critique.... This world of timeless time is accompanied by the emergence of a space of flows in which 'localities become disembodied from their cultural, historical, geographical meaning, and reintegrated into functional networks, or into image collages,'” ibid.
} 
time patterns matter less and less." ${ }^{267}$ As such, "due to the intensifying transmission of information via computer and satellite communication, the relationship between time and movement across space has changed. Duration has been compressed to zero. The intensive electronic present is no longer part of chronological time. Real-time has to be conceptualized as chronoscopic time."268

Part of the significance of this new development is that some "proponents of the 24/7 economy" are of the "opinion that day and night rhythms, as much as the weekly and seasonal patterns, will transform into one homogeneous global pattern." Through this new pattern, economic powers will lead in "the implementation of abstract time within a regime that has become internalized as a hegemonic metric." ${ }^{269}$ In other words, progress in science effectively eliminates or mitigates the traditional experience and meaning of time (and freedom) in every way-not just theoretically, but technologically and socially, such as with online social networking venues like Facebook. ${ }^{270}$ In what

${ }^{267}$ Luchien Karsten, Globalization and Time (New York, NY: Routledge, 2013), 359.

${ }^{268}$ Karsten, Globalization and Time, 359.

${ }^{269}$ Karsten, Globalization and Time, 359-360.

${ }^{270}$ For a specific example, on Facebook, a popular social networking site, "researchers concluded that Facebook-related stimuli can lead to an underestimate of time [elapsed] compared to general internet use, but that both lead to a distortion of time," Mark Prigg, "Why We Fall Into a 'Facebook Hole': Researchers Say Our Perception of Time is ALTERED When We Go Online," at http://www.dailymail.co.uk/sciencetech/article-42010 18/Face-really-alter-perception-time.html (accessed February 7, 2017), addition mine. In a complementary note, the designers of the Facebook 'like' and 'swipe down to update' features regret intentionally designing them to be addictive in time-wasting ways. See Paul Lewis, “'Our Minds Can be Hijacked': The Tech Insiders Who Fear a Smartphone Dystopia," at https://www.theguardian.com/technology/2017/oct/05/smartphone -addiction-silicon-valley-dystopia (accessed October 6, 2017). Why this is particularly important is that the post-postmodern or digimodern milieu conditions the context within which education takes place today. See, for example, Carl A. Raschke, The Digital Revolution and the Coming of the Postmodern University (New York, NY: Routledge Falmer, 2003); David M. Berry, and Anders Fagerjord, Digital Humanities: Knowledge and Critique in a Digital Age (Cambridge, UK: Polity Press, 2017); and Juha Suoranta and Tere Vadén, Wikiworld (New York, NY: Pluto Press, 2010). Suoranta and Vadén observe that "Heidegger thought that the ultimate danger of technology does not lie in its possible breakdowns (nuclear disaster, climate change, and so on) but rather in the fact that technology does not fail but works smoothly and faultlessly in its own hermetic realm, making us think of ourselves as resources," leading to the fear that the "teaching machines'" of a technologized educational system "enhanced with information technology will work seamlessly together with technological rationality so that all emancipatory potential is finally lost," that is, technocratic rationality undermines authentic human freedom and democratic values, ibid., 9. For some works outlining this pessimistic tone, see James Bridle, New Dark Age: Technology and the End of the Future (Brooklyn, NY: Verso, 2018); John Michael Greer, Dark Age America: Climate Change, Cultural Collapse, and the Hard Future Ahead (Gabriola Island, BC: New Society Publishers, 2016); Maggie Jackson, Distracted: The Erosion of Attention and the Coming Dark Age (Amherst, NY: Prometheus Books, 2008); and Jane Jacobs, Dark Age Ahead (New York, NY: Random House, 2004). For more on the overall situation concerning technology and the future, see Adam Greenfield, Radical Technologies: The Design of Everyday Life (Brooklyn, NY: Verso, 2018); and the Heideggerian philosopher Federico Campagna, Technic and Magic: The Reconstruction of Reality (London, UK: Bloomsbury, 2018). For an article that addresses the challenge of turning knowledge into something more meaningful than merely accepting advances in technology, see Leena Pylkkö, "Back to Content: Nelson Goodman as Philosophical Basis for Multiliteracy," in Qualitative and 
may be an apt comparison, then, the digital world of the internet creates its own "digital relativity"271 that places the cyberworld in a distinct relationship with and within itself apart from the world-that is, digital spaces are able to interact almost simultaneously (theoretically unimpeded from always operating at the maximum speed of causation), while at the same time, various sub-communities emerge in the cyberworld that are separated from each other's spheres of influence, yet which are still (mirroring quantum phenomena) effectively (though not technically) non-locally connected. Alternately explained, digital communities compete for relatively independent digitally but not literally connected spheres of connectivity, ${ }^{272}$ while simultaneously separating from others who are connected only within their own respective digital spheres, while both such group types are yet further (and possibly farther) separated from those who still live "off the grid" around the planet. ${ }^{273}$ Relatedly, in different ways for those on or off the grid in such a world, humans face the prospects of being defined digitally, which has far reaching consequences. ${ }^{274}$

By contrast, in the humanities, progress or time has been described as a temporal "spiral that starts from a center, rising or diving to higher degrees of reflection, but always revolving around that nucleus. In humanistic knowledge there is no progress but difference, a sort of Moses' bush perennially burning without being consumed."275 Here Scripture seems to affirm and side with the humanities, in that "the two cultures have opposing attitudes: logic abhors the paradoxes, art pampers them." ${ }^{276}$ Concerning freedom in the humanities, contrary to the sciences where freedom is

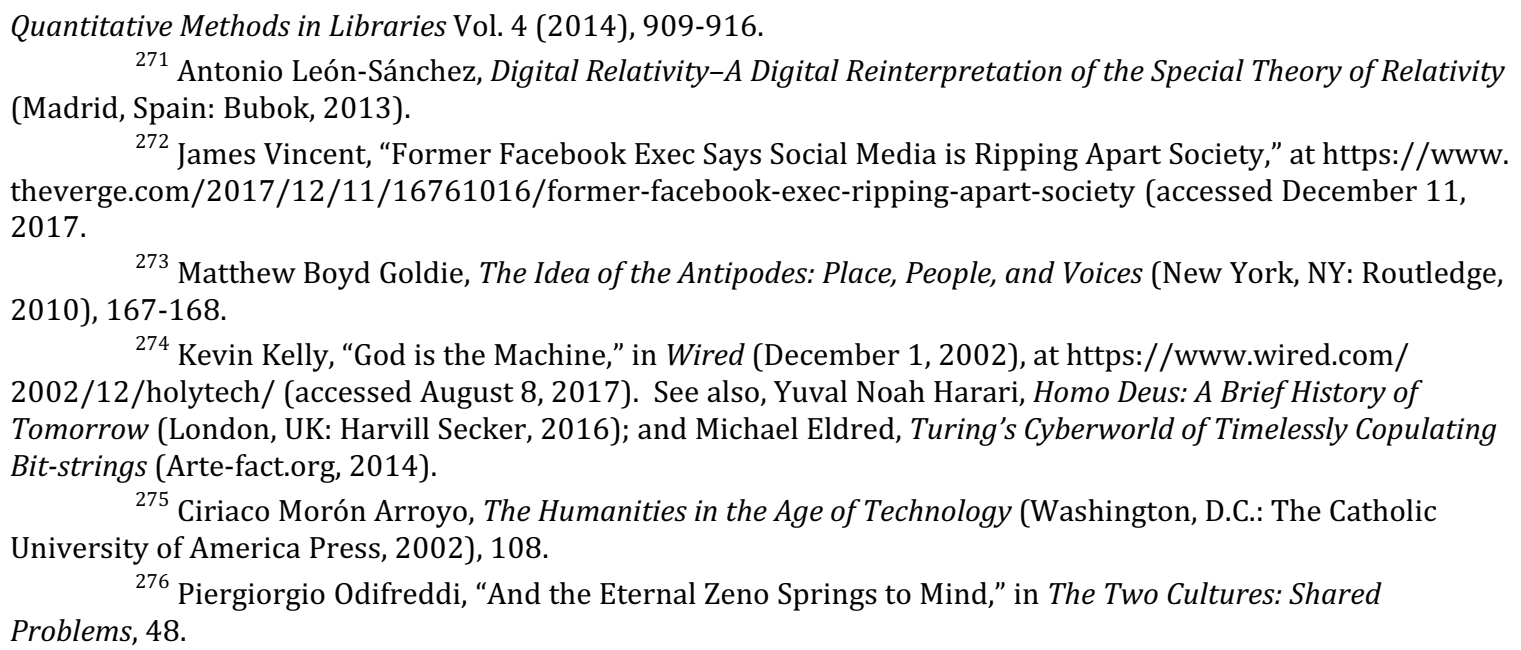


relative to the objective status of that which we are relating to, namely our power, wealth, and health-one finds in the humanities that the freedom of "human thinking is founded on the miracle of the great nought, the no-thing," ${ }^{277}$ the absence of anything. It is the world of creative poetical selfreflection. And, at the same time, for the humanities it is precisely one's relationship to this no-thing that constitutes genuine temporal living. ${ }^{278}$

What is of particular interest, then, is that collectively, these contrasting pictures present the paradox of two coexisting but incompatible perspectives that are dominant in today's world, in that it is the humanities that emphasize the perspective of the passage of time (life-lived-as-a-whole), yet progress is here exchanged for the difference found through a circular or spiral movement, and focused upon self-reflection through an introspection of our past and an anticipation of the future to understand the depths and limitations of our freedom more fully. ${ }^{279}$ Conversely, in the standard

${ }^{277}$ Arroyo, The Humanities in the Age of Technology, 154.

${ }^{278}$ According to Scott Campbell, Heidegger "explains that factical life temporalizes as a crash (Strurz) through the nothingness. This means that the temporality of factical life is such that it is hidden within different modes of life's objectivity. By objectifying itself, life denies or says 'no' to its temporality. As such, factical life's temporality is negatived; it is hidden. It becomes clear from this analysis that nothingness is related to factical life.... As such it indicates the Being of factical life, that is, the Being of Dasein, in that Heidegger understands Being to be not a being or thing, but rather no-thing. No-thingness, in this sense, is, as the later Heidegger makes clear, the withdrawn illumination of Being within beings," Scott M. Campbell, The Early Heidegger's Philosophy of Life: Facticity, Being, and Language (Bronx, NY: Fordham University Press, 2012), 9-10. Campbell adds that "the factical experience of life was meant to apply equally well to science, religion, or any of the humanities," ibid., 50 .

279 "This anticipatory running forward into the most extreme possibility of myself, which I am not yet, but will be, means to be futural. I myself am my future by virtue of this anticipatory running forward. I am not in the future but rather am myself futural. Being guilty is nothing other than carrying the past around with oneself, for being guilty is a kind of being past. In this state of being guilty, we can see how one holds onto the past and how along with this human Dasein, through its actions, comes authentically into the present. In being resolved, Dasein is its future, in being guilty it is its past, and in acting it comes into the present. The being-there of Dasein is nothing other than being-time. Time is not something that I encounter out there in the world, but is what I myself am. In running forward anticipatorily, being guilty, and acting, time itself is there for us. Time characterizes the whole of Dasein. At any particular time, Dasein is not only in the moment but rather is itself within the entire span of its possibilities and its past. It is remarkable how, in acting in the direction of the future, the past comes alive and the present vanishes. Those who act authentically live from out of the future and also can live from out of the past; the present takes care of itself. Time constitutes the whole of my Dasein and also defines my own being at every moment. Human life does not happen in time but rather is time itself," Martin Heidegger, "Wilhem Dilthey's Research and the Struggle for a Historical Worldview," tr. Charles Bambach, in Supplements: From the Earliest Essays to Being and Time and Beyond, ed. John van Buren (Albany, NY: State University of New York Press, 2002), 169. See also, David Couzens Hoy, The Time of Our Lives: A Critical History of Temporality (Cambridge, MA: The MIT Press, 2009), 23. Hoy explains that, for Heidegger, "'in each case Dasein itself is time,"' and "the phrase 'in each case' suggests that time is relative to each particular Dasein. This clarification leads to a further problem, however, insofar as it implies that there are as many different times as there are lives. This claim would be hard to reconcile with the standard Kantian intuition that time is one," ibid., 23. 
conception of the sciences, it is the timeless mathematical formulas applied to nature, viewed deterministically as an unalterable chain of cause and effect, ${ }^{280}$ that construct new technologies which count as progress and the expansion of freedoms, particularly in the external realm of power, wealth, and health. Furthermore, experientially, our lives become lived within an understanding of time that emphasizes the "timeless present" ${ }^{\text {"281 }}$ as what actually matters, as we are encouraged to "live in the moment ${ }^{\prime 282}$ in the contemporary world of innumerable experiential possibilities, regardless of, or separated from, our pasts and futures, and our actual historical futures are oriented toward merely expanding our access to the freedoms granted us by power, wealth, and health.

It was, as noted above, Heidegger, the "father of postmodernism," 283 who arguably first articulated and thus most clearly initiated the official divide and ensuing competition among philosophers between the two academic cultures of the (modern) sciences and (postmodern) humanities which was described and critiqued a few decades later by Snow. The content of Snow's critique is important, as it directly addresses freedom and time. Snow claimed scientists should take the lead in any new third culture because only "scientists have the future in their bones" and their

\footnotetext{
${ }^{280}$ Arroyo, The Humanities in the Age of Technology, 196. "Finding the cause-effect relationship... is the key feature of the scientific method. All types of classification that do not help to predict the behavior of things are not scientific. Technology is founded on the possibility of that prediction on the basis of laws discovered through the cause-effect relationship," ibid.

${ }^{281}$ This is reflected in different ways philosophically and historically. Historically, the concept of the timeless present builds upon the early Greek philosophers Pythagoras, Parmenides, and the later platonist Plotinus, where a temporal "now" intersects with the eternal "now" in which the "timeless present" resides, as I will discuss later. Giannis Stamatellos, Plotinus and the Presocratics: A Philosophical Study of Presocratic Influences in Plotinus' Enneads (Albany, NY: State University of New York Press, 2007), 112. Stamatellos explains that "for Plotinus every act of intelligence is timeless. ... The 'real being' involves eternity and not time, therefore the intelligible nature is characterized by the lack of any temporal tenses," ibid. As such, any notion of progress would be the engagement of our minds with that which is timeless; knowing, understanding, and implementing the "timeless" is equal to "advancing" progress, because it is a movement toward what is "truth." From a more modern "spiritual" perspective, as Caroline Myss observes, "the closer you get to your true self, the more you live in eternity; the more you live in the timeless present, which includes thought of the past, the present, and the future, all occurring in the timeless now. So think about the past and future all you want: Just watch them arise in the present," Caroline Myss, Entering the Castle: An Inner Path to God and Your Soul (New York, NY: Free Press, 2007), xviii.

${ }^{282}$ Harvie Ferguson observes that it seems "contemporary life is wholly [lived] in the present. Now we live 'for the moment' and are provided with innumerable ways of intensifying the instantaneous 'now' of something that is taking place. The excitement of roller-coaster rides, bungee jumping, being drunk, gambling, eroticism, sport, news, performances of all sorts, thunderstorms, beauty and all other 'saturated' phenomena is just that they overwhelm the living moment with content in such a way as to mark it as occurring 'right now,'” Harvie Ferguson, Self-Identity and Everyday Life (New York, NY: Routledge, 2009), 165.

${ }^{283}$ Anthony Pagden, The Enlightenment: And Why it Still Matters (Oxford, UK: Oxford University Press, 2013), 327.
} 
technology is "the only hope of the poor." ${ }^{284}$ Snow believed that "man doesn't live by bread alone," but also by "scientific revolution," ${ }^{285}$ and hence scientists are the only ones who can bring to the poor the bread of freedom. The historians Colin Hempstead and William Worthington affirm that "the primary ethical justification of modern technology across the $\left[20^{\text {th }}\right]$ century was the conquest of nature $\ldots$ as the pursuit of freedom." This view was emphasized and "reiterated ... by C. P. Snow (1959)" in the middle of the century, who sought through the pursuit of technology the "realization of material welfare and human freedom." ${ }^{286}$

Naturally, those from the humanities or humane sciences were among those most displeased by Snow's belief that scientists should lead the way toward the mediation of the ultimate interests of mankind and the technology that the sciences may bring. As Hempstead and Worthington, in their continuing critique, observed, "during the second half of the century, however, the new technological world itself came to be recognized as requiring its own adaptations. Freedoms were not themselves always free," 287 but rather the freedoms technology may grant society can burden society as well (e.g., nuclear discoveries enabling the control of tremendous energy that can become weaponized and

${ }^{284}$ Snow, The Two Cultures, 11 (emphasis mine), 25.

${ }^{285}$ Snow, The Two Cultures, 78. For an updated account of the significance surrounding Snow's claims within contemporary society, see Allan C. Ornstein, Excellence Vs. Equality: Can Society Achieve Both Goals? (New York, NY: Routledge, 2016), 14-19.

${ }^{286}$ Colin Hempstead and William Worthington, "Technology and Ethics," in Encyclopedia of $20^{\text {th }}$-Century Technology Vol. 2, eds. C. Hempstead and W. Worthington (New York, NY: Routledge, 2004), 785. Irving Horowitz affirms that "the love affair of policy-makers, academic pundits, and hard-core positivists with the world of science" came about because "in the nineteenth century, science was as identified with progress as bacon is with eggs. This optimism has given way to a pandemic mistrust of science by all sorts of elites. Popular displeasure became transparently evident in the waning decades of the twentieth century. Mistrust of science has only deepened in the first years of the new millennium. The ease with which scientific products are converted into destructive weaponry only partially accounts for the new skepticism about conventional claims. Unanticipated negative human consequences of actual discoveries in areas ranging from genetic engineering to wireless communication are at least as important an element in popular concerns. Nonetheless, professional assertions about the benefits of science continue unabated.... [All this is particularly important to understand within the historic context that] social reformers have been quick to follow suit [in praising science]. Marx envisioned doing for society what Newton had done for physics, what Darwin had done for biology, and what Mendeleyev had sought to achieve in his Periodic Table for chemistry: providing a blueprint for the social universe. The early history of socialism, like capitalism before it, was tied directly to the rise of science as a purposive goal, a Western way of life, and not simply a series of formal operations. Indeed, this utopian vision of science as a blueprint for society lasted deep into the twentieth century. Scientism displaced science as a working code for radical analysis," Irving Louis Horowitz, "Two Cultures of Science: The Limits of Positivism Revisited," in Journal of Policy History Vol. 16 \# 4 (2004), 332-347; 332-333.

${ }^{287}$ Hempstead and Worthington, "Technology and Ethics," 785. 
general technological abuse of nature creating ecological disasters being merely the most obvious examples ${ }^{288}$ ).

Others from the humanities, like the economist Ernst Schumacher, were among those most displeased by Snow's belief that scientists should lead the way toward the mediation of the ultimate interests of mankind and the technology that the sciences may bring. As he put it, "What do I miss, as a human being, if I have never heard of the Second Law of Thermodynamics? The answer is: Nothing." ${ }^{289}$ His comments reflect the sentiments of many others, such as Albert Levi, who similarly noted that Roger Scruton, a philosopher of art, was "unhappy with Snow's moralism." Rather, “in contrast to Snow, Scruton believes that our contemporary situation has greater need of the humanities than ever before and that they alone can keep us in touch with a world from which science ... has banished all traces of personal meaning." It is, rather, "art [that better] serves [as] ... the expression of human freedom." ${ }^{290}$ Not only secular scholars in the humanities such as Scruton, but religionists, like noted Christian apologist Clive S. Lewis, who was at Cambridge University near Snow, evidently "saw a great threat in the misuse of natural science, with its triumphalist appeal to

\footnotetext{
${ }^{288}$ For example, see the work of Majia Nadesan, Crisis Communication, Liberal Democracy, and Ecological Sustainability: The Threat of Financial and Energy Complexes in the Twenty-First Century (New York, NY: Lexington Books, 2016).

${ }^{289}$ Ernst Friedrich Schumacher, Small is Beautiful: Economics as if People Mattered (New York, NY: HarperCollins, 2010), 92. Schumacher explains that "[British] Lord Snow tells us that when educated people deplore the 'illiteracy of scientists' he sometimes asks 'How many of them could describe the Second Law of Thermodynamics?' The response, he reports, is usually cold and negative. 'Yet,' he says, 'I was asking something which is about the scientific equivalent of: Have you read a work of Shakespeare's?' Such a statement challenges the entire basis of our civilisation. What matters is the tool-box of ideas with which, by which, through which, we experience and interpret the world. The Second Law of Thermodynamics is nothing more than a working hypothesis suitable for various types of scientific research. On the other hand-a work by Shakespeare: teeming with the most vital ideas about the inner development of man, showing the whole grandeur and misery of human existence. How could these two things be equivalent? What do I miss, as a human being, if I have never heard of the Second Law of Thermodynamics? The answer is: Nothing. And what do I miss by not knowing Shakespeare? Unless I get my understanding from another source, I simply miss my life. Shall we tell our children that one thing is as good as another-here a bit of knowledge of physics, and there a bit of knowledge of literature? If we do so, the sins of the fathers will be visited upon the children unto the third and fourth generation," ibid., 91-92.

${ }^{290}$ Levi and Smith, Art Education, 170.
} 
mathematics and experimentation, one in which human freedom and accountability might be cast aside as outdated illusions." ${ }^{291}$

The concept of time, in its pragmatic sense, and in its relationship to freedom, is also an issue for the sciences and humanities. The psychiatrist Volney Gay succinctly pinpoints the problem for scientists when he explains:

The difference between the humanities and the sciences appears in the way each subject is taught. In the natural sciences instructors use current textbooks that they assume contain the best of previous scientific efforts. Because the sciences advance, more or less in a linear way, the latest is usually best. This is never said about humanistic disciplines like philosophy or literary criticism.... B. F. Skinner, the most famous American psychologist of the late twentieth century, lamented [this] ... in Beyond Freedom and Dignity (1971). There he complained that humanists and even psychologists continued to read Plato and other ancients "as if they threw light on human behavior."292

Gay continues, "Heidegger illustrates the problem of progress in the humanities. For at the center of Heidegger's thought is the rejection of the idea of progress, especially in its twentieth-century guise in which technology and the march of science dominate consciousness." 293 Indeed, "it is clear that Heidegger does not judge 'mere advancement of [scientific] knowledge' as the highest goal of the university." 294 Gay, as one who admits to having "cast my lot with the scientists," ${ }^{295}$ finds this "a tragic error." 296

${ }^{291}$ Mary Stewart Van Leeuwen, A Sword between the Sexes?: C. S. Lewis and the Gender Debates (Grand Rapids, MI: Brazos Press, 2010), 43. Leeuwen notes that Snow hoped for social scientists to help bridge the gap between the humanities and natural sciences, "but Lewis was skeptical... [and] saw practitioners of the social sciences mainly as shallow thinkers and the lackeys of technologically minded natural scientists," ibid. C. S. Lewis' distaste for the ethical overreach of scientists is obvious in some of his fictional works, such as in C. S. Lewis, That Hideous Strength (New York, NY: Scribner, 1996).

292 Gay, Progress and Values in the Humanities, 54.

293 Gay, Progress and Values in the Humanities, 54.

294 Gay, Progress and Values in the Humanities, 60.

295 Gay, Progress and Values in the Humanities, 52.

${ }^{296}$ Gay, Progress and Values in the Humanities, 60. Gay elaborates by explaining, "it is easy to say what counts as progress in some endeavors: an economy progresses when it produces more wealth and better jobs, when the standard of living goes up and child mortality goes down. A science progresses when its theories explain more, with fewer anomalies, and it enhance our ability to control phenomena of interest. Medical sciences progresses when it helps increase the quality of life and eliminates a disease like polio. In all these cases we feel justified in using the word progress because we can cite agreed-upon measures of success. Poverty, ignorance of natural laws, diseases and scourges are bad; diminishing them counts as good," ibid., 53. Contrastingly, "it is much more difficult to say what counts as progress in those parts of life assigned to the humanities. In these areas, such as art, religion, education, and philosophy, what counts as success is not so clear. For example, looking back over the history of European painting, experts may agree that Impressionism differs form Modernism (which succeeded it) and both differ from Post-modernism (the most recent), but counting the last as progress is not affirmed universally," ibid., 53-54. 
In contrast, however, while some acknowledge that "science" is a "powerful engine for progress, ${ }^{297}$ this should not be taken to mean that there is no such thing as progress in the humanities, even if "progress in the areas of the humanities is often difficult to perceive with certainty, document objectively, and quantitate or measure."298 It may appear true that "science looks forward while many philosophers look backward," ${ }^{299}$ but Dennis Heffner believes this to be an exhibit of wisdom. Heffner believes we should be alarmed that "scientific progress has" "'infected' society so much that it has contributed to, colored, and maybe even distorted perceptions of progress in the humanities." ${ }^{300}$ Heffner warns that the "grand ... delusion of unlimited progress" that dominates throughout the technologized modern world is "pervasive, persistent, and profound," but ultimately ungrounded. ${ }^{301}$ Rather, history has shown most philosophical problems to be of a nature that endure through time, thus this should temper our optimism about the unlimited progress the scientifictechnological world appears to offer us. ${ }^{302}$ Despite everything that science has given the world that could be described as progress, it has never found a way to integratively reconcile itself with the more traditional philosophical problems that relate to "ethics, morality," and political "governance."303

\footnotetext{
${ }^{297}$ Heffner, Unlimited Progress: The Grand Delusion of the Modern World, 13.

${ }^{298}$ Heffner, Unlimited Progress: The Grand Delusion of the Modern World, 6.

${ }^{299}$ Neuman, Reviving the Living: Meaning Making in Living Systems, xvi.

${ }^{300}$ Heffner, Unlimited Progress: The Grand Delusion of the Modern World, 6. Heffner adds, "that
} progress is limited in science and technology, this limitation has import for the humanities and of course for political attitudes. Arguments for tempering irrational exuberance about progress in the scientific sphere implies a need for mitigating overenthusiastic ideas of progress in the humanities since ideas of progress in the latter have been influenced so much by progress in the sciences," ibid., 6-7.

${ }^{301}$ Heffner, Unlimited Progress: The Grand Delusion of the Modern World, xii.

${ }^{302}$ Put simply, “technology doesn't solve humanity's problems. It was always naïve to think so. Technology is an enabler, but humanity has to deal with humanity's problems. I think we're both over-reliant on technology as a way to solve things and probably, at this moment, over-indexing on technology as a source of all problems, too," Sundar Pichai, as cited in David Gelles, “Sundar Pichai of Google: 'Technology Doesn't Solve Humanity's Problems,"” at https://www.nytimes.com/2018/11/08/business/sundar-pichai-google-corner -office.html? (accessed November 8, 2018).

${ }^{303}$ Heffner, Unlimited Progress: The Grand Delusion of the Modern World, 99. The issue of morality is central, of course, to the issues that any religionists or theologians might be interested in understanding, and will be returned to below insofar as it relates to freedom and time. For more on the "problem" of morality and ethics in philosophy and science, see the essays in Tamler Sommers, ed., A Very Bad Wizard: Morality Behind the Curtain $2^{\text {nd }}$ ed. (New York, NY: Routledge, 2016); and James Davison Hunter and Paul Nedelisky, Science and the Good: The Tragic Quest for the Foundations of Morality (New Haven, CT: Yale University Press, 2018). Hunter and Nedelisky explain that, in reality, the scientific quest for the foundations of morality "has been fundamentally redirected. The science of morality is no longer about discovering how we ought to live-though it is still often presented as such. Rather, it is now concerned with exploiting scientific and technological knowhow in order to achieve practical goals grounded in whatever social consensus we can justify. The science of 
Viewed in such a way, technology, in every new generation, brings with it the potentiality for contributions that may be called good and evil, or freedom and enslavement, that lay beyond the intentions and power of our choices-most humans are hapless victims and helplessly passive beneficiaries of technology's own intrinsic and internalized telos or end goal. ${ }^{304}$ Whether, however, technology contains an ultimately neutral, good, or evil telos constitutes part of the core of the debate between the two cultures. ${ }^{305}$ As will be detailed more below in chapter 4, although Heidegger technically remains neutral toward science and technology per se, he also provocatively suggests that the intrinsic metaphysics undergirding technology is actually inclined toward evil by its nature, as it

morality, then, has evolved into an engineering project rooted in morally arbitrary goals," ibid., 197. Their view reaches toward, but still does not quite penetrate, into Heidegger's even more negative assessment that no matter what moral goals we have, the excessive use of science will distort them, making humans a means to an end, rather than a highlighting humanity as the end in itself.

${ }^{304}$ From a Heideggerian perspective on this point, see Richard Rojcewicz, Gods and Technology: A Reading of Heidegger (Albany, NY: State University of New York Press, 2006), 142-152. Interestingly, Theodore J. Kaczynski, the "Unabomber" who attacked U.S. government buildings, shared a similar more radicalized view concerning the relationship of technology to philosophy. See Theodore J. Kaczynski, with an introduction by David Skrbina, Technological Slavery: The Collected Writings of Theodore J. Kaczynski (Port Townsend, WA: Feral House, 2010). For more practical observations, see Hossein Bidgoli, ed., The Handbook of Technology Management, Supply Chain Management, Marketing and Advertising, and Global Management Vol. 2 (Hoboken, NJ: John Wiley \& Sons, 2010), 283; Brian Brown, Paul Crawford, and Carolyn Hicks, Evidence-Based Research: Dilemmas and Debates in Health Care (Berkshire, UK: Open University Press, 2003), 159; Stefanie Paluch, Remote Service Technology Perception and its Impact on Customer-Provider Relationships: An Empirical Exploratory Study in a B-to-B-Setting (Doctoral Thesis, TU Dortmund University, 2011), 74; Jakki Mohr, Sanjit Sengupta, and Stanley Slater, Marketing of High-Technology Products and Innovations $3^{\text {rd }}$ ed. (Upper Saddle River, NJ: Prentice Hall, 2010), 262. Concerning the young in particular, see Wided Batat, "An Adolescent-centric Approach to Consumer Vulnerability," in Consumer Vulnerability: Conditions, Contexts and Characteristics, eds. Kathy Hamilton, Susan Dunnett and Maria Piacentini (New York, NY: Routledge, 2016), 109-111.

Of course, some might suggest that the uses and ends of, or the telos within, technology do not lay beyond our choices, but merely seem inevitable by humans who have access to "unlimited" technology. See Douglas Sloan, "Preface: Toward an Education for a Living World," in Education for Peace and Disarmament: Toward a Living World, ed. Douglas Sloan (New York, NY: Teachers College Press, 1983), 1-14.

${ }^{305}$ See, for example, Jeremy Locke, The End of All Evil (www.endofevil.com, 2006), 83, 91; and Daniel Burrus, "Is Technology Good or Evil?," at https://www.huffingtonpost.com/daniel-burrus/is-technologygood-or-evi_b_1826270.html (accessed August 24, 2012). See also, Rollo May, Freedom and Destiny (New York, NY: Norton, 1999), 143, 167, 174, 196, 226; and Gil Germain, Thinking About Technology: How the Technological Mind Misreads Reality (Lanham, MD: Lexington Books, 2017), 76-82. Germain observes that "the assertion that there is $a$ path to the truth-the scientific path-is deeply embedded in contemporary Western culture. It is replayed in the distinction between myth and reason" that Plato explored, ibid, 82. Furthermore, "thinking about technology alters perception and it is in the realm of perception that freedom resides," ibid., xii.

All this is related, in some manner, to the predictions made by those suggesting Artificial Intelligence will displace humans, as depicted in the popular Matrix and Terminator films. For more, see Patrick Caughill, “Artificial Intelligence Is Our Future. But Will It Save Or Destroy Humanity?," at https://futurism.com/ artificial-intelligence-is-our-future-but-will-it-save-or-destroy-humanity/ (accessed September 29, 2017); and Hannah Osborne, "Stephen Hawking AI Warning: Artificial Intelligence Could Destroy Civilization," at http://www.newsweek.com/stephen-hawking-artificial-intelligence-warning-destroy-civilization-703630 (accessed November 7, 2017). 
denies freedom because of the boundless domains it seeks to dominate, which inevitably includes the human being itself. ${ }^{306}$ Accordingly, while it cannot be denied that the rise in technology has raised the overall standard of living of countless billions, arguably the very same technological advances have not only coincided with, but also caused, the rapid rise of global wealth disparities, which causes great social unrest and has helped encourage the displacement of humanities' oriented careers. ${ }^{307}$

The positions expressed above present a direct contrast between how freedom is understood in its primary sense within the sciences and humanities, respectively. Is freedom better expressed through an inward reflection on human existence, including that freedom of choice which is manifested through personalized artistic expression $?^{308}$ Or is freedom best expressed through the progress of technology that enables more humans to exist more comfortably and do more things, ${ }^{309}$ sometimes risking grave consequences for the environment, ${ }^{310}$ while also hazarding impinging upon the freedoms of others outside those in the spheres of power? ${ }^{311}$

${ }^{306}$ Brett Frischmann and Evan Selinger, Re-Engineering Humanity (Cambridge, UK: Cambridge University Press, 2018). Frischmann and Selinger suggest that it is possible we are moving toward "a world where engineered determinism governs," which "is a world where fully predictable and programmable people perform rather than live their lives. Such a world would be tragic," ibid., 244, xi.

${ }^{307}$ The very same technologies that raise the standards of living for so many at the same time enable the simultaneous merged centralization and global expansion of mega-corporations which generate very wealthy people at the top, which in turn creates animosity between this new mega-rich class and 'all the rest,' as they fight over power and who should have the wealth that has been generated. Of course, how certain megacorporations and their technology damage the ecosystem is yet another consequence of the rapid rise of technology. For more, see Matt Taibbi, The Divide: American Injustice in the Age of the Wealth Gap (New York, NY: Random House, 2014).

${ }^{308}$ Within the frame of reference of the Humanities as articulated by Heidegger, Aubrey Neal explains: The later Heidegger's obsession with language, elaborated upon throughout his writings that often took "lavish etymological liberties," fail as scholarship. Yet at the same time they nevertheless, "as a genre of moral poetry unique to Heidegger and his time," "succeed admirably." Neal continues, "Heidegger believed the modern moral life was betrayed by modern language," because "modern language prevents us from 'seeing' history," and "he wants to 'see' history with a moral knowledge of what history 'should' be," Aubrey Neal, How Skeptics Do Ethics: A Brief History of the Late Modern Linguistic Turn (Calgary, Alberta, Canada: University of Calgary Press, 2007), 216.

${ }^{309}$ Gay, Progress and Values in the Humanities, 59.

${ }^{310}$ See, for example, Charles S. Brown and Ted Toadvine, eds., Eco-Phenomenology: Back to the Earth Itself (Albany, NY: State University of New York Press, 2003). An irony here is that it is often the scientistic Left that advances the Green or environmentalist movement, yet it is their same scientistic impulse which created the opportunities of abusing nature through technology in the first place.

311 "One of the most fundamental traits of modernization is a vast movement from fate to choice in human affairs .... The paradox here is that modern technology also supplies the means by which powerful institutions can control the lives of individuals. Thus the totalitarian state is made possible by modern technology. The great drama of modernity is this dynamic tension between liberation and re-enslavement," Raymond Aron, History, Truth, Liberty: Selected Writings of Raymond Aron, ed. F. Draus (Chicago, IL: The University of Chicago Press, 1965), 349. Alternately put, "since technology has a logic of its own, it inevitably 


\section{The Two Cultures and Religion: Where is the Real Debate?}

To explain the tension above another way, it may be helpful to ask it again from a traditional religious perspective: how can humanity better free itself? None other than Joseph Ratzinger (Pope Benedict XVI) has reminded us that "the era we call modern times ... has been determined from the beginning by the theme of freedom," and by the "striving for new forms of freedom."312 The question then, becomes, is freedom best found through science and technology or literature and the arts? From a biblical (which is also literature and as such a part of the humanities) point of view, bread does grant one freedom to live another day, and better technology is one way to make more bread. But what freedom (2 Cor 3:17) does the truth of the bread of life grant us (John 6:47-51; Deut 8:3, Matt 4:4, Matt 14:13-21, Mark 6:30-44, Luke 9:10-17, John 6:1-15)? Are these freedoms in opposition or tension, or if not, which should have priority? And what is their conceptual interrelationship, especially on matters of perfection in morality?

Indeed, and the issue is surely subtle, the whole notion of spiritual progress as a goal is brought into a new light by the above conundrum. Is spiritual progress a movement forward (advancement in our understanding of doctrines and the machinery of church ministries and ecclesiastical structures and policies, on both smaller and larger scales, like with the scientists, or a circular movement inward

has unanticipated and unintended effects. Historically, the same technologies that liberate often enslave, and sometimes even do both simultaneously," Mark C. Taylor, Speed Limits: Where Time Went and Why We Have So Little Left (London, UK: Yale University Press, 2014), 291; and Judy Wajcman, Pressed for Time: The Acceleration of Life in Digital Capitalism (Chicago, IL: The University of Chicago Press, 2015), 175. Wajcman observes that some feel "'we are enslaved by speed,"' ibid., 175, and the ability "to choose how to spend your time is central to an individual's sense of freedom," ibid., 62. The dualism inherent in this enslavement can be contrasted with the paradoxical liberation speed can bring. An interesting example, from many potential ones, drawn from technology would be this: "undoubtedly, in the early twentieth century, the car represented freedom for many and, arguably, had a greater impact on women than on men. Notably the automobile appeared at the same time that women were striving for freedom in the home and in politics. At first, women were almost exclusively passengers. It was the electric automobile that gave upper-middle-class women the freedom to leave home and break free of the control of their husbands," ibid., 53. She notes a similar thing occurred for African Americans, ibid., 54. Conversely, the impact of smartphones has increased the speed of communications to the point that now workers "are much more likely to be required to read and respond to work-related e-mails when not at work," thus re-enslaving us to the speed which at first liberated us, ibid., 141.

${ }^{312}$ As cited in Kenneth L. Grasso and Robert P. Hunt, "Introduction," in Catholicism and Religious Freedom: Contemporary Reflections on Vatican II's Declaration on Religious Liberty, eds. Kenneth L. Grasso and Robert P. Hunt (Lanham, MD: Rowman \& Littlefield, 2006), xvi. 
toward the heart (repentance and actually voluntarily living lives oriented by selfless love), ${ }^{313}$ akin to what artists and poets might describe? If both, then this study has an increased significance, because they too are often seen to be in tension if not outright conflict, especially when individuals relate to the corporate body and engage in scientific endeavors to advance policy reforms to advance either utilitarian (secular) freedom or moral freedom, for both the one and the many-religious ethical convictions merely replicate the tensions surrounding the scientific methodological impulse in the humanities and third culture social sciences. This is so whether it is freedom in relation to materiality, belief, or activity, for those from certain nationalities and regions, religions, ethnicities, or genders. ${ }^{314}$

Michael Polanyi, a Christian scientist who later focused on more philosophical themes, correctly observed the surface cause of the competition between the two cultures in the increasingly secularized academy in the $20^{\text {th }}$ century, in that as many philosophers were so impressed by the positive achievements in the physical sciences in the $19^{\text {th }}$ and $20^{\text {th }}$ centuries, such as the mathematization of physics, "they decided to liquidate philosophy altogether and divide up its subject-matter among different sciences. A number of new sciences which took man or human affairs as their subject, were formed at the time and appeared to serve this purpose. Psychology and Sociology were acclaimed as the principal legatees in this sharing out of the substance of philosophy.

\footnotetext{
313 This would reflect some of the issues relating to the "social gospel" and "moral gospel." For more, see Michael F. Younker, "The American Socio-Political Spider Web and the Rise of Global Christianity," in the Journal of the Adventist Theological Society Vol. 25 \#1 (2014), 148. Of course, both the social and moral gospels could be said to possess both more scientific and artistic elements, depending on how morality and sociality are conceived-hence, the problem of the two cultures is yet again replicated in each of them. In this case, the extreme Left and extreme Right both lean more scientific concerning their specific areas of focus, while leaning more toward the humanities in areas they do not emphasize. Were they to merge, the consequences would be fascinating.

${ }^{314}$ For example, the issue of women's spiritual equality in Christian leadership is also explicitly bound up within the issue of freedom. Note Kevin DeYoung, Freedom and Boundaries: A Pastoral Primer on the Role of Women in the Church (Enumclaw, WA: Pleasant Word, 2006); E. Jane Dempsey Douglass, Women, Freedom, and Calvin (Philadelphia, PA: The Westminster Press, 1985), 9; Janette Hassey, No Time For Silence (CBE, 1986); and Letty M. Russell, Household of Freedom: Authority in Feminist Theology (Philadelphia, PA: The Westminster Press, 1987). To concisely illustrate how freedom may intersect with women in the church is as follows. Those that see the role of leaders (in perhaps both the church and society) as reserved for men similarly see the role the woman as reserved for the home and child-rearing. This is due to their very natures, it is claimed. Thus, a man and woman are only 'free' if they are true to their God-designed natures, and fulfilling their intended roles. Ironically, as society moved toward a "two-earner" standard for the middle class, this forced (or enslaved) women to work outside the home (see n. 495), and thus they are no longer free to choose to be a 'house-wife,' even as they are often free today in many church denominations to choose to be a leader.
} 
This philosophy-to-end-all-philosophy may be designated, if somewhat loosely, as Positivism." ${ }^{315}$ of course, this impulse directly challenged and affected religious studies and seminaries as well, starting in the $19^{\text {th }}$ century, the consequences of which would be far reaching. ${ }^{316}$

Also importantly, although many might correctly point out that the original positivism movement ran its course during the early $20^{\text {th }}$ century, the existence of the New Atheism movement of the $21^{\text {st }}$ century suggests it has not died easily-it has merely morphed into scientism, ${ }^{317}$ a more

\footnotetext{
${ }^{315}$ Michael Polanyi, The Logic of Liberty (Chicago, IL: The University of Chicago Press, 1951), 9-10. See also, Rudolf Steiner, Nature's Open Secret: Introductions to Goethe's Scientific Writings (Hillside House, UK: Rudolf Steiner Press, 2000).

${ }^{316}$ For the situation in many schools in America, see Younglae Kim, Broken Knowledge: The Sway of the Scientific and Scholarly Ideal at Union Theological Seminary in New York, 1887-1926 (Lanham, MD: University Press of America, 1997). Kim explains that the rise of science "changed the definition of higher learning. The goal of higher education, which used to be identified with the mastering of the classics in the old-time college, became the advancement of knowledge in scientific and practical subjects in order to keep up with the industrializing society after the Civil War," ibid., 4. However, this also meant that as "science, mostly natural science, moved into the center stage of higher learning," "science became a religiously significant vocation' in the mid- and late nineteenth century which played the role of verification of other knowledge" outside the strict domain of natural science. Many of "the intellectuals who shared this conviction drew on Protestantism's traditional commitment to correct belief, but placed more emphasis on this commitment exactly while responding to the epistemological transformations wrought by the successful programs of modern philological, historical, and natural sciences. What it meant to 'know' narrowed considerably under the influence of these programs.' 'Knowledge,' which used to be a means to moral and spiritual ends, had become a commodity to be utilized for practical purposes. In order to maintain scientific objectivity and technical applicability, a special and focused knowledge of a specific area was required rather than a generalist approach to everything in an ever more complicated social condition. 'Professionalism and utilitarianism' took over places that used to be occupied by common sense and absolute ethics," ibid., 4-5. The ultimate consequence worth observing here is that "with this new current epitomized as 'the scientific-scholarly ideal of the new university,' theological seminaries, particularly, which has been in the context of or in connection with colleges or universities, were very susceptible to or even enthusiastic about the demands for the new propensity in higher learning," ibid., 5 . In many cases, however, the result was that by "holding fast to the scientific and scholarly ideal of the new university," many seminaries "took the lively step of exodus from the authoritarian church which seemed to make theology obsolete and irrelevant in the modern society," and their new emphasis on science led directly to the 'death of God' theology in the 1960 's, ibid., 8 . Kim believes that "the seminary reform in the late nineteenth and early twentieth centuries intensified the tendency of the loss of distinctiveness of theological study while uncritically accommodating the ideal of the newly established 'scientific and scholarly' university," ibid., 9; see also, David A. Hollinger, "Justification by Verification: The Scientific Challenge to the Moral Authority of Christianity in Modern America," in Religion and Twentieth-Century American Intellectual Life, ed. Michael James Lacey (New York, NY: Cambridge University Press, 1989), 119. Ultimately, from the American perspective, after the Civil War, "the highest hopes for the church's new engagement with American higher education depended on those college and university faculty members who had come under the influence of the theological renaissance [of the 1930's].... By the end of the 1960's, however, nearly all these undertakings were in deep trouble, and the hopes that had attended them were fading, if not already dead," Douglas Sloan, Faith and Knowledge: Mainline Protestantism and American Higher Education (Louisville, KT: Westminster John Knox Press, 1994), 179.

${ }^{317}$ See the works of Stephen LeDrew, The Evolution of Atheism: The Politics of a Modern Movement (Oxford, UK: Oxford University Press, 2016); Michael Ruse, Darwinism As Religion: What Literature Tells Us about Evolution (Oxford, UK: Oxford University Press, 2017); Jackson Lears, "Afterward: One of the Therapeutic Culture's Most Persuasive Critics Considers the Historical Category Anew," in Rethinking Therapeutic Culture, eds. Timothy Aubry and Trysh Travis (Chicago, IL: The University of Chicago Press, 2015), 214; and C. Marvin Pate, From Plato to Jesus: What Does Philosophy Have to Do with Theology? (Grand Rapids, MI: Kregel, 2011),
} 
complex and pervasive movement than some suppose, ${ }^{318}$ and giants of the past, like the Christian

scientist Newton, are now enlisted as allies of atheism. ${ }^{319}$ Perhaps expectedly, it must be noted that

139. Jackson Lears explains that "the extraordinary revival of mechanistic positivism, seen in everything from pop-evolutionary thought to the New Atheism and the cult of neuroscience, has made it clear that scientism is the appropriate ideology for our neoliberal moment.... Scientism is a revival of the nineteenth-century positivist faith that a reified science has discovered (or is about to discover) all the important truths about human life. Precise measurement and rigorous calculation, from this view, are the basis for finally settling all the old metaphysical and moral controversies, explaining consciousness and choice, replacing ambiguity with certainty. The most problematic applications of scientism have usually arisen in the behavioral sciences, where the varieties and perversities of experience have often been reduced to quantitative data that are alleged to reveal an enduring 'human nature,"' Lears, "Afterward: One of the Therapeutic Culture's Most Persuasive Critics Considers the Historical Category Anew," 214. Alternately put, "Scientism is the belief, or the ideal, that there are no genuine explanations other than those of the natural sciences. Positively stated, scientism is the ideal that the explanations of science be in principle complete, not needing supplementation by philosophy or theology. This ideal provides a strong incentive to deny the existence of causes except those with which natural science can deal, namely, natural causes," David Ray Griffin, God and Religion in the Postmodern World: Essays in Postmodern Theology (Albany, NY: State University of New York Press, 1989), 75. In this regard, "clashes between" the two cultures are often assumed by scientists today to be falsely resolved through the multiplication of scientistic complexification-indeed, "it is just this which is happening today. Systems theory, for example, distinguishes three types of system: (a) living systems, (b), mental systems, and (c) social systems. All three of these are described using the same terminology. That which a century ago would have been a naive demonstration of positivism is today a model of the refinement of a theoretical concept," Giga Zedania, "Beyond the Two Cultures: Foreword," in Gigi Tevzadze, Evolution of Social Behavior to Homo and After, tr. P. J. Hillery (Tbilisi, Georgia: Ilia State University Press, 2013), xvi-xvii.

${ }^{318}$ Some, such as Arthur Buehler, argue that "scientific materialism is so inculcated in our modern western worldview (even among people who consider themselves very religious) that its paramount influence is hardly ever recognized. Often called scientism, the dogma of scientific materialism has become in its extreme form, to use Religious Studies vocabulary, scientific fundamentalism.... It emerged in the nineteenth century and is still the dominant paradigm in the academy if not Euro-American culture in general. We are trained as scholars in the postmodern academy to approach our studies without any religious dogmatism but this training has not given us an equal ability to discern between open-ended rational inquiry and the unconscious dogmatism of scientism.... The scientific-materialist paradigm is [also] still the underlying mainstream perspective in twenty-first-century humanities," Arthur F. Buehler, "Researching Sufism in the Twenty-First Century: Expanding the Context of Inquiry," in The Bloomsbury Companion to Islamic Studies, ed. Clinton Bennett (New York, NY: Bloomsbury Academic, 2013), 95. Similarly, Michael Lerner believes that "scientism has so deeply sunk into the consciousness of most people in the society who have ever undergone the 'mind treatment' that is dumped onto children by the public school systems and massively reinforced by the media, that by the time they are adults they swear loyalty to the dominant religion of scientism in their personal lives, their lives in the workplace or profession, and in their public statements about what they believe and profess," as cited by Tom Clark, "The Specter of Scientism," at http://www.naturalism.org/philosophy/new-age/the-specter-ofscientism (accessed February 11, 2018).

${ }^{319}$ Although Newton was a theist, many questions abound about his orthodoxy (he was antitrinitarian) and the overall consequences of his beliefs. Accordingly, some have claimed that "although he was a believer, Newton and his contemporaries help demonstrate what disbelief-or, in his case, limited belief-can contribute to science. His rejection of some of the more mystical and intrusive conceptions of God was probably necessary in order to give the sun and the planets leave to abide by equations. Newton's physics, the point is, benefitted from the rejection of some religious belief.... Science usually does. Its progress, we might say, is 'defined' by the diminution of God.... And the tendency of scientists-Newton among them-to push aside assumptions they considered irrational or unhelpful certainly helped. Newton's ability to leave God entirely out of the first edition of Principia Mathematica greatly helped." As such, "Newton, the scientist, probably was responsible for subtracting-denouncing-among the most important of God's qualities: his daily responsibility for the workings of the heavens," Mitchell Stephens, Imagine There's No Heaven: How Atheism Helped Created the Modern World (New York, NY: St. Martin's Press, 2014), 91, 90. See also, Angela Tilby, Soul: God, Self and New Cosmology (New York, NY: Knopf Doubleday, 2010). 
scientistic atheists oppose Heidegger vigorously, ${ }^{320}$ and scientism has even impacted Catholic

thinkers in profound ways, as the influence of academic philosophy in society has struggled to locate

any relevancy alongside the declining role of the humanities in general. ${ }^{321}$ Scientism is, arguably, and

unconsciously to many, the dominant force in the entire Western academy ${ }^{32}$ today, and there appears

${ }^{320}$ Alex Rosenberg explains that "Heidegger is scientism turned upside down." "So, should scientism worry? Certainly not about Heidegger's version [of reality]," which posits "that subjectivity is the most important fact about us, that science can't explain it, and that we therefore have to reject science as the correct description of reality" as we "build our picture of reality up from the nature of subjective experience." Rather, "almost everything he wrote is just laughably wrong when it's intelligible at all," Alex Rosenberg, The Atheist's Guide to Reality: Enjoying Life Without Illusions (New York, NY: W. W. Norton \& Company, 2011), 231. Heideggerians, of course, are opposed to scientism, see, for example, Frederick A. Olafson, Naturalism and the Human Condition: Against Scientism (New York, NY: Routledge, 2001).

${ }^{321}$ As noted by the Catholic philosopher John J. Conley, "Churched Philosophy,” at http://www. americamagazine.org/issue/churched-philosophy (accessed October 17, 2016). "Contemporary philosophy has a problem. No one outside the philosophical tribe seems to be listening. The most abstract of the humanities, philosophy grows ever more marginal," ibid. Conley also importantly and interestingly insists that, nevertheless, as "Pope Emeritus Benedict repeatedly reminded his listeners that the church's Hellenic philosophical impetus cannot be sliced off from an illusory pristine Gospel.... Augustine's Platonism and Aquinas's Aristotelianism model the synthetic passage through both Athens and Jerusalem that each Christian generation must undertake. For all their ecclesiastical contributions, the social sciences simply cannot engage the properly philosophical questions of the nature of truth or the destiny of the human soul. The universalist tenor of [traditional] philosophical discourse also permits the church to find common ground with more secular social-justice agents impervious to faith-based appeals to Scripture or tradition," ibid. Whether one agrees with Conley's conclusions or not, his comments reflect critical issues that must be addressed, especially concerning the platonic origin of the original humanities, which impacts upon philosophy's influence, purpose, and content, especially in areas like social justice. Heidegger's understanding of the humanities contrasts sharply with Conley's.

${ }^{322}$ See the discussion in Charles R. Bambach, Heidegger, Dilthey, and the Crisis of Historicism (Ithaca, NY: Cornell University Press, 1995), 27-29. Speaking broadly, "scientism functions as a useful term to describe those movements within philosophy and the natural and human sciences which identify reliable knowledge with the idea of science itself," and understood as such, scientism has come to dominate the academy. "It is not a stretch to suggest that our modern age really is, in some important senses, the age of science. Success at manipulating the world, as technology provides, strengthens our sense that science is showing us what really is the case in the world we inhabit.... Scientism is an enframing of life and world that has generated such enthusiasm and enjoyed such popularity that it often receives unquestioned acceptance by scholars and by the public. Partly because scientism has become the new orthodoxy, understanding the implications of enframing ourselves and our world in the way scientistic thinkers do is a matter of great significance and consequence," Richard N. Williams, "Introduction," in Scientism: The New Orthodoxy, eds. Richard N. Williams and Daniel N. Robinson (London, UK: Bloomsbury, 2015), 2. This is not to say, however, that there aren't significant segments of the academy and society that resist this, as the existence of the two cultures testifies. 
no signs of this subsiding anytime soon. ${ }^{323}$ They have seized control of the wheel that guides the

broader third culture. ${ }^{324}$

Notably, Polanyi's observations echoed many of Heidegger's, who had earlier bemoaned that in

the rising age of the scientific worldview the human was becoming a mere mathematical-biophysical

machine. ${ }^{325}$ Thus, the stage was set for the human, and his inner feeling of non-mathematically-

${ }^{323}$ See William W. Cobern, "Worldview, Science, and the Understanding of Nature," in the Scientific Literacy and Cultural Studies Project (ScholarWorks at WMU, 2005), available at http://scholarworks.wmich.edu /cgi/viewcontent.cgi?article=1021\&context=science_slcsp; Bruce Thornton, "The Dangerous Rise of Scientism," at https://www.hoover.org/research/dangerous-rise-scientism (accessed June 8, 2016); Thomas Burnett, "What is Scientism?," at https://www.aaas.org/page/what-scientism (accessed February 11, 2018); and Steve McIntosh, Evolution's Purpose: An Integral Interpretation of the Scientific Story of Our Origins (New York, NY: Select Books, 2012), 35-36, 120-132, 166-169. An irony worth observing at this point is that this is the primary reason why older traditional theological-metaphysical inquiry is shunned in mainstream secular culture-the older Platonic dualism between a timeless mathematical realm and a transitory-temporal realm has been reduced into a single conflated deterministic-temporal realm, one that doesn't need any "metaphysics" except mathematics. Yet, at the same time, Heidegger has also been accused of criticizing metaphysics-yet his reasons in doing so were very different-he considered the classical method an attempt to find God or salvation, which he thought ridiculous. See, for example, Martin Heidegger, Ontology-The Hermeneutics of Facticity, tr. John van Buren (Bloomington, IN: Indiana University Press, 1999), 16. Heidegger laments that in his day it seemed as though "the great industry of philosophy ... is geared merely to ensuring that one will not come too late for the 'resurrection of metaphysics' which-so one has heard-is now beginning, where one knows only the single care of helping oneself and others to a friendship with the loving God which is as cheap as possible, as convenient as possible, and as profitably direct as possible into the bargain inasmuch as it is transacted through an intuition of essences," ibid.

${ }^{324}$ Karl Giberson, "Scientific Fundamentalism and Its Cultural Impact," at https://biologos.org/ uploads/projects/Giberson_white_paper.pdf (accessed January 28, 2019). Giberson notes that "the gospel of scientific fundamentalism" "is remarkably analogous to its arch enemy, biblical fundamentalism" in tone, ibid. "The scientific fundamentalists are being called new atheists although there is nothing new about them. They preach a common and familiar sermon from the shared scripture of science: the world religions are collections of false superstitions, not merely wrong, but foolish and dangerous. They lead us to shoot abortion doctors, fly planes into buildings, persecute homosexuals, and squander natural resources. They make us racist, homophobic and sexually uptight," ibid.

${ }^{325}$ Martin Heidegger, Four Seminars, tr. Andrew Mitchell and François Raffoul (Bloomington, IN: Indiana University Press, 2003), 55. Heidegger was recounted to share later in his life, "modern experimental physics constantly searches for the laws of motion, just as Aristotle had. This would be the meaning of the fundamental universal formula, insofar as all the possibilities of movement in their infinite variety could be deduced. Heidegger now asks what the discovery of this formula would mean for physics. The answer runs: the end of physics. Such an end would entirely alter the human situation," ibid. Later Heidegger observed, "here, more disturbing than the conquest of space, there appears the transformation of biology into biophysics. This means that the human can be produced according to a definite plan just like any other technological object. In this context, nothing is more natural than to ask whether science will be able to stop in time. Such a stop is nevertheless fundamentally impossible," ibid. All this, of course, merely follows upon the heels of Heidegger's earlier work, when he contended that "What is the fundamental trait of modern metaphysics? Modern metaphysics is determined by the fact that the entirety of the traditional problematic comes under the aspect of a new science, which is represented by mathematical natural science," Heidegger, The Fundamental Concepts of Metaphysics: World, Finitude, Solitude, 54. Again, in critiquing the work of Kant, Heidegger explains, "mathematical natural science gives an indication of this fundamental conditional connection between ontic experience and ontological knowledge. However, its function for the laying of the ground for metaphysics exhausts itself therein, for the reference to this conditional connection is not yet the solution to the problem. It is rather only a statement of the direction in which it, to be understood in its more fundamental universality, must first be sought. Whether it can be found only there, and whether it can be found at all, i.e., whether the 
calculative or "scientific" freedom, ${ }^{326}$ to rebel, by leaping into the post-modern. ${ }^{327}$ Or, as Michael Mack explains, language and "literature engages with a realm beyond numbers. It is the sphere of feeling that cannot be measured. This immeasurable aspect of our life nevertheless constitutes a substantial part of the human mind and we cannot wish it away as C. P. Snow has famously done."328

Thus, from the perspective of one in the humanities, Yuval Levin noted that "Snow believed the future of a society would be determined by the character and quality of its scientific education. But in fact, the future came to be determined by a society's sensitivity to human freedom and dignity, and to individual rights-that is, by the character of its politics." ${ }^{329}$ As Levin further observed, "Snow accused the 'traditional culture' [and its literary caretakers] of overlooking the significance of science, and in part he was right. But he was guilty of precisely the equal and opposite oversight. He failed to appreciate the significance of politics, not only for the general future of the West, but also for the particular future of science. The two cultures are in fact deeply dependent on one another." ${ }^{330}$ Yet,

idea of a Metaphysica Specialis in general can be projected in accordance with the concept of positive (scientific) knowledge-precisely this should first be determined," Martin Heidegger, Kant and the Problem of Metaphysics $5^{\text {th }}$ edition, tr. Richard Taft (Bloomington, IN: Indiana University Press, 1997), 7. Overall, then, Stefano Franchi and Güven Güzeldere accurately summarize Heidegger's motivation to separate philosophy, and with it, the humanities, from the sciences when they observe that "the spectacular advances in the exact sciences" would "act ... as the 'liquidator' of the humanities in general and more specifically of philosophy" itself, Stefano Franchi and Güven Güzeldere, "Machinations of the Mind: Cybernetics and Artificial Intelligence from Automata to Cyborgs," in Mechanical Bodies, Computational Minds: Artificial Intelligence from Automata to Cyborgs, eds. Franchi and Güzeldere (Cambridge, MA: Massachusetts Institute of Technology, 2005), 119. See also, Tamar Sharon, Human Nature in an Age of Biotechnology: The Case for Mediated Posthumanism (New York, NY: Springer, 2014), 140; and Joseph Weizenbaum, "Limits in the Use of Computer Technology: Need for a Man-Centered Science," in Toward the Recovery of Wholeness: Knowledge, Education, and Human Values, ed. Douglas Sloan (New York NY: Teachers College Press, 1984), 149-158.

${ }^{326}$ The Heideggerian psychologist Louis Berger expresses concerns that "seriously raise the possibility that any theory of the usual [scientific] type ... may in some fundamental way be inadequate and inappropriate for a psychoanalytic approach to the study of man," even though the majority of psychologists continue to search for such theories, Louis S. Berger, Issues in Psychoanalysis and Psychology: Annotated Collected Papers (Victoria, BC: Trafford Publishing, 2002), 7.

327 "Yet, if this is madness, there is method in it, for Heidegger himself points out that if the question really is how to break out of the constrictions of the prevailing metaphysical tradition, then we cannot argue our way out, since all the forms of argument we could possibly use are familiar to the tradition. We cannot argue our way out, we can only leap-and it is entirely consistent with the discontinuity introduced by such [quantum?] leaps that we land in strange and unfamiliar surroundings. On the far side of the leap, the world looks different," George Pattison, The Later Heidegger (New York, NY: Routledge, 2000), 17 (addition mine).

${ }^{328}$ Mack, Philosophy and Literature in Times of Crisis, 20. One need only think of the challenges faced in sports, such as baseball, where mathematics and statistics play a key role. Yet, as important as statistics are, they do not encompass the entirety or purpose of why people choose to play and watch the game.

${ }^{329}$ Yuval Levin, Imagining the Future: Science and American Democracy (New York, NY: Encounter Books, 2008), 47.

${ }^{330}$ Levin, Imagining the Future, 47. 
despite Levin's acknowledgment of their connectedness, their apparent mutual dependance belies a very uneasy relationship, a philosophical problem that has deeply impacted the place of religion and theology within the philosophical conflict which has generated the two cultures. As Immanuel Wallerstein explained, the "division of knowledge of the two cultures came to mean as well creating a high barrier between the search for the true and the search for the good and the beautiful," ${ }^{331}$ which places religion, and theology, as disciplines that also seek after both the true and the good and beautiful, into a place filled with contentious tension-as religionists agree there are tensions but disagree upon where the tensions really lie. In the following section I will explain why this is so in more detail, as the consequences of the two cultures' war for the study of religion and theology are significant, even while relatively infrequently acknowledged. ${ }^{332}$

\section{The Science and Religion Dialogue: A Dead End?}

The significance of the developments behind the emergence of the two cultures of the humanities and the sciences, and also their apparently symbiotic failings in the eyes of some philosophers, ${ }^{333}$ cannot be overstated for an understanding of the role of religious studies in the

\footnotetext{
${ }^{331}$ Immanuel Wallerstein, World-Systems Analysis: An Introduction (Durham, NC: Duke University Press, 2004), 3.

${ }^{332}$ Furthermore, some of the more prominent individuals to acknowledge the issue, such as Alister McGrath, offer a "solution" that merely preserves the tension. That is, he simply affirms "orthodox" Christianity as historically enduring and thus intrinsically legitimated, and seeks scientific evidence that is compatible with it. Alister E. McGrath, Scientific Theology: Nature (New York, NY: T\&T Clark, 2006), 33-36. Many find such an approach wholly inadequate. McGrath's mild "concern" against those worried about "the danger of basing the dialogue between the natural sciences and Christianity on a transient revision of a classical theological position" using the traditional platonic tools closes many postmodern doors, and as such, his "position ... that the classic Christian formulations of faith are perfectly adequate to function as the basis of a scientific theology" that would resolve the clash of the two cultures appears short-sighted at best, given the classic orthodox position helped create the problem in the first place, ibid., 41-42, 214.

${ }^{333}$ Many have come to believe that "twentieth-century modernism is committed to the separation of what C. P. Snow called 'the two cultures' of science and the humanities," a separation doomed to failure, Robert F. Garnett, Jr., "Rhetoric and Postmodernism in Economics," in The Elgar Companion to Economics and Philosophy, eds. John Bryan Davis, Alain Marciano, and Jochen Runde (Glos, UK: Edward Elgar Publishing, 2004), 234. Michael Mack, as noted above, suggests a reason for the failure while insightfully linking the two cultures into the divide between modernism and postmodernism: "strikingly, the divide between two cultures, between nature and society, between science and politics is constitutive of modernity's consciousness.... We have never been modern for the reason that the modern purification project-premised as it is on the radical separation between nature and society-has actually never been put to practice nor could it have ever been realized ... because these nominally separated spheres are actually similarly constituted and in need of mediation. The project of modernity obfuscates or even denies the existence of subjectivity and the invisible... Modernity could be defined as the unconscious of the invisible, as the unconscious of affect."

However, "postmodernism recognizes that there is something wrong with the modern insistence on
} 
academy during the $19^{\text {th }}$ and $20^{\text {th }}$ centuries. Although the present contours of the tension were first intimated by the theistic scientist and "father" of the scientific method, Francis Bacon (1561-1626), ${ }^{334}$ it was toward the end of the $19^{\text {th }}$ century when John Draper and Andrew White first openly declared that a state of war existed between science and religion, though notably for them it more meant science and the Church. ${ }^{335}$ Ever since that time, these two co-existing domains, which both claim to provide an authentic or accurate understanding of what we can know about reality, have presented an increasingly challenging dualism to harmonize before both the public and the world of scholarship.

One of the foundational problems that motivates this study is that since the time of Heidegger and Snow, perhaps the most important question to emerge in exchanges between proponents of science as an agnostic enterprise (often proposed by those who view methodological naturalism as closely related to ontological naturalism ${ }^{336}$ but clearly distinguishable from, although still related to, scientific or scientistic methodologicalism), and proponents of religion, has been whether philosophy, and especially theology and religion, best belong within the culture of the sciences or humanities. Of course, many from those in the 'culture of religion,' which Snow had placed within the humanities, claimed, perhaps naïvely, that properly understood, religion reconciled or harmonized the two

objectivity and visibility, but it abstains from further commitments that would investigate modernity's unconsciousness.... 'Postmodernism is a symptom, not a fresh solution. It lives under the modern Constitution, but it no longer believes in the guarantees the Constitution offers,'” Mack, Philosophy and Literature in Times of Crisis, 19-20. Or, alternately put, "in postmodernism, the ultimate consequence of modernism is recognized and played out.... Postmodernism basically entails the realization that modernism's objectification of the subject is but the first term of an infinite regress," Rosen, Dimensions of Apeiron: A Topological Phenomenology of Space, Time, and Individuation, 196. For an example of post-moderns who live under the "modern Constitution" but refuse to acknowledge modernity's unconscious, one could point toward naïve Heideggerians who refuse to engage contemporary physics philosophically, choosing instead to preserve the two cultures, which has helped spawned the ambiguities present in the post-postmodern condition.

${ }^{334}$ Edward Grant, A History of Natural Philosophy: From the Ancient World to the Nineteenth Century (Cambridge, UK: Cambridge University Press, 2007), 296, 306; Steven Matthews, Theology and Science in the Thought of Francis Bacon (Burlington, VT: Ashgate, 2007), 110; and Perez Zagorin, Francis Bacon (Princeton, NJ: Princeton University Press, 1998), 49.

${ }^{335}$ John William Draper, History of the Conflict Between Religion and Science (New York, NY: D. Appleton, 1897, 1874), and Andrew Dickson White, History of the Warfare of Science with Theology in Christendom, 2 vols. (New York, NY: D. Appleton, 1922, 1896).

336 "Methodological naturalism is a methodological commitment to employing in inquiry only the norms and methods of inquiry of the empirical sciences together with their logico-mathematical auxiliaries. This, the claim is, is the only way we legitimately and securely can fix belief," Kai Nielsen, Naturalism and Religion (Amherst, NY: Prometheus Books, 2001), 136. For more on scientistic naturalism, see J. P. Moreland and William Lane Craig, Philosophical Foundations for a Christian Worldview (Downers Grove, IL: InterVarsity Press, 2003), 307-367. For the meaning of ontological naturalism, see Earl Stanley B. Fronda, Wittegenstein's (Misunderstood) Religious Thought (Boston, MA: Brill, 2010), 135 n. 3, which will be discussed further below. 
cultures' differences. ${ }^{337}$ As Lloyd Sandelands recently opined, optimistically, "in God, the 'two cultures' of science and humanities identified by Snow (1959) are reconciled."338 Nevertheless, despite such positive and simplistic assertions such as the above from Sandelands, the divide in the broader academic and popular communities continues to grow, ${ }^{339}$ not dissipate, and religionists themselves have divided as well, with religious modernists favoring the sciences ${ }^{340}$ and religious postmodernists favoring the humanities, ${ }^{341}$ as they realized the depth and implications of the issues separating the two cultures. Why religionists have themselves become divided between the sciences and humanities is of critical importance, and warrants further examination (of course, related

\footnotetext{
${ }^{337}$ In even as popular a venue as LIFE magazine an editorial opined in 1962: "both 'cultures'-science and humanities-seem in growing need of a superior guide, a transcendent religious reconciliation," LIFE magazine, "Two Cultures Harmonized Under God," (April 20, 1962), 4.

${ }^{338}$ Lloyd E. Sandelands, An Anthropological Defense of God (New Brunswick, NJ: Transaction Publishers, 2007), 93 n. 2.

${ }^{339}$ This is affirmed by the contemporary scientist-theologian Alister McGrath. "Little seems to have changed since 1959 [when Snow shared his lecture]. The debate continues, and raises the question as to whether there is any possibility of reversing-or at least eroding-the divorce between the natural sciences and humanities. Might there be a basis for a unitary foundation for human knowledge, while avoiding the rationalist imperialism of the Enlightenment, so rightly derided and critiqued by its opponents," questions McGrath, Scientific Theology: Nature, 33-34.

${ }^{340}$ For recent examples, see Brian S. Bull, "Why are Science and Religion Still Fighting?" in Understanding Genesis: Contemporary Adventist Perspectives, eds. Brian Bull, Fritz Guy \& Ervin Taylor (Riverside, CA: Adventist Today Foundation, 2006), 23-34; Brian S. Bull and Fritz Guy, "Then A Miracle Occurs," ibid., 53-69; and Owen J. Flanagan, The Problem of the Soul: Two Visions of Mind and How to Reconcile Them (New York, NY: Basic Books, 2003).

${ }^{341}$ This is true to differing degrees with different individuals, many of whom are somewhat dualistic in how they emphasize the humanities and sciences, given the state of development of the natural sciences operative within their historical contexts. Note that the humanities can be construed broadly at times, including platonically-just because someone reserves a special role for the "humanities" in religious discourse does not mean they do or do not also conform to the standard scientific suppositions of their day. Overall, Protestantism as a movement has maintained a consistent dualism within its philosophy in this regard. From such a wider perspective, one could claim, with Steven Ozment, that the "humanities became for Protestant theologians what Aristotelian philosophy had been to late medieval theologians-the favored handmaiden of theology; the rhetorical arts served the more basic task of communicating true doctrine," Steven Ozment, The Age of Reform 1250-1550: An Intellectual and Religious History of Late Medieval and Reformation Europe (New Haven, CT: Yale University Press, 1980), 315. More specifically, beyond the original Protestants like Martin Luther and John Calvin, one could trace an emphasis in the humanities through the works of Friedrich Schleiermacher, Paul Tillich, Reinhold Niebuhr, H. Richard Niebuhr, and C. S. Lewis, and also the 'secular' theologians, building off of the "death of god" movement instigated through the work of the philosopher Friedrich Nietzsche, such as Paul van Buren, Harvey Cox, Thomas Altizer, and William Hamilton. See, in particular, Sloan, Faith and Knowledge, 111-149; Sverre Raffnsøe, Philosophy of the Anthropocene: The Human Turn (Hampshire, UK: Palgrave Macmillan, 2016); and Colin E. Gunton, Revelation and Reason: Prolegomena to Systematic Theology, ed. P. H. Brazier (New York, NY: T\&T Clark, 2008), 160-161.
} 
pragmatic and political concerns are also surely important factors-but perhaps these are related to a core philosophical concern). ${ }^{342}$

The Emergence of the Real Conflict and the Ongoing Crisis in the Third Culture: An Opportunity for Religion to Find a Place?

Probably the most popular recent proposals of the possible relationship between the two domains of natural science and religion has been Ian Barbour's four options: 1) conflict, 2) independence, 3) dialogue, and 4) integration. ${ }^{343}$ In this schema, the former two are more naturally paired together, as are the latter two. Without question there have been advocates for each of these general alternatives in recent times. Not surprisingly, within religious circles, efforts at dialogue and integration have been the preferred options to maintain an elevated status for the significance of religion, such as has been sought by prominent figures like John Polkinghorne, Philip Clayton, ${ }^{344}$ and others supported by the Templeton Foundation. However, this fact encourages an interesting result. Owing to the broadly secular nature of the mainstream world of scientific research and scholarship in the $21^{\text {st }}$ century, which has shown relatively little interest in the interaction between science and

\footnotetext{
${ }^{342}$ For example, given that the sciences and technology have eclipsed the arts and humanities in overall popularly perceived usefulness to society, an air of elitism has developed amongst science departments in the universities. In such a climate, the humanities are often denigrated. In response, the humanities have sought to carve out a space for themselves, by creating their own type of intellectual elitism, separating themselves by "inaccessible discourse" which has made them "seem part of an excluding agenda" rather than an inclusive one, whether religious or otherwise. Contrastingly, the elites within the sciences promote their elitism precisely by engaging the public, and showing "that their research outcomes have public benefit," and that they desire to promote "the public understanding of science," Jan Parker, "Speaking Out in a Digital World: Humanities Values, Humanities Processes," in Humanities in the Twenty-First Century: Beyond Utility and Markets, eds. Eleonora Belfiore and Anna Upchurch (Hampshire, UK: Palgrave Macmillan, 2013), 47.

${ }^{343}$ Ian G. Barbour, Religion and Science: Historical and Contemporary Issues (New York, NY: HarperCollins, 1997), 77-105; see also his further articulation of these options in Ian G. Barbour, When Science Meets Religion: Enemies, Strangers, or Partners? (New York, NY: HarperCollins, 2000).

${ }^{344}$ For example, note the scientist and theologian John Polkinghorne, Science and Religion in Quest of Truth (London, UK: Yale University Press, 2011), 22, where he shares that "dialogue ... is the premise on which the enquiry pursued in this book is based," which leads him toward the possibility of integration, ibid. Similarly, Philip Clayton observes that "it is a strange paradox. Much evidence suggests that a genuinely integrative theology does not and perhaps cannot exist in our day and age. Yet the need for an open-ended dialogue between contemporary philosophy and science and the Christian tradition is greater than ever," Clayton, Adventures in the Spirit: God, World, Divine Action, vii.
} 
religion through either dialogue or integration, openly religious scholars have often been limited to pursuing their quest exclusively within sympathetic religious audiences. ${ }^{345}$

In other words, the general outcome has been that despite the best efforts of many contemporary religionists to engage the world of science and scientists, religionists generally remain funneled by the mainstream secular academy into the first and second relational options, that of conflict or independence. For example, the agnostic paleontologist and philosopher of science Stephen Jay Gould, a contemporary of Barbour, popularized and encouraged such independence through his support of the two non-overlapping magisteria of science ("the age of rocks") and religion ("the rock of ages"). ${ }^{346}$ For Gould, religion, and Christianity in particular, encourages conclusions (particularly its central claims concerning an afterlife, God, and the imago dei inspiring human exceptionalism, and ethics ${ }^{347}$ ) that are either not part of natural science's magisterium or are not

\footnotetext{
${ }^{345}$ The reasons for the above situation are complex, but important to understand. Put simply, dialogue and integration are themselves dependent on a secular scholarly world that has created an atmosphere that sees science and religion as either independent or in conflict; there would not be any need for dialogue and integration if conflict or independence were not first assumed, which the secularized academy knows very well. The foundation of this problem rests upon the fact that the concepts and methodology of "science" are presupposed as a medium of communication for all four options. This means the success or utility of dialogue and integration are dependent upon the advances from a scholarly world originating independent or conflicting presuppositions and conclusions. A circularly question begging situation, leaving dialogue and integration meaningless if conflict or independence were not somehow assumed in the first place. Accordingly, secularists see no reason to engage religion; the possibility of dialogue and integration are the fantasies of religionists. See also, Heidi A. Campbell and Heather Looy, eds., $A$ Science and Religion Primer (Grand Rapids, MI: Baker Academic, 2009), 11. They share, disapprovingly, that there appears to be a "widespread myth that science and religion are antagonistic, or at best unrelated, ways of viewing the world," ibid. However, Campbell and Looy, like Polkinghorne and Clayton, insist that "science and religion have always been inextricably intertwined, and recent years have seen a surge toward open, explicit dialogue and research on their relationships," pointing toward the third and fourth options of Barbour's, dialogue and integration, as the most common for committed theists, ibid. However, for an illustration of how conflict or independence often win out over explicit efforts at dialogue and integration, note Francis Collins, The Language of God: A Scientist Presents Evidence for Belief (New York, NY: Free Press, 2006). In this book, Collins essentially argues that blind Darwinian evolution is compatible with theism-and one of the key pieces of evidence he relies on is 'junk DNA.' Collins made this attempt to bridge his theism with science for the sake of conforming to the prevailing scientific consensus. However, Collins is aggressively critiqued for this 'bridging' effort by many fellow theistic scientists who prefer Intelligent Design over Darwinism, and who argue that there actually isn't much 'junk DNA' after all. See, for example, Jay Richards, ed., God and Evolution (Seattle, WA: Discovery Institute, 2010). Here multiple scientists argue that theists like Collins do a disservice to theism, especially Christianity, in their efforts to harmonize mainstream science with religion. The battle then turns to whether or not the ID movement is scientific, a matter very much unresolved.

${ }^{346}$ Stephen Jay Gould, Rocks of Ages: Science and Religion in the Fullness of Life (New York, NY: Ballantine Publishing Group, 1999), 5-6. See also, Stephen Jay Gould, The Hedgehog, the Fox, and the Magister's Pox: Mending the Gap between Science and the Humanities (New York, NY: Harmony Books, 2003).

${ }^{347}$ Warren D. Allmon, "The Structure of Gould: Happenstance, Humanism, History, and the Unity of His View of Life," in Stephen Jay Gould: Reflections on His View of Life, eds. Warren D. Allmon, Patricia H. Kelley, and Robert M. Ross (Oxford, UK: Oxford University Press, 2009), 38-39.
} 
verifiable (owing to inconclusive and incomplete data), leaving religion and religionists generally irrelevant to scientists operating their craft within the natural world through methodological naturalism. Gould's call to 'let religion be,' taken so boldly by an atheist, represents one of the strongest overtures of 'friendship' given by an atheist in acknowledgment of the failures of scientism's overreach-yet it should be realized that this friendship comes with a price. ${ }^{348}$

Within such a situation as what Gould has encouraged, rather than any explicit conflict becoming prominent, the independence between the sciences and religion becomes the most prominent feature of the relationship, and many religionists and scientists have accepted this reality as the best that can be pragmatically achieved. What's important about this is that the many apparent non-overlapping aspects (e.g., free-will, the nature of the afterlife, etc.) of the differing domains of science and religion encourages most religionists to assume either a naïve harmony between standard operational scientific methodology and religion or, in fewer cases, a total apathy that leads to the irrelevance of any discussion of their interaction or relationship. Within the broader circles of religionists this situation ultimately only encourages more 'endless' conversations seeking dialogue and integration by religionists with fellow believing scientists that are typically ignored by their atheist and agnostic colleagues, or, less frequently, but more radically as just noted, it generates an openly antagonistic stance of accepting the conflict or outright independence leading to the complete

\footnotetext{
${ }^{348}$ Essentially, it could be suggested, or it appears, that Gould has, not necessarily maliciously, 'tricked' some religionists into feeling accepted at the table of dialogue or discourse, but at the same time, Gould has encouraged religionists to often unconsciously become comfortable with accepting the central tenet of the scientific worldview-that is, that "supernatural explanations and concepts" have no place at the table of scientists, science, and scientific explanations, which cements into place a permanent dualism between science and religion. One of the additional consequences of this is that religionists have often fallen prey to attempts to reconcile science and religion at a superficial level, based upon a particular understanding of the current scientific worldview controlled by scientists like Gould. As such, religionists expose themselves to the possibility that if "the scientific worldview shifts, the connection may well be lost," Thomas J. McFarlane, "The Non-dual Root of Science and Religion," in The Rose+Croix Journal Vol. 10 (2014), 44. That is, today, religionists are often caught trying to reconcile their views with a prior presuppositional acceptance of standard science-regardless of what scientific interpretations may say in the near future, or how science itself may change in the future, or an awareness of alternative views of science in the present. Thus, for example, typically many "conservatives" try to scientifically prove a recent creation, while "liberals" try to prove biblical theology is compatible with whatever basic conclusions the scientific community makes about earth history and time. In both cases, conservative or liberal religionists are arguing for a concordance between standard scientific methodology and their interpretations of Scripture because they are not critically exploring alternative views of appropriate conclusions from scientific evidence in relationship to textual evidence.
} 
irrelevance of the entire discussion. ${ }^{349}$ For example, theistic evolutionists often cause the worst problems from a sociological perspective, antagonizing religious conservatives while likewise generating no serious respect from most atheist scientists, who then see religionists as mere compromisers introducing irrelevant additional concepts.

Obviously, if the focus is on "non-overlapping" areas, independence is often accepted without much of a fight from either side, although this likewise cements into place, often unconsciously to religionists, "the humanities" onto the side of religion within debates between science and religion, which lowers the reputation, value, and status of religion in the eyes of the scientistic Western academy and its many atheists and agnostics. Unfortunately, however, the net result of such a stance of non-overlapping domains appears to, as history shows, merely 'kick the can down the road' until developments in the religious humanities and sciences again force a conflict (especially in explicitly overlapping areas, which are continually reevaluated, such as protology and eschatology), and such conflicts almost inevitably involve dimensions of how freedom and time should relate to society, that is, the conflicts emerge most sharply through the third cultures of psychology and psychiatry, economics, and the socio-political sciences, as will be explored below.

This happens because there are significant ramifications involved with becoming too comfortable with Gould's suggestion of non-overlapping magisteria. This is because most scholars are well aware that, at least at a surface reading or interpretation of the Bible and of nature, there are obvious significant conflicts between the biblical text and the conclusions of the community of

\footnotetext{
${ }^{349}$ This holds true for multiple understandings of "science" and "religion" as the dominant features underlying worldviews. For example, a rigid mechanistic view of nature alongside an idealization of the Platonic 'beauty of mathematics' can be equated with the design argument for a Creator, whereas a "neoplatonic-magical-spiritualist tradition, which was the main opponent of the mechanical philosophy in the seventeenth-century battle of the worldviews, can, as a religious and scientific naturalism, be regarded as a premodern precursor to the postmodern naturalistic worldview developed by [the mathematician Alfred North] Whitehead," a process philosopher. David Ray Griffin, Religion and Scientific Naturalism: Overcoming the Conflicts (Albany, NY: State University of New York Press, 2000), 19. The point is, in either a platonic or neoplatonic form, religionists can be encouraged to "let science be" just as atheist scientists wish, when some of them openly offer to "let religion be" at peace in an effort to preserve the autonomy and influence of science and the scientific community and its worldview. Heidegger himself partly acquiesced to this demand of the scientists, stating that "philosophy is neither for nor against science but instead leaves it to its own craving to find profit in securing ever more efficiently and quickly ever more useful results and thus in anchoring ever more firmly the dependence of needs and wants in the respected result and in its surpassing," Heidegger, Contributions to Philosophy (Of the Event), 122.
} 
scientists, and adhering firmly to a stance of mere independence between science and religion will not

long suffice. It is at this point that philosophical reflection on the relationship between science and

religion becomes paramount and necessary. As the Catholic philosopher John Haught attempts to

explain for those who aim to see harmony between science and religion, while critiquing religionists

who are harsh critics of science:

It may not be science but scientism that is the enemy of religion. The implicit conflation of science with scientism, [religious supporters of science] will argue, is what lies at the root of most modern opposition by scientists to religion. Without usually being aware of it, [religious] scientific skeptics have uncritically fused the scientific method with scientism, a belief system that assumes, without any scientific demonstration, that science is the only appropriate way of looking at things. And so it is little wonder that [religiously-minded scientific skeptics] quite ingenuously conclude that science opposes religion. [This] ... method of contrast, however, prohibits the conflation of scientific method with any belief system, be it religious or secular, since sooner or later such a facile sort of union leads to unnecessary conflict. ${ }^{350}$

Interestingly, and to cut to the heart of the matter, what Haught's position clearly suggests is that methodologically, agnostic naturalism and biblical naturalism (and also theology!) shouldn't really be any different operationally and even conceptually. ${ }^{351}$ It is only their presuppositions and conclusions, which affect their choice of content from the available scientific, biblical, historical, and archaeological data, that are sometimes radically different. In other words, the (theistic or atheistic) scientist and biblical historian/theologian may agree that the accurate conclusions of "honest" scientists and historians/theologians concerning the data of the natural world will arrive at the same (or

${ }^{350}$ John F. Haught, Science and Religion: From Conflict to Conversation (Mahwah, NJ: Paulist Press, 1995), 17. Haught further explains the implications of the above for those who see harmony between science and religion, in that "for this reason [religious opponents of science] . . cannot join forces with [any] ... defense of traditional religious culture against the evils of 'science.' For, as far as they [including Haught] are concerned, it is not really science, ... but scientism that emptied modern culture of its religious depth. We must clearly and consistently distinguish science from scientism.... [We must not acquiesce] in the conflation of science and scientism that skeptics call by the innocuous name 'science,' and this failure to be clear about the distinction is what causes ... misdirected rage," ibid., 17. See also, John F. Haught, Science and Faith: A New Introduction (Mahwah, NJ: Paulist Press, 2012).

${ }^{351}$ Though not holding Haught's specific conclusions, the recent creationist Ken Ham would similarly insist, "both evolutionists and biblical creationists can practice good operational science-in fact, biblical creationists really have a far better foundation for it (a basis for the laws of logic and the laws of nature as a result of creation, not random processes)," Ken Ham, Six Days: The Age of the Earth and the Decline of the Church (Green Forest, AR: Master Books, 2013), 61. As Ham further complains, a popular atheistic evolutionist like Bill Nye "continually attempts to claim that a Christian's historical science will stop people from doing operational science-but this is nonsense!," ibid., 62. See also, Jason Lisle, Discerning Truth: Exposing Errors in Evolutionary Arguments (Green Forest, AR: Master Books, 2010), 21; and Derrick McCarson, Origins: An In-Depth Study of Genesis 1-11 (Bloomington, IN: CrossBooks, 2012), 32. 
compatible, in the case of absent or missing evidence) conclusions for overlapping questions of biblical significance (e.g., support or lack thereof for some specific geological evidence of a flood event, either local or global, ${ }^{352}$ and archaeological evidence for or against a Davidic dynasty and kingdom ${ }^{353}$ ) if there is in fact only one real reality of "objects" to interpret through the scientific methodology-Haught's point is precisely that the "scientific method" isn't the problem. ${ }^{354}$

\footnotetext{
${ }^{352}$ For an example of outspoken advocates of a global flood, see Ken Ham and Bodie Hodge, $A$ Flood of Evidence: 40 Reasons Noah and the Ark Still Matter (Green Forest, AR: Master Books, 2016). See also, Leonard Brand and Arthur Chadwick, Faith, Reason, \& Earth History: A Paradigm of Earth and Biological Origins by Intelligent Design $3^{\text {rd }}$ ed. (Berrien Springs, MI: Andrews University Press, 2016); and Harold G. Coffin, Robert H. Brown, and L. James Gibson, Origin by Design rev. ed. (Hagerstown, MD: Review and Herald, 2005).

${ }^{353}$ For examples of critics of Scripture's account, see Michael Nathanson, Between Myth \& Mandate: Geopolitics, Pseudohistory \& the Hebrew Bible (Bloomington, IN: AuthorHouse, 2014), 287; and Emanuel Pfoh, The Emergence of Israel in Ancient Palestine: Historical and Anthropological Perspectives (New York, NY: Routledge, 2009), 16-19. For a defense by those holder a higher view of the biblical account, see Iain William Provan, V. Philips Long, and Tremper Longman III, A Biblical History of Israel (Louisville, KT: Westminster John Knox Press, 2003), esp. 193-238. For a broad commentary on the above fields, including archaeology, and how they relate to philosophy, see Tim Ingold, Making: Anthropology, Archaeology, Art and Architecture (New York, NY: Routledge, 2013).

${ }^{354}$ Haught argues for a relationship built on "contact," which preserves, "without in any way interfering with scientists' own proper methods," a "religious faith [which] can flourish alongside of science in such a way as to co-produce with it a joint meaning that is more illuminating than either can provide on its own," Haught, Science and Religion: From Conflict to Conversation, 18. Of course, what the given scientist's views on biblical presuppositionalism are will make a difference in what harmony would be expected on an issue like Noachian flood geology. As such, the proper nature of what biblical hermeneutics is in itself and truly accurate natural science are of paramount importance if harmony is to be expected, returning the issue into a circularity of hermeneutical method and primacy, as will be discussed more below. In the present context, it might be merely noted that all forms of Christianity, be they conservative Protestantism, liberal Protestantism, and both modern conservative and liberal Catholicism, claim to support science, and claim science supports them-both in the evidential conclusions of the scientific communities they respect, and also methodologically, which is the key point. For examples within Protestantism, see Peter Harrison, The Bible, Protestantism, and the Rise of Natural Science (Cambridge, UK: Cambridge University Press, 1998); and Leslie A. Muray, Liberal Protestantism and Science (Westport, CT: Greenwood Press, 2008). Critically, Muray correctly shares "what distinguishes the Age of Science are not just the great scientific discoveries of that era" "but, perhaps even more importantly, the rise of inductive scientific reasoning. This rationality was not the kind of premodern deductive reasoning that assumed certain things to be true and then reasoned why that was so. Rather, it created hypotheses, tested them, and then drew conclusions based on the evidence. In the broader philosophical and cultural arena, the emphasis on this kind of reasoning led to a sense that it was legitimate to question authority, in fact to question everything-whether it be the divine right of kings, the authority of the Bible, of the Pope, or of the church, Roman Catholic or Protestant," ibid., 7-8. The point, then, at present, is that the consensus appears to suggest that "contrary perhaps to what one would have expected, a more fully biblical world view has, since the sixteenth century, favoured the rise of modern science and of the world picture connected with it. The model of the world as an organism was replaced by that of the world as a mechanism; the whole development from Copernicus to Newton has rightly been called the mechanization of the world picture," Hooykaas, Religion and the Rise of Modern Science, 13. Nevertheless, Hooykaas importantly admits that "of course, the machine model offers no adequate picture. The maker of a machine is under severe restrictions by the character of the materials, whereas the creator creates his materials himself; once it has been made, a machine has a certain independence, but the God of the biblical authors never abandons his work, as this would mean its reduction into nothingness. The image of a god-mechanician, then, is subordinate to that of a god-creator, but it is not at odds with it, as is the image of a god begetting the universe. Thus the idea of a world-machine, though not to be found in the Bible, fits in better with its spirit than the idea of a world-organism," ibid., 15. On the contrary, it was none other than Francis Bacon who suggested that "what nature really is cannot be adequately expressed
} 
Thus, while the methodological naturalism that is advocated for by those biased against

Scripture may not seem desirable for religionists, according to Haught, religionists must also keep in mind that scientific methodologicalism ${ }^{355}$ isn't the problem. There will be eventual harmony because the harmony is founded upon a presupposition that assumes the scientific method is valid ${ }^{356}$ for both

by the simile of a 'machine', and who God really is cannot be aptly represented by the term 'mechanician'. It cannot be done even by reducing natural science to mathematics and by calling God, 'for want of a wide word', a great mathematician," ibid., 16.

${ }^{355}$ On its own, of course, most (incorrectly, for the Heideggerian) believe "methodology does not involve a direct claim about reality, and so a methodological stance should not be judged 'right' or 'wrong.' Instead, it is a matter of being useful or not," Richard H. Jones, Reductionism: Analysis and the Fullness of Reality (London, UK: Associated University Presses, 2000), 143. Contrastingly, methodologicalism refers to the belief that proper methodology solves all problems-scientific methodologicalism thus naturally assumes that whether it is nature or Scripture (including both its language and historical-scientific claims), the scientific approach by virtue of its intrinsic method will resolve either domain's problems. In this sense, both the historicalgrammatical and historical-critical methodologies appeal to an identical 'scientific' method, as does scientific methodological naturalism.

It may be apropos here to observe that two of the chief philosophers of science during the $20^{\text {th }}$ century, Karl Popper and Thomas Kuhn, famously debated the nature of science and the scientific method, both in person, but more so through their writings. In brief, Popper argued that science is based upon hypotheses that must be tested and affirmed or falsified-the concept of 'falsification' features prominently in his work. Sound evidence which doesn't fit with the hypothesis must logically cause the given hypothesis to be rejected. Any hypothesis which cannot be affirmed through the challenge of falsification is not scientific. However, it must also be pointed out that no or very vew hypotheses can ever be said to be fully proven. Over time, the body of evidence that is consistent with a successful hypothesis accumulates to the extent that it becomes regarded as a theory, for example the theory of relativity or theory of anthropological evolution. Most 'positivists' concerning the progress and utility of science favor Popper's approach.

Alternatively, Kuhn suggested that the concept of 'normal science' covers those situations where scientists work on various topics within a central paradigm. In contrast to Popper, Kuhn's view was that the results of experiments that do not conform to a prevailing paradigm should be considered incorrect or errors on the part of the researchers rather than findings which damage the consensus view. However, as the conflicting evidence increases, a crisis point may arrive where a new consensus view is arrived at, and such a turning point generates a paradigm shift. This usually happens fairly rapidly. Kuhn suggests this punctuated progress of knowledge best reflects the reality that scientists are humans and humans possess both conscious and unconscious biases. Of course, Kuhn's view also advances the suggestion that the majority opinion should rule until it is not the majority opinion. There is a great burden of proof on minority or dissenting opinions.

Nevertheless, the view of paradigm shift hinge moments accounting for how science 'lurches' forward won wide support, and Kuhn is the more cited and read of the two.

In sum, Popper's view is considered more in harmony with how "science" works in practice-that is, methodologically. Kuhn's perspectives are more philosophical and delve into the sociological realities of operative science over time. Neither one, however, really questions daily operative science or the scientific method per se. For more, see Steve Fuller, Kuhn Vs. Popper: The Struggle for the Soul of Science (Chichester, West Sussex: Columbia University Press, 2004). What Fuller points out is that, in many ways, the debate between Popper and Kuhn represented the two cultures war, with Kuhn the "American Heidegger," ibid., 110. In an irony of history, Kuhn's ideas won the popular debate against Popper's ideas, but the world of operative science still works very much along the veins of Popper's ideas-that is, the two cultures still persist in force. See also, Karl Popper, The Logic of Scientific Discovery (New York, NY: Routledge, 2002); and Kuhn, The Structure of Scientific Revolutions.

${ }^{356}$ The background context for this tension resides in the fact that within Christianity there is disagreement about the nature of nature, and its relationship with modern science and its popularly received conclusions. The fact is, many Christian intellectuals who now support variants of theistic evolution also claim the conclusions of scientists in their support; note the popular work by Mark A. Noll, The Scandal of the Evangelical Mind (Grand Rapids, MI: Eerdmans, 1994), and the response by Carl Trueman, The Real Scandal of 
biblical history (archaeology) and natural history (geology, paleontology, anthropology), ${ }^{357}$ as well as

the Evangelical Mind (Chicago, IL: Moody Publishers, 2011). As Peter Harrison explains, "in educated circles, religious resistance to science has a bad name. The most conspicuous contemporary manifestation of such resistance-young earth creationism-is associated with religious fundamentalism, right-wing politics, irrationalism, and ignorance," Peter Harrison, "Is Science-Religion Conflict Always a Bad Thing? Some Augustinian Considerations," at https://biologos.org/blogs/archive/is-science-religion-conflict-always-a-bad -thing-some-augustinian-considerations (accessed March 16, 2015). Harrison continues, "prominent instances of science-religion conflict-contemporary and historical-play a central role in our present discussions of science and religion. Those who dismiss religion regard these instances of conflict as emblematic of the irrationalism of faith; those in many prominent Christian groups use them to support the generalization that such conflict undermines the credibility of religion and gives succor to its opponents. For this reason, the default position amongst this latter group is an advocacy of peaceful relations between science and religion. This is accomplished by proposing either that science and religion occupy separate spheres or, more commonly, that science and religion offer complementary or even overlapping perspectives on the world," ibid. Representing a more nuanced position, Harrison admits that certain conflicts may be acceptable, but "creation science and the Galileo affair offer examples in which the relevant science seems undeniably correct," ibid. Thus, the more scientifically astute Christians will be theistic evolutionists. Such groups include "contemporary Catholicism, Anglicanism, Lutheranism, and most Reformed Churches." Importantly, however, Harrison continues, "these groups have a recognizable identity in science-religion discussions and have been labeled, often in pejorative terms, as 'accommodationists' or 'neo-harmonizers.' Among these groups we see two approaches to the issue. One position, what I shall call the 'strong irenic position,' is that conflict between science and religion is, in principle, not possible." "The strong irenic position assumes that both science and religion are, in some sense, truth tracking, which is to say that both seek to provide access to truth. It follows that conflict between science and religion is impossible because there is only one ultimate truth about things, and if both science and religion are accessing this truth, conflict between them is not possible. One traditional way in which this stance has been expressed is the motif of the 'two books'-the book of nature and the book of Scripture. Since both 'books' have been authored by God, they cannot be in conflict with each other." In contrast, "the alternative view, what I will call a 'weak irenic position,' holds that concord between science and religion has certainly been true for much of Western history, but that the peace between science and religion is more a matter of contingent historical circumstances. It is not that conflict is impossible for some set of principled reasons; it is just that the content of science for much of history past has just happened not to conflict with religion." Favoring the weak irenic position, Harrison suggests that "the fact is that science sometimes gets things wrong. This seems undeniable from what we know from the history of science. Prudence suggests keeping a respectable distance between science and Christianity. In the specific case of evolution it cannot be doubted that the basic idea of descent with modification is well founded. But it is not a demonstrative truth; nor does it follow that every aspect of the theory is well founded, particularly those that remain the subject of debate within the field itself. It is also important to distinguish well-established theories from what are claimed to be their broader religious and philosophical implications, which may be considerably speculative," ibid. Of course, not all will agree with Harrison's 'weak irenic' position, or his more specific conclusions about evolution and the theory of descent. In other words, Harrison has offered no philosophical solution to the tension, merely let it be as it may, and sort the details out later.

${ }^{357}$ See, for example, Leonard Brand with David C. Jarnes, Beginnings: Are Science and Scripture Partners in the Search for Origins? (Nampa, ID: Pacific Press, 2006), 7. Brand explains, making reference to Gould's two magisteria of science and religion, that "I believe science and religion are complementary and not exclusive of each other. This doesn't mean that we can easily resolve conflicts between the two. Neither scientific results nor the words of Scripture tell lies. However, sometimes we read something between the lines that isn't really there," ibid., 7-8. In limiting the discussion between science and religion to one concerning the history of the earth and the life on it, however, Brand has, at least here, dismissed any acknowledgment of the humanities proper, and the strictly metaphysical questions therein, such as the nature of the integration of morality into science, and the nature of free-will, and the problems that science may encounter as it seeks to understand them. In other words, I don't disagree with Brand that "in recent centuries, scientific interpretations have contradicted biblical interpretations, and in some of these conflicts, the scientific side has prevailed. Some people have concluded that this outcome has demonstrated the validity of Gould's approach. In this book, I will examine the suspicion that this trend has gone too far and that people have, without sufficient reflection, limited religion-Scripture-to only the realm of 'ultimate meaning and moral value,'” ibid., 7. The concern I am highlighting is that the method of science, regardless of any presuppositions about methodological 
theology and metaphysics. ${ }^{358}$ Although the above supposition seems reasonable, as will be seen below, it seems Haught's intentions historically have and will inevitably fail-the question is, why?

The answer is complicated by the essence of what science is and can accomplish in relation to what it is the humanities seeks to uncover and understand. The key here is that religionists may be attuned to complaining about methodological naturalism as it is used by openly antagonistic atheists, but most of them don't complain about scientific methodologicalism and its limits. In this, they leave open unconsciously the possible conflation of methodological naturalism with ontological naturalism, ${ }^{359}$ while ignoring the scientific or scientistic methodologicalism already operative in much of religion and theology.

The point at present is, while the above thesis by Haught may prove acceptably or reasonably true given further or future standard scientific evidence (that is, evidence accepted by a broad consensus) and "correct" Scriptural interpretation, about, for example, Creation or a global Noachian flood, ${ }^{360}$ in some areas the issues become even more controversial by their very nature. For but one

naturalism or the Scriptural testimony, causes a problem for the humanities in itself as well as the classic natural sciences. I do not mean to suggest that Brand would deny what I have just described-indeed, colleagues of his acknowledge the shortcomings and limitations of science, such as Ariel A. Roth, Origins: Linking Science and Scripture (Hagerstown, MD: Review and Herald, 1998), 26-30, 285-297; and Ariel A. Roth, Science Discovers God: Seven Convincing Lines of Evidence for His Existence (Hagerstown, MD: Autumn House with Review \& Herald, 2008), 190-209. Nevertheless, the presentation of the issues as such by both scholars leaves the humanities adrift in methodological uncertainty that they have not explored-what methods are appropriate to the humanities and metaphysics that are not a mere mirror of the method of science?

${ }^{358}$ Any "discovery made by" the "method" of "methodological naturalism" "is secondary to" the "commitment" to the method, Todd P. Loftin, "A Mixed Approach to the Science Curriculum," in Journal for the Philosophical Study of Education Vol. 1 (Bloomington, IN: AuthorHouse, 2012), 72.

${ }^{359}$ In defense of this distinction, Robert Pennock claims that the methodological naturalist is only committed to one thing, "a method of inquiry," Robert T. Pennock, Tower of Babel: The Evidence Against the New Creationism (Cambridge, MA: The MIT Press, 1999), 190. As such, methodological naturalism is to be distinguished from ontological naturalism, the latter of which would preclude supernaturalism. Pennock even further suggests that "science" is not "materialist and deterministic," but remains open to indeterministic causal processes-though not all scientists nor religionists would agree, depending on their own presuppositions, ibid., 190. Along these lines, Earl Fronda explains, "it is crucial not to confuse methodological naturalism with ontological naturalism: the former is a method of inquiry, while the latter is a belief about the constitution of reality. Methodological naturalism does not necessarily have anything to do with (pre) judging what could possibly exist and what could not, or what can possibly happen and what cannot, while ontological naturalism has everything to do with all of that.... Ontological naturalism is an anti-thesis to supernaturalism, as such the former is partly defined by its polar opposition to the latter. But methodological naturalism can conceivably have nothing to do with supernaturalism at all; supernaturalism is just too irrelevant to be placed within the purview of its consideration," Fronda, Wittegenstein's (Misunderstood) Religious Thought, 135-136 n. 3.

${ }^{360}$ To help illuminate the two culture's conflict here, it is noteworthy that a world class Hebrew scholar, James Barr, who does not accept the Genesis 1-11 account as true, nevertheless accepts, as a humanities scholar, the fact that the author(s) of Genesis intended Gen 1-11 to be read literally and historically as depicting 
popular example, the Intelligent Design (ID) movement, ${ }^{361}$ which seeks to establish the legitimacy of

a six day creation and global flood. See the discussion by John D. Morris, The Young Earth: The Real History of the Earth-Past, Present, and Future (Green Forest, AR: Master Books, 2007), 30. Conversely, John Walton and Tremper Longman III sense the need to argue, from the humanities alone, that Genesis 1-11 presents a worldview compatible with the long ages supposed in modern science, as he realizes, absent his argument, that those such as Barr are essentially correct. "It is our conclusion that Genesis 6-8 describes a worldwide, not a local flood. This conclusion leaves us with what at first read, at least from our twenty-first-century Western perspective, is an error or at least a contradiction. The Bible describes a worldwide flood, yet absolutely no geological evidence supports a worldwide flood. While some people believe that this means that science must be wrong if the Bible is right, we believe that if science is right, then it leads us to a better interpretation of the biblical material," John H. Walton and Tremper Longman III, The Lost World of the Flood: Mythology, Theology, and the Deluge Debate (Downers Grove, IL: InterVarsity Press, 2018), 49. What is remarkable about the above is that Walton likewise claims that his work does not focus "on scientific issues because I am not a scientist, and those issues are complex." Rather, he simply asserts that "we do not find human origins stories in Genesis 2 that make scientific claims. That does not mean that modern scientific theories are therefore correct by default-it just means that we can consider scientific claims on their own merit rather than dismissing them because they contradict biblical claims," John H. Walton, with N. T. Wright, The Lost World of Adam and Eve: Genesis 2-3 and the Human Origins Debate (Downers Grove, IL: InterVarsity Press, 2015), 181. For interpreters of Scripture, this places the debate solely within the humanities in an ironic way apart from science, as the scientific evidence is essentially 'settled.' The only thing left to do is figure out what 'creative' interpretation of Scripture corresponds with the general body of scientific evidence. Of course, their claim, as non-scientists, that "absolutely no geological evidence" exists for a global flood is an obvious overstatement inviting challenges. See, for example, Mike Oard, Flood by Design: Receding Water Shapes the Earth's Surface (Green Forest, AR: Master Books, 2011). See also, John H. Walton, The Lost World of Genesis One: Ancient Cosmology and the Origins Debate (Downers Grove, IL: IVP Press, 2009), 56-57, and the critique of his ideas about Hebrew cosmology by Randall W. Younker and Richard M. Davidson, "The Myth of the Solid Heavenly Dome: Another Look at the Hebrew Raqia," in Andrews University Seminary Studies \#1 (2011), 125-147.

${ }^{361}$ The debate over whether or not the ID (Intelligent Design) movement is scientific rages on in some circles, though it seems to have lost steam in the overall academy-but it critically depends upon how science itself is defined, an equally unresolved issue within the two cultures' conflict. Nevertheless, for obvious reasons, most proponents of ID wish to be seen as promoting good "science." See, for example, Ingo Brigandt, "Intelligent Design and the Nature of Science: Philosophical and Pedagogical Points," in The Philosophy of Biology: A Companion for Educators, ed. Kostas Kampourakis (New York, NY: Springer, 2013), 228; and Scott F. Gilbert, "Evolutionary Developmental Biology and Intelligent Design," in Biological Evolution: Facts and Theories: A Critical Appraisal 150 Years After 'The Origin of Species', eds. Gennaro Auletta, Marc Leclerc, and Rafael A. Martínez (Roma: Gregorian \& Biblical Press, 2011), 691-700. For a sample of other prominent supporters of a "scientific" ID, see, for example, Stephen Sills, The Basis for Christianity (Los Angeles, CA: Stephen Sills, 2016); William A. Demski, Intelligent Design: The Bridge Between Science \& Theology (Downers Grove, IL: InterVarsity Press, 1999); Stephen C. Meyer, Signature in the Cell: DNA and the Evidence for Intelligent Design (New York, NY: HarperCollins, 2009); and Michael J. Behe, Darwin's Black Box: The Biochemical Challenge to Evolution (New York, NY: Touchstone, 1998). For some general responses by critics, first by theists, see Kathryn Applegate and J. B. Stump, eds. How I Changed My Mind About Evolution: Evangelicals Reflect on Faith and Science (Oxford, UK: Lion Hudson with BioLogos, 2016); Kenneth R. Miller, Only a Theory: Evolution and the Battle for America's Soul (London, UK: Penguin Books, 2008); Kenneth R. Miller, Finding Darwin's God: A Scientist's Search for Common Ground Between God and Evolution (New York, NY: HarperCollins, 1999); and Richard F. Carlson and Tremper Longman III, who address issues in Genesis, with Science, Creation and the Bible: Reconciling Rival Theories of Origins (Downers Grove, IL: InterVarsity Press, 2010). For broader critiques by atheists or agnostics against ID, see Niall Shanks, God, The Devil, and Darwin: A Critique of Intelligent Design Theory (Oxford, UK: Oxford University Press, 2004); Matt Young and Taner Edis, eds. Why Intelligent Design Fails: A Scientific Critique of the New Creationism (New Brunswick, NJ: Rutgers University Press, 2006); Lenny Flank, Deception by Design: The Intelligent Design Movement in America (St. Petersburg, FL: Red and Black Publishers, 2007); Andrew J. Petto and Laurie R. Godfrey, eds. Scientists Confront Intelligent Design and Creationism (New York, NY: W. W. Norton \& Company, 2007); Albert DeBenedictis, Evolution or Creation?: A Comparison of the Arguments, $3^{\text {rd }}$ ed. (Bloomington, IN: Xlibris Corporation, 2014), 51; and Paul F. Lurquin and Linda Stone, Evolution and Religious Creation Myths: How Scientists Respond (New York, NY: Oxford University Press, 2007), 137. A common complaint, in general, is that the Intelligent Design movement is not scientific in the first place, as it is not 
irreducible complexity within microbiology to support (designer) theism in contrast to atheistic evolutionary Darwinism, ${ }^{362}$ operates under the same general parameters and goals. Namely, it seeks to line up what it sees as a 'taller' pile of standard scientific evidence, or 'chips' on its side of the poker table, hoping to eventually call the atheist side's bluff of possessing superior evidence and force, in the least, the begrudging acquiescence of atheists to acknowledge each perspective's scientific grounding, if one side is unable to emerge the clear victor. For another equally controversial example, that has also entered into the mainstream science and religion debates, one can peruse the debates concerning the science used in presentations of anthropogenic and natural climate change. ${ }^{363}$

Collectively, the above common examples from the debates between scientists and religionists represent the general situation that the "science and religion" discussions face before the public and even amongst many scholars. It is a reductionistic debate dominated by a competition between a

testable, so many consider it pseudo-science, or an ironic appeal to the humanities that is sometimes unacknowledged by creationists. See specifically, Larry A. Witham, Where Darwin Meets the Bible: Creationists and Evolutionists in America (Oxford, UK: Oxford University Press, 2002), 129; and Gilbert LaFreniere, The Decline of Nature: Environmental History and the Western Worldview (Corvallis, OR: Oak Savanna Publishing, 2012), xiii. Compare with the creationist Mike Manea as he suggests that creationists must alter their approach to articulate a new scientific creationism, "A Better Way to Fight Evolution: Part 1: Science's Naturalistic Bias," at https://thecompassmagazine.com/blog/a-better-way-to-fight-evolution-part-1-sciences- naturalistic-bias (October 28, 2015); and note also the work on temporality which critiques classical science in cosmology by Unger and Smolin, The Singular Universe and the Reality of Time, 42.

${ }^{362}$ Interestingly, Darwinism is also arguably mechanistic. In contrast to many who claim it highlights randomness (or freedom) in nature as part of its process, Marjorie Haight suggests this is not the case, and that Darwinism is still entrenched within a classical mechanistic paradigm. See David F. Haight and Marjorie A. Haight, The Scandal of Reason: Or Shadow of God (Lanham, MD: University Press of America, 2004), 353 n. 20.

${ }^{363}$ The point I wish to raise by mentioning climate science is in relation to the above issues concerning how Christians argue for intelligent design and geological evidence favoring a global flood-mainstream Christians do not, nor does anyone else, typically wish to be seen as supporting a non-scientific humanitiesoriented hermeneutic of reality to support their suppositions. They want to be seen as scientific. In like manner, some religionists have recently been caught up in the debates about the scientific evidence for climate change. Here, again, the debate is not thought to be between the sciences and humanities, but is an argument about who has the better science. See, for example, Tim Ball, The Deliberate Corruption of Climate Science (Mount Vernon, WA: Stairway Press, 2013) versus Andrew Dessler, Introduction to Modern Climate Change, $2^{\text {nd }}$ ed. (Cambridge, UK: Cambridge University Press, 2016). For more, see Christopher Booker, The Real Global Warming Disaster: Is the Obsession with 'Climate Change' Turning Out to be the Most Costly Scientific Blunder in History? (New York, NY: Continuum, 2009); Mark Steyn, ed., "A Disgrace to the Profession" (Woodsville, NH: Stockade Books, 2015); Lawrence Solomon, The Deniers: The World-renowned Scientists who Stood Up Against Global Warming Hysteria, Political Persecution, and Fraud (USA: Richard Vigilante, 2010); Ernest Kinnie, Modern Science in Crisis: Best to be Aware of the Influences on Scientists that Affect the Validity of Their Work (USA: Pronoun, 2017); Martin Lack, The Denial of Science: Analysing Climate Change Scepticism in the UK (Bloomington, IN: AuthorHouse, 2013); and James Lawrence Powell, The Inquisition of Climate Science (New York, NY: Columbia University Press, 2011). For explicit treatments of the topic that discuss religion, and also integrate issues from the humanities, see James Wanliss, Resisting the Green Dragon: Dominion, Not Death (Burke, VA: Cornwall Alliance, 2010) versus Michael S. Northcott, A Political Theology of Climate Change (Grand Rapids, MI: Eerdmans, 2013). 
specific scientifically delineated presuppositional biblical history versus the secular scientifically dominated study of anthropological, archaeological, and geological history. In pragmatic terms, it has also become in recent decades an unending dialogue or conversation because both sides are convinced they have enough or sufficient "scientific" data favoring them, regardless of the nuances and differences in their respective conclusions. In other words, most of the traditional "science and religion" debates assume the nature and relevance of science as a methodological given (note that science is often seen, incorrectly, as indistinguishable from methodological naturalism as the schema of method), and, as such, atheistic science and religion essentially become two competing scientific endeavors because the "objects" they believe they investigate are a priori scientized. ${ }^{364}$ Each seeks to 'out science' their competitor through a better assemblage of 'objective facts' supporting a given assumption from or interpretation of methodologically scientized nature or methodologically scientized Scripture. ${ }^{365}$

${ }^{364}$ Drori, “Rationalizing Global Consciousness: Scientized Education as the Foundation of Organization, Citizenship, and Personhood," 93. Drori explains that "scientization is the penetration of science-like logics and scientific-like practices into everyday life in general and into the everyday life of education in particular," ibid., 93. In the present application, it is the turning of 'something' into something apprehendable by science-likeness, that somehow had been resistant to this likeness, to make it 'easier' to understand. It is thus a mode and method of reductionism and objectificationism.

${ }^{365}$ It is important to note that the popular "historical-grammatical" approach to biblical hermeneutics that is used by many "conservative" scholars is, in practice or effect, actually conditioned by scientific (and hence mathematical/ platonic/timeless) presuppositions-specifically it operates under certain scientific presuppositions about the nature of the ontology of language-that is, in the method language is also scientized. Through such a method, biblical "inerrantists" have tried "to [scientifically] prove the validity and truthfulness of the Bible based on certain scientific, historical, grammatical, demonstrable, and rationalist categories," R. Daniel Shaw and Charles E. Van Engen, Communicating God's Word in a Complex World (New York, NY: Rowman \& Littlefield, 2003), 35 (addition mine). Note, in particular, the work by Tiago Arrais, "The Influence of MacroHermeneutical Assumptions Upon Biblical Interpretation: A Brief Evaluation of the Historical Grammatical Method," in Scripture and Philosophy: Essays Honoring the Work and Vision of Fernando Luis Canale, eds. Tiago Arrais, Kenneth Bergland, and Michael F. Younker (Berrien Springs, MI: Adventist Theological Society Publications, 2016), 295-319; 310, 312 n. 77, 316-317. See also, Douglas J. Moo and Andrew David Naselli, The Problem of the New Testament's Use of the Old Testament," in The Enduring Authority of the Christian Scriptures, ed. D. A. Carson (Grand Rapids, MI: Eerdmans, 2016), 704-706; Paul Seely, "The Subordination of Scripture to Human Reason at Old Princeton," in Interdisciplinary Perspectives on the Authority of Scripture: Historical, Biblical, and Theoretical Perspectives, ed. Carlos R. Bovell (Eugene, OR: Pickwick, 2011), 32; Carlos R. Bovell, Rehabilitating Inerrancy in a Culture of Fear (Eugene, OR: Wipf \& Stock, 2012), 23-44; and Tim Reddish, Science and Christianity: Foundations and Frameworks for Moving Forward in Faith (Eugene, OR: Wipf \& Stock, 2016), 28. Curiously, as many would dispute Reddish's conflation of historical-criticism with the historical-grammatical method-see the explanation in Douglas W. Kennard, A Critical Realist's Theological Method: Returning the Bible and Biblical Theology to be the Framer for Theology and Science (Eugene, OR: Wipf \& Stock, 2013), 211-but concisely serving my point, even if it is a confusion of concepts for some, Reddish asserts that "with the Age of Reason came what is referred to as the historical-critical method, which is still very influential today. The Enlightenment rejected traditional sources of authority, such as Scripture, monarchy, and the church, and replaced them with the use of reason and the scientific method. Consequently historical-grammatical criticism 
Overall, what's important to observe is that philosophical, and hence methodological, reasoning within the above situation concerning the relationship between science and religion often devolves into the mere utilization of the scientific method (as the presupposed perfected balance of rationalism and empiricism ${ }^{366}$ ) to describe the relationship of objects in their various domains, however radically, even categorically, different these domains may be, for example, ancient pottery, literary texts, or geochemical data. Put simply, proper reasoning typically understands and exclusively utilizes "science" as "the organization of objectively verifiable sense experience" ('sense experience' here understood, of course, as our detached or Cartesian use of sight, sound, touch, and taste). The general

treats the Bible like any other book of antiquity. This approach was-and is-enhanced by the study of linguistics, ancient languages and literature, together with history, archaeology, and other related academic disciplines. Since this method has no theological commitment to orthodoxy, Scripture is not regarded as divinely authored. Indeed, such a claim is deemed an irrelevance in studying the text. This new paradigm was therefore seen as an unprejudiced, or 'scientific,' approach to study historical works.... Moreover, this approach examined the historical, cultural, social, and political context of each biblical book... [as well as] geographical locations [that might offer more] insights [to] ... the modern reader," ibid., 28-29. Reddish continues, through the Enlightenment, "the human authors were given greater freedom and responsibility in the way that they collected and presented their material. Consequently, the assumed uniformity of God's revelation throughout the whole of the Bible was also challenged," ibid., 29. It is noteworthy to compare Tim Reddish with David Paul Parris, Reading the Bible with the Giants: How 2000 Years of Biblical Interpretation Can Shed New Light on Old Texts (Eugene, OR: Cascade Books, 2015), 91-92 (additions mine). Parris explains that "during the Enlightenment, with the rise of the modern scientific method and its claims to objectivity by means of repeatable methodology, the humanities came under increasing pressure in the universities. How could fields like theology, history, or music validate their truth claims? One of the solutions put forward and widely accepted was that by emulating the sciences the humanities could employ some form of methodology so that they too could make objective truth claims in their research.

"In the field of biblical studies this has filtered down to us in various forms of the historicalgrammatical method, whereby the interpreter attempts to discern the original author's intentions by means of a historical methodology, along with a detailed grammatical analysis of the text. The work of E. D. Hirsch Jr. has been popular among evangelical theologians for buttressing this approach. Like any hermeneutical approach, this model has its strengths and weaknesses.... The Platonic ideal that a text ... possesses one, timeless, unchanging meaning stands behind this method's goal to recover the author's intentions. It is a static conceptualization of meaning," ibid, 92. For yet another recent example of a scholar (more correctly than many realize) conflating the historical-critical and historical-grammatical methods, see Shawn B. Redford, Missiological Hermeneutics: Biblical Interpretation for the Global Church (Eugene, OR: Pickwick Publications, 2012), 86 n. 3., 117. Redford refers to the "scientific historical-grammatical method," ibid., 117, and shares that "the official name for the historical-critical method would be the historical-grammatical method," ibid., 86 n. 3. For more on understanding the context of philosophical hermeneutics in relationship to the issues surrounding "science" and the historical-grammatical method, see Gary B. Madison, The Hermeneutics of Postmodernity: Figures and Themes (Bloomington, IN: Indiana University Press, 1988); and Tomasz Kalaga, Literary Hermeneutics: From Methodology to Ontology (Newcastle upon Tyne, UK: Cambridge Scholars Publishing, 2015), esp. 53-56.

${ }^{366}$ The consensus view is that, historically, "it was not until science emerged in the $16^{\text {th }}$ century that rationalism and empiricism were wed and sensory information provided that which was reasoned about. Science therefore minimized the extremes of both rationalism and empiricism," Hergenhahn, An Introduction to the History of Psychology, 34. Or, rather, for the humanities, science cemented into place two false alternatives from the same Greek sources as the grounding place for a third false or philosophically incomplete yet remarkably useful synthesis-science. However, the catastrophe of this failure, in the eyes of Heideggerians, is seldom realized. 
consensus is that "what makes a discipline science is neither the object studied nor the method [in the sense of microscopes, customer surveys, or Hebrew and Greek lexicons and etymological analysis] used but the systematic pursuit of knowledge and its organized presentation.."367 What has been lost, then, in recent discussions between the sciences and religion is just what role the contemporary postmodern humanities really have within them, ${ }^{368}$ which has left the theological world distracted and misguided in its pursuit of other issues, whether legitimate or not in some cases, that may seem more naturally a part of the humanities. ${ }^{369}$ Put another way, science presumes a certain ontology,

\footnotetext{
${ }^{367}$ As explained by Augustine Perumalil, Critical Issues in the Philosophy of Science and Religion (Kashmere Gate, Delhi: Indian Society for Promoting Christian Knowledge, 2006), 1 (emphasis mine). Perumalil recognizes different kinds of objects and realizes science will function differently for physics than from some other area of study, but in the end, he still assumes some common understanding of "systematic" which resembles the mathematical; c.f. Robert Rosen, Essays on Life Itself, 63. Perumalil represents the common attitude, and thus can't escape the rationalist-empiricist duality centered upon mathematization. Nevertheless, as Perumalil further attempts to explain, "Both science and philosophy are cognitive enterprises seeking to acquire objective knowledge, knowledge that is free from personal preferences and biases. [Natural] science pertains to the knowledge of the physical world.... Science relies on verification before accepting truths about facts. Its aim is to uncover the regularities in nature and describe them in the form of scientific laws, so that they can be used for explaining past events and predicting and controlling future events." "Philosophy, on the other hand, is a logical discipline which relies on critical and systematic reflection. Instead of the experimental method, philosophers exercise their rational faculty for the discovery of truth.... While science reduces everything to certain mathematical formulas, and makes a skeleton out of the rich and complex reality, philosophy enfleshes and enlivens empirical reality by adding to it meaning, significance, and qualitative interpretation." However, "despite these differences in aim, approach, point of view, method and formal object, the intimate relationship between philosophy and science cannot be ignored. Since science in its broad sense refers to any systematic study, philosophy is a science in this broader sense," Perumalil, Critical Issues in Philosophy of Science and Religion, 22-23, see also 6 (emphasis mine). Perumalil's view, of course, subtly contrasts contradictorily with Martin Heidegger's perspective. Note, Wilson, "Placing Bergmann," in Ontology and Analysis: Essays and Recollections about Gustav Bergmann. Wilson explains that for Heidegger, "science seeks objectivity.... The [objective] pattern explored is one of change, yet it is a general pattern, universal, and therefore timeless change brought to a standstill," ibid., 238. Heidegger consistently critiqued this perspective, thus, "Heidegger has challenged any philosophy that uses the system of 'mathematical logic' as a tool in ontology," ibid., 236.

${ }^{368}$ For a clear example of one who fails to appreciate the depths of postmodernism, see the otherwise good study by Peter Harrison, The Territories of Science and Religion (Chicago, IL: The University of Chicago Press, 2015). Harrison acknowledges the significance of Snow's contribution, ibid., 167. Harrison also observes that, in some ways, the conflict is actually philosophical in nature, ibid., 167-173, but he fails to discuss the actual philosophical issues postmodernism brought to the table. See also, Colin Dickey, "Two-Way Monologue: How to Get Past Science vs. Religion," at https://lareviewofbooks.org/article/two-way-monologue-how-to-getpast-science-vs-religion\#! (accessed August 1, 2015).

369 "Throughout the 1970's, 1980's, and continuing to the present, various contextualized theologies such as liberation theology, black theology, Latin American theology, feminist theology, womanist theology and Asian theology have increased. Their theologies appear to be moving in every direction each for its own sake, with the exclusive interests of overcoming Western-white-male-centered theology, on the one hand, and destroying the barriers between cultures and among religions, on the other hand. Meanwhile, the issues on the limitation of modern scientific ways of knowing in perceiving subjective [humanities' oriented] reality/religious matters and the recovery of subjective-objective-qualitative knowing through the cultivation of genuine theological knowing and knowledge remain unaddressed. Therefore, current theological efforts, even with good intentions, can hardly hit the target of the problem in theology," Kim, Broken Knowledge, 8-9 (addition mine). The irony here is that these various ethnic ('white' or 'black') or gender based theologies may indeed
} 
based upon a certain understanding of onticity, which preconditions any epistemology that follows;

conversely, the postmodern humanities begin by questioning reality at the ontic and ontological

levels, which then forces a more critical approach towards the epistemologies one employs.

The purpose of this present contemporary overview is not to take sides in who might or should

win the war of "objective scientific facts" on overlapping matters of interest to secular scientists and religionists, but rather to point toward a deeper conflict between them. The real, growing, and unresolved problem within the above situation owes itself not merely to the lack of resolution between religionists and secularists concerning overlapping scientific questions about earth and human history. Rather, the real problem lies in the fact that both of Barbour's latter two options of dialogue or integration for the resolution of the conflict between science and religion appear to be merely a mask for the deeper philosophical conflict ${ }^{370}$ between the sciences and humanities, the two

lay claim to the Heideggerian "story creation" method-reality is a story, and stories do matter. But if these efforts are undertaken in isolation from a more inclusive philosophical perspective, they may fall short of usefulness. In any case, for example, Tina Chanter observes that "Heidegger's ontological approach ... foreshadowed certain gestures that have been taken up and developed in various strains of feminist thought and race theory. Heidegger's rethinking of history is perhaps the privileged example of this tendency," Tina Chanter, Time, Death, and the Feminine: Levinas with Heidegger (Stanford, CA: Stanford University Press, 2001), 76. See also, Paul C. Taylor, Race: A Philosophical Introduction $2^{\text {nd }}$ ed. (Malden, MA: Polity Press, 2013), 153; Charles W. Mills, Blackness Visible: Essays on Philosophy and Race (Ithaca, NY: Cornell University, 1998), xiv; Alessandra Raengo, Critical Race Theory and Bamboozled (New York, NY: Bloomsbury, 2016), 55-56; Jinaki Abdullah, "Bismillah-Message to the Blackman Revisited: Being and Power," in Africana Islamic Studies, eds. James L. Conyers Jr., and Abul Pitre (Lanham, MD: Lexington Books, 2016), 59-60; and Neil Roberts, "Fanon, Frantz (1925-1961)," in the Encyclopedia of Political Theory, ed. Mark Bevir (Thousand Oaks, CA: SAGE Publications, 2010), 492-494.

${ }^{370}$ The tacit existence of this tension concerning dialogue and integration is, perhaps, most obvious when comparing the philosophies of John Polkinghorne and Lydia Jaeger, two Christian scientist-theologians. On the one hand, Polkinghorne adopts a view of natural science that would be sympathetic to Bernard d'Espagnat, namely, one supporting a 'veiled reality' for the location of the spiritual realm. See John C. Polkinghorne, Science and the Trinity: The Christian Encounter with Reality (London, UK: Yale University Press, 2004), 76-77; John C. Polkinghorne, One World: The Interaction of Science and Theology (West Conshohocken, PA: Templeton Foundation Press, 2007), 24-25; and d'Espagnat, On Physics and Philosophy, 376-381. Notably, d'Espagnat's conclusion is that "what science deals with is, to repeat, empirical reality, to which the notion of a 'veil' does not apply," ibid., 378, but d'Espagnat defines Being, which is of especial interest to the humanities, by suggesting that it cannot be reduced "to material components," and thus it is "impossible to believe consciousness to be just a product of matter, that is, of empirical reality." As such, "Being" is where "the archetypes of some of our feelings, great longing, love, etc.," are located, that is, they are "hidden there," ibid., 463. In summary, d'Espagnat separates the humanities and 'metaphysics' from science, while suggesting they nevertheless are somehow connected in a fully integrative and dialogue friendly way.

On the other hand, Lydia Jaeger supports a view, as her critics note, that posits no room for any physical evidence of a metaphysical reality. "The scientific world view articulated by Jaeger and a host of others is that science will slowly reveal, hidden within the all-too-apparent mess, a truer and more fundamental reality that is beautiful, clean and entirely orderly. This tidy image of nature is governed thoroughly by laws:

essentially those of high theory physics. Physics, then, ends up as the ultimate arbiter of reality, her sparse laws pervading and ordering the natural world. This familiar image of nature dates at least to the scientific 
cultures conflict that has been previously described above. ${ }^{371}$ Although not directly engaged in typical science and religion discussions, Gary Van Den Heuvel concisely pinpoints this issue in a pointedly succinct comment: "One might offer up simple answers to why the [Platonic-Cartesian] dualism picture holds so stubborn. Modernists and [some] post-modernists, evolutionists and creationists, all continue to operate under the same false assumptions. Assumptions left unquestioned, unnoted." He continues, "Jonah Lehrer mused at the end of his ... book" about "C. P. Snow's famous claim there are 'two cultures-art and science.' Lehrer wrote that Snow's hope for a third culture ... is 'now a genuine

revolution and remains influential. For all of our advances, the image of an orderly, deterministic, clockwork universe, with its roots in a particular vision of monarchical divine governance, has been surprisingly enduring. . .. [However, an] abundance of recent scholarship in Science Studies constitutes a quiet revolution in terms of the received view of natural order. This scholarship is not about the standard philosophical question of realism and anti-realism in science. The questions at hand are more precisely about dominion-how far the reach of physics' laws extends (or any laws for that matter)-and autocracy-whether physics reigns supreme and by herself, or is one part of a more motley assembly of sciences. The studies mentioned above suggest that physics is not even an autocrat in her own domain, much less autocratic across all of nature. The answer that physics might be just one among many sciences is a revolution in terms of our thinking about the relationship among the sciences and about the order of nature," Nancy Cartwright and Eric Martin, "Queen Physics: How Much of the Globe is Painted Red?," in God and the Scientist: Exploring the Work of John Polkinghorne, eds. Fraser Watts and Christopher C. Knight (New York, NY: Routledge, 2012), 71-72.

${ }^{371}$ What is interesting about the above debate between the ideas of Polkinghorne and Jaeger is that it illustrates the "two cultures" debate already exists within the science and religion discussions, but in a sometimes masked or unacknowledged form. As Polkinghorne observes, the debate between Bohm and d'Espagnat is part of the "science wars" which are really, already, about the role of the "humanities" in some form or another; see Polkinghorne, Science and the Trinity: The Christian Encounter with Reality, 76-77; and Polkinghorne, Science and Religion in Quest of Truth, 37-38. For more on how and why the Copenhagen view of quantum mechanics represents the residue of the humanities and its place in the conflict of the "two cultures," see Fjelland, "The 'Copenhagen Interpretation' of Quantum Mechanics and Phenomenology, 53-66. Fjelland summarizes by explaining that "both phenomenology and (the Copenhagen interpretation of) quantum mechanics are regarded as 'subjectivist' [by the traditional and reductionistic mainstream interpretation of science] and therefore anti-science. Hence it is no accident that they are both under fire in the 'science wars,'” ibid., 63-64. It is, ironically, the "science wars" that preserve the crisis in liberal theology. See Russell Re Manning, "On Revising Natural Theology: John Polkinghorne and the False Modesty of Liberal Theology," in God and the Scientist: Exploring the Work of John Polkinghorne, 197-215. Manning correctly perceives that "liberal theology is in a situation of crisis," as it is "assailed by scientistic naturalisms on the one hand and various theological dogmatisms on the other," ibid., 197. As such, the attempted alliance "between Christian faith and modern knowledge" is threatened as "either party is increasingly being squeezed and risks collapsing into either simply a theological baptism of scientific naturalism or a de facto theological positivism," ibid., 198.

The critical insight here is that in the case of Polkinghorne, his method of dialogue and integration preserves the conceptual disjuncture between the ineffable (quantum) realm and standard empirical science, following d'Espagnat, that leaves the "science wars" intact while likewise repressing the humanities beneath the sciences. Furthermore, and importantly, Polkinghorne has not truly merged them or resolved their overlapping concerns on protology and eschatology; see Polkinghorne, Science and Religion in Quest of Truth, 59, 106-107. Conversely, Jaeger has likewise, in her own efforts at dialogue and integration, merely assumed Haught's basic thesis that eventually good standard science will harmonize with good exegesis-while also, in her case in particular, dismissing the idea that quantum physics can illuminate metaphysics in fresh ways, and thus she has dismissed the value of the humanities and Heidegger outright given her a priori presuppositions and assumptions about the 'infinite' domain of science. See Lydia Jaeger, What the Heaven's Declare: Science in the Light of Creation, tr. Jonathan Vaughan (Eugene, OR: Cascade Books, 2012), 59, 77. 
cultural movement.' Lehrer lamented, however, the shortcomings of this movement [dominated by scientists] and wrote of the need of a fourth culture. He continued, 'But before we can get a fourth culture, our two existing cultures must modify their habits." ${ }^{372}$ Importantly, he concludes, "our need for a new way of seeing is greater than our need for more [scientific] facts.."373

The point above is that too often dialogue and integration between science and religion assume the form of some sort of pragmatic nullification of the problem between science and religion by replacing the problematic conclusions with an emphasis on the ever renewed methodological harmony in their disparate inquiries, a scientistic methodological harmony that is presupposed will 'someday' in the distant hazy future attain satisfactory conclusions for science and religion through dialogue and integration. ${ }^{374}$ However, given this doesn't seem to be working, and furthermore appears to lead into some very intractable problems, the question then becomes, should religion or theology simply be an alternative application of science, obeying it methodologically ${ }^{375}$ in virtually

\footnotetext{
${ }^{372}$ Gary Van Den Heuvel, Wealth of Shenanigans: The Tactile Underbelly of Concept (Morrisville, NC: Lulu Press, 2016), 182-183 (addition mine).

${ }^{373}$ Heuvel, Wealth of Shenanigans: The Tactile Underbelly of Concept, 184, addition mine (the original is in bold print).

374 This lack of methodological critique is readily apparent in some of the most recent works addressing science and religion. For example, the two cultures, Heidegger, continental philosophy, and postmodernism are barely mentioned in the recent summary work with Paul Copan, Tremper Longman III, Christopher L. Reese, and Michael Strauss, eds. Dictionary of Christianity and Science: The Definitive Reference for the Intersection of Christian Faith and Contemporary Science (Grand Rapids, MI: Zondervan, 2017).

${ }^{375}$ For example, some claim that "modernism" and the scientific auspices it alone provides grants a philosophical framework that allows for the single metanarrative of Christianity or any other religion, and as such Christians should side with modernistic science insofar as it wars against the relativistic postmodern humanities. See the explanations in, for example, Erick Tonning, Modernism and Christianity (New York, NY: Palgrave Macmillan, 2014); and John P. Bequette, Christian Humanism: Creation, Redemption, and Reintegration (Lanham, MD: University Press of America, 2007), 1-6. Matei Calinescu explains, "however different, the modern projects are all premised on a finalistic vision of universal history, and in this sense Christianity ... is constitutively modern. All the major 'stories of emancipation' of modernity are essentially secularized variations on the Christian paradigm," Matei Calinescu, “On Postmodernism (1986)," in Modernism: Critical Concepts in Literary and Cultural Studies (Vol. IV 1985-1991), ed. Tim Middleton (New York, NY: Routledge, 2003), 81. Note also, Ervin Taylor, "Creation, Evolution, and Theology: The Role of Method in Theological Accommodation [Review]/Fernando Canale," in Andrews University Seminary Studies Vol, 46, \# 1 (2008), 88. Conversely, as Iain Thomson explains, postmodernism is not, despite claims suggesting otherwise, a rejection of any metanarrative. Rather, the contributions of Heidegger were designed to explain how any narrative was possible at all! Without the humanities, there is no story or (individual) stories. Rather, "the uncoupling of scientific progress from the advancement of human freedom" is a rejection of a specific "metanarrative" that Heidegger found contradictory with human nature itself, namely, that "scientific progress" is actually always progress that unfetters humanity, Thomson, Heidegger, Art, and Postmodernity, 131-132.
} 
every respect? Or should religion find its place as a more hermeneutically oriented humanity, or

neither, or both, if the latter is even possible?

Indeed, at this point, it is of critical importance to emphasize that biblical hermeneutics, ${ }^{376}$

itself, is also already entwined within the two cultures' conflict $^{377}$ for every manner of topic within its

${ }^{376}$ Although I believe that the present study does have significant implications for biblical hermeneutics, I cannot enter into this debate in any detail here. For a sample of works I consider particularly insightful and representative of the current issues, see Canale, The Cognitive Principle of Christian Theology: A Hermeneutical Study of the Revelation and Inspiration of the Bible; Gerhard Maier, Biblical Hermeneutics, tr. Robert W. Yarbrough (Wheaton, IL: Crossway Books, 1994); Walter C. Kaiser and Moisés Silva, An Introduction to Biblical Hermeneutics: The Search for Meaning (Grand Rapids, MI: Zondervan, 1994); Kevin J. Vanhoozer, Is There a Meaning in This Text? The Bible, the Reader, and the Morality of Literary Knowledge (Grand Rapids, MI: Zondervan, 1998); Kevin J. Vanhoozer, The Drama of Doctrine: A Canonical-linguistic Approach to Christian Theology (Louisville, KT: Westminster John Knox Press, 2005); Grant R. Osborne, The Hermeneutical Spiral: $A$ Comprehensive Introduction to Biblical Interpretation (Downers Grove, IL: IVP, 2006); Anthony C. Thiselton, The Two Horizons: New Testament Hermeneutics and Philosophical Description (Grand Rapids, MI: Eerdmans, 1980); Robert L. Thomas, Evangelical Hermeneutics: The New Versus the Old (Grand Rapids, MI: Kregel, 2002); and Mark Alan Bowald, Rendering the Word in Theological Hermeneutics: Mapping Divine and Human Agency (New York, NY: Routledge, 2016).

${ }^{377}$ That the hermeneutics of Scripture one employs must also bow the knee to a philosophical critique of the nature of philosophical reasoning utilized in a given hermeneutical method is, perhaps, the most critical insight one may glean from the current crisis for biblical Christians. Scriptural hermeneutics cannot avoid philosophy. One cannot naïvely interpret Scripture without already employing a philosophical method and assumptions about the nature of ontology and epistemology, assumptions that may be difficult to extract from Scripture itself. The point here is that such a critique has often been ignored. Gary Madison, however, insightfully points out that "one of the major ongoing debates in hermeneutics [in general]" is one in which "two divergent and irreconcilable tendencies" are manifested, namely those developed within the contrasting works of E. D. Hirsch and Heidegger's student H. G. Gadamer. Madison explains that "the principal difference between these two leading theorists is that whereas Gadamer seeks to defend what is proper to the humanities against encroachment by the ideal of 'scientific' knowledge and to this end attacks the concept of 'method,' arguing that method, as it is understood in the positive sciences, has no role whatsoever to play in the humanities, Hirsch, inspired by logical positivism, argues that there is or should be no significant difference between the empirical sciences and the humanities and that the hypothetical-deductive method as advocated by positivist-style philosophers of science is as applicable in the matter of literary textual interpretation as it is in the physical sciences. The main thrust of Hirsch's criticism of Gadamer is that his position opens the door to arbitrariness and cannot therefore serve to make the métier of the interpreter a serious, respectable business." Madison continues, "this conflict is an extremely fundamental one, in that it involves two irreconcilably different theories of understanding and interpretation. It is a conflict between what could be called positivistic hermeneutics and phenomenological hermeneutics," Madison, The Hermeneutics of Postmodernity: Figures and Themes, 25-26. Madison attempts to argue for a complex middle position which is often rejected by both sides.

At this point, it may be important to emphasize that the "subject-object" relationship, which has been the crux of much discussion concerning Heideggerian or postmodern hermeneutics, is fatally flawed on one major point. In the context of this study concerning the correct interpretation of the natural sciences, as Haas explains, in harmony with Pylkkö, "if quantum theory demonstrates that the sciences stand between the natural and human world in such a way that they form a part of everything they investigate, the usual distinction between subject and object, inner and outer world, body and soul-like the Cartesian difference between res extensa and res cogitans that Heidegger 'destructures' in Being and Time-cannot be maintained," Haas, The Irony of Heidegger, 151-152. What follows from this is that the content of knowledge can be neither classical (where the object determines the content), nor modern (where the subject determines the content), nor postmodern (where subject and object both contribute to the content). For an overly reductionistic and flawed presentation of these ideas, see Canale, The Cognitive Principle of Christian Theology: A Hermeneutical Study of the Revelation and Inspiration of the Bible, 46, 74-86. The reason that all three methods fail is because what constitutes a subject and object in the world can't be properly destructured as Heidegger and Canale proceeded to do, 
domain, not excluding theological concepts and history as well as in matters pertaining to natural and human history. However, for many still unaware of this, hermeneutical reasoning within the current situation surrounding biblical exegesis typically merely involves shifts in presuppositions about where the best place to begin one's scientific journey should be, and what preliminary "conclusions" we should expect along the way to make our poker chip pile of evidence appear higher and more persuasive-to force one to look at all the "scientific" evidence we've "won" to our side, whether through bluffing or otherwise. It becomes, in essence, a battle between a scientistic-methodological naturalism and a scientistic-methodological Scripturalism.

Yet, it cannot be ignored that the escalating tensions described above between the sciences and the humanities precursors a deeper debate now taking place within hermeneutics. This new debate integrally impacts upon the interpretation of Scripture and everything else, and its foundation has been building for some time and is still developing, but often subconsciously to the public eye. The substance of this debate reshapes the conflict between science and religion, because the nature of the "human mind" seemingly presents unique challenges not found in normal natural science, as

\footnotetext{
because such subjects and objects don't exist in the first place to contribute to something called 'knowledge.' If there are no subjects and objects, as conceived traditionally by any one of the three major models, then knowledge can't be the result of some relationship between them, whether classical, modern, or postmodern. Yet, more specifically, the critical error of Canale is to suppose that there are "facts of revelationinspiration" that are anywhere near analogous to the "facts" of science which he supports as "real and certain." Canale, The Cognitive Principle of Christian Theology: A Hermeneutical Study of the Revelation and Inspiration of the Bible, 46. The position advocated by both Bohm and Pylkkö, as will be analyzed below, dismisses both of these assumptions (assuming Scripture is constituted by language, i.e., is literature, the same would hold true for Scripture), however, they do so in different ways. Put succinctly, then, Canale has made in Scriptural hermeneutics a similar error to the one that Heidegger made of the natural sciences, at least according to the thinking of those like Bohm and Pylkkö. Namely, Heidegger left natural science alone, as endowed with indisputable 'mathematical facts of nature,' whereas Canale left Scripture alone, as endowed with indisputable 'facts' of some unspecified sort concerning language. However, language, which constitutes Scripture, is not so easily treated as a body of "timeless" objective facts to merely be interpreted as having historical significance, as Canale has done. Language itself must be, in the least, historically situated to be historically interpreted-extrabiblical work is necessary for interpreting Scripture that involves ambiguous elements.

Pragmatically, one consequence of rejecting the received biblical text/language as the conveyer of some platonic-timeless body of linguistic meaning is that while it may be true that the received text is "accurate enough," it is still possible that the meanings of specific words and the historical-cultural contexts behind them have been lost. In other words, the Bible has not passed down to us some trans-temporal (platonic-timeless) body of meanings-the succeeding generations of copyists and translations have not brought the original cultural contexts with them, fully. Rather, only further archaeological evidence (archaeology is the "third biblical language") may shed light on the meanings behind the texts. This removes the classical "scientific method" from the equation, however, because sometimes valuable discoveries are not subject to the whim of the searcher-there are no falsifiable hypotheses that can be made-rather, such insights may be completely subject to the whims of "random chance" discoveries.
} 
commonly interpreted. Any serious attempts at the latter two of Barbour's options, namely dialogue or integration, through a presupposed scientific harmony, appear to ultimately succumb to the pressures of one of the first two options that favor conflict or independence. The breaking point is that many in the humanities simply reject the notion that the scientific method has universal validity in all disciplines, especially over matters of the mind, human cultures, and languages (where the boundaries are much debated), which is also where religion often enters the scene. Indeed, religion's involvement in the issues becomes particularly complex when connected to various third cultures, specifically historical, ${ }^{378}$ psychological, ${ }^{379}$ and sociological ${ }^{380}$ inquiries, which also exist and are

\footnotetext{
${ }^{378}$ Some claim that "no historian is, or can be, truly impartial or truly scientific, in the sense that a chemist or a physicist or a biologist can be impartial and scientific. Every historian is not only conditioned by, but dominated by his own fate, and none has ever been able to surmount that fate," Henry Steele Commager, "Is There a 'Philosophy of History?,'” in Mind Science and History, eds. Howard Evans Kiefer and Milton Karl Munitz (Albany, NY: State University of New York Press, 1970), 306; and Richard Taylor, "Can There Be a Science of Human Behavior? (A Response)," ibid., 35. Ernst Breisach similarly explains that many believe "causal laws could not be the primary concern of historians, who wish as keenly to know what Caesar did as why he did it. 'In short, the value of history is not scientific. Its true value is educational'" or humane, Ernst Breisach, Historiography: Ancient, Medieval, and Modern $3^{\text {rd }}$ ed. (Chicago, IL: The University of Chicago Press, 2007 ), 286. Note also, for how theology interacts with this discussion, Jacques Maritain, On the Philosophy of History (South Bend, IN: Aeterna Press, 2015); and G. Ernest Wright, God Who Acts: Biblical Theology as Recital (London, UK: SCM Press, 1952), 117. Wright explains that a God who truly enters our earthly space and time is intrinsic to many Jewish theologians and the Hebrew Bible. Wright suggests the need to return to a view of a "temporal" God and a theology that uses the "categories drawn from the Bible itself, instead of from propositional dogmatics" and that takes the "historical movement and interaction of the Bible" with divinity seriously, ibid., 115-116. See also, Paul R. House, Old Testament Theology (Downers Grove, IL: InterVarsity Press, 1998), 34. God's historicality and acts in history are the ground of the Jewish interpretation of the Hebrew Scriptures according to both Wright and House. Note also, Arrais, A Study on the Influence of Philosophical Presuppositions Relating to the Notion of the God-human Relation Upon the Interpretation of Exodus. The challenge of reconciling the Scriptural account of human and natural history with science remains, of course, a critical component of what it is Scripture and history challenge the believer to believe.

${ }^{379}$ For example, when the Holy Spirit is invoked as a deterministic or causal factor for human behavior, such as with Calvinism. See Gay, Progress and Values in the Humanities: Comparing Culture and Science, 51-52. "Metapsychology is the attempt to give a scientific grounding to human experience.... Christian authors who cite the Holy Spirit as a causal influence in human lives are engaged in metapsychology" or, in actuality, a non-scientific parapsychology, ibid., 51. Such efforts amount to the defense of "religious beliefs against the encroachment of scientific discoveries about the mind," ibid., 52. Gay believes such Christian metapsychologists articulate "a goal for psychology that it cannot reach," namely that by examining our "inner experience in finer and finer detail," we can discover "new information at every level," through our "faith in the infinite depth of personality." Gay rejects such a view, declaring himself one who has "cast" his "lot with the scientists." Gay admits to being impressed that for some "five hundred years now, one form of general inquiry, what is known as the scientific method, has produced advances in understanding not produced by any other method," ibid., 51-52. Gay's conclusion is striking. If such metapsychological beliefs remained allied with religion, and "religion and science are always with us, then there will always be at least two competing ways to view human beings," ibid., 112. See also, Frank A. Gerbode and John Durkin, Beyond Psychology: An Introduction to Metapsychology (Loving Healing Press, 2013). For the role of parapsychology in reshaping a worldview, see Joseph M. Felser, The Way Back to Paradise: Restoring the Balance Between Magic and Reason (Charlottesville, VA: Hampton Roads, 2005); and Madison, Understanding: A Phenomenological-Pragmatic Analysis, 70-114. A popular theologian Ellen G. White expressed it as following: "One of the great evils which has attended the quest of knowledge, the investigations of science, is that those who engage in these researches too often lose sight of the divine
} 
foundational within the interpretation of Scripture. This conflict over the domain of the validity of the scientific method exists (whether acknowledged or not) for all devout religionists who believe in the privacy and sanctity of the heart and a "personal relationship" with Jesus Christ through the Holy Spirit, ${ }^{381}$ yet in general are convicted that the natural world, however infinitely complex, remains thoroughly accessible through scientific and mathematical methods. ${ }^{382}$

character of pure and unadulterated religion. The worldly-wise have attempted to explain upon scientific principles the influence of the Spirit of God upon the heart. The least advance in this direction will lead the soul into the mazes of skepticism. The religion of the Bible is simply the mystery of godliness; no human mind can fully understand it, and it is utterly incomprehensible to the unregenerate heart," Ellen G. White, Testimonies for the Church Vol. 4 (Mountain View, CA: Pacific Press, 1948), 585. Elsewhere White shares, "some may say, 'If we believe the Bible, why does not the Lord work miracles for us?' He will, if we will let Him. When a human mind is allowed to come under the control of God, that mind will reveal the miracle-working power of God; the power of the mind in action is like the miracle-working power of God," Ellen G. White, Spalding and Magan Collection (Silver Spring, MD: Ellen G. White Estate, Inc., 1985), 240.

${ }^{380}$ Where, as has been noted above, a controversy resides concerning the methods of science and the humanities over the subject matter of religion; i.e., is religious studies a part of the sciences or humanities? See again, for example, Wainwright, "Introduction," in God, Philosophy, and Academic Culture: A Discussion Between Scholars in the AAR and the APA, 3-12.

${ }^{381}$ Noteworthy is that the very idea of a "personal relationship" with Jesus has recently been critiqued. See, for example, Jay Boyd, "The Problem with 'A Personal Relationship with Jesus'” at http://www.hprweb.com /2014/07/the-problem-with-a-personal-relationship-with-jesus/ (accessed May 4, 2017) and Derek Flood, "A Personal Relationship with God?" at http://www.huffingtonpost.com/derek-flood/personal-relationship-withgod_b_914065.html (accessed May 4, 2017). Both these critics come from the Left side of Christianity which is siding with the more progressively minded scientists. Their goal in this context is to 'socialize' Christianity upon quasi-marxist mathematical principles.

${ }^{382}$ Concerning the mathematical nature of the natural world, as noted above, Lydia Jaeger is one such Christian theist who advocates essentially a mathematicalism, and creates a hard dualism, of sorts, between the heart and nature as a result, supporting a modal-logical or multi-layered reality based loosely on the work of the philosopher and epistemologist Herman Dooyeweerd, A New Critique of Theoretical Thought: The Necessary Presuppositions of Philosophy (Lewiston, NY: Edwin Mellen Press, 1997), although she differs with him on some key points. She claims that although "quantum mechanics introduced the idea of chance at the most basic level of our physical theories," "nonetheless, quantum probabilities can still be described by strict mathematical formulae. Quantum theory has not left us in a disturbing world of fairly tales, where anything can happen," Lydia Jaeger, What the Heaven's Declare: Science in the Light of Creation, 59; 77. Jaeger believes that a deep mathematical "description of Cosmic Order" is possible, Lydia Jaeger, "Cosmic Order and Divine Word," in Spiritual Information: 100 Perspectives on Science and Religion, ed. Charles L. Harper, Jr. (West Conshohocken, PA: Templeton Foundation Press, 2005), 151; see also Lydia Jaeger, Einstein, Polanyi, and the Laws of Nature (West Conshohocken, PA: Templeton Press, 2010), esp. 180-183, 227. For a critique of her views, see Cartwright and Martin, "Queen Physics: How Much of the Globe is Painted Red?," 71; Younker, "A Dialogue Between Contemporary Perspectives and Ellen White on Divine Action and Quantum Physics," 136-137; and J. B. Stump, Science and Christianity: An Introduction to the Issues (Malden, MA: John Wiley \& Sons, 2017), 128; 131. Stump also interestingly explains that the Eastern tradition of Christianity approached nature differently, with less emphasis on order. "God did not create the world fully formed, but it is bursting with potential. The fact that the potential is not realized right now is to recognize the created order as 'fallen.' Science describes the current state of creation and the way it works in laws of nature, but these are statements about the way it behaves in this less-than-mature state. When something 'miraculous' happens (perhaps the origin of life and of consciousness are possible candidates for this), it might not be explainable according to these provisional natural laws. But those are not the laws of the 'natural' state that is to come. Miracles are the breaking through of the age that is to come," ibid., 131. In the Western Christian tradition, however, following the work of William Ockham and William Perkins, the idea that "once we understand how something works naturally, then it is no longer necessary or prudent to also appeal to God," became popular. Accordingly, in the Western tradition, 
In other words, it may be that the current status of science within religion should be considered

more in parallel to the sciences and humanities as two deeply differing cultures that equally divide

religious adherents. That is, religionists side equally with either the sciences or humanities, in

differing contexts, for different reasons. ${ }^{383}$ Furthermore, again, as has long been acknowledged in the

"either God did it or it came about through natural causes" became the standard position for how to explain any event, creating a harsh dichotomy between the two that continues to challenge us today, ibid., 122.

Contrastingly, other theologians such as Ellen White simply 'let be' the tension between the intellect and the 'heart,' offering no explanation: "Were the men for whom Christ has died devoid of moral nature, or were the gospel to be submitted to the understanding, to be decided by the intellect alone, men might approach it as they approach a mathematical problem. But this is not the case. The great truths of salvation are to be planted in the heart. The science of redemption is as high as heaven, and its value is infinite," White, Ms69-1897; and "The gospel does not address the understanding alone. If it did, we might approach it as we approach the study of a book dealing with mathematical formulas, which relate to the intellect alone.... The Word of God is what it claims to be in the sixth chapter of John-the bread of life-for it represents the body and blood of the Son of God. Its aim is the heart. It addresses our moral nature, and takes possession of the will," White, Lt5-1898.

${ }^{383}$ Earl Fronda expresses well the general sentiment of religionists that side with the humanities, in that "it is the [humanistic] religionistic attitude that predisposes one to deem certain phenomena inexplicable in principle. This is an attitude that is given to take certain phenomena to be inherently mysterious and to relish in their mystery. It takes this attitude to recognize a phenomenon as absolutely inexplicable in purely mundane terms and as such label it 'miracle'. And the direction that this attitude takes is towards the state of being held in worshipful awe by the mystery. The mystery itself becomes a source of edification....

"In contrast, the scientistic attitude holds that in principle all phenomena that really occurred can be explained in terms that are free of any religious or magical overtones. If this attitude is in any way dismissive of miracles, it is not necessarily dismissive of the possibility of the occurrence of such and such an inexplicable phenomenon (like the resurrection of Jesus) but of the attitude, that such a phenomenon is intrinsically inexplicable (which is what a miracle is supposed to be: an intrinsically inexplicable phenomenon). Even if the accounts of Jesus turning water into wine, multiplying loaves of bread, walking on water, even resurrecting, were proven beyond reasonable doubt to be factual, they would be taken not as eternal mysteries but as extremely fascinating phenomena that generate puzzles that are extremely tough-but, in principle, not impossible-to solve. No phenomenon that had actually occurred is to be taken as inherently mysterious; and if there is mystery shrouding a phenomenon, it is to be taken as something less an object of relish or a source of edification than an enigma to be cracked. They would not at all be termed 'miracles'.

"From the standpoint of one with the scientistic attitude, the concept 'miracle' itself is not only alien to the scientific discourse, but worse, considering it is a bane to the spirit of progressive science, and as such is an anathema. But the spirit of science is by nature predisposed to searching for explanations to anything that draws human curiosity, and if necessary, break taboos in the process of the search. The progress of science depends to a large extent on the assumption that no phenomenon that in fact occurred is beyond scientific explanation. It is possible, even in the age of space exploration and nanotechnology, that some scientists would declare some phenomenon a miracle. A case of miracle is declared when the scientists concerned have given up searching for a scientific explanation. To say that such and such is a miracle is in effect to suggest that such and such can never ever be taken up scientifically. Calling a phenomenon that defies all current understanding a 'miracle' effectively puts an end to scientific activity. But scientists who proffer miracles as explanation betray the spirit of science. The proffering of miracles is an indication of the failure of scientists qua scientist, not an indication of the failure of science." "One who takes the scientistic attitude to a phenomenon looks at it with cold, calculating, even brazen, inquisitiveness," Fronda, Wittgenstein's (Misunderstood) Religious Thought, 135137. It is interesting to compare the above with Ellen White, a popular theologian: "Science is too limited to comprehend the atonement; the mysterious and wonderful plan of redemption is so far-reaching that philosophy cannot explain it; it will ever remain a mystery that the most profound reason cannot fathom. If it could be explained by finite wisdom, it would lose its sacredness and dignity. It is a mystery that One equal with the eternal Father should so abase himself as to suffer the cruel death of the cross to ransom man; and it is a mystery that God so loved the world as to permit his Son to make this great sacrifice," Ellen White, "Man's Obligation to God," in The Signs of the Times April 3 (1884); and Ellen White, The Spirit of Prophecy Volume Four 
two cultures debates between the sciences and humanities, but has often been ignored within the

debates between science and religion, the division is itself centered upon the proper role and domain

of the scientific method and technique. ${ }^{384}$

It has been variously claimed that only deeper or sub-presuppositional thinking or critical

ontological reflection can escape the above situation ${ }^{385}$ that forces dialogue and integration into

(1884), 345-346. "To many, scientific research has become a curse; their finite minds are so weak that they lose their balance. They cannot harmonize their views of science with Scripture statements, and they think that the Bible is to be tested by their standard of 'science falsely so called.' Thus they err from the faith, and are seduced by the devil. Men have endeavored to be wiser than their Creator; human philosophy has attempted to search out and explain mysteries which will never be revealed, through the eternal ages. If men would but search and understand what God has made known of himself and his purposes, they would obtain such a view of the glory, majesty, and power of Jehovah, that they would realize their own littleness, and would be content with that which has been revealed for themselves and their children.

"It is a masterpiece of Satan's deceptions to keep the minds of men searching and conjecturing in regard to that which God has not made known, and which he does not intend that we shall understand. It was thus that Lucifer himself was cast out of Heaven. He became dissatisfied because all the secrets of God's purposes were not confided to him, and he entirely disregarded that which was revealed concerning his own work in the lofty position assigned him. By arousing the same discontent in the angels under his command, he caused their fall. Now he seeks to imbue the minds of men with the same spirit, and to lead them also to disregard the direct commands of God," ibid.

${ }^{384}$ To state it again, the perspective that "science, while not the whole of culture, is the most important part and should determine and give meaning to all the rest" leads to a position that "denies any independent knowledge value to philosophy or the humanities and, of course, to Revelation and theology," Robert J. Henle, "Science and the Humanities," 3-4. Henle explains, "Science would, in this new [emerging third] culture, [displace and] play all the knowledge roles played by philosophy, theology and the humanities in pre-scientific culture," ibid., 5. Gary Madison further observes, "scientific knowledge is nothing more than the expression of a certain intellectual technique: the scientific method. This technique has proven useful for certain purposes, but the failure on our part to realize its inherent limitations has had as its consequence the accelerating reduction of all cultural values to those of science," Madison, Understanding: A Phenomenological-Pragmatic Analysis, 11. Madison adds that "the problem of the Two Cultures ... is highly concrete and urgent. It has ... a strictly theoretical aspect to it, for what is ultimately at issue is the proper theoretical way in which to view language, understanding (truth), and reality," ibid., 22.

${ }^{385}$ See Maurice Merleau-Ponty, "Einstein and the Crisis of Reason," in Signs, tr. R. C. McCleary (Evanston, IL: Northwestern University Press, 1964), 192-197. The concepts of "depth" and "flesh" may point most directly to the major philosophical development and train of thought that is pertinent here. Building off of the conceptual framework laid down by Heideggerian insights, they were introduced formally by the philosopher Maurice Merleau-Ponty, The Primacy of Perception: And Other Essays on Phenomenological Psychology, tr. Carleton Dallery (Evanston, IL: Northwestern University Press, 1964), 172-173; and Maurice Merleau-Ponty, The Visible and the Invisible: Followed by Working Notes, tr. Alphonso Lingis (Evanston, IL: Northwestern University Press, 1968), 143. "Merleau-Ponty depicts a dynamic depth of the flesh that unfolds in and through encounters with difference. The flesh, he explains, is 'a new type of being,' pregnant with potential sense expressions, with an ever expanding horizon of possibility," Molly Hadley Jensen, "'Fleshing' Out an Ethic of Diversity," in Merleau-Ponty and Environmental Philosophy: Dwelling on the Landscapes of Thought, ed. Sue L. Cataldi and William S. Hamrick (Albany, NY: State University of New York Press, 2007), 199. "By Flesh MerleauPonty intended to indicate something which had no name in traditional Western philosophy.... Flesh, as a voluminous medium, is a 'pure' depth-a depth without any distance on itself," Sue L. Cataldi, Emotion, Depth, and Flesh: A Study of Sensitive Space: Reflections on Merleau-Ponty's Philosophy of Embodiment (Albany, NY: State University of New York Press, 1993), 60. Importantly, however, it must be noted that a "difficulty with this terminology lies in its inevitable identity with substantive banal flesh, an identity we have constantly to deny even though it is the basic bodied experience we must always depend on as the basis for our understanding. There is a certain irony in the need to disembody, even dematerialize flesh, in order that it help us more fully 
conflict or independence, not merely prior presuppositional decisions about what constitutes a valid starting point from which to epistemically interpret the objects that scientific reasoning and methodology considers and measures. From many of those working from sub-presuppositional perspectives, science can be understood to have no definable upper or "outer limits," in that it can continue forever in some respects, but importantly it is also pointed out that science does have lower or "inner limits"386 it cannot penetrate or even identify, since "science does not think,"387 as Heidegger so (in)famously put it. This has led some, especially those sensitive to the concerns of the humanities and religion, to point toward the "exhaustion of secular [scientific] reason" which has "led a number of philosophers and politicians to call for a return to religion," because, simply put, on the "level of world view thinking ... science clashes with religion." ${ }^{388}$

What the purpose of the above account of the relations between science and religion, and the sciences and humanities, has been is to sharpen the focus upon the role and purpose of any "third culture" concerning the possibility of unity and integration. ${ }^{389}$ Given the situation above, is the current "culture of religion" truly capable of serving as the "third culture" Snow alluded to and which

understand our being lived-bodies," Sam Gill, Dancing Culture Religion (Lanham, MD: Lexington Books, 2012), 121 n. 21. See also, Rajiv Kaushik, Art, Language and Figure in Merleau-Ponty: Excursions in Hyper-Dialectic (New York, NY: Bloomsbury, 2013), 11; Komarine Romdenh-Romluc, Merleau-Ponty and Phenomenology of Perception (New York, NY: Routledge, 2011), 110-113; and Floyd Merrell, Entangling Forms: Within Semiosic Processes (Göttingen, Germany: Walter de Gruyter, 2010), 41-42. Alternately, Rosen has sought to "demonstrate that the concept of depth put forward by Maurice Merleau-Ponty (1964), and of time-space advanced by Martin Heidegger (1962/1972), respond to the challenge of unification in science by offering a new understanding of space, time, and dimensionality," for "Merleau-Ponty's integration of space and time goes considerably further than Einstein's," Rosen, The Self-Evolving Cosmos, 43, 55.

${ }^{386}$ Gary Brent Madison, On Suffering: Philosophical Reflections on What it Means to be Human (Hamilton, Canada: Les Érables, 2013), 434.

${ }^{387}$ Heidegger, What is Called Thinking?, 8, 135. As a reminder, without doubt such a phrase as Heidegger's can "catapult philosophy to a certain source of a higher truth which is not understandable for nonphilosophers, meaning: to make a perfect separation of philosophy from a theoretical treatment of the reality that surrounds us," Andrzej Przyłębski, Sense, Meaning, and Understanding: Towards a Systematic Hermeneutical Philosophy (Zürich, Switzerland: Lit Verlag, 2013), 49-50.

${ }^{388}$ Jens Zimmermann, Humanism and Religion: A Call for the Renewal of Western Culture (New York, NY: Oxford University Press, 2012), 29.

${ }^{389}$ K. Gopalan remarks: "it is unfortunate that in many countries ... there is a great divide between the humanities and the sciences-between the arts and the sciences-the so-called 'two cultures." He believes that "it is time that we go back to that situation [in which there was only one culture]. [The] integration of science and humanities-science and culture, science and spirituality-seems to be the only means of solving the numerous problems threatening mankind today," K. Gopalan, "Challenges of Higher Education in Science and Technology," in Education in India, Vol. 2, ed. Shubha Tiwari (New Delhi, India: Atlantic Publishers, 2006), 15. 
Sandelands embraced, harmonizing or "reconciling" the cultures of the sciences and humanities, and what it would mean if it could? Would religion merely mediate between the two cultures of the sciences and humanities, leaving each of them for the most part, respectively, in an isolated or dualistic peace, or should religion displace the two cultures altogether as a superior culture, whatever this might mean $?^{390}$

The above question is pertinent because some believe "there can no more be a scientific culture than there can be a scientific religion; culture, like religion, addresses the question which science leaves unanswered: the question what to feel. The knowledge that it bestows on us is a knowledge not of facts nor of means but of ends: the most precious knowledge we have." Thus, at the end of the day, a culture's "meaning lies in the ethical vision that it perpetuates," ${ }^{391}$ and science and its technique has thus far been unable to satisfactorily explain away the humanities and their human need for something more personal, for feelings, and answers, to what is right or wrong in both individual and universal circumstances and contexts.

Therefore, the differences between mediating and displacing are significant. Should theology and religious studies 1) remain tied to their historical methodological traditions that culminated in scientific modernism, 2) or should religious studies embrace postmodernism and its methods, 3) or

\footnotetext{
${ }^{390}$ As previously noted above, Søren Brier has observed that already, pragmatically or sociologically, "we are moving into a Third Culture." Furthermore, "we have discovered that science, philosophy, and religion cannot eliminate metaphysics and that neither can Protestant Christianity. Today we must work with metaphysics in a reflective way," Brier, Cybersemiotics: Why Information Is Not Enough, 142.

${ }^{391}$ Roger Scruton, Modern Culture (New York, NY: Continuum, 2005), 17. "Many people will find the view that I am advancing preposterous. It seems too far from our post-modern experience, too much a legacy of ways of thinking that are no longer available.... In a certain measure I share this scepticism. Yet I can find no alternative account that explains either the history of high culture [as manifested in the humanities] or its power," ibid. (addition mine). Scruton suggests that "the two cultures perhaps stem from the same psychic need-the need for an ethical community into which the self can be absorbed, its transgressions overcome and forgiven, and its emotions re-made in uncorrupted form. The community offered by art is only imagined, born from the currents of sympathy that animate the realm of fictions. But consolation from imaginary things is not an imaginary consolation.... The universal religions are precisely those whose deities reside not in idols or temples [i.e., "real" things] but in texts [which allow imaginative engagement], and the God of Israel makes explicit in the second commandment that, being defined by a text (the tables of the law), he can tolerate no 'graven images'. The text has the universality of thought: it emancipates itself from place and time [or a metaphysics of "presence" which is actually timelessness] and addresses itself to all who can read or hear" in all times and places; it is, thus, omni-spatial and temporal, ibid., 19 (latter addition mine). For more on why the "indirectness" of a text takes us beyond a metaphysics of presence, see the explanation of "presence" in relation to Being in Wolfgang Walter Fuchs, Phenomenology and the Metaphysics of Presence: An Essay in the Philosophy of Edmund Husserl (The Hague, The Netherlands: Martinus Nijhoff, 1976), 7-8.
} 
should religion straddle the line, dualistically using both methods, 4) or can religion emerge from their tensions and identify its own methods of inquiry and discourse as an independent third culture? The problem is in the questions that individuals like Sandelands leave unasked, such as, in what way does religion, or God, reconcile the two cultures? And why should secular scientists or those in the secular humanities accept his claim, and what difference would it make to their respective cultures and their continually growing tensions in popular society? What is at stake is the place of religion within society and academic discourse.

Throughout the rest of this study, the above questions should be kept in mind. Although it is not the purpose of this study to answer these questions per se, they are important questions to ask in relation to this study, because some scientists remain confident that modernistic "western science will likely outlive postmodernism. It may already have."392 For "science and modernism" both have "deep links with ... metaphysics, because they both share the notion that the earth and the world ... speak their truths to us, not vice versa." "Physics and metaphysics share the same stage" "because both say ... that an understanding of life comes from watching and listening to the earth." Thus, "modernism," or the "belief in science, is deeper than postmodernism." 393

Such a viewpoint may be an accurate reflection of the trends in some of the variant and conflicting forms and results of post-postmodernism, such as digimodernism, which dominates the information fed to many in the younger generations. From such a perspective, there is no need for any harmonization between the sciences and humanities, through either God or any third culture, which lets the current contradictory understandings of freedom and time remain as an uncomfortable status quo those favoring the sciences sometimes willfully dismiss, with a tacit assumption that the primary error rests within the less influential humanities. Such optimism, however, appears unfounded as a genuine solution when surveying some of the rest of the recent societal landscape and other alternate forms of post-postmodernism, such as metamodernism, which is inclined to see the

\footnotetext{
392 Hendrix, "Fighting Out of Context: Culture Wars Within and Without Science Fiction, from Snow to Sokal," 46. Hendrix's claim is not far-fetched at all. Post-postmodernism has arrived, and it brings with it many continuations of the scientific-modernistic impulse.

${ }^{393}$ Bob Davis, Skills Mania: Snake Oil in Our Schools? (Toronto, Canada: Between the Lines, 2000), 175.
} 
need for further mediation and integration between the two cultures, and which may allow for some

“dialectical tension." ${ }^{394}$

Additionally, and also serving as a summary, an important point of clarity must be emphasized concerning the historical heritage of Christianity and its role in mediation between the two cultures and the rise of modern scientism, the most pointed rejection of religion. It was the rationalist nature of mathematics which inspired the original neo-Platonic "timeless forms" of the humanities-astheology found in the Augustinian tradition. Throughout the ensuing history of Catholic thought, the sacramentalism within Catholicism also became grounded on rationalist neo-Platonism, thus linking ethics and soteriology very closely with neo-Platonism. ${ }^{395}$ The later rise of empirical-deterministic Platonism (note the 'depth' or hierarchical aspect of the "neo" was effectively removed or

\footnotetext{
${ }^{394}$ See, for example, George Newlands, The Transformative Imagination: Rethinking Intercultural Theology (Burlington, VT: Ashgate, 2006), viii, 116, 137, 142, 153.

395 To be clear, as it does cause confusion in the literature, neo-Platonists distinguished (correctly or not) two branches of mathematics in Plato-the first, or purely rationalist application, was to mathematics used abstractly (numbers and formulas that were timelessly true), and the second was physics, which took mathematics and applied it to geometry and then the real world through the work of Euclid around 300 BC, especially in areas such as architecture (thus it was applied only to an embryonic degree in nature itself prior to the rise of modern science). Architectural geometry and physics as such are already neo-Platonic in this sense (numbers were abstractions originating from some timeless ether-world, which were then mediated to humans through architecture and later nature), but often the term "neo-Platonic" is typically reserved for discussions about a more mystical union of Being as it is associated with forays into metaphysics and spirituality. Accordingly, in this study the modern atheistic view of mathematical natural science will be characterized as a "de-neo-ized" mathematical Platonism. Nevertheless, the original neo-Platonic distinction between abstract mathematics and physics should not be forgotten, as the physical manifestation of timeless truth (the Sacraments) present the logic for the Sacraments as manifestations of a timeless, non-physical but physically present divine reality. For a discussion on the original neo-Platonic understanding of mathematics, see Jacob Klein, Greek Mathematical Thought and the Origin of Algebra, tr. Eva Brann (New York, NY: Dover Publications, 1968), 10-16; and Burt C. Hopkins, The Origin of the Logic of Symbolic Mathematics: Edmund Husserl and Jacob Klein (Bloomington, IN: Indiana University Press, 2011), 154-170. Note also, Antii P. Balk, Saints and Sinners: An Account of Western Civilization (London, UK: Thelema Publications, 2008), 551-559; Naomi Zack, The Handy Philosophy Answer Book (Canton, MI: Visible Ink Press, 2010), 52; David Albertson, Mathematical Theologies: Nicholas of Cusa and the Legacy of Thierry of Chartres (Oxford, UK: Oxford University Press, 2014), 60-62; Paul Plass, "Neoplatonism," in Medieval Italy: An Encyclopedia L-Z, Vol. 2, ed. Christopher Kleinhenz (New York, NY: Routledge, 2004), 764-766; Gay, The Enlightenment: The Rise of Modern Paganism, 251; Henry Chadwick, Studies on Ancient Christianity (Burlington, VT: Ashgate, 2006), 150; James Wilberding and Christoph Horn, Neoplatonism and the Philosophy of Nature (Oxford, UK: Oxford University Press, 2012); Algis Uždavinys, Orpheus and the Roots of Platonism (London, UK: The Matheson Trust, 2011); and Gregory Shaw, Theurgy and the Soul: The Neoplatonism of Iamblichus $2^{\text {nd }}$ ed. (Kettering, $\mathrm{OH}$ : Angelico Press, 2014). John Milbank and Aaron Riches assert in the foreword to Shaw's book that "the liturgical practice of Christianity ... inherits significantly from the cultic practices of Greek philosophy. In this regard the recovery of the thought and influence of the Syrian Neoplatonist Iamblichus (c.245-c.325) may prove, in time, to stand at the very heart of a new selfunderstanding of Western culture and religion-one ... now freshly aware of ... how Christian liturgy, the sacramental practice of the Church and the metaphysics of the Incarnation owe a perhaps significant debt to the pagan Platonic tradition," John Milbank and Aaron Riches, "Foreword: Neoplatonic Theurgy and Christian Incarnation," v-vi.
} 
transformed-scientism's only explicit metaphysics is mathematics) within modern science shook the foundations of the rationalist neo-Platonic humanistic-theology of the Catholic tradition. However, as time passed, and the scientistic and authoritarian impulses of positivism within empirical Platonism undercut the authority of the Catholic tradition, ${ }^{396}$ what has often been missed is that the authority of the Catholic church was originally grounded on rationalist neo-Platonism itself, and was thus merely replaced by the 'authority' of empiricized Platonism in modern natural science and its corollary scientism. ${ }^{397}$ That is, "one of the reasons that our science makes universal claims ... is that it borrows from 'the Christian religion' its notions of universal applicability. The modern idea of religion made it possible for Christianity to claim to be the one true religion. Modern science now claims an analogous universal applicability," ${ }^{198}$ which was easy to do, as it is built on the same platonic foundation.

\footnotetext{
396 "With the emergence of modern mathematics, this verbal basis for Western life and thought-this trusted covenant between word and world-began to crumble "The most decisive change in the tenor of Western intellectual life since the seventeenth century,' writes Steiner, 'is the submission of successively larger areas of knowledge to the modes and proceedings of mathematics'.... In cardinal respects, reality itself was redefined. It now began outside verbal language, in the untranslatable world of a pure mathematics that no longer required a real relation between symbol and word. Truth became quantitative rather than qualitative, impersonal rather than personal, empirical rather than intuitive, mathematical rather than metaphysical. It was perceived, increasingly, as an abstract relation between numbers, rather than as a reality arrived at through referential signs," Nathan D. Mitchell, Real Presence: The Work of Eucharist (Chicago, IL: Liturgy Training Publications, 2001), 86.

${ }^{397}$ An irony in this is that Protestantism also favored Plato over Aristotle in the rise of modern science, and thus Protestantism is awkwardly linked with a de-neo-ized Platonic scientism against Catholicism-even though Catholicism had its own roots in Platonism and neo-Platonism prior to its Platonic-Aristotelian synthesis. This has made it difficult for Protestants to critically reflect upon their own reliance on Platonic roots. Put as concisely as possible, modern science is also a Platonic-Aristotelian synthesis. Contemporary Catholicism is a synthesis of the same. Each, however, emphasizes one side of the synthesis in certain contexts, yet Platonism is the foundational ground of both. For more, see Robert H. Nelson, God? Very Probably: Five Rational Ways to Think about the Question of God (Eugene, OR: Cascade Books, 2015), 65-79, esp. 70-71. Nelson explains, "in the history of Western religion, one great line of thought runs from Plato, to the later Neoplatonists of the ancient world, to Augustine who synthesized Platonism with Christianity, and then to the Protestant Reformation that in the sixteenth century newly looked back to Augustinian theology for inspiration (Martin Luther was originally an Augustinian monk). For Aristotle, by contrast, Thomas Aquinas in the thirteenth century was the great synthesizer of Aristotelian thought with Christian theology. The great 'protest' of the Reformation in the sixteenth century was significantly against the medieval scholastic theology of the Catholic Church, against Aquinas, and against Aristotle.

"The favoring of Platonic over Aristotelian sources in the Reformation proved to be a great advantage in terms of setting the stage for the development and advancement of the scientific method and the eventual discovery by Kepler, Galileo, Newton, and others in the sixteenth and later centuries of the mathematical workings of the physical universe," ibid., 70-71. See also, Eric W. Gritsch and Robert W. Jenson, Lutheranism: The Theological Movement and Its Confessional Writings (Philadelphia, PA: Fortress Press, 1976), 103-109.

${ }^{398}$ Harrison, The Territories of Science and Religion, 191-192.
} 
Thus, philosophically speaking, the work of the Catholic thought leaders today is to reclaim the church's authority from the postmodern skepticism that results from the abuses of scientism ${ }^{399}$ by reintroducing the "neo" part of rationalist neo-Platonism ${ }^{400}$ back into empirical Platonism, and then bring them both back into the fold of an expanded rationalist neo-Platonic empiricist sacramentalism. ${ }^{401}$ In this endeavor, and when seeking to understand the past history of the humanities and theology, what is critical to keep in mind is the constancy of the authoritative role of neo-Platonism in Catholicism, ${ }^{402}$ even with Aristotle's and Thomas Aquinas's insights in mind, and the

\footnotetext{
${ }^{399}$ Hans Boersma acknowledges and supports the irony of the "paradoxical argument ... that postmodern skepticism is simply the logical outcome of modern claims of certainty," Hans Boersma, Heavenly Participation: The Weaving of a Sacramental Tapestry (Grand Rapids, MI: Eerdmans, 2011), 155.

${ }^{400}$ Neoplatonism seeks to overcome the Platonic cleavage between thought and reality, or Ideals and Forms. This is because Platonism is characterized by its method of abstracting the finite world of Forms (humans, animals, objects) from the infinite world of the Ideal, and One. Neoplatonism, however, follows "Plotinus's famous maxim that the Absolute or One 'has its center everywhere but its circumference nowhere."' The One thus emanates 'elsewhere' hierarchically to all lower or lesser beings. However, without the 'connective tissue' of Neoplatonism's emanationism and the rejoining of all reality to the One, all would result in fragmentation, John J. Cleary, ed., The Perennial Tradition of Neoplatonism (Leuven, Belgium: Leuven University Press, 1997), xxxi-xxxiv. See also, Adam Potkay, The Story of Joy: From the Bible to Late Romanticism (Cambridge, UK: Cambridge University Press, 2007), 32-34; and Albert Camus, Christian Metaphysics and Neoplatonism, tr. Ronald D. Srigley (Columbia, MO: University of Missouri Press, 2007). See also, Joseph S. Flipper, Between Apocalypse and Eschaton: History and Eternity in Henri de Lubac (Minneapolis, MN: Fortress Press, 2015), 108-110; Rick Franklin Talbott, Sacred Sacrifice: Ritual Paradigms in Vedic Religion and Early Christianity (Eugene, OR: Wipf and Stock, 1995), 275-282; Paul A. Hughes, Neoplatonist Stew: Or, How Sacramentalism, Mysticism, and Theurgy Corrupted Christian Theology (Liberty, TX: God's Trombone/Lulu Press, 2014), 87; and David W. Congdon, The God Who Saves: A Dogmatic Sketch (Eugene, OR: Cascade Books, 2016), 159-160, where Congdon explains about the soteriocentric ecclesiology centered in the Sacraments.

${ }^{401}$ In this endeavor, all of society and nature are implicated. For more on this, I recommend my own study, Younker, "From Metaphysics to Templephysics: Situating the Significance of Fernando Canale's Contributions for the 'Christian Philosopher,'” 194-259. Many Catholics are engaged in this endeavor, but a prominent one would be the liberation theologian Leonardo Boff. His contribution is explained by Mathai Kadavil, The World as Sacrament: Sacramentality of Creation from the Perspectives of Leonardo Boff, Alexander Schmemann, and Saint Ephrem (Peeters Publishers, 2005), 132. See also his work, Leonardo Boff, Ecology \& Liberation: A New Paradigm (Maryknoll, NY: Orbis Books, 1995). For comparable perspectives, see Matthew Fox, A Spirituality Named Compassion: Uniting Mystical Awareness with Social Justice (Rochester, VT: Inner Traditions International, 1999); and Dale A. Johnson, Einstein at Prayer, Jesus in the Lab (New Sinai Press, 2006), 26.

${ }^{402}$ Exemplar of this would be the work of David C. Schindler, "Truth and the Christian Imagination: The Reformation of Causality and the Iconoclasm of the Spirit," in Communio 33 (Winter 2006), 521-539; David C. Schindler, "What's the Difference? On the Metaphysics of Participation in a Christian Context," in The Saint Anselm Journal 3.1 (Fall 2005), 1-27; David L. Schindler, “'In the Beginning was the Word': Mercy as a 'Reality Illuminated by Reason," in Communio 41 (Winter 2014), 751-773; Michael Hanby, "The Gospel of Creation and the Technocratic Paradigm: Reflections on a Central Teaching of Laudato Si," in Communio 42 (Winter 2015), 724-747; Adrian J. Walker, “'Constitutive Relations': Toward a Spiritual Reading of Physis," in Being Holy in the World: Theology and Culture in the Thought of David L. Schindler, eds. Nicholas J. Healy, Jr., and David C. Schindler (Grand Rapids, MI: Eerdmans, 2011), 123-161; David C. Schindler, The Catholicity of Reason (Grand Rapids, MI: Eerdmans, 2013); Esther Lightcap Meek, Contact with Reality: Michael Polanyi's Realism and Why It Matters (Eugene, OR: Cascade Books, 2017), 291; Lizette Larson-Miller, Sacramentality Renewed: Contemporary Conversations in Sacramental Theology (Collegeville, MN: Liturgical Press, 2016), 9; Stephen L. Hastings, Whole-
} 
original understanding of the neo-Platonists that distinguished classical abstract mathematics as simply "Platonic," while geometry and physics were reserved for an authentically "neo-Platonic mathematics." ${ }^{403}$ The question of whether there is an alternative "solution" to the crisis of the humanities and sciences, other than through neo-Platonism, ${ }^{404}$ is a part of the inquiry driving this study.

In the following section I will briefly demonstrate that the existing pragmatic "third cultures" that Snow mentioned are, in fact, divided between those more inclined to the sciences and those more inclined toward the humanities, and, furthermore, the division between their respective adherents is directly related to the roles of freedom and time. Demonstrating the place religion has in this situation will provide the data necessary to evaluate whether religion presently is a true mediatorial third culture that can properly navigate the tensions between the two cultures, or whether we must search for another pathway.

\section{The Divide Within the "Mediatory" Third Culture Disciplines Concerning Freedom and Time and the Place of Religion}

The purpose of this section is to show that some of the central "third culture" disciplines which Snow initially referred to, namely psychology and psychiatry, economics, and the socio-political sciences, are themselves today, 1) divided between scientific/modern tendencies versus humanities/postmodern tendencies, and 2) the issues of freedom and time are what constitutes the core of their divides. Thus, what remains is to 3) discover what role or place religionists have in this situation, to reveal whether or not religion is actually positioned to mediate between scientific and

Earth Ethics for Holy Ground: The Development and Practice of 'Sacramental' Creation Spirituality (Lanham, MD: Lexington Books, 2017); Paul Tyson, Returning to Reality: Christian Platonism for our Times (Cambridge, UK: The Lutterworth Press, 2015); and Paul Tyson, De-Fragmenting Modernity: Reintegrating Knowledge with Wisdom, Belief with Truth, and Reality with Being (Eugene, OR: Cascade Books, 2017).

${ }^{403}$ Note again, Hopkins, The Origin of the Logic of Symbolic Mathematics: Edmund Husserl and Jacob Klein, 95, 154-197; and the essays in R. Baine Harris, ed., Neoplatonism and Contemporary Thought: Part One (Albany, NY: State University of New York Press, 2002).

${ }^{404}$ For example, Boersma states that "the dilemma we now face [concerning the collapse of atheistic modernism into postmodernism], while serious, is by no means without resolution. If it is true that the spurious certainty of modernity resulted from the late medieval undoing of the [neo] Platonist-Christian synthesis, then we may expect that the Great Tradition offers resources that allow for the recovery of a solid grounding of human truth claims, a grounding that avoids both the Scylla of modern presumption and the Charybdis of postmodern abdication," Boersma, Heavenly Participation: The Weaving of a Sacramental Tapestry, 157 (additions mine). 
humanities oriented concerns. Overall, what the first two points above demonstrate is a reduplication of the broader academic culture war between the sciences and the humanities within the third culture disciplines. What is important to discover is whether the "culture of religionists" is itself already internally divided along similar lines, and if freedom and time are the lynchpin to the divisions even when religion is involved. This exploration will reveal whether the present general manifestation of religion, and the theologies it contains, is relevant for society, or an unnecessary reduplication of a preexisting philosophical conflict.

Below the study will proceed to survey some contemporary literature on each of the three major third culture disciplines, focusing especially on the role that freedom, time, and the place religion has within them. Before beginning, it must be noted that even in journalism connections to Snow's two cultures have been observed, ${ }^{405}$ indicative of just how widespread the conflict has infected society, and that even "talking" (or writing) about the issues sometimes brings about similar problems, a residue of our age of "fake news" in the early $21^{\text {st }}$ century. ${ }^{406}$ Depending on where and how one was raised and educated, escaping some of the residual components of the two cultures can be very difficult, a reality that is hopefully made clear below. At the same time, of course, the study will attempt to "report" on the situation accurately.

${ }^{405}$ David Berry, Journalism, Ethics, and Society (Burlington, VT: Ashgate Publishing, 2008), 112.

${ }^{406}$ Representing one of the greatest dangers of digimodernism, a variant of post-postmodernism, is the phenomena of "fake news," which, as a polarizing agent, is facilitated by the speed of technology. Greg Gordon cites research that shows there has been a large increase in the amount of fake news being spread all over the world. See Greg Gordon, "Fake, Misleading Social Media Posts Exploding Globally, Oxford Study Finds," at https://www.mc clatchydc.com/news/nation-world/national/ national-security/article215188910.html (accessed July 19, 2018). For more, see Geoffrey Baym, "Real News/Fake News: Beyond the News/ Entertainment Divide," in The Routledge Companion to News and Journalism, ed. Stuart Allan (New York, NY: Routledge, 2010), 374-383; Stephen Currie, Sharing Posts: The Spread of Fake News (Referencepoint Press, 2017); Jason Stanley, How Propaganda Works (Princeton, NJ: Princeton University Press, 2015); Robert W. Janke and Bruce S. Cooper, News Literacy: Helping Students and Teachers Decode Fake News (New York, NY: Rowman \& Littlefield, 2017); and Kerry Wood, Fake News; MSM: The Illegitimate Press (DHSG Press, 2017). 
Freedom and Time within the Third Culture Disciplines of Psychology and Psychiatry

The sister disciplines of psychology and psychiatry are currently facing a significant crisis in the $21^{\text {st }}$ century. ${ }^{407}$ It has been described as a direct parallel to Snow's two cultures. "Although some psychologists fall at either end of the scientific-humanistic continuum, most psychologists would fall at various points in between. Instead of describing psychology in terms of two cultures, a description in terms of several cultures would be more accurate," leaving psychology in a rather confused state. It appears as if "two essentially incommensurable cultures exist in psychology," pulling people in opposite directions, with individual psychologists uncomfortably oscillating between the two, depending on their own presuppositions and areas of interest, ${ }^{408}$ though most probably feel pressure

\footnotetext{
${ }^{407}$ See, for example, Gary Greenberg, The Book of Woe: The DSM and the Unmaking of Psychiatry (New York, NY: Penguin Group, 2013); Jerome Kagan, Psychology's Ghosts: The Crisis in the Profession and the Way Back (New Haven, CT: Yale University Press, 2012); R. Philip Buckley, Husserl, Heidegger and the Crisis of Philosophical Responsibility (Dordrecht, The Netherlands: Kluwer, 1992); Berger, Psychotherapy as Praxis: Abandoning Misapplied Science; Louis S. Berger, Psychoanalytic Theory and Clinical Relevance (Hillsdale, NJ: The Analytic Press, 1985); Madison, On Suffering: Philosophical Reflections on What it Means to be Human; Nicholas A. Cummings and William T. O'Donohue, eds. Understanding the Behavioral Healthcare Crisis (New York, NY: Routledge, 2011); and, for recent popular articles, see John Horgan, "Psychiatry in Crisis! Mental Health Director Rejects Psychiatric 'Bible' and Replaces With Nothing," Scientific American (May 4, 2013), available at http://blogs.scientificamerican.com/cross-check/psychiatry-in-crisis-mental-health-director-rejects-psychiatric -bible-and-replaces-with-nothing/ (accessed July 20, 2015); and B. A. Nosek et al., "Estimating the Reproducibility of Psychological Science," in Science 28, Vol 349 No. 6251 (August, 2015), 943-951.

${ }^{408}$ B. R. Hergenhahn and Tracy Henley, An Introduction to the History of Psychology, $7^{\text {th }}$ ed. (Belmont, CA: Wadsworth, 2014), 617. Michael Robertson and Garry Walter concur the same is true within contemporary psychiatry. "There is ... a divided state of knowledge in psychiatry.... The integration of the humanities with science is a source of both strength and weakness for psychiatry. Psychiatry is the quintessential third culture," Robertson and Walter, Ethics and Mental Health, 180. Similarly, writing from the background of medicine and psychiatry, Allen Dyer shares that "two very different approaches to ethics have emerged partly as a response to the stunning perplexities of modern technology.... The tension between objectivity and subjectivity pervades ethical reflection in medicine.... Part of the tension in medicine stems from a 'two cultures' dichotomy that has persisted in Western society since the Enlightenment, in which there is open conflict between the commitments of the 'sciences' camp, with an emphasis on objectivity, fact, abstraction, and certainty, and the cause of the 'humanities,' with an emphasis on subjectivity, value, emotion, and experience," Allen R. Dyer, Ethics and Psychiatry: Toward Professional Definition (American Psychiatric Press, 1988), 3. Dyer continues, "the pronouncement by C. P. Snow-that the sciences and humanities have come to represent two cultures that have so little in common that they never meet-has been widely accepted. Yet this conclusion must ultimately be unacceptable for modern medicine. Is Snow right [that the objectivist sciences should rule]? Or is [the Heideggerian] Michael Polanyi right when he suggests that because of the unspecifiable elements in the human process of scientific discovery, the objectivist account of knowing is false?" Dyer, Ethics and Psychiatry, 3-4. "Medicine has seemed in many ways to be the fulfillment of the Enlightenment promise of a better world through control of nature, but this ambition is acquired at high human cost. What ends should technology serve? The question cannot be answered impersonally. Ideally the profession of medicine should be in a good position to bridge the cultural gap between the sciences and the humanities with its dual epistemological heritage, the art and science of medicine. However, both medical practitioners and the public have been led to misperceive the nature and larger human setting of medical technology, to misvalue it and thus to be led by it to grandiose expectations. The result is a highly technological approach to medical practice. In spite of this, medicine is more than just medical technology," ibid., 4. Dyer's own opinion is that, "it is an interesting footnote
} 
to align with the sciences because of its respectability. Indeed, "the idea that psychology is a science that can and does-and indeed, must-pursue legitimate scientific methods to make progress" ${ }^{\prime 409}$ is a common sentiment. In any case, the same tension within psychology also holds true for its sister disciplines, such as psychiatry and psychoanalysis, which exist "at the intersection of two vertices: the [technocratic] medical and [humanistic] religious." ${ }^{\text {"10 }}$ Thus, some have controversially subdivided

on history that the false ideals of objective knowledge have largely been discredited by philosophers and physical scientists while still largely held to by medical and behavioral scientists," ibid. Importantly, Dyer is aware that "physicists recognized that they could not measure both the position and velocity of very small particles without their participation affecting the outcome of the measurement, the so-called 'Heisenberg Uncertainty Principle.' Thus it was recognized that the most precise of sciences, like all human activities, required judgments of determination. This is a striking analogy for psychiatric practice-and all of medical practice as well-in which the outcome of any investigation is greatly influenced by the participation of the observer, or conversely by the absence of the participation of the physician/scientist," ibid. See also, Karsten R. Stueber, Rediscovering Empathy: Agency, Folk Psychology, and the Human Sciences (Cambridge, MA: MIT Press, 2006); and Jodi Halpern, From Detached Concern to Empathy: Humanizing Medical Practice (Oxford, UK: Oxford University Press, 2001). Halpern affirms that Heidegger offers important insights that relate to the concept of empathy, ibid., 55, 76-81, 96 n. 18.

For the primary similarities, although there are differences, between Michael Polanyi and Martin Heidegger, see Theodore Kisiel, "Scientific Discovery: Logical, Psychological, or Hermeneutical?," in Phenomenology: Critical Concepts in Philosophy Vol. 3: Phenomenology on Science, Art, and Ethics, eds. Dermot Moran and Lester E. Embree (New York, NY: Routledge, 2004), 48. "Polanyi sees the entire process of discovery-from initial investiture, through the exploratory phase, to the final commitment to its outcome-as being under the sway of what he calls the 'ineffable domain,' and Heidegger calls Being. And the pretheoretical know-how that he calls personal knowledge is a near kin to Heidegger's Seinsverständnis," ibid.

${ }^{409}$ Peter Ayton, "Why Does Psychology Need Methodology?," in Laboratory Psychology: A Beginner's Guide, ed. Julia Nunn (East Sussex, UK: Psychology Press Ltd., 1998), 1. Ayton reminisces about a time when he was "an undergraduate psychology student" and "one of my contemporaries complained to our tutor that they had chosen to study psychology because they: '... wanted to understand people-not to measure them doing 'silly things' and turn them into numbers .... At this time I was rather impressed by this argument and rather shocked by my tutor's characteristically robust response. He answered by suggesting that, if the student simply wanted to ponder the nature of people, then they might be better off reading the novels of Jane Austen or Tolstoy-but we were here to do science.

"This sharp remark echoes the distinction that was identified by C. P. Snow in the 1950's according to which there are two separate cultures of thought that are attributable to the nature of educational attitudes. The culture of the literary intellectuals and the culture of the scientists view each other with mutual suspicion. According to Snow the position was then worsening; he could recall there had been a time when the two sides could at least manage 'a frozen smile' but that they were by then incapable of communicating. My tutor and student colleague certainly didn't manage a smile of any description. Instead there was one of those awkward moments when two people discover that they have attitudes that will require more effort than they believe the other is prepared (or able) to make to understand why they are wrong," ibid., 1-2. The above illustration, pitting the naïve student, as a representative of the humanities, against a more scientifically minded tutor, well represents the general situation of the subservient humanities to the dominant sciences in the academy today.

${ }^{410}$ Nancy McWilliams, Psychoanalytic Psychotherapy: A Practitioner's Guide (New York, NY: The Guilford Press, 2004), 3. McWilliams observes that at the rise of the discipline, there was tremendous pressure to classify psychoanalysis as a science, as it would increase its prestige, ibid., 7. 
psychology's two cultures roughly as follows-with psychiatry siding with the sciences, and psychoanalysis with the humanities, ${ }^{411}$ albeit this classification remains complex and disputed. ${ }^{412}$

In defense of a psychiatry's third culture status while acknowledging the confusion, Daniel Cordle observes, "there are at least three problems with the two cultures model: first, science is undeniably part of [the broader, including the humanities, popular] culture; second, 'there are overlaps between literary and scientific modes of knowing'; and third, the debate 'encourages the unthinking acceptance of stereotypical definitions of literature and science. ${ }^{413}$ Concerning psychiatry itself, Halliwell similarly believes that the problem with the simplistic bifurcation of the two cultures is that disciplines like "medicine and psychiatry" inhabit a "unique space." Although they are "seen by some as a specialist sphere of knowledge akin to the natural sciences, medicine was viewed by others as a human-centered project more akin to the arts." ${ }^{414}$ Nevertheless, although "the medical humanities grew in the ... space between the poles of science and the arts," "this middle space was rarely comfortable," ${ }^{415}$ which remains the situation today. What is important about this is that the

\footnotetext{
${ }^{411}$ More succinctly, "until recently," “Anglo-American psychoanalysis and continental European philosophical hermeneutics, the study of meaning and interpretation," were "separated not only geographically and by different languages, but also by the two cultures of which C. P. Snow wrote, those of the sciences and the humanities. Psychoanalysis in England and the United States has been dominated by the natural and social sciences. Psychoanalysis in Europe, and France in particular, has largely been associated with the humanities, literature, and history, with influences of anthropology and linguistics." Such a heritage interestingly links European psychoanalysis with philosophers such as "Johann Gottfried von Herder, Friedrich Schleiermacher, Wilhelm Dilthey, Edmund Husserl, and Martin Heidegger, each of whom assigned central importance to language, meaning, dialogue, and emotion, as distinct from the Enlightenment emphasis on the natural sciences, causality, sense data, and metaphysics. Hans Georg Gadamer, Maurice Merleau-Ponty, and Emmanuel Levinas were among those who, following Husserl and Heidegger, carried forward the agendas of hermeneutics into mid- to late twentieth-century discourse. At the same time, Jacques Derrida brought hermeneutics into the postmodern avant garde. Their views profoundly impacted psychoanalysis in Europe....

"Meanwhile, Anglo-American psychoanalysis, rooted in science and pragmatism, maintained the biosocial emphasis which Freud, based upon his neurological education and the psychiatric bias of his time, strongly advanced. For them, meanings and interpretation were of importance but beholden to scientific proof and causal explanation. As a result, Freudian, ego psychological, and object relations theories were cast in terms of natural and social science. Ideologically at least, and despite their differences, they adhered to the framework of the empirical sciences, "Victor L. Schermer, Meaning, Mind, and Self-Transformation: Psychoanalytic Interpretation and the Interpretation of Psychoanalysis (London, UK: Karnac Books, 2014), 1-2.

412 This is true especially for those who try to merge Freud with Heidegger. See, for example, Havi Carel, Life and Death in Freud and Heidegger (Amsterdam, The Netherlands: Rodopi, 2006), xvi-xvii. Concerning "the question about the scientific status of psychoanalytic theory, it seems that there can be no simple answer to the question because the question itself assumes we have a clear idea of what 'science' is," ibid., xvi.

${ }^{413}$ As cited in Martin Halliwell, Therapeutic Revolutions: Medicine, Psychiatry, and American Culture, 1945-1970 (London, UK: Rutgers University Press, 2013), 10.

${ }^{414}$ Halliwell, Therapeutic Revolutions: Medicine, Psychiatry, and American Culture, 1945-1970, 10.

${ }^{415}$ Halliwell, Therapeutic Revolutions: Medicine, Psychiatry, and American Culture, 1945-1970, 10.
} 
ambiguity surrounding the third culture status of medicine and psychiatry has profound ethical

ramifications. ${ }^{416}$

The central divide in the disciplines of psychology and psychiatry revolves around the role of

freedom, or human freewill, and time. This is clear from the work of Hans Eysenck, who asserts that

"what is clear is that there is a profound split within psychology between the two cultures, the

scientific and the humanistic." He remains pessimistic about any "epistemic armistice." The divide is

between a "sensate system" characterized by "empiricism and normalism," where "all events are

completely determined," and an "ideational system" which sees reason, revelation, and mysticism "as

primary sources of knowledge," and it is in this latter system where "free will and religion" are best

located ${ }^{417}$ Eysenck, briefly surveying the origins behind how the cultures developed, believes there is

${ }^{416}$ Carson Strong shares, "What C. P. Snow described as the 'two cultures' does in fact exist within medical schools. Most medical students have a background of heavy study in the natural sciences, and they view medicine as itself a science. Many have come to view ethics as 'soft' because it is nonquantifiable and therefore regard it as not susceptible to rigorous thinking. This perception makes communication between the two cultures difficult. Many in the field of medicine did not understand what is involved in medical ethics. It was regarded as focusing on a search for the 'right answers,' and when there is no clear right answer, a natural conclusion is that ethics is a waste of time," in Carson Strong, "Medicine and Philosophy: The Coming Together of an Odd Couple," in The Development of Bioethics in the United States, ed. Jeremy R. Garrett, Fabrice Jotterand, and D. Christopher Ralston (New York, NY: Springer, 2013), 126-127. As I have already noted above, but is worth reiterating, both historically and philosophically, Snow's formalization of the "two cultures" in 1959 initiated or reinvigorated an important debate about who should maintain the ethical gateway of society. Historically, this was because Snow's view had a broad "reach during the Cold War, when science and technology were priorities for research funding. He claimed that whereas literary culture often held the high moral ground in dealing with the complex human condition, some writers [from the literary culture] had shown themselves to be morally (and politically) suspect for dallying with extreme ideologies in the 1930s, and he asserted that science was actually a deeply ethical activity in which scientists were responsible for the welfare of humanity." Thus, "rather than bracketing off moral issues, Snow's two cultures argument wrestled ethics back into science," Halliwell, Therapeutic Revolutions: Medicine, Psychiatry, and American Culture, 1945-1970, 9. Halliwell goes on to observe that within the "intellectual posturing ... at the peak of Cold War anticommunism," it was difficult "to think outside a binary paradigm. The best one could hope for was balance, but very few critics were able to map out a middle space that would draw together elements from the arts and sciences without becoming skewed by one or other pole." As Halliwell observes, for the mathematician Jacob Bronowski, "the trap was an artificial division between 'thinkers' and 'feelers,' in which artists are seen as uncritical and scientists appear to be intent on destroying culture with unspiritual materialism. The emphasis on physical science and technology during the Cold War was one reason for the perceived divide, but Bronowski affirmed that" the "real issue is 'the lack of a broad and general language in our culture' that could provide a multidimensional perspective to link personal and social activities," ibid., 10. Of course, such a broad and general language, or mediatorial third culture, has not been found that satisfies all parties.

${ }^{417}$ Hans J. Eysenck, “The Growth of a Unified Scientific Psychology: Ordeal by Quackery," in Annals of Theoretical Psychology Vol. 5, eds. Arthur W. Staats and Leendert P. Mos (New York, NY: Plenum Press, 1987), 94. In support of this, E. Rae Harcum similarly argues that the freedom of the will is necessary for any meaningful psychology insofar as religion is concerned. He believes that a "humanistic science of psychology" alone presumes that the human being "possesses some freedom of will," E. Rae Harcum, Applied Psychology for Servant Religion: A Religious Behavioral Science Promotes Personal and Social Welfare (New York, NY: Hamilton Books, 2014), 9. 
sufficient evidence to point toward an "eternal opposition developing through history" between these two approaches in understanding reality. ${ }^{418}$ As such, given how this history continues into the present, Eysenck believes that "there seems to be no doubt that psychology is plagued by contradictions so profound as to threaten its integrity as a unified discipline.."19

John Bargh affirms that "during the short history of psychology as a science, the issue of whether free will exists and (if it does) how much of a role it plays has been responsible for more major paradigm shifts than any other" issue. ${ }^{420}$ As Bargh correctly observes, historically, the father of the discipline of modern psychology, Sigmund Freud, "was one of the first (and the most influential) who initially challenged the entrenched assumption that unless one was mentally ill, one was in complete control of one's thoughts, desires, and actions." ${ }^{241}$ The lack of control Freud believed he observed led to, in his own thinking as well as most experimental psychology that developed in the aftermath of his work, a "growing dissatisfaction with the unreliability of conscious introspection" as a data-gathering technique which ultimately resulted in the "violent" rejection of free will as nothing more than "an illusion" during the early $20^{\text {th }}$ century by many psychologists. ${ }^{422}$

What is particularly interesting is that time also factors into the debate about free will in an important way. It was, as the father of the discipline, Freud's own vision of psychology, which held

${ }^{418}$ Eysenck, “The Growth of a Unified Scientific Psychology: Ordeal by Quackery," 95.

${ }^{419}$ Eysenck, "The Growth of a Unified Scientific Psychology: Ordeal by Quackery," 95.

${ }^{420}$ John A. Bargh, "Automatic Information Processing: Implications for Communication and Affect," in Communication, Social Cognition, and Affect, eds. Lewis Donohew, Howard E. Sypher, and Edward Tory Higgins (Hillsdale, NJ: Lawrence Erlbaum, 1988), 9.

${ }^{421}$ Bargh, "Automatic Information Processing: Implications for Communication and Affect," 9.

${ }^{422}$ Bargh, "Automatic Information Processing: Implications for Communication and Affect," 9. In like manner to Bargh, James Easterbrook observed that "the ideas of freedom and of personal will and responsibility have been used for centuries in social philosophy, but not in recent psychology." Yet, he continues, the situation is changing. "Psychological knowledge has advanced to the point at which investigators are discussing 'perceived freedom,'” "'personal causality,"' and even "'the illusions of control and freedom.'” As such, the situation that still reigns today suggests a lack of evidence for freedom, and accordingly "scientific psychology is waiting for the old concept of free will to organize such evidence" for itself, and thus still "hesitates to use " the concept of free will today. James A. Easterbrook, The Determinants of Free Will: A Psychological Analysis of Responsible, Adjustive Behavior (San Francisco, CA: Academic Press, 1978), 7. As many others concur, from William James in the $19^{\text {th }}$ century to today, "most actual psychologists have no hesitation in denying that freewill exists,"a position, to be clear, with which James himself did not concur. William James, as cited in Leonard A. Kennedy, ed., Images of the Human: The Philosophy of the Human Person in a Religious Context (Chicago, IL: Loyola Press, 1995), 315. 
little room for free will, ${ }^{423}$ in whose methods one can find the goal of freeing people from their pasts ${ }^{424}$

(though not from time, and it is his definition of time that is critical here ${ }^{425}$ ). It is a complex theory

\begin{abstract}
${ }^{423}$ For collected analysis of his statements, see, for example, Edward Erwin, "Freud's Rejection of Free Will," in The Freud Encyclopedia: Theory, Therapy, and Culture, ed. Edward Erwin (London, UK: Routledge, 2002), 214-217; Dilman, Free Will: An Historical and Philosophical Introduction, 179-182; Carl E. Begley, Afraid to Believe in Free Will: The Human Tendency to Avoid Responsibility for Free Choices (Bloomington, IN: WestBow Press, 2010), 3-7; Richard Askay and Jensen Farquhar, Apprehending the Inaccessible: Freudian Psychoanalysis and Existential Phenomenology (Evanston, IL: Northwestern University Press, 2006), 330; and Richard Oerton, The Nonsense of Free Will: Facing Up to a False Belief (Leicestershire, UK: Matador, 2012), 19-20.

${ }^{424}$ It is not merely to Freud, however, to whom one may search for similar modernist sentiments. As
\end{abstract} the literary critic David Daiches observes of the assumed truism, "We cannot escape from the past, for it has created us; yet we must escape from the past if we are to live in the real world," David Daiches, "Scott's Redgauntlet," in From Jane Austen to Joseph Conrad, eds. Robert C. Rathburn and Martin Steinmann, Jr. (Minneapolis, MN: University of Minnesota, 1958), 59. In like manner, a number of other complex philosophical trends converge in Freud's thinking, including connections with Friedrich Nietzche. Peter Berkowitz, for one, connects the two. Berkowitz observes that, in Nietzsche, "at the peak of his reflections, the life dedicated to liberating the will from the myriad ways in which it is enslaved and imprisoned is the good life. Human excellence, so understood, consists in knowing and mastering the forms of necessity that condition the will," Peter Berkowitz, Nietzsche: The Ethics of an Immoralist (New York, NY: Harvard University Press, 1996), 266. Berkowitz adds that Nietzsche "interprets freedom ... as the most comprehensive form of creation, that is, making the world in which you live by mastering the most exalted and intractable forms of necessity-time and eternity.... [F]rom the perspective of Nietzsche's account of freedom, both Kantian autonomy [wherein one acts out of respect for the moral law that both legislates the self and is recognized as universal] and social contract political liberty appear as forms of slavery, since both enslave the self at the mercy of forces it has neither made nor mastered," ibid., 267. Within such a complex milieu concerning freedom, Freud is thus found to be in close company with a philosopher like Nietzche-both were obsessed with understanding how it is that man is guided by forces beyond his control. Indeed, "Freud read Nietzsche with trepidation, fearing that Nietzsche had already said it all, and called him the most profound of psychologists." The primary interests of both involved "the operation of the individual will as a selection of forces within the overall Will to Power, a selection of forces which gives us the illusion of freedom and free will," William Plank, The Quantum Nietzsche: The Will to Power and the Nature of Dissipative Systems (Lincoln, NE: Writers Club Press, 1998), 355. "The entire discussion on [Arthur] Schopenhauer's, Nietzsche's, and Freud's various positions on the in-itself, will, unconscious, and repression engages another fundamental metaphysical issue-that of freedom and determinism. If the human being is intrinsically an interplay of unconscious and conscious thoughts and instinctual impulses, both demanding satisfaction and forever running up against walls of unacceptability, how can there possibly be any 'free will'?" Askay and Farquhar, Apprehending the Inaccessible: Freudian Psychoanalysis and Existential Phenomenology, 136. See also, Paul-Laurent Assoun, Freud and Nietzsche, tr. Richard L. Collier, Jr. (New York, NY: Continuum, 2000).

${ }^{425}$ For more on the concept of time in Freud, see Joel Pearl, A Question of Time: Between Philosophy and Psychoanalysis (in Hebrew) (Ramat Gan, Israel: Bar-Ilan University Press, 2011), and his English adaptation of this in Joel Pearl, $A$ Question of Time: Freud in the Light of Heidegger's Temporality (Amsterdam, The Netherlands: Rodopi, 2013), 5. Pearl expresses the view that Freudian "psychoanalytic treatment ... takes place upon temporal planes, but the manner in which these plans are addressed, both in the clinical encounter and in theory, presupposes an axis of linear time which precludes the event of temporality from being present as a distinct phenomenon. Temporal planes are addressed through a causally contextual matrix, which discovers any given moment upon an axis which includes events preceding and succeeding it. The metaphysical assumption that time is, in fact, a linear phenomenon and could be observed as a quantifiable sequence of intervals actually obscures a more basic locus of time, in which past, present and future are bound together into a single fabric. A complex notion of time such as this is offered by ... Martin Heidegger.

"Unlike Freud, Heidegger does not consider linear time as resulting from a causal scheme of occurrence, but rather as derivative of existential time. This notion of time, which Heidegger refers to as 'temporality', is unique in that it construes the field in which things occur in the world in light of a temporal fabric in which past, present and future are inseparable. According to this view, human experience should be understood not through scientific categories which posit a linear notion of time, but in light of an ontology based upon the temporal tapestry characteristic of human existence," ibid. "Freud reduces the phenomenon of time to 
Freud advanced, the details of which cannot be fully expounded upon here, beyond noting that he sought to find a way for people to find "freedom from history" but not a "freedom in history." ${ }^{426}$ In other words, Freud sought to encourage people to 'live for the moment' alone. Such expressions are employed frequently by many within the world of sometimes dubious self-help psychology, who are often constrained to look for a variety of explanatory models based upon mystical or spiritual sources to maintain their timeless, live for the moment approach toward freedom. ${ }^{427}$ Or, as explained in the

the very sequence of intervals [like Aristotle]. The problem with this approach is that ... the sequence [of stimuli, in this case) itself cannot account for the phenomenon of the period. Alternately, the sequence of intervals already presupposes the existence of the period as a duration which manifests itself between moments and within each moment. In fact, the theoretical model offered by Freud, much like the Aristotelian notion of time, is imprisoned in a linear view of time which fails to distinguish the phenomenon of time from empirical phenomena. We consequently find, at the root of Freud's 'Project', a notion of time based upon a linear temporal axis comprised of intervals that in themselves have no duration. These intervals succeed one another in a manner which, though quantifiable, still remains fundamentally atemporal. Freud's superimposition of the period on his theoretical model is not an isolated incident, but a symptom of his entire theoretical framework," ibid., 87. See also, ibid., 143 n. 56. Compare with Michael Guy Thompson, The Truth About Freud's Technique: The Encounter with the Real (New York, NY: New York University Press, 1994), 201-202.

${ }^{426}$ Richard H. Armstrong, A Compulsion for Antiquity: Freud and the Ancient World (Ithica, NY: Cornell University, 2005), 215. For some additional historical context, note that "modernism initially took shape under a banner bearing the slogans 'faith in reason' and 'technology.'... Under this banner [Sigmund] Freud contributed therapeutic expression of drives, enabling the $20^{\text {th }}$ century human beings to affirm their biological selves, live for the moment and deny the magnitude and character-molding features of suffering," Hans L. Zetterberg, Sociological Endeavor, eds. Richard Swedberg and Emil Uddhammar (New Brunswick, NJ: Transaction Publishers, 1999), 204. Note also, Michael S. Roth, "Freud's Use and Abuse of the Past," in Rediscovering History: Culture, Politics, and the Psyche, ed. Michael S. Roth (Stanford, CA: Stanford University Press, 1994), 338. "Freud points to the core of the psycho-analytic conception of neurosis: an unpractical bondage to the past. The emphasis on 'practicality' was a deliberate attempt to play to the sympathies of his American auditors. Attention to real and immediate things is practical, and such attention may require the kind of freedom from the past that was at the heart of American culture (especially as seen by Europeans). Psychoanalysis, Freud wanted his New England auditors to know, was on the frontier of science aiming at freedom from the past," ibid. See also, Amir Eshel, Futurity: Contemporary Literature and the Quest for the Past (Chicago, IL: The University of Chicago Press, 2013), 276 n. 43.

${ }^{427}$ Many popular self-help psychology books share this advice in some form or another. For example, Guy Finley assures us that "nothing founded in thought can serve to reveal the unthinkable plans that the Extraordinary Life holds in store for anyone willing to leap into the moment without a parachute. Never mind those old fears of falling. Just jump! Being willing to risk failing is a prerequisite for fearless living.... The temporary rush of adrenalin has nothing in common with one's awakening to the reality of a timeless, fearless life," Guy Finley, Let Go and Live in the Now: Awaken the Peace, Power, and Happiness in Your Heart (Boston, MA: Red Wheel/Weiser, 2004), 183. God plays relatively little role in his book. Rather, "it is said God created man free. That is a great misunderstanding. Freedom cannot be given to anyone-even by our all-loving Creator himself. God has given to man the biggest thing he can-that is, the possibility to become free," ibid., 64. Guy adds, "to succeed in our quest, we need a new and higher understanding of our own being. For this peace that we seek resides within us; it is not to be found anywhere else, which leads us to the next step in our search. To enter the silent world of peace requires that we learn the secret of being still. We must discover and enter into our own still being," ibid., 75. Compare with Manfred B. Steger and Perle Besserman, Grassroots Zen (Boston, MA: Tuttle Publishing, 2001), 35: "In order to find the rhythm of your life, you've got to close the gap between yourself and everything you do-not by following the steps in your head, but by dancing it with your entire bodymind.... Most important, we've got to leap into the moment-whatever it has in store for us-if we really want to dance," ibid. 
context of his opponents' perspectives, "whereas Freud thought it a good thing to seize the moment, because the present is the only time that one has, for Heidegger those who are preoccupied with the present live in a temporal wasteland. Those who lack such access to the presence of the past... can only wonder about how long the present will go on. They live in the world of mundane time, the clock marking a succession of moments, each of which is for the time being all the time that one has: the 'Now.' These moments become lost in the past, which cannot be brought into the present." ${ }^{428}$

Furthermore, although some detect a dualism in Freud's thought similar to that of Descartes or others, ${ }^{429}$ the point at present is that the concepts of time and history remain very important within psychology, ${ }^{430}$ and yet often, when they do appear, they appear within the context of merely illustrating that humans are slaves to their self-perceptions of time, and we often prioritize the present. ${ }^{431}$ In any case, there can be little doubt that a supposition such as free will involves categories for psychologists that are difficult to think about in contrast to what physicists consider,

\footnotetext{
${ }^{428}$ Richard K. Fenn, "Epilogue: Toward a Secular View of the Individual," in The Blackwell Companion to Sociology of Religion, ed. Richard K. Fenn (Malden, MA: Blackwell Publishing, 2003), 458.

${ }^{429}$ For example, see Harold Bloom, Ruin the Sacred Truths: Poetry and Belief from the Bible to the Present (New York, NY: Harvard University Press, 1989), 154. Bloom explains that "freedom, for Freud, had to be freedom from the past, but never from time, the Jewish (and Freudian) reality principle. Pragmatically, Jewish freedom is freedom of interpretation, though Jewish (and Freudian) memory results in all meaning being overdetermined. What is freedom where everything is overdetermined, where character is fate, and there are, after all, no accidents? Freud's scientism, not his Jewishness, led to his proud embrace of the reductive, but his path out of his own reductionism proved to be his quite Jewish variety of dualism...". "Freud's dualism ... [sees] the psyche is at civil war, but what it wars with, in itself, is the injustice of outwardness, the defensive disorderings of the drives, the unnecessary sufferings that rob us of the freedom that yet can be our time," ibid.

${ }^{430}$ In therapy, there is actually a dual dynamic at play, as some forms of therapy attempt to free patients of their pasts by walking them through them, to "deal" with them, so to speak, before they encourage their patients to spring into the future. In these cases, however, the "escape from the past" is more acutely felt by the therapist, as they need to ideally escape from the past experiences that have shaped their own perceptions, and could affect what they draw out of a patient in therapy sessions. Such methods place "the therapist in the position of having to know the patients's inner world of experience in order to understand or predict. Yet how do clinicians climb into that world? How do they escape from the past experiences that have shaped their own perceptions?," Timothy J. Trull and Mitchell J. Prinstein, Clinical Psychology ${ }^{\text {th }}$ ed. (Belmont, CA: Wadsworth, 2013), 391.

${ }^{431}$ Oleg Urminsky, "The Role of Psychological Connectedness to the Future Self in Decisions Over Time," in Current Directions in Psychological Science Vol. 26 \#1 (2017), 34-39. Urminsky essentially suggests that what humans know about their potential future(s) dictates what they do in the present. Our free-will would then be conditioned or determined by our ability to see ourselves extended over time, which is conditioned by various other factors. Of course, what motivated Urminsky's study in the first place was that most "people are impatient, often preferring benefits they will receive soon over more delayed benefits, in a way that is difficult to fully explain on the basis of economic factors alone," ibid., 34. That is, most people live in the timeless "now." Yet, even when they don't, it is a certain conceived continuity of self that then determines the choices one makes.
} 
such as "matter-energy," and "space and time," and that free will, or "free choice," if it exists, is "a littleunderstood agency that is capable of breaking most of the rules of scientific psychiatry." 432

From a somewhat broader psycho-sociological perspective, it is important to mention that, "as with the majority of human experiences, conceptualizations of time and approaches toward time show great diversity across cultures. The importance of understanding cultural differences in time cannot be overstated in today's world.."333 Indeed, "the relationship to time and the manner in which it is conceptualized are a central factor in distinguishing between various cultures." ${ }^{434}$ Even "the structure of the language prevalent within a certain culture is also linked to the conceptualization of time within that same culture. For example, if a certain culture has no linguistic concepts pertaining to the past, present or future, in a distinct manner, it is highly likely that the members of this culture themselves do not make any distinctions between the past, present and future. Behaviorally, they operate within a 'single time space."' 435

\footnotetext{
${ }^{432}$ John O. Beahrs, Limits of Scientific Psychiatry: The Role of Uncertainty in Mental Health (New York, NY: Brunner \& Mazel, 1986), 37.

${ }^{433}$ C. Ashley Fulmer, Brandon Crosby, and Michele J. Gelfand, "Cross-cultural Perspectives on Time," in Time and Work: Vol. 2: How Time Impacts Groups, Organizations, and Methodological Choices, eds. Abbie J. Shipp and Yitzhak Fried (New York, NY: Psychology Press, 2014), 69. Additionally note that the claim has been made that "neuroscience also holds promise to further our understanding of the relationship between time and culture. For example, using neuroimaging, neuropsychology, and monkey physiology, Hubbard and Teuscher have found that the common conceptualization of time as space across cultures is based on a common region associated with both time and space within the parietal lobe. They thus suggest that the prevalence of conceptualizing time as space may be due to brain-based structure. Clearly, more research is needed to understand the relationship between neural bases and cross-cultural differences in temporal orientations. Such research has potential to help illuminate the extent to which cross-cultural temporal differences are due to nature (e.g., the preexisting neural wiring) or to nurture (e.g., the physical, cultural, social, and economic environments)," ibid., 68-69.

${ }^{434}$ Dan Zakay and Dida Fleisig, "Psychological Time, Time Perspective, Culture and Conflict," in Culture and Neural Frames of Cognition and Communication, ed. Shihui Han and Ernst Pöppel (New York, NY: Springer, 2011), 126.

${ }^{435}$ Zakay and Fleisig, "Psychological Time, Time Perspective, Culture and Conflict,” 126. Interestingly, "this is evident in the lack of ability amongst very young children to conceptualize time and the differences between past, present and future," ibid. Note also, "time blocks that incorporated the activities of an entire culture such as the Enlightenment or early nineteenth century were organized by shared metacognitive viewpoints," thus showing a "connection between the formal structure of time and the formal structures of syntax and grammar," Mark E. Blum, Continuity, Quantum, Continuum, and Dialectic: The Foundational Logics of Western Historical Thinking (New York, NY: Peter Lang, 2006), 225, back cover.
} 


\section{The Place of Religion within Psychology and Psychiatry}

Religion and theology cannot avoid the critical issues that are found in contemporary psychology, psychiatry, and related sciences of the brain and mind. Many of the most forceful contemporary challenges to the concept of free will come from the work of aggressively atheistic scientists, advocates of scientism, who work in fields related to the mind or brain science. The antimetaphysical views of these reductionary scientistic-positivists, which represent some of the more extreme scholars inspired by Snow's request for a third culture, explicitly deny the "metaphysical objects" mentioned above by Kant are worthy for study at all; not only God, perhaps an easier or more obvious target for atheists, but also human freedom. ${ }^{436}$ Furthermore, and importantly, the ideas of these scientistic-positivists have penetrated into popular Western culture as well, limiting meaningful discussions about God, freedom, and time in many circles of mainstream academic culture. ${ }^{437}$ Part of the reason why this has happened is because these atheistic scientists and psychologists have now, entering into the middle of the $21^{\text {st }}$ century, long had "easy access to what C. P. Snow called the 'corridors of power' ... [and the] 'good lunch,"'438 namely prestigious academic positions and connections with politicians for funding their research and enjoying a 'pleasant life.'

\footnotetext{
${ }^{436}$ Jorge J. E. Gracia, Metaphysics and Its Task: The Search for the Categorial Foundation of Knowledge (Albany, NY: State University of New York Press, 1999), xi. "In their [scientistic positivists] attempt to reduce all discourse to scientific discourse, they reduced ethics and aesthetics to empirical psychology, leaving no place in their scheme for human freedom and the self. ..". Of course, historically, as well as today, "the [reactionary] result [by parts of society] was a return to metaphysics, to a metaphysics of life, humanity, and values," ibid. Such scientistic positivists had "thought that metaphysics, with its purely theoretical goal and its speculative method, was an obstacle to progress" and the contrasting utilitarian freedom that, for example, Snow advocated, ibid. In the end, however, "metaphysics seems to be a natural thing for human beings to do," leading toward its continual resurgence, ibid., xiii. However, the challenge by the scientistic-positivists continues today. For more recent nuances to the debate, see, for example, Alexander Saxton, "The God Debates and the Materialist Interpretation of History," in Reasonable Perspectives on Religion, ed. Richard Curtis (Lanham, MD: Lexington Books, 2010), 26.

${ }^{437}$ One cannot safely "challenge" the conclusions of scientists on many issues today and maintain access to the corridors of power in the academic, and sometimes political, world-this creates, of course, an unhealthy atmosphere in which it is possible that even good "science" is corrupted by "human" agendas, let alone the methods of science causing problems in their own right. See Curtis White, The Science Delusion: Asking the Big Questions in a Culture of Easy Answers (Brooklyn, NY: Melville House, 2013). See also, Clark Coogan, Escape from Planet Lame (Jacksonville, FL: Plain Thinking Publishers, 2005).

${ }^{438}$ White, The Science Delusion, "What's a Good Lunch?"
} 
A few such outspoken contemporary scientistic atheists would include the philosophers Galen Strawson ${ }^{439}$ and Derk Pereboom, ${ }^{440}$ the cultural critic David Silverman, ${ }^{441}$ and the microbiologists Sam Harris $^{442}$ and Jerry Coyne. ${ }^{443}$ Most scholars allied with this group explicitly deny free will. Coyne, for

\footnotetext{
${ }^{439}$ Galen Strawson, Freedom and Belief (Oxford, UK: Oxford University Press, 2010). Interestingly, see also, Garrett, What is this Thing Called Metaphysics?, 115-116, where Garrett explains that Strawson's argument that free will and ultimate moral responsibility are incoherent falls into an infinite temporal regression.

${ }^{440}$ See, for example, Derk Pereboom, Free Will, Agency, and the Meaning of Life (Oxford, UK: Oxford University Press, 2014); and Derk Pereboom, Living Without Free Will (Cambridge, UK: Cambridge University Press, 2001).

${ }^{441}$ David Silverman, Fighting God: An Atheist Manifesto for a Religious World (New York, NY: St. Martin's Press, 2015).

${ }^{442}$ For example, see Sam Harris, Free Will; Sam Harris, The End of Faith: Religion, Terror, and the Future of Reason (London, UK: W. W. Norton \& Company Ltd, 2005); Sam Harris, Letter to a Christian Nation (New York, NY: Vintage Books, 2008); and Sam Harris, The Moral Landscape: How Science Can Determine Human Values (New York, NY: Free Press, 2010). Harris, perhaps the cover picture of modern scientism, explains the far reaching consequences of his views as follows, where I share them at some length: "If there are right and wrong answers to ethical questions, these answers will be best sought in the living present.... The pervasive idea that religion is somehow the source of our deepest ethical intuitions is absurd. We no more get our sense that cruelty is wrong from the pages of the Bible than we get our sense that two plus two equals four from the pages of a textbook on mathematics," Harris, The End of Faith, 171-172. Elsewhere Harris observes, "while the argument I make in this book is bound to be controversial, it rests on a very simple premise: human well-being entirely depends on events in the world and on states of the human brain. Consequently, there must be scientific truths to be known about it. A more detailed understanding of these truths will force us to draw clear distinctions between different ways of living in society with one another, judging some to be better or worse, more or less true to the facts, and more or ethical. Clearly, such insights could help us to improve the quality of human life-and this is where academic debate ends and choices affecting the lives of millions of people begin," Harris, The Moral Landscape, 2-3. Harris later adds, "The laws of nature do not strike most of us as incompatible with free will because we have not imagined how human action would appear if all cause-and-effect relationships were understood. But imagine that a mad scientist has developed a means of controlling the human brain at a distance: What would it be like to watch him send a person to and fro on the wings of her 'will'? Would there be even the slightest temptation to impute freedom to her? No. But this mad scientist is nothing more than causal determinism personified. What makes his existence so inimical to our notion of free will is that when we imagine him lurking behind a person's thoughts and actions-tweaking electrical potentials, manufacturing neurotransmitters, regulating genes, etc.-we cannot hep but let our notions of freedom and responsibility travel up the Puppet's strings to the hand that controls them. To see that the addition of [e.g., quantum] randomness does nothing to change this situation, we need only imagine the scientist basing the inputs to his machine on a shrewd arrangement of roulette wheels. How would such unpredictable changes in the states of a person's brain constitute freedom?

Swapping any combination of randomness and natural law for a mad scientist, we can see that all the relevant features of a person's inner life would be conserved-thoughts, moods, and intentions would still arise and beget actions-and yet we are left with the undeniable fact that the conscious mind cannot be the source of its own thoughts and intentions. This discloses the real mystery of free will: if our experience is compatible with its utter absence, how can we say that we see any evidence for it in the first place?," ibid., 216, n. 102. Harris also observes that the capability of genuine human choices must be distinguished from the same ability as advocated by proponents of free will, in that "our belief in free will arises from our moment-to-moment ignorance of specific prior causes.... Many people confuse determinism with fatalism.... Of course, there is a distinction between voluntary and involuntary actions, but it does nothing to support the common idea of free will (nor does it depend on it). The former are associated with felt intentions (desires, goals, expectations, etc.) while the latter are not. All of the conventional distinctions we like to make between degrees of intent-from the bizarre neurological complaint of alien hand syndrome to the premeditated actions of a sniper-can be maintained: for they simply describe what else was arising in the mind at the time an action occurred. A voluntary action is accompanied by the felt intention to carry it out, while an involuntary action isn't. Where our intentions themselves come from, however, and what determines their character in every instant, remains
} 
example, recently asserted that "the notion of 'free will-a linchpin of many faiths-now looks increasingly dubious as scientists not only untangle the influence of our genes and environments on our behavior, but also show that some 'decisions' can be predicted from brain scans several seconds before people are conscious of having made them." Coyne further claims that "most scientists and philosophers are now physical 'determinists' who see our genetic makeup and environmental history as the only factors that, acting through the laws of physics, determine which decisions we make." He continues by observing that this "kicks the props out from under much theology, including the doctrine of salvation through freely choosing a savior, and the argument that human-caused evil is the undesirable but inevitable by-product of the free will vouchsafed us by God." ${ }^{\prime 44}$ This is not to say that there aren't some mainstream secular evolutionary scientists and philosophers who don't allow for some sort of genuine human freedom, such as Julian Baggini ${ }^{445}$ and Daniel Dennett, ${ }^{446}$ but the broader world of psychology, seemingly bound to science and its methods for many to maintain respectability, has cemented the two cultures conflict into the discipline of psychology, with free will and time the often disputed centerpieces.

However vigorous the obvious objections of some atheists may be to religion, or free will, what is pertinent to this study is to observe that "for many, there appears to be a conflict or rift between Christianity and psychology, since Christianity is based on ... Scripture and psychology is based on the observation of human beings as natural entities, i.e., as products of environment and heredity." ${ }^{447}$

perfectly mysterious in subjective terms. Our sense of free will arises from a failure to appreciate this fact: we do not know what we will intend to do until the intention itself arises. To see this is to realize that you are not the author of your thoughts and actions in the way that people generally suppose. This insight does not make social and political freedom any less important, however. The freedom to do what one intends, and not to do otherwise is no less valuable than it ever was," or so at least Harris believes, ibid., 105-106.

${ }^{443}$ For example, see Jerry A. Coyne, Faith Versus Fact: Why Science and Religion are Incompatible (New York, NY: Penguin Books, 2015).

${ }^{444}$ Coyne, Faith Versus Fact: Why Science and Religion are Incompatible, 15-16. For a critique of Coyne's work, see Kevin Timpe and Jonathan D. Jacobs, "Free Will and Naturalism: How to Be a Libertarian, and a Naturalist Too," in The Blackwell Companion to Naturalism, ed. Kelly James Clark (Malden, MA: John Wiley \& Sons, 2016), 319-335.

${ }^{445}$ Julian Baggini, Freedom Regained: The Possibility of Free Will (Chicago, IL: The University of Chicago Press, 2015).

${ }^{446}$ Daniel C. Dennett, Freedom Evolves (New York, NY: Penguin Books, 2004).

${ }^{447}$ John D. Carter, Psychology and Christianity: Integrative Readings (Nashville, TN: Abingdon Press, 1981), 18. 
Yet, despite the tension that exists between Christians and psychology in general, ${ }^{448}$ even more important than any surface competition between Christianity and secularism, even within Christian psychology, is the fact that "both theoretically and methodologically ... psychology is the uneasy home of two competing and progressively more evenly matched cultures, the first positivist and scientistic, the second post-positivist and humanistic." Furthermore, in what can only be said to be yet another replication of the two cultures conflict, it seems that "Christian psychologists can be found in both cultures, and in each case can give plausible reasons for maintaining that their preferred camp is where thoughtful Christians should cast their lot."449 Indeed, "perhaps the most intriguing aspect of ... the 'two cultures' in psychology" is "the failure of the theism/atheism dimension to enter into the picture at all." Rather, "theism and atheism are no differently distributed among [scientific] behavioral and [humanistic] non-behavioral psychologists." ${ }^{\prime 40}$ This is probably because, put simply, some people are born with a predilection for either enjoying or being gifted with mathematics, and others are not. ${ }^{451}$ What role culture may play in this is highly debated, but appears as a secondary factor in relation to genetic predispositions.

\footnotetext{
${ }^{448}$ For more on psychology and Christianity, see for example, Eric L. Johnson, ed. Psychology \& Christianity: Five Views (Downers Grove, IL: InterVarsity Press, 2010); Stanton L. Jones and Richard E. Butman, Modern Psychotherapies: A Comprehensive Appraisal (Downers Grove, IL: InterVarsity Press, 1991); John D. Carter and Bruce Narramore, The Integration of Psychology and Theology: An Introduction (Grand Rapids, MI: Zondervan, 1979); Stephen P. Greggo and Timothy A. Sisemore, eds. Counseling and Christianity: Five Approaches (Downers Grove, IL: InterVarsity Press, 2012); David N. Entwistle, Integrative Approaches to Psychology and Christianity: An Introduction to Worldview Issues, Philosophical Foundations, and Models of Integration $2^{\text {nd }}$ ed. (Eugene, OR: Cascade Books, 2010); and Everett L. Worthington Jr., Coming to Peace with Psychology: What Christians Can Learn from Psychological Science (Downers Grove, IL: InterVarsity Press, 2010).

${ }^{449}$ Mary Stewart Van Leeuwen, “Psychology's ‘Two Cultures': A Christian Analysis,” in Psychology \& Christianity Integration: Seminal Works that Shaped the Movement, ed. Daryl H. Stevenson, Brian E. Eck, and Peter C. Hill (Batavia, IL: Christian Association for Psychological Studies, 2007), 114.

${ }^{450}$ Van Leeuwen, "Psychology's 'Two Cultures': A Christian Analysis," 116 (additions mine).

${ }^{451}$ Ben Clausen and Gerald Wheeler, The Book of Beginnings: Creation and the Promise of Redemption (Hagerstown, MD: Review and Herald, 2006), 69. Clausen, a Christian, explains that from a young age he found that "math was my favorite subject because it "has only one correct answer,'" ibid. But that believers have this same experience of either liking or not liking mathematics seems to be innate or inherited. See Melissa E. Libertus, Lisa Feigenson, and Justin Halberda, "Preschool Acuity of the Approximate Number System Correlates with School Math Ability," in Developmental Science Vol 14 \# 6 (Nov. 2011), 1292-1300.
} 
Within Christianity the above tension is well illustrated in the differences found between two professors of psychology and counseling associated with the Southern Baptist denomination, ${ }^{452}$ Eric L. Johnson ${ }^{453}$ and Heath Lambert. ${ }^{454}$ Johnson seeks an integrative approach that learns from tradition and science alongside but in theory subordinated to Scripture, while Lambert wishes to promote a robust view of Scripture alone for an understanding of the human condition and counseling. Given the above, one could conclude, then, that perhaps one of the more interesting insights to be gleaned from the broader situation is that some Christians are trying to integrate their faith with a secular discipline already in crisis, while others, in not engaging psychology, are merely encouraging further cultural isolation that is a complex result of the replicating effect of the two cultures conflict within Christianity itself.

One final, and highly controversial, point that is nevertheless worthy of inclusion here is that several recent studies appear to have found a correlation between genetics and a person's sociopolitical orientation (the broader issues of which will be discussed below), which means, essentially, that our psychology is based upon genetics. It has been asserted that "authoritarianism, religiosity, and conservatism are 'different manifestations of a single latent and significantly heritable factor,'”455 and that these patterns roughly fall into the dividing line within most societies that parallels the

\footnotetext{
${ }^{452}$ See, for example, Bob Allen, “Critics Say Seminary Professor’s Departure Reveals Faculty Rift between Faith and Science," at https://baptistnews.com/article/critics-say-seminary-professors-departurereveals-faculty-rift-faith-science/ (accessed September 14, 2017).

${ }^{453}$ Eric L. Johnson, Foundations for Soul Care: A Christian Psychology Proposal (Downers Grove, IL: InterVarsity Press, 2014); and Eric L. Johnson, God and Soul Care: The Therapeutic Resources of the Christian Faith (Downers Grove, IL: InterVarsity Press, 2017).

${ }^{454}$ Heath Lambert, $A$ Theology of Biblical Counseling: The Doctrinal Foundations of Counseling Ministry (Grand Rapids, MI: Zondervan, 2016); and Heath Lambert, 95 Thesis for an Authentically Christian Commitment to Counseling at https://s3-us-west-2.amazonaws.com/acbcdigitalresources/resources/2017\%2C+95+Theses +of+Biblical+Counseling/95+Theses+-+Heath+Lambert.pdf (accessed September 14, 2017); also available at https://biblicalcounseling.com/ninety-five/ (accessed September 19, 2017).

455 Thomas B. Edsall, citing the work of the psychologists Steven Ludeke, Wendy Johnson, and Thomas J. Bouchard Jr., in "How Much Do Our Genes Influence Our Political Beliefs?" at https://www.nytimes. com/2014/07/09/opinion/thomas-edsall-how-much-do-our-genes-influence-our-political-beliefs.html (accessed February 16, 2017). See also Steven Ludeke, Wendy Johnson, and Thomas J. Bouchard Jr., "'Obedience to Traditional Authority:' A Heritable Factor Underlying Authoritarianism, Conservatism and Religiousness," in Personality and Individual Differences Vol. 55, Issue 4 (August, 2013), 375-380; and Chris Mooney, "Your Genes Tell You How to Vote," at http://www.motherjones. com/mojo/2013/12/genetics-twins-politics-religion (accessed February 16, 2017).
} 
Conservative (Right) - Progressive (Left) divide in the Western world. ${ }^{456}$ The reason this point is relevant to this study is that authoritarianism and conservatism are naturally related to freedom and time, though in very complex ways that cannot be elaborated upon here. ${ }^{457}$ Indeed, an important point that must be mentioned here is that the third cultures do not always align with the impulses found in broader society. That is, for example, at the socio-political level, libertarianism is more often associated with the secular Right, not the explicitly religious Right, religious Left, or secular Left, ${ }^{458}$ yet it promotes a more acute awareness of freedom and time than the Left or the religious Right. In any case, it seems that the tension within religion concerning the "sciences of the mind" represents a reduplication of the scientific and humanistic tendencies in the third culture disciplines of psychology and psychiatry. ${ }^{459}$

\footnotetext{
${ }^{456}$ John R. Hibbing, Kevin B. Smith, and John R. Alford, Predisposed: Liberals, Conservatives, and the Biology of Political Differences (New York, NY: Routledge, 2014), esp. 45-48, 72, 93-96.

${ }^{457}$ The key point here is that while the ethical framework (morality) that the religious right sometimes imposes is based upon timelessness (the origin of ethics), their economic model is generally based upon temporality. Conversely, however, the religious left contains timelessness at the core of their ethics as well, but in their case, it is primarily located in their socio-economic concerns, while their other moral concerns may or may not also be based in timelessness.

${ }^{458}$ It may be a rarer position, then, and one grounded with an openness toward agnosticism, but as Steven Shriffrin acknowledges, "it would be possible to believe in liberal theology and conservative politics, but that combination is not much alive on the American political scene." In any case, "secular conservatives exist" and some of them may qualify for the group of theologically liberal yet politically 'conservative' individuals found in some strains of libertarianism or classical liberalism. Steven H. Shiffrin, "The Religious Left and Church-State Relations: A Response to Kent Greenawalt and Bernie Meyler," in Cornell Journal of Law and Public Policy Vol. 19 (2010), 762.

${ }^{459}$ To make just a quick observation to dissolve some potential misunderstandings, most 'classical liberals' and even some libertarians, who support great individual freedom, are nevertheless, for complicated reasons, associated with the Republican political party in the United States which is known to be more conservative, or respectful of the past (time). See, for example, Hibbing, Kevin B. Smith, and John R. Alford, Predisposed: Liberals, Conservatives, and the Biology of Political Differences, 11; and Gary Brent Madison, The Logic of Liberty (Westport, CT: Greenwood Press, 1986), x. Madison explains, concerning the meaning of the term liberal, and also I would suggest for a soft libertarian, that "in contemporary American usage the term [liberal] has, unfortunately, come to function as a synonym for what would otherwise, and more correctly, be designated as a 'socialist'. 'Liberals' are those who are at the left end of the democratic spectrum. It is not in this sense at all that we shall be using the term. Those in the United States who are today called 'liberals' are very far indeed from being liberals as we understand the term.... The liberalism we shall be discussing is what today is often referred to as 'classical liberalism'. This is the political philosophy which is embodied in, for instance, the constitution that James Madison drafted for the new American Republican.... Liberalism is thus not a new philosophy, the latest creation of the fashion salons of ideas. As a political philosophy, it antedates both conservatism .... and modern socialism. It is in fact the oldest of modern political philosophies. Because of this, there is a tendency among many people to think-according to the principle that 'newer is better'-that it has somehow been superseded and rendered out of date by more recent political ideas," unfortunately, ibid. For more on the complexities of the political scene today, see also David Azerrad, "America Divided: The Republican Party in Theory and Practice," at http://www.heritage.org/conservatism/commentary/america-dividedthe-republican-party-theory-and-practice (accessed October 22, 2017). Azerrad, quoting Ronald Reagan as a representative of modern conservatism, observes the conviction that "I believe the very heart and soul of
} 
In summary, it appears that psychology and psychiatry, and other closely related fields, are indeed divided between the two cultures. Critically, understandings or uses of freedom and time are central to that divide, demonstrating the critical role philosophy has in grounding these third culture disciplines. Lastly, religionists are deeply divided as well, showing that religion and theology have not been able to provide a resolution to the problem. In the following section, the study will continue the present examination of the third cultures within the contemporary debates surrounding economics.

\section{Freedom and Time within the Third Culture Discipline of Economics}

The field of global monetary economics, or macroeconomics, is currently divided between two great camps. As William Tabb observed, "the contrasting cultures that C. P. Snow saw ... have I think a parallel in a division between two cultures within economics that has always been present since economics was first understood as a separate intellectual undertaking." Tabb continues, "it is not surprising that economics, which has roots in moral philosophy and its aspirations in being a 'real' science (for example like physics), should be caught in this two-cultures tension." ${ }^{460}$ Others, like Richard Bronk, are similarly aware of the divide and have remarked that "sadly, Snow's plea for renewed efforts to bridge the chasm... has so far had relatively little effect. Nowhere is this more evident than in the discipline of economics." ${ }^{461}$ This remains so simply because within economics "the

\footnotetext{
conservatism is libertarianism,' Ronald Reagan once explained. 'The basis of conservatism is a desire for less government interference or less centralized authority or more individual freedom, and this is a pretty general description also of what libertarianism is,"' ibid. For a Christian that comes close to articulating Gary Madison's view, see D. Eric Schansberg, Turn Neither to the Right Nor to the Left: A Thinking Christian's Guide to Politics and Public Policy (Greenville, SC: Alertness Ltd, 2003). In the above sense, classical liberalism shares the traditional or conservative conviction that man is 'sinful,' not innately good. See also, James Burnham, with John O'Sullivan and Roger Kimball, Suicide of the West: An Essay on the Meaning and Destiny of Liberalism (New York, NY: Encounter Books, 2014), 53.

${ }^{460}$ William K. Tabb, Reconstructing Political Economy: The Great Divide in Economic Thought (New York, NY: Routledge, 1999), 5. "Snow's discussion ... paints a picture not unfamiliar to those who have watched theorists and institutionalists, orthodox and heterodox, and other categories among economists talk about the way they do economics," ibid. See also, Melvin W. Reder, Economics: The Culture of a Controversial Science (Chicago, IL: The University of Chicago Press, 1999), 333-335; and James R. Hackney Jr., Under Cover of Science: American Legal-Economic Theory and the Quest for Objectivity (London, UK: Duke University Press, 2007).

${ }^{461}$ Richard Bronk, The Romantic Economist: Imagination in Economics (Cambridge, UK: Cambridge University Press, 2009), 48. See also, Steve Keen, Debunking Economics: Revised and Expanded Edition: The Naked Emperor Dethroned? (New York, NY: Zed Books, 2011).
} 
elaboration in mathematical and statistical handling does not mean that the theory in question can be verified. The gap between the theory and the reality always provides a difficult dilemma for the nonnatural scientist" ${ }^{\prime 462}$ working in a discipline like economics that is so deeply interwoven with and besotted by the complexities and uncertainties of human behavioral patterns. The fact is, economics as a discipline is divided between "'theorists who seek to trap the inner secrets of the economy in their models and the practitioners who live in a world of action, where time is precious, and understanding is limited, nothing is certain, and non-economic considerations are always important and often decisive."'463

At the risk of an overly simplistic reductionism, yet nevertheless clearly making the point, there are two dominant camps within theoretical economics circles today, the Keynesian (John Maynard Keynes) and Austrian/Chicago (Friedrich Hayek) schools of thought. ${ }^{464}$ Both of them developed their ideas from out of the crisis facing the world following the First World War, and both would contribute to western capitalism. As Bruce Caldwell explained, Keynes and Hayek "differed profoundly in their responses to the interwar world that they inhabited. Both observed a world gone mad. Keynes saw salvation in a thorough revision of the liberal order. Hayek saw it in the rediscovery of one. Their debate over this question continues to this day; it is perhaps the most important issue that democratic regimes, old or new, must address." ${ }^{465}$ Roger Garrison confirmed the enduring nature of their differences, sharing that "many of the monetary and theoretical issues that were at the heart of

\footnotetext{
${ }^{462}$ Akira Iida, Theory \& Policy Making: Reconfiguring the Future (North Clarendon, VT: Tuttle Publishing, 2004), 28.

${ }^{463}$ Sir Alec Cairncross, as cited in Iida, Theory \& Policy Making: Reconfiguring the Future, 148-149.

${ }^{464}$ The Keynes (Anglophone-analytic) vs. Hayek (Austrian-continental) debate has long defined discussions on economic matters for the United States and most of the rest of the Western world. See Nicholas Wapshott, Keynes - Hayek: The Clash that Defined Modern Economics (New York, NY: W. W. Norton, 2011); Lawrence H. White, The Clash of Economic Ideas: The Great Policy Debates and Experiments of the Last Hundred Years (Cambridge, UK: Cambridge University Press, 2012); and G. R. Steele, Keynes and Hayek: The Money Economy (New York, NY: Routledge, 2001). See also, Mark Skousen, Vienna \& Chicago: Friends or Foes?: A Tale of Two Schools of Free-Market Economics (Washington, D.C.: Regnery Publishing, 2005); and David L. Prychitko, ed. Why Economists Disagree: An Introduction to the Alternative Schools of Thought (Albany, NY: State University of New York Press, 1998). I will not enter into detailed discussions surrounding post-Keynesianism, Marxist, and the neoclassical perspective, etc. They are not relevant for this study, being merely variations on a theme from neo-Keynesianism and Austrianism, as will be noted below where relevant.

${ }^{465}$ Bruce Caldwell, "Introduction," in The Collected Works of F. A. Hayek Vol. IX: Contra Keynes and Cambridge-Essays, Correspondence, ed. Bruce Caldwell (Chicago, IL: The University of Chicago Press, 1995$), 48$.
} 
the Keynes-Hayek debate have never been resolved; they have just been swept under the rug"466 over time, leaving the dirt of yesteryear's problem concealed but never removed from the floor or foundations of economic theory. Of course, this is not to say that adherents of their original ideas have not made significant modifications to their theories. The development of neo-Keynesianism, and various adjustments to Hayek's approach alongside other like-minded thinkers, such as his mentor Ludwig von Mises, having been made and developed in somewhat distinct directions. But the debate still centers around Keynes and Hayek's names and ideas for the present purposes of this study. ${ }^{467}$

In any case, there is little doubt that today one represents a more "scientific" (neo-Keynesian ${ }^{468}$ ) approach to economics, and the other a softer "humanities" (Austrian) approach that is more libertarian. Charles Morris shares that, “Neo-Keynesian' is the mathematized version of Keynesianism.... The 'New Keynesians' are present-day economists like Paul Krugman,"469 a frequent contributor to the New York Times. David Colander likewise explains, "the neo-Keynesian theoretical revolution was a revolution that attempted to deal with the macro [economic] puzzle with the available mathematical tools." ${ }^{\text {"70 }}$ Conversely, Thomas Woods explains, "Austrians reject the mathematization of the discipline that other paradigms have encouraged, and dismiss artificial

\footnotetext{
${ }^{466}$ Roger Garrison, "Foreword," in The Hayek-Keynes Debate: Lessons for Current Business Cycle Research, John P. Cochran and Fred R. Glahe (Lewiston, NY: Edwin Mellen, 1999), x.

${ }^{467}$ For a broader history of economics during the past century, see J. E. King, A History of Post Keynesian Economics Since 1936 (Cheltenham, UK: Edward Elgar, 2002).

${ }^{468}$ As it will be discussed below, it is worth pointing out that neo-Keynesianism does differ from Keynes's original emphasis in some ways. For example, Keynes himself was not personally so fond of mathematics and certainty, as most neo-Keynesians are, but the theories that developed out of Keynes's fundamental ideas went in that direction. Keynes did write, however, about psychological laws. For more, see Wesley Pech, "Behavioral Economics and the Economics of Keynes," at http://webs.wofford.edu/pechwj/pech_ milan_behavioral_keynes_27april09.pdf (accessed October 24, 2017). For more on the thought of Keynes in relation to uncertainty and mathematics, see the essays in Jochen Runde and Sohei Mizuhara, eds. The Philosophy of Keynes's Economics: Probability, Uncertainty and Convention (New York, NY: Routledge, 2003).

${ }^{469}$ Charles R. Morris, The Sages: Warren Buffett, George Soros, Paul Volcker, and the Maelstrom of Markets (New York, NY: PublicAffairs, 2010), 8, in footnote. See also, Daniel Yergin and Joseph Stanislaw, The Commanding Heights: The Battle Between Government and the Marketplace That Is Remaking the Modern World (New York, NY: Simon \& Schuster, 1998), 40.

${ }^{470}$ David Colander and Roland Kupers, Complexity and the Art of Public Policy: Solving Society's Problems from the Bottom Up (Princeton, NJ: Princeton University Press, 2014), 108.
} 
models that reduce man to a mere atom.."471 The contrast is clearly evident in most practicing theoreticians of the two dominant schools.

Lately, it seems that the neo-Keynesian theory has come to dominate macroeconomics. Concerning the historical circumstances which motivated this, Roger Backhouse and Philippe Fontaine proposed that after the failed hopes of human progress collapsed into the disaster of the Second World War, it was thought that only pure science could save humanity from future disasters. As such, the war "brought economists together with mathematicians, statisticians, engineers, and more generally, natural scientists in a way that had profound consequences for the way the discipline was conceived." ${ }^{472}$ Francis Castles concurred that "economics [in the post World War II context] ... developed an avowedly empiricist and positivist approach to its material, and sociology, at least the more modern schools, seems to be following in its footsteps." ${ }^{473}$ Ever since, an "excessive devotion to [mathematical] formalism" has dominated economics. ${ }^{474}$

In what should be, by now, a predictably recurring theme, the heart of the divide between the two dominant schools of thought in contemporary monetary economic theory is the role of freedom and time. Gene Callahan explains, "Austrians ... emphasize the freedom and unpredictability of human action" ${ }^{\mathbf{4 7 5}}$ in contrast to their opponents who mostly ignore such elements, preferring to see strongly predictable patterns in human behavior. Similarly, Ronald Chadderton wrote that "Austrian

\footnotetext{
${ }^{471}$ Thomas E. Woods, The Church and the Market: A Catholic Defense of the Free Economy (Oxford, UK: Lexington Books, 2005), 217. See also, Friedrich August Hayek, A Free-Market Monetary System (Auburn, AL: Ludwig von Mises Institute, 2008, 1974), 55-56. "There is danger in the exuberant feeling of ever growing power which the advance of the physical sciences has engendered and which temps man to try, 'dizzy with success,' to use a characteristic phrase of early communism, to subject not only our natural but also our human environment to the control of a human will. The recognition of the insuperable limits to his knowledge ought indeed to teach the student of society a lesson of humility which should guard him against becoming an accomplice in mens' fatal striving to control society," ibid.

${ }^{472}$ Roger E. Backhouse and Philippe Fontaine, "Introduction," in The History of the Social Sciences Since 1945, eds. Roger Backhouse and Philippe Fontaine (Cambridge, NY: Cambridge University Press, 2010), 6. See also, Tim B. Thornton, From Economics to Political Economy: The Problems, Promises, and Solutions of Pluralist Economics (New York, NY: Routledge, 2017), 216; and Gary B. Madison, The Political Economy of Civil Society and Human Rights (New York, NY: Routledge, 1998), 150.

${ }^{473}$ Francis G. Castles, Pressure Groups and Political Culture: A Comparative Study (New York, NY: Routledge, 2009, 1967), xiii.

${ }^{474}$ Thornton, From Economics to Political Economy, 216.

${ }^{475}$ Gene Callahan, Economics for Real People: An Introduction to the Austrian School, $2^{\text {nd }}$ Edition (Auburn, AL: Ludwig von Mises Institute, 2004), 316. See also, Chris Matthew Sciabarra, Total Freedom: Toward a Dialectical Libertarianism (University Park, PA: The Pennsylvania State University Press, 2000), 378.
} 
economics is about freedom," ${ }^{\text {"76 }}$ and "the two central elements of Austrian economics are time and ignorance. This means the passage of 'real time,' the evolution of knowledge, and the real uncertainty of an unknowable future."477

In contrast to the above, "the neoclassical [and neo-Keynesian] framework is static [or timeless] in nature, which prevents dynamic elements of change and evolution," explains Christopher Coyne. ${ }^{478}$ What neo-Keynesian "current economic analyses ... is based on" is an understanding of "analytical time" that is "essentially timeless," ${ }^{479}$ observes Jagdish Handa. Continuing, Handa observes that "Keynesians historically, and many Keynesian economists even now, eschew the concept of the long run," in part because of "Keynes' famous dictum that 'in the long run, we are dead,"'480 and thus living in the present or 'now' is all that matters. Indeed, Handa forcefully points out the explicit connection between contemporary Keynesian economics and its "timeless" nature by noting that it does "not embrace time 'as a fundamental feature of reality."' ${ }^{81}$ Similarly, for Keynes, it has been suggested there is no robust understanding of freedom or free will at play in his economic theories. ${ }^{482}$

${ }^{476}$ Ronald A. Chadderton, Purposeful Engineering Economics (London, UK: Springer, 2015), 6.

${ }^{477}$ Chadderton, Purposeful Engineering Economics, 7.

${ }^{478}$ Christopher J. Coyne, "Economics as the Study of Coordination and Exchange," in Handbook on Contemporary Austrian Economics, ed. P. J. Boettke (Cheltenham, UK: Edward Elgar Publishing, 2010), 21 (addition mine). Neoclassical economics, together with neo-Keynesian economics, forms the neoclassical synthesis which dominates mainstream economics today. For more on the relationship between neoclassical and neo-Keynesianism, see Richard P. F. Holt and Steven Pressman, "Empirical Analysis and Post Keynesian Economics," in Empirical Post Keynesian Economics: Looking at the Real World, eds. Richard P. F. Holt, Steven Pressman (New York, NY: Taylor \& Francis, 2007), 3-20; and Peter Flaschel and Alfred Greiner, A Future for Capitalism: Classical, Neoclassical and Keynesian Perspectives (Cheltenham, UK: Edward Elgar, 2011).

${ }^{479}$ Jagdish Handa, A Reformulation of Keynesian Economics (Toh Tuck Link, Singapore: World Scientific Publishing, 2015), 50-51.

${ }^{480}$ Handa, A Reformulation of Keynesian Economics, 51.

${ }^{481}$ Handa, A Reformulation of Keynesian Economics, 3. Handa observes that "the mathematical models which have dominated physics since the days of Isaac Newton have replaced processes unfolding in time with 'timeless laws,'” ibid.

${ }^{482}$ See, for example, the assessments of Keynes by Murray N. Rothbard, Keynes the Man (Auburn, AL: Ludwig von Mises Institute, 2010), 49-54; Piero V. Mini, John Maynard Keynes: A Study in the Psychology of Original Work (New York, NY: St. Martin's Press, 1994), 100; Mark Skousen, Dissent on Keynes: A Critical Appraisal of Keynesian Economics (Greenwood Publishing Group, 1992), 158; Sylvie Rivot, Keynes and Friedman on Laissez-Faire and Planning: 'Where to Draw the Line?' (New York, NY: Routledge, 2013), 40-41; and Steele, Keynes and Hayek: The Money Economy, 168. 
If one were wondering if connections have been made between the independently developed Austrian views of freedom and time in economics, and Heideggerianism in philosophy, ${ }^{483}$ and quantum physics in the natural sciences, ${ }^{484}$ the answer would be affirmative, and the same is true for neoclassicalism and Keynesianism, which have been, respectively, directly compared to Newton's and Einstein's theories about the physical world. ${ }^{485}$ Given that some of the more influential economists of today, such as Krugman, believe that "Keynesian economics remains the best framework we have for making sense of recessions and depressions," one may rightly wonder whether or not the problem of the two cultures is again at the heart of the challenges that face the world's economic debates ${ }^{486}$ as it continues to struggle to place itself on solid financial ground in the $21^{\text {st }}$ century. ${ }^{487}$

${ }^{483}$ For example, the philosopher of Austrian economics, Don Lavoie, certainly saw and made the connections. Yet, it must be reiterated that Heidegger and Hayek developed their ideas independently as they were not directly aware of each other's works-though Hayek was aware of some who had been influenced by Heidegger. For more, see Wayne J. Froman, "Hermeneutics in Economics: On the Status of 'As-If' Functions," in Humane Economics: Essays in Honor of Don Lavoie, ed. Jack High (Cheltenham, UK: Edward Elgar, 2006), 164172. See also, Karen I. Vaughn, Austrian Economics in America: The Migration of a Tradition (Cambridge, NY: Cambridge University Press, 1994), 129-130; Gary B. Madison, "Phenomenology and Economics," in The Elgar Companion to Austrian Economics, ed. Peter J. Boettke (Cheltenham, UK: Edward Elgar, 1994), 38-47; Roger Koppl, "Scientific Hermeneutics: A Tale of Two Hayeks," in Explorations in Austrian Economics, ed. Roger Koppl (Bingley, UK: JAI Press, 2008), 99-122; Yuichi Shionoya, "Austrian Subjectivism and Hermeneutical Economics," in Subjectivism and Objectivism in the History of Economic Thought, eds. Yagi Kiichiro and Yukihiro Ikeda (New York, NY: Routledge, 2012), 73-90; and Stephen D. Parsons, "Hayek and the Limitations of Knowledge; Philosophical Aspects," in Hayek: Economist and Social Philosopher: A Critical Retrospect, ed. Stephen F. Frowen (New York, NY: St. Martin's Press, 1997), 63-86.

${ }^{484}$ See, for example, Paul Erickson, The World the Game Theorists Made (Chicago, IL: The University of Chicago Press, 2015), 47-49; Jeffery S. McMullen, "Perspective Taking and the Heterogeneity of the Entrepreneurial Imagination," in What is so Austrian about Austrian Economics?, eds. Steven Horwitz, Pierre Desrochers, and Roger Koppl (Bingley, UK: Emerald Group Publishing, 2010), 131-135; and Roger Koppl, "Introduction to 'Entangled Political Economy,"' in Entangled Political Economy (Advances in Austrian Economics Vol. 18), eds. Roger Kopl and Steven Horwitz (Bingley, UK: Emerald Group Publishing, 2014), 1.

${ }^{485}$ See the excellent study by Teodoro Dario Togati, Keynes and the Neoclassical Synthesis: Einsteinian Versus Newtonian Macroeconomics (New York, NY: Routledge, 1998). Togati regards "the models of the Neoclassical Synthesis as 'Newtonian' or 'Classical' macroeconomics, in contrast with Keyne's 'Einsteinian' macroeconomics," ibid., xxvi. Both, of course, are dominated by mathematical formalism. For more general remarks on the relationship between economics and physics, see Philip Mirowski, More Heat Than Light: Economics as Social Physics: Physics as Nature's Economics (Cambridge, UK: Cambridge University Press, 1989).

${ }^{486}$ As quoted in Handa, A Reformulation of Keynesian Economics, 2. Handa describes an interesting contemporary application of the issues as follows: "In response to Krugman's views on the failings of macroeconomics and the need to revert to old-style Keynesian economics, Cochrane argued that the failure was not that of macroeconomics but of the policies that had been pursued: 'The sad fact is that few in Washington pay the slightest attention to macroeconomics research, in particular with a serious intertemporal dimension. Krugman's simple macroeconomics has dominated policy analysis for decades and continues to do so.... If a simple failure of ideas caused bad policy, it is simpleminded Keynesianism that failed," ibid., 2 n. 3. See also, J. H. Cochrane, "How Did Paul Krugman Get It So Wrong?" in Economic Affairs \#31 (2011), 36-40.

${ }^{487}$ Another application of the two cultures impacting the global economic situation relates to the fact that new technologies in automation (applied science) are putting many jobs at risk, and societies and economies around the world may struggle to adapt to this in humane ways. Hence, technology and automation 
Relatedly, the two major opposing economic theories which Keynes and Hayek articulated, and

the developments which they helped inspire into their current forms, are variants of capitalism on

Hayek's side, and variants of capitalism alongside Marxism and socialism on Keynes's side. The

important point about this is the connection the latter group has with science, in that both capitalism

and communism have advocates who have derived their legitimization from the two major scientific

paradigms to dominate the modernistic era, ${ }^{488}$ namely, Newtonian science for capitalism, ${ }^{489}$ and

both improves the lives of some while potentially adversely impacting the lives of many others. See, for example, Martin Ford, Rise of the Robots: Technology and the Threat of a Jobless Future (New York, NY: Basic Books, 2015); Martin R. Ford, The Lights in the Tunnel: Automation, Accelerating Technology, and the Economy of the Future (Acculant Publishing, 2009); Thomas H. Davenport and Julia Kirby, Only Humans Need Apply: Winners and Losers in the Age of Smart Machines (New York, NY: HarperCollins, 2016); Jerry Kaplan, Humans Need Not Apply: A Guide to Wealth and Work in the Age of Artificial Intelligence (Grand Rapids, MI: Integrated Publishing Solutions, 2015); Erick Brynjolfsson and Andrew McAfee, Harnessing Our Digital Future: Machine, Platform, Crowd (New York, NY: W. W. Norton \& Company, 2017); Erik Brynjolfsson and Andrew McAfee, The Second Machine Age: Work, Progress, and Prosperity in a Time of Brilliant Technologies with a new introduction (New York, NY: W. W. Norton \& Company, 2016); Erik Brynjolfsson and Andrew McAfee, Race Against the Machine: How the Digital Revolution is Accelerating Innovation, Driving Productivity, and Irreversibly Transforming Employment and the Economy (Digital Frontier Press, 2011); Mark Skilton and Felix Hovsepian, The $4^{\text {th }}$ Industrial Revolution: Responding to the Impact of Artificial Intelligence on Business (New York, NY: Palgrave Macmillan, 2018); Carl Benedikt Frey and Michael A. Osborne, "The Future of Employment: How Susceptible are Jobs to Computerisation?," at https://www.oxfordmartin.ox.ac.uk/downloads/academic/The_Future_of_Employment. pdf (accessed September 17, 2013); Klaus Schwab, The Fourth Industrial Revolution (New York, NY: Random House, 2017); Patrick Lin, Keith Abney, and Ryan Jenkins, eds. Robot Ethics 2.0: From Autonomous Cars to Artificial Intelligence (Oxford, UK: Oxford University Press, 2017); Bhoopathi Rapolu, The Race for Work: Escape Automation, Transform Your Career and Thrive in the Second Machine Age (Charleston, SC: CreateSpace, 2016); and, for an older work, Wassily Leontief and Faye Duchin, The Future Impact of Automation on Workers (Oxford, UK: Oxford University Press, 1986).

For some Heideggerian critiques of the situation concerning technology, culture, and the economy, see Stanley Aronowitz and William DiFazio, The Jobless Future: Sci-Tech and the Dogma of Work (Minneapolis, MN: University of Minnesota Press, 1994), esp. 77-80; Donald E. Polkinghorne, The Case for a Judgment-Based Practice of Care (Albany, NY: State University of New York Press, 2004); 35-46; Fred Dallmayr, Mindfulness and Letting Be: On Engaged Thinking and Acting (Lanham, MD: Lexington Books, 2014); 115-122; Fabio Grigenti, Existence and Machine: The German Philosophy in the Age of Madness (1870-1960) (New York, NY: Springer, 2016), 41-46; and Mark Coeckelbergh, "Drones, Morality, and Vulnerability: Two Arguments Against Automated Killing," in The Future of Drone Use: Opportunities and Threats from Ethical and Legal Perspectives, ed. Bart Custers (Berlin, Germany: Springer-Verlag, 2016), 229-240.

${ }^{488}$ Recently this has come to be called "econophysics" in the literature. "Econophysics is a relatively new multidisciplinary branch of economics where the models developed in physics are applied in modeling economic processes," Matti Estola, Newtonian Microeconomics: A Dynamic Extension to Neoclassical Micro Theory (Cham, Switzerland: Palgrave Macmillan, 2017), 19. However, the basic principles and analogies between physics and economics are much older.

${ }^{489}$ The "founding father" of capitalism held Newton's perspectives on science in high esteem. See Frank H. Solomon, Capitalism: An Analysis and Summary of Adam Smith's Wealth of Nations $2^{\text {nd }}$ ed. (Bloomington, IN: Archway Publishing, 2013), 191-195. See also, Rogene Bucholz, Reforming Capitalism: The Scientific Worldview and Business (New York, NY: Routledge, 2012), 123-132; Aaron Lecklider, Inventing the Egghead: The Battle over Brainpower in American Culture (Philadelphia, PA: University of Pennsylvania Press, 2013), 59; J. Foster, "Competitive Selection, Self-Organization and Joseph A. Schumpeter," in Capitalism and Democracy in the $21^{\text {st }}$ Century: Proceedings of the International Joseph A. Schumpeter Society Conference, Vienna 1998 "Capitalism and Socialism in the $21^{\text {st }}$ Century," eds. Dennis C. Mueller and Uwe Cantner (Berlin, Germany: Springer-Verlag, 2001), 317-334; and Neville Morley, Theories, Models, and Concepts in Ancient History (New York, NY: Routledge, 
Einsteinian Relativity theory for Marxist communism and socialism. ${ }^{490}$ This is not to suggest that variants of capitalism derived from Hayek's thought can not be grounded in science, but rather that some of its popular more libertarian advocates have declined to do so, whereas advocates of capitalist neo-Keynesianism prefer to see their discipline in a scientific way. In any case, advocates of most of the variants of economics listed above aside from Austrians have drawn support from science, and when they do, they all support timelessness, but in cleverly distinct ways, analogously as radically similar and dissimilar to the differences between Newton's and Einstein's views of physics. ${ }^{491}$ This may be a contributing factor to our current economic crisis in the contemporary world-neither of the major epistemological "alternatives" of Newton or Einstein, when applied to economics, actually represent a fundamentally different perspective on the relationship of freedom to time because they neglect critical ontological reflection. ${ }^{492}$

2004), 15.

${ }^{490}$ Charles D. Ameringer, The Socialist Impulse: Latin America in the Twentieth Century (St. Gainseville, FL: University Press of Florida, 2009), 98; Stephen G. Brush with Ariel Segal, Making $20^{\text {th }}$ Century Science: How Theories Became Knowledge (Oxford University Press, 2015), 349; J. B. S. Haldane, The Marxist Philosophy and the Sciences (New York, NY: Routledge, 2016; 1938); and Paul R. Josephson, Physics and Politics in Revolutionary Russia (Berkeley, CA: University of California Press, 1991), 237.

${ }^{491}$ Justin P. Holt, The Social Thought of Karl Marx (Singapore: Sage Publications, 2015), 50, 111-116, 193-198; John Hughes, The End of Work: Theological Critiques of Capitalism (Malden, MA: Blackwell, 2007), 78; Douglas Charles Rossinow, Visions of Progress: The Left-liberal Tradition in America (Philadelphia, PA: University of Pennsylvania Press, 2008), 112; and Sean Creaven, Against the Spiritual Turn: Marxism, Realism, and Critical Theory (New York, NY: Routledge, 2010), 197.

${ }^{492}$ Kathryn Dean, Capitalism and Citizenship: The Impossible Partnership (New York, NY: Routledge, 2003), 29, 88-89, 149-153. "To summarize, both capitalism and science (as knowledge intended for impersonal and efficient mastery of the world) are expressions of a two-worlds rationality involving the evaluation of 'objects' from the point of view of a desirable or truthful state (reality) against which everyday objects fall short and to which they should conform. The capitalist reality is value; the scientific reality is truth. Where science becomes directly implicated in value's reproduction, as has been happening increasingly since the 1980 s, the truth which scientists seek is one which will bring objects into line with the needs of value. In any case, both capitalism and science manifest an impersonal, monological, abstract form of rationality which proceeds by subsuming particulars (identifiable at the level of appearances) under a supposed universal (identifiable at the level of reality). In terms of our understanding of human flourishing, this is a world-dissolving rationality in that it is indifferent to particularity and to the needs of creatures who need completion through the constitution of a common sense. It attends to humanity in a way which is ignorant of, or indifferent to, this human need." Ultimately, "the dialectic of exchange and use has now moved on in a way which has engendered a contradiction between the need for nomological (determining) science and capital's tendency to reduce the world to process, therefore to undermine the specific subject/object constancy which modern science has both presupposed and helped, for a time, to reproduce. Beyond this, the innate inadequacies of science are becoming evident as scientific knowledge is practically fed into the world and, simultaneously, capitalism's need for science becomes ever more urgent. For the moment this need is being met in a remarkable way by postmodern sciences," ibid., 150, and note also, 150-159. Dean also explains that the "postmodern sciences are sciences which rediscover those real attributes of nature to which modern science has been blind; such attributes include movement, complexity, relationality and situatedness. In addition, science is recognized as an 'active intellectual 


\section{The Place of Religion within Economics}

Whatever the state of the economic debates may be in the secular world, economics, as the progressive-leaning Pope Francis has made clear, even when he differs from other more conservative Catholics, ${ }^{493}$ is also a very important concern of religionists today. ${ }^{494}$ What frames much of the debate today, again, rests upon the role of ethics and morality in economics. Namely, how can or should ethics appear in economics? Some, such as Shlomo Maital, complain that within "the divide between C. P. Snow's two cultures, the humanities and sciences, 'economics has fallen on the pocket calculator side,' when in fact it could have been a lasting bridge between them." Maital argues that "economics as a discipline took several wrong turns," and he suggests "economics should get itself back on track,

construction' rather than the transparent mirroring of an object. The shift of emphasis from substance to relation, from the uniform and universal to the specific and the unique, that the new sciences promise, the abrogation of the observer's god-like status, seem to promise respect for the richness and complexity of nature manifested in the possibility of a dialogue within nature rather than an instrumentalizing discourse about nature. Nature is apparently accepted in all of its complexity and determinism is recognized as exceptional and local rather than universal. For these reasons, critics of modern science have, as noted earlier, welcomed these developments as a move away from the 'totalizing totalitarian claims' of a science that applies only to simple, stable objects. Unfortunately, these developments have, if anything, enhanced rather than minimized the practical hubris displayed by modern science," ibid., 152. This is because, as Dean also observes, "the demotion of organisms to flows of information is nurturing a scientific orientation which is, if anything, more hubristic and instrumental than that of modern science. The difference is that whereas modern sciences normalized determinacy, postmodern sciences normalize indeterminacy. However, as it turns out, the latter opens up previously inconceivable opportunities for commodification as geneticists turned entrepreneurs begin to put science more directly and immediately at the disposal of value," ibid., 153.

${ }^{493}$ See, for example, Mark and Louise Zwick, "Pope Wants a Church of the Poor and For the Poor, but a Well-known Catholic Writer Rejects Saint Francis of Assisi," at http://cjd.org/2013/07/05/pope-wants-achurch-of-the-poor-and-for-the-poor-but-a-well-known-catholic-writer-rejects-saint-francis-of-assisi/ (accessed September 10, 2017). The Zwicks' suggest that to understand the deep philosophical divides in economics between Catholics, "the most helpful analysis ... comes from David L. Schindler.... Schindler believes that neoliberals too readily accept the claim that technology and some liberal institutions are 'neutral,' rather than having, as they do, an interior logic of utilitarianism and perhaps even atheism (David L. Schindler, Heart of the World, Center of the Church). Schindler points out that the term Liberal comes from the nineteenth century and its philosophical base is the same for both political and economic conservatism and liberalism. Both put the emphasis on rights and freedom from coercion. Some on the left advocate freedom of choice on life and social issues while many on the right of the spectrum advocate economic libertarianism. Both are missing the boat in some profound ways," ibid. See, in particular, David L. Schindler, Heart of the World, Center of the Church: Communio Ecclesiology, Liberalism, and Liberation (Grand Rapids, MI: Eerdmans, 1996); and Damon Linker, "What Do Conservative Catholics Want from Pope Francis?" at http://theweek.com/articles/451208/ what-conservative-catholics-want-from-pope-francis (accessed February 11, 2014).

${ }^{494}$ Pope Francis, Evangelii Gaudium (Rome, Italy: Vatican Press, 2013), 46. See also, John Gehring, The Francis Effect: A Radical Pope's Challenge to the American Catholic Church (Lanham, MD: Rowman \& Littlefield, 2015), 184, 173, 11, 189; Austen Ivereigh, The Great Reformer: Francis and the Making of a Radical Pope (New York, NY: Henry Hold and Company, 2014), 213; and Paul Vallely, Pope Francis: The Struggle for the Soul of Catholicism (New York, NY: Bloomsbury, 2015), 217. For an evaluation of the wholistic nature of Francis's teachings in continuity with the Catholic tradition, see David L. Schindler, "Habits of Presence and the Generosity of Creation: Ecology in Light of Integral Human Development," in Communio 42 (Winter 2015), 574593. 
by restoring behavior and explicit values as central concerns ..., in order to build the missing ethical foundations ${ }^{\text {"495 }}$ of economics.

The ways in which to proceed to build an ethical foundation, however, are quite complicated. Again, at the risk of simplification, but directly reflected in the very words of Keynes and Hayek, their movements roughly correspond to the Left (Keynes) and Right (Hayek) of contemporary Western Christianized economic discourse. The Catholic economist John Médaille explains why, at least at a surface level: "In the case of Keynes and Hayek," "the difference is the different position that distributive justice has in each theory." "In the case of Hayek, justice simply isn't an issue; his major concern is with freedom. It is noteworthy that he uses the term 'justice' just three times, but 'freedom' eighty-seven times." Conversely, Médaille points out, "Keynes did his theorizing in the midst of [the economic collapse following the First World War]. Freedom was less of an issue to him, while saving the situation was of primary importance. Keyne's recipe for saving the system was the (re)distribution of wealth and income. He used the term 'freedom' only four times, but the term 'distribution' fifty-seven times." ${ }^{496}$ The struggle over which approach can claim the ethical or moral high ground, as well as be more effective, remains intensely disputed. ${ }^{497}$

\footnotetext{
495 Shlomo Maital, "Reclaiming Moral Sentiments: Behavioral Economics and the Ethical Foundations of Capitalism," in the Handbook of Contemporary Behavioral Economics: Foundations and Developments, ed. Morris Altman (New York, NY: Routledge, 2015), 203. Maital cites Peter J. Dougherty, Who's Afraid of Adam Smith: How the Market Got Its Soul (Hoboken, NJ: John Wiley \& Sons, 2002), 66. Maital further observes that "there is a fundamental paradox at the core of economics, its models and methods. Economics rules. But its practitioners, economists, are frequently reviled," Maital, "Reclaiming Moral Sentiments," 202. The central problem for Maital is that "economists purposely and deliberately disqualified themselves from addressing the central debate confronting the world-the moral and ethical foundations of capitalism and globalization. Capitalism and globalization have brought enormous wealth to a few and prosperity to many. But they have brought poverty or stagnation to distressingly many others," ibid., 203. Unfortunately, "over time, the legitimacy of studying human behavior disappeared from the economic agenda and was replaced by the abstract modeling of superhuman agents. Then moral principles too were banned, the result was the paradox of the universal embrace of economics' central idea and the social distaste for those who preach and teach it," ibid., 203.

${ }^{496}$ John Médaille, Toward a Truly Free Market: A Distributist Perspective on the Role of Government, Taxes, Health Care, Deficits, and More (Wilmington, DE: ISI Books, 2010), 18-19.

${ }^{497}$ Compare Raimondo Cubeddu, The Philosophy of the Austrian School (New York, NY: Routledge, 1993), 137-139; and Peter Koslowski, Principles of Ethical Economy, tr. David W. Lutz (Dordrecht, The Netherlands: Kluwer, 2001), with David Andrews, Keynes and the British Humanist Tradition: The Moral Purpose of the Market (New York, NY: Routledge, 2010), 90-91; and Robert Skidelsky, Keynes: The Return of the Master (New York, NY: PublicAffairs, 2009), 131-151. Skidelsky explains, revealingly, that "Keynes made the commonsense judgement that it is easier for people to be good ... if they have a certain level of material comfort. In this way, economic and political action to improve material conditions could be [ethically] accommodated," ibid., 135.
} 
What is also of particular interest about the situation in economics concerning the two cultures is that the Christian Right ${ }^{498}$ and Christian Left, ${ }^{499}$ respectively, have long emphasized either a more libertarian freedom or redistributive justice as the better way to make more people better off (that is, contribute to 'social justice' and the 'common good'500 and equality), and, for reasons that this study

\footnotetext{
${ }^{498}$ See, for example, Eric R. Crouse, The Cross and Reaganomics: Conservative Christians Defending Ronald Reagan (Lanham, MD: Lexington Books, 2013), 47; David Chilton, Productive Christians in an Age of Guilt Manipulators: A Biblical Response to Ronald J. Sider (Institute for Christian Economics, 1985); Chad Hovind, Godonomics: How to Save Our Country-and Protect Your Wallet-Through Biblical Principles of Finance (Colorado Springs, CO: Multnomah Books, 2013); Ronald H. Nash, Poverty and Wealth: Why Socialism Doesn't Work (Richardson, TX: Probe Books, 1986); Ronald H. Nash, Poverty and Wealth: The Christian Debate Over Capitalism (Westchester, IL: Crossway Books, 1986); and, even more radical in his positions, John W. Robbins, Freedom and Capitalism: Essays on Christian Politics and Economics (Unicoi, TN: The Trinity Foundation, 2006). In an interesting footnote to the role of the Christian Right in economics, the issue of gender equality and family roles emerges. A greater percentage of those on the Right would favor a return to single-earner families, in which the husband would be the breadwinner and the wife would be free to stay home and care for children. For a discussion of the socio-economic issues, see Bradford Plumer, "The Two-Income Trap," at http://www.motherjones.com/politics/2004/11/two-income-trap (accessed May 15, 2017). Corollary to this, a more left-leaning Catholic, David L. Schindler, affirms that the capitalistic-technological culture we live in creates a culture of distraction that discourages the young from marrying, creating many single adults; as cited in Matt Hadro, "How a 'Culture of Distraction' is Keeping Millennials from Marrying," at http://www.catholic newsagency.com/news/how-a-culture-of-distraction-is-keeping-millennials-from-marrying-28537/ (accessed September 10, 2017).

${ }^{499}$ For example, note the works by Ronald J. Sider, Rich Christians in an Age of Hunger: Moving from Affluence to Generosity (Nashville, TN: Thomas Nelson, 2015); Jim Wallis, Rediscovering Values: On Wall Street, Main Street, and Your Street (New York, NY: Howard Books, 2010); Charles E. Gutenson with Jim Wallis, Christians and the Common Good: How Faith Intersects with Public Life (Grand Rapids, MI: Brazos Press, 2011); and Brantley W. Gasaway, Progressive Evangelicals and the Pursuit of Social Justice (Chapel Hill, NC: The University of North Carolina Press, 2014), 66.

${ }^{500}$ These two phrases have become almost ubiquitous in the current discussion, and are usually emphasized by left-leaning progressive scholars or the more scientifically minded, and are the particular focus of many in the Roman Catholic tradition, which coined the phrase social justice. For literature on the topic, see the Pontifical Council for Justice and Peace, Compendium of the Social Doctrine of the Church (Washington, D. C.: USCCB, 2004); S. J. Hughson, Connecting Jesus to Social Justice: Classical Christology and Public Theology (Lanham, MD: Rowman \& Littlefield, 2013); Jerry Windley-Daoust, Primary Source Readings in Catholic Social Justice (Winona, MN: Saint Mary's Press, 2007); Charles E. Curran, Catholic Social Teaching, 1891-Present: A Historical, Theological, and Ethical Analysis (Washington, D. C.: Georgetown University Press, 2002); José I. Lavastida, Health Care and the Common Good: A Catholic Theory of Justice (Lanham, MD: University Press of America, 2000); Philip S. Keane, Catholicism and Health-Care Justice: Problems, Potential and Solutions (Mahwah, NJ: Paulist Press, 2002); J. Brian Benestad, Church, State, and Society: An Introduction to Catholic Social Doctrine (Washington, D. C.: The Catholic University of America Press, 2011); and Thomas Massaro, Catholic Social Teaching in Action: Living Justice (New York, NY: Rowman \& Littlefield, 2008). Note also, William F. Murphy, Jr., "Introduction," in Martin Rhonheimer, The Common Good of Constitutional Democracy: Essays in Political Philosophy and on Catholic Social Teaching (Washington, D.C.: The Catholic University of America Press, 2013), xxxvi-xxxvii; Mary Elsbernd and Reimund Bieringer, When Love is Not Enough: A Theo-ethic of Justice (Collegeville, MN: The Liturgical Press, 2002); the essays in Martin Schalg and Juan Andrés Mercado, eds. Free Markets and the Culture of Common Good (New York, NY: Springer, 2012); and, from a more progressive Protestant perspective, George Van Pelt Campbell, "A Biblical Theology of the Common Good," in Bibliotheca Sacra 172 (April-June 2015), 139-153.
} 
can't penetrate into presently, it appears both can't be emphasized equally. ${ }^{501}$ of course, the issues are more complex than I can explore here. What matters is that, indeed, Christians are almost equally divided in their socio-economic views, and some of the larger faith groups, such as Catholics, are equally divided as well between the Right and Left on economic issues. ${ }^{502}$ Indeed, the labels Keynesian and Austrian frequently receive attention by Christian economic activists, with individuals and groups siding strongly on one side or the other. For example, in the United States, the Tea Party, a more conservative libertarian secular group that includes many Christians, is decidedly Austrian, ${ }^{503}$ while various liberal or Progressive Christians have sided more with Keynes, ${ }^{504}$ when not alternately or also embracing Marx. ${ }^{505}$

\footnotetext{
${ }^{501}$ To illustrate this, note the more libertarian and conservative Catholic critics of the progressive Catholic trends, such as Michael Novak and Paul Adams, Social Justice Isn't What You Think It Is (New York, NY: Encounter Books, 2015).

${ }^{502}$ For example, see Doug Bandow and David L. Schindler, eds. Wealth, Poverty \& Human Destiny (Wilmington, DE: ISI Books, 2003). The two editors each selected advocates of their respective positions creating an alternating sample of the two perspectives throughout the volume, with selected Catholics on both sides. Jeremy Beer, writing the preface, explains, "the essays presented here by editors Doug Bandow and David L. Schindler present, in essence, two very different points of view: the first, represented by Bandow's contributors, tends to construe free-market economics as the real-world option that most benefits the poor, even while it emphasizes the moral and social context in which this sort of economic system must be embedded. These contributors also argue for the essential compatibility of the liberal (that is to say, free-market) economic order with Christian teaching and belief. Schindler's essayists are not as sanguine about the new capitalist order; they regard it as depending on a philosophical [scientific atomistic] liberalism that is not neutral but fundamentally opposed to Christian theology and social thought. Furthermore, they view this liberalism as subtly undermining the possibilities of achieving individual virtue and genuine community," ibid., viii (additions mine).
}

Also noteworthy would be Gerd-Rainer Horn, Western European Liberation Theology: The First Wave (1924-1959) (Oxford, UK: Oxford University Press, 2008). Horn explains how the Catholic liberation theology movement had a complex pre-history which led into Vatican II. For more on liberation theology's continuing relevance, see Tim Noble, The Poor in Liberation Theology: Pathway to God Or Ideological Construct? (New York, NY: Routledge, 2014).

${ }^{503}$ See, for example, Stephen Johnston, Tea Party Culture War: A Clash of Worldviews (Enumclaw, WA: WinePress, 2011), 71-84; which builds on previous generations of Christian critics of Keynesian theory, such as Ian Hodge, Baptized Inflation: A Critique of "Christian" Keynesianism (Institute for Christian Economics, 1986). In defense of conservatism in relationship to economic generosity, also note Arthur C. Brooks, Who Really Cares: The Surprising Truth about Compassionate Conservatism (New York, NY: Basic Books, 2006); and Arthur C. Brooks, The Road to Freedom: How to Win the Fight for Free Enterprise (New York, NY: Basic Books, 2012).

${ }^{504}$ David R. Brockman, Dialectical Democracy Through Christian Thought: Individualism, Relationalism, and American Politics (New York, NY: Palgrave Macmillan, 2013), 111, 129; and Gary Dorrien, Social Ethics in the Making: Interpreting an American Tradition (Malden, MA: Wiley-Blackwell, 2011), 254-255. See also, Médaille, Toward a Truly Free Market: A Distributist Perspective on the Role of Government, Taxes, Health Care, Deficits, and More, 11-33. For an historical perspective, see Vincent Geoghegan, Socialism and Religion: Roads to Common Wealth (New York, NY: Routledge, 2011).

505 "Marx and Keynes identified flaws in the neoclassical story. Keynesian analysis leads to adaptation; Marxian analysis leads to revolutionary change," Paul G. King and David O. Woodyard, The Journey Toward Freedom: Economic Structures and Theological Perspectives (East Brunswick, NJ: Associated University Presses, 1982), 108. King and Woodyard add, "Keynes viewed himself as challenging the economic orthodoxy, but his 
In a repetition of what was shared above concerning the biological roots of socio-political

leanings within psychology, and a sign of what is to come in the next section, this does often amount to in the secular world, in the United States and elsewhere with their equivalents, respectively, the Republican Party being (unfaithful and inconsistent) advocates of the Austrian theory, ${ }^{506}$ while the Democrat Party has been (unfaithful but more consistent) advocates of various forms of Keynesianism ${ }^{507}$ alongside other Left-leaning movements like Occupy Wall Street. ${ }^{508}$

Their struggle has helped contribute to the ongoing contemporary economic crisis facing America, and the entire globe, in the $21^{\text {st }}$ century, as the advantages and risks of technological automation ${ }^{509}$ face the futures of many people, and the value and cultural values of the individuals

theories gave it new life," 105. See also Mark Skousen, The Big Three in Economics: Adam Smith, Karl Marx, and John Maynard Keynes (New York, NY: Routledge, 2015), 102-103.

${ }^{506}$ Of course, Tea Party advocates observe that "the orthodox Keynesian economic theory ... has guided both Democratic and Republican parties from the 1930s to the present," Ronald T. Libby, Purging the Republican Party: Tea Party Campaigns and Elections (Lanham, MD: Lexington Books, 2014), 22. See also, Wapshott, Keynes - Hayek: The Clash that Defined Modern Economics, 293; and Ken Buck with Bill Blankschaen, Drain the Swamp: How Washington Corruption is Worse than You Think (Washington, D.C.: Regnery Publishing, 2017).

${ }^{507}$ Gary Dorrien, The Obama Question: A Progressive Perspective (Lanham, MD: Rowman \& Littlefield Publishers, 2012), 95; William Milberg and J. E. King, in Conversations with Post Keynesians, ed. J. E. King (London, UK: St. Martin's Press, 1995), 63; Carles Boix, Political Parties, Growth and Equality: Conservative and Social Democratic Strategies in the World Economy (Cambridge, UK: Cambridge University Press, 1998), 7; John Eatwell and Murray Milgate, The Fall and Rise of Keynesian Economics (Oxford, UK: Oxford University Press, 2011), 384; Peter de Haan, From Keynes to Piketty: The Century that Shook Up Economics (London, UK: Palgrave, 2016); Ellen Russell, New Deal Banking Reforms and Keynesian Welfare State Capitalism (New York, NY: Routledge, 2008), 6-7; Theodore Rosenof, Economics in the Long Run: New Deal Theorists and Their Legacies (Chapel Hill, NC: The University of North Carolina Press, 1997); and Thomas Hoerber, Hayek vs Keynes: A Battle of Ideas (London, UK: Reaktion Books, 2017), 62-63.

${ }^{508}$ Observe the comments by Majia Holmer Nadesan, "Neofeudalism and the Financial Crisis: Implications for Occupy Wall Street," in Understanding Occupy from Wall Street to Portland, eds. Renee Guarriello Heath, Courtney Vail Fletcher, and Ricardo Munoz (Lanham, MD: Lexington Books, 2013), 37, 48; and John Shannon, Keynesian Economics: The Cancer in America (Bloomington, IN: AuthorHouse, 2012), 51.

${ }^{509}$ Much of this is directed against Keynesianism, as it has been the more dominant economic theory. As Xavier Suarez commented recently, "Democrats, including President Obama, subscribe[d] enthusiastically to the spending side of Keynesian theory. Republicans, on the other hand, prefer to stimulate the economy by cutting taxes. The net effect of their combined policies is enormous deficits." "This combination happens when the Congress and the presidency are controlled by different parties. It can also happen when the Congress itself is divided-with the House in the hands of the Republicans and the Senate in the hands of the Democrats. Unless the president has ... diplomatic skills ..., what results is incoherent economic policy, marked by ludicrous budget deficits," Xavier L. Suarez, The Wealth of a Nation (Bloomington, IN: AuthorHouse, 2014), 203-204. Furthermore, blistering critiques of Keynes continue to emerge. Note Henry Hazlitt, The Failure of the "New Economics": An Analysis of the Keynesian Fallacies (Whitefish, MT: Kessinger Publishing, 2010). Overall, the socio-economic landscape is a mess, and it is clear that the confusion in the West's economic theories and policies are influencing the rest of the world. This has many ramifications as one surveys the global landscape. See, for example, the provocative books by Jonah Goldberg, Suicide of the West: How the Rebirth of Tribalism, Populism, Nationalism, and Identity Politics is Destroying American Democracy (Danvers, MA: Crown Forum, 2018); Amy Chua, Political Tribes: Group Instinct and the Fate of Nations (New York, NY: Penguin Press, 2018); 
behind the numbers are debated or forgotten. ${ }^{510}$ Within such a context, and without offering a solution to the crisis, the cautionary note by Paul King and David Woodyard nevertheless remains poignant and motivates a continual resistance against the scientization of economics, especially given the congruence of interests between economics and theology. They assert that all too often, "the use of story is alien to the analytic economist.... Most modern economists interpret events and behavior by applying their analytic tools and examining quantitative data. Economists think of themselves as living by cold reason and logic, not by stories; but they often ignore the wide range of assumptions and assertions that are carried in their analytic structure."511 Rather than accept such a cold approach, they recommend that all should remember that "economic analysis is actually the beginning of a story that attempts to interpret reality; as such" its theories are "neither timeless nor universal. ${ }^{n 12}$

In summary, it appears that the most significant controversy in Western economic theory has fallen prey to the conflict between the two cultures, through the rise of the neo-Keynesian and Austrian schools of thought. Importantly, the foundational divide between the two schools of thought

\footnotetext{
Amy Chua, Day of Empire: How Hyperpowers Rise to Global Dominance-and Why They Fall (New York, NY: Anchor Books, 2007); Amy Chua, World on Fire: How Exporting Free Market Democracy Breeds Ethnic Hatred and Global Instability (New York, NY: Anchor Books, 2004), as well as Edward Conard, Unintended Consequences: Why Everything You've Been Told about the Economy is Wrong (New York, NY: Penguin, 2012); Steven Brill, Tailspin: The People and Forces Behind America's Fifty-Year Fall-and Those Fighting to Reverse It (New York, NY: Knopf, 2018); and Edward Conard, The Upside of Inequality: How Good Intentions Undermine the Middle Class (New York, NY: Penguin Random House, 2016).

${ }^{510}$ Many people feel their job is 'meaningless,' leading to societal depression. See Rutger Bregman, "A Growing Number of People Think Their Job Is Useless-Time to Rethink the Meaning of Work," at https://www.weforum.org/agenda/2017/04/why-its-time-to-rethink-the-meaning-of-work (accessed September 18, 2018). Bregman explains, "Our definition of work ... is incredibly narrow. Only the work that generates money is allowed to count toward GDP. Little wonder, then, that we have organized education around feeding as many people as possible in bite-size flexible parcels into the employment establishment. Yet what happens when a growing proportion of people deemed successful by the measure of our knowledge economy say their work is pointless?" "That's one of the biggest taboos of our times. Our whole system of finding meaning could dissolve like a puff of smoke. The irony is that technological progress is only exacerbating this crisis. Historically, society has been able to afford more bullshit jobs precisely because our robots kept getting better. As our farms and factories grew more efficient, they accounted for a shrinking share of our economy. And the more productive agriculture and manufacturing became, the fewer people they employed. Call it the paradox of progress: the richer we become, the more room we have to waste our time. It's like Brad Pitt says in Fight Club: too often, we're 'working jobs we hate so we can buy shit we don't need,"' ibid. Of course, the looming crisis of automation may create the scenario for many where they have no job at all.

${ }^{511}$ King and Woodyard, The Journey Toward Freedom: Economic Structures and Theological Perspectives, 35 .

${ }^{512}$ King and Woodyard, The Journey Toward Freedom: Economic Structures and Theological Perspectives, 35-36.
} 
concerns their conceptions about the role of freedom and time. Finally, religionists find themselves equally divided between the two schools of economic thought, demonstrating that, at present, religionists are not serving any role in resolving the issues. Also, given the present trajectories of the different movements, it does not appear any real progress is being made toward a resolution. Rather, a permanent polarization appears to be in the probable forecast of the foreseeable future.

Freedom and Time within the Third Culture Disciplines of the Socio-Political Sciences Roger Masters opined, regretfully, that the "separation of political theory from scientific research on human nature is doubtless related to what C. P. Snow called the divorce between the "Two Cultures."”513 Stephen Rowe concurs, stating that there are presently “two Western worldviews, with the scientific dominating over the humanistic/relational" which was recognized "with C. P. Snow's groundbreaking book." Rowe continues by commenting that understanding the two cultures is critical to understanding contemporary "political theory." ${ }^{514}$ Furthermore, even within politics, the problem replicates itself again. "Policy-making shared many similar knowledge utilization characteristics as the situation which existed between scientific researchers and those involved in the humanities within university settings. This was a relationship which C. P. Snow had referred to as involving 'two cultures' which spoke to each other but rarely if ever understood what each other said." Thus, by analogy, "policy-makers and analysts" could also be considered "to be divided into 'two communities' of knowledge producers [i.e., the sciences] and consumers [i.e., the humanities] whose relationship ... [is] fraught with the potential for misunderstandings." ${ }^{515}$

\footnotetext{
${ }^{513}$ Roger D. Masters, The Nature of Politics (New Haven, CT: Yale University Press, 1989), xi. Masters continues, "in our universities, the natural sciences are divided from the humanities and social sciences.... As a result, despite excellent popularizations of the latest scientific findings, most academic studies of human behavior do not integrate an understanding of biology and evolution with the analysis of politics, economics, or sociology," ibid.

${ }^{514}$ Stephen C. Rowe, Overcoming America / America Overcoming: Can We Survive Modernity? (Lanham, MD: Lexington Books, 2012), 42. Rowe continues, the misunderstandings have led freedom to alternately be misconstrued as "the tendency to understand relationships in terms of either absolute equality or dominancesubmission. Earlier ideas of mutuality and unity in diversity began to fade or be relegated to the sidelines of modern life," ibid., 41, 44-45. For a broader perspectives on Christianity and socio-economics and politics, see Schansberg, Turn Neither to the Right Nor to the Left: A Thinking Christian's Guide to Politics and Public Policy.

${ }^{515}$ Sarah Giest, Michael Howlett, and Ishani Mukherjee, "The Relevance of the Academic Study of Public Policy," in The Relevance of Political Science, ed. Gerry Stoker, B. Guy Peters, and John Pierre (London, UK: Palgrave, 2015), 126 (additions mine).
} 
This is not to say that some don't desire science and politics to merge-something that could happen in a variety of ways ${ }^{516}$ This is clearly the hope of advocates of scientism, such as Sam Harris ${ }^{517}$ and many others, ${ }^{518}$ who have sided with Snow ${ }^{519}$ within the two cultures' war. Yet, many of those who are directly entangled within the conflict, such as René von Schomberg, express a cautionary alarm concerning any such hope because scientific evidence is often fraught with uncertainties. Rather, "in the interchange between the value spheres, [of] science and politics, a contradiction arises: an appeal to science seems necessary (because of the complexity of the issues), but is not possible (since there is a controversy and lack of knowledge) and [therefore] what is impossible, an appeal to a [scientific] source which can provide authoritative data, becomes necessary." Schomberg perceives that "in the entanglement of this contradiction science seems to change into its counterpart: it becomes a strategic means for [subjectively motivated human] political action"520 rather than a neutral or objective body of data to consider. Schomberg explains the pragmatic reality as follows: “Interest groups ... look for scientific experts who share their political objectives. Science does not provide authoritative data for consensual action and science can not adequately code the problems in terms of truth [as reflected in the religious humanities]. Instead the respected value sphere [within the divided interests within religionists or secular humanists] causes the multiplication of dissent and

${ }^{516}$ Such a merging could occur at different levels-philosophically or more sociologically. For example, as Nancy Scola's recent article reveals, Washington D.C.'s political system, particularly its lobbyist system, could be automated. See Nancy Scola, "Can Washington Be Automated?: An Algorithmic Lobbyist Sounds like a Joke-But it's Already Here-Here's Who the Robots are Coming for Next," at https://www.politico.com/ magazine/story/2018/01/05/washington-automation-congress-politics-lobbying-policy-216216 (accessed January 17, 2018).

${ }^{517}$ Harris, The Moral Landscape, 2-3.

${ }^{518}$ For example, Abdus Salam and Azim Kidwai assert that "science and technology are ... the shared heritage of all mankind. East and West, North and South have all participated equally in their creation in the past as, it is hoped, they will in the future-the joint endeavor in science becoming one of the unifying forces among the diverse peoples on this globe," and that no one better recognized this than "C. P. Snow," "a man with vision," Abdus Salam and Azim Kidwai, "A Blueprint for Science and Technology in the Developing World," in Worldwide Science and Technology Advice to the Highest Levels of Governments, ed. William T. Golden (New York, NY: Pergamon Press, 1991), 64. For more advocates of political policies based upon science, see, for example, Stephen Bocking, Nature's Experts: Science, Politics, and the Environment (Piscataway, NJ: Rutgers University Press, 2004). Note also, Theodore M. Porter, Trust in Numbers: The Pursuit of Objectivity in Science and Public Life (Princeton, NJ: Princeton University Press, 1995).

519 Charles P. Snow, Science and Government (Cambridge, MA: Harvard University Press, 2013).

${ }^{520}$ René von Schomberg, "Introduction," in Science, Politics and Morality: Scientific Uncertainty and Decision Making, ed. René von Schomberg (Dordrecht, The Netherlands: Springer Science, 1993), 2 (addition mine). 
conflict [within the sciences] about important policy issues." ${ }^{\prime 21}$ The point to be drawn from

Schomberg, in general, is that it appears that no matter what one might wish for, science has an

uneasy place alongside politics.

As Francis Castles commented, for many it seems "the general tone of political studies is not ... a

scientific one. ${ }^{522}$ Rather, it appears that, for some, politics shouldn't even attempt to be scientific, ${ }^{523}$

despite the fact that more and more political groups appeal to science to support their positions. ${ }^{524}$

Directly representing Heideggerian influences in the realm of political discourse, Gary Madison shares

plainly, “[classical or conservative political] liberalism is a philosophy, not a science. Thus, the

function of theory in this instance is not what it is in the realm of science and technology.",525

${ }^{521}$ Schomberg, "Introduction," in Science, Politics and Morality, 2. David Hess affirms that "although scientized decision making is neither value-free nor politically neutral, it is often framed as both," David J. Hess, Undone Science: Social Movements, Mobilized Politics, and Industrial Transitions (Cambridge, MA: The MIT Press, 2016), 60. Hess adds that "the level of scientization [in governance and society] refers to the extent to which decision making in the policy field is restricted to technical criteria such as risk assessment or is more open to evaluation that makes reference to the social effects and social desirability of a new technology. As the world has become technically more complex and more rationalized, the level of scientific and technical complexity has increased in many policy fields. With this change, policy debate can become more technical, and the role of experts from government, academia, and industry is likely to be more important in many issue areas. However, the importance of expert input and advice to a policy process is not the same as scientization. It is possible to have a broad policy debate that includes social values and also to make extensive use of technical expertise such as risk analysis; the two are not necessarily incompatible," even if it often appears so in practice, ibid., 60-61.

${ }^{522}$ Castles, Pressure Groups and Political Culture: A Comparative Study, xiii.

${ }^{523}$ Castles, for one, believes that politics "neither could nor should attempt ... the aims and methods of the scientific disciplines." "Even to suggest the possibility of a predictive science of politics is to run into the philosophical problem of the value-impregnation of supposedly factual material in the study of man," Castles, Pressure Groups and Political Culture: A Comparative Study, xiii.

${ }^{524}$ This is because, as Pierre Bourdieu is aware, "we know that every exercise of power is accompanied by a discourse aimed at legitimizing the power of the group that exercises it; we can even say that it is characteristic of every power relation that it takes on its full force only in so far as it disguises the fact that it is a power relation. In a word, the politician is someone who says 'God is on our side'. The modern equivalent of 'God is on our side' is 'public opinion is on our side'. That is the fundamental effect of the opinion poll: it creates the idea that there is such a thing as a unanimous public opinion, and so legitimizes a policy and strengthens the power relations that underlie it or make it possible," Pierre Bourdieu, Sociology in Question, tr. Richard Nice (London, UK: Sage Publications, 1993), 150. In a world where science is king, with queen physics serving him, it is only logical that science, whether originating from the scientists who operate their craft in the natural world, or in the social world, is invoked for political purposes. This is a problem in itself. But the problem does not end here. The challenge then becomes whether the "poling agencies are [also] subordinated to political interests," which "very strongly governs both the meaning of the answers and the meaning given to them on publication of the findings," ibid., 150. See also, Hess, Undone Science: Social Movements, Mobilized Politics, and Industrial Transitions, 1-26, 54.

${ }^{525}$ Madison, The Logic of Liberty, 201. See also, Madison, The Political Economy of Civil Society and Human Rights, 54-56. Daniel Sarewitz further explains the relevance of Madison's point: "The fact that indeterminacy is not only inevitable but essential to democracy-something to be embraced rather than overcome-does not comport well with a scientific worldview whose most legitimating measures of success are predictive certainty and control of nature. Having created the material welfare and technological infrastructure on which democracy has now come to depend, the significance of Enlightenment science for the democratic 
Conversely, however, from its inception, the strongest proponents of "progressivism" have "believed

it to be a scientific approach to politics, ${ }^{\prime 26}$ and its advocates appear far from conceding their

positions.

It is worth briefly observing, in passing, that the conflict of the two cultures it not merely

reflected within politics, but throughout Western social and sociological studies ${ }^{527}$ in general,

process itself seems murky. The issue here is not only that science and technology constantly transform the structure of society (usually without the consent of the governed), but also that over the past half-century or so, they have become tools that are called on to assist in the explicit improvement of democratic process-helping to resolve political dispute, set priorities for action, and manage social change. Through scientific eyes the mechanisms that enable democracy-politics, laws, bureaucracy-may look not just messy and irrational but subject to scientific correction. But the quest for scientifically based certainty and control in the political realm can conflict with democratic ideals by demanding, and fueling a demand for, that which is fundamentally incompatible with civil society: closure" and the denial of freedom, Daniel Sarewitz, "Human Well-being and Federal Science-What's the Connection?," in Science, Technology \& Democracy, ed. Daniel Lee Kleinman (Albany, NY: State University of New York Press, 2000), 92. See also in the same volume, Sandra Harding, "Should Philosophies of Science Encode Democratic Ideals?," 121-138. Harding believes that we must not fall prey to the idea that "there is one and only one group or culture of humans that can develop ... science. As the histories of science reveal, elements of many different cultures' science and technology traditions have found a home in western-now, 'international'-science at one point or another, just as elements of western sciences have been integrated into other knowledge systems. All knowledge systems are hybrids; their ability to continue to grow comes from the access they have to continually new cognitive and material-natural and technological-resources.... Such a perspective could lead to prioritizing the development of significantly different knowledge systems rather than of only one perfect system. And here is just one way that philosophies of modern sciences could encode democratic ideals more effectively with benefits both for democratic social movements and for maintaining the cognitive resources every knowledge system needs to flourish," ibid., 137.

${ }^{526}$ James Ostrowski, Progressivism: A Primer on the Idea Destroying America (Buffalo, NY: Cazenovia Books, 2014), 1. See also, John Marini, "Progressivism, Modern Political Science, and the Transformation of American Constitutionalism," in The Progressive Revolution and Political Science: Transforming the American Regime, eds. John Marini and Ken Masugi (Lanham, MD: Rowman \& Littlefield, 2005), 221; Sidney A. Person, Jr., Reflections on American Progressivism (New Brunswick, NJ: Transaction Publishers, 2014); and Andrew Feffer, The Chicago Pragmatists and American Progressivism (Ithaca, NY: Cornell University Press, 1993), 5-8, 19, 30, 54-58.

${ }^{527}$ As the philosopher and sociologist Edgar Morin observed, "the lack of communication between the two cultures risks grave consequences for both. The humanistic culture revitalizes the works of the past; the scientific culture focuses on the discoveries of the present. Humanism is a general culture that, through philosophy, essays, and novels, poses fundamental human problems and encourages reflection. Scientific culture encourages a form of thought devoted to theory, not a reflection on man's fate or the future of science itself. Scientific culture provides fundamental knowledge and understanding concerning the universe, life, and human beings, but it is devoid of a reflexive and introspective dimension. The mill of humanistic culture no longer receives and grinds the crucial wheat of scientific knowledge. The boundary between the two cultures runs straight through the heart of sociology and, as a result, that discipline finds itself split in two rather than providing a shuttle that links the two," Edgar Morin with Stéphane Hessel, The Path to Hope, tr. Antony Shugaar (New York, NY: Other Press LLC, 2012), 53-54. "We must replace our way of thinking that breaks down with a mind-set that knits things together, and that linkage demands that a unilinear and unidirectional concept of causation be replaced by a looped, multireferential concept of causation, that the rigidity of classical logic be corrected by a dialectic capable of entertaining notions that are at the same time complementary and antagonistic, and that an understanding of the integration of elements into a whole necessitates an appreciation of the integration of everything within those elements," ibid., 54. But it should not be understood as a mere dialectic, rather, as explained elsewhere, "Morin's complex concept of the dialogic" is "not an either/or logic of either cultural clashes or cultural creativity; not a dialectic whereby two cultures are somehow subsumed in a higher synthesis; but a dialogic, where cultures and interactions can be complementary, concurrent, and 
including in the vital field of educational theory. Within educational theory the popular concept of 'learning outcomes' directly relates to the role of scientism ${ }^{528}$ in the process of education. ${ }^{529}$ The issue at stake in the creation of learning outcomes concerns what kinds of knowledge and skills are to be taught and learned, and how this is to be done in the most measurable way. It is the tendency of most traditional and contemporary educators to reduce the learning process to scientifically objective and thus commodifiable 'learning outcomes' that can be imposed upon the student. ${ }^{530}$ Such a method has

antagonistic all at the same time," Alfonso Montuori, "Foreword," in Edgar Morin, Vidal and His Family: From Salonica to Paris-The Story of a Sephardic Family in the Twentieth Century, tr. Deborah Cowell (Portland, OR: Sussex Academic Press, 2009), ix. See also, Rosenau, Distant Proximities: Dynamics Beyond Globalization, 12.

${ }^{528}$ For a critique of the dominance of scientism in modern education, see Emery J. Hyslop-Margison and M. Ayaz Naseem, Scientism and Education: Empirical Research as Neo-Liberal Ideology (New York, NY: Springer, 2007), 4-5, 82, 96-97. See also, Kieran Egan, Getting it Wrong from the Beginning: Our Progressivist Inheritance from Herbert Spencer, John Dewey, and Jean Piaget (London, UK: Yale University Press, 2002); and Paul Fairfield, Education After Dewey (New York, NY: Continuum, 2009), 25, 47.

${ }^{529}$ See, for example, Richard Arum, Josipa Roksa, and Amanda Cook, Improving Quality in American Higher Education: Learning Outcomes and Assessments for the $21^{\text {st }}$ Century (San Francisco, CA: Wiley, 2016).

${ }^{530}$ See Paul Gibbs, Heidegger's Contribution to the Understanding of Work-Based Studies (New York, NY: Springer, 2011), 41; Scott Webster and Ann Ryan, Understanding Curriculum: The Australian Context (Sydney, NSW: Cambridge University Press, 2014), 72; Max van Manen, Pedagogical Tact: Knowing What to Do When You Don't Know What to Do (New York, NY: Routledge, 2016), 123; and Angus Brook, "The Potentiality of Authenticity in Becoming a Teacher," in Exploring Education Through Phenomenology: Diverse Approaches, ed. Gloria Dall'Alba (West Sussex, UK: John Wiley \& Sons, 2009), 53-65. Roger Foster explains that "enormous economic pressure on institutions of higher education, together with the perceived need to determine a scientific measurement of teaching 'effectiveness' and of the rigor of a program of study, have created the universal urge to specify what educators do in the form of an objective, measurable and standardized product. The name for this product in current academic jargon is 'learning outcomes.' As their name suggests, learning outcomes are intended to describe an outcome or action that is demonstrable and assessable. They identify the skills and knowledge that a learner is supposed to have acquired on the successful completion of a course of study. As one critic of the learning outcomes movement has noted, it operates on the presumption that 'education is production and that faculty, students, and administrators must learn to engage in it as efficiently as possible. It assumes and conditions others to assume that knowledge and learning are commodities.' In the pressure to schematize the work of teaching as the production of 'learning outcomes,' we can discern the very same force of the imperative of fungibility and measurability that corrupt the whole of contemporary experience. A learning 'outcome,' after all, is a standardized measure for the educational value of the experience that the student partakes of in the college classroom. Here, the student is promised, and the teacher dedicated to produce, a fungible and measurable return on the investment of college life. One cannot, of course, place a measurable value on the activity of reading a book. And, as any teacher is aware, the profoundest effect on the lives of students almost always takes time to germinate, when the fragile seeds that take root in the mind often take years to fully develop, and work their effects long after any 'outcomes' have been assessed, catalogued and measured. Indeed, as critics have pointed out, 'the most fruitful and valuable feature of higher education is the emergence of ideas, skills and connections, which were unforeseen, even by the teacher.... The commodification of knowledge and the attempt to define learning outcomes precisely are antithetical to good educational practice,"' Roger S. Foster, Adorno and Philosophical Modernism: The Inside of Things (Lanham, MD: Lexington Books, 2016), 11. See also, Steven Hodge, Martin Heidegger: Challenge to Education (New York, NY: Springer, 2014). A related issue would be that of "common core" educational standards. See Nicholas Tampio, Common Core: National Education Standards and the Threat to Democracy (Baltimore, MD: Johns Hopkins University Press, 2018). 
received criticism by both Heideggerian ${ }^{531}$ and Bohmian ${ }^{532}$ inspired educators. Both groups of them have attempted to move past the classical scientific paradigm for education-that is, from merely a classical epistemological approach toward an ontological view of education. ${ }^{533}$ The point of departure between Heidegger and Bohm would concern what we can do to mitigate the vast over scientization of education. Heideggerians typically would say that it is not possible to re-scientize the affective or emotional and subjective (religious?) sides of reality into learning outcomes, ${ }^{534}$ while Bohmians, ever the integrationists, would try to objectify the subjective, ${ }^{535}$ just as Bohm tried to deterministically objectify the indeterminate quantum realm. ${ }^{536}$ Such debates continue to dominate the landscape of educational theory. Although the culture of educational scientists often assumes it is their task to transmit the 'truth' to their students, as Jacqui Boddington observed, "Heidegger has it that teaching is

\footnotetext{
${ }^{531}$ For example, see Philip M. Bamber, Transformative Education Through International ServiceLearning: Realising an Ethical Ecology of Learning (New York, NY: Routledge, 2016), 37-38.

${ }^{532}$ André P. Grace and Tonette S. Rocco, Challenging the Professionalization of Adult Education: John Ohliger and Contradictions in Modern Practice (San Francisco, CA: Jossey-Bass, 2009), 80-81.

${ }^{533}$ Thuy T. Vu and Gloria Dall'Alba, "Becoming Authentic Professionals: Learning for Authenticity," in 'Becoming' a Professional: An Interdisciplinary Analysis of Professional Learning, ed. Lesley Scanlon (New York, NY: Springer, 2011), 96.

${ }^{534}$ Paul Standish, Beyond the Self: Wittgenstein, Heidegger, and the Limits of Language (Aldershot, UK: Avebury, 1992), 93, 125, 180, 261.

${ }^{535}$ Rosen, Science, Paradox, and the Moebius Principle, 261-262. For more, see Mike Askew, Transforming Primary Mathematics (New York, NY: Routledge, 2012), 130; Kathy L. Guthrie and Kathleen Callahan, "Liberal Arts: Leadership Education in the 21 ${ }^{\text {st }}$ Century," in Reclaiming Higher Education's Purpose in Leadership Development, eds. Kathy L. Guthrie and Laura Osteen (San Francisco, CA: Jossey-Bass, 2016), 26; Valerie A. Brown, Robert Dyball, Meg Keen, Judy Lambert, and Nicki Mazur, "The Reflective Practitioner: Practising What We Preach," in Social Learning in Environmental Management, eds. Rob Dyball, Valerie A. Brown, and Meg Keen (Sterling, VA: Earthscan, 2005), 237.

${ }^{536}$ Popper, Quantum Theory and the Schism in Physics: From the Postscript to the Logic of Scientific Discovery, 174-175. Bohm, for his part, of course, does not support a simplistic content-based view of education. His emphasis on "dialogue" brings a more nuanced focus to just how the subjective is objectified. For more, see Jim Knight, High-Impact Instruction: A Framework for Great Teaching (Thousand Oaks, CA: Corwin, 2013), esp. 139.
} 
more difficult than learning because of the requirement to let [students] learn"537 toward open and unanticipated ends; "the teacher must be capable of being more teachable than the apprentices."

Thus, it would seem, that sociologically and politically "our time is characterized by a fundamental and deep paradox. On the one hand, developments in information technology, transportation technology and the rise of powerful multinational corporations, give genuine meaning to the oft-repeated slogan that we live in a 'global village."' Yet, "while we may all live in a global village, we do so in increasing disciplinary isolation. C. P. Snow lamented two disconnected cultures, a scientific culture and a humanities culture. If anything Snow's concerns have ramified. We now have a dizzying multiplicity of sub-sub-sub cultures where we seem only to engage fellow travelers in our own special interest group. Identity politics has replaced the politics of the melting pot, and one can get the impression that there is little engagement between sub-cultures beyond each jockeying for a larger piece of the pie" ${ }^{\prime 39}$ of money, power, and influence. What must be done, then, at present is to locate what it is that divides the socio-political discourse in general, and to observe that their conjoined interest in the sphere of legal discourse to advance and guide societal agendas reveals, with precision, the divide between the two cultures concerning the relation of freedom and time.

\footnotetext{
${ }^{537}$ Jacqui Boddington, “All Together Now?," in The Pedagogy of Compassion at the Heart of Higher Education, ed. Paul Gibbs (New York, NY: Springer, 2017), 221 (addition mine). Boddington notes that the "confluence of the cognitive and affective domain starts to reposition achievement and development as not simply" "an acquisition of skill and/or knowledge but in our ways of being. This is a development more tricky to establish against the learning outcomes" found in the dominant scientized pattern, and "there is a tension here-for our ambition as educators may well be to drive transformational learning-but to achieve it, we are required to work with the ambitions of our cohorts, not force them to demonstrate our own," ibid., 221. All this gains importance because recent "suggestions that universities have seen a shift from disciplinary power to pastoral power might be seen to be demonstrated in the call for pedagogies of co-creation to support the partnership/engagement agenda" that encourages more social engagement or activism in the political and scientific arenas, ibid., 221. The aims of such engagement then becomes the focal point-are they scientized or still humanitarian based?

${ }^{538}$ Heidegger, What is Called Thinking?, 15. For more context, see Thompson, Heidegger on Ontotheology: Technology and the Politics of Education, 168; and Miguel de Beistegui, Heidegger and the Political (New York, NY: Routledge, 1998), 60. Beistegui explains, "thus, the true and most fruitful relation between teacher and student is one that Heidegger characterizes as 'struggle' (Kampf), a relation which aims to keep the opposition between leading and following alive. Why must this opposition not be overcome? Because only in and through it does true questioning arise and is science made possible," ibid.

${ }^{539}$ Davis Baird, "Navigating Nanotechnology Through Society," in Nanotechnology: Societal Implications II: Individual Perspectives, eds. Mihail C. Roco and William Sims Bainbridge (Dordrecht, The Netherlands: Springer, 2007), 75-76. Baird continues, "in the sciences, the drive toward specialization and the multiplicity of technical jargons that has come with specialization have sharply limited the ability of researchers to engage across disciplines-let alone engage with those in the humanities and social sciences," ibid., 76. Baird's observation demonstrates the arrival of post-postmodernism.
} 
Indeed, although previously neglected throughout much of history, "law has an essential relation to time [and perhaps more obviously freedom], as has been recognized by a number of legal scholars in recent times." ${ }^{540}$ Christopher Meckstroth expressed that "in recent years, a number of leading theorists have drawn attention to [the] ... historical dimension of democracy," and added that "what this entails and whether it is indeed necessary remain highly controversial." ${ }^{\prime 41}$ More specifically, as Pierre Manent recently opined, "everyone sees how modern society is forever seeking compromises between the increasingly imperious legitimacy of present consent, the need to confirm at every instant that consent has indeed been given, and the impossibility of doing that." Yet, why this matters is because "this is a practical impossibility but it is also a moral one. One is obliged to assume that over a certain period of time consent has indeed been given. For example, a democratic government is assumed to be legitimate when the electorate has cast a majority vote for it and the consent of this electorate is assumed to last until the next scheduled election.."542 This "solemn consent, which is confirmed every four ... years [in the United States], is more and more enveloped if not replaced by consent that is continually" "evaluated day after day through the use of [sometimes questionable] polls" which measure the "degree of consent" day by day. ${ }^{543}$ However, Manent believes, "this often renewed liberty that accepts nothing from the past, which at every [timeless] instant creates itself forever anew, is freedom as [existentialist philosopher] Jean-Paul Sartre defines it." "But it is also the

\footnotetext{
${ }^{540}$ Jacques de Ville, “The Gift and the Meaning-Giving Subject: A Reading of Given Time," in Prospects of Legal Semiotics, eds. Anne Wagner and Jan M. Broekman (New York, NY: Springer, 2010), 91 n. 11 (addition mine).

${ }^{541}$ Christopher Meckstroth, The Struggle for Democracy: Paradoxes of Progress and the Politics of Change (Oxford, UK: Oxford University Press, 2015), 15. See also, Louis E. Wolcher, Beyond Transcendence in Law and Philosophy (Abingdon, Oxfordshire, UK: Birkbeck Law Press, 2005), 50-52.

${ }^{542}$ Pierre Manent, A World Beyond Politics?: A Defense of the Nation-state, tr. Marc LePain (Princeton, NJ: Princeton University Press, 2006), 117-118.

${ }^{543}$ Manent, A World Beyond Politics?: A Defense of the Nation-state, 118 (additions mine). Manent explains the consequences of the situation, as he sees them: "Thus we are witnessing a transformation of temporality. Time is becoming for us what it was for God in Descartes's philosophy, a succession of instants distinct from one another. Just as creation according to Descartes was maintained in being by the divine will exercising itself at every instant of time as a 'continuous creation,' our institutions, our communities, our couples are maintained in their legitimate being by our will, private or public, which exercises itself and must express itself more and more at every instant of time. It is in this continuous creation of consent that individuals are truly authentic individuals. They become what they are precisely by actively exercising their liberty ever anew, at every instant, by refusing to take on any obligation from the past, even if that past be that of our own choice," ibid.
} 
dominant idea of freedom today, the socially active idea that is incessantly transforming morals and sentiments," and, Manent wonders, "to what extent can it really be thought or be lived?"544

The political philosophers Jed Rubenfeld, whom Meckstroth noted, and Charles Sherover, are two in particular who have observed that the core issues dividing political and legal theories center on how freedom and time are conceived. Specifically, both Sherover ${ }^{545}$ and Rubenfeld ${ }^{546}$ believe Heidegger's explications of freedom and time help explain the central issues dividing different conceptions of the political order. ${ }^{547}$ Sherover believes that "my temporality" "depends upon my use of my freedom. And this freedom is the freedom of my temporal options enabled by my social order." ${ }^{\prime 548}$ Rubenfeld reverberates Sherover's observation by noting that "the call to live in the present

\footnotetext{
${ }^{544}$ Manent, $A$ World Beyond Politics?: A Defense of the Nation-state, 118 (addition mine). Manent explains, "The expression of consent necessarily opens a certain future, whether that future is determined by an institution or not. Even in our democracies that are governed, as was said, by polls, no one would dream of calling for the resignation of a government not long after an election even if the polls were very unfavorable. The government is still supported by the legitimate impetus of electoral consent. Thus, consent of itself entails a certain duration or promise. In fact, it was by the promise that consent was produced in predemocratic societies. But promise ran contrary to modern consent. It was held that one of the most specific and also most noble human traits was the capacity to promise and to keep promises, since in that way our liberty overcomes time and fortune. To renege on one's promise, to break one's oath, was the act of a soul deprived of nobility. The promise par excellence was valid for a lifetime, until death and sometimes beyond death. (Sartre, of course, would say that a promise so conceived is the death of liberty, since there is no guarantee that what one promises at a certain instant one will want to promise at the next. One is no less a slave for being a slave to oneself)," ibid, (emphasis original). For more on the issues pertaining to politics, present consent, authority, and coercion, see Munroe Eagles, Politics: An Introduction to Modern Democratic Government (Peterborough, Ontario: Broadview Press, 2008), 26; Jeremy Waldron, Political Political Theory: Essays on Institutions (New York, NY: Harvard University Press, 2016); and Jeremy Webber, "The Meanings of Consent," in Between Consenting Peoples: Political Community and the Meaning of Consent, eds. Jeremy Webber, Colin M. Macleod (Vancouver, BC: The University of British Columbia, 2010), 17.

${ }^{545}$ Charles M. Sherover, Time, Freedom, and the Common Good: An Essay in Public Philosophy (Albany, NY: State University of New York, 1989), 266-267, n.13. Sherover explains that "the most incisive examination of the pervasive structure of human temporality was provided by Heidegger and it is primarily on his analysis that mine depends," ibid.

${ }^{546}$ Jed Rubenfeld, Freedom and Time: A Theory of Constitutional Self-Government (New Haven, CT: Yale University Press, 2001), 33, 80, 138. For a critique of Rubenfeld's views, see Richard A. Posner, Law, Pragmatism, and Democracy (New York, NY: Harvard University Press, 2003), esp. 380-383 for how Posner evaluates Rubenfeld's views on science.

${ }^{547}$ Within the Western context, to link Heidegger with democracy and freedom is not a thing lightly done, given Heidegger's associations with Nazism. As Frank Schalow notes, "Sherover ... boldly linked Heidegger's thought to democratic practice by accentuating their mutual interest in human freedom," Schalow, Departures: At the Crossroads Between Heidegger and Kant, 131 (emphasis original). See also, Sonia Sikka, Heidegger, Morality and Politics: Questioning the Shepherd of Being (Cambridge, UK: Cambridge University Press, 2018), 11-38.

${ }^{548}$ Sherover, Time, Freedom, and the Common Good, 52. Sherover emphasizes that "We are social beings whose lives all severally flow together," ibid. Gregory Johnson, on Sherover's behalf, describes the key points as follows: "Sherover ... lays out a number of important distinctions, one of the most significant being between the time of nature and the time of man: of causal processes in the physical world on the one hand and of human thinking, planning, and deciding on the other. The temporal flow of natural processes is from the past through
} 
portrays freedom as something that we ought to have, or at least aspire to have, here and now. If

modern man wants what he wants here and now, what he wants first of all here and now is

freedom. ${ }^{549}$ Rubenfeld notes the irony of the above, in that, in "truth ... every effort to 'emancipate'

ourselves from time, no matter how successful, must, in order to be successful, entrench itself in

time." ${ }^{550}$ In other words, through modernity's obsession, which is manifestly evident in the political

world, to "live for the present,"

present or momentary happiness over meaning extended over time, ${ }^{552}$ a choice that can have both

the present to the future. The temporal flow of human action moves in the opposite direction, from future to present to past. The temporality of nature is a push from behind into what lies ahead. It is the temporality of causal determinism, causes coming before effects, effects coming after causes in an endless chain. Freedom, according to Sherover, has it own temporality. Human freedom exists insofar as we are presently confronted with different possibilities for temporal development; we can and must decide on which possibilities to make actual and which to discard. Once we decide on a new course of action into the future, it creates a new present that becomes past, Gregory R. Johnson, "Preface," in Charles M. Sherover, Are We In Time?: And Other Essays on Time and Temporality (Evanston, IL: Northwestern University Press, 2003), x.

${ }^{549}$ Rubenfeld, Freedom and Time, 7.

${ }^{550}$ Rubenfeld, Freedom and Time, 6.

${ }^{551}$ Rubenfeld, Freedom and Time, 3, 5, 14-16, 28-35. Similarly, the Heideggerian philosopher Harvie Ferguson, needing no perspicacious insight, observes: "Contemporary life is wholly in the present. Now we live 'for the moment' and are provided with innumerable ways of intensifying the instantaneous 'now' of something that is taking place. The excitement of roller-coaster rides, bungee jumping, being drunk, gambling, eroticism, sport, news, performances of all sorts, thunderstorms, beauty and all other 'saturated' phenomena is just that they overwhelm the living moment with content in such a way as to mark it as occurring 'right now,'” Ferguson, Self-Identity and Everyday Life, 165. Ferguson continues, our lives are so structured today that our experiences are defined by "the intensification of the moment," such that we can easily distinguish "it sharply from a "before and 'after'." The effect is that, perhaps surprisingly, "these events are readily forgotten. Far from being 'unforgettable' they enter memory in the attenuated form of 'having taken place' while preserving nothing of the moment itself." "Hence their ceaseless repetition, their continuing novelty as the everyday mini-traumas in which is discovered the comfort of oblivion," ibid. Ferguson also adds insightfully that "what is involved here is a distinctive and important transformation of the relationship of the experiencing subject to their experience. Where, for classical modernity, experience is experience of the world to which the subject is continually linked, in the excited moment of the present experience becomes an indicator of self-presence. The world, that is to say, is reduced to being a desideratum of the self-aware subject. The point of heightened momentary awareness is to furnish proof of self-presence. This is profoundly different to the structure of experience taken-for-granted by the most insightful of its investigators in the modern period. For Kant, as for Descartes, it made no sense to 'prove' self existence. The self was a precondition of any kind of experience and experience, while an unreliable guide to the nature of exterior reality, is always self-experience. But in the twentieth century people learned, above all, to doubt themselves, to want a world that proved they existed. But they were caught in a deeper paradox. The intensification of the moment, its artificial separation as pure immediacy, had the effect of dissolving selfhood into the irresistible transience of the 'now'," ibid., 165-166.

${ }^{552}$ Lal Krishna Advani, My Take (New Dalhi, India: Prabhat Prakashan, 2014), 84. Advani, citing Rubenfeld, states, "the present can never deliver one thing: meaning. The ways of happiness and meaning are not the same. To find happiness, a man need only live in the present: he need only live for the moment. But if he wants meaning-the meaning of his dreams, his secrets, his life-a man must reinhabit the past, however dark, and live for the future, however uncertain. Thus, nature dangles happiness and meaning before us all, insisting only that we choose between them," ibid. Notably, it is in the present alone that the power, wealth, and health we possess can be utilized and enjoyed, though temporal planning is necessary to seek or retain them. 
tremendous personal and political consequences. Similarly, for Sherover, only "as we acknowledge the heritage of the past and the lessons it bears," are we "increasingly enabled to evaluate the offerings of futurity. The continuing task of our freedom is to reconcile them. Our future cannot be created de novo. It can only be built out of the genuine possibilities which the historically rooted present presents as viable options." ${ }^{\prime 553}$ Freedom is never simply an escape from the past, freedom always acknowledges the past, and must do so, even as new possibilities present themselves that either surprise us or arise within our anticipatory expectations.

Others, though, while certainly aware of the past (it is in politics that most clearly, perhaps, a tacit awareness of time is always present in some form), wish to emphasize the present over the past for a variety of reasons. One such prominent political theorist was Thomas Hobbes in the $17^{\text {th }}$ century, who argued for a "break with the view of legitimacy as resulting not from present consent but previous submission"554 and precedence. Such prioritizations of the present over the past can take many forms in the socio-political world. For example, many groups of victims of longstanding violent conflicts view every instance of "wrong" done to them in the past as equally and poignantly relevant in the present. If one million of someone's ethnic/biological ancestors were killed wrongly by another specific ethnic group a century ago, then to "balance" the equation one million of the offending group's ethnic/biological descendants living today must suffer death in repayment. Although "history" is explicitly brought into their reasoning, the use of history becomes a conflation of all times into the immediate present through an analogous "timeless" math equation- 1 past death $=1$ present death-regardless of other concerns related to guilt and innocence of the individuals involved. Many other types of examples could be provided to make a similar point, ${ }^{555}$ and the collection of

${ }^{553}$ Sherover, Time, Freedom, and the Common Good, 230.

${ }^{554}$ See the explanation of Hobbes's reasoning in David Wootton, "Introduction," in Divine Right and Democracy: An Anthology of Political Writing in Stuart England, ed. David Wootton (Indianapolis, IN: Hackett Publishing, 2003), 58; and also David Wootton, "Hobbes, the Reformation, and the Scientific Revolution," in Modern Political Thought: Readings from Machiavelli to Nietzsche, ed. David Wootton (Indianapolis, IN: Hackett Publishing, 1998), 98.

${ }^{555}$ Although I will refrain from delving into specific historical instances where my example or similar examples may be relevant, for cursory introductions to related themes, see Michael Mann, The Dark Side of Democracy: Explaining Ethnic Cleansing (Cambridge, UK: Cambridge University Press, 2005), esp. 4, 28, 41. 
essays edited by Jie-Hyun Lim, et al., exploring how a collective group memory can serve to create, for better or worse, an "ever present past" in the socio-political world provides some of these perspectives. $^{556}$

The above illustrative and complex theoretical example aside, Rubenfeld, however, believes that it is, rather, only "the idea of human being as being-over-time" that "completes the work necessary to situate commitment in human freedom. Living in the present is a radically inadequate expression of freedom for a being whose being is over-time." It is only by acting in such a way as to "put himself in a certain relation with his own temporally extended existence" that he can actuate the conditions necessary for genuine freedom. ${ }^{557}$ "There is no such thing as a 'present person." ${ }^{\text {"558 }}$ Rather, "the ideal of freedom as acting on nothing other than present will is in the end unintelligible-and doubly so. The I who would be free in this way does not exist in the present, and the action he undertakes is always entrained in a temporal trajectory that extends into the past and future." ${ }^{\prime 59}$ Rubenfeld concludes that "freedom in the human sense is the struggle for authorship of one's being-overtime." ${ }^{560}$

Sherover and Rubenfeld's reasoning directly addresses one of the most important debates in legal theory today, and that is, whether political freedom requires temporal commitment. ${ }^{561}$ For

\footnotetext{
${ }^{556}$ For example, see Jie-Hyun Lim, Barbara Walker, and Peter Lambert, eds. Mass Dictatorship and Memory as Ever Present Past (New York, NY: Palgrave Macmillan, 2014), especially Jie-Hyun Lim and Peter Lambert, "Introduction: Coming to Terms with the Past of Mass Dictatorship," 1-16.

${ }^{557}$ Rubenfeld, Freedom and Time, 140-141.

${ }^{558}$ Rubenfeld, Freedom and Time, 140.

${ }^{559}$ Rubenfeld, Freedom and Time, 141.

${ }^{560}$ Rubenfeld, Freedom and Time, 141.

${ }^{561}$ To briefly restate Rubenfeld's primary legal thesis, Richard Church opens his critique by asking, from within a specifically American context, "why do nine Supreme Court Justices have the power to overturn the choices of a majority in a democratic nation? This question, known as the counter-majoritarian problem, has driven constitutional theory for the past 40 years," and "is the question at the heart of Jed Rubenfeld's" book. Rubenfeld's response, as Church sees it, is "that freedom and democracy require temporal extension, precluding either freedom or democracy from being reduced to the immediately present majority will of a people." Therefore, "checks on the immediate will of the people at the heart of constitutional judicial review are not only democratically permissible but a necessity," Richard P. Church, "Answering the Dispersed Self and Nation: A Response to Jed Rubenfeld's Freedom and Time: A Theory of Constitutional Self Government," in the Journal of Law \& Religion (Vol. XXI, 2006), 349. Church continues, Rubenfeld's most significant contribution lies in the fact "that democracy and constitutional commitments, are analogous to the achievement of personal freedom, selfhood, and moral agency, which he suggests also require temporal extension." This is what motivates Rubenfeld to first make his case for the nature of personal moral life as temporal before applying that argument by "analogy to the democratic nation," ibid. See also, Paulina Ochoa Espejo, The Time of Popular
} 
Rubenfeld's part, he emphasizes that "government by present voice is incompatible with law, because law can never be merely spoken. It requires a writing; it requires language preserved over time. Law is always written." ${ }^{562}$ He summarizes his thesis by contending that rule by the commitment of written law actually "reaffirms the central role of time and commitment in human freedom, human rationality-in human being itself." 563 Sherover concurs, "that my society provides the context within which my temporality is exercised is ... apparent," "for . . society is itself temporally constituted."564 This "shows, most prominently, in my language. Any language is not merely a mode of communication. It is an instrument for generational development," "the necessary condition for the accumulation of knowledge, customs, and evaluative norms to be handed on." "Language ... binds a community together" and "is its means for maintaining itself, in its living present, as a bond that is continuous with the past that it sees itself passing on to its posterity." ${ }^{\prime 56}$ For Sherover, it appears undeniable that "on whatever social level, all organization and all purposive activity is temporally structured." ${ }^{566}$ Rubenfeld agrees by sharing that "to achieve self-government a people must do more than seize the moment. A people must attempt the reigns of time." ${ }^{\prime 56}$

Rubenfeld illustrates this in the context of Constitutionalism by noting that "when originalism [that is, the interpretive method of trying to rule via the original historically rooted intentions of the law's creators] locates the authoritative democratic voice in a past moment, the values of legality are preserved. The two moments minimally necessary for the existence of law are now in place: one at

Sovereignty: Process and the Democratic State (University Park, PA: The Pennsylvania State University Press, 2011), 138-140.

${ }^{562}$ Rubenfeld, Freedom and Time, 86. Rubenfeld elaborates on this point by stating that "a people can govern itself only by both being governed by its past and governing its future.

"This double intrusion of past and future into present voice explodes the entire constellation of concepts behind the speech-modeled ideal. It explodes the picture of self-government as an ideal type of 'being in the present.' A people never governs itself in its own here and now. It will have governed itself in its own there and then if it successfully maintains its constitutional past and projects itself and its law into the future. A constitution can never be founded in a sublime moment from a revolutionary past. It can find its foundations only-in its own future," ibid.

563 Rubenfeld, Freedom and Time, 102.

${ }^{564}$ Sherover, Time, Freedom, and the Common Good, 46.

${ }^{565}$ Sherover, Time, Freedom, and the Common Good, 46.

${ }^{566}$ Sherover, Time, Freedom, and the Common Good, 50.

${ }^{567}$ Rubenfeld, Freedom and Time, 87. 
which law is established (the 'original' or founding moment) and another at which it is to be enforced (the present moment)." ${ }^{\prime 58}$ The effect of such a view is that "the present moment secures the virtues of legality only by giving up ... the right to rule itself by its own living voice," and accepting an authority from the past. ${ }^{59}$ In brief, the past, while never to be conflated with the present, must be kept 'alive' to secure the living generation's freedom for the future, though this does not mean the past must dominate the present or future, as if it totally limits it.

Rubenfeld's vigorous defense of a temporally extended view of law is not without its detractors, from many different angles, including some of those who deny we even possess free-will, ${ }^{570}$ and is in direct contrast to that of "presentism." ${ }^{571}$ Presentism represents what is probably the more popular opinion today, ${ }^{572}$ and many advocates of presentism insist that a weakness of temporally extended constitutionalism is that it is based too much upon "who the constitutional authors are, not on what they have authored, ${ }^{, 573}$ and as such brings in too much of the authors and their contexts into the text. Rather, for presentists, "in order to conceive of a relationship of allegiance based on the identity of the constitution's authors, rather than on its contents, and, at the same time, to take seriously the 'burden of judgement' concerning the legitimacy of the constitutional order, the author-based conception of legitimacy centers on the conceit that we, the observant citizen-readers, are 'identical' to those

\footnotetext{
${ }^{568}$ Rubenfeld, Freedom and Time, 87.
}

${ }^{569}$ Rubenfeld, Freedom and Time, 87. Rubenfeld points to a contradiction inherent in those who would render justice on the basis of "timeless truths." "As soon as democracy is rendered in the language of hypothetical consent or timeless truths, the actual truth is that the living have lost their speech-modeled right to be their own masters in the here and now," ibid. In other words, if one believes that the 'present will' of people should be based upon timeless truths that cannot be identified with a foundation in time, then the present evaporates, leading to a loss of control for those voices currently living, leaving those seeking to reconcile the 'present will' for the justification for rapid change upon a basis in 'timeless truths' caught in a contradiction.

${ }^{570}$ James B. Miles, The Free Will Delusion: How We Settled for the Illusion of Morality (Leicestershire, UK: Matador, 2015). Miles argues that "it is the conceit of [the idea of] freedom of the will that today ensures that so many at the bottom are denied any chance of social and economic advancement. Some free will theorists even argue that we need not be concerned with ideals of equality, fair play and opportunity," back cover.

${ }^{571}$ Jed Rubenfeld, Revolution by Judiciary: The Structure of American Constitutional Law (Cambridge, MA: Harvard University Press, 2005), 76-78, 90-97. For more on what "presentism" represents philosophically, see the section exploring the contributions of Parmenides and Heraclitus below in the appendix.

${ }^{572}$ Stephen M. Griffin, American Constitutionalism: From Theory to Politics (Princeton, NJ: Princeton University Press, 1996), 166. Griffin, himself no supporter of presentism, nevertheless claims that "American constitutional law implicitly embodies a presentist bias," ibid.

${ }^{573}$ Antoni Abat i Ninet, Constitutional Violence: Legitimacy, Democracy and Human Rights (Edinburgh, UK: Edinburgh University Press, 2013), 79. 
constitutional authors, ${ }^{\prime 574}$ which denies authentic personhood to those living today, as well as denying the living generation access to any newly discovered or realized 'self-evident' timeless truths which, in fact, are argued to have actually grounded the rationale of the United States in the first place. ${ }^{575}$ Thus, for presentists, the "true meaning of the Constitution' could be understood as something in the service of a priori notions of self-evident truths-or some other natural-law." ${ }^{n 76}$ To be clear, "it's not that these things" are to be "supplanted [by] the Constitution. It's that the Constitution was only 'true' to the extent that it accurately captured them. For some, this is precisely what a constitution was for-the reason why you would even have one, ${ }^{\prime \prime 77}$ because there are timeless 'self-evident truths.' Of course, the point is that if our understanding of what constitutes a timeless self-evident truth were to change from those conceived by the Founders as inscribed in the Constitution, then the Constitution becomes something we must overcome to find liberty, and not the protectorate of freedom. ${ }^{578}$

Of course, Rubenfeld is aware that much of what he proposes flies in the face of traditional understandings of rational discourse, and leave him trapped within the confines of certain necessary paradoxes which are preferable to the contradictions he sees in his opponents that relates to the reasoning process itself. ${ }^{579}$ Rubenfeld believes "that democracy cannot rationally pursue governance by present popular will, meaning that it ought rather to pursue governance by enduring popular

${ }^{574}$ Abat i Ninet, Constitutional Violence: Legitimacy, Democracy and Human Rights, 79.

575 The phrase, "we hold these Truths to be self-evident," from the Declaration of Independence, represents the very heart of the justification for the American experiment. That there is much controversy and discussion surrounding them and their actual meaning should probably be no surprise. See (no author), "We Hold These Truths": The Meaning of the Declaration: The Natural Rights Principles on which the Nation's Government is Based as Formulated in the Declaration of Independence (Culver City, CA: MindSparks, 2008), 10; Paul Aron, We Hold These Truths. ...: And Other Words that Made America (Williamsburg, VA: Rowman \& Littlefield, 2008); and Rob Wright, We Hold These Truths to be Self Evident.: Where is the Self in Government? (Raleigh, NC: 2013). For a copy of the founding documents for the United States of America, see The Declaration of Independence \& the Constitution of the United States (New York, NY: Bantam Dell, 2008).

${ }^{576}$ Sean Wilson, The Flexible Constitution (Lanham, MD: Lexington Books, 2013), 147.

${ }^{577}$ Wilson, The Flexible Constitution, 147.

${ }^{578}$ This is, essentially, the point of the progressive Beto O'Rourke, a candidate for the U.S. Senate in 2018. He openly asks, "Does this still work?" "Can [the U.S.] still be managed by the same principles that were set down 230-plus years ago?" As cited by David French, "Beto's Constitutional Folly," in National Review (January 16, 2019), at https://www.nationalreview.com/2019/01/betos-constitutional-folly/ (accessed January 16, 2019).

${ }^{579}$ Rubenfeld, Freedom and Time, 111; 103-130. Rubenfeld, Revolution by Judiciary: The Structure of American Constitutional Law, 96. 
commitments. Instead of a powerful argument from rationality against the possibility of collective self-governance, we have a powerful argument from rationality in favor of commitmentarianism,",580 or the rule of law via commitments (rather than merely originalism's "intentions" ${ }^{\text {"581 }}$ ). Rubenfeld argues that "rationality requires an actor faced with a problem of intransitive preferences to forswear acting on present will and instead to commit himself to a course of action." ${ }^{252}$ In other words, for Rubenfeld what actually constitutes social rationality and social freedom requires a commitment to $a$ course of action over time through the establishment of law. Any attempt to free oneself or a social community within a present moment or time, especially through appeals to any form or understanding of justice as a set of hypostatically timeless ideals or norms, ultimately enslaves and irrationalizes the individual and society. Thus, Rubenfeld believes, any idealized notion we may have that the present moment, and it alone, provides all the necessary data to presume that the will of the present majority represents an undebatably superior route to truth is suspect.

As in the economic debates above, there is a direct connection with the theories mentioned above and the general sentiments of the members of the "liberal" and "conservative" socio-political

\footnotetext{
${ }^{580}$ Rubenfeld, Freedom and Time, 115 (emphasis original).

${ }^{581}$ Technically, Rubenfeld argues for an intriguing modified version of originalism, which he calls commitmentarianism. See Rubenfeld, Freedom and Time, 184-185; and Rubenfeld, Revolution by Judiciary: The Structure of American Constitutional Law, 13-19, 71-124. In his view, if "the judiciary's essential task in constitutional cases is to hold the nation to its constitutional commitments, both originalism and the ahistorical schools of interpretation are necessarily flawed. Originalism wants judges to adhere to all original intentions, failing to see that some of these intentions-the No-Application Understandings-are not commitments and therefore command no special interpretive deference. By contrast, the ahistorical approaches (such as moralism and process-based interpretation) do not acknowledge the binding force of specific, substantive commitments laid down in the past, and therefore fail to see that some of the original understandings-the Application Understandings-remain inviolable," ibid., 19. Rubenfeld explains that "Constitutional rights are prohibitory (meaning that their function is to prohibit at least some acts by some actors). Let us say, as a shorthand, that a prohibitory law applies to those actions it prohibits, and that it does not apply to those actions it does not prohibit. So I will call specific understandings of what a constitutional right prohibits Application Understandings, and of what it does not prohibit, No-Application Understandings. Moreover, for reasons I will clarify later, I will call the original Application Understandings of a constitutional right its foundational or core applications.... Similarly, ... I will call Application Understandings any specific understandings of what such a provision authorizes, while the No-Application Understandings are specific understandings of what such a provision does not authorize, ibid., 14. See also, Walter M. Frank, Making Sense of the Constitution: A Primer on the Supreme Court and Its Struggle to Apply Our Fundamental Law (Carbondale, IL: Southern Illinois University Press, 2012), 193-194.

${ }^{582}$ Rubenfeld, Freedom and Time, 114. Rubenfeld is well aware that "the standard modern account of rationality, which is traceable at least to Hume and which dominates contemporary decision theory, economics, and much analytic philosophy, holds action to be rational if it maximizes satisfaction of the agent's present aims or preferences," ibid., 117.
} 
and legal philosophies in the United States. For example, many liberals advocate for the Constitution of the United States to be viewed as an evolving or "living document," subject to the whims of the wisdom contained within the people living in the present moment (presentism). Here, it must be understood that the word 'living' is not intended as a reference to its continuing relevance or validity, ${ }^{583}$ but rather 'living' means open to reinterpretation according to the present context. Opponents of a "living Constitution" are referred to as "originalists," or those who seek to uphold the Constitution's meaning as it was written in its original historical context. Thus, the two groups may be described as those advocating an evolving "living Constitution" or a previously "written Constitution." ${ }^{584}$

Advocates of the "living document" theory believe that certain legal language must be interpreted differently as history unfolds and circumstances change. Defenders of an "originalist" view of a written Constitution, which is the position Rubenfeld conditionally supports through a

${ }^{583}$ Louis E. Wolcher, Law's Task: The Tragic Circle of Law, Justice and Human Suffering (New York, NY: Routledge, 2016), 169-209. The two dominant conceptions of time in the Western tradition are that of linear time and existential time, neither of which is truly Heideggerian. "The contrast between linear time and existential time allows us to notice a peculiar inconsistency or paradox in Western thought: $(a)$ the belief that authoritative religious and legal norms can produce meaning and provide support for the rightness of right action is best grounded in the idea of linear time; and yet $(b)$ the belief that it is possible for human beings to escape fate and freely choose their own destinies is best grounded in the idea of existential time," ibid., 188-189. The "living Constitution" reflects this paradox-appealing to timeless norms that are inaccessible in the flux of existential time.

${ }^{584}$ Daniel Lessard Levin, Representing Popular Sovereignty: The Constitution in American Political Culture (Albany, NY: State University of New York Press, 1999), 99. 
modified (very Heideggerian ${ }^{585}$ ) and complex version of it, "commitmentarianism," sharing that if a law's words need to be changed, or a new law created, then do so appropriately through the democratic process, paying heed to serious past commitments, rather than legislating from the judicial bench. ${ }^{587}$ The point is, at the core, it is the intersection of how freedom and time are involved in the art of interpretation and the appeal to a view of ethical justice that then impacts upon concepts of law and democracy, which creates the conflict. Lastly, it is noteworthy that religion engages the above issues in at least two important ways, as explained in the next section.

\section{The Place of Religion within the Socio-Political Sciences}

There are two important observations to make about the relationship of religion to the contemporary socio-political sciences. First, one or the other of the two general views of legal theory

\footnotetext{
${ }^{585}$ Note the focus on commitment and temporality by Rubenfeld that is attributed to Heidegger. For more on Heidegger's own emphasis on commitment and temporality, see Edward Joseph Echeverria, Criticism and Commitment: Major Themes in Contemporary 'Post-critical' Philosophy (Amsterdam, The Netherlands: Rodopi, 1981), 177. "Heidegger draws a distinction between the sense of the past as Vergangenheit, a state of affairs where some entity once present is gone for good, and the sense of the past as Gewesenheit, a 'having been' which still conditions the 'is'. Man is a historical being with a past in the sense of Gewesenheit, and this past, a 'having been', is an essential aspect of 'what' Dasein is and will be. By introducing these two different senses of the past, Heidegger seeks to restore a positive relation to the historical past, one that does not make the 'presence' of the subject alien to history," ibid. Note also, James Luchte, Heidegger's Early Philosophy: The Phenomenology of Ecstatic Temporality (New York, NY: Continuum International Publishing, 2008), 146. Luchte explains on behalf of Heidegger, "in its freedom, Dasein is responsible to itself, it gives itself a possibility of commitment. Its commitments are its 'world'. Dasein in its situated freedom projects 'world', it holds itself in this world as that which is binding to itself, a counter hold that preserves a self-chosen commitment.... The world is a 'nothing'- not a 'thing' in the world, but instead a projection of temporal commitments amid ecstatic temporality," ibid.

${ }^{586}$ For Rubenfeld's original statement of his position, see Jed Rubenfeld, "Reading the Constitution as Spoken," in Yale Law Journal 104 (1995), 1119-1185. For a brief critique and commentary on Rubenfeld's view, see Abner S. Greene, Against Obligation: The Multiple Sources of Authority in a Liberal Democracy (Cambridge, MA: Harvard University Press, 2012), 181-187.

${ }^{587}$ For various perspectives on the issues relating to originalism and presentism, see Dennis J. Goldford, The American Constitution and the Debate Over Originalism (Cambridge, UK: Cambridge University Press, 2005), 55-76; Peter Ludlow, Living Words: Meaning Underdetermination and the Dynamic Lexicon (Oxford, UK: Oxford University Press, 2014), 64-65; David A. Strauss, The Living Constitution (Oxford, UK: Oxford University Press, 2010); Ron Paul, The Revolution: A Manifesto (New York, NY: Grand Central Publishing, 2008); Jack M. Balkin, Living Originalism (London, UK: Belknap Press, 2011), 3-4; Ronald Dworkin, Freedom's Law: The Moral Reading of the American Constitution (Oxford, UK: Oxford University Press, 2005), 4; James A. Curry, Richard B. Riley, and Richard M. Battistoni, Constitutional Government: The American Experience $5^{\text {th }}$ ed. (Dubuque, IA: Hunt Publishing, 2003), 110; John W. Compton, The Evangelical Origins of the Living Constitution (Cambridge, MA: Harvard University Press, 2014); Robert H. Bork, The Tempting of America: The Political Seduction of the Law (New York, NY: Touchstone, 1991); and Antonin Scalia and Bryan A. Garner, Reading Law: The Interpretation of Legal Texts (Rochester, New York: Thomson/West, 2012).
} 
are often favored by each side of the ongoing culture wars in America, ${ }^{588}$ here specifying the Religious

Right (conservative Republicans) who favor Constitutional “originalism," ${ }^{589}$ and the Religious Left

(progressive Democrats) who favor an evolving "living" Constitution. ${ }^{590}$ Both interpretations

\begin{abstract}
${ }^{588}$ See my own preliminary evaluation of the situation in Younker, "The American Socio-Political Spider Web and the Rise of Global Christianity," 132-188. The American culture war between "conservatives" and "progressives" is thus distinct from, but also very much related to, the culture wars between the sciences and the humanities. Each side of the American culture war replicates elements of the sciences and humanities division in complex ways I cannot detail here, though it is true that the Right favors the "humanities" over the Left's favoring of the "sciences." Of course, it is much more complex than this, as each side has replicated its own internal divisions for various issues, thus representing a furthering of the replication effect for all Christians and secularists on either side of broader cultures wars at the social level. Put simply, as will be seen, both the Right and Left can be equally scientific/Platonic or anti-platonic. For example, the Moral and Social Gospels, respectively, are both Platonic ethical constructs that advocate for 'timeless' legal results. That is, through better planning and scientific-calculative machinery, the church and society can be engineered into perfection according to a prior timeless legal ethical template.
\end{abstract}

For an interesting recent analysis with statistics, see Kevin Quealy, "Your Rabbi? Probably a Democrat. Your Baptist Pastor? Probably a Republican. Your Priest? Who Knows," at https://www.nytimes.com/ interactive/2017/06/12/upshot/the-politics-of-americas-religious-leaders.html?src=twr\&_r=0 (accessed June 12, 2017). For more on the American/Western culture wars, see James Davison Hunter, Culture Wars; The Struggle to Define America: Making Sense of the Battles over the Family, Art, Education, Law, and Politics (New York, NY: Basic Books, 1991); Jonah Goldberg, Liberal Fascism: The Secret History of the American Left, From Mussolini to the Politics of Change (New York, NY: Random House, 2007); Daniel J. Flynn, A Conservative History of the American Left (New York, NY: Random House, 2008); George Hawley, Right-Wing Critics of American Conservatism (Lawrence, KS: University of Kansas Press, 2016); David P. Gushee, The Future of Faith in American Politics: The Public Witness of the Evangelical Center (Waco, TX: Baylor University Press, 2008); and Jonathan Haidt, The Righteous Mind: Why Good People are Divided by Politics and Religion (New York, NY: Vintage Books, 2013). It is also important to add that, from a broad perspective, as Paul Hollander observes, it "is not a peculiarly American or capitalist phenomenon but one that is central to modernity and secularization which lead to 'the growing determination to live for the moment,'” Paul Hollander, Anti-Americanism: Irrational \& Rational (New Brunswick, NJ: Transaction Publishers, 2003), 75.

${ }^{589}$ Stephen M. Engel, American Politicians Confront the Court: Opposition Politics and Changing Responses to Judicial Power (New York, NY: Cambridge University Press, 2011), 338. "Originalism is said to legitimize judicial constitutional interpretation because it provides a strict underlying interpretive principle: interpretation must be grounded in the text of the Constitution, which represents the singular and precise act of popular sovereignty [at a particular moment in time]. That act fixed the meaning of the text, and that original meaning always trumps meanings that might have been given to it by subsequent generations.... Of course, what counts as evidence of this original meaning is hotly debated among contemporary originalists," ibid. Importantly, in the contemporary context, what is noteworthy is that "the Reagan administration latched onto it as the constitutional vision of the contemporary Republican Party," ibid. Of course, it must also be remembered that the purpose, in the minds of Republicans, of their philosophy is to "make men free." See Heather Cox Richardson, To Make Men Free: A History of the Republican Party (New York, NY: Basic Books, 2014). See also, Lewis L. Gould, Grand Old Party: A History of the Republicans (Oxford, UK: Oxford University Press, 2003); Eric Foner, Free Soil, Free Labor, Free Men: The Ideology of the Republican Party Before the Civil War (Oxford, UK: Oxford University Press, 1995); Ben Carson, America the Beautiful: Rediscovering What Made This Nation Great (Grand Rapids, MI: Zondervan, 2012), 39; and Ben Carson, One Nation: What We Can All Do To Save America's Future (New York, NY: Penguin Group, 2014), 175-179.

${ }^{590}$ For more, see, for example, the discussions in Eric R. Claeys, "The National Regulatory State in Progressive Political Theory and Twentieth-Century Constitutional Law," in Modern America and the Legacy of the Founding, eds. Ronald J. Pestritto and Thomas G. West (Lanham, MD: Lexington Books, 2007), 37, 69; Arthur W. Hunt III, The Vanishing Word: The Veneration of Visual Imagery in the Postmodern World (Eugene, OR: Wipf \& Stock, 2003), 225; Marie Stacey, The Election of Ideologies: Do You Know Where You Stand? (New York, NY: iUniverse, 2008), 59; Steven H. Shiffrin, The Religious Left and Church-State Relations (Princeton, NJ: Princeton University Press, 2009), 14, 47; Jim Hester, Fourth and Long: Making America a Championship Team 
obviously have implications for their competing views of religious freedom. Second, there is a direct

parallel between how each side attempts to interpret the Bible, which can be compared, as a legal

text, to the American (or any other nation's) Constitution. ${ }^{591}$

Biblical originalists believe the Bible should be interpreted in a way that seeks after the original

intentions (sometimes, of course, including an ironically reductionistic platonic-like timeless inerrant

understanding of the given truths) and context of the author(s), while more progressive liberal

perspectives push for the Bible to be viewed as a "living" text, adapting and changing according to the

majority consensus or subjective 'evidence of the day' in which the reader currently lives, ${ }^{592}$

(Indianapolis, IN: Dog Ear Publishing, 2007), 23-24; Norman Geisler and Frank Turek, Legislating Morality: Is it Wise? Is it Legal? Is it Possible? (Eugene, OR: Wipf \& Stock, 1998), 105-106; Mark C. Miller, The View of the Courts from the Hill: Interactions between Congress and the Federal Judiciary (Charlottesville, VA: University of Virginia Press, 2009), 111; Frederick S. Lane, The Court and the Cross: The Religious Right's Crusade to Reshape the Supreme Court (Boston, MA: Beacon Press, 2008), 84; Richard A. Epstein, How Progressives Rewrote the Constitution (Washington, D. C.: Cato Institute, 2006); Richard A. Epstein, The Classical Liberal Constitution (Cambridge, MA: Harvard University Press, 2014); David Horowitz, Take No Prisoners: The Battle Plan for Defeating the Left (Washington, D. C.: Regnery Publishing, 2014); Ellis Washington, The Progressive Revolution: History of Liberal Fascism through the Ages Vo. 5 (Lanham, MD: Hamilton Books, 2017), 24, 412-414; Douglas E. Schoen, Hopelessly Divided: The New Crisis in American Politics and What It Means for 2012 and Beyond (Lanham, MD: Rowman and Littlefield, 2012), 137; and James Lane Buckley, Freedom at Risk: Reflections on Politics,

Liberty, and the State (New York, NY: Encounter Books, 2010), 99-108. For a perspective directly addressing the issue in relation to religious liberty, see Andrew Koppelman, Defending American Religious Neutrality (Cambridge, MA: Harvard University Press, 2013). Also, for a critique from a more critical conservative who sees the "living Constitution" in both sides, see Bradley C. S. Watson, Living Constitution, Dying Faith:

Progressivism and the New Science of Jurisprudence (Wilmington, DE: ISI Books, 2009).

${ }^{591}$ See, for example, R. C. Sproul, Knowing Scripture (Downers Grove, IL: InterVarsity Press, 2009), 4951; Thomas C. Grey, "The Constitution as Scripture," in the Stanford Law Review 37 (1984), 1-14; and Herman Philipse, "Antonin Scalia's Textualism in Philosophy, Theology and Judicial Interpretation of the Constitution," in Holy Writ: Interpretation in Law and Religion, ed. Arie-Jan Kwak (New York, NY: Routledge, 2016), 15-46. See also, Aharon Barak, Human Dignity: The Constitutional Value and the Constitutional Right, tr. Daniel Kayros (Cambridge, UK: Cambridge University Press, 2015), esp. 70-72.

592 John Hoffman claims that "a theology of hope [unfortunately] ... does not escape from the past. In its promise-hope image, it leaves the future too dependent upon the past and fails to take seriously the presentfuture dimension and thus the role of experience," John Charles Hoffman, Law, Freedom, and Story: The Role of Narrative in Therapy, Society, and Faith (Waterloo, ON: Wilfrid Laurier University Press, 1986), 130. Where Hoffman takes this notion, however, is important. Hoffman observes that "Martin Luther and the Protestant Reformation represented a rebellion against the nomic tyranny of ecclesiastical structures and defined faith, a rebellion expressed by Luther in his appeal to the Bible as the Word of God. Yet this, in turn, has taken form in new idolatry of the past. Scripture has become the divine nomos, the new rigidity," from which we must now escape, ibid., 129. Similarly, Tom Driver advocates that Christianity deliver itself from a theology of hope rooted in the Christ of the first century and his teachings, Tom Driver, Christ in a Changing World: Toward an Ethical Christology (Hertford, NC: Crossroad, 1981). For Driver, however effective the Bible may have been in the past at expressing the truth, "it cannot" provide "the adaptive and creative strategies which are necessary now for the survival of humanity on earth,"” ibid., 83. Similarly, Hoffman questions why "must we assume that the 'infinite commitment of God to human finitude' in Jesus indicates something done but once and once only for all time" which "imprisons God within the likeness of Jesus?" Hoffman, Law, Freedom, and Story, 130; Driver, Christ in a Changing World, 60. Driver and Hoffman want a "transnomic" Christianity that rejects "any kind of pastgiven order or structure, which limits [our] present conceptualization. Nomic Christology is not able to respond 
emphasizing the "now" (and also the scientific ideal of progressive yet also platonically-timeless like truth $^{593}$ ) and incorporating various "reader-response" theories. ${ }^{594}$ Overall, in any case, as the constitutional scholar Akhil Amar so clearly stated it, “America's Constitution embodies a particularly expansive temporal ambition," and this must be kept foremost in our minds because "like other creatures, humans live every moment in the moment, but unlike the rest of God's creation, we humans also consciously and conscientiously plan for the distant future, not just for ourselves but for our posterity." ${ }^{295}$

In summary, throughout the socio-political sphere, in both the secular and religious contexts, the issues of freedom and time are at the core of the polarizing divides that face society today. Such divides include legal interpretive theories, as well as religious interpretive theories insofar as they intersect with the secular State. Religionists, once again, appear to be replicators of a secular divide. Currently, it appears this polarizing trajectory will continue indefinitely, and it appears no pathway exists for any harmonization or reconciliation.

\section{Summary on the Third Culture Crisis and the Failure to Find a Place for Religion}

Overall, then, within the paradigmatic mediating third cultures of psychology and psychiatry, economics, and the socio-political sciences, the same can be said of each-it is, fundamentally, their differing utilization of the concepts of freedom and time that divides how their respective specialists approach each of these disciplines at a foundational level. Of course, many attempt, consciously or

adequately to the new" situations and contexts that we as individuals and communities face, Hoffman, Law, Freedom, and Story, 130; Driver, Christ in a Changing World, 47.

${ }^{593}$ Put concisely, for many contemporary progressives who emphasize science, truth is "timeless" and our 'temporal' journey to this timeless truth is dominated by how we perceive said truth in the timeless present "now." Time, then, is reinterpreted as a burden of some sort, a necessary baggage that accompanies our pursuit of "timeless truth" through the most important time, which is the "timeless present now."

${ }^{594}$ For more, see Robert L. Plummer, 40 Questions about Interpreting the Bible (Grand Rapids, MI: Kregel, 2010), 128; Robert M. Fowler, Let the Reader Understand: Reader-Response Criticism and the Gospel of Mark (Harrisburg, PA: Trinity Press International, 1996); Richard N. Soulen and R. Kendall Soulen, Handbook of Biblical Criticism, $3^{\text {rd }}$ ed. (Louisville, KT: Westminster John Knox Press, 2001), 156-158; and John M. Court, "Introduction," in Biblical Interpretation: The Meanings of Scripture-Past and Present, ed. John M. Court (New York, NY: T\&T Clark, 2003), 8. Court explains that a "literary critical reading [of Scripture], or reader response," is "essentially a present-day dialogue with the biblical text," ibid.

${ }^{595}$ Akhil Reed Amar, The Constitution Today: Timeless Lessons for the Issues of Our Era (New York, NY: Basic Books, 2016), 19. 
unconsciously, to inhabit both sides of the two cultures, with questionable success. Indeed, it is important to point out that there is not necessarily a consistency within the views held by various individuals amongst the differing third cultures, that is, it is possible someone may favor a more scientific approach in one area, like economics, while a less scientific approach in another, such as psychology.

This suggests a number of subtle and contradictory dualisms likely exist in the minds and worldviews of many scholars-it is not necessarily easy to be consistently temporal or timeless, or free or determined, in one's orientation in every field (nor would I wish to imply, at this particular juncture, that it is necessarily "better" or "worse" to hold such subtle dualisms in one's worldview). Indeed, an important observation that must be shared here is that many people in the popular and scholarly worlds might have mistakenly assumed that timelessness (that is, determinism and objective certitude) would be most naturally associated with right-leaning "conservatives" and the emphasis of the sciences in modernism (a link which is somewhat correct at times, though very misleading), and that the subjective temporality (freedom and subjectivity) and progressivism of the humanities would fit more logically with "liberal" or left-leaning postmodernism. However, this is, in fact, not correct in the critical third cultures, as has been established above. ${ }^{596}$ The influence of

\footnotetext{
${ }^{596}$ Indeed, there are two major and popular exceptions to the above pattern that I have presented of the third cultures, in which I have divided conservatives and liberals into two opposing camps. To some it may seem a surprise to see "temporality" of a Heideggerian sort associated with conservatives, and liberals or progressives associated with "timelessness." In response to such an observation, I would concur that it is true that many conservative or "right" leaning Christians, like neo-Calvinists, would clearly disavow Heidegger and support timelessness in their general view of God and reality (including science), even if they support, for example, what I've labeled Heideggerian socio-economic ideas. See, for example, Ronald H. Nash, The Light of the Mind: St. Augustine's Theory of Knowledge (Lima, OH: Academic Renewal Press, 2003); Nash, Poverty and Wealth: The Christian Debate Over Capitalism; and Gordon H. Clark, A Christian View of Men and Things: An Introduction to Philosophy (Jefferson, MD: The Trinity Foundation, 1991), for two such "moderate" conservatives who are theological Platonists but economic Heideggerians, at least pragmatically. Additionally, it is also true that many of those in the "postmodern arts" and even theology certainly could be described as supporting a more temporal or non-scientific view of their discipline, even as they often lean to the "left" socio-economically. Note, for example, Jeffrey W. Robbins, Radical Theology: A Vision for Change (Bloomington, IN: Indiana University Press, 2016), 44-52, for a Leftist-communist advocate of Heideggerian thought. While these realities are true, such oddities are to be expected as reduplications of the complex tensions between freedom and time that are indeed replicated in every major discipline and culture. For example, Heidegger himself is the father of 'postmodernism,' a 'liberal' development, but was also connected with Nazism, a 'Right' leaning movement. As they say, "it's complicated" sometimes and a simple analysis of a situation often only illuminates part of the picture! Nevertheless, the way I have attempted to frame the debate, and what the data reveals, within the third cultures, is, I believe, more insightful in cutting to the heart of the tensions concerning freedom and time as they are being presented in the contemporary $21^{\text {st }}$ century context.
} 
science has dominated the third cultures, even in the era of postmodernism, as now seen clearly within post-postmodernism, inverting the expected correlations between timelessness and temporality in the contemporary third cultures, even while preserving them within other aspects of contemporary cultures (e.g., theology and religion itself).

In other words, the Religious Right and secular Left are equally inclined toward the timelessness of objective absolutes, whereas the secular Right and Religious Left contain more elements of temporality. ${ }^{597}$ Alternately put, it appears the dominant extremes of both the Right and Left incline more and more toward timelessness, ${ }^{598}$ while moderates are more likely to embrace forms of temporality. Of course, there are crossovers between the various sub-groups of the above categories in complex ways that cannot be detailed here, but the tendencies persist. In any case, the point should not be lost that for ironic reasons, it is clear that likely both extremes of the polarization which incline toward timelessness are neglecting to fully consider critical parts of the overall situation-and thus it is no wonder that their alienation seems at times the most extreme. That is, certain advocates of moral (Rightist) absolutism and (Leftist) scientism maintain their conflict despite sharing similar conceptions of freedom and time. Of course, in all likelihood either one or both of these two ideological positions misinterpret their data or overstate their arguments on certain points-but this cannot be examined here.

The work of Bohm and Pylkkö must be understood within the tensions depicted above. It is precisely the conflict within the third culture which illustrates the need for deeper, more reflective

\footnotetext{
${ }^{597}$ Though it may be a rarer position, and one grounded with an openness toward agnosticism, nevertheless, as Shriffrin pointed out, "it would be possible to believe in liberal theology and conservative politics, but that combination is not much alive on the American political scene." In any case, moderate or somewhat secular conservatives do exist and some of them qualify for the group of theologically liberal yet politically 'conservative' individuals found in some strains of libertarianism or classical liberalism. Shiffrin, "The Religious Left and Church-State Relations: A Response to Kent Greenawalt and Bernie Meyler," 762.

${ }^{598}$ Again, I would recommend my own study to help illustrate this phenomena. See Younker, "The American Socio-Political Spider Web and the Rise of Global Christianity." See also, Gary L. Drescher, Good and Real: Demystifying Paradoxes from Physics to Ethics (Cambridge, MA: Massachusetts Institute of Technology, 2006), 5-7. Drescher observes correctly that quantum physics has helped inspire a "convergence between positivism and relativism" that "is a bit reminiscent of the way extreme left-wing politics sometimes resembles its right-wing counterpart," ibid., 5-6. Notably, Drescher considers the empiricist-positivist (objectivist) Bertrand Russell part of the left or liberal side of politics, whereas Heidegger is seemingly labeled part of the (subjectivist) right side associated with conservative culture.
} 
thinking, of the sort that Bohm and Pylkkö provide. Only at the level of reflection they offer can one hope to find a way to move beyond the impasse within the third culture, which has, thus far, had its foundational concepts dictated to it by the broader two cultures which are in conflict. Therefore, the crisis within the third culture can only be addressed by those who have an awareness of the broader situation ailing the two cultures. The link between the more practical third cultures and philosophy has thus been established. The question remains, of course, what role theology or religion might have in any resolution to the conflict. At the same time, however, the replication within religion of a secular philosophical conflict should force secularism into a position of humility, as well, as it too has offered no solution to the conflict. ${ }^{599}$

${ }^{599}$ Jacques Berlinerblau, The Secular Bible: Why Nonbelievers Must Take Religion Seriously (New York, NY: Cambridge University Press, 2005). 


\section{CHAPTER 3}

\section{DAVID BOHM'S VIEW ON THE RELATIONS OF FREEDOM AND TIME}

\section{Introduction}

The purpose of this chapter is to examine the work of David Bohm concerning his view on the concepts of freedom, time, God, and their interrelationships. To do so, first I will provide a biographical sketch of Bohm and explain the value of his published ideas within the context of the two cultures and the scientific contributions of Einstein. Next I will examine Bohm's view of time, both for nature and the humanities, and then Bohm's view of freedom, both for nature and the humanities, and follow that by explaining the relations of freedom and time within his published work. After this, I will detail his views on the concept of God and their value for continuing theological reflection, especially as they might pertain to freedom and time. Lastly I will evaluate the coherence of Bohm's ideas concerning freedom and time before providing my concluding thoughts on his contributions.

\section{Biographical Sketch}

David Bohm's life represents an interesting, and tragic, story, and one worthy of touching upon before introducing and examining his ideas about science, freedom, time, and the divine. Indeed, as has been recently observed, biography has been a neglected part of philosophical research, and thus this study would be remiss to neglect highlighting those portions of Bohm's life that illustrate the connections between one's living context and the ideas one develops while a scientist or philosopher. $^{600}$ Noteworthy is that a sympathetic biography of Bohm's life and work has already been

\footnotetext{
${ }^{600}$ Typically, "historians of science are remarkably silent about biography as a product of and contributor to the social and political formation of modern science and its identities.... Individual lives-either embodied life trajectories or literary representations of such trajectories-do not have a real habitation in the professional reflection about science in history and culture; biography seems to be the ugly duckling in today's discussions about historiographical approaches and science studies methodologies," Thomas Söderqvist,
} 
written by a friend and collaborator, F. David Peat, Infinite Potential: The Life and Times of David Bohm. ${ }^{601}$ Below I will provide an overview of the pertinent details of Bohm's life and work insofar as they help position his academic contributions on freedom and time.

Born in Pennsylvania in 1917 to a family of humble means, Bohm eventually studied under the eminent physicist J. Robert Oppenheimer (who helped develop the atomic bomb) at the University of California at Berkeley, and received his Ph.D. at the age of 26 in 1943. While still a graduate student, he discovered a particular collective movement of electrons in a plasma, which came to be called the Bohm-diffusion, drawing some attention to his name, and establishing his reputation as a promising young physicist. ${ }^{602}$ Later, in 1951, then employed at Princeton University, Bohm published the first of his books, Quantum Theory ${ }^{603}$ (1951), which soon afterward became one of the standard textbook expositions of the orthodox Copenhagen interpretation of quantum physics, which had been so named after Niels Bohr's science labs in Copenhagen during the 1920's and 30's. Bohm sent copies of his new book to several of the well-known physicists of his day, but most of them ignored his kindly personal gesture at the time and declined to return any feedback. One exception was Albert Einstein, his senior colleague who was also working at Princeton, and who wrote back to Bohm and shared with him that "he had never seen quantum theory written and explained as clearly and concisely"604 as what Bohm had done, and invited him over to discuss Bohm's book, ${ }^{605}$ and several more conversations soon followed.

Both Bohm and Einstein expressed to each other their dissatisfaction with the predominant Copenhagen view, of which Einstein never offered support, and its explicit acceptance of

"Introduction: A New Look at the Genre of Scientific Biography," in The History and Poetics of Scientific Biography, ed. Thomas Söderqvist (New York, NY: Ashgate Publishing, 2016), 3.

${ }^{601}$ Peat, Infinite Potential: The Life and Times of David Bohm.

${ }^{602}$ Detlef Dürr, Sheldon Goldstein, Roderich Tumulka, and Nino Zanghì, "David Bohm," at http://www.mathematik.uni-muenchen.de/ bohmmech/rt/bohmbio.pdf (accessed February 15, 2017). See also, Chandrankunnel, Philosophy of Quantum Mechanics: Quantum Holism to Cosmic Holism: The Physics and Metaphysics of Bohm, 4.

${ }^{603}$ David Bohm, Quantum Theory (Englewood Cliffs, NJ: Prentice-Hall, 1951).

${ }^{604}$ According to A. R. Bordon, Ultimate Thought: Life in a Bicausal Universe (Morrisville, NC: Lulu Press, 2010), 7.

${ }^{605}$ Max Jammer, Einstein and Religion: Physics and Theology (Princeton, NJ: Princeton University Press, 1999), 227. 
indeterminism and a paradoxically dualistic complementarity in nature. ${ }^{606}$ Although Einstein and Bohm would later part ways philosophically, particularly over the issue of nonlocality, Bohm acknowledged the profound influence these discussions with Einstein had on him to seek a fully causal and deterministic theory of quantum mechanics. Thus, although Einstein would disagree with the direction Bohm later took to create such a theory, they were united on a basic desire for a more complete, that is, causal and deterministic, picture of quantum behavior than what the Copenhagen interpretation offered. They felt this was necessary to preserve reality as objectively "real," and avoid anti-realism or outright subjectivism. This is because the randomness contained within Copenhagen interpretation is generated through the uncertainty of location, which simultaneously generates the possibility of nonlocality-that is to say, as some interpret it, during the 'pause' of a particle's uncertain location, the particle doesn't actually exist anywhere specifically, but potentially exists in more than one place-as such it is not considered empirically local and 'real.'

Shortly after Bohm's early conversations with Einstein, in 1952 Bohm formulated and published his first attempt of an alternative interpretation of quantum theory that would preserve causal temporal determinism and realism, via the existence of what he termed "hidden variables" ${ }^{\prime 67}$ that accommodated the phenomenally nonlocal activity of quantum particles, which some have labeled 'neorealism.' ${ }^{608}$ In fact, it was merely a reformulation of an earlier attempt to do the same by Louis de

\footnotetext{
${ }^{606}$ Chandrankunnel, Philosophy of Quantum Mechanics: Quantum Holism to Cosmic Holism: The Physics and Metaphysics of Bohm, 4.

${ }^{607}$ David Bohm, "A Suggested Interpretation of the Quantum Theory in Terms of 'Hidden Variables,'” Physical Review 85 (1952), 166-193.

${ }^{608}$ Paul L. Nunez, Brain, Mind, and the Structure of Reality (Oxford, UK: Oxford University Press, 2010), 239. As such, the "subtle" but "major distinction between the Bohm and Copenhagen interpretations" is this: " $A$ Bohm particle actually has a definite location at a certain time even though we can never know its exact location because of uncertainty caused by multiple nonlocal influences [which are presently hidden]. This is the basis for the label 'neorealism.' The behavior of a Bohm quantum particle is then somewhat analogous to a classical gas molecule being rapidly bumped unpredictably by other molecules, but with major differences: (1) The Bohm quantum particle may be 'bumped' (nonlocally) by particles at arbitrarily large distances. (2) The so-called 'bumps' are not random; they occur according to quantum principles and depend critically on the measuring device. (3) 'Bumps' need not add significant energy to the Bohm particle; rather, they guide the manner of energy use, analogous to the role of messenger RNA in protein synthesis in living cells. In philosophical terms, the Copenhagen interpretation focuses more on epistemology (how knowledge is obtained), whereas Bohm's formalism focuses more on ontology (what is actually true)," ibid., 239. In summary, "in traditional [Copenhagen] quantum mechanics, the uncertainty principle is taken as a fundamental property of the universe" associated with the "strange collapse of the wavefunction" via measurement, as such, "no further explanation is deemed possible. By contrast, Bohm[ian] mechanics 'explains' the uncertainty principle in terms of
} 
Broglie's 1927 pilot-wave model, of which Bohm had been previously unaware, but Bohm, more so than de Broglie, fully appreciated the philosophical significance of such an alternative interpretation. ${ }^{609}$ The reception to his interpretation, while deemed mathematically impressive, was less than tepid, and his theory did not attract any serious attention by mainstream practicing physicists. Notwithstanding this, however, it is important to note that just a few years after his conversations with Einstein in 1959, Bohm, this time with another colleague in England, where Bohm had since relocated, helped experimentally establish that quantum physics does indeed support nonlocal correlations in magnetic fields with electrons, and the Aharonov-Bohm effect, again named after him, remains intensively studied ${ }^{610}$ and his efforts here again granted him continuing credit as a serious physicist. This situation would change, however.

As time passed, alongside his more technical articles, which he continued to publish, especially during the 50's, Bohm continued to explore his new alternative causal interpretation, which came to be known as Bohmian Mechanics (BM), and its philosophical consequences, of which the reception by others remained less than welcoming. Contemporary experiments during his life seemed to have refuted certain aspects of Bohm's theory, such as the predicted and confirmed violation of John Bell's inequality theorem, which rules out local hidden variable theories, but defenders of Bohm note that his theory does not require local hidden variables, and is compatible with nonlocality-it is a non-local hidden variables theory. ${ }^{611}$ Noteworthy is that Bell was actually sympathetic to Bohm's work. ${ }^{612}$ In any case, throughout the following decades of the 70's and 80's, Bohm introduced some new physicalphilosophical terminology to describe what he believed to be a more accurate description of the totality of reality, which culminated with him generally de-emphasizing, though not abandoning, the terminology of "hidden variables" and a causal interpretation of quantum mechanics in favor of his

unpredictable nonlocal influences, potentially from distant parts of the universe," ibid., 239.

${ }^{609}$ Dürr, Goldstein, Tumulka, and Zanghì, "David Bohm."

${ }^{610}$ Dürr, Goldstein, Tumulka, and Zanghì, "David Bohm."

${ }^{611}$ James T. Cushing, "The Causal Quantum Theory Program," in Bohmian Mechanics and Quantum Theory: An Appraisal, eds. James T. Cushing, Arthur Fine, and Sheldon Goldstein (Dordrecht, The Netherlands: Springer, 1996), 1-21; 6.

${ }^{612}$ Bell, “Speakable and Unspeakable in Quantum Mechanics,” 1-2. 
introduction of a timeless "Implicate Order"613 and the holomovement or holoflux ${ }^{614}$ in the 80 's as a fuller ontological theory of nature and reality, which continued receiving a number of subtle modifications until he passed away in 1993.

It was mostly during his latter career that Bohm began to author, and co-author, his more philosophical articles and books, starting first with Causality and Chance in Modern Physics ${ }^{615}$ (1957), which was then followed by several more philosophical works in the 80 's and 90 's, with the most prominent being Wholeness and the Implicate $\operatorname{Order}^{616}$ (1980), Unfolding Meaning ${ }^{617}$ (1985), The Ending of Time: Where Philosophy and Physics Meet ${ }^{618}$ (1985; with Jiddu Krishnamurti), Science, Order, and Creativity ${ }^{619}$ (1987; with F. David Peat), Changing Consciousness: Exploring the Hidden Source of the Social, Political and Environmental Crises Facing our World ${ }^{620}$ (1991; with Mark Edwards), Thought as a System ${ }^{621}$ (1992), and, finishing the final touches on the book with his co-author the week he died, The Undivided Universe: An Ontological Interpretation of Quantum Theory ${ }^{622}$ (1993; with B. J. Hiley). Following his death, some collections of dialogues and letters he had exchanged with friends and other materials of his were also published. ${ }^{623}$

The story of Bohm's transition from a mainstream laboratory physicist working with Oppenheimer, to writing in support of the standard Copenhagen interpretation, and then conversing

${ }^{613}$ Specifically, David Bohm, "Hidden Variables and the Implicate Order," Zygon 20 (1985), 111-124.

${ }^{614}$ Mark A. Schroll, “Understanding Bohm's Holoflux: Clearing Up a Conceptual Misunderstanding of the Holographic Paradigm and Clarifying its Significance to Transpersonal Studies of Consciousness," in the International Journal of Transpersonal Studies Vol. 32 \# 1 (2013), 140-163.

${ }^{615}$ David Bohm, Causality \& Chance in Modern Physics (New York, NY: Routledge, 1957).

${ }^{616}$ Bohm, Wholeness and the Implicate Order.

${ }^{617}$ David Bohm, Unfolding Meaning: A Weekend of Dialogue with David Bohm (Gloucestershire, UK: Foundation House, 1985).

${ }^{618}$ Jiddu Krishnamurti and David Bohm, The Ending of Time (New York, NY: HarperOne, 1985).

${ }^{619}$ David Bohm with F. David Peat, Science, Order, and Creativity: A Dramatic New Look at the Creative Roots of Science and Life (New York, NY: Taylor \& Francis e-Library, 2011).

${ }^{620}$ David Bohm with Mark Edwards, Changing Consciousness: Exploring the Hidden Source of the Social, Political and Environmental Crises Facing our World (San Francisco, CA: Harper, 1991).

${ }^{621}$ David Bohm, Thought as a System (New York, NY: Taylor \& Francis e-Library, 2004).

${ }^{622}$ Bohm with Hiley, The Undivided Universe: An Ontological Interpretation of Quantum Theory.

${ }^{623}$ Most notably, David Bohm, with Lee Nichol, ed. On Dialogue (London, UK: Routledge, 1996); Bohm, On Creativity; David Bohm with Jiddu Krishnamurti, Limits of Thought: Discussions (London, UK: Routledge, 1999); Bohm with Biederman, Bohm-Biederman Correspondence: Creativity and Science; and Bohm, The Essential David Bohm. 
with Einstein about the problems of the standard view, to finally an outcast physicist who found more comfort in a philosopher's shoes, is more complicated than the above details reveal, and the rest of the story is both significant and interesting. His problems began quite early, during his doctoral studies in the 1940's (in fact, his doctoral thesis was never formally written or defended, as the U.S. government classified his research because of its relevance to its nuclear bomb program; his advisor Oppenheimer vouched for him that he had done the relevant research), when many of his fellow classmates, and other physicist professors, became involved in communist left-leaning political groups near Berkeley as well as Princeton. Indeed, Bohm himself did become a member of the Communist Party in America in 1942, which he left nine months later because of local internal squabbling, but even such limited involvement at all soon came to be regarded as a crime. In the late 1940 's, he was required to testify before a grand jury concerning his involvement. Although his own personal behavior had always been exemplary (he possessed a mild, temperate personality), his past involvement with communist groups, however brief, made his problems with the U. S. government's House Committee on Un-American Activities very real, as did his unwillingness to share the names of friends that may have had communist sympathies. ${ }^{624}$

Ultimately, Bohm did lose his American passport, which was confiscated upon his arrival in Brazil in 1951, and thus he was forced to apply for Brazilian citizenship to acquire a new passport to continue any global travels, which in turn obliged him to abandon his US citizenship at that time. Despite his desire to regain his US citizenship and passport, he was unable to do so for over 30 years,

\footnotetext{
${ }^{624}$ F. David Peat, Pathways of Chance (Grosseto, Italy: Pari Publishing, 2007), 71. See also, Mansoor Niaz, Critical Appraisal of Physical Science as a Human Enterprise: Dynamics of Scientific Progress (Dordrecht, The Netherlands: Springer, 2009), 152. It is important to observe that the "McCarthy Era" of American history, which saw widespread implications throughout American culture, was a trying time for America. Led by Senator Joe McCarthy, the "Red Scare" represented the concern, during the cold war with Soviet Russia, that communism might infiltrate American politics and society. Given the historical circumstances, aspects of their concerns may have appeared justified, but, in context, it led to an extremely excessive amount of witch-hunting which cost the reputations of many innocent American citizens, and also represented one of America's gravest threats to the freedom of speech. For more on this period, see John McCumber, Time in the Ditch: American Philosophy and the McCarthy Era (Evanston, IL: Northwestern University Press, 2001), who points out that Heideggerianism (with Heidegger's Nazi connections) also saw oppression, and thus the analytic sciences came to dominate; Richard M. Fried, Nightmare in Red: The McCarthy Era in Perspective (New York, NY: Oxford University Press, 1990); Martin H. Redish, The Logic of Persecution: Free Expression and the McCarthy Era (Stanford, CA: Stanford University Press, 2005); and J. Dee Kille, Academic Freedom Imperiled: The McCarthy Era at the University of Nevada (Reno, NV: University of Nevada Press, 2004).
} 
only finally reclaiming his American citizenship again in 1986 following a lawsuit against the US

government. ${ }^{625}$ Part of the problem for him was that, while he was no true radical, an offer for him to

have his American citizenship restored in 1960 required him to "prove" his anti-communist political

views, essentially forcing him to write about politics in an anti-communist way for the public. He was,

for several reasons, related to both his personal dignity and his actual sympathy for certain

communist and Marxist ${ }^{626}$ philosophical positions, ${ }^{627}$ unwilling to do this. Thus, after 1951, Bohm

spent most of the rest of his life in Brazil and England as a result, and as such his influence in the

United States surely suffered to a some degree, notwithstanding his known Marxist leanings.

The challenges his reputation faced were not limited to his flirtations with communism,

however. During the latter portion of Bohm's career, his long-term engagement with "mystics" like

Jiddu Krishnamurti ${ }^{628}$ and the Dalai Lama again drew sharp criticism from his fellow physicists and

other scientists, although such associations (which were true) hardly should have singled him out for

criticism, as many of the first generation of quantum physicists at some point or another were

${ }^{625}$ Olival Freire Jr, The Quantum Dissidents: Rebuilding the Foundations of Quantum Mechanics (19501990), with a foreword by Silvan S. Schweber (Dordrecht, The Netherlands: Springer, 2015), 54-57. See also, Kenneth W. Ford, Building the H Bomb: A Personal History (Toh Tuck Link, Singapore: World Scientific Publishing, 2015), 134; and Abraham Pais, J. Robert Oppenheimer: A Life (Oxford, UK: Oxford University Press, 2006), 107-108.

${ }^{626}$ According to Murray Gell-Mann, a young "David told me that as a Marxist he had difficulty believing in quantum mechanics. (Marxists tend to prefer their theories to be fully deterministic.)," in Murray Gell-Mann, The Quark and the Jaguar: Adventures in the Simple and the Complex (New York, NY: Henry Holt and Company, 1994), 170. Peat affirms that, at least earlier in his life, Bohm believed that "only Marxism has the power to transform society and create greater human freedom," Peat, Infinite Potential: The Life and Times of David Bohm, 142 .

${ }^{627}$ It is important to observe that Bohm's work as a physicist did overlap with his political views. In other words, Bohm drew inspiration from his observations in physics to formulate his political views. For example, he once shared, in plasma I saw "a model of society where I wanted to begin to understand the relation of the individual and the collective. Where one did not greatly interfere with the individual freedom and yet could understand collective action," as cited in Alexei B. Kozhevnikov, Stalin's Great Science: The Times and Adventures of Soviet Physicists (London, UK: Imperial College Press, 2004), 272, 275. See also, Wilson W. S. Au, Reclaiming Communist Philosophy: Marx, Lenin, Mao, and the Dialectics of Nature (Charlotte, NC: Information Age Publishing, 2017), 133; and James T. Cushing, Quantum Mechanics: Historical Contingency and the Copenhagen Hegemony (Chicago, IL: The University of Chicago Press, 1994), 152.

It is not only Bohm that had left-leaning sympathies, however. Einstein also had leftist leanings. See David Topper, How Einstein Created Relativity out of Physics and Astronomy (New York, NT: Springer, 2013), 220.

${ }^{628}$ For a recent work describing their relationship, see David Edmund Moody, An Uncommon Collaboration: David Bohm and J. Krishnamurti (Ojai, CA: Alpha Centauri Press, 2017); and Hanegraaff, New Age Religion and Western Culture: Esotericism in the Mirror of Secular Thought, 143. 
engaged with reading "eastern" and other mystical traditions. ${ }^{629}$ In any case, the openness with which he entertained such speculations certainly damaged his professional reputation in the 1980's and 1990 's, and turned him into something of an icon for the New Age spiritualist fringes. ${ }^{630}$

With the general picture concerning Bohm's questionable connections concerning his reputation having been shared, a few final points must be given as a reminder of his influence and significance from a biographical perspective. First, Bohm's ideas do represent the original trajectory of Einstein, and Bohm retains a following amongst a minority group of serious physicists even today; these scholars consider Bohm the only physicist faithful to the older scientific paradigm, and often identify with his outcast status. Second, Bohm touches upon philosophical issues that large numbers of people in the humanities sympathize with, whether for New Age religious reasons or otherwise, and this can't be lightly dismissed-Bohm actually wants to transcend traditional scientism. ${ }^{631}$ Third, Bohm is not only favorably cited by important Catholic philosophers, like David L. Schindler, who may represent the most penetrating American Catholic philosopher of the early $21^{\text {st }}$ century, but Bohm personally attended and presented at a conference on science and religion organized by Schindler at the University of Notre Dame, demonstrating his willingness to work with religionists, even if he

\footnotetext{
${ }^{629}$ Several key early quantum physicists who supported the Copenhagen view, such as Werner Heisenberg, were "apparently influenced by mystical thinking," Jonathan Allday, Quantum Reality: Theory and Philosophy (Boca Raton, FL: CRC Press, 2009), 318; see also Phil Mason, Quantum Glory: The Science of Heaven Invading Earth (Maricopa, AZ: XP Publishing, 2010), 40, where Mason asserts the mainstream physicist Erwin "Schrödinger was a full blown pantheist who was deeply immersed in Eastern mysticism," ibid; Ken Wilber, ed. Quantum Questions: Mystical Writings of the World's Greatest Physicists (Boston, MA: Shambhala, 2001); Gary Zukav, The Dancing Wu Li Masters: An Overview of the New Physics (Ebury Publishing, 2012); Fritjof Capra, The Tao of Physics: An Exploration of the Parallels Between Modern Physics and Eastern Mysticism (Boston, MA: Shambhala, 2010); Arun Bala, Complementarity Beyond Physics: Niels Bohr's Parallels (New York, NY: Palgrave Macmillan, 2017), 1-70; and Mara Beller, Quantum Dialogue: The Making of a Revolution (University of Chicago, 1999). Beller suggests that even in science "ideas can properly be understood only by an analysis of their local theoretical and sociopolitical emergence and use," which lends support to the mutual interaction and influence between philosophy and physics, ibid., 172. Lisa Zyga suggests that mysticism should have a place in the study of the history of quantum interpretation-we must know what took place. Lisa Zyga, "Quantum Mysticism: Gone but Not Forgotten," at https://phys.org/news/2009-06-quantum-mysticism-forgotten.html (accessed June 9, 2017).

${ }^{630}$ Albert, in Nochimson, David Lynch Swerves: Uncertainty from Lost Highway to Inland Empire, 196. See also, Hanegraaff, New Age Religion and Western Culture: Esotericism in the Mirror of Secular Thought, 62-76; and Sutapas Bhattacharya, The Oneness/otherness Mystery: The Synthesis of Science and Mysticism (Delhi: Motilal Banarsidass Publishers, 1999), 418-420, 438-493.

${ }^{631}$ Stephen Jarosek, Transcending Scientism: Mending Broken Culture's Broken Science (Raleigh, NC: Lulu Press, 2016).
} 
himself was not 'religious' (he had a Jewish background but was not observant as an adult). ${ }^{632}$ Indeed, Schindler praised Bohm for articulating what "could be summed up as an effort to interpret the basic order and activity in the (physical) universe in terms of love." ${ }^{\prime 633}$ And fourth, ironic as it may appear in light of the previous point, Bohm's ideas also remain very popular today with Sufi Islamic scholars, ${ }^{634}$ which elevates the significance of Bohm's ideas for understanding one of the most significant challenges of the $21^{\text {st }}$ century, that is the enigma of Islam in its encounter with the West and Christianity. ${ }^{635}$

${ }^{632}$ David L. Schindler, ed. Beyond Mechanism: The Universe in Recent Physics and Catholic Thought (Lanham, MD: University Press of America, 1986). The essays in this book were the result of a conference entitled "Beyond Mechanism: The Universe in Recent Physics and Catholic Thought," which was sponsored by the North American edition of the journal Communio: International Catholic Review, and was held at the University of Notre Dame in the spring of 1984. The context of the conference was the contribution of David Bohm to contemporary theoretical physics. Bohm was present and presented his own paper, and in this book containing the papers of the conference he shared his reactions to the other papers presented.

${ }^{633}$ Schindler, Ordering Love: Liberal Societies and the Memory of God, 357 n. 11. When Schindler shared this suggested interpretation of Bohm's work with Bohm, Bohm's reply was, roughly, "'Yes, of course, but I can't use such language with physicists."” Schindler testified that "Bohm ... was a man of profound humility and gentleness and compassion, and in fact quite shy, though his being and manner exuded a genius and passion for inquiry after the truth in all of its mystery that were the equal of any man I have ever met," ibid.

${ }^{634}$ For example, see Kyle J. Shuebrook, "Science and Sufism: A Discussion of David Bohm and Ibn alArabi," term paper, at https://www.academia.edu/2272891/Science_and_Sufism_A_Discussion_of_ David_Bohm_and_Ibn_al-Arabi (accessed August 24, 2017).

${ }^{635}$ The early $21^{\text {st }}$ century interactions between Catholicism and Islam remain fraught with complexities, reflecting an equally complex history. See, for example, Christopher Lamb, “Why Pope Francis' Approach to Islam Breaks the Mold of Benedict and Previous Popes," at https://www.americamagazine.org/ faith/2017/05/03/why-pope-francis-approach-islam-breaks-mold-benedict-and-previous-popes (accessed May 3, 2017); and Maureed Mullarkey, "In Wake of Manchester, Pope Francis Asserts Equivalence between Islam And Christianity," at http://thefederalist.com/2017/05/30/wake-manchester-pope-francis-assertsequivalence-islam-christianity/ (accessed May 30,2017). For more on the broader contours of Islam, especially in relationship to science, see Robert R. Reilly, The Closing of the Muslim Mind: How Intellectual Suicide Created the Modern Islamist Crisis (Wilmington, DE: ISI Books, 2010). For more on the complexities of Islam, see Peter G. Riddell and Peter Cotterell, Islam in Context: Past, Present, and Future (Grand Rapids, MI, Baker, 2003); Bernard Lewis, The Middle East: A Brief History of the Last 2,000 Years (New York, NY: Scribner, 1995); Stephen Schwartz, The Other Islam: Sufism and the Road to Global Harmony (New York, NY: Doubleday, 2008); Stephen Schwartz, The Two Faces of Islam: Saudi Fundamentalism and Its Role in Terrorism (New York, NY: Doubleday, 2003); Llewellyn Vaughan-Lee, Prayer of the Heart in Christian \& Sufi Mysticism (Point Reyes, CA: The Golden Sufi Center, 2012); James Fadiman and Robert Frager, eds. Essential Sufism (San Francisco, CA: Harper San Francisco, 1997); Peter C. Phan and Diana Hayes, eds. Many Faces, One Church: Cultural Diversity and the American Catholic Experience (New York, NY: Sheed \& Ward, 2005); and Joseph Pérez, The Spanish Inquisition: A History, tr. Janet Lloyd (London, UK: Yale University Press, 2005). 


\section{Bohm's Contribution Within the Context of the Two Cultures}

Bohm himself, particularly later in his career, clearly acknowledged his place within the two cultures, ${ }^{636}$ and his desire to remedy the ailment that kept them apart-an ailment he knew centered on notions of freedom and time in the sciences and humanities. ${ }^{637}$ What lies at the center of Bohm's critique of the situation is his rejection of the status quo in science. "Fundamental notions like order and structure condition our thinking unconsciously, and new kinds of theories depend on new kinds of order." ${ }^{638}$ Both scientists and artists drew encouragement from Bohm's work to think "outside the box." ${ }^{139}$ This was because, Bohm believed, unfortunately, "physics has become almost totally committed to the notion that the order of the universe is basically mechanistic." In this view, "order" is understood to describe an atomistic world that is "constituted of entities which are outside of each other, in the sense that they exist independently in different regions of space (and time) and interact through forces that do not bring about any changes in their essential natures. The machine gives a typical illustration of such a system of order," ${ }^{640}$ and is also deterministic in principle, or ontologically timeless. ${ }^{641}$ This is reflected in the universal and deterministic laws sought after by Newton which were assumed to be "eternally valid," and thus appealing to something "that lay beyond time." ${ }^{142}$ It is

\footnotetext{
${ }^{636}$ Bohm frequently referred to the work of the scientist and artist as similar-and both of them in contradistinction to the work of mechanist science, which he rejected. For example, Bohm, On Creativity, 34-35. Bohm believed that "this division of art and science is temporary," and because "it didn't exist in the past" "there's no reason why it should go on in the future," as cited in John Horgan, The End of Science: Facing the Limits of Knowledge in the Twilight of the Scientific Age (New York, NY: Basic Books, 2015), 85. As Emily Horton explains, "even recognising Bohm's slightly eccentric standing within the scientific academy however, his reputation is substantial, and perhaps more importantly for this chapter, his interest in the psychological and social implications of an otherwise abstract science makes him a valuable locus of literary inspiration," Horton, Contemporary Science Fictions: Affect and Ethics in the Modern British Novel, 120.

${ }^{637}$ Bohm, The Essential David Bohm, 258. Bohm and Peat, Science, Order, and Creativity, 99-100. See also, Douglas Sloan, Insight-Imagination: The Emancipation of Thought and the Modern World (Westport, CT: Greenwood Press, 1983), 119-124.

${ }^{638}$ Bohm, as cited in Horgan, The End of Science, 84.

${ }^{639}$ Bohm, as cited by McCarthy, Remapping Reality, 76.

${ }^{640}$ Bohm, Wholeness and the Implicate Order, 219. See also, David Bohm, Causality and Chance, Letters to Three Women, ed. Chris Talbot (Cham, Switzerland: Springer, 2017), 164; and Bohm, The Essential David Bohm, 11-23.

${ }^{641}$ Bohm, Causality and Chance, Letters to Three Women, 164. Bohm explains, standard "laws not only determine the future in a mechanical sense; i.e., in the sense of determining quantitative changes in the arrangements of entities whose intrinsic character is fixed. The causal laws also tell when qualitative changes will occur and may define the characteristics of the new entities that can come into being," ibid., 164.

${ }^{642}$ Bohm and Peat, Science, Order, and Creativity, 102.
} 
noteworthy that, for Bohm, even the standard interpretation of quantum phenomena does not escape mechanism, for example, through randomness or probability. ${ }^{643}$ Of course, Bohm's views on time will be expanded upon below.

Bohm's ultimate rejection of the abstract mathematical ${ }^{644}$ or quantitative and mechanistic heart of atomistic reductionist science drove him to seek after a conception of nature that opened to view a "qualitative infinity" that went "beyond mechanism." ${ }^{645}$ If Bohm is correct, as Pylkkänen observes, then the near universally accepted "scientific ontology has to give up the mechanistic order as fundamental." ${ }^{\prime 646}$ The consequence of this surrender on the part of science, in Bohm's mind, is that this will allow "science" to return us toward seeking an "understanding" of reality, rather than viewing science as the lense through which we see reality, a reality composed of mere "prediction," as is done with "technology." ${ }^{647}$ Thinking of reality as something we should "understand" rather than merely "predict" reorients our focus to the human side of things, and an emphasis on "meaning.",648 One of the key points Bohm would emphasize is that the externally mechanistic picture of "technologized" atomistic science which dominates the world contributes to a widespread sense of psychological fragmentation ${ }^{649}$ that separates us from each other and from finding common meanings

${ }^{643}$ Peat, From Certainty to Uncertainty: The Story of Science and Ideas in the Twentieth Century, 61. Peat explains, "Bohm believed that this persistent failure to unify physics exposes the limits of our current way of thinking in science. What is needed is not a brilliant new idea or a novel piece of mathematics. The issue is much deeper than piecing together a unified theory of relativity and quantum theory. It involves changing our way of thinking about the physical world," ibid., 61 .

${ }^{644}$ Bohm did not reject mathematics per se in relationship to philosophy, but recognized its limitations more clearly. See the work by Steven Rosen, who corresponded with Bohm. Rosen, Science, Paradox, and the Moebius Principle: The Evolution of a 'Transcultural' Approach to Wholeness, 218-268. See also, Horgan, The End of Science, 85.

${ }^{645}$ Bohm, The Essential David Bohm, 17. See also, Bohm, Causality \& Chance in Modern Physics, 36-39.

${ }^{646}$ Pylkkänen, Mind, Matter and the Implicate Order, 52.

${ }^{647}$ Bohm, Unfolding Meaning: A Weekend of Dialogue with David Bohm, 30.

${ }^{648}$ David Bohm, "Meaning and Information," in The Search for Meaning: The New Spirit in Science and Philosophy, ed. Paavo Pylkkänen (Wellingborough, UK: Crucible, 1989), 43-85. Bohm also shared that "if we said that we only discover things, that would say that the whole of time and space are already determined, and we merely find out what's there, right? And then we would raise the question: What about us? Who are we? Are we part of time and space? So are we determined too in that way? Now I think that it would be better to say that time and space are not determined, but rather, that they are like meaning, they are part of meaning. Now we said that meaning is ambiguous, and that leaves room for creativity," Bohm, Unfolding Meaning, 130.

${ }^{649}$ See his comments in Bohm and Edwards, Changing Consciousness, 6. Bohm explained, "this [deficient] way of thinking has been given a name: fragmentation. The word fragment means to smash, to break up. It doesn't mean to divide. The parts of a watch could be divided, but they could still make up the whole. However, if you smashed the watch, you would get fragments, parts just arbitrarily broken up.... 
with each other. ${ }^{650}$ Bohm's solution was to introduce a radically new theory of multi-dimensional or multi-layered wholism (the implicate and explicate orders, ${ }^{651}$ of which there may be infinitely many implicate ones), to bring together both an understanding of nature (physics), the human brain and mind, ${ }^{652}$ as well as human language, societies, cultures, and the environment, ${ }^{653}$ that rejects the deficient fragmented view of reality that dominates the sciences and society. The influence of Bohm's ideas has been spread widely, from the fields of medicine and psychiatry ${ }^{654}$ to discussions about

Fragmentation consists of false division, making a division where there is a tight connection, and also false unification, uniting where there is not unity," ibid. Note also, Krishnamurti and Bohm, The Limits of Thought.

${ }^{650}$ This concern led Bohm to develop an interest in "dialogue." See Bohm, On Dialogue. For an analysis of Bohm's use of the concept, see Mario Cayer, "The Five Dimensions of Bohm's Dialogue," in Dialogue as a Means of Collective Communication, eds. Bele H. Banathy and Patrick M. Jenlink (New York, NY: Kluwer, 2005), 161-192. Note also, in the same volume, Lee Nichol, "Wholeness Regained: Revisiting Bohm's Dialogue," 17-28.

${ }^{651}$ Bohm, Wholeness and the Implicate Order, 225. "In terms of implicate order one may say that everything is enfolded into everything. This contrasts with the explicate order now dominant in physics in which things are unfolded in the sense that each thing lies only in its own particular region of space (and time) and outside the regions belonging to other things," ibid.

652 David Bohm, "A New Theory of the Relationship of Mind and Matter," in Philosophical Psychology Vol. 3, No. 2 (1990), 271-286. See also the explanations of Bohm's work by Jenny Wade, Changes of Mind: $A$ Holonomic Theory of the Evolution of Consciousness (Albany, NY: State University of New York Press, 1996), 7-26; William W. Demastes, Staging Consciousness: Theater and the Materialization of Mind (Ann Arbor, MI: The University of Michigan Press, 2002), 76-93; Ernest Lawrence Rossi, Dreams, Consciousness, Spirit: The Quantum Experience of Self-Reflection and Co-Creation, $3^{\text {rd }}$ ed. (Phoenix, AZ: Zeig, Tucker \& Theisen, 2000), 169-174; Michael Talbot, The Holographic Universe (New York, NY: Harper Collins, 1991), 1-58; Paavo Pylkkänen, "Consciousness in the Light of Quantum Theory," in Integrating Eastern and Western Perspectives, eds. Prem Saran Satasangi, Stuart Hameroff, Vishal Sani, Pami Dua (New Delhi, India: New Age Books, 2016), 23-34; Paavo Pylkkänen, "Fundamental Physics and the Mind: Is There a Connection?," in Quantum Interaction, eds. Harald Atmanspacher, Claudia Bergomi, Thomas Filk, and Kirsty Kitto (New York, NY: Springer, 2015), 3-11; and Pylkkänen, Mind, Matter and the Implicate Order, 93-156.

${ }^{653}$ Bohm, Wholeness and the Implicate Order, 1-2, 188-190. See also, Mutambo Mpanya, "Scientific Knowledge in the Context of Environmental Justice," in Environmental Crisis or Crisis of Epistemology?: Working for Sustainable Knowledge and Environmental Justice, ed. Bunyan Bryant (New York, NY: Morgan James, 2011), $139,155$.

${ }^{654}$ Bohm himself referred to the potential of his work for medicine in the broad sense; see Bohm, The Essential David Bohm, 289-300. For the use of his ideas by others, see, for example, see Irene J. Dabrowski, "David Bohm's Theory of the Implicate Order: Implications for Holistic Thought Processes," in Issues in Integrative Studies No. 13 (1995), 1-23; Jacques Kriel, Matter, Mind, and Medicine: Transforming the Clinical Method (Atlanta, GA: Rodopi, 2000), 59-70; Larry Malerba, Green Medicine: Challenging the Assumptions of Conventional Health Care-A New Synthesis of Ancient and Modern Healing Traditions (Berkeley, CA: North Atlantic Books, 2010), 143; Nader Butto, Unified Integrative Medicine: A New Holistic Model for Personal Growth and Spiritual Evolution (Bloomington, IN: AuthorHouse, 2014); Jennifer T. Gehl with Marc S. Micozzi, The Science of Planetary Signatures in Medicine: Restoring the Cosmic Foundations of Healing (New York, NY: Simon and Schuster, 2017); Farzad Goli, "Medical Practice in/with the Semiosphere," in Biosemiotic Medicine: Healing in the World of Meaning, ed. Farzad Goli (New York, NY: Springer, 2016), 234; Carlisle Holland, Under the Eagle's Wing: Medicine, Mind, Metaphysics (Sebastopol, CA: 2007), 146; and Michael H. Cohen, Beyond Complementary Medicine: Legal and Ethical Perspectives on Health Care and Human Evolution (Ann Arbor, MI: The University of Michigan Press, 2000), 81, 187. 
political theories, ${ }^{655}$ as well as religion, as noted above, which also places him directly within the third culture discussion. All of the above said, however, it must be emphasized the Bohm did seek a more universal order through his theories. ${ }^{656}$ He was not an irrationalist, nor was seriously accused of such despite his connections with mystics. Noteworthy is that Heidegger had a similar experience.

The particular focus of this study, however, is Bohm's ideas about freedom and time, topics to which he invested considerable attention. In light of Bohm's desire to reconcile Einstein's relativity theory with quantum theory, ${ }^{657}$ an unresolved difficulty that has bewildered the physics community for decades, a brief explanation is necessary of Einstein's theory and Bohm's work to reconcile relativity with quantum theory, particularly as they relate to the concepts of freedom and time. To do this an overview will be given of why Einstein's space-time has created such a challenge for the concepts of freedom and time, including especially the when of the concept of freedom. Following this, the study will then briefly describe Einstein's influence upon theology, and establish Bohm as an exemplar of Einstein's original hope for physics, despite his significant modifications. Then the study will examine Bohm's views on freedom and time.

\section{Einstein's Contribution: Space-Time}

To understand the relevance of relativity for conceptualizing time, one must recall that under the longstanding historical configuration, from Pythagoras, Plato, and Aristotle, through to Descartes, Newton, and Kant, time was understood via the guiding threads of mathematical sequentiality and motion (regularity). In particular, for Newton and Kant, time was understood in an absolute way alongside space, either in nature itself or as a background a priori constant in the universe that derived its meaning and accessibility from a mathematized sequentiality and extendedness.

\footnotetext{
${ }^{655}$ See, for example, Mónica Judith Sánchez Flores, Political Philosophy for the Global Age (New York, NY: Palgrave Macmillan, 2005), 25-29.

${ }^{656}$ Flores, Political Philosophy for the Global Age, 28-29. Flores explains, "both implicate and explicate orders should be seen as perspectives on an intellectual contemplation of universal order that remains rooted in the belief on an essential human transcendental connection to that order," ibid.

${ }^{657}$ Peat, Infinite Potential: The Life and Times of David Bohm, 204. See also, Art Hobson, Tales of the Quantum: Understanding Physics' Most Fundamental Theory (Oxford, UK: Oxford University Press, 2017), 127129; and Jeffrey A. Barrett, "On the Nature of Measurement Records in Relativistic Quantum Field Theory," in Ontological Aspects of Quantum Field Theory, eds. Meinard Kuhlmann, Holger Lyre, and Andrew Wayne (London, UK: World Scientific, 2002), 168.
} 
Because for modern and contemporary era scientists the universe is constituted by matter and energy in motion, an interesting problem can be intuited from the above conceptualization of time, and it's a problem that came to the forefront because of some empirical problems that were uncovered in the late $19^{\text {th }}$ century. Physics has, for some time, been understood to see "nature as a set of localized entities [i.e., 'tiny balls'] which can only interact with one another contiguously from point to point through space. This idea certainly fits with our intuition of the world, as it would with Newton's," ${ }^{658}$ as well as the intuitions of Descartes, Kant, and, lastly, the world of physics in the early $20^{\text {th }}$ century, including even the widely influential Einstein and the early Bohm-despite the recent introduction of Maxwell's electromagnetic waves, which both saw as 'objective. ${ }^{659}$ The problem that arose in the early $20^{\text {th }}$ century was that our ability to detect smaller and smaller localized entities or 'tiny balls' which interact with each other externally reached a limit upon which the phenomena observed appeared to require a new explanation, namely, relativity. Of course, as one might expect, astute theologians have not ignored the discoveries and debates taking place between the physical scientists. Following the normal lag-time between the dissemination of scientific publications to theological readers, the significance of relativity has become prominently featured within the discussions of many leading theologians as they ponder the nature of the relationship between God, nature, and time ${ }^{660}$ making relativity a topic that cannot be ignored when discussing freedom and time.

\footnotetext{
${ }^{658}$ Nicolas Gisin, with a foreword by Alain Aspect, Quantum Chance: Nonlocality, Teleportation and Other Quantum Marvels (Geneve, Switzerland: Springer, 2014), 2 (addition mine).

${ }^{659}$ While Einstein's theory required Maxwell's electromagnetic waves, the problem he had with quantum physics later would relate to the behavior of light's particle properties and objectivity. A. Douglas Stone, Einstein and the Quantum: The Quest of the Valiant Swabian (Princeton, NJ: Princeton University Press, 2013), 34-35, 89, 285. It is worthwhile to observe that Bohm has been criticized for this presupposition by fellow critics of the standard paradigm, particularly for how it appears in his early pilot-wave model. See Maxmilian A. Schlosshauer, Decoherence: And the Quantum-To-Classical Tradition (New York, NY: Springer, 2008), 356-357.

${ }^{660}$ Among the many scientists, philosophers, and theologians engaging the issues, some of the more prominent individuals include William Lane Craig, Robert J. Russell, and John Polkinghorne. See, for example, Polkinghorne, Science and Religion in Quest of Truth; Laurence W. Wood, God and History: The Dialectical Tension of Faith and History in Modern Thought (Lexington, KY: Emeth Press, 2005), 283; and Robert John Russell, Cosmology: From Alpha to Omega (Minneapolis, MN: Fortress Press, 2008).
} 
In some ways, the consequences of the behavior of nature as we commonly experience it (common sense) lead naturally into the theory of relativity. ${ }^{661}$ The reasoning can be explained as follows, and its 'intuitiveness' is worth elaborating upon. If one were to take an action, be it with their hands and legs, or voice, then there is, despite appearances, a causal-temporal chain of activity or motion which brings about the desired conclusion to their act. In the more obvious example, if three boxes are lined up almost next to each other, with a gap of a $1 / 2$ meter between them, and I push one of them such that the other two are lined up directly opposite my push, then the act of my pushing the one box reacts upon the other two, in order, from my push of the first box, which then moves toward the second box, which, upon reaching localized contact, becomes a push of two boxes in motion toward the third box. Upon the first two boxes reaching the third box, if the individual has sufficient strength to provide the necessary force, then their act of pushing the first box, which then moves the second box, will also conclude with the third box being moved. We typically have no problem understanding the original act of pushing as an act initiating a causal-temporal chained sequence of motions which results in the third box also moving.

In like manner to the above illustration, although historically it has not so easily been understood intuitively, if one were to take an action with their voice in an attempt to communicate, one might "think" that their voice acts instantaneously (after all, they "hear themselves 'instantly"'), and that any delay in the response (if they give a command) by those listening is a delay contained within the individual who is receiving the command (through this other person's own act of thinking about the command). In reality, however, even before a sophisticated understanding of the

\footnotetext{
${ }^{661}$ Bohm, The Special Theory of Relativity, 186-187. Bohm explains, "at first sight the point of view" of relativistic physics "may seem to be very different to that of 'common sense' (as well as of the older Newtonian physics)." However, "the difference between the notions of common experience and those of relativity theory arise mainly because of certain habitual ideas concerning this experience," but "now a great deal of new, but fairly well confirmed, scientific evidence [exists] suggesting that our actual mode of perception of the world (seeing it, hearing it, touching it, etc.) is much closer in character and general structure to what is suggested by relativistic physics than it is to what is suggested by prerelativistic physics. In the light of this evidence it would seem that nonrelativistic notions appear more natural to us than relativistic notions, mainly because of our limited and inadequate understanding of the domain of common experience, rather than because of any inherent inevitability of our habitual mode of apprehending this domain," ibid.
} 
propagation of sound waves, which requires the presence of a field of particles, ${ }^{662}$ one could intuit, by standing on one side of a canyon and shouting, that in some way a causal-temporal process was unfolding that led to the delayed echoes that followed. One's voice acts through some sort of spatial medium (the "air") in such a way that a sequence of causal-temporal processes unfolds which can be measured by a watch-thus creating a link between an act and the actions that follow as they unfold through motions in space as the causal-temporal sequence completes itself. Given that our voice travels through air much faster than mankind was able to travel until just 1947 when the sound barrier was broken, our ancestors could easily have viewed it as some sort of maximum speed ${ }^{663}$ of causality (around $1,235 \mathrm{~km} / \mathrm{h}$ ). However, modern physics would demonstrate this not to be the case-indeed, physics would show that the speed of sound was variable depending on the elasticity of the medium it was traveling through (sound waves propagate through water about 4.3 times faster than air), and that sound waves simply weren't the fastest form of causality.

An interesting problem presents itself through the above illustrations. The discrepancy in the various speeds of given types of actions (pushing or speaking) one can take and the mediums they are enacted within illustrates that causality appears tied to the speed at which a given action takes place. This forces one to inquire whether or not time itself is tied to any specific speed at which causaltemporal sequences take place. It would be hard, for example, to deny time a special relationship to the fastest causal action that nature or man can make; or, conversely, were time some sort of universal absolute operating in the background or outside of nature, then it would be hard to attribute any causal-temporal action as taking place "faster" than that universal absolute. The speed

\footnotetext{
${ }^{662}$ For a description of this mathematics and physics of wave propagation, see Julian L. Davis, Mathematics of Wave Propagation (Princeton, NJ: Princeton University Press, 2000). Importantly, Davis reminds us that "a physical medium such as air is needed to propagate sound waves.... Indeed, any elastic medium, be it solid, liquid, or gas, can transmit sound," ibid., 30. Her point is that "sound waves cannot be propagated in a vacuum," ibid. The same assumption was, seemingly mistakenly, assumed to be the case for light waves.

663 'Speed,' is, of course, when measured, expressed in an arbitrary number 'chosen' by humans. But when used as the relative phenomena to measure 'faster' than 'slower' in nature, the word still can function meaningfully for the present discussion.
} 
of time becomes the question and the problem-is it finite or infinite? And what are the consequences of each answer? ${ }^{664}$

For example, regardless of how fast the fastest speed of an initial causal-temporal action may be, from a theoretical perspective, it cannot be infinite, or a paradox would ensue, rendering the initial causal-temporal action indistinguishable from any later or the final action in the temporal-chain, creating an appearance of either or both instantaneous timelessness (absolute simultaneity) or spacelessness, especially if all causes were ultimately a part of some sort of universal absolute time (all of reality's causes would or could be said to unfold in one "timeless" instant). ${ }^{665}$ The consequence of apparent spacelessness results because there is no evident function of the space in between an initial causal-temporal act and its final causal-temporal act. There is no "time" for the space to "do" anything which mediates the temporal moments-in such a situation where a causal-temporal action takes place infinitely (timelessly) fast it also takes place spacelessly. Imagine a row of dominoes arranged such that when one is pushed, the rest fall in sequence. Imagine how odd it would be if upon pushing the first domino, the last domino in the sequence fell immediately. In such a case, there is no real discernable temporality or historicality if no intermediate link in the chain can be articulated-and infinite speed makes such distinguishability impossible in principle, even if theoretically logically possible. Any freedom associated with the initiation of such causal-temporal chains also becomes, in principle, potentially timeless or atemporal, particularly in relation to other causal chains, because freedom must be excised from any other temporal-chain or be considered deterministic in a way that impacts upon its influence in the given temporal-chain being studied. Conversely, however, if there is any arbitrary limit to which causal-temporal chains are constrained, then another set of mysteries ensue, the ones that rest at the heart of relativity.

\footnotetext{
${ }^{664}$ Russell, Quantum Shift: Theological and Pastoral Implications of Contemporary Developments in Science, 6-9; and Paul Davies, "That Mysterious Flow," in Scientific American, at https://www.scientificamerican .com/article/that-mysterious-flow-2006-02/ (accessed February 1, 2006).

${ }^{665}$ Of course, many causal-temporal sequences we observe in nature may appear at first glance to have taken place immediately, but closer investigation proves this not to be the case.
} 
The innovation of Einstein was to follow the above problem of time, or more precisely causaltemporality, ${ }^{666}$ to its logical end in the empirical (meaning, the world of physical mathematizedlocalized entities) world. ${ }^{667}$ Operating under the assumption that the question of time or causaltemporality as a universal background constant is irrelevant to an understanding of the empirical world in itself, Einstein essentially ascertained the speed of causality in the natural world to be the speed of light. Thus, what Einstein uncovered is that the above problem concerning the speed of time does indeed have an empirical, not merely abstract rational-logical, manifestation. Light photons (and other sub-atomic particles) in their movement represent the apparently evident maximum speed of physical entities. ${ }^{668}$ However, what this entails, philosophically and scientifically, leads to startling conclusions that defy, at first glance, traditional psychological common sense, but upon deeper reflection, are actually the consequence of common sense. ${ }^{669}$ And it is this latter realization that creates some of the deepest mysteries concerning the concept of time, including raising anew the problem of the potential existence of absolute time, especially as it might relate to physical causality.

\footnotetext{
${ }^{666}$ Karen C. Fox and Aries Keck, Einstein A to Z (Hoboken, NJ: John Wiley \& Sons, 2004), 44.

${ }^{667}$ Hans Reichenbach, The Rise of Scientific Philosophy (Berkeley, CA: University of California Press,
} 1951), 150-156. Reichenbach explains that "the causal definition of time order leads to an indeterminacy with respect to the temporal comparison of events at distant points. It does so because of the limiting character of the speed of light. Absolute time, that is, unambiguous simultaneity, would exist in a world in which there were no upper limit for the speed of signals. But because in our world the speed of causal transmission is limited, there is no absolute simultaneity. The causal theory of time explains the meaning of temporal sequence and of simultaneity in such a way that the explanation is applicable to the world of classical physics as well as to our world, in which the speed of causal transmission is subject to an upper limit and simultaneity is not unambiguously defined," ibid., 154.

${ }^{668}$ David Bohm, "Insight, Knowledge, Science, and Human Values," in Toward the Recovery of Wholeness: Knowledge, Education, and Human Values, ed. Douglas Sloan (New York NY: Teachers College Press, 1984), 14-15.

${ }^{669}$ Reichenbach, The Rise of Scientific Philosophy, 155-156. "Scientific analysis has led to an interpretation of time very different from the experience of time in everyday life. What we feel as the flow of time has been revealed to be identical with the causal process that constitutes this world. The structure of this causal flux has been discovered as being of a much more complicated nature than is exhibited by the time presented in direct observation-until some day with the conquest of interplanetary distances the time of everyday life will have become as complicated as that of the theoretical science of today. It is true that science abstracts from emotional content in order to proceed to logical analysis. But it is also true that science opens up new possibilities, which some day might acquaint us with emotions never experienced before," ibid. 
What the theory of relativity requires is that if the actions that initiate causal-temporal sequences are finite in speed and can be localized ${ }^{670}$ spatially, ${ }^{671}$ then time itself can be localized spatially alongside the newly realized reality of local causality, ${ }^{672}$ which creates the very concept of the relative space-time that is associated with Einstein's theory ${ }^{673}$ The logic is as follows. If there is a non-infinite maximum speed of causality, then, were one (or, as the thought experiment goes, a person, which is actually impossible within the theory itself ${ }^{674}$ ) to approach and then attain the maximum speed of causality, which scientists claim to be known as light, then the effects of time (aging and temporal passing) would slow and then cease to transpire, even as other objects were 'encountered' ${ }^{675}$ along our journey at this speed. That is, 'light' never ages or changes because it exists at the speed of causality. It does not or cannot 'think,' because thinking would require internal changes at 'some' physical level, which cannot occur with a particle always intrinsically moving at the maximum speed.

Indeed, as we understand it, any clock and its disparate components, if they were actually moving at the speed of light, could not "tick" because such an action of motion ("ticking") would need to exceed the speed of causality if the clock were not preserved in an artificial bubble (as imagined with the subspace 'warp bubbles' or 'warp fields' of Star Trek or Star Wars science fiction-however,

${ }^{670}$ All of the points here are controversial in themselves, but cannot be penetrated into here in depth.

${ }^{671}$ For an example article illustrating the complexities surrounding the crucial subjects of time and space, see George Musser with Tim O’Brien, “Let's Rethink Space: Does Space Exist Without Objects, or is It Made by Them?," at http://nautil.us/issue/32/space/lets-rethink-space (accessed August 8, 2017); and Markopoulou, "Space Does Not Exist, So Time Can."

${ }^{672}$ Émile Meyerson, The Relativistic Deduction: Epistemological Implications of the Theory of Relativity (Dordrecht, Holland: D. Reidel, 1985), xxxviii-xxxix, xliii-xliv. Notable here is that Einstein himself did not always draw the same conclusions about space-time that his fellow scientists did-in some cases he didn't think of them, or in others never bothered to question, dispute, or rebut them.

${ }^{673}$ J. Stachel, "Development of the Concepts of Space, Time and Space-Time from Newton to Einstein," in 100 Years of Relativity: Space-time Structure: Einstein and Beyond, ed. Abhay Ashtekar (Toh Tuck Link, Singapore: World Scientific, 2005), 13-14, 20-21.

${ }^{674}$ David Bohm, “On Insight and its Significance, for Science, Education, and Values," in Education and Values, ed. Douglas Sloan (New York, NY: Teachers College Press, 1980), 12. "If we were to reach the speed of light, some of the basic relationships common to all matter would cease to make sense," as "they would drift apart," and "disintegrate," ibid., 12.

${ }^{675}$ As noted directly above, there can really be no true relational (psychological-mental) encounter because all relations that occur at the speed of light are intrinsically external, not internal. There is no 'time' to think at the speed of light-so the relations encountered at the speed of light are more like objects bouncing off each other, not true relationships that can enjoy mutual reflection and internally extended dynamics. The theory of relativity defines no theory of mind. 
no current theories suggest such bubbles are possible). The same would hold true for cellular decay processes, as well as, unfortunately for sci-fi aficionados, mental processes. According to what standard physics and neuroscience currently tell us, it is not possible to think at the speed of light for the above reasons. ${ }^{676}$ An important point to note here is that mass and energy, two other key components of Einstein's equations, restrict any ordinary object from ever actually attaining the speed of light or causality-thus the realm of mortals appears destined to age, albeit however slowly, relative to how fast we can eventually make ourselves move. ${ }^{677}$ It is this physically theoretical scenario that allows us to almost "freeze" ourselves by moving near the speed of light, while still alive, and 'transport' ourselves in a certain sense into the 'future.' In any case, the speed of light functions empirically as an arbitrary limit of what the concept of speed can be to us, given the other apparently evident constraints of the physical world. ${ }^{678}$ In an irony of conceptual definitions, light photons cannot "rest" given they are only capable of moving at the speed of light, which is constant in a vacuum. Yet, from our point of view, to attain the speed of light and somehow retain consciousness would entail perpetual "rest" because we would, theoretically, perceive the world in a timeless way. ${ }^{679}$

\footnotetext{
${ }^{676}$ The popular science-fiction presentations of warp speed or lightspeed in, respectively, Star Trek and Star Wars, require the existence of a "bubble" to protect the individuals inside as they travel at and beyond the speed of light-which is around 1,080 million $\mathrm{km} / \mathrm{h}$. No theories currently suggest such bubbles are possible-the fastest a human has yet traveled is a mere microscopic fraction $(1 / 27,069)$ of that of light, at $39,897 \mathrm{~km} / \mathrm{h}$. For an interesting discussion about infinite speed, see Gouesbet, Hidden Worlds in Quantum Physics, 401-404. Also note, Taylor, Speed Limits: Where Time Went and Why We Have So Little Left, 291; Brigitte Vallabhajosula, Murder in the Courtroom: The Cognitive Neuroscience of Violence (Oxford, UK: Oxford University Press, 2015), 13; Frank Tallis, Hidden Minds: A History of the Unconscious (New York, NY: Arcade, 2011), 113; and David A. Grandy, The Speed of Light: Constancy + Cosmos (Bloomington, IN: Indiana University Press, 2009), $1-20,54$.

${ }^{677}$ Bohm, The Special Theory of Relativity, 158. See also, Vlad Van Rosenthal, From the Big Bang to the Big Crunch: A Simplified Look at a Not-So-Simple Universe (Bloomington, IN: iUniverse, 2011), 144-145; and Marino Dobrowolny, Causality and Time: From Relativity to Quantum Physics (USA: Youcanprint, 2017), 30. Interesting to observe here is that since time in physics is based upon actual motion in a fundamental sense, the standard theory of the Big Bang as an origin event does initiate the existence of time in any meaningful sense for physicists.

${ }^{678}$ The question of why seemingly certain deterministic laws or properties of matter allow the theory of light which contains the speed of causality, on the one hand, and restrict other parts of matter from attaining it without falling apart, is itself an interesting question, of course.

${ }^{679}$ Bohm, The Special Theory of Relativity, 118. Also see, Stephen J. Hage, Let There Be Light: Physics, Philosophy \& The Dimensional Structure of Consciousness (USA: Algora, 2013), 7; Hemant Gupta, Joy From Deep Within: True Nature of Your Quantum Self (Bloomington, IN: Xlibris, 2010), 46; and Gary Nickolaus, The Physics of God: Quantum Mechanics and All That Is, On Earth As It Is In Heaven (Bloomington, IN: Xlibris, 2012), 60, 99, $103,109,119$.
} 
The consequences of the above are fascinating when one attempts to compare multiple entities moving near or at the speed of light that are spatially distant from one another. Because no signal can travel faster than the speed of causality or light, it is impossible to accurately describe whether the beginning or ending of other temporal causal-chains that are outside each other's relative communicative time-spaces are actually earlier or later than each other-there is no singular "objective" timeframe or timespace from which one can determine the order if all of the relevant events are not causally related, meaning, in active communication (sending and receiving signal impulses) at the speed of light. ${ }^{680}$ The principle of relativity also has other consequences that effect our powers of perception. For example, if two cars pass each other at $80 \mathrm{~km} / \mathrm{h}$ and $120 \mathrm{~km} / \mathrm{h}$, respectively, then for either driver the other car appears to be driving at the relative speed of $(80$ $\mathrm{km} / \mathrm{h}+120 \mathrm{~km} / \mathrm{h}) 200 \mathrm{~km} / \mathrm{h}$. However, if two spaceships were to fly past each other, each flying at $.75 c(c=$ the speed of light $)$, then the relative speed for each pilot would not appear as one might expect, at $1.5 c$, but rather less than $c$, as within the frame of reference of either pilot, the other must appear as less than or equal to $c$, even though for an external observer, the speed would appear "correct" at $1.5 c{ }^{681}$ It is this feature of localized relative perception that contributes to the relativity of time in a world where time has a finite maximum.

Of course, some of the mysteries, and even paradoxes, of relativity's theoretical implications are rather bizarre. For example, it has often led to interpretations that deny the ultimate existence of time, since the "time" we see in relativity is merely the symmetry of various motions unfolding in space-space is primary or more fundamental than time. Relativity, interpreted as such, becomes a deterministic continuum that doesn't allow for genuine change ${ }^{682}$ and Einstein's three dimensions of

\footnotetext{
${ }^{680}$ Bohm, The Special Theory of Relativity, 159. See also, Julian Schwinger, Einstein's Legacy: The Unity of Space and Time (Mineola, NY: Dover, 2002), 74.

${ }^{681}$ Martin Gardner, Relativity Simply Explained, illustrated by Anthony Ravielli (Mineola, NY: Dover, 1997), 51.

${ }^{682}$ See, for example, Barbour, The End of Time: The Next Revolution in Physics; Dan Falk, "A Debate Over the Physics of Time," Quanta Magazine (July 19, 2016) at https://www.quantamagazine.org/a-debate-over-thephysics-of-time-20160719/ (accessed August 9, 2017); and Lisa Zyga, "Scientists Suggest Spacetime has No Time Dimension," at https://phys.org/news/2011-04-scientists-spacetime-dimension.html (accessed August 8, 2017). See also, Davide Fiscaletti, The Timeless Approach: Frontier Perspectives in $21^{\text {st }}$ Century Physics (Toh Tuck Link, Singapore: World Scientific, 2016), 5.
} 
space + one dimension of time are more correctly interpreted as four dimensions of space. ${ }^{63}$ In this latter interpretation, in particular, time travel into one's past, ${ }^{684}$ or even future, become theoretically or mathematically possible, although most still believe impossible. ${ }^{685}$

It is important to note here that, philosophically, the consequences of relativity are not tied to any specific empirical or scientific reality concerning the speed of light. Rather, they appear logically necessary, given the manifestation of finite causal-temporal actions in any empirical reality. The actual speed of light that we have uncovered in our empirical reality is irrelevant. Any maximum speed of causality that originates in localized entities (including, seemingly, humans) that is not strictly infinite will create the mysteries and problems of relativity, whether or not light is even the medium through which that maximum is derived.

Notably, the problem of "timelessness" becomes apparent given either "extreme" of a given speed of causality. If temporal-causality were ultimately infinite in speed, as noted above, then timelessness would appear to result as a consequence. All of reality would theoretically play out in a single instant in spite of the fact of so-called logically temporal moments. However, if temporalcausality is inherently or deterministically finite (either with the 'constant velocity motion' of special relativity, or alongside gravity in general relativity), as it appears to be in the empirical world we inhabit, which lends support to the assumptions grounding Einstein's special relativity, it is both empirically and mathematically difficult to locate a preferred or cosmic frame of reference, ${ }^{686}$ thus

\footnotetext{
${ }^{683}$ Many authors have attempted to describe this. See, for example, Louis S. Jagerman, The Mathematics of Relativity for the Rest of Us (Victoria, B.C.: Trafford, 2001), 68-103.

${ }^{684}$ J. Richard Gott III, Time Travel in Einstein's Universe: The Physical Possibilities of Travel Through Time (New York, NY: Houghton Mifflin, 2002).

${ }^{685}$ Such as Stephen Hawking, A Brief History of Time, upd. $10^{\text {th }}$ anniversary ed. (New York, NY: Bantam, 1998), 160-167.

${ }^{686}$ For an explanation of why this is so, see Michael Redhead, "The Conventionality of Simultaneity," in Philosophical Problems of the Internal and External Worlds: Essays on the Philosophy of Adolf Grünbaum, eds. John Earman, Allen I. Janis, Gerald J. Massey, and Nicholas Rescher (Pittsburgh, PA: University of Pittsburgh Press, 1993), 114-120. One such effort to restore a cosmic frame of reference is found in the Lorentzian interpretation of relativity which requires some sort of æther and a more mechanistic view of nature. Redhead asserts that "accepting the neo-Lorentzian approach depends on one's understanding of what constitutes a scientific explanation. The neo-Lorentzians seem to be arguing on the basis of a crude causal approach to explanation, whereas modern physics has followed the unification approach that a good explanation is one that subsumes many disparate empirical regularities under the deductive closure of a unified set of theoretical principles. On this account the Einstein approach is clearly superior to the Lorentzian; indeed Einstein's own contribution to scientific methodology largely consists in arguing from formal general principles rather than detailed causal
} 
encouraging the deterministic block world of Minkowski's four-dimensional space-time (three of space + one of temporal motion), which, again, is perhaps more accurately described as four dimensions of space mathematically, ${ }^{687}$ that is, as a timeless four-dimensional block-space. This is the view that maintains a tenuous plurality position amongst the physics community, even as they vigorously debate the meaning of it, especially in relation to issues in cosmology, where an evolutionary progression and expanding universe are now assumed. Concerning cosmology, however, it must be noted that what is conceived of as 'time' in standard cosmology still only expresses time in a one-dimensional way.

Despite everything that has been shared above concerning the majority perspective, there is an alternative interpretation of relativity theory that maintains more of our "common sense" intuitions. ${ }^{688}$ Even if a preferred cosmic frame (a revival of Newtonianism ${ }^{689}$ with three true dimensions of space + one independent dimension for temporal chang $e^{690}$ ) were able to be located

mechanisms," ibid., 114-115. See also, Jeffrey Koperski, The Physics of Theism: God, Physics, and the Philosophy of Science (West Sussex, UK: John Wiley \& Sons, 2015), 104-133, esp. 124-125; Oliver Johns, Analytical Mechanics for Relativity and Quantum Mechanics $2^{\text {nd }}$ ed. (Oxford, UK: Oxford University Press, 2011), 360-362; and, for a controversial defense of the Lorentzian theory and its substitutability with Einsteinian relativity, see László E. Szabó, "Lorentzian Theories vs. Einsteinian Special Relativity-a Logico-empiricist Reconstruction," at http://philsci-archive.pitt.edu/5339/1/leszabo-lorein-preprint.pdf.

${ }^{687}$ Michael Silberstein, W. M. Stuckey, and Michael Cifone, "An Argument for 4D Block World from a Geometric Interpretation of Nonrelativisitic Quantum Mechanics," in Relativity and the Dimensionality of the World, ed. Vesselin Petkov (New York, NY: Springer, 2007), 199. "Most natural philosophers are inclined to accept that special relativity unadorned implies the block world view. Among those who might agree that special relativity unadorned implies a block world are those who think that quantum theory provides an excellent reason," ibid., 199.

${ }^{688}$ Albrecht Giese explains the view that "physicists' understanding of relativity and the way it is handled is up to present days dominated by the interpretation of Albert Einstein, who related relativity to specific properties of space and time. The principal alternative to Einstein's interpretation is based on a concept proposed by Hendrik A. Lorentz, which uses knowledge of classical physics alone to explain relativistic phenomena.... [It can be shown] that on the one hand the Lorentz-based interpretation provides a simpler mathematical way of arriving at the known [empirical] results for both Special and General Relativity. On the other hand, it is able to solve problems which have remained open to this day. Furthermore, a particle model will be presented, based on Lorentzian relativity and the quantum mechanical concept of Louis de Broglie [a precursor to Bohm], which explains the origin of mass without the use of the Higgs mechanism. It is based on the finiteness of the speed of light and provides classical results for the particle properties which are currently only accessible through quantum mechanics," Albrecht Giese, "A Particle Model Explaining Mass and Relativity in a Physical Way," in Unified Field Mechanics: Natural Science Beyond the Veil of Spacetime, eds. Richard L. Amoroso, Louis H. Kauffman, and Peter Rowlands (Toh Tuck Link, Singapore: World Scientific Publishing, 2016), 131 (additions mine).

${ }^{689}$ Craig, Time and the Metaphysics of Relativity, 229-233, 236.

${ }^{690}$ Koperski, The Physics of Theism: God, Physics, and the Philosophy of Science, 124. 
temporally and spatially (perhaps in an “æther" ${ }^{\text {"991 }}$ ), which mitigates the effects of relativity, a finite maximum speed of causality still creates a variety of logical problems concerning the concept of time in itself. ${ }^{692}$ Is temporal-causality ultimately frozen at a specific rate of change as a "background æther" to all physicality, or does it take place relative to the motions of physical entities at a level we don't yet understand (while lacking any empirical data)? What, then, is the relationship between physical reality and time? The efforts of those, such as the philosopher William Lane Craig, who has endeavored to restore a tensed A-theory of time to explain relativity building off the work of Hendrik Lorentz, ${ }^{693}$ have not been able to answer these questions to the satisfaction of many physicists working with empirical data. Instead, Craig's efforts to restore a cosmic background time, following Newton, that supposedly preserves the reality of time, only resuscitates within theological circles (since he does his work openly as a theist) the crisis of time's relationship to empirical natural science $^{694}$ and the humanities, particularly the roles of the subject and object, and their relationship

${ }^{691}$ The æther is a background 'non-material' medium within which all exists that is. In the somewhat more recent history of science, it was supposed at first that an æther was the medium through which light propagated, whereas sound was transmitted through more "substantial" mediums, such as air and water. The æther in this sense was the medium of 'empty space' above the sky, that is, outer space. For the use of the concept in primarily scientific history (as opposed to merely mythological history), see Sir Edmund Whittaker, $A$ History of the Theories of Aether and Electricity: Vol. 1 The Classical Theories, and Vol. 2 The Modern Theories (1900-1926) in one volume (Mineola, NY: Dover, 1951); Kenneth F. Schaffner, Nineteenth-Century Aether Theories (Oxford, UK: Pergamon Press, 1972); and Loyd S. Swenson, Jr., The Ethereal Aether: A History of the Michelson-Morley-Miller Aether-Drift Experiments, 1880-1950 (Austin, TX: University of Texas Press, 1972). Of course, and relevant for the present study, some think Einstein's rejection of the æther was a mistake. See Sid Deutsch, Einstein's Greatest Mistake: Abandonment of the Aether (Bloomington, IN: iUniverse, 2006).

${ }^{692}$ Antoine Suarez, "Entanglement and Time," at https://arxiv.org/pdf/quant-ph/0311004.pdf (accessed October 4, 2018). The problem is thus, and directly relates to Bohm's contribution: "if one tries to cast nonlocal causality into only one preferred frame it is not more reasonable to connect a 'cause' event to an 'effect' event in that frame rather than in some other frame. Effectively a single preferred frame ('quantum ether') is 'experimentally indistinguishable': The predictions would remain the same if one assumes that the preferred frame is a virtual entity changing from experiment to experiment.

"One is tempted to think that Bohm introduces absolute time just because he wishes to justify a causal description, but in the end, an untraceable "quantum ether" is essentially the same as deciding arbitrarily which event depends on which one. What is more, in the particular case, possible in principle, of both measurements taking place at exactly the same time in the preferred frame, the only way of establishing which event depends on which is by arbitrary decision. Actually, Bohmian Mechanics can be considered a causal description but not a real temporal one, and to date it has not led to experiments capable of distinguishing it from Quantum Mechanics," ibid., 2. It is for this reason that Bohmian mechanics remains essentially, in the neo-Platonic and Kantian mold, 'timeless.'

${ }^{693}$ Craig, God, Time, and Eternity: The Coherence of Theism II: Eternity, 143-246. For another explanation of this problem, see http://www.anti-relativity.com/primer3.htm (accessed August 22, 2017).

${ }^{694}$ Redhead, "The Conventionality of Simultaneity," 114-115. DeWeese, God and the Nature of Time, 231-232. 
within science. ${ }^{65}$ It may be helpful to briefly describe why Craig's efforts are not widely considered satisfying by many scientists and Heideggerian philosophers.

Craig's utilization of the neo-Lorentzian transformations to mitigate special relativity's oddities, which preserves a singular preferred ('timeless instant') frame for the cosmos (a universal time which advances through a sequence of mathematizable "nows"), entails the re-abstracting and remathematization of both time and time in nature in a deterministic way, thus truly reviving Newton's key perspective about matter, space, and time as a priori givens, ${ }^{696}$ though now highlighting Newton's notion of time in both a physical and metaphysical way. All of the old unresolved questions that surrounded Newtonian time resurface, including the problem concerning the meaning of the flow of time over which the ancients Pythagoras and Zeno wrestled-namely, whether time is continuous or discrete-while neglecting the Heideggerian perspective completely. Furthermore, the neo-Lorentzian transformations which primarily relate to the time-dilation problem in special relativity create problems for general relativity (gravity) that Craig does not satisfactorily address, and as such ties time to nature in ways that need further elaboration that may or may not be forthcoming. ${ }^{697}$ But the primary concern with Craig's views center on the problem of absolute determinism in nature and

\footnotetext{
${ }^{695}$ Perhaps most forcefully brought out by Steven M. Rosen, “Bridging the 'Two Cultures': MerleauPonty and the Crisis in Modern Physics," in Cosmos and History: The Journal of Natural and Social Philosophy Vol. 9 No. 2 (2013), 1-12; Steven M. Rosen, "Why Natural Science Needs Phenomenological Philosophy," in Progress in Biophysics and Molecular Biology Vol. 119, Issue 3 (December 2015), 257-269, esp. 265; Steven M. Rosen, "Quantum Gravity and Taoist Cosmology: Exploring the Ancient Origins of Phenomenological String Theory," in Biophysics and Molecular Biology, Vol. 131 (2017), 34-60; Rosen, The Self-Evolving Cosmos: A Phenomenological Approach to Nature's Unity-in-Diversity, 11-15; Rosen, Dimensions of Apeiron: A Topological Phenomenology of Space, Time, and Individuation, 118-120; and Rosen, Science, Paradox, and the Moebius Principle: The Evolution of a "Transcultural" Approach to Wholeness, 65-68.

${ }^{696}$ Notably, however, Craig does not follow Newton in supporting a non-relational view of time, or that space is an absolute. See Craig, "God, Time and Eternity," for his argumentation for a relational view. In essence, Craig's relational view of time means that God's eternity should be understood as timeless, and that when the universe began, time also began, as it is dependent relationally upon God or personhood. Craig thus supports an A-theory of time that is relational. That is, the past, present, and future are only relationally real, as time began only once God initiated the creation of things/beings other than himself. Nevertheless, Craig's view supports the basic intuitions of Newton on time, absent Newton's emphasis on God's eternal temporality construed in a mathematized way. See also, James Bishop, "God \& Time: A Relational \& A-Theory View of Time," at https://jamesbishopblog.com/2017/08/06/god-time-a-relational-a-theory-view-of-time/ (accessed August $6,2017)$.

${ }^{697}$ Koperski, The Physics of Theism: God, Physics, and the Philosophy of Science, 126, 134. "Proponents of cosmic time believe that nature has temporal relations that GTR fails to capture. Research continues and I don't believe there will ever be, as some late nineteenth-century scientists hoped, a 'final physics' where all of the questions are answered," ibid., 134.
} 
quantum physics, of which the standard Copenhagen interpretation does allow for some randomness or indeterminism, which Craig is inclined to reject. ${ }^{698}$

This latter issue is a problem, specifically, because Craig, by following the early deterministic pilot-wave model of de Broglie and Bohm ${ }^{699}$ to resolve the quantum paradoxes (Bohm never fully abandoned this model, but ceased to emphasize it as much in most of his later more philosophical writings $^{700}$ ), denies any indeterminism in nature by means of promoting "hidden variable" correlations, and thereby again departs from the majority of quantum physicists, even as he maintains the view popular with other scientists. In any case, as Craig notes, Bohm's view does maintain a minority following, particularly with those favoring deterministic realism. ${ }^{701}$ Thus, in what can only be described as an irony, Craig denies the physics community's favored mathematicalempirical approach to the special theory of relativity while favoring the less popular abstract mathematical approach of Lorentz, which creates problems for gravity, and particularly problems for Bohm's model to maintain both objectivism and determinism in the quantum realm. ${ }^{702}$ In each instance, Craig eschews mainstream mathematical-empiricism in favor of mathematical-rationalism; that is, an abstract Platonic but still mathematized reasoning.

\footnotetext{
${ }^{698}$ Craig and Moreland, Philosophical Foundations of a Christian Worldview, 279; and William Lane Craig, Reasonable Faith: Christian Truth and Apologetics $3^{\text {rd }}$ ed. (Wheaton, IL: 2008), 260-261.

${ }^{699}$ Recall that Bohm first proposed an ontological model with "hidden variables" to account for the apparent randomness and nonlocality implied by the Copenhagen view if quantum mechanics, with the purpose of preserving a uniform temporal-determinism, amongst other issues. See Bohm, "Hidden Variables and the Implicate Order."

${ }^{700}$ Worthy of note, however, is that Bohm returned to the idea of hidden variables in his final book (1993), with some revisions, The Undivided Universe: An Ontological Interpretation of Quantum Theory, 28-72.

${ }^{701}$ Craig, Time and the Metaphysics of Relativity, 227-229; Hobson, Tales of the Quantum: Understanding Physics' Most Fundamental Theory, 126-129; and http://www.preposterousuniverse.com/blog/2013/01/17/ the-most-embarrassing-graph-in-modern-physics/ (accessed August 24, 2017). The significance of the de Broglie-Bohm model will be revisited below as I discuss Bohm's views of time and freedom.

${ }^{702}$ See, for example, Michael Dickson and Rob Clifton, "Lorentz-Invariance in Modal Interpretations," in The Modal Interpretation of Quantum Mechanics, ed. Dennis Dieks and Pieter E. Vermaas (Dordrecht, The Netherlands: Kluwer, 1998), 34. Dickson and Clifton summarize by stating, "We are therefore left in the following situation: granted stability, there must be a preferred frame, but there is apparently no way for any experiment to determine what this frame is; without stability, modal [Bohmian hidden variables type] interpretations must either again violate fundamental Lorentz-invariance, or accept some fairly unpalatable consequences, noted in Section 4. The modal interpretation therefore requires stability to maintain plausibility, but cannot have fundamental Lorentz-invariance. Just as the Bohm theory does, the modal interpretation needs a preferred frame that, nevertheless, cannot be found. As Bell ... said of the Bohm theory, 'it seems an eccentric way to make a world,"' ibid., 34 (addition mine).
} 
Yet, it is the overall consequences of Craig's position that are critical. By advocating Bohm's early pilot-wave model and a cosmic preferred reference frame for time, Craig appears to commit himself to what will appear empirically as non-local (super-luminal) correlations without empirically traceable causation ('things happen' in nature that cannot be traced empirically, but Craig's views require that they are in fact naturalistically deterministic), in addition to assuming absolute determinism in nature. ${ }^{703}$ It must be added that Craig would not support such an absolute determinism in humans, as he is a libertarian, ${ }^{704}$ but this creates a hard dualism in his view between nature and man that returns one to the beginning of the problem of the two cultures and their relationship to freedom and time..$^{705}$ In other words, through his support of Bohm's early pilot-wave

703 "Quantum physics describes a universe in which everything is a consequence of ripples in matter fields and radiation fields. Bohm's notion is that, in addition to these fields, for every quantum (every ripple) there is a precisely located point particle that is guided, or piloted, by the ripples, and these particles are the things we observe directly in experimental outcomes.... According to the pilot-wave model, quantum fields also really exist, so the universe is made of both extended quantum fields and isolated point particles. The entire system-fields plus particles-is deterministic. Given the initial configuration of all the fields, and the initial positions and velocities of all the particles, the entire future and past of the universe is determined. Such a deterministic universe was Bohm's reason for devising this model," Hobson, Tales of the Quantum:

Understanding Physics' Most Fundamental Theory, 127. Gouesbet further explains, "the pilot wave theory, which makes exactly the same empirical predictions as quantum mechanics, is therefore strictly in the same epistemological position as quantum mechanics itself.... The fact that quantum theory and pilot wave theory make identical predictions has been used against the pilot wave. Holding fast inside the realm of quantum mechanics, the proponents of the Copenhagen interpretation viewed the pilot wave, standing outside of the holy circle, as a superstructure or as being metaphysical. If we refer to the epistemological language of Popper, the pilot wave indeed is not metaphysical. Being falsifiable (although simultaneously with quantum mechanics), it is on the scientific side, not on the metaphysical side, of Popper's famous demarcation line," Gouesbet, Hidden Worlds in Quantum Physics, 210. In a similar manner, elsewhere Gouesbet comments, "elaborating on Schrödinger's equation, Bohm demonstrated that the usual quantum mechanics can be recast in another framework exhibiting Newton-like hidden trajectories, forming a deterministic sublevel below the quantum level.... Now, a most important fact is that the pilot wave is empirically equivalent to quantum mechanics.... We ... have, in this example, two empirically equivalent theories with conflicting ontologies: the orthodox quantum mechanics exhibiting an intrinsic indeterminacy, and the heretical pilot wave relying on the deterministic motion of hidden trajectories. In the pilot wave framework, indeterminacy is no more of an intrinsic nature. It is simply the consequence of our lack of knowledge concerning hidden trajectories. Probabilities are no more intrinsic, but now receive a classical interpretation, like when tossing a coin, where our inability to predict the outcome of the toss merely reflects our ignorance of initial conditions (and our inability to carry out computations which are much too complicated)," Gérard Gouesbet, "From Theories by Lorenz and Mie to Ontological Underdetermination of Theories by Experiments," in The Mie Theory: Basics and Applications, eds. Wolfram Hergert and Thomas Wriedt (New York, NY: Springer, 2012), 89.

${ }^{704}$ William Lane Craig, "Ducking Friendly Fire: Davison on the Grounding Objection," in Philosophia Christi 8:1 (2006), 161-166, esp. 163 n. 4. See also, Steven B. Cowan and James S. Spiegel, The Love of Wisdom: A Christian Introduction to Philosophy (Nashville, TN: B\&H Publishing, 2009), 232.

${ }^{705}$ Owing to this fact, Craig supports a dualism between the body and soul-that is, the soul exists apart from the body in some 'timeless' or meta-natural realm (and as such, the time of humanity and the time of nature are severed, however the time of humanity may be conceived). William Lane Craig, "Doctrine of Man (Part 5) at https://www.reasonablefaith.org/podcasts/defenders-podcast-series-2/s2-doctrine-of-man/ doctrine-of-man-part-5/ (accessed December 6, 2017); and his colleague J. P. Moreland, "The Soul and Life 
model, Craig ultimately commits himself to an abstract mathematized and deterministic (therefore scientific) view of natural reality-all for the oddly linked sake of preserving a cosmic universal absolute time (he connects this with $\mathrm{God}^{706}$ and it also, I would suggest, is intimately tied into his support for 'timeless' "middle knowledge" as a means of granting God prior timeless foreknowledge of the future ${ }^{707}$ ) which is mysteriously connected with nature empirically, but is also associated with an

Everlasting: Introduction," in Philosophy of Religion: A Reader and Guide, ed. William Lane Craig (New Brunswick, NJ: Rutgers University Press, 2002), 429-446.

${ }^{706}$ Craig, Time and the Metaphysics of Relativity, 235, 239-240.

${ }^{707}$ For two of his many expositions of the position of Molina's middle knowledge, see William Lane Craig, The Only Wise God: The Compatibility of Divine Foreknowledge and Human Freedom (Eugene, OR: Wipf and Stock, 2000); and William Lane Craig, "Doctrine of God Part 15: God's Middle Knowledge," at https://www.youtube.com/watch?v=882AGGzDJmk (accessed May 8, 2019). For a critique of Craig, see Christian Tapp, "Eternity and Infinity," in God, Eternity, and Time, eds. Edmund Runggaldier and Christian Tapp (New York, NY: Routledge, 2016), 99-116. For more on Molinism, see also, Thomas P. Flint, Divine Providence: The Molinist Account (Ithaca, NY: Cornell University Press, 1998); and Sze Sze Chiew, Middle Knowledge and Biblical Interpretation: Luis de Molina, Herman Bavinck, and William Lane Craig (New York, NY: Peter Lang, 2016). For Molina's own exposition, see Luis de Molina, On Divine Foreknowledge: Part IV of the Concordia, tr. Alfred J. Freddoso (Ithaca, NY: Cornell University Press, 1988). The significance of middle knowledge as a solution to the problem of freedom and divine omniscience may not be a resolved matter, however. As Ron Highfield observes, God "chooses the universe in which Abraham obeys the command to leave Ur, Judas betrays Jesus, Peter denies the Lord three times, Paul persecutes the church before his conversion, you and I are born." However, what this also entails is that "middle knowledge allows God to choose from all possible worlds to create the one he wants to create, without determining the choices of free creatures. God chooses to actualize the precise and infinitely complex set of circumstances in which each human being makes the choices God wants made," Ron Highfield, Great Is the Lord: Theology for the Praise of God (Grand Rapids, MI: Eerdmans, 2008), 323. The idea that our world, in all its particularities, is the "best" possible, or, more precisely in Craig's terminology, 'feasible' world, where everyone makes the choices 'God wants made' is controversial-it also implicates every instance of natural evil and suffering as somehow ideal. There is an implicit contradiction in such reasoning. It seems to initiate an infinite regression on why absolutely everything that has happened was part of the only feasible 'best' world that could be, which God was obliged to want to choose, because it was the best feasible where all the choices made were the ones that would bring about the greatest glory to God and happiness to creatures, and were thus the ones God wanted. As Craig put it, of all the feasible worlds God could create, "this [one] may be the best God could get," Craig, "Doctrine of God Part 15: God's Middle Knowledge," 24:45-24:48.

Noting that Craig has forced a dualism into his understanding of God, man, freedom, and nature, I think the following comment insightful. Donald Gelpi observes that "the debate remained unresolved [between Augustinian Thomists and Molinists whom Craig supports] because neither side thought to challenge the dualism which in no small measure created the problem in the first place: operational dualism and a dualistic understanding of the relationship between time and eternity. By locating freedom in the essentially spiritual [and timeless] faculty of the will Thomism made it impossible to think of God moving the will efficaciously to act one way and not another without denying freedom of choice. Similarly, projecting into the Godhead a Neoplatonic theory of divine knowledge inevitably called into question the freedom of choice which God foreknows with necessary and immutable antecedent knowledge. Molina saw the problem, but the contrived character of his solution suggests that he needed to carry his critique ... much further than he did," Donald L. Gelpi, The Gracing of Human Experience: Rethinking the Relationship between Nature and Grace (Eugene, OR: Wipf \& Stock, 2007), 109-110; see also x, 4-5, 167, 170-171, 201, 331, 348 (additions mine). Gelpi suggests that the (loosely Heideggerian American precursor) philosopher Charles Sanders Peirce offers a fresher way to think about the relationship of philosophy and theology. 
unempirical æther. ${ }^{708}$ All of these postulations are deeply problematic and divisive in both the physics and theological communities, and also empirically unprovable or possibly already falsified, and, importantly, the real victim of his views appears to be any intelligible concept of freedom in nature, including the human being, which Craig separates from nature. ${ }^{709}$ The problem of the two cultures remains unresolved in Craig's view, as a consequence of the fact that it remains unresolved in the disciplines and theories of those upon whom he relies. Of course, this again illustrates that theologians or 'theological philosophers ${ }^{\prime 710}$ must be cautious when proceeding from certain

\footnotetext{
${ }^{708}$ Martin Gardner, Did Adam and Eve Have Navels?: Debunking Pseudoscience (New York, NY: W. W. Norton \& Company, 2000), 75. "In Bohm's revolutionary theory, as refined by his associate Basil Hiley, particles are as real as golf balls. At all times they have precise, unfuzzy properties such as position and momentum, and precise paths through space-time. The particles are never waves. Associated with each is an invisible, undetectable wave in a field which Bohm called the 'quantum potential.' Its pilot waves are real waves, not probability waves. They guide the particle's motion in a manner somewhat like the way a river's wave guides the movement of a floating leaf, or, in a better analogy, the way radar information guides a ship. This quantum field, like the fields of gravity and electromagnetism, permeates all of space-time, but unlike those fields its intensity doesn't diminish with distance. Also unlike other fields, it exerts no force on particles. Essentially it is a wave of undecaying information. It is the ad hoc nature of this undetectable pilot wave that reminds so many of Bohm's antagonists of the old stagnant aether of the nineteenth century, a substance that could not be detected as a carrier of electromagnetic waves, and that Einstein had discarded as useless," ibid.

${ }^{709}$ Specifically, Craig is a dualist interactionist. See https://www.youtube.com/watch?v=Sd95H_f0mGo (accessed December 21, 2017). This is in contrast to other prominent philosophers such as Nancey Murphy, an anthropological monist or materialist. For a critique of dualist interactionism, see James W. Cornman, Keith Lehrer, and George Sotiros Pappas, Philosophical Problems and Arguments: An Introduction $4^{\text {th }}$ ed. (Indianapolis, IN: Hackett, 1987), 139-153; and for a broader biblical critique of the issues in anthropology, see Marla A. Samaan Nedelcu, "What Makes Humans Human? Personal Ontology in the Creation Narrative of Day Six (Gen. 1:24-31)," in Scripture and Philosophy: Essays Honoring the Work of Fernando Luis Canale, 382-407. It is not insignificant that recent empirical studies claim to have falsified Bohm's pilot-wave model interpretation of quantum mechanics, and free-will plays a key factor, according to Antoine Suarez, "Nonlocal 'Realistic' Leggett Models Can be Considered Refuted by the Before-Before Experiment," at http://www.quantumphil.org/ SuarezF0OP201R2.pdf (accessed May 27, 2008); 4. Suarez explains that "the 'single preferred frame' is not refuted by the before-before experiment, but is not a coherent picture: it does not make sense to maintain the spook of nonlocality [while] giving up the experimenter's freedom, since one can get rid of both 'mysteries' (freedom and nonlocality) by choosing deterministic local pictures that are fully compatible with relativity, like Super-determinism and Many-Worlds," ibid. See also, Gisin, Quantum Chance: Nonlocality Teleportation and Other Quantum Marvels, 90; Antoine Suarez, "Bohm's 'Quantum Potential' Can be Considered Falsified by Experiment," at https://arxiv.org/pdf/1410.2014.pdf (accessed October 8, 2014); Antoine Suarez, "Time and Nonlocal Realism: Consequences of the Before-Before Experiment," at https://arxiv.org/pdf/0708.1997.pdf (accessed August 15, 2007); Antoine Suarez, "Leggett's Inequality, the Before-Before Experiment, and Free Will on the Part of Nature," at https://arxiv.org /pdf/0801.3050.pdf (accessed December 21, 2017); Suarez, "Entanglement and Time"; and André Stefanov, Hugo Zbinden, and Nicolas Gisin, "Quantum Correlations with Spacelike Separated Beam Splitters in Motion: Experimental Test of Multisimultaneity," in Physical Review Letters Vol. 88 Num. 12 (March 25, 2002), 1-4. Note also, Bob Doyle, http://www.informationphilosopher.com/ solutions/scientists/suarez/ (accessed August 24, 2017).

${ }^{710}$ I distinguish 'theological philosophers' from philosophical theologians here in that Craig is proceeding from a theological assumption to derive philosophical-scientific conclusions, and all this generally outside Scripture.
} 
assumptions about the nature of God's relationship to nature owing to a presumption about the 'nature' of nature.

In summary, what the era of relativity has brought to scientific thought and worldview formation has been a number of puzzles that seem to encourage very different views about the nature of time. This holds true through its namesake, relativity, which banishes time into a mere dimension of space and makes time relative to the localized individual in a deterministic world, or a mere return to a Newtonian worldview, through some advanced mathematical gymnastics, which preserves us a certain comfort that "all is right" with our common sense, yet also preserves the problems of how time relates to our physical world and humans, as well as ignores the fundamental question of how freedom enters the picture. The introduction of quantum physics did not help resolve the situation relativity introduced. Firstly, it introduced randomness and nonlocality, which broke apart the cohesiveness of time and physical causality, which appeared to banish freedom into randomness and timeless-ness, as freedom could not be associated with any story in space-time. Bohm's work, and the intuitions of many others like Einstein, insisted a causal-deterministic model must exist which would remove the randomness and or nonlocality, which would also restore, with its cosmic preferred frame, a single cosmic time. But, if so, the theories thus far suggested would only seem yet again to banish freedom entirely, or once more push it into a metaphysical timeless realm, as Kant and d'Espagnat have done. It is now toward the particular question of freedom in relation to Einsteinian time and Bohmian mechanics that this study turns.

\section{When's Freedom?}

The significance of Einstein's contributions to a theory of physical time cannot be overstated, for the simple reason that in both the special and general theories of relativity, the scientific paradigm, as a fusion of rationalism and empiricism, truly did run its course. So far as how time is conceived, Relativity is the consequence of the scientific paradigm carried out completely, even accounting for the relational aspects of wave field mechanics. So long as standard Aristotelian-Newtonian conceptions of time and space endured unchecked, the idea that temporal-causation represented 
some sort of global metric concealed the fact that the question of when freedom existed remained unasked in a critical way, because the 'common sense' temporal flow of time masked the question of freedom's temporal location.

However, by exposing science's (and therefore also Einstein's, as the paradigmatic scientist) commitments to realism, continuity, completeness, locality, causality, and determinism, ${ }^{711}$ it was shown that through the theory of relativity, empirically-mathematically, nature does reveal some sort of an order that appears to preclude the reality of absolute time, that is, in it time becomes construed in a mathematically relative and timeless way. The discovery of this and its widespread acceptance forced a more critical reflection to be cast upon the concept of freedom, and for the first time the forceful (i.e. empirical) realization came about that freedom either 1) didn't exist, ${ }^{712}$ or 2) was supratemporal. That is, outside the causal-temporal ${ }^{713}$ orders of nature's timeless relativity, or "timeless" in an even deeper non-material way, which is reflected in many subtle ways throughout the history of how political philosophers have understood freedom since the dawn of modern science, ${ }^{714}$ as well as

${ }^{711}$ Arkady Plotnitsky, Complementarity: Anti-Epistemology After Bohr and Derrida (Durham, NC: Duke University Press, 1994), 182. Plotnitsky explains that "from or before Newton to Einstein and beyond" the "homogeneous account of the [physical] world" "would imply determinism," and it must be kept in mind that "the significance of determinism for Einstein, as against other aspects of his positions-such as realism, continuity, completeness, or locality-is at times overstressed. The point, however, is relatively minor. For determinism is an inevitable counterpart of Einstein's views of reality and completeness, as emphasized by Bell in his analysis of Einstein's exchanges with Born; and presupposed or inferred, deterministic causality is equally significant for Bohm and Bell. Moreover, in physical and philosophical terms, all their key ideas are derived from classical deterministic models, and it is difficult to suspend the metaphysical determination of their views of physics, all the claims for pragmatism notwithstanding," ibid., 182.

712 This was, of course, Einstein's own view as noted above. See also, Jammer, Einstein and Religion: Physics and Theology, 181; David A. Shiang, God Does Not Play Dice: The Fulfillment of Einstein's Quest for Law and Order in Nature (Lexington, MA: Open Sesame, 2011), np; and Andrew Robinson, Einstein: A Hundred Years of Relativity (Princeton, NJ: Princeton University Press, 2015), 151. See also, Smolin, Time Reborn: From the Crisis in Physics to the Future of the Universe, xxii; Barbour, The End of Time: The Next Revolution in Physics, 324.

${ }^{713}$ In effect, given the standard constraints of the scientific worldview, "an act of free will" seems "timeless and ... mysterious. Both intrude into thoughts about the chain of cause and effect and are apt to cause a breakthrough, a turning point in the process going on at the time," Begley, Afraid to Believe in Free Will: The Human Tendency to Avoid Responsibility for Free Choices, 19.

${ }^{714}$ Following Kant, for whom "freedom ... [is] timeless," “'independent of all empirical conditions,'” Patrick R. Frierson, What is Human Being (New York, NY: Routledge, 2013), 238. This remains a point of sore criticism today, as Derek Parfit comments, "some of Kant's claims about our timeless freedom are not even vaguely intelligible. On Kant's view, for example, though everything that happens in the spatio-temporal world is fully causally determined, everything that happens is also in part jointly brought about by a vast number of free and separate decisions, made timelessly, by all of the rational beings who ever live," Derek Parfit, On What Matters (two-volume set), ed. Samuel Scheffler (Oxford, UK: Oxford University Press, 2011), 269. The influence of Kant is significant. In a fascinating contrast and comparison, Andrew Russ shows how both Kant and Marx relied upon "the timeless operations of freewill" which impositions "our noumenal freedom upon the 
much of modern psychology. ${ }^{715}$ The point to be drawn from this is that relativity brought scientific

evidence to the table of philosophy that encouraged the complex musings of past philosophers about

the possibility of timelessness.

Although it can safely be said that most scientists were aware by the dawn of the early twentieth

century that standard scientific perspectives on nature did not encourage any 'lively' view of human

phenomena of nature," Andrew R. Russ, The Illusion of History: Time and the Radical Political Imagination (Washington, D. C.: The Catholic University of America Press, 2013), 121. Russ further elaborates, explaining that "Kant's regulated operations of free will blind to time" encouraged "Marx's compelled operations of will beckoned to change time," toward an idealized 'timeless' future, ibid., 121. "Marx delves further into the future in order to affirm the realities of timeless dignity. Yet as he does so he is forced to depreciate the timeless thought and ideals that are the foundation of his project. It is the future dimension of the timeless that was the unwitting drive of Marx and the Young Hegelians," ibid. Russ further expounds the influence of "timeless" freedom upon political and social theory. The philosophy of Jean-Jacques "Rousseau" "represents the nostalgic pangs of loss within Kant's commanding conception of the timeless morality. In many ways it creates a bond for Kant's timelessness with the virtues of the past, or more accurately, favors the illusions of the past reflecting upon the surface of timelessness's abstract expanse. The social contract is like an intellectual/political structural antenna for the reception of an imagined past. With the timeless will and a universal morality as its sponsors, the social contract is a future mechanism for the faint reminding of a previous innocence, a memorial of past dignity for heartening moral use in the future.

"On the other side of the spectrum is Marx's philosophy. In the same vein as Rousseau, his philosophy is a particular type of historical imagining upon the endless ocean of timelessness. In Marx's case, timelessness is projected into the future. Rather than bearing the marks of reminiscence, melancholy, defeated nostalgia, and future artificial communion, with the past, Marx's future represents the hopeful, cataclysmic promise of new historical life, an as yet unfulfilled future pledged to history by Kantian morality's timeless break with history. Marx views philosophy as having closed the doors of the past behind him, giving him only one directive ... the future. Rousseau's yearning preoccupation with the past saw him create a theoretical future state similar to Communism. Correspondingly, Marx's rampant fury for the future made his stark vision of Communism (a vision of progressive denunciation, simplification, and depletion of society's institutional complexity) appear very much in accord with Rousseau's depleted and unadorned state of nature. Marx is the vague and distant, yet boisterous horizon of timelessness, whereas Rousseau is the guilt-ridden reflection of history's once chaste precedents. Both thinkers allowed timelessness to spill from its lofty heights, directing it in a privileged temporal direction. Let us imagine Kant's ethical mountain with two rivers cascading down its sides. One river flowed both literally and imaginatively to the past, whereas the other flowed to the future. As such, there was bound to be an inevitable and unintended temporal backflow when dealing with the thoughts descending from this height. This is certainly part of the reason these two thinkers so closely resemble each other, as their imaginings of past and future are capable of becoming secondary waves of each other," ibid., 195. See also, Robert Trundle, From Physics to Politics: The Metaphysical Foundations of Modern Philosophy (New York, NY: Routledge, 1999), 131-132.

${ }^{715}$ Amihud Gilead expresses this as follows: "Time and temporality have to do with the physical realization, namely actualization, of our mind, not with our mind as such, as purely possible-psychical. Everything psychical as such, as purely possible, must be atemporal, and only the physical-actual is subject to time and temporality," Amihud Gilead, Necessity and Truthful Fictions: Panenmentalist Observations (New York, NY: Rodopi, 2009), 5. Gilead continues, "our sense of actuality consists in our acquaintance with the physical. By means of this acquaintance alone we acquire the experience of time and temporality. Without experiencing the physical-actual, we would have no temporal experience. Without the only possible actualization, the physical realization, of our mind as a body, time and temporality would remain merely ideas or pure possibilities for us. This is so, because our psychical life in itself, including our memories and recollections, is necessarily atemporal and not subject to temporal conditions. Atemporality is a necessary condition for remembering. Things remembered are quite different from actual things, which are inseparable from temporality," ibid., 5. 
freedom, most of society, and the community of scientists in particular, appeared comfortable ignoring this problem. ${ }^{716}$ In contrast, however, the challenge of relativity was real, at least for physicists. The discomfort that many had with time's relativity did inspire, in particular, the Lorentzian transformations in an effort to maintain a global-cosmic uniform absolute preferred time frame. These transformations appear to obtain their goal in special relativity, but when the gravitational fluxes of general relativity are introduced, the concept of a uniform absolute time frame again encounters difficulties. However, in either case, the issues of determinism remained a problem, as the Newtonian picture never 'resolved' the question of whether freedom was temporal or timeless, but, rather, left the issue wide open. The ambiguity of Newtonianism was exposed in two different directions through relativity and quantum physics, which concurred and conflicted with it in respectively different ways. ${ }^{717}$

Given that quantum physics appeared to reveal an inherent temporally realized randomness in nature (one can only deduce its random nature by accepting some sort of temporal time), a fierce debate ensued about whether the randomness was merely an epistemic limitation or an actual ontic reality, a debate that continues today. ${ }^{718}$ Bohm's early "hidden variables" proposal to the problem of randomness sought to restore a causal-deterministic picture, ${ }^{719}$ and in the process a preferred reference frame for time, which together would restore ontological timelessness. However, as noted

\footnotetext{
${ }^{716}$ This is part of what Doyle would refer to as the scandal of philosophy concerning free will. See Doyle, Free Will: The Scandal in Philosophy, 15-17.

${ }^{717}$ Heidi Ann Russell explains clearly the primary point of contention, namely that "the irreconcilable nature of quantum mechanics and general relativity has to do with the way each disagrees with Newtonian physics. While Newtonian physics explains the world we can observe and in which we interact with a great deal of success, general relativity describes the world of the very large on a cosmic scale, and quantum theory describes the world of the small on an atomic level. In doing so, general relativity accepts the assumptions that Newton made about the relationship between observers and the system they observe but altered Newton's understanding of time and space. Quantum mechanics alternatively accepted Newton's understanding of time and space as an unchanging background but altered Newton's understanding of the relationship between the observer and the observed. Consequently, one of the great issues that faces science today is the fact that these two theories which have been so successful in describing and explaining the way things work on their respective levels do not agree with one another," Russell, Quantum Shift: Theological and Pastoral Implications of Contemporary Developments in Science, 163.

${ }^{718}$ For example, see Andrew Whitaker, Einstein, Bohr and the Quantum Dilemma: From Quantum Theory to Quantum Information $2^{\text {nd }}$ ed. (Cambridge, UK: Cambridge University Press, 2006).

${ }^{719}$ Weinert, The Scientist as Philosopher: Philosophical Consequences of Great Scientific Discoveries, 229; and Louisa Gilder, The Age of Entanglement: When Quantum Physics was Reborn (New York, NY: Alfred A. Knopf, 2008), 391.
} 
above, many physicists remain unsupportive of Bohm's efforts. In any case, whether through the Lorentzian transformations to restore a preferred reference frame within relativity, or the Bohmian "hidden variables" (for quantum mechanics), within these debates the question of freedom's "when" takes prominence. This is especially the case in certain experiments which explore quantum randomness and nonlocality, such as the delayed-choice experiment, ${ }^{720}$ because there is an indeterminate amount of "time" between the measurable events, and the 'free' choices of the scientists also seem to be involved. The when of freedom becomes a much more complex question, and one that may involve both spatial and temporal interpenetration. ${ }^{721}$ That is, the 'present' may not be merely a consequence of the immediately prior 'moment,' nor is, perhaps, the immediately 'future' moment merely ensuant to the present moment. Different moments of the past affect upon the present independently, and the occurrences of the present may not be seen in the ontology of the immediate future but emerge only at a later time. Alternately, it is also theoretically possible for given

\footnotetext{
${ }^{720}$ Nadeau and Kafatos, The Non-local Universe: The New Physics and Matters of the Mind, 48-51. The results of this experiment appear to demonstrate that "the wave-like or particle-like status of a photon at one point in time can be changed later in time by choosing to measure or observe one of these aspects in spite of the fact that the photon is traveling at light speed.... It is as if we caused something to happen 'after' it has already occurred. These experiments ... unambiguously disclose yet another of the strange aspects of the quantum world-the past is inexorably mixed with the present and even the phenomenon of time is tied to specific experimental choices," ibid., 50.

${ }^{721}$ E. Megidish, A. Halevy, T. Shacham, T. Dvir, L. Dovrat, and H. S. Eisenberg, "Entanglement Swapping between Photons that have Never Coexisted," in Physical Review Letters 110 (22 May 2013), at https://arxiv.org/pdf/1209.4191.pdf. See also, Elise Crull, "You Thought Quantum Mechanics was Weird: Check out Entangled Time," at https://aeon.co/ideas/you-thought-quantum-mechanics-was-weird-check-outentangled-time (accessed February 2, 2018). Some describe it as follows. Together, "what the principle of relativity and quantum theory reasserts is the primacy of flux, change, movement and spatio-temporal interpenetration. Things, entities and apparently solid substances are but the temporal coalescence of matterenergy, and the actual world is a ceaseless process involving the becoming of such event-entities," Robert Chia, "The Shaping of Dominant Modes of Thought: Rediscovering the Foundations of Management Knowledge," in The Foundations of Management Knowledge, ed. Paul Jeffcutt (New York, NY: Routledge, 2004), 181. For more, see, for example, Alexander Styhre, The Innovative Bureaucracy: Bureaucracy in an Age of Fluidity (New York, NY: Routledge, 2007), 75-80; Sunny Y. Auyang, How is Quantum Field Theory Possible? (Oxford, UK: Oxford University Press, 1995), 140; V. J. Rydnik, ABC's of Quantum Mechanics, tr. George Yankovskey (Honolulu, HI, University Press of the Pacific, 2001), 138; Graham Smetham, Quantum Buddhism: Dancing in Emptiness-Reality Revealed at the Interface of Quantum Physics \& Philosophy (Sussex, UK: Shunyata Press, 2010), 90; and Kay Larson, Where the Heart Beats; John Cage, Zen Buddhim, and the Inner Life of Artists (London, UK: The Penguin Press, 2012), 354. Naturally, such implications draw interest from those in the humanities, such as Arthur Berndtson, Power, Form, and Mind (Toronto, Canada: Bucknell University Press, 1981), 163. Berndtson shares, "apart from memory, psychical time differs from physical time in that it has interpenetration of times rather than mutual externality of times. The inward texture of emotion is undoubtedly the most secure locus of psychical time. An emotion, such as joy, has a subtle diversity of qualities, which coexist with spatial interpenetration and succeed with temporal interpenetration," ibid., and Ben Goertzel, The Hidden Pattern: $A$ Patternist Philosophy of Mind (Boca Raton, FL: BrownWalker Press, 2006), 28-29, 53, 120.
} 
aspects of various disparate distant past and future elements to impact upon the 'empirical' present directly, rather than temporally through the flow of time that would appear to be sequentially logical. ${ }^{722}$

Very importantly, in one of the critical oddities of how the quantum world is described by physicists, an important residue of the language of temporal-causation from a Newtonian and especially a relativistic perspective is often retained when describing the anomalous behavior of the quantum world. Any attempts to describe free-will in relation to temporal sequences or other aspects of freedom, are by definition, being outside the accepted parameters of relativistic deterministic temporal-causation, "timeless" by definition. ${ }^{723}$ The speed of causality determines any concept of time, and, despite the challenges to relativity theory found in quantum phenomena, the speed of causality has not yet been successfully or satisfactorily defeated. As such, the linguistic options appear limited within a given causal paradigm. What is unfortunate in the case of quantum mechanics is that it was first articulated within a newly inaugurated paradigmatic framework (relativity) that had already disposed of the Newtonian picture, but retained the Newtonian foundation concerning the power of defining time. In other words, in Newtonianism a "common sense" cosmic absolute time was assumed in a coextensive relationship with temporal determinism, and so anything that existed outside of that framework was logically "timeless." Furthermore, however, from the standard relativistic perspective which Einstein inaugurated, since time has already been explicitly transformed into a type of timelessness, violations of this timelessness produce nothing but an even more abstracted form of timelessness, or so it seems in most literature about time generated from the sciences. ${ }^{724}$

\footnotetext{
${ }^{722}$ For an overview of some of these speculations, see John James, The Great Field: Soul at Play in a Conscious Universe (USA: Elite Books, 2007), 49-71, 165-166.

${ }^{723}$ Landvik, "At the Speed of Light," 83-88. It is important to observe that the puzzle of "how fast" time travels, whether associated with empirical evidence or not, helps create the problem of describing time. As the study has described above, any arbitrary limit to the speed of time or causality creates the paradoxes of relativity concerning any universal time and locality. From within any such given arbitrary system, whatever works outside that system must be "timeless," at least in the minds of many physicists.

${ }^{724}$ For example, Suarez, "Quantum Randomness, Free Will and Evolution;” and Antoine Suarez, "Preface," in Is Science Compatible with Free Will?: Exploring Free Will and Consciousness in the Light of Quantum Physics and Neuroscience, ed. Antoine Suarez and Peter Adams (New York, NY: Springer, 2013), vii. See also, Antoine Suarez, "Any Nonlocal Model Assuming 'Local parts' Conflicts with Relativity," at
} 


\section{Einstein's Influence Upon Theology}

The influence of Einstein upon theology is a complex question, one which cannot be treated fully here. ${ }^{725}$ However, two major trajectories can be stated, which have been mentioned above as well. First, Einstein both denied any sort of subjective time was either real or accessible to science, and his deterministic view of nature precluded any freedom. Fascinatingly, however, Einstein also seemed at times to believe that morality was compatible with determinism. ${ }^{726}$ Many theologians have noted these sometimes more and sometimes less clearly expressed convictions of Einstein, and a few of them have found ways to incorporate them into their theology-one such obvious match would be with Calvinists, especially concerning Einstein's timelessness, but also determinism. ${ }^{727}$ On the other hand, Einstein also denied a belief in any personal God, and thus he also contributed greatly to a new generation of atheists-again, not a surprise, given Einstein's own appreciation for Spinoza, whose views are debated but for whom it is clear there was no personal God. ${ }^{728}$ Furthermore, the actual life of Einstein exhibited, as Richard Crockatt described it, "seemingly contradictory understandings of freedom." That is, "there is no simple way of making sense of Einstein's" views, and "it is easy, and sometimes distorting, to pick statements from different moments in an individual's life that exhibit contradictions, but these statements are anything but isolated instances."729 Crockatt continues, “Einstein's philosophical determinism was deeply rooted in his conception of science," while at the

https://arxiv.org/pdf/1304.4801.pdf (accessed September 3, 2017); and Robert Lanza with Bob Berman, Biocentrism: How Life and Consciousness are the Keys to Understanding the True Nature of the Universe (Dallas, TX: Benbella Books, 2009), 102-105.

${ }^{725}$ One of the more interesting recent attempts is Steven Gimbel, Einstein's Jewish Science: Physics at the Intersection of Politics and Religion (Baltimore, MD: The Johns Hopkins University Press, 2012).

${ }^{726}$ Yemima Ben-Menahem, “Struggling with Causality: Einstein's Case," in Einstein in Context, eds. Mara Beller, Robert S. Cohen, and Jürgen Renn (Cambridge, UK: Cambridge University Press, 1993), 308; and Vucinich, Einstein and Soviet Ideology, 207. "As Einstein saw them, the physical and moral worlds obeyed the rigorous authority of determinism. He treated the inexorable power of causality as the basic mechanism of scientific explanation in both the physical and social order. He could not accept Heisenberg's principle of indeterminacy for the simple reason that it violated the law of cosmic unity. Einstein readily admitted that Spinoza's powerful arguments in favor of ethical determinism played a vital role in shaping his worldview," ibid.

${ }^{727}$ Note, for example, R. D. Kernohan, The Realm of Reform: Presbyterianism and Calvinism in Changing Scotland: Reflections (Handsel Press, 1999), 50, 141-142; and Jaeger, Einstein, Polanyi, and the Laws of Nature.

${ }^{728}$ David Mills, Atheist Universe: The Thinking Person's Answer to Christian Fundamentalism (Berkeley, CA: Ulysses Press, 2006), 11-12. See also, Jammer, Einstein and Religion: Physics and Theology, 48-51; 147.

${ }^{729}$ Richard Crockatt, Einstein and Twentieth-Century Politics: 'A Salutary Moral Influence' (Oxford, UK: Oxford University Press, 2017), 155. 
same time, "his equal and opposite devotion to individual freedom in the social and political spheres was evidently a psychological need, which was manifested in his fierce independence and hatred of coercion." Thus, it would seem that "Einstein's own separation between the method of natural science and his approach to political and social questions"730 clearly illustrates the tensions and paradoxes between the "two cultures" that is the focus of this study. ${ }^{731}$

In any case, the common denominators in Einstein's broader influence appear to be the advocation of an orderliness in nature, so much so that determinism reigns supreme, a lack of emphasis on any personal God, and an ambiguity concerning the reality of processual time. An added complexity to the situation surrounding Einstein is that "everyone" wants to count such a genius as an ally in one way or another. ${ }^{732}$

\section{Bohm as an Exemplar of Einstein}

In relation to the previous section, there are four notable reasons that among the generation overlapping and then succeeding him, Bohm best exemplifies the trajectory of Einstein's ideals, and thus influence.

\footnotetext{
${ }^{730}$ Crockatt, Einstein and Twentieth-Century Politics: 'A Salutary Moral Influence', 155. Overall, however, the poignant clarity of Einstein nevertheless still rings clearly in his words "'I do not believe in human freedom in the philosophical sense.' Everybody acts 'not only under external compulsion but also in accordance with inner necessity.' Schopenhauer's famous saying that 'a man can do what he wants but not want what he wants' had been, he added, 'a very real inspiration to me since my youth [and] a continual consolation in the face of life's hardships,'” Einstein, as cited in ibid., 155.

731 "Henri Bergson proposed to Einstein to eliminate the paradoxical appearance of his theory and 'reconcile it with men as men' by 'a distinction between physical truth and truth,' or between the physicist's time and the layman's time, not reserving the attributes of 'real' or 'truth' only for the former. Maurice MerleauPonty, who reported this encounter between Einstein and Bergson, is entirely sympathetic to the latter's attempt to obtain Einstein's cooperation in reconciling the 'concrete world of our perception' with science and in allowing physics to 'freely develop its paradoxes without authorizing unreason,"' Yaron Ezrahi, "Einstein and the Light of Reason," in Albert Einstein, Historical and Cultural Perspectives: The Centennial Symposium in Jerusalem, eds. Gerald Holton and Yehuda Elkana (Princeton, NJ: Princeton University Press, 1982), 264.

${ }^{732}$ See, for example, John Marsh, The Liberal Delusion: The Roots of Our Current Moral Crisis (La Vergne, TN: Arena Books, 2012), 72-74. Einstein was, no doubt, clever, and his many comments on the relevant subjects can take people in many directions, insofar as his personal views are concerned. His actual influence, however, appears to support a conflicted legacy.
} 
First, the early Bohm's work to articulate a deterministic theory of quantum mechanics was clearly the goal of Einstein, ${ }^{733}$ even if Einstein wasn't necessarily pleased with the evidently nonlocal results of Bohm's model ${ }^{734}$ (nor was Bohm at times, thus his continual adjustments). Second, Bohm's ideas were influenced by, and in turn have influenced others, concerning social and political issues, ${ }^{735}$ reflecting Einstein's similar influence upon others. Bohm's interests in the "humanities" is, perhaps, unmatched amongst the top physicists of his generation. Third, Bohm's tentative remarks and interest in the subject of God and theology shares some of the sentiments made in the ambiguous comments by Einstein. Fourth, and lastly, Bohm has awakened fresh critical thinking by others about the nature of the divine and divine action in the world, ${ }^{736}$ yet, as with Einstein, without necessarily intentionally seeking to do so.

Having covered the above background information concerning Bohm, in the following sections Bohm's specific ideas about the natures of time and freedom will be explored, focusing on his later philosophical writings.

\section{Bohm's View of Time}

To understand Bohm's view of time, one must first understand what it is not. So as a first step toward explaining Bohm's view of time as a representative of the sciences, Bohm's view must be positioned as in distinct contrast with those of Descartes ${ }^{737}$ and Newton, ${ }^{738}$ as well as Einstein, ${ }^{739}$ the

\footnotetext{
${ }^{733}$ Peat, Infinite Potential: The Life and Times of David Bohm, 104; Landvik, "At the Speed of Light," 8687; Holland, The Quantum Theory of Motion: An Account of the de Broglie-Bohm Causal Interpretation of Quantum Mechanics, 15-26; Jammer, Einstein and Religion: Physics and Theology, 227; and Weinert, The Scientist as Philosopher: Philosophical Consequences of Great Scientific Discoveries, 229. See also, Robert J. Russell, "The Science of Light and the Light of Science: An Appreciative Theological Reflection on the Life and Work of Charles Hard Townes," in Visions of Discovery: New Light on Physics, Cosmology, and Consciousness, eds. Raymond Y. Chiao, Marvin L. Cohen, Anthony J. Leggett, William D. Phillips, and Charles L. Harper, Jr. (Cambridge, UK: Cambridge University Press, 2011), 762-763.

${ }^{734}$ Plotnitsky, Complementarity: Anti-epistemology After Bohr and Derrida, 172.

735 Peat, Infinite Potential: The Life and Times of David Bohm, 56-72, 110, 113.

${ }^{736}$ Peters, Science, Theology, and Ethics, 112.

${ }^{737}$ Bohm and Peat, Science, Order, and Creativity, 101; Bohm, Unfolding Meaning, 19-20; Bohm, Wholeness and the Implicate Order, 250; and Bohm, "A New Theory of the Relationship of Mind and Matter," 271-286.

${ }^{738}$ Bohm, Wholeness and the Implicate Order, 5-6. As such, Bohmian inspired accounts "aim ... to take us from our deeply received scientific worldview and, derived from it, our view of the 'real world' in which we live-namely, from the understanding of the world that was spawned by Newton and modern physics, to an entirely different, newly vibrant, surprising, partially unknowable world of becoming which the living, evolving
} 
primary figures that dominate the scientific conception of time. The most obvious points of confusion will come from the facts that the mechanistic fusion of Descartes' and Newton's deterministic temporality is seen to be a false temporality concealing timelessness, and Einstein's deterministic space-time falls prey to timelessness in a perhaps more obvious manner, as it fully integrates the maximum speed of causality with spatialization. ${ }^{740}$ Yet, despite these different conceptions of timelessness operative in the sciences, Bohm will instaurate timelessness yet again in a fresh way. The point at present is that because timelessness has so many faces, it is undoubtedly confusing. That said, it must be quickly noted that Bohm did not consider his ideas or anyone's ideas that might move beyond current physics to be simple-to overcome the fragmentary way of thinking ${ }^{741}$ presupposed by modern science is not easy, and "to expect an answer in a few minutes makes even less sense than to ask how to develop a theory as new as Einstein's was when he was working on it." ${ }^{1742}$ Left with such a challenge, which is also applicable to simply explaining Bohm's own views, the following examination of Bohm's ideas will endeavor to be as concise and accurate as possible.

\section{Time in Nature}

Bohm explains that within the standard understanding of physics, "time is an abstraction from movement, becoming, and process. This view was implicit in Heraclitus ${ }^{1743}$ and has remained a

world-biological, economic, cultural-co-creates, in an often unprestatable mystery," Stuart A. Kauffman, "Foreword: Evolution beyond Newton, Darwin, and Entailing Law," in Beyond Mechanism: Putting Life Back Into Biology, eds. Brian G. Henning and Adam C. Scarfe (Lanham, MD: Lexington Books, 2013), 1.

${ }^{739}$ Bohm, Wholeness and the Implicate Order, 31. Bohm expresses the view that "one who is similar to Einstein in creativity is not the one who imitates Einstein's ideas, nor even the one who applies these ideas in new ways, rather, it is the one who learns from Einstein and then goes on to do something original, which is able to assimilate what is valid in Einstein's work and yet goes beyond this work in qualitatively new ways," ibid.

${ }^{740}$ Within the theory of relativity, "as you move faster and faster according to relativity your time rates slow down and the distance gets smaller, so as you approach very high speeds your own internal time and distance become less, and therefore if you were at the speed of light you could reach from one end of the universe to the other without changing your age at all," because time has not transpired for you as no causes or experiences could take place, Bohm, The Essential David Bohm, 153.

${ }^{741}$ For more on this challenge, see Horton, Contemporary Science Fictions: Affect and Ethics in the Modern British Novel, 119-121.

${ }^{742}$ Bohm, Wholeness and the Implicate Order, 22-23.

${ }^{743}$ David Bohm, “Time, The Implicate Order, and Pre-Space," in Physics and the Ultimate Significance of Time: Bohm, Prigogine, and Process Philosophy, ed. David Ray Griffin (Albany, NY: State University of New York Press, 1986), 177. Within physical theories of time, one must "consider the distinction of past, present, and future. In general, what we are conscious of as now is already past, even if only by a fraction of a second. It takes time to produce and organize a meaningful show of this content in consciousness. Moreover, the 
constant throughout history, with but few detractors. ${ }^{744}$ What distinguishes Bohm's view of time

from his predecessors in the scientific tradition concerns the innovations necessary to integrate the

discoveries of quantum phenomena with relativity, with a focus on the significance of "becoming."145

The major criticism Bohm has against classical descriptions of time in physics is that there is an

organization of abstract knowledge takes a lot longer than does that of the relatively immediate sensory experience. The conscious content of the moment is therefore of that which is past and gone. The future is not yet. The present is, but it cannot be specified in words or in thoughts, without its slipping into the past. When a future moment comes, a similar situation will prevail. Therefore, from the past of the present we may be able to predict, at most, the past of the future. The actual immediate present is always the unknown. All possibilities of prediction evidently depend on the assumption that the movement is sufficiently slow, regular, and unambiguously related to what comes next, that the difference between the time to which our perceptions and knowledge actually refer and the present makes no significant difference. This is evidently true in a wide range of circumstances. But, in at least two key areas, it is not.

"First, in human consciousness itself, what actually happens in its ground may be very fast, irregular, and ambiguously related to the content that can be specified. Therefore, the use of the past to determine what a human being is and what he will be can be seriously questioned, if this is carried beyond a certain very limited and probably rather superficial domain.

"Second, according to modern physics, microprocesses are also very fast, irregular, and ambiguously related to what comes next. Indeed, it is not in general possible to relate the specifiable information content unambiguously to succeeding events (this is just the essential meaning of the Heisenberg uncertainty relations, as interpreted by Bohr). Here, too, the relevance of the usual notions of time may be questioned. What seems to be called for is that we recognize that the 'point event' of relativity theory cannot in general have an unambiguous meaning," ibid., 182-183. Additionally, Bohm observes that the "full development of the concept of time requires the following elements": 1) A recurrent (generally periodic) process, which establishes the measure of time; i.e., what is meant by equal time intervals (e.g., the seasons, the waves in a resonant cavity, etc.). Note that such processes are clearly reversible. 2) An irreversible process, which establishes an irreversible order of time (e.g., as with the increase of entropy). 3) A fairly stable memory, which enables time intervals in the recurrent (periodic) process to be registered. Such stability of memory evidently requires the irreversibility of time, or else the nested succession of moments could not be maintained, as registered in whatever structure may be the basis of retention of information in memory, ibid., 182.

${ }^{744}$ Bohm and Peat, Science, Order, and Creativity, 98-105. Of course, whether the secularized flux of time after the medieval period during the rise of science is meaningfully 'temporal' is still in question. It would likely still be construed as deterministic, as Bohm would surely acknowledge, but here he glosses the issue.

745 "Relativity theory describes space-time as completely analyzable down to dimensionless points related by absolute causal laws. In this theory, the whole of space-time has to be considered as a block in which there is no possibility of giving meaning to a moment 'now,' except perhaps as a subjective illusion. But as we have also seen, quantum mechanics has gone a long way toward the dissolution of the very basis of this picture. It suggests that there are objective but context-dependent moments extended in some sense, as well as ambiguously located in space and time," Bohm, "Time, The Implicate Order, and Pre-Space," 184. Furthermore, "if reality is ultimately only the totality of space-time, which is constituted of point events, then becoming has no meaning; it is, indeed, an illusion. But with extended moments it is possible to enfold the past of a given moment as a nested structure (as happens, for example, in memory) that is present in that actual moment. So the moments are not isolated or merely externally related point events but are, instead, internally related extended structures and processes," ibid. Bohm adds, "here we may usefully consider the example of a motion picture. Human consciousness does not ordinarily resolve time differences much shorter than about a tenth of a second. The motion picture camera may take as many as ten pictures during this interval, each slightly different from the other. The perception of all of these pictures at once, 'fused' in some moment 'now,' gives rise to a sense of movement and becoming, in which each experienced moment is felt to be 'flowing' without a break into the next. But if the pictures are more than a tenth of a second apart, one senses a series of 'jumps' and 'jerks' between disjoint images rather than an unbroken flowing movement of becoming. Clearly this means that the sense of becoming is based on the copresence of a number of slightly different images, in any one (ambiguous) moment of consciousness," ibid., 184-185. 
"assumption that the macrolevel is merely a convenient mode of analysis introduced by us, which means that it is subjective, whereas only the ultimate microlevel is objective and independent of how we think about it.".746 Of course, in science, operating under the presuppositions of Newton and Einstein, becoming was an illusion. Thus, Bohm's theory advances the idea that "there is no ultimate level. There are only relatively autonomous and independent contexts, in which the differences in what is left out make no significant difference in the context in question. So macrocontext and microcontext are both objective, and yet both are abstractions." ${ }^{747}$ We are thus able to think about being and becoming in a new way in relation to abstraction and context, as will be seen below.

Bohm draws upon the work of Polanyi concerning tacit knowing to explain that knowing cannot always be "explicitly denoted or verbalized (e.g., as in knowing how to ride a bicycle). The key point is that becoming is sensed most directly in this highly implicit, tacit, nonlocalizable, and nonspecifiable way." Rather, "deeply and inwardly all becoming, and not merely that which takes place in our conscious experience, is of this nature."748 Because of this, "it follows ... that becoming is not merely a relationship of the present to a past that is gone. Rather, it is a relationship of enfoldments that actually are in the present moment. Becoming is an actuality," and one that "continues in all succeeding moments," that is, "the two principles of the being of becoming and the becoming of being" must be woven together, ${ }^{749}$ something that has not occurred in standard science.

${ }^{746}$ Bohm, “Time, The Implicate Order, and Pre-Space," 181.

${ }^{747}$ Bohm, "Time, The Implicate Order, and Pre-Space," 181. For example, as the irreversibility of time applies to aging, "there is more to time than aging. Many systems of different age may be in contact at the same time, while many systems of the same age exist at different times." Likewise, "there is evidently more to irreversibility than just loss of information. For example, a very important kind of irreversibility is found in memory. In each moment, there may be enfolded a memory of its past, in which, in turn, there may be enfolded a memory of its past, and so on. Memory is thus in a kind of nested order of enfoldment.... This is clearly a fundamental kind of irreversibility. However, the possibility of relative independence of the present from the distant past arises because differences in highly enfolded memories will, in general, make little difference within the context of the present. This is somewhat reminiscent of how entropy works," ibid., 181-182.

${ }^{748}$ Bohm, "Time, The Implicate Order, and Pre-Space," 185.

${ }^{749}$ Bohm, "Time, The Implicate Order, and Pre-Space," 185. Thus, "explicate 'moments' that unfold have a certain temporal thickness, a certain duration. Moments are temporal segmentations of unfoldment. Unfoldings through belonging-together take a brief time. This is 'a moment where what has been is separated from what is yet to come.' Within this brief duration time becomes nonlocal," Gordon Globus, The Transparent Becoming of World: A Crossing Between Process Philosophy and Quantum Neurophilosophy (Amsterdam, The Netherlands: John Benjamins, 2009), 132. 
It is critical to understand that the above description is just the first step in Bohm's proposal. That is, the nested sequence of enfoldments of past moments which unfold into the present, and then future moments, represents the "horizontal" implicate order, ${ }^{750}$ which correlates most closely with the generation of our perception of the standard or explicate Newtonian and Einsteinian order of temporal causation (that is, the explicate Newtonian order is not fundamental, but it remains the point of reference to describe the horizontal implicate order concerning time). There is also, however, a "vertical" implicate order, which consists of an indefinite or even infinite number of layers-that is, there is movement not merely horizontally, or from past to present to future as described above through enfolded or nested moments, but there is also movement in which "any given level is unfolding (in principle creatively) from levels that are more comprehensive and more fundamental." ${ }^{\text {751 }}$ Bohm suggests one way to understand this is to think of, "for example, a solid object" which "may at first be disturbed only mechanically by outside forces, but if its temperature is raised it eventually melts or evaporates. This is understood by going to a new context, in which the existence of a solid is seen to depend on a deeper and more universal atomic structure." However, "as long as we do not assume that there is an ultimate and fundamental context, the reality of the solid is not denied. The atomic structure and the properties of solids are both real in their contexts, which are, however, limited abstractions from a total reality that cannot be grasped in any specifiable context." ${ }^{752}$ Of course, to complete the analogy, as physics has been further advanced, unexpected and nonintuitive layers beneath the atomic level have been discovered, and the subatomic level contains its own behaviors, and, again yet further, beneath the subatomic level, a layer of fields exists which contains its own distinct behaviors. This illustrates, in a manner, how there could theoretically be many deeper implicate or super-implicate orders. ${ }^{753}$

\footnotetext{
${ }^{750}$ Bohm, “Time, The Implicate Order, and Pre-Space," 186. For more, see Bohm, "The Implicate Order: A New Approach to the Nature of Reality," in Beyond Mechanism: The Universe in Recent Physics and Catholic Thought, 13-37.

${ }^{751}$ Bohm, "Time, The Implicate Order, and Pre-Space," 186.

752 Bohm, "Time, The Implicate Order, and Pre-Space," 187.

${ }^{753}$ For more on the super-implicate order, see Bohm and Peat, Science, Order, and Creativity, 177-188; and Bohm, The Essential David Bohm, 139-157.
} 
It is important to keep in mind that the explicate order (the Newtonian common-sense order) is not to be seen "as separate, standing over and against an implicate order with which it would be in relationship. Rather, the explicate order is a kind of relatively independent 'constituent' of the implicate order, with which it fuses and interprenetrates."754 Bohm explains, "one may obtain a good image of what is meant here by thinking of this 'constituent' as a kind of hologram, which is an implicate 'counterpart' of the explicate order. However, within its context the explicate order has a kind of relatively independent reality corresponding to that which we instinctively and unconsciously attribute to 'real things' in ordinary experience. But the ground of this reality is the overall implicate order, in which it lies as a 'constituent."'755

The meaning of time features prominently in this new description of the vertical implicate orders. Given that in the physics of "modern quantum-mechanical field theory the 'vacuum state' has, properly speaking, no physically meaningful notion of time at all in it," and furthermore, "if time has to be abstracted from an ordered sequence of changes in an actual physical process, we would be justified in saying that the vacuum state is, in a certain sense, 'timeless' or 'beyond time,' at least as time is now known, measured, and experienced."${ }^{756}$ Because there is a fundamental unity between the observer and the observed in the Bohmian view of reality, Bohm proposes that "each moment of time is a projection from the total implicate order... The projection of each of these moments is a

\footnotetext{
${ }^{754}$ Bohm, “Time, The Implicate Order, and Pre-Space," 188. The interpenetration Bohm speaks of here belies what is an important conceptualization of the relationship between the implicate and explicate orders that can be intriguingly contrasted with that of, for example, Dooyeweerd. For a recent summation, see Jonathan Chaplin, Herman Dooyeweerd: Christian Philosopher of Civil Society (Notre Dame, IN: University of Notre Dame Press, 2016); and Lydia Jaeger, "Beyond Emergence: Learning from Dooyeweerdian Anthropology?," in The Future of Creation Order: Vol. 1, Philosophical, Scientific, and Religious Perspectives on Order and Emergence, eds. Gerrit Glas and Jeroen de Ridder (Cham, Switzerland: Springer, 2018), 236.

755 Bohm, "Time, The Implicate Order, and Pre-Space," 188. Thus, "in a way, the explicate order and its counterpart as a 'constituent' of the implicate order are like two views of one object. In the explicate order, all the essential relationships prevailing in the context to which this order applies are displayed in such a way that they stand out, sharply and clearly visible. In a domain in which the implicate context is relatively independent and autonomous, this display is clearly a correct representation of whatever is within this context. But in a broader domain, one has to bring in the dependence of the implicate counterpart on the entire implicate order, and in doing this we are, as it were, seeing the same context from two different views and interpreting these through a single and more comprehensive view," ibid.

756 “Or, more accurately, in the vacuum state the 'state-function' (which represents the whole of space and time) oscillates uniformly at a frequency so high that it is utterly beyond any known physical interpretation All the physically significant properties of these states are then completely independent of this 'zero-point' oscillation," Bohm, "Time, The Implicate Order, and Pre-Space," 189.
} 
basically creative act, not completely determined by antecedent moments (though ... it is in general related to these moments in a way that is part of a higher order of creativity [originating from within the totality of the implicate order])."757

The implications of what this means, put more simply, can be understood in how Bohm relates all this to 'natural laws.' Bohm suggests that the relationships between different moments may "determine general laws that held in broad contexts. These would permit prediction (usually approximate and statistical) of the qualities of later moments in terms of those of earlier moments. But here we recall that knowledge is in the past in any given moment, and from the past in an earlier moment all that we can predict is the past in a later moment. So laws will take the form of generally valid relationships between the nested sets of projections of its past enfolded in one moment and the corresponding set enfolded in another moment." This means "laws will take the form of generally valid relationships between the nested sets of projections of its past enfolded in one moment and the corresponding set enfolded in another moment. The special creative quality of each moment cannot, however, be predicted in this way," ${ }^{\prime 758}$ as there always may be underlying influences from elsewhere in the broader implicate order.

It should be kept in mind here that "all these relationships have to be understood primarily as being between the implicate 'counterparts' of the explicate moments. That is to say, we no longer suppose that space-time is primarily an arena and that the laws describe necessary relationships in the development of events as they succeed each other in this arena. Rather, each law is a structure that interpenetrates and pervades the totality of the implicate order. To formulate such a law is more like painting a 'whole picture' than it is like trying to find a set of dynamical equations for determining how one event follows another. Such dynamical equations will appear only as approximations and

\footnotetext{
${ }^{757}$ Bohm, “Time, The Implicate Order, and Pre-Space," 189. From a temporal point of view, "all these projections into any given moment will have the past of the entire universe as their potential content, which is thus enfolded into the moment in question. In fact, however, moments that are distant in time and space from the one under discussion will generally enfold very weakly (with the result that ... each moment can be understood, at least up to a point, in its own relatively independent context)," ibid., 191.

${ }^{758}$ Bohm, “Time, The Implicate Order, and Pre-Space," 191.
} 
limiting cases valid in explicate contexts. ${ }^{759}$ Bohm also appeals to the notion of "pre-space" as the primary source of space-time, suggesting that space-time is "a kind of very fine 'foam' out of which the familiar patterns and forms of continuous space, time, and matter emerge as approximations on the large-scale level. ${ }^{760}$ Accordingly, "because the structure of the foam is given by quantum laws, one should more accurately regard pre-space as a form of the implicate order., ${ }^{761}$

Because of the dynamic nature of the implicate or generative orders, it will be seen that the "ordinary explicate order will now come out only as a relatively invariant context in a much vaster implicate order, containing new features that go beyond those of current space-time and geometrical structures in a radical way." 762 One of the interesting "possibilities ... afforded" by these proposals is that "we can now take for granted neither the relative order of moments nor their relative separation, as measured in terms of a time interval." ${ }^{763}$ Rather, "different moments of time are thus (almost) unconnected in any direct way." Instead, "each moment becomes the succeeding moment with which it is connected." At the same time, however, because "process and becoming can be understood in terms of an implicate order, in which vast stretches of time may, in principle, be enfolded," ${ }^{\prime 764}$ this means that historically distant moments may be more intricately connected than historically close moments. This is, of course, in direct contrast to "current relativistic theories in physics [which] describe the whole of reality in terms of a process whose ultimate element is a point event, i.e., something happening in a relatively small region of space and time." Bohm proposes, instead, "that the basic element be a moment which, like the moment of consciousness, cannot be precisely related to measurements of space and time, but rather covers a somewhat vaguely defined region which is

\footnotetext{
${ }^{759}$ Bohm, "Time, The Implicate Order, and Pre-Space," 191. Therefore, "fundamentally, the principles from which the law flows will involve qualities like harmony, order, symmetry, beauty, etc. It has to be kept in mind, however, that breaks in the form of disharmonies, asymmetries, etc., can provide the ground or achieving these qualities anew in a richer way and at a higher level. Perhaps this general feature of the universal order is the reason that the search for symmetries that are later 'broken' has been proving to be fruitful in the development of modern quantum-mechanical field theories," ibid., 191-192.

${ }^{760}$ Bohm, "Time, The Implicate Order, and Pre-Space," 192.

${ }^{761}$ Bohm, "Time, The Implicate Order, and Pre-Space," 192.

${ }^{762}$ Bohm, "Time, The Implicate Order, and Pre-Space," 194.

${ }^{763}$ Bohm, "Time, The Implicate Order, and Pre-Space," 194.

${ }^{764}$ Bohm, “Time, The Implicate Order, and Pre-Space," 195.
} 
extended in space and has duration in time. The extent and duration of a moment may vary from something very small to something very large, according to the context under discussion (even a particular century may be a 'moment' in the history of mankind)." ${ }^{765}$ Yet, "as with consciousness, each moment has a certain explicate order, and in addition it enfolds all the others, though in its own way.

So the relationship of each moment in the whole to all the others is implied by its total content: the way in which it 'holds' all the others enfolded within it.".766

Bohm's suggested interpretation of time recognizes that "it would be inconsistent ... to suppose that the vacuum state and its modifications represent the ultimate and unique ground of all reality. Rather, even these are a limited context having only relative independence and autonomy. There will therefore have to be yet deeper and more comprehensive orders within which this context is embedded. The 'vacuum state' will thus not be absolute and self-contained." ${ }^{1767}$ Rather, Bohm continues, "it too will now be treated as a kind of explicate order, in relationship to a yet more inward implicate order that goes far beyond all that physics has thus far been able to treat (including relativity, quantum theory, the 'big bang', etc.). This possibility is indeed already foreshadowed by the fact that in current quantum-mechanical field theory there is available an infinite set of 'nonequivalent' vacuum states." As such, this "will open the way for a new kind of time, which has primarily to do with the development of the vacuum state itself." Bohm proposes that there may be "a succession of vacuum states, all enfolded in the deeper implicate order, as ordinary time intervals are enfolded in the vacuum state."768 This overall movement of the vacuum state fields Bohm labels the "holomovement," and it is by its very nature "undefinable and immeasurable." ${ }^{769}$ Importantly, by

\footnotetext{
${ }^{765}$ Bohm, Wholeness and the Implicate Order, 262-263. Accordingly, Bohm is circumventing the question of whether time or causation has some specific finite speed, such as the speed of light.

${ }^{766}$ Bohm, Wholeness and the Implicate Order, 263. Bohm adds that "in certain ways this notion is similar to Leibniz's idea of monads, each of which 'mirrors' the whole in its own way, some in great detail and others rather vaguely. The difference is that Leibniz's monads had a permanent existence, whereas our basic elements are only moments and are thus not permanent. Whitehead's idea of 'actual occasions' is closer to the one proposed here, the main difference being that we use the implicate order to express the qualities and relationships of our moments, whereas Whitehead does this in a rather different way," ibid., 263.

${ }^{767}$ Bohm, "Time, The Implicate Order, and Pre-Space," 196.

${ }^{768}$ Bohm, "Time, The Implicate Order, and Pre-Space," 197.

${ }^{769}$ Bohm, Wholeness and the Implicate Order, 191.
} 
giving "primary significance to the undefinable and immeasurable holomovement implies that it has no meaning to talk of a fundamental theory, on which all of physics could find a permanent basis, or to which all of the phenomena of physics could ultimately be reduced." Rather, "each theory will abstract a certain aspect that is relevant only in some limited context, which is indicated by some appropriate measure."770 So far as how this relates to the explicate order, "whatever persists with a constant form is sustained as the unfoldment of a recurrent and stable pattern which is constantly being renewed by the enfoldment and dissolved by unfoldment." Were the "renewal" to cease, "the form vanishes." ${ }^{171}$

Bohm suggests that within the infinite depths of the implicate order or holomovement, time should be understood to be "very slow in relationship to the ordinary physical times that are enfolded in it. For this reason, the vacuum state will be subject to a kind of long-range evolution (corresponding roughly to the ancient Greek notion of 'aeons'). On the other hand, in relationship to the deeper implicate order, even the immeasurably fast oscillations of the vacuum state ... may now have a meaning. A new system of time will have been introduced that is both very fast and very slow compared with ordinary physical times."772 This ultimately leads one to understand reality in terms of an infinite number of implicate or timeless orders, and likewise many temporal orders. Bohm notes that "relativity theory has already led us to expect many different systems of time and space, and these are abstracted from different contexts of process. Quantum theory has led us further to the notion that one system of time and space may be enfolded in relationship to another and that all our

${ }^{770}$ Bohm, Wholeness and the Implicate Order, 191.

${ }^{771}$ Bohm, The Undivided Universe: An Ontological Interpretation of Quantum Theory, 299. Thus, "the notion of a permanently extant entity with a given identity, whether this be a particle or anything else, is therefore at best an approximation holding only in suitable limiting cases," ibid. As Bohm also explains, "the explicate order, which dominates ordinary 'common sense' experience as well as classical physics, appears to stand by itself. But actually this is only an approximation and it cannot be properly understood apart from its ground in the primary reality of the implicate order, i.e. the holomovement. All things found in the explicate order emerge from the holomovement and ultimately fall back into it. They endure only for some time, and while they last, their existence is sustained in a constant process of unfoldment and re-enfoldment, which gives rise to their relatively stable and independent forms in the explicate order," ibid., 320.

${ }^{772}$ Bohm, "Time, The Implicate Order, and Pre-Space," 197. Bohm suggests that "a good analogy is to consider a radio wave carrying a television program. The very fast radio wave contains enfolded within it the much slower times that are depicted in the program," ibid. 
common systems are enfolded in the vacuum state."773 It is only a small step from this to "go further" and "contemplate much greater systems that enfold even the vacuum state with its oscillation and evolution. In all these relationships, any one system has its 'timeless' enfoldment in another (or in others). But each system has to be seen in both aspects, i.e., of time and of a relatively 'timeless' enfolded state." ${ }^{774}$ In other words, Bohm believes that it should "be remembered ... that the vacuum state itself will be associated with very short distances," and that "the smallest particles known are much bigger ... in size. So there is much room for many further interwoven levels of 'time and 'timelessness' between these limits. There is no reason to suppose that physics, in its current approach, can exhaust all levels of this kind." Moreover, Bohm asserts that "there may be biological times of various kinds, neurophysiological times, psychological times (both conscious and unconscious) going on, perhaps to levels of which we have at present no notion at all. Each of these levels of time is a relatively independent and autonomous context. Because there is no 'bottom level,' any given level is not completely grounded in any other specifiable set of levels, nor is its explicate aspect as time grounded completely in any particular implicate order of 'timelessness.' Each level and each aspect makes a certain contribution of its own to reality as a whole."175

Bohm's theory of the implicate orders points towards some interesting insights about the possible nature of eternity. Bohm theorizes that "if it were possible for consciousness somehow to

773 Bohm, “Time, The Implicate Order, and Pre-Space," 197.

${ }^{774}$ Bohm, "Time, The Implicate Order, and Pre-Space," 197. Thus, "in the time aspect is comprehended the becoming of being, while in the 'timeless' aspect is comprehended the being of becoming. Since we do not contemplate any ultimate level, it is implied that at any stage in the development of our knowledge these two aspects have always to be woven together for a proper understanding of the nature of time and space. The implicate order is characterized not by an ultimate level in which time is totally absent, but rather by a vast range of interwoven times that enfold other times in nonlocalizable ways and are in turn thus enfolded in still other times," ibid., 197-198. See also, Bohm and Peat, Science, Order, and Creativity, 223-228. Elsewhere, however, Bohm simplifies his presentation of the issues to assert that "existentially speaking or logically speaking, time originates out of the timeless," Bohm, The Essential David Bohm, 153.

${ }^{775}$ Bohm, "Time, The Implicate Order, and Pre-Space," 198. Bohm adds, "as long as we restrict ourselves to some finite structures of this kind, however extended and deep they may be, then there is no question of complete determinism. Each context has a certain ambiguity, which may, in part, be removed by combination with and inclusion within other contexts. Any given explicate context will thus not be a mere 'shadow play' of a deeper implicate context. Everything is ultimately open, as new contexts may always come in. Because of this openness there is a possibility for creativity and this possibility will, of course, include the action of human beings. If we were to remove all ambiguity and uncertainty, however, creativity would no longer be possible," ibid., 198. See also, Bohm and Peat, Science, Order, and Creativity, 194-196. 
reach a very deep level, for example, that of pre-space or beyond, then all 'nows' would not only be similar-they would all be one and essentially the same. One could say that in its inward depths now is eternity, while in its outward features each 'now' is different from the others." Understand, here "eternity means the depths of the implicate order, not the whole of the successive moments of time."776 Bohm openly speculates about what this means, philosophically. "Is eternity just something like the holomovement, with no specifiable order or pattern, or does it perhaps ultimately go beyond such description altogether?"777 Bohm provides no answer.

In summary, it may be helpful to keep mind that what Bohm is doing is attempting to explain how the disparate theories of physics, namely Newtonian, Einsteinian relativity, and quantum physics may all contribute to a singular theory of time-this has required him to postulate multiple levels of order or time and timelessness, namely, the explicate and implicate orders, the implicate of which may be many or infinite and from which the explicate is unfolded. However, it must be noted clearly that all Bohm's notions of time and timelessness are still determined in a 'physical' way. At this point, it may be helpful to see how Bohm connects his theory of time more directly to the concerns in the humanities-that is, the human condition and society.

Time in the Humanities

As Emily Horton reminds readers of Bohm, an "important sidenote on Bohm, necessary to contextualize his significance, is that ... his work," "interested as much in language, psychology and philosophy" as it is "in science," "has made his writing unpopular among a large portion of the scientific community."778 As Bohm expresses his point of view, his complaint is that "the prevailing tendency in science" is "to think and perceive in terms of a fragmentary self-world view," one which

\footnotetext{
${ }^{776}$ Bohm, "Time, The Implicate Order, and Pre-Space," 199. Therefore, for Bohm, "'now' is the intersection of eternity and time. On its inward side, 'now' is ... ultimately the same as eternity. On its outward side, it participates in movement. To go further than this and to ask what the origin of this movement overall is would seem to take us beyond what can be done with thought," ibid.

${ }^{777}$ Bohm, “Time, The Implicate Order, and Pre-Space," 199.

${ }^{778}$ Horton, Contemporary Science Fictions: Affect and Ethics in the Modern British Novel, 119.
} 
"pervades almost the whole of our society."779 Such a fragmentary world-view also separates physics from psychology, literature, sociology, politics, cultures, and religion and theology. Bohm laments this separation, believing that it leads to disharmony and confusion.

Bohm is aware that the issue of time (and freedom) in the humanities requires several components-first, to connect time to life, second, to the individual, and third, to society. Concerning the first issue, of placing time and the basic order of life within a broader context of inanimate matter versus living matter, Bohm observes that "it is necessary, for the understanding of life, to go beyond the quantum theory and the superimplicate order, into an infinity of generative and implicate orders from which present theory has been abstracted." However, Bohm adds, "in doing so . . . it is not intended to seek the 'ultimate origin of life' in a reductionist way by going, for example, to an even more fundamental microscopic theory than the quantum theory. Rather it is being proposed that a deeper generative order is common to all life and to inanimate matter as well. It is not therefore an attempt to explain life in terms of matter, but rather to see how both emerge out of a common overall generative order. Within this order there is room for new kinds of 'pools of information' from which life could be generated. The wholeness of the living being, and even more of the conscious being, can then be understood in a natural way, rather as the wholeness of the molecule and the superconducting system is understood. (Although it must not be forgotten that life is much subtler and more complex than molecules and superconducting systems)."780 Understood in this way, "life is no longer seen as the result of somewhat fortuitous factors, which perhaps happened only on an isolated planet, such as Earth. Rather it is seen to be enfolded universally, deep within the generative order." ${ }^{781}$ In short, Bohm is proposing a new "way of looking at the nature of reality" that "can be extended to all life, and even to what is normally called inanimate matter. The root of what is manifest in these forms lies in the ultimate depths of the implicate and generative orders of the

\footnotetext{
${ }^{779}$ Bohm, as cited in Horton, Contemporary Science Fictions: Affect and Ethics in the Modern British Novel, 120.

${ }^{780}$ Bohm and Peat, Science, Order, and Creativity, 198-199. Bohm adds, "it does not appear likely that the essence of life is to be understood in terms of the details of conventional quantum theory," ibid., 198.

${ }^{781}$ Bohm and Peat, Science, Order, and Creativity, 199.
} 
totality of matter, life, and mind. In this sense, therefore, even inanimate matter must have some kind of mental aspect." As such, Bohm suggests it is necessary to "go beyond the usual approaches in which mind and matter are two separate but interacting streams, or in which consciousness is considered as just a material process." ${ }^{\text {782 }}$ That is, "there is no absolutely sharp 'cut' or break between consciousness, life, and matter, whether animate or inanimate. Of course each of these can be analyzed in thought as categories with a degree of relative independence upon each other. This makes it possible for each to be studied, up to a point, in its own right. But more generally, each of the stages of consciousness ... can be regarded as lying somewhere along the 'stream' of the generative order."${ }^{783}$

One of the significant ways this might modify the current scientific consensus concerns "the current approach in biology and the theory of evolution," which treat the "explicate and sequential orders as basic." ${ }^{784}$ Bohm notes that "it is assumed that ultimately everything in nature can be reduced to explanations using such orders, for example, in terms of atoms, molecules, DNA, cells, and other structures. But if the generative order is basic to inanimate matter, then it is even more essential for the understanding of life. In the explicate and sequential orders, life appears to arise as a fortuitous chance combination of molecules which leads, in a more or less mechanically determined way, to further developments which produce ever higher and more complex forms." ${ }^{785}$ However, "while this approach can be admitted as significant for study, it is now seen as an abstraction and approximation in the light of the generative order." ${ }^{1786}$

\footnotetext{
782 Bohm and Peat, Science, Order, and Creativity, 209. Thus, although "it seems reasonable to conclude that consciousness always has a material aspect or side than can in principle be studied scientifically," it is also true that "no matter how far science goes, there is always more and the totality will always elude the grasp of science," ibid. See also, Bohm, The Essential David Bohm, 103-120.

783 Bohm and Peat, Science, Order, and Creativity, 210.

${ }^{784}$ Bohm and Peat, Science, Order, and Creativity, 197.

${ }^{785}$ Bohm and Peat, Science, Order, and Creativity, 197-198.

${ }^{786}$ Bohm and Peat, Science, Order, and Creativity, 198. Bohm thus critiques the standard mechanistic neo-Darwinian theory of evolution-while it may be "valid in its proper domain, it represents an abstraction from a much larger implicate and generative order, and its main significance is to be found in its relationship to this latter order. As a matter of fact, there are a number of features, within the neo-Darwinian view, that appear to be unsatisfactory and that give rise to problems of interpretation. In particular, an individual organism is regarded as being an expression of its genetic material, within a particular environment. To be sure, this environment has an effect on the individual expression of genetic material and on the variations in the overall form of a plant or animal. For example, plants of identical genetic stock but grown in the absence of certain
} 
Beyond the lower levels of biological life and time, however, Bohm's comments about the fully realized human and society are also important, and build directly off of his other reflections. First, it is worth reiterating that Bohm believes that "the current reliance of the neurosciences on everyday notions of space, time, and causality may prove inadequate, and eventually notions from quantum theory may have to be brought into the field. ${ }^{787}$ If the human being is understood as possessing a relationship to time that is analogous to what has been discussed above, then there may be significant consequences to an understanding of the human and time in this new conceptualization.

Because, for Bohm, there can be no rigid divide between mind and matter, and reality is manifested through the explicate and implicate orders, it follows that mind or consciousness exist both in an explicate and implicate way, but the latter is primary. As such, "consciousness is basically in the implicate order as all matter is and therefore it's not that consciousness is one thing and matter another. Rather consciousness is a material process and consciousness is itself in the implicate order, as is all matter, and consciousness manifests in some explicate order, as does matter." ${ }^{788}$ Bohm explains that the difference concerns their "state of subtlety. Consciousness is possibly a more subtle form of matter and movement, a more subtle aspect of the holomovement. In the nonmanifest

\footnotetext{
minerals will be stunted in comparison with those grown under normal conditions. However, it is believed that the environment has no effect on the genetic material itself, other than to contribute to random mutations and determine, through natural selection, which forms will survive. Hence, while the environment affects the actual physical makeup of the individual plant or animal, its only action on the genetic material itself is to induce random changes. In this sense chance is assumed to play an absolute role in evolution as well as in the origin of life; just as it is believed to be absolute within the conventional interpretation of quantum theory." However, "while this overall approach may be adequate when it comes to the explanation of relatively small changes and variations, it may not be sufficient to account for more spectacular changes, such as the appearance of an entirely new species. For major evolutionary changes require the coordinated development of many different pieces of genetic code. It is not sufficient, for example, to give a bird wings if it is to fly. In addition its bones must be made lighter while at the same time maintaining their strength, feathers must be aerodynamically adapted, the center of gravity must shift, the breastbone and musculature must develop, and changes in metabolism are required to provide sufficient energy for flight. If such changes do not all occur together and in a coordinated fashion, then they may well be disadvantageous to survival. It is difficult to understand how so many of the highly coordinated chances demanded by evolution could have come about by fortuitous chance combinations of small random mutations." Thus, "it is proposed here that the generative order enfolds orders that go beyond those that can be contained even in the quantum domain, orders that have so far been 'hidden' to science. Such orders may involve implicit totalities of structure of the organism which can all emerge together.... [Such an] active generation of new order, from levels that are at present 'hidden' to science" [should be seen as in contrast to] “a more or less mechanical adaptation to an existing order," ibid., 199-200.

${ }^{787}$ Bohm and Peat, Science, Order, and Creativity, 62. For Bohm's earliest suggestion of this, see Bohm, Quantum Theory, 168-172.

${ }^{788}$ Bohm, The Essential David Bohm, 148.
} 
[implicate] order there is no separation in space and time. In ordinary matter this is so and it's even more so for this subtle matter which is consciousness. Therefore if we are separate it is because we are sticking largely to the manifest world as the basic reality where the whole point is to have separate units, relatively separate anyway, but interacting. In nonmanifest reality it's all interpenetrating, interconnected, one. So we say deep down the consciousness of mankind is one."789 For the individual, specifically, Bohm suggests we keep the following in mind. Bohm suggests that "the actual moment of existence-this present-is in some sense beyond [linear] time. That is, everything that we see, and everything that we can recognize, depends on thought, on the past, on knowledge. This enters into our perception. We see all forms and shapes, and so on. Without thought we would not be able to say what we see, or even see anything very definite." However, "thought takes time, and thinking takes a lot of time." Thus, even though "thought" is "very fast" it "still takes some time. Now ordinarily, when we look at this chair, for example, we say we can think about it and say we know it; but we only know its past," even if for all "practical purposes, its present is not very different from its past." Yet, nevertheless, our knowledge of the chair is "from its past." Bohm continues by sharing that "most of science and technology is based on that kind of knowledge; but when we come to processes that are extremely fast and subtle, then that kind of knowledge no longer holds." ${ }^{\prime 790}$ The point, for Bohm, is that "if we try to look into our own consciousness and ... look at what we are, what we will see is what we have been." "Thought takes time. Therefore, whatever thought presents us, the content of consciousness is a little behind the actual present.... Consciousness" reaches "into depths that are very subtle and fast."791 This means that while "at first

${ }^{789}$ Bohm, The Essential David Bohm, 148-149. Thus, "in any given period of time, the whole of time may be enfolded. It's implied in the implicate order when you carry it through: the holomovement is the reality and what is going on in the full depth of that one moment of time contains information about all of it," ibid., 148. Bohm's comment on "the consciousness of mankind is one" could be overly interpreted-his real point is that, ultimately, we are all 'actually' connected. For more on Bohm's views on this, see Bohm, The Undivided Universe: An Ontological Interpretation of Quantum Theory, 134-159.

${ }^{790}$ Bohm, Unfolding Meaning, 127.

${ }^{791}$ Bohm, Unfolding Meaning, 127. Bohm thus subtly distinguishes "between thinking and thought." "Thinking, clearly, takes a lot of time because you've got to work it all out. And if you're dealing with something as fast as the mind, you can't really think it out because it's going faster than you can think." Bohm suggests that "one of the difficulties is that the thoughts contain all sorts of presuppositions which limit us and hold us in rigid grooves. What we have to do is to discover these presuppositions and get rid of them-get free of them," ibid., 36-37. 
sight, we tend to conclude that the past and the future are each well defined in their being, with no ambiguity as to what they are," "a more careful analysis shows that essential aspects of the being of each are in their relation to the other. Thus, there is some ambiguity in past and future," and "we experience this ambiguity in certain ways directly. For when we try to say 'now,' we find that by the time we have said it, the time that we meant is already past, and no longer 'now.' And if we try to do it with clocks, so as to be more precise, quantum theory implies that a similar ambiguity would arise because of the quantal structure of matter. In fact, there is no known way to make an unambiguous distinction between past and future."792

Bohm uses an interesting illustration to bring together the above points for his explanation of the meaning of time, and its relationship to "space" within a quantum paradigm. Bohm explains that "there are two views of space. One view is to maintain that the skin is the boundary of ourselves, that there's the space without and the space within. The space within is the separate self, obviously, and the space without is the space which separates the separate selves, right?" Bohm continues, therefore, "to overcome the separation you must have a process of moving through that space, which takes time.... But if we looked at it as a holomovement with this vast reserve of energy and empty space where matter itself is that small wave on empty space, then we should really say that the space as a whole is the ground of existence and we are in it. So the space doesn't separate us, it unites us. Therefore it's like saying that there are two separate points and a certain dotted line connecting them, which shows how we think they are related; or to say there is a real line and that the points are abstractions from that [line]." However, it may be more accurate to say, "the line is the reality and the points are abstractions. In that sense we say that there are no separate people, you see, but [rather] that" this notion of separation is "an abstraction which comes by taking certain features of the whole as abstracted and self-existent.."793 In this sense, space is more fundamental and more real than the objects in it. And, for time, the interval between the moments is the real, rather than the moment

\footnotetext{
${ }^{792}$ Bohm, Bohm-Biederman Correspondence: Creativity and Science, 15.

${ }^{793}$ Bohm, The Essential David Bohm, 149. See also, Bohm, Thought as a System, 229-235.
} 
itself, which is timeless or "atemporal." ${ }^{\text {"794 }}$ Accordingly, if "space is what is real, then ... the measure of space is not what is real. The measure of space is what matter provides. So space goes beyond the measure of space. ${ }^{795}$ In like manner, with time. "If ... the interval is real, then the measure of time cannot be taken as fundamental. Therefore we are already outside of what we ordinarily would call time. But rather, if we have silence and 'emptiness,' it does not have the measure either of space or of time." Otherwise, we would have "fragmentation.",796

Within nature, the human, and society, this principle would hold true. "Events are like the points," and so "if you look at nature and say" that "there's no event in nature," then one might say “it's just flowing. It's the mind that abstracts and puts an event in there." ${ }^{\prime 797}$ This is not to say Bohm doesn't believe that "the distinguishing characteristics" or events "have their place in a certain limited domain of the explicate order and of the manifest," but that they are not to be seen as fundamental. All of this follows logically from Bohm's view of the radically nonlocal quantum world. ${ }^{798}$

Bohm highlights (without discounting earlier or other developments) two major eras in the development of a concept of time in society, before articulating his own perspective. Bohm suggests that the "medieval worldview is essentially that of a timeless order in which each thing has its proper place, so that even the temporal order of history can be accommodated within the timeless order." Bohm traces this "back to the ancient Greeks," for it was "Aristotle [who] wrote of an eternal order of

${ }^{794}$ Bohm, The Essential David Bohm, 148. "The moment is atemporal, the connection of moments is not in time but in the implicate order," ibid., 148.

${ }^{795}$ Bohm, The Essential David Bohm, 149.

${ }^{796}$ Bohm, The Essential David Bohm, 150. For more on fragmentation, see Bohm, Wholeness and the Implicate Order, 36-53; and Bohm, Thought as a System, 3-26; and Bohm with Krishnamurti, Limits of Thought: Discussions, 70-84.

${ }^{797}$ Bohm, The Essential David Bohm, 150. See also, Bohm, Wholeness and the Implicate Order, 14. "This view implies that flow is, in some sense, prior to that of the 'things' that can be seen to form and dissolve in this flow. One can perhaps illustrate what is meant here by considering the 'stream of consciousness.' This flux of awareness is not precisely definable, and yet it is evidently prior to the definable forms of thoughts and ideas which can be seen to form and dissolve in the flux, like ripples, waves and vortices in a flowing stream," ibid., 14.

${ }^{798}$ For more, see Bohm and Peat, Science, Order, and Creativity, 80-90. Bohm suggests that "There is great reluctance on the part of physicists to consider such nonlocality seriously, even though it does lie at the heart of the formal implications of quantum theory. Because theories in terms of local interactions have been so successful over the past few centuries, the concept is now seen as both necessary and inevitable. But, in fact, there does not appear to be any intrinsic reason to rule out nonlocal forces. However, a general attitude has arisen out of the tacit infrastructure of ideas over the last few centuries which prejudices scientists to any serious consideration of nonlocality," ibid., 91. 
increasing perfection, going from earthly matter to heavenly matter. An important aspect of this order is that each object has a proper place in the order of things, so that motion of bodies can be understood as a striving to reach this proper place. Within such an order it became natural to view the universe as a single organism." ${ }^{799}$ However, Bohm asserts that "by the time of the Middle Ages this general scheme had become so comprehensive that it found its eternal basis in the order of religion and philosophy, from which laws, morals, and ethics, which regulated the temporal concerns of society, had their ground." As such, "society as a whole, and each citizen, was regarded as an image of the total, overarching eternal order. Within this framework each individual was able to find a place and a meaning for his or her life." Bohm believes that "to have a single, encompassing meaning for the universe, society, and the individual was a strong and positive aspect of this eternal order. However, society was not without its share of drawbacks, for the freedoms and rights of individuals were severely restricted and authority was predisposed to become absolute." ${ }^{800}$

Yet, this era of the medieval organism gave "rise to the new secular order in which everything was regarded as being subject to the flux of time." 801 Bohm argues that "now nothing had any special space, and motion was reduced to a mechanical process that had no ultimate goal and was therefore going nowhere in particular. The notion of comparing the universe to an organism also gave way to comparing it to a mechanism, and the favorite image of the eighteenth century was that of clockwork." ${ }^{802}$ This new "secular order was atomistic in nature, and as a result, the individual came to

${ }^{799}$ Bohm and Peat, Science, Order, and Creativity, 99. See also, Bohm, Unfolding Meaning, 1-3.

${ }^{800}$ Bohm and Peat, Science, Order, and Creativity, 99-100.

${ }^{801}$ Bohm and Peat, Science, Order, and Creativity, 100. Bohm adds that "the 'new secular order' is incidentally the motto on the great seal of the United States," ibid.

${ }^{802}$ Bohm and Peat, Science, Order, and Creativity, 100. Thus, as Bohm elsewhere explains, "despite the radical differences between Newtonian physics and the world below the atom, physicists continue to make calculations using exactly the same mathematics that Newton employed-spatial coordinates and differential equations. Covering the quantum world with a coordinate grid means that, in a very fundamental sense, little has changed between Descartes and Newton on one hand, and Bohr and Heisenberg on the other," ibid. "A 'mechanistic' attitude toward science ... tends to limit the growth of our concepts in an arbitrary and dogmatically conceived way. Such a mechanistic attitude refers not only, however, to the mechanistic determinists, but also to the 'mechanistic indeterminists', who insist that in the quantum of action, we have reached an ultimate, indivisible, and unanalyzable entity, which will never be found to have a structure understandable in terms of a deeper level. In fact, the quantum of action presents many aspects of the ultimate particles of the atomists, so that the insistence that the quantum will never be analyzed is as mechanistic as a theory of point particles following determined orbits. Similarly, the insistence that chance + probability are not subject to a causal analysis at a deeper level constitutes a mechanistic attitude toward these things, since chance 
assume a more prominent role in society. This new attitude, of course, helped to bring about an increasing value to human freedom. However, this positive aspect had to be weighed against the negative features. One of the most important of these was that the individual, and indeed the whole society, along with the moral and ethical principles needed for good regulation, no longer had any ultimate meaning." ${ }^{803}$ Such a new world was set within "the context of an immense and purposeless mechanical universe, indifferent to human values and to human fate," ${ }^{804}$ where "the earth is a mere grain of dust in an immense universe of material bodies ... constituted of atoms, molecules, and structures built out of them, as if they were parts of a universal machine." ${ }^{\prime 85}$ This worldview is encapsulated in the contributions of Descartes and Newton, which, when followed through empirically, unexpectedly led directly into Einstein's theory of relativity, and the fragmentation of our worldview.

Bohm explains that "this whole transformation from the old eternal order has brought in its wake a movement away from the absolute and toward the idea that things are inherently relative and

+ probability are conceived of as existing in themselves and functioning under all possible circumstances according to fixed rules.

"Another important problem is that of irreversibility in time. In any mechanistic point of view, nothing basically new ever happens. The future is conceived of as some rearrangement of fixed types of already existent possibilities. The mechanistic determinists say that the precise future events are already determined by the existing state of things, while the mechanistic indeterminists say that only the probability is determined. But they both agree on an essential point. The general character of the kinds of events that can happen, the kinds of things that can exist, is already determined by some fixed set of rules. The choice of which of the particular allowed combinations will actually happen is fixed by some mechanical factors existing in the system, according to the mechanistic determinists. According to the mechanistic indeterminists, it is fixed by an equally mechanical 'chance' which is conceived of as absolute and not itself capable of change or development. We may make an analogy of a man who is offered the possibility of 100 different ways of being executed. The deterministic school of executioners would choose the way according to certain definite factors, e.g., the chemical concentration of the blood, the wave-length of the light emitted from his skin, etc. The indeterministic school would choose the way by spinning a roulette wheel. The non-mechanistic school would seek a qualitative change - i.e., to find a way to escape execution, taking advantage of all factors, both 'determinate' and 'chance.' So the essential point is that because of the infinite complexity and depth of the laws governing the nature of matter, no preassigned scheme of things can remain adequate forever, not even if it is restricted to being a general framework or outline. But this is just what most people find it difficult to accept-perhaps because our society requires us to accept the idea that a certain general form of social organization is inevitable, although within this general framework, we may make various quantitative changes, either by chance, or by determinate rule, as we please, as long as nothing essential is ever changed," Bohm, Causality and Chance, Letters to Three Women, 164-165. See also, Bohm, Causality \& Chance in Modern Physics, 65-66.

${ }^{803}$ Bohm and Peat, Science, Order, and Creativity, 100.

${ }^{804}$ Bohm and Peat, Science, Order, and Creativity, 100.

${ }^{805}$ Bohm, Unfolding Meaning, 1. Thus, the world and man are only parts of a whole without meaning, wherein "man is basically insignificant," ibid., 2. 
dependent on conditions and contexts. But in fact this was the deeper meaning of giving pride of place to time, rather than to eternity, which originally took place at the end of the Middle Ages." ${ }^{806}$ Thus, today, "the essential meaning of time is that everything is mutable and transient ... hence the temporal order is essentially one of change and transience." Bohm is aware that Newton "attempted to formulate universal laws that were assumed to be eternally valid, and therefore were appealing to something that lay beyond time. However, these laws were eventually found to hold only under certain limited conditions and could not be, in this sense, eternal." ${ }^{\text {"07 }}$ Thus, Bohm argues, "clearly science has reached the point at which everything, in principle, becomes subject to ultimate dissolution within the flux of time. All traces of the eternal order, with its natural cycles and harmonies, have now been swept away." ${ }^{\prime 80}$ This is important because:

These far-reaching changes have not been confined to science alone but have swept into every area of life. In earlier times, for example, people regarded the order of society as eternally determined, perhaps by divine decree. Even though important changes did occur throughout the Middle Ages, for the most part they did not seriously affect those who went through the unchanging and recurring cycles of their lives. However, following the change from eternal to secular order, a series of rapid transformations took place in science and technology, the scale and scope of commerce and industry, the growth of nationalism, and the extension of the general goals of European civilization. For example, the rise of science was followed by a decrease in the importance of religion. Within the scientific order, many religious beliefs appeared to lose their credibility and the progress brought by technology substituted new goals, aims, and values. As the eternal verities and absolute truths became eroded, the older systems of morals and ethics seemed less significant and, in the end, dissolved into a general form of relativism. This change of order even reached into the family as the impersonal ties of commerce, industry, and bureaucracy began to dominate human relationships. ${ }^{809}$

Bohm here expresses a nostalgia concerning the harmony of past eras, while at the same time he clearly realized the many shortcomings of the bygone age. In any case, Bohm clearly sees many consequences for today from the overall historical developments, which impact upon all of human life.

\footnotetext{
${ }^{806}$ Bohm and Peat, Science, Order, and Creativity, 102.

${ }^{807}$ Bohm and Peat, Science, Order, and Creativity, 102.

${ }^{808}$ Bohm and Peat, Science, Order, and Creativity, 102-103.

${ }^{809}$ Bohm and Peat, Science, Order, and Creativity, 103.
} 
Bohm sees the need for a "new order" to "emerge in a creative way," wherein it will be "necessary to [revisit] ... the whole notion of order." ${ }^{810}$ Primary to this new conception of order is the rejection of the atomistic fragmentary worldview which dominates in standard science. ${ }^{811}$ Rather, Bohm, following what he sees as the direct implication of his inference of the quantum world's nonlocality, suggests physical theories "are not 'descriptions of reality as it is' but, rather, everchanging forms of insight, which can point to or indicate a reality that is implicit and not describable or specifiable in its totality." ${ }^{\prime 12}$

The first step in identifying a solution, for Bohm, is to recognize that "art, science, technology, and human work in general, are divided up into specialities, each considered to be separate in essence from the others. Becoming dissatisfied with this state of affairs, men have set up further interdisciplinary subjects, which were intended to unite these specialities, but these new subjects have ultimately served mainly to add further separate fragments." ${ }^{813}$ Overall, then, "society as a whole has developed in such a way that it is broken up into separate nations and different religious, political, economic, racial groups, etc. Man's natural environment has correspondingly been seen as

\footnotetext{
${ }^{810}$ Bohm and Peat, Science, Order, and Creativity, 105. Bohm believes that "up to now, those who have called for major changes in society have given little importance to the question of creativity. Indeed history shows that there has been little conscious realization of what actually takes place during a major change, or where accumulated changes are leading. In general, society changes when a mass of people simply react to particular problems and pressures which have been allowed to accumulate. Even when a few individuals have attempted to confront the issue of change in a creative way they have been hampered by the various issues and problems already brought to light in this book. People, for example, generally tend to be rigidly attached to the tacit infrastructure of their cultural milieu so that they resist all social change in a blind and often destructive way. Others, however, are rigidly attached to the call for revolutionary change and pursue their ends in a similarly blind fashion. Clearly what is called for is a kind of free play within the individual and society so that the mind does not become rigidly committed to a limited set of assumptions, or caught up in confusion and false play. Out of this free play could emerge the true creative potential of a society," ibid., 104-105.

${ }^{811}$ Bohm, Wholeness and the Implicate Order, 11. Bohm explains that "the particular content of the atomic theory was such as to be especially conducive to fragmentation, for it was implicit in this content that the entire world of nature, along with the human being, including his brain, his nervous system, his mind, etc., could in principle be understood completely in terms of structures and functions of aggregates of separately existent atoms. The fact that in man's experiments and general experience this atomic view was confirmed was, of course, then taken as proof of the correctness and indeed the universal truth of this notion. Thus almost the whole weight of science was put behind the fragmentary approach to reality," ibid.

812 Bohm, Wholeness and the Implicate Order, 21-22.

${ }^{813}$ Bohm, Wholeness and the Implicate Order, 1.
} 
an aggregate of separately existent parts, to be exploited by different groups of people." ${ }^{814}$ For Bohm, the very "notion that all these fragments are separately existent is evidently an illusion, and this illusion cannot do other than lead to endless conflict and confusion. Indeed, the attempt to live according to the notion that the fragments are really separate is, in essence, what has led to the growing series of extremely urgent crises that is confronting us today." ${ }^{\prime 15}$ Thus, for Bohm, "as is now well known, this way of life has brought about pollution, destruction of the balance of nature, over-population, world-wide economic and political disorder, and the creation of an overall environment that is neither physically nor mentally healthy for most of the people who have to live in it. $^{816}$

The path beyond the first step is to rebuild our notions of humanity and society around a new conception of order, namely the implicate order described above. Thus, Bohm wants to "restore objective reality to the conventional understanding of quantum mechanics. Rejecting the nonrealist inferences of the Copenhagen interpretation, Bohm insists that the wholeness implicit in a reality structure founded on quantum discontinuity, context-dependent form (the wave-particle duality) and nonlocality is actual, that it matters, and that it warrants serious investigation." ${ }^{\prime 817}$ That is, a 'realist' interpretation of reality, inspired by quantum phenomena, will prove to be both nonlocal and objective. The paradox in this very fact inspires the whole of Bohm's vision. "Relativity and quantum theory agree, in that they both imply the need to look on the world as an undivided whole, in which all

\footnotetext{
${ }^{814}$ Bohm, Wholeness and the Implicate Order, 2. Similarly, Bohm adds, "each individual human being has been fragmented into a large number of separate and conflicting compartments, according to his different desires, aims, ambitions, loyalties, psychological characteristics, etc., to such an extent that it is generally accepted that some degree of neurosis is inevitable, while many individuals going beyond the 'normal' limits of fragmentation are classified as paranoid, schizoid, psychotic, etc.," ibid.

${ }^{815}$ Bohm, Wholeness and the Implicate Order, 2. Bohm acknowledges, of course, that "to some extent, it has always been both necessary and proper for man, in his thinking, to divide things up, and to separate them, so as to reduce his problems to manageable proportions; for evidently, if in our practical technical work we tried to deal with the whole of reality all at once, we would be swamped," ibid.

${ }^{816}$ Bohm, Wholeness and the Implicate Order, 2. "Individually there has developed a widespread feeling of helplessness and despair, in the face of what seems to be an overwhelming mass of disparate social forces, going beyond the control and even the comprehension of the human beings who are caught up in it," ibid.

${ }^{817}$ Ian Greig, "Quantum Romanticism: The Aesthetics of the Sublime in David Bohm's Philosophy of Physics," in Beyond the Finite: The Sublime in Art and Science, eds. Roald Hoffmann and Iain Boyd Whyte (Oxford, UK: Oxford University Press, 2011), 116.
} 
parts of the universe, including the observer and his instruments, merge and unite in one totality." ${ }^{818}$

However, because "there is little or no room for such orders within currently accepted notions of physics, chemistry, biology, and other sciences," "whatever could be the basis for such [new] order in natural processes" that would help us understand "life, consciousness, and intelligent perception" "would probably be apprehended as 'no order at all" ${ }^{819}$ by the dominant scientific community. Bohm realizes he faces an uphill task.

The goal is to seek, for both the individual and society, a connection with the totality through the implicate order. ${ }^{820}$ Bohm's ruminations about this often take a mystic appearance, as he refers to the need for illumination from a timeless realm, as true illumination cannot have its source "in the material process" of the explicate or mechanistic order and its causal-temporality ${ }^{821}$ However, while there can be no doubt of the neo-Platonic flair to Bohm's philosophy, some, such as Don Handelman, insist this is somewhat of a mischaracterization. ${ }^{822}$ In any case, for the moment, the question then becomes, what is the totality?

Bohm suggests that the dissolution of the mechanistic-atomistic core of standard physics into the indivisible and wholistic quantum realm will not reveal some final return to an atomistic ultimate

\footnotetext{
${ }^{818}$ Bohm, Wholeness and the Implicate Order, 13.

${ }^{819}$ Bohm and Peat, Science, Order, and Creativity, 132. That is, "what is commonly called disorder or randomness," ibid.

${ }^{820}$ Bohm and Peat, Science, Order, and Creativity, 147-148. "The implicate order will be found to have a broader significance, not only in physics but also in biology, consciousness, and the overall order of society and each human being," ibid., 148-149.

${ }^{821}$ Bohm, The Ending of Time, 148. Bohm suggests that "cause implies time," and inner illumination cannot proceed from causes in the explicate or material world, ibid. Bohm believes, rather, that "the material process generally operates in a kind of darkness, and therefore it has set itself on a wrong path," ibid., 148-149.

822 "Bohm's physics and the cosmological re-imagining that it indicates have been labeled 'mysticism' of a neo-Platonic kind. But this is a misunderstanding, regardless of whether Bohm's cosmology is accurate or not (for as Bohm would maintain, the nature of the universe is an enduringly open question that conditions any scientific attitude and its continually changing understanding and reconfigurations). Unlike neo-Platonism, Bohm's perspective is not grounded in religion and involves no deus ex machina. If it is 'mystical,' it rather bears some connection within esotericism (in the Veda, or Kabbalah, or even more so Spinoza's philosophy), which argues for deeper 'truth' as secreted (hidden and released) within the formations and reflections that claim truth but also conceal it (that indeed must conceal it). It is in the concealment of unconcealment that another far more accurate or approximate truth resides. Bohm's differs from this mystical/esoteric tradition in that his philosophy is dependent on science (on the testing of evidence in relation to cosmological contingency and potential). That is, Bohm breaks with metaphysical traditions whose conceptual principles or parameters of understanding remain unchanging," Don Handelman, One God, Two Goddesses, Three Studies of South Indian Cosmology (Leiden, The Netherlands: Brill, 2014), 13.
} 
substance or building blocks of reality. ${ }^{823}$ Rather, "the notion that all is flux ... denies such a

supposition. Rather, it implies that any describable event, object, entity, etc., is an abstraction from an

unknown and undefinable totality of flowing movement. This means that no matter how far our

knowledge of the laws of physics may go, the content of these laws will still deal with such

abstractions, having only a relative independence of existence and independence of behavior. So one

will not be led to suppose that all properties of collections of objects, events, etc., will have to be

explainable in terms of some knowable set of ultimate substances. At any stage, further properties of

such collections may arise, whose ultimate ground is to be regarded as the unknown totality of the

universal flux.." ${ }^{824}$

Bohm suggests that the primary problem in the humanities is that the "rigid conditioning of the

tacit infrastructure of scientific thought has led to a fragmentation in science and to an essential

breakdown in communication." ${ }^{825}$ This breakdown has led to a similar "rigidity in the tacit

infrastructure of the individual and society. The tacit infrastructure of society at large is contained in

what is generally called culture." Of course, "within each society, however, there are many

subcultures which are all somewhat different, and which are either in conflict with each other, or

\footnotetext{
${ }^{823}$ Thus, "to help indicate how our world view has to change, we first note that the atoms originally thought to be the basic 'building blocks' have since been split into electrons, protons, and neutrons. But these so-called elementary particles have in turn been shown to have an as yet very poorly known deeper structure, and to be capable of transformation, allowing for the creation and annihilation of an apparently unlimited number of further new unstable particles of a similar nature. It is clear that these particles are very unlikely to be ultimate and basic building blocks either. Thus far, the search for such basic constituents has failed; and, indeed, the goal seems to retreat to the horizon each time that we think we are approaching it." "However, in spite of this failure there has been a sort of faith, widely accepted in current scientific research, that sooner or later such constituents must be discovered. This faith is probably based on a tacit conclusion that nothing else is possible but that the universe is constituted out of some kind of basic particles, and so it appears that the only real task is to discover just what the nature of these particles actually is." Importantly, "in such a view, the notion of an ultimate set of particles constituting the whole universe seems to be no restriction on our way of thinking at all, because it appears that one has infinite freedom in the choice of properties that these particles might have. But, of course, it is a serious restriction in fact. One may understand something of the nature of this restriction by considering a man who is walking on a vast, practically limitless, planar surface and who concentrates his attention almost exclusively on a very complex system of paths along which he can continue to walk indefinitely, without noticing that he is limited in not being able in this way to look at what is above or below this surface. Similarly, by keeping one's mind narrowly focused on the limitless elaboration of complex paths of analytical thought about the supposed particle constitution of the whole of reality, one may easily lose sight of the fact that in this way one's attention never leaves the 'plane' defined by the particle concept as a whole," Bohm, On Creativity, 91-92.

${ }^{824}$ Bohm, Wholeness and the Implicate Order, 62-63.

${ }^{825}$ Bohm, The Essential David Bohm, 294.
} 
more or less ignore each other as having mutually irrelevant aims and values. Such subcultures, along with the overall culture, are generally rigidly restricted by their basic assumptions, most of which are tacit and not open to awareness and attention." ${ }^{\prime 26}$ To be clear, the point here is that there is a connection between the fragmentary nature of standard science and the fragmentation evident in both individuals and the cultures that make up society. That is, "the major barriers to such an order are not technical," "rather they lie in the rigid and fragmentary nature of our basic assumptions., ${ }^{827}$

The concept of time plays a major role in this rigidity and fragmentation. Bohm believes "the gulf between individual consciousness and social consciousness is similar to a number of other gulfs," such as "between the timeless and time orders," ${ }^{828}$ or between contingency and necessity, as will be seen below in exploring the idea of freedom. ${ }^{829}$ The problem is, "science is predicated on the concept that science is arriving at truth-at a unique truth.... In a way, science has become the religion of the modern age. It plays the role which religion used to play of giving us truth; hence different scientists cannot come together any more than different religions can, once they have different notions of truth." ${ }^{130}$ Unfortunately, "science ... tends to be caught up in necessity, which then leads to false play

\footnotetext{
${ }^{826}$ Bohm, The Essential David Bohm, 296. Bohm adds that in "a consideration of society, clearly there is also a vast amount of misinformation in circulation which acts toward society's degeneration. The media and various modern means of communication have the effect of rapidly disseminating and magnifying this misinformation, just as they do with valid information. It should be clear that by "misinformation" is meant a form of generative information that is inappropriate, rather than simply incorrect statements of fact. In a similar way a small 'mistake' in DNA can have disastrous consequences because it forms part of the generative order of the organism and may set the whole process in the wrong direction.

In society, the generative order is deeply affected by what has a very general significance. Indeed the generative order may be regarded as the concrete activity of the general. This takes the form of general principles, general aims, and generally accepted values, attitudes, and beliefs of all kinds that are associated with the family, work, religion, and country. In going from these general principles to the universal, it is clear that the effect on the generative order will become yet more powerful. When a given principle is regarded as universally valid, it means that it is taken as absolutely necessary. In other words, things cannot be otherwise, under any circumstances whatsoever. Absolute necessity means 'never to yield.' To have something in the generative order that can never give way, no matter what happens, is to put an absolute restriction on free play of the mind, and thus to introduce a corresponding block to creativity that is very difficult to move," ibid., 292.

${ }^{827}$ Bohm, The Essential David Bohm, 300.

${ }^{828}$ Bohm, The Essential David Bohm, 298. See also, Bohm and Peat, Science, Order, and Creativity, 227.

${ }^{829}$ Bohm, Thought as a System, 69-73.

${ }^{830}$ Bohm, The Essential David Bohm, 330. Thus, the fundamental problem within science is that "in the prevailing mechanistic approach ... elements, assumed to be separately and independently existent, are taken as constituting the basic reality. The task of science is then to start from such parts and to derive all wholes through abstraction, explaining them as the results of interactions of the parts. On the contrary, when one works in terms of the implicate order, one begins with the undivided wholeness of the universe, and the task of science is to derive the parts through abstraction from the whole, explaining them as approximately separable, stable and recurrent, but externally related elements making up relatively autonomous sub-totalities, which are
} 
and a serious blockage of creativity." Yet, "it is now clear that the assumptions of absolute necessity, with their predispositions to unyielding rigidity, are ... part of a much broader spectrum of similar responses that pervade society as a whole. General principles, values, and assumptions, which are taken ... to have absolute necessity, are ... a major source of the destructive misinformation that is polluting the generative order of society." ${ }^{831}$ That is, the temporal order is typically one of causation in a deterministic way, whereas the timeless one delves deep into the generative or implicate order and is thus more the source of the streaming flux of reality. ${ }^{832}$ Thus, owing to the underlying timeless nature of the implicate and generative order, one could say that all of history and the multiplicity of objects or events in it could be seen as "ripples" within the implicate foam, whose "meaning depends on understanding what underlies the ripples." ${ }^{133}$

For Bohm there is an intimate connection between the physical or empirical sciences, properly investigated, and the social or human world. Studied correctly, they reveal a fundamental harmony that belies the traditional scientific ontology or understanding of order. Of course, notions of time, and freedom, are central to how we understand nature and society. Bohm's new understanding of nature which reveals interpenetrating layers of implicate and explicate orders suggests a fundamentally new way of understanding the concept of order. It is an entirely new theory of reality. Yet, nonetheless, because Bohm operates within prior definitions of the meaning of time, he is still limited by their vocabulary. For Bohm, the concept of time is still primarily associated with localized sequential causation, as it is for virtually all physicists. Because a wholistic and undivided interpretation of quantum phenomena violates all three of these principles, that means that ultimately, reality consists of a deeper timeless aspect from which sequentiality and spatiality emerge as special cases. ${ }^{834}$ Of course, Bohm resists placing either the timeless or temporal orders in a

to be described in terms of an explicate order," ibid., 86.

${ }^{831}$ Bohm, The Essential David Bohm, 293.

${ }^{832}$ Bohm and Peat, Science, Order, and Creativity, 195-196.

833 Bohm, The Essential David Bohm, 151.

${ }^{834}$ Bohm and Peat, Science, Order, and Creativity, 312. Thus, "the incompatibilities between quantum theory and relativity cannot be resolved from within an 'order between' but require a new order that lies beyond the limits of both approaches. Such an order may also involve 'an order beyond' two points in space. That is, an order beyond continuity versus discontinuity," ibid. 
primary position-they both have roles to play in our understanding of reality, within their mutual 'dialogue' of sorts. ${ }^{835}$ Thus, as Bohm concludes his own ruminations about time, there is a saying "that 'now' is the intersection of eternity and time. On its inward side, 'now' is, as we have seen, ultimately the same as eternity. On its outward side, it participates in movement. To go further than this and to ask what the origin of this movement overall is would seem to take us beyond what can be done with thought. Is eternity just something like the holomovement, with no specifiable order or pattern, or does it perhaps ultimately go beyond such description altogether?" Here, again, Bohm leaves us with the same open question. ${ }^{836}$

\section{Bohm's View of Freedom}

In this section, Bohm's view of freedom will be described. As will be seen, in many ways his view of freedom parallels his view of time-they are integrally related. This fact, of course, merely mirrors what has already been revealed above throughout the study concerning freedom and time. Concerning Bohm's view of freedom, it is important to point out that one of the primary questions concerning Bohm's philosophy has to do with how his early pilot-wave model relates to the concept of freedom. It is commonly believed that Bohm's original 1952 hidden variable interpretation's primary goal was to restore absolute determinism in nature. ${ }^{837}$ In many respects, this would be a valid assumption. However, this fact has obscured the developments in Bohm's philosophy that occurred over the following decades. Bohm's final articulation of a hidden variable theory does not

${ }^{835}$ Bohm and Peat, Science, Order, and Creativity, 195-196, 225-228.

${ }^{836}$ Bohm, "Time, The Implicate Order, and Pre-Space," 199. Bohm continues, "what indeed can we say about the infinite totality that would comprehend eternity, time, and their relationship? There are evidently severe difficulties in the attempt to go into this question. Clearly, to try to grasp the infinite in terms of the finite will lead to paradoxes and contradictions. For example, is the totality determinate or not? Evidently, since by hypothesis it already contains everything, there is nothing outside itself that could determine it (i.e., set its limits). This would imply that the totality is completely indeterminate. Yet, because it is and because there is nothing else to affect it or to alter it, it cannot be other than it is. And so it is completely necessary and, in this sense, completely determinate. This is almost a tautology. If the totality is $X$ (including whatever ambiguity is present in it), then this $X$ is the determinism of the totality," ibid.

${ }^{837}$ Pylkkänen, Bohm-Biederman Correspondence: Creativity in Art and Science, xix. See also, d'Espagnat, On Physics and Philosophy, 84; Marius Backmann, Humean Libertarianism: Outline of a Revisionist Account of the Joint Problem of Free Will, Determinism and Laws of Nature (Piscataway, NJ: Rutgers University, 2013), 47; and David Lindley, Where Does the Weirdness Go?: Why Quantum Mechanics is Strange, But Not As Strange As You Think (New York, NY: Basic Books, 1996), 120-121. 
require a strict or absolute determinism to reign throughout nature and thus, by implication, within

humanity ${ }^{838}$ Below I will examine the salient features of Bohm's view of freedom in both nature and

the humanities-noting that he conflates the two in a somewhat similar manner to how he views time.

\section{Freedom in Nature}

One of the most important features of Bohm's view of the physical world is that it contains aspects of both necessity and contingency. ${ }^{839}$ "There is a real freedom in the universe, in the sense that every form of necessity has its limits." ${ }^{\prime 840}$ Yet Bohm's articulation of their relationship is subtle. That is, Bohm, argues, "we discover in each part of the universe certain relations that are necessary (laws) and certain properties that are contingent. By broadening the part of the universe under consideration, we may show that some things that were contingent in the narrower context are necessary in the broader context. But then we will have introduced new contingent properties in the broader context, which will be necessary in a still broader context and so on without limit." ${ }^{841}$

Thus, Bohm suggests, it may be that "in the holomovement, there is still an overall necessity" or a 'holonomy,' "but its laws are no longer mechanical. Rather ... its laws will be in a first approximation those of the quantum theory, while more accurately they will go beyond even these, in ways that are at present only vaguely discernible." ${ }^{842}$ It is important here to observe that Bohm

\footnotetext{
${ }^{838}$ Bohm, The Undivided Universe: An Ontological Interpretation of Quantum Theory, 2-3. Bohm and Hiley share that "we regard all theories as approximations with limited domains of validity. Some theories may be more nearly determinate, while others are less so. The way is open for the constant discovery of new theories, but ultimately, these must be related coherently. However, there is no reason to suppose that physical theory is steadily approaching some final truth. It is always open (as has indeed generally been the case) that new theories will have a qualitatively different content within which the older theories may be seen to fit together, perhaps in some approximate way. Since there is no final theory, it cannot be said that the universe is either ultimately deterministic or ultimately indeterministic. Therefore we cannot from physical theories alone draw any conclusion, for example, about the ultimate limits of human freedom," ibid.

${ }^{839}$ Bohm, Bohm-Biederman Correspondence: Creativity in Art and Science, 50-51. "Inanimate matter is then to be regarded as a relatively autonomous sub-totality in which, at least as far as we now know, life does not significantly manifest. That is to say, inanimate matter is a secondary, derivative, and particular abstraction from the holomovement (as would also be the notion of a 'life force' entirely independent of matter). Indeed, the holomovement which is 'life implicit' is the ground both of 'life explicit' and of 'inanimate matter', and this ground is what is primary, self-existent and universal. Thus we do not fragment life and inanimate matter, nor do we try to reduce the former completely to nothing but an outcome of the latter," Bohm, Wholeness and the Implicate Order, 247.

${ }^{840}$ Bohm, Bohm-Biederman Correspondence: Creativity in Art and Science, 12-13.

${ }^{841}$ Bohm, Bohm-Biederman Correspondence: Creativity in Art and Science, 31.

${ }^{842}$ Bohm, Wholeness and the Implicate Order, 230, 198.
} 
distinguishes the indeterminism or randomness of standard quantum theory as described in the Copenhagen interpretation, which remains mechanistic for him, ${ }^{843}$ from his multilayered implicate and explicate order schemata. That is, the necessity and contingency within nature are not, strictly speaking, to be found in the interactions of parts to parts alone, but in the relation of parts to the whole, including its many layers. It is this feature that distinguishes Bohm's philosophy from any other mainstream theory.

Bohm sees his theory as a direct consequence of the longstanding and widely observed tensions between relativity theory and quantum theory. He notes that "relativity theory requires continuity, strict causality (or determinism) and locality. On the other hand, quantum theory requires non-continuity, non-causality and non-locality. So the basic concepts of relativity and quantum theory directly contradict each other. It is therefore hardly surprising that these two theories have never been unified in a consistent way. Rather, it seems most likely that such a unification is not actually possible." ${ }^{844}$ Only from such a direct conclusion is it then possible to suggest that "what is very probably needed instead is a qualitatively new theory, from which both relativity and quantum theory are to be derived as abstractions, approximations and limiting cases." ${ }^{845}$ Bohm believes that perhaps the best starting point is to recognize that "the basic notions of this new theory evidently cannot be found by beginning with those features in which relativity and quantum theory stand in direct contradiction. The best place to begin is with what they have basically in common. This is

\footnotetext{
${ }^{843}$ Bohm, Wholeness and the Implicate Order, 222. Quantum "indeterminism is ... not a serious challenge to a mechanistic order, i.e., one in which the fundamental elements are independently existent, lying outside each other, and connected only by external relationships," ibid. Bohm adds, "three key features of the quantum theory ... do, however, clearly show the inadequacy of mechanistic notions. Thus, if all actions are in the form of discrete quanta, the interactions between different entities (e.g., electrons) constitute a single structure of indivisible links, so that the entire universe has to be thought of as an unbroken whole. In this whole, each element that we can abstract in thought shows basic properties (wave or particle, etc.) that depend on its overall environment, in a way that is much more reminiscent of how the organs constituting living beings are related, than it is of how parts of a machine interact. Further, the non-local, non-causal nature of the relationships of elements distant from each other evidently violates the requirements of separateness and independence of fundamental constituents that is basic to any mechanistic approach," ibid., 222-223.

${ }^{844}$ Bohm, Wholeness and the Implicate Order, 223.

${ }^{845}$ Bohm, Wholeness and the Implicate Order, 223.
} 
undivided wholeness. Though each comes to such wholeness in a different way, it is clear that it is this to which they are both fundamentally pointing." ${ }^{\prime 46}$

A focus on a wholeness that can somehow unite what are otherwise disparate concepts is what leads Bohm to conclude that "necessity and contingency" are "always operating" together. ${ }^{847}$ The "notion of necessity is crucial to our whole ordering of thought; as is its opposite, which is contingency." ${ }^{848}$ Such a situation, Bohm believes, "implies the interweaving of simple orders of necessity and infinite orders of randomness in a potentially infinitely complex structure of law. What is randomness in one context may reveal itself as simple orders of necessity in another broader context. And vice versa, what is a simple order of necessity in one context may reveal itself as chance in another broader context." ${ }^{849}$ Importantly, this relationship is one that can be repeated, indefinitely. Thus, "in a still broader context, both are to be seen as extremes in the rich spectrum of orders of varying degrees that lies between them. Thus, there is no need to fall into the assumption of complete determinism (although this may in certain fairly broad contexts be a correct abstraction and approximation). Nor is there any need to assume that chance and indeterminism rule absolutely (though these too will provide correct abstractions and approximations in their appropriate contexts)." Rather, "no matter which system of law may be appropriate in the context that is currently under investigation, there is always room for something more and something

\footnotetext{
${ }^{846}$ Bohm, Wholeness and the Implicate Order, 223. Of course, for Bohm, "to begin with undivided wholeness means, however, that we must drop the mechanistic order. But this order has been, for many centuries, basic to all thinking on physics.... The mechanistic order is most naturally and directly expressed through the Cartesian grid. Though physics has changed radically in many ways, the Cartesian grid (with minor modifications, such as the use of curvilinear coordinates) has remained the one key feature that has not changed. Evidently, it is not easy to change this, because our notions of order are pervasive, for not only do they involve our thinking but also our senses, our feelings, our intuitions, our physical movement, our relationships with other people and with society as a whole and, indeed, every phase of our lives. It is thus difficult to 'step back' from our old notions of order sufficiently to be able seriously to consider new notions of order," ibid., 223224.

${ }^{847}$ Bohm, Thought as a System, 71.

${ }^{848}$ Bohm, Thought as a System, 70. "Thus, Every time we have a regularity, we must have some limit to this regularity. Of course, this may later be described as a new and more complicated regularity, applying in a broader context. But then the broader context will have its own irregularities. Wherever there are regularities, there must be irregularities. Wherever there is law, there must be lawlessness. These are opposite and universal categories, which we assert together about everything (like necessity and contingency)," Bohm, BohmBiederman Correspondence: Creativity in Art and Science, 34.

${ }^{849}$ Bohm and Peat, Science, Order, and Creativity, 129.
} 
different-something that will be more subtle and that has the ultimate potential for being a manifestation of creativity, ${ }^{\prime 850}$ which is one of the primary expressions of freedom..$^{851}$

Bohm makes clear that his new conception of order is in contrast to the conception of order operative in Newtonianism or the Copenhagen interpretation of quantum phenomena. That is, "in the quantum theory (at least as this is usually interpreted), it does not seem to be possible to maintain the notion of the interweaving of the orders of chance and necessity as abstractions from infinite order with unlimited creative potential." The principal difficulty that blocks such a conception, Bohm explains, is "because a system of particles cannot simply be treated by analysis into independently existent but interacting constituent particles. Rather, the quantum theory implies a certain quality of wholeness in the sense that a system cannot be dealt with properly as a set of separate parts. Hence in the usually accepted interpretation, there is no way to discuss how randomness might arise.

Randomness is therefore assumed to be a fundamental but inexplicable and unanalyzable feature of nature, and indeed ultimately of all existence." ${ }^{852}$ Of course, "such an approach complements Bohr's notion of the inherent ambiguity of concepts at the quantum mechanical level," as for Bohr "within the range of this ambiguity, the quantum theory implies that the experimental results will fluctuate with an irreducible kind of randomness. And thus the very nature of quantum mechanical ambiguity will

${ }^{850}$ Bohm and Peat, Science, Order, and Creativity, 129.

851 "The mind" in "a more natural state of freedom" is one in which "originality and creativity begin to emerge, not as something that is the result of an effort to achieve a planned and formulated goal, but rather as a by-product of a mind that is coming to a more nearly normal order of operation. And this is the only way in which originality and creativity can possibly arise, since any effort to reach them through some planned series of actions or exercises is a denial of the very nature of what one hopes to achieve. For this reason, originality and creativity can develop only if they are the essential force behind the first step.

"This means that it is up to each person to make the first step for himself, without following another, or setting up another as his authority for the definition of what creativity is and for advice on how it is to be obtained. Unless one starts to discover this for himself, rather than to try to achieve the apparent security of a well-laid-out pattern of action, he will just be deluding himself and thus wasting his efforts. To realize this fact is very difficult indeed. Nevertheless, one has to see that, to determine the order in which one functions psychologically by following some kind of pattern, is the very essence of what it means to be mediocre and mechanical." "Certain kinds of things can be achieved by techniques and formulae, but originality and creativity are not among these. The act of seeing this deeply (and not merely verbally or intellectually) is also the act in which originality and creativity can be born," Bohm, On Creativity, 31-32.

${ }^{852}$ Bohm and Peat, Science, Order, and Creativity, 130. 
imply a corresponding limit to the possibility of meaningful order."${ }^{\text {853 }}$ Thus, Bohm is arguing for a new concept of order that incorporates multiple levels or kinds of orders, which allows for ambiguity when scaling indefinitely or infinitely upward or downward, but not arbitrary limits at a given scale that are absolute. It is, again, his emphasis on layers of orders provides his unique vision for a way out of the morass of ambiguity that may exist in any given layer. Fragmentation and disorder ensue when one lets any given layer of order determine all possible meanings or order in all layers.

Having articulated the essence of Bohm's view of freedom in the sciences, it is now appropriate to see how he integrates freedom into the humanities in particular, for both the individual and society.

${ }^{853}$ Bohm and Peat, Science, Order, and Creativity, 130. Bohm, of course, objects to this limitation. Rather, Bohm "proposes the notion that everything that happens takes place in some order (which, however, depends on broader contexts for its meaning). Therefore, while there is ambiguity within particular contexts, the notion of an ultimate limit to the meaning of order that holds in all possible contexts is not admitted. For example ... the causal interpretation of the quantum theory ... [suggests] a further kind of order.... This order, which underlies the randomness implied in the probabilistic laws of the quantum theory, can be understood as the causally determined motion of the particle under the quantum potential. Because this latter potential gives rise to a complex and highly irregular force, the motion will in general be fairly chaotic. In such complex systems, an essentially random order is to be expected which explains the probabilistic assumptions of the theory.

"However, as proposed at the end of the discussion on the causal interpretation of the quantum theory in the previous chapter, such a simple deterministic theory is an abstraction, which is valid only up to a point. Beyond this point, one may have to consider the possibility that even the basic laws of the particles involve orders of infinite degree, which reflect levels of reality beyond those treated adequately by the current quantum theory. In a certain approximation, this may be considered as a random order. But as we have indeed already suggested earlier, the motion may more generally be in an order of very large or infinite degree, which is in the rich domain between simple orders of low degree and infinite chaotic or random orders. When understood in terms of the causal interpretation, the quantum theory is therefore capable of fitting into the general notion of the interweaving of chance and necessity, considered as lying at the extremes of an infinitely rich order that is context dependent. In quantum theory this order is at present hidden in the contexts available so far in physics, because science has not been able to respond with the necessary subtlety of meaning. But in contexts that may one day be discovered, new possibilities for creativity within such orders may be revealed, and these context orders will then cease to be "hidden."

"The notion that both simple regularity and randomness in a given context may contain orders that are "hidden" in that context, but which can be revealed in other contexts, is of quite general significance. For example, the order of a language or music cannot be found by studying the regular orders of vibration in sound waves, or the almost random orders of motion of the molecules in the air that carries them. Indeed, unless the mind is free of rigid commitments to familiar notions of order, such as the kind described above, it cannot provide a context within which basically new orders might be perceived. When music and art explore new orders, these are not even apprehended by those who are rigidly habituated to the older and more familiar ones. It is quite possible that in nature, there are further new orders, going beyond those that can be comprehended in terms of the quantum theory, even with its causal interpretation, as extended by the notion of orders of infinite degree in the motions of the particles," ibid., 130-132. 


\section{Freedom in the Humanities}

As with time, there is a direct relationship between Bohm's view of freedom in nature and freedom in the humanities. Below I will examine Bohm's comments on freedom within the context of the individual and society. In this context, it is important to again point out that, overall, there remains within the human the forces of necessity and contingency, together, just as in all of nature. ${ }^{854}$ In describing Bohm's view of freedom in the humanities, then, there are three distinct issues to discuss. First, there is the issue of free will within the individual. Second, the closely related issue of the meaning of human freedom in general, focused on the individual. And third, the issue of freedom in society, which includes cultures and religions. Below I will examine Bohm's perspective on each of them.

In discussing free will, Bohm challenges the status quo in a more innovative way than is typically done by philosophers and theologians, as Bohm is focused on the physical aspect of the problem, in to which he brings his unique perspective on physical reality. Yet, that is not to say that Bohm doesn't engage with some issues that are very much apropos to the way a theologian might discuss free will. For example, Bohm acknowledges that in recent western philosophical circles, "freedom has been commonly identified ... with free will or with the closely associated notion of freedom of choice. In these terms, the basic question is: Is will actually free, or are our actions determined by something else (such as our hereditary constitution, our conditioning, our culture, our dependence on the opinions of other people, etc.)? Alternatively, can we or can we not choose freely among whatever courses of action may be possible?"855 Bohm disagrees with positioning the question in this way, viewing it as incomplete, for "such a way of putting the question presupposes that the mind is always able to know what are the various alternative possibilities and which of these is the best. Evidently, however, if one does not have correct knowledge of the consequences of one's actions, freedom of will

\footnotetext{
${ }^{854}$ Even more pointedly, Bohm would write of the "happy union' of contingency and necessity," that is, there is a "necessary contingency" within reality, Bohm, Bohm-Biederman Correspondence: Creativity in Art and Science, 50. "Necessity and contingency interweave and ... each calls for the other... That is just the way science, art, and every other form of human endeavor go," ibid., 51.

${ }^{855}$ Bohm, "Freedom and the Value of the Individual," in The Essential David Bohm, 254.
} 
and choice have little or no meaning. It must be admitted that, in most of human life, lack of knowledge of what will actually flow out of one's choice prevails." ${ }^{1856}$

Bohm thus sees an intimate connection between knowledge and freedom, and thus for him it can be rightly said that "the principal barrier to freedom is ignorance." ${ }^{\text {"57 }}$ But stating it this way, in isolation, will open one up to one of Bohm's most important critiques about the nature and meaning of knowledge. Instead, Bohm suggests the principle barrier to freedom is ignorance "mainly of 'oneself' and secondarily of the 'external world."'858 Indeed, it is this dual ignorance that is the "main barrier to true individuality," for "any human being who is governed by opinions and models unconsciously picked up from the society is not really an individual," but rather "such a person is a particular manifestation of the collective consciousness of humankind." ${ }^{859}$ Thus, "a genuine individual could only be one who was actually free from ignorance of his or her attachment to the collective consciousness," because "individuality and true freedom go together and ignorance (or lack of awareness) is the principal enemy of both." ${ }^{860}$

Bohm elaborates on the above concept by sharing that although "we may perhaps be free to choose as we will, we are not free to will the content of the will. Evidently, this content is a key factor determining what sort of person one actually is, and yet it appears somehow to be 'given."' For Bohm,

\footnotetext{
${ }^{856}$ Bohm, "Freedom and the Value of the Individual," in The Essential David Bohm, 254. In this regard, Bohm echoes Jiddu Krishinamurti, Truth and Actuality (London, UK Harper \& Row, 1978), 149. "We think that having the capacity to choose gives us freedom," but "choice is the very denial of freedom. You choose when you are not clear, when there is no direct perception, and so you choose out of confusion, and so there is no freedom in choice-psychologically, that is.... Psychologically we think we are free when we have the capacity to choose. And we are saying that choice is born out of confusion, out of the structure of thought, and therefore it is not free," ibid. Elsewhere, in a conversation between Bohm and Krishnamurti, Bohm explains that the original freedom for man is not to choose, but "to have the capacity to make this mistake." That is, "there is a universal order," and "it is part of the order of the universe that this particular mechanism can go wrong. If a machine breaks down, it is not disorder in the universe, it is part of [a] universal order." Note that this disorder "is not ... at the level of the universe," but rather "at the level of man" there is "disorder." Man has lived from the beginning in this disorder "because he is still ignorant," and even though he is a part of the whole, one "could say that the possibility of creation is also the possibility of disorder. That if man had the possibility of being creative, there would also be the possibility of mistake. It could not be fixed like a machine, always to operate in perfect order. The intelligence [within man] would not have turned him into a machine that would be incapable of disorder," Bohm, in Krishnamurti, The Ending of Time, 34-35.

${ }^{857}$ Bohm, "Freedom and the Value of the Individual," in The Essential David Bohm, 256.

${ }^{858}$ Bohm, "Freedom and the Value of the Individual," in The Essential David Bohm, 256.

${ }^{859}$ Bohm, "Freedom and the Value of the Individual," in The Essential David Bohm, 256.

${ }^{860}$ Bohm, "Freedom and the Value of the Individual," in The Essential David Bohm, 257.
} 
the significance of this question becomes particularly clear when we note that "people so often seem to be unable actually to do the good things that they have (apparently freely) resolved to do. No person can be said to be free who is for reasons of internal confusion unable consistently to carry out his or her chosen aims and purposes, for evidently such a person is driven by inner compulsions of which he or she is unaware. This inner lack of freedom is far more serious than a lack arising from external constraints or a lack of adequate knowledge of external circumstances." ${ }^{861}$

One of the key forms of ignorance which inhibits us and "destroys freedom and prevents true individuality" is an "ignorance of the activity of the past." As Bohm's theory of time suggests, "although the past is gone, it nevertheless continues to exist and to be active in the present, as a nested structure of enfoldments, going into even the distant past, which are carried along (with modifications) from one moment to the next." ${ }^{862}$ That is, it is not merely the consequences of some mechanical deterministic result of the past which inhibits us, but an ignorance of the 'present' past in the present-the reason the past can free or inhibit us is because the past is present today as echoes within the implicate order. ${ }^{863}$ The past is really present in a partial or weakened manner, even as our

\footnotetext{
${ }^{861}$ Bohm, "Freedom and the Value of the Individual," in The Essential David Bohm, 255. Thus, although "there has been an enormous expansion of scientific knowledge, especially in the last century, along with a flood of many other kinds of knowledge (this has been called the 'information explosion')," "has all this knowledge contributed to our general freedom in any significant way? Or has it not, in many ways, led to yet further unresolvable entanglements in the problem of trying to establish orderly and harmonious human relations?," ibid., 254. Indeed, to the contrary, our efforts to "try constantly to improve our knowledge" often end in futility. "But as we have seen, reality is infinite both in its depth and in its extension. Although relatively independent contexts do exist, such independence is always limited. Very often the question of what these limits are is obscured not only by ignorance but also by the sheer complexity of the entangled web of interrelationships on which the consequences of our decisions may depend. It often does not seem to be at all likely that we will be able by increasing our knowledge alone even to keep up with this ever-expanding and agglomerating mass of interdependent processes, especially in the field of human relations (consider, for example, what is happening today in politics and in economics)," ibid., 254.

${ }^{862}$ Bohm, "Freedom and the Value of the Individual," in The Essential David Bohm, 257.

${ }^{863}$ For more on the context of knowledge, Bohm observes that "the past is also absolutely necessary in its proper area (as, for example, it contains essential knowledge of all sorts), but when the past operates outside awareness it gets caught up in absurdities of every kind and becomes something like the sorcerer's apprentice, which just keeps on functioning mechanically and unintelligently, to bring about destructive consequences one does not really want.

"This brings us to the question: can the past contain adequate knowledge of its actual activity in the present? As I have already pointed out, the content of knowledge (which is necessarily of the past) cannot catch up with the immediate and actual present, which is always the unknown. Since the activity of the past is actually taking place in the present, this too is inherently unknown. Thus, knowledge cannot 'know' what it is actually doing right now. As an example, one may 'know' from hearsay or from general conclusions drawn from particular experiences that people of a certain race are inferior. When this 'knowledge' responds to a particular member of this race, one's immediate perception is shaped, colored, and twisted so as to present that person as
} 
knowledge of it is equally weak, unknown, or deficient, yet this is in contradistinction to the common view which places merely the consequences of the past present in a cold, mechanically distant way.

To explain this point, it must be noted that Bohm also believes that "we are primarily the present, which is the unknown," and "the past is, in its actuality, merely a part of this present that is also active in the present, and therefore it too is the unknown. All that we know is the content (i.e., the meaning) of the past that is gone." 864

In such a situation, "the aid of moralistic injunctions, telling people to 'pull themselves together' and to choose, once and for all, what is right and good," ${ }^{865}$ has little meaning. What is needed is a greater self-awareness wherein our consciousness may "sink into its implicate (and now mainly unconscious) order. It may then be possible to be directly aware, in the present, of the actual activity of past knowledge." ${ }^{\prime 866}$ Only when this is done may "the mind may be free of its bondage to the active confusion that is enfolded in its past. Without freedom of this kind, there is little meaning even in raising the question as to whether human beings are free, in the deeper sense of being capable of a creative act that is not determined mechanically by unknown conditions in the untraceably complex interconnections and unplumbable depths of the overall reality in which we are embedded." ${ }^{867}$ It is

inferior. One is not aware of just how all this is actually taking place, as it happens very rapidly and in very subtle ways. Moreover, the whole process is accompanied by a great deal of distortion and self-deception. For example, as one perceives the "inferiority" of the other person, thus implying one's own "superiority," one experiences a short, sharp burst of intense pleasure. To sustain the pleasure the mind continues with further false thoughts along this line while concealing from itself the fact that it is doing so. Clearly, because the response from accumulated knowledge always lags behind actuality and because, in cases such as this, the mind is caught up in feeling the need to distort, it is not possible through such knowledge alone thoroughly to free the mind of such prejudices," Bohm, "Freedom and the Value of the Individual," in The Essential David Bohm, 257258.

${ }^{864}$ Bohm, "Freedom and the Value of the Individual," in The Essential David Bohm, 258-259. Bohm adds, and this content "resembles the actual present only for those contexts in which changes are slow and regular enough so that the difference between past and present makes no significant difference," ibid., 259.

${ }^{865}$ Bohm, "Freedom and the Value of the Individual," in The Essential David Bohm, 255.

${ }^{866}$ Bohm, "Freedom and the Value of the Individual," in The Essential David Bohm, 258.

${ }^{867}$ Bohm, "Freedom and the Value of the Individual," in The Essential David Bohm, 258. That is, "if we are the unknown, which is the present, then time can be seen in its proper meaning only in the context of that which is beyond time (i.e., the holomovement or eternity).... Implicitly, this is well known to us. No one will be creative who does not have an intense interest in what one is doing. With such an interest, one can see that one will be at most only dimly conscious of the passage of time. That is to say, though physical time still goes on, consciousness is not organized mainly in the order of psychological time; rather, it acts from the holomovement. On the other hand, if the mind is constantly seeking the goal of finishing its task and reaching its aim (so that it is organized in terms of psychological time) it will lack the real interest needed for true creativity," ibid., 259. 
within this context that Bohm asserts that "to treat the whole meaning of existence in terms of time alone will lead to arbitrary and chaotic limitation of this existence, which then takes on the quality of being rather mechanical. If we are to be creative rather than mechanical, our consciousness has to be primarily in the movement beyond time," ${ }^{\prime 68}$ because human creativity "arises directly from the 'timeless' holomovement" ${ }^{869}$ of the infinite layers in their dance. ${ }^{870}$

Therefore, it is the notion of "mechanical" necessity that figures prominently in Bohm's thinking as a key problem, for the "grosser mechanical existence in time" typically dominates individuals, and unfortunately it seems to be of "supreme value" ${ }^{871}$ to society. Within Bohm's perspective, however, "in any mechanistic point of view, nothing basically new ever happens." Whether one is a mechanistic determinist, or a mechanistic indeterminist, "they both agree on an essential point. The general character of the kinds of events that can happen, the kinds of things that can exist, is already determined by some fixed set of rules." ${ }^{872}$ Bohm's understanding of human freedom, and its reliance upon the deeper implicate orders, requires the freedom of humans to exceed the mechanistic picture which dominates the western worldview.

Bohm carefully distinguishes two concepts to elaborate on his point about mechanism and human freedom. He believes "a distinction" must be made "between 'determinism' and 'causality.' Although both words have roughly the same meaning, their implications are different. For causality implies (a) that if you know the causes, you can predict the effects," but also "(b) that if you change

${ }^{868}$ Bohm, "Freedom and the Value of the Individual," in The Essential David Bohm, 259.

${ }^{869}$ Bohm, "Freedom and the Value of the Individual," in The Essential David Bohm, 259.

${ }^{870}$ Bohm and Peat, Science, Order, and Creativity, 215. Thus, for Bohm, to emphasize his point, "thought is part of the physical.... Thought is a more subtle form of the physical.... Thought is part of a material process. It goes on in the brain, the nervous system, and really the whole body and everything; it's all one system.... Within the body thought is conveyed by nervous signals; there is a code of some sort, which we don't know too well.

"We're saying that thought is a material process; it has reflexes that just go on by themselves. And if you have an insight or perception that this is true, then that will actually affect you. An insight or a perception of truth may deeply affect the material process, which includes all the reflexes. But if we merely have an intellectual or inferential knowledge of what is going on, then it doesn't touch this process deeply," Bohm, Thought as a System, 149-150.

${ }^{871}$ Bohm, "Freedom and the Value of the Individual," in The Essential David Bohm, 260.

${ }^{872}$ Bohm, Causality and Chance, Letters to Three Women, 164. 
the causes, you can change the effects in a predictable way." ${ }^{873}$ On the other hand, "determinism implies only predictability. In fact, with complete determinism, it would be impossible for us ever to change anything. ${ }^{\prime 74}$ Bohm suggests that if there were only one or a finite order, that is the explicate order, then a complete causality of this order would imply a complete determinism of all reality.

However, "if there are an infinite number, then the two concepts part company. For we can have complete causality at every level, in the sense that we can use this causality to change the world in a predictable way, with the error in the predictions dependent only on our level of knowledge; whereas we can in no sense conceive of the world as completely determined." ${ }^{875}$ Furthermore, in connection with this, "note that the statement that new things can come into existence is consistent with causality, only if what is already in existence has an infinite number of levels. For if we have a finite number of causal levels, then the future is already contained logically in the present, but not if we have an infinite number. The appearance of qualitatively new things with time is possible with an infinite number, because the effects of the limitless number of lower levels can always surge up into a higher level (and vice versa) producing qualitative [changes. Whereas in the deterministic model the finite number of levels limits any changes to things to be] describable as a [mere] rearrangement of things already in existence."${ }^{876}$

All of the above directly relates to how Bohm conceives of human freedom. For Bohm elaborates upon his theory further by sharing that "the nightmare of complete determinism is avoided" if one accepts "the concept of a limitless number of levels" which suggests that "the work of science is never finished and leads one at each level to seek" resolutions to the contradictions "at the next level etc. Thus it provides a motive power for continual development and growth." ${ }^{877}$ As such,

\footnotetext{
${ }^{873}$ Bohm, Causality and Chance, Letters to Three Women, 255.

${ }^{874}$ Bohm, Causality and Chance, Letters to Three Women, 255.

${ }^{875}$ Bohm, Causality and Chance, Letters to Three Women, 255.

${ }^{876}$ Bohm, Causality and Chance, Letters to Three Women, 255.
}

${ }^{877}$ Bohm, Causality and Chance, Letters to Three Women, 254. Bohm states that "I think that the explicit recognition of a limitless number of levels would be a big step forward in science. Most of the errors of both the positivist and the $19^{\text {th }}$ century 'mechanical' materialists spring from an implicit assumption that the laws of nature will some day finally be understood in terms of a limited number of hypotheses. From this comes the nightmare of a mechanically determined universe that follows an inevitable course. To avoid this nightmare, positivists and idealists have given up causality and assumed a 'spontaneous' (i.e., uncaused) element in 
"although each level is causal, the totality of levels cannot ever be taken into account. Thus, as a matter of principle, we can say that complete determinism could not even be conceived of, yet, each level can be determined. Here, we part company with the believers in 'spontaneity' for we say that what appears to be spontaneous is caused by factors, in principle, knowable, but now hidden to us." ${ }^{878}$ Yet, Bohm believes, "to be able to say this without implying complete determinism, we must assume an unlimited number of levels. It is the unlimited number of levels which give matter its 'nonmechanical' aspects, for if the analysis of physical laws could ever be completed, the theory would either be deterministic + 'mechanical,' or 'indeterministic' and 'spontaneous.' Another interesting point-if there are an infinite number of levels, we can expect that all existing limitations (such as speed of light and uncertainty principle) can be overcome with the aid of more fundamental levels. Thus, by the use of causal laws, humanity can move toward [a] freedom"879 beyond the seemingly deterministic explicate order we live within. Conversely, of course, "in the ignorance of causal laws, humanity is enslaved either to determinism or to 'spontaneity,' which, being pure accident, is just as tyrannical. ${ }^{\prime 880}$

Bohm has thus suggested that it is an awareness of the causal laws that leads one toward freedom. Yet, Bohm has subtly separated causal laws from determinism. In this sense, one can perceive a difference between mechanical necessity and absolute necessity. That is, "absolute necessity is the same as freedom," yet freedom is "also creativity." Indeed, "creativity is an absolute necessity-in some sense. But there's also the mechanical necessity which blocks it." ${ }^{\prime 81}$ Bohm realizes

physical processes. This is the real 'human' meaning of Bohr's point of view in quantum mechanics, which has its counterpoint in Bergson's 'elan-vital,' etc. But in practice, because the 'spontaneous' element is uncaused, it is beyond scientific knowledge-it can only be 'experienced' at each instant of time-and this means that the scientifically understandable aspects of reality are restricted to a limited number of levels. Thus, both points of view tend to cramp the development of science, because they discourage a search for 'deeper' causes than those already known. In politics, it is the same. Mechanical determinism leads one to believe that what already exists is permanent, and the 'elan-vital' leads us to believe that although changes are always taking place, they are spontaneous, beyond understanding and control, so that it is of no use to interfere with them, a conclusion very satisfactory to the existing powers [(such as the Pope's fondness for theories of a mysteriously changing universe)]," ibid.

\footnotetext{
${ }^{878}$ Bohm, Causality and Chance, Letters to Three Women, 254.

${ }^{879}$ Bohm, Causality and Chance, Letters to Three Women, 254-255.

${ }^{880}$ Bohm, Causality and Chance, Letters to Three Women, 255.

${ }^{881}$ Bohm, Unfolding Meaning, 44.
} 
that the concept of "necessity is a very interesting question.... The opposite of necessity is contingency.... Absolute necessity cannot be touched. It doesn't yield. What is contingent can yield to pressure from the outside." Bohm illustrates their dynamic coexisting nature by again referring to an illustration with a chair. "If we take this chair, it has a certain kind of necessity that it hold together; but it's contingent on certain conditions. If you were to raise the temperature it would start to burn, and it would go to pieces. If you hit it too hard it would break. So it's subject to external contingencies-this necessity. Now normally necessity in science should be limited by contingency, and this contingency in turn is another form of necessity, which in turn has another context in which it's contingent. That is, the ordinary mode of analysis by thought weaves between necessity and contingency. It cannot do otherwise; and that's a necessity." ${ }^{182}$ In the same manner as thought, "in some way which is hard to express, freedom requires both necessity and contingency." ${ }^{\prime 83}$

What's significant is that Bohm ties all of the above into his ruminations about the ultimate meaning of freedom for humanity, in many subtle ways, and for which he acknowledges there is still much uncertainty. ${ }^{884}$ Thus he asserts that our relationship to the causal laws will always be somewhat dialectical, for a "mere recognition of necessity does not liberate us. For example, we all recognize the necessity that we must die, but we go on dying whether we like it or not. To be free of death we would have to understand the limitations of the laws that make death necessary, and to take

\footnotetext{
${ }^{882}$ Bohm, Unfolding Meaning, 44. "Since the very idea of a 'thing' implies limitation and finiteness, we could say that in a sense, there is really no "thing" in the world. Even chairs, tables, etc., which seem at first sight to be limited 'things' are not really so. If we apply a little heat, the molecules go into movement and they dissolve away into gas. Put them into an atomic pile and even their atoms would dissolve away into other atoms and energy. At very high energies all kinds of particles transform into each other. Thus, there are really no final or eternal limits on what any 'thing' actually is, or can become. Such limits are only of relative validity, i.e. the limitations are themselves limited in their domains of validity. Thus, even the simplest 'things' are really infinite, and much more so, the same holds for man, who is infinitely more complex and subtle in his make-up," Bohm, Bohm-Biederman Correspondence: Creativity in Art and Science, 12.

${ }^{883}$ Bohm, Thought as a System, 220. "Freedom would require some contingency, in the sense that if things couldn't be otherwise then there would be no freedom. But freedom would also require some necessity, because if there were no necessity our intentions would have no meaning. We might intend to do something, but if nothing holds with any necessity then anything may happen, no matter what we intend," ibid.

${ }^{884}$ Bohm, "Freedom and the Value of the Individual," in The Essential David Bohm, 258. "This leads us to a more fundamental question of what the relationship is between the truly free human being and the totality that goes beyond the explicate order, beyond the implicate order, and beyond time and space. To pose this question is of course itself subject to questioning, since one may ask whether one has properly laid the ground for doing so," ibid.
} 
the appropriate steps to remove ourselves from the dominion of these laws." ${ }^{185}$ Of course, if the laws that make death necessary are related to some deeper implicate order, then the solution to death could not be found in the explicate mechanistic order alone in which essentially all modern western society and its individuals operate.

Additionally, Bohm also asks the question, "what is the positive content of freedom? In other words, after we have removed ourselves from the dominion of necessity, what will we do? The answer to this question is I think, closely related to the nature of art." Bohm suggests that what we are really asking ourselves is "what are we, most essentially, after we have removed all external factors that now limit us?' I suggest that each one of us is something infinite, which at least reflects the infinite totality. This something should itself be a kind of whole. That is, it should have the kind of completeness, unity, integral character, etc., that is in a good picture. In such a picture, one cannot analyze the whole into separately existing parts (e.g. spots of paint etc.). Rather, to the extent that the picture is a real work of art, the justification of each part is only in the whole picture." ${ }^{\prime 86}$ Bohm connects this concept with space and time. He shares, "with regard to our own existence in time and space, we do not say that the past completely determines the future, for this would deny novelty to the future and wholeness to our existence in time. Rather, we say that the past in some way limits the future." This is not to say that there is not "room for something new to exist in its own right. The freedom of each new thing to be what it really is, is limited by the past. This limitation applies to ourselves as well as to everything else in the world." ${ }^{887}$ However, "insofar as we understand these limitations, we can remove ourselves from their dominion and we can, in a sense, make room to allow us to be what we are, i.e. a complete, whole person, not only at one moment, but over a whole lifetime. In such a mode of existence there is genuine freedom, in the sense that the future is not fully

\footnotetext{
${ }^{885}$ Bohm, Bohm-Biederman Correspondence: Creativity in Art and Science, 13. Bohm adds, "the more fundamental origin of the necessity of death is in our own internal processes that constitute our mode of life. And these are what we must understand if we are really to prolong life in a fundamental way," ibid.

${ }^{886}$ Bohm, Bohm-Biederman Correspondence: Creativity in Art and Science, 13.

${ }^{887}$ Bohm, Bohm-Biederman Correspondence: Creativity in Art and Science, 13.
} 
determined by the past any more than, for example, the left-hand side of a picture is fully determined by its right-hand side, ${ }^{\prime 888}$ even though the right-hand side must always be half of the whole.

As noted above, but worth reiterating, Bohm believed that "the concept of the infinity of levels must be an integral part" of a theory of nature and reality, and this helped explain a coherent view of social freedom as well. For an infinite number of levels alone "clears up endless sources of paradoxes." For "this $\infty$ of levels is intimately connected up, both with quantum theory, and with probability. For the causal laws at each level arise from the existence of chaos at lower levels." ${ }^{889}$ For an illustration of what this means, "scientists ... have a tendency to feel that their general framework of ideas already includes all possibilities, and that only the 'details' need to be filled in. This creates the illusion of 'freedom' since they think they are 'free' to do everything that can possibly be done." However, "actually they are confined by not being able to see the limitless possibilities that are visible as soon as one gets out of the customary conceptual framework." ${ }^{890}$ That is, in the typical scientist's worldview, "the world is looked on as made up of fixed types of elements. 'Freedom' consists only in being able to rearrange the pattern of the elements. Thus, there are rich, middle class and poor people. If a man can move from one class to another, he is said to be 'free.' Even the socialists tend to hold such views, since they essentially want to put everybody in the middle class." However, Bohm

${ }^{888}$ Bohm, Bohm-Biederman Correspondence: Creativity in Art and Science, 13. It is critical to observe that, for Bohm, his disagreement "with Bohr is that he stops with just giving the limitations on the older mechanistic and deterministic points of view, and discourages the development of new categories of thought concerning space, time, existence, etc., in which one will see the reasons for these limitations. Thus, if determinism is limited, this need not be a complete mystery. It may only mean that we must have a different idea of what things are, which shows quite naturally why determinism is limited. If we get a different idea of time and of what is to be meant by existence in time, then we see a natural reason why the past would not determine the future," ibid., 15-16.

${ }^{889}$ Bohm, Causality and Chance, Letters to Three Women, 292. "For example, the gas laws are valid at our scale, only because of chaotic molecular motions. Likewise, I believe theat the causal laws governing the motion of electrons arise from the existence of chaotic motions of the particles of the substratum, out of which electrons are made, etc. ad infinitum," ibid.

${ }^{890}$ Bohm, Causality and Chance, Letters to Three Women, 292. Bohm also notes that, in his opinion, "mathematicians seem to be particularly bad, in this respect. For they seem to feel that because of the iron-clad logic of their proofs, nothing has been 'put over on them.' Thus, there is nothing (except for details) that they could possibly be overlooking. The task of mathematicians then reduces to an endless grinding out of detailed theorems, and the excellence of a mathematician is measured by his output of such theorems per year (Physicists are just as bad in their own respective way, however). The $\infty$ of levels, as applied to math concepts immediately shows the error of this point of view. For each set of concepts must be based on a still more fundamental set, etc. ad infinitum. Gödel's work demonstrates this, since he has shown that no complete selfconsistent system of theorems is possible, which provides their own basis (i.e. their own proof of consistency), ibid. 
suggests, "nobody notices the fact that the entire system of elements and classification is itself not inevitable, and is indeed the product of the existing structure of society. Thus, people become cynical, because they see no way out of the same old merry-go-round.." ${ }^{891}$ But all of this is based upon a mistake, in Bohm's view, namely the imagined reality in which all "'that which is' is permanent," or all that is may merely "move around and change, but only in a superficial way, since in essence, the kinds of things that exist, and the laws governing their motion are conceived of as fixed." ${ }^{892}$ However, for Bohm, the subtly multi-layered dialectical "nature of things (including human beings) may change with conditions, and it is already a serious interference with human freedom not to have the opportunity to realize these changes, when they are necessary. Thus, in a capitalistic society, a person is not free to become what he is ready to become, and needs to become, in order to continue to exist as an integrated human being." ${ }^{1393}$

As one can intimate from the above, Bohm was indeed a sharp critic of what he considered to be the scientific-capitalistic worldview that dominated the 1950's-1980's U.S., a period in which one must keep in mind the context of Bohm's musings on politics-that of the 'red scare' in the United States. Writing about his own concerns about being jailed, which never did occur despite them confiscating his passport, Bohm shared that "if they stick me in jail, quite a few people will be led to see the hypocrisy of the claim that the U.S. is part of the so-called 'free world.' Moreover, it's not only true that no man can be totally free while another is in jail, but also that no man is totally in jail while there are people outside to fight for his freedom and that of other people as well." ${ }^{894}$

${ }^{891}$ Bohm, Causality and Chance, Letters to Three Women, 295.

${ }^{892}$ Bohm, Causality and Chance, Letters to Three Women, 295.

${ }^{893}$ Bohm, Causality and Chance, Letters to Three Women, 295.

${ }^{894}$ Bohm, Causality and Chance, Letters to Three Women, 107. Bohm adds that he sees his own work as "part of a fight against the insanity that has taken over this [U.S.] nation both indirectly and directly. It is indirectly so in the sense that all efforts towards a rational understanding of nature are also directed at removing the feeling of helplessness with which man confronts his problems. But even more directly, I feel that the more I can accomplish in the time that is left, the more of a blow that I deliver to the people who may put me in jail. For such an action on the part of the government will then be seen more clearly by people everywhere and especially in other nations as an exposure of the actual nature of our system, which is now trying to deny freedom to anyone who will not give up the most elementary concepts of decency," ibid. 
Overall, however, Bohm believed that freedom, and creativity, in the social sphere was blocked by a wide range "of rigidly held assumptions that are taken for granted by society as a whole.... Every society holds additional assumptions that are of such a shaky nature that they are not even admitted into discussion." ${ }^{895}$ Indeed, Bohm thought that "there is therefore an unspoken requirement that everyone must subscribe to these assumptions, but that no one should ever mention that any such assumptions indeed exist. They are tacitly denied as operating within society, and even this denial is denied." ${ }^{\prime 86}$ Bohm argued that "the overall effect is to lead people to collude in 'playing false' so they constantly distort all sorts of additional thoughts in order to protect these assumptions. Such bad faith enters deep into the overall generative order of society. These rigidities and fixed assumptions, many of which must not be mentioned but must nevertheless be defended, may be compared with a kind of pollution that is constantly being poured into the stream of the generative order of society." Striking a realist tone, Bohm thought that "it makes no sense to attempt to 'clean up' parts of this pollution farther downstream while continuing to pollute the source itself. What is needed is either to stop the pollution at its source, or to introduce some factor into the stream that naturally 'cleans up' pollution." ${ }^{897}$

To list but a few examples of 'pollution,' Bohm suggested that "in society, the generative order is deeply affected by what has a very general significance. Indeed the generative order may be regarded as the concrete activity of the general. This takes the form of general principles, general aims, and generally accepted values, attitudes, and beliefs of all kinds that are associated with the family, work, religion, and country."${ }^{\prime 898}$ These general principles, when universalized within a society, can assume a dangerous form. For "when a given principle is regarded as universally valid, it means that it is taken

\footnotetext{
${ }^{895}$ Bohm and Peat, Science, Order, and Creativity, 236.

${ }^{896}$ Bohm and Peat, Science, Order, and Creativity, 236.
}

${ }^{897}$ Bohm and Peat, Science, Order, and Creativity, 236. Within "a consideration of society, clearly there is also a vast amount of misinformation in circulation which acts toward society's degeneration. The media and various modern means of communication have the effect of rapidly disseminating and magnifying this misinformation, just as they do with valid information. It should be clear that by 'misinformation' is meant a form of generative information that is inappropriate, rather than simply incorrect statements of fact. In a similar way a small 'mistake' in DNA can have disastrous consequences because it forms part of the generative order of the organism and may set the whole process in the wrong direction," ibid., 238.

${ }^{898}$ Bohm and Peat, Science, Order, and Creativity, 238. 
as absolutely necessary. In other words, things cannot be otherwise, under any circumstances

whatsoever. Absolute necessity means 'never to yield.' To have something in the generative order that can never give way, no matter what happens, is to put an absolute restriction on free play of the mind, and thus to introduce a corresponding block to creativity that is very difficult to move."${ }^{899}$

This is not to say Bohm didn't recognize that "both the individual and society require a certain stability, and for this, thought must be able to hold itself fixed within certain appropriate limits and with a certain kind of relative necessity," ${ }^{900}$ but an excess, which could be a very small number, of absolute necessities in a society would always prove destructive. Of course, and pertinently, various political nationalisms, ${ }^{901}$ as well as religions, including Christianity, and the very idea of God, often fall prey to being absolute necessities. ${ }^{902}$ Whenever God becomes an absolute necessity to be conceived of in a certain way, conflict is inevitable. ${ }^{903}$ Yet, for Bohm, perhaps the most significant block to individual, and social, freedom and creativity is the ontology of mechanistic science-an ontology that has not limited itself to merely the 'physical as such,' but has permeated or infected all of social society in innumerably subtle ways. Thus, "science, which is in principle dedicated to the truth, tends

${ }^{899}$ Bohm and Peat, Science, Order, and Creativity, 238.

${ }^{900}$ Bohm and Peat, Science, Order, and Creativity, 238.

${ }^{901}$ Bohm wrote, "for example, if somebody attributes to the center the quality of being a certain nation, then you must distinguish another nation as not belonging to this center. So it fragments mankind in order to hold the center together. Therefore the entire world is fragmented indefinitely, shattered into fragments," Bohm, Limits of Thought: Discussions, 97.

${ }^{902}$ Bohm, Thought as a System, 25. As Bohm put it, "it's no use just saying that love will take care of everything. People have said that for ages, but it hasn't done it. The Christian religion was based on the idea that God is love. They said that there is one God who is pure love, and Christ, and so on. Nevertheless, the Christians fought not only other religions but they also fought each other violently. They carried out very violent religious wars lasting centuries and did terrible things. Now I'm sure these people didn't intend to get into that; they had another intention. But because of the way they were thinking about their religion they couldn't help it. Theological ideas, for example, took over from ideas of love. Or there was a question of the religion being connected with the monarchy or power, or whatever. So violence doesn't stop merely by saying, 'we'll act based on love,' because that can become just an idea that gets absorbed into the system," ibid.

${ }^{903}$ Bohm explains, "the notion of reality is also clearly very important in our whole psychic make-up. The difference between being real or unreal or illusory is crucial. So the notion of necessity creates a powerful reflex-'it really has to be that way.' If we not only add emotion and repetition to the reflex, but also add the notion of necessity, the reflex becomes very powerful-especially if we say 'it's always necessary.' Something may be necessary some of the time, but then it may have to turn aside at another time. But if we say 'it's always necessary,' that means it is absolutely necessary, it cannot turn aside. For instance, if we say that the nation is sovereign, then that becomes absolute necessity and there's no way of turning that aside. And if two nations assert their sovereignty in the same place, what can they do? There is no way to turn aside, and therefore they have to fight. Or two religions in the same way-'God is absolute necessity,' and 'God has got to be this way and not that way,'” Bohm, Thought as a System, 71. See also, Bohm and Peat, Science, Order, and Creativity, 265-266. 
to be caught up in necessity which then leads to false play and a serious blockage of creativity."1904 Undergirding the ontology of science, of course, is a restrictive concept of absolute necessity. ${ }^{905}$

Bohm's concern about societies caught up on absolute necessities is that they unwisely try to "deal with ... misinformation by trying to prevent it from entering its fabric, or attempting to 'cure' it with some form of therapy." For example, "on a rather superficial level, there are laws to prevent false information and information which may engender hatred, anger, and prejudice from being spread about various races, religions, and groups. Writers, dramatists, and filmmakers go some way to making people aware of prejudices and rigidly fixed attitudes." ${ }^{906}$ Yet, Bohm believes, "in the long run, all these attempts are limited by the overwhelming, and yet often very subtle, pressures within society toward colluding to defend one's own group and its ideas. In addition, there is the whole problem of the intolerance and mistrust that have grown up between nations, religions, ideologies, and other groups which go all the way down to the family itself. To some extent psychotherapy and group therapies can help to clear up individual misinformation of this kind, which may go back to early childhood, or start in a later phase of life. But these approaches have very little effect in the larger sphere of society as a whole." ${ }^{907}$ Of course, for Bohm, "a particularly important piece of misinformation is the key assumption that creativity is necessary only in specialized fields [such as the arts and drama, but not the sciences]. This assumption pervades the whole culture, but most people are generally not aware of it, ${ }^{\prime 908}$ which limits their freedom. ${ }^{909}$ Only as humanity together in

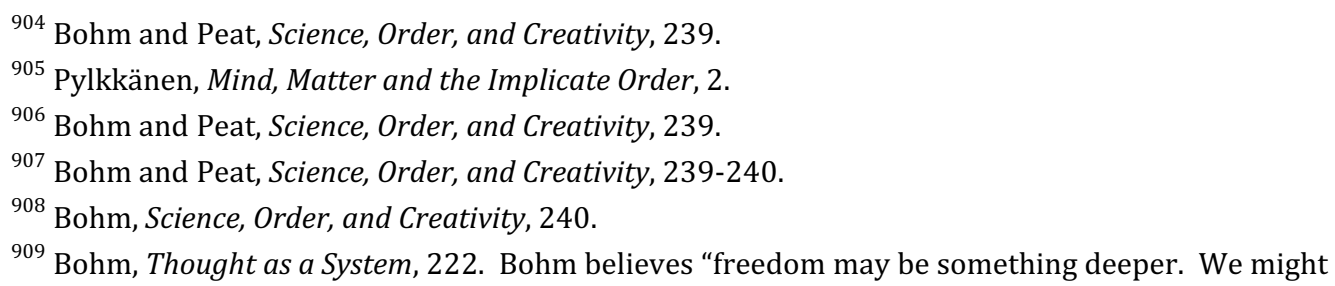
think of an artist, a creative artist, who is creating a work of art. There are many possible contingencies-ways of putting his materials here or there and with different techniques. It's open. That's the field in which he can work. And then from some perception-by some sense of internal necessity, some creative perception of necessity-he must begin to develop how this is to be done. Otherwise it won't hold together, it won't have any value or any meaning. In other words, freedom is the creative perception of a new order of necessity," ibid. Or, perhaps, "when somebody comes out with a new order of necessity, other people may not see it right away and it looks to them just like contingency. So they say 'this is rubbish.' In many cases it may be rubbish, but then occasionally it isn't," ibid., 223. 
dialogue, through a mutual suspension of our "tacit individual and cultural infrastructures," free our minds "to move in quite new ways." 910

Overall, in summary, Bohm's view is that "the essence of freedom" is "to realize one's true potential."111 To realize one's potential, it is important to integrate oneself within the flow of the implicate timeless holomovement and give "sustained and serious attention to how unfreedom arises basically from identification with the [mechanistic] past, in which the mind commits itself to act as if it were determined mechanically in the ways in which grosser levels of matter are determined. We have to use the past, but to determine what we are from it is the mistake." ${ }^{912}$ We must realize "that we are the unknown, which is beyond time." This will allow our minds "to give time its proper value, which is limited and not supreme. This is what makes freedom possible, in the sense of realizing our true potential for participating harmoniously in universal creativity, a creativity that also includes the past and future in their proper roles."${ }^{913}$ For Bohm, this should occur at both the individual and societal levels, as they are ultimately both part of one undivided whole.

Below, the relations of freedom and time will be explicitly stated in Bohm's writings for comparative purposes with Pylkkö in the following chapter. Additionally, the potential of Bohm's ideas about freedom and time for theological reflection will also be briefly explored, prior to a fuller assessment and synthesis of the state of theological reflection about freedom and time alongside Bohm's and Pylkkö's contributions in chapter 5.

\section{Bohm's View on the Relations of Freedom and Time}

As can be seen from the above examination of Bohm's views of time and freedom, Bohm clearly sees them as related concepts-they are two sides of the same coin, so to speak. However, determining the precise relations of freedom and time in Bohm's writings for the purposes of this study requires one to distinguish between his understanding of mechanistic time, the holomovement, and what may

\footnotetext{
${ }^{910}$ Bohm and Peat, Science, Order, and Creativity, 244.

${ }^{911}$ Bohm, "Freedom and the Value of the Individual," in The Essential David Bohm, 260.

${ }^{912}$ Bohm, "Freedom and the Value of the Individual," in The Essential David Bohm, 260.

${ }^{913}$ Bohm, "Freedom and the Value of the Individual," in The Essential David Bohm, 260.
} 
most precisely be called 'common sense' or psychological time. Implicit in this is a tension between the former two and the latter.

For Bohm, mechanistic time is the time strictly associated with physical causation. This is time as delimited by the speed of light, and thus time understood in the Einsteinian manner. Because such an understanding of time disallows genuine changes, such time may, more properly, be thought of as ontologically timeless. ${ }^{914}$ Because this dominant paradigm is overarching all disciplines, not merely physics, Bohm is faced with the distinct problem of finding a new way to position his theory of time, as well as freedom, into a culture that is predisposed not to accept it. The challenge and ambiguity surrounding his problem is recognized, for example, in David Ray Griffin's observation that "the status of freedom, causality, and time are in the same boat. The denial of one implies, finally the denial of the others. If time is unreal, in the sense that from an ultimate perspective there is no distinction between past, present, and future, then there can be no freedom, in the sense of selfdetermination in the moment." ${ }^{915}$ Thus Griffin, as has been affirmed repeatedly throughout this study, sees that the conceptual linkage between them all is bound together. Griffin, for his part, critiques Bohm about his view of time, believing that Bohm contradicts "our deepest intuitions about time, freedom, and causation," ${ }^{916}$ precisely because he must position them 'elsewhere' than what the overarching paradigm allows. Therefore, because time is mechanistic in Bohm's understanding, what counts for 'time' must therefore be 'timeless.' In like manner, the source of freedom originates out of the timeless realm beyond mechanism.

However, while Bohm himself does use the language of 'timelessness,' a careful study of his views on time and freedom reveal that they are not, necessarily, entirely timeless. The movement of time, however, may be seen more in a vertical rather than horizontal way, emphasizing the

\footnotetext{
914 Thus, sympathetically to Bohm, others speak of "the narrow framework of the timeless materialenergy paradigm of physics" which maintains the original "Platonian idea," which fails to appreciate Bohm's contribution to expand our view of physics, Josef Šmajs, Evolutionary Ontology: Reclaiming the Value of Nature by Transforming Culture (Amsterdam, The Netherlands: Rodopi, 2008), 23.

${ }^{915}$ David Ray Griffin, "Bohm and Whitehead on Wholeness, Freedom, Causality, and Time," in Physics and the Ultimate Significance of Time, 127-153, 152.

${ }^{916}$ Griffin, “Bohm and Whitehead on Wholeness, Freedom, Causality, and Time," 152.
} 
relationship of now and eternity more closely. Furthermore, the very word holomovement implies his understanding of timelessness is not static according to the platonic tradition. Yet, while the holomovement emphasizes the verticality, rather than horizontality, of movement, this is not to say that no horizontal 'movement' of time is possible. Rather, Bohm merely wishes to strongly emphasize that reality's verticality is much more important than the abstraction of any given vertical level which may in a given context be viewed horizontally. No horizontal perspective of any particular level of reality should be prioritized against the overall greater infinity of verticality. In this sense, reality is not necessarily strictly timeless in a static way, even if its timeless aspect is more important to emphasize. ${ }^{917}$

Freedom, of course, rests in the same situation as time. While Bohm certainly emphasizes the origin of freedom and, what is for him its closely associated concept, creativity, in the 'timeless' vertical depths of reality, this is all done to escape the thought and actions of humanity that seem restricted to the explicate, mechanistic, temporal-deterministic paradigm. Any spark of originality or newness cannot originate from mechanistic thinking. Indeed, free will would have no meaning were it to only be connected to the order of mechanism. Therefore, while Bohm describes freedom as timeless, I would suggest that freedom is in the same situation as time. Bohm's emphasis on the vertical orders of reality places freedom within the infinite depths of the 'timeless' implicate orders, yet this may not mean that freedom is strictly timeless. Rather, freedom originates from out of a series of 'time orders' that are distinct from the temporal-deterministic time order that dominates the Einsteinian mechanistic order. That said, however, from a pragmatic point of view, both freedom and time remain timeless from the point of view of the mechanistic paradigm that dominates western philosophy.

Lastly, all of the above tensions are again present when one examines Bohm's views of time and freedom in both the individual and social spheres, owing to Bohm's emphasis on the unity and undivided wholeness of reality. This point will be critiqued more below in the evaluation of the

${ }^{917}$ Bohm, “Time, The Implicate Order, and Pre-Space,” 197. 
coherence of Bohm's thought. For now, what is pertinent is to examine Bohm's usage of the concept of God and to see how his views of time and freedom might contribute to theological reflection on the concepts of time and freedom.

\section{Bohm's Usage of the Concept of God}

It need not be restated that Bohm was a physicist by training. That said, however, Bohm's theories, as an exercise in the practice of physics, creates many interesting questions that one might ponder from a theological perspective, especially when addressing the God-world relationship, and Bohm was certainly aware of the interest religious people had in his theories. Interestingly, it must be observed that Bohm strongly resisted having his theory of infinite levels called or be equated with a "religion," ${ }^{118}$ yet he was also amenable to addressing the topic and was not an 'anti-theist.' Below I will briefly explore Bohm's thoughts about God and the divine.

Bohm was directly asked on occasion whether a creator God existed in his implicate order, and

his most detailed response was that, simply put:

The issue is not raised. I have an idea of an implicate order and beyond that a superimplicate order, and so on, to orders that are more and more subtle. I say there are many more subtle levels. The word "subtle" has a root subtext meaning "finely woven." You may think of nets of consciousness that are finer and finer, or we may think of capturing finer and finer aspects of the implicate order. This could go on indefinitely. Then it's up to the individual. I think there is an intelligence that is implicit there. A kind of intelligence unfolds. The source of intelligence is not necessarily in the brain. The ultimate source of intelligence is much more enfolded into the whole.

Now, as far as the question whether you want to call that "God," this depends on what you mean by the word, because taking it as a personal God might restrict it in some way. The suggestion is that there is something like life and mind enfolded in everything. If you carry that to the ultimate, then that might be what some of the religious people mean by the word "God." But the word "God" means many different things to different people, and it becomes hard to know exactly what is implied. The implicate order does not rule out God, nor does it say there is a God. But it would suggest that there is a creative intelligence underlying the whole, which might have as one of the essentials that which was meant by the word "God." 919

Bohm continues, noting that "any picture which we make through thought is limited, and even the idea of the implicate order is limited, although" it may go "beyond previous limits." However, "only

\footnotetext{
${ }^{918}$ Bohm, Causality and Chance, Letters to Three Women, 312.

${ }^{919}$ Bohm, On Creativity, 106-107.
} 
the ultimate is unlimited," and as soon "as you say more about the unlimited you begin to limit it." Bohm actually notes that "in the Hebrew religion when they said the name of God is only 'I am,' and nothing more should be said," they were appropriately unlimiting God. Unfortunately, in his view, as time passed "they did not carry that out in a coherent way," and began limiting God later. ${ }^{921}$

Kevin Sharpe, in his analysis of the role of God in Bohm's metaphysics, also explores many other thinkers who have engaged with Bohm's ideas. Sharpe observes that many believe Bohm's work certainly points toward certain transcendent features of nature which could correspond to divine presence, ${ }^{922}$ yet without necessarily requiring pantheism or panentheism. Indeed, for Bohm it appears clear "that the universe is not divine is especially important. Rather, he regards the universe as he does any scientific theory; it is inherently incomplete and depends on what is beyond it."${ }^{\prime 923}$ Sharpe, for his part, argues for the idea that Bohm's holomovement could serve as an image of God. ${ }^{924}$ But, again, this defies Bohm's own stated intentions. In any case, Bohm's view of reality creates a whole new conception of the potential descriptions one might give for the God-world relationship, which has been picked up and supported by the contemporary and leading Catholic theologian David L. Schindler. ${ }^{925}$

In summary, Bohm did not see himself as a theologian, but as a scientist. That is not to say his view of science was at odds with many other scientists, but Bohm still maintained his ideas were a genuine endeavor of scientific exploration (something akin to 'phenomenal empiricism'). It should be noted that empiricism played a key role in motivating his more metaphysical speculations, yet, at the

\footnotetext{
${ }^{920}$ Bohm, On Creativity, 107. Thus, if you say "'the unlimited is God, and by God I mean this and this and this,' then you begin to limit it. I think it is essential not to limit God, if you believe in God," ibid.

${ }^{921}$ Bohm, On Creativity, 107.

922 Sharpe, David Bohm's World: New Physics and New Religion, 92.

${ }^{923}$ Sharpe, David Bohm's World: New Physics and New Religion, 93. Sharpe suggests that "Bohm does not believe God is the holomovement or that God contains the holomovement, but rather he thinks the divine is beyond the holomovement, beyond all implicate orders. God is beyond them in ways that defy our ideas. In Bohm's scheme, the holomovement is part of the created order," ibid., 92-93.

${ }^{924}$ Sharpe, David Bohm's World: New Physics and New Religion, 94-98.

${ }^{925}$ David L. Schindler, Heart of the World, Center of the Church: Communio Ecclesiology, Liberalism, and Liberation, 173 n. 51, 221-236; David L. Schindler, "David Bohm on Contemporary Physics and the Overcoming of Fragmentation," in International Philosophical Quarterly Vol. 22 \# 4 (Dec. 1982), 315-327; and David L. Schindler, "The Given as Gift: Creation and Disciplinary Abstraction in Science," in Communio (Vol. 38, Spring 2011), 65 n. 15,87 n. 45.
} 
same time, his metaphysics were genuinely meta-physics in the sense that he was seeking to create a more complete theory of physics that went beyond the limits of contemporary physics (which contains its own metaphysics ${ }^{926}$ ). In chapter 5 I will return to Bohm's concepts of freedom and time and explore them in relationship to the current crisis of the two cultures as it pertains to the role of theology as a potential mediator.

\section{Evaluation of the Coherence of Bohm}

Bohm's physics and 'meta' physics present a genuine alternative to the previous historical trajectories. Evaluating their overall coherence would be a complex task-and one that is not within the purview of this study addressing his conceptions of freedom and time. This makes the challenge of evaluating the coherence of his ideas twofold in nature. First, one would have to consider the entire scope of philosophical and physical problems that are considered to be of significance in a total or overall system of thought. This has been attempted by several individuals, and it is probably safe to say they have exposed some problems with Bohm's ideas as a philosopher, although the technicalities involved in exploring and detailing them cannot be repeated here, beyond noting that one of the sorest points of criticism remains whether Bohm has successfully distinguished mind, matter, and the individual. ${ }^{927}$ That said, however, Bohm's ideas on time and freedom merit their own analysis and evaluation.

The coherence of Bohm's ideas about freedom and time raises the issue of what coherence means. That is, if one were to seek to find an underlying schema to determine the meaning of coherence, one would already be passing judgement on the nature of freedom and time. What can be said, in this instance, is that Bohm's ideas about freedom and time are a reaction to the contradictions plaguing the previous historic positions about freedom and time. This is evidenced most clearly in

\footnotetext{
${ }^{926}$ Burtt, The Metaphysical Foundations of Modern Science.

${ }^{927}$ The respondents to Bohm in the following works offer helpful critiques of Bohm's overall ideas. See the essays in Physics and the Ultimate Significance of Time, ed. David R. Griffin, as well as the essays in Beyond Mechanism: The Universe in Recent Physics and Catholic Thought, ed. David L. Schindler; Rosen, Dimensions of Apeiron: A Topological Phenomenology of Space, Time, and Individuation, 118-120; and Floyd Merrell, Signs Becoming Signs: Our Perfusive, Pervasive Universe (Bloomington, IN: Indiana University Press, 1991), 31-58, 142.
} 
Einstein's view, where freedom is rejected to make room for an understanding of time that is determined and causative. Thus, Einstein's view is internally coherent, but allows for no freedom. In like manner, Descartes and Newton's views on freedom and time were coherent, in that they abided by the rules they themselves set out for these concepts. But both of these programs have left many contemporary philosophers uneasy and dissatisfied, chief among them Heidegger and Bohm.

With respect to the above, Bohm's views are, perhaps, one of the most coherent integrated packages that exists for the concepts of freedom and time that has interdisciplinary attraction, more explicitly uniting, to a greater degree, the humanities and sciences than has been done by any other major school of philosophy. ${ }^{928}$ His theory unites freedom and time into one unified concept, that both allows for their comfortable co-existence, while also negating any 'easy' path that could disprove his ideas. Of course, were his implicate orders not infinite, then his theory would collapse, and true timelessness and a denial of freedom would result.

\section{Conclusion}

In this chapter David Bohm's views on freedom and time were examined. Additionally, a biographical sketch of Bohm was provided, as well as some background context concerning Bohm's place within the two cultures, the relationship of his ideas with Einstein's contributions, as well as how influential they have been upon theological reflection about freedom and time. The key points from this overview revealed that Bohm's relationship with politics and Einstein heavily influenced his own theories, albeit he developed them in unique ways.

Concerning Bohm's view of freedom, what is noteworthy is that he locates it within the infinite totality of a multi-ordered and layered nature. Of course, Bohm's notion of what constitutes order is significant, as it allows for multiple kinds of orders to overlap. Thus, freedom is located within the time of nature. Turning toward time itself, time is also a product of the infinite totality of a multiordered and layered nature. As such, differing layers of nature will reveal relative degrees of

\footnotetext{
${ }^{928}$ As asserted by the Catholic Gavin D'Costa, Theology in the Public Square: Church, Academy, and Nation (Carlton, Victoria: Australia: Blackwell Publishing, 2005), 212-213.
} 
temporality and timelessness in relation to each other. Bohm remains agnostic on any ultimate level of timelessness or temporality, but allows for the possibility of the latter, while generally utilizing the language of the former.

In the following chapter an examination of Pauli Pylkkö's ideas will be undertaken, following the same basic approach as undertaken with Bohm. Then, in chapter 5, I will compare and contrast them directly, and explore how their approaches might fit within the crisis of the two cultures and the place of theology as a mediator. 


\section{CHAPTER 4}

\section{PAULI PYLKKÖ’S VIEW ON THE RELATIONS OF FREEDOM AND TIME}

\section{Introduction}

The purpose of this chapter is to examine the work of Pauli Pylkkö concerning his view on the concepts of freedom, time, God, and their interrelationships. To do so, first I will provide a biographical sketch of Pylkkö and explain the value of his published ideas within the context of the two cultures and the philosophical contributions of Heidegger. Next I will examine Pylkkö's view of time, both for nature and the humanities, and then Pylkkö's view of freedom, both for nature and the humanities, and follow that by explaining the relations of freedom and time within his published work. After this, I will detail his views on the concept of God and their value for continuing theological reflection, especially as they might pertain to freedom and time. Lastly I will evaluate the coherence of Pylkkö's ideas concerning freedom and time before providing my concluding thoughts on his contributions.

\section{Biographical Sketch}

Hailing from the gloomy arctic wastelands of Finland, ${ }^{929}$ Pauli Pylkkö's work remains relatively obscure outside of the Finnish academy. Nevertheless, his writings have garnered interest within a relatively small circle of philosophers of science and interdisciplinarians, particularly those pursuing issues in quantum and cognitive neuroscience. ${ }^{930}$ Undertaking studies in philosophy in both Finland

\footnotetext{
${ }^{929}$ Pylkkö's own description-much of his work has been done during "the gloomy arctic nights ... in which a Finnish philosopher almost always works," Pylkkö, The Aconceptual Mind, xi-xii.

${ }^{930}$ Noteworthy is that three of the few schools in the world with programs dedicated to conducting research in quantum neuroscience are located at the University of Skövde in Sweden, the University of Helsinki in Finland, and the Center for Cognitive Neuroscience at the University of Turku/Åbo, also in Finland. Pylkkö has co-edited or contributed to several volumes originating from professors at these schools. One of his more prominent philosophical collaborators is Paavo Pylkkänen, who has worked extensively with Bohm's ideas.
} 
and the United States, Pylkkö completed his Ph.D at Florida State University in 1988 in the philosophy of language. ${ }^{931}$ Thereafter, however, and reminiscent of his ideological mentor Heidegger himself in certain ways, Pylkkö has, for the most part, abandoned any formal academic career following the publication of his only book in English, The Aconceptual Mind: Heideggerian Themes in Holistic Naturalism (1998), to more fully live out his philosophical beliefs in relative seclusion amidst Finland's natural landscapes. ${ }^{932}$ Even some of his admirers, such as the late psychologist Louis Berger, reported it impossible to track him down and correspond with him as of $2011 .^{933}$

Inclined toward an agnostic austerity, and, like Heidegger, lamenting the rise and dominance of technology in society which he feels rules people's lives more than people rule their technology, Pylkkö has been accused of obscurantism and cultural elitism, especially through his attacks on scientism ${ }^{934}$ and interest in the uniqueness of the Finnish language, ${ }^{935}$ just as Heidegger was accused of the same with his German language. That said, Pylkkö has remained active through 2015 by writing several self-published philosophy books in Finnish, ${ }^{936}$ alongside the occasional article in

${ }^{931}$ Pauli Pylkkö, Logic, Formal Languages, and Formal Language Identification: Some Logical Properties of the Languages in the Chomsky Hierarchy, and an Interrogative Model of Formal Language Identification (Florida State University doctoral dissertation, 1988). His primary adviser was Jaakko Hintikka.

932 Just as Heidegger's later emphasis on poetry illustrated his desire to "live out" the authentic philosophical vision he believed in through "the Event" representing the joining of Being and language, Pylkkö turned toward a more rural and poetically naturalistic lifestyle freed from the encumbrances of academia to live out his vision of the 'meaningful' philosophical life.

${ }^{933}$ Louis Berger shared that he "tried quite hard over several years in a number of ways to get in touch with him ...., but he seems to have disappeared into anonymity. Even his publisher did not know how to contact him," Louis S. Berger, Language and the Ineffable: A Developmental Perspective and Its Applications (Lanham, MD: Lexington Books, 2011), 45 n. 93.

${ }^{934}$ For example, his critique against Kari Enqvist. See Pylkkö, "Fysiikkaviikari Filosofian Ihmemaassa-eli Olisiko Tiedeuskovaisuutta Hoidettava Lääkkeillä ja Kirurgialla? Kari Enqvistin Kuoleman ja Unohtamisen Aikakirjat ja Muita Hänen Kirjoituksiaan."

${ }^{935}$ Arto Tukianinen, "Pylkkö, nurjailija," at http://www.artotukiainen.net/pylkko_eurooppa.pdf (accessed April 5, 2011); Pauli Pylkkö, "Huomautuksia Arto Tukiaisen esseeseen "Katsokaa taivaan lintuja," at http://www.artotukiainen.net/pylkko.html (accessed April 5, 2011); and Pauli Pylkkö, "Suomen kieli on vetäytymässä ja jättämässä meidät rauhaan toisiltamme," in Filosofinen, Niin \& Näin, Aikakauslehti (1/98), at http://www.netn.fi/198/netn_198_pylkko.html (accessed January 18, 2011).

${ }^{936}$ Although Pylkkö revisits the topics of freedom and time on occasion, his focus in these Finnish works is not directly on either freedom nor time, nor do they make any notable advance over his earlier English works on these themes, yet, nevertheless, I will cite them below as appropriate. Note, in particular, Pauli Pylkkö, Ernst Jünger-Marmorijyrkänteillä, tr. Pauli Pylkkö (Kiel, Finland: Uuni Verlag, 1999), and his own chapter, "Lemuurien yö-Ernst Jünger ja kansallissosialismi," 155-198; Pylkkö, Richard Wagner Ajattelijana: Antimodernisti, Luonnonmystikko, Gnostikko; Pauli Pylkkö, Luopumisen Dialektiikka (Taivassalo, Finland: Uuni, 2009); Pauli Pylkkö, Ajatus ja Kädet (Taivassalo, Finland: Uuni, 2013); and Pauli Pylkkö, Kielikuva ja Mielikuva-Ja Muita Dialektisia Esseitä (Taivassalo, Finland: Uuni, 2015). 
Finnish journals. Perhaps his best known work has been a translation, with commentary, of Friedrich W. Schelling's classic On Human Freedom (1809) into Finnish. ${ }^{937}$ His wife, Leena, is also active as a scholar, writing on art and education.

\section{Pylkkö's Contribution Within the Context of the Two Cultures}

Contemporary $21^{\text {st }}$ century western culture is no longer, as noted above, meaningfully 'postmodern.' That ship has sailed into the past, so to speak. We now live in the age of postpostmodernism, hypermodernism, or digimodernism. The reason for this is succinctly explained by Mónica Flores, when she observes, "science and philosophy differentiate or unify the universe artificially to indulge reason into observing a coherent kind of order in the world." Within this process of artificial differentiation or unification, the typical consequence of "the postmodern views on the essential multiplicity of social reality (plurality turned infinite)," is that "whatever it is that we call universe remains a relevant category for intellectual contemplation of reality in the hard scientific way, the one that produces effective technology." ${ }^{\prime 938}$ That is, the relativism of postmodern social reality has collided into the pervasive technologized side of our scientific worldview. Our world now has more " 1 ' $\mathrm{s}$ " and " 0 ' $\mathrm{s}$ " managing it than ever before, and this digital absoluteness has effectively mitigated much of what made the postmodern world postmodern. The ethical arguments for ecological policies, the promise of ever more advanced technologized healthcare systems, etc., demonstrate that we now face ethical problems that are framed as scientific and thus absolute. Almost everyone uses cellphones and the internet. Technology has become the new 'god,' and it is virtually omnipresent. Social or moral relativism may still exist, but it has been transformed by these new technologies, and must coexist on the technological superhighway to retain influence. Thus, our contemporary relativism no longer operates within geographically isolated territories, but rather must now navigate via one overarching network-the way differing viewpoints are shared and

\footnotetext{
${ }^{937}$ Pauli Pylkkö, F. W. J. Schelling: Ihmisen Vapaudesta, tr. Pauli Pylkkö (Kiel, Finland: Uuni Verlag, 2004). Note his own commentary on Schelling in the same volume, "Schelling ja panteismikiista," ibid., 141-222. For a recent English translation, see F. W. J. Schelling, Philosophical Investigations into the Essence of Human Freedom, tr. Jeff Love and Johannes Schmidt (Albany, NY: State University of New York Press, 2006).

${ }^{938}$ Flores, Political Philosophy for the Global Age, 29.
} 
propagated is still regulated and controlled by technology. It is within this context that Pylkkö's ideas have emerged.

The primary motive driving Pylkkö is that he doesn't believe that philosophers, scientists, and specialists from basically every other discipline in the Western academy, have taken quantum phenomena seriously enough-in this Pylkkö, too, rejects the Copenhagen interpretation as adequate, if it is understood to simply be limited to a part of nature. ${ }^{939}$ The lack of attention by the Western academy is especially true in cognitive science and its relationship to linguistics, but also applies within many other broader philosophical themes, including essentially everything from epistemology and ontology to sociology. ${ }^{940}$ The implications are exactly that significant, everything must be reevaluated in light of quantum phenomena in his eyes, something that humans are naturally loathe to do, for we highly value our common sense and traditions, especially when they have worked so well for us in many areas, and they seem necessary for everyday life.

As the subtitle of his English book suggests, Pylkkö's work is organized around Heideggerian themes, with an additional focus particularly on Heidegger's engagement with science. Although their philosophical relationship is an uneasy one ${ }^{941}$ a struggle of sorts between a master and his disciple who must ultimately rebuke the master, ${ }^{942}$ Pylkkö essentially agrees with and draws inspiration from Heidegger. Pylkkö sets out to demonstrate that Heidegger's ideas are not fairing well in general and especially not well in the scientific disciplines through what he calls the dogmatic understanding of

\footnotetext{
${ }^{939}$ Pauli Pylkkö, “Eliminative Holism as a Solution to Bohr's Puzzle of Two Languages," in Brain, Mind and Physics, eds. Paavo Pylkkänen, Pauli Pylkkö, and Antti Hautamäki (Amsterdam, Netherlands: IOS Press, 1997), 140-156.

${ }^{940}$ Pylkkö, The Aconceptual Mind, xx.

${ }^{941}$ Pylkkö, The Aconceptual Mind, xiii-xiv. "A difficult and complex master-disciple relationship is not a Finnish privilege but a familiar theme in many cultures. For example, the relationship between Husserl and Heidegger oscillated between love and hate, and later Heidegger and his disciples reperformed similar stormy scenes. It seems that the landscape around Heidegger's legacy is filled with demons of suspicion, erotic rivalry, jealousy and aggression, and even today it is hardly possible to write about Heidegger's thinking without participating in a perpetual philosophical Walpurgisnacht [a Halloween of sorts] which is taking place within the sphere of his influence," ibid.

942 "Heidegger will not be handled softly either: what is vital in his thinking is sieved out and planted into a foreign soil, and the rest is renounced or reversed with no regret," Pylkkö, The Aconceptual Mind, xviii.
} 
science. ${ }^{943}$ Thus, whatever adherents Heidegger may have in postmodern philosophical circles, including the arts and the philosophy of language, even theology, ultimately his influence is insignificant in the areas of society where science matters most (e.g., technology and medicine, including cognitive science ${ }^{944}$ and psychology), and because of the power of these areas over all of society, our age is, essentially, the age of science and modernism (thus, the post-postmodernism or digimodernism referred to above), and not postmodernism.

Although Pylkkö prefaces his introduction to Heidegger with a prominent and intriguing account of Heidegger's ideological and political connections with Nazism, and the various controversies related to it, they do not detract from, but rather accentuate, Pylkkö's discussions concerning Heidegger's central philosophical themes and contributions which draw the most attention from contemporary postmodern and existentialist philosophers. The same is true of his interest in Finnish linguistics and semiotic theory, which he explores at some length. ${ }^{945}$ To the contrary, Pylkkö shows how there are linkages between Heidegger's ideas and their social implications, including our uses of language.

\footnotetext{
943 "Dasein is in bad shape, as if a disease had overtaken the most central notion of Martin Heidegger's thinking. The symptoms of the disease include the almost inevitable elitism, preclusion of democracy, discrimination on the ground of language, cultural background and ethnicity, intolerance, and, yes, ultimately Nazism, too," Pylkkö, The Aconceptual Mind, 1.

${ }^{944}$ Pylkkö, The Aconceptual Mind, 5-6, 13, 26.

${ }^{945}$ Pylkkö, The Aconceptual Mind, xiii-xxvi. As Pylkkö discusses and illustrates, in some circles, especially so in Europe, Heidegger can barely be mentioned by name without intense discussions on Nazism ensuing shortly thereafter. The connection between the two in every arena, including his philosophy, is still intensely debated. To this end, Pylkkö devotes an entire chapter in his book, "Is Nazism Humanism?," 213-264, to discussing whether or not Nazism fulfilled Heidegger's conception of humanism. Although they are not the focus of my critique and study, that Pylkkö applies his ideas at the socio-political level, in particular the historical climate in Nazi Germany and the linguistic tradition and situation in Finland (see his chapter, "Nationally Unique Meanings," 265-280, for an applied example of his ideas to linguistics and cultural theory, with specific examples from Finnish), actually demonstrates a useful account of how truly far-reaching the implications of a "quantum philosophy" might be for philosophy in general, regardless of his actual perspective on these two examples. See also, Pauli Pylkkö, "Ontological Nihilism, or, the Meaning of the So-called Finnish Passive Construction," in Snow, Forest, Silence: The Finnish Tradition of Semiotics, ed. Eero Tarasti (Bloomington, IN: Indiana University Press, 1999), 54-66. As such, Pylkkö skillfully weaves together one of the best works to date on connecting scientific and philosophical theories to socio-political theories through his analysis of Heidegger, Nazism, and Finnish linguistics. As a pioneer in such interdisciplinary work, there are no doubt many aspects concerning his suggestions that could use refinement if not outright adjustments that I will not probe, yet nevertheless, his work on both the philosophical and sociological levels stand on their own.
} 
In outlining the philosophical side of his own work, Pylkkö accomplishes the task of bringing Heidegger up to date by "naturalizing" Dasein ${ }^{946}$ by asking the question of whether modern science is necessarily onto-theo-logical as Heidegger assumed, ${ }^{947}$ and which I will examine more below. Pylkkö does this through his interpretation of quantum physics, where the present study will focus special attention as it pertains to freedom and time. Through his inquiry he seeks to establish that the essential ontological temporality Heidegger discussed, and thus in some manner Dasein itself and its privileged access to Being, are empirically and phenomenally observable through quantum physics in a comparable or analogous manner to what Heidegger had described. ${ }^{948}$ This in turn directly relates to any fundamental ontology of nature that is correspondingly constructed. Put simply, contrary to what traditional Heideggerians might believe, a complex and phenomenal understanding of Being is not something that is discoverable only by philosophers (those in the 'humanities') sitting comfortably in their office armchairs thinking deeply; specific and common sense interpretations of the empirical phenomena located in quantum physics reveal and even demand a phenomenological understanding of reality along Heideggerian lines according to Pylkkö. Heideggerians need not fear, though, that Pylkkö has turned Being into a being. Not at all, so he claims. Pylkkö merely believes that the conditions that constitute Heidegger's justification for the identity of Being as a non-entity are justifiable given certain nondogmatic interpretations of quantum physics (thus "physical stuff") that posits reality ultimately consists of phenomena that are not entities as all traditional mainline or dogmatic philosophies of science have assumed, and in fact exhibit a dynamic that resembles Heidegger's emphasis on and descriptions about temporality and freedom.

\footnotetext{
${ }^{946}$ Pylkkö, The Aconceptual Mind, "Dasein Naturalized," 1-26. See also, Pauli Pylkkö, "Dasein Naturalized," in Analecta Husserliana, Vol. XLIX, eds. Marlies Kronegger and Anna-Teresa Tymieniecka (Dordrecht, The Netherlands: Kluwer Academic Publishers, 1996), 203-218.

${ }^{947}$ Pylkkö, The Aconceptual Mind, “Is Modern Science Necessarily Onto-Theo-Logical?," 27-76. Heidegger "didn't take seriously the possibility that science itself, or related nondogmatic philosophical naturalism, may have already been able to abandon the view which presents nature simply as a collection of external objects and science as a project which attempts to find out the universal laws which govern the behavior of external objects," Pylkkö, The Aconceptual Mind, 57.

${ }^{948}$ Pylkkö is not alone in making this assertion. For example, see Georg Franck, "Mental Presence and the Temporal Present," in Brain and Being: At the Boundary Between Science, Philosophy, Language and Arts, eds. Gordon Globus, Karl H. Pribram, and Giuseppe Vitiello (Amsterdam, The Netherlands: John Benjamins, 2004), 50 .
} 
Therefore, Pylkkö feels able to deconstruct our classical assumptions concerning logic and language (logos) along Heideggerian lines through Pylkkö's understanding of quantum phenomena. ${ }^{949}$ Additionally, Pylkkö asks what is noncomputational in recent consciousness studies, in an effort to uncover problems and answers surrounding the free-will versus determinism debate. Pylkkö also discusses Heidegger's place in neuroscience and consciousness studies within this context. ${ }^{950}$ Pylkkö then turns toward distinguishing his three central descriptive terms, that of the mechanical, nonmechanical, and amechanical, which he applies to conceptuality as well, as the conceptual, nonconceptual, and his overarching thrust, the aconceptual. ${ }^{951}$ He also sets out to explain how the subject-object relationship and subjectivism should relate to and be understood through an understanding of science or nature in a nonclassical or nondogmatic way, as a naturalistic holism, where he addresses an atheoretical view of language from the context of the later Heidegger and Wittgenstein's language games, which Pylkkö also critiques, followed by the application of his aforementioned ideas to Heidegger's Nazism and Finnish language and culture. ${ }^{952}$

In summary, through his naturalization of Heidegger's central themes, Pylkkö is attempting to show how a bridge might be created between the two cultures through science itself. That is to say, "the weakest link in the essence of technology, where the dominance of technology may begin to break down, lies within the most perplexing department of modern science itself, namely in quantum theory and in its aconceptual and holistic nature." ${ }^{953}$ Through an appreciation of this aconceptual

${ }^{949}$ Pylkkö, The Aconceptual Mind, “Unique Language Problem,” 145-178.

${ }^{950}$ Pylkkö, The Aconceptual Mind, “What is Noncomputational in Recent Consciousness Studies?,” 77114. Again, Pylkkö is not alone in exploring connections between Heidegger and quantum physics for cognitive science. As Gordon Globus shares, “There is one unique fact that is forgotten within Heidegger's purview, the fact, crudely put, that no brain, no Da-Sein. Turn the brain to mush and the Lichtung goes dark.... Who would deny this?... No future scientific revolution will change the fact's significance. Such a fact cannot be simply ignored, but must find its place in the Heideggerian scheme," Gordon Globus, The Postmodern Brain (Amsterdam, The Netherlands: John Benjamins Publishing, 1995), 37.

${ }^{951}$ Pylkkö, The Aconceptual Mind, “On Surprise,” 115-144.

952 Pylkkö, The Aconceptual Mind, “Gaming Without Subjects,” 179-212. For more on Pylkkö’s views of language, see Pylkkö, "Ontological Nihilism, or, the Meaning of the So-called Finnish Passive Construction," 5466.

953 Pylkkö, The Aconceptual Mind, 75. This does not mean, however, that Pylkkö is an optimist on whether his efforts will succeed. Rather, it may turn "out that metaphysical thinking and its immediate heir, technological thinking, 'cannot be abolished, like an opinion,' for they are simply too deeply embedded in our world to be destroyed," Wolcher, Beyond Transcendence in Law and Philosophy, 96. This may remain true even if "the scientific commitment to explaining everything according to the principle of causality makes the idea of 
holism, Pylkkö believes the concepts of freedom and time may find renewal. Thus, while Pylkkö also may draw inspiration from the sciences (in particular, from quantum physics, similar to Bohm) for his efforts at mediating the crisis of the two cultures, his more explicit and parallel dependence upon Heidegger, the contemporary 'father' of the humanities, positions him as one in sympathy with the problems Heidegger raised. Of course, it is worth noting that Pylkkö's contributions have already been cited by others as helpful in addressing a wide variety of third culture issues, especially in the areas of education, ${ }^{954}$ psychology and psychotherapy, ${ }^{955}$ as well as political theory, ${ }^{956}$ ethics, ${ }^{957}$ linguistics, ${ }^{958}$ and music. ${ }^{959}$ In each instance, the underlying motive of these authors is to help move beyond the impasse of the two cultures. Additionally, it is noteworthy that recently the Finnish community of philosophers have developed a notable interest in key contemporary philosophical issues, as noted by Sami Pihlström. ${ }^{960}$

human freedom appear foolish and wrong, for the Western philosophical tradition has always imagined freedom as the uncaused origin of our thoughts and actions," ibid., 52.

954 Ya-hui Su, "Lifelong Learning as Being: The Heideggerian Perspective," in Adult Education Quarterly Vol. 61 \#1 (2011), 65; and Ya-hui Su, "The Constitution of Agency in Developing Lifelong Learning Ability: The 'Being' Mode," in Higher Education Vol. 62 (2011), 399-412.

${ }^{955}$ Leila Haaparanta, "Finnish Studies in Phenomenology and Phenomenological Studies in Finland: Interfaces of Analytic Philosophy and Phenomenology," in Analytic Philosophy in Finland, ed. Leila Haaparanta and Ilkka Niiniluoto (Amsterdam, The Netherlands: Rodopi, 2003), 491-510. "An important Finnish contribution, which was inspired by Heidegger, was Pauli Pylkkö's work in consciousness studies," ibid., 499. See also, Louis S. Berger, Human Development, Language, and the Future of Mankind, 160 n. 14, 164 n. 33, n. 44; Berger, Language and the Ineffable: A Developmental Perspective and Its Applications, 38-45; Louis S. Berger, Averting Global Extinction: Our Irrational Society as Therapy Patient (Lanham, MD: Jason Aronson, 2009), 51, 59 n. 72; Louis S. Berger, Humanity's Madness: Consequences of Becoming Literate (Forsyth, GA: Forsyth Books, 2011), 41; and Berger, The Unboundaried Self, 98-112.

${ }^{956}$ Lauro Ericksen C. De Oliveira, "A Phenomenological Justification for the Flexibilization of Protection Principle in the Labor Law System by the Argument of Reality's Feasibility Primacy Principle being used on Employers Side," in Prisma Jur. Vol. 12 \#2 (Dec. 2013), 571 n. 15; and Vadén, Heidegger, Žižek and Revolution, 3 n. 2, 81-84.

957 Tere Vadén, "Ethics and Gods: How is Local Ethics Possible," in Continental Philosophy Review 37 (2004), 433 n. 10.

958 Tere Vadén, "What is 'Local Thinking'?," in Re-ethnicizing the Minds?: Cultural Revival in Contemporary Thought, ed. Thorsten Botz-Bornstein and Jürgen Henglebrock (Amsterdam, the Netherlands: Rodopi, 2006), 235 n. 4, n. 5.

${ }^{959}$ Tere Vadén, “Between Žižek and Wagner: Retrieving the Revolutionary Potential of Music," in the International Journal of Žižek Studies Vol. 6 \#3 (2012), 6. See also, for a Heideggerian perspective on music, Michael Eldred, Thinking of Music (Charleston, SC: CreateSpace, 2015).

${ }^{960}$ Sami Pihlström, "Pragmatistic Influences in Twentieth Century Finnish Philosophy: From Preanalytic to Post-analytic Thought," in Analytic Philosophy in Finland, ed. Leila Haaparanta and Ilkka Niiniluoto (Amsterdam, The Netherlands: Rodopi, 2003), 511-536. 
Below, Heidegger's work, with some commentary by Pylkkö, will be examined which set the foundation for Pylkkö's reenvisioning the concepts of freedom and time. Of course, as already noted, Pylkkö credits his philosophical heritage to Heidegger. Given Heidegger's iconic status as the leader of the philosophical 'humanities,' it is necessary to trace an outline of Heidegger's main themes which Pylkkö engages. This will prove helpful for a couple reasons.

First, Pylkkö's corpus of writings is not as voluminous as Bohm's, and second, Pylkkö does not always explain in depth some of the Heideggerian themes he relies upon. Thus, the above objective will be accomplished by first reviewing the key ideas from Heidegger, especially his notion of timespace, which have repositioned the discussion about freedom and time, and then identifying precisely why the where of Heidegger's concept of freedom creates such difficulties for traditional scientists. I will then briefly review the significant impact Heidegger has and continues to have on theology, and establish Pylkkö as an heir of his work. I will then proceed to focus on Pylkkö's views of freedom and time.

\section{Heidegger's Contribution: Time-Space}

Despite Heidegger's many detractors, most of whom are happy to point out that his work employs "a language which has often served to mystify rather than enlighten,"961 it has nevertheless also been previously suggested on more than one occasion to be "a possible and fruitful endeavor 'to read the philosophy of Heidegger as a whole as a philosophy of freedom.."'962 Accordingly, Heidegger's work appropriately launches an inquiry into the issues of freedom and his more widely discussed interest, time. ${ }^{963}$ To succinctly distinguish Heidegger's views from those of his detractors in a manner that is also relevant for the theological focus of this study, one can turn toward his popularized term

\footnotetext{
${ }^{961}$ Charles M. Sherover, Heidegger, Kant, and Time (Bloomington, IN: Indiana University Press, 1971), 5.

962 Davis, Heidegger and the Will: On the Way to Gelassenheit, 71. Davis approvingly cites the opinion of Figal, Martin Heidegger: Phänomenologie der Freiheit, 23.

${ }^{963}$ For an excellent introduction to Heidegger that is apropos to this study, see Michael Eldred, Being Time Space: Heidegger's Casting of World (Arte-fact.org, 2014).
} 
of "ontotheology" 964 as the symptomatic description of all metaphysical ${ }^{965}$ thinking in the Western

\footnotetext{
${ }^{964}$ For a fairly complete list of the occurrences of the terms "ontotheology" and "ontotheological" in Heidegger's corpus of writings, see Jaran François, "L'ontothéologie dans l'oeuvre de Martin Heidegger: Récit d'une confrontation avec la pensée Occidentale," in Philosophie 91 (2006), 62. Although conceptually originating with issues Aristotle addressed, the term itself first appeared in the writings of Immanuel Kant, where "ontotheology" referred to a specific type of transcendental theology that focused on cognizing the existence of God through merely conceptions without any reference to experience. As Kant put it, "Transcendental theology is either that which thinks of deriving the existence of the primitive being from an experience in general [a posteriori], and is termed cosmotheology, or it believes to cognize the existence of this Being through mere conceptions, without the aid of the least experience [a priori], and is termed ontotheology," Immanuel Kant, Critick of Pure Reason, tr. Francis Haywood (London, UK: William Pickering, 1848), 439. Incidentally, Kant ultimately rejected both methods in themselves. Heidegger, who uses it for the first time around 1930-31 in a lecture (Hegels Phänomenologie des Geistes), uses it in a related but decidedly different manner which will be shortly elaborated upon. The origin of the three components of the term "onto-theo-logy" come from three Greek words, on meaning "being," theos meaning "god," or in philosophy sometimes the "absolute" or unifying ground, and logos meaning literally "word," "speech," or "reason(ing)" (thus logic), although it has also assumed the philosophical meaning of "knowledge," especially in the context of "knowledge/study of something," thus its frequent appearance as "-logy" in biology, etc.

${ }^{965}$ Metaphysics is a difficult term to define precisely due to varying usages. In addition to the Kantian definition given at the beginning of the study, essentially, the study of metaphysics attempts to clarify the fundamental notions by which people understand the world and that which lies beyond our immediate perception, and their interrelationships. Such notions include existence (ontology), the definition of object, subject, God, space, time, causality, property, and possibility, through two basic questions answered as broadly as possible: 1) "What is there?" (ontology) and 2) "What is it like?" (epistemology) or "How does one explain it?" Especially in the latter senses as an explanation of what something is like, it is considered "meta" or beyond simple descriptive physics. It is an attempt to systematize our various, often disparate, observations into a harmonious whole. The foundational sub-disciplines of metaphysics which articulate the above questions would be ontology, which investigates the basic categories of being or existence and how they relate to each other; i.e. a theory of the world and its workings, and epistemology, which studies how or through what process we come to know the ontic properties and categories that an ontology addresses. Which has precedence is disputed. In Heideggerian thought, however, ontology and metaphysics become somewhat synonymous due to Heidegger's novel understanding of Being as approached through his notion of fundamental ontology. For example, Heidegger states, "fundamental Ontology means that ontological analytic of the finite essence of human beings which is to prepare the foundation for the metaphysics which 'belongs to human nature.' Fundamental ontology is the metaphysics of human Dasein [being-there i.e. human existence] which is required for metaphysics to be made possible. It remains fundamentally different from all anthropology and from the philosophical. The idea of laying out a fundamental ontology means to disclose the characteristic ontological analytic of Dasein as prerequisite and thus to make clear for what purpose and in what way, within which boundaries and with which presuppositions, it puts the concrete question: What is the human being?," Heidegger, Kant and the Problem of Metaphysics, 1. In this context, then, it can be shared that "Being" (often capitalized) assumes a very technical meaning, especially so in relationship to Heideggerian thinking. In short, it expresses the possibility for things to exist in contradistinction to nothing or nonexistence. As the precondition for anything to exist, Being must $b e$, therefore articulating its nature is of interest. It is not an object, or entity (an ordinary lower-case being, such as colors, numbers, trees, or people), or ultimately even human consciousness per se, but rather an abstract concept or object of thought, and one that, according to Heidegger, has been sorely neglected by most philosophers throughout history, and a concept of which we have access to only through Dasein, our "being-there" in the world.
} 
tradition. Ontotheology also represents the crystallization ${ }^{966}$ of his divisive ${ }^{967}$ yet landmark critique against classical Western philosophy and theology. All philosophers and theologians have had to either implicitly ${ }^{968}$ or explicitly ${ }^{969}$ assume a position sympathetic to his assertion and hence his revisioning of ontology in his effort to overcome ontotheology, or justify their opposition to why they felt his critique was not insurmountably necessary.

Although many familiar with Heidegger's Being and Time and his ontological project may see inquiries into ontotheology within the overpowering shadow of Being and Time and its themes,

\footnotetext{
${ }^{966}$ Although only hinted at in Being and Time (1927), Heidegger began in 1930 to speak "more explicitly about the highest being as the ground of being." As time passed, and "the more Heidegger interprets philosophers of modern times, the more he sees the unity and connectedness of ontology and theology. He also emphasizes, more than before, the notion of the ground as the theological element of ontology," Ben Vedder, Heidegger's Philosophy of Religion: From God to the Gods (Pittsburgh, PA: Duquesne University Press, 2007), 107. Vedder notes that by 1936 in his lecture course on Schelling and freedom, Heidegger began to strongly emphasize "the connectedness and unity of ontology and theology" in classical metaphysics, ibid., 108.

${ }^{967}$ Even more than divisive, the mere mention of Heidegger sometimes generates downright hostile reactions. The extremely negative atmosphere that occasionally surrounds Heideggerian philosophy is well explained by Richard M. McDonough, Martin Heidegger's Being and Time (New York, NY: Peter Lang, 2006), xixiii. The content of these criticisms include Heidegger's intimate involvement with Nazism, that his writings are "incomprehensible," and that his disciples sometimes employ a "pretentious style and terminology of their own" that suggests a lack of "real philosophical content." As such, some philosophers don't take Heidegger's work seriously, considering it a more "quasi-religious prophecy" "dressed up in an obscure and pretentious pseudoontological language," ibid., xi-xiii. However, McDonough considers such extreme reactions ill considered.

${ }^{968}$ Implicitly, because of the all-encompassing nature of Heidegger's claim: "Western metaphysics ... . since its beginning with the Greeks has eminently been both ontology and theology.... Metaphysics is ontotheo-logy," Heidegger, Identity and Difference, 54; 121. His chapter in Identity and Difference entitled "The OntoTheo-Logical Constitution of Metaphysics," 42-75, is his most explicit address on the issue, although it is a recurring theme throughout his works after Being and Time.

${ }^{969}$ Representatives from many viewpoints across the philosophical (analytic and continental thinkers) and theological spectrum (Protestant and Catholic, conservative and liberal) could be submitted. For example, Heidegger's fellow continental philosopher Jacques Derrida, Of Spirit: Heidegger and the Question, tr. Geoffrey Bennington and Rachel Bowlby (Chicago, IL: University of Chicago, 1991), suggests Heidegger started down the right path though perhaps didn't go far enough in his critique, while the analytic philosopher William F. Vallicella, A Paradigm Theory of Existence: Onto-Theology Vindicated, and theologian Jeffrey W. Robbins, Between Faith and Thought: An Essay on the Ontotheological Condition, explicitly engage Heidegger's critique while arguing that ontotheology is necessary, and includes acceptable theological implications, and is thus merely in need of a re-imaging or rethinking but not necessarily an overcoming as Heidegger suggested. Conversely, more postmodern Christian theologians such as Jean-Luc Marion, God Without Being, tr. Thomas A. Carlson (Chicago, IL: University of Chicago, 1995), and Jean-Luc Marion, The Visible and the Revealed, tr. Christina M.

Gschwandtner (New York, NY: Fordham University Press, 2008), Merold Westphal, Overcoming Onto-Theology: Toward a Postmodern Christian Faith (New York, NY: Fordham University Press, 2001), Brian Ingraffia, Postmodern Theory and Biblical Theology (Cambridge, UK: University of Cambridge, 1995), and Stanley J. Grenz, The Named God and the Question of Being: A Trinitarian Theo-Ontology (Louisville, KY: Westminster John Knox Press, 2005), have suggested a genuinely biblical theology of revelation avoids the pitfalls of ontotheology, although they (and others) argue for this in different ways. Likewise, several defenders of classical Augustinian and Thomistic theology have also responded to the debate similarly though through differing methods. Prominent amongst contemporary Catholics would be Conor Sweeney, Sacramental Presence after Heidegger: Onto-theology, Sacraments, and the Mother's Smile (Eugene, OR: Cascade Books, 2015).
} 
freedom and necessity are also equally at stake. ${ }^{970}$ Heidegger even plainly stated that "philosophy is intrinsically a strife between necessity and freedom." ${ }^{\prime 971}$ To grasp why this is so, and has been neglected by many thinkers, it will help to concisely review Heidegger's complaint concerning classical metaphysics and its ontotheological condition and his solution through both his own words and as it is commonly perceived by a sample of theologians and philosophers. This will illustrate how profound Heidegger's influence has been upon recent theology, which explains why he has contributed so much to the crisis of the two cultures, as well as defamed the role theology might have played in mitigating the conflict between the cultures by implicating it as the very heart of the problem. Expectedly, many theists have strongly objected to Heidegger's assertion. So, what precisely is it about Heidegger's ontotheological critique of metaphysics that creates a problem for theists?

D. Stephen Long opines that, "ontotheology ... is when theology becomes so defined by a specific metaphysics that our speech about God fails because we make God an item in the world. When we say 'God' we primarily speak in terms of being and causality such that God becomes nothing more than a necessary concept that traces a cause back to its origin." ${ }^{972}$ Similarly, with the historical background in mind, the postmodern Christian theologian Merald Westphal explains ontotheology as follows:

[Heidegger] derives the term from Aristotle and applies it to Hegel. Aristotle had sought to develop a science of being as such, not this dimension of being or that region, but being qua

\footnotetext{
${ }^{970}$ As seen clearly in Martin Heidegger, Phenomenological Interpretation of Kant's Critique of Pure Reason, 26-27. Originally written in 1928, the year after the publication of Being and Time, Heidegger stated, "the understanding of being is the most original condition for the possibility of human existence.... It is in ontology, i.e., philosophy, that being becomes explicitly and specifically a thematic object. Accordingly, philosophy becomes the freely undertaken task of elucidating and unfolding the understanding of being which belongs to the essence of human existence. But precisely because understanding of being as such-either as preontological or ontological-is the most original and necessary condition for the possibility of human existence, the undertaking of the task of elucidation of this understanding, i.e., philosophy, is the freest possibility of human existence. Only where the most original necessity is binding, only there is the highest freedom first possible," ibid., 26-27.

${ }^{971}$ Heidegger, Schelling's Treatise on the Essence of Human Freedom, 58. He adds, "and in that it belongs to philosophy as the highest knowledge to know itself, it will produce from itself this strife and thus the question of the system of freedom." Furthermore, "Philosophy arises, when it arises, from a fundamental law of Being itself ... philosophy is ... the unifying strife between necessity and freedom," ibid., 58.

972 D. Stephen Long, Speaking of God: Theology, Language, and Truth (Grand Rapids, MI: Eerdmans Publishing, 2009), 50.
} 
being. But to carry out his project, subsequently known as ontology, Aristotle discovered that he needed to posit God, not the God of Abraham, Isaac, and Jacob, to be sure, but the impersonal, oblivious Unmoved Mover. With this, ontology becomes theology, or, as Heidegger puts it, onto-theology. The key idea is that there is a highest being who is the key to the meaning of the whole of being. Surely every Christian theology makes this affirmation in relation to the triune God, just as Spinoza makes it in relation to the allencompassing energy/process he calls Nature, and Hegel makes it in relation to the allencompassing energy/process he calls Spirit. So, it is assumed, every Christian theism falls prey, along with these modern pantheisms, to Heidegger's critique of onto-theology. ${ }^{973}$

Thus, at the center of the ontotheological condition is a static stillness, and Unmoved Mover, or allcoercing force, that legitimizes our representations and organizes our conceptions of ultimate reality, including the changes we perceive, as firmly grounded on that which persists in an unchanging representation. Or, as Iain Thomson artfully describes the pragmatic result, “ontotheology" effectively

${ }^{973}$ Merald Westphal, “Onto-theology, Metanarrative, Perspectivism, and the Gospel," in Christianity and the Postmodern Turn: Six Views, ed. Myron Penner (Grand Rapids, MI: Brazos Press, 2005), 144. Heidegger moreover asserts that generally speaking theologians who inherited this Greek philosophical heritage didn't stop there, but rather frequently "in the course of the history of ontotheological inquiry the task has arisen not only of showing what the highest being is but of proving that this most supreme of beings is, that God exists," Martin Heidegger, "Kant's Thesis about Being," tr. Ted E. Klein, Jr. and William E. Pohl, in Pathmarks, ed. William McNeill (Cambridge, UK: Cambridge University Press, 1998), 341. With both these insights in mind, then, Westphal would describe himself as "philosophically closer to my postmodern friends who do not share my faith than to the Christian philosophers who do," Westphal, "Onto-theology," 141, if they truly do embrace the ontotheological attitude Heidegger references. However, Westphal does not fully concur with Heidegger that Christian history posits such a clear place for total human conceptual understanding of the highest being. He believes that many "Christian thinkers [are] eager to preserve the mystery of God and the limits of human understanding," an attitude he believes is "fundamental to the theologies of Augustine and Aquinas, of Luther and Calvin, and, not to be too Western, of every orthodox theology I have ever encountered. Each of these traditions, to mention only some, refuses in its own distinctive way to make total transparency to human understanding the condition for God's entry into human discourse. They affirm that to posit God is to affirm mystery, not to make everything clear. Christian theology, taken as a (very complex) whole, is more a sustained critique of onto-theology than an instance of it. On this point Christianity has been 'postmodern' from the start, not a precursor of the Enlightenment project," ibid., 146. This is in contrast to how Heidegger obviously viewed Christian history in general, as well as how some traditionalists view the same history. Additionally, Westphal also further explains the difficulty surrounding the entire discussion by stating that "Even when our systematic theologies subordinate philosophical analysis to biblical exegesis, they can and sometimes do become systems in an onto-theological sense. I am reminded here of Camus's definition of the world of myth as a world of all answers and no questions. Just to the degree that our theologies become mythical in this sense, perhaps with the aid of a high view of scripture, they become onto-theological. In them, no doubt against our conscious intentions, God becomes the One Who Makes Our System Work, who sees to it that we are never at a loss conceptually, that we always have THE ANSWERS," ibid., 147. In this context, Westphal also considers what he sees as the appearance of onto-theology in the work of classic theologians, such as Aquinas: "Although Thomistic theology has deep anti-onto-theological substance, the format of the Summa Theologiae pictures what I have in mind here. Questions have no function other than to introduce our answers," thus fulfilling part of what inspired Heidegger's onto-theo-logical complaint in the first place, ibid., 147. Westphal also alerts users of the divisive and controversial nature that the term can evoke, for "the term [onto-theology] is often used by assistant professors who have appointed themselves campus terrorists and, alas, by senior scholars who should be more careful, as a kind of sci-fi conceptual zapper. You aim it at any theology archaic enough to affirm a transcendent, personal creator and vaporize it by intoning the magic word," ibid., 144. 
shields "a particular sense of what is and what matters from the corrosive sands of time."1974

Accordingly, he explains that for Heidegger, "all Western metaphysical systems make foundational

claims best understood as 'ontotheological,' [whereby] metaphysics establishes the conceptual

parameters of intelligibility by ontologically grounding and theologically legitimating our changing

historical sense of what is."${ }^{\prime 975}$

Of course, Heidegger's interest was in smashing the ontotheological shield that protects our sense of what is from the sands of time, which he felt didn't need nor indeed can be shielded from time; that time is what ultimately points us toward the meaning of Being and, therefore, derivatively the phenomenal condition of what human existence (for Heidegger called Dasein, "being-there") actually is, namely, an ecstatic temporality. ${ }^{976}$ A dynamic ecstatic temporality that governs all philosophical endeavors, for "philosophy cannot be defined and ought not be defined; philosophy can only be 'lived,' and that is the end of the story."1977 Thus, in Heidegger's thinking, one must recognize that with the linking of ontology and theology, their individual distinctiveness is conflated. ${ }^{978}$

Metaphysics as a whole forgets what authentic Being (on) is, through a prior predication on what God

\footnotetext{
${ }^{974}$ Iain Thomson, “Ontotheology," in Interpreting Heidegger: Critical Essays, ed. Daniel O. Dahlstrom (Cambridge, UK: Cambridge University Press, 2011), 108.

${ }^{975}$ Iain Thomson, “Ontotheology? Understanding Heidegger's Destruktion of Metaphysics,” in the International Journal of Philosophical Studies, 8 \#3 (2000), 297. See also, Thomson, Heidegger on Ontotheology: Technology and the Politics of Education, 2. Interestingly, Thomson believes that "Heidegger's notorious antipathy to metaphysics thus obscures the fact that, on his view, it is metaphysics which unifies and secures our successive historical 'epochs.' A series of metaphysical ontotheologies anchor our successive constellations of historical intelligibility, temporally securing the intelligible order by grasping it from both ends of the conceptual scale simultaneously (as it were), both ontologically (from the inside out) and theologically (from the outside in)," ibid., 29.

976 "Dasein must be called originally and fitly the temporal entity simply as such," Heidegger, The Basic Problems of Phenomenology, 271.

${ }^{977}$ Martin Heidegger, Phenomenological Interpretations of Aristotle, tr. Richard Rojcewicz (Bloomington, IN: Indiana University Press, 2001), 13.

${ }^{978}$ Daniel J. Hill and Randal D. Rauser, Christian Philosophy A-Z (Edinburgh, UK: Edinburgh University Press, 2006), 132. Hill and Rauser explain it thus, "Heidegger coined the term 'ontotheology' to refer to his identification of ontology (study of being) with theology (study of God). According to Heidegger, Western Philosophy has been adversely impacted by the linking of the study of beings with the Supreme Being. The result is that the distinct emphases of each have been conflated, such that Being (the object of theology) is erroneously conceived of as $a$ being. This fallacious conflation produces the God of the philosophers, an objectification of the absolute that is appropriately rejected. Christian theologians that adopt Heidegger's analysis see it as presenting a criticism of the conflation of philosophical conceptions of God with the God of biblical revelation," ibid., 132.
} 
(theos) and beings are, as we constitute meaning or knowledge (logos) about and through them; ${ }^{979}$ we forget what differentiates Being from beings, because we've made 'god' a being representing Being.

For Heideggerian thinking, any philosophy or theology which leans toward a logical positivism or causal determinism thus falsely presumes a place for Being, freedom, and God that is structurally knowable, ${ }^{980}$ and thus assumes the divine God, if they are in fact theists, ${ }^{981}$ or theos as the Absolute in the Greek sense akin to the timeless Unmoved Mover or uncaused cause, within this structure to justify the structure. Theos as God or the Absolute then serves as the unifying ground in the system, making all beings conceptually dependent upon the postulation of a static God or Absolute as the origin and cause of all other beings. ${ }^{982}$ Consequently, all our knowledge of the world and its laws, and of God, necessarily reduces to this certain and timeless origin and its concomitantly static

\footnotetext{
${ }^{979}$ Therefore, "The nature of philosophy as a factually unknown and structurally unknowable path of thought is restricted by an economy of faith. Likewise with theology, as the science of faith, theology at its best testifies to the irreducible mystery of its source in revelation and to the unapproachable and incomprehensible aim of its desire in God. However, once theology becomes onto-theological that mysterious source and incomprehensible aim are reduced to the order of [ordinary] beings.... On a more fundamental level, the ontotheological problem is part and parcel of the overall degeneration of Western thought and the consequent troubles of Western technological culture. The problem in a nutshell is the human desire for mastery and ontotheology contributes to this by presuming knowledge [logos] regarding the "first cause" [Being; on] of philosophy and the "highest being" [God; theos] of theology," Wikipedia, The Free Encyclopedia, "Ontotheology," at http://en.wikipedia.org/wiki/Ontotheology (accessed January 19, 2011).

980 "Change" per se is not what is here denied; rather that all change derives from, or originates from, that which does not change. Heidegger, Phenomenological Interpretation of Kant's Critique of Pure Reason, 41. "Up until now [especially Kant] metaphysics claimed to be a theoretical knowledge of the supersensible, i.e., God, freedom, and immortality. These are no ordinary objects of inquiry with which metaphysics is concerned," ibid., 41. He also suggested that "in spite of all Kant's attempts to reshape the concept of metaphysics, ... genuine metaphysics remains an ontic science of supersensible beings. For him 'the supersensible' is 'the final goal of metaphysics'-supersensible in us, above us, and after us, namely: freedom, God, and immortality," ibid., 11.

${ }^{981}$ Dale Jacquette, an agnostic and opponent of Heidegger and a strong advocate of the primacy of logic, makes this distinction crystal clear, recognizing that the honest ontotheologist does not actually need the divine God, by affirming that "if we can complete the project of pure and applied ontology without assuming that God exists, then the concept of God from an explanatory standpoint is philosophically bankrupt, however spiritually rewarding," in Dale Jacquette, Ontology (Slough, UK: Acumen Publishing, 2002), 257. Jacquette suggests that this can indeed be done. In this sense, it is merely theos and not God that is required to make metaphysics "work," ibid., 257.

982 Brian Duignan, ed. Ancient Philosophy: From 600 BCE to 500 CE (Britannica Education Publishing, 2011), 103-105. Duignan credits Aristotle for unifying philosophy by sharing "Thus, at the supreme point of Aristotle's causal hierarchy stand the heavenly movers, moved and unmoved, which are the final cause of all generation and corruption. And this is why metaphysics can be called by two such different names. When Aristotle says that first philosophy studies the whole of being, he is describing it by indicating the field it is to explain; when he says that it is the science of the divine, he is describing it by indicating its ultimate principles of explanation. Thus, first philosophy is both the science of being qua being and also theology," ibid., 105. The ultimate unmoved mover, of course, is “God" in "Aristotle's system," ibid., 105.
} 
knowability, ${ }^{983}$ making any such philosophical or theological views so constructed generally adhere to the tradition of ontotheology that Heidegger describes. Explained simply, either a static God or a static Absolute grounds reality as that one thing in which all the apparent transitoriness of reality is united. Reality is understood ontotheologically.

Various efforts by philosophers have filled out the details concerning the uneasy relationship between a static ground and all transitory appearances; between determinism and freedom. Indeed, such a pastime constituted the "favorite game of philosophers" beginning with the pre-Socratics. ${ }^{984}$ Most scholars agree the real formalization of the situation originates near the start of classical philosophy with Plato's Idealism, which began to utilize elements of the above understanding of a theos in describing the essence of the Platonic Idea and the Forms which had a close relationship to mathematics. ${ }^{985}$ It is this understanding that can be directly traced back as the origin of ancient natural philosophy which divided human thought from the natural world, where the common psychological experience of time was contrasted with timelessness according to the Platonic separation, wherein the physical was 'temporal' and the mental was 'timeless. ${ }^{986}$ This will become an

\footnotetext{
${ }^{983}$ This also suggests an intimate relationship between ontology and epistemology; one's epistemology is limited by one's ontology for Heideggerian thinking. Therefore, ontology has primacy over epistemology.

${ }^{984}$ J. T. Fraser, et al., Time, Science, and Society in China and the West: The Study of Time V, 3.

985 "Throughout much of his writing, Plato asserts a dualistic reality. Inspired by mathematical knowledge and moral concerns, Plato argues that there exists an ever-changing, temporal world of physical objects accessible to the senses as well as a timeless world of ideal Forms graspable by the mind only through abstract thinking. These Forms have three functions: 1) as models or patterns for physical objects, e.g., a chair imitates or somehow participates in the form "chairness;" 2) as standards of conduct, e.g., if one understands the definition of justice itself, one knows how to be just; and 3) as the objects of genuine knowledge, e.g., knowledge of beauty is not gained by recognizing beautiful people or art, but by intellectually grasping the permanent, eternal form of beauty itself," in Christian D. Von Dehsen, ed. Lives \& Legacies: An Encyclopedia of People Who Changed the World: Philosophers and Religious Leaders (Phoenix, AZ: The Oryx Press, 1999), 156. In like manner, "Platonic Idealism, as traditionally interpreted, identifies absolute being with timeless Ideas or disembodied essences. These, organically united in the Good, are the archetypes and dynamic causes of existent, material things," in Dagobert D. Runes, ed. The Dictionary of Philosophy (New York, NY: Kissinger Publishing, 2006), 137. Additionally, "Pure Idealism or Immaterialism identifies ontological reality (substance, substantives, concrete individuality) exclusively with the ideal, i.e., Mind, Spirit, Soul, Person, Archetypal Ideas, Thought," ibid., 137.

${ }^{986}$ Fraser, et al., describe it well, "The separation of the changing from the permanent, the unpredictable from the predictable, distinguishing a perspective of becoming from a perspective of being in the human experience of time, has been a favorite game of philosophers ever since the pre-Socratics held their own time-society meetings along the shores of Magna Graeca and on the islands of the Aegean Sea.

"Little did they anticipate that by the time of Newton a particular way of separating the lawful from the unpredictable would have become the formal basis of a new natural philosophy that, through its offspring, the Industrial Revolution, would change the patterns of Western life. Neither could they have guessed that the Pythagorean duality of sky-geometry on the one hand and earth-existence on the other would have become,
} 
ironic anecdote of history, in that it was first nature, in contradistinction to the static beauty of mathematics, which presented evidence favoring temporality as the authentic reality. However, with the dawn of the modern Newtonian picture of natural science, it became nature that solidified the correctness of philosophical or ontological timelessness, at least in the minds of most philosophers. In this understanding, which derives from Platonic influences, the temporal is only understood and defined in relationship to a timeless eternity for its meaning; time is little more than the measurement of the motions of objects alongside other objects which must relate to their own timeless essences. ${ }^{987}$ In other words, the transitory aspect of reality, nature, initially depended on a postulated nontransitory ground, which later became 'confirmed' by the successes of modern science, whereby that which was initially seen as clearly transitory grew to be understood in increasingly timeless terms. It is this that allowed the temporal appearance of nature to become so solidly grounded in timelessness to derive its meaning and usefulness. Of course, the timeless grounding of natural science has been reinforced through tremendous practical successes. Everything from the technology that drove our visit to the moon and the computer revolution which is allowing you to read this study are theoretically based on timeless mathematics as their ground.

Aside from many who embrace the general themes of Christianity in their ontotheologically saturated philosophy ${ }^{988}$ from the $4^{\text {th }}$ century onward which is directly targeted as part of Heidegger's ontotheological critique, Heidegger's criticisms also include most of contemporary science and mathematics as ontotheologically impregnated and thus philosophically bankrupt, as Heidegger

through the labors of Plato, the paradigm of scientific thought concerning the nature of time.

"The cutting of the pie of human time experience into no more and no less than two slices-the eternal and the temporal-proved to have been necessary for the formulation of the Galilean laws of motion and for all subsequent laws of physical science.

"The success of the natural sciences, which all employ this dichotomy, appears to have demonstrated that the division of the world into time and the timeless was an undebatable fact of nature. The duality entered the metaphysical foundations of physics, and through it became a dogma of contemporary knowledge in general," in Fraser, et al., Time, Science, and Society in China and the West: The Study of Time V, 3. He notes "the sharp division of the world into what is temporal and what is timeless, sometimes identified with a division between what is judged physical and what is regarded as mental," ibid., 3.

${ }^{987}$ Fraser, et al., Time, Science, and Society in China and the West: The Study of Time V, 3. Fraser reacts to this by bemoaning the "rigidity of defining time by its contrast to the timeless (to eternity)," ibid., 3.

${ }^{988}$ One could describe it in different ways depending on the context and Heidegger's concerns, ontotheologically saturated philosophy, philosophically bankrupt theology. 
repeatedly emphasized through his criticisms on the place of technology in society and its

relationship to philosophy, wherein technology "rages about ... like an unshackled beast." ${ }^{\prime 989}$ Indeed,

Heidegger claimed that the fundamental trait of modern metaphysics is that it is "determined by the

fact that the entirety of the traditional problematic comes under the aspect of a new science, which is

represented by mathematical natural science." This he connects explicitly with classical theology as

he continues, "if metaphysics asks concerning the first causes, concerning the most general and

highest meaning of beings, in short concerning what is highest, ultimate, and supreme, then this kind

of knowing must be commensurate with what is asked about. Yet that means: it must itself be

absolutely certain," ${ }^{\prime 990}$ and where there is absolute certainty, there is no capability of contingency or

${ }^{989}$ Heidegger went so far as to claim that "technology ... rages about in the 'world' today like an unshackled beast," in Martin Heidegger, The Metaphysical Foundations of Logic, tr. Michael Heim (Bloomington, IN: Indiana University Press, 1984), 215. See also, Martin Heidegger, The Question Concerning Technology and Other Essays, tr. William Lovitt (New York, NY: Harper \& Row, 1977); and Heidegger, Identity and Difference, 72. If the call toward a genuine reflection on ontology is not heeded, "the rule of metaphysics [as ontotheology] may rather entrench itself, in the shape of modern technology with its developments rushing along boundlessly," ibid., 72. Similarly, "Although two seemingly different conceptions of science are now seemingly struggling against each other-science as technical and practical professional knowledge and science as a cultural value in itself-nevertheless both are moving along the same decadent path of a misinterpretation and disempowering of the spirit.... The regions of science lie far asunder. Their ways of handling their subject matters are fundamentally different. This disintegrated multiplicity of disciplines is meaningfully maintained ... [and] the rootedness of the sciences in their essential ground has atrophied. In all its areas, science today is a technical, practical matter of gaining information and communicating it. No awakening of the spirit at all can proceed from it as science. Science itself needs such an awakening," Martin Heidegger, Introduction to Metaphysics, tr. Gregory Fried and Richard Polt (New Haven, CT: Yale University Press, 2000), 50-51. Heidegger defines his use of "spirit" here by sharing, "we determine the essence of the spirit briefly in this way: Spirit is neither empty acuity, nor the noncommittal play of wit, nor the understanding's boundless pursuit of analysis, nor even world reason, but rather spirit is originally attuned, knowing resolution to the essence of Being. Spirit is the empowering of the powers of beings as such and as a whole. Where spirit rules, beings as such always and in each case come more into being <wird ... seiender $>$. Asking about beings as such and as a whole, asking the question of Being, is then one of the essential fundamental conditions for awakening the spirit," 52.

${ }^{990}$ Heidegger, The Fundamental Concepts of Metaphysics: World, Finitude, Solitude, 54. Heidegger adds that "thus, via the guiding thread of the mathematical idea of knowledge, the entire problematic of traditional metaphysics assumes the task of carrying out this demand in the strict sense and thus also of raising metaphysics, understood in terms of its content, to the formal level of an absolute science. The problem of absolute certainty is above all the fundamental problem of modern philosophy, not in the sense of an epistemology, but sustained and guided by the problem of the content of metaphysics itself.... The development of modern metaphysics is sustained by this priority of the problem of certainty with a view to metaphysical knowledge. From there the modification of the body of problems and disciplines occurs," ibid., 5455. Heidegger blames, amongst others, Descartes for this trend. "Did not Descartes, who determined the fundamental orientation of modern philosophy, want nothing other than to furnish philosophical truth with the character of mathematical truth and wrest mankind from doubt and unclarity? From Leibniz the saying has been handed down: "Sans les mathématiques on ne pénètre point au fond de la Metaphysique": "Without mathematics one cannot penetrate into the ground of metaphysics. This is surely the most profound and sweeping confirmation of what is proposed straightaway and for everyone as absolute truth in philosophy.

"Yet if it is as clear as day that philosophical truth is absolutely certain truth, why does precisely this endeavor on the part of philosophy never succeed? Regarding this endeavor concerning absolute truth and 
freedom to be otherwise. This would have significant implications were supersensible beings, such as God, freedom, and immortality, pursued within metaphysics alongside mathematical entities, which is precisely what Heidegger says classical metaphysics sought to do, ${ }^{991}$ and technology does the same today. ${ }^{992}$ On the other hand, any indeterminist, relativist, or subjectivist philosopher, such as those commonly found in more postmodern circles, will likely side with Heidegger that ontotheology must be overcome in search of authentic Being by way of its disclosure through a temporal ecstatic (a temporally 'extended outside oneself' or self-reflectiveness) existentialism, wherein we have access to Being through its revelation to us as thinking human beings (Dasein); i.e., that being which is concerned with its own being. Where or in what distinguishable role God is philosophically relegated to in the cosmos we experience in such thinking is the great unknown and unanswered question in Heidegger's work. In either case, whether one agrees or disagrees with him, it is hard to avoid Heidegger's critical assessment and either lean towards affirming or rejecting his ontotheological description of classical metaphysics, if any major philosophical or theological position is followed through to its expected end.

In summary, concerning ontotheology, the key to grasping the essence of Heidegger's construal of metaphysics as ontotheology is that the idea of God, including his Christian appearance, through most of history was philosophically understood to represent an absolute, unmodifiable and simple

certainty, do we not instead throughout the history of philosophy constantly see one catastrophe after another? Thinkers such as Aristotle, Descartes, Leibniz, and Hegel have to put up with being refuted by a doctoral candidate. These catastrophes are so catastrophic that those concerned do not even notice them," ibid., 16. For Heidegger, philosophy is not "what is accessible to everyone straightaway like 2 times 2 is 4," ibid., 16. Rather, "mathematical knowledge does not necessarily need to be borne by the inner substance of man. Such a situation is impossible in principle for philosophy. This emptiest and at the same time least binding knowledge as regards human substance-mathematical knowledge-cannot become the measure for the richest and most binding knowledge imaginable: philosophical knowledge," ibid., 17.

${ }^{991}$ Recall, that Heidegger claims classical metaphysics is precisely pursuing these objects within metaphysics, "Metaphysics claimed to be a theoretical knowledge of the supersensible, i.e., God, freedom, and immortality. These are no ordinary objects of inquiry with which metaphysics is concerned," Heidegger, Phenomenological Interpretation of Kant's Critique of Pure Reason, 41.

992 Thus Heidegger shares, if the call toward a genuine reflection on ontology is not heeded, "the rule of metaphysics [as ontotheology] may rather entrench itself, in the shape of modern technology with its developments rushing along boundlessly," Heidegger, Identity and Difference, 72. 
structure, ${ }^{993}$ immutable (impassible) ${ }^{994}$ and timeless. ${ }^{995}$ This means the philosophical place of God in reality represented the most fundamental ontic piece in the metaphysical puzzle, the ground upon which everything else depended, in a manner reminiscent of the role of mathematics for everything (all things can be numbered) to conceptually make sense for the Greeks. All ontology and epistemology correspondingly and submissively complied to this perfectly mathematical-logical ${ }^{996}$ and causal chain. In such a picture, the freedom of Being, even the human being, Dasein, necessarily becomes an afterthought or cumbersome addition, ontologically obliterated or emasculated in such a way as to correspond to the metaphysical structure, if actual freedom is allowed at all, ${ }^{997}$ whereas Heidegger views freedom as part of the essential element defining existence. ${ }^{998}$ Heidegger's ultimate complaint of the ontotheological condition of classical metaphysics could be construed as answering

\footnotetext{
${ }^{993}$ For descriptions of the classical tradition, see Jay Wesley Richards, The Untamed God: A Philosophical Exploration of Divine Perfection, Immutability, and Simplicity (Downers Grove, IL: InterVarsity Press, 2003); and Anthony Kenny, The God of the Philosophers (Oxford, UK: Clarendon Press, 1987).

${ }^{994}$ For an exposition of this, see Arthur W. Pink, The Attributes of God (Grand Rapids, MI: Baker Books, 2006), 46-50; and Bruce A. Ware, An Evangelical Reexamination of the Doctrine of the Immutability of God (Ann Arbor, MI: University Microfilms, 1987; Ph.D. Dissertation, Fuller Theological Seminary, 1984).

${ }^{995}$ For a defense of this in theology, see Nelson Pike, God and Timelessness.

${ }^{996}$ Heidegger emphasizes at great length how the timeless-mathematical understanding of theos affects one's logos, understood here as the mathematical-logical component of metaphysics, thus one's theos, ontos, and logos correspond to one another. Note, for example, Martin Heidegger, Logic: The Question of Truth, tr. Thomas Sheehan (Bloomington, IN: Indiana University Press, 2010). Note in particular Heidegger's connection between logic and the mathematical-logical principle of non-contradiction in relationship to Being; see Martin Heidegger, Being and Truth, tr. Gregory Fried and Richard Polt (Bloomington, IN: Indiana University Press, 2010), 44-54; Martin Heidegger, The Principle of Reason, tr. Reginald Lilly (Bloomington, IN: Indiana University Press, 1991), 17-18; and Heidegger, The Metaphysical Foundations of Logic, 52-57.

${ }^{997}$ Of course, any variant of fatalism or absolute determinism will wave off the sort of freedom Heidegger is pushing for as an illusion a priori. Interestingly, in the history of theological inquiry, the piercing logic of this timeless God without freedom is evident in the work of some Calvinists and the doctrine of "Double Predestination" given the timeless foreknowledge of God. In such views, "the type of freedom affirmed by Calvinism [is] (deterministic freedom)," Michael D. Robinson, The Storms of Providence: Navigating the Waters of Calvinism, Arminianism, and Open Theism (Lanham, MD: University Press of America, 2003), 50. See also, Charles Partee, The Theology of John Calvin (Louisville, KT: Westminster John Knox Press, 2008), 244-247, and William Johnson, who observes, "for Calvin single predestination seemed illogical. If God decreed salvation for some, Calvin reasoned, this must mean that God decreed damnation for others. Any other view seemed to leave the fate of the reprobate to chance, which Calvin believed challenged the absolute sovereignty of God," in William Stacy Johnson, John Calvin: Reformer for the $21^{\text {st }}$ Century (Louisville, KT: Westminster John Knox Press, 2009), 47. Of course, this does not mean Arminianism and Open Theism are "off the hook" of ontotheological commitments, either.

${ }^{998}$ Heidegger, Phenomenological Interpretation of Kant's Critique of Pure Reason, 15. "Human Dasein which has a world is a being who is concerned with its own existence, indeed in such a way so as to choose itself or give itself over to choice. The existence which always makes up our being-though not the only determinant-is a matter of our freedom; and only a being which can be resolved and has resolved itself in such and such a way can have a world. World and freedom as basic determinations of human existence are most closely related," ibid., 15.
} 
negatively the question of whether we can say the timeless and static 'God' of metaphysics allows for any truly free, ecstatic, or living God. ${ }^{999}$ Of course, while he certainly left the divine God question open, overall Heidegger expressed little emphasis or interest in discussing just what philosophy might have to say about God, instead focusing on a more human-centered analysis. What later scholarship took away from Heidegger's ontotheological critique ${ }^{1000}$ was understandably a general skepticism about the role of God in philosophy, ${ }^{1001}$ which has become the dominant position in philosophy departments in the West, and still in some other parts of the world.

The implications of Heidegger's ontotheological critique are indeed expansive. The above comments from Heidegger about metaphysics being determined by modern mathematical natural science are particularly important in demonstrating this, because of the role that mathematical natural science (physics) would have in defining time with the advent of Einstein's relativity. Indeed, contrary to some, as Trish Glazebrook argues correctly, I believe, Heidegger was very much a philosopher of science. Accordingly, "what are taken to be Heidegger's many and significant contributions to philosophy-that is, his overcoming of metaphysics, his rereading of the ancients, his critique of technology and representational thinking, his vision and revision of language, truth and thinking-have at their core an inquiry into science that drove his thinking for sixty years." ${ }^{1002}$

With the above in mind, it is therefore critical to distinguish Heidegger's Dasein philosophy from nature, or natural science, as it is typically understood. Heidegger stated, for example, that "in nature, there is neither historicity nor unhistoricity... Nature is without history because it is atemporal."1003

\footnotetext{
${ }^{999}$ As Heidegger summarized it, "The god-less thinking which must abandon the god of philosophy, god as causa sui, is thus perhaps closer to the divine God. Here this means only: god-less thinking is more open to Him than onto-theo-logic would like to admit," for before "the god of philosophy," "man can neither pray nor sacrifice to this god. Before the causa sui, man can neither fall to his knees in awe nor can he play music and dance before this god," Heidegger, Identity and Difference, 72.

${ }^{1000}$ It must be again clearly noted that generally speaking, ontotheology, expectantly given the inertia of history, does not have a great reputation. As Thomson put it, "upon hearing the expression 'ontotheology,' many philosophers start looking for the door,” in Thomson, “Ontotheology?,” 107.

${ }^{1001}$ Or, more than skepticism, downright denial or opposition, as is the premise of Peter S. Dillard, Heidegger and Philosophical Atheology: A Neo-Scholastic Critique (New York, NY: Continuum Publishing, 2008).

1002 Trish Glazebrook, Heidegger's Philosophy of Science (New York, NY: Fordham University Press, 2000), 12-13.

${ }^{1003}$ Martin Heidegger, Logic as the Question Concerning the Essence of Language (Albany, NY: State University of New York Press, 2009), 115.
} 
Notably, the same is true for animals who are "poor in world." ${ }^{1004}$ As such, within Heidegger's view of philosophy, nature, understood mathematically, did indeed consist of classical "timeless" entities or beings. ${ }^{1005}$ Heidegger, it seems clear, sought no direct quarrel with the natural sciences themselves as respective positive sciences or regional ontologies, but he was concerned with how the sciences might negatively impact upon philosophy's own unique purpose. ${ }^{1006}$

Indeed, it could not be said that Heidegger was simply neutral toward science, either, but rather condescendingly suggested that "philosophy is neither for nor against science but instead leaves it to its own craving to find profit in securing ever more efficiently and quickly ever more useful results and thus in anchoring ever more firmly the dependence of needs and wants in the respective result and in its surpassing." ${ }^{1007}$ Or, in more straightforward language, "philosophy is completely different from 'world-view' and is fundamentally distinct from all 'science.' Philosophy cannot by itself replace either world-view or science; nor can it ever be appreciated by them. Philosophy cannot at all be measured by anything else but only by its own now shining, now hidden, essence." For "if we attempt to calculate whether philosophy has any immediate use and what that use might be, we will find that

${ }^{1004}$ Heidegger, The Fundamental Concepts of Metaphysics: World, Finitude, Solitude, 185-277.

1005 "What resides in what-is-known in mathematical natural-scientific knowledge? ... This question is not asking about the totality of the results these sciences produce but rather about the thought-content of any and every result qua result of mathematical physics. To put it more precisely: not the thought-content but rather what has to be thought, i.e., what belongs to the known as-such in any mathematical natural science. In the most general terms this known-as-such is nature." "Phenomenologically understood, nature is an entity which can be discovered within the world and of which it can be said that it underlies all worldly things and all worldly ontological connections insofar as they are determined by materiality-in short, nature can be found in everything of the world," Heidegger, Logic: The Question of Truth, 258.

${ }^{1006}$ Pylkkö, The Aconceptual Mind, 24, 54, 101. "Heidegger ... wanted to leave science in peace. According to Heidegger's view, ... natural science is doomed to remain dogmatic and philosophically naive," ibid., 101. As Heidegger put it, "naturalism coincides with the discovery of nature.... The discovery of nature in question is the discovery of it as the object of a special science, the mathematical science of nature. Naturalism is a consequence of this discovery of nature. That is to say, the type of being and object in the context of nature becomes the guide to the content in comprehending every sort of being and objectivity. Accordingly, the specific rigor of the mathematical science of nature serves as the criterion for every domain of being and epistemic determination of it." This leaves, then, the question concerning "the extent to which a determinate idea of a science and object of this sort has in fact expanded to the thematic field of philosophy, in what sense the objective field of philosophy and its method are subjected to the idea of the mathematical science of nature," because "the basic character of this science, apart from its rigor, is distinguished by the fact that its results can be formulated in laws...". The danger, then, is that "the first aspect of the effect of naturalizing philosophy lies in the fact that this same naturalist tendency leads to the naturalization of consciousness," Martin Heidegger, Introduction to Phenomenological Research, tr. Daniel O. Dahlstrom (Bloomington, IN: Indiana University Press, 2005), 47-48. He continues later, "The object of natural science is nature as physical nature, as the unity of a completely determinate, thingly being," ibid., 50. See also, Heidegger, What is a Thing?, 65-119.

${ }^{1007}$ Heidegger, Contributions to Philosophy (Of the Event), 122. 
philosophy accomplishes nothing." ${ }^{1008}$ Alternately explained, there is no immediate purpose in humanity's temporal experience, in itself. The fact we live "temporal" lives does not tell us what to do with them. For Heidegger, science has nothing to do with describing the temporality of human existence. Through the experience of living, however, philosophy opens up "new domains of questioning,",1009 including uses for science and technology, and also possibly morality, ethics, and God.

The primary and present purpose of understanding Heidegger's relationship to science in all its facets, however, is that it greatly impacts upon how Heidegger understands his view of time-indeed, one could argue his view of time is precisely a reaction to the concept of time within the scientific worldview. Heidegger's view of time is in direct contrast to that of Einstein and Kant, for example. Heidegger, first explaining how Kant and many scientists think, asserted that "time is not something present out-there. It is not something that can be empirically intuited. But that means that time in itself is not determinable. I cannot determine any 'now' in an absolute way by way of the pure preview of the whole of time, because any determinate 'now' always already bespeaks a 'now, when .... Every now-determination is essentially relative to some present thing; and only to the degree that this present thing (with regard to which time is determinable at all) can be fixed, is a determination of time possible."1010 Moreover, eventually “Einstein arrived at this same framework for determining time by pursuing some quite specific concrete problems in physics. The principle of the theory of relativity-that all time is the time of a certain place-is a principle that is grounded in the very essence of time, insofar as what is present in the sense of being present in nature can be determined only place-wise-i.e., only in terms of a place and relative to a place. There is no absolute perception of time. In a certain sense, as regards something present in nature, I can never simply and directly fix its 'now' as given absolutely." ${ }^{1011}$ In this light, although "Einstein's theory of relativity ... established the opinion that traditional philosophical doctrine concerning time" had "been shaken to the core

\footnotetext{
${ }^{1008}$ Heidegger, Basic Questions of Philosophy: Selected 'Problems' of Logic', 4.

${ }^{1009}$ Heidegger, Basic Questions of Philosophy: Selected 'Problems' of Logic', 5.

${ }^{1010}$ Heidegger, Logic: The Question of Truth, 290.

${ }^{1011}$ Heidegger, Logic: The Question of Truth, 290.
} 
through the theory of physics," "this widely held opinion is fundamentally wrong. The theory of relativity in physics does not deal with what time is but deals only with how time, in the sense of a now-sequence, can be measured." Rather, it asks "whether there is an absolute measurement of time, or whether all measurement is necessarily relative, that is, conditioned. The question of the theory of relativity could not be discussed at all unless the supposition of time as the succession of a sequence of nows were presupposed beforehand."1012 As such, "if the doctrine of time, held since Aristotle, were to become untenable, then the very possibility of physics would be ruled out" ${ }^{\prime 1013}$ as absolute.

Elsewhere Heidegger tied all this into the life sciences, criticizing, for example, the hope of any "universal" formula in physics, while at the same time surmising about its dreadful implications concerning determinism. ${ }^{1014}$ Nevertheless, he forcefully asserted that the quest for such a formula was inevitable in our scientific age, as it is tied to the inner essence of science itself to seek such formulas. ${ }^{1015}$

The significance of Heidegger's relationship with natural science in general is important, and worthy of special emphasis, as it is in contrast to his view of philosophy. As Pylkkö observed, "one can detect a strong inclination towards hermeneutic dualism ... in Heidegger's view, and this

\footnotetext{
1012 Martin Heidegger, Zollikon Seminars: Protocols-Conversations-Letters, ed. Medard Boss, with tr., Franz Mayr and Richard Askay (Evanston, IL: Northwestern University Press, 2001), 57.

${ }^{1013}$ Heidegger, Zollikon Seminars: Protocols-Conversations-Letters, 57. Heidegger continues, "in addition to the predominant opinion that physics has caused the downfall of the traditional metaphysical doctrine of time, there is a further opinion frequently held nowadays that philosophy lags behind natural science. Contrary to this, it must be pointed out that contemporary natural scientists, in contrast to scientists working on the level of Galileo and Newton, have abandoned vigorous philosophical reflection and no longer know what the great thinkers thought about time.... If physicists make judgments about metaphysics, which is quite absurd in itself, then one must demand that physicists first reflect on metaphysical ideas, for instance, this idea about time. Of course, physicists can do this only if they are prepared to go back to the underlying suppositions of physics, and beyond this, to what remains and continues to be standard in this domain as acceptio, even when the physicist is unaware of it. It is no accident that in a strict sense modern science's selfcritique is lacking today. It is not due to negligence or laziness on the part of the respective scientists. It is due to blindness determined by the destiny of the present age," ibid., 57-58.

${ }^{1014}$ Heidegger, Four Seminars, 55. "Modern experimental physics constantly searches for the laws of motion, just as Aristotle had. This would be the meaning of the fundamental universal formula, insofar as all the possibilities of movement in their infinite variety could be deduced." Concerning "what the discovery of this formula would mean for physics," "the answer runs: the end of physics. Such an end would entirely alter the human situation," ibid., 55.

${ }^{1015}$ Heidegger observed, in the life sciences, "here, more disturbing than the conquest of space, there appears the transformation of biology into biophysics. This means that the human can be produced according to a definite plan just like any other technological object. In this context, nothing is more natural than to ask whether science will be able to stop in time. Such a stop is nevertheless fundamentally impossible," Heidegger, Four Seminars, 55.
} 
distances him from all forms of naturalism, including nondogmatic and holistic naturalism," ${ }^{1016}$ in his philosophizing. That is, essentially, the way we study nature is fundamentally different from the way we study man, regardless of the fact that man is a part of nature. Indeed, were Heidegger correct about the nature of existence, in particular human existence, as fundamentally temporal, then the modern scientific enterprise, including such disciplines as cognitive-neuroscience, would be fundamentally unable to reach any deeper understanding of humanity. Of course, Heidegger was no scientist. Thus, while "the contemporary scientist... will be pained by the poverty of Heidegger's analysis of ontic truth as such,"1017 it seems clear that Heidegger felt that the "forgetfulness of Being to which science bears witness is not merely due to the ineptitude of scientists, but due as well to the fact that Being as a-lêtheia [or unconcealedness] conceals itself as source in the very beings to which it gives rise.... [Therefore, in science there is] a failure to admit the limitations of the scientific method," a "refusal to admit the deeper level of presence beneath the object-ness in beings that cannot be submitted to controlled experiment."1018

As his career advanced, and his articulation of Dasein, and later Being, evolved, Heidegger began to employ newer terminology to describe his views in contrast to that of the dominant scientific paradigm for philosophy and theology. One of the key terms introduced was that of "time-space," which is deceptively an apparent mirror opposite of Einsteinian "space-time." The details surrounding time-space will be explored shortly, but first, it may prove helpful to retread Heidegger's pathway toward his an understanding of Being and ontology and their relationship to time and temporality in general, noting, however, that the details between Dasein and Being, and temporality in general, cannot be explored here in depth. That being so, a brief but deep delve into Heidegger's works is necessary, and will prove helpful in examining Pylkkö's work, which often presumes his reader has some familiarity with Heidegger. This will also establish the pathway that led Heidegger toward his ontotheological critique, which he articulated with more precision later in his life.

\footnotetext{
${ }^{1016}$ Pylkkö, The Aconceptual Mind, 54.

${ }^{1017}$ William J. Richardson, “Heidegger's Critique of Science," in Heidegger on Science, ed. Trish Glazebrook (Albany, NY: State University of New York, 2012), 43.

${ }^{1018}$ Richardson, “Heidegger's Critique of Science," 42.
} 
The primary means by which Heidegger sought to deconstruct classical metaphysics started with his effort to re-ask what the ultimate 'ground' of existence was, that is, what the nature of Being is. ${ }^{1019}$ A basic explanation shared from Iain Thomson will introduce the context of the problem as it is typically perceived:

As ontology, metaphysics searches for the most general ground of beings; it looks for what all beings share in common. Ontologists understand the Being of beings in terms of that being beneath or beyond which no more basic being can be 'discovered' or 'fathomed' (ergründet). This 'exemplary being' then comes to play the ontological role of 'giving the ground' (ergründen) to all other beings, in the sense that this basic ontological being designates that kind of being in whose being all other beings share and by which they are thus unified or composed. ${ }^{1020}$

For Heidegger, however, in what will become typical of his piercing level of inquiry, leaving the question in the above descriptive format will not suffice. "Why are there beings at all instead of nothing?" rings as his opening salvo. ${ }^{1021}$ The real question thus posed in the articulation of the quest for Being is, namely, the meaning of Being, which is a question that Heidegger considered long forgotten, ${ }^{1022}$ "concealed from metaphysics during its long history from Anaximander to Nietzsche." ${ }^{1023}$ To Heidegger, serious questioning about the meaning of Being was neglected because it was evidently assumed that if Being were the "most universal concept,"1024 then it must also be self-

\footnotetext{
${ }^{1019}$ This basic question occupies virtually all of his writings, a corpus which is quite expansive when his published lecture notes are included. I will focus on a sample of his major works to define the general lines of his thought.

${ }^{1020}$ Iain Thomson, “Ontotheology? Understanding Heidegger's Destruktion of Metaphysics,” 301-302.

${ }^{1021}$ Martin Heidegger, Introduction to Metaphysics, 1. He continues, "just as it is the broadest question, the question is also the deepest: Why are there beings at all ...? Why-that is, what is the ground? From what ground do beings come? On what ground do beings stand? To what ground do beings go? The question does not ask this or that about beings-what they are in each case, here and there, how they are put together, how they can be changed, what they can be used for, and so on. The questioning seeks the ground for what is, insofar as it is in being. To seek the ground: this means to get to the bottom <ergründen>. What is put into question comes into relation with a ground. But because we are questioning, it remains an open question whether the ground is a truly grounding, foundation-effecting, originary ground; whether the ground refuses to provide a foundation, and so is an abyss; or whether the ground is neither one nor the other, but merely offers the perhaps necessary illusion of a foundation and is thus an unground. However this may be, the question seeks a decision with respect to the ground that grounds the fact that what is, is in being as the being that it is. This why-question does not seek causes for beings, causes of the same kind and on the same level as beings themselves. This why-question does not just skim the surface, but presses into the domains that lie 'at the ground,' even pressing into the ultimate, to the limit," ibid., 3. 1022 Heidegger, Being and Time, 1.

${ }^{1023}$ Martin Heidegger, "Introduction to 'What is Metaphysics?'," in Pathmarks, tr. Walter Kaufmann (Cambridge, UK: Cambridge University Press, 1998), 280. ${ }^{1024}$ Heidegger, Being and Time, 2.
} 
evident, the clearest concept needing "no further discussion"1025 as the indefinable ground or “indeterminate immediate."

Lamentably, Heidegger asserts that this understanding makes the meaning of Being "rather the most obscure of all ${ }^{1027}$ and applicably otiose, in addition to revealing a form of philosophical laziness for failing to properly ask the question of Being and its meaning. For, he feels, no need has been seen to ask it anymore, because we have forgotten the importance of the question, making the forgetting of the question a double forgetting, of the question and its value. ${ }^{1028}$ Therefore, a new way of looking at the question is necessary for Heidegger, a way that both separates and then unites our naïve notions and questions about the onticity of beings, or everyday entities [Seiende] such as trees and chairs, from that which "grounds" their existence, Being $[$ Sein $] .{ }^{1029}$ He continues by stating, "What is asked about in the question to be elaborated is Being, that which determines beings as beings, that in terms of which beings have always been understood no matter how they are discussed. The Being [Sein] of being 'is' itself not a being [Seiende]."1030 Therefore, "insofar as Being constitutes what is asked about, and insofar as Being means the being of beings, beings themselves turn out to be what is interrogated in the question of Being." ${ }^{1031}$ This is entirely different than the typical study of entities which seeks

1025 Heidegger, Being and Time, 1-2.

${ }^{1026}$ Heidegger, Being and Time, 2, quoting Hegel. Heidegger blames everyone from the Greeks to Hegel for this obfuscation of the question of Being.

${ }^{1027}$ Heidegger, Being and Time, 2.

${ }^{1028}$ Heidegger, Being and Time, 1-2 "This question has today been forgotten-although our time considers itself progressive in again affirming 'metaphysics.' All the same we believe that we are spared the exertion.... Not only that. On the basis of the Greek point of departure for the interpretation of being a dogma has taken shape which not only declares that the question of the meaning of being is superfluous, but even sanctions its neglect. It is said that 'being' is the most universal and the emptiest concept. As such it resists every attempt at definition. Nor does this most universal and thus indefinable concept need any definition. Everybody uses it constantly and also already understands what is meant by it. Thus what troubled ancient philosophizing and kept it so by virtue of its obscurity has become obvious, clear as day, such that whoever persists in asking about it is accused of an error of method," ibid., 1-2.

${ }^{1029}$ Not only trees and chairs. Heidegger relates the above to the human being as follows: "Thus if we properly pursue the question 'Why are there beings at all instead of nothing?' in its sense as a question, we must avoid emphasizing any particular, individual being, not even focusing on the human being. For what is this being, after all!," Heidegger, Introduction to Metaphysics, 4.

${ }^{1030}$ Heidegger, Being and Time, 5.

${ }^{1031}$ Heidegger, Being and Time, 5. This is a critical concept to grasp. "The first philosophical step in

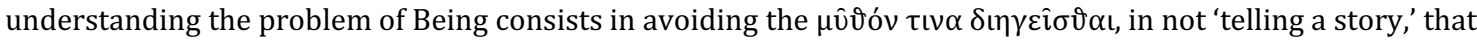
is, not determining beings as beings by tracing them back in their origins to another being-as if Being \{Sein\} had the character of a possible being \{Seienden\}. As what is asked about, Being thus requires its own kind of demonstration which is essentially different from the discovery of beings. Hence what is to be ascertained, the 
only ontic properties and problems; there is no inner reflective or interrogative dynamic involved in typical ontic inquiries, such as in zoology, biology, chemistry, or physics.

At this point, it is important to point out that Heidegger is not insensitive to accusations from potential opponents that he is 'inventing' his notion of Being; creating something from, or where, there is 'nothing.'1032 Although I will not here outline his lengthy treatments on Aristotle and Kant concerning the issue of Being, suffice it to say that he defends his reasoning by asserting that "authentic philosophizing will only then be able to come upon the Question of Being if this question belongs to the innermost essence of Philosophy."1033 If we can 'find it,' it's only because it was there all along. ${ }^{1034}$ Thus, while his method of approaching the question may be relatively novel, the question itself is not new in his mind-it has been asked before, and was always capable of being asked.

meaning of Being, will require its own conceptualization, which again is essentially distinct from the concepts in which beings receive their determination of meaning," ibid, 5.

${ }^{1032}$ For example, Rudolf Carnap and other logical positivists advanced this suggestion.

${ }^{1033}$ Heidegger, Kant and the Problem of Metaphysics, 158. Heidegger explains it elsewhere as follows: "The relationship of man to Being is obscure. Nonetheless, we everywhere and continually stand within it wherever and whenever we comport ourselves toward beings. When and where would we-ourselves beingsnot comport ourselves toward beings? We keep hold of beings and at the same time hold ourselves in the relationship to Being. This is to say that we stand in the differentiation of beings and Being. Such differentiation sustains the relationship to Being and supports relations with beings. It prevails, without our being aware of it. Thus it appears to be a differentiation whose differences are not differentiated by anyone, a differentiation for which no differentiator 'is there' and no region of differentiation is constituted, let alone experienced. One might almost surmise and maintain correctly that with what we call the 'differentiation' between Being and beings we have invented and contrived something that 'is' not and that above all does not need 'to be."'

"But a glance and metaphysics and into its history soon teaches us otherwise. The differentiation of beings and Being shows itself as that selfsame from which all metaphysics arises and also, in arising, inevitably escapes, that selfsame which it leaves behind as such, and outside its domain, which it never again expressly considers and no longer needs to consider. The differentiation of beings and Being makes possible every naming, experiencing, and conceiving of a being as such. In Greek, the being is called to on; addressing a being as being and, furthermore, grasping a being take[s] place in logos. One can therefore circumscribe the essence of metaphysics, which explicitly brings beings as such to word and concept, in the name 'onto-logy,'” Martin Heidegger, Nietzsche Vols. 3 \& 4, ed. David Farrell Krell (San Francisco, CA: Harper \& Row, 1991), 153-154.

${ }^{1034}$ As Heidegger explains, "if we ask about the possibility of comprehending something like Being, we do not then invent this 'Being' and violently force it into \{becoming\} a problem in order, perhaps, to take up again a question from the philosophical tradition. Rather, what is asked about is the possibility of comprehending what all of us as human beings already and permanently understand. For its part, the Question of Being as a question concerning the possibility of the concept of Being, springs forth from the preconceptual understanding of Being. Thus the question concerning the possibility of the concept of Being is once again driven back a step to the question concerning the essence of the understanding of Being in general. The task of the laying of the ground for metaphysics, grasped in a more original way, is therefore transformed into the elucidation of the inner possibility for the understanding of Being. The working-out of the Question of Being so conceived brings about for the first time the decision as to whether and in what way the problem of Being by itself shows an inner relation to finitude in human beings," Heidegger, Kant and the Problem of Metaphysics, 158. 
As Heidegger breaks the problem of the meaning of Being down, he realizes that "to work out the question of Being means to make a being-one who questions-transparent in its being. Asking this question, as a mode of being of a being, is itself essentially determined by what is asked about in it-Being." ${ }^{1035}$ Heidegger declares that "this being \{Seiende\}, which we ourselves in each case are and which includes inquiry among the possibilities of its being, we formulate terminologically as Dasein [being-there]. The explicit and lucid formulation of the question of the meaning of Being requires a prior suitable explication of a being (Dasein) with regard to its being," ${ }^{1036}$ for which such a task the human happens to be in a privileged position. ${ }^{1037}$ Therefore, a unique 'ontic' property is granted the

${ }^{1035}$ Heidegger, Being and Time, 6-7.

${ }^{1036}$ Heidegger, Being and Time, 7. He comes to this position by stating, "if the question of Being is to be explicitly formulated and brought to complete clarity concerning itself, then the elaboration of this question requires, in accord with what has been elucidated up to now, explication of the ways of regarding Being, of understanding and conceptually grasping its meaning, preparation of the possibility of the right choice of the exemplary being, and elaboration of the genuine mode of access to this being \{Seienden\}. Regarding, understanding and grasping, choosing, and gaining access to, are constitutive attitudes of inquiry and are thus themselves modes of Being of a particular being, of the being we inquirers ourselves in each case are," 6.

${ }^{1037}$ Though Dasein is not to be thought equivalent to the human being anthropologically speaking. As Heidegger explains, "that we human beings comport ourselves toward beings is obvious. Faced with the task of representing beings, we can always specify any being: a being which is not like us and which is also not our equal, a being which is like we ourselves are, and a being which is not like us but which nevertheless, as a self, is our equal. The being is known to us-but Being? Are we not seized with vertigo when we \{try to determine such a thing, even if we should comprehend it properly?," Kant and the Problem of Metaphysics, 158. However, Heidegger continues that despite its elusiveness, "With the question concerning Being as such, we are poised on the brink of complete obscurity. Yet it is worthwhile not to evade this prematurely, but to bring the full peculiarity of the understanding of Being closer to us. For as impenetrable as the obscurity is which shrouds Being and its meaning, still it remains certain that, at all times and in the entire field of the openness of beings, we understand what Being is in order to concern ourselves with the what-Being and the so-Being of beings, in order to experience and dispute the that-Being, in order to decide about the true-Being of the being, and in order to mistake it. In every expressing of a proposition, e.g., 'today is a holiday,' we understand the 'is,' and equally what Being is.... If the understanding of Being did not occur, man could never be as the being which he is, and this would be so regardless of the wonderful faculties with which human beings have been equipped. Moreover, man is a being in the midst of beings in such a way that for man the being which he himself and the being which he is not are always already manifest. We call this mode of the Being of human beings existence. Existence is only possible on the grounds of the understanding of Being.

"In man's comportment toward beings which he himself is not, he already finds the being as that from which he is supported, as that on which he has depended, as that over which, for all his culture and technology, he can never become master. Depending upon the being which he is not, man is at the same time master of the being which he himself is.

"With the existence of human beings there occurs an irruption into the totality of beings, so that now the being in itself first becomes manifest, i.e., as being, in varying degrees, according to various levels of clarity, in various degrees of certainty. This prerogative, however, of not just being among other beings which are also at hand without these beings becoming manifest as such to themselves, but rather fof being\} in the midst of the beings, of being surrendered to it as such, and itself to have been delivered up as a being-for this prerogative to exist harbors in itself the need to require the understanding of Being," ibid., 159-160. 
human being, the property of generating logos, or the letting be seen, to evaluate with language, to synthesize, and to determine trueness from falseness:

Dasein is a being that does not simply occur among other beings. Rather it is ontically distinguished by the fact that in its being this being is concerned about its very being. Thus it is constitutive of the being of Dasein to have, in its very being, a relation of Being to this being. And this in turn means that Dasein understands itself in its being in some way and with some explicitness. It is proper to this being that it be disclosed to itself with and through its being. Understanding of Being is itself a determination of being of Dasein. The ontic distinction of Dasein lies in the fact that it is ontological. ${ }^{1038}$

From this insight, Heidegger advanced what he believed was a fundamentally new way of questioning our questions about existence that differs radically from what had dominated philosophy for millennia, since after the Greeks. And it undeniably involves what he admits is a multi-layered problem, in that through the application of the question of Being to its apprehension by and through the human being one encounters the problem of the "metaphysics of metaphysics"1039 that troubled Kant. It was this that inhibited Kant from ever attaining or even attempting a true "theory of knowledge" according to Heidegger, making the method of Kant's Critique of Pure Reason misguided in its very title, though still profoundly insightful for its internal consistency and exposure of the issues. ${ }^{1040}$

Yet, then the question may be asked: How exactly does the 'concept' of Dasein relate to or differ from classical metaphysics, of which Kant represents the pinnacle for Heidegger? The answer lies in Heidegger's understanding of the nature of the difference between the ground of beings, Being, and

${ }^{1038}$ Heidegger, Being and Time, 11.

${ }^{1039}$ Heidegger, Kant and the Problem of Metaphysics, 161, citing Kant.

${ }^{1040}$ Heidegger, Kant and the Problem of Metaphysics, 161. "Hence, the laying of the ground for metaphysics is grounded in a metaphysics of Dasein. Is it astonishing, then, that a laying of the ground for metaphysics at the very least must itself be metaphysics, and indeed a preeminent one?

"Kant, in whose philosophizing the problem of the possibility of metaphysics was awake to a degree found in none before or after him, must have understood all too little of his innermost intention if this connection did not appear to him.... [Yet,] in 1781, he wrote to his friend and disciple Markus Herz about this work: 'This kind of investigation will always remain difficult, for it is equivalent to the Metaphysics of Metaphysics ...'," ibid., 161. 
the being of the human as Dasein, and our analysis of their differences and relationship ${ }^{1041}$ which will be elaborated upon below.

Heidegger continues his dissection of the duality of the question involved in finding the ground of beings and Being by sharing that "the problem of the laying of the ground for metaphysics is rooted in the question concerning the Dasein in man, i.e., concerning his innermost ground, concerning the understanding of Being as essentially existent finitude."1042 This leads toward a transformation of the problem, one that displaces the work of the metaphysics of classical ontology's efforts to uncover the ground of beings by the "metaphysics of Dasein as fundamental ontology."1043 Rather than taking any ordinary being or entity and beginning one's ontological speculations accordingly (be it a tree, microphysical particle, animal, or human speculations about God derived from the former three), Heidegger believes that a true grounding of Being can only be apprehended through an analysis of that special being which particularly has access to Being, namely Dasein, ${ }^{1044}$ which is to say one cannot access either beings or Being directly, but only through Dasein. But this analysis of Being

\footnotetext{
${ }^{1041}$ This is in part what Heidegger feels justifies his quest to "overcome" metaphysics, and is related to the objectivity of a transcendental reality, something which Kant desperately sought after. Elsewhere Heidegger elaborates on this by writing, "[classical] Metaphysics is a fate in the strict sense, which is the only sense intended here, that it lets mankind be suspended in the middle of beings as a fundamental trait of Western European history, without the Being of beings ever being able to be experienced and questioned and structured in its truth as the twofoldness of both in terms of metaphysics and through metaphysics.

"This fate, which is to be thought in the manner of the history of Being, is, however, necessary, because Being itself can open out in its truth the difference of Being and beings preserved in itself only when the difference explicitly takes place. But how can it do this if beings have not first entered the most extreme oblivion of Being, and if at the same time Being has not taken over its unconditional dominance, metaphysically incomprehensible, as the will to will which asserts itself first and uniquely through the sole precedence of beings (of which is objectively real) over Being?," Martin Heidegger, The End of Philosophy, tr. Joan Stambaugh (Chicago, IL: University of Chicago Press, 1973), 90-91.

${ }_{1043}^{1042}$ Heidegger, Kant and the Problem of Metaphysics, 161.

${ }^{1044}$ Heidegger, Kant and the Problem of Metaphysics, 162. As Heidegger elaborates, "No anthropology [as the understanding and study of the human being as an entity like any other] which understands its own particular questioning and the presuppositions thereof can even claim to develop the problem of a laying of the ground for metaphysics, let alone carry it out. The necessary question for a laying of the ground for metaphysics, namely, that of what man is, is taken over by the metaphysics of Dasein.

"The expression is ambiguous in a positive sense. The Metaphysics of Dasein is not just metaphysics about Dasein, but is the metaphysics which occurs necessarily as Dasein. But for that reason: it can never become metaphysics 'about' Dasein, as for example zoology is about animals. The Metaphysics of Dasein is no fixed and ready-for-all 'organon' at all. It must always be built up anew amid the transformation of its idea in the working-out of the possibility of metaphysics," ibid., 162.
} 
through Dasein needs its own analysis; the philosophical quest is thus thrust into what appears a

unique and penetrating self-analysis.

Of course, if Being, Dasein, and beings (entities) were all of the same essential nature as

Heidegger believes they commonly were viewed throughout history, the above situation would

indeed create the problem of a pointless circularity. Recall, however, that Dasein is a peculiar being,

an ontological being, a being concerned with itself. This reveals that Dasein is capable of the

disclosure of knowledge in a meaningfully rich way. ${ }^{1045}$ It is also a "situated" being. A "being-there."

Where is the "there" of our being? Heidegger responds that the "there" is the phenomena of the

unique 'human' relationship to beings, ${ }^{1046}$ and that through being "in-the-world" new beings may and

${ }^{1045}$ Heidegger, Being and Time, 30-32. Heidegger deals with the origins and meaning of the word logos at great length in Logic: The Question of Truth and The Metaphysical Foundations of Logic. In Being and Time he shares concerning the nature of the word $\lambda$ ó ${ }^{\circ} \varsigma$ as it is used in Greek by Plato and Aristotle; "If we say that the basic meaning of $\lambda$ ó $\gamma$ os is discourse $\{$ Rede\}, this literal translation becomes valid only when we define what discourse itself means. The later history of the word $\lambda$ ó ${ }^{\circ}$, and especially the manifold and arbitrary interpretations of subsequent philosophy, constantly conceal the authentic meaning of discourse-which is

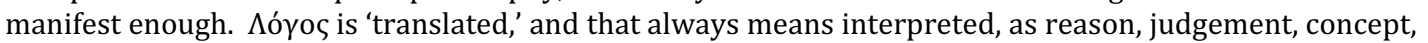
definition, ground, relation. But how can 'discourse' be so susceptible of modification that $\lambda$ ó $\gamma$ os means all the things mentioned, and indeed in scholarly usage? Even if $\lambda$ ó $\gamma$ os is understood in the sense of a statement, and statement as 'judgment,' this apparently correct translation can still miss the fundamental meaning-especially if judgment is understood in the sense of some contemporary 'theory of judgment.' $\Lambda$ ó judgment, in any case not primarily, if by judgment we understand 'connecting two things' or 'taking a position' (by endorsing or rejecting).

"Rather, $\lambda$ ó $\gamma \circ \varsigma$ as discourse really means $\delta \eta \lambda$ ôิv, to make manifest 'what is being talked about' in discourse," Being and Time, 31. This property is part of Dasein; Dasein allows beings to be made manifest. "Furthermore, because $\lambda$ ó ${ }^{\circ}$ ऽ lets something be seen, it can therefore be true or false. But everything depends on staying clear of any concept of truth construed in the sense of 'correspondence' or 'accordance'.... , 31. He also adds, "because the function of $\lambda$ ó $\gamma$ os lies in letting something be seen straightforwardly, in letting

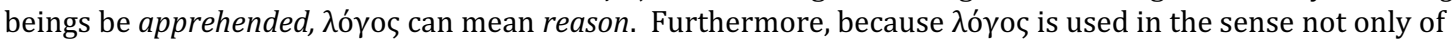
$\lambda \varepsilon$ ' $\varepsilon \mathrm{v}$ but also of $\lambda \varepsilon \gamma$ ó $\mu \varepsilon v o v$ (what is pointed to as such), and because the latter is nothing other than the

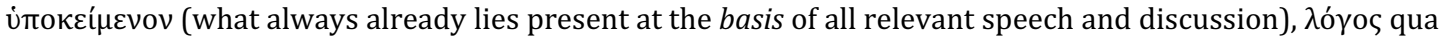
$\lambda \varepsilon \gamma$ ó $\mu \varepsilon v o v$ means ground, ratio. Finally, because $\lambda o ́ \gamma o \varsigma$ as can also mean what is addressed, as something that has become visible in its relation to something else in its 'relatedness,' $\lambda$ ó $\gamma$ os acquires the meaning of relation and relationship," ibid., 32.

${ }^{1046}$ Being is always in a position, a place, of positing or representing things to us, as either percipere or perceptio, as in taking something to oneself, or repraesentare, as in holding something opposite oneself or to hold present to someone, Heidegger, "Kant's Thesis about Being," 343. Where "is" this relationship for Dasein, one might ask? It is in no "one" location. Of course, this means that one can't "locate" this "there" anywhere as such. Analogically, being-there is not a being. As it is only located in the phenomena of a relationship, a profound insight is granted: "Ontology is possible only as phenomenology," Being and Time, 33. Phenomenology, which Heidegger derived from the work of Edmund Husserl, means here simply, " $\dot{\alpha} \pi о \varphi \alpha i ́ v \varepsilon \sigma \vartheta \alpha \iota \tau \grave{\alpha}$ $\varphi \alpha \iota v o ́ \mu \varepsilon v \alpha$-to let what shows itself be seen from itself, just as it shows itself from itself. That is the formal meaning of the type of research that calls itself 'phenomenology.' ... 'To the things themselves!,'” ibid., 32. As such, it is unlike any other -ology of ordinary beings or entities. Utilizing the epoché of Husserl's phenomenological method, it takes the whole as is, as a unity, and <holds > it there in brackets while it studies it free from judgments. For more, see Oded Balaban, "Epoché: Meaning, Object, and Existence," in Phenomenology World-Wide: Foundations, Expanding Dynamics, Life-Engagements: A Guide for Research and Study, ed. Anna- 
must enter into relationships (of different sorts) with Dasein, because Dasein, ontologically

understood, is care (Sorge), it cares for beings. ${ }^{1047}$

However, intrinsic to this being-in-the-world and its care is also a critical realignment and displacement of the classical subject-object relationship. Heidegger interrogatively asks, "for what is more obvious than the fact that a 'subject' is related to an 'object' and the other way around? This subject-object-relation must be presupposed. But that is a presupposition which, although it is inviolate in its own facticity, is truly fatal, perhaps for the very reason, if its ontological necessity and especially its ontological meaning are left in obscurity."1048 For the typical subject-object-relationship is viewed as an external relationship, a relationship that directly pertains to two identifiable entities, e.g., a chair or insect. But Dasein as being-in-the-world is not a "chair" or "insect" as subject, and does not regard the tree as simply an "object." Such an interpretation would rest on a prior assumption of the way in which the subject comes to know the object, about which Heidegger claims history has been silent. ${ }^{1049}$ Dasein is an "inbetween" in its own right, with an attunement toward other beings, but as such, it must ontologically be analyzed prior to any theory of the relationship of subject ${ }^{1050}$ to

Teresa Tymieniecka (Dordrecht, The Netherlands: Kluwer Academic Publishers, 2002), 103-113.

${ }^{1047}$ Heidegger, Being and Time, 57. Therefore, "Dasein is never 'initially' a sort of a being which is free from being-in, but which at times is in the mood to take up a 'relation' to the world. This taking up of relations to the world is possible only because, as being-in-the-world, Dasein is as it is." In like manner, "the saying used so often today, 'human beings have their environment \{Umwelt\},' does not say anything ontologically as long as this 'having' is undetermined. In its very possibility this 'having' has its foundation in the existential constitution of being-in. As a being essentially existing in this way, Dasein can explicitly discover beings which it encounters in the environment, can know about them, can avail itself of them, can have the 'world.' The ontically trivial talk about 'having an environment' is ontologically a problem. To solve it requires nothing less than defining the being of Dasein beforehand in an ontologically adequate way," ibid., 58.

${ }^{1048}$ Heidegger, Being and Time, 59. It must be comprehended that "Dasein has an understanding of its own being at its disposal, no matter how indeterminately that understanding functions. However, no sooner was the 'phenomenon of knowing the world' understood than it was interpreted in an 'external,' formal way. The evidence for this is the interpretation of knowledge, still prevalent today, as a 'relation between subject and object' which contains about as much 'truth' as it does vacuity. But subject and object are not the same as Dasein and world," ibid., 60. Indeed, as is added as a parenthetical footnote, "Certainly not! So little that even putting them together in order to reject this is already fatal," ibid., 60.

${ }^{1049}$ Heidegger, Being and Time, 60. "But in this [external] approach, which has many variations, the question of the kind of being of this knowing subject is completely omitted, though its way of being was always included tacitly in the thematic when one spoke of its knowing. Of course, one is sometimes assured that the subject's inside and its 'inner sphere' is certainly not to be thought as a kind of 'box' or cabinet.' But what the positive meaning is of the 'inside' of immanence in which knowing is initially enclosed, and how the character of being of this 'being inside' of knowing is founded in the kind of being of the subject, about this there is silence."

${ }^{1050}$ Particularly understood here as an "objectized subject" along the lines of how Heidegger sees Kant's own understanding. "It appears as if Kant has abandoned the Cartesian position of the prediscovered isolated subject. But that is only illusion. The fact that Kant requires any proof at all for the 'existence of things 
object. Thus the possibility of the "subject" relating to "objects" in a world out there is where the study of Dasein takes place, not from within the typical subject-object dichotomy.

Thus, as Martta Heikkilä explains, for Heidegger, “Only Dasein has a world ... [and] the existential character of Dasein constitutes the original disclosure of being-in-the-world- the 'there' (da) of Dasein is to be understood as this disclosure (Erschlossenheit)." ${ }^{1051}$ Yet Dasein is always more than what it factually is, as Dasein lives or exists in its future possibilities. However, this living is to be understood as something possible and not something that is actual or factual, as it may be thought of more precisely, Dasein "steps forth" into the world. In this way, it is "ecstatic" and extends outside of itself, ${ }^{1052}$ making a relationship to beings possible. The being of Dasein, which is constituted by beingin-the-world, is itself its "there" or $D a$.

In his published lecture notes, Heidegger further elaborates on it and its connection to consciousness as follows, "Dasein is described as follows: Da-sein. The Da is the clearing and openness of what is, as which a human stands out. Representation, the knowledge of consciousness, is something totally different... Consciousness is only possible on the ground of the $D a$, as a derivative mode of it."1053 In Heidegger's view, Kant, with his idealism of the absolute idea, was satisfied with believing objectivity and that which is represented through consciousness to be properly grounded in representation. Heidegger, however, required a $d a$ wherein consciousness and object 'play,' a clearing of being, in which something present comes to meet something else present. A difference between the presence of things or Dasein allowing things have a presencing of themselves. Thus, the capability of consciousness to transition from objects present Heidegger calls temporality, from which his emphasis on time conceptually emerges, and thus its relationship to Dasein becomes

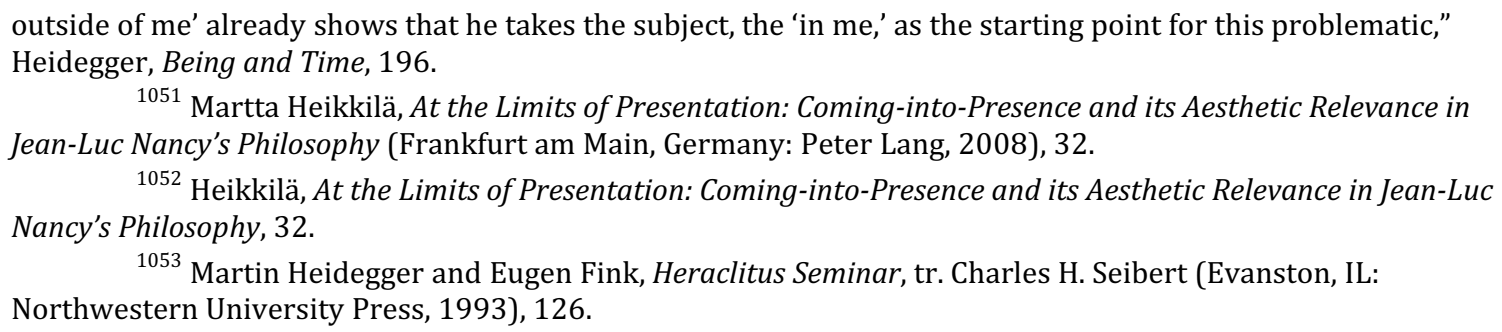


clarified. "Dasein must be called originally and fitly the temporal entity simply as such."1054 As such, "time is the way in which the mind lets itself be given anything at all. It is the most original, universal form of how-something-can-be-given; it is the mind's original, universal self-affection. As the self's way of letting itself be concerned about anything, it is the ontological condition of the possibility of meeting up with anything."1055 Heidegger continues, "this being-affected [Affektion] does not rest on sensation, i.e., is not a character of any empirical intuition, it must be designated 'pure' selfaffection." 1056 Therefore, "temporality is the condition of the possibility of all understanding of being; being is understood and conceptually comprehended by means of time."1057

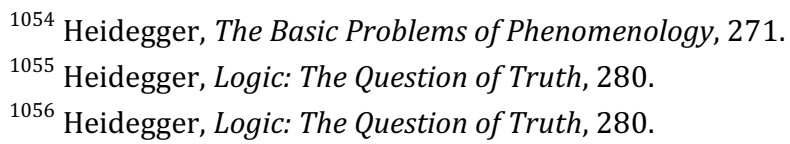

${ }^{1057}$ Heidegger, The Basic Problems of Phenomenology, 274. Heidegger explains at a depth this study need not penetrate the differing levels and meanings of time and temporality in their relationships to Being, Dasein, and beings, ibid., 227-274. In summary, "the essential structure of temporality is the self-enclosed ecstatic-horizonal unity of future, past, and present in the sense explained. Temporality \{Zeitlichkeit\} is the condition of the possibility of the constitution of the Dasein's being. However, to this constitution there belongs understanding of being, for the Dasein, as existent, comports itself toward beings which are not Daseins and beings which are. Accordingly, temporality must also be the condition of possibility of the understanding of being that belongs to the Dasein. How does temporality make such understanding of being possible? How is time as temporality the horizon for the explicit understanding of Being as such, if Being is supposed to be the theme of the science of ontology, or scientific philosophy? In its role as condition of possibility of the understanding of Being, both pre-ontological and ontological, we shall call temporality Temporality \{Temporalität\}, ibid., 274. See also ibid., 256-274, which distinguishes temporality [Zeitlichkeit] from Temporality [Temporalität] from time; and Heidegger, Being and Time, 221-225, 319-354.

For more, see Karin de Boer, "The Temporality of Thinking: Heidegger's Method, from Thinking in the Light of Time: Heidegger's Encounter with Hegel," in Heidegger's Being and Time: Critical Essays, ed. Richard F. H. Polt (Oxford, UK: Rowman \& Littlefield Publishers, 2005), 33-46. As de Boer shares, "it is quite understandable that these different modes of temporality are difficult to distinguish. After all, the Temporality that grounds every understanding of being is itself a specific modification of temporality.... Yet the principle is simple. What Heidegger calls temporality is ultimately nothing more than a kind of construction that makes possible to gain insight into the proper dynamic-divided in and against itself-of life, thinking, and the history of thinking. It is therefore meaningless to ask whether there is such a thing as primordial time. The character of the temporality that concerns Heidegger is in itself such that Present constantly threatens to break away from its juncture with the other temporal ecstasies," ibid., 42. Unfortunately, many Heideggerian scholars, following Heidegger's own words, still often confuse ordinary time with originary time especially so in their relationship to the temporality of Dasein. For example, when it is asserted that "Time is temporality," one might be led to equate them as 1:1. This would be to mistake the difference between ordinary notions of time and the temporality of the Dasein which is to be thought of as a place, yet one which is not in space.

To make sense of this, it must be recalled and understood that temporality involves a situatedness, the

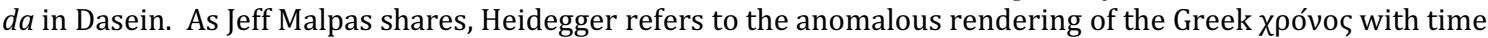

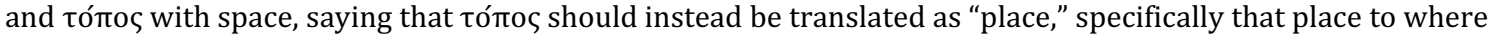
something appertains. He then likens $\chi \rho$ óvoৎ to "the appurtenance of a being to its dwelling place," Jeff E. Malpas, Heidegger's Topology: Being, Place, World (Cambridge, MA: Massachusetts Institute of Technology Press, 2006), 103. See also, Martin Heidegger, Parmenides, tr. André Schuwer and Richard Rojcewicz (Bloomington,

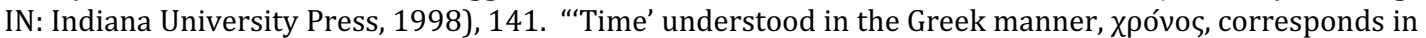

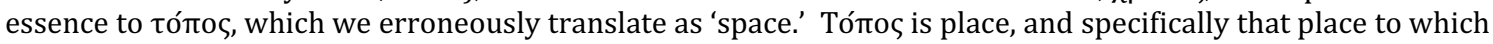

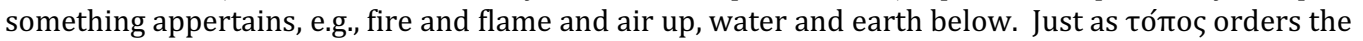


To summarize this study's outline of Heidegger's first steps in his project to discover the

meaning of Being, I quote Heidegger himself:

In our elucidation of the task of ontology the necessity arose for a fundamental ontology which would have as its theme that being which is ontologically and ontically distinctive, namely Dasein. This must be done in such a way that our ontology confronts the cardinal problem, the question of the meaning of Being in general. From the investigation itself we shall see that the methodological meaning of phenomenological description is

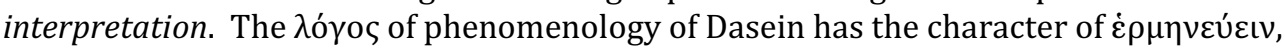
through which the proper meaning of Being and the basic structure of the very being of Dasein are made known to the understanding of being that belongs to Dasein itself. Phenomenology of Dasein is hermeneutics in the original signification of that word, which designates the work of interpretation. But since the discovery of the meaning of Being and of the basic structures of Dasein in general exhibits the horizon for every further ontological research into beings unlike Dasein, the present hermeneutic is at the same time "hermeneutics" in the sense that it works out the conditions of the possibility of every ontological investigation. ${ }^{1058}$

At this point the question must be asked again directly: As it has thus far been developed, how does Heidegger's rethinking of the question of Being relate to or differ from classical metaphysics, especially the ontotheological condition? The answer lies in Heidegger's understanding of the 'timeless' ground that classical metaphysics assumes, the nature of the difference between the ground of Being and beings, and the method of our analysis of their difference and relationship. Although the key to Heidegger's contribution has already been revealed as a radical temporality, for an appreciation of the full significance of the above question in such a way that it will also illuminate the freedom of time-space, it is necessary to directly comment on the "ontological difference," which will also provide a brief reencapsulation of the ontotheological condition of classical metaphysics.

appurtenance of a being to its dwelling place, so $\chi \rho o ́ v o \varsigma$ regulates the appurtenance of the appearing and

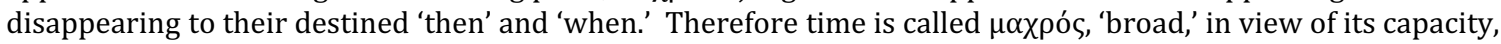
indeterminable by man and always given the stamp of the current time, to release beings into appearance or hold them back. Since time has its essence in this letting appear and taking back, number has no power in relation to it. That which dispenses to all beings their time of appearance and disappearance withdraws essentially from all calculation," ibid. Similarly, "the Greeks have no word for 'space.' This is no accident, for they do not experience the spatial according to extensio but instead according to place (topos) as chöra, which means neither place nor space but what is taken up and occupied by what stands there. The place belongs to the thing itself," Heidegger, Introduction to Metaphysics, 69. Heidegger also shares, "The term 'Dasein' neither takes the place of the term 'consciousness,' nor does the 'matter' designated as 'Dasein' take the place of what we represent to ourselves when we speak of 'consciousness.' Rather, 'Dasein' names that which is first of all to be experienced, and subsequently thought accordingly, as a place-namely, as the locality of the truth of Being." "What the term 'Dasein' means throughout the treatise Being and Time is indicated already by the guiding thesis: 'The "essence" of Dasein lies in its existence, '” Heidegger, "Introduction to 'What is Metaphysics,"' 283.

${ }^{1058}$ Heidegger, Being and Time, 35. 
The necessity of rethinking the previously noted difference between Being (Sein) and beings

(entities or Seiende) constitutes what is often considered Heidegger's foremost transitional insight, referred to as the ontological difference, ${ }^{1059}$ and is worthy of special attention in its own right, even as it will retread some of the concepts already covered. Heidegger asserts that it is the specific rethinking (not merely the identification of the differences between Sein and Seiende) of this difference that classical metaphysics, as ontotheology, could and can not make, and which singularly identifies and leads to his contribution concerning the true nature of Being. One of the leading authorities of Heidegger's works, Joan Stambaugh, summarizes the issues as follows:

For Heidegger, ... thinking is concerned with Being in regard to its difference from beings. Heidegger doesn't ask about Being as the ground of beings; he goes from what is as yet unthought, from the difference between Being and beings as difference (the ontological difference), to that which is to be thought, the oblivion of that difference. The difference is nothing that man has somehow "forgotten." Oblivion belongs intrinsically to difference. Instead of progressing toward an all-inclusive totality, thinking for Heidegger attempts to move forward by the step back into the realm of the essence of truth which has never yet come to light. This step back allows Being as difference to come before thinking without being its object. The step back, which is actually a direction and a manner of thinking and not an isolated step of thought, leads out of metaphysics into the essential origin of metaphysics.

[Classical] metaphysics does not heed the ontological difference as difference. It looks at the different elements of that difference. It sees the difference between Being and beings, but it is concerned primarily with Being as the ground of beings and thus never sees the difference as difference. Heidegger characterizes this difference as the difference between Overwhelming and Arrival. The difference grants a "Between" in which the Overwhelming of Being and the arrival in beings are held toward each other and yet held apart. This Between is perdurance [a holding out]. In the perdurance of the difference of Overwhelming and Arrival reigns clearing. In a conversation about the meaning of clearing, Heidegger stated that clearing is the (non-metaphysical) presupposition for revealing and securing. It is the most fundamental presupposition for anything to be or to happen at all... The problem here is that the concepts of metaphysics: Being-beings, ground-what is grounded, are no longer adequate to express the thinking which takes

${ }^{1059}$ Absent as a phrase in Being and Time, it is still there conceptually, ibid., 8-13, 220. For other significant definitions and discussion, see Heidegger, The Basic Problems of Phenomenology, 227-330; Heidegger, Nietzsche Vols. 3 \& 4, 150-158; and Heidegger, Identity and Difference, which constitutes his most direct elucidation of the issue. For secondary discussions on this major point of Heidegger's work, see, Slavoj Žižek, The Parallax View (Cambridge, MA: Massachusetts Institute of Technology Press, 2006), 23-24. Not surprisingly, it is on this point that many of the criticisms of Heidegger begin, for example, see Cristina Lafont, Heidegger, Language, and World-Disclosure, tr. Graham Harman (Cambridge, UK: Cambridge University Press, 2000), 179-288. Lafont demonstrates how far reaching the ontological difference extends in Heidegger's thought, encompassing essentially every element of his project, even into issues such as the status of $a$ priori and a posteriori knowledge and its relationship to language, something which she critically examines and challenges. 
place in the realm reached by the step back. These concepts name what is different, they are unable to name the difference itself. ${ }^{1060}$

What is said to be revealed here by Stambaugh is a pattern of thinking that developed early on in the history of philosophical reflection that contains an elusive element, the unthought difference between Being and beings. And it is this difference which eventually exposes what would become Heidegger's conception of time-space as the site of meaning of Dasein. Thus it is now that time-space may be described.

As Heidegger's thinking developed, he proceeded from an analytic of Dasein as being-in-theworld temporally to focus more on the meaning of Being itself, of which Dasein is privileged to have access. Of course, technically these are separate questions. Within both of them, however, remains the core concern of the experience of Being. "In the Heideggerian perspective, the ultimate goal of Dasein's existence is the experiencing of Being. He is transcendence by his very nature and has a destiny that goes beyond his everyday concerns. Dasein is not merely called to be a being-in-theworld, but is destined to be a being that is open to Being."1061 The 'site' through which this all happens is called time-space, the arena where our temporal experiencing of existence takes place, including our encounter with the truth of who we are-noting here that 'truth' and 'true things' are not the same. ${ }^{1062}$ "Fortunately," as Peter Dillard explains, "it is not necessary to determine the exact nature of time-space in order to see why Heidegger thinks that an insight into the relation between truth and time-space deconstructs all metaphysics in a single stroke or 'leap,' as he calls it." 1063

\footnotetext{
${ }^{1060}$ Joan Stambaugh, "Introduction," in Identity and Difference, 16-18. She adds, "Heidegger leaves us with the question: do our Western languages have an intrinsic metaphysical structure so that they are forever destined to be onto-theo-logical in their nature or do they harbor other possibilities of thinking?," ibid., 18.

${ }^{1061}$ Vensus A. George, The Experience of Being as Goal of Human Existence: The Heideggerian Approach (Washington D. C.: Council for Research in Values and Philosophy, 2000), 17.

1062 Miguel de Beistegui, The New Heidegger (New York, NY: Continuum, 2005), 80-81. See also Heidegger, Contributions to Philosophy (of the Event), 294.

${ }^{1063}$ Peter S. Dillard, Non-Metaphysical Theology After Heidegger (New York, NY: Palgrave Macmillan, 2016), 37. Essentially, for Heidegger, the fact that humans 'think' about and are influenced by the distant past and orient their present actions to accomplish far distant future goals (that might impact their grandchildren and beyond), is not reflected anywhere else in nature, the animal kingdom (though some dispute this for certain higher mammals), or anywhere in any physicist's understanding of 'time,' which remains very one-dimensional. Thus, for Heidegger, the four dimensions refer to the past, the present 'place,' the ecstatic-shining present of self-awareness, and the future. Thus, when Heidegger says 'nature has no time,' this is what he means. It is a philosophical argument for 'human' exceptionalism.
} 
For Heidegger, the manifestation of Being, the 'irrupting event' or Ereignis of Being, takes place as history in a time-space play room. ${ }^{1064}$ Within this play, which has no reason or 'why,' Being grants Dasein access to itself and the world. That is, "man is not the lord of the beings, but the shepherd of Being." ${ }^{1065}$ The giving that gives time brings together the past, present, and future into one unity. The "future, past and present" "belong together in the way they offer themselves to one another." ${ }^{1066}$ With their "presencing, there opens up what we call time-space. But with the word 'time' we no longer mean the succession of a sequence of nows. Accordingly, time-space no longer means merely the distance between two now-points of calculated time, such as we have in mind when we note, for instance: this or that occurred within a time-span of fifty years." Rather, "time-space now is the name for the openness which opens up in the mutual self-extending of futural approach, past and present." ${ }^{1067}$ That is to say, their openness "provides the space in which space as we usually know it can unfold. The self-extending, the opening up, of future, past and present is itself prespatial; only thus can it make room, that is, provide space"1068 or locality. Time is prior to and privileged over space, ${ }^{1069}$ and the question of the speed of time does not occur in any absolute or uniform way. ${ }^{1070}$

Hence, "time-space as commonly understood, in the sense of the distance measured between two time-points, is the result of time calculation. In this calculation, time represented as a line and parameter and thus one-dimensional is measured out in terms of numbers. The dimensionality of time, thought as the succession of the sequence of nows, is borrowed from the representation of three-dimensional space." However, this common assumption is an error, as "prior to all calculation of time and independent of such calculation, what is germane to the time-space of true time consists

\footnotetext{
1064 George, The Experience of Being as Goal of Human Existence: The Heideggerian Approach, 153.

1065 Martin Heidegger, as cited in Sebastian Alackapally, Being and Meaning: Reality and Language in Bhartrhari and Heidegger (Delhi: Motilal Banarsidass, 2002), 149.

${ }^{1066}$ Martin Heidegger, On Time and Being, tr. Joan Stambaugh (Chicago, IL: The University of Chicago Press, 2002), 14.

${ }^{1067}$ Heidegger, On Time and Being, 14.

1068 Heidegger, On Time and Being, 14.

${ }^{1069}$ Michael Eldred, A Question of Time (North Charleston, SC: CreateSpace, 2015), 164-170.

1070 John Urry, "Speeding Up and Slowing Down," in High-speed Society: Social Acceleration, Power, and Modernity, eds. Hartmut Rosa and William E. Scheurman (University Park, PA: The Pennsylvania State University Press, 2009), 188.
} 
in the mutual reaching out and opening up of future, past and present. Accordingly, what we call dimension and dimensionality in a way easily misconstrued, belongs to true time and to it alone. ${ }^{1071}$ Thus, true time is seen as the only authentic dimension, not "as the area of possible measurement, but rather as reaching throughout, as giving and opening up."1072

Heidegger thus believed that "existence is temporal: here time is no measure (something like numbers in history, dates), but instead existence has in itself this specific stretch, this temporality, that on the basis of the anticipation of something futural, that is placed in [its] care, it also takes care of its past and thereby brings itself into the present." Thus, "past-present and future are not dimensions shoved next to one another, but instead determine the how of existence in a unitary way." ${ }^{1073}$ In contrast to Descartes, with whom was a "concern for the idea of science" which "shapes a specific ontology which is clung to as the sole possibility of interrogating existence," this "tendency [is instead] towards burying existence itself." 1074 Rather, for Heidegger "historicity is a basic determination of existence itself,"1075 which is to say, existence always contains "a temporal stretch between birth and death." Any "care about certainty [of a scientific sort] is at the same time a concern that temporality remain absent,"1076 if it were tied into the concept of the meaning of Dasein's existence itself. Thus, Heidegger's conception of time-space includes an internal pre-spatial stretch or spannedness, within which “the space or 'span' opened up by the 'now's' simultaneous relation to both past and future" then becomes the essential feature of existence. ${ }^{1077}$ In Heidegger's words

\footnotetext{
${ }^{1071}$ Heidegger, On Time and Being, 14. See also, Schatzki, The Timespace of Human Activity, 65.

1072 Heidegger, On Time and Being, 15.

${ }^{1073}$ Heidegger, Introduction to Phenomenological Research, 242. "Temporality is stretch itself,"
} Heidegger, The Basic Problems of Phenomenology, 270. Edward Echeverria further explains, "Heidegger draws a distinction between the sense of the past as Vergangenheit, a state of affairs where some entity once present is gone for good, and the sense of the past as Gewesenheit, a 'having been' which still conditions the 'is'. Man is a historical being with a past in the sense of Gewesenheit, and this past, a 'having been', is an essential aspect of 'what' Dasein is and will be. By introducing these two different senses of the past, Heidegger seeks to restore a positive relation to the historical past, one that does not make the 'presence' of the subject alien to history," Echeverria, Criticism and Commitment: Major Themes in Contemporary 'Post-critical' Philosophy, 177.

${ }^{1074}$ Heidegger, Introduction to Phenomenological Research, 219.

1075 Heidegger, Introduction to Phenomenological Research, 218.

${ }^{1076}$ Heidegger, Introduction to Phenomenological Research, 216-217. Hence, "care about certainty diverts every question about being into a question about being-an-object for science," ibid., 217.

${ }^{1077}$ McMullin, Time and the Shared World: Heidegger on Social Relations, 118. See also Schatzki, The Timespace of Human Activity, 42-63. 
"expressed time, the now, is dimensionally future and past... each now stretches itself out as such, within itself, with respect to the not-yet and the no-longer. The transitory character of each now is nothing but ... the spannedness of time..1078 That is to say, the being of time possesses both an absence and presence; the past and future are absent, yet present. ${ }^{1079}$

In summary, Heidegger's conception of time-space was conceived in direct contradistinction to that of the legacy of time in science which culminated in space-time, but was also present in all prior understandings of 'temporality' which he saw as 'vulgar' sequentiality. The entire ontotheological edifice of classical metaphysics is undone, in Heidegger's mind, by his radical emphasis on the unique temporality of the human being's access to reality, through Being, which underlies it. The human being is seemingly alone in its privileged three-dimensional temporality, in contrast to other animals, and nature understood scientifically, and thus capable of uniquely entering into time-space spans.

The remaining issue concerns the implications of what time-space means for the concept of freedom, which, while already intimated at in the above, will now be examined directly.

\section{Where's Freedom?}

The question one may have is, what does Heidegger hope to attain through his conception of time-space? Of what use is it, and how does it impact upon his conception of freedom, particularly its where of existence?

Peter Dillard, for one, believes that Heidegger's time-space seems to provide the conceptual apparatus to counteract the problem that "if there were only the interplay of past and future giving rise to the present, then nothing would prevent every present from happening immediately, allowing for no succession of presents and the decisions associated with them. In short, all of time would be

${ }^{1078}$ Heidegger, The Basic Problems of Phenomenology, 273-274.

${ }^{1079}$ Gregory B. Smith, Martin Heidegger: Paths Taken, Paths Opened (Lanham, MD: Rowman \& Littlefield, 2007), 80, 90. See also, Michael Eldred, The Digital Cast of Being: Metaphysics, Mathematics, Cartesianism, Cybernetics, Capitalism, Communication (Lancaster, UK: Gazelle Books, 2009), 56; and Martin Heidegger, Introduction to Philosophy-Thinking and Poetizing, tr. Phillip Jacques Braunstein (Bloomington, IN: Indiana University Press, 2011), 51. "Every present moment is an ambiguous ambiguity. If we only search in the present for that which is, we will never find it, because what is present remains ambiguous, and this ambiguity stems directly from what exceeds the present and exists more so than does the present," ibid., 51. 
given at once," reflecting a timeless ontology. ${ }^{1080}$ Within Heidegger's account, then, other themes, like truth, emerge as the temporary stabilization of a particular present, or historical epoch, through the working out of future possibilities latent in past potentials. ${ }^{1081}$ Or, as Frank Schalow argues, Heidegger's "temporality comes into its own by granting a place and by introducing through it an expanse of possibility, what Heidegger ... describes as 'time-space."' Thus, "in the temporal moment" a "projection of what can be is always the fruition of what already is: freedom and necessity intersect," and "in this regard, Heidegger's view of freedom resembles more the Christian emphasis on the gathering and dispersion of possibilities through logos than the existentialist deification of choice for its own sake."1082 Others, such as Daniela Vallega-Neu, emphasize the importance of other issues Heidegger addresses, such as the fact that "Heidegger embraces errancy as part of what occurs in the clearing," noting that "errancy needs to be sharply distinguished from falsity, a notion that presupposes truth as correctness" rather than truth as part of the 'care' mode of the relationality within the being of Dasein. ${ }^{1083}$ In all of the above accounts, one can see that freedom plays a critical role. Heidegger himself wrote a surprising amount about freedom, most of which cannot be explored here. Nevertheless, a few of his comments will prove insightful.

Heidegger begins his most notable discussion about freedom in The Essence of Human Freedom (1930) by noting that it is an introduction to philosophy, and as such contains a unique object as its subject: Man and his freedom. ${ }^{1084}$ Heidegger observes that "freedom is not some particular thing among and alongside other things." ${ }^{1085}$ Tracing the modern problem of human freedom to Kant,

${ }^{1080}$ Dillard, Non-Metaphysical Theology After Heidegger, 37. Dillard suggests that perhaps "Heidegger is suggesting that space, unlike the things occupying it, is in some sense given all at once. Thus, within the unitary phenomenon of time-space, the feature of being given all at once is allocated to space, leaving the time open to become articulated into a succession of distinct presents emerging from the interplay between past and future," ibid., 37.

1081 Dillard, Non-Metaphysical Theology After Heidegger, 37.

${ }^{1082}$ Schalow, Heidegger and the Quest for the Sacred: From Thought to the Sanctuary of Faith, 124.

1083 Daniela Vallega-Neu, Heidegger's Poietic Writings: From Contributions to Philosophy to The Event (Bloomington, IN: Indiana University Press, 2018), 83. Errancy here means the possibility of error from the true. It is possible not to be accurate only if this is indeed possible-the being of Dasein allows this possibility.

${ }^{1084}$ Heidegger, The Essence of Human Freedom, 1. "We shall be considering man and not animals: not plants, not material bodies, not the products of craft and technology, not works of art, not God, but man and his freedom," ibid., 1.

${ }^{1085}$ Heidegger, The Essence of Human Freedom, 93. 
Heidegger asserts that for Kant, the problem of freedom was conceived within its relationship to causality, such that the traditional understanding of the being of beings was in accord with "traditional metaphysics," where the "fundamental category of being as being-present" (timelessly) was assumed. ${ }^{1086}$ If this is not the case, however, and "causality is a problem of freedom" rather than freedom a problem of causality, then "the problem of being in general is in itself a problem of freedom."1087 Thus, although classical philosophy viewed the "problem of being" as the "fundamental problem of philosophy as such," with freedom a later consideration, ${ }^{1088}$ for Heidegger this is reversed. "The question concerning the essence of human freedom is the fundamental question of philosophy, in which is rooted even the question of being." ${ }^{1089}$ This is a surprising statement to one familiar with Heidegger's Being and Time, where freedom is not extensively explored. It seems Heidegger, by following the leading question of Being, has now moved toward what grounds it, which is really an Abgrund, or abyss, creating the possibility of freedom. Thus, "the question concerning the essence of freedom is the fundamental problem of philosophy, even if the leading question thereof consists in the question of being." ${ }^{1090}$

Heidegger must acknowledge that he is unable to show how it may be so that causality is a problem of freedom, and not the reverse. Yet this is his thesis and the situation he faces. ${ }^{1091}$ As such, in "fixing the direction of our inquiry," "we must possess the diversity and breadth of a horizon. In respect of freedom," "we can establish, concerning the fundamental direction of our essential

\footnotetext{
${ }^{1086}$ Heidegger, The Essence of Human Freedom, 203. Being, as presence, represents constancy. Again, Heidegger explains "The interpretation of the Kantian problem of freedom was necessary because we recognized that, in the metaphysical tradition, the question of freedom concerns a particular kind of causality. Kant treats the problem of causality as such, as well as the problem of freedom as a particular kind of causality, in a more radical manner than anyone else. Once the problem of freedom is understood in a metaphysical sense, controversy with Kant is not only unavoidable, but must stand in the forefront. Once freedom is understood as a metaphysical problem, the question is already raised as to whether freedom is a kind of causality, or whether, on the contrary, causality is a problem of freedom," ibid., 203.

${ }^{1087}$ Heidegger, The Essence of Human Freedom, 203.

${ }^{1088}$ Heidegger, The Essence of Human Freedom, 203.

${ }^{1089}$ Heidegger, The Essence of Human Freedom, 203.

${ }^{1090}$ Heidegger, The Essence of Human Freedom, 205.

${ }^{1091}$ Heidegger, The Essence of Human Freedom, 204. Heidegger admits that his "basic thesis, which we have seemingly forced into philosophy by violent means, is not a statement that can be theoretically proven by the limited methods of a science. For it says nothing at all about anything present. To be sure, it says something about essence. But essence is not capable of straightforward examination. Essence remains closed off to us as long as we ourselves do not become essential in our essence," ibid., 204.
} 
questioning"1092 that "the essence of freedom only comes into view if we seek it as the ground of the possibility of Dasein, as something prior even to being and time."1093 This in effect repositions the entire situation concerning freedom, wherein "what now emerges is that the problem of freedom is not built into the leading and fundamental problems of philosophy, but, on the contrary, the leading question of metaphysics is grounded in the question concerning the essence of freedom." ${ }^{1094}$ This makes Kant's connection of freedom within a framework of causality irrelevant; on the contrary, as noted above, causality is a problem of freedom. ${ }^{1095}$ Therefore, "if we are seeking out freedom as the ground of the possibility of existence, then freedom must itself, in its essence, be more primordial than man." ${ }^{1096}$ This means that "man is only an administrator of freedom, i.e., he can only let-be the freedom which is accorded to him, in such a way that, through man, the whole contingency of freedom becomes visible." 1097 To echo an earlier comment, "man is not the lord of the beings, but the shepherd of Being,"1098 holds true for freedom as well-man is not the lord of Kantian or spontaneous 'timeless' freedom, but a shepherd of the freedom given him by an irruption of Being's temporality. Of course, it must be pointed out here that Heidegger is elucidating what he considered to be the prior conditions of possibility for the existential aspect of freedom, in contrast to what might be called simply ethical or

${ }^{1092}$ Heidegger, The Essence of Human Freedom, 93.

${ }^{1093}$ Heidegger, The Essence of Human Freedom, 93.

${ }^{1094}$ Heidegger, The Essence of Human Freedom, 93.

1095 Heidegger, The Essence of Human Freedom, 93. "But if our essential questioning must take this direction, if the fundamental problem of philosophy must be viewed from this perspective, then it is irrelevant whether Kant was correct to interpret freedom within the framework of causality. Even if he was not correct in this, still, according to the new thesis, causality, movement, and being as such, are grounded in freedom. Freedom is not some particular thing among and alongside other things, but is superordinate and governing in relation to the whole," ibid., 93.

${ }^{1096}$ Heidegger, The Essence of Human Freedom, 93.

${ }^{1097}$ Heidegger, The Essence of Human Freedom, 93. "Human freedom is the freedom that breaks through in man and takes him up unto itself, thus making man possible. If freedom is the ground of the possibility of existence, the root of being and time, and thus the ground of the possibility of understanding being in its whole breadth and fullness, then man, as grounded in his existence upon and in this freedom, is the site where beings in the whole become revealed, i.e., he is that particular being through which beings as such announce themselves," ibid., 93-94.

${ }^{1098}$ Heidegger, as cited in Alackapally, Being and Meaning: Reality and Language in Bhartrhari and Heidegger, 149. 
moral freedom, ${ }^{1099}$ or even freedom of the will. ${ }^{1100}$ Heidegger reveals the necessity of a multidimensionality for freedom, as well as time-free will itself depends upon a certain prior configuration of freedom in relationship to time. ${ }^{1101}$

All of the above comments by Heidegger about freedom are also connected to his conception of time-space. Heidegger wrote that "time-space is grounded as the site of the moment for the decision" of Dasein. ${ }^{1102}$ “Time-space ... possesses nothing of 'time' and 'space' in themselves as ordinarily understood," "yet it does contain a development toward these, indeed in a greater richness than could previously arise through the mathematization of space and time."1103 Heidegger actually suggests that it is Dasein's ability to conceal itself in a "self-withholding" that allows for the opening of time-space, and that this is a "god" like feature. ${ }^{1104}$ Time-space is where Dasein encounters the truth of its existence, where it makes choices that determine what it is to be. Concerning the concept of god and time-space, Heidegger suggested that "God-lessness is the blockage of the time-space of an appearance of a divine realm."1105 If there were any 'god,' then it could only appear through the

\footnotetext{
${ }^{1099}$ For Heidegger, "Existence as understanding of Being is letting-be: freedom," and thus "the lettingbe in comportment toward beings in the midst of beings is freedom (not ethically!-letting-be). There is freedom only out of and as liberation. According to its essence, the liberation to freedom can be guided only by that toward which it properly liberates, thus by existence and by what has the priority therein-the understanding of Being and what manifests itself in this understanding. Only if the issue is Being in the understanding of Being and in its sovereignty can this liberation to the freedom of existence occur," Martin Heidegger, The Beginning of Western Philosophy: Interpretation of Anaximander and Parmenides, tr. Richard Rojcewicz (Bloomington, IN: Indiana University Press, 2015), 70-71.

1100 That is, we cannot choose to have free-will-there is something about existence which makes this possible in itself-we inherit and inhabit this reality by virtue of being what we are. It is upon this prior question where Heidegger's focus is located. "Only because this being is, in its essence, defined by selfhood can it, in each case, as factical, expressly choose itself as a self. The 'can' here includes also its flight from choice. What then is implied by this possibility grounded in selfhood, this possibility of choosing oneself expressly or of fleeing the choice? What essentially is concomitantly chosen in the express choice of oneself?" "Here, however, is the origin of 'possibility' as such. Only through freedom, only a free being can, as transcending, understand being-and it must do so in order to exist as such, i.e., to be 'among' and 'with' beings." Absent this choice, it must be pointed out that "only a free being can be unfree." Therefore, "here we also have to remove freedom from the traditional perspective where emphasis is placed on self-initiating spontaneity, sua sponte, in contrast to a compulsive mechanical sequence," Heidegger, The Metaphysical Foundations of Logic, 189-191; 192.

${ }^{1101}$ Heidegger, The Metaphysical Foundations of Logic, 191-192.

${ }^{1102}$ Heidegger, Contributions to Philosophy (of the Event), 301.

${ }^{1103}$ Heidegger, Contributions to Philosophy (of the Event), 305.

${ }^{1104}$ Heidegger, Contributions to Philosophy (of the Event), 302-303. See also, Martin Heidegger, Mindfulness, tr. Parvis Emad and Thomas Kalary (New York, NY: Continuum, 2006), 81.

${ }^{1105}$ Martin Heidegger, The Event, tr. Richard Rojcewicz (Bloomington, IN: Indiana University Press, 2013), 74.
} 
freedom accorded by time-space. Of course, Heidegger uses "time-space" at times in two different ways. First as the opening of a clearing where Dasein makes decisions, and second as a more expansive statement on the transitions of philosophical paradigms, which includes the function or appearance of any god-at times these meanings intersect. ${ }^{1106}$ That is to say, a Dasein can commit itself through its decisions to a new paradigm. ${ }^{1107}$

For Heidegger, "freedom is not somehow the 'essence' of be-ing as though be-ing could be classified and subordinated to 'freedom,' but rather 'freedom' sways in and as be-ing."1108 Accordingly, "in the 'free-play of the time-space' of be-ing, philosophy risks the truth of be-ing. Thus philosophy neither belongs to gods nor man, it is neither something that grows out of the earth nor is it a product of the world: It is the midpoint in the intersection of all beings." A place where "neither calculation nor empty hope can sustain" any crossing into time-space, ${ }^{1109}$ as time-space is the fullness of the ecstatic clearing, "the opening of Being itself," and "not the wherein of beings."1110

Thus, Being, which is only understood and conceptually comprehended by means of time, ${ }^{1111}$ has a special relationship to our ability to reason and engage a world at all, for such is possible only by means of freedom. ${ }^{1112}$ Heidegger reasons that an "account of laws governing thinking pushes us back

${ }^{1106}$ Heidegger, The Event, 64. "History is not merely in transit to another age within the previous timespace of metaphysics; on the contrary, time-space itself is becoming other, inasmuch as it is only now being illuminated in its essence as Da-sein," ibid., 64.

${ }^{1107}$ Heidegger, Mindfulness, 17, 78. "Be-ing itself is the en-owning of this decision and its 'free-play of time-space,"' ibid., 78.

${ }^{1108}$ Heidegger, Mindfulness, 84. To emphasize some of his concepts, Heidegger 'played' with his terminology at times. Here, 'be-ing' emphasizes the nonstatic nature of being.

${ }^{1109}$ Heidegger, Mindfulness, 32. See also Heidegger, Basic Questions of Philosophy: Selected 'Problems' of Logic', 132 .

${ }^{1110}$ Heidegger, Schelling's Treatise on the Essence of Human Freedom, 188. See also, Martin Heidegger, The History of Beyng, tr. Jeffrey Powell and William McNeill (Bloomington, IN: Indiana University Press, 2015), $105,49$.

1111 "[Time] is the condition of possibility of the fact that there is Being (not entities). Time does not have the kind of being of any other thing; rather, time \{constantly\} unfolds \{zeitigt\}. And this unfolding constitutes the temporality of time.... But the difficulty in apprehending time goes hand-in-hand with the peculiar temporality of time itself: the fact that first and foremost time conceals itself and gets recognized only in and as the non-authentic forms it takes," Heidegger, Logic: The Question of Truth, 338; Heidegger, The Basic Problems of Phenomenology, 274; and "The primordial ontological ground of the existentiality of Dasein ... is temporality," Heidegger, Being and Time, 224.

${ }^{1112}$ Heidegger shares that the "result of a philosophical effort has a character fundamentally different from the acquisition of particular sciences. To be sure, philosophizing-and it especially-must always proceed through a rigorous conceptual knowledge and must remain in the medium of that knowledge, but this knowledge is grasped in its genuine content only when in such knowledge the whole of existence is seized by 
into the question of the conditions of their possibility. How must that being which is subject to such laws, Dasein itself, be constituted so as to be able to be thus governed by laws?"1113 His answer is clear: "Obligation and being governed by law, in themselves, presuppose freedom as the basis for their own possibility. Only what exists as a free being could be at all bound by an obligatory lawfulness. Freedom alone can be the source of obligation. A basic problem of logic, the lawgovernedness of thinking, reveals itself to be a problem of human existence in its ground, the problem of freedom." 1114

As Heidegger attempts to articulate the relationship of how logic and metaphysics are grounded in the understanding-of-being that is determined by the ontological difference, he can only assert that if the operation of cognition through the principles of logic toward attaining truth are "grounded in the principle of ground, this means these ground principles too can only be interpreted from out of the ground of ground, i.e., from freedom, and that means from temporality."1115 With this, the concepts of logic, freedom, and temporality are closely linked. When this concept is grasped, we can appreciate Heidegger's remark that "the whole of Kant's Critique of Pure Reason is a circling around the problem of transcendence-which in its most primordial sense is not an epistemological problem, but the problem of freedom."1116 Indeed, a view such as Kant's understands the problematic entirely different from Heidegger. For Kant, freedom is essentially an epistemological problem; for Heidegger, it is ontological. "Being-in-the-world must also be primordially bound up with or derived from the basic feature of Dasein's existence, namely, freedom." For, Heidegger continues, "only where there is freedom is there a purposive for-the-sake-of, and only here is there world. To put it briefly, Dasein's

the root after which philosophy searches-in and by freedom," Heidegger, The Metaphysical Foundations of Logic, 18.

1113 Heidegger, The Metaphysical Foundations of Logic, 19.

${ }^{1114}$ Heidegger, The Metaphysical Foundations of Logic, 19-20.

${ }^{1115}$ Heidegger, The Metaphysical Foundations of Logic, 219. See also, Shirley, Heidegger and Logic: The Place of Lógos in 'Being and Time', 116.

${ }^{1116}$ Heidegger, The Metaphysical Foundations of Logic, 164-165. As such, "Heidegger saw that the constraints on thought imposed by classical or traditional logic ('a court of justice, established for all eternity,' of which the principle of non-contradiction was the cornerstone, were unacceptable," Brenner, Logic in Reality, 242. 
transcendence and freedom are identical! Freedom provides itself with intrinsic possibility; a being is, as free, necessarily in itself transcending."1117

In summary, the concepts of freedom and time-space were important to Heidegger, becoming more prominent in the post-Being and Time period of his thinking. To answer the question of where freedom is located in Heidegger's perspective, one must say that it is located in Being, yet appears only (so far as we are aware) in man, who administrates or shepherds it within his own time-space, but does not control it, as if it were merely a possession. Freedom is fundamentally temporal in nature, simultaneously interacting with the past, present, and future. It is not accessible to standard science and its methods, nor has any meaningful dependence upon or a relationship to nature understood scientifically. That is to say, freedom is located elsewhere or nowhere in relation to Einstein's all inclusive space-time ${ }^{1118}$ which so dominates popular views of contemporary physics and mainstream philosophy, including evolutionary progression (a renewed form of the Newtonian moving now-line) in cosmologic theories, that any overstatement on this point would prove difficult.

${ }^{1117}$ Heidegger, The Metaphysical Foundations of Logic, 185.

${ }^{1118}$ Michael Eldred helpfully interprets Heidegger as follows: "The mind (voûs) is the same as the presencing and absencing of presents as such through which presents come to light and so are $\pi \varepsilon \varphi \alpha \tau(\sigma \mu \varepsilon \dot{v o v}$. The temporally ecstatic play of presencing and absencing needs mind that is open to such a play to present itself as such. Otherwise the play of presencing and absencing is not, i.e. has no spectator and witness. Conversely, minding is only possible within open, three-dimensional, 'pre-spatial' (vorräumlich) time-space, for the mind can only bring to light that which presents itself somehow in the time-clearing."

"The pre-spatiality of the mind in its sameness with the time-clearing implies, in particular, that minding is not tied to the sensuously present in its physical, material apartness and extension, and can even be pre-occupied with a non-sensuous space, such as in the case of geometry. Indeed it can be said that much occurs without taking place. For instance, all the thoughts of a conceptual nature that occur to you have no place. Even more than that, the time-clearing itself is nowhere; it is no 'where' at all. Thus, in its sameness with the time-clearing, the mind is also no 'where' at all. Here, 'mind' does not mean the seat of rationality or cognition, but the openness to and identification with the time-clearing per se in attuned understanding, so that it encompasses also that which is traditionally called 'soul.' Hence neither mind nor soul are located in the body; rather, the human body, for as long as it lives, takes part in the soul, i.e. the time-clearing, that animates, i.e. enlivens it. Individual mortals enter and leave the time-clearing-that's life. Conversely, any thing that is somewhere, i.e. extended, must present itself in the time-clearing to be at all. This implies that the time-clearing is prior to world."

"The open, three-dimensional time-clearing is the same as the mind for which humans, to be human beings, are used and into which each individual human being is cast, to which each is exposed and in which each is immersed, where beings qua beings present and absent themselves for the mind. Each individual exposed to this play of presencing and absencing in the temporal clearing of mind has its own individual perspective on the play. The individuality of the viewing angles, e.g. my very own (jemeinig) and your very own (jedeinig) perspective, for the play of presencing and absencing is the originary splintering of truth conceived as disclosure, so to speak, the atomic fission of truth into individual atoms. Minding is 'for the sake of' beings' temporal presencing and absencing in the time-clearing, which is being's medium. Being 'is' ecstatic time. Without this open time-clearing for the presentation for beings, there would be no minding (vociv), nothing minded/thought (vón $\mu \alpha$ ), no mind (voûs) whatever," Eldred, A Question of Time, 145-146. 


\section{Heidegger's Influence Upon Theology}

As Steven M. Rosen noted, "when philosophy is practiced in the fashion of a Martin Heidegger, its original scope becomes evident. Issues of ultimate meaning are addressed that are intimately linked to the central issues of religion." ${ }^{1119}$ Correspondingly, Heidegger's relationship to and influence upon theology requires a brief exploration of his writings. Thus far, numerous studies have fruitfully examined the relationship of Heidegger's primary writings to religion and theology, ${ }^{1120}$ a topic of which Heidegger's major written works frequently allude, but almost always only indirectly (that is, he makes numerous references to "God" but never attempts to do any proper theology). ${ }^{1121}$

Despite Heidegger's reticence to undertake any systematic treatment of the topic of theology proper, several of his early lecture notes which are now published elaborate quite extensively on the phenomenology of religious life as seen and interpreted through the early Christians through his reading of Paul's writings and several church fathers. ${ }^{1122}$ A perusal of them may prove illuminating, so far as showing how others, either implicitly or explicitly, have meaningfully appropriated Heidegger's insights for theological purposes. In his early notes, Heidegger considered the concept of "factical life experience" ${ }^{1123}$ fundamental for the Christian, going so far as to say that "Christian

${ }^{1119}$ Rosen, Science, Paradox, and the Moebius Principle, 185.

${ }^{1120}$ For example, John R. Williams, Martin Heidegger's Philosophy of Religion (Canadian Corporation for Studies in Religion, 1977); John D. Caputo, The Mystical Element in Heidegger's Thought (New York, NY: Fordham University Press, 1990); John D. Caputo, Demythologizing Heidegger (Bloomington, IN: Indiana University Press, 1993); Benjamin D. Crowe, Heidegger's Phenomenology of Religion: Realism and Cultural Criticism (Bloomington, IN: Indiana University Press, 2008); and Ben Vedder, Heidegger's Philosophy of Religion: From God to the Gods.

${ }^{1121}$ George Kovacs bemusedly comments that a meaningful analysis of the place of "God" in Heidegger's writings is inhibited because "perhaps there are too many references to God in Heidegger's works. If the total number of references to this problem were counted, we might be surprised to see how often and in how many ways the problem of God and the question about the Holy enter. ..", in George Kovacs, The Question of God in Heidegger's Phenomenology, 21.

${ }^{1122}$ Heidegger, The Phenomenology of Religious Life. This work was not made available publicly in German until 1995, so many earlier examinations of Heidegger's religious views by commentators were not complete. Also, it is obviously clear that Heidegger's views on religion significantly evolved throughout his life, from an early Catholic background to Lutheranism to a general atheism during and following his time supporting the National Socialist Party.

${ }^{1123}$ Heidegger, The Phenomenology of Religious Life, 6-7. This phrase appears to be a precursor to his later concept of 'Dasein.' 'The problem of the self-understanding of philosophy has always been taken too lightly. If one grasps this problem radically, one finds that philosophy arises from factical life experience. And within factical life experience philosophy returns back into factical life experience. The concept of factical life experience is fundamental. The designation of philosophy as cognitive, rational comportment says nothing at all; with this designation, one falls prey to the ideal of science, thus obscuring precisely the main difficulty.

"What is called 'factical life experience?' 'Experience' designates: (1) the experiencing activity, (2) that 
religiosity lives temporality,"1124 and that the question of religious life as such can only be formulated and understood phenomenologically. ${ }^{1125}$ All these concepts, especially temporality, ${ }^{1126}$ feature

which is experienced through this activity. However, we use the word intentionally in its double sense, because it is precisely the fact that the experiencing self and what is experienced are not torn apart like things that expresses what is essential in factical life experience. 'Experiencing' does not mean 'taking-cognizance-of' but a confrontation-with, the self-assertion of the forms of what is experienced. It has both a passive and an active sense. 'Factical' does not mean naturally real or causally determined, nor does it mean real in the sense of a thing. The concept 'factical' may not be interpreted from certain epistemological presuppositions, but can be made intelligible only from the concept of the 'historical.' At the same time, however, 'factical life experience' is a danger zone for independent philosophy since the ambitions of the sciences already validate themselves in this zone," ibid., 6-7

${ }^{1124}$ Heidegger, The Phenomenology of Religious Life, 55, 73, 83, 84, 97. It must be recalled that Heidegger is five years away from his first lectures explicitly dealing with the nature of time; nevertheless his comments here are formative and central to his early philosophy of religion. His key comments are as follows: "The factical life experience of the Christians is historically determined insofar as it always begins with the proclamation. The connection of the Christian to the surrounding world is discussed in 1 Cor. 1:26-27; 7:20. The significances of life remain, but a new comportment arises. We want to follow further the problem of proclamation in such a way that we leave matters of content entirely aside; now it must be shown that Christian religiosity lives temporality. What meaning communal-worldly and surrounding-worldly relations have for the Christian must be understood; and if they do, in what way. Christian factical life experience is historically determined by its emergence with the proclamation that hits the people in a moment, and then is unceasingly also alive in the enactment of life. Further, this life experience determines, for its part, the relations which are found in it.

"For all its originality, primordial Christian facticity gains no exceptionality, absolutely no special quality at all. In all its absoluteness of reorganizing the enactment, everything remains the same in respect to the worldly facticity. The accentuation of the Christian life has the manner of enactment: 1 Thess. 3:3; 5:9. All primary complexes of enactment lead together toward God, are enacted before God. At the same time, the $\dot{\alpha} v \alpha \mu \varepsilon ́ v \varepsilon ı v\{$ waiting\} is an obstinate waiting before God. The obstinate waiting does not wait for the significances of a future content, but for God. The meaning of temporality determines itself out of the fundamental relationship to God-however, in such a way that only those who live temporality in the manner of enactment understand eternity," ibid., 83-84.

Heidegger defines "temporality" in here as follows: "If the historical is taken as the formally indicated, it is not thereby asserted that the most general determination of 'historical' as a 'becoming in time' delineates a final sense. This formally indicating determination of the sense of historical is neither to be regarded as one which determines the objective historical world in its historical structural character, nor as one which describes the most general sense of the historical itself. 'Temporal' is, preliminarily, still taken in an entirely undetermined sense: one does not know at all which time is being spoken of. So long as the sense of 'temporal' is undetermined, one could understand it as \{something\} not prejudicing; one could mean: insofar as each objecthood constitutes itself in consciousness, it is temporal, and with that one has won the fundamental schema of the temporal. But this 'general-formal' determination of time is no foundation; rather it is a falsification of the problem. For with that a framework for the time-phenomenon has been predelineated from out of the theoretical. Rather, the problem of time must be grasped in the way we originally experience temporality in factical experience-entirely irrespective of all pure consciousness and all pure time. The way is thus reversed. We must ask, rather, what is temporality originally in factical experience? What do past, present, and future mean in factical experience? Our way takes its point of departure from factical life, from which the meaning of time is won," ibid., 44-45.

${ }^{1125}$ Heidegger, The Phenomenology of Religious Life, 24, 43, esp. 55-56, 58. Heidegger defines the term here as follows: "What is phenomenology? What is phenomenon? Here this can be itself indicated only formally. Each experience-as experiencing, and what is experienced-can 'be taken in the phenomenon,' that is to say, one can ask: 1 . After the original 'what,' that is experienced therein (content). 2. After the original 'how,' in which it is experienced (relation). 3. After the original 'how,' in which the relational meaning is enacted (enactment).

"But these three directions of sense (content-, relational-, enactment-sense) do not simply coexist. 'Phenomenon' is the totality of sense in these three directions. 'Phenomenology' is explication of this totality of

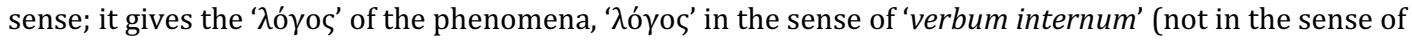


prominently in his later works, and form part of his ongoing influence on theology. ${ }^{1127}$ Later in his life, god and religion remained topics he returned to even when his agnostic trends are more pronounced. Aside from whether his views evolved or not, however, as Otto Pöggeler shares, "the question of God appears from the very beginning of Heidegger's pathway of thought,"1128 and therefore cannot be ultimately avoided, despite some commentator's best efforts to do so. ${ }^{1129}$

To appreciate the still ongoing influence Heidegger has had upon theology, it is important to observe the difference between what he calls the philosophical presentation of a "world-view" and genuine philosophy for its own sake, ${ }^{1130}$ which was a theme he would take up again and again insofar

logicalization)," ibid., 43. He adds, "A phenomenon must be so stipulated, such that its relational meaning is held in abeyance. One must prevent oneself from taking it for granted that its relational meaning is originally theoretical. The relation and performance of the phenomenon is not preliminarily determined, but is held in abeyance. That is a stance which is opposed to science in the highest degree. There is no insertion into a material domain, but rather the opposite: the formal indication is a defense $\{A b w e h r\}$, a preliminary securing, so that the enactment-character still remains free. The necessity of this precautionary measure arises from the falling tendency of factical life experience, which constantly threatens to slip into the objective, and out of which we must still retrieve the phenomena," ibid., 44.

${ }^{1126}$ Perhaps Heidegger's most fascinating use of temporality in this lecture series concerns "how the $\pi \alpha \rho$ ov ${ }^{\prime} \alpha$ stands in my life, that refers back to the enactment of life itself. The meaning of the 'When,' of the time in which the Christian lives, has an entirely special character. Earlier we formally characterized: 'Christian religiosity lives temporality." It is a time without its own order and demarcations. One cannot encounter this temporality in some sort of objective concept of time. The when is in no way objectively graspable.

"The meaning of this temporality is also fundamental for factical life experience, as well as for problems such as that of the eternity of God. In the medieval period these problems were no longer grasped originally, following the penetration of Platonic-Aristotelian philosophy into Christianity, and today's speculation which speaks of God increases the chaos. The pinnacle of the error is reached today in projecting onto God the concept of validity," Heidegger, The Phenomenology of Religious Life, 73.

1127 One of his more intriguing comments occurs in Heidegger, Being and Time, 406, n.13. Here he shared that "we do not need to discuss in detail the fact that the traditional concept of eternity in the significance of the 'standing now' (nunc stands) is drawn from the vulgar understanding of time and defined in orientation toward the idea of 'constant' objective presence. If the eternity of God could be philosophically 'constructed,' it could be understood only as more primordial and 'infinite' temporality. Whether or not the via negationis et eminentiae could offer a possible way remains an open question," ibid., 406 n. 13.

${ }^{1128}$ Otto Pöggeler, Der Denkweg Martin Heideggers (Neske, 1990), 261 (translation mine; original reads as "Die Gottesfrage steht von Anfang an über dem Denkweg Heideggers."

${ }^{1129}$ William Richardson comments, "one final word. The altogether central place of foundational thought in Heidegger's endeavor forces us to treat in one way or another almost all of his principal themes. There is one problem, however, that we resolutely avoid: the problem of God. This is not because there is nothing to say about God in Heidegger's thinking. On the contrary, it is because there is too much to say for it to be said merely by indirection," William J. Richardson, Heidegger: Through Phenomenology to Thought (New York, NY: Fordham University Press, 2003), xliv.

${ }^{1130}$ Heidegger, The Phenomenology of Religious Life, 8. "Philosophy is to be liberated from its 'secularization' to a science, or to a scientific doctrine of world-views. The derivation of science from philosophy is to be determined positively. Today, one usually assumes a standpoint of compromise: in its particularity, philosophy is said to be a science, but its general tendency is to present a world-view. In this, however, the concepts 'science' and 'world-view' remain vague and unclarified. How can one reach the selfunderstanding of philosophy? Apparently, the path of scientific deduction is cut off in advance through our thesis. This self-understanding cannot, further, be reached through reference to the 'object' of philosophy; 
as it is central for his understanding of the goal or purpose of philosophy. ${ }^{1131}$ In regards to the distinct differences and similarities Heidegger saw between philosophy and theology, one must consider a key lecture he delivered the very year Being and Time was published, 1927, when Heidegger declared that "there is no such thing as a Christian philosophy; that is an absolute 'square circle."”1132 Rather than being a negative assessment of theology, however, his rationale is based upon his narrow definition of philosophy as "the possible, formally indicative ontological corrective of the ontic and, in particular, of the pre-Christian content of basic theological concepts. But philosophy can be what it is without functioning factically as this corrective."1133 In other words, like all positive sciences, theology studies

philosophy does not, perhaps, deal with an object at all. Perhaps one may not even ask for its object. Through mystical intuitions we would cut off the problem in advance.

"The point of departure of the path to philosophy is factical life experience. It seems, however, as if philosophy is leading us out of factical life experience. In fact, that path leads us, as it were, only near philosophy, not up to it. Philosophy itself can only be reached through a turning around of that path, but not through a simple turning which would orient cognition merely toward different objects but, more radically, through an authentic transformation. Neo-Kantianism (Natorp) simply reverses the process of 'objectification' (of the cognition of objects) and thus arrives at the 'subjectification' (which is supposed to represent the philosophical, psychological process). In this, the object is merely drawn from the object into the subject, whereas cognition qua cognition remains the same unclarified phenomenon.

"Factical life experience is very peculiar; in it, the path to philosophy is made possible and the turning around which leads to philosophy is enacted. This difficulty is to be understood through a preliminary characterization of the phenomenon of factical life experience. Life experience is more than mere experience which takes cognizance of. It designates the whole active and passive pose of the human being toward the world: If we view factical life experience only in regard to the experienced content, we designate what is experienced-what is lived as experience \{das Erlebte\}-as the 'world,' not the 'object.' 'World' is that in which one can live (one cannot live in an object)," ibid., 8.

${ }^{1131}$ Heidegger makes very similar comments in The Basic Problems of Phenomenology, 4-15.

"Philosophy is the theoretical conceptual interpretation of Being, of Being's structure and its possibilities. Philosophy is ontological. In contrast, a world-view is a positing knowledge of beings and a positing attitude toward beings; it is not ontological but ontical. The formation of a world-view falls outside the range of philosophy's tasks, but not because philosophy is in an incomplete condition and does not yet suffice to give a unanimous and universally cogent answer to the questions pertinent to world-views; rather, the formation of a world-view falls outside the range of philosophy's tasks because philosophy in principle does not relate to beings," ibid., 11.

1132 Martin Heidegger, "Phenomenology and Theology," tr. James G. Hart and John C. Maraldo, in William McNeill, ed. Pathmarks, 39-62, 53. This lecture was given the same year his work Being and Time was published. In like manner, "there is likewise no such thing as a neo-Kantian, or axiological, or phenomenological theology, just as there is no phenomenological mathematics. Phenomenology is always only the name for the procedure of ontology, a procedure that essentially distinguishes itself from that of all other, positive sciences."

${ }^{1133}$ Heidegger, "Phenomenology and Theology," 53. "Philosophy, as the free questioning of purely selfreliant Dasein, does of its essence have the task of directing all other nontheological, positive sciences with respect to their ontological foundation. As ontology, philosophy does provide the possibility of being employed by theology as a corrective. . . if indeed theology is to be factical with respect to the facticity of faith. The demand, however, that it must be so employed is not made by philosophy as such but rather by theology, insofar as it understands itself to be a science," ibid., 52-53. 
an object, in this instance, faith. ${ }^{1134}$ This distinguishes it entirely from philosophy, which studies

Being, that is, a non-entity, an open and ever changing path of thought which encounters beings,

including, possibly, the being of faith, and insomuch as it may do this, it may alter how we discuss

faith, but doesn't change faith in itself. ${ }^{1135}$

Importantly, however, Heidegger's understanding of theology as "the science of faith"1136 is quite

different from what he considers the common conception of the definition of theology as the "science

of God," for "God is in no way the object of investigation in theology, as, for example, animals are the

theme of zoology. Theology is not speculative knowledge of God. And we hit upon the concept of

theology no better when we expand the theme and say: The object of theology is the all-inclusive

relationship of God to man and of man to God. In that case theology would be the philosophy or the

\footnotetext{
${ }^{1134}$ Heidegger, "Phenomenology and Theology," 45. Heidegger defines faith as "the believingunderstanding mode of existing in the history revealed, i.e., occurring, with the Crucified. The totality of this being that is disclosed by faith-in such a way, indeed, that faith itself belongs to the context of its disclosure-constitutes the character of the positum that theology finds before it. Presupposing that theology is enjoined on faith, out of faith, and for faith, and presupposing that science is a freely performed, conceptual disclosure and objectification, theology is constituted in thematizing faith and that which is disclosed through faith, that which is 'revealed.' It is worthy of note that faith is not just the manner in which the positum objectified by theology is already disclosed and presented; faith itself is a theme for theology." He continues, "Furthermore, faith not only motivates the intervention of an interpretive science of Christianness; at the same time, faith, as rebirth, is that history to whose occurrence theology itself, for its part, is supposed to contribute," ibid., 45.

${ }^{1135}$ Heidegger, "Phenomenology and Theology," 53. "This peculiar relationship [between philosophy and theology] does not exclude but rather includes the fact that faith, as a specific possibility of existence, is in its innermost core the mortal enemy of the form of existence that is an essential part of philosophy and that is factically ever-changing. Faith is so absolutely the mortal enemy that philosophy does not even begin to want in any way to do battle with it. This existentiell opposition between faithfulness and the free appropriation of one's whole Dasein is not first brought about by the sciences of theology and philosophy but is prior to them. Furthermore, it is precisely this opposition that must bear the possibility of a community of the sciences of theology and philosophy, if indeed they are to communicate in a genuine way, free from illusions and weak attempts at mediation," ibid, 53.

${ }^{1136}$ Heidegger lists four points in his extended definition of theology as the science of faith. "(1) Theology is the science of that which is disclosed in faith, of that which is believed. That which is believed in this case is not some coherent order of propositions about facts or occurrences which we simply agree to-which, although theoretically not self-evident, can be appropriated because we agree to them. (2) Theology is accordingly the science of the very comportment of believing, of faithfulness-in each case a revealed faithfulness, which cannot possibly be any other way. This means that faith, as the comportment of believing, is itself believed, itself belongs to that which is believed. (3) Theology, furthermore, is the science of faith, not only insofar as it makes faith and that which is believed its object, but because it itself arises out of faith. It is the science that faith of itself motivates and justifies. (4) Theology, finally, is the science of faith insofar as it not only makes faith its object and is motivated by faith, but because this objectification of faith itself, in accordance with what is objectified here, has no other purpose than to help cultivate faithfulness itself for its part....

"In summary, then, theology is a historical science, in accordance with the character of the positum objectified by it.... [furthermore], Theology is systematic only when it is historical and practical. It is historical only when it is systematic and practical. And it is practical only when it is systematic and historical," Heidegger, "Phenomenology and Theology," 45-48.
} 
history of religion." ${ }^{1137}$ With that in mind, it must be noted that faith is a unique object of study for Heidegger, as it involves a circularity of sorts, for faith is what both motivates and constitutes the study of faith. ${ }^{1138}$ Furthermore, along these lines Heidegger suggested that if faith opposed a "conceptual interpretation, then theology would be a thoroughly inappropriate means of grasping its object, faith. It would lack something so essential that without this it could never become a science in the first place." 1139

One may dispute Heidegger's contentions about theology. Indeed, whether theology is the study of God, of faith, or, perhaps, of some other object, such as Scripture, are open debates. Overall, in any case, Heidegger has had a profound impact on post-modern theologies, especially those that rely on more penetrating usages of the concepts of freedom and time, as well as more subtle and complex, even paradoxical, ways of thinking about theological problems. One recent example of this is seen in Cameron Freeman's work, ${ }^{1140}$ but there are many others who have utilized him for a variety of purposes, such as Fernando Canale for understanding the biblical sanctuary and biblical reasoning, ${ }^{1141}$ as well as others, such as Catholics, who are often more critical and reactionary in nature, though they do acknowledge Heidegger's contributions. ${ }^{1142}$

\footnotetext{
${ }^{1137}$ Heidegger, "Phenomenology and Theology," 48-49. "In no case may we delimit the scientific character of theology by using an other science as the guiding standard of evidence for its mode of proof or as the measure of rigor of its conceptuality. In accord with the positum of theology (which is essentially disclosed only in faith), not only is the access to its object unique, but the evidence for the demonstration of its propositions is quite special. The conceptuality proper to theology can grow only out of theology itself. There is certainly no need for it to borrow from other sciences in order to augment and secure its proofs. Nor indeed can it attempt to substantiate or justify the evidence of faith by drawing on knowledge gains from other sciences. Rather, theology itself is founded primarily by faith, even though its statements and procedures of proof formally derive from free operations of reason," ibid., 49.

${ }^{1138}$ Heidegger, "Phenomenology and Theology," 45.

${ }^{1139}$ Heidegger, "Phenomenology and Theology," 45.

${ }^{1140}$ Freeman, Post-metaphysics and the Paradoxical Teachings of Jesus: The Structure of the Real, 11-36, 73-110, 121-125, 221-260.

${ }^{1141}$ Fernando Canale, "Absolute Theological Truth in Postmodern Times," in Andrews University Seminary Studies Vol. 45 \#1 (Spring 2007), 87-100; and Canale, "Philosophical Foundations and the Biblical Sanctuary."

${ }^{1142}$ Sweeney, Sacramental Presence after Heidegger: Onto-theology, Sacraments, and the Mother's Smile.
} 
Another common feature of Heidegger's influence is that he is widely acknowledged as the champion and lover of paradox, ${ }^{1143}$ which is a theme that directly relates to any coalescing of freedom and determinism. Heidegger frequently alludes to the "paradoxical" nature of Being and freedom, though with a precise and ironic care he avoids explicitly embracing it, even as he acknowledges its inevitability for thinking about the question of Being. ${ }^{144}$ The reasoning behind Heidegger's very deliberate usage of the word "paradox," which occurred with more frequency later in his career as he moved beyond Dasein to discussing Being itself, ${ }^{1145}$ can perhaps be explained as follows, which may help also show why it remains attractive to some theologies. Heidegger realizes full well that his

${ }^{1143}$ Even friendly advocates of Heidegger's work, as noted by Richard McDonough, observe that Heidegger has a "love of paradox" and "obscurantism," Richard M. McDonough, Martin Heidegger's Being and Time, xiv, xxvi n. 4. See also, John D. Caputo, The Mystical Element in Heidegger's Thought, 63-64; Mark A. Wrathall, Heidegger and Unconcealment: Truth, Language, and History (Cambridge University Press, 2011), 28; David Wood, Thinking After Heidegger (Malden, MA: Blackwell Publishers, 2002), 90; and Jeffrey Andrew Barash, "Historical Meaning in the Fundamental Ontology of Being and Time, from Martin Heidegger and the Problem of Historical Meaning," in Heidegger's Being and Time: Critical Essays, ed. Richard F. H. Polt (Oxford, UK: Rowman \& Littlefield Publishers, 2005), 170.

${ }^{1144}$ For example, see Martin Heidegger, Basic Concepts, tr. Gary E. Aylesworth (Bloomington, IN: Indiana University Press, 1993), 68-69. He writes, "Being: casting itself toward us and cast away by us. This looks like a 'contradiction.' However, we do not wish to capture what opens up here in a formal schema of formal thinking. Everything would merely become weakened in its essence, and essence-less, under the appearance of a 'paradoxical' formula." For "if, in the manner just presented, thinking encounters insurmountable difficulties, and sees itself placed into a situation where there is no way out, then it can yet deliver itself from peril in the way previous thinking has done. We have already refrained from the nearest available technique of discerning a contradiction and playing, so to speak, with a 'paradox.' For relinquishing thought is the most deplorable way for thought to accomplish its task. Nevertheless, according to the way of thinking practiced until now in the otherwise usual questions of philosophy, one could undertake still other and subsequent reflections in respect to the impasse now arrived at. In view of this situation where there is no way out, where, on the one hand, Being cannot be avoided, and, on the other hand, investigating Being immediately makes it into a 'being' and thus destroys its essence, one gives up the question of Being altogether and declares it to be a pseudoquestion. Or else one decides to acknowledge the now exposed impasse ('aporia'). One must then come to terms with it in some way. In such cases, the popular technique of making a virtue of necessity offers itself as a salvation. Accordingly, we could say in respect to our impasse that Being itself forces us into this situation with no way out and even brings it about. Therefore, Being would show itself to be what is represented as at once both unavoidable and yet ungraspable. What it shows itself to be in this way, this impasse, is precisely its essence. The impasse that Being brings with it is Being's own mark of distinction. Therefore, let us take the impasse as the predicate with whose help the decisive assertion about Being can be won. It states: Being is every time, with every attempt to think it, converted into a being and thus destroyed in its essence; and yet being, as distinguished from all beings, cannot be denied. Being itself has just this kind of essence: it brings human thinking into an impasse. When we know that, we already know something essential about Being," ibid., 68-69. See also, Martin Heidegger, "On the Essence of Truth," tr. John Sallis, in Pathmarks, 149; and Martin Heidegger, "On the Question of Being," tr. William McNeill, in Pathmarks, 299, where he shares, "talk of the subjectity (not subjectivity) of the human essence as the foundation for the objectivity of every subjectum (everything present) appears in every respect to be paradoxical and contrived," ibid., 299.

${ }^{1145}$ Heidegger's increasing usage of "paradox" in his later writings (E.g. Basic Writings and "Letter on 'Humanism') appears to coincide with his admissions of the weaknesses and failures of his early work around the Being and Time era-that is, Heidegger abandoned his more 'scientific' effort to describe time. 
understanding of being will invite criticisms of paradox. ${ }^{1146}$ Were the timeless grounding power of ontotheology true, his thinking would be not only a paradox, but in fact a contradiction. ${ }^{1147}$ It is because Heidegger believes that he has established that his understanding of Being is necessary to explain the phenomena we experience that he avoids labeling his view a paradox. Therefore, it seems to be the case in his mind, because it is true, and necessarily so for thinking and reasoning itself, it needn't technically be called a paradox. However, because when we think and interact within a world of objects or beings, we almost inevitably slide into timeless-like thinking, be it in mathematics or other sciences, or even in plain common sense, therefore he must admit Being appears paradoxical. ${ }^{1148}$ This is especially true since he expresses no desire to undercut specific scientific disciplines in themselves, only critique them insofar as they are treated as metaphysically grounding. Whether this tactic by Heidegger is sufficient for handling the objections his ideas faced or not cannot be resolved here. One thing, however, is clear, and that is given his understanding of Being definitely appears paradoxical to his opponents, dogmatically insisting it isn't is not a fruitful tactic for winning converts. Heidegger's increasing usage of the word may have indicated an awareness of this situation.

In any case, the point is that any serious theology must encounter the issues raised by Heidegger's analysis of Being, time, and reality. This would include those that address the relationship of science and divine action in the natural world as well. Additionally, it can hardly be said that Heidegger was neutral to the philosophical trends that were popular in the West during his time, particularly its embrace of scientism in many sectors, ${ }^{1149}$ and in particular he loathed the

${ }^{1146}$ Heidegger, “Letter on 'Humanism,'” 253, 261.

${ }^{1147}$ Therefore, Heidegger spends a great deal of effort denouncing the validity of the law of noncontradiction for metaphysical questions. Again, see in particular Heidegger's connection between logic and the principle of non-contradiction in relationship to Being in Heidegger, Being and Truth, 44-48; Heidegger, The Principle of Reason, 17-18; and Heidegger, The Metaphysical Foundations of Logic, 52-57.

${ }^{1148}$ For the "origin of the contradiction is still more questionable than its appearance" in such cases, Heidegger, Schelling's Treatise on the Essence of Human Freedom, 114.

${ }^{1149}$ At many points in his career Heidegger directed his criticism toward science. "The efforts of the great philosophers are directed toward what is in every sense ultimate, universal, and of universal validity. The inner struggle with the puzzles of life and the world seeks to come to rest by establishing the ultimate nature of these. Objectively stated: every great philosophy realizes itself in a worldview - every philosophy is, where its innermost tendency comes to unrestricted expression, metaphysics," in Martin Heidegger, Towards the Definition of Philosophy, tr. Ted Sadler (New York, NY: Continuum Press, 2002), 7. This is a problem because 
connections between traditional ontotheological philosophy and Catholicism, about which Heidegger

frequently and strongly opined. ${ }^{1150}$

\section{Pylkkö as an Exemplar of Heidegger}

In relation to the previous section, there are four notable reasons that among contemporary

philosophers, Pylkkö best exemplifies the trajectory of Heidegger's ideals, and thus influence.

First, Pylkkö unquestionably represents one of the most radical advocates of Heidegger's

work. ${ }^{1151}$ Sadly, it is not possible to gauge what Heidegger's response to the work of someone like

that which is most universal is always "science." Heidegger stated that "science is knowledge and knowledge has objects. Science determines and fixes objects in an objective manner." He also shares that "A science of experiences would have to objectify experiences and thus strip away their non-objective character as lived experience and event of appropriation," by which he means it can't be done. "Lived experience does not pass in front of me like a thing, but I appropriate [er-eigne] it to myself, and it appropriates [er-eignet] itself according to its essence. If I understand it in this way, then I understand it not as process, as thing, as object, but in a quite new way, as an event of appropriation," ibid., 60. Elsewhere, Heidegger, in another of his more expressive moments, shared that "modern 'science' is now for the first time coming into its own: for it is now becoming close to life and at the same time may more than ever adhere obstinately to its past. It now carries out the feat of being at once 'close to life' and also 'solitary' and is both of these accompanied by an increasing commendation of the indispensability of such masters of calculation who will presumably still bring about 'gigantic' accomplishments." Upon so doing, however, "what if there were no more 'life' (here: essential relations to beings themselves) at all-what would then be the point of 'nearness to life' and 'remoteness to life' and the feat of coupling these together?" Rather, "the danger for 'science,' in case it is still worthy of danger, is not that 'freedom' is taken from it, i.e., that the form of constraint is merely altered. On the contrary, the danger is that 'science' will no longer have the resources to recognize that it is fused into the process of machination, such as even to disappear therein.... "'Science' lacks the courage for what it itself already is as a product of modernity," Martin Heidegger, Ponderings: II-VI, tr. Richard Rojcewicz (Bloomington, IN: Indiana University Press, 2016), 298.

${ }^{1150}$ Heidegger bemoaned, "those who today falsify the last remainder of philosophy by turning it into a scholasticism of worldview in order to make themselves up to date should at least summon up enough insight and enough rectitude of thinking that they make St. Thomas Aquinas their patron-the only patron saint appropriate to them-in order to learn from him how one can be uncreative in the great style and yet can place very astutely essential thoughts into the service of belief and give belief a decisive basic structure. Why is this not happening? Because even this extensive heteronomy of thinking lacks power, and above all lacks the certainty of craft. The confusion is so great that these 'political' philosophies, ones 'tied to the people,' are never recognized as wretched imitations of scholasticism." Heidegger continues, "The grotesqueness is complete when all this confusion is joined by the 'struggle' against the Catholic Church-a 'struggle' which has still not at all found-and cannot find-its opponent as long as it thinks with too short a sight (and too narrow a mind) of that which constitutes the foundations of this Church: the adapted metaphysics of Western thinking in general, in which these 'worldview struggles' are so inextricably entangled that they do not surmise how much they themselves participate with their 'opponent' in the same brittle foundations (unquestionability of being, groundlessness of truth, essential determination of the human being)," Heidegger, Ponderings: II-VI, 292-293.

${ }^{1151}$ As Louis Berger explains on his behalf, "Pylkkö develops a nontraditional, elaborate, rich, evocative, but also elusive ontological-epistemological framework designed to address the cluster of Heideggerian issues, and this framework is the common ground that integrates his critical analyses of apparently highly diverse, unrelated themes. His major concern, however, is with 'naturalized' science and philosophy." As such, Pylkkö seeks to explore "whether an alternative, a nondogmatic science and a nondogmatic philosophy, is possible, and how it might look," Berger, The Unboundaried Self: Putting the Person Back Into the View from Nowhere, 99. 
Pylkkö might be, but importantly, Pylkkö is not the only one inspired by Heidegger to advance the possibilities Pylkkö seeks to explore in some detail. For example, scholars such as Ernesto Spinelli have also independently realized that "if we consider the many conceptual conundrums to do with time, space, locality and materiality thrown up by quantum physics it is both evident and somewhat startling to note how closely such conundrums resonate with the inter-relational principle that underpins existential phenomenology,"1152 ${ }^{112}$ wich certainly includes Heideggerian versions of it. Here, speculation runs rampant, though, necessarily, given the situation. Similarly, Georg Franck notes that Being, understood primordially as concept-less awareness, "turns into intentional consciousness as soon as the awareness becomes selective. The totally entangled quantum whole turns into a selection of possible states as soon as observables are identified. In both cases, something particular emerges by way of reducing the one extreme and allowing the other mode of existence to enter."1153 As such, he thinks that "what we are facing [here in quantum physics] is an ontological complementarity of presence and materiality... The more materiality the less presence, and vice versa. This ontological complementarity is one of the fundamental conditions of existing as a conscious brain: of Dasein."1154 Thus, Pylkkö is clearly not alone to see the connections between quantum physics and Heideggerian philosophy, even if Pylkkö has taken the step of exploring them in perhaps the most detailed and evocative way. Second, Pylkkö's ideas were influenced by, and in turn have influenced others, concerning social and political issues, ${ }^{1155}$ reflecting Einstein's influence upon others. Of course, Pylkkö can't compete with Einstein and Heidegger's, nor even Bohm's, influence throughout the academy, but his ideas are nevertheless quite innovative, and hold great potential. Pylkkö's interest

\footnotetext{
${ }^{1152}$ Ernesto Spinelli, Practising Existential Psychotherapy: The Relational World (Thousand Oaks, CA: SAGE Publications, 2007), 18.

${ }^{1153}$ Franck, "Mental Presence and the Temporal Present," 65. Franck is referring to the quantum wavefunction collapse, wherein a probability wave that describes the theoretical location of a particle "spontaneously" "collapses" into a specific location upon the scientist's decision to measure the particle. See, for example, Paolo Grigolini, Quantum Mechanical Irreversibility and Measurement (Singapore: World Scientific Publishing, 1993), 78-81, 167-173, 388-397. Compare with Heidegger's understanding of Dasein's capabilities. David Krell explains: "Dasein is the kind of Being that has logos-not to be understood derivatively as reason or speech but to be thought as the power to gather and preserve things that are manifest in their Being," David Farrell Krell, "General Introduction: The Question of Being," in Martin Heidegger, Basic Writings, ed. David Farrell Krell (London, UK: HarperPerennial, 2008), 19.

${ }^{1154}$ Franck, "Mental Presence and the Temporal Present," 66.

${ }^{1155}$ For example, Vadén, Heidegger, Žižek and Revolution, 3 n. 2, 81-84.
} 
in the "sciences" is, perhaps, unmatched amongst contemporary Heideggerian philosophers today, ${ }^{1156}$ and his synthesis of the issues in philosophy of science is fairly comprehensive. Third, Pylkkö's tentative remarks and interest in the subject of God and theology shares some of the sentiments made in the ambiguous comments by Heidegger. And, lastly, fourth, while Pylkkö has not been cited by others concerning the nature of the divine and divine action in the world, as Heidegger has, there is no doubt that Pylkkö's ideas could deeply affect such discussions.

Having covered the above background information concerning Pylkkö, in the following sections Pylkkö's specific ideas about the natures of time and freedom will be explored. First, his views on time in general will be examined, and then his views of time for the humanities.

\section{Pylkkö's View of Time}

To understand Pylkkö's view of time, one must first understand what it is not. So as a first step toward explaining Pylkkö's view of time as a representative of the humanities, Pylkkö's view must be positioned as in distinct contrast with that of Heidegger, the primary figure that dominates the conception of time operative in the humanities, as well as, of course those from the sciences. The most obvious points of confusion will come from the facts that the idealistic or nonphysical nature of time in Heidegger is incorporated into nature in a way that contrasts with how scientists typically view nature-as deterministic (or, possibly, indeterministic chance). Thus, Heidegger's nondeterministic (neither purely random nor deterministic) temporality is now unveiled in a new way. Yet, despite these different conceptions of temporality operative in Heidegger's and Pylkkö's works, Pylkkö doesn't merely instaurate temporality again in a directly analogous manner to Heidegger's, but rather reenvisions it.

The point at present is that because temporality can have more than one face, it is undoubtedly confusing. That said, it must be quickly noted that Pylkkö does not consider his ideas to be simple.

\footnotetext{
${ }^{1156}$ Part of the reason for this is that Heidegger himself appeared to 'give up' on science as a vehicle toward philosophical truth. "The attempt to restore an essential truth to 'science' through its reacceptance into 'metaphysics' must one day (that day has come for me) be seen as a futile endeavor. For, every reacceptance into the question-worthiness of beyng signifies a dissolution 'of science,' and 'science' will precisely resist this and would prefer a new servitude in order to save | this 'cultural value' and indeed, in view of the zeal for 'cultural politics,' will encounter no impediments to that servitude," Heidegger, Ponderings II-VI, 336.
} 
For he realizes that to overcome the dogmatic way of thinking about science is not easy, and it may be that the aconceptual naturalistic attitude he advances “must concede that man's relationship with nature cannot be exhausted by a single, logically consistent theory."1157 That is to say, Pylkkö is resistant to the very idea of 'models' of reality. That said, the following presentation will endeavor to be as concise as possible.

\section{Time in Nature}

What primarily distinguishes Pylkkö's view of time from Heidegger is that for Pylkkö, there can be no transcendent idealized 'temporal time' or 'Dasein' beyond 'nature' where time hides or is given. There can be no abstracted time-space, terminology Pylkkö does not specifically use, incidentally, though it is implied, and shared by a couple of kindred thinkers. ${ }^{1158}$ How Pylkkö arrived at this

${ }^{1157}$ Pylkkö, The Aconceptual Mind, 15.

1158 Thus, for Pylkkö, nature itself must manifest the qualities Heidegger attributed to his temporal time-space. Pylkkö is not alone in suggesting such evidence may exist. See, for example, Palmer, The Fragmentation of Being and the Path Beyond the Void: Speculations in an Emergent Onto-Mythology, 129-139; and Trish Glazebrook, "Zeno Against Mathematical Physics," in Journal of the History of Ideas Vol. 62 No. 2 (April, 2001), 193-210. Glazebrook concludes, "mathematical descriptions of physical reality fail, as apparent from the paradoxical results they engender," ibid., 209. As Michael Eldred explains, in general harmony with Pylkkö, concerning the problem of how mathematics and physics relate to time: "Another way of looking at this is that countable time only ever defines a segment of space-time containing also irrational numbers and already in principle an irrational number cannot be counted, i.e. it cannot be made present within the counting process so that continuous motion would have to pass through points in space that are outside assumed countable time! Hence we can conclude that if time is conceived mathematically as a continuous real variable, it cannot be counted, and if it is conceived as countable, i.e. as the counting number lifted off a highly regular, periodic movement, it is not continuous, but is a regular sequence of discrete, temporal 'quantum' leaps. Modern physics is apparently unaware of this antinomy between the presumed continuity of time and its discreteness as counted. If it saw this antinomy and took it seriously, it would have to concede that the paradoxes of quantum mechanics arise already within the problematic of classical mechanics.

"Let us approach the problematic duality of continuity and discreteness from another angle. Modern physics tells us that there is a limit to the divisibility of physical bodies which is reached with sub-atomic entities, which are the smallest of all possible physical entities. These smallest of physical entities, however, cannot be pinned down by determinate space-time co-ordinates, but only within a segment of space-time $\Delta(\mathrm{x}, \mathrm{y}, \mathrm{z}, \mathrm{t})$ whose smallness is dependent upon the Planck constant, whose dimension, in turn, is not simply a (wave)length, but the action of an energy over time. This localization to a chunk of space-time lends the subatomic entity its properties as a particle (e.g. a mass moving with a certain momentum), whereas its indeterminacy within this chunk lends it its wave characteristics as a pure vibration or quivering or energetic disturbance of a segment of space-time itself. This quivering can be regarded as quantized energy and is a kind of continuity of matter within particle discreteness, specifically, a continuity within six-dimensional time-space which holds its ecstasies together. Matter itself is then conceivable as bundled energy waves, i.e. as a compact quivering of time-space. Hence, for instance, the physicist Erwin Schrödinger writes, 'it is declared that the atom in reality is nothing more than the refraction phenomenon of an electron wave so to speak captured by an atomic nucleus.'

"The break with the scientific conception of time as a one-dimensional variable, that ties time to an instant must be made to see this properly. The energetic quivering that a sub-atomic particle is is a quivering of a segment of time-space, to distinguish it from the space-time of mathematical physics. Because time itself is 
conclusion is by asking questions that Heidegger never felt obligated to answer, such as how his understanding of Dasein, temporality, and Being, could be reconciled with natural science. ${ }^{1159}$ Pylkkö considers Heidegger's position incomplete and inadequate, and moreover asserts that Heidegger hinted they could not be reconciled. ${ }^{1160}$ Pylkkö is not hesitant to share that if they cannot be

both present and absent together, i.e. three-dimensionally stretched, it is itself quantitatively indeterminate (i.e. it cannot be determined as a single number), even apart from, or prior to, the indeterminacy of any counting of it, which, as we have seen, is always discrete and empirically finite. Since being itself cannot be reduced to presence pure and simple, there are no points in time, but rather there is or exists only a quivering, an undecidable togetherness-in-unity of past, present and future together with the three spatial dimensions that enables movement and is itself the originary energetic movement. The co-ordinate $t$ in a chunk of space-time $\Delta$ $(\mathrm{x}, \mathrm{y}, \mathrm{z}, \mathrm{t})$ imagined as present cannot capture the three-dimensional nature of time itself, but only its moment of presence, its now. The variable $t$ stretches into both earlier and later time, both of which are present as absent, thus inducing also an indeterminacy of position as there-then complementing the here-now. Such twofold presence as absence cannot be expressed mathematically since numbers (including co-ordinates, intervals) are only ever present or absent, but not both together. Moreover, and crucially, since time is now thought genuinely as three-dimensional, and thus as endowed with three independent temporal dimensions, the temporal dimension of the future cannot be determined from the temporal dimension of the present. The future is not conceivable as an extrapolation (linear or otherwise) from the present now-point, and what is to come (the there-then) cannot be written down mathematically as a function of the here-now-point, $\mathrm{t}$, i.e. as $\mathrm{f}(\mathrm{x}, \mathrm{y}, \mathrm{z}, \mathrm{t})$," Eldred, The Digital Cast of Being: Metaphysics, Mathematics, Cartesianism, Cybernetics, Capitalism, Communication, 131-133.

${ }^{1159}$ Pylkkö observes that Heidegger was aware "that actually the notion of physical object is destroyed in modern atomic physics but adds that he will not deal with the problem in this context. It is obvious that the destruction of the microphysical object in the Copenhagen interpretation fits neither Heidegger's picture of science nor what the self-image of science should be in Heidegger's opinion. No wonder therefore, that Heidegger hurries onwards to other problems," Pylkkö, The Aconceptual Mind, 60. In support of Pylkkö but including some references of Heidegger beyond those Pylkkö seems aware of, Heidegger expressed his familiarity of the natural sciences and nature, in particular, physics, late in his career as follows: "Hence physics, in all its retreating from the representation turned only toward objects that has alone been standard till recently, will never be able to renounce this one thing: that nature announces itself in some way or other that is identifiable through calculation and that it remains orderable as a system of information.... It seems as though causality is shrinking into an announcing-an announcing challenged forth-of standing-reserves that must be guaranteed either simultaneously or in sequence," in Martin Heidegger, The Question Concerning Technology and Other Essays, tr. William Lovitt (New York, NY: Harper \& Row, 1977), 23. Again, later in his career he noted Max Planck's thesis about being which says '“The real is what is measurable.' The meaning of being is thus measurability, whereby it is not so much a matter of establishing 'how much,' but ultimately of only serving to master and dominate the being as object," Heidegger, Four Seminars, 53-54. Herein he sees the perils that many physicists fall into in their obsessions for answers to objects and an object's relationship to being. Heidegger similarly insightfully opines concerning "the universal world formula, which Heisenberg [and Einstein] had long worked on. Insofar as this theory is possible, it could not become a description of nature; it can be only a principal analogy: what one must take into account so that, in any event, one can count on something. But what is the fundamental determination of nature for physics? Is it calculability? Then there is still the question of what is calculable. Something like energy? Again, we first need to understand this word. Actually, modern experimental physics constantly searches for the laws of motion, just as Aristotle had. This would be the meaning of the fundamental universal formula, insofar as all the possibilities of movement in their infinite variety could be deduced. Heidegger now asks what the discovery of this formula would mean for physics. The answer runs: the end of physics. Such an end would entirely alter the human situation. It would place the human being before the following decisions: -either to open up to an entirely new relation to nature; -or, after the work of research is concluded, to settle into the mere thoughtless exploitation of the discovery," ibid., 55.

1160 "Heidegger seems to have thought that nondogmatic science is impossible, and, in this respect, his view accords surprisingly well with the implicit view which dogmatic scientists themselves hold. According to Heidegger, the world view of modern natural science is either dualistic (Cartesian) or, what is even worse, 
reconciled, then essentially one will be obliged to admit to irreconcilable dualisms that are inherently contradictory, not merely paradoxical. Most of the Enlightenment philosophers were comfortable with this tension, Descartes in particular. If Being, or Dasein, is an object of thought, then does it have a tangible analogy or effect in the "real" world? If one answers no, then philosophy has no meaning, and Heidegger's thoughts are worthy of nothing. If one answers yes, then how does it relate to the "body" or "brain," assuming any 'normal' view of realism? ${ }^{1161}$

Heidegger never cared to give a detailed answer to the above question concerning the relationship of his ideas to the nature of natural science, making his work on the surface appear nearly irrelevant to contemporary society where knowledge of the natural world, including neuroscience and cognitive science, is ever increasing in significance for medicine and other areas. Are not the parts in my brain "regular" physical matter at the microscopic level? To put it succinctly, if science is never able to "read" one's thoughts, then there will be some sort of an explanation for the reason "why." There will be a "limit" reached that will provide context to explain the conceptual or structural abyss beyond science. Pylkkö, for one, believes there are no exclusive "objects of thought"

materialistic or crudely pragmatic, in which case the chances that it succeeds in dealing well with human experience are, if possible, even weaker. Therefore, Heidegger's picture of science and the self-image of dogmatic science are not, after all, too far from one another, though Heidegger, unlike many dogmatic scientists, thought that the scientific attitude is necessarily limited in its ability to approach human experience and that science arises within the Dasein experience and is, therefore, not independent of it," thus creating the tension of their coexistence, Pylkkö, The Aconceptual Mind, 40. Heidegger expressed no clear way out of the tension of accepting science's self-image while naysaying its applicability to all human experience, which dogmatic scientists would insist upon. Therefore, a stark contrast between them must be somehow necessary. Furthermore, Pylkkö claims that "According to Heidegger's line of thinking, it would, for example, be impossible to give an adequate description of the Dasein experience, let alone of the authentic Dasein experience, in the language of modern neuroscience." Therefore, "the impossibility is of a strictly categorical nature, and no version of naturalism, no matter how nondogmatic, can escape it," ibid., 53. Additionally, Pylkkö interprets Heidegger to believe that it isn't "possible that human experience of Being could become thoroughly intertwined with the scientific attitude," which orients his criticism of Western science to presuppose "a crisp and categorical contrast between the subject and the object, whereas in the authentic Dasein experience the contrast is violently challenged and eventually dismantled," ibid., 52-53. Pylkkö objects to this violence, seeing it as necessary for Heidegger, but not for nondogmatic naturalism of the sort he advocates.

${ }^{1161}$ Again, as Globus shared, "there is one unique fact that is forgotten within Heidegger's purview, the fact, crudely put, that no brain, no Da-Sein. Turn the brain to mush and the Lichtung goes dark.... Who would deny this? ... No future scientific revolution will change the fact's significance. Such a fact cannot be simply ignored, but must find its place in the Heideggerian scheme," Globus, The Postmodern Brain, 37. Pylkkö, however, takes this even further, denying that a brain, as we currently understand it, is truly necessary for an asubjective experiential center. Pylkkö, The Aconceptual Mind, 97-99. 
of which an open-minded or nondogmatic science of the natural world will be unable to tell us something about them and how they work.

Of course, Pylkkö is hardly the first to measure time by physics. Although Newton, and those prior to him, had understood time in an idealized-mathematical way, outside of nature, Einstein incorporated time into nature and, ultimately, eliminated it by doing so because of its inner determinism. Heidegger returned time into the idealized position Newton had accorded to it, but this time de-mathematized it, making it "temporal." In a sudden about face, Pylkkö's purpose is to reinstate time into physics, but now in a Heideggerian "temporal" way inspired by quantum physics. ${ }^{1162}$

Because Pylkkö has linked philosophy with nature, which brings with it significant consequences, ${ }^{1163}$ this means he is obligated to formulate new terminology to express this, as well as reinterpret the meaning of time in nature, as well as for humanity. As such, Pylkkö's project is to encourage a transition toward a less conceptually restrictive understanding of nature, that allows for Heidegger's understanding of Dasein. Pylkkö believes the initial evidence pointing toward this possibility has been reached through current quantum theory. Pylkkö calls this immediate and unstructured primitive experience "aconceptual experience." In many ways the Heideggerian terminology 'being and time' is roughly analogous to Pylkkö’s understanding of "aconceptuall ${ }^{164}$

1162 Pylkkö, The Aconceptual Mind, 70-73, 108, 122-123, 201.

1163 Pylkkö, The Aconceptual Mind, 43. "Nondogmatic naturalism may expose science to problems which are even harder than what standard science is used to facing. Questions which resemble traditional philosophical questions will now belong to the task field of nondogmatic scientists too. Typically, such problems of circularity which were sketched earlier [in the context of philosophy]... have to be addressed now within science itself," ibid., 43.

${ }^{1164}$ Pylkkö notes that "a special task is reserved for the letter $a$. When a word, $w$, is prefixed with it, the resulting word, $a w$, represents an attempt to move beyond the dichotomy which is presupposed in the meaning of $w$. Thus aconceptual doesn't equal in meaning nonconceptual but represents an attempt to dissolve the conceptual-nonconceptual dichotomy. Similarly, amechanical means something that precedes the contrast of the mechanical and the nonmechanical," Pylkkö The Aconceptual Mind, 12. 
experience."1165 Pylkkö's aconceptual experience is "unarticulated, prelogical, and what mind and

language primarily is." ${ }^{1166}$ It is also physically grounded in a holistic physical ${ }^{1167}$ reality. ${ }^{1168}$

By aconceptual, Pylkkö is rejecting the dualistic line between the conceptual and nonconceptual as binding for all reality. The aconceptual flux is prior to conceptual formation, but it itself is neither conceptual nor nonconceptual. Without it, there would be no concepts. This is possible because materialism and naturalism aren't what they were commonly thought to be. Rather, "if nondogmatic naturalism is possible, we will be forced to use the word naturalism in a highly anomalous way. Naturalism will mean man's peculiar willingness to understand his relation with nature. This requires openness to natural phenomena and sensitivity to the two-way influences which flow between man and nature. In anomalous naturalism, natural science is not supposed to approach

1165 Pylkkö explains that "experience covers here both nonhuman experience and nonpersonal human experience. It is collective, or, properly speaking, it can be so holistic that it destroys the boundaries which are said to separate persons from one another. This makes the problem of solipsism and privacy less acute in this context. This view of experience which covers experience of all times everywhere represents a movement away from the unsettled Sein-Dasein dualism which dominates Heidegger's Being and Time," Pylkkö, The Aconceptual Mind, xxii.

${ }^{1166}$ Pylkkö, The Aconceptual Mind, 13. "Our Dasein is so ineradicably in our language that we could say that we are our language," ibid., 18. "Genuine naturalism views language and mind in terms of experience. Experience as such and our neural conception of experience support each other at least in this respect: just as any two experiences are never identical, two neural processes aren't identical either," ibid., 19.

${ }^{1167}$ Pylkkö, "Eliminative Holism as a Solution to Bohr's Puzzle of Two Languages," 144. “Genuine physical holism encourages a skeptical stance toward classical physical objects and confers to them only the modest status of historically and psychologically useful fictions which may help us to visualize or imagine (more or less misleadingly) what quantum formalism, in some counterfactual sense, could be about. Physical holism claims that what is called 'physical reality' is an indivisible whole and doesn't consist of systems and subsystems. Within standard scientific realism, physical things are often thought to be systemic in the sense that the future states of the things which we study can be explained comprehensively in terms of their allegedly separable subsystems. Physical holism says that this classicalness assumption is naturalistically ungrounded. Physical holism must be accompanied by a suitable view of language, perception and human experience which, from the very beginning, abandons the assumption that there are persistent and separable macrophysical objects. The view must not assume that language and mind, or what they are about, consist of macrophysical objects and systems," ibid., 144. Thus, "physical holism conforms nicely with meaning holism. Because there are no classically separable physical systems, then words, or any other sequences of speech, cannot serve as constituents of sentences or of any other sequences of speech. Because there are no decomposable physical systems in the first place, what we call 'sentences' are not something that can be decomposed into constituentlike subsystems; neither can words or their alleged combinations refer to such systems. ..". Rather, "as genuinely biological events, word meanings are inseparable, fuzzy, diffuse and perpetually changing processes which vary along the verbal context, the situation where the words are uttered and the state of the speaker's brain," ibid., 144.

${ }^{1168}$ Pylkkö, The Aconceptual Mind, 13. Pylkkö explains that because we "associate subjectivity strongly with the conceptual organization of experience we say also that, in aconceptual experience, there is no such hierarchy and perspective which characterize the subject's presence. The experience is, so to speak, holistically everywhere," ibid., 13. 
nature from an external or objectifying perspective, as if nature consisted of a set of things the existence of which is independent of experience and lies somewhere outside of it."1169 Thus, for Pylkkö, naturalism need no longer be "dogmatic," or bound to Einstein's view of nature as object based and causally deterministic. Pylkkö's view of nature is more inclusive: nature itself must possess the potentiality for time of the sort that is experientially meaningful for both nature and humanity together. As such, all of nature has a history or experience of sorts, animate and inanimate alike; all reality shares one fundamental aconceptual time-space, ${ }^{1170}$ although this is not to say individuals do not constitute unique derivative time-spaces, ${ }^{1171}$ nor is this to say that Pylkkö understands 'space' in the manner of most physicists. Yet, this is not to say the animate and inanimate are identical. Different configurations of coalesced 'matter' can still be said to constitute the necessary conditions to call some matter animate or alive and other matter inanimate, so far as biology can determine. Underlying them both, however, is a more primordial relational physical reality which allows any experience at all. ${ }^{1172}$

The key component of Pylkkö's view of time is that physical reality, meaning nature, is holistically entangled or enmeshed, owing to the bizarre properties of quantum phenomena, which exhibit random, non-local, and nonseparably holistic behavior. ${ }^{1173}$ These phenomena are the

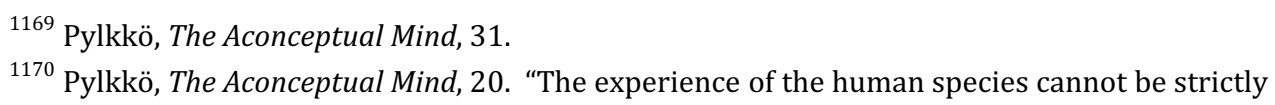
separated from nonhuman animal experience," ibid., 20. That is to say, there are commonalities by natural necessity due to the common origin, and this experience extends beyond the cognitive realm. Experience for Pylkkö "covers experience of all times everywhere," ibid., xxii. See also, again, Palmer, The Fragmentation of Being and the Path Beyond the Void: Speculations in an Emergent Onto-Mythology, 129-139.

${ }^{1171}$ Pylkkö, The Aconceptual Mind, 78, 121, 123. See also, Kent D. Palmer, "How Simultaneous Multiple Independent Times Impact Our 'Ways of Being': Dimensional Splintering of Time Modulates the Kinds of Being," at https://www.academia.edu/35853850/How_Simultaneous_Multiple_Independent_Times_Impact_Our_Ways _of_Being (accessed September 16, 2018).

1172 "Originally all experiences belong together and the partition of experience into subjectivities was never strict and perfect in the first place," Pylkkö, The Aconceptual Mind, 161.

1173 "The research program of natural science which was launched in the early seventeenth century has, with the invention of quantum theory, come to the end of its road. The reason for this is that the research program was initiated with the overly optimistic expectations as regards the prospects of finding a comprehensive and consistent rational explanation of natural phenomena. Quantum theory frustrated these expectations seriously. This is so mainly because of the collapse of the wave function, the existence of which is accepted by most of the well known interpretations. The collapse forces us to accept a step from the deterministic and mechanical Schrodinger equation to statistical measurement results, and this step from determinacy to indeterminacy lacks rational foundation. The theory is unable to explain why this sudden burst of chance and indeterminacy happens. Wolfgang Pauli drew the conclusion that nature has eventually disclosed 
inspiration for the meaning of the aconceptual, in contrast to conceptual or nonconceptual. No individual or isolated parts or objects can be clearly discerned, isolated, or ultimately controlled in an aconceptual experience, as it is an inseparable ensemble and neither mechanical nor nonmechanical in its behavior. ${ }^{1174}$ It is what the quantum as world appears to be, non-locally enmeshed yet containing random behavior, meaning noncomputable or noncalculable. As such, he postulates that "there occur brain phenomena which" can only "be described adequately ... [with] quantumtheoretical notions." ${ }^{1175}$ But this means that science itself has become holistic, encompassing properties that were previously only granted to the rational mind, namely experiential time, freedom and inseparability. Of course, he will understand this freedom differently than it has traditionally been understood, which will be examined below.

The important thing to note, however, is how Pylkkö's view relates to the ground of reality which grants reality its possibilities. Pylkkö himself never addresses this in a precise manner similar to what Heidegger does, but this does not mean his ideas don't have implications for the issue. Gordon Globus, who is also a neurophilosopher and fellow strong Heideggerian sympathizer, explains that for Pylkkö, "bald randomness [is] at the very ground of existence."1176 This is essentially an accurate statement of Pylkkö's view, but it is also misleading. Pylkkö does assert that an aconceptual randomness lies at the foundation of reality, and that this relates to the ongoing flux of reality, but this does not mean reality is entirely left to randomness. ${ }^{1177}$ Many of the forces of nature at the chemical

its irrational face which had been covered for about three hundred years under the thin mask of exaggerated rationality. The mask's scaffold is the carefully built edifice of classical science and classical logic," Pylkkö, The Aconceptual Mind, 39.

${ }^{1174}$ Pylkkö, "Indeterminacy and Experience," 326-327. "A physical event is said to be inseparable if and only if its evolution in time cannot be predicted from its alleged subsystems," ibid., 323 . With that in mind, "Where the human thought goes is a matter which cannot be decided by any conceptual, let alone mechanical, method. Human thought remains ultimately unpredictable and aconceptual. The situation can be compared to the collapse of the wave function of quantum physics: Just as it is with microphysical phenomena, we are, at most, always able to tell a posteriori where a thought has ended to," ibid., 327.

1175 Pylkkö, The Aconceptual Mind, 29-30.

${ }^{1176}$ Gordon G. Globus, Quantum Closures and Disclosures: Thinking-Together Postphenomenology and Quantum Brain Dynamics, 108.

${ }^{1177}$ Pylkkö, The Aconceptual Mind, 81-82. "Strictly speaking, it is not ... necessary to assume that genuine randomness and inseparability reign." Rather, "it is sufficient if we assume that the human brain is immediately related to such a physical environment where random and inseparable phenomena occur," ibid., 82. 
and biological level continue along their general paths-now more as strong tendencies than strict laws. Yet, to assert that some physical behavior is random does not mean that there are no law-like forces at all at work in nature, but that those forces do not prevent or preclude randomness in itself, they merely interact with it.

In summary, concerning time, what makes time, or experience, possible for Pylkkö are the three phenomena of quantum physics of nonlocality, entanglement, and randomness. Because these properties are necessary for the human experience of time, they must also exist in nature. This means that nature, too, experiences 'time,' and nature and humanity's time are bound together as one. This does not mean, however, that Pylkkö doesn't offer explicit comments concerning human time which will now be examined.

\section{Time in the Humanities}

Given that time is the 'how' of reason's structure for Heidegger, and thus the ground of all 'science,' Pylkkö also must account for how this process could be fully naturalized. Therefore, for Pylkkö, science itself must become a new enterprise, ${ }^{1178}$ and may be better described as something called "man's interactive thinking of nature," or "nature as a human experience."1179 As such, if "the human mind and language are originally aconceptual experience which is not controlled by a rational, representative and autonomous subject, then the study of the human mind and language cannot simply begin with concepts and theories. Something which is aconceptual cannot be understood comprehensively in any purely conceptual framework."1180 Rather, the "human mind, language and

\footnotetext{
${ }^{1178}$ See also, Berger, The Unboundaried Self, and P. Kyle Stanford, Exceeding Our Grasp: Science, History, and the Problem of Unconceived Alternatives (Oxford, UK: Oxford University Press, 2006).

${ }^{1179}$ Pylkkö, The Aconceptual Mind, xx. "Natural science is essentially tied to the metaphysics of subjectivity and this view reduces the human mind and language into a representational mechanism," ibid., 101. Thus, "consciousness, especially modern Western consciousness which is shaped by modern Western common sense thinking, is biased to encourage such an approach to the study of the human mind which emphasizes its conceptual organization, and, therefore, consciousness almost necessarily sides with concepts in the struggle between the conceptual and the aconceptual in the human experience. Especially this holds for the scientific consciousness. It is plausible that consciousness, as it is equipped with concepts, especially with those of recent science, either ignores aconceptual experience as something irrelevant, perverse and crazy, or fails completely to observe the aconceptual in our experience," ibid., 93.

${ }^{1180}$ Pylkkö, The Aconceptual Mind, xxii. "From this kind of amorphous and astructural experience, things, objects and concepts may be derived as special, reified forms of experience which will, however, always remain partly entangled with their low aconceptual origin. Any science, including modern natural science,
} 
environment encompass an indivisible flow of perpetually changing experience. And, as with quantum-physical effects, we just decide to ignore the overall holism of the human mind in certain contexts" ${ }^{1181}$ and choose classical thinking instead.

For Pylkkö, human existence is primarily an ongoing aconceptual experience, one that is not an exercise in our evolving toward ever greater dogmatic clarity of absolute truths. The subjective aspects of reality cannot nor should not be eliminated, as they are intertwined with the external or socalled objective reality out there in nature. Rather, quantum "microphysical phenomena as such, that is, as human experience, are indeterminate and inseparable," and it is these features of nature which generate within us "the feeling that the future is, not only hidden, but genuinely open and indeterminate in us, so that it is not contained in the past and cannot be rationally derived from it either."1182 For Pylkkö, there is no ultimate barrier that exists between the external and inner worlds. Rather, they contain a holism that nevertheless allows what appears as an 'inner' experience. Owing to the nature of quantum phenomena, one may say that within the individual "perhaps there is an overall direction in the flow of experience; but, at the same time, if the flow is holistic enough, its causal organization may become distorted and the past and future could become entangled with one another,"1183 in a manner somewhat reminiscent of Heidegger's view of the three dimensions of time. Pylkkö's perspective on time in the humanities extends further, however, into the 'past.' He suggests that "biological evolution itself seems to have misguided us by providing us with a nervous system whose conception of knowledge is less than elegant and which contradicts the best of our

which tries to free itself from dogmatic objectivism, must study the preconceptual and preobjectual stage of (human and nonhuman) experience and derive its objects from it," ibid., xxii.

${ }^{1181}$ Pylkkö, The Aconceptual Mind, 70-71.

1182 Pylkkö, The Aconceptual Mind, 106.

${ }^{1183}$ Pylkkö, The Aconceptual Mind, 73. As such, "we must be careful with such words as cause and influence. Experiential action is not causal in any theoretical sense (say that of classical physics), because the experience which 'causes' a reaction in an experiential context loses its identity by becoming inseparably entangled with that experience which is 'caused' by it, namely, with that which is traditionally called 'effect.' Therefore, in the experiential realm, we cannot keep the cause and the effect separated and they become intertwined into an indivisible whole, and it is this that we, in our atheoretical language, call experiential interaction," ibid., 158. Thus, "extreme forms of commonality, such as objectuality ... arise from indeterminate and holistic experience through repetition," ibid., 157. Elsewhere, however, Pylkkö asserts that "consciousness has a clear temporal (irreversible) dimension. It has a direction towards the future, but at the same time, it has the ability to live simultaneously in the present and in the future," Pylkkö, Kielikuva ja Mielikuva-Ja Muita Dialektisia Esseitä, 80 (translation mine). 
physical theory, quantum theory." ${ }^{1184}$ Indeed, "it is not only our modern culture and its technology which lure us to explain our experience in terms of 'things' or 'external objects,' both concrete and abstract. The desire for objects runs deeper, namely in our genes. For the sake of argument, let us adopt here some notions of the biological sciences .... Our nervous system, due to its genetically determined structure, almost forces us to perceive and think in terms of external objects." ${ }^{1185}$ However, Pylkkö cautions, one must not simply assume "that evolution, in some realistic sense of temporal order, preceded the human experience. Rather, the evolutionary story, if properly interpreted, provides one interesting way to understand and organize human experience." ${ }^{1186}$ Indeed, that biological evolution "has endowed our brain with several rivaling, and not necessarily mutually compatible, ways to organize our experience may have had repercussions in the fragmentation of our culture. For example, the fact that we have several incompatible alternative frameworks of physics, such as classical physics, the theory of relativity and quantum physics, may reflect certain incompatible innate tendencies which our nervous system possesses for experience handling."1187 The above suggestions about human origins means that Pylkkö must also challenge much of what is termed 'common sense.' The aconceptual origins of human experience require him to

${ }^{1184}$ Pylkkö, The Aconceptual Mind, 13. Pylkkö suggests that "the human mind was there before external objects and the human language before concepts. Therefore, experience is not to be described in terms of externalization and conceptualization alone. There is much more to the mind than what can be conceptualized and experienced as external or internal objects. And, if cognition is something that can be comprehensively conceptualized, then, trivially, there is more to the mind than cognition alone," ibid., 12.

${ }^{1185}$ Pylkkö, The Aconceptual Mind, 12. It seems "the reificational processes are partly innate, coded into our genetic heritage, partly caused by maturation and learning. It seems that mammalian evolution has endowed our brain with a solid tendency to adopt a thing-based ontology. At the same time, related neural mechanisms codify some other experiences into the internal furniture of the self. These internalized experiences form a kind of conceptual system, a hierarchy and perspective of interests which we attach to the experience of being a subject. However, this may not be the only tendency with which the evolution has endowed our brain. We could say that the natural prephysics with which our brain is endowed is not only or purely classical. In addition to classicalness, certain nonreificational or aconceptual tendencies have been effective in the evolution of the mammal brain too. Thus biological evolution may have equipped us with several, mutually incompatible, experiential capabilities," ibid., 49-50.

${ }^{1186}$ Pylkkö, The Aconceptual Mind, 50.

${ }^{1187}$ Pylkkö, The Aconceptual Mind, 51. Pylkkö continues, "Heidegger certainly had good reasons to remind us of that our Modern Western culture, which is dominated by the interests of technology, tends to overemphasize the reificational aspect of our experience. In general, we could say that each cultural environment chooses to support and enhance a certain innate inclination in our neural organization, and vice versa. During the last three hundred years in particular, such organization of human experience which tends to objectify the experience has been particularly dominant, and we could add: intolerantly so. It was this dominance that Heidegger wanted to challenge when he coined the notion of onto-theo-logic," ibid., 51. 
"renounce some central dogmas of common sense, including crude versions of folk psychology, folk ontology and folk semantics, and, along with common sense, all standard common-sense-based conceptions of mind, language and science." Of course, this "restriction is a consequence of a requirement which says that a notion can be said to be naturalistically acceptable only if it can be constructed in experiential, neural, behavioral, social and historical terms, and this requirement will renounce most of the standard grammatical, logical and ethical notions, as well as the notions of classical science, as normative fictions." ${ }^{1188}$ To better understand the implications of this for humanity, it must be kept in mind that "the intensity of aconceptual experience varies perpetually and aconceptuality is the main source of experiential intensity. Thus, we don't say that when a person has a regular everyday experience with external common sense objects, like sticks and stones, that his experience is as intensive as the ultimate apersonal experience of a tantric mystic or political zealot. Nature isn't that democratic. There is a difference in experiential intensity involved."1189 This means that, to a great degree, religious experiences are valid, but also highly 'subjective.' That is, if one were to decide to describe aconceptual experience verbally, "we have (infinitely) many different discourses available, ranging from poetry and religious language to neurobiological and connectionist language." However, while this may be so, "one of the main restrictions that we want to impose upon these languages, as well as upon an adequate description of these languages, is that they should not resort to strong structural notions, especially not to standard logical, grammatical, Newtonian and ethical notions. Any attempt to use such notions would preclude the possibility of finding an adequate description"1190 by reducing them into a form more simple than their reality.

${ }^{1188}$ Pylkkö, The Aconceptual Mind, 13.

${ }^{1189}$ Pylkkö, The Aconceptual Mind, 13. As Pylkkö explains, "the reificational aspect of experience floats like a sloop on the high seas of aconceptual experience," ibid., 50-51.

${ }^{1190}$ Pylkkö, The Aconceptual Mind, 13. Of course, an "intensive aconceptual experience, as it reaches up to certain extreme stages, is what remains of the authentic Dasein experience after naturalization. The aconceptual experience is unstructured and holistic to such an extent that even the so-called authentic cannot be sharply distinguished from the inauthentic. The experience is essentially impure and open to all sort of natural, social and historical influences and disturbances. But even at its most extreme level, the experience has grown continuously and without categorical gaps from everyday experience, though everydayness here is not commonsensically explainable. This means, among other things, that our present-day everydayness is, through its aconceptual nature, already ineradicably contaminated by the scientific culture. Thus, no way to experiential purity is available. Even our most intensive religious, political and aesthetic experiences carry ingredients which originate from the scientific attitude," ibid., 14. 
While for Pylkkö there is a fundamental connection or unity between man and nature, it is also precisely the randomness of the quantum phenomena which generates the possibility of 'uniqueness,' which, when applied to the human, makes unique human experiences possible. This penetrates into every aspect of humanity, including cultures and languages. "There are no pure, nonhistorical or completely nonsocial experiences which remain constant and which would not vary as a function of the environment where they take place. Even the greatest joy, dread and rage are influenced by the environment where they arise. But this doesn't mean that meanings are culturally determined. Nature puts limits to such determination attempts."1191

This aspect of aconceptual experience, far from eliminating the individual, actually makes a form of individualism and communities possible. For Pylkkö, "genuine naturalism views language and mind in terms of experience. Experience as such and our neural conception of experience support each other at least in this respect: just as any two experiences are never identical, two neural processes aren't identical either. Even what is colloquially called 'one and the same person' can never return to a previous experience; analogously, his brain processes never return to a previous state. In other words, there are no persistent brain states. Experience is unique and irreversible."1192 Yet, this does not mean that individuals exist in isolation. Rather, because the individual is interwoven with his community and all of nature, aconceptuality "relativizes all meaning to a 'unique experiential history.' We could have also said 'unique neural history.' But this doesn't mean that we are dealing only with an experiential-neural history of one person (solipsism) because neural naturalism blurs the boundaries of persons, too, and it makes no sense to speak of experience only in terms of 'one' nervous system. Rather, we should speak of the experiential history of a community or even of the

\footnotetext{
${ }^{1191}$ Pylkkö, The Aconceptual Mind, 18. As such, "experiences which any two or more persons attach to the allegedly same verbal expression can never be identical with each other, and the direction in which an experience will transform a person represents something genuinely unpredictable only if the change is unique, something that no one else (including the person himself) has gone through before. Therefore, meaning (of what we carelessly call 'one and the same expression') varies from person to person (which means that actually there is no 'one and the same expression' after all). Experience is also open to social, ethnic, linguistic and other historical influences from the speaker's environment because the experiences which the speaker is able to attach to an expression do not arise in a cultural vacuum," ibid., 18.

1192 Pylkkö, The Aconceptual Mind, 19.
} 
human species."1193 Of course, "even species solipsism which this view might imply can be avoided because the experience of the human species cannot be strictly separated from nonhuman animal experience."1194

One other major point Pylkkö makes concerns the development of history within a culture group. Because of the fact that each cultural experience is unique and relative, it is also, in some manner, untranslatable. As such, "if there is any hope of ever finding acceptable conditions for intercultural dialogue, the conditions will be based neither on any common conceptual ground nor on rational patterns of conjoint action. For example, science is unable to provide such a ground or rationality of action. This view is perfectly naturalistic; actually, its negation, the universality claim of Western science, is deeply antinaturalistic." Pylkkö adds that in addition, "this kind of relativism doesn't automatically guarantee equality among cultures because every standard notion of equality presupposes either that a universal conceptual ground can be found or a common rationality unites human action," ${ }^{1195}$ but no such ground exists. As such, the hope for any truly universal culture is dim, as their experiences will always subtly differ.

One point of particular emphasis in Pylkkö's discussion of time in the humanities concerns what could be called his focus on synchronic time and diachronic time. What this distinction highlights is that Pylkkö sees temporality manifest both within the human life overall (including, perhaps, evolutionary development), as well as within the 'moment,' so to speak. That is, time is a part of the evolving reality of humanity, as well as what constitutes the individual's day-to-day experiences, such as dreaming and being awake. ${ }^{1196}$

1193 Pylkkö, The Aconceptual Mind, 19.

${ }^{1194}$ Pylkkö, The Aconceptual Mind, 20. "From this kind of relativized point of view, human experience is wild, untamed and culturally extremely heterogeneous: no universal logic, grammar, ontology, religion, ethics or science is able to unify it without violating the local uniqueness and variety of experience. And our notion of experience may be so wide that it covers phenomena from humans down to the 'behavior' of electrons," ibid., 20.

1195 Pylkkö, The Aconceptual Mind, 20.

${ }^{1196}$ Pylkkö, The Aconceptual Mind, 8. See also, Berger, The Unboundaried Self, 108-109; and Gregory Bateson and Mary Catherine Bateson, Angels Fear: Towards an Epistemology of the Sacred (New York, NY: Macmillan, 1987), 106-107. 
In summary, for Pylkkö, what time consists of is unique irrepeatable aconceptual experiences. ${ }^{1197}$ This is made possible by the random yet inseparable phenomena of the quantum ground of reality. Without the aconceptual ground, experiential time as such would not be possible, both for nonhuman as well as human reality. What remains is to focus on how freedom manifests itself within Pylkkö’s view.

\section{Pylkkö's View of Freedom}

Pylkkö's view of freedom, as for time, requires an interconnected view of the human and the rest of nature. In the following, first Pylkkö's view of freedom in nature will be described, and then his view of freedom in the human and society. Again, Pylkkö derives his views from a Heideggerian background, which was shared above, and will not be focused on below.

\section{Freedom in Nature}

Because of the nature of holism exhibited in Pylkkö's view, ultimately, the freedom in nature and humanity are 'one,' in that they share a common ground. That is, what makes freedom possible in humans is that nature is such that this freedom is possible. This means that one of the major issues of the role of freedom in nature in general concerns the fact that nature is not subject to standard or dogmatic scientific presuppositions. That is, our view of nature currently limits us from seeing any freedom in nature. ${ }^{1198}$ Pylkkö believes this situation must change. Thus, "every theory which has room for genuine indeterminacy and chance has drawn a limit for the theoretical reason, and, therefore, the limits which standard scientific explanation cannot surpass. Whether it is God or Devil who reigns beyond the limit, I am not willing to guess here. But whatever it is, all that good theories

${ }^{1197}$ Pylkkö, The Aconceptual Mind, 107-108.

1198 "If science actually is what dogmatic scientists claim, namely, a project which searches for general and consistent laws of how external things behave, then the answer to our original question whether modern science is onto-theological is trivially: yes. If the credo that science reveals to us what the lawful relations of external things are is tenable, and if the related folklore of how the human mind and language are related to the things is basically correct, then modern science is certainly very onto-theo-logical indeed, the epitome of philosophical naiveté. Alternatives for dogmatic science, as well as for the dogmatic self-image of science, are rare and often classified as scientifically irrelevant or even unscientific," Pylkkö, The Aconceptual Mind, 39. 
seem to be able to do is that they reveal to us in which sense and to what extent we are irrational,"1199 at least as the word is used and understood by the vast majority of scientists.

Freedom, in nature, is indeed based upon fundamentally indeterminate and unpredictable quantum-level behavior. That is, there "seems to be an irrational aspect in quantum phenomena, and that aspect is the unexplainable step from determinism to randomness" ${ }^{1200}$ as one proceeds from macro- to microphysics. Thus, if it is true, as has been widely argued, that "physical phenomena are irreducibly indeterminate and inseparable," then "already the formalism of the quantum theory and related measurements which attempt to impose upon these holistic phenomena a formal and mechanical frame which never really fits ... generates a bunch of paradoxes." ${ }^{1201}$ Thus far, there is no way beyond this impasse in contemporary physics aside from speculations of a Bohmian fashion. Even the standard Copenhagen view, by inversely reducing the individual randomness to statistical patterns, ignores the fundamental problem. Pylkkö's real concern, of course, is not to dwell upon the contingency of nature, but to focus on what this means for humanity. Below his works on the nature of human freedom, for both the individual and society, will be explored.

Freedom in the Humanities

For Pylkkö, "indeterminate and unpredictable neural events" are indeed "one of the sources of human freedom. If chance is an irreducible aspect of microphysical phenomena, and it turns out that quantumphysical terms are necessary in the proper description of the human brain, then we have found some ingredients for a naturalistically credible view of the origin of human freedom."1202 Otherwise, we are left with a number of contradictions in neuroscience which are no longer tenable in contemporary physics. Pylkkö's view, of course, is in direct contrast to "all traditional versions of dualism," which "rest heavily on the idea that there exists a conscious subject which reflects the things of the world with the help of its concepts, and that it is the freedom of the subject's will that

\footnotetext{
1199 Pylkkö, “Eliminative Holism as a Solution to Bohr's Puzzle of Two Languages,” 154.

${ }^{1200}$ Pylkkö, The Aconceptual Mind, 86.

${ }^{1201}$ Pylkkö, The Aconceptual Mind, 86.

1202 Pylkkö, The Aconceptual Mind, 104.
} 
vaults man above the causally closed world of things."1203 For example, Pylkkö notes that his "view of freedom as aconceptual experiential randomness is in conflict with many renowned theories of human freedom. The problem of human freedom, for example with Kant, is often understood as the problem of how rational thinking can be autonomous, that is, free of external influence, and therefore nature, for example the human body and its natural demands, is seen as a hindrance of freedom."1204 Or, alternately put, tradition has told us that the "human will is said to be free it if is not dominated by unconscious obsessions, natural passions or biological drives." But Pylkkö thinks that "this line of thinking leads to the conclusion that it is exactly the natural or animal aspect of the human being which is not free, and that it is the freedom of the will which somehow elevates the human being above the obsessively and blindly unfree nature."1205 Yet, after hundreds of years of traditionalists attempting to follow this philosophical impulse, Pylkkö's analysis of the situation would suggest it has finally failed. ${ }^{1206}$ This does not mean the idea of a free-will is utterly eliminated-it merely suggests that there is a random freedom at play in the lower animal, and even lower still, physical, aspects of reality, which generate some of the possibilities of human freedom.

The idea that freedom is related to randomness, however, does not mean that it is "necessary to assume that genuine randomness and inseparability reign in the human brain." Rather, "it is sufficient if we assume that the human brain is immediately related to such a physical environment

${ }^{1203}$ Pylkkö, The Aconceptual Mind, 29.

${ }^{1204}$ Pylkkö, The Aconceptual Mind, 104. The problem with Kant's thesis is that it "rests on the idea that nature is mechanical and deterministic, whereas the human mind is free exactly because it is able to wrench itself above and away from its low natural origins. This version of antinaturalism is so popular that even such thinkers who would otherwise like to distance freedom from rational thinking and associate it with unconscious creativity, negativity, deviation from norms, and so on, still see nature as the enemy of freedom, as if the rationally graspable law-likeness were the ultimate essence of nature," ibid., 104-105. See also, Pylkkö, "Indeterminacy and Experience," 321-329; and Pylkkö, Kielikuva ja Mielikuva-Ja Muita Dialektisia Esseitä, 142, 406.

1205 Pylkkö, "Indeterminacy and Experience," 323-324.

1206 "The problem of the freedom of the human mind is, among other things, the problem of how standard natural science is able to attribute to the physical such properties which we expect the human mind to possess. For example, if the relationship between the human body/brain and mind proves seriously problematic, we have good reasons to suspect that our conception of the body is designed to satisfy the separation and individuation conditions of classical natural science. Only the classical notions of thing and body, not human experience as a whole, satisfy the classical separation and individuation principles. As long as our conception of science conforms with the most dogmatic aspects of standard classical science, the freedom of the human mind either escapes our explanation or appears as a paradoxical anomaly," Pylkkö, The Aconceptual Mind, 112. 
where random and inseparable phenomena occur. This suggests, among other things, that the so-called freedom of will should be associated, not directly with the results of the choices which we allegedly make in conscious thinking, speaking and planning, but with such genuinely aconceptual ingredients of our experience which, in some sense, precede conscious thinking, speaking and planning."1207 That is, we can say that the view of freedom as partly a random process finds "one of the sources of freedom, not only in nature, but in the 'lowest level' of natural phenomena, that is, among microphysical phenomena. This would be so even if it were practically feasible or almost necessary to consider the human brain as a classical system. If we want to attain proper understanding of the behavior of living organisms in the natural environment, we cannot ignore all of the influences which random microphysical phenomena exercise upon the organism." ${ }^{1208}$ It is noteworthy that Pylkkö is not alone amongst contemporary philosophers and scientists in seeing randomness or genuine indeterminism in nature, and a part of what constitutes the conditions to make meaningful nondeterministic human freedom possible. ${ }^{1209}$ That is, freedom is not fully random, but random indeterminism is a required ingredient. All of this relates, quite naturally, into the issue of time, as well. For "at the moment of an aconceptual experience, the future lies open and unpredictable in us, waiting to be unfolded and evading the controlling grasp of reason. Some part of the future always remains irreducible to past events, and no conceptual or rational means, let alone mechanical means, can help us to predict its course with comprehensive accuracy."1210

Pylkkö attempts to demonstrate how randomness may play a major role in human life, including in such areas as psychological surprise, and also political and cultural developments. That is to say, humans are 'surprised' when something violates their typical conceptions, which conform to standard scientific presuppositions. Of course, such surprises can prove desirable or undesirable, but in either

\footnotetext{
${ }^{1207}$ Pylkkö, The Aconceptual Mind, 82.

${ }^{1208}$ Pylkkö, The Aconceptual Mind, 105.

${ }^{1209}$ Doyle, Free Will: The Scandal in Philosophy, 225.

${ }^{1210}$ Pylkkö, The Aconceptual Mind, 104.
} 
case, they constitute some of the strongest aconceptual experiences humans have. ${ }^{1211}$ In like manner, playing or "gaming is not only rule-following, but also an experiential environment in which we can encounter the remnants of our freedom"1212 and its aconceptual origin.

Pylkkö explores the political ramifications of his views at some length as well. For example, he argues that those who suggest, such as the philosopher Paul Feyerabend, "that societies which are dedicated to freedom and democracy" must merely "treat science as one tradition among many others, without conferring any privilege to scientific truths, and without allowing science and scientists to decide social or political issues outside of scientific communities,"1213 are missing a fundamental problem, even as they correctly attempt to critique the dominant role of science. The main "unaddressed problem with this view is that it is far from obvious that democratic persons, thinking habits and institutions can, even in principle, treat technology and science as one tradition among others, let alone challenge the power of technology and science in any other than a superficial and diluted manner."1214 This is so because, "on the one hand, democratic thinking and the related individualistic notion of freedom, which Feyerabend cherishes, and, on the other hand, the modern technological and science-inspired conception of man and man-nature relations, are parallel outgrowths and mutually depending derivations from the very notion of Western subjectivity" that grounded the rise of science in the first place. "Thus, if we expect democratic persons, thinking habits and institutions to question seriously the role of technology in our societies and in the global arena in general, we are, most probably, expecting, not only too much, but also something impossible."1215

Corresponding to the above, Pylkkö favors a more local or nationalistic picture of democracy that is more respectful of regional cultures. This is because he believes any democracy, but especially

\footnotetext{
${ }^{1211}$ In the case of surprises, "what triggers the eruption of our energy and becomes experienced as surprise must somehow be deviant or even perverse with respect to the conceptions which our expectations consist of. It must be something in front of which our semiotic habits turn out to be helpless.... Surprise disarms our semiotic intelligence temporarily and reveals the uncertainty on which its concepts lie. Surprise comes out of this temporary helplessness or disorientation during which intelligence is not fully in control," Pylkkö, The Aconceptual Mind, 116.

1212 Pylkkö, The Aconceptual Mind, 117.

1213 Pylkkö, The Aconceptual Mind, 186.

${ }^{1214}$ Pylkkö, The Aconceptual Mind, 186.

1215 Pylkkö, The Aconceptual Mind, 186.
} 
those grounded on science, represent a "program to unify locally varying human experience."

However, such democracies have "turned life" into "a welfare state" of "monotonous boredom and

slow ecological disaster." At the same time, they destroy unique local cultures with "no regret."1216

Only a new way of thinking, opened up by the possibility that "non-Western thinking, or thinking in

the Western periphery, because of its marginal position and its immediate connection to asubjective

and aconceptual local experience and a nontechnological environment, may provide a revitalizing

point of view to these problems." ${ }^{1217}$

Of course, Pylkkö is aware that, at least for Heidegger, some of the above impulses led to his

support of the National Socialist movement. ${ }^{1218}$ Indeed, Pylkkö credits the Nazi movement for being

precisely the kind of genuinely aconceptual experience that constitutes a people, and, as such, it is not possible to provide a 'rational academic' theory for how and why it emerged and did what it did. ${ }^{1219}$

\author{
${ }^{1216}$ Pylkkö, The Aconceptual Mind, xxv. \\ ${ }^{1217}$ Pylkkö, The Aconceptual Mind, xxv. See also, Pylkkö, Luopumisen Dialektiikka, 236; and Pylkkö, \\ Ajatus ja Kädet, 92. \\ 1218 Pylkkö, The Aconceptual Mind, xv-xvii. \\ 1219 "It is often difficult for academic scholars to admit that world-historical events are inspired and
} shaped by openly nonacademic ideas, that is, by ideas which must appear to them as immature, inadequate, unscientific, and often almost ridiculous. Contrary to these, academic theories themselves are usually highly intellectualist and tend to picture man as overly rational, goal-directed and autonomous. Therefore, they often fail to find a balance between rational, irrational and arational ingredients of human experience and behavior. When academic theories are forced to deal with such partly obscure, violent, arational and even partly irrational events as, for instance, Nazism, the World Wars and recent genocides, they give in to the temptation to introduce some "hidden variables" with the help of which these obscure and obnoxious events are rationalized. Typically, the intellectualist bias tends to suppress the experiential aspect of Nazism and replace it by the agenda of secret but rational motives. A popular explanation along this line is to see Nazism as a conspiracy of Capital against the Workers. It is hard for us to admit that, from the Nazi point of view, Hitler's war was a war against the International Jewry (Judentum), and against Bolshevism and the International Capital as special manifestations of the Jewish conspiracy, and that the rationality of the war, however thin it may have been, was in Hitler's endeavor to save the authenticity of the German culture. Yet this is what Hitler and the other Nazi leaders seriously believed they were doing. In order to understand the Nazi movement, this must not be ignored and replaced by profound and overly rationalizing hidden motive explanations.

"The national revolutionary experience had its hidden, unconscious and aconceptual aspects, too, but these aspects cannot be reduced to some intellectually controllable variables. The Germans were not searching for their missing identity so desperately that they became second-rate, almost schizophrenic, imitation Frenchmen.... There was no hidden logic, unconscious (Freudian) code or other veiled agenda. Instead, there was something thoroughly aconceptual involved, and it seems that every purely intellectualist theory ... is in serious trouble as it attempts to deal theoretically with something which remains strongly, though not completely, atheoretical. Actually, it is questionable whether any theory of Nazism can be adequate, assuming that the word theory is used in a regular logical and conceptual sense. Only certain relatively rational aspects of Nazism are theoretically accessible, and every thinking that lacks access to the genuine aconceptuality will always fail to comprehend Nazism adequately. What is needed for the proper understanding of Nazism is an access to the experiential asubjectivity and aconceptuality which may be so intensive that even the identity of the understanding subject is in danger. Thus, it is not the theoreticity of the theoretical attitude alone that 
Yet, within a broader perspective, Pylkkö is pointing out that a culture's "experiential uniqueness is open to perpetual influence and change which may, however, be unpredictable and conceptually uncontrollable. Some influences may arise from straight confusion and misunderstanding; others are based on more careful thinking, even on interpretations which try to shift meanings over cultural barriers from one language into another." ${ }^{1220}$ Yet, nonetheless, "genuine intercultural dialogue which is not one-directional is based on interpretation," and the aconceptual reality of any "interpretative influence lacks method and rules," and thus "it may be partly accidental, sometimes almost miraculous, but, at the same time, it may be the only way to preserve cultural variety under the pressure of global unification, and even the future of democracy may rest on its prospects." ${ }^{\text {2221 }}$

With such concerns in mind, it is obvious that Pylkkö objects to any global unification through dogmatic science and its authoritarian ontotheological character, ${ }^{1222}$ yet, at the same time, he acknowledges that "the best that democracy can offer to us is variety, perpetual change, tolerance and such struggle which enhances change and allows the variety to flourish." ${ }^{1223}$ However, "this doesn't

makes the explanation of Nazism impossible; what makes it impossible is that the theoretical attitude, as a manifestation of reason, accepts and utilizes the inhibitive role which the monitoring subject exercises upon the rest of the human experience. Reason is always selfish, and, therefore, a biased judge when it has to encounter some aconceptual experiences. Nazism as such lies relatively open and unhidden before anyone who is not afraid of adopting the asubjective approach," Pylkkö, The Aconceptual Mind, 225-227, and 216.

${ }^{1220}$ Pylkkö, The Aconceptual Mind, 279.

${ }^{1221}$ Pylkkö, The Aconceptual Mind, 279.

${ }^{1222}$ Pylkkö, The Aconceptual Mind, 279. Any "universalism is an illusion, not much more than a misnomer for the globalization of Western ideas, and its practical consequence will be cultural unification, even if universalism is advocated under such seemingly well-intending banners as 'intercultural communication' and 'global human rights.' Modern Western technology and science, including logic and grammar, as well as the related ideals of the Enlightenment, are products of local Western culture whose claim of universal validity is pretentious," ibid., 279. Pylkkö would thus concur with James Rosenau, who argues that "so dominant in contemporary consciousness is the assumption that authority must be centralized that scholars are just beginning to grapple with how decentralized authority might be understood," "but the question of how to think about a world that is becoming 'domesticated' but not centralized, about a world after 'anarchy,' is one of the most important questions today facing not only students of international relations but of political theory as well," Alexander Wendt, as cited in James N. Rosenau, "The Governance of Fragmegration: Neither a World Republic Nor a Global Interstate System” (modified 2000), at http://aura.u-pec.fr/regimen/_fich/_pdf/pub_ 002.pdf (accessed September 16, 2018). See also, Christopher R. Counihan and Mark J. Miller, "Competing for Global Talent in an Age of Turbulence," in Competing for Global Talent, eds. Christiane Kuptsch and Pang Eng Fong (Geneva, Switzerland: International Labour Organization, 2006), 259-277; and Keith Carlisle and Rebecca L. Gruby, "Polycentric Systems of Governance: A Theoretical Model for the Commons," The Policy Studies Journal Vol. 00, \#00 (2017), 1-26.

${ }^{1223}$ Pylkkö, The Aconceptual Mind, 208. Through his naturalization of Dasein, which Heidegger resisted as he wanted it reserved for the German people alone, Pylkkö is suggesting that "by introducing tolerance, we open Dasein to intercultural interpretation and foreign influence. This doesn't yet make Dasein peaceful or nonviolent. On the contrary, by acknowledging irreducible cultural uniqueness we deny the possibility of such 
necessarily suggest peaceful or nonviolent action, because peace is often utilized as a powerful method of cultural unification. Thus, at their best, democratic gaming arrangements might influence and shape the emergence of subjectivity in a way that would enhance the intuitively important goals of variety, change and tolerance. In doing that, democracy should neutralize all such trends of power processes which tend to unify our experience and reach a totally comprehensive grip of our minds." ${ }^{\prime 224}$ That is, it is better to have a little disharmony and tolerant variety, than a total harmony that intolerantly eschews unique cultures and freedom. ${ }^{1225}$ For this to be recognized, however, one must acknowledge that the "origin of tolerance lies in accepting natural and experiential indeterminacy. Every serious naturalist says that either the objects to which culturally intolerant ideas refer are not (do not exist) at all, or if a community defines some ideas in a culturally intolerant way and the objects to which they refer must, in some sense, be said to 'be,' then their demand of universality is pretentious and they are actually just local fictions."1226

Pylkkö, for his part, and in harmony with some of Heidegger's sentiments, ${ }^{1227}$ prefers cultures that are farther away from technology's dominance than nearer to it, as the closer one is to nature, the more likely one is to be conscious of one's aconceptual origin. ${ }^{1228}$ As the sympathizer to Pylkkö, Louis Berger, explains, "it is difficult for us to save ourselves by ourselves because, Heidegger maintains, while we think science-technology is value-neutral and that we can use it for good or evil, that we are its masters, this is utterly wrong. Actually, without our realizing it, technological thinking is a way of

\footnotetext{
intercultural communication which is based on the idea of a ground of common meaning. This may fuel violence just as easily as peace in intercultural personal or national relations because both alternatives may be based on a proper interpretation. Culturally tolerant shamanism doesn't preclude the possibility that a shaman resorts to violence in his attempt to preserve the uniqueness of his culture against the unification pressures of the Western science. Thus tolerance doesn't imply nonviolence. A culturally unified world which is dominated by modern technology and democracy will be peaceful indeed," and also lacking freedom and cultural diversity, ibid., 24.

${ }^{1224}$ Pylkkö, The Aconceptual Mind, 208.

1225 "The major pitfall of nearly all regular theories of democracy (equality, tolerance, and so on) is that they deal only with the end product and upper layer of the organizing processes through which the subject emerges. This end product, the enlightened, rational and autonomous Western subject, is not only a culturally and historically specific local commodity, but a thin upper layer of the Western mind itself. It is far from obvious that this layer which makes itself manifest in conceptual and theoretical thinking and rational planning can picture the rest of the mind in an unbiased way," Pylkkö, The Aconceptual Mind, 189.

${ }^{1226}$ Pylkkö, The Aconceptual Mind, 23.

${ }^{1227}$ Vadén, Heidegger, Žižek and Revolution, 74-75.

${ }^{1228}$ Pylkkö, Ajatus ja Kädet, 34-38.
} 
being in the world that totally dominates and leads us (and has done so for millennia), no matter how hard we try to control it: 'Everywhere we remain unfree and chained to technology, whether we passionately affirm or deny it."'1229 In the technological West, Pylkkö explains, fundamentally "we believe in reason and that everything that is, is reasonable, and that everything that is possible can be explained through reasonable explanations,"1230 but in reality this is all an unfounded myth.

In summary, for Pylkkö, freedom is grounded in the quantum phenomena that has generated the concepts of randomness, inseparability, and nonlocality. Owing to these features of nature, the human mind and its freedom is also associated with randomness and uncontrollable elements. This is not to say that the human mind does not also make choices, or is not also predisposed by other neuroscientific principles, but that the ground which makes these choices possible must also include an aconceptual quantum realm. The consequences of this are broad and significant, and Pylkkö articulates how an aconceptual view of democracy differs from one grounded upon classical or dogmatic science alone. Issues of tolerance and universality are given new meanings and roles, and Pylkkö's valuing of cultural variety highlights his newfound purpose of what democracy can and should do for society, which is far more limited than its advocates would typically suggest. Below, Pylkkö's view on the relations of freedom and time will be examined.

\section{Pylkkö's View on the Relations of Freedom and Time}

As can be seen from the above examination of Pylkkö's views of time and freedom, Pylkkö clearly sees them as related concepts-they are two sides of the same coin, so to speak. However, determining the precise relations of freedom and time in Pylkkö's writings for the purposes of this study requires one to distinguish between his understanding of causal forces and random forces in

\footnotetext{
${ }^{1229}$ Berger, Humanity's Madness: Consequences of Becoming Literate, 33. Citing Martin Heidegger, "The Question Concerning Technology," tr. William Lovitt, with David Farrell Krell, in Martin Heidegger, Basic Writings, ed. David Krell (New York, NY: HarperCollins, 1993), 321. Berger continues, technology "is in charge. Isn't our present-day mess more than ample evidence? We seem unable to curb the devastation and threats made possible by contemporary technology and science (we say that things 'have gotten out of control')-and this, incidentally, is why relying on just more and better technology and science to solve our daunting problems, why relying heavily or even exclusively on exotic technological, 'cutting-edge' green solutions, probably harbors more problems than it solves and unwittingly may well launch us on a parallel path that in the long run leads to just as dangerous an end-a path that really isn't a true alternative," ibid., 33.

${ }^{1230}$ Pylkkö, Ajatus ja Kädet, 9, translation mine.
} 
nature, in addition to any weakened concept of free-will within humans that remains. That is to say, for Pylkkö, it is their combination that determines the flow of time, and all of reality is also inseparably linked. One cannot really say, in quantum physics, that the past is fully no more, and the future is fully not yet-they are intertwined, and yet neither fully determines or is determined by the other. This is in partial contrast to Heidegger, who only saw time as an experience for the privileged being (Dasein).

In the above sense, however, for Pylkkö, it can be argued that all of reality is truly ontologically temporal. Everything is constantly in a state of flux and change, and there is no such thing as a timeless platonic permanency. ${ }^{1231}$ Because he applies it to every discipline, the consequences are significant, and Pylkkö is faced with the distinct problem of finding a new way to position his theory of time, as well as freedom, into a culture that is predisposed not to accept it.

Pylkkö supports a more horizontal view of reality. What this means is that he does not seek for any inner or hidden explanations to the puzzle of human freedom in relationship to a deterministic view of natural science. Pylkkö allows the tension to exist, opting more for what his sympathizer Berger would refer to an "all-encompassing fundamental paradox" stemming from a number of disparate paradoxes. Rather than "hiding or ignoring the various apparently separate paradoxes, or seemingly explaining them away by scientistic means," we should "not do violence to the underlying mysteriousness of being in the world," and "honestly" acknowledge "the inescapableness of that paradox."1232 Thus, the only way past the paradox, for Pylkkö, is to truly accept the implications of the paradox and move beyond the conceptual-nonconceptual impasse into an aconceptual reality-there is no other 'resolution' possible. ${ }^{1233}$

\footnotetext{
${ }^{1231}$ Pylkkö, “Eliminative Holism as a Solution to Bohr's Puzzle of Two Languages,” 140-156.

${ }^{1232}$ Berger, Averting Global Extinction: Our Irrational Society as Therapy Patient, 52. See also, Guy Burneko, "It's Child's Play: Contemplative Anthropocosmic Creativity," in World Futures: The Journal of New Paradigm Research Vol. 70:8 (2014), 500-503.

1233 "In order to avoid these paradoxes, nondogmatic naturalism might suggest, among other things, that natural language and the human mind are primarily aconceptual and asubjective experience. In order to produce things, concepts and subjects, the experience has to be reified by repeated associations which eventually shape the experience into what creates the impression that some internal objects (concepts) and external objects (things) are present," Pylkkö, The Aconceptual Mind, 69. For alternate, but somewhat compatible reflections, see Kent D. Palmer, "Intertwining of Duality and Nonduality," at http://www.isss.org/ 2000meet/papers/20163.pdf (accessed September 16, 2018); Kent D. Palmer, "Questioning the Terminology of
} 
The all-encompassing nature of Pylkkö's theory does make it relatively simple to position his views on the relations of freedom and time for both the sciences and humanities. That is, they are directly parallel. Owing to the general unity and undivided wholeness of reality, both time and freedom originate from out of a universal temporality that is aconceptual.

What remains is to examine Pylkkö's usage of the concept of God and to see how his views of time and freedom might contribute to theological reflection on the concepts of time and freedom.

\section{Pylkkö's Usage of the Concept of God}

When examining Pylkkö's usage of the concept of God, the shadow of Heidegger's ontotheological critique of Western philosophy must be kept in mind. That said, Pylkkö spends considerably less space than even Heidegger explicitly discussing God or the idea of theos, except to say that mankind now needs no god to realize that the technological attitude need not be taken as an absolute. ${ }^{1234}$ Recall that, for Heidegger, the traditional 'ontotheological' conception of God was actually 'godless.'

For Pylkkö, his conception of the role of the divine is demonstrated most clearly in the following comment, where he shares that, Heidegger "was not willing to admit, or even to see, that the weakest link in the essence of technology, where the dominance of technology may begin to break down, lies within the most perplexing department of modern science itself, namely in quantum theory and in its

Nonduality: An Exploration of the Foundations of Nonduality," at http://nondual.net/nds11 a03.pdf (accessed September 16, 2018); Kent D. Palmer, "An Approach Toward Being, Existence, and Manifestation: From the Kindness of Being to the Face of the World and Beyond," at http://archonic.net/fe00v01.pdf (accessed September 16, 2018); and Kent D. Palmer, "Advanced Systems Theory for Systems Engineers: Introduction to the Anti-thesis," at http://holonomic.net/sd00V01.pdf (accessed September 16, 2018).

${ }^{1234}$ Pylkkö, The Aconceptual Mind, 75-76. Or, as Heidegger explained, "The modern position is the 'technological.' It is not technological because there are steam engines and then the combustion motor, but there are these things because the epoch is technological. What we call modern technology is not only a tool and a means, over and against which today's man can be a master or servant. Before and beyond these possible attitudes technology is an already decided mode of world-interpretation, which determines not only the means of transportation, subsistence, and recreation but also the possibilities for any human attitude whatsoever. It preforms them according to their capacity for implementation. That is why technology is mastered only where it is affirmed from the outset and without reservation. That means the practical mastery of technology in its unconditional development already presupposes a metaphysical subjugation to technology. Accompanying this subjugation within us is an attitude that grasps everything according to plan and calculation, and does so with a view to vast time-spans in order willfully and knowingly to secure what can last for the longest possible duration," Heidegger, Basic Concepts, 14. 
aconceptual and holistic nature.... Heidegger resigned to the mercy of divine help and proclaimed that only God can save us. But perhaps the salvation, or the end of onto-theo-logic and the dominance of Gestell, needs no God to be accomplished. Maybe the Gestell itself is able to do it."1235 In other words, the situation facing Heidegger inspired him "to speak of the history of Western thinking as a history of forgetfulness of Being (Seinsvergessenheit). According to this vision, the essence of technology (Technik), the Gestell, is an overwhelming frame of mind which forces us to think and experience in terms of external objects and internal concepts." Unfortunately, for Heidegger, "this frame of mind leads us to a kind of experiential desert or waste land, and the force of the frame can be overcome only after our thinking has adopted a crucial turn. Heidegger seems to have thought that we cannot take the turn without God's help. Now, in the light of [physicist Wolfgang] Pauli's view of the irrational aspect of statistical causality, it seems that the Gestell needs no divine help in preparing its way down: the Gestell, the core of technology, contains the seeds of its own destruction."1236 Nature has shown us an escape from its perceived determinism and a pathway to 'freedom' without any explicit 'god.' The significance of this cannot be overstated, as it in essence defends Heidegger's basic demand for an overcoming of the perils of ontotheology through the very heart of the contemporary world's embracement of ontotheology, namely, natural science and its technology, something which Heidegger all too well recognized. ${ }^{1237}$

For Pylkkö, then, 'science' is not a tool which can ultimately cut nature at its joints, ${ }^{1238}$ because nature itself exposes a transcendent quality within itself. This is not a divinization of nature,

1235 Pylkkö, The Aconceptual Mind, 75-76.

${ }^{1236}$ Pylkkö, The Aconceptual Mind, 75-76. That is, "the primordially physical, or physis, as Heidegger would have put it, is not exhausted by the notion of bodyhood and thingness. Rather, our habit to think of the physical in terms of bodies and things is an attempt to domesticate the physis, tame it in order to make it serve certain technological purposes. Quantum theory and some of its interpretations remind us that this taming process can never be perfect, and the physis aspect of nature always remains partly unreliable. If this is so, at least one of the ingredients which has contributed to the rise of the so-called body-mind problem is dissolved. The physical is not reducible to the behavior of classical bodies," Pylkkö, The Aconceptual Mind, 75-76.

${ }^{1237}$ For Pylkkö, then, he hopes to have delivered the ultimate dagger for justifying the necessity of overcoming ontotheology if the primary reason ontotheology is still accepted by someone is their implicit acceptance of modern science.

${ }^{1238}$ Globus, Quantum Closures and Disclosures, 111. Globus explains that "Pylkkö would deny the traditional belief that 'science cuts nature at her joints,' because he thinks of nature as quantum nature which really doesn't have any joints; the joints, he thinks, are merely fictions that change over time," ibid., 111. 
however, any more than the Leibniz identity principle, which is central to mathematics, is a divinization of sorts functioning as a metaphysical ground. ${ }^{1239}$ That is to say, the way the scientist commonly uses mathematics divinizes mathematics as much as Pylkkö divinizes nature. The question, then, that is pertinent becomes understanding the relationship between philosophy and theology. Pylkkö believes that, "according to Being and Time, philosophical understanding, especially understanding of man and his relation to Being, cannot be based on any positive study of nature alone because there is a categorical order of direction in Heidegger's philosophical approach," and, Pylkkö continues, "studies of nature, as they are normally carried out, are never at the beginning of the order."1240 However, if a nondogmatic naturalism is accepted, this categorically ordered flow can be revised. Science itself can become an aid to philosophy. Or, more accurately, there is nothing but philosophy left-classical science, grounded on mathematical platonism, including its residue found in the scientific picture of nature, is destroyed once and for all, including for any form of anthropology or natural theology. ${ }^{1241}$ Natural science, understood classically, doesn't actually exist as something philosophically meaningful or metaphysically grounding anymore; it is nothing but the remnants of ontotheology infecting philosophy like a virus, reproducing itself through a universal objectivization which seeks dominance in all fields. Classical science is, therefore, not philosophically useful for Pylkkö; it is deficient and unhealthy for philosophy, in that it is forever unable to bring to the human an understanding of himself as a philosophical being open to the divine. ${ }^{1242}$

\footnotetext{
${ }^{1239}$ Pylkkö, The Aconceptual Mind, 103; and Pylkkö, “Eliminative Holism as a Solution to Bohr's Puzzle of Two Languages," 154.

1240 Pylkkö, The Aconceptual Mind, 56-57.

${ }^{1241}$ Pylkkö, Ajatus ja Kädet, 40. Pylkkö believes that, contrary to traditional interpretations, the apostle Paul "rejects the coarsest version of dualism in spirit and body," ibid., 40 (translation mine).

${ }^{1242}$ In this sense, Ellen White could be cited for support of Pylkkö's thesis from a theological perspective, as she shares "many illustrations from nature are used by the Bible writers, and as we observe the things of the natural world, we shall be enabled, under the guiding of the Holy Spirit, more fully to understand the lessons of God's word. It is thus that nature becomes a key to the treasure house of the word, Ellen G. White, Education (1903), 120. Again, "he who studies most deeply into the mysteries of nature will realize most fully his own ignorance and weakness. He will realize that there are depths and heights which he cannot reach, secrets which he cannot penetrate, vast fields of truth lying before him unentered," ibid., 134. "In the natural world we are constantly surrounded with mysteries that we cannot fathom. The very humblest forms of life present a problem that the wisest of philosophers is powerless to explain. Everywhere are wonders beyond our ken," Ellen G. White, Steps to Christ (1892), 106. "In nature, God has given mysteries to command our faith. This must be so. We may be ever searching, ever inquiring, ever learning, and yet there is an infinity beyond," Ellen G. White, The Ministry of Healing (1905), 431. "There are ... men of noble qualities whom God would use in his
} 
The significance of Pylkkö's view of nature for theology is seen when contrasted with Heidegger, or his other more traditional followers. For example, Globus and Pylkkö represent two ways of applying Heideggerian thinking. If Heidegger is seen as more supportive of process philosophy, where mathematics is still preserved a role, as Globus believes, then ontotheology may still be valid for certain domains. ${ }^{1243}$ Or if Pylkkö and Berger are correct, then whatever reality is, it is consistent in all its 'domains,' meaning there is only one ground to reality, and everything else must ultimately conform to this ground-in the case of Pylkkö this is an aconceptual ground. ${ }^{1244}$ Thus, these two separate Heideggerian approaches define differing conceptually possible appearances of the 'divine,' yet without committing to the existence of the divine-they are both agnostic approaches.

In summary, Pylkkö does not see himself as a theologian, but as a philosopher in the traditional sense-an explorer of reality, in his case, particularly nature. That is not to say his view of philosophy is not at odds with many other philosophers, but Pylkkö still maintains his ideas are a genuine endeavor of philosophical exploration (something akin to 'phenomenological empiricism'). It should be noted that 'nonclassical' empiricism played a key role in motivating his more 'metaphysical' speculations, yet, at the same time, his metaphysics are no longer meta-physics because he is seeking

cause; but the bewitching power of Satan has been cast over them like a spell. Science, falsely so-called, would lead them to reason away the very foundation of true religion. It has so confused their senses that the testimony of the Spirit and word of God is questioned. Doubts are entertained because they cannot harmonize these with their views of science and natural principles.... It is the duty and privilege of all to use reason as far as man's finite faculties can go; but there is a boundary where man's resources must cease, Ellen G. White, "True Worth," in The Review and Herald December 29 (1896). For, "the gospel does not address the understanding alone. If it did, we might approach it as we approach the study of a book dealing with mathematical formulas, which relate to the intellect alone.... The Word of God is what it claims to be in the sixth chapter of John-the bread of life-for it represents the body and blood of the Son of God. Its aim is the heart. It addresses our moral nature, and takes possession of the will," Lt5-1898. See also, White, The Spirit of Prophecy Volume Four, 390; and Ellen G. White, Evangelism (1946), 593. "Henceforth we shall have a constant contest. Science, so-called, and religion will be placed in opposition to each other, because finite men do not comprehend the power and greatness of God, ibid, 593. One could interpret her view of false science as the view of deterministic science supported by popular philosophers of science-those who seek to elevate the 'mathematical science' of 'natural principles.'

1243 Globus, Quantum Closures and Disclosures, 108. Globus accuses Pylkkö of an "assault" on "metaphysics," something Globus resists, as he would like to preserve some form of the metaphysics undergirding traditional science. See also, Globus, The Transparent Becoming of World, 67-82, 150.

${ }^{1244}$ Berger, The Unboundaried Self, back cover. "Virtually any field when its treats its 'objects of study' as detached from persons, as having an independent existence," is flawed, ibid. Berger supports paradoxes as necessary for a correct understanding of reality. He hopes to "integrate and unify the scattered paradoxes that dog attempts to understand the adult's Being-in-the-world. Instead of running into a set of apparently separate and diverse enigmas ... at every turn, one faces one fundamental and unifying paradox," ibid., 134. 
to create a more complete theory of 'philosophical-physics' that goes beyond the limits of contemporary classical physics (which contains its own metaphysics ${ }^{1245}$ ).

\section{Evaluation of the Coherence of Pylkkö}

Pylkkö's philosophical speculations, drawing inspiration from contemporary quantum physics, present a genuine alternative to the previous historical trajectories. Evaluating their overall coherence is a complex task-and one that is not within the purview of this study addressing his conceptions of freedom and time. This makes the challenge of evaluating the coherence of his ideas twofold in nature. First, one would have to consider the entire scope of philosophical and physical problems that are considered to be of significance in a total or overall system of thought. This has not yet been done, though Globus, ${ }^{1246}$ Berger, ${ }^{1247}$ and Vadén ${ }^{1248}$ have certainly explored the significance of his work, and again, as with Bohm, it is probably safe to say they have exposed some problems with Pylkkö's ideas as a physicist and philosopher, although the technicalities involved in exploring and detailing them cannot be repeated here, beyond noting that one of the sorest points of criticism remains, as with Bohm, whether Pylkkö has successfully distinguished mind, matter, and the individual, ${ }^{1249}$ or weakened free will beyond recognition, ${ }^{1250}$ as well as ignored critical concepts that Heidegger also may have neglected, such as the meaning of purposeful wisdom. ${ }^{1251}$ Indeed, Pylkkö's admission that "the best that philosophical work can ever hope to do is to shed the cool, lonely and weak light of disillusion upon the human condition"1252 is surely pessimistic in tone. That said, however, Pylkkö's ideas on time and freedom merit their own analysis and evaluation.

\footnotetext{
${ }^{1245}$ As articulated by Burtt, The Metaphysical Foundations of Modern Science.

${ }^{1246}$ Globus, Quantum Closures and Disclosures, 96-112.

1247 Berger, The Unboundaried Self, 98-112.

${ }^{1248}$ Vadén, Heidegger, Žižek and Revolution, 83.

${ }^{1249}$ Globus, Quantum Closures and Disclosures, 110-111.

${ }^{1250}$ Globus, Quantum Closures and Disclosures, 108. Cf. Pylkkö, The Aconceptual Mind, 133-134.

${ }^{1251}$ A penetrating critique of Heidegger's understanding of wisdom, in contradistinction to knowledge and science, reveals alternate avenues for understanding Heidegger and his potential flaws that have generally been neglected. See Kent D. Palmer, "Heidegger's Error: Philosophy without Sophia," available at https://www.academia.edu/35704153/Heideggers_Error_Philosophy_without_Sophia (accessed September 16,

1252 Pylkkö, The Aconceptual Mind, 38.
} 2018). 
The coherence of Pylkkö's ideas about freedom and time raises the issue of what coherence means. That is, if one were to seek to find an underlying schema to determine the meaning of coherence, one would already be passing judgement on the nature of freedom and time. What can be said, in this instance, is that Pylkkö's ideas about freedom and time are a reaction to the contradictions plaguing the previous historic positions about freedom and time. This is evidenced most clearly in both Heidegger and Einstein's views, where freedom is either accepted dualistically in an idealistic temporality that has 'no' relationship to nature understood scientifically, as with Heidegger, or rejected to make room for an understanding of time that is determined and causative, as with Einstein. Thus, arguably, both Heidegger's and Einstein's views are both internally coherent, but allow for no freedom in a single coherently unified theory of reality-Einstein couldn't find room for freedom in his perfect universe, and Heidegger's temporality couldn't find room for any comprehensible relationship to the deterministic natural science which dominates among scientists. As such, both of these programs have left many more inquiring scientists and contemporary philosophers uneasy and dissatisfied, chief among them Bohm and Pylkkö.

In respect of the above, Pylkkö's views are, perhaps, also one of the most coherent integrated packages that exists for the concepts of freedom and time that has interdisciplinary attraction, more explicitly uniting, to a greater degree, the humanities and sciences than has been done by any other major school of philosophy. His theory unites them into one unified aconceptual concept, that both allows for their comfortable co-existence, while also negating any 'easy' path that could disprove his ideas. Of course, were his understanding of the quantum world incorrect, then his theory would collapse, and a return to some form of timelessness and a denial of freedom could result.

\section{Conclusion}

In this chapter Pauli Pylkkö's views on freedom and time were examined. Additionally, a biographical sketch of Pylkkö was provided, as well as some background context concerning Pylkkö's place within the two cultures, the relationship of his ideas with Heidegger's contributions, as well as how influential they have been upon theological reflection about freedom and time. The key points 
from this overview revealed that Pylkkö's interest in politics and Heidegger heavily influenced his own theories, albeit he developed them in unique ways.

Concerning Pylkkö's view of freedom, what is noteworthy is that he locates it within a single aconceptually grounded nature. Of course, Pylkkö's notion of what constitutes order is significant, as it seeks to explain how multiple kinds of orders develop. Thus, freedom is located within the time of nature. Turning toward time itself, time is also a product of nature as a single aconceptually grounded flowing reality. There is no platonic realm of abstract objects which can function as a metric or clock for time. As such, all of nature reveals a single aconceptual temporality. Pylkkö remains agnostic on any ultimately definable meaning of the flow of temporality, but allows for its possibility.

In the following chapter I will compare and contrast Bohm and Pylkkö directly, and explore how their approaches to the concepts of freedom and time might fit within the crisis of the two cultures and the place of theology as a mediator. 


\section{CHAPTER 5}

\section{COMPARATIVE ANALYSIS OF BOHM'S AND PYLKKÖ'S VIEWS ON THE RELATIONS OF FREEDOM AND TIME WITH A VIEW TOWARD THEIR THEOLOGICAL SIGNIFICANCE}

\section{Introduction}

The purpose of this chapter is to provide a comparative analysis of the concepts of freedom and time as represented in the writings of Bohm and Pylkkö, as examined previously in this study, and to position them within the two cultures with the goal of exploring the projected significance reception their ideas might receive with broader exposure to more scientists, philosophers, and theologians who are seeking to integrate the two cultures and theology. Through a direct examination of the two of them, the contrasts between them will become clearer. The comparison will proceed as follows. First, I will compare and contrast Bohm's and Pylkkö’s views on time, then freedom, and then their views on the relationship of freedom and time. This will be followed by comparing their views on the concept of God, including touching upon the implications their views may have for God's relationship to freedom and time. The above will be followed by an analysis on the projected significance and reception of Bohm's and Pylkkö's views by others within the context of the conflict between the two cultures, including theologians engaging the issues. This will include an analysis on how biblical theology as a discipline remains open to further development on the concepts of freedom and time-that is, briefly probing what issues in particular remain unresolved within biblical theology that may be particularly open to the insights offered by Bohm and Pylkkö concerning the concepts of freedom and time. I will then summarize the potential future contributions that the ideas of Bohm and Pylkkö may yet provide, tying the work of Bohm and Pylkkö more directly into the situation uncovered in chapter 2 concerning the third culture. 


\section{Comparison of Bohm and Pylkkö}

Bohm and Pylkkö provide an interesting case study, in that they are, respectively, a scientist and a philosopher, who are both dissatisfied with the current state of affairs in science and philosophy. Their point of entry into the discussions is similar-the breakdown of classical physics through the dawn of the quantum era. Beyond this, however, their pathways diverge, but in ways that are parallel in relationship to the trajectories they started from, namely, the relation of Einstein's and Heidegger's ideas to their own, respectively. Bohm insists that the objectivity that drove Einstein's philosophy of science must be preserved in some clear manner, whereas Pylkkö inherits Heidegger's disdain for scientific methodology and must integrate his destruction of it into natural science itself, discarding any remnant of the classical dogmatic science. This makes Bohm and Pylkkö uniquely suited for a comparison that may illuminate the current and future trajectory of discussions within and between the realms of natural science and philosophy.

\section{Bohm and Pylkkö on Time}

For both Bohm and Pylkkö, time is intimately related to the phenomena of natural science. However, both of them depart radically from the typical understanding of classical science on what this means. As such, Bohm and Pylkkö are both outliers from the general discussions taking place within each of the two cultures. That is, they operate within the efforts of those seeking a third culture.

For Bohm, the usage of the word 'time' is still essentially understood in the classical way, meaning, the speed of activity in the explicate order. This is equivalent to the speed of light, and ties Bohm to Einstein. It remains, for obvious reasons, very difficult to escape the implications of Einstein's theory from an empirical perspective. If there were a finite maximum speed of causality, then, essentially, that means for all conceivable purposes that speed would be the speed of time. Temporality would thus be defined by this speed. Bohm accepts this basic thesis, but rejects that it possesses the meaningfulness that the advocates of the Newtonian, Einsteinian, or Copenhagen perspectives claim it does. 
Ironically, in that the speed of time as defined by light also relativized (localized) time, as well as eliminated it subjectively (made reality deterministic or timeless) for Einstein, the early Bohm pilotwave model reverts to a neo-Newtonian perspective that does seek to reinstate a universal cosmic time. However, this universal cosmic time is not meaningful in the same way as it would be for Newton, as Bohm seeks to show how reality is ever 'deeper' than it appears, by emphasizing how the implicate orders reveal an ultimately undefinable and immeasurable holomovement. ${ }^{1253}$ This means that the apparently deterministic explicate order and its 'objects' is not the final word on the meaning of time, nor is a simplistic underlying layer which is 'timeless' in relation to it, or 'temporal' in some 'new' way. Rather, there are innumerable deeper implicate 'timeless' orders that show that reality is not limited by the speed of light or causality as it appears in Einstein's theory of relativity. Whether there is a flow or overall movement 'forward' in time is not necessarily denied, but is also not meaningful in the same way that most think it is, as the 'moment' itself has infinite 'timeless' depth, that is, eternity is still in the moment.

For humanity, the same principle applies, but in a very subtle way. Bohm would suggest we are accustomed to thinking of the individual as primary-it is from someone's perspective that reality coheres and has meaning. However, this would be analogous to placing our emphasis on the explicate order at the expense of the implicate orders. Experience is both an inward and outward concept-we are inextricably entangled with one another physically, not merely 'socially,' as we commonly think of the term. Humanity, and nature with it, are entangled within one experiential 'movement,' and it is only through looking inward into the implicate order that we can, individually and as a society, escape 'time' and find meaning and freedom. ${ }^{1254}$ Of course, one might suggest that Bohm does allow for an

\footnotetext{
${ }^{1253}$ Bohm, The Essential David Bohm, 131. Again, to emphasize the point, for Bohm, giving "primary significance to the undefinable and immeasurable holomovement implies that it has no meaning to talk of a fundamental theory, on which all of physics could find a permanent basis, or to which all the phenomena of physics could ultimate be reduced. Rather, each theory will abstract a certain aspect that is relevant only in some limited context, which is indicated by some appropriate measure," ibid., 131.

${ }^{1254}$ Bohm, The Essential David Bohm, 277. Bohm believes that "experience is an inseparable fusion of the outward and inward. If there's no consciousness, there's no knowledge." Bohm continues, noting that "the word 'conscious' means 'knowledge'; it's 'conscience'; 'ponsciare' means 'to know.' 'Conscience' would mean 'to know it all together.' In ancient times, when the word was formed, it did mean what everybody knew, all together. Consciousness was inherently belonging to everybody. Since then we have gotten the idea of private consciousness, that each person is a separate individual whose consciousness is entirely separate. And that's
} 
overall movement, and this may be so. Nonetheless, it is important to retain the language of timelessness precisely because whatever it is that this temporal movement may be, it completely defies the speed of causation in the explicate world, which dominates our day-to-day experience. That is, pasts and futures are interwoven in infinitely deep ways in the implicate order, so that any use of the word 'time' is certain to be a distortion. ${ }^{1255}$

Conversely, for Pylkkö, the usage of the word time immediately takes upon itself a new meaning, as it did for Heidegger. This point alone can be the cause of confusion. Unlike for an advocate of either traditional or modified Newtonianism, for Pylkkö, time is not connected merely to the process of 'change' or 'motion' in physics, or to an abstract background 'process,' but rather is tied into redefining the very meaning of the individual thing or 'moment' itself-there is no such 'thing'! Because one cannot identify any isolated or individual quantum particle absolutely without time factoring in to its interpretation, this means that the 'moment' itself is entangled with an ecstatic temporality. That is, the past, present, and future are entangled in a fuzzy way that contradicts the dogma of classical science. ${ }^{1256}$ Time cannot be said to possess any particular speed, either, as it is not possible to precisely measure the speed of causality in a non-locally entangled world with inherent randomness. Pylkkö remains reticent to accept any causal interpretation of quantum physics, which eliminates any underlying temporal metric. Rather, for Pylkkö, time may best be represented by the idea of a flow of random, and thus unique, 'motions' which constitute an experience. The meaning of time is aconceptual experience, never some scientific measurement, which is, in actuality, impossible. In this sense, time is immediately brought into the humanities in a more profound way, as time truly depends on our experience of it. No arbitrary abstract measurement of time defines time. Contrary to

\footnotetext{
the way he experiences it because that's what he knows. On the other hand you can ask, is it truly private? Isn't it formed from the general consciousness, which passes on the pool of information? I could refer to the Greek word 'idiosyncrasy'; its root means 'private mixture.' The idiosyncrasies of a person are his particular mixture of the general ingredients." "That's the suggestion: that this consciousness is general, and by looking at the general consciousness we get to the generating root of consciousness. If we try to look at our own consciousness, we're looking way up on a top branch somewhere, and we won't be anywhere near the root," ibid., 277.

${ }^{1255}$ Bohm, The Essential David Bohm, 148-150.

${ }^{1256}$ Pylkkö, The Aconceptual Mind, 73.
} 
Bohm, for whom time was primarily the limited explicate manifestation of a part of nature, for Pylkkö, because there are no clearly definable separable parts of nature, all of nature is essentially temporal by definition. ${ }^{1257}$

What Bohm and Pylkkö share, however, is the idea that all of reality is one-that is, that all physical reality is holistically enmeshed, an idea inspired primarily through quantum nonlocality. For Pylkkö, this enmeshing may involve features that are intrinsically unpredictable and untranslatably unique, ${ }^{1258}$ whereas for Bohm, the enmeshing is more holonomic, revealing a law of the whole, or an infinite layer of sub-totalities which may have relatively autonomous descriptions available. ${ }^{1259}$ of course, what Bohm and Pylkkö would both resist is any 'new whole' which seeks to comprehend all of reality within a single valid or general order. ${ }^{1260}$ For Bohm, this is impossible because nature will always continue to unveil new orders, of which the non-mechanistic or non-externalistic character of the implicate order is highlighted, whereas Pylkkö appears to jump straight to the conclusion that the ultimate substrate of reality is somehow aconceptual randomness, and all other perceived orders, of which he only identifies the aconceptual quantum layer and the scientifically amenable explicate layer, are derivative or soft. ${ }^{1261}$

The consequences and projected reception of Bohm's and Pylkkö's views on time within the two cultures milieu will be examined more explicitly below, but what is pertinent at present is to compare Bohm and Pylkkö on the concept of freedom.

\section{Bohm and Pylkkö on Freedom}

To begin, again, with Bohm, freedom remains a very important concept for him. For Bohm, freedom is something that is neither intrinsically tied into the 'flow' of causal laws (time), nor is it

${ }^{1257}$ Pylkkö, The Aconceptual Mind, 142-143.

${ }^{1258}$ Pylkkö, The Aconceptual Mind, 167.

${ }^{1259}$ Bohm, The Essential David Bohm, 136.

${ }^{1260}$ Bohm, The Essential David Bohm, 137.

${ }^{1261}$ Globus explains that for Pylkkö "the aconceptual ... is situatedness, which is never present, but is prior to presence. The aconceptual participates in the interaction from which presence is explicated. The aconceptual is 'implicate'" and the conceptual is manifest in the 'explicate' order, Globus, Quantum Closures and Disclosures, 104. See also, Pylkkö, The Aconceptual Mind, 172. 
pure spontaneity, which he also views as tyrannical. Bohm artfully navigates through the language used in these issues, as for him, something that is necessary is not necessarily deterministic. That is, it may be that contingency and creativity are themselves necessary. All of physical reality, which constitutes everything that is for Bohm's philosophy, contains a conjoined mixture of necessity and contingency. Freedom is in itself a manifestation of both necessity and contingency. ${ }^{1262}$ The location of freedom, however, poses a challenge for Bohm. Rather than seeing freedom as something spontaneously emerging in a 'moment' of exercised will existing outside our physical nature, freedom is located within the infinite depths of the implicate orders. That is to say, the past is indeed a limiting factor on freedom, but does not predetermine what the future may bring in any absolute way beyond certain limitations-Bohm's analogy for this is that the left side of a picture limits what the whole picture may represent, but does not actually dictate what the right side alone may contain.

Accordingly, our past delimits what our present may be, but does not completely determine what our future could be, beyond the fact that our past must be a part of the whole of who we are and become. Of course, Bohm also believes we cannot sharply distinguish our past from our future-they are also entangled as a whole. That is, it is never fully possible to ascertain which aspects of our past are determining our future, as our pasts are interwoven in the depths of the total implicate order. True freedom comes from recognizing that the implicate depths allow for qualitative changes, not merely rearrangements of that which already exists explicately.

Conversely, Pylkkö simply rejects the notion that anything but random indeterminateness can ultimately generate a key part of what is required for our experiential sensation of freedom. ${ }^{1263}$ True freedom is that which makes the unique possible. This means that we may participate in aconceptual experiences that cannot be copied or translated-indeed, the majority of our lives, or those portions which have specifically personal meaning, can be placed within this category. And these aconceptual experiences are what constitute the qualitatively original and irrepeatable and indeterminate 'surprises' of our lives. It is our relationship to these unique and irrepeatable aconceptual

\footnotetext{
1262 Bohm, Thought as a System, 220.

1263 Pylkkö, The Aconceptual Mind, 106, 156.
} 
experiences which define who we are-not that which we primarily share with others in general, and which can be repeated. Of course, it is possible for groups of people to share in a specific nondeterminate aconceptual flow, and this is what constitutes what we might properly refer to as a culture. In contrast to Bohm, Pylkkö places great value on society allowing these nondeterminate aconceptual experiences to flow naturally. That is, Pylkkö wishes to preserve local cultures and their distinctiveness, in virtually all cases (including privileged cultures). This is not to deny that all cultures are in some manner interrelated, but nevertheless Pylkkö also wishes to emphasize the aconceptual experiential flows that constitute sub-groups. Bohm, for his part, while likewise eschewing the dominance of a technocratic or mechanistic scientism which restricts our freedom, wishes to place much greater emphasis on individuals and societies seeking an underlying harmonious wholeness through an awareness of the role that mechanistic causality plays in their lives, and thus a deeper understanding of how our united oneness in the implicate order should draw us together into a dialogue with liberating potential. ${ }^{1264} \mathrm{Bohm}$, while quite realistic about the challenges, still holds out hope that humanity can draw together and solve problems collectively. Pylkkö prefers to see our separate cultures and diversity as a positive in themselves, and believes that while we are indeed all part of one reality, what preserves our freedom is our acceptance of our relationship to the underlying unique random and nondeterminate flows we experience as individuals and smaller communities and cultures. That is, variety is the spice of life, and freedom is only preserved by resisting any underlying homogeneity and allowing for the conflicts that diversity may bring. This is not to say Pylkkö should be thought of as seeking conflict, but, rather, it is an acquiescence that tensions between cultures are more fruitful than they are destructive-and that differences are unavoidable anyway so long as totalitarianism is to be rejected.

Bohm and Pylkkö on the Relations of Freedom and Time As already noted above in the respective summaries for Bohm and Pylkkö, the relationship between freedom and time is revealed through the fact that each determines the other-they are

${ }^{1264}$ Bohm, The Essential David Bohm, 294-302, 313, 323. 
equiprimordially co-constituted. For Bohm, this means that freedom is located in the infinite implicate timeless depths which escape the apparent determinism which rules in the causal flow of time in the explicate order. ${ }^{1265}$ Because causal-time is, in itself within its domain, deterministic, freedom must somehow represent an escape from time. Bohm speculates on newer 'timeless' times, but this idea remains on the metaphysical side of his work.

For Pylkkö, however, the very opposite is true. True temporal time is itself defined by its aconceptual flow, which generates the unique aspects of both nature and human experiences. ${ }^{1266}$ Correspondingly, freedom is also primarily defined by the randomness and entanglement which undergirds the temporal flux. The so-called causal-time operative in classical science is dismissed on two grounds. First, because it is actually not as determinative or law-based as most scientists may claim it to be, because nature contains an intrinsic randomness that ultimately evades meaningful law-likeness (even in the Copenhagen view). ${ }^{1267}$ Second, because causal-time is by definition determinative in the mechanistic paradigm, it is therefore at the same time ontologically timeless. ${ }^{1268}$ Neither is actually meaningfully substantial in Pylkkö's view-they both function to hide or mask the reality of human existence.

The impasse presented in the respective views of Bohm and Pylkkö appears to revolve around a fundamental disagreement concerning the appropriate definition of natural science, and also, science more generally. Because of the significant implications of a disagreement at this level, and the foundational significance of freedom and time as evidenced above, the tension between them is not easily dismissed, while, at the same time, their affinities point toward a common insight into the

1265 Bohm, Causality and Chance: Letters to Three Women, 254-255.

${ }^{1266}$ Pylkkö, Kielikuva ja Mielikuva-Ja Muita Dialektisia Esseitä, 80. Pylkkö asserts that "consciousness has a clear temporal (irreversible) dimension. It has a direction towards the future, but at the same time, the ability to live simultaneously in the present and in the future," ibid., 80 (translation mine). This is in contrast, of course, to the mechanistic laws which are considered reversible.

${ }^{1267}$ Pylkkö, The Aconceptual Mind, 39, 86-87, 105, 271. Or, alternately put, "every law of physics, pushed to the extreme, will be found to be statistical and approximate, not mathematically perfect and precise," John Archibald Wheeler, At Home in the Universe (American Institute of Physics, 1996), 293. See also, Peter Grzybek, "On the Science of Language In Light of the Language of Science," in Contributions to the Science of Text and Language: Word Length Studies and Related Issues, ed. Peter Grzybek (Dordrecht, The Netherlands: Springer, 2007), 1-15.

${ }^{1268}$ Pylkkö's critique applies, of course, to the social level as well. Hence, his sharp criticism of Marxism, which relies on a deterministic view of time; see Pylkkö, Ajatus ja Kädet, 446-447. 
contemporary world's conundrum concerning freedom and time. Although they did not explicitly do so, one could postulate, for example, that different kinds of freedom and time (e.g., existential and moral) exist at different levels (for Bohm), or in different aconceptual flows (Pylkkö), bringing together the neuroscientist, psychologist, and theologian. These kinds of issues will be revisited below when exploring how their work has been and is likely to be received in the near future within the broader two cultures milieu.

\section{Bohm and Pylkkö on God}

Neither Bohm nor Pylkkö are openly theists. However, at the same time, their work is agnostic, neither explicitly favoring nor challenging the idea of God. At the same time, it could be said that both of them would be critical of the traditional, limited or more reductionist conceptions of a timeless God that have dominated throughout history.

Bohm, for example, claims that the issue of God is not raised or considered in his view of nature. His work is merely a philosophy or metaphysics of nature. It is not impossible that some intelligence pervades within the infinite implicate depths, that is manifest in the totality, but defining this apparent intelligence itself as God, or the totality of God, would limit God, which Bohm rejects. ${ }^{1269}$ Bohm is very aware that the word "God" is not as important as the conception we have of God-and conceptions are not merely a matter of 'attributes,' but of more intangible aspects such as what does it mean to have attributes or qualities.

Pylkkö, similarly, rejects the notion that God is necessarily involved in his philosophy of nature. He declines to offer any explicit suggestion concerning whether any God resides behind nature. ${ }^{1270}$ At the same time, Pylkkö essentially agrees with Heidegger that God, if he exists, should be conceived of as 'alive,' in an aconceptual way. Pylkkö would suggest that if 'God' were to appear through or in nature, he would have to do so in a manner consistent with nature's aconceptuality. ${ }^{1271}$ At the same

${ }^{1269}$ Bohm, On Creativity, 106-107.

${ }^{1270}$ Pylkkö, "Eliminative Holism as a Solution to Bohr's Puzzle of Two Languages," 154.

${ }^{1271}$ Pylkkö, Kielikuva ja Mielikuva-Ja Muita Dialektisia Esseitä, 61, 76-77, 86-88. Pylkkö, like Heidegger, is highly critical of Catholic theology. He shares that "the science of the Satanic techno-science should have been put where it belongs: in the cellar basement." Instead, "the Church clung to this weaker theology and lost the 
time, nature needs no 'god' to escape from the godless or deistic determinism that classical science attributed to it. Nature has its own 'wildness,' or divine spark, in a Heideggerian sense. ${ }^{1272}$

In summary, then, Bohm and Pylkkö share their greatest similarity on the 'God' question. Their philosophies are both agnostic, but open to the idea of God. For Bohm, the place of God is more mysterious, hidden, perhaps, within the infinite implicate depths. It is difficult to envision a personal God in Bohm's scheme. For Pylkkö, God is possible, though not required, and were God to appear, we should not be so surprised that he do so in a more private 'religious' way, as most religious traditions are far more open to aconceptuality than classical science. In this, Pylkkö more readily preserves a place for religious cultures against the cultural dogma and homogeneity of western science, or any other homogenous culture that, by virtue of the definition of homogenous, eschews the experiential aconceptuality that undergirds Pylkkö's view of reality.

So far as God's relationship to freedom and time are concerned, both Bohm and Pylkkö offer intriguing alternatives to the popular views, both historic and contemporary. While they did not explicitly comment on this question, proffering a few comments on their behalf may be useful. Hopefully, such comments will remain true the general spirit of their theories.

Without any doubt, Bohm's concept of an infinity of layers as a solution to the problem of freedom also makes the ultimate question of time ambiguous-whether this is good or bad is a separate question. Bohm furthermore seems uninterested in evading the language and conceptuality inherent in 'timelessness,' but it is possible to construe the infinite regression of layers as a way to

world-historical struggle," because it "fused natural science, materialism and atheism ... into a distinctive subset of theology," which has destroyed the Church's philosophical vitality, ibid., 88 (translation mine). At the same time, however, Pylkkö affirms in a positive way that "the problem of dualism cannot be ignored after it has come to life. Its creation ... can at most be hampered and delayed by the assumption that the material and spiritual have a common pre-conceptual basis that is neutral in terms of categorization. In the light of this difficulty," it is good to observe that "controversy lives and radiates its energy at the heart of Christian thinking. In the Christian world of thought, the divine essence and human essence of Jesus are difficult to accept, making it compulsory for us to speak of a virgin, and to say that we believe because it is absurd...". Unfortunately, "theologians blame themselves for this." Yet, "if a two thousand year-old attempt to prove God's existence would have succeeded, religion would at the same time become impossible." Rather, "we should not say we believe because it is absurd. We should say utterly dialectically: we consider the religious attitude as acceptable, sometimes even wise, because we recognize and acknowledge the limits of reason. The dialectics must move on both sides of the limit of reason," Pylkkö, Ajatus ja Kädet, 125-126 (translation mine).

1272 Pylkkö, The Aconceptual Mind, 75-76. Alternately put, God is not a 'tame' Lion, to borrow the popular analogy from C. S. Lewis' Chronicles of Narnia. 
bypass the problem of 'cold' or static timelessness in the original platonic conception. The infinite timelessness within the implicate orders is not the simplistic dualistic timelessness of mathematical objects in the traditional platonic scheme. It is a much 'warmer' neo-platonic timelessness, in that this very same timelessness is what generates the possibility of freedom, in Bohm's theory. Whether this really 'works' as a scientific theory is an open question-Bohm's theory is a metaphysical one at present-and may be by definition unprovable. The holomovement is beyond definition, utterly undefinable and immeasurable. In any case, his theory opens up the possibility of God being infinitely 'timeless,' so to speak, in a way that is also open to freedom precisely because it represents an infinite depth to plumb.

On the other hand, for Pylkkö, precisely because aconceptual experience is the very meaning of time, God may also be somehow analogously temporal in the same manner as nature; the creation is a mirror, as it were, of its creator. Because the meaning of time is by definition related to an indeterminate freedom and temporally ecstatic existence, this means that God's time perhaps could include various aconceptual and entangled features, unifying the past, present, and future in unexpected ways. Indeed, one of the more novel features of Pylkkö's theory or interpretation of empirical quantum phenomena is to explicitly unite two of its most interesting and puzzling features-entanglement and randomness. ${ }^{1273}$ Together, these two features are what make possible aconceptual experience, which means, the past and future will be entangled, but the present may involve random or indeterminate elements altering our access to and thus the significance of the past even as it likewise conditions the possibilities of the future. If God's experience of freedom and time were similar, then he could theoretically act in the world in a similar manner. Thus, through divine intentionality, there may be ever new significance to the past that we can uncover in the present, while at the same time, the living present cannot ever determine the future which always remains open and unknown, yet also paradoxically a part of the past's evolving meaning. Theoretically, this

1273 Pylkkö, The Aconceptual Mind, 106. Pylkkö claims that "microphysical phenomena as such, that is, as human experience, are indeterminate and inseparable, and it is the measurement and the quantum formalism which attempt to render indeterminate and inseparable phenomena as determinate and separable and which thereby yield paradoxes into the interpretation of quantum theory. The measurement and the formalism belong to the mechanical and fictitious aspects of the phenomenal," ibid., 106. 
could open up the possibility that God simply relates to time in ways we cannot fully imagine, because, for Pylkkö, our logic itself is a product and victim of platonic classical science. Accordingly, our classical logical problem of divine foreknowledge and human freedom may simply be misconceived, and overly bound to classical logic and its conceptions of freedom and time as presence without absence. That is, if the past and future are nondeterminately entangled with the present in some way, perhaps God can see these entanglements in ways we cannot imagine. If we've failed to understand freedom and time thus far, why should we think we understand God's time and freedom could be the new question. Yet, this is my speculation of what Pylkkö's theory might offer to a theology of freedom and time, and not one that is demonstrable, though I will elaborate more on this below. Pylkkö's physical theory certainly does not intrinsically encourage any 'foreknowledge' that is understandable beyond the normal predictability of classical scientific tendencies or laws. It should also be noted that Bohm's views could entertain a similar conclusion to that of Pylkkö's. In any case, Pylkkö's theory clearly shares Bohm's basic conviction that the totality of reality is undefinable and immeasurable in ways that are more forceful and expansive than what is found in classical theology, which was and remains dependent on the methods of classical science.

\section{Summary of the Comparative Analysis of Bohm's and Pylkkö's Views}

Bohm's and Pylkkö's views on freedom, time, and their relationship create a sharp contrast, that is at the same time deeply committed to resolving the same historic problems about freedom and time. It seems, then, given the generally unsatisfying options tradition has left to us, we are 'forced' to choose between a radical temporality, or, on the other, an infinity of layers of order making time seem superfluous. Yet, Bohm and Pylkkö both proffer what could be construed as superior alternatives to the stalemate facing contemporary mainstream philosophy's divided camps-indeed, in many ways Bohm and Pylkkö have identified common problems, and their solutions do have an air of similarity about them, even while diverging in very different directions. At the same time, both also offer innovative pathways forward which may better account for synthesizing any conception of the divine 
into the broader 'scientific' enterprise of knowledge seeking and philosophical reflection, while similarly allowing for the divine to evade the restrictions of Heidegger's ontotheological critique.

Nevertheless, even given the above, it is unlikely that either Bohm or Pylkkö will see any broad acceptance of their ideas within either the scientific or philosophical communities in the near future, absent some unforseen cataclysmic changes to the intellectual world. The reason for this is simply because too many individuals are committed to one or the other of the two cultures, either the sciences or humanities, or various socio-political identities identified with them. With this in mind, it becomes important to assess just what their significance may be for the advancement of science and philosophy. What is their contribution actually worth? And what kinds of changes could actually bring their ideas more acceptance?

\section{The Projected Reception of Bohm's and Pylkkö's Insights Within the Crisis of the Two Cultures and Theological Reflection}

In chapters 1 and 2, it was uncovered that disagreement about the foundational concepts of freedom and time constitute the foundational dividing line for the widespread conflict of the two cultures, the sciences and humanities. Additionally, it was shown that several third culture disciplines, specifically psychology and psychiatry, economics, and the socio-political sciences, that straddle the sciences and humanities, are also divided because of the role of how the concepts of freedom and time are operative within them. The question then became, what is the best way forward? Furthermore, what role will religion and theology have in resolving the conflict of the two

cultures, if thus far they have merely replicated the conflict? This section of the study is designed to respond to the "so, what?" question that a study in philosophical concepts must address to be 'relevant.'

The speculative philosophies of Bohm and Pylkkö were selected and examined in chapters 3 and 4 because they push forward theories about the natures of freedom and time that challenge several longstanding and still widely held assumptions that, nevertheless, others today think are not well grounded, and have actually helped create and encourage the tensions between the two cultures, which has significant 'real world' implications. Yet, while Bohm and Pylkkö may push the discussion 
forward, this does not mean their respective views are widely accepted, or will be, in the near or more distant future. With this in mind, the purpose of this important section of this study is to both examine and speculate about the roles that Bohm's and Pylkkö's ideas, or ideas similar to theirs, may have in advancing any 'resolution' to the crisis of the two cultures, and also the role that theology or religion may have in such progress.

This section will proceed as follows. First, the role of freedom, time, and God will be explored in the natural sciences. ${ }^{1274}$ The prominent theme of divine action in the world will also be touched upon here, but this will be done through focusing on the relationship of Bohm's and Pylkkö's ideas to the mainstream philosophical currents operative today, all of which have been alluded to above and throughout the study. Specifically, the metaphysical and theological frameworks utilizing the 1) dogma of classical science (the Platonic/Cartesian/Kantian dualism), and 2) the neoplatonic Copenhagen synthesis, will all be briefly discussed. Note that assuming a position on the above philosophical or metaphysical frameworks is not the purpose of this study, but rather, to position the reception of Bohm and Pylkkö's contributions within the divisions facing these frameworks and their use by theists concerning the use of freedom and time, and how Bohm's and Pylkkö's ideas might integrate with them in the future.

${ }^{1274}$ Here the work of Martin Hanna, who has carefully explored the science and theology dialogue, will prove useful as a general guide. Hanna suggests that "there is a sense in which nature is the widest context for theology," even if "sin has darkened human minds so that they do not perceive the light of general revelation in nature and special revelation in Scripture," Martin F. Hanna, "Science and Theology: Focusing the Complementary Lights of Jesus, Scripture and Nature," in Journal of the Adventist Theological Society Vol. 6 \#2 (Fall 1995), 22. This noetic effect of $\sin$ is not an issue that will be explored in the present study, but the end effect is that "the problem of the relationship between science and theology is complicated by the fact that there are no universally accepted definitions for these terms," which has left us with "various conceptions of science and theology result[ing] in a large number of conflicting theoretical frameworks or models," ibid., 6-7. Within this milieu, however, Hanna accurately observes that "in-part knowledge is real knowledge," and "nature is a general revelation which provides the context for Jesus and Scripture." Thus, "the Bible speaks neither about God in isolation from the world nor about the world in isolation from God," ibid., 26-27. For more on Hanna's work on synthesizing the key elements of science-theology models, see Martin F. Hanna, "The Servant-Master Roles of the Laws of Christ, of Scripture, and of Nature," in Journal of the Adventist Theological Society Vol. 9 \#1-2 (1998), 278-309; and Martin F. Hanna, The Cosmic Christ of Scripture: How to Read God's Three Books-Comparing Biblical Perspectives with the Writings of Ellen White (Berrien Springs, MI: Andrews University Lithotech, 2006). 
Second, the role of freedom, time, and God will be explored within the humanities, including their relationship to theology, particularly biblical theology. ${ }^{1275}$ The study previously touched upon the role of freedom and time in biblical hermeneutics, and here this issue will be explored in connection to several core theological topics, that have also been mentioned above, that centrally involve the issues of freedom and time, namely, 1) the question of religious pluralism, 2) politics and social justice, 3) the atonement, the biblical Sanctuary, sacramentalism, and salvation, 4) the reality of biblical prophecy, 5), the biblical Sabbath and rest, and 6), the biblical concept of the 'remnant' or the idea that truth, absent the bliss of heaven, is intrinsically a (democratically) minority position. Again, observe that the purpose of this study is not to offer any polemic position about these theological issues, but to clarify in what way Bohm's and Pylkkö's contributions might fit into the already existing divisions facing the above issues, which are, again, centered upon differing conceptions of freedom and time. Lastly, of course, were theology's conception of freedom and time to be modified, then the way theology interacts with the other contemporary third culture disciplines, such as psychology and psychiatry, economics, and the socio-political sciences, would correspondingly be modified, though the full implications of this cannot be explored here.

God, Freedom, and Time in the Natural Sciences

\section{The Dogma of Classical Science and Dualism}

The dogma of classical Newtonian science, with its Platonic/Cartesian/Kantian dualistic philosophical centerpiece, retains a very powerful influence in western societies, conscious to most, yet also unconsciously or in unexpected ways to many others. Its strictly empirical or monistic variant, scientism (or naturalism), is also highly influential, but receives much more criticism by both

\footnotetext{
${ }^{1275}$ Here I will follow the lead, 'in spirit,' of John C. Peckham, Canonical Theology: The Biblical Canon, Sola Scriptura, and Theological Method. Peckham insists that the Scriptural canon alone "is the objective rule or standard to which interpretation should discernibly correspond," ibid., 160. In the spirit of a tota Scriptura desire, I will highlight the key biblical-theological issues which have divided the Christian community and excise from them how the concepts of freedom and time are central to them in relation to the approach of this study, which is philosophical in nature, and not exegetical.
} 
theists and postmoderns alike. ${ }^{1276}$ In any case, the influences of classical dualistic science and scientism together form a two-pronged fork that has pinned almost all of the western world against an epistemological and ontological wall. Because of their sharp internal disagreements, as noted above, people today often believe that vibrant discussions about science and religion are taking place, but, as the Heideggerian would observe, the scientific core of the methodologicalism common to both of them is often neglected, leaving the vibrant discussions moving down a dead-end pathway. In any case, it's important to briefly describe what constitutes the theological disagreement between the two, and to explain its consequences amongst the major groups of Christianity, including for the issue of divine action in the world.

First, for example, within the Calvinist, neo-Calvinist, and Reformed traditions, ${ }^{1277}$ there is a strong desire to emphasize order within the created natural world, ${ }^{1278}$ and logic within philosophy, ${ }^{1279}$ and utter transcendence (even to the point of irrationalism, though there are disagreements on this point) within theology. ${ }^{1280}$ They dismiss the formal platonic dualism, ${ }^{1281}$ eschew scientistic

\footnotetext{
${ }^{1276}$ Arguably, in the agnostic mainstream world, scientism is the common thread grounding western society-however, it cannot control anything on its own, as it is tempered by the political-democratic oscillations between various groups. That is, democratic capitalism tempers its direct influence, but the lowest common denominator between the various political groups would be some sort of scientism-the one thing they sort of agree about. Of course, this doesn't mean that the groups agree on what constitutes good science, hence, the divisions remain acute.

${ }^{1277}$ Included here would be those who navigate through some of these groups, such as the Calvinist John Feinberg, No One Like Him: The Doctrine of God. Feinberg's discussions about temporality and freedom are still fully conditioned by the traditional analytic presuppositions. That is, despite brief references to Heidegger, his views do not engage true Heideggerian temporality and quantum physics in any meaningful way. Much of the broader contemporary neo-Calvinist and Reformed theologians operate under either Einsteinian or Newtonian worldviews-while temporality of a sort can appear here, it does not, as noted throughout this study, approach Heideggerianism. In this, Feinberg follows many other contemporary American analytic philosophers, such as Craig.

${ }^{1278}$ Chief amongst their many advocates would be Herman Dooyeweerd, A New Critique of Theoretical Thought: The Necessary Presuppositions of Philosophy; and more recently Vern S. Poythress, Redeeming Science: A God-Centered Approach (Wheaton, IL: Crossway Books, 2006); and Lydia Jaeger, Einstein, Polanyi, and the Laws of Nature.

${ }^{1279}$ As noted by Gordon H. Clark, Logic (Unicoi, TN: Trinity Foundation, 1985).

${ }^{1280}$ For example, see Gregory Reynolds, The Word is Worth a Thousand Pictures: Preaching in the Electronic Age (Eugene, OR: Wipf and Stock, 2001), 34-35; and B. A. Bosserman, The Trinity and the Vindication of Christian Paradox: An Interpretation and Refinement of the Theological Apologetic of Cornelius Van Til (Cambridge, UK: James Clarke \& Co., 2015), 50-58.

${ }^{1281}$ Gordon H. Clark, Thales to Dewey: A History of Philosophy-An Entertaining and Enlightening Survey of the World's Great Thought (Grand Rapids, MI: Baker Book House, 1957), 96.
} 
empiricism, ${ }^{1282}$ but generally retain the scientific methodology (and its intrinsic dualism) and seek lawful order and determinism within the natural world. Owing to the fact that they support a transcendent timeless God prior to created time and deterministic predestination, for Calvinists, there is a long legacy of support for Einstein, including in the works of those such as Thomas Torrance. ${ }^{1283}$ As one might surmise, given the above, many Calvinists would be very open to integrating the work of Bohm-especially his earlier work which emphasized a deterministic interpretation of quantum phenomena, absent his later thoughts on freedom. Within Bohm's pilot-wave theory, "followers of Einstein and über-Calvinists" can "assert that chance is a manifestation of our ignorance but God or Nature knows which path the particle took, and it had no real choice."1284 In this paradigm, God could be said to have decreed the relevant laws for nature and society, as eternal decrees. They may overlap, but they ultimately all share a common denominator as causal-laws. Along this vein, the sphere sovereignty theory of Herman Dooyeweerd could easily be accommodated to incorporate Bohm's insights, ${ }^{1285}$ as could the partially Reformed theology of William Lane Craig, as noted above, which could include a more subtle version of Molinism or Middle Knowledge. ${ }^{1286}$ Additionally, though it will not be detailed here, as it has already been noted above, Catholic ${ }^{1287}$ Sufi Islamic, ${ }^{1288}$ and Eastern theologies could also easily incorporate Bohmian ideas. Notably, all of the prior groups favor

${ }^{1282}$ Alvin Plantinga, “Scientism: Who Needs It?," in Scientism: Prospects and Problems, eds. Jeroen de Ridder, Rik Peels, and René van Woudenberg (Oxford, UK: Oxford University Press, 2018), 230; Clark, $A$ Christian View of Men and Things, 197-228; and Carl F. H. Henry, God, Revelation and Authority 6 Vols. (Grand Rapids, MI: Crossway Books, 1999).

${ }^{1283}$ For an overview, see again Van der Meer, "European Calvinists and the Study of Nature: Some Historical Patterns and Problems," 103-130, esp. 121-123. See also, Thomas Torrance, Theological and Natural Science (Eugene, OR: Wipf \& Stock, 2005), "Einstein and God," 17-34.

${ }^{1284}$ Dillard W. Faries, Amazing Grace of Quantum Physics (Eugene, OR: Pickwick, 2017), 205.

${ }^{1285}$ Jitse M. Van der Meer, "Is There a Created Order for Cosmic Evolution in the Philosophy of Herman Dooyeweerd?," in The Future of Creation Order: Vol. 1, Philosophical, Scientific, and Religious Perspectives on Order and Emergence, eds. Gerrit Glas and Jeroen de Ridder (Cham, Switzerland: Springer, 2017), 191.

${ }^{1286}$ Although James Bradley does not describe it here, it is possible that Bohm's implicate orders could contain God's foreknowledge of future events in a somewhat different way than in the Molinist account. For an interesting overview, see James Bradley, "Randomness and God's Nature," in the American Scientific Affiliation: A Fellowship of Christians in Science Vol. 64 \#2 (June 2012), at https://www.asa3.org/ASA/PSCF/2012/PSCF6-12 Bradley.pdf (accessed September 30, 2018). See also, Robert John Russell, “A Response to David Bohm's 'Time, the Implicate Order and Pre-Space,' in Physics and the Ultimate Significance of Time: Bohm, Prigogine, and Process Philosophy, 209-218, 214.

${ }^{1287}$ For example, Schindler, "David Bohm on Contemporary Physics and the Overcoming of Fragmentation."

${ }^{1288}$ As noted above, Shuebrook, "Science and Sufism: A Discussion of David Bohm and Ibn al-Arabi." 
some form of theistic evolution or long ages. On the other hand, it seems Heideggerian ideas, especially the randomness and aconceptuality of Pylkkö, would struggle to find any resonance with the standard logical-scientific worldview common within contemporary Calvinism. ${ }^{1289}$

Second, for the traditional Arminian, the dualism present in classical science is a pleasant occurrence. This is because time, for Arminians and still most others, is still viewed in a Newtonian way (the cosmic background clock), and because nature is typically seen as lawlike and deterministic, it is necessary for Arminians to assume, somewhat like Kant, that libertarian free-will exists in some noumenal timeless soul. ${ }^{1290}$ Thus, the separation of anthropology from classical science provides the justification for much of the theological framework for both Arminian and Calvinist thought, not to mention Lutherans, and many others. For them, however, unlike Bohm, positing an infinity of layers which are ultimately somewhat deterministic provides no special added value. For Calvinists, the added implicate layers, which are mysterious to us, could provide the 'hidden determinism' that guides human wills, yet keeps humanity ignorant while only God knows the outcomes. However, for the Arminian, Bohm's insights appear to merely continue the old paradigm, without offering any actual support to Arminian convictions about free will. On the other hand, Heideggerian insights could be incorporated into an Arminian framework more easily, if so desired, ${ }^{1291}$ though, it is difficult to see how Pylkkö’s particular version would be attractive. Arminians would likely prefer to maintain the fundamental conceptual dualism between philosophy (including theology), and natural science that Heidegger maintained.

${ }^{1289}$ J. Glenn Friesen, “Current Reformational Philosophy and the '95 Theses on Herman Dooyeweerd,'” 9-11 (2007), at https://jgfriesen.files.wordpress.com/2016/12/reformational.pdf (accessed September 29, 2018).

${ }^{1290}$ Machuga, Three Theological Mistakes: How to Correct Enlightenment Assumptions about God, Miracles, and Free Will, 253. Again, Gardner explains, "Kant's view can be compressed as follows: In the spacetime world of your experience, the world investigated by science, causal determinism must be assumed; in this sense the will is not free. But morality is meaningless unless the will is somehow free. For practical reasons, therefore, we must assume that the human soul, considered as a noumenon, a thing in itself, belongs to a transcendent, timeless realm, and in this realm it is truly free. How empirical determinism and noumenal freedom can be reconciled, however, is a mystery utterly beyond our finite minds," Gardner, The Whys of a Philosophical Scrivener, 413, n. 8.

${ }^{1291}$ Olson, Arminian Theology: Myths and Realities, 174. 
In both cases, however, a singular point remains acute. Whether one is inclined toward a more Calvinistic view, or Arminian view, of freedom or the lack thereof, it is undeniable that the Newtonian worldview that their adherents each assume today is also one of the reasons for the rise of deism, precisely because the natural world is viewed all too easily as a closed causal system. Not that Newton's own thinking required this, but it is undeniable that the logic he employed could easily be adjusted in such a way as to encourage a more 'hand's off' relationship between God and nature. ${ }^{1292}$ The question, then, of the mode of divine action remains highly ambiguous in the Newtonian picture, so far as comprehending a synthetic conceptual consonance between God's acts, human acts, and the world. $^{1293}$

\section{The Dogma of the Neoplatonic Copenhagen Science}

Although it has still not penetrated the mainstream theological or scientific cultures which remain quite Newtonian, the Copenhagen interpretation of quantum mechanics has drawn the attention of several prominent Christian theologians and philosophers with a special interest in science, for example, John Polkinghorne, John Robert Russell, Nancey Murphy, ${ }^{1294}$ and Alvin Plantinga, ${ }^{1295}$ though these individuals do not by any means all agree with each other fully on how to employ for theological purposes the basic Copenhagen view or similar collapse interpretations. Yet, given their stature and influence, the Copenhagen interpretation is arguably more widely accepted today by many other leading theologians than the more simplistic classical science of Newton. It has also been embraced by a wide variety of Christian physicists from different backgrounds, including

\footnotetext{
1292 Plantinga, Where the Conflict Really Lies: Science, Religion, \& Naturalism, 85.

${ }^{1293}$ Rejecting the closed-universe hypothesis which is common for the secular Newtonian, Glauber Araújo suggests that God's miracles should "be interpreted as events in nature produced by a supernatural cause," that are nevertheless "not ... to be understood as opposing natural laws." At the same time, he believes "miracles do not need to be taken as gaps in our understanding of the natural world, but phenomena originated in a supernatural cause. They can be taken as evidence of the openness of creation to its Creator," Glauber Araújo, "Miracles and Natural Law: Are They Compatible?," in Journal of the Adventist Theological Society Vol. 28 \#2 (Autumn, 2017), 137-138. Although his intentions are to protect miracles and God's ability to act in our world, the conceptual ambiguity of how God does so is left entirely intact. It is difficult to see why his view is superior to, or dismisses, that of Alvin Plantinga, who utilizes quantum collapse events. See ibid., 135, and Plantinga, Where the Conflict Really Lies: Science, Religion, \& Naturalism, 91-125.

${ }^{1294}$ For example, Nancey Murphy and George F. R. Ellis, On the Moral Nature of the Universe: Theology, Cosmology, and Ethics (Minneapolis, MN: Fortress, 1996).

1295 Plantinga, Where the Conflict Really Lies: Science, Religion, \& Naturalism, 91-125.
} 
both some neo-Calvinists and Arminians. At the same time, however, it must be noted that it has thus far been less attractive to theists or physicists from other major Eastern world religions, which promote a more monistic, nondual, or unitary view of reality, which is more compatible with something along the lines of Bohm's theory. ${ }^{1296}$

In essence, what the Copenhagen interpretation of quantum mechanics postulates is an ontological indeterminism in nature, rather than merely the epistemological uncertainty found within chaos theory. That is, the 'uncertainty principle' declares that, really truly, nature possesses an inherent randomness that is operative at the microphysical level. In this, there is ironically a tentative alliance with the work of Pylkkö. ${ }^{1297}$ Given that the Copenhagen perspective represents the broadest 'plurality' or consensus view amongst contemporary physicists, as one might imagine, the uncertainty principle it contains seems to provide room for reasonable speculations by Christians concerning the locus of divine action in nature. ${ }^{1298}$ Plantinga, for one, and perhaps with one of the more innovative suggestions, proposes that if one assumes that "the macroscopic physical world supervenes on the microscopic, God could thus control what happens at the macroscopic level by causing the right microscopic collapse-outcomes."1299 Plantinga's speculations extend further, however. He suggests that there is a conceptual consonance between God and humanity. For, if "God has endowed human selves ... with the power to act freely," that is, to "freely cause events in the physical world,"1300 then it may be that "the specific proximate events human beings can cause are quantum collapse-outcomes. The thought would be that God's action constitutes a theater or setting

\footnotetext{
${ }^{1296}$ Not that it is accurate to be reductionistic with Eastern religions, but this is a general trend. For more, see James W. Sire, The Universe Next Door: A Basic Worldview Catalog (Downers Grove, IL: InterVarsity Press, 2009), 147; Mark T. Unno, "Buddhism, Christianity, and Physics: An Epistemological Turn," in The Boundaries of Knowledge in Buddhism, Christianity, and Science, ed. Paul David Numrich (Göttingen, Germany: Vandenhoeck \& Ruprecht, 2008), 80-104; and Milton Scarborough, Comparative Theories of Nonduality: The Search for a Middle Way (New York, NY: Continuum, 2009).

${ }^{1297}$ Indeed, Pylkkö was originally inspired by the Copenhagen view before moving beyond it through the addition of Heideggerian insights. See Pylkkö, The Aconceptual Mind, 21, 59-60, 86, 105.

${ }^{1298}$ Michael J. Dodds, Unlocking Divine Action: Contemporary Science \& Thomas Aquinas (Washington, D. C.: The Catholic University of America Press, 2012), 140-145.

${ }^{1299}$ Plantinga, Where the Conflict Really Lies: Science, Religion, \& Naturalism, 116. Note that Plantinga utilizes the Ghirardi-Rimini-Weber collapse theory, which is not too dissimilar to the Copenhagen view, though Plantinga describes their differences in more detail than will be done presently, ibid., 115. ${ }^{1300}$ Plantinga, Where the Conflict Really Lies: Science, Religion, \& Naturalism, 119.
} 
for free actions on the part of human beings and other persons-principalities, powers, angels, Satan and his minions, whatever. God sets the stage for such free action by causing a world of regularity and predictability; but he causes only some of the collapse-outcomes, leaving it to free persons to cause the rest."1301 If this were so, then "our action in the world (though of course vastly smaller in scope) resembles divine action in the world; this would be still another locus of the imago dei. Here we see a pleasing unity of divine and human free action, as well as a more specific suggestion as to what mechanism these actions actually involve."1302 Of course, such a unity comes at the cost of maintaining the original Platonic/Kantian dualism, ${ }^{1303}$ and its accompanying problem of a consistently coherent conception of time, causality, and freedom. This is because there is still no way to determine the location of human freedom, or the temporal relationship between collapse outcomes-the human 'mind' is still removed into a Platonic/Kantian timeless realm, similarly to what Rocco Boni has articulated, as will be seen below.

The challenge to the above view stems from the fact that Plantinga, and those sharing similar views as his, re-introduce some sort of 'cause' back into the random uncaused Copenhagen indeterminacy found at the quantum level. ${ }^{1304}$ That is, "only by a selective use of the tenets of both groups [namely, those who argue that all events have a cause, and those that argue indeterminate events have no cause] can a conceptual framework be forged in which a divine cause for quantum events may [be] seen as possible (Russell) or (Murphy) necessary."1305 Thus, the

proponents of quantum divine action ... borrow from the Copenhagen interpretation the tenet that there are no natural causes of quantum events while simultaneously ignoring its conviction that such events require no causes. They then adopt the tenet of the opponents of the Copenhagen interpretation that some causes are needed for quantum events while ignoring their conviction that these causes must be natural and discoverable by empirical science. Proponents of quantum divine action are then in a position to affirm a divine cause for quantum events (since, as the opponents of the Copenhagen interpretation

${ }^{1301}$ Plantinga, Where the Conflict Really Lies: Science, Religion, \& Naturalism, 119-120.

1302 Plantinga, Where the Conflict Really Lies: Science, Religion, \& Naturalism, 120.

${ }^{1303}$ Plantinga, Where the Conflict Really Lies: Science, Religion, \& Naturalism, 119 n. 41. In particular, a 'substance dualism' along the lines of J. P. Moreland, "A Defense of a Substance Dualist View of the Soul," in Christian Perspectives on Being Human: A Multidisciplinary Approach to Integration, eds. J. P. Moreland and David M. Ciocchi (Grand Rapids, MI: Baker, 1993), 55-79.

${ }^{1304}$ Dodds, Unlocking Divine Action: Contemporary Science \& Thomas Aquinas, 145-146.

1305 Dodds, Unlocking Divine Action: Contemporary Science \& Thomas Aquinas, 145. 
maintain, some cause is needed), and to assert that this divine cause cannot interfere with any natural causes (since, as the proponents of the Copenhagen interpretation maintain, there simply are no natural causes at the quantum level with which such a divine cause could possibly interfere). ${ }^{1306}$

Howsoever their views may further be articulated, the end of it requires Murphy and Plantinga to be obliged to choose between either a complete divine determinism, which begins to eerily mirror Bohm's theory of 'hidden variables, ${ }^{1307}$ or some sort of partial divine determinism in parallel with a partial human causative-determinism which defies any easy scientific explanation-they have defaulted into a Platonic/Kantian dualism which removes both God and humanity from nature, and the role of either real or imagined quantum level randomness again becomes a question. That is, if God and humans are 'causing' some of the 'random' collapse events at the quantum level, who or what is causing the other collapses, and what is their purpose? They do not say, and, as such, one is left with, once more, an uncomfortable "ontological gap" between nature, man, and God. Either real randomness exists, or it doesn't. If it doesn't, then although the epistemological uncertainty uncovered at the quantum level may appear a clever way to encourage us to think more deeply about freedom, it really serves no purpose but to deceive us. If it does exist, then the gap between which random events God chooses to intervene upon, which random events humans are allowed to choose to intervene upon, and which ones God just 'lets happen randomly' in contradistinction from the rest of nature's apparent Newtonian law-abidingness, defy any scientific explanation. What would it mean for God to let randomness reign in a part of reality, and what is the nature of the interface between what is caused by willful intent versus that which is not? This does not preclude Plantinga's suggestion from being correct, but it still contains 'gaps' which further exploration and explanation could either defeat or significantly modify, and if such exploration uncovered nothing, then we would be left with 'gaps.'

\footnotetext{
${ }^{1306}$ Dodds, Unlocking Divine Action: Contemporary Science \& Thomas Aquinas, 145; and Plantinga, Where the Conflict Really Lies: Science, Religion, \& Naturalism, 119.

${ }^{1307}$ Dodds, Unlocking Divine Action: Contemporary Science \& Thomas Aquinas, 147. Nancey Murphy concludes her essay that, "to put it crudely, God is the hidden variable," Nancey Murphy, "Divine Action in the Natural Order: Buridan's Ass and Schrödinger's Cat," in Philosophy, Science and Divine Action, eds. F. LeRon Shults, Nancey C. Murphy, and Robert John Russell (Leiden, The Netherlands: Brill, 2009), 283. See also, Philip Clayton, God and Contemporary Science (Edinburgh, Scotland: Edinburgh University Press, 1997), 217-219.
} 
The selected authors above, and their allies, have thus far provided no solution to this problem, although one can see that, were their intimations correct, it is possible Pylkkö's work might provide an interesting pathway to explore. However, this is very unlikely to occur, for one simple reason, with two manifestations. Those adhering to the Copenhagen view, in any of its variants (of which the most dominant position is an anti-realistic version ${ }^{1308}$ ), are deeply committed to the preeminent applicability of 'classical mathematical science' in some domain, either a Platonic mathematical realm or empirical-physical realm, or both.

D’Espagnat's 'veiled reality,' which preserves a hidden 'timeless' platonic realm from the confines of empirical natural science, ${ }^{1309}$ helps guide the thinking of many Christian scientists familiar with quantum physics. ${ }^{1310}$ Taking d'Espagnat's ideas one step further, perhaps the most clear and spirited defense of a dualistic quantum world alongside classical natural science comes from Rocco Boni, who, building off of the Copenhagen interpretation of quantum mechanics, ${ }^{1311}$ supports a view of reality that mixes quantum non-physicalism with mathematical objective realism. ${ }^{1312}$ This means

\footnotetext{
${ }^{1308} \mathrm{Li}$ Li makes reference to "the most influential interpretation is the 'orthodox Copenhagen interpretation,' which has been criticized as a positivistic and vague theory, and which always concludes with anti-realism," Li Li, "On Complementarity Reality," in Realism and Anti-Realism in the Philosophy of Science, eds. Robert S. Cohen, Risto Hilpinen, and Qui Renzong (Dordrecht, The Netherlands, Springer, 1996), 343. See also, Lars-Göran Johansson, Interpreting Quantum Mechanics: A Realistic View in Schrödinger's Vein (New York, NY: Routledge, 2016).

${ }^{1309}$ As such, the experimental results, for all domains that are deemed relevant, are reserved for standard or classical Newtonian science. Note Stephen Prickett, Narrative, Religion and Science: Fundamentalism Versus Irony, 1700-1999, 74-75; Philip Clayton, Religion and Science: The Basics (New York, NY: Routledge, 2012), 81; and Stefan Djupsjöbacka, Dialogue in the Crisis of Representation: Realism and Antirealism in the Context of the Conversation between Theologians and Quantum Physicists in Göttingen 1949-1961, 51, 270.

${ }^{1310}$ See, for example, Schins, "Quantum Theory: A Pointer to an Independent Reality-A Discussion of Bernard d'Espagnat's 'Veiled Reality,"' 173-182. Schins believes that d'Espagnat's work has shown that quantum mechanics supports "a new kind of causality which is located outside space-time, and may be undiscoverable by man," and in this "'veiled reality' one is faced with the question of the existence of God," ibid., 181. Schins adds, "if science is ever to give us an ingredient for a philosophical proof of the existence of God, what better suited fact could it offer but the existence of an independent, external world, that can impossibly originate from the human mind?," ibid., 182.

${ }^{1311}$ As a reminder, "the Copenhagen Interpretation stresses actual randomness of individual events at the quantum level. A minority of physicists (Bohm is the most prominent) insist that the quantum mechanics must operate at the level of ensembles of particles. Here, interaction would allow complex processes to emerge that may look random or chaotic, due to 'hidden' (unknown/unpredicted) variables. This is the more likely position at the level of social processes," John Smith and Chris Jenks, Qualitative Complexity: Ecology, Cognitive Processes and the Re-Emergence of Structures in Post-Humanist Social Theory (New York, NY: Routledge, 2006), 280 n. 10.

1312 Rocco Boni, Quantum Christian Realism: How Quantum Mechanics Underwrites and Realizes Classical Christian Theism (Indianapolis, IN: Xlibris, 2016), 4-5.
} 
that the mathematical wave-function which describes the quantum state of an isolated quantum system as a complex-valued probability amplitude is objectively real, yet non-physical-Boni is therefore a critical realist. ${ }^{1313}$ At the same time, the wave-function produces real, physical effects. That is, physical effects are generated from out of a non-physical, but mathematical, substrate in the quantum realm. ${ }^{1314}$ As Boni explains, "the quantum substance, whatever it is, is unmistakably platonic, being strikingly akin to Plotinus' nous, or soul essence as found within the neo-Platonic hierarchy of Being."1315 Therefore, "the theistic implications ... are quite clear. The physical universe is continually emanating from an elemental substrate with distinctively mind-like properties. I say 'mind-like' because the quantum wave-function, as an abstract store of existential possibilities, comprises a sphere of volitional freedom from whence choices (in the form of quantum event outcomes) derive."1316

Further analysis of Boni's provocative thesis cannot be accomplished here, other than to note that Boni dwells upon the fact that, "like relativity, quantum mechanics is a mathematical way of describing reality." Yet, "the deep and irreducible difference between mathematics and natural languages results in the fact that the narrative translations of exactly the same set of equations can yield quite different results depending on the translator's narrative templates." ${ }^{1317}$ In any case, for

\footnotetext{
${ }^{1313}$ Boni, Quantum Christian Realism: How Quantum Mechanics Underwrites and Realizes Classical Christian Theism, 47.

${ }^{1314}$ Boni embraces what is referred to in the literature as "wave function ontology," wherein the wave function is a real thing, albeit metaphysical. See Valia Allori, "Primitive Ontology and the Structure of Fundamental Physical Theories," in The Wave Function: Essays on the Metaphysics of Quantum Mechanics, eds. Alyssa Ney, and David Z. Albert (Oxford, UK: Oxford University Press, 2013), 58-75; and Peter J. Lewis, Quantum Ontology: A Guide to the Metaphysics of Quantum Mechanics (Oxford, UK: Oxford University Press, 2016).

${ }^{1315}$ Boni, Quantum Christian Realism: How Quantum Mechanics Underwrites and Realizes Classical Christian Theism, 6.

${ }^{1316}$ Boni, Quantum Christian Realism: How Quantum Mechanics Underwrites and Realizes Classical Christian Theism, 9.

${ }^{1317}$ Elana Gomel, Postmodern Science Fiction and Temporal Imagination (New York, NY: Continuum, 2010), 71. Gomel continues, "Stephen Weinberg, for example, whose favorite writer is the gloomy late Victorian George Gissing, a determinist like Hardy and Zola, translates quantum mechanics in a way that preserves an almost Newtonian view of the laws of nature. While acknowledging that the 'historical accidents' seem to play an irreducible role in both cosmology and biology, he still hopes that we will discover the way 'in which the behavior of any physical system is completely determined by its initial conditions and laws of nature,"' and "Hawking also attempts to reconcile quantum theory with a modified version of classical determinism by arguing that universal laws exist, though they may be probabilistic in nature. Brian Greene candidly confesses that he is torn between his emotional allegiance to the narrative concept of temporality and his rational acceptance of the frozen river of Einsteinian spacetime. He refers to Einstein's own resignation that science
} 
Boni, what can be said of his view is that it is distinctly and thoroughly neo-platonic, preserving two realms, even if they are now much more 'closely' or intimately related than in Plato's original conception. ${ }^{1318}$ Yet, in relation to the work of Bohm and Pylkkö, two critiques must be noted. First, in relation to Bohm, Boni openly admits that the "wave-function collapse is both instantaneous and discontinuous," and that concerning the question of how this happens, or in what way God interposes within this process, "science has no answer.... At this point in the quantum account science hits an explanatory wall." ${ }^{1319}$ Bohmians, who reject the Copenhagen interpretation, would not find this attractive, for it rejects the possibility that there are underlying implicate orders, or an infinity of nature to scientifically investigate, whatever new nonmechanistic forms it may take. 'Mind' is simply too non-physical for Boni. He has no rationale for how or why the brain and mind interface in the way they do-science is quite classical in our common everyday world, and mind is 'non-physical' in a way we also cannot comprehend. Ironically, and in support of Bohm's basic original thesis, 'God' or enabled-humans are the 'supernatural' 'hidden variable,' once again. ${ }^{1320}$ Thus, despite attempts to do so, Boni also doesn't fully escape mechanistic science-for him there is simply the mechanistic physical world standard science investigates, conjoined mysteriously with the quantum realm which platonically contains the probabilistic mathematical wave-function which 'generates' events in conjunction with 'mental-willed' activity. Yet, this is still a mechanics driven approach to reality, as all internalist mathematics are in any purported platonic realm. ${ }^{1321}$

cannot grasp the fundamental human experience of time as flowing from the past to the future," ibid., 71-72. ${ }^{1318}$ Boni, Quantum Christian Realism: How Quantum Mechanics Underwrites and Realizes Classical Christian Theism, 65, 86. 'Quantum dualism is not the exact 'Platonism' of classical thought but it is nonetheless 'platonistic' in that the physical derives ... [from] the metaphysical. What's more, in this physical reality, wavefunction is the abstract 'Ideal.' And it keeps physical reality percolating into being, particle-by-particle," ibid., 86. Boni does not, however, assert that "God" is this second realm-rather, there is for Boni three realms. The physical, the metaphysical, and the supernatural, ibid., 70 n. 101.

${ }^{1319}$ Boni, Quantum Christian Realism: How Quantum Mechanics Underwrites and Realizes Classical Christian Theism, 87.

${ }^{1320}$ For "that which is random from inside the universe, may be fully determined by God from outside the universe. The rules of quantum physics allow for just this sort of behind-the-scenes action," Boni, Quantum Christian Realism: How Quantum Mechanics Underwrites and Realizes Classical Christian Theism, 120. Yet, Boni also allows for some 'undetermined' outcomes as well, see also, ibid., 89 n. 128. That is to say, we don't really know whether we are freely determining our choices or whether they are random.

${ }^{1321}$ Boni, Quantum Christian Realism: How Quantum Mechanics Underwrites and Realizes Classical Christian Theism, 67. See also, Mark Rowlands, Externalism: Putting Mind and World Back Together Again (New York, NY: Routledge, 2014), 18-19. Boni's solution, then, is merely one that reverts us back to Plato, Descartes, 
At the same time, Boni is forced to vacillate on the question of God and 'time,, ${ }^{1322}$ attempting to maintain a di-polar (Whiteheadian) dualism upholding timelessness and some form of temporality. His preferred vehicle for divine foreknowledge is the 'middle-knowledge' platform, which he happily shares is "an intrinsically platonistic concept," for "quantum reality speaks to the existence of both abstract entities and physical entities-wherein the former gives rise to the latter."1323 That is to say, Boni believes metaphysically objective possibilities generate 'selectable' realities by the divine or human mind/will. On these and the above points, Pylkkö would offer his own critique. Boni offers no attempt to unify the quantum realm with the scientific conceptuality which rules the classical realm. He leaves no room for either a Bohmian nonmechanistic order, nor anything similar to Pylkkö's notion of the aconceptual, which for Pylkkö is what defines the uniqueness of the individual human experience or existence. ${ }^{1324}$ The soul/mind is also too rational in Boni's depiction for Pylkkö, as the quantum randomness doesn't meaningfully contribute to any irrationalism within the human brain. ${ }^{1325}$ Boni still faces a mind-body problem, and the question of the origin of irrationality. That is, Boni has left unanswered just what is the nature of natural patterns or laws? And what, exactly, is the status of randomness in nature, without letting the quantum empirical reality devolve into another deterministic divine 'hidden variable' solution? Boni here oscillates, unable to decide. ${ }^{1326}$

and Kant. Boni is able to provide fascinating empirical phenomena on behalf of his argument, that move far beyond Plato and Descartes, but, at the end of the day, his fundamental ontology is the same as that of Plato. Contrast his view with that of Sara N. Hottinger, Inventing the Mathematician: Gender, Race, and Our Cultural Understanding of Mathematics (Albany, NY: State University of New York Press, 2015), 49-88. That is, Boni must posit a special place for the timeless platonic mathematical realm.

1322 "It is obvious to me, that both static time and fluid time exist within realms metaphysical, in, by, and through abstract objects.... It thus seems that there is (1) physical time (or creaturely time, such as we experience), of which God is outside. As well as (2) metaphysical time (such as the (a) static and (b) fluid times associated with Platonic/quantum entities), of which God is also outside. And finally (3) God's time, which, while 'outside of' (and/or beyond) all others, nonetheless encompasses each," Boni, Quantum Christian Realism: How Quantum Mechanics Underwrites and Realizes Classical Christian Theism, 84 n. 124.

${ }^{1323}$ Boni, Quantum Christian Realism: How Quantum Mechanics Underwrites and Realizes Classical Christian Theism, 85; 67.

${ }^{1324}$ Pylkkö, The Aconceptual Mind, xxii, 31, 58, 113; and Boni, Quantum Christian Realism: How Quantum Mechanics Underwrites and Realizes Classical Christian Theism, 65.

1325 Pylkkö, The Aconceptual Mind, 77, 181, 185, 241.

${ }^{1326}$ Boni, Quantum Christian Realism: How Quantum Mechanics Underwrites and Realizes Classical Christian Theism, 120, 89 n. 128. 
Additionally, Pylkkö would reject the platonic status Boni attributes to the wave-function, ${ }^{1327}$ which doesn't take seriously enough the experiential activity of humans. Lastly, it is important to observe that Boni's understanding of 'time' lacks the Heideggerian four-dimensional ontology of timespace. ${ }^{1328}$ That is to say, as Michael Eldred observes, "it is to be noted that the indeterminacy relation between position and momentum, insofar as it is conceived to go hand in hand with the dual nature of sub-atomic entities as both particle and wave, is postulated as a spatial indeterminacy; a temporal indeterminacy and what this could mean do not appear on the quantum physicist's [Boni's] list of perplexities."1329

In summary, both classical science and quantum science have long tentacles of influence stretching throughout theological discourse in the $21^{\text {st }}$ century. Bohm and Pylkkö's insights have a mixed relationship toward such theological discussions. Without any doubt, despite many contemporary detractors, Bohm's metaphysics could be incorporated into the framework of classical science assumed by traditional Christianity, particularly Calvinistic, Catholic, Islamic, and Eastern

${ }^{1327}$ Pylkkö, The Aconceptual Mind, 103-104. "The status of the quantum formalism as a macrophysical entity is fictional, and, therefore, there is not much point to insist that the Schrödinger equation and other related formalisms provide realistic descriptions of some microphysical processes," ibid., 104; and "even natural numbers should not be seen ... as some sort of abstract or a priori structures. Numbers of all kind belong to the realm of human experience," Pylkkö, "Eliminative Holism as a Solution to Bohr's Puzzle of Two Languages," 140$156,153$.

${ }^{1328}$ Eldred, The Digital Cast of Being: Metaphysics, Mathematics, Cartesianism, Cybernetics, Capitalism, Communication, 137-167. Even "with observational indeterminacy, which in turn induces the postulation of a theoretical indeterminacy (complex wave-function superposition of infinite possibilities for the phase state of a quantum entity), modern mathematical physics has come up against an (unbeknowns to it: temporontological) obstacle in its striving to govern motions of all kinds by mathematically formulated laws and has had to retreat from totally precalculable determinacy to probabilistic precalculability, which is still quantifiable and calculable. This is still removed, however, from the insight that movements can have wholly unforeseen outcomes or that they can be free and that physical beings per se, as changeable, are not solely present at an instant," ibid., 146. Thus, "the break with the scientific conception of time as a one-dimensional variable, $t$, that ties time to a real instant must be made to see quantum superposition properly, but at the price of sacrificing the causaldeterminist time-evolution of a quantum wave-function provided by the Schrödinger equation. Time itself must be conceived as three dimensional," ibid., 162. See also, Eldred, A Question of Time, 223. Thus, the criticism of the Heideggerian against the classical physicist is when does the 'will' exercise itself to determine a quantum collapse? The 'when' question is uncritically assumed in a one-dimensionally temporal way in Boni's account, and as such, becomes essentially a matter of 'where' the collapse spatially happens, which is the 'timeless' mathematical void of the 'present' instant.

${ }^{1329}$ Eldred, The Digital Cast of Being: Metaphysics, Mathematics, Cartesianism, Cybernetics, Capitalism, Communication, 150. Eldred refers to the Heideggerian notion of four-dimensional time-space in contrast to the one-dimensional linear concept of temporality, which is assumed by arguably all physicists doing standard scientific research. Specifically, the quantum formula $\Delta E \cdot \Delta t \succsim \hbar$ only refers to a one-dimensional time indeterminacy. 
traditions. Pylkkö’s insights are less likely to receive any serious attention, but some Heideggerian influences could certainly impact many variants of religion, including Arminianism, as well as various nationalist or Protestant cultural Christian groups. On the other hand, concerning the contemporary Copenhagen consensus, a much more complex situation exists. Bohm's views were developed to directly counter the Copenhagen view. ${ }^{1330}$ Yet, ironically, many of the theists who have accepted and tried to work within the Copenhagen perspective accept one of Bohm's basic tenets as a vehicle to allow for divine action-they insert 'God' as the 'hidden variable' to resolve their distaste of sheer randomness. This would displease Bohm. Conversely, however, Pylkkö would fully endorse the basic conclusion of the Copenhagen view that there is randomness in nature. However, Pylkkö would part ways with the advocates of the Copenhagen view who maintain a sharp dualism dividing reality between the 'timeless void' outside space-time, and the deterministic (thus also timeless) mathematized classical science that reigns over the rest of nature. Pylkkö would suggest that nature must be thought of as a genuinely wholistic temporal aconceptual experience, and if there were any 'God' behind nature, his mode of presence in our world must be similarly constituted to that nature.

God, Freedom, and Time in the Humanities

\section{The Question of Religious Pluralism}

One of the major questions that has challenged adherents of Christianity, Judaism, and Islam, just to name the most significant three in the west, which also have the most deeply rooted exclusivist traditions, ${ }^{1331}$ is the question of religious pluralism, which has found many supporters recently among

\footnotetext{
${ }^{1330}$ Bohm, Bohm-Biederman Correspondence: Creativity in Art and Science, 13. It is critical to observe that, for Bohm, his disagreement "with Bohr is that he stops with just giving the limitations on the older mechanistic and deterministic points of view, and discourages the development of new categories of thought concerning space, time, existence, etc., in which one will see the reasons for these limitations. Thus, if determinism is limited, this need not be a complete mystery. It may only mean that we must have a different idea of what things are, which shows quite naturally why determinism is limited. If we get a different idea of time and of what is to be meant by existence in time, then we see a natural reason why the past would not determine the future" as it does in standard physical theories, ibid., 15-16.

${ }^{1331}$ Frank Julian Gelli, "Mystery and Plural Faiths: Religious Diversity as Expression of the Quest for a Deus Absconditus," in Islam and Global Dialogue: Religious Pluralism and the Pursuit of Peace, ed. Roger Boase (Burlington, VT: Ashgate, 2010), 227-243, 227.
} 
those in the academy and political sphere. ${ }^{1332}$ Many Christians have long insisted that Christ is the only savior, which they base on a straightforward reading of Scripture (Acts 4:12) ${ }^{1333}$ At the same time, it has also been recognized by many, to varying degrees, that salvation is conditionally available to those who have never heard the name of Jesus, or been given a twisted presentation of his character. ${ }^{1334}$ The nuances and subtleties of the biblical testimony on the salvation of the improperly evangelized or unevangelized cannot be probed here. What is of interest at present is what role do the issues of freedom and time have in the concept of religious pluralism, specifically in the context of the conceptions of freedom and time examined within this study, as well as the views of Bohm and Pylkkö? Where is the world headed on the question of religious pluralism and harmony? While complete answers to such questions are obviously not possible here, a few comments can be made about how conceptions of freedom and time may guide future thinking on these questions.

First, as recognized by Jerry Walls and Joseph Dongell, religious views based upon the metaphysics and theology undergirding classical science and its determinism, such as Calvinists, as noted above, are prone to be very exclusivist. ${ }^{1335}$ The same is often true of Muslims and Jews who hold similar convictions. ${ }^{1336}$ Yet, the point at present is to emphasize that very often, the key idea uniting their exclusivist perspectives is an understanding of overall determinism-this is certainly true for the Calvinist and many Muslims. There is an irony in this, in that a common timeless metaphysics unites them all, but it has assumed distinctly unique socio-cultural-religious manifestations, which pit them firmly against each other. However, the precise nature of the timeless metaphysics grounding

\footnotetext{
${ }^{1332}$ For example, see the more open-minded pluralist S. J. Samartha, One Christ-Many Religions: Toward a Revised Christology (Eugene, OR: Wipf and Stock, 1991). For more discussion on this, see Adam B. Seligman, ed. Religious Education and the Challenge of Pluralism (Oxford, UK: Oxford University Press, 2014). 1333 As argued by the exclusivist Ronald H. Nash, Is Jesus the Only Savior? (Grand Rapids, MI: Zondervan, 2010).

${ }^{1334}$ Representative of this more inclusive attitude would be Clark H. Pinnock, $A$ Wideness in God's Mercy: The Finality of Jesus Christ in a World of Religions (Grand Rapids, MI: Zondervan, 1992).

1335 Jerry L. Walls and Joseph R. Dongell, Why I Am Not a Calvinist (Downers Grove, IL: InterVarsity Press, 2004), 195.

${ }^{1336}$ For example, see Esra Akay Dag, Christian and Islamic Theology of Religions: A Critical Appraisal (New York, NY: Routledge, 2017); Zain Ali, Faith, Philosophy and the Reflective Muslim (New York, NY: Palgrave Macmillan, 2013); and Terence Lovat and Robert Crotty, Reconciling Islam, Christianity, and Judaism: Islam's Special Role in Restoring Convivencia (New York, NY: Springer, 2015), 19-23.
} 
them is also one of fragmentation, which is a product of atomistic modern science, and the philosophy that it is built upon, which undergirds the metaphysics of much western Christian theology, as well as Islam. In light of this fact, the insights of Bohm and Pylkkö become highly relevant.

Bohm suggests that all of reality and society are, in fact, an integrated whole, and as such we should seek dialogue to overcome our fragmentation. By delving deeper into the implicate order, all cultures can found common ground and overcome their differences. ${ }^{1337}$ There is a deeper realism which can unite us all, bringing us a common understanding of freedom and (timeless) time. Bohm, for one, is certainly an idealistic pluralist at heart. Interestingly, as noted above, representatives from the world's largest religions, namely Catholicism, Islam, and Eastern religions, are all very supportive of Bohm's globalist efforts. ${ }^{1338}$ Conversely, Pylkkö's critique of the fragmenting nature of classical science is actually quite similar to Bohm's. ${ }^{1339}$ Pylkkö believes classical science is an oppressive culture which, by its very nature is a totalizing hegemony that ultimately denies freedom. As such, in Pylkkö's understanding, the very idea of genuine freedom and unity in qualitative diversity is not possible within the homogenous scientific-world-culture. However, rather than focus on seeking some alternative underlying metaphysical ground to provide harmony which would continue the realist-scientific impulse of Bohm, leaving freedom and time ambiguous, Pylkkö would prefer to focus on the value of unique languages and cultures, including religious ones. Pylkkö believes that the best we can do in the current world, which is dominated by science, is to retreat into our own respective cultures, and preserve them and the freedom they contain as unique experiences. ${ }^{1340}$ The utopian dream of a peaceful globalization is doomed to failure, because of science and its metaphysics and ethics. In this, he would share the sentiment of Rosenau that today's world is best described as one

\footnotetext{
${ }^{1337}$ Bohm and Peat, Science, Order, and Creativity, 147-148.

${ }^{1338}$ In particular, see Moazziz Ali Beg, The Ideological Integration of East and West: An Enquiry Concerning World Peace (New Delhi, India: Global Vision Publishing, 2005), 184-185. A recent poll indicates that a majority of the world favors globalism, not nationalism. See "Majority of World Population Support Globalism," at https://www.straitstimes.com/world/europe/majority-of-world-population-supports-globalismsurvey-finds (accessed January 20, 2019). Esseitä, 89.

${ }^{1339}$ Pylkkö, The Aconceptual Mind, 51. See also, Pylkkö, Kielikuva ja Mielikuva-Ja Muita Dialektisia

${ }^{1340}$ Pylkkö, Kielikuva ja Mielikuva-Ja Muita Dialektisia Esseitä, 130-138; Pylkkö, Luopumisen Dialektiikka, 203.
} 
experiencing fragmegration, because overall, somehow "the world is simultaneously moving ... in opposite directions, ${ }^{1341}$ both fragmenting and integrating, thus the movement of the world is to contradict itself. This is true both within non-Christian movements, as well as within Christianity. ${ }^{1342}$

\section{Political and Social Justice}

Deriving an acceptable understanding of social ethics or social justice still divides the world in poignant ways. Given that the major world religions have thus far failed to agree upon any universally applicable ethical framework, ${ }^{1343}$ nor has any one individual religion yet stepped forward with the dominance to do so itself, worthy of note is that one of the primary impulses to guide our fragmegrated global thinking on ethics has been the metaphysics beneath classical science-indeed, "the development of modern science is tightly interwoven with modern concepts of social ethics." ${ }^{1344}$ This is seen in the work of such diverse thinkers as Darwin, Marx, and the authors of western capitalism and democracy. However, this has introduced the possibility of the 'religion' of scientism, which has brought its own pitfalls, for some claim science simply cannot incorporate or outright rejects "the reality of ethical, religious, and artistic insight." ${ }^{1345}$ The modern scientific world's social ethics, if it can be said to have one, is that of individualism and equality, of which the latter concept has many subtle and debated facets which blend with egalitarianism, which is not the same. In any case, equality of opportunity, equality before the law, equality of outcomes, etc., often compete with each other in a democracy driven by science, which tempts us with the idea that all of the previous equalities are attainable. However, these are, in many ways, also contradictory, in that it is not possible to treat everyone equally, as not all are equal (in many ways, not just abilities or skills-i.e., people have different needs, for example. How does a society feed everyone equally when some

\footnotetext{
${ }^{1341}$ Rosenau, Distant Proximities: Dynamics Beyond Globalization, 12.

1342 The Christian world has been and continues to change rapidly, with multiple 'centers of Christianity' emerging. Timothy C. Tennent, "Paradigm Shifts in the Global Revitalization of Christianity," in Bibliotheca Sacra 175 \#699 (July-September, 2018), 339.

${ }^{1343}$ Vic McCracken, ed. Christian Faith and Social Justice: Five Views (New York, NY: Bloomsbury, 2014).

${ }^{1344}$ John C. Caiazza, The Crisis of Progress: Science, Society, and Values (New York, NY: Transaction Publishers, 2016), 3.

${ }^{1345}$ Caiazza, The Crisis of Progress: Science, Society, and Values, 53.
} 
'need' more to eat?). Conversely, individualism, through the vehicle of capitalism, promotes the idea that what one earns is what one deserves. These two ideas are the spawn of the metaphysics undergirding the atomism of classical science, according to both Bohm and Pylkkö, as well as a number of other thinkers. And therein lies the problem. Although it is widely ignored in contemporary American society, for example, especially by more conservative thinkers, the contention by some (who are also conservative) is that the intrinsic ethics of the West is unethical, ${ }^{1346}$ precisely because, being grounded in the metaphysics of classical science, it denies the existence of genuine freedom and time, ${ }^{1347}$ and fragments society, making social ethics impossible. History is playing out as more a competition of oppositions than progress toward any true or unitary freedom, and technology has only enabled greater inequalities. What is particularly interesting about this situation is that, especially in the United States, Christianity has become a divided witness, split between the Religious Right (Moral Gospel) and the Religious Left (Social Gospel), and these competing emphases have diluted the Christian witness overall. Interestingly, Catholics and Seventh-

\footnotetext{
1346 "If today the crucial problem of political philosophy is that of providing a rational justification for ethical norms and principles ..., it is precisely because after the rise of modern science it is no longer possible, that is to say, no longer rationally valid, to attempt to explain the factually existing world in terms of entelechies and teleological causes." For "there is no place for teleology in the realm of scientific discourse. That the rise of mechanistic science is what has rendered problematic the whole notion of natural law or right... 'is caused by the victory of modern natural science,"' Strauss, cited by Madison, The Logic of Liberty, 258. See also, Pylkkö, Luopumisen Dialektiikka, 8-89, 197-198.

${ }^{1347}$ Madison, The Political Economy of Civil Society and Human Rights, 41-74. Of course, the Catholic D. L. Schindler has also made this point at length. Schindler, Heart of the World, Center of the Church: Communio Ecclesiology, Liberalism, and Liberation, 133, 164, 174. See also, David C. Schindler, Freedom From Reality: The Diabolical Character of Modern Liberty (Notre Dame, IN: University of Notre Dame Press, 2017); and David C. Schindler, Love and the Postmodern Predicament: Rediscovering the Real in Beauty, Goodness, and Truth (Eugene, OR: Cascade Books, 2018), 49-63. Or, as Michael Eldred critically observes, unfortunately "the world's most prestigious universities today subscribe to the view that philosophy has outlived its usefulness for the deepest questions confronting humanity today. Philosophy is preserved as a kind of artefact of the West's cultural heritage, commemorating historical beginnings and immured in ivory tower humanities departments where scholars spend their days, while the really crucial, 'relevant' thinking, the thinking that ultimately makes a difference [in] how [to] live, [is] done in institutes of natural and social science. There is a distinction popular today among the educated between 'soft' and 'hard' science or knowledge. 'Soft' knowledge is regarded as a kind of cultural embellishment to living that relies on 'fuzzy' concepts about things like humankind's 'humanity,' its 'soul,' etc. 'Hard' science, by contrast, is unquestioningly taken to be where the important, decisive thinking with implications for humankind gets done," Michael Eldred, Social Ontology: Recasting Political Philosophy Through a Phenomenology of Whoness (Piscataway, NJ: Rutgers, 2008), 3.
} 
day Adventists stand apart as two of the more evenly divided groups, showing a sensitivity to both sides, yet, thus far, no ability to transcend the two cultures' crisis toward some sort of resolution. ${ }^{1348}$

Bohmians would suggest, as one might expect, that there can be a 'scientific' ethics, grounded on the reality of nature in its infinite depths. ${ }^{1349}$ Promoting dialogue, creativity, and oneness in truth are the ultimate ethical goal. Without any doubt, Bohm's vision is one grounded in collectivism-albeit, in the minds of his advocates, a friendly collectivism. ${ }^{1350}$ Conversely, Pylkkö would eschew any social ethics that is not formed with the protections of the minority cultures in mind. ${ }^{1351}$ No overriding culture should ever be given preeminence in coercively defining a social ethics or social justice that binds everyone together-conversely, no culture, with the exception of those who would do direct violence to another, should ever be ostracized. Every group should be allowed to live in their pocket, voluntarily choosing their associations, with only the most basic human rights guaranteed. ${ }^{1352}$ The 'ethical' thing to do is respect the ethics of others-spheres of experiential persuasion would be the most appropriate method of sharing and expanding the influence of an ethical perspective. His views thus lean more to the libertarian side, but his path of reasoning to get there is far more unique and encompassing than most libertarian political philosophers.

\section{The Atonement, the Biblical Sanctuary, Sacramentalism, and Salvation}

Having briefly addressed some basic concerns in the humanities relating to freedom and time, the explicitly biblical and Christian concepts of the atonement, the sanctuary, and sacramentalism will

\footnotetext{
${ }^{1348}$ Younker, "The American Socio-Political Spider Web and the Rise of Global Christianity." See also, Alden Thompson, Beyond Common Ground: Why Liberals and Conservatives Need Each Other (Nampa, ID: Pacific Press, 2009).

${ }^{1349}$ John David Garcia, The Ethical State: An Essay on Political Ethics (Wexford College Press, 2003), esp. 25-26; and Lisbeth Lipari, Listening, Thinking, Being: Toward an Ethics of Attunement (University Park, PA: The Pennsylvania State University, 2014).

${ }^{1350}$ Kozhevnikov, Stalin's Great Science: The Times and Adventures of Soviet Physicists, 271-273.

${ }^{1351}$ Pylkkö, Ajatus ja Kädet, 78.

1352 This is in general harmony with others, such as Hunter and Nedelisky, Science and the Good: The Tragic Quest for the Foundations of Morality, 213. Upon analyzing science's failures to unify morality, they suggest "what if the only way to achieve even minimally shared understanding is through our differences? This framing of the question is only reinforced by the fact that, historically, there has never been a generic morality capable of distilling all of the varieties of moral understanding and experience. Historically speaking, moralities only exist in their particularity and in the particular communities that sustain them," ibid., 213.
} 
be addressed. Of course, all of these issues pointedly relate to soteriology. Although a detailed biblical review of the issues is not possible here, an attempt will be made to address the salient points insofar as they impact upon the concepts of freedom and time.

It was Heidegger who wryly noted the words of his predecessor Georg W. F. Hegel, that "'a civilized people without metaphysics' is like an 'otherwise copiously decorated temple without the Holy of Holies."’1353 Without any doubt, the sanctuary and atonement in the Old Testament dominate critical discussions about the biblical conception of the relationship between God and humanity. What is critical here is to pinpoint the role that freedom and time are understood to perform in the biblical text on these themes. Most commentators agree that the process or method of salvation for humanity is depicted in the sanctuary service in the Old Testament. ${ }^{1354}$ Four major models have been proposed for understanding the soteriological process depicted in Scripture and its relevance for today.

First, the dominant historical perspective is that of the continuum model depicted through the Sacraments. This is the understanding of Roman Catholics, as well as most Orthodox faiths and a few Protestants. ${ }^{1355}$ Here, the anti-typical Jewish sacrifices met Christ at the Cross, but continue today in literal renewal, alongside the other sacraments. That is, Christ objectively wrought the material of salvation, which is subjectively applied to us materially to be effective. It is important to note that this view recognizes the singularity of the Cross event, yet it also understands the eucharistic divine-

\footnotetext{
${ }^{1353}$ Heidegger, Parmenides, 100. Heidegger cites the 1812 edition of Hegel's The Science of Logic. A recent translation can be found in Georg Wilhelm Friedrich Hegel, The Science of Logic, tr. George Di Giovanni (Cambridge University Press, 2010), 8.

${ }^{1354}$ For example, Robin Ryan, Jesus and Salvation: Soundings in the Christian Tradition and Contemporary Theology (Collegeville, MN: Liturgical Press, 2015), 3; Ronald S. Wallace, The Atoning Death of Christ (Eugene, OR: Wipf and Stock, 1997), 2-4, 57-58; Roy Gane, Cult and Character: Purification Offerings, Day of Atonement, and Theodicy (Winona Lake, IN: Eisenbrauns, 2005). Gane observes that the purpose of the sanctuary system was to show "the way not only to freedom from condemnation, but also to healing of character, which is defined in terms of loyalty to Yнwн," ibid., xix. See also, M. L. Andreasen, The Sanctuary Service (Hagerstown, MD: Review and Herald, 2006); Frank B. Holbrook, The Atoning Priesthood of Jesus Christ (Berrien Springs, MI: Adventist Theological Society, 1996); and Roy Gane, Who's Afraid of the Judgment?: The Good News about Christ's Work in the Heavenly Sanctuary (Nampa, ID: Pacific Press, 2006).

${ }^{1355}$ Joseph Martos, Deconstructing Sacramental Theology and Reconstructing Catholic Ritual (Eugene, OR: Wipf and Stock, 2015); and Congdon, The God Who Saves: A Dogmatic Sketch, 159-161.
} 
human interface, which mediates salvation, in a 'timeless' way. ${ }^{1356}$ In like manner, according to contemporary leading Catholic theologians, freedom must also be understood in an analogous 'timeless' way as a relationship to the truth, ${ }^{1357}$ which has implications for the role of Catholic

\begin{abstract}
${ }^{1356}$ See again, Younker, "From Metaphysics to Templephysics: Situating the Significance of Fernando Canale's Contributions for the 'Christian Philosopher,'” 208-230. Concerning the 'timeless' manner in which the eucharist is understood, Matthew Tan writes "it is important to note that securing space in a way that sets the Church as a political community in its own right can only be complete with a liturgical interruption of an often overlooked dimension of modernity, postmodernity and their subsequent cultural manifestations-time. Thus it is important to first consider how eucharistic space challenges the conception of time within the
\end{abstract} state/society/market complex. What is important to note, first of all, is that time is not the result of scientific distillation but is 'structured through social practices.'" Unfortunately, "modern time-sometimes called 'clock' time-operates as a seamless stream of repeated units of measure that are constantly being replicated in the present, then irrevocably lost to the past. This is the flattened time that sustains both the state and the market as political communities, since both are founded on confining all reality to the [deterministic?] temporal, coupled with the imperative to compress the processes of life into reified commodities whose value can be discerned in a single moment in the present. Eucharistic practice poses a challenge to the status quo because the Eucharist interrupts this flattened time by having eternity 'enter history,' making the liturgy a simultaneously historical and eschatological event that transforms temporal, and indeed political, experience." There is thus a simultaneous looking back and eschatological looking forward that makes the modern compartmentalization of past, present and future 'lose their fixed character.' The Eucharist thus interrupts 'clock' time because the liturgy presumes a confusion of past, present and future in a single moment." Tan continues, "this is given a sharper focus in the offering of bread and wine. The 'in the now' offering of bread and wine casts the participants' minds back to the events leading up to Jesus' death and Resurrection. This can be a simple memorial of a past event, but remember that the endpoint of the eucharistic liturgy is the reception of the Body of Christ. Recall that these elements to the participant are not merely symbolic and pointing to the past, but are real and present 'in the now.' This reception 'in the now' of a real Body of Christ that is the result from that same single sacrifice took place in the past, denotes a bringing forward of that past event into the present. The liturgical sacrifice both as a memorial of Jesus' bounded historical death and resurrection as well as part of a heavenly liturgy collapses the duality between historical (Kronos) and eternal (Kairos) time. Participants are reminded that the Eucharist is not a replication of a past sacrifice that occurred in a past time, but of one that is continuing outside of time in 'the heavenly Jerusalem ... [with] innumerable angels ... \{and\} the assembly of the firstborn enrolled in Heaven. This participation in the Kairos, where past, present and future meet, is what brings into the now the seemingly unknown events of the future into a single moment," Matthew John Paul Tan, Justice, Unity, and the Hidden Christ: The Theopolitical Complex of the Social Justice Approach to Ecumenism in Vatican II (Eugene, OR: Pickwick, 2014), 69-71 (additions mine). One can easily see the Bohmian-like description of time utilized by Tan.

1357 This point is important, and controversial, revealing a subtle rift within contemporary Catholicism. From a philosophical-theological perspective, the critical nature of the connection between truth and freedom from within the Catholic neoplatonic context is explained well by Barry Hudock, when he expounds upon the rationale behind the 1965 Catholic statement on religious freedom, Dignitatis Humanae. Hudock quotes Karol Wojtyła, later known as Pope John Paul II, to explain "it is in the truth that the human person achieves his own proper perfection, for the truth corresponds to his rational nature and constitutes the firmest foundation for true freedom." Again, "there is no freedom without truth." This must be seen in contrast to the American Catholic philosopher John Courtney Murray, who was "disappointed in this development. He saw it as an unnecessary embellishment and a potential threat to what ought to have been the church's principled commitment to the right to religious freedom. It is a short step, he argued, for a government-be it Catholic or Communist-that sees itself as possessing truth to decide it must impose that truth and repress error for the good of the people," Barry Hudock, “Freedom, Truth, and Human Dignity': The Other Conflict Behind “'Dignitatis Humanae,", at https://www.commonwealmagazine.org/freedom-truth-and-human-dignity (accessed February 18, 2016). For more on this, see David L. Schindler, "Freedom, Truth, and Human Dignity: An Interpretation of Dignitatis Humanae on the Right to Religious Freedom," in Freedom, Truth and Human Dignity: The Second Vatican Council's Declaration on Religious Freedom: A New Translation, Redaction History, and Interpretation of Dignitatis Humanae, eds. David L. Schindler and Nicholas J. Healy, Jr. (Grand Rapids, MI: Eerdmans, 2015), 129130; Pope Benedict XVI, Joseph Ratzinger in Communio Vol. 2: Anthropology and Culture, eds. David L. Schindler 
theology in society. For David L. Schindler, and others who have inspired him, such as Joseph

Ratzinger (later Pope Benedict XVI) and Hans Urs von Balthasar, authentic freedom must escape the

shackles of the purported neutrality of the Cartesian-scientific rationality of modernity, which

grounds classical Western/American liberalism. ${ }^{1358}$ Schindler's exposition is indeed penetrating,

cogently aware of the two cultures conflict, ${ }^{1359}$ and specifically incorporates Heideggerian and

Bohmian premonitions about science and technology. ${ }^{1360}$ Schindler suggests that modern society's

and Nicholas J. Healy (Grand Rapids, MI: Eerdmans, 2013), 188-199. See also, Glenn W. Olsen, On the Road to Emmaus: The Catholic Dialogue with America and Modernity (Washington, D.C.: The Catholic University of America Press, 2012), 125-187; David T. Koyzis, Political Visions \& Illusions: A Survey \& Christian Critique of Contemporary Ideologies (Downers Grove, IL: InterVarsity Press, 2003), 68-71; Peter Casarella, "Public Reason and Intercultural Dialogue," in At the Limits of the Secular: Reflections on Faith and Public Life, ed. William A Barbieri Jr. (Grand Rapids, MI: Eerdmans, 2014), 51-84; and Edward Barrett, Persons and Liberal Democracy: The Ethical and Political Thought of Karol Wojtyla/Pope John Paul II (Lanham, MD: Lexington Books, 2010), 9093. Note also, Michael Hanby, "Beyond Mechanism: The Cosmological Significance of David L. Schindler's Communio Ontology," in Being Holy in the World: Theology and Culture in the Thought of David L. Schindler, eds. Nicholas J. Healy, Jr., and David C. Schindler (Grand Rapids, MI: Eerdmans, 2011), 162-192; and Cyril O'Regan, "Martin Heidegger and Christian Wisdom," in Christian Wisdom Meets Modernity, ed. Kenneth Oakes (New York, NY: Bloomsbury T\&T Clark, 2016), 37-58.

${ }^{1358}$ Schindler, Heart of the World, Center of the Church: Communio Ecclesiology, Liberalism, and Liberation, 164, 174. "Catholics cannot successfully challenge the mechanistic-subjectivistic worldview implied in modern formal-critical methodological procedures (in the dominant liberal understanding of these) if they challenge this worldview only when it takes an overtly moral or religious form, only when it thus becomes a matter of formal concern within the disciplines of ethics and theology. On the contrary, Catholics must challenge the mechanistic-subjectivistic worldview in all of its analogous forms down through all of the disciplines," ibid., 174. Rather, Schindler insists that it "is not that we should refuse to endorse modern freedom, but only that our endorsement should coincide with an awareness that freedom, even modern freedom, presupposes, willy-nilly, some anthropology (ontology, theology). Any endorsement of modern freedom must therefore coincide with an evaluation of the anthropology which has always-already given that freedom its meaning. In the present context, this means that we must consider carefully the extent to which modern freedom has from its origins been shaped by the liberal disjunction between subjectivity and objectivity, or, again, has been infected by the liberal dualism of will and intelligence, with its corresponding voluntaristic subjectivity and mechanistic objectivity.... Unless we recognize the ambiguity of present-day freedom at its very source, we risk colluding in the development of a culture that can easily, however paradoxically, become the death of freedom. Unless we grasp the ambiguity of modern freedom in its roots, we will not be able to understand how, for example, modernity's achievement of 'rights' can, by virtue of its own dynamic-and precisely coincident with the positive aspects of this achievement-invert into a kind of 'totalitarianism,"' ibid., 182. This is important because, for Schindler, "the Anglo-American" liberalism is already founded upon an anthropology that includes "a metaphysics and a theology-thus (unwittingly) smoothing the way for the triumph of the liberal conception of man" which makes "liberalism particularly dangerous at this momentous time in history," ibid., 36, as it denies man his essential freedom as it actually leads into a culture of death. Elsewhere Schindler again reiterates, from the broad perspective, "an economic system itself already embeds, indeed is also, a theology and an anthropology and a culture," David L. Schindler, "'Homelessness' and Market Liberalism," in Wealth, Poverty \& Human Destiny, 349. For one whose views directly contrast with Schindler, see Jacques Berlinerblau, How to Be Secular: A Call to Arms for Religious Freedom (New York, NY: Houghton Mifflin, 2012).

${ }^{1359}$ Schindler, Ordering Love: Liberal Societies and the Memory of God, 330. Schindler here addresses, in particular, secularism and religionism, within the context of the Right and Left within America, but his entire critique is premised upon an awareness of the sciences and humanities.

${ }^{1360}$ Schindler, Ordering Love: Liberal Societies and the Memory of God, 278-279. 
obsession with and addiction to deterministic technologies creates a culture of death coincident with an implicit theology (or atheology) that denies freedom. ${ }^{1361}$ For Schindler, authentic freedom is not, following the modernistic Western mind, merely the allowance of a belief in something and autonomy from coercion (a negativized freedom from), but also always a relation to truth and the participation in practices and actions (a positivized freedom for), ${ }^{1362}$ which takes on extra significance when one

${ }^{1361}$ Schindler, Ordering Love: Liberal Societies and the Memory of God, 128. Following alongside the Heideggerian (and Bohmian) suggestion that the modern world is ontotheological through its technological nature, Schindler argues that "the question of metaphysical, and indeed also by implication theological, truth cannot be avoided in statecraft, even in the case of the liberal-juridical state. The would-be deferral of metaphysics attempted in liberal-juridical statecraft is mediated by metaphysical assumptions: those of a technological instrumentalism that leads unwittingly to a paradoxical inversion of liberalism's fundamental goals and purposes," ibid., 128. The basic point for Schindler is that religious freedom is not possible if we have a deficient understanding of personal freedom and free-will, and that a paradox is entailed here, as the most common framework within which the modern concept of freedom exists, that of scientific progress over time through technology, actually leads to a loss of freedom and a culture of death. Schindler's alternative, interestingly, includes a subtle introduction of religion into society to liberate society's institutions through his redefinition, or restoration in his perspective, of the true meaning of freedom, which includes, in particular, an intrinsic relationship to truth. As Schindler explains, the common American "definition of religious freedom" "insists that it is merely offering a formal-juridical freedom to [or freedom from] all religions, while at the same time it (tacitly) mediates its appeal to freedom via a definite theoretical (if typically unconscious) dualism. The non-triviality of this maneuver becomes especially clear when we note its implications with respect to any nonWestern (or nonliberalized) religion-with respect to any country where a traditional (or non-dualistic) worldview still predominates. In countries, for example, where certain forms of Orthodoxy, Islam, Judaism, Native American-Indian, or African religion still prevail, an invitation to adopt the juridical notion of religious freedom amounts to nothing less than an invitation to adopt the theological dualism of liberalism-albeit, again, only in the name of a purely formal commitment to the principle of freedom." However, if the dualistic technologized-rationalized freedom of liberalism actually denies authentic freedom, then what "liberalism does in effect is invite other countries to adopt a religious freedom, not which leaves a traditional religion intact but which on the contrary requires transformation of that religion, requires that it subscribe to an alternative religious truth. Failure to be clear about this implies nothing less than the paradox of imparting a [supposed] truth about freedom unconsciously and blindly-and just so far unfreely," Schindler, Heart of the World, Center of the Church: Communio Ecclesiology, Liberalism, and Liberation, 66-67 (latter addition mine).

1362 Schindler, "Freedom, Truth, and Human Dignity: An Interpretation of Dignitatis Humanae on the Right to Religious Freedom," 48-49, 87-90, 165 n. 23, 191 n. 136-137, 192 n. 138. See also, Edward, Persons and Liberal Democracy: The Ethical and Political Thought of Karol Wojtyla/Pope John Paul II, 91; Douglas Farrow, Desiring a Better Country: Forays in Political Theology (Montreal, Canada: McGill-Queen's University Press, 2015), 166 n. 33; Matthew Levering, Biblical Natural Law: A Theocentric and Teleological Approach (New York, NY: Oxford University Press, 2008), 1-21; William T. Cavanaugh, Theopolitical Imagination: Christian Practices of Space and Time (New York, NY: T \& T Clark, 2002), 15-21, 57, 68, 87; and the essays in Daniel Philpott and Ryan T. Anderson, eds. A Liberalism Safe for Catholicism: Perspectives from 'The Review of Politics' (Notre Dame, IN: Notre Dame University Press, 2017). For the work of an advocate of Schindler's general theo-political philosophy, see Matthew John Paul Tan, Justice, Unity, and the Hidden Christ: The Theopolitical Complex of the Social Justice Approach to Ecumenism in Vatican II, esp. 10-13, 38-49, 59, and 69-87. Schindler is a critic of both the American religious "Right" and secular "Left," and thus would agree, fundamentally, with Phyllis Schafly and George Neumayr, No Higher Power: Obama's War on Religious Freedom (Washington, D.C.: Regnery Publishing, 2012), and Elizabeth Shakman Hurd, Beyond Religious Freedom: The New Global Politics of Religion (Princeton, NJ: Princeton University Press, 2015), 13, 52, 60. Hurd insists that, deep down, the liberal definition of religious freedom only includes one's freedom to belief, but not freedom to practice, thus creating a dualism, and it is this tension that lies at the heart of many religious conflicts around the world and the challenge of the West's interventions to insert the Western concept of freedom into cultures that have a different understanding of religious freedom. Of course, this problem can manifest itself in the West, as well. 
takes into account the ethical/moral/religious freedom that the Catholic Sacramental view advocates for, including its unique relationship to space, freedom, and time within a framework that includes the common good and social justice-good works of a variety of kinds are necessary for salvation, which is intrinsic to the subjective side of the sacraments. Catholic Sacramental theology is, therefore, intrinsically public and political. ${ }^{1363}$ As already noted above in several places, Catholic theology is very open to the ideas Bohm has explored in physics and metaphysics concerning the concepts of freedom and time-and aside from Bohm, Catholics have in recent times relied on quantum analogies to support a 'timeless' realm wherein the Sacraments are vivacious. ${ }^{1364}$ This is not to say Bohm is a 'Catholic' physicist, were there such a thing, but there are obvious points of commonality in their metaphysics, and Bohm may provide a pathway to solutions for them which they have long sought concerning the relationship between religion and science. On the other hand, it seems clear that Pylkkö's views on freedom and time are utterly at odds with the framework operative in Catholic theology.

Second, in the Calvinistic view of the sanctuary the process of salvation ultimately proceeds from the timeless decree of God. ${ }^{1365}$ Although the event of the Cross is manifestly real and historical,

\footnotetext{
${ }^{1363}$ Younker, "From Metaphysics to Templephysics: Situating the Significance of Fernando Canale's Contributions for the 'Christian Philosopher,'” 220 n. 59, 221 n. 62. What makes this so important is that some actually argue that, philosophically, "what makes religious freedom impossible is the fact that laws regulating religion need to have some way of distinguishing what counts as religion. In a country without a designated authority to make such decisions such as the United States, such decisions are very difficult to locate. Religion is not a naturally occurring object which comes with bright line borders. Most who write about religious freedom in the United States minimize this problem. I do not agree that it should be minimized," Winnifred Fallers Sullivan, The Impossibility of Religious Freedom (Princeton, NJ: Princeton University Press, 2018), xx-xxi. Of course, if science were to ground religion in a Bohmian-Catholic way, then religion would have an intrinsic claim to authority via a newly enlarged view of natural theology.

${ }^{1364}$ The Sacramental view is very compatible with the work of d'Espagnat and the Copenhagen view in general. Whether this is ultimately satisfactory for Catholics, however, remains a question. Note Hughes, Neoplatonist Stew: Or, How Sacramentalism, Mysticism, and Theurgy Corrupted Christian Theology, 29; and Donald Keefe, "Faith, Science and Sacramental Realism," in Institute of Theological Encounter with Science and Technology Vol. 30 \#2 (Spring 1999), 1-11.

${ }^{1365}$ William Sparkes Morris, The Young Jonathan Edwards: A Reconstruction (Carlson Publishers, 1991), 419. The "Scholastic notion of the idea of knowledge, only realized or realizable in God, who knew all things, past, present, and future, in a timeless moment, dominated Calvinist metaphysics. It was a direct heir of the rich heritage of that Scholastic metaphysics which for so long characterized High Calvinism (in even such thinkers as Arminius)," ibid., 419.
} 
in the common use of the word, history plays out precisely as God decreed. ${ }^{1366}$ That is to say, it is not really temporal. Some individuals were created to be saved, and others were created for damnation, and their wills could not will otherwise. The traditional Calvinistic perspective also emphasizes the two major dispensations or Covenants (out of possibly seven or eight), the first, given to Moses, and the second, instaurated through Christ and explained by Paul, ${ }^{1367}$ which represent differing ways through which salvation was attained. As has already been discussed above, the Calvinistic perspective fundamentally retains a timeless metaphysical framework which makes freedom impossible, even more so than in the Catholic understanding.

Calvinists have had little desire to ameliorate the crisis of the two cultures. For them, it is irrelevant. Ongoing conflict appears inevitable from within this perspective. In this sense, Bohm's early ideas could certainly find resonance with Calvinists and their view of history, while his later work would prove too speculative, and perhaps even too open to genuine creativity. Conversely, again, Pylkkö's efforts to reconceptualize freedom and time find nothing in common with the Calvinist perspective.

Third, many believers aligned with the general Arminian perspective support the general sentiment supporting the two covenants as depicted above for Calvinists, however, the freewill of the believers is much more strongly emphasized. This particular perspective has branched into two forks. One group emphasizes the popular idea of "once saved, always saved,"1368 with corresponding

\footnotetext{
${ }^{1366}$ For an overview of John Calvin's theology, see Paul Helm, John Calvin's Ideas (Oxford, UK: Oxford University Press, 2004), 312-313. See also, Oliver D. Crisp, "Calvin on Creation and Providence," in John Calvin and Evangelical Theology: Legacy and Prospect-In Celebration of the Quincentenary of John Calvin, ed. Sung Wook Chung (Colorado Springs, CO: Paternoster, 2009), 47.

${ }^{1367}$ See, for example, Jeong Koo Jeon, Calvin and the Federal Vision: Calvin's Covenant Theology in Light of Contemporary Discussion (Eugene, OR: Resource Publications, 2009); John P. Bradbury, Perpetually Reforming: A Theology of Church Reform and Renewal (New York, NY: Bloomsbury, 2013); Robert Saucy, The Case for Progressive Dispensationalism: The Interface Between Dispensational and Non-Dispensational Theology (Grand Rapids, MI: Zondervan, 2010); Lewis Sperry Chafer with John F. Walvoord, Major Bible Themes: 52 Vital Doctrines of the Sacred Scriptures Simplified and Explained (Grand Rapids, MI: Zondervan, 1974), 128; Craig A. Blaising and Darrell L. Bock, eds. Dispensationalism, Israel and the Church: The Search for Definition (Grand Rapids, MI: Zondervan, 1992); and P. P. Jones, Decoding Jesus: A Comparison between John Calvin and Ellen G. White's Views (Houston, TX: Strategic Books Publishing, 2014).

1368 of course, for the Calvinist, this is understood more precisely as the "perseverance of the saved," rather than "once saved, always saved," as noted in the following footnote. For an exposition of this view, see Robert Metevia, Secure Forever: Once Saved Always Saved (Bloomington, IN: WestBow, 2012); and Lloyd A. Olson, Eternal Security: Once Saved Always Saved (Mustang, OK: Tate Publishing, 2007).
} 
Christian behavior varying in intensity and commitment (legal justification becomes synonymous with experiential sanctification). The second group (consisting of traditional Methodists, some Baptists, and some other "Evangelicals") focuses on the idea of conversion (accepting a legal and personal justification) and a new life in Christ, which includes the possibility of "falling away"1369 from the faith. This second group further subdivides into those who more seriously emphasize maintenance and growth in the spiritual life to varying degrees (sanctification), and those who distinctly push such growth toward perfectionism, which can take on extreme forms when applied corporately (these groups are often Calvinist in their leanings). ${ }^{1370}$

Bohm's and Pylkkö's insights relate to the above groups in subtle and more complex ways. First, the very idea of 'conversion' which is so emphasized in the second group, seems to indicate a qualitative change. This is supported by both Bohm and Pylkkö as an actual possibility-a genuine temporal or qualitative change, rather than merely a rearrangement of previous ingredients, may be a reality through conversion, and that it may appear mysterious is only in general harmony with the potential operations of the Holy Spirit as depicted in Scripture. Of course, the possibility of "falling away" also preserves a high view of freedom and temporality. Conversely, at the same time, the 'instantaneous' and permanent change attributed to "once saved, always saved," appears to disallow any serious view of temporality. It is a 'timeless' or instantaneous change that doesn't appear to accompany any other qualitative changes-whatever change is alleged to occur is apparently only in the ethereal platonic realm. Concerning the group emphasizing perfectionism, it is possible to conceive of this in either perspective, that of Bohm or Pylkkö, as a qualitative or temporal change. However, at the same time, when perfectionism is viewed within a corporate perspective, the concern

\footnotetext{
${ }^{1369}$ Gene Stone, Are You Believing the Once Saved Always Saved Lie? Can a Born Again Christian Go to Hell? (Maitland, FL: Xulon, 2005). Observe that "the predestination doctrine and 'the once saved always saved doctrine'" are not the same. "They are the same in the respect that both teach you cannot lose your salvation once you're saved, but 'the O.S.A.S. doctrine' teaches man chooses God. The predestination doctrine teaches God picks us. However, they are both false doctrines because they teach once a person is saved, they lose their free will. Simply put, they teach a Christian cannot choose to backslide to hell," ibid., 5. See also, Stephen Pippin, Once Saved Always Saved: Satan's Greatest Trick (Bloomington, IN: WestBow, 2015).

${ }^{1370}$ For a recent critical history and overview, see Michael J. McVicar, Christian Reconstruction: R. J. Rushdoony and American Religious Conservatism (Chapel Hill, NC: The University of North Carolina Press, 2015).
} 
about freedom becomes a serious question. Legal templates which are rigorously enforced ('timelessly') creates many problems in the realm of social justice and ethics, as noted above.

Fourth, from within the general Arminian perspective, Seventh-day Adventists have promoted a distinct perspective that declines to adhere to the conventional understanding of the "two covenants" or a dispensational view. ${ }^{1371}$ In this perspective, there was always only one salvific covenant-the one originally given to Adam and Eve, ${ }^{1372}$ and its fundamental conditions have never changed.

Distinguishing the ceremonial law from the moral law more deliberately than some others, Adventists do not believe the Jewish festivals and feasts are necessary to observe, even if they maintain a more elevated and continuing educational value than most others grant them. ${ }^{1373}$ However, the Sabbath (see below) does have enduring value as part of the moral law. However, the most distinct feature of the Adventist perspective includes the concordance between the Heavenly and earthly sanctuaries, of which the latter was a copy (Ex 25:40, Acts 7:44, Heb 8:5). ${ }^{1374}$ In this view, God and the ontology grounding soteriology are united. ${ }^{1375}$ There is no separate platonic realm where God resides-heaven is a real place somewhere, and the process of salvation involves activity in heaven as well as earth. ${ }^{1376}$ Here, an overemphasis on certain aspects of the divine reality ('transcendence') should not eclipse the biblical testimony of a literal heaven or of the angelic realm of activity as a real place throughout all of

\footnotetext{
${ }^{1371}$ See, for example, Hans K. LaRondelle, The Israel of God in Prophecy: Principles of Prophetic Interpretation (Berrien Springs, MI: Andrews University Press, 1983); MacCarty, In Granite Or Ingrained?: What the Old and New Covenants Reveal about the Gospel, the Law, and the Sabbath; and Larry Alavezos, A Primer on Salvation and Bible Prophecy (TEACH Services, 2010), 60.

1372 Afolarin Olutunde Ojewole, The Seed in Genesis 3:15: An Exegetical and Intertextual Study (Berrien Springs, MI: Adventist Theological Society Publications, 2002).

${ }^{1373}$ Ron du Preez, Feast-Keeping and the Faithful: Should Adventists Observe the Annual Feast Days? (Lansing, MI: Omega Media, 2011).

${ }^{1374}$ Elias Brasil de Souza, The Heavenly Sanctuary/Temple Motif in the Hebrew Bible: Function and Relationship to the Earthly Counterparts (Berrien Springs, MI: Adventist Theological Society Publications, 2005); and Richard M. Davidson, Typology in Scripture: A Study of Hermeneutical Typos Structures (Berrien Springs, MI: Andrews University Press, 1981).

${ }^{1375}$ Fernando Canale, A Criticism of Theological Reason: Time and Timelessness as Primordial Presuppositions (Berrien Springs, MI: Andrews University Press, 1987); and Canale, "Philosophical Foundations and the Biblical Sanctuary." See also, Younker, "From Metaphysics to Templephysics: Situating the Significance of Fernando Canale's Contributions for the 'Christian Philosopher;'” and Edwin W. Reiner, The Atonement (TEACH Services, 2001).

${ }^{1376}$ Andreasen, The Sanctuary Service; Holbrook, The Atoning Priesthood of Jesus Christ; and Gane, Who's Afraid of the Judgment?: The Good News about Christ's Work in the Heavenly Sanctuary.
} 
biblical history. The salvation process is also intricately related to the function and purpose of prophecy (see below), uniting God's relationship to soteriology and history in yet another way. ${ }^{1377}$

Obviously, the works of Bohm and Pylkkö were not intended to directly relate to the finer details of many specific biblical themes, and obviously there are significant points of divergence between their thought and any essentially biblical theology. Nonetheless, in parallel to the Arminian position above, there is no doubt that the emphasis on reality's 'depth,' with Bohm, and the non-platonic aconceptual experiential flow of reality and the role of 'inner' unique religious language, with Pylkkö, ${ }^{1378}$ could find some resonance with a Sanctuary model. In particular, the idea that soteriological ontology, prophetic history, and freedom flow together in one united heavenly and earthly experiential reality is something thus far only carefully articulated in the Adventist view. Conversely, the mystical tone of Bohm, and his lack of emphasis on time, detract somewhat from his value to the biblical material. In either case, however, the conceptual replacements of freedom and time found in Bohm and Pylkkö could be productively explored alongside Adventist theology's emphasis on the Sanctuary and its narrative flow.

\section{The Reality of Biblical Prophecy}

Without any doubt, the phenomena of divine foreknowledge apparently manifested in biblical prophecy has attracted significant attention over the past two millennia, and will likely remain a philosophical and interpretive puzzle. ${ }^{1379}$ of course, some have questioned the precise nature of prophecy in Scripture. The issue of how conditional prophecy is related to divinely enacted fulfillment is one point, but the possibility of genuine foresight of future events is quite another, and

\footnotetext{
Press, 2010).

${ }^{1377}$ Marvin Moore, The Case for the Investigative Judgement: Its Biblical Foundation (Nampa, ID: Pacific

${ }^{1378}$ In this regard, although it may not appear obvious, the work of Peckham in Canonical Theology: The Biblical Canon, Sola Scriptura, and Theological Method is critical. That is to say, the canon of Scripture presents a unique language experience that can only be obtained through 'living' within it.

${ }^{1379}$ See, for example, LeRoy Edwin Froom, The Prophetic Faith of Our Fathers 4 Vols. (Washington, D.C.: Review and Herald, 1950).
} 
remains a highly contentious issue. ${ }^{1380}$ Yet, overall, despite the obvious philosophical conundrum prophecy may present, most Christians have agreed that the biblical text presents the reality of this phenomena, ${ }^{1381}$ and many concur that as history has unfolded it has corresponded to the biblical witness in several instances, including for purposes related to salvation history. In other contexts, such as in eschatology ${ }^{1382}$ and theodicy, ${ }^{1383}$ divine foreknowledge remains especially controverted.

Classical timelessness and determinism, while philosophically possible, have proven widely unpopular in recent literature with philosophers, and have contributed to the two culture's crisis. The perennial question, for many Christian philosophers and theologians, is whether there is an alternative that evades the ultimate denial of prophecy and foreknowledge while preserving freedom. This is, historically, the question at the foundation of God's relationship to time. While any suggestion of Bohm and Pylkkö providing the solution to the question of God's relationship to time would be very premature, it may be safe to say their way of thinking about freedom and time is very different from the options presented to the history of philosophical thought prior to them. It is actually helpful, and encouraging, that their work did not develop within the confines of seeking clarity on the role of God in philosophy, which has often sidetracked deeper and more innovative reflection in Christian history. Yet, both of their approaches present genuinely alternative ways of conceptualizing the relationship of freedom and time that could, possibly, allow for more creative synthetic hypotheses affirming the reality of prophecy and freedom from within the purview of the divine. The effort to articulate this further, however, must continue in some future work.

\footnotetext{
${ }^{1380}$ As evidenced by the openness of God movement, for example, as seen in Clark Pinnock, Richard Rice, John Sanders, William Hasker, and David Basinger, The Openness of God: A Biblical Challenge to the Traditional Understanding of God (Downers Grove, IL: InterVarsity Press, 1994).

${ }^{1381}$ Fernando Canale, Basic Elements of Christian Theology: Scripture Replacing Tradition (Berrien Springs, MI: Andrews University Lithotec, 2005), 104-133.

1382 This is especially true with the 'big picture' and apocalyptic prophecies of Daniel and Revelation-do they depict preterism, futurism, or historicism? Although the issue of God's relationship to time is more complicated with historicism, the biblical data seems to point in that direction. For historicist accounts, see, for example, Shea, Daniel: A Reader's Guide; and Austin Cooke, An Enduring Vision: Revelation Revealed: An Historic and Prophetic, Verse-by-Verse Exposition of John's Apocalypse (TEACH Services, 2014).

${ }^{1383}$ John C. Peckham, Theodicy of Love: Cosmic Conflict and the Problem of Evil (Grand Rapids, MI: Baker, 2018); and Gregory A. Boyd, God at War: The Bible \& Spiritual Conflict (Downers Grove, IL: InterVarsity Press, 1997).
} 


\section{The Biblical Sabbath, Rest, and Morality as a Science}

The biblical Sabbath represents perhaps the strongest testimony from Scripture that God does have a very real relationship, of some kind, to time. ${ }^{1384}$ This is so because it is not merely a command or requirement for humanity to fulfill, but a commitment on the part of God to the world and humanity, ${ }^{1385}$ and as such was instituted at the creation of life on earth in its basically current form. ${ }^{1386}$ It is highly significant that the Sabbath is given a place as part of the moral law, and as such, predates any exclusively Jewish ceremonies. ${ }^{1387}$ There is an irony that the Sabbath is sometimes viewed as a burden or legalistic requirement, that is, somehow as a limitation on our freedom. However, some scholars reflecting on the meaning of the Sabbath have rejected this assumption. ${ }^{1388}$ Rather, through the obedience of rest we are acknowledging we are not saved by works, but saved by God's work on our behalf (Ex 31:13, "I am the Lord who sanctifies you"), and thus the Sabbath is indeed a gift to believers that was, is, and always will be true. ${ }^{1389}$ This is in complete contrast to any legalism or sacramental ritual or other works-based approach to salvation. The Sabbath is the

\footnotetext{
${ }^{1384}$ Abraham Joshua Heschel, The Sabbath: Its Meaning for Modern Man, with Sylvia Heschel (New York, NY: Farrar, Straus and Giroux, 2005), 16.

${ }^{1385}$ Bacchiocchi, Divine Rest for Human Restlessness: A Theological Investigation of the Good News of the Sabbath, 61-67.

${ }^{1386} \mathrm{I}$ am aware there is an interesting discussion concerning the meaning of the days of creation. See, for example, John C. Lennox, Seven Days That Divide the World: The Beginning According to Genesis and Science (Grand Rapids, MI: Zondervan, 2011); Andrew J. Brown, The Days of Creation: A History of Christian Interpretation of Genesis 1:1-2:3 (Blandford Forum, UK: Deo Publishing, 2014); C. John Collins, Reading Genesis Well: Navigating History, Poetry, Science, and Truth in Genesis 1-11 (Grand Rapids, MI: Zondervan, 2018); and David Snoke, A Biblical Case for an Old Earth (Grand Rapids, MI: BakerBooks, 2006). However, I remained persuaded that a close reading of the text indicates it was intended as literal and analogous to our weekly cycle today. See Gerhard Hasel, "The 'Days' of Creation in Genesis 1: Literal 'Days' or Figurative 'Periods/Epochs' of Time?” Origins 21 (1994), 5-38; Trevor Craigen, “Can Deep Time Be Embedded in Genesis?,” in Coming to Grips With Genesis: Biblical Authority and the Age of the Earth, eds. Terry Mortenson and Tahne Ury (Green Forest, AR: Master Books, 2012), 193-210; Fernando Canale, Creation, Evolution, and Theology: The Role of Method in Theological Accommodation (Berrien Springs, MI: Andrews University Lithotech, 2005); and Marco T. Terreros, Theistic Evolution and Its Theological Implications (Medellin, Colombia, Marter Editions, 1994).

${ }^{1387}$ Jo Ann Davidson, “The Decalogue Predates Mount Sinai: Indicators from the Book of Genesis," in Journal of the Adventist Theological Society Vol. 19 \#1-2 (2008), 61-81.

${ }^{1388}$ Wayne Muller, Sabbath: Finding Rest, Renewal, and Delight in Our Busy Lives (New York, NY: Bantam Books, 2000); Brueggemann, Sabbath as Resistance; Saying No to the Culture of Now; Baab, Sabbath Keeping: Finding Freedom in the Rhythms of Rest; Swoboda, Subversive Sabbath: The Surprising Power of Rest in a Nonstop World; Tonstad, The Lost Meaning of the Seventh Day; and Davidson, A Love Song for the Sabbath.

1389 Concerning the Sabbath in Hebrews 4, it can be said that "the soteriology in Hebrews has a past, present, and future perspective" and that "within the context of Heb 3-4 the multiple temporal designations seem to indicate that the warning is a present goal rather than an exclusive future soteriological one for the audience of Hebrews," Erhard H. Gallos, Katapausis and Sabbatismos in Hebrews 4 (Andrews University, Berrien Springs, MI: Doctoral Dissertation, 2011), 187.
} 
creation of a 'time-space' for free restful contemplation of God, where onward rush of techno-time is slowed down to fit our distinctly creaturely and relational natures. Contrary to those who would see the Sabbath as a rigid ethical demand, the very fact that it is ambiguous in our physical world, with shifting sunrise and sunset patterns, is a testimony of its aconceptual nature-that is, it is more than it seems, and evades a simplistic understanding of scientific clock time. It is, by definition, an example of relational time, not merely numerical time. This is seen perhaps most clearly in the very reality of how Sabbath can be 'counted,' especially in places where the sun never sets or rises for months at a time. ${ }^{1390}$ In like manner, as a socially grounded relational temporal reality, it defies any simplistic analogy to the relationships of particles or waves in physics.

Another major issue that relates to the Sabbath and morality concerns the relationship of morality and ethics themselves to 'science.' To explain the two facets of this point, it may be helpful to refer to the traditional Jewish saying that 'if only one Sabbath were kept perfectly, the Messiah would immediately come.1391 Because the Jew's understanding of the Messiah implied by this saying has not come ${ }^{1392}$ one could infer the Jews have collectively never kept the Sabbath properly. However, the key point to be noted here is that a theological result is only brought about by obedience to an insight wrought through a theological (textual or humanities) source. Science, alone, does not reveal the truth of the Sabbath, let alone 'how' to observe or remember it. Neither nature, nor the scientific method, reveal to us anything specific about a Sabbath. However, the Jewish saying noted above proposes that some sort of 'scientifically' perfect obedience to a non-scientific truth would bring

${ }^{1390}$ The Seventh-day Adventist author and co-founder Ellen White was explicitly aware of the problems associated with the "date line" and the fact the sun never sets or rises for months at a time in locations to the extreme north or south. She did not consider these matters with which people should overly concern themselves, seeking a pragmatic solution. See Ellen G. White, Selected Messages Book 3 (1980), 317-319. All this reflects a 'quantum' like view of time and its inherent relational fuzziness.

${ }^{1391}$ Stephen Watkins, Jesus Our Jewish Messiah Vol. One: Once in Time (Flagstaff, AZ: Lessons from Heaven Publications, 2009), 115.

${ }^{1392}$ It must be briefly explained that, from the Christian understanding, this saying is flawed in two ways. First, because the Jews' obedience to their own laws had nothing to do with the first coming of Christ. Secondly, because the perfect obedience of a corporate group requires coercion, and enslaves the obedient to the disobedient. Thus, it is also not a requirement for the Christian's second coming of Christ, either. 
about a theological result-at least in the minds of some Jews. ${ }^{1393}$ This represents a merging of the non-scientific (a Sabbath) with nature and the scientific method (causation, determinism, and objectivism) in a way that is not easily understood or justified, philosophically. However, this union is not merely seen in the above Jewish example, but is in fact quite common throughout Christianity and other religions, both in relationship to either Sunday or Friday, or some other divine moral command.

Indeed, the second facet of the mysterious relationship that some suggest exists between morality and science concerns the nature of sin. Put simply, does death ensue as a natural consequence of sin, in some sort of deterministic way? Or does God have to intervene to insure that the consequences of disobedience or sin are properly punished? The answers to such questions, as well as the issues directly above, intrinsically involve understandings of freedom and time. This can be seen, for example, in the work of Timothy Jennings and his understanding of the nature of sin. Jennings explains that "the real problem with sin is that sin itself damages and destroys. It destroys the sinner and damages others. Because sin mars the image of God within, persistence in sin brings its own punishment-death." ${ }^{1394}$ To be specific, "many people view [sin] as breaking one of God's rules, and the trouble with disobeying one of His rules is that it requires Him to impose a penalty the minimum being death. But this is a fundamental misunderstanding about $\sin .{ }^{1395}$ Rather, for Jennings, "sin destroys because it involves living outside of the universal principles on which God has based life and health. Those principles are both natural and moral."1396 That is to say, sin follows deterministic scientific principles. ${ }^{1397}$ "Sin is like cancer. It leads to death for the same reason that

\footnotetext{
${ }^{1393}$ For example, see E. P. Sanders, Jewish Law from Jesus to the Mishnah: Five Studies (Minneapolis, MN: Fortress, Press, 2016), 8-31; and David J. Rudolph, A Jew to the Jews: Jewish Contours of Pauline Flexibility in 1 Corinthians 9:19-23 $2^{\text {nd }}$ ed. (Eugene, OR: Pickwick, 2016), 201.

${ }^{1394}$ Timothy R. Jennings, Could It Be This Simple? A Biblical Model for Healing the Mind (Hagerstown, MD: Autumn House, 2007), 100.

${ }^{1395}$ Jennings, Could It Be This Simple? A Biblical Model for Healing the Mind, 100.

${ }^{1396}$ Jennings, Could It Be This Simple? A Biblical Model for Healing the Mind, 103.

${ }^{1397}$ Jennings, Could It Be This Simple? A Biblical Model for Healing the Mind, 107. "We must understand the difference between God's rules and God's law. His law is the universal principles that govern life-for example, the law of gravity, the law of love, and the law of liberty. God's rules are the tools He uses, while we are children, to protect us from the damage that results from violating His law. Until we grow up to understand and incorporate His law into our own hearts and minds, we need the rules. But after we grow up, the rules are no longer necessary," ibid., 107. He continues, "imagine that one of your rules for your 5-year-old was that she had to brush her teeth before bedtime each night. Suppose that I approached your child and told her, "You don't have to brush your teeth because Mommy said so. Rather, you have to brush your teeth because of the second
} 
cancer does-it actually destroys the tissues and organs that sustain life. When someone dies from cancer, death is not an externally imposed penalty but the inevitable result of unimpeded cancer.."1398 When applied to the Sabbath commandment, the question immediately becomes, what, exactly, is the natural consequence of disobeying the Sabbath? What, so to speak, natural law is analogously fulfilled upon our disobedience? That is to say, even if science concluded that occasional rest was beneficial to me, what difference does it make whether I rest on Tuesday or Saturday? The point is that, obviously, there is no immediately logical scientific consequence for not resting on Sabbath. The truth of the biblical Sabbath is to be found within the humanities side of the two cultures.

Conversely, there is an alternative understanding of the nature of sin, and one that separates sin from any scientific or deterministic (timeless) outcome. ${ }^{1399}$ As Ellen White understands and interprets the narrative of Adam and Eve's first sin in Genesis 3, "there was nothing poisonous in the fruit of the tree of knowledge itself, nothing that would cause death in partaking of it. The tree had been placed in the garden to test their loyalty to God."1400 Thus, upon their sin of eating the forbidden fruit, God drove "the transgressors from the garden, and by cherubim and a flaming sword would

law of thermodynamics, which states that things tend toward disorder. So if you don't brush your teeth, they will decay," ibid., 107. Jennings' point is that God's "rules" reflect His laws, and that, like with brushing teeth and cancer, they have 'natural' or more specifically logically necessary consequences.

1398 Jennings, Could It Be This Simple? A Biblical Model for Healing the Mind, 103. Thus, "unless someone intercedes, cancer will kill. That is what intercession is about-God steps in to stop the natural progression / consequences of sin in our lives," ibid., 103. See also, Timothy R. Jennings, The God-Shaped Heart: How Correctly Understanding God's Love Transforms Us (Grand Rapids, MI: Baker Books, 2017).

${ }^{1399}$ The view advocated by Timothy Jennings is 'timeless' in the technical, ontological sense, in that he insists sin brings about its own consequences, that is, death, in some sort of way analogous to the way cancer follows the scientific laws of its 'being.' But this is not obviously nor necessarily correct, and may lead to the idea that freedom is similarly ontologically 'timeless.' That is, once a choice for sin had been made, how, when, or in what way does a choice for good intervene? Is it at some arbitrary moment? Or is freedom, like sin, temporal, and require a temporal response from God? The idea that sin does not naturally bring about its own consequences, but rather that God must intervene to punish sinners, promotes the idea that sin is a special kind of temporal concept, with temporal consequences (though these temporal consequences should not be narrowly understood as deterministic scientific consequences). Understood temporally, God intervenes to punish while likewise initiating a temporal rescue operation. Thus, temporal realities that are not deterministic may orient us toward a more subtle view of God's solution to the sin problem. Yet, the overall point to be noted here concerns the intricate relationship of freedom and time to morality and ethics in general.

${ }^{1400}$ Ellen G. White, "The Test of Loyalty," in The Signs of the Times February 13 (1896), par. 7. She adds, "The Sabbath is a test to this generation. In obeying the fourth commandment in spirit and truth, men will obey all the precepts of the Decalogue. To fulfill this commandment one must love God supremely, and exercise love toward all the creatures that he has made. The Lord exhorts us to 'remember the Sabbath day, to keep it holy;' and since this is his exhortation, will any one charge us with wearying them in bringing this commandment to their remembrance?," ibid., par. 8. 
guard the way of the tree of life, so that man could not approach unto it and eat of its fruit, which perpetuates immortality." ${ }^{1401}$ What White is suggesting is that Adam and Eve's sin did bring about temporal consequences (a new 'time-space' reality for Adam and Eve and their descendants), but not any specific scientific consequence in itself, that is, some sort of natural progression in space-time. Rather, God's actions dictated much of the new reality facing Adam and Eve after their sin, including any changes in the natural world. The key factor that made eating the fruit sin was not that the fruit was bad for them, but that God asked them not to eat it-and for at least three reasons, in White's view, it was not necessary that they eat it. First, God had provided everything they actually did need for sustenance. All the other fruits were equal in taste and beauty. Second, the real fruit that mattered was the fruit from the tree of life, which somehow 'metaphysically' did provide special life-sustaining power beyond a direct act of God, indicative of the conditional immortality Adam and Eve possessed prior to the Fall. And third, through obedience to God in this simple matter somehow protected them from other sinful deviations. Only at the tree of knowledge could they be tempted by the Serpent. All of this, together, kept them in a mutually trustful relationship with God. ${ }^{1402}$ Sin is primarily about trust in God, which requires a continuous temporal extension through freedom.

An understanding of the work of Bohm and Pylkkö may be important if a clearer understanding of moral law and ethics is ever to be philosophically obtained. The "where" of the existence of morality cannot be seen from a simple or dogmatic scientific view of nature or reality-and seeking 'analogous' social laws which mirror the conceptual basis of natural laws may not be adequate, either, as is done in the Dooyeweerdian schema. ${ }^{1403}$ Life is more complex, perhaps even implicate or aconceptual, in comparison to the scientific understanding which predominates the world. Also, that

${ }^{1401}$ Ellen G. White, Early Writings (1882), 126-127. See also, Ellen G. White, Testimonies to Ministers and Gospel Workers (1923), 134. "Adam and Eve transgressed the law of God. This made it necessary for them to be driven from Eden and be separated from the tree of life, to eat of which after their transgression would perpetuate sin. 'So He drove out the man; and He placed at the east of the Garden of Eden cherubims, and a flaming sword which turned every way, to keep the way of the tree of life.' Man was dependent upon the tree of life for immortality, and the Lord took these precautions lest men should eat of that tree 'and live forever'become immortal sinners," ibid., 134 .

${ }^{1402}$ Ellen White's writings allude to "other worlds" in which there were "two trees" as in our Eden, reflective of possible connections with the book of Job. White, Early Writings, 39-40. The point is, God never removed His "rules" (as suggested by Jennings) from these worlds.

${ }^{1403}$ Dooyeweerd, A New Critique of Theoretical Thought: The Necessary Presuppositions of Philosophy. 
the moral law is ultimately connected with freedom and time so explicitly raises interesting questions about the natures of both freedom and time, respectively. It brings them both into the humanities, and thereby places them beyond any simple scientific understanding of freedom or time. Some of the mysteries surrounding the actual observance of the Sabbath are also put into better perspective by understanding it in a more implicate, aconceptual and relational way. Perhaps it is not simply ' 24 hours' once per week within space-time, but a subtly more complex specific time-space within which God relates to the earth and humanity, and humanity may relate to God.

\section{The Biblical Concept of the 'Remnant' and the Protection of the Political Minority}

The concept of a "Remnant" of faithful believers is prevalent throughout Scripture, and presents a variety of questions and challenges for contemporary theology. ${ }^{1404}$ What is at stake in all theologies that promote the idea of a remnant or minority holding special significance at any time, but particularly the 'end' of earthly history concerns the 'vitality' of truth as a ground of reason. This is a challenge because it is, essentially, the goal of every religion to persuade others, that is, nonbelievers, of the truth of their assertions. Similarly, absent any specific religious or theological faith-based conviction, the goal of philosophy is similarly to establish a ground of reason which is universally applicable-something which 'everyone' can agree about which allows the creation of a majority 'consensus.' It is thought that such consensus would somehow, if properly grounded, provide for 'peace and harmony.' Yet, what if the world is not collectively going to get morally better? What if the collective scientific-technological progress the world may enjoy does not in any directly meaningful way contribute to moral progress, but may, in fact, aid, hasten, or facilitate greater evil? ${ }^{1405}$

\footnotetext{
${ }^{1404}$ See, for example, Ángel Manuel Rodríguez, ed. Toward a Theology of the Remnant: An Adventist Ecclesiological Perspective (Silver Spring, MD: Biblical Research Institute, 2009); Billy Broadwater, Exposing the Fallacies of the Pre-Tribulation Rapture: A Biblical Examination of Christ's Second Coming (Bloomington, IN: WestBow Press, 2014); Nelson Walters, Rapture: Case Closed? (Ready for Jesus Publications, 2017); and Richard L. Guthrie, The Rapture: From the Ground Up-A Detailed Study on the Rapture of the Church (Bloomington, IN: WestBow Press, 2014).

1405 John F. Walvoord, “Is Moral Progress Possible?,” in Bibliotheca Sacra 175 \#699 (July-September, 2018), 259-270. If it is a given that technology has continually progressed through history and been continually applied to the corporate level above the individual, observe the implications of the following. Walvoord suggests of the letters in Revelation that "if these historical churches were also representative of the course of church history, a glance at the development of moral issues throughout the period shows at once that the last stage of the church is one of apostasy and decay which only the judgment of God can cure. There is certainly no
} 
The above problem is intricately related to the conflict of the two cultures. The reason for this is that the origins of the conflict date, at least traceably, to the very dawn of Western history with the Greeks. Pythagoras, or Pythagoreanism, to be more precise, represents the first serious movement toward the development of a formal ontology, that is, the study of reality as such, that would further develop alongside Pythagorean insights with Parmenides and later Plato. Pythagoras was concerned with establishing indisputable or objective truth, ${ }^{1406}$ and he found it in mathematics. ${ }^{1407}$ But any such ontology grounded on the 'timeless' truth of mathematics evidently became quickly integrated with

hope here of a gradual change. The church does not begin in a corrupt stage and develop into a godly church, but rather in its growth and extension there is a corresponding deterioration," ibid., 266. Yet, at the same time, individually "the Christian can hope for moral progress in his own heart. The provision of God is ample for this and is built upon a proper foundation of new life and a new nature. The indwelling presence of the Holy Spirit ministers to him, and he is taught the truths of the Scriptures indiscernible to the natural mind. The reality of fellowship with God, of communion in prayer, of association with God in doing the work of God ... all have their important place," ibid., 269.

${ }^{1406}$ Pythagoras did much to establish the parameters of the concept of truth in the sciences for all of Western history, as explained by Nicholas Kardaras, How Plato and Pythagoras Can Save Your Life: The Ancient Greek Prescription for Health and Happiness (San Francisco, CA: Conari Press, 2011), 151. Many have surmised that Pythagoras was influenced by Persians, such as Zoroaster. Notably, "Zoroaster saw the human condition as the mental struggle between $a s ̌ a ~(' t r u t h ')$ and $d r u j$ ('lie'). According to Zoroaster, it was our purpose to sustain $a s ̌ a$ through active participation in life and the exercise of constructive thoughts, words, and deeds. These teachings are believed to have greatly influenced the still-quite-young Pythagoras; indeed, some historians believe that it was Zoroaster who had the greatest influence on Pythagoras's ideas of philosophy as purification," ibid., 151.

${ }^{1407}$ As Aristotle related it, "the so-called Pythagoreans ... believed that the principles of mathematics were peculiar to all the things which exist. And since in mathematics, numbers come first in a natural way (physei), and since they saw in them, rather than in fire, earth or water, many features similar to the things which are and those liable to coming-to-be, they inferred that ... the elements of numbers (stoicheia) were elements of all the things which exist," as cited by Claudia Maggi, "Iamblichus on Mathematical Entities," in Iamblichus and the Foundations of Late Platonism, eds. Eugene Afonasin, John Dillon, and John F. Finamore (Leiden, The Netherlands: Koninklijke Brill, 2012), 75-90, 76. Maggi explains that Aristotle's account represents "the first historical-doxographic acknowledgment of Pythagorean mathematical ontology," and that Aristotle himself "traces Pythagoras' paternity for many Platonic doctrines, thus paving the way for identifying Pythagoreanism with Platonism" and "this identification was to be the key to the Neoplatonic tradition after Plotinus," ibid. As Iamblichus related it, "Pythagoras is said to have been the first to call himself a philosopher, a word which heretofore had not been an appellation, but a description," as cited in Algis Uždavinys, The Golden Chain: An Anthology of Pythagorean and Platonic Philosophy (Bloomington, IN: World Wisdom, 2004), 19. "[Pythagoras] was the first to give a name to philosophy, describing it as a desire for and love of wisdom, which later he defined as the science of objectified truth. Beings he defined as immaterial and eternal natures, alone possessing a power that is efficacious, as are incorporeal essences," ibid., 28. The "first essence is the nature of Number and 'reasons'," ibid., 19. Similarly, Philolaus shared the Pythagorean conviction that "truth is the proper, innate character of Number," ibid., 49. 
theology. ${ }^{1408}$ In an insightful and penetrating paragraph, Bertrand Russell explains the significance of

what he sees as Pythagoras' enduring influence concerning both philosophy and theology:

The combination of mathematics and theology, which began with Pythagoras, characterized religious philosophy in Greece, in the Middle Ages, and in modern times down to Kant. Orphism before Pythagoras was analogous to Asiatic mystery religions. But in Plato, Saint Augustine, Thomas Aquinas, Descartes, Spinoza, and Kant there is an intimate blending of religion and reasoning, of moral aspiration with logical admiration of what is timeless, which comes from Pythagoras, and distinguishes the intellectualized theology of Europe from the more straightforward mysticism of Asia. It is only in quite recent times that it has been possible to say clearly where Pythagoras was wrong.... The whole conception of an eternal world, revealed to the intellect but not to the senses, is derived from him.... But for him, theologians would not have sought logical proofs of God and immortality. But in him all this is still implicit. ${ }^{1409}$

Russell continues, critically adding that "rationalistic as opposed to apocalyptic religion has been, ever since Pythagoras, and notably ever since Plato, very completely dominated by mathematics and mathematical method," ${ }^{1410}$ which remains true within Christianity and many variants of Islamic

\footnotetext{
1408 "At the core of Pythagoras's teaching was an absolute reverence for the purity and perfection of numbers (which he considered divine) and numerical relationships," David W. Nelson, Judaism, Physics and God: Searching for Sacred Metaphors in a Post-Einstein World (Woodstock, VT: Jewish Lights Publishing, 2005$), 103$. This connection also exists, intriguingly, in the apocryphal Book of Wisdom written around 50 B.C. (Wisdom 11:20b, "but thou hast ordered all things in measure and number and weight"). "Since the book describes Jewish doctrine in terms of Hellenistic philosophy, one may assume that its author was familiar with Pythagorean ideas. The Pythagorean-Platonic idea of number and geometry was later combined with biblical tradition and became a part of the spiritual synthesis worked out by the church fathers and the Scholastics as they tried to reconcile the timeless laws of God with the temporal and unpredictable fate of man. Around the end of the fourth century St. Augustine took it for granted that the truths of number are universal and eternal. In On Free Will he remarked that although wisdom may or may not be the same as number, it is clear that both are true and immutably true," Julius Thomas Fraser, Time, Conflict, and Human Values (Chicago, IL: University of Illinois, 1999), 48.

${ }^{1409}$ Russell, History of Western Philosophy, 37. Russell further explains that "mathematics is, I believe, the chief source of the belief in eternal and exact truth, as well as in a super-sensible intelligible world. Geometry deals with exact circles, but no sensible object is exactly circular; however carefully we may use our compasses, there will be some imperfections and irregularities. This suggests the view that all exact reasoning applies to ideal as opposed to sensible objects; it is natural to go further, and to argue that thought is nobler than sense, and the objects of thought more real than those of sense-perception. Mystical doctrines as to the relation of time to eternity are also reinforced by pure mathematics, for mathematical objects, such as numbers, if real at all, are eternal and not in time. Such eternal objects can be conceived as God's thoughts. Hence Plato's doctrine that God is a geometer," ibid., 37. Again, "Theology, in its exact scholastic forms, takes its style from the same source. Personal religion is derived from ecstasy, theology from mathematics; and both are to be found in Pythagoras," ibid., 37.

${ }^{1410}$ Russell, History of Western Philosophy, 37. It is not insignificant that Pythagoras was one of the earliest philosophers in the Greek tradition known to promote the transmigration and immortality of the soul, and that the timeless world beyond the physical world inspired his ideas. Charles H. Kahn, Pythagoras and the Pythagoreans: A Brief History (Indianapolis, IN: Hackett Publishing, 2001), 4; and Constantine J. Vamvacas, The Founders of Western Thought-The Presocratics: A Diachronic Parallelism between Presocratic Thought and Philosophy and the Natural Sciences, tr. Robert Crist (New York, NY: Springer Science, 2009), 58. "In his fundamental teaching concerning the immortality of the soul, Pythagoras brings about a decisive point of departure in the history of western thought.... Pythagoras would be the first in Europe to preach that it is the spirit and not the flesh that is the principle carrier of human existence. Man can be considered a 'microcosm'-a
} 
tradition, especially Sufism. ${ }^{1411}$ His observation that apocalyptic religion is in some way antagonistic to rationalistic mathematical religion and reasoning forces one to entertain thoughts that question the role of time and science in relationship to eschatological theology today.

likeness and epitome of the universe, the 'macrocosm'. He is composed of the material body, which is subject to continual change, development and decay, and of the immaterial, ever-moving soul, a mental essence, which has its own existence. The human soul 'is immortal because it is a portion of the immortal divine essence from which it was detached.'

"For the first time in Greek thought, the soul is viewed as a self-existent entity over against the mortal body, which is considered its ephemeral prison. Soon the meaning of the soul will be identified with the selfawareness of the individual. This significant point marks the origin of the attempt to conceive the spirit as an indestructible entity, which is in diametrical opposition to matter. Worthy of note is the fact that this process of the division between spirit and matter, which will have a catalytic influence on the subsequent development of European thought, did not arise out of scientific interest or practical need, but from a deep religious predisposition toward spiritual purification and the soul's assimilation into the divine.

"The soul's existence precedes the body's, and is interred in the body in order to expiate for some undefined sin. The aim of human life is for the soul to return and identify with the ... divine universe, from which it has fallen. This evolutional path of the soul toward the divine is achieved through ascetic life and purification within a series of reincarnations .... The notion of reincarnation is not something new. The new element is the ethical dimension introduced by the Pythagorean teaching," ibid., 58-59.

1411 "The qualitative evaluation of numbers by the Pythagoreans found many supporters in Islam, since the Muslims saw therein a clear expression of the necessities inherent in the concept of God and the cosmos. It should be kept in mind that in such discussions, 'one' is not considered a number, any more than the Lord is thought of as a vassal. But to say one is to say two, three, and so on, ad infinitum, since one is one-half of two, one-third of three, and so forth. The dualities inherent in this approach are fundamental, since they are already implicit in one, the source of number, and explicit in two, the first of the numbers. Two corresponds to the first creation, the prototype of everything in created existence. God is one and only one, but everything other than God is two or more. The Ikhwān al-Ṣafā' make this point succinctly while reminding us of the three Koranic verses that speak of 'two of every kind,' such as God's command to Noah concerning what to place in the Ark: 'Carry in it two of every kind' (Q11:40).

Everything below God is 'two of every kind,' since He is the One, the Unique, the Everlasting, 'who did not give birth and was not born' [Q112:3].

The qualitative relationship between one and the numbers is summarized by the Ikhwān in describing the position of Pythagoras. In brief, since God is one and everything other than God is incomparable with Him, everything else must be two or more. But since all things are also similar to God in some manner, they partake of a certain oneness," Sachiko Murata, The Tao of Islam: A Sourcebook on Gender Relationships in Islamic Thought (Albany, NT: State University of New York Press, 1992), 59. See also, I. M. N. Al-Jubouri, History of Islamic Philosophy: With View of Greek Philosophy and Early History of Islam (Herford, UK: Authors OnLine, 2004), 49-50; The Royal Embassy of Saudi Arabia, "Islam and the Development of Knowledge," in Encountering the World of Islam, ed. Keith E. Swartley (Downers Grove, IL: InterVarsity Press, 2005), 64; Muzaffar Iqbal, Science and Islam (Westport, CT: Greenwood Press, 2007), 86; Talal Ghannam, The Mystery of Numbers: Revealed Through their Digital Root (Charleston, SC: CreateSpace, 2011), 25-26; Durre S. Ahmed, Islam and the West: A Psychological Analysis (Sustainable Development Policy Institute, 1993), 43; Rafiq Zakaria, Discovery of God (Tardeo, Mumbai: Popular Prakashan, 2000), 183; Godefroid de Callataÿ, Ikhwan al-Safa': A Brotherhood of Idealists on the Fringe of Orthodox Islam (London, UK: Oneworld Publications, 2012); Seyyed Hossein Nasr, The Heart of Islam: Enduring Values for Humanity (New York, NY: HarperCollins, 2004), 19; Eva Désirée van den Berg, Language of the Heart: A Sufi Interpretation of Form and Meaning in Contemporary Society (New York, NY: Blue Dome Press, 2012); and Joscelyn Godwin, The Golden Thread: The Ageless Wisdom of the Western Mystery Traditions (Wheaton, IL: Theosophical Publishing House, 2007), 35-37. Godwin notes that "we ultimately have Pythagoras to thank" for the fact that today "most people learn much more mathematics in school than they will ever put to practical use, because it is believed that it trains the mind in a way useful for any discipline," ibid., 37. Note also potential ties between Pythagoras, Freemasonry and Sufi Islam, in David Livingstone, Black Terror White Soldiers: Islam, Fascism \& the New Age (Sabilillah Publications, 2013), 204-205; and Pythagoras and Jewish number mysticism in Diana Lobel, A Sufi-Jewish Dialogue: Philosophy and Mysticism in Bahya Ibn Paqūda's Duties of the Heart (Philadelphia, PA: University of Pennsylvania Press, 2007), 66-67. 
The importance of Pythagoras, however interesting it may be in its own right, is also worthy for highlighting the origins of the significance of the two cultures and the explanation of their enduring nature. ${ }^{1412}$ Indeed, some believe, such as Underwood Dudley, that "number mysticism would have appeared even if Pythagoras had never lived. Numbers have power, and they will exert it. As evidence of the power of numbers, notice that there is no such thing as alphabet mysticism even though alphabets go back to before the time of Pythagoras.... The letters of the alphabet are symbols very like the digits of our number system, standing for sound instead of quantity, but they do not inspire mystical insights. Numbers do."1413 In other words, there is a latent or implicit universality hidden within mathematics that inspires awe in a unique omni-cultural way. Russell similarly asserted that "the opposition of the rational and the mystical [which can be said to be analogous to the two cultures $\left.{ }^{1414}\right]$, which runs all through history, first appears, among the Greeks, as an opposition between the Olympic gods and those other less civilized gods who had more affinity with the primitive beliefs dealt with by anthropologists. In this division, Pythagoras was on the side of mysticism, though his mysticism was of a peculiarly intellectual sort. He attributed to himself a semidivine character,"1415 and thus in many ways represents the first individual to seek after a "third culture" that harmonizes the sciences and humanities (vis-à-vis mysticism), with a clear favoritism

\footnotetext{
${ }^{1412}$ Heidegger infamously critiqued essentially all of Western thought as a building up upon the Pythagorean/Platonic rationalist foundation (Greek "metaphysics"), for which "modern science and technology" were "but the culmination and ultimate logical consequence of Platonic rationalism," Madison, Understanding: A Phenomenological-Pragmatic Analysis, 13. Yet, I concur with Madison that "unlike Heidegger ... I do not believe that the history of Western thought is nothing but the history of [Pythagorean/Platonic] rationalism.... Ever since the ancient Greeks, from time to time, people have protested against the dominant presuppositions of our rationalist culture and have sought to expose its underlying prejudices.... The entire history of philosophy therefore can be looked upon as being made up of two basic movements. First is the dominant current of rationalism and, within this current, a counter-current, which attempts to bring us back to a more just appreciation of our powers and limits," ibid., 13-14. Madison's comments reflect an awareness of the broader and deeper tension between the "two cultures" that has always existed.

1413 Underwood Dudley, Numerology: Or, What Pythagoras Wrought (The Mathematical Association of America, 1997), 14-15.

${ }^{1414}$ Recall that Heideggerians sometimes embrace, or are accused of, supporting a "mystical" view of truth. Note Kurtz, Skepticism and Humanism: The New Paradigm, 30.

${ }^{1415}$ Russell, History of Western Philosophy, 32.
} 
shown toward the rationalism of the mathematical world, ${ }^{1416}$ of which neoplatonism was the eventual historical result.

What Pythagoras initiated, then, was a tension, illustrated today through the two cultures' conflict, between reason as a universal public ground, and positions maintained by the minority, that may be deemed irrational. The resultant problem from this for theology can be stated succinctly-there is simply no way that any interpretation of Scripture will attain the universal acceptance that mathematics and science have attained in recent Western history. When it comes to prophetic interpretation and eschatology (apocalyptic religion), this may be especially true, and raises difficult problems for any apocalyptic religion, because the role of any evil agent taking over or somehow widely affecting the world is always assumed to be irrational. The inverse possibility, that evil may be deemed rational, and truth irrational, from a historical and technical perspective, is less often considered. In either case, the problem for the Remnant is that their ability to engage the world, and save people from it, relies upon their persuasive power which typically appeals to truths assumed to share a universally rational basis that the majority will irrationally reject. If such a Remnant is itself confused about its relationship to rationality within the realm of public discourse, then confusion may be expected. ${ }^{1417}$

As seen in the exposition of their works above, Bohm and Pylkkö represent opposite approaches to the goal of universal consensus in philosophy. Bohm seeks it; Pylkkö rejects it, preferring to see truth as the sheltered and shared cultural experience of a few within clustered groups. Both realize, ironically, that despite the best efforts of the adherents of the platonic tradition to unify all philosophy

\footnotetext{
${ }^{1416}$ Pythagoreanism asserted that "number and calculation are the ruling force not only in the natural world but also in human relations and morals, and only in so far as they are heeded can society be harmoniously organized," William K. C. Guthrie, A History of Greek Philosophy: Vol. 1: The Earlier Presocratics and the Pythagoreans (Cambridge, UK: Cambridge University Press, 2000), 336.

${ }^{1417}$ For example, George Knight suggests that Seventh-day Adventists, an apocalyptic Remnant denomination, precisely because of our wavering commitment to our apocalyptic vision, are failing to attain their goal. George Knight, The Apocalyptic Vision and the Neutering of Adventism: Are We Erasing Our Relevancy? (Hagerstown, MD: Review and Herald, 2008). Part of the challenge Adventists face is that they can't seem to find their place amidst the world, retaining a divided socio-political worldview and witness, including in relationship to eschatology. See Younker, "The American Socio-Political Spider Web and the Rise of Global Christianity," 132-188; and Michael F. Younker, "Adventist Eschatology in Relation to the Religious Left and the Religious Right," in Journal of the Adventist Theological Society Vol. 23 \#2 (Autumn, 2012), 190-242.
} 
(and thus 'theology') around mathematics, the neutered religion of scientism (the only 'purified' residue of Plato) existing today fails to account for the 'messiness' of humanity throughout the world's many cultures and religions. Mainstream scientism is too sterile to ultimately bring universal unity-in part this is surely because the scientism within the technocratic world today favors an atomistic approach that separates and privileges the 'priests' of the scientific and techno-business world over and against the lower classes, many of whom may be religious, ${ }^{1418}$ which ultimately creates a cultural rift between the elites and have-nots. The question, then, of the nature of the political, and its relationship to theology, becomes a poignant problem. ${ }^{1419}$ Or, as the Heideggerian

${ }^{1418}$ William Meyer perceptively recognizes that "in a world seemingly awash in religion, the [common $19^{\text {th }}$ century] assertion that religion would gradually fade from the stage of human affairs seems rather naive. Indeed, as one commentator observes, 'Religion is no longer the opiate of the masses; we now have religion on speed!' Yet if the secularization thesis was mistaken concerning the overall influence of religion, it appears to have been at least partly correct with regard to the marginalization of theology. By 'theology' I mean systematic reflection on and critical assessment of the meaning and truth of religious claims. If theology was the queen of the sciences in the medieval context, it is at best a neglected stepchild in the modern framework; if it was then at the center of intellectual and university life, it is now at the periphery. Thus, at the same time that religion has increased its influence on and visible presence in the contemporary world, theology has remained a muted voice on the sidelines of the cultural conversation. What this combination translates into, one might say, is the increasing ascendancy of an uncritical and untutored religious voice in society.... Put simply, the modern world has never figured out how to address religious claims seriously in public," leaving us today with "mass folk theology,' William J. Meyer, Metaphysics and the Future of Theology: The Voice of Theology in Public Life (Eugene, OR: Pickwick Publications, 2010), 1-2. Meyer also explains that, in his view, the contemporary world is divided between "religion on one side" and "a secularistic outlook on the other, and the notion of the secular or secularity in between. This middle set of terms is meant to indicate a modern commitment to reason and experience, rather than to authority and tradition, as the grounds of adjudicating truth claims and other claims to validity," ibid., 2. Writing as a religionist, Meyer hopes to merge the secular commitment to reason with religion, for, "stepping back, we see here two widespread and opposing tendencies [amongst religionists]: one side affirms modern secularity but privatizes religion and comprehensive convictions; the other side reasserts substantive convictions but resists modern secularity. Over against each of these prevailing views, I argue that the persistent problem is and has been our inability to fully integrate religion and modernity, that is, to fully affirm and redeem comprehensive claims within the context of modern secularity.... Our cultural inability to integrate religion and modernity ... is directly related to the marginalization of theology," ibid. 5. Meyer thus recognizes the operative reality of the two cultures, though he sides with the 'sciences' and modernity, hoping to synthesize science with religion. In any case, the critical observation at present is how theology has been demoted beneath religion, precisely because of the enduring power of the two cultures within an era of postpost-modernity. That is to say, the age of "social media" has given great power to the masses, who are mired in a strange mixture of influences-both the secular sciences (which they utilize daily without understanding) and the humanities (their folk beliefs, including religious ideas). That is to say, many are now religious without religion, and often do not understand exactly what influences impact upon themselves, other than perhaps through various celebrity figures. See Pete Ward, Gods Behaving Badly: Media, Religion, and Celebrity Culture (Waco, TX: Baylor University Press, 2011), 76-80.

${ }^{1419}$ Many have recognized this phenomena. For a revealing critique of how religion and freedom intersect with the political, see Carl A. Raschke, Force of God: Political Theology and the Crisis of Liberal Democracy (New York, NY: Columbia University Press, 2015), 81, 83, 91-92. Raschke observes that "one of the reason[s] the very idea of a political theology, especially a 'global' political theology, makes us uncomfortable is that we are virtually hypnotized these days, particularly in America, to think-politically-solely in terms of an economy of entitlement and resentment, which we mistakenly associated with some vague idea of 'justice.' [The Heideggerian philosopher Giorgio] Agamben has forced us decisively into rethinking our 'economic' and 
philosopher Michael Eldred explains, "at best, politics, the state and public discourse" "can guarantee and leave only open space for that world-shaping creativity which eventuates unpredictably through certain individuals." That is to say, "the state ... can only institutionalize forms of universal freedom that come to be enjoyed by everybody" as a "possibility. Hence there is a hiatus between the highly visible realm of politics and its strifeful occurrences that are the stuff of news and normal historiography" because the state cannot universalize "a guaranteed realization but only ... a potential, with all the uncertainty and risk associated with such individual freedom."1420

If this is indeed true, that the state, or any overarching culture or collection of concepts, such as that of science, cannot actually bring about the freedom of the individual, but only its possibility, by condition of the very nature of freedom itself as always and only contained in aconceptual unique 'individual' experiential flows within local communities, then it is impossible that true theology can ever be politically realized, if true theology has as its task the realization of the truth of freedom within the individual within an overarching corporate body. What is being said here is that regardless of its universal applicability, theology faces a distinct challenge if it is thought that it could ever simply, by democratic means, become recognized as 'true' in a politically universalizable sense and grant its soteriologically poignant gift of freedom to people politically through the state, and any attempt to do so will always face 'resistance,' either peaceful or otherwise, because of the reality of what freedom really is.

\footnotetext{
'ecumenical' models of the new global political as ultimately the 'God' question. We are ... all now political theologians, mainly because all theology is political and all politics is theological," ibid., 83. Raschke continues, "the 'reversal of Platonism' may have happened in [postmodern] epistemology and language theory, but the reversal itself has been dramatically reversed when it comes to the codes and modes of symbolization that matter significantly in our personal lives. Political economy should have gone the way of structural linguistics, but instead it has reverted to Platonism of a very odd sort," ibid., 92. Note also, Carl Schmitt, Political Theology, tr. George Schwab (Chicago, IL: University of Chicago Press, 2006), 36. Schmitt asserts that, "all significant concepts of the modern theory of the state are secularized religious concepts," ibid., 36; and Clayton Crockett, Radical Political Theology: Religion and Politics After Liberalism (New York, NY: Columbia University Press, 2013), where he shares the "distinction between religious and secular is breaking down, so that it is no longer possible to consistently and rigorously separate and oppose the sacred and the profane ... [and] if religion and secularity cannot be neatly separated, we cannot fully separate or distinguish political philosophy from political theology," ibid., 2; and Jeffrey W. Robbins, Radical Democracy and Political Theology (New York, NY: Columbia University Press, 2011), 162-165.

${ }^{1420}$ Eldred, A Question of Time, 118.
} 
The result of this situation is relatively simple. Philosophy, and theology, must recognize the intrinsic challenge of investigating the value of the quest to seek universality for its ground, and the relationship this question has for the essence of the purpose of philosophy and theology in relationship to freedom and time. If correct Scriptural theology is indeed a theology for the remnant, then it must also internalize within itself why it is a remnant. As it would be portrayed in popular theology, sin is irrational, and the truth is rational. Without questioning the motive and intent behind this assumption, a curious reversal is presented within the clash of the two cultures: From a technical perspective, is the rejection of truth a move toward the 'irrationality' of temporal freedom, or a move toward the 'universal' ground of timelessness? Is it possible that perhaps the reason most people will not choose the truth is because they prefer to ground their reason in the universally transcendent and timelessly popular and accessible, instead of a God whose present actions are rooted in the immanence of prior but now 'inaccessible' temporal-historical acts? ${ }^{1421}$

\section{Summary}

Above, the projected reception of Bohm's and Pylkkö's insights within the crisis of the two cultures and theology was briefly considered. Of course, much of the material was speculative in nature, as the consideration of their work on freedom and time has not occurred amongst many individuals representing the various movements, ideas, and cultures mentioned. What was accomplished, however, was a brief consideration of their main themes in the context of several important trends in contemporary philosophy and theology. Specifically, the reception of Bohm's and Pylkkö's works was considered in the context of the role of freedom and time in the natural sciences and the humanities, both viewed from within a theological lense.

Bohm's and Pylkkö's ideas would likely receive a mixed reaction amongst those working on issues in the natural sciences, in areas such as the locus of divine action. This is because some of the

${ }^{1421}$ Wright, God Who Acts: Biblical Theology as Recital, 115-117. Again, Wright suggests the need to adhere to a view of a "temporal" God and a theology that uses the "categories drawn from the Bible itself, instead of from propositional dogmatics" and that takes the "historical movement and interaction of the Bible" with divinity seriously, ibid., 115-116. 
major positions, such as the classical view of science, are committed to views opposing them, such as complete determinism, or a platonic dualism separating the scientific world from the 'spiritual' world. At the same time, aspects of their work may be received favorably. Concerning their efforts in the humanities, several issues of general significance were addressed that are affected strongly by the concepts of freedom and time. Here, the potential role of Bohm and Pylkkö was considered to have far more vitality and potential. Many aspects of the issues of religious pluralism, social ethics, soteriology, prophecy, the biblical Sabbath, and the role of truth in a democracy, were considered, and in each case Bohm's or Pylkkö's ideas, or both of their works, could contribute in very innovative ways toward resolving or clarifying longstanding problems or puzzles. ${ }^{1422}$ More work should be done on the potential role of Bohm's and Pylkkö's ideas for the humanities. Naturally, of course, were this done, then the divisions within the other third cultures could also be correspondingly modified.

Overall, it may be difficult to overstate the potential significance of what Bohm and Pylkkö could offer to theology. For example, the concepts of prophecy, morality, and the remnant point toward potentially very different conclusions and goals than what is typical amongst secularists and even many popular religionist movements. At the same time, Bohm and Pylkkö each provide an alternative conception of what it is philosophy is trying to do in relation to science, and their fresh conceptualizations force one to view each of the third culture disciplines in radically new ways-which are not yet fully articulated. This is because their ideas about freedom and time are fundamentally different from what traditional philosophy has suggested possible. Whether or in what way the existing third cultures will adapt to accommodate their ideas remains an open question, however, because as noted above, many individuals are deeply committed to favoring one or the other of the

\footnotetext{
${ }^{1422}$ Appropriating the words of the late eminent archaeologist William Foxwell Albright, Bohm and Pylkkö both possess that rare "capacity for [the] intuitive grasp of wide fields of perception which has characterized certain figures of the last 250 years.... We need refer only to ... the fantastic previsions of future technology by Jules Verne, or to the glimpses into the future on the part of ... Ellen White.... On the other hand, it is no accident that logically trained specialists are seldom able to predict the future; this is notoriously true of physical scientists, historians, and other academic folk." Such perception qualifies these thinkers, in Albright's view, in a certain broad sense, as prophets, as the focus of true prophets was often their "moral and religious content," that is, forth-telling and not mere fore-telling. William Foxwell Albright, From the Stone Age to Christianity: Monotheism and the Historical Process (Garden City, NY: Doubleday Anchor Books, 1957), 18-19. As discussed above, the contributions of Bohm and Pylkkö to the concepts of freedom and time help us understand how moral and religious content function within the philosophical and scientific world.
} 
two cultures. At the same time, the fragmegration of the world also suggests that a true third culture movement is in fact already underway, and those rallying around figures like Bohm and Pylkkö show that there is a desire by many to move beyond the broader two cultures' impasse. Just how all this may unfold remains a mystery at present. 


\section{CHAPTER 6}

\section{SUMMARY AND CONCLUSIONS}

As Martin Heidegger once opined, the "hermeneutics" guiding true philosophy is not a science at all, "but in fact something preliminary which runs in advance of it and has its own reason for being." "What is at issue in it," he continued, "is not to become finished with it as quickly as possible, but rather to hold out in it as long as possible."1423 Unfortunately, Heidegger claimed that we today have "become so pithless and weak-kneed that we are no longer able to hold out in the asking of a question." Rather, when "one philosophical medicine-man cannot answer" a question, the people then "run to the next"1424 medicine-man that can seemingly answer the question. The resultant conclusion for Heidegger was that "the great industry of philosophy" of his day was "geared merely to ensuring that one will not come too late for the 'resurrection of metaphysics' which ... knows only the single care of helping oneself and others to a friendship with the loving God which is as cheap as possible, as convenient as possible, and as profitably direct as possible." ${ }^{1425}$

Arguably, salvation is not 'cheap.' It cost a lot, and is now free, with sometimes inconvenient conditions. Yet whether Heidegger's view of philosophy is ultimately correct or not, it certainly seems true that today there is an impatience when doing the work of a meta-physician. For it seems that, indeed, "'a civilized people without metaphysics' is like an 'otherwise copiously decorated temple

\footnotetext{
${ }^{1423}$ Heidegger, Ontology: The Hermeneutics of Facticity, 15-16.

${ }^{1424}$ Heidegger, Ontology: The Hermeneutics of Facticity, 16.
}

${ }^{1425}$ Heidegger, Ontology: The Hermeneutics of Facticity, 16. Heidegger also remarked, "the efforts of the great philosophers are directed toward what is in every sense ultimate, universal, and of universal validity. The inner struggle with the puzzles of life and the world seeks to come to rest by establishing the ultimate nature of these. Objectively stated: every great philosophy realizes itself in a worldview - every philosophy is, where its innermost tendency comes to unrestricted expression, metaphysics," in Heidegger, Towards the Definition of Philosophy, 7. Heidegger considers this unfortunate, indeed a "paradox," whereupon the impulses of philosophy always lead naturally to its negation and collapse into a mere worldview, closing the mind from further world-participation and creation, ibid., 8-10, 128. 
without the Holy of Holies."'1426 In our quest to fill and articulate the metaphysical reality behind the veil, however, we must be careful, for we risk encroaching upon that place where blood is required (Heb 9:7-12), that we are not fit to bear or to bleed. The veil conceals the one and only true MetaPhysician, and the only blood that heals.

As Kant noted, and Heidegger concurred, the task of metaphysics is to wrestle with the concepts of God, freedom, and immortality, which is existence in relation to time. ${ }^{1427}$ These are indeed no ordinary objects or concepts. Rather, in addition to God, the concepts of freedom and time have fascinated and bewildered the most inquisitive minds for millennia. In recent times, their collectively and deeply interlocked natures have also been recognized-they impact upon one another in many ways. The first member of the trifecta, God, has come to be primarily defined by his relationship to freedom and time. Everything that can be meaningfully said about God is ultimately dependant upon God's relationship to freedom and time-even the love of God. As such, freedom, and time are branches descending into a divine trunk, with roots that ultimately disappear beneath the surface and receive their nutrients from where it seems philosophical or theological investigation may not easily penetrate-we seem only to understand the concepts a posteriori, to use Kant's language, or as the fruit from the tree encountered in life. At the same time, the Scriptures offer little direct help in clarifying these three concepts. One suggestion that has been offered is that the Sanctuary alone reveals their breadth and depth-and this is a mystery still unfolding. ${ }^{1428}$ In what follows, a summary of the study will be given, highlighting the key points covered in sequence. I will then offer a summarial conclusion, followed by some suggestions for further research.

\footnotetext{
${ }^{1426}$ Heidegger, Parmenides, 100.

${ }^{1427}$ Kant, Critique of Pure Reason, 792; 640, 602, 3; and Heidegger, Phenomenological Interpretation of Kant's Critique of Pure Reason, 41.

${ }^{1428}$ Younker, "From Metaphysics to Templephysics: Situating the Significance of Fernando Canale's Contributions for the 'Christian Philosopher.'”
} 


\section{Summary of Study}

The findings of this study indicate that the mid-20th century rise of the two academic cultures of the sciences and humanities, specified by C. P. Snow and exemplified through the contributions of Albert Einstein and Martin Heidegger, brought to an apex a long developing conflict about two fundamental and interrelated philosophical concepts-freedom and time. Put simply, Einstein's philosophy of science ultimately led to the denial of the existence of freedom (certainly within the realm of 'science'), and interpreted time in a 'timeless' deterministic way, as illustrated in the common understanding of his relativistic four-dimensional space-time. Conversely, Heidegger moved beyond both the temporal 'flux' of Heraclitus' and Newton's moving 'now' line of time as well as Einstein's space-time, and the 'timeless' freedom advocated by philosophers like Kant, to propose a genuinely ecstatic (outside of or beyond itself) four-dimensional time-space, which actually exists pre-spatially and also apart from any notion of classical science. For him, then, freedom is also understood ecstatically and temporally, with its commitments and possibilities tied into the past and future simultaneously. With freedom and time interpreted in essentially opposite and therefore contradictory ways, the impact of this conflict has been far-reaching, especially and importantly in theology, which has duplicated the conflict, producing conflicting foundational theologies. This has left the discipline of theology functionally inert sociologically, as well as leaving contemporary secularized philosophy and metaphysics, in general, in a confused disarray. ${ }^{1429}$

Prior to the work of Einstein and Heidegger the conflict already existed. In fact, it has been present during every period of history, starting with the early Greeks. ${ }^{1430}$ However, prior to the contemporary age, it was typically only present in a prolonged nascent form. However, upon the arrival and dissemination of Einstein's and Heidegger's ideas, the conflict broke out quite quickly and forcefully in the academic and, however directly or indirectly, even public consciousness.

Furthermore, within this milieu the concepts of freedom and time have created a conundrum for

\footnotetext{
1429 "Introduction," 1-51; “Einstein's Contribution: Space-Time," 214-236; and "Heidegger's Contribution: Time-Space," 302-341.

1430 “Appendix A: The Historical Development of Freedom and Time," 455-531.
} 
contemporary philosophy and theology, as well as the sciences. Are freedom and/or time intelligible concepts to discuss within the sciences at all ${ }^{1431}$ In the instances of both Einstein and Heidegger, the concepts have been shown to have a nonexistent or separate relationship to 'natural science.' This has transferred the locus of discussion concerning the concepts of freedom and time into a 'neverland,' with neither culture capable of claiming rights to it, and theology has not yet shown the ability to bridge the gap without simply taking sides and thus perpetuating the conflict (two common examples are divine timeless foreknowledge and open theism). Closely related to the above quandary, the traditional 'science and religion' debates have also been seen to be misguided. They share in the unresolved philosophical problem relating to the concepts of freedom and time, and, owing to the shared 'scientific' method of approaching problems in both science and religion in the general academy, the discussion is bound to end in a stalemate that merely points toward the need for reexamining the concepts of freedom and time. ${ }^{1432}$

Snow, and others, lamented the crisis of the two cultures. However, Snow's proposed solution, the creation of a 'third culture' to mediate the two cultures, has failed to resolve the crisis. This is for two primary reasons. First, in Snow's mind, the third culture would primarily consist of scientists leading the way, and dictating to the humanities their priorities. This endeavor has essentially failed. Second, the mediating 'third cultures,' that of the social sciences, including such disciplines as psychology and psychiatry, economics, and the socio-political sciences, have themselves become deeply entangled within the fundamental crisis of the two cultures concerning the very concepts of freedom and time and how they should function within their disciplines. Owing to this fact, and that theology and religious perspectives which engage these mediatorial third cultures have likewise reduplicated the divide concerning freedom and time, has left the third cultures inert in their ability

\footnotetext{
1431 "The Context of Freedom and Time Within the 'Two Cultures' Milieu," 94-107.

1432 “Einstein's Contribution: Space-Time," 214-236; and “Heidegger's Contribution: Time-Space," $302-$ 341.
} 
to progress beyond the fundamental divide between the two cultures, and, at least thus far, theology itself has also shown itself to be equally inadequate. ${ }^{1433}$

Although the conflict over the concepts of freedom and time is now generally well recognized by close observers of the developments in philosophy and society, and its effects are virtually omnipresent, it is still widely neglected by many specialist practitioners within either one of the two cultures, which, as 'cultures,' do indeed often operate within isolated 'bubbles.' This has only led philosophy and society unwittingly down a path into a widespread implicit contradiction, the consequences of which are just now beginning to reach an explicit or critical stage throughout societies at large. To put this in context, the contemporary early $21^{\text {st }}$ century political polarization in the United States and other nations is traceably related to the two cultures' conflict over the natures of freedom and time. ${ }^{1434}$ With that in mind, the assessments of experts attuned to the conflict appear to show that efforts to assuage the tensions at a surface level do not appear to work. A fundamental conceptual replacement of the concepts of freedom and time appears the only way to properly understand why we got where we are, and what pathways are viable ways forward.

One of the more promising avenues for finding conceptual replacements for freedom and time, and the reconceptualization of the two cultures themselves, is found in the perplexing and mysterious realm of quantum physics. ${ }^{1435}$ Unfortunately, the quantum phenomena can be interpreted in at least four contradictory ways. ${ }^{1436}$ First, as simply a continuation of the classical world, pending just a bit more information (that may or may not be forthcoming-in harmony with the early Bohm). Second, as providing a possible support for the traditional dualism concerning the mental and physical world (the standard Copenhagen view). Third, as opening up the possibility of a new way of

\footnotetext{
1433 “The Divide Within the 'Mediatory' Third Culture Disciplines Concerning Freedom and Time and the Place of Religion," 147-201.

1434 "Introduction," 1-51.

1435 "The Revolutionary Implications of Quantum Physics and Its Impact Upon Freedom and Time, the Two Cultures, and the Necessity of a Third Culture," 69-93.

${ }^{1436}$ Other interpretations besides the four views mentioned here do exist-such as the 'many worlds' view, but, in many respects, such interpretations are more variations of the four mentioned here than they are genuine alternatives. For example, the 'many worlds' view is entirely monistic physically, deterministic, and yet also Platonistic in that 'other worlds' exist-in this case, infinitely many, which actually creates an ironic similarity to Bohm's view, although its rationale is completely different and incompatible with Bohm's.
} 
seeing physical reality, one oriented towards an infinite depth of interwoven yet differentiated layers which retain, in many core respects, the classical image of science-David Bohm's later view, building off Einstein. And fourth, as indicative of the need to break down the reign of classical science altogether, not merely for the study of nature, but dissolving its very methodology as applied even in the social sciences-Pauli Pylkkö's view, building off Heidegger.

For the purposes of true conceptual replacement, and through a review of the potential of the first two options to actually aid in resolving the conflict, it was determined that Bohm's and Pylkkö's proposals ${ }^{1437}$ do offer the most potential for progress beyond the impasse between the two cultures. First, Bohm's views of freedom and time are indeed distinct from previous concepts that have dominated throughout history. He believes that there are many different layers with differing orders within reality that are all interconnected, in contrast to the atomistic view which dominates classical science. What distinguishes his view from others is that the different layers may necessarily involve the appearance of disorder from the perspective of a higher or lower order. Because of the infinite complexity of reality, it is impossible to actually perceive any absolute determinism in nature which grants one meaningful freedom. Correspondingly, the meaning of time is transformed into one of relative degrees of temporal and timeless vertical orders in various relationships to each other throughout an overall 'timeless' holomovement. Critically, the social spheres are also included within the various posited layers. ${ }^{1438}$

Second, Pylkkö's views of freedom and time are also distinct from most concepts that have dominated history. Pylkkö also believes that all of reality is fundamentally interconnected. However, he also believes that the relationship between order and disorder is itself one of the key fundamental features exhibited in nature, and that randomness plays a critical role. He also dismisses the idea of any residual 'timeless' platonic realm. Freedom and time are fundamentally constituted by their relationship to the interconnected or nonlocal yet locally manifested random events of nature, creating an aconceptual experiential flow. Because this basic feature is common to all reality,

\footnotetext{
1437 "Bohm as an Exemplar of Einstein," 238-239; and "Pylkkö as an Exemplar of Heidegger," 350-352.

1438 “David Bohm's View on the Relations of Freedom and Time,” 202-293.
} 
including the social spheres, the concepts of freedom and time Pylkkö articulates are operative at every level, guiding the meaning of social and cultural movements, as well as those in physics. As such, rather than freedom being an exceptional case within a deterministic world, determinism is rather the 'illusion' within a more fundamentally free world, noting that freedom here is tied to random temporally and nonlocally extended events. ${ }^{1439}$ Laws, including natural ones, can only exist within an underlying framework that possesses freedom of some sort-and this freedom should be considered foundational, rather than the laws, though this is not to dismiss the existence of laws nor their necessity, either in nature or at the social level.

Bohm's and Pylkkö's theories, while in some ways similar and parallel efforts to resolve a common problem, are nevertheless very different and incompatible in other ways. The most important feature of their incompatibility is found in the opposite terminology they use, which in some ways perpetuates one of the most fundamental conflicts between the two cultures. Bohm retains and endorses the language of timelessness, whereas Pylkkö retains and endorses the language of temporality. As such, in some ways, while indeed moving beyond the precise characteristics of the broader conflict between the two cultures, they too perpetuate it. If nothing else, this illustrates clearly that, indeed, freedom and time are the fundamental concepts both creating and dividing the two cultures. Furthermore, because of the close relationship freedom and time have in relation to the idea of God, divergent theologies are inevitable so long as this crisis persists. ${ }^{1440}$

The remaining question to address then became in what way could Bohm's and Pylkkö's ideas contribute to problems created by the two cultures within the dialogue between science and religion, and within the sphere of theology itself, particularly in what ways they might be received within the dominant paradigms already operative in these areas. Within the sciences, it appears unlikely that either the dogmatic classical view or the neoplatonic Copenhagen view will welcome the insights of Bohm and Pylkkö. In part, this is because of the powerful dominance of the scientific culture, which controls so many sectors of society and the academy. Bohm and Pylkkö will likely remain outsiders

\footnotetext{
1439 “Pauli Pylkkö’s View on the Relations of Freedom and Time,” 294-382.

1440 “Comparison of Bohm and Pylkkö,” 384-395.
} 
to this dominance for some time, if not permanently. Theologies that embrace the sciences 'as they are' will only be open to limited aspects of the work of Bohm, and less so, Pylkkö. Ironically, tenets of each of their ideas are also present in the most advanced interpretations of physics. Specifically, overall determinism within the realm of 'science,' which is in harmony with the earlier Bohm, and the acceptance of genuine randomness 'in some manner' within nature, which is in harmony with Pylkkö. Both of these are accepted by many mainstream theologians supportive of the scientific community. However, the synthetic work that Bohm and Pylkkö have each attempted challenges the status quo in ways which the scientific community overall, as a culture, will likely find unpalatable. The same would be true for the many theologians who show great deference to science today. ${ }^{1441}$

Conversely, within the realm of the humanities, the work of both Bohm and Pylkkö is likely to find much greater resonance, or, at the same time, elicit even sharper disagreement. The concepts of freedom and time play a central role in several major issues intersecting the humanities with theology, including religious pluralism, politics and social justice, soteriology alongside the Sanctuary and atonement, the reality of biblical prophecy, the Sabbath and rest, and the biblical concept of the Remnant and the philosophical significance of a minority holding the truth. ${ }^{1442}$ In all of these areas, Bohm's and Pylkkö's conceptions of freedom and time could profoundly transform these socioreligious, theological, and biblical issues by modifying our views of how freedom and time intersect with hermeneutics and thus theology itself. However, in most cases, the trajectories their ideas would encourage concerning these areas would be in opposite directions. Thus, the theoretical continuation of the two cultures' impasse may endure. Nevertheless, theologians are far more likely to find Bohm's and Pylkkö's ideas attractive, and the integration of their thinking, especially Bohm's, has already begun to take place.

\footnotetext{
1441 “The Projected Reception of Bohm's and Pylkkö’s Insights Within the Crisis of the Two Cultures and Theological Reflection," 395-410.

1442 “The Projected Reception of Bohm's and Pylkkö’s Insights Within the Crisis of the Two Cultures and Theological Reflection," 410-439.
} 


\section{Conclusions}

Differing conceptions of freedom and time reveal a deeper rift within philosophy and theology than some may realize, and this is manifest through an examination of their influence throughout many third culture disciplines, in which religion is also now present. The philosophical speculations of Bohm and Pylkkö offer a breath of fresh air into what has become, to a great degree, a very stale and divisive debate. The traditional paradigms are failing to satisfy either the intellectually curious, or the masses, and a more integrative approach must be sought, or academic philosophy, and academic theology with it, will only lead to continuing conflicts of the sort that already occur within more popular naïve cultural encounters.

Given the above examination into the work of Bohm and Pylkkö, this study offers the following specific conclusions. First, the contrasting descriptions of freedom and time given by Einstein and Heidegger do fundamentally conflict, and their differences have had a profound impact on philosophy, science, and theological reflection. Second, essentially all further sub-disciplines, particularly the third culture disciplines that most directly impact human societies and the earth, are also profoundly affected by the contradictory tension. Third, the more classic 'science and religion' debate, as well as a host of other related issues, such as the nature of hermeneutics, are also profoundly affected by this conflict. Fourth, potential avenues toward ameliorating the conflict are present in the contributions of Bohm and Pylkkö. However, fifth, the conceptions of freedom and time presented in Bohm and Pylkkö also conflict, leaving philosophy and theology with a primordial choice between timeless time and determinism or, perhaps, its accompanying timeless freedom or temporal time and temporal nondeterminate freedom. It is not one that need be left merely theoretical, however, as the impact and consequences of their ideas can be traceably worked out in both a variety of disciplines as well as within theology. This allows one to a posteriori explore the issue, rather than leaving it merely an abstract hypothetical question. This does not mean a resolution is simple to achieve, but that there is more research that can be undertaken to obtain more knowledge about the concepts.

Lastly, sixth, this study brings to clearer light several issues pertaining to freedom and time that some theologians and theistic scientists are simply unaware of or passively ignoring. Many do 
operate, consciously or unconsciously, within a 'bubble.' This state of things cannot continue, or their respective contributions will slide into irrelevancy on one side or contribute unknowingly or unnecessarily toward a deepening of the polarization. The reality is, many biblical interpreters simply ignore the debates between science and religion, but if the philosophical issues undergirding both disciplines and discussions are in fact rooted in common concepts, then greater interdisciplinary efforts should be pursued to fully appreciate and critique the impact philosophy has upon both theology and science. ${ }^{1443}$ Biblical exegesis is directly impacted by the clash of the two philosophical cultures, yet many theologians remain unaware of the depth and significance of this reality. ${ }^{1444}$ Our ability, as theologians, to navigate the issues and questions facing the $21^{\text {st }}$ century requires we engage this conflict intelligently, and in this we can learn from both Bohm and Pylkkö, as well as others who have advanced similar approaches, such as Theodore Kisiel and Charles Peirce. ${ }^{145}$ This may alter

\footnotetext{
1443 "The hermeneutical in general pertains to the process of exposing hidden meanings. The exegesis of Biblical and classical texts, the interpretation of the human actions that constitute history, understanding a poem .... reading the historical signs of the times-all of these aporetic situations have variously been regarded under the purview of a hermeneutic. But Heidegger goes further and holds that man's existence in the aporia of Being is hermeneutical through and through. By implication, he thereby rejects the view which restricts the hermeneutical approach to the humanities and excludes the natural sciences. That the hermeneutical also has a bearing on the natural sciences is corroborated by Polanyi, when he affirms the indeterminate number of possibilities latent in the reading of scientific theories, much like the texts that over the centuries have come to be known as classical," Kisiel, "Scientific Discovery," 48.

1444 "Language sustains and conveys the dynamics of ... transmission through its own subliminal historicity, according to which words used in varying historical contexts yield new and unforeseen possibilities of meaning. Language is tacit both in its use, where-like a tool in its unobtrusive service-we tend to overlook words in favor of their subject matter, and in the way it reveals this subject matter, where what is said is pregnant with an indeterminate wealth of the unsaid. As a tacit means of relating to a tacit reality, language thus involves a double withdrawal.... Basically, we don't control language as we do a tool, we dwell in it as in the fabric of our Being. Before it is conventional and instrumental and thereby under human control, language belongs to the situation which it reveals-receiving its determinations from what it discloses, from the world which it articulates. It is through this transparent medium that we discover our world and, at times, can breach its horizon to glimpse the ineffable domain which addresses us through it," Kisiel, "Scientific Discovery," 50.

${ }^{1445}$ See, for example, Peter Ochs, Peirce, Pragmatism and the Logic of Scripture (Cambridge, UK: Cambridge University Press, 1998). As Kisiel explains, rather than remain wedded to specific paradigms for doing academic work, we may need to practice abduction or "retroduction," Charles S. Peirce's names "for the logic of discovery," which operate "somewhere in between induction and deduction, alternately moving from parts to whole and from whole to parts. The resulting global vision is not an inductive summary of the particulars, but is only suggested by them. Their essential structure must be read from the nuanced hints which they offer. These clues occur in a larger context which permits them to be recognized as clues calling for a certain direction of interpretation. By interpreting the clues which emerge from it, this larger context of our world of presuppositions is what we really interpret or expose. What we ultimately interpret are not facts, for facts are never isolated and independent of their context. Or if you want, it is a world fact, a field, rather than an atomic fact which is being interpreted. And since the context from which clues emerge is fundamentally ontological, it follows that interpretation is not merely an arbitrary subjective procedure of fabricating intellectual constructions and imposing them on the data, as modern epistemology by and large asserted. Interpretation moves in a circle which is guided by the hermeneutical character of the ontological dimension in
} 
how we relate to many past paradigms, especially in science, the arena which Bohm and Pylkkö have exposed as far more vibrant and open for philosophical reflection than has generally been previously realized. ${ }^{1446}$ Obviously, given the attention to the subject matter in the present study, it would seem that there is value to critically engaging the more dominant culture, particularly in the academy, which is that of the sciences. ${ }^{1447}$ The dominance of 'science' as such must always be critically addressed, especially by those from within the discipline of theology. ${ }^{1448}$ Yet, at the same time, the 'science' of today is immensely complex, and the work of physicists and philosophers like Bohm and Pylkkö make this abundantly clear.

which it occurs," Kisiel, "Scientific Discovery," 52. See also, Peckham, Canonical Theology, 212-220, 257.

${ }^{1446}$ An adulation of Isaac Newton went as follows, "Nature and Nature's laws lay hid in night-God said, 'let Newton be,' and all was light." To which "Heidegger, in one of his more poetic and Heraclitean moods, might reply: But Nature loves to hide from light-So let concealment be and guard the night." Kisiel adds, this "does not mean, as is commonly charged, a surrender to the occult and mystical, but rather a receptivity that looks beyond all that has already been discovered toward the inexhaustible source that promises further discoveries now unforeseeable and even unthinkable. The great Newton himself was not a stranger to this attitude: 'I do not know what I may appear to the world, but to myself I seem to have been only like a boy playing on the seashore, and diverting myself in now and then finding a smoother pebble or a prettier shell than ordinary, whilst the great ocean of truth lay all undiscovered before me," Kisiel, "Scientific Discovery," 56. Concurring with Kisiel's comment on Newton is Ellen G. White, Education (1903), 133-134.

1447 "When it comes to science, it seems that we are not too far from recent excesses of the cult of the hero. Recall the idolization and even superstition that followed upon the phenomenon of Einstein. The press flocked to him for comments on all and sundry subjects, as one consults an oracle. He was a superman, a thaumaturgist, and perhaps more-'the consecrated place, the tabernacle of some supernatural operation.' Even his body must have been different from ours, so that a study of the neural energy and subtle circuits of his brain might give us some glimpse of the secret of the sixth sense which evoked the beatific vision of relativity," Kisiel, "Scientific Discovery," 56.

1448 "Science has lately developed highly speculative formulas whose ultimate meaning and relation to reality are difficult to fathom. That such formulations, which at times even defy common sense, are yet capable of changing the world has aroused a cult of superstition and idolization beyond reasonable bounds....

Evidently an age that can no longer point to a Universal Reason as the source of human insight must still have its miracle workers.

"Einstein himself was the last of the classical scientific rationalists.... Bergson once suggested to Einstein that scientific time and simultaneity need not contradict the common experience of time and simultaneity, but in fact presuppose this experience as a prescientific evidence out of which physics formulates its more special truth. Einstein admitted that the time we experience is the starting point for our ideas on time, but this holds only for each of us individually and hence is but a limited 'psychological' experience without ontological validity and universal value. Science alone gives the truth about time. There is no other reason but the physicist's," Theodore J. Kisiel, "Merleau-Ponty on Philosophy and Science," in Phenomenology and the Natural Sciences: Essays and Translations, ed. Joseph J. Kockelmans (Evanston, IL: Northwestern University Press, 1970), 254. This stubbornness by the Einsteinian physicist will remain a challenge for theology-for, if he were right, then biblical theology has been displaced. If he is wrong, we may still learn from him, but biblical theology still retains its own inner vibrancy. 


\section{Suggestions for Further Research}

The greatest lacuna that this study leaves open for future research concerns specifically how a more advanced applications of the research of Bohm and Pylkkö might productively engage the range of theological issues mentioned in chapter 5 , in particular, the theological issues directly addressing biblical concepts, such as with soteriology and the Sanctuary. In like manner, how the work of Bohm and Pylkkö would interact with the concepts of freedom and time in a variety of world religions and their corresponding sacred writings would reveal much about the likely debates concerning freedom and time the world will face in the near future. If notable similarities and differences were identified in such a study, it might point toward some predictable patterns we could expect to see develop. Yet, while such research would probably prove illuminating, it is also important to acknowledge the reality that careful scholarship and study do not dictate what people will actually believe-freedom and time, at least as construed through the work of Bohm and Pylkkö, are not merely theoretical concepts, but ideas that dominate the life of the individual and the lives of people groups in ways that are highly charged with personal and corporate identities, and are, inevitably so it seems, difficult to predict with precision. On that note, and given that this may be true, it could prove helpful to observe that for both Bohm and Pylkkö personally, persuasion is regarded as the best way to move humanity forward toward freedom in time.

Beyond the above, however, this study would recommend that continued efforts be advanced in the physics community to continue their evolving 'best understanding' of the actual nature of the physical world. It is, after all, such studies and discoveries that motivated Bohm and Pylkkö in the first place. Several physicists, many of whom have been noted above throughout the study, are undertaking this goal, and their results could further define the value of Bohm's and Pylkkö's work, and thus the usefulness of this study. This is, of course, a critical area of significance for any endeavor to further unite the disparate disciplines-the two cultures of the sciences and humanities-as they are presently constructed.

Additionally, one major point of emphasis in future work could be to further refine and define the significance of the distinctions between 'moral' and 'existential' freedom. In neither of the above 
authors is this distinction clearly articulated, although one could infer its potential presence in all of their work. However, at times the two concepts seem to overlap in Bohm's and Pylkkö's writings, or have their full significance reduced, at least when contrasted with their presence in the history of theological reflection. From a biblical perspective, the concept of morality may prove significantly more important and complex, even as the biblical testimony on existential freedom may lack some of the diversity of discussion that has taken place within the history of philosophical reflection. In like manner to the above, it seems that science and philosophy reveal the possibility of distinguishing different kinds or orders of time-from the physical, to the personal-existential, to the moral, to the social-and all these kinds of times, so distinguished, may prove worthy of further study and articulation in relation to what Bohm and Pylkkö have done. 


\section{APPENDIX A: THE ORIGINS OF FREEDOM AND TIME}

The study above provided an overview of the situation concerning freedom and time in the two cultures and mediatorial third culture disciplines. Below I will trace the Western origins behind the above situation to uncover whether or not the problem revealed between the two culture is a recent problem, or a relatively new one. In turn, I will examine the development of the origins behind the concepts of freedom and time to provide additional background for the epoch-defining conceptions of them introduced above by Einstein and Bohm, and Heidegger and Pylkkö, in chapters 3 and 4, respectively.

\section{The Origins of the Concepts of Freedom and Time}

The purpose of briefly exploring the origins of the concepts of freedom and time is to expose whether or not the tensions revealed in the study above were present at the conception of philosophical reflection about them in the Western tradition. In other words, although the recent manifestation of the two cultures can be, in some ways, described as a contemporary problem with a recent history, this study wishes to establish that perhaps problems underlying the contemporary development of the two cultures reflect a more deeply historically rooted phenomena of contention. Demonstrating that this may be the case will help situate the contexts within which Bohm and Pylkkö operate, and legitimate the crisis driving the innovative approaches they attempt to articulate as solutions.

Below I will share a chronological presentation of the major figures who addressed the issues of freedom and time during the dawn of Western history, aiming to chart their potential or direct influences upon one another and following generations. Of course, some figures emphasize either freedom or time more extensively or exclusively, as will be noted. Indeed, it is important to keep in

mind that freedom and time were usually discussed separately in the ancient history. The depth of their interrelatedness is a "discovery" of relatively recent times, and one that has been only slowly 
worked out. ${ }^{1449}$ Also, time received much more explicit attention in ancient philosophy, and thus it is with time where I will begin my review. It is also not my intent to focus on every individual who addressed the issues, rather, in particular, to focus on tracing out any changes that were introduced into the concepts. This means some more prominent figures in theological or philosophical history, even if they addressed freedom and time, may be passed by briefly, or even ignored, in favor of those originating new wrinkles into the concepts. Simply too many people have weighed in on the concepts to cover them all. My approach here is to trace the development of the ideas 'in themselves over chronological time,' rather than to provide a full historical presentation of the ideas.

I have focused my chronological presentation on Western figures, with merely a few comments on Eastern (primarily Asian) figures where appropriate. Although other perspectives could be included, particularly for the concept of time, such as the ancient Egyptian, African, Babylonian, or Mayan cultures, which all developed sophisticated calendars based upon astronomy and cyclical seasonal patterns, ${ }^{1450}$ it was the ancient Greeks who first developed sophisticated "philosophies of space and time," ${ }^{\prime 451}$ and it is them upon whom the credit for Western civilization is frequently attributed, including for theories of political freedom. ${ }^{1452}$ Thus, it is with the Greeks where I will begin, leaving some other cultures somewhat neglected, though I will still include them within footnotes where relevant. For example, it is worth noting from the outset that Asian history parallels the Western heritage that dominates the academic world today, in that Asian history explicitly reflects a conscious awareness of the "two cultures" phenomena, ${ }^{1453}$ thus presenting an opportunity

${ }^{1449}$ Bouton, Time and Freedom, 14-15.

${ }^{1450}$ Jonathan Raper, Multidimensional Geographic Information Science (New York, NY: Taylor \& Francis, 2005), 85. Raper notes that virtually "all these early systems of time were cyclical" patterns in nature and "temporal," and functioned to organize society. "The interest in time led to the study of natural cycles such as the tides, the phases of the moon and the movement of the star constellations," ibid. These cyclical views of time are presumed to have dominated the earliest reflections on time owing to basic observations from astronomy and natural seasonal patterns.

${ }^{1451}$ Raper, Multidimensional Geographic Information Science, 85.

${ }^{1452}$ Charles M. Sherover, ed. The Development of the Democratic Idea: Readings from Pericles to the Present (New York, NY: Washington Square Press, 1974), xii, 1.

${ }^{1453}$ See, for example, Yung Sik Kim, Questioning Science in East Asian Contexts: Essays on Science, Confucianism, and the Comparative History of Science (Leiden, The Netherlands: Koninklijke Brill, 2014), esp. 1334, 131-158. 
for a fruitful contrast on some other occasion with the Western intellectual tradition within which the present study is primarily conducted.

The Origin of Time in Western Philosophy and Theology

In this section I will proceed to briefly highlight the early developments within the Western tradition concerning the concept of time. The rationale behind the figures that I have selected is to focus upon major developments, not merely further affirmations of previously introduced ideas later in history. What this primarily means is that the early Greeks, namely, Hesiod, Pythagoras, Zeno, Parmenides, Plato, and Aristotle, will receive more attention than Augustine and Aquinas, who essentially integrated and synthesized the preceding individuals' ideas, sometimes agreeing, sometimes disagreeing in the details, but never substantially departing from their earlier forbears. Notably, I will begin with the concept of time, as it received much more explicit treatments in antiquity, and then return and explain how freedom fits into their picture in the following section.

As an additional introductory observation, the role and importance of the ancient Hebraic concept of time should also be included and described in a brief prefatory way, as the Hebrew bible and other extra-biblical Jewish literature should be fully acknowledged as a source of the widely influential Judeo-Christian roots of broader Western civilization. As several have pointed out, the Hebrew Old Testament and Greek era New Testament concepts of time, while not necessarily clear or precise, appear to emphasize a linear or chronological perspective, with an emphasis on the past, present, and future, although in Hebrew such words do not exist as we understand them. ${ }^{1454}$

Yet, this is not to say that time was not also intimately associated with seasonal patterns and the cycles of the heavens or on other opportunistic events or "realistic" time; it appears to function in both a chronological and cyclical way, and this without even entering upon a discussion of the concept of eternity. ${ }^{1455}$ Indeed, in various other extra-biblical sources, it is "process" more than time

\footnotetext{
${ }^{1454}$ Cary Stacy Smith and Li-Ching Hung, "Bible and Time," in Encyclopedia of Time: Science, Philosophy, Theology, \& Culture, ed. H. James Birx (Thousand Oaks, CA: SAGE Publications, 2009), 87.

${ }^{1455}$ Note the classic work of James Barr, Biblical Words for Time $2^{\text {nd }}$ ed. (Eugene, OR: Wipf \& Stock, 2009, 1962); and Winfried Vogel, The Cultic Motif in the Book of Daniel (New York, NY: Peter Lang, 2010), 111112. See also, Thomas McEvilley, The Shape of Ancient Thought: Comparative Studies in Greek and Indian
} 
itself that appears to be the focus on the Jewish mind, and the concept of time as a continuum-of time or for chronological purposes appears absent. ${ }^{1456}$ Notwithstanding this tension, any concept of time is also profoundly impacted by God's activity and the concept of predictive prophecy and the eschaton, which distinguishes it from most other conceptions of time. ${ }^{1457}$ Of course, reconciling predictive prophecy with human freedom is one of the tensions that has helped produce and replicate the problem of the two cultures throughout history, encouraging the notion that God is "timeless" while the creation and creatures alone are "temporal." In any case, the Hebrews, as well as other cultures, like the Filipinos, ${ }^{1458}$ appeared to see time in a more "qualitative" way ${ }^{1459}$ rather than the generally "quantitative" way of the Greeks, as will be demonstrated below. Most importantly, however, the Bible speaks of two major events that dominate how "time" functions, and these events are the first

Philosophies (New York, NY: Allworth Press, 2012), 69. McEvilley summarizes by sharing that a "circular view of time is part of the shape of ancient thought and one of the major differences between ancient and modern attitudes. Most Indian and Greek philosophers taught such a view. In the early stages of the Greek tradition, versions of it are either found in the works of or attributed to Hesiod, Pythagoras, Anaximander, Anaximenes, Heraclitus, Diogenes of Apollonia, Xenophanes, and Plato-not to mention later schools like the Stoics. In India, it was the standard view of Hindu, Buddhist, and Jain philosophers. It was the most widespread, indeed the normal or ordinary, view of time among ancient philosophers in both Greece and India.

Judeo-Christian-Islamic tradition has featured a linear view of time: While the seasonal cyclicity of the fertility calendar is echoed in the recurrence of holy days, time overall is conceived as a straight-line segment which began at a certain time (Creation) and will end at a certain time (the Last Judgment). This view of time seems to have originated with Zoroaster and has since come to dominate the three western religions whose view of time grew essentially from Zoroastrian origins: Judaism, Christianity, and Islam. In the secularized West, a linear view still holds-usually as an expression of the idea of ongoing scientific progress-but without clear enunciation of its beginning and end," ibid. What McEvilley misses, however, is that Heidegger would critique both these views of time, the cyclical and the linear, as timeless, and McEvilley also here fails to introduce the dualism between Christian and Islamic views of time and a (timeless?) eternity. Also, it is questionable whether one should combine or keep separate the historic Jewish and Christian views of time from the biblical view of time.

${ }^{1456}$ Sacha Stern, Time and Process in Ancient Judaism (Littman Library of Jewish Civilization, 2003).

${ }^{1457}$ Vogel, The Cultic Motif in the Book of Daniel, 112.

${ }^{1458}$ Manuel B. Dy, Jr., Philosophy of Man: Selected Readings $2^{\text {nd }}$ ed. (Makati City, Philippines: Goodwill Trading, 2001), 110. "While the Westerner marks time with a calendar or a watch, the Semite marks time in his consciousness," and "the Hebrew concept of human time also holds true for the Filipino concept of time," ibid.

${ }^{1459}$ It has been claimed that "the BH [Biblical Hebrew] verbal system is tenseless and aspectual-as has been repeated so often ever since the end of the nineteenth century-it is because 'while for us [Indo-Europeans] actions are oriented objectively, impersonally, and spatially, the Hebrews think subjectively, personally, and temporally,"' whatever that means," Tal Goldfajn, Word Order and Time in Biblical Hebrew Narrative (Oxford, UK: Clarendon Press, 1998), 10. Note also the assessments by George E. Thompson, God Is Not Fair, Thank God!:

Biblical Paradox in the Life and Worship of the Parish (Eugene, OR: Resource Publications, Wipf and Stock, 2014), 177; and Brevard Childs, Myth and Reality in the Old Testament (Eugene, OR: Wipf \& Stock, 1962), 76. 
coming of Christ (messianism) ${ }^{1460}$ and the second coming of Christ (the eschaton and parousia). ${ }^{1461}$

Both of these "temporal" events are transformationally temporal, altering the identity, purpose, and

situation of God's people in ways that are highly significant and intensely disputed. As such, the Bible

offers plenty of source material for a much richer discussion on freedom and time than can be offered

here.

However, there is a more precise point to be made here in our introduction to the biblical concept(s) of time: It appears, in most commentaries, to merely encompass the range of possibilities that philosophy has independently discovered. That is, the same tensions that exist between the two cultures concerning time appear innately grounded in the most authoritative scholarly interpreters of the Scriptural concept of time. ${ }^{1462}$ Put simply, it appears Scripture does not, or, wishes not, to answer the question of time in a technical way ${ }^{1463}$ amenable to the Western tradition, and to seek any such interpretation about time absent philosophical analysis or reflection leaves open the possibility that one is still employing presuppositions uncritically concerning the nature of the language employed in interpretations of Scripture, especially as it pertains to time.

${ }^{1460}$ For example, see Michael Walzer, In God's Shadow: Politics in the Hebrew Bible (London, UK: Yale University Press, 2012), 169-171.

${ }^{1461}$ Wilkinson, Christian Eschatology and the Physical Universe, 108-111. Wilkinson observes that many "systematicians ... devalue the importance of time," but Scripture encourages no such devalued readings. Rather, he believes we should "maintain the interdependency but also see the space-time distinctiveness of particular actions of God in specific events." Thus, one can "see ... that time is a much richer concept than simple [i.e., timeless] models would indicate," ibid., 108 (addition mine).

1462 This is the conclusion of DeWeese in his survey of Scripture in God and the Nature of Time, 109. "Attempts to drive 'the' biblical view of time from the vocabulary or the text of the Bible are doomed from the outset," ibid. James Barr concurs, "if such a thing as a Christian doctrine of time has to be developed, the work of discussing and developing it must belong not to biblical but to philosophical theology," Barr, Biblical Words for Time, 156. Of course, this is not to say that the Bible should be subjugated to philosophy, but, merely that, at the foundational level of these philosophical concepts, Scripture cannot be said to provide adequate information alone outside of a hermeneutical circle with nature, reason, and philology to provide a complete statement on these concepts, if such a thing even exists.

1463 "Although it may seem to us modern Westerners that Hebrew had an inadequate vocabulary for the expression of its historical consciousness, this may be attributed to the lack of a desire to express temporality with absolute preciseness," John R. Wilch, Time and Event: An Exegetical Study of the Use of "ēth in the Old Testament in Comparison to Other Temporal Expressions in Clarification of the Concept of Time (Leiden, The Netherlands: E. J. Brill, 1969), 103. See also, Barr, Biblical Words for Time, 14. "We should do well to remember that we do no honour to the Bible by wringing from its words answers to questions which were not in fact in the minds of those who used these words, and that by so doing we may only obscure the undivided attention with which the biblical writers concentrated upon their own themes," ibid. 


\section{The Origin of the Concept of Time in Ancient Greece and the West}

In turning toward the Greeks, first, it is noteworthy that insofar as what scholarship has

uncovered, "in the history of language, words for time are long preceded by words for past, present, and future, and the theoretical concept of time makes a relatively late appearance."1464 Furthermore, although many, such as the theologian Fernando Canale, ${ }^{1465}$ have traced the first explicit reflections on time in relation to the concept of "Being" to the Greek philosopher Parmenides (c. 515 B.C.- ?), and there is no doubt that Parmenides' reflections, alongside that of Heraclitus (c. 535-475 B.C.) were influential and significant, ${ }^{1466} \mathrm{I}$ believe it is more accurate to trace the origins of reflections on time earlier than Parmenides and his contemporary Heraclitus, even while remaining within the ancient Greek context. ${ }^{1467}$

Indeed, "the earliest work to develop an explicit conception of space and time may have been Hesiod's mythological and philosophical treatise 'Theogony' dating from the $7^{\text {th }}$ century BC." ${ }^{1468}$ In this complex and much disputed (and evolving ${ }^{1469}$ ) mythological account concerning the origin or

\footnotetext{
${ }^{1464}$ Jon E. Roeckelein, "Early Greek and Later Philosophical Theories of Time," in Elsevier's Dictionary of Psychological Theories, ed. Jon E. Roeckelein (Boston, MA: Elsevier, 2006), 176.

${ }^{1465}$ See Canale, A Criticism of Theological Reason: Time and Timelessness as Primordial Presuppositions, 76-84.

${ }^{1466}$ Adam Frank, About Time: From Sun Dials to Quantum Clocks, How the Cosmos Shapes our Lives - and We Shape the Cosmos (London, UK: Oneworld Publications, 2012), 51. "The themes of Heraclitus and Parmenides would reverberate across millennia to our own time.... There is a constancy in the questions humans ask about the universe and there is change in the answers that dominate one culture or another as the centuries pass. Understanding this balance is critical," ibid.

${ }^{1467}$ As Panagiōtēs Tzamalikos reminds us, "despite erroneous claims for the contrary, the Greeks did employ time, along with space, as a frame for their thought-form.... [M]any ancient Greeks provided their accounts of the question of time, expressed in terms of problems of beginning, becoming, enduring and ceasing," in Panagiōtēs Tzamalikos, Origen: Cosmology and Ontology of Time (Leiden, The Netherlands, Koninklijke Brill, 2006), 180.

${ }^{1468}$ Raper, Multidimensional Geographic Information Science, 86. See also, Tzamalikos, Origen: Cosmology and Ontology of Time, 180. For a translation of Hesiod's Theogony, see Hesiod, Theogony and Works and Days, tr. and ed. Catherine M. Schlegel and Henry Weinfield (Ann Arbor, MI: The University of Michigan Press, 2006), 21-54. For an alternate introductions and translations, see Hesiod, Works and Days and Theogony, tr. Stanley Lombardo, with Robert Lamberton (Indianapolis, IN: Hackett Publishing, 1993); Hesiod, Theogony \& Works and Days, tr. and ed. Stephanie Nelson and Richard Caldwell (Indianapolis, IN: Hackett Publishing, 2009), 1-20; and Hesiod, Hesiod's Calendar: A Version of Hesiod's Theogony and Works and Days, tr. Robert Saxton (Manchester, UK: Carcanet, 2010).

${ }^{1469}$ As the centuries passed, modifications to Hesiod's work were sometimes made. Note Stephen Scully, Hesiod's Theogony: From Near Eastern Creation Myths to Paradise Lost (Oxford, UK: Oxford University press, 2015); and Fritz Graf, Greek Mythology: An Introduction, tr. Thomas Marier (Baltimore, MD: The Johns Hopkins University Press, 1996), esp. 79-100, 196.
} 
descent of the Greek gods, the natures of "space and time" "can be described in general terms as a progression of the world from Chaos to Cosmos." ${ }^{1470}$ In many interpretations of the Theogony, "time is considered so important that it is personified, along with Earth as a god. Gaia (Earth) appears and eventually gives birth to Kronos (Father Time)."1471 In other words, "the world emerges from a state of 'chaos' (a timeless and spaceless state) into 'chronos' (ordered time) when 'gaia' (the earth) appears."1472 However, some have suggested that "chaos is associated with a 'higher' linear time while chronos is associated with 'cyclic' time,"1473 suggesting some sort of tension in how time, and space, were conceived. What is also noteworthy is that "subsequent cosmogonical and cosmological speculation [after Hesiod] followed two separate paths. One was that of mythological poetry, the other that of philosophical reflection-in short, Orphism and Presocratic philosophy"1474 (Orpheus was seemingly a mythical poet ${ }^{1475}$ believed to exist prior to the $6^{\text {th }}$ century B.C.). One might, then,

\footnotetext{
${ }^{1470}$ Donna J. Peuquet, Representations of Space and Time (New York, NY: The Guilford Press, 2002), 13.

${ }^{1471}$ Peuquet, Representations of Space and Time, 13. See also the essays in G. R. Boys-Stones and J. H. Haubold, eds. Plato and Hesiod (Oxford, UK: Oxford University Press, 2010).

${ }^{1472}$ Raper, Multidimensional Geographic Information Science, 86. Concurring is Kathryn Stoddard, The Narrative Voice in the Theogony of Hesiod (Boston, MA: Brill, 2004), 139. "While the Titanomachy is ... an event that occured on the divine level and has little to do with mortals or mortal time, it consists of a series of actions that must be put into some kind of (chrono)logical order if they are to be comprehensible to a human audience. Hesiod ... narrated the Titanomachy as if it had a beginning, a middle, and an end-i.e. as if it had taken place in mortal time. Once he moves to the Tartarus section, however, Hesiod can make a dramatic shift from a temporal environment in which one event follows another to a dimension in which time and space are not wholly distinct from each other. Our perception of 'normal' (i.e. terrestrial) temporal progression becomes blurred as we enter the realm of timeless time that is the mirror opposite of the timeless dimension that the Muses, descending from Helicon, lately quit.

"In an interesting doublet to the space/time confusion invoked by the anvil that falls from earth to Tartarus, the Muses' parallel journey form the realm of the gods to earth is marked, as I observe above, by a word that denotes space rather than time. Instead of making the transition from the Muses' timeless dance on Helicon (2-8) to their katabasis (9-21) by telling us that they 'once' came down to meet Hesiod, the narrator declares that they came down 'from there' ( $\check{\varepsilon} v \theta \varepsilon v 9)$. The narrator further obscures the temporal environment of this passage by telling us that the goddesses 'were traveling' ( $\sigma \tau \varepsilon \hat{x} \chi 0 v$ ), the temporally noncommittal imperfect being used instead of a past-aspect-insistent aorist. The notion of time does not make an appearance

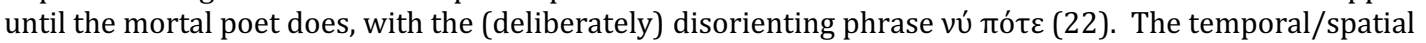
confusion that introduces the Tartarus passage [is] thus comparable to the ambiguity that accompanies the Muses' descent from 'divine' Helicon to terrestrial Helicon. In these parallel moments of transition we are made aware that we are crossing not only a boundary of physical space, but traveling from one dimension to another," ibid. Hesiod presents "time in the underworld as if it had physical form and substance," ibid., 140.

${ }^{1473}$ Raper, Multidimensional Geographic Information Science, 86. See also, Murad Davudovich Akhundov, Conceptions of Space and Time (Cambridge, MA: Massachusetts Institute of Technology Press, 1986), $55-60$.

${ }^{1474}$ Graf, Greek Mythology: An Introduction, 96.

${ }^{1475}$ Radcliffe G. Edmonds III, Redefining Ancient Orphism: A Study in Greek Religion (Cambridge, UK: Cambridge University Press, 2013), 3-4. Edmonds concludes, "there is no Orpheus to whom we can look; only the name of Orpheus," ibid., 4. "The people of the ancient Greco-Roman world attributed to the mythical poet
} 
accurately trace the beginnings of the "two cultures"1476 to the very dawn of Greek thought, and both streams of thinking also later permeated throughout early Hellenized Christian reflections. ${ }^{1477}$

Of course, some have pointed out that ancient Egyptian culture, saturated with myth and stories of deities, seems to have strongly influenced the development of Greek Orphism, or the belief in the divine realm, including the idea of the transmigration of souls through reincarnation alongside related ideas. ${ }^{1478}$ Such possibilities suggest that the Greeks may not have been as original, in some ways, as is sometimes supposed. In any case, again, the point to be emphasized from the above is that it appears the interrelationship of space and time, and the tension between the timeless and temporal, occurs virtually immediately at the dawn of Greek thought, and, as will be uncovered below, this tension persisted.

Two other key early figures must be singled out before returning to Parmenides and Heraclitus, the more widely acknowledged Greek philosophical fathers of time. And these two figures are

Orpheus a number of poems," evidently granting him some "semi-divine background," ibid.

${ }^{1476}$ I would suggest this loose connection fits surprisingly well, concurring with Radcliffe Edmond's definition of orphism that characterizes it as "extra-ordinary religious phenomena," thus placing itself outside common-sense notions of "science" and thus also outside both rationalism and empiricism. This is the same accusation that Heidegger, and many religious figures, have faced. See Edmonds III, Redefining Ancient Orphism: A Study in Greek Religion, 7.

${ }^{1477}$ As noted by Miguel Herrero de Jáuregui, Orphism and Christianity in Late Antiquity (Berlin, Germany: Walter de Gruyter, 2010). Jáuregui asserts that "modern interest in the Orphic tradition arose from the perception of its similarities with Christianity, and this is still one of the main reasons for the curiosity that Orphism arouses among scholars of ancient religion. Both are deeply asymmetrical entities that, however, share some apparently common elements, particularly appealing for the contrast these offer with the conventional image of Greek religion. The survival of the soul after death and its reward or punishment in the next world," for example, as well as "an original state of moral impurity from which only believers are purified" and the possibility of "an individual and intimate relation with divinity" and "the possibility of passing beyond the border between the human and the divine," ibid., 1. Concerning their broader historical connections, some have seen "in Orphism a process whereby the Greek spirit was being prepared for the reception of the greater Christian truth to come. Alternatively, others saw it as the seed of a Hellenistic spiritual decadence, which would lead eventually to the final disappearance of the Classical spirit. Yet others envisioned it as a kind of Protestant reform of traditional Dionysiac worship. All of these interpretations are informed by the underlying idea that Orphism is a forerunner of Christianity in the Greek world," ibid., 2. The danger is that "it is only a small step, and one very easy to take, from postulating spiritual precedence to supposing historical dependence. Here the study of Orphism is framed within a broader intellectual fashion, the comparison of Christianity with ancient mystery cults," ibid. This step was often taken by earlier scholars, as "the overwhelming presence of Greek philosophy in the formation of Christian dogma made it appear logical to posit similar processes with regard to ritual and religious experience," ibid.

${ }^{1478}$ Wim van den Dungen, "The Impact of Ancient Egypt on Greek Philosophy against Hellenocentrism, against Afrocentrism in Defence of the Greek Miracle," at http://www.maat.sofiatopia.org/hermes1.htm (accessed January 17, 2017). See also, Edmonds, Redefining Ancient Orphism: A Study in Greek Religion, 13, 17, 52 . 
Anaximander (c. 610-546 B.C.) and Pythagoras (very little is known about him or his work directly, but what is attributed to him is very significant ${ }^{1479}$ ), born c. 570 B.C. The first, Anaximander, formally introduced the concept of apeiron, meaning the 'unbounded' or 'infinite', into philosophy, as well as probably the first technical use of arché as a primordial origin point or ground. ${ }^{1480}$ These concepts relate integrally to time, as the "ultimate origin" of all things in a causal chain are located in the apeiron, which is everlasting and ageless, and thus essentially divine for Anaximander. ${ }^{1481}$ Also noteworthy is that according to Adam Drozdek, Anaximander subjugates physics to theology, by saying that the participation of nature in the divine is evident when things pass away, that is, dissolve back into the apeiron. "Destruction thus amounts to divinization of sorts."1482 Importantly, the universe created from the "stuffs" of apeiron are "limited in time and space, but the matrix of the universe, the Apeiron itself, is unlimited both spatially and temporally. The Apeiron always existed and always will exist; it is everywhere outside the heavens. The Apeiron is thus very firmly seated in the spatio-temporal framework," because "the Apeiron encompasses everything" which "means that it is outside the fiery wheels of the heavens and extends infinitely in space." ${ }^{1483}$ In summary, the concept of apeiron appears somewhat analogous to Being and god, and introduces the significance of the concept of infinity into both theology and time.

The second figure, Pythagoras, is particularly significant. The eminent philosopher Bertrand Russell stated that "I do not know of any other man who has been as influential as he was in the sphere of thought. I say this because what appears as Platonism is, when analyzed, found to be in

\footnotetext{
${ }^{1479}$ Kahn, Pythagoras and the Pythagoreans: A Brief History, 5. For more biographical information about Pythagoras, see Christiane L. Joost-Gaugier, Measuring Heaven: Pythagoras and His Influence on Thought and Art in Antiquity and the Middle Ages (Ithaca, NY: Cornell University Press, 2006).

${ }^{1480}$ Adam Drozdek, Greek Philosophers as Theologians: The Divine Arche (New York, NY: Routledge, 2016), 8-9. See also, Robert J. Roecklein, Plato versus Parmenides: The Debate over Coming-into-Being in Greek Philosophy (Lanham, MD: Lexington Books, 2011), 45-46; and Karl Popper, The World of Parmenides: Essays on the Presocratic Enlightenment, ed. Arne F. Petersen (New York, NY: Routledge, 1998), 36-39.

${ }^{1481}$ Drozdek, Greek Philosophers as Theologians: The Divine Arche, 9.

1482 Drozdek, Greek Philosophers as Theologians: The Divine Arche, 12.

${ }^{1483}$ Drozdek, Greek Philosophers as Theologians: The Divine Arche, 9.
} 
essence Pythagoreanism." ${ }^{1484}$ Again, whether or how precisely the man called Pythagoras or his followers created the movement after his namesake is inconsequential, what is attributed to him by reasonably early sources is what matters at present. The key to understanding the contributions of Pythagoras derive from his modern namesake in mathematics and geometry, the Pythagorean theorem, ${ }^{1485}$ for which it must be noted that his insights into the value of numbers has indeed provided the background for many advances in mathematics, music theory, and other areas of modern science. It is to his name that we may first attribute the idea of a "mathematical conception of the cosmos." ${ }^{1486}$ The present purpose, however, is to highlight the fact that it appears Pythagoras elevated "numbers" into a high status for philosophy, not merely "science" in our more modern conception of the word. ${ }^{1487}$ "Pythagoras attributed divinity to [the] One, because the One seemed to him to have inexhaustible power and was therefore like the Infinite and Indeterminate of Anaximander, and because the One was also the source of all determination and limitation.... It is easy enough for us to understand how Pythagoras arrived at the conclusion that the One has divine power over a series of numbers; the One contains in itself both the odd and the even numbers." ${ }^{1488}$ Furthermore, "we can see an analogy between the power of Anaximander's Apeiron over the universe and the power of the divine One over the odd and the even numbers; these numbers are derived from the One, and are 'opposites,' just as the opposites air and fire, day and night, are separated out of the Apeiron." ${ }^{1489}$ As such, it's important to understand that, for Pythagoreans, the "One is not a mere

${ }^{1484}$ Russell, History of Western Philosophy, 37. For concurring views, also see Hersh, What is Mathematics, Really?, 93-95; and Philip Sidney Horky, Plato and Pythagoreanism (Oxford, UK: Oxford University Press, 2016). Horky argues that, contra a few skeptics, Platonists were likely profoundly influenced by 'mathematical Pythagoreanism.'

${ }^{1485}$ There is some debate as to whether the man we assume to be Pythagoras actually first articulated the theorem that bears his name, but this discussion is not germane to the present study. As to the theorem itself, in mathematics, the Pythagorean theorem, also known as Pythagoras's theorem, is a fundamental relation in Euclidean geometry among the three sides of a right triangle. It states that the square of the hypotenuse (the side opposite the right angle) is equal to the sum of the squares of the other two sides.

${ }^{1486}$ Kahn, Pythagoras and the Pythagoreans: A Brief History, 37.

${ }^{1487}$ For an examination of his number theory and its influence, see D. L. Bradley, In the Academy of Plato (Raleigh, NC: Lulu Press, 2015), 113-152.

1488 Roy Kenneth Hack, God in Greek Philosophy to the Time of Socrates (London, UK: Humphrey Milford, 1931), 49.

${ }^{1489}$ Hack, God in Greek Philosophy to the Time of Socrates, 49. 
number; it is an affirmation of divine causal Unity set against the plurality of changing things within the cosmos, ${ }^{1490}$ and thus Pythagoras is explaining his perspective on the philosophical problem of the One and the Many that would concern many later thinkers including Parmenides and Plato, alongside numerous others throughout history.

Of course, within the context of this study, it must be noted that "the Pythagoreans made a serious attempt to deal with the question of time as such." It is "they [who] point out that 'before' and 'after' make sense only in time, whereas eternity is a timeless perpetual 'now',' thus introducing explicit reflections on eternity in contrast to our common sense perceptions. ${ }^{1491}$ On the other hand, the Pythagoreans were also said to "identify the chronological with the logical," which would be in contrast to "Parmenides and Zeno" who "argued that they are incompatible,"1492 as will be seen below. Further complicating their views, the Pythagoreans were also said to be fascinated with the circle, and thought that time should be perceived in a circular way in accord with their observations of celestial bodies. ${ }^{1493}$ Given this, what Pythagoras meant when he asserted that time was the "soul, or procreative element, of the universe,"1494 is likely that time should be seen in a circular way. In any case, there is no doubt that the subject of time interested Pythagoras and his followers, and that their emphasis on numbers (mathematics) had a profound influence on later philosophers. ${ }^{1495}$ Indeed, the subtlety and diversity contained within their early reflections centers upon the combination of their work on time with their reflections on mathematics, which paved the way for all the mathematical

${ }^{1490}$ Hack, God in Greek Philosophy to the Time of Socrates, 50.

1491 Tzamalikos, Origen: Cosmology and Ontology of Time, 180-181.

${ }^{1492}$ G. J. Whitrow, "Reflections on the History of the Concept of Time," in The Study of Time: Proceedings of the First Conference of the International Society for the Study of Time, eds. J. T. Faser, F. C. Haber, and G. H. Müller (New York, NY: Springer-Verlag, 1972), 4.

${ }^{1493}$ See P. E. Ariotti, "The Concept of Time in Western Antiquity," in The Study of Time II: Proceedings of the Second Conference of the International Society for the Study of Time, eds. J. T. Fraser and N. Lawrence (New York, NY: Springer-Verlag, 1975), 72.

${ }^{1494}$ Roeckelein, The Concept of Time in Psychology: A Resource Book and Annotated Bibliography, 21.

1495 Roeckelein, The Concept of Time in Psychology: A Resource Book and Annotated Bibliography, 21. Roeckelein asserts that "while the early Greek philosophers-even Parmenides and Heraclitus-apparently took time for granted, they generated significant questions that involved time. In addition to the concept of change and its influence on the concept of time, it is certain that the speculation of Pythagoras regarding number had a direct formative influence later on Aristotle's philosophy of time, and paradoxical problems such as Zeno's directed philosophical attention critically toward the concept of time," ibid. 
conceptions of time $\mathrm{e}^{1496}$ that followed after them, and which dominated how Plato and Aristotle later addressed the mysteries of time. ${ }^{1497}$ One could probably safely assert that the Pythagoreans originated all the major conceptions of time that would follow alongside mathematical conceptions, particularly the circular and chronological perspectives.

Given all of the above, one can also see how Pythagoras, or Pythagoreanism, to be more precise, represents the first movement toward a formal ontology, that is, the study of reality as such, that would further develop alongside Pythagorean insights with Parmenides and later Plato. Pythagoras was concerned with establishing indisputable or objective truth, ${ }^{1498}$ and he found it in mathematics. ${ }^{1499}$ But any such ontology grounded on the 'timeless' truth of mathematics evidently became quickly integrated with theology. ${ }^{1500}$ In an insightful and penetrating paragraph, Russell

\footnotetext{
${ }^{1496}$ Michael Eldred, "The Digital Cast of Being Metaphysics, Mathematics, Cartesianism, Cybernetics, Capitalism, Communication," at http://www.arte-fact.org/dgtlon_e.html (accessed January 23, 2017).

${ }^{1497}$ Ariotti, "The Concept of Time in Western Antiquity," 72-75.

${ }^{1498}$ One from the sciences is cited here to illustrate how some today respond to his idea. Kardaras, How Plato and Pythagoras Can Save Your Life: The Ancient Greek Prescription for Health and Happiness, 151. Many have surmised that Pythagoras was influenced by Persians, such as Zoroaster. Notably, "Zoroaster saw the human condition as the mental struggle between aša ('truth') and $d r u j$ ('lie'). According to Zoroaster, it was our purpose to sustain $a s ̌ a$ through active participation in life and the exercise of constructive thoughts, words, and deeds. These teachings are believed to have greatly influenced the still-quite-young Pythagoras; indeed, some historians believe that it was Zoroaster who had the greatest influence on Pythagoras's ideas of philosophy as purification," ibid.

${ }^{1499}$ As Aristotle related it, "the so-called Pythagoreans ... believed that the principles of mathematics were peculiar to all the things which exist. And since in mathematics, numbers come first in a natural way (physei), and since they saw in them, rather than in fire, earth or water, many features similar to the things which are and those liable to coming-to-be, they inferred that ... the elements of numbers (stoicheia) were elements of all the things which exist," as cited by Maggi, "Iamblichus on Mathematical Entities," 76. Maggi explains that Aristotle's account represents "the first historical-doxographic acknowledgment of Pythagorean mathematical ontology," and that Aristotle himself "traces Pythagoras' paternity for many Platonic doctrines, thus paving the way for identifying Pythagoreanism with Platonism" and "this identification was to be the key to the Neoplatonic tradition after Plotinus," ibid. As Iamblichus related it, "Pythagoras is said to have been the first to call himself a philosopher, a word which heretofore had not been an appellation, but a description," as cited in Algis Uždavinys, The Golden Chain: An Anthology of Pythagorean and Platonic Philosophy (Bloomington, IN: World Wisdom, 2004), 19. "[Pythagoras] was the first to give a name to philosophy, describing it as a desire for and love of wisdom, which later he defined as the science of objectified truth. Beings he defined as immaterial and eternal natures, alone possessing a power that is efficacious, as are incorporeal essences," ibid., 28. The "first essence is the nature of Number and 'reasons'," ibid., 19. Similarly, Philolaus shared the Pythagorean conviction that "truth is the proper, innate character of Number," ibid., 49.

1500 "At the core of Pythagoras's teaching was an absolute reverence for the purity and perfection of numbers (which he considered divine) and numerical relationships," Nelson, Judaism, Physics and God: Searching for Sacred Metaphors in a Post-Einstein World, 103. This connection also exists, intriguingly, in the apocryphal Book of Wisdom written around 50 B.C. (Wisdom 11:20b, "but thou hast ordered all things in measure and number and weight"). "Since the book describes Jewish doctrine in terms of Hellenistic philosophy, one may assume that its author was familiar with Pythagorean ideas. The Pythagorean-Platonic idea of number and geometry was later combined with biblical tradition and became a part of the spiritual synthesis worked out by
} 
explains the significance of what he sees as Pythagoras' enduring influence concerning both

philosophy and theology:

The combination of mathematics and theology, which began with Pythagoras, characterized religious philosophy in Greece, in the Middle Ages, and in modern times down to Kant. Orphism before Pythagoras was analogous to Asiatic mystery religions. But in Plato, Saint Augustine, Thomas Aquinas, Descartes, Spinoza, and Kant there is an intimate blending of religion and reasoning, of moral aspiration with logical admiration of what is timeless, which comes from Pythagoras, and distinguishes the intellectualized theology of Europe from the more straightforward mysticism of Asia. It is only in quite recent times that it has been possible to say clearly where Pythagoras was wrong.... The whole conception of an eternal world, revealed to the intellect but not to the senses, is derived from him. But for him, Christians would not have thought of Christ as the Word; but for him, theologians would not have sought logical proofs of God and immortality. But in him all this is still implicit. ${ }^{1501}$

Russell continues, adding that "rationalistic as opposed to apocalyptic religion has been, ever since

Pythagoras, and notably ever since Plato, very completely dominated by mathematics and mathematical method,"1502 which remains true within Christianity and many variants of Islamic

the church fathers and the Scholastics as they tried to reconcile the timeless laws of God with the temporal and unpredictable fate of man. Around the end of the fourth century St. Augustine took it for granted that the truths of number are universal and eternal. In On Free Will he remarked that although wisdom may or may not be the same as number, it is clear that both are true and immutably true," Fraser, Time, Conflict, and Human Values, 48.

${ }^{1501}$ Russell, History of Western Philosophy, 37. Russell further explains that "mathematics is, I believe, the chief source of the belief in eternal and exact truth, as well as in a super-sensible intelligible world. Geometry deals with exact circles, but no sensible object is exactly circular; however carefully we may use our compasses, there will be some imperfections and irregularities. This suggests the view that all exact reasoning applies to ideal as opposed to sensible objects; it is natural to go further, and to argue that thought is nobler than sense, and the objects of thought more real than those of sense-perception. Mystical doctrines as to the relation of time to eternity are also reinforced by pure mathematics, for mathematical objects, such as numbers, if real at all, are eternal and not in time. Such eternal objects can be conceived as God's thoughts. Hence Plato's doctrine that God is a geometer," ibid. Again, "Theology, in its exact scholastic forms, takes its style from the same source. Personal religion is derived from ecstasy, theology from mathematics; and both are to be found in Pythagoras," ibid.

${ }^{1502}$ Russell, History of Western Philosophy, 37. It is not insignificant that Pythagoras was one of the earliest philosophers in the Greek tradition known to promote the transmigration and immorality of the soul, and that the timeless world beyond the physical world inspired his ideas. See, Kahn, Pythagoras and the Pythagoreans: A Brief History, 4; and Vamvacas, The Founders of Western Thought-The Presocratics: A Diachronic Parallelism between Presocratic Thought and Philosophy and the Natural Sciences, 58. "In his fundamental teaching concerning the immortality of the soul, Pythagoras brings about a decisive point of departure in the history of western thought.... Pythagoras would be the first in Europe to preach that it is the spirit and not the flesh that is the principle carrier of human existence. Man can be considered a 'microcosm'-a likeness and epitome of the universe, the 'macrocosm'. He is composed of the material body, which is subject to continual change, development and decay, and of the immaterial, ever-moving soul, a mental essence, which has its own existence. The human soul is immortal because it is a portion of the immortal divine essence from which it was detached'.

"For the first time in Greek thought, the soul is viewed as a self-existent entity over against the mortal body, which is considered its ephemeral prison. Soon the meaning of the soul will be identified with the selfawareness of the individual. This significant point marks the origin of the attempt to conceive the spirit as an indestructible entity, which is in diametrical opposition to matter. Worthy of note is the fact that this process of the division between spirit and matter, which will have a catalytic influence on the subsequent development of 
tradition, especially Sufism. ${ }^{1503}$ His observation that apocalyptic religion is in some way antagonistic to rationalistic mathematical reasoning forces one to entertain thoughts that question the role of time and science in relationship to theology today.

The importance of Pythagoras, however interesting it may be in its own right, is also worthy for highlighting the origins of the significance of the two cultures and the explanation of their enduring nature. ${ }^{1504}$ Indeed, some believe, such as Underwood Dudley, that "number mysticism would have appeared even if Pythagoras had never lived. Numbers have power, and they will exert it. As evidence of the power of numbers, notice that there is no such thing as alphabet mysticism even though alphabets go back to before the time of Pythagoras.... The letters of the alphabet are symbols very like the digits of our number system, standing for sound instead of quantity, but they do not

European thought, did not arise out of scientific interest or practical need, but from a deep religious predisposition toward spiritual purification and the soul's assimilation into the divine.

"The soul's existence precedes the body's, and is interred in the body in order to expiate for some undefined sin. The aim of human life is for the soul to return and identify with the ... divine universe, from which it has fallen. This evolutional path of the soul toward the divine is achieved through ascetic life and purification within a series of reincarnations .... The notion of reincarnation is not something new. The new element is the ethical dimension introduced by the Pythagorean teaching," ibid., 58-59.

1503 "The qualitative evaluation of numbers by the Pythagoreans found many supporters in Islam, since the Muslims saw therein a clear expression of the necessities inherent in the concept of God and the cosmos. It should be kept in mind that in such discussions, 'one' is not considered a number, any more than the Lord is thought of as a vassal. But to say one is to say two, three, and so on, ad infinitum, since one is one-half of two, one-third of three, and so forth. The dualities inherent in this approach are fundamental, since they are already implicit in one, the source of number, and explicit in two, the first of the numbers. Two corresponds to the first creation, the prototype of everything in created existence. God is one and only one, but everything other than God is two or more. The Ikhwān al-Safä' make this point succinctly while reminding us of the three Koranic verses that speak of 'two of every kind,' such as God's command to Noah concerning what to place in the Ark: 'Carry in it two of every kind' (Q11:40).

Everything below God is 'two of every kind,' since He is the One, the Unique, the Everlasting, 'who did not give birth and was not born' [Q112:3].

The qualitative relationship between one and the numbers is summarized by the Ikhwān in describing the position of Pythagoras. In brief, since God is one and everything other than God is incomparable with Him, everything else must be two or more. But since all things are also similar to God in some manner, they partake of a certain oneness," Murata, The Tao of Islam: A Sourcebook on Gender Relationships in Islamic, 59.

${ }^{1504}$ Heidegger infamously critiqued essentially all of Western thought as a building up upon the Pythagorean/Platonic rationalist foundation (Greek "metaphysics"), for which "modern science and technology" were "but the culmination and ultimate logical consequence of Platonic rationalism," Madison, Understanding: A Phenomenological-Pragmatic Analysis, 13. Yet, I concur with Madison that "unlike Heidegger ... I do not believe that the history of Western thought is nothing but the history of [Pythagorean/Platonic] rationalism.... Ever since the ancient Greeks, from time to time, people have protested against the dominant presuppositions of our rationalist culture and have sought to expose its underlying prejudices... The entire history of philosophy therefore can be looked upon as being made up of two basic movements. First is the dominant current of rationalism and, within this current, a counter-current, which attempts to bring us back to a more just appreciation of our powers and limits," ibid., 13-14. Madison's comments reflect an awareness of the broader and deeper tension between the "two cultures" that has always existed. 
inspire mystical insights. Numbers do."1505 In other words, there is a latent or implicit universality hidden within mathematics that inspires awe in a unique omni-cultural way. Russell similarly asserted that "the opposition of the rational and the mystical [which can be said to be analogous to the two cultures $\left.{ }^{1506}\right]$, which runs all through history, first appears, among the Greeks, as an opposition between the Olympic gods and those other less civilized gods who had more affinity with the primitive beliefs dealt with by anthropologists. In this division, Pythagoras was on the side of mysticism, though his mysticism was of a peculiarly intellectual sort. He attributed to himself a semidivine character,"1507 and thus in many ways represents the first individual to seek after a "third culture" that harmonizes the sciences and humanities (vis-à-vis mysticism), with a clear favoritism shown toward the rationalism of the mathematical world. ${ }^{1508}$

All of Pythagoras' achievements, debated as they may be, lead directly into the contributions of Parmenides. ${ }^{1509}$ For, as Francis Cornford observed, it is very possible to read the work of "Parmenides, the discoverer of logic," as merely "an offshoot of Pythagoreanism." Moreover, "Plato himself [also found] in Pythagoreanism the chief source of his inspiration.."1510 It is thus a great irony that the origins of mystical religion in the Greek tradition, as well as the forerunner of scientific rationalism, two streams of thought that are now seen to be in competition, can be traced to the same

${ }^{1505}$ Dudley, Numerology: Or, What Pythagoras Wrought, 14-15.

${ }^{1506}$ Recall that Heideggerians sometimes embrace, or are accused of, supporting a "mystical" view of truth. Note Kurtz, Skepticism and Humanism: The New Paradigm, 30.

${ }^{1507}$ Russell, History of Western Philosophy, 32.

${ }^{1508}$ Pythagoreanism asserted that "number and calculation are the ruling force not only in the natural world but also in human relations and morals, and only in so far as they are heeded can society be harmoniously organized," Guthrie, A History of Greek Philosophy: Vol. 1: The Earlier Presocratics and the Pythagoreans, 336.

${ }^{1509}$ Although it may be true that "only one early source gave Parmenides even the remotest link with Pythagoras or the Pythagoreans," the compatibility and logical progression of their work is undeniable. Kitty Ferguson, The Music of Pythagoras: How an Ancient Brotherhood Cracked the Code of the Universe and Lit the Path from Antiquity to Outer Space (New York, NY: Walker \& Company, 2008), 104.

${ }^{1510}$ Francis MacDonald Cornford, From Religion to Philosophy: A Study in the Origins of Western Speculation (New York, NY: Cosimo, 2009; 1912), 194. Note also, however, Christoph Riedweg, Pythagoras: His Life, Teaching, and Influence, tr. Steven Rendall (Ithaca, NY: Cornell University Press, 2005), who observes that "in scholarly research, there is a considerable difference of opinion regarding the relation of Parmenides to Pythagoras," though their potential connections are clear enough, 115. On the related point, "the notion that Plato was a Pythagorean and the Timaeus a Pythagorean dialogue is ... commonplace in Proclus and earlier Neoplatonists," Ronald F. Hathaway, Hierarchy and the Definition of Order in the Letters of Pseudo-Dionysius: A Study in the Form and Meaning of the Pseudo-Dionysian Writings (The Hague, The Netherlands: Martinus Nijhoff, 1969), 117. 
figure, Pythagoras, ${ }^{1511}$ who probably had himself been influenced by Egyptian and farther Eastern sources in India, including possibly the Persian philosopher Zoroaster or one of his followers. ${ }^{1512}$ But this cannot be resolved here, and in any case it is now toward Parmenides in whom this study must turn. ${ }^{1513}$

Parmenides (c. 515-450 B.C.), the most widely acknowledged “'Father' of ontology, theology, logic, metaphysics-in short, the 'Father' of Western philosophy,"1514 and founder of the Eleatic school in Lucania, Italy, stands large in any study concerning the roots of philosophy in the Western/Greek tradition. Standing near, but opposite him, and equally influential, is Heraclitus (c. 535-475 B.C.). The relevant contributions of these two men are straightforward: "The notion of change is central to the philosophy of Heraclitus."1515 Contrastingly, "Parmenides felt that there was such a gulf between what is and what is not" that we should acknowledge that "what is is, and what is not is not, for all

${ }^{1511}$ Cornford, From Religion to Philosophy: A Study in the Origins of Western Speculation, 194.

1512 Riedweg, Pythagoras: His Life, Teaching, and Influence, 7-8; and Margaret S. King, Unveiling the Messiah in the Dead Sea Scrolls (Indianapolis, IN: Xlibris, 2012), 37. See also, Felix M. Cleve, The Giants of PreSophistic Greek Philosophy: An Attempt to Reconstruct Their Thoughts Vol. 2 (Dordrecht, The Netherlands: Springer Science, 1969), 519-520. Cleve notes that "only philologists are always thinking of [the] transfer" of ideas, not necessarily mathematicians, in relationship to the universality of mathematics as a language, ibid., 520.

1513 Concerning mysticism in its later manifestations, see Oliver Davies and Rowan Williams, God Within: The Mystical Tradition of Northern Europe (Hyde Park, NY: New City Press, 1988; 2006), 3-4. Davies and Williams speak, for example, of the "Neoplatonist... school of mysticism which describes a direct and unmediated experience of God in which the soul rises or is raised beyond the material world to share, briefly, in the glory of the Godhead," ibid., 3. In the Greek tradition the material world was temporal, and the nonmaterial world was timeless. See also, Evelyn Underhill, Mysticism (Stilwell, KS: Digireads.com Publishing, 2005), 43. Underhill shares that mysticism is that which is the "extreme point at which man's nature touches the Absolute: that his ground, or substance, his true being, is penetrated by the Divine Life which constitutes the underlying reality of things; this is the basis on which the whole mystic claim of possible union with God must rest," "'at once the solemn sense of Timeless Being ... and the conviction that Life is good,"' ibid., 43. On the contrary side, however, David Henry observes that "Paul's mysticism is an objective, temporally conditioned mysticism. It is temporally conditioned rather than timeless, because it concerns two worlds that are in motion rather than static. The earthly world is moving toward not-being, and the superearthly world is moving toward being. In this era between Christ's death and resurrection and the Parousia, the two worlds are in contact," David Paul Henry, The Early Development of the Hermeneutic of Karl Barth as Evidenced by His Appropriation of Romans 5:12-21 (Mercer University Press, 1985), 69.

${ }^{1514}$ Vishwa Adluri, Parmenides, Plato and Mortal Philosophy: Return from Transcendence (New York, NY: Continuum, 2011), 34. "Paraphrasing A. N. Whitehead [and his famous remark that all of Western philosophy is a series of footnotes to Plato], Gallop says 'Plato's own writings might be said to have consisted in footnotes to Parmenides of Elea,"' ibid., 35. The heritage from Pythagoras, to Parmenides, to Plato, then, is attested to by Kardaras, How Plato and Pythagoras Can Save Your Life, 196. Kardaras asserts that "whether there was actually any personal meeting between Pythagoras's disciples, Parmenides, and Socrates, is unclear; what is apparent is that Pythagoreans influenced Parmenides and, in turn, Parmenides' Eleatic school influenced platonic thinking," ibid.

${ }^{1515}$ Trevor Curnow, Wisdom in the Ancient World (London, UK: Bristol Classical Press, 2011), 85. 
time. Consequently, change is impossible. Where Heraclitus built his system around change, Parmenides built his system around denying it."1516 Although these foundational figures didn't discuss human freedom as we would today, one can imagine the implications that their views suggest. ${ }^{1517}$ Naturally, as one might expect, in many ways one might suggest Parmenides represents the culture of rational-scientists, while Heraclitus supports the flux of uncertainty in the humanities, although it's a bit more complicated than that, as I'll share below. It's also important to point out that Parmenides' rejection of change appears to be complete-changelessness belongs to the domain of divinity. "Although in the extant fragments Parmenides does not identify Being with God," "Actius informs us that he did call his unmoved Being God," and as such, it can be argued that "for Parmenides, Being is God." ${ }^{1518}$

The significance of Parmenides's and Heraclitus's ideas for the concept of time are as follows. Parmenides' emphasis on denying change required a strict continuity to Being (reality), whereas Heraclitus' emphasis on change and transience implied an emphasis on becoming. These "dual aspects of time,"1519 that of the continuity of being (timeless/static linear time) contrasted with temporal becoming (existential time), have, to this day, been generally recognized as unreconciled concepts, placing logical reasoning and the empirical world we perceive around us in tension-there has always been and remains an intrinsic if mysterious connection between the concept of time and

${ }^{1516}$ Curnow, Wisdom in the Ancient World, 85.

${ }^{1517}$ One important issue to point out is that "Parmenides [also] limits the validity of the moral law to Being. Processes perceived in the world are the result of the distorting perception which gives an appearance that things are what they seem to be. The processes have no objective validity; they are subjective and hence deceptive renderings of true reality. As such, they hardly could be considered just and necessary. The moral law is the law of Being located outside the confines of time and space. Inside the spatio-temporal framework there is no objectivity, no justice, no necessity. In this, Parmenides spiritualizes the moral law .... For Parmenides, the moral law is divine so that it does not enter the realm of the perceptible world because this world is not real, it is the result of the operation of the human sensory apparatus and naming conventions," Drozdek, Greek Philosophers as Theologians: The Divine Arche, 49. Later, "Plato creates a more moderate system by assuming that an extratemporal realm is prior to the world and, with it, time is created by the Demiurge; the moral law manifests itself in the world, if only indirectly, because the idea of ideas is the idea of the good and everything which exists is an instantiation of an idea that constitutes the domain of being," ibid.

1518 Drozdek, Greek Philosophers as Theologians: The Divine Arche, 50.

${ }^{1519}$ Roeckelein, “Early Greek and Later Philosophical Theories of Time," 176. 
the reality of motion (and space) in physics. ${ }^{1520}$ As Robert Huerta simplified it, "if Heraclitus insisted that everything is change or motion, Parmenides just as emphatically believed that nothing changes or moves. For Parmenides, the change and flow of the apparent world is an illusion caused by deceptive sense perception. The Parmenidian world is one, indivisible, homogenous, and continuous, eternal in a timeless present; a finite, self-contained plenum 'like a well-rounded ball in its mass."’1521 Yet, in contrast to Parmenides' viewpoint, "Heraclitus found stability in change," and "embraced the world of alteration and posited that all was perpetual change, a never-ending flux." "We step and do not step in the same rivers; we are and we are not."' Heraclitus "believed that the apparent contradictions of the world masked an underlying harmony produced by those very same contradictions," and compared them to "a back-bending ... bow or lyre."”1522 "To Heraclitus the world was perpetually changing, driven by the eternal conflict of opposites." ${ }^{1523}$ Both of these extremes (that of absolute timelessness for all reality, and that of absolute flux for all reality) would receive modification by their philosophical successors, Plato, Aristotle, and others.

Yet, before proceeding to them, it is important to point out the most significant defender of Parmenidian philosophy was Zeno, his disciple, who transformed Parmenides's insights into a new logical argument that would prove very persuasive because it was based upon mathematics rather than perception. However, prior to explaining how Zeno would influence later thinkers, including Plato and Aristotle, it is necessary to pause and offer an acute diagnosis of what Heraclitus and Parmenides actually accomplished. Yes, one could say they initiated the pathways that would lead to each of the two cultures, but they did not complete the journey, as the development of their work would wait until later thinkers. This is because there is an interesting but key point to be elicited

\footnotetext{
${ }^{1520}$ B. G. Sidharth, When the Universe Took a U-turn (London, UK: World Scientific, 2010), 130. See also, Helen Buss Mitchell, Roots of Wisdom: A Tapestry of Philosophical Traditions (Stamford, CT: Cengage Learning, 2015), 21-23.

${ }^{1521}$ Robert D. Huerta, Vermeer and Plato: Painting the Ideal (Cranbury, NJ: Rosemont Publishing, 2005), 21.

1522 Huerta, Vermeer and Plato: Painting the Ideal, 21.

1523 Raper, Multidimensional Geographic Information Science, 86.
} 
from their mostly contrasting perspectives that highlights the importance of later Heideggerian

insights. As Louis Wolcher explains:

Belief in the truth of existential time-linear time's 'other', so to speak- ... has ancient roots. Its idea ultimately goes back to a premise that unites the otherwise competing philosophies of two of the West's most important pre-Socratic thinkers, Parmenides and Heraclitus: namely, the idea that time and being are unified in the form of an eternal now. Parmenides conceived of existential time in terms of eternally stable being; whereas Heraclitus described it in terms of a ceaseless event of becoming in the now. Despite their many differences, however, neither philosopher interpreted true time in terms of duration. Instead, a quintessentially existential conception of time underlies both theories: a united and abiding time-space determines its object either as the non-durational present existence of beings (Parmenides) or as the non-durational present autogenesis of beings (Heraclitus). ${ }^{1524}$

Not even Newton, as shall be seen further below, who emphasized duration as that which was

measured mathematically absent any relation to objects, would interpret time as having intrinsic

\footnotetext{
${ }^{1524}$ Wolcher, Law's Task: The Tragic Circle of Law, Justice and Human Suffering, 179. Wolcher further explains: "In existential time, the now has only one dimension, not the three of linear time; it is 'a rising up from nothing and a disappearance into nothing' [as Heidegger put it]," ibid., 179. Additionally, "longstanding attachment in the West to the lived metaphors of linear time and horizonal (existential) time has created an extremely interesting tension or contradiction in Christian theology-and derivatively, in legal theory-on the question whether meaningful (i.e. meaning-full) language as such possesses generative 'power'. On the one hand, Christianity tells us (and law agrees): 'In the beginning was the word [logos]' (John 1:1). In the beginning was the word of God that, once spoken, must have determined the world; in the beginning, too, was the word of the law, which, once written, must have determined correct (if not just) legal outcomes. On the other hand, the Western theological and philosophical tradition is also sophisticated enough to know that 'the distinction between preservation and creation is only a conceptual one' [Descartes]. That is, since the first beginning is no longer with us in the present, there must be something homologous to a first beginning that operates each and every instant to keep things going.

"This implies the need to posit the existence of something like a continuous act or event of creation, either along the 'line' of linear time or within the 'horizon' of existential time. The following assertions and arguments on the theme of 'continuous creation' are typical: (a) 'God created the world in such a way that he still creates it without ceasing' [Eckhart]. (b) 'God alone is the primary Unity ... from which all monads, created and derived, are produced, and are born, so to speak, by continual fulgurations of the Divinity from moment to moment' [Leibniz]; $(c)$ 'God is not only the cause of the commencement of the existence of things, but also of their continuation in existence' [Spinoza]; and $(d)$ 'It is strange that one says God created the world and not: God is creating, continually, the world. For why should it be a greater miracle that it began to be, rather than that it continued to be?' [Wittgenstein].

"The metaphor of a line induces us to look for a first cause at the 'beginning' of time, and then to look for continuous acts of mini-creation, so to speak, which enable beings to proceed along the timeline from moment to moment. And while it is true that the horizon metaphor of existential time jettisons the idea of a historically distant first cause, it, too, makes us want to look for a continuous act or event of creation (and recreation) in the eternal now-time. One the one hand, as Kafka ... remarks, 'It's only our notion of [linear] time that allows us to speak of the Last Judgment', because this notion presupposes that the actions we take during our lives will be judged only when the world arrives at a particular, but distant, point on the timeline. But on the other hand, the horizon metaphor of existential time seems to make every moment into a last judgement, or, as Kafka puts it, a court marshal convened on the spot," ibid., 183.
} 
durancy of its own ${ }^{1525}$-that is, that time, even in the "now," itself already includes the past, an anticipated future, and the present, within itself. ${ }^{1526}$

To place the above in further context, it may be helpful here to observe that the $20^{\text {th }}$ century philosopher, J. M. E. McTaggart distinguished two theories of time, namely the A-theory, ${ }^{1527}$ which is often associated with Heraclitus, and the B-theory, ${ }^{1528}$ which is associated with Parmenides. In neither of these instances, ${ }^{1529}$ however, is the significance of intrinsic durancy emphasized or explored; this issue has only been touched on tangentially in this study above through the work of Rubenfeld who utilizes Heidegger. The issue of time's intrinsic durancy was explored specifically in the work of Bohm and Pylkkö chapters 3 and 4, respectively. What must be pointed out here is that both Parmenides and Heraclitus can be interpreted as supporters of "presentism" in a broad sense, ${ }^{1530}$

\footnotetext{
${ }^{1525}$ For Newton, "absolute, true and mathematical time, of itself, and from its own nature, flows equably without relation to anything external, and by another name is called duration," as cited in Samuel Sambursky, Physics of the Stoics (Princeton, NJ: Princeton University Press, 1959), 101.

${ }^{1526}$ Heidegger, of course, introduced the concept of intrinsic ecstatic durancy into the philosophy of time with gusto. See Canales, The Physicist \& the Philosopher: Einstein, Bergson, and the Debate That Changed Our Understanding of Time, 139-152, 252-264. Canales explains that Heidegger saw it necessary to proceed even further than Bergson, to "tackle aspects of time in a way that was not limited by the dual perspective of 'clock' versus 'lived' time," ibid., 148.

${ }^{1527}$ To reiterate, in the A-theory events are ordered in terms of past, present, and future and the present can be understood to emphasize the role of the flowing "subjective present"-this is often associated with Heraclitus, Augustine, Newton, and also sometimes "presentism" today, and is often connected with "tensed time" and "dynamic time."

${ }^{1528}$ In the B-theory pairs of events are ordered in terms of either member of the pair preceding the other or being simultaneous with it; this is also called the tenseless theory, and emphasizes an objective perspective-this is often associated with Parmenides and Einstein, and is also called "static time." It can also be referred to as "presentism," though this is not done as often as with the A-theory. Rather, it is typically thought to contradict it. See, for example, Simon Saunders, "How Relativity Contradicts Presentism," in Time, Reality and Experience, ed. Craig Callender (New York, NY: Cambridge University Press, 2002), 277-292.

${ }^{1529}$ J. M. E. McTaggart, “The Unreality of Time," Mind 17 (1908), 457-474. For a contemporary overview of the A-theory and B-theory, see Prosser, Experiencing Time, 1-21; Garrett, What is this Thing Called Metaphysics?, 94; and Mullins, The End of the Timeless God, 18-19. See also, Marc A. Pugliese, The One the Many and the Trinity: Joseph A. Bracken and the Challenge of Process Metaphysics (Washington, D. C.: The Catholic University of America Press, 2011), 172 n. 34; and Ronald C. Hoy, "Heraclitus and Parmenides," in A Companion to the Philosophy of Time, eds. Adrian Bardon and Heather Dyke (West Sussex, UK: John Wiley \& Sons, 2013), 929, esp. 27 n. 19. See also Brenner, Logic in Reality, 239-240.

${ }^{1530}$ See Bardon, A Brief History of the Philosophy of Time, 85-86; Lawrence B. Lombard, "Time for a Change: A Polemic against the Presentism-Eternalism Debate," in Time and Identity, eds. Joseph Keim Campbell, Michael O’Rourke, Harry S. Silverstein (Cambridge, MA: The MIT Press, 2010), 49-78; and Francesco Berto, Existence as a Real Property: The Ontology of Meinongianism (New York, NY: Springer, 2013), 100-101.
} 
especially when contrasted with Heidegger. ${ }^{1531}$ Yet, the discussions on time were to take a different pathway into the present, as a review of the history will show.

To return toward Zeno of Elea, the most famous of Parmenides's disciples, leads us to the author of a series of celebrated paradoxes of motion that have puzzled, and continue to puzzle, thinkers for 2,500 years. Although they were originally constructed around the idea of motion in the physical world ${ }^{1532}$ (where they remain a contentious puzzle-Heideggerian scholars still say Zeno's mathematical paradox actually affirms that mathematics does not ultimately underlay physical nature ${ }^{1533}$ ), they were also originally ${ }^{1534}$ and remain applied to the concept of time. ${ }^{1535}$

What the paradoxes entail, in essence, is that it is impossible to traverse any given distance, without having to first cross half that distance. Given that there are an infinity of "halves" to cross, it is therefore impossible to cross any distance. Despite the fact that common sense perception tells us we do in fact successfully traverse various distances, the power of this mathematical puzzle retains a mysterious power even today, a power that dominated the minds of the ancients who were first discovering the mysteries of the mathematical world (the mathematical solution to Zeno's paradox depends upon fairly recent discoveries in differential calculus and the realization that an infinite sum can still be a finite number; however, whether the theoretical solution calculus provides actually describes the physical realization of the solution is yet another question or problem that remains

\footnotetext{
${ }^{1531}$ Hans Pedersen, "Approaching the Debate Over Tensed and Tenseless Theories of Time From a Heideggerian Perspective," 12-23; see also Marie-Luise Schubert Kalsi, Meinong's Theory of Knowledge (Boston, MA: Martinus Nijhoff, 1987); and Keller Husserl and Heidegger on Human Experience, 68, for a discussion of another thinker, Alexius Meinong, who wrestled with similar problems concerning the durancy of time and objects.

${ }^{1532}$ For example, see Sheldon Joseph Chow, Zeno's Paradoxes and Problems with Infinity in the Physical World (Canada: Dalhousie University, 2006).

1533 See Glazebrook, “Zeno Against Mathematical Physics,” 193-210.

${ }^{1534}$ Joseph Mazur, Zeno's Paradox: Unraveling the Ancient Mystery Behind the Science of Space and Time (New York, NY: Plume Publishers, 2007). Roeckelein concurs, "although Zeno's paradoxes were concerned primarily with the problem of motion, they raised theoretical difficulties both for the notion of time as continuous or infinitely divisible, and the notion of temporal atomicity. Xenocrates (396-314 B.C.), Anaxagoras, and Democritus originated and advanced the atomic theory which occasionally figured in temporal problems and solutions of Zeno's paradox: if time consists of the indivisible moments, often referred to as "chrons," motion consists of imperceptible jerks that may explain how the arrow actually strikes the target," Roeckelein, "Early Greek and Later Philosophical Theories of Time," 176.

${ }^{1535}$ As explained by Victor J. Crome, Zeno's Paradoxes and the Passage of Time (New York, NY: City University of New York, 2007).
} 
disputed, as it would indicate Heraclitus was right, and all is "flux,"1536 at least within an atomistic conception of the world, ${ }^{1537}$ which creates yet further problems ${ }^{1538}$ ). The above puzzle actually created a distinct separation between space and time for Pythagoreans which was supported by Zeno. "Space was represented by geometric figures whose configuration may ... be temporally dependent, as, for example, in the movement of the shadow on a sundial," but true reality was timeless, as time was "the soul of the universe" located outside our temporal world of appearances, foreshadowing Plato's solution, ${ }^{1539}$ or, as Zeno reportedly also said, time was "the interval of movement [in the Cosmos] which holds the measure and standard of swiftness and slowness,"1540 which foreshadows both Plato and Aristotle, as will be seen below.

The historical heritage of Parmenides and Zeno is considerable. Brian Rotman explains how he believes this came to be, and I quote him at length, for he raises some critical points:

Parmenides, like Plato and the Christian theologians after him, separated the universe into the world of appearance, the gross physical habitation of the senses, always in motion, heterogeneous and fragmented, and the world of reality, the world of pure form, God, unchanging Being, which was full, homogeneous, indivisible, timeless and One. To give assent and credence to such a bifurcation it is necessary to be convinced, at least it was so for Greek thinkers, by rational argument. One had to be logically persuaded that change and plurality, however much they seem real to us, must be illusions, mere dream-like phenomena of appearances which seem to be but in truth are not and can never be part of Being. Parmenides, and more famously his disciple Zeno, gave many arguments defending his unitary static cosmos.... Zeno's celebrated paradoxes (in which a stadium was impossible to traverse, arrows could never arrive at their targets, Achilles could never overtake the tortoise, and a moving body must always fail to pass another body) had a profound effect on the structure of Greek thought-on its mathematics no less than its theology and cosmology-far beyond their original focus of defending the Parmenidean 'one' from the pluralism of Pythagorean number mysticism.... There is no record of the

${ }^{1536}$ For proposed resolutions to the paradox (which take on a very Heraclitian flare), see Peter Lynds, “Zeno's Paradoxes: A Timely Solution," at http://philsci-archive.pitt.edu/archive/00001197 (Accessed January 20, 2017). See also, Brian Palmer, "What Is the Answer to Zeno's Paradox? Why Achilles Actually Can Catch a Tortoise in a Race," at http://www.slate.com/articles/health_and_science/science/2014/03/zeno_s_paradox_ how_to_explain_the_solution_to_achilles_and_the_tortoise.html (Accessed January 27, 2017).

${ }^{1537}$ Helge S. Kragh, Conceptions of Cosmos: From Myths to the Accelerating Universe: A History of Cosmology (Oxford, UK: Oxford University Pres, 2007), 16; and Paul Cartledge, Democritus: Democritus and Atomistic Politics (Phoenix, AZ: 1998).

${ }^{1538}$ Nickolas Roubekas explains that the atomistic theory (later adopted by Newton) has important consequences. "Democritus's atomistic theory [of nature] explains scientifically what humans failed to explain" through religion, and thus in many ways precursors a naturalistic explanation of nature that excludes God and religion, Nickolas P. Roubekas (New York, NY: Routledge, 2017), 37.

${ }^{1539}$ Raper, Multidimensional Geographic Information Science, 86.

${ }^{1540}$ Sambursky, Physics of the Stoics, 101. 
conclusions argued for by Zeno having been refuted, or any indication that the paradoxes were the subject of disabling criticism, or could be explained away.... If ... we focus on mathematics, then it is plausible to hold ... that, far from ignoring them, Greek mathematicians were shocked ... into a certain kind of silence, an unarticulated mistrust and suspicion of the ideas of motion and of plurality.... What the Zeno-Parmenides interdiction of motion ... engendered within Greek mathematics was a hypostasised literalism ... which influenced mathematics from the time of Euclid to the Renaissance (and beyond: a version of Parmenidean stasis is central to the dominant present-day conception of mathematics in which mathematicians are supposed to apprehend eternal truths about entities-'structures'-in an unchanging, timeless, static, extra-human world). ${ }^{1541}$

The main points to take away from Rotman's synopsis are that Zeno's paradoxes, which relied upon mathematics, helped cement into place Parmenides' primary contention-that a timeless unity represents Being or the true Reality. Furthermore, although Pythagoras's ideas could support a "mathematical pluralism" of sorts (an infinity of numbers), which Zeno's arguments seem to reject, it was nevertheless the power of Pythagoras's own veneration of the world of "timeless" mathematics that ironically supported Zeno.

The only real issue dividing Pythagoras and Zeno (and thus Parmenides) was whether reality, that is, nature and motion (and thus time) should be represented through discrete or discontinuous separable units (a continuity of consecutive atomistic points) or as a continuous indivisible whole, ${ }^{1542}$ both of which can be used in support of timelessness. Pythagoras's ideas initially supported a discrete (based on whole numbers) view of mathematical nature and motion (and time), but the discovery of irrational numbers ${ }^{1543}$ (infinity) lent tentative support to Zeno and Parmenides. All that 62.

${ }^{1541}$ Brian Rotman, Signifying Nothing: The Semiotics of Zeno (London, UK: Macmillan Press, 1987), 61-

1542 Mazur, Zeno's Paradox: Unraveling the Ancient Mystery Behind the Science of Space and Time, 14-15. Mazur explains, "the Pythagoreans influenced many, including Zeno. In particular, the notion that lines were made from strings of points like threats of minuscule beads beguiled him. However, Zeno and Parmenides refuted that [particular] Pythagorean notion, and argued that if a line were made of a finite number of points, then time, too, must be built from a finite number of instants and the days would pass not in a smooth continuous flow but in discrete increments, each like a grain of sand falling in an hourglass," ibid. The problem of whether time (and nature) were discrete or continuous has plagued philosophers ever since. In either case, however, the foundational "timeless" nature or objectivity of mathematics endures. Of course, the debate, even then, led to the rise of Atomism under Democritus, which would have long lasting consequences. See Andrew Pyle, Atomism and Its Critics: From Democritus to Newton (New York, NY: Thoemmes Press, 1997).

${ }^{1543}$ Jenner Barretto Bastos Filho, "The Quantum Debate: From Einstein to Bell and Beyond," in Physics Before and After Einstein, ed. Marco Mamone Capria (Amsterdam, The Netherlands: IOS Press, 2005), 214. "The hard core of the Pythagorean research programme is the idea that the essence of reality is mirrored in whole numbers and their ratios. In short, according to Pythagoreans, numbers rule all things. However, the Pythagoreans stumbled on a very great difficulty which was, at that time, an insurmountable contradiction and 
really matters, for the present purpose of this study (more will be shared below), is that each possible solution merely represents a finite timelessness or an infinite timelessness, and as such "the complex of fundamental problems that makes its first appearance in the paradoxes of Zeno is still live in modern logic and mathematics," and that "Zeno's polemical argumentation" undeniably is responsive to issues found in "Pythagorean philosophy and mathematics." ${ }^{1544}$ How to reconcile the "many" of Pythagoras's mathematical world of whole numbers (or at least rational integers) with the "One" of Parmenides (recalling that in some versions of Pythagoreanism the number "One" was also elevated) would become the unsatisfactorily resolved goals of Plato and Aristotle, as will be explained shortly.

In summary, then, 'Parmenides' doctrine of the One had been ridiculed by some on the grounds that it led to consequences which contradicted it.... Zeno therefore set out to show that the hypothesis of those who opposed Parmenides ... led to even more ludicrous consequences,",1545 and the trio of Parmenides and Zeno, along with their predecessor Pythagoras, ${ }^{1546}$ won the day, and the

constituted a traumatic discovery, with serious consequences for their programme. They discovered the incommensurability of the diagonal of the square and its side, i.e. that the ratio $(d / a)$, where $d$ denotes the diagonal of the square and $a$ denotes its side, cannot be written as a ration of whole numbers. In fact, if we allow that the ratio $(d / a)$ is a rational number, then this can be shown to lead to a contradiction according to which a certain integer is both even and odd. The unavoidable conclusion is that rational numbers do not cover all of conceptual reality," ibid. Filho continues, "it is essential to emphasize that the incommensurability problem appearing in the context of arithmetic is not itself a geometric problem. This circumstance played a central role in the context of the history of the competition between the arithmetic and the geometric programmes; the reason for this can be easily understood. For example, when Socrates (the main character of Plato's dialogue Meno) asks the slave boy how long is the side of a square having twice the area of another given square, the answer is that the side of the square having a double area is equal to the diagonal fo the other square. The exact solution can be drawn on the earth (or on the sand) without ambiguity and without contradiction. Therefore, the incommensurability problem does not arise geometrically.

"Plato also noted this extremely important fact and therefore rated geometry as superior to arithmetic as a world-view. This was, according to Popper, the Platonic and Euclidean Programme. Classical mechanics and the general theory of relativity are frequently considered as emblematic examples of the extraordinary success of the geometric programme in the history of physics.

"In spite of this traumatic affair, the Pythagorean programme resurrected from its ashes-like the phoenix-and played an important and even decisive role in several developments of physics. The branches in which the Pythagorean central idea had most success were electrolysis, the physics of oscillations (normal modes of vibration, as in a vibrating string) and quantum mechanics," ibid.

${ }^{1544}$ Walter Burkert, Lore and Science in Ancient Pythagoreanism, tr. Edwin L. Minar, Jr. (Cambridge, MA: Harvard University Press, 1972), 285.

1545 Árpád Szabó, The Beginnings of Greek Mathematics, tr. A. M. Ungar (Dordrecht, The Netherlands: Springer Science, 1978), 248.

${ }^{1546}$ It is worth emphasizing that the victor of the debate between Zeno and Pythagoras on whether reality was "One" or "Many" is, or has become, almost irrelevant to the question of whether reality is timeless or not, as mathematics in either case supported "timeless" truths, and the world of mathematics became the exemplar location of where debates about nature, motion, and time would take place, as it alone, whether in struggling with irrational numbers or discrete integers, represented "objective" and universal truth. 
millennia that followed. Following after the contributions of Pythagoras, Heraclitus, Parmenides, and

Zeno, the four most important pre-Socratic philosophers, the name of Plato (c. 428-348 B.C.), a

student of Socrates, and in turn a teacher of Aristotle, towers above all others in the history of

Western philosophy. While Plato's contributions were many, his attempted resolution to the tensions

between Heraclitus and Parmenides are what interest this study, and which also lead into his own

insights on the nature of time, and also of freedom.

It is important to make clear that Plato was greatly influenced by the tensions introduced by

Parmenides (being) and Heraclitus (becoming), as well as Pythagoras and Zeno. ${ }^{1547}$ Plato did not

dispute the basic assertion of Pythagoras that established mathematics as the ideal objective

science, ${ }^{1548}$ and this would have a profound effect on his own contributions. T. Rudavsky affirms, it is

As a reminder, it is worth observing that there is a mirror-like similarity to the view of metaphysics (which includes the nature of time) as mathematics and metaphysics as theology: "The nature of the reality of mathematical objects and the objectivity of mathematical statements constitute two of the deepest problems in the philosophy of mathematics. Objectivity would imply a fundamental harmony between the structure of the human mind and the intelligibility of the universe; it would imply that knowledge arrived at through mathematical theories accurately represents the nature of the world and that there is an intrinsic harmony between the nonempirical, logical worlds of the mind and the empirical worlds of experience. But there are huge difficulties with such a view, and some have even suggested that logic itself is empirical.... It is possible, in other words, to construct an internally coherent mathematical theory without supposing that any reality exhibiting the properties corresponding to that theory can be found in the physical universe. Indeed, mathematics seldom regards the physical universe as an appropriate criterion to employ in deciding upon the intrinsic interest of its theories, and once the question is asked it is not easy to say why the physical universe should be the final arbiter of 'reality' except under one particular preference.... This description [given above] shows a prima facie similarity between the mathematical and theological enterprises. It is possible to construct countless internally consistent theologies without supposing that there is an objective reality, a god or gods, to whom they refer. To the numerous major world religions can be added a large number of variants, each with its distinctive way of speaking about a god or some kind of ultimate reality. The nature of the reality of theological objects and the objectivity of theological statements constitute two of the deepest problems in the philosophy of religion," Puddefoot and Fernandez, "Mathematics and Theology," 1010-1013, 1010. As to the question of who won the historical debate, Zeno or Pythagoras, on rational discreteness or irrational continuity, one must answer that until the advent of quantum physics, space and time were seen as continuous. Now, some believe they are discrete. Note the work by Tony Fleming, Self-Field Theory: A New Mathematical Description of Physics (Boca Raton, FL: CRC Press, 2012), 4. Yet, the present point is that the question of whether reality is discrete or continuous needs no resolution for the broader 'big-picture' mathematical projection of reality to predominate.

1547 "Zeno raised" questions about "reality and ... the nature of abstract time. Plato and Aristotle in different ways ... attempted to provide answers," Ariotti, "The Concept of Time in Western Antiquity," 73.

${ }^{1548}$ For the Greeks, "Pythagoras's discoveries established mathematics as a certain and reliable body of knowledge about the real world that could be obtained by rational thought. Mathematical relations-immutable, verifiable, and true without regard to time or circumstance-were of a higher order of reality, superior to the sensible inexact realities of the physical world. It was but a brief step to postulate a perfect, intelligible reality set against an imperfect sensible universe," which Plato soon set out to do. "Plato sought to resolve one of the great problems of Greek philosophy, the question of the One and the many," which "arose in large part because of the work of ... Pythagoras," Huerta, Vermeer and Plato: Painting the Ideal, 21. 
"against the backdrop of his Presocratic predecessors," especially Parmenides and Heraclitus, that Plato tried "to resolve the paradoxes of change and permanence."1549

What is of ultimate significance in Rudavsky's explanation of Plato's work is that "Plato distinguishes between eternity (aionios) and everlastingness (aidios): everlastingness is 'the nearest approach to eternity of which sensible things are capable."”1550 More specifically, as Ariotti explains, “in Plato's conception of time, "time ... belongs to the world of appearances or physical world. More precisely, time came into being, and will cease to be, with the ordered universe." ${ }^{1551}$ He adds, "time is [also] mathematical and this mathematical nature is insured ... by the motions of the planets."1552 Ariotti notes the irony in Plato's definitions, for, "in spite of such a genesis and nature, time for Plato is not real; for there are no real 'comings-into-being' in the physical world, but merely appearances, copies. Real are only the forms, unchanging, eternal, and essentially static. Time, as a feature of the physical world is one such an appearance, one such copy ... the image of a form." ${ }^{1553}$ This is likely due to the fact that Pythagoras's influence had been great upon Plato, by "means of his association of time with number and celestial motions." ${ }^{1554}$ Overall, it is clear that Plato's views on time were dominated by cyclical and mathematical notions of time that de-emphasize any true linear time or flux. In other words, unlike Heraclitus, even Pythagoras, and also Aristotle, as will be shown shortly, Plato didn't seem to have a clear understanding of chronological time; "chronological time" was also "in the realm

${ }^{1549}$ T. M. Rudavsky, Time Matters: Time, Creation, and Cosmology in Medieval Jewish Philosophy (Albany, NY: State University of New York Press, 2000), 10. Huerta concurs, "Plato tried to bridge the intellectual abyss between the One and the many, between the many sided way of Heraclitus and the monism of Parmenides," Huerta, Vermeer and Plato: Painting the Ideal, 21.

${ }^{1550}$ Rudavsky, Time Matters: Time, Creation, and Cosmology in Medieval Jewish Philosophy, 10.

${ }^{1551}$ Ariotti, “The Concept of Time in Western Antiquity," 73. He quotes Plato, Timaeus, 38B: “Time came into being together with the heaven, in order that, as they were brought into being together, so they may be dissolved together, if ever their dissolution should come to pass," ibid.

${ }^{1552}$ Ariotti, "The Concept of Time in Western Antiquity," 73. Again, quoting Plato, Timaeus, 38B: "in order that Time might be brought into being, Sun and Moon and five other stars-'wanderers,' as they are called-were made to define and preserve the numbers of Time," ibid.

1553 Ariotti, "The Concept of Time in Western Antiquity," 73.

${ }^{1554}$ Ariotti, "The Concept of Time in Western Antiquity," 74. Ariotti quotes Plato, Timaeus, 38B: "eternity ... abides in unity, an everlasting likeness moving according to number-that which we have given the name Time," ibid. 
of appearances."1555 Not only because this physical world was a "shadow" of some ideal invisible or hidden Form, but because the physical world's time was cyclical owing to the celestial motions. ${ }^{1556}$ Plato essentially denies chronological time altogether. Notably, in passing, it is worth mentioning that Plato's thoughts on time "exerted an enormous influence upon [extra-biblical] Jewish cosmogonic and cosmological writing." 1557

Plato's influence is virtually unquestioned today, with the assessment of W. M. Priestley appearing quite accurate: "western philosophy has been described as a series of footnotes to the writings of Plato. Yet, as we know from the warning on his gate ('Let no one ignorant of geometry enter here!'), Plato's philosophy was influenced by his conception of mathematics. The Pythagorean spirit lives in Plato." ${ }^{1558}$ Given that "the formation of Plato's cosmology was shaped by ... Pythagorean number mysticism and Parmenidian ontology," ${ }^{1559}$ one can easily see how "in Plato's conception of time both the Pythagorean and Eleatic [Parmenidean] strands of thought come to a common nexus. Time, for Plato, belongs to the world of appearances or physical world. More precisely, time came into being, and will cease to be, with the ordered universe,"1560 and as such all

\footnotetext{
${ }^{1555}$ Leslie Jaye Kavanaugh, The Architectonic of Philosophy: Plato, Aristotle, Leibniz (Amsterdam, The Netherlands: Amsterdam University Press, 2007), 43. "For Plato, time is not linear; rather, time is a circular orbit, a rhythmic rotation," ibid, 42. "Time does not proceed from the past into the future, but is ordered according to number of the moving and sensible planetary patterns. Time is cyclical," ibid., 43.

${ }^{1556}$ Ariotti, "The Concept of Time in Western Antiquity," 74. "Time . . . is defined by the planetary motions. But such motions are circular, that is they partake in the attribute of the circle. Therefore, they are in themselves continuous," and thus the continuity of time is assured, but not in any chronological way, ibid.

${ }^{1557}$ Rudavsky, Time Matters: Time, Creation, and Cosmology in Medieval Jewish Philosophy, 10.

${ }^{1558}$ W. M. Priestley, Calculus: A Historical Approach (New York, NY: Springer-Verlag, 1979), 37. Priestley notes that "mathematics, in Plato's time, was enjoying vigorous activity." The "eternal was of paramount interest to Plato, transitory things being of less value. What is important is the power to prevail against the ravages of time. To Plato, mathematics seemed to possess this power. The theorems of the Pythagoreans will live, even if the Greek language should die. Plato became enamoured of mathematics," ibid. Plato "believed that the Pythagorean theorem existed, in some sense, long before Pythagoras. The connection between the ideas involved was there always. It was waiting to be discovered.... Plato began to think that all enduring knowledge must be like this. Knowledge consists of ideas, or eternal forms, and their great web of connections," ibid.

${ }^{1559}$ Barry Sandywell, Presocratic Reflexivity: The Construction of Philosophical Discourse C. 600-450 BC (New York, NY: Routledge, 1996), 57.

${ }^{1560}$ Ariotti, "The Concept of Time in Western Antiquity," 73. Ariotti quotes Plato as follows: "Time came into being together with the heaven, in order that, as they were brought into being together, so they may be dissolved together, if ever their dissolution should come to pass," ibid. "Furthermore, time is mathematical and this mathematical nature is insured, Plato thought, by the motions of the planets: ' ... in order that Time might be brought into being, Sun and Moon and five other stars-'wanderers', as they are called-were made to define and preserve the numbers of Time,"' ibid. Ariotti continues, "and yet, in spite of such a genesis and
} 
time is merely cyclical or mathematical appearances, and not really real. The true reality was

timeless. Having thus surveyed Plato's views on time, it is necessary to turn now toward his student,

Aristotle.

In contrast to the rationalist Plato, his more empiricist disciple Aristotle (c.385-323 B.C. ) did

view time as 'real.' As Ariotti explains of Aristotle, "the physical world, far from being an appearance, is real, and ... all that there is." Furthermore, "this world has a temporal structure, and hence, time is not only real, but important. Nevertheless, the importance of time in Aristotle's science should not be exaggerated; time is not one of his fundamental concepts."1561 Aristotle, rather, focused on his schema of causes and ends, as well as motion and change in themselves. Time is derivative to these concepts.

For Aristotle, time does not have an independent existence, but, rather, time is 'physicalized' in that it is "perceived only when there is change or motion." ${ }^{1562}$ Aristotle recognized that change is not always consistent, however, happening faster or more slowly. As such, he postulated that time was a number, as did Plato and Pythagoras, but a unique, "special kind of number. For while numbers are formed from the discrete, irreducible unit, 'there is no minimum' for time."1563 Ariotti explains that for Aristotle, "time is a number in the sense that it is the numerable aspect of motion.."1564 Indeed, as

nature, time for Plato is not real; for there are no real 'comings-into-being' in the physical world, but merely appearances, copies. Real are only the forms, unchanging, eternal, and essentially static. Time, as a feature of the physical world is one such an appearance, one such copy. More precisely, time for the Athenian is the image of a form. Having reflected the Pythagorean influence by means of his association of time with number and celestial motions, Plato also showed the influence of the Eleatic [Parmenidean] strand by denying reality to time: '. . . (the demiurge made) of eternity that abides in unity, an everlasting likeness moving according to number-that which we have given the name Time.' In spite of his denial of a reality for time, Plato's contribution to the development of the concept was important. For he conceived time as the number or, better, series of numbers of specific motions. He thus provided for time a metric, or metrics, understood as the revolutions of the planets. Furthermore, by relating time with number, Plato showed that he was aware of the need for insuring for time not only indefinite, but also uniform progression. Plato, however, conceived numbers as discrete, indivisible wholes. But if so, how could temporal continuity be insured? It could not. Continuity of time however, could be insured by one of those forms which Plato called the 'more remote' principles of reality, namely the circle which, in its line or circumference is continuous. Now, time, according to his view, is defined by the planetary motions. But such motions are circular, that is they partake in the attribute of the circle. Therefore, they are in themselves continuous. But if so, time, which they defined, has to be continuous," ibid., 73-74 (addition mine).

${ }^{1561}$ Ariotti, "The Concept of Time in Western Antiquity," 74.

1562 Ariotti, "The Concept of Time in Western Antiquity," 75.

1563 Ariotti, "The Concept of Time in Western Antiquity," 75.

${ }^{1564}$ Ariotti, "The Concept of Time in Western Antiquity," 75. He quotes Aristotle to say: "time is not movement, but only movement insofar as it admits of enumeration. A proof of this: we discriminate more or less by number, but more or less movement by time. Time then is a kind of number," ibid. 
Aristotle put it, "[time] is simply the number of continuous movement, not of any particular kind of it,"1565 and Aristotle thus sided, in part, with Heraclitus, contra Plato, in suggesting that there was a sort of subjective flux, relative to each motion, in the constant and diverse motions that were occurring in the world, and that this time could be perceived as linear, again, contra Plato. But in its linearity it could best be described as a mere sequence of "nows"1566 that were isolated (or timelessly abstractable into frozen 'now' points) from any of the other "nows" that preceded or succeeded the present 'now.' In any case, it can be argued that Aristotle is the first true Greek father of a conception of linear time. ${ }^{1567}$ However, importantly, this time was only perceivable through the mathematical measurement of the motions that divided the "nows." Additionally, Aristotle also tied these motions into the celestial bodies, which "instantiate and reify time because they alone observe all the necessary conditions"1568 of constant motion and are perfect circles. Indeed, as Aristotle put it, "the revolution of the heaven is the measure of all motions, because it alone is continuous and unvarying and eternal,"1569 and this focus upon the celestial bodies in some ways detracts from his linear

78.

${ }^{1565}$ Aristotle, Physics, VI, 9, 240 a1, as quoted by Ariotti, "The Concept of Time in Western Antiquity,"

${ }^{1566}$ Heidegger interpreted Aristotle as follows: “Aristotle's concept of time ... characterizes time primarily as a sequence of nows, where it should be noted that the nows are not parts from which time is pieced together into a whole. The very way in which we translated Aristotle's definition of time-hence the way we interpreted it-was intended to indicate that, when he defines it with reference to the earlier and later, he is defining it in terms of time as that which is counted in connection with motion." Heidegger continues, "what Aristotle presents as time corresponds to the common prescientific understanding of time," Heidegger, The Basic Problems of Phenomenology, 256-257.

1567 "The idea that time is linear can be traced to Aristotle's determination of time as number and enumerated movement with respect to bodies that retain their unity even though the 'now' in which they move is always different. Linear time portrays its subject matter as an endless series of arithmetically distinct 'moments'-represented as $\mathrm{t} 1, \mathrm{t} 2, \mathrm{t} 3$, and so on-in which each particular moment, though undeniably unique in its individual being, is never content merely to lie down inertly between the moment before and the moment after. Instead, each moment vitally connects (somehow) with its predecessor and successor in such a way as to create the causal nexus.... Considered from the point of view of linear time, human beings live their lives from moment to moment within a span of time lying on a universal timeline, where all 'events' have both a determinate temporal beginning and a determinate temporal end. Somewhere in this conception of time can be glimpsed the origin of calendars and clocks, as well as the plethora of human technologies for reckoning dates, eras, successions of events, and causal relations. The radical humanisation [although not in a Heideggerian way] of linear time, first clearly articulated by Kant, coincided historically with the emergence of Western capitalism and the widespread availability of clocks and watches designed to measure 'it' (i.e. time). In the modern era the idea that time is linear is thus ultimately technological: it serves to facilitate" the reign of process and the linking of time to the logic of processes and procedures, Wolcher, Law's Task: The Tragic Circle of Law, Justice and Human Suffering, 178-179 (addition mine).

${ }^{1568}$ Ariotti, "The Concept of Time in Western Antiquity," 78.

${ }^{1569}$ Aristotle, Physics, VI, 9, 240 a1, as quoted by Ariotti, "The Concept of Time in Western Antiquity,"

78. 
emphasis-in some ways foreshadowing the multiple "relativistic" linear and deterministic times of Einstein's theory.

In summary of Aristotle's contributions, although Aristotle does indeed embrace a form of chronological time and the notion that time includes an infinite series of moments succeeding from the past to the future, it is subordinated to movement or motion, and therefore includes both a subjective element as well as reducing time to space. ${ }^{1570}$ Time is not, however, "absolute" in the cosmic sense, as it would be later for Newton. Lastly, it is noteworthy that if time is merely the measure of motion, then there is not really any room for discussing freedom in relation to it. Rather, they would seem to be merely accidentally related, insofar as freedom might alter particular motions. ${ }^{1571}$ Furthermore, and lastly, the issue of "Being" remained unaltered by Aristotle-he did not rethink the foundations of ontology ${ }^{1572}$ nor fundamentally modify the work of Pythagoras, Parmenides, or Plato, on the issue of time-for Aristotle, time retained its mathematized core, in his case specified as the numbering of motion or mathematical sequentiality.

In the following centuries, very little would change in how time was perceived and conceptualized, other than different emphases and combinations of what the above figures outlined.

\footnotetext{
1570 Nathan Widder, Reflections on Time and Politics (University Park, PA: The Pennsylvania State University, 2008), 13.

${ }^{1571}$ Note, for example, Felix Ó. Murchadha, The Time of Revolution: Kairos and Chronos in Heidegger (New York, NY: Bloomsbury Academic, 2013), 192. Murchadha discusses Heidegger's critique of Aristotle: “As Heidegger makes clear in his interpretation of Aristotle, movement means becoming-other. Mere routine is characterized by a leveled off form of such becoming-other: for example, the transition from the now of meal time to the now of work. There is no break in such becoming-other, on the contrary it grounds-as Aristotle also recognized-the constancy of time. However, without such becoming-other of chronological time there would be no possibility of the kairos. The rupture of the kairos is possible only due to the fragility of chronos," ibid. Thus, where there is no kairos, "transformation into the future [is not possible]. In this sense, the kairos is the time between liberation from ... and a freedom for ... between negative and positive freedom. If the kairos is, then this 'between-space' is purely contingent," ibid., 86.

1572 This is pointed out by Canale, A Criticism of Theological Reason: Time and Timelessness as Primordial Presuppositions, 89-95. Furthermore, because of this, the frequent description of Plato as the rationalist and Aristotle as the empiricist is not fully accurate. This observation is made most clearly by Hegel. See Paul Redding, "Hegel's Lectures on the History of Ancient and Medieval Philosophy," in The Oxford Handbook of Hegel, ed. Dean Moyar (Oxford, UK: Oxford University Press, 2017), 612-613. Redding explains, "the priority of change and movement over the static that had first emerged in Zeno is expressed in Aristotle's metaphysics in terms of the conception of energia. Like Heraclitus, Aristotle treated change as fundamental, but in contrast to Heraclitus, for Aristotle change was not mere alteration but 'self-preservation within identity with self' or 'within the universal.' While Heraclitus captured the way 'a stream is ever-changing,' Aristotle captures the fact that it is 'also ever the same.' This dynamic and concrete equivalent to the abstract 'Idea' of Platonic philosophy is found in Aristotle in various forms," ibid., 612-613.
} 
Their tensions would be reproduced within the Christian tradition, with God usually assuming merely the timeless character that the Greeks assigned to their own conception of the absolute, which following the Pythagorean tradition, often assumed a mathematical hew. Augustine, a lover of mathematics and numbers, ${ }^{1573}$ adopted a neo-Platonic perspective, ${ }^{1574}$ and Thomas Aquinas authored the neo-Platonic-Aristotelian synthesis. ${ }^{1575}$ Finally, Isaac Newton (1643-1727) formalized an abstract mathematical, ${ }^{1576}$ absolute ${ }^{1577}$ and universal ${ }^{1578}$ view of time, or a mathematical sequentiality of flowing but discretely isolated "nows"1579 (following Plato and Aristotle), separating it from the specific motions of the world ${ }^{1580}$ (celestial or otherwise), and making time dependent on God. Time and space were a priori givens for Newton, and the present "now" was all that was real, making

${ }^{1573}$ Hersh, What is Mathematics, Really?, 103-106.

${ }^{1574}$ Most importantly, it has been suggested that Augustine, after Plato, denied the ultimate reality of time altogether, thus linking himself with Kant and Einstein. See Ralph Blumenau, Philosophy and Living (Exeter, UK: Imprint Academic, 2005), 368 n. 11.

${ }^{1575}$ DeWeese, God and the Nature of Time, 111-158. See also the work by Luc J. Wintgens, Legisprudence: Practical Reason in Legislation (New York, NY: Routledge, 2016), 14; and Chander Behl, Anatomy of Spirituality: Portrait of the Soul (Victoria, BC: Friesen Press, 2015), 280-281.

${ }^{1576}$ Weinert, The Scientist as Philosopher: Philosophical Consequences of Great Scientific Discoveries, 112. Newton's view of time "can be interpreted as a mathematical notion of time," ibid. See also, Eva Brann, What, Then, Is Time? (New York, NY: Rowman \& Littlefield, 1999), 153.

${ }^{1577}$ Newton's time is absolute "because Newton makes time independent of any material processes in the universe," Weinert, The Scientist as Philosopher: Philosophical Consequences of Great Scientific Discoveries, 112.

${ }^{1578}$ Newton's time is universal "because for Newton, as for every physicist and philosopher before Einstein, all observers, wherever they are placed in the universe, measure the same time and length intervals. With Einstein, the concept of absolute and universal time is abandoned. Time becomes simply what a clock measures. As clocks behave differently in different physical situations, time becomes relativized," Weinert, The Scientist as Philosopher: Philosophical Consequences of Great Scientific Discoveries, 112. See also, Stephen D. Snobelen, "Isaac Newton: His Science and Religion," in Science, Religion and Society: An Encyclopedia of History, Culture, and Controversy, eds. Arri Eisen and Gary laderman (New York, NY: Routledge, 2015), 355-369.

${ }^{1579}$ Peter K. McInerney, Time and Experience (Philadelphia, PA: Temple University Press, 1991), 125. "The explicit commonsense conception of the nature of time portrays it in the following way: 'Time shows itself as a sequence of 'nows' which are constantly 'present-at-hand', simultaneously passing away and coming along. Time is understood as a succession, as a 'flowing stream of nows', as the 'course of time'.' Now-time is ordinarily thought to be a peculiar type of present-at-hand entity that intrinsically passes. Such time is composed of parts or 'nows' that are sequentially ordered and that have a 'privileged part' (the present), which constantly changes in the direction of later dates. This commonsense conception was formalized in Newton's theory of an absolute time that intrinsically passed independently of the material entities that exited within time," ibid., 125.

1580 "The linear time of Newton's physics is not part of nature but an abstraction," Nicholas Rescher, Process Metaphysics: An Introduction to Process Philosophy (Albany, NT: State University of New York Press, 1996), 96. Note also, Brent D. Slife, Time and Psychological Explanation (Albany, NY: State University of New York Press, 1993), 22, 258. For Newton, "time is spatialized (in a line metaphor). Time preserves the traditional independence of beings by keeping the beings separate from one another in time (e.g., sequencing of family members). Of course, time itself is separate from beings, existing as Newton put it, 'of itself, and from its own nature ... without relation to anything external,"' ibid., 258. 
Newton a presentist, following in the tradition of Augustine. ${ }^{1581}$ It's important to remember that all of them ended up, especially Newton, adopting a hybrid of the Heraclitian flux or flow within a mathematical view of time reflecting and reacting to Zeno's original formulation of the problem even if they disagreed with Zeno's rejection of change or time, as Newton did. ${ }^{1582}$ Newton's influence was profound upon many philosophers, such as John Locke (1643-1704) $)^{1583}$ and Immanuel Kant (17241804), the latter of whom separated the neumena (things in themselves) from phenomena (appearances), ${ }^{1584}$ and who in turn set the paradigm within which academic philosophy operated until Heidegger entered the scene and Einstein shocked the world of scientists. At the risk of reductionism, all other philosophers' contributions reflected merely variations on the above themes.

Notwithstanding the above majority interpretation within the Christian/Western tradition, which was usually repeated generationally to protect God's perfection and His foreknowledge of

\footnotetext{
1581 "Augustine proposed that the present is a knife edge between the past and the future and could not contain any extended period of time. This seems evident because, if the present is extended, it must have separate parts-but these must be simultaneous if they are truly part of the present. ... Contrary to Saint Augustine... William James said that time is 'the short duration of which we are immediately and incessantly sensible'," Mike Hockney, The Omega Point (Hyperreality Books, 2013), presentism. See also, Benjamin L. Curtis and Jon Robson, A Critical Introduction to the Metaphysics of Time (New York, NY: Bloomsbury Academic, 2016), 89-114.

1582 Jordan Ellenberg, How Not to Be Wrong: The Power of Mathematical Thinking (New York, NY: Penguin Books, 2015), 40-47. Note also, Sambursky, Physics of the Stoics, 101; P. B. Scheurer, "The Surprises of Newtonian Determinism," in Newton's Scientific and Philosophical Legacy, eds. P. B. Scheurer and G. Debrock (Boston, MA: Kluwer Academic, 1988), 142; and Francisco S. N. Lobo, "Nature of Time and Causality in Physics," in Psychology of Time, ed. Simon Grondin (Bingley, UK: Emerald Group Publishing, 2008), 396-397.

${ }^{1583}$ James L. Axtell, “Locke, Newton and the Two Cultures," in John Locke: Problems and Perspectives: A Collection of New Essays, ed. John W. Yolton (Cambridge, UK: Cambridge University Press, 1969), 165-182. Axtell observes that Newton, the father of the scientific culture, eventually won over Locke to the value of mathematics, even though Locke was more comfortable in the humanities culture and wasn't actually very good at higher mathematics. Nevertheless, while Locke appreciated Newton's mathematical contributions and their application to nature, Lock retained in his philosophy of education a preference for the empirical sciences over the rationalist-mathematical sciences, as the proper foundation of a general education in natural philosophy, ibid., 179-180. For more on Locke's significance in navigating the two cultures in their incipient stage, see Madeline Muntersbjorn, "Morality and Mathematics," in Mathematical Cultures: The London Meetings 2012-2014, ed. Brendan Larvor (Switzerland, Springer Birkhäuser, 2016), 387-408; Steven Forde, Locke, Science, and Politics (Cambridge, UK: Cambridge University Press, 2013); and Peter R. Anstey, John Locke and Natural Philosophy (Oxford, UK: Oxford University Press, 2011).

${ }^{1584}$ Max Jammer, "A Consideration of the Philosophical Implications of the New Physics," in The Structure and Development of Science, eds. Gerard Radnitzky and Gunnar Andersson (London, UK: D. Reidel Publishing, 1979), 44; and Michael Friedman, Kant's Construction of Nature: A Reading of the Metaphysical Foundations of Natural Science (Cambridge, UK: Cambridge University Press, 2013), xiv. "The name of Newton occurs far more often than that of any other author [in Kant's works]," ibid.
} 
human free decisions, ${ }^{1585}$ a number of select individuals offered more emphasis on the Heraclitian temporal and dynamic presentations of reality, notably John Duns Scotus (c. 1266-1308) ${ }^{1586}$ and the precursor of Protestantism William Ockham (1287-1347) ${ }^{1587}$ who was probably the first in the West to articulately construe God in temporal terms. ${ }^{1588}$ It is surely no accident that Scotus and Ockham were two of the figures that Heidegger focused on early his career, ${ }^{1589}$ and the uneasy and contentious mentor-mentee relationship of the ideas of Scotus and his younger contemporary, Ockham, are similar in many ways to the relationship between the father of phenomenology, Edmund Husserl, and his student, Heidegger. ${ }^{1590}$ Yet, in returning to the origins of the rise of temporality, it must also be

1585 This is an important point to emphasize. Almost every philosopher or theologian in the classic Christian tradition to address God's relationship to time maintained God's essential atemporality (or timelessness) because of the need to protect God's omniscience or foreknowledge.

${ }^{1586}$ DeWeese, God and the Nature of Time, 185-193. Scotus is particularly interesting because he evidently had a profound influence upon Heidegger. For an exploration of Scotus's influence upon Heidegger, see Philip Tonner, Heidegger, Metaphysics and the Univocity of Being (New York, NY: Continuum, 2010).

${ }^{1587}$ Interestingly, Ockham is notable for his criticisms of the Papacy and its abuse of power denying individuals freedom during his time; see, for example, Takashi Shogimen, Ockham and Political Discourse in the Late Middle Ages (Cambridge, UK: Cambridge University Press, 2007), 75-77; and Arthur Stephen McGrade, The Political Thought of William Ockham: Personal and Institutional Principles (Cambridge, UK: Cambridge University Press, 1974).

1588 "Ockham saw God as subject to time. Consequently, for God, as for humans, the future has not yet happened. This leads Ockham into an awkward situation, as he tries to maintain God's knowledge of future contingents," Alexander S. Jensen, Divine Providence and Human Agency: Trinity, Creation and Freedom (New York, NY: Ashgate, 2014), 45. For a contemporary effort to do so in line with his thinking, see In-Kyu Song, Divine Foreknowledge and Necessity: An Ockhamist Response to the Dilemma of God's Foreknowledge and Human Freedom (Lanham, MD: University Press of America, 2002). Ockham was committed to an "essential temporality in every creature, [an] idea which he so strongly defended against St. Thomas Aquinas and Duns Scotus.... Ockham believed that it is impossible for a creature to possess the fullness of its being in one instant without any succession in its very being. What is produced must be in time," Philotheus Boehner, "Introduction," in William Ockham, Philosophical Writings, tr. and ed. Philotheus Boehner, and Stephen F. Brown (Indianapolis, IN: Hackett Publishing Company, 1990), xliv.

${ }^{1589}$ Martin Heidegger, with Theodore J. Kisiel and Thomas Sheehan, Becoming Heidegger: On the Trail of His Early Occasional Writings, 1910-1927 (Evanston, IL: Northwestern University Press, 2007), 107. Heidegger wrote, "After graduation [in 1913], my initial intention inclined toward an investigation of late scholasticism, above all Ockham, in order to obtain, by way of this illumination of late Scholastic thought, a concrete and broad infrastructure for the scientific understanding of the history of the genesis of Protestant theology and thereby of the central contexts of problems of German idealism. My preoccupation with Ockham made a return to Duns Scotus urgent for me," ibid. See also, Philip Tonner, "Between Medieval and Modern Beholding: Heidegger, Deleuze and the Duns Scotus Affair," in Heresy and the Making of European Culture: Medieval and Modern Perspectives, eds. Andrew P. Roach and James R. Simpson (New York, NY: Ashgate, 2013), 422.

${ }^{1590}$ S. J. McGrath, The Early Heidegger \& Medieval Philosophy: Phenomenology for the Godforsaken (The Catholic University of America Press, 2006), 104; and DeWeese, God and the Nature of Time, 194. McGrath observes that "Heidegger [sought] to bring out the analogy between Scotus's metaphysics and Husserl's phenomenology," McGrath, The Early Heidegger \& Medieval Philosophy, 104. DeWeese observes that "Ockham follows the logic of Duns Scotus' position beyond where even Duns Scotus himself went, and in so doing he apparently gives us the earliest sketch of a theory of divine temporality," DeWeese, God and the Nature of Time, 194. Heidegger followed a similar relational pattern with his mentor, Husserl, expanding a new view of time 
noted that Luis de Molina (1535-1600) and his contemporary Francisco Suárez (1548-1617) were also open to some aspects of temporality ${ }^{1591}$ (and the trio of Scotus, Ockham, and Suárez are singled out for criticism by some contemporary Catholics who consider themselves the guardians of the traditional perspective ${ }^{1592}$ ).

Moving even further along the pathway of history and reflection about time, in the newly emerging American philosophical tradition that began in the $18^{\text {th }}$ and $19^{\text {th }}$ centuries, but which was soon forgotten by many who focused on the European contributions, the neglected (until very recently) works of the father of pragmaticism, a variant of pragmatism, Charles Sanders Peirce ${ }^{1593}$ (1839-1914), and his fellow pragmatists Josiah Royce ${ }^{1594}$ (1855-1916), George H. Mead ${ }^{1595}$ (18631931), and Alfred Hodder ${ }^{1596}$ (1866-1907), amongst others, such as William James ${ }^{1597}$ (1842-1910),

and temporality through the methods of his predecessor in phenomenology. See also, Daniel 0. Dahlstrom, Heidegger's Concept of Truth (Cambridge, UK: Cambridge University Press, 2001), 132. "Heidegger's critique of what Husserl has made of phenomenology suggests strongly that there is another trajectory for phenomenology, but hardly one incompatible with Husserl's undertaking. ... [H]eidegger's principal reason for ... [criticizing Husserl] is not to demonstrate that Husserl's conception of phenomenology is self-refuting. His main objective is to persuade his students that phenomenology, as a philosophical method, has a different destiny," ibid.

${ }^{1591}$ DeWeese, God and the Nature of Time, 201-208. Given that Molina utilizes a novel idea, "Middle Knowledge," in which essentially God foreknows the future because God knows what any person's free will would hypothetically do in any given situation, Molina's contribution is important. However, many who have utilized this idea, including Molina himself, but also contemporaries such as William Lane Craig, have implemented it in a platonic way, such that God is a atemporal or timeless prior to His original act of creation. Thus, time is fundamentally related to creation or the "motions" of the created order. Whether Middle Knowledge can function without such divine atemporality is another matter for another place-I'm inclined to disagree that it resolves any problems concerning God's relationship to freedom and time. For more on Craig's view, see Craig, God, Time, and Eternity: The Coherence of Theism II: Eternity, 60.

${ }^{1592}$ Sweeney, Sacramental Presence after Heidegger: Onto-theology, Sacraments, and the Mother's Smile, 29-30.

${ }^{1593}$ For example, Charles Sanders Peirce, Peirce on Signs, ed. James Hoopes (Chapel Hill, NC: The University of North Carolina Press, 1991), 41-50; and Floyd Merrell, Peirce, Signs, and Meaning (Buffalo, NY: University of Toronto Press, 1997), 37. "Peirce's conception of 'logic' in the 'broadest possible sense' embraces temporality," ibid.

${ }^{1594}$ See, Jacquelyn Ann K. Kegley, Josiah Royce in Focus (Bloomington, IN: Indiana University Press, 2008), 33. "Royce clearly believes temporality to be central to life, thought, and all reality," ibid. See also, Dwayne A. Tunstall, Yes, But Not Quite: Josiah Royce's Ethico-Religious Insight (Bronx, NY: Fordham University Press, 2009), 110-130; Randall E. Auxier, Time, Will, and Purpose: Living Ideas from the Philosophy of Josiah Royce (Chicago, IL: Open Court, 2013), 72, 126, 379 n. 25; and Jarvis, The Conception of God in the Later Royce.

${ }^{1595}$ For example, George Herbert Mead, The Philosophy of the Present (Amherst, NY: Prometheus Books, 1992). See also, Maurice A. Natanson, The Social Dynamics of George H. Mead (The Hague, The Netherlands: Martinus Nijhoff, 1973), 39-43; Berit O. Brogaard, "Mead's Temporal Realism," in Transactions of the Charles S. Peirce Society Vol. XXXV, No. 3 (Summer, 1999), 563-593; and Gary A. Cook, George Herbert Mead; The Making of a Social Pragmatist (Chicago, IL: University of Illinois Press, 1993), 142-156.

${ }^{1596}$ Alfred Hodder, The Adversaries of the Sceptic, Or, The Specious Present: A New Inquiry into Human Knowledge (New York, NY: The Macmillan Company, 1901). Hodder, in particular, has received very little attention amongst contemporary $21^{\text {st }}$ century philosophers, despite the fact his ideas clearly foreshadow and 
could also be said to support a view of temporality very much in line with or anticipatory to Heidegger's own suggestions. ${ }^{1598}$ The collection of names in the group above, all whom happen to be Americans from the $19^{\text {th }}$ and dawn of the $20^{\text {th }}$ century, are interesting because their thinking developed around the same time as their European counterparts, yet with relative independence. That is, they developed parallel philosophical ideas concerning time just prior to Heidegger's own reflections about time. ${ }^{1599}$ On this point, it must also be noted, Heidegger probably did not have much if any exposure to their ideas, which is not true of some probable Asian influences upon Heidegger. ${ }^{1600}$

mirror Heidegger's.

${ }^{1597}$ For example, see Jeremy Carrette, William James's Hidden Religious Imagination: A Universe of Relations (New York, NY: Routledge, 2013), 183; Charlene Haddock Seigfried, William James's Radical Reconstruction of Philosophy (Albany, NY: State University of New York Press, 1990), 43-49; Richard Dennis MacAdam, Temporality and Ethics in William James (Boston, MA: Boston College, 1976); and Lanei M. Rodemeyer, Intersubjective Temporality: It's About Time (Dordrecht, The Netherlands, Springer, 2006), 134 n. 201.

${ }^{1598}$ See, for example the efforts to favorably compare and contrast pragmatism and phenomenology, especially in regards to time, with Sandra B. Rosenthal and Patrick L. Bourgeois, Pragmatism and Phenomenology: A Philosophic Encounter (Amsterdam, The Netherlands: B. R. Grüner, 1980); Ronald Bruzina and Bruce Wilshire, eds. Phenomenology: Dialogues and Bridges (Albany, NY: State University of New York Press, 1982); Carl B. Sachs, Intentionality and the Myths of the Given: Between Pragmatism and Phenomenology (New York, NY: Routledge, 2014); and Bruce Wilshire, The Primal Roots of American Philosophy: Pragmatism, Phenomenology, and Native American Thought (University Park, PA: The Pennsylvania State University Press, 2000).

${ }^{1599}$ See the illustrative work by Richard J. Bernstein, The Pragmatic Turn (Malden, MA: Polity Press, 2010). For an excellent treatment of the development of philosophical ideas integrating the European thinkers with contemporary American concerns, see Charles M. Sherover, From Kant and Royce to Heidegger: Essays in Modern Philosophy, ed. Gregory R. Johnson (Washington, D. C.: The Catholic University of American Press, 2003).

${ }^{1600}$ Heidegger has frequently had his writings and Zen Buddhism favorably compared, alongside Taoism and other Asian philosophical traditions, which apparently have much in common and have mutually inspired each other in recent times. See Louis Roy, Mystical Consciousness: Western Perspectives and Dialogue with Japanese Thinkers (Albany, NY: State University of New York Press, 2003), 146; Newman Robert Glass, Working Emptiness: Toward a Third Reading of Emptiness in Buddhism and Postmodern Thought (Atlanta, GA: Scholars Press, 1995), 29-31. Glass observes "The extreme claim would be this: Heideggerian presencing is Buddhist enlightenment," 31. Additionally, for more recent comparative efforts, see Warwick Fox, Toward a Transpersonal Ecology: Developing New Foundations for Environmentalism (Albany, NY: State University of New York Press, 1995), 250-251; Manuel Valasquez, Philosophy: A Text with Readings (Boston, MA: Wadsworth, 2011), 178; Tonner, Heidegger, Metaphysics and the Univocity of Being, 123; Caputo, The Mystical Element in Heidegger's Thought; Sonya Sikka, Forms of Transcendence: Heidegger and Medieval Mystical Theology (Albany, NY: State University of New York Press, 1997); and Anthony J. Steinbock, Phenomenology and Mysticism: The Verticality of Religious Experience (Bloomington, IN: Indiana University Press, 2007), 150. Steinbock writes, "in my view, Heidegger sketches most profoundly the view that I contrast with that of the mystics," in the sense of a productive dialogue, ibid. For more, see, Matthew C. Bagger, The Uses of Paradox: Religion, Self-Transformation, and the Absurd (Chichester, West Sussex: Columbia University Press, 2007), 67. Bagger comments on "Heidegger's well-known fascination with the Tao-te-ching. Taoism attracted him because it poses the 'question of Being' while dwelling in a language which does not by its very structure confuse the 'Being of beings' with a being," ibid. Other literature includes Joan Stambaugh, "Heidegger, Taoism and the Question of Metaphysics," in Journal of Chinese Philosophy 11 (1984), 337-352; Reinhard May and Graham Parkes, Heidegger's Hidden Sources: East Asian Influences on His Work (New York, NY: Routledge, 1996); and Katrin Froese, Nietzsche, Heidegger, and Daoist Thought: Crossing Paths In-Between (Albany, NY: State University of New York, 2006). 
This whole situation is noteworthy, in that if Heidegger's primary ideas about time and reality were being independently developed elsewhere around the same time, or even earlier in Asia, then it further reenforces the poignancy of the crisis of the two cultures as existing beyond merely the mind of one person, namely, Heidegger. It's not simply Heidegger against Einstein and the cult of scientific culture; Heidegger merely became the more famous name to dominate the new discoveries about humanity and time.

For example, one could argue that the Buddhist Zen philosopher Dōgen Zenji (1200-1253), founder of the Sōtō school of Zen, amongst others, held very similar ideas to that of Heidegger concerning the centrality of time for Being, ${ }^{1601}$ which suggests that the Far East had also long been aware of the tensions inherent in the two cultures. Thus, while Heidegger may be the father of the cultural and academic movement of temporality in the West, the problems he raised exist(ed) independently from his mind in both Europe, America, and in earlier periods of Asian history, just as Pythagoras may have been the first to articulate what inevitably others already knew (allegedly in the Far East) or would, presumably, have later discovered, concerning certain mathematical formulae.

\footnotetext{
Tomonobu Imamichi has even suggested Heidegger's original idea behind Dasein came from Eastern philosophy, Tomonobu Imamichi, In Search of Wisdom: One Philosopher's Journey, tr. Mary E. Foster (International House of Japan, 2004), 123. To bolster the probability and fruitfulness of this potential connection, it is noteworthy that Heidegger was known to have had several conversations with Asian monks which were mutually beneficial, as noted by Heinrich Wiegand Petzet, Encounters and Dialogues with Martin Heidegger, 1929-1976, tr. Parvis Emad and Kenneth Maly (Chicago, IL: The University of Chicago Press, 1993), 159-183. Lastly, on one occasion in the middle of his career, Heidegger was reported to have enthusiastically commented about a book he had just read by the Zen Buddhist monk and philosopher, Daisetz Suzuki, "if I understand this man correctly, this is what I have been trying to say in all my writings," William Barrett and Daisetz T. Suzuki, Zen Buddhism (New York, NY: Random House, 1996), xii.

${ }^{1601}$ See, for example, Joan Stambaugh, Impermanence is Buddha-nature: Dōgen's Understanding of Temporality (Honolulu, HI: University of Hawaii Press, 1990). Stambaugh sees significant similarities between the $13^{\text {th }}$ century Zen Buddhist philosopher Dōgen and the German $20^{\text {th }}$ century postmodern philosopher Martin Heidegger. As Kevin Schilbrack similarly explains, "what is, according to Dōgen, is temporal.... 'Time, just as it is, is being, and being is all time,"” Kevin Schilbrack, "Metaphysics in Dōgen," Philosophy East \& West, Vol. 50 \#1 (Jan. 2000), 37. See also, Steven Heine, Existential and Ontological Dimensions of Time in Heidegger and Dōgen (Albany, NY: State University of New York Press, 1985); Esperanza Ramirez-Christensen, Emptiness and Temporality: Buddhism and Medieval Japanese Poetry (Stanford, CA: Stanford University Press, 2008); Hee-Jin Kim, Dōgen on Meditation and Thinking: A Reflection on His View of Zen (Albany, NY: State University of New York Press, 2007); and Rein Raud, “The Existential Moment: Re-reading Dōgen's Theory of Time," in Philosophy East and West Vol. 62, No. 2 (April 2012), 153-173.
} 


\section{Summary on the Origin of Time in Ancient Greece and the West}

There are three primary conclusions that can be derived from the above survey on the origins of time in the Western (Greek) tradition. The first two can be attributed to "the ceaseless flux of Heraclitus and the unitary stability of Parmenides." But these two merely prepare the way for "the Pythagorean belief that proper thinking required an ordered way of life," which "was the third main

influence on future Greek philosophy." ${ }^{1602}$ It is this third influence that may, in fact, be the most dominant and important of the three. The Pythagorean idea of "proper thinking" emphasized the "at times magical powers of numbers," ${ }^{1603}$ which continues today in many both implicit and explicit ways. Importantly, the "timeless" aspect of reality is best preserved, both implicitly and explicitly, through the conjunction of mathematics and technology as manifested in their utilization and manipulation of nature. Furthermore, from an historical perspective, it is important to realize that "modern, everyday scientific and philosophical concepts of space and time can be clearly traced to primitive mythological and religious notions." ${ }^{1604}$ Thus, "the changes in the concepts of space and time" through the centuries were "far from a complete evolutionary metamorphosis. The constancy of a few basic, parallel threads throughout this long historical evolution of thought is striking." ${ }^{1605}$ It appears, then, that it is true indeed that there is seldom anything new under the sun, and the two cultures originated their conflict very early in history.

The Origin of Freedom in Western Philosophy and Theology

Robert Kane summarized the issue plainly when he shared that "the multifaceted issue of free will" is "'arguably the most difficult ... in philosophy."'1606 As we've seen already, however, the mystery of freedom has some tough competition with the mystery of time. In any case, in this section, I will seek to recover the historical origins surrounding the mystery of free-will, as well as other

\footnotetext{
1602 John Peterman, On Ancient Philosophy (Belmont, CA: Thomson \& Wadsworth, 2008), 44.

${ }^{1603}$ Peterman, On Ancient Philosophy, 44.

${ }^{1604}$ Peuquet, Representations of Space and Time, 13.

1605 Peuquet, Representations of Space and Time, 13.

${ }^{1606}$ Robert Kane, The Significance of Free Will (New York, NY: Oxford University Press, 1996), 3, citing Susan Wolf, Freedom Within Reason (New York, NY: Oxford University Press, 1990), vii.
} 
forms of freedom such as political liberty, in the Western tradition. In particular, I will briefly trace the origins of the ideas of political freedom, existential or "free-choice" freedom, ethical freedom, and religious freedom-sometimes, of course, discussions surrounding them overlap. Notably, despite having complex histories of their own over very long periods of development, all of them have been also profoundly effected by the rise of the modern disciplines of physics and biology.

It is important to observe, including within the structure and flow of this study, that many things pertaining to the dominance of the sciences in conceptions of time also applies to freedom. I addressed some of the issues relating to science and time first, as historically they were more explicitly addressed and understood first in relation to time. Freedom is, in this sense, time's slightly more enigmatic twin, but also the one with the most poignant significance in society, historically and in the present. People "care" very passionately about freedom, as the American pioneer Patrick Henry made clear in his 1775 speech to the Second Virginia Convention, advocating for what would become the Revolutionary War, by crying, "give me liberty, or give me death!"1607 Note, he didn't say, "give me time or give me death!" Rather, freedom is, understood within the context of Henry's quote, somehow more valuable than time itself, though Henry would surely have acknowledged that freedom without common-sense experiential time ("life") is meaningless. It is for this reason, regardless of other possible philosophical reasons, that it remains the first term in the pairing of "freedom and time" in the contemporary Western tradition, including within this study.

As was done above, it is important to begin with a comment on how the concept of freedom appears in Scripture. In brief, what can be said succinctly is that it appears, like time, in an ambiguous way in Scripture. ${ }^{1608}$ The nature of free-will is simply not conceptually clear in relation to the

${ }^{1607}$ David J. Vaughan, Give Me Liberty: The Uncompromising Statesmanship of Patrick Henry (Elkton, MD: Cumberland House, 1997), 85. It is not insignificant that in this instance, Patrick Henry invoked God Himself, essentially sharing that it would be treason against God not to take a stand for "liberty," even if in doing so he might face "death," ibid., 84-85.

1608 The Scriptures, particularly the New Testament, use the "paradoxical language which equates subjection to the divine lordship with freedom," Richard Bauckham, "Using the Bible to do Politics: Freedom," in Third Way (April 1985), 7. While many Christians are obviously comfortable with accepting the concept of Christ as Lord, this does indeed create many complex paradoxes which must be resolved or clarified to be intelligible philosophically when it comes to understanding freedom here on earth in the personal, social, and political spheres. See also, for example, the essays in Michael Welker, Quests for Freedom: Biblical-HistoricalContemporary (Göttingen, Germany: Neukirchener Verlagsgesellschaft, 2015); Albert J. D. Walsh, A Pastoral 
concepts of sinful nature, natural/biological propensities and natural laws, the Holy Spirit, and divine foreknowledge. The ambiguity evidently present in the canon of Scripture has helped produce the two cultures, not resolve or dissolve them. Nevertheless, how freedom and time relate in the Bible itself would be a worthy study, but, for reasons I've intimated above concerning time, it may not easily provide a resolution to a problem that resides in philosophical reasoning itself, which has already been engaged in dialogue with the text of Scripture for millennia; as such, it appears at present that Scripture and philosophy are a symbiotic whole concerning the problems of freedom ${ }^{1609}$ and time. As such, the proffered supposition is that the present study may prove insightful prior to any corresponding biblical survey on the concepts of freedom and time. Not because human reasoning is superior to Scripture, but rather because it may be possible that our natural world, even if cursed, may provide new or fresh analogies (relativity theory, quantum physics, etc.) with which we may wrestle before attempting to decode the ambiguous lexical issues and etymological roots of the biblical words for freedom and time.

In a similar manner to the above section on time, as the study reviews the origins of freedom below, the focus will be on the most important originators of the different concepts and their modern interpreters, and not provide a full chronological account. Also, as with the above review of the origins of time, the purpose of the inquiry below on the origins of freedom is to expose the deeply rooted nature of the conflict between the two cultures, and not to offer an original exposition of the

Proposal for an Evangelical Theology of Freedom: A Respectful Response to the Expressed Hope of Dr. Karl Barth (Eugene, OR: Wipf \& Stock, 2013); Peter Addinall, Philosophy and Biblical Interpretation: A Study in NineteenthCentury Conflict (Cambridge, UK: Cambridge University Press, 1991), 236-241, which addresses Kant's work.

${ }^{1609}$ David Ciocchi asserts plainly: "Anyone who wants a genuinely biblical understanding of what it is to be a human being will discover that the concept of freedom is essential to that understanding. This discovery is likely to lead to another insight-that understanding freedom requires some help from the discipline of philosophy." He also adds, insightfully, that "it can be misleading ... to talk about the concept of freedom. There is in fact a whole family of freedom concepts," David M. Ciocchi, "Human Freedom," in Christian Perspectives on Being Human: A Multidisciplinary Approach, eds. J. P. Moreland and David M. Ciocchi (Eugene, OR: Wipf and Stock, 1993), 87. Of course, this is not to say that philosophical reasoning could or should ever be sovereign over the biblical text. Rather, "The contemporary concept of freedom is deficient in having no real idea of what freedom is for," which only Scripture can reveal, Richard Bauckham, The Bible in the Contemporary World: Hermeneutical Ventures (Grand Rapids, MI: Eerdmans, 2015), 77; see also, Richard Bauckham, God and the Crisis of Freedom: Biblical and Contemporary Perspectives (Louisville, KT: Westminster Jon Knox Press, 2002). The present problem then becomes, of course, that Christians disagree on what freedom is for according to the Scriptures, and their disagreements appear to place them as replicators of the war between the two cultures. 
selected figures views' in themselves. Conflicts concerning their interpreters must be set aside for this study.

\section{The Origin of the Concept of Freedom in Ancient Greece and the West}

Of all the freedoms that one may discern in academic work, it is social or political freedom (liberty) that first occurs in a serious way within the historical records of Western civilization. And, as with time, the most significant early contribution to the concept of freedom occurred in ancient Greece, and involved the tensions of balancing political liberty, authority, and equality. It is no small irony, of course, worthy of noting at the outset, that although political liberty was discovered relatively early in recorded history, in the eras ensuing since then, political liberty has more often than not been difficult to find. ${ }^{1610}$ In early Greece, however, as Sherover explains the well known story, around 594 B. C., "in the city of Athens, the birthplace of Western Civilization, the democratic concept was first forged, its virtues, problems and promises first critically examined. The Athenian innovation of democratic government looms as one of the great revolutionary turning points in the history of human development."1611

The key figure in Athens at the time was a merchant named Solon, who was evidently charged

with the responsibility of fixing an economic crisis in the city. ${ }^{1612}$ Although Solon is credited by many for first introducing the idea of democracy, or the equal voting rights of all (at least adult males), it is more probable that the credit should go to his Greek successor Pericles (d. 429 B. C.), who helped overthrow a later oppressive oligarchy that had come to control Athens. ${ }^{1613}$ Yet, to focus upon what

${ }^{1610}$ John Dunn, Democracy: A History (New York, NY: Atlantic Monthly Press, 2005), 13-14.

"Democracy ... began as an improvised remedy for a very local Greek difficulty two and a half thousand years ago, flourished briefly but scintillatingly, and then faded away almost everywhere for all but two thousand years, ibid.

${ }^{1611}$ Sherover, The Development of the Democratic Idea: Readings from Pericles to the Present, 1.

1612 Sherover, The Development of the Democratic Idea: Readings from Pericles to the Present, 1.

${ }^{1613}$ Sherover, The Development of the Democratic Idea: Readings from Pericles to the Present, 1 . See also, Maria Noussia Fantuzzi, Solon the Athenian, the Poetic Fragments (Leiden, The Netherlands: Koninklijke Brill, 2010), 25. Fantuzzi observes that "the immediate impact of [Solon's reforms] on the management of power can hardly be termed 'democratic,' since the most important public duties were still reserved for ... the wealthiest citizens, the majority of whom were already nobles. ... Nevertheless, Solon's reforms probably marked a turn toward timocracy, although without major disruption to the preceding aristocratic regime, because he granted access to the political power to those with sufficient wealth regardless of land-ownership, thus opening doors to the emergence of nouveaux riches whose origins lay outside the landed $\gamma \varepsilon \dot{v} \eta$ of the 
Solon did accomplish for political liberty, according to Ron Owens, is that Solon introduced two particularly noteworthy plans. First, he required the cancellation of all debts, apparently aiming this reform at a particular group within Athens that was exerting oppressive control over the rest of the city as debt collectors. ${ }^{1614}$ This wealthy group had, allegedly, taken "more than their allotted share," and had "also deliberately acted in a manner which sought to deprive others of, and to prevent them from receiving, that which was their particular due."1615 Second, and also related to the issue of money, Solon created a prohibition on the offering of a person as security for a loan, which established the conditions necessary for the later development of a concept of political liberty. ${ }^{1616}$

Yet, despite the foreshadowing of the concept of "liberty" within Solon's contributions, the critical point of Owens' interpretation of what Solon accomplished is that, at heart, "whilst [Solon's] economic reforms were, amongst other things, decidedly political in their outcomes, in that they sought to resolve a serious conflict between the contesting and politically opposed parties, it is difficult to assign political considerations as their primary motivation or as their underlying rationale." Rather, "fundamentally, the reforms were aimed at resolving a conflict which, in its very nature, was a conflict over morality." 1617

The point to be deduced from the above is that, from its inception, economics and politics were grounded upon a 'religious' concern-that of the relation of morality to the economic and political realm. As such, Solon can be credited with introducing rational 'thinking' into morality at the social level, for Solon's "ability to 'ignore present mockery"' was "based upon his own rational appraisal of what is right, considered from a long-range perspective." Thus, "Solon was [one of the first to offer a]

Eupatridai [ruling group], ibid., 25.

${ }^{1614}$ Ron Owens, Solon of Athens: Poet, Philosopher, Soldier, Statesman (Portland, OR: Sussex Academic Press, 2010), 128-129.

1615 Owens, Solon of Athens: Poet, Philosopher, Soldier, Statesman, 129.

${ }^{1616}$ Owens, Solon of Athens: Poet, Philosopher, Soldier, Statesman, 128.

${ }^{1617}$ Owens, Solon of Athens: Poet, Philosopher, Soldier, Statesman, 129. See also, Bernard Randall, Solon: The Lawmaker of Athens (New York, NY: The Rosen Group, 2004), 36; and Fantuzzi, Solon the Athenian, the Poetic Fragments, 132. Speaking of Solon's work and poetry, Fantuzzi comments, "framing political activity in the context of a general ethical scheme certainly meets the ideas of archaic morality," ibid. Solon seemed concerned about "the difference between righteous and unjust wealth," ibid., 148. There is a "distinction between 'proper and god-given' and 'unjustly obtained' wealth, ibid. 
formal repudiation of the shame morality," wherein shame is based upon the ideas of specific powerful groups or other individual's perspectives besides one's own. ${ }^{1618}$ Solon's new emphasis on the role of common rationality in public life or politics will prove important, as it foreshadows Plato's contributions, as will be noted below.

First, however, it is to the influence of Pericles that we must briefly turn. Pericles was the greatest of the early Greeks to expound upon what would become a true understanding of a democratic government (again, limited to adult males). The Athenian city-state, following his influence, represented a direct democracy, where each man had his vote. ${ }^{1619}$ Nevertheless, whatever one may think of Solon's and Pericles' contributions within their context, ${ }^{1620}$ at least one major issue that both Solon and Pericles neglected would consume much attention by later thinkers. And that is the issue of the protection of the rights of the minority. This shortcoming can be illustrated in more than one way, yet perhaps most poignantly through the "system of ostracism," wherein "a meeting of the Assembly would decide whether an ostracism should be held, and then all the citizens would write the name of the person that they wanted to leave the city on a small piece of pottery called an ostracon. The pieces of pottery were then counted and the person whose name appeared most often was expelled from the city for ten years."1621 Despite the obvious potential abuses of the system of ostracism for unlucky individuals, its harshest application, which came some years later, was the death sentence of Socrates (c. 469-399 B. C.). This instance has long best represented, in the minds of many, the greatest failure of the rule of the democratic majority. As Sherover explains, at least

${ }^{1618}$ John David Lewis, Solon the Thinker: Political Thought in Archaic Athens (New York, NY: Bloomsbury Academic, 2006), 39. Lewis adds that it appears Solon "shifted ... from a 'dependent' to an 'independent' standard [of judging morality]. This interpretation differentiates Hector [another ancient Greek] more fundamentally from Solon. 'Independent' acknowledges the higher value placed on one's own conclusions than on the pressures of the crowd; it is a focus on the facts and not on other people. Philosopher Leonard Peikoff's definition of 'independence as primary orientation to reality and not to other men' is virtually a restatement of Solon [fragment] 11.7-8," ibid., 39-40.

${ }^{1619}$ Harnish Aird, Pericles: The Rise and Fall of Athenian Democracy (New York, NY: The Rosen Publishing Group, 2004), 33. For more on Pericles, see Stephen V. Tracy, Pericles: A Sourcebook and Reader (Berkeley, CA: University of California Press, 2009); and Thomas R. Martin, Pericles: A Biography in Context (New York, NY: Cambridge University Press, 2016).

${ }^{1620}$ For a recent and critical work about Pericles, see Incent Azoulay, Pericles of Athens, tr. Janet Lloyd (Princeton, NJ: Princeton University Press, 2014).

${ }^{1621}$ Aird, Pericles: The Rise and Fall of Athenian Democracy, 35. 
according to Plato, "Socrates was guilty of nothing more than the advocacy of unpopular opinions." Thus, "because Socrates, by insightful questioning, raised doubts about many popular foibles and exposed the philosophic ambiguities of popular pronouncements, he incurred the wrath of a number of leading citizens,"1622 and, in his instance at least, tragically felt obligated to commit suicide.

Sherover summarizes the situation simply-the Athenians "did not develop any viable concept of the rights of a minority dissenting from the will of the majority,"1623 exposing the first and what remains the greatest problem and flaw of democracy as the system most consider to best illustrate political liberty, one that has plagued it in every instance of its application in the governance of a nation, including in the representative democracy (Republic) of the United States. ${ }^{1624}$ What is important about this from an historical perspective is that the failures of the rule of popular majority in Athens gave rise to the very rationale that would reject it, that of Plato's notion of the "philosopher-

${ }^{1622}$ Sherover, The Development of the Democratic Idea: Readings from Pericles to the Present, 2.

${ }^{1623}$ Sherover, The Development of the Democratic Idea: Readings from Pericles to the Present, 2.

${ }^{1624}$ See the explanation of Loren J. Samons II, What's Wrong with Democracy?: From Athenian Practice to American Worship (Berkeley, CA: University of California Press, 2004), 11-13, 70. 
king." ${ }^{1625}$ Indeed, ironically, it is Pericles himself, as an evidently charismatic person, that can be described as "the prototype for Plato's philosopher-king” through his powerful "personality."1626

Indeed, Plato's basic argument was that the only truly just political order must combine "wisdom" with "power," which is best expressed through presence of a "philosopher-king" or wise ruler. ${ }^{1627}$ Of course, understanding what constitutes "wisdom" then becomes paramount. Plato elevated his notion of timeless mathematical reasoning as philosophy, construed in his uniquely influential way, as the model or paradigm for others to follow. ${ }^{1628}$ Plato's defense of his system is that

\footnotetext{
${ }^{1625}$ Sherover explains the overall situation as follows: "Plato is generally regarded as the first great western philosopher; he has had a profound influence to the present day on the development of our civilization. It is reasonable to believe that a large number of his convictions were developed from his very personal involvement with what he regarded as the martyrdom of Socrates. That Socrates, whom Plato regarded as the wisest of men, should be condemned by the court of a democracy, was unforgivable. It may, in large part, explain the opposition to democratic politics which is to be found in his Republic. From the vantage point of political philosophy, the prime significance of Plato's most famous book was the repudiation of the democratic concept; his ideal state was to be governed by men specially trained to govern wisely, men who would be guided by their insight into reason alone and who would be unhampered by custom or by [flawed human] laws.

"The rule of trained wise men, the philosopher-kings, remained his ideal. But as his thought matured he grudgingly came to terms with political realities. In two of his late dialogues, the Statesmen and Laws, he turned his attention away from his 'ideal' form of government to what he termed the 'second best,' the best form that it is possible to attain. In this best of possible states he sought to combine the virtues of a wise ruler with the virtues of popular control; in the absence of a truly wise philosopher-king, some degree of popular control of government, some direct participation of the demos, the people, was essential in order to ward off tyranny. In the absence of the ideal state of the philosopher-kings, he developed the thesis that government should be by laws and not by men. This is to say that government should not be at the whim of the individual ruler or monarch but by universal or general regulations which are applied to persons in authority as well as to the lowliest citizen.

"Plato combined the virtues he saw in the intelligent administrations of the affairs of state by trained officials under laws with the participation of the populace in the formation of those laws; he thus suggested a 'mixed' form of government in which the virtues of aristocracy and popular control were combined. This concept of mixed government was developed by Aristotle, amplified by Cicero (106-143 B.C.), reinvented by Montesquieu (1689-1755) and as such it became the guiding principle of the system of 'checks and balances' embodied in the American Constitution in 1789," Sherover, The Development of the Democratic Idea: Readings from Pericles to the Present, 3 (additions mine). Balancing this "mixed" state remains the paradox of modern political philosophy.

${ }^{1626}$ Mason Hammond, City-state and World State in Greek and Roman Political Theory Until Augustus (Biblo and Tannen, 1966), 11.

${ }^{1627}$ William Desmond, Philosopher-Kings of Antiquity (New York, NY: Continuum, 2011), 15, 19-20.

${ }^{1628}$ Desmond, Philosopher-Kings of Antiquity, 164; Douglas J. Soccio, Archetypes of Wisdom: An Introduction to Philosophy (Boston, MA: Cengage Learning, 2016), 155. Of course, Plato is merely building off of "the Pythagoreans, or perhaps even Pythagoras himself already," who had "established as a strict rule that it was permitted to philosophize only if one tied the problems to mathematical-geometrical formulation. For then no differences of opinion were possible, ultimately, and so there was a guaranty against disunity," Cleve, The Giants of Pre-Sophistic Greek Philosophy: An Attempt to Reconstruct Their Thoughts Vol. 2, 518. All this, of course, must be understood within a context that understands that "being politicians, the Pythagoreans had ... first of all to establish organization and authority," for the Pythagoreans represented "the culture [of] politicians, and their ultimate goal an education of mankind," and from such an "interpretation everything else could easily be understood; above all, the impact on Plato," for whom, within the culture of "politics, [the] education of mankind" "is exactly also the ideal of Plato, in his older years at least, when he was no longer so close to Socrates
} 
the philosopher-king would be "the servant of a fundamental social order," that is, it is 'Reason' and not the man that grounds the philosopher-king's just rule. ${ }^{1629}$ However, as Roger Huard observes, the implementation of a true philosopher-king alongside freedom seems perpetually impossible, as it mixes an idealized (timeless) view of wisdom and truth with "political forms" that must be realized in "humans." ${ }^{1630}$ The implication being that "Plato is not concerned about the free choice of the right way

and Parmenides, but to Pythagoreanism," ibid. Notably, "all of that Platonic vision that mankind will arrive at happiness when goodness and wisdom will combine with power-an idea that afterwards, by way of the Civitas Dei of St. Augustine, was to have such far-reaching historical consequences-, this hope for the rule of a spiritual minority in the multitude's own very best interest-, all this appears to be just Pythagoreanism in its most genuine and original form," ibid. See also, Charles P. Webel, The Politics of Rationality: Reason Through Occidental History (New York, NY: Routledge, 2014), 205. Webel summarizes the critical points as follows, and I quote at length: "The avowal that nature and society corrupt us, and that reason remains a theoretical and practical unity with critical potential, has been central to the rationalist metaphysics from Plato to the Frankfurt School [founded in 1923].

"In sum, the great rationalist thinkers have tended to agree that human knowledge must take the form of universally valid and objective laws or principles that are often mathematical in expression and that 'reproduce' the underlying, essential, rule-governed structure of physical reality. They have argued that the terms they employ have universal applicability and real, ontologically distinct referents. Ethically, most rationalists have thought that moral values, while methodologically distinct from natural facts, nonetheless must possess the same characteristics as scientific judgements-universalizability and strict necessity-in order to be intersubjectively and cross-culturally valid. And in terms of political acuity and historical sensitivity, figures such as Plato, Descartes, Leibniz, Kant, and Hegel have tended to be elitist and aristocratic, individuals whose social and political judgments were often inflexible, authoritarian, and naive attempts to 'deduce' historical laws from a priori norms.

"When confronted with what they perceived to be 'unreasonable' historical agents and events, rationalists have often asserted that an ideal reality-whether factually described by theoretical reason or postulated as an ethical ideal by practical reason-could eventually be 'made flesh.' Either history and human nature would be reshaped to conform to the 'ideal world,' due to the political efficacy of those agents (such as philosopher-kings or virtuous princes) who had wedded power to truth, or the empyrean would remain accessible only to an August coteries of properly trained and morally inspired theorists.

"The 'intuition' or belief that an axiomatic, deductive 'science' of nature-a science whose first principles could be known to be true entirely a priori and without recourse to observation and experimental refutation-is all too compatible with a system of beliefs about the 'timeless' efficacy of reason in politics, society, and history that is prone to promulgating rigid blueprints for authoritarian social arrangements.... When the model of a timeless, ahistorical reason is transferred uncritically from the domain of epistemology to the cauldron of history, should history not conform to the dictates of reason, the once rational lawgiver could become a dictator," ibid., 205. In historic support of the basic thesis that timeless mathematics can promote civil society, one need look no further than Aristotle, who commented that "the discovery of calculation ends faction and promotes unanimity. Where it has entered, unfair advantage is impossible and equality established, since it is what enables us to agree over our contracts with one another. Through it the poor receive from the powerful, and the rich give to those in need, for both are confident that thus they will have their rightful share," Aristotle, as cited in Guthrie, A History of Greek Philosophy: Vol. 1: The Earlier Presocratics and the Pythagoreans, 336. Unfortunately, Aristotle's dream has never been realized, nor does it seem possible to do so upon his starting point.

${ }^{1629}$ N. Jayapalan, Comprehensive Study of Plato (Rajouri Garden, New Delhi: Atlantic Publishers, 2002),

53.

${ }^{1630}$ Roger L. Huard, Plato's Political Philosophy: The Cave (New York, NY: Algora Publishing, 2007), 43. Desmond comments that "the thread of 'Platonism' link[s] them all, a leitmotif that is a variation of the more widespread 'religion' of sacred kingship: the physical city should be organized under a rational wisdom, just as the cosmos is organized under eternal [timeless] Ideas," Desmond, Philosopher-Kings of Antiquity, 20 (addition mine). 
by the citizens of his state; he only insists that they follow the right way, as established by the objective reasoning of the philosopher."1631 As Hannah Arendt explained, for Plato, "theology ... was part and parcel of 'political science,' and specifically that part which taught the few how to rule the many."1632 Thus, rather, history has shown they cannot be brought together in a satisfying way, leading Plato's “isomorphism of [the free-willed] human and [the timeless ideal] city to its inevitable yet paradoxical conclusion," ${ }^{1633}$ that temporally and historically-rooted humans aren't so simple, unable to be able to be treated as merely numbers, and not names with free-will. The division between the sciences and humanities (two cultures) strikes (or first struck) again, albeit in a nascent and embryonic form, as the mathematized empirical sciences had not yet developed in Plato's rationalist mind. And, in what should amount to an unsurprising footnote, the same tension played out in ancient China and throughout the Far East as well, and continues today. ${ }^{1634}$

In what is an important consequence of the above "paradox," it must be noted that although mankind may be unable to realize their union, the Platonic utopian ideal came to a new evolutionary

\footnotetext{
${ }^{1631}$ Mordecai Roshwald, Liberty: Its Meaning and Scope (Westport, CT: Greenwood Press, 2000), 35. Plato rejects an "environment ... in which ideas roam freely through the expanse of time, continuously striving for truth, or rather trying to increase truth and decrease falsehood. Plato would have as little patience with such an open-ended process as would a teacher of geometry who would be prevented by trivial arguments from finishing the proof of a theorem at one session. For Plato truth is never elusive, but reachable, and so demanding to be reached. The quest for truth is not, essentially, a process progressing through time but a logical effort, in principle timeless. Therefore, if the quest requires the condition of intellectual freedom, as it obviously does, this is limited to the process of thinking, to rigorous dialogue, aiming at a definitive answer. Once this answer is attained, there is no more need to throw it into the arena of renewed controversy than there would be to submit to a new discussion the verities of mathematics," ibid. Roshwald further adds, "[Plato] gives less freedom to the subjects of the philosopher-king than was granted to the subjects of the ruling God by the Bible. The latter were considered as capable of choosing between right and wrong and were thus given the freedom to make a decision as sovereign beings. The former were denied any choice, were denied the dignity of free human beings, and thus could be deprived of the liberty to think and to speak," ibid., 35-36.

1632 Hannah Arendt, Between Past and Future: Eight Exercises in Political Thought (London, UK: Penguin Books, 2006), 131. Arendt adds that "nothing, indeed, is more suggestive in this context than that it was Plato who coined the word 'theology,' for which the passage in which the new word is used occurs again in a strictly political discussion, namely in The Republic, which the dialogue deals with the founding of cities. This new theological god is neither a living God nor the god of the philosophers nor a pagan divinity; he is a political device, 'the measurement of measurements,' that is, the standard according to which cities may be founded and rules of behavior laid down for the multitude," ibid., citing Plato's Republic book 2, 379a. See also, Abraham Melamed, "Medieval and Renaissance Jewish Political Philosophy," in History of Jewish Philosophy, ed. Daniel H. Frank and Oliver Leaman (New York, NY: Routledge, 1997), 352-388. Melamed observes that Jewish and Islamic political philosophers were especially drawn to Plato, as well as much of Christianity, for much the same reasons, that of seeking to establish eternal principles of order.

${ }^{1633}$ Huard, Plato's Political Philosophy: The Cave, 44.

${ }^{1634}$ Shiping Hua, Scientism and Humanism: Two Cultures in Post-Mao China (1978-1989) (Albany, NY: State University of New York Press, 1995).
} 
stage of implementation in the theology of Augustine. Through his work, the possibility of applying the "Platonic 'doubling' of [human] reality and [Ideal] truth to a Christian cosmology was realized."1635 Subsequently, "Plato's ironic notion of the philosopher king ... got replaced in Christian theology by the mystery of the Holy Trinity where an inscrutable God holds dominion over all that exists." Thus, “Augustine subverted Plato's irony and solved his 'problem' as to whether the philosopher-king could ever exist by replacing him with God in Heaven, a being that not only exists but is the source of everything that exists." However, this only meant that "the replacement of the philosopher-king with God" would shift "the matter of Plato's [paradoxical] isomorphic comparison of man and city to a different location, ${ }^{1636}$ heaven, and then consequently the Church on earth. ${ }^{1637}$ In other words, the paradox was moved from this world to heaven, where "God," merely by being God, resolved it, and then the paradoxical problem returned to earth through the Church, which, as has already been noted, is not providing any solutions vis-à-vis the world writ large (contra Plato, the city-state is, therefore, not like the individual but larger and easier to examine). The Church is, as ever, merely the replicator

\footnotetext{
${ }^{1635}$ Huard, Plato's Political Philosophy: The Cave, 44.

${ }^{1636}$ Huard, Plato's Political Philosophy: The Cave, 44.
}

1637 The inclusion of the Church as the earthly vehicle of Plato's heaven would have consequences. "In historical terms," the inclusion of the "Christian church," would amount to "essentially any person or institution that claimed to know how to interpret and implement the word of God in this world." This would bring God to earth in a 'political' way. "And again the irony of making this isomorphic comparison becomes completely lost and replaced by the literal, albeit mysterious, identity of our souls with God in the kingdom of heaven-the City of God. That this did violence to Plato's thought, violence we seem unable to correct or mend, can be seen in each of the prevailing myths used to explain the structure of the world-the Christian Garden versus Plato's Cave. Whereas Augustine believed in the Fall of man, Plato argued for an ascent from the cave. A further bracing irony: what precipitated the fall from grace and initiated the turn and ascent in the cave and upwards to the light was one and the same thing-knowledge!

"It is no accident that we members of the Christian West-of whatever stripe, and especially, I hasten to add, modern scientists-think of ourselves more as children of Adam rather than as prisoners in Plato's mythical cave. We are for this reason most apt to think of ourselves as less ambitious than Plato in our quest to know the truth. We assume that our epistemological goals are more in tune with our limited rational capacities. Plato, I have argued, becomes the audacious even arrogant thinker we find in our textbooks of Western Philosophy, because we read and interpret him in a context that makes him appear audacious and arrogant. Plato is seen to make claims about knowing things we have concluded either can't be known or don't exist... which in the Augustinian worldview amounts to the same thing," Huard, Plato's Political Philosophy: The Cave, 44-45. However, the less audacious attitude of scientists is misleading, as 'the prevailing 'scientific' assumption is that our present limitations in understanding the human condition are entirely a function of and shortfall in scientific knowledge that is yet to be acquired. Greater understanding about how the brain works, which is to say how it causes thought... will ultimately unlock the mysteries of how we humans fit into the vast overarching E=MC ${ }^{2}$ cosmos," ibid., 47. Overall, in short, it appears that we are "faced with a choice among three prevailing myths-the Cave, the Garden, or... E=MC ${ }^{2}$. In reality, we have tended to vacillate between $\mathrm{E}=\mathrm{MC} \mathrm{C}^{2}$ and the Garden and bury the Cave beneath this vacillation. This choice has deep implications for how we think about the moral and political universe we inhabit," ibid., 49. 
of the original philosophical problem wrought out through the origins of the merits of democracy versus Plato's philosopher-king. Every era of history has struggled with this in turn, with some form of philosopher-king (via the later implementation of the divine right of kings ${ }^{1638}$ ) the far more common solution.

The question is, then, is political freedom best realized through mere democracy, or something called reason? How should they be reconciled if (or when) they differ? Is the despotism of the majority (and their 'interpretation' of truth) worth the risk, or what does it mean to insure political liberty through truth itself? If one answers "truth itself," then is this truth timeless, as it was for Plato, or temporal? How does one account for potential changes in what is considered true or truth? Philosophers, and theologians, have been unable to reconcile them to the satisfaction of an enduring majority, and hence, the two cultures are intimately related to politics and not just individual freewill.

In any case, the concept of political freedom or liberty would receive many minor adjustments (and radical implementations in various contexts) throughout history, ${ }^{1639}$ but within ancient Greece all the primary philosophical issues had already been exposed. Such issues included the idea of positive freedom, or the freedom of being able to do things, and participate in public life, yet, such positive freedoms, when exercised democratically, raised the issue of negative freedom, or the freedom of the minority to be protected from something, such as a decision with which the minority strongly disagreed. Counterbalancing these two well illustrates the challenges that the problem of freedom faces in the political sphere, as well as the personal sphere. ${ }^{1640}$

\footnotetext{
${ }^{1638}$ Note the classic work by John Neville Figgis, The Divine Right of Kings $2^{\text {nd }}$ ed. (Cambridge, UK: University Press, 1922).

${ }^{1639}$ For a history of the implementation of democracy in various nations, see Roger Osborne, Of the People, By the People: A New History of Democracy (London, UK: Random House, 2011).

${ }^{1640}$ For more on the issues, see Hans Theodorus Blokland, Freedom and Culture in Western Society, tr. Michael O'Loughlin (New York, NY: Routledge, 1997), 2-4. One of the "most important" questions "in political science" concerns the articulation of "negative' and 'positive' freedom. This could be dubbed an emancipation dilemma, a dilemma because it is a matter of two significant, but also partly conflicting, values which cannot be simultaneously fully realized and which will inevitably have to be weighed up against each other," ibid., 2. For more, see Matthew H. Kramer, The Quality of Freedom (Oxford, UK: Oxford University Press, 2003), 2. Whether strictly in a political context or not, Kramer correctly observes that "within the general concept of freedom there are markedly different varieties and conceptions that cannot all be subsumed under a single coherent theory; any comprehensive treatment of those varieties and conceptions must involve an acknowledgment of their
} 
In turning toward personal freedom, there are two important facets to mention. First, there is

the issue of ethical or moral freedom, which, of course, is often tied into the political or corporate notion of freedom that has been described above, and was already recognized by Solon and his contemporaries. The protection of the minority, a problem that originated very early and remains alive today, can easily be considered the origin of the problem of religious freedom as well. Furthermore, whether or not ethics or morality should be considered timeless or temporal ${ }^{1641}$ has been the determinative factor in many forms of Christianity, virtually all of which embraced a

irreducible divergences. Most famous among those divergences, of course, is the distinction between negative liberty and positive liberty," ibid. Kramer believes it obvious that "the doctrine of positive liberty and the doctrine of negative liberty are genuinely in competition as ways of fleshing out the general concept of freedom," ibid.

${ }^{1641}$ It is critical to point out that for Plato, ethics and morality were conceived in a "timeless" way. As Christopher Falzon explains, "Plato's account of morality is bound up not only with his conception of the self but also with his account of knowledge.... For Plato, to comprehend the true nature of things is to have knowledge of the forms, the timeless, unchanging essences of things that exist beyond the shifting world of sense experience. Now these include the forms of moral ideals and virtues, wisdom, courage, temperance and, above all, the form of the good. What Plato is saying is that there is one universal, objective form of the good life, which we can discover through our reason. Accordingly, discovering the good life is a rational task, like determining the principles of mathematics.... We can only fulfil ourselves through knowledge of these timeless forms and, above all, through knowledge of the good. Individual harmony and order thus mirrors the larger order of the world of forms. So in the last analysis, the basis of morality for Plato is not to be found in human nature but in his conception of ultimate, objective reality, the world of the forms.

"Plato's view of morality involves the emphasis on reason that we have already seen in his views on knowledge and the self. And many have found his moral account too intellectualistic and rationalistic. Can we know what the right thing to do is, in the way that we can have mathematical or scientific knowledge? Is establishing the right thing to do, or the proper life to lead, anything like gaining knowledge of the world? Equally, is there really only one correct answer to what it is to lead the good life, which reason can discover, as Plato seems to imply? Might there not be a variety of ways in which one can be good? ... Plato's emphasis on reason means that his notion of mental harmony is a rather repressive, authoritarian one, marked by suspicion and hostility towards desire. What this means for morality is that being moral, living the good life, requires firmly controlling and restraining the desires. It is an ascetic morality, a morality of stern self-denial.... This kind of moral authoritarianism might be less a recipe for mental health than itself a source of disharmony and illness," Christopher Falzon, Philosophy Goes to the Movies: An Introduction to Philosophy $2^{\text {nd }}$ ed. (New York, NY: Routledge, 2007), 109. See also, Peter Vardy, The Puzzle of Evil (New York, NY: Routledge, 1997), 93-96. It is important to point out that some Christians, such as Ellen White, see the situation very differently than Plato: "Were the men for whom Christ has died devoid of moral nature, or were the gospel to be submitted to the understanding, to be decided by the intellect alone, men might approach it as they approach a mathematical problem. But this is not the case. The great truths of salvation are to be planted in the heart. The science of redemption is as high as heaven, and its value is infinite," White, Ms69-1897. She elsewhere again offers a contrast to Plato's ascetic morality, by sharing: "It is the Spirit that causes to shine into darkened minds the bright beams of the Sun of Righteousness; that makes men's hearts burn within them with an awakened realization of the truths of eternity; that presents before the mind the great standard of righteousness, and convinces of sin; that inspires faith in Him who alone can save from sin; that works to transform character by withdrawing the affections of men from those things which are temporal and perishable, and fixing them upon the eternal inheritance. The Spirit recreates, refines, and sanctifies human beings, fitting them to become members of the royal family, children of the heavenly King," Ellen White, God's Amazing Grace (Hagerstown, MD: Review and Herald, 1973), 194. Note, of course, that White's understanding of temporal and eternal reflect a distinct conception of these concepts. 
timeless template, albeit in different ways, for example through the development of the Roman Catholic sacramental system, including especially their contemporary expansion into the arena of social justice ${ }^{1642}$ following the Second Vatican Council (1962-1965), ${ }^{1643}$ and Christian Dominianism and Reconstructionism. ${ }^{1644}$ In other words, most forms of Christian (and secular scientistic) perfectionisms, attained through the engines of social progressivism or utopianism, ${ }^{1645}$ be they categorized as Left leaning or Right leaning in today's socio-political parlance ${ }^{1646}$ (including especially amillennialist and postmillennialist views of eschatology ${ }^{1647}$ ), generally can be described as seeking

\footnotetext{
1642 Notably, Catholics invented the phrase "social justice" in the 1840's For more, see Thomas Patrick Burke, "The Origins of Social Justice: Taparelli d'Azeglio," in Modern Age: A Conservative Review Vol. 52, No. 2 (Spring 2010), 97-106; and Thomas Patrick Burke, The Concept of Justice: Is Social Justice Just? (New York, NY: Continuum, 2011).

${ }^{1643}$ See, once more, Younker, "From Metaphysics to Templephysics: Situating the Significance of Fernando Canale's Contributions for the 'Christian Philosopher,'” 208-230.

${ }^{1644}$ My suggestion would be that the key point to take away from, for example, Reconstructionism, is that although they do seek to resolve the dilemma of the One and the Many, they do so without a serious investigation about how time and freedom factor into that problem. For classic works outlining the philosophies of these movements, see Rousas J. Rushdoony, The Roots of Reconstruction (Vallecito, CA: Ross House Books, 1991), 301, 838, 1035; Rousas J. Rushdoony, The One and the Many (Vallecito, CA: Ross House Books, 1971); Steve C. Halbrook, God is Just: A Defense of the Old Testament Civil Laws: Biblical Theocracy, Justice, and Slavery versus Humanistic Theocracy, 'Justice,' and Slavery $2^{\text {nd }}$ ed. (Theonomy Resources Media, 2014); and Julie J. Ingersoll, Building God's Kingdom: Inside the World of Christian Reconstruction (Oxford, UK: Oxford University Press, 2015). For more on related theories of religious ethics, see Timothy R. Cunningham, How Firm a Foundation?: An Exegetical and Historical Critique of the 'Ethical Perspective of [Christian] Reconstructionism' Presented in Theonomy in Christian Ethics (Eugene, OR: Wipf \& Stock, 2012), 39, 101, 164-166; Jim Mason, An Unnatural Order: The Roots of Our Destruction of Nature: Why We are Destroying the Planet and Each Other (New York, NY: Lantern Books, 2005), 26, 33; Anthony Kishko, The Decline and Fall of the United States, Part 1 (Bloomington, IN: Xlibris, 2012), Russell Sharrock, Spiritual Warfare: A Struggle for Truth (Morrisville, NC: Lulu Press, 2007), 39; Rebecca Joyce Frey, Fundamentalism (New York, NY: Infobase Publishing, 2007), 63; and David John Marley, Pat Robertson: An American Life (Lanham, MD: Rowman \& Littlefield, 2007), 57.

1645 The point here is not that, obviously, progressivism and utopian Christian visions don't involve "time," but that the "ends" justifying their moral and ethical agendas are "timelessly grounded," and thus any true 'Heideggerian' temporality is dismissed. Thus, the actual role or purpose of "time" (and freedom) in their systems becomes, from a Heideggerian perspective, questionable. "For more than 2,000 years, those longing to mend their fractured souls have sought their cure in the pages of Plato's dialogues.... [In both] the medieval religious and philosophical traditions of Islam ... [and] Christianity," it appears that, "in truth, there is hardly an intellectual or spiritual dimension of modern life that is not in some way indebted to him," M. A. Soupios, The Greeks Who Made Us Who We Are: Eighteen Ancient Philosophers, Scientists, Poets and Others (Jefferson, NC: McFarland \& Company, 2013), 134-135. See also, Peter S. Hawkins, Getting Nowhere: Christian Hope \& Utopian Dream (Eugene, OR: Wipf and Stock, 1985); Nancy Warehime, To Be One of Us: Cultural Conflict, Creative Democracy, and Education (Albany, NY: State University of New York Press, 1993), xxiii; and Frank E. Manuel and Fritzie P. Manuel, Utopian Thought in the Western World (Cambridge, MA: The Belknap Press of Harvard University Press, 1979).

${ }^{1646}$ Note the work of Ryszard Legutko, The Demon in Democracy: Totalitarian Temptations in Free Societies (New York, NY: Encounter Books, 2016).

${ }^{1647}$ For descriptions of the basic contours of millennialism, see Stanley J. Grenz, The Millennial Maze: Sorting Out Evangelical Options (Downers Grove, IL: IVP Press, 1992). The important point to be made here is that there are indeed profound similarities in both progressivist, amillennialist, and postmillennialist perspectives on where the history of the world is "going." Are things getting "better" or, conversely, "worse," as
} 
after some sort of ethical template that can be described as timeless (objective) in the technical sense. $^{1648}$

The significance of whether ethical freedom (the ability to attain the good or moral life and maintain it) should be construed as timeless or temporal was explored in chapter 5 where the

premillennialist eschatology suggests, where Christ will return prior to the millennium referenced in Revelation 20:1-6? See also, Pate, From Plato to Jesus: What Does Philosophy Have to Do with Theology?, 289, 300. Pate suggests, controversially, that it seems "time dealt a mortal blow to liberal postmillennialism-the catastrophic events of the twentieth century rendered it an untenable position.... It is obvious that in abandoning the gospel of salvation, the social gospel exalted the many (earthly utopia) over the one (heavenly kingdom of God), ibid., 289. See also, Cathy Gutierrez, Plato's Ghost: Spiritualism in the American Renaissance (Oxford, UK: Oxford University Press, 2009), 5, 12-13, 180 n. 10. Gutierrez notes that American "spiritualists have overwhelmingly been written about in scholarship as at the forefront of postmillennial ideas about time, even if the believers themselves had a tenuous relationship to Christianity. Their belief in progress as the ultimate form of salvation, and its ties specifically to science, are irrefutable. However, I will argue that the understanding of time is more complex than the simple transcending of history, and that the Spiritualists represent a pervasive conflict in nineteen-century American concepts of time." Indeed, "millennialism is a love affair with history, although the love is frequently an unhappy one. Believers seek to make sense of the world by plugging contemporary events into God's ultimate plan; whether that plan is understood as gradual progress or cataclysmic destruction matters less than the outline of history. In all cases, time itself is rendered meaningful and trustworthy, having a clear beginning, middle, and end, and God's hand in history is active and assured." However, ironically, "in the larger scheme of postmillennialism, this focus on the importance of history ... led to the downfall of notions of progress. ..". This is, in part, because "spiritualists fused a paradox into the heart of their progressive agenda: the wisdom required to advance was to be found in the past. As a neoplatonic project, Spiritualist writing on memory and the dead came increasingly to resemble Plato's favorite theory of recollection, in which the soul's progress consists of remembering that which it had known before it was incarnated. Caught in these two opposing concepts of time, in which humanity advanced toward perfection only with the aid of the past, Spiritualists articulated this snarl of epistemology in discussions of the memories of the dead," ibid., 12-13.

${ }^{1648}$ Russ, The Illusion of History: Time and the Radical Political Imagination, 3. "Timelessness is here understood with regard to a moral and philosophical sense that pervades these thinkers' projects, inasmuch as they all invoke a morality that is philosophically designed to transcend the historico-temporal realm. It is a timelessness that walks hand in hand amid these thinkers' primary concern with freedom. Freedom, for them, is understood primarily to exist in separation from the contingencies of history and time, and yet to be the precondition for a morality that they believe should be imposed upon time and history. Here lies the contradiction that animates these projects' social dissatisfaction.

"With these thinkers we have the opportunity to dissect a political consciousness that is captivated by an intellectual cleavage. This cleavage is with differing degrees based around a dualism that separates nature from culture, determinism from freedom, reason from experience, and science from morality. The most formal and sophisticated extrapolation of this problem was supplied by Immanuel Kant, who, taking his cue from Rousseau, upheld an immaterial concept of the free moral will as the transcendent source of moral and political directives. The seat of man's duty and the prescriptions for what he ought to do are to be found within himself and not embedded in the world, history, or society. The transcendence that characterizes this equating of freedom, morality, and the will constitutes the timeless and ahistorical nature that" corresponds to "the radical political imagination" and utopianism, ibid., 3. What is in common with all utopian thinkers is that "the timelessness in the thought of these thinkers seeks out historical and temporal expression, but in so doing, cultivates illusory visions of, and standards for, history. Furthermore, this need of timeless freedom manifests itself in these thinkers each favoring one direction of time exclusively over the others," for example, "Rousseau's philosophy has a predilection for the past, while Marx's preference is for the future, and that Foucault's is predominantly concerned with the present." "The exclusivity of a past, a present, or a future by these thinkers with regard to time comprises the basis of their respective illusions of history. Paradoxically .... these distinctive visions of history are simply various privileged attempts by the timeless mind to transcend or annul history," ibid., 4. 
theological consequences of Bohm and Pylkkö's views were examined, as ethical freedom is considered by most to be derivative to the question of whether we have free-will at all, ${ }^{1649}$ although for many it is precisely because we are thought to be, as humans, amenable or subject to morality that makes free-will so pressing an issue. ${ }^{1650}$ Put simply, if we are completely determined, then ethics is not as important as it would be if we were free to choose right and wrong choices about certain issues, which elevates the significance of personal responsibility. ${ }^{1651}$

The second issue that is centrally bound up with the question of freedom concerns the issue of free-will or free choice, which has been called the most important question in philosophy, not only historically, but in the present, where it is frequently suggested that "whether free will is a reality is an increasingly urgent problem, both from a scientific and a social point of view," precisely because "the question of human freedom is a vexing point of tension between humane and scientific worldviews," especially at a time when, "from a scientific point of view, all forms of behavior are increasingly seen as the causal products of cellular interactions within the central nervous system,

\footnotetext{
${ }^{1649}$ As is noted by, for example, John S. Callender, Free Will and Responsibility: A Guide for Practitioners (Oxford, UK: Oxford University Press, 2010), 1-18.

${ }^{1650}$ The context of the issues are well explained by Papia Mitra, "human beings commonly believe that they are free to choose what they can do in any given set of circumstances. Even those who, like Heidegger, acknowledge the 'facticity' of the universe which limits us, argue that men are free to choose their decisions. The Minimal Free Will Thesis (MFT) holds that, at least some of the time, someone has more than one course of action that they can perform. Determinism argues that only one course of action is open. However, MFT does not necessarily solve the problem of whether such actions are truly free. It tells us that an individual chooses from a set of options, and even why she does so. But this has no necessary connection with what Shaw calls 'should' and 'ought'. Such terms are normative terms, and what she 'should' do might not be included in the options. This is one reason why philosopher Saul Smilansky argues that, although we don't have free will in the traditional sense, it is necessary to believe in it for the sake of morality. If people believe that they are not responsible for their action, then society would collapse. Free will, therefore, is a necessary fiction," Papia Mitra, "Artificial Intelligences and Karma: An Evaluation of Information Technology in Light of J. L. Shaw's Concept of Moral Free Will," in Comparative Philosophy and J. L. Shaw, eds. Purushottama Bilimoria and Michael Hemmingsen (Dordrecht, The Netherlands, Springer, 2016), 250. See also, Saul Smilansky, Free Will and Illusion (Oxford, UK: Clarendon Press, 2002). The idea that what one 'should' or 'ought' to do may not be possible, or that the 'second best' choice may be the only option, is yet another important issue, that, unfortunately can't be pursued here.

${ }^{1651}$ This is not to say, however, that within the two cultures milieu, that determinists don't defend their own unique version of moral responsibility. For more on this issue, see Smilansky, Free Will and Illusion, and Lene Bomann-Larsen, "Communicative Revisionism," in Moral Responsibility: Beyond Free Will and Determinism, eds. Nicole A. Vincent, Ibo van de Poel, and Jeroen van den Hoven (New York, NY: Springer, 2011), 141-160. All of the essays in this book presume determinism to be true.
} 
which themselves are substantially influenced by the toss of genetic dice that occurred when each of us was conceived."1652

Indeed, further muddying the waters, some prominent philosophical theologians, such as Nancey Murphy, suggest that "there is no such thing as a will and that we would be better off speaking in terms of voluntary versus involuntary actions." ${ }^{1653}$ In any case, as Murphy also explains concerning the big picture, in many of the questions "today" concerning free will, the "challenges are taken to come from particular sciences: physics, genetics, or neurobiology. What all of these have in common is that they are in one way or another opposing some concept of human freedom to some concept of determinism." ${ }^{1654}$ The problem here is that science, and its presumption of 'temporal determinism' (i.e. ontological timelessness) as 'cause and effect', rule tout court as the primordial metaphysical presupposition, and thus much of the literature today is structured as a simple contrast between compatibilists and incompatibilists, that is, between those with a reductionistic understanding that assumes "free will either is or is not compatible with determinism"1655 of some form or another. Murphy concedes that the opposing positions on these issues have been laid down for millennia, and that there is no likely answer to emerge which would satisfactorily solve the paradoxical enigma between determinism, indeterminism, and freedom. Despite the intercultural problems (especially for the two cultures) that this situation creates, to understand and appreciate the historical reasons behind why this situation has arisen, and why it has been fiercely challenged by many from the humanities, including Heidegger, requires us to examine the origins of the problem of freedom in the Western tradition.

The history behind the puzzle of personal free-will or freedom, in the West, also takes us back to the beginning of the Greek's philosophical speculations. As will be seen with the concept of time and

\footnotetext{
1652 William T. Newsome, "Human Freedom and 'Emergence,"” in Downward Causation and the Neurobiology of Free Will, eds. Nancey Murphy, George F. R. Ellis, and Timothy O'Connor (New York, NY: Springer-Verlag, 2009), 53.

1653 Nancey Murphy, "Introduction," in Downward Causation and the Neurobiology of Free Will, eds. Nancey Murphy, George F. R. Ellis, and Timothy O'Connor, 2.

${ }^{1654}$ Murphy, "Introduction," in Downward Causation and the Neurobiology of Free Will, 2.

${ }^{1655}$ Murphy, "Introduction," in Downward Causation and the Neurobiology of Free Will, 2.
} 
political liberty, most of the major contours of the issue were discovered very early, and underwent only a few major developmental twists through time, with some of them coming quite recently through quantum physics. Yet, prior to turning toward the first 'philosophers', its important to point out that, as Bob Doyle explains:

Before there was anything called philosophy, religious accounts of man's fate explored the degree of human freedom permitted by superhuman gods. Creation myths often end in adventures of the first humans clearly making choices and being held responsible. But a strong fatalism is present in those tales that foretell the future, based on the idea that the gods have foreknowledge of future events. Anxious not to annoy the gods, the mythmakers rarely challenge the implausible view that the gods' foreknowledge is compatible with human freedom. This was an early form of today's compatibilism, the idea that causal determinism and logical necessity are compatible with free will. ${ }^{1656}$

The above insight on the pre-philosophical history are important, in that they surely continued to influence later developments in subtle ways-the idea of a Being that is above the human has been around in seemingly every ancient culture into the untraceable past. Unfortunately, I cannot pursue the further study of such stories and myths here.

In turning toward the most important first Greek philosophers to address the concept of personal freedom or free will, it may be an irony that Heraclitus, "the philosopher of change," actually believed that there were laws or rules behind all the changes in the world. ${ }^{1657}$ As Eugene Bales explains, "Heraclitus's emphasis on constant change is balanced with his other claim that all change is lawlike and orderly because all is Logos fundamentally. The law of constant change is simply that of the warfare of opposites." ${ }^{1658}$ What is interesting is that the target of Heraclitus's assertions was probably the Pythagoreans [and Parmenides], who insisted that "everything is basically harmonious and peaceful," which is "utterly opposed to [Heraclitus's] insistence that everything is in conflict."1659

${ }^{1656}$ Doyle, Free Will: The Scandal in Philosophy, 69.

${ }^{1657}$ Doyle, Free Will: The Scandal in Philosophy, 70.

${ }^{1658}$ Eugene F. Bales, Philosophy in the West: Men, Women, Religion, Science (Bloomington, IN: Xlibris, 2008), 15. Bales understand's Heraclitus's Logos to be "the unifying principle or arche of the universe, an intelligence directing the universe, imposing unity and order on all things, and accounting for the capacity of human reason to know the order of things. Logos within us is intelligence." Of course, "Heraclitus understood this intelligence in virtually materialistic terms as fire," but this should not detract from his main point, ibid.

${ }^{1659}$ Bales, Philosophy in the West: Men, Women, Religion, Science, 15. Bales perceives that, very likely, “Heraclitus's notion of Logos would pass on to Stoicism, Neoplatonism, and, to some extent, Christianity. His emphasis on the lawlike nature of the change of opposites became dialectic in the hands of Hegel and Marx. The emphasis on constant change and the attack on the notion of permanence found echoes in Nietzsche, Heidegger, and the process philosophers in recent times. In many ways, his influence is more pronounced in the last two 
In other words, it would appear that "the main difference between Heraclitus and Parmenides [and the Pythagoreans] is not that the one is for change and the other for permanence. Both recognize order and law but differ on the role of the Logos in an ordered world. Heraclitus considers the Logos as a permanent law of change, because it is a living soul, the One and All. Parmenides, on the other hand, sees it only as [the] law of contradiction,",1660 a manifestation of the irrationality of change. As such, it may be misleading to see the history of philosophy as the development of the two systems as if they were in a "polar antagonism," as they have always developed in relationship to the other's assertions. ${ }^{1661}$

As Alf Ross explains, it is likely "personal experience of the political changes of the time that is reflected in Heraclitus' law of change. Until his day the philosophers had tried to understand the world as a collection of things and to discover its immutable elements. Heraclitus asserts that everything is in a state of eternal flux-the world is a constant process of events, not a collection of things." ${ }^{1662}$ As such, putting his two emphases together, it is likely that Heraclitus saw a "universal law" that held "sway over everything in existence." As such, his law of change may represent an intimation that there is a "connection between human laws and the forces that rule the world,"1663 although he does not specify in any technical way just what this force or Logos might be (and very importantly, some speculate Heraclitus did allow for "chance"1664).

There is an important point to extract from the law of change that Heraclitus posited, and it is that free-will cannot be derived simply from the concept of change, a very important observation.

centuries than it was in the first century after his death. But probably his most famous Greek admirer was, of all people, Plato, whose understanding of the physical universe was much indebted to Heraclitus. But Plato did not think Heraclitus provided any direct insight into the nature of the reality beyond the physical universe. For this, Plato turned to another Greek intellectual ... Parmenides," ibid., 15-16.

${ }^{1660}$ Alexander Sissel Kohanski, The Greek Mode of Thought in Western Philosophy (Cranbury, NJ: Associated University Presses, 1984), 258 n. 40.

${ }^{1661}$ Kohanski, The Greek Mode of Thought in Western Philosophy, 258 n. 40.

${ }^{1662}$ Alf Ross, On Law and Justice (Berkeley, CA: University of California Press, 1959), 232. For more on the social context of Heraclitus, see Richard G. Geldard, Remembering Heraclitus (England: Lindisfarne Books, 2000).

1663 Ross, On Law and Justice, 232.

1664 Theodoros Christidis, "Probabilistic Causality and Irreversibility: Heraclitus and Prigogine," in Between Chance and Choice: Interdisciplinary Perspectives on Determinism, eds. Harald Atmanspacher and Robert Bishop (Exeter, UK: Imprint Academic, 2002), 179. 
Heraclitus did not actually explicitly connect his notion of change to freedom. Rather, Heraclitus's "stance on free will" was "ambiguous,"1665 because he also suggested the overall Logos directs our actions, and "it is [the] law also, to obey the will of the One"' Logos. ${ }^{1666}$ This is not to say Heraclitus denies free will, but that it is certainly limited and not an "absolute freedom." Instead, as David Skrbina argues of Heraclitus's position, "to the extent that we embody Logos, we do in fact have a component of freedom .... Thus, determinism holds throughout the universe, but one that is compatible with an element of freedom-a freedom that is manifest, perhaps, only when we understand our true nature."1667 This, of course, only returns us to the mystery of their relationship.

Overall, one can see how the notion that "laws could produce an ordered cosmos out of chaos" by some of the early Greeks was prescient, as most current models of the universe begin "with a state of minimal information and maximum disorder," and order then emerges. ${ }^{1668}$ Furthermore, what Heraclitus bequeathed to the history of philosophy was very much a foreshadowing of all that would follow-en emphasis on law-likeness in the nature of Logos or Reality, and yet continual flux or change. Two seeming opposites that somehow coexist-a statement not just of Heraclitus, but of the situation that exists today. It is not without interest that Skrbina observes that the tension within Heraclitus "compares well with Heidegger's"1669 views, which will be even more pronounced when Pylkkö's views are also considered, as will be seen below. Heidegger let the tension be, just as

\footnotetext{
1665 David Skrbina, The Metaphysics of Technology (New York, NY: Routledge, 2015), 27.

${ }^{1666}$ Heraclitus fr. 33, as cited in Skrbina, The Metaphysics of Technology, 21.
}

${ }^{1667}$ Skrbina, The Metaphysics of Technology, 21-22. Skrbina suggests that "in Heraclitus, then, we find that ... the divine Logos as original ordering principle of the cosmos and as a mind/matter composite, generating and directing all things; a monistic physical universe as embodiment of the pyr aeizoon, the everliving ether; a clear determinism, but a compatibilist one that allows for a measure of freedom; and a suggestion of evolutionary progression. We humans, and all things on Earth, are part of the Logos revealing itself to itself. Ultimately there is only the self-revealing Logos, and when we understand this and our role in it, we then gain a small degree of free thought and action. The Logos moves in us and through us, and ultimately it will move beyond us-or so Heraclitus suggests," ibid., 22. One may detect in Heraclitus, then, an element of "pantheism" within the Logos, although it is ambiguous, for the Logos was "somehow 'separated from us,' hidden away. It directs the cosmos from afar," which is in contrast to the Stoics, for whom "Nature is God," ibid., 27.

1668 Doyle, Free Will: The Scandal in Philosophy, 70.

${ }^{1669}$ Skrbina, The Metaphysics of Technology, 28. Christidis would similarly argue, "Heraclitus supported a theory of nature, in which there is a general and common law, logos, which imposes measure on physical processes, but war, the strife between the opposites, is a ruling factor through which an infinite variety of changes occur in such a way as to give chance the possibility to intervene in them, and time to play the role of a king in the cosmic play," Christidis, "Probabilistic Causality and Irreversibility: Heraclitus and Prigogine," 180. 
Heraclitus did, between the law-likeness of nature, with some sort of freedom within our human existence. This is not to say they share the same views, particularly concerning time, but that there are indeed elements supportive of a productive comparison, again illustrating the historically rooted nature of the problem behind the rise of the two cultures.

Following after Heraclitus, two other key early Greek figures in the discussion on freedom and determinism would be Democritus (c. 460-370 B.C.) and Leucippus, his purported mentor (c. $5^{\text {th }}$ century B.C.). As Doyle observes, they, with "extraordinary prescience, claimed that all things, including humans, were made of atoms in a void, with individual atomic motions strictly controlled by causal laws." Ironically, Doyle notes, “Democritus wanted to wrest control of mans' fate from arbitrary gods and make us more responsible for our actions." However, he and Leucippus can actually be said to be just as responsible for originating "two of the great dogmas of determinism, physical determinism and logical necessity, which lead directly to the modern problem of free will and determinism." ${ }^{1670}$ Indeed, Leucippus expressed clearly that “'nothing occurs at random."”1671

The Pythagoreans, Socrates, Plato, and also Aristotle, whom will be discussed more momentarily, could offer nothing particularly original to the above problem, except to initiate the process of locating freedom within some sort of immaterial, timeless, world. If the Good and morality were a part of the timeless Forms, similar to mathematics, then freedom was attained by seeking this realm and escaping ignorance-truth and freedom became closely associated, in Plato's peculiarly distinct way. ${ }^{1672}$ Thus, it appears that because Plato could do nothing more than seek to 'escape' the problem of material determinism and causal law, he settled on the idea that participation in the timeless forms, however this might be understood, is what constituted liberation for the human, ${ }^{1673}$

\footnotetext{
${ }^{1670}$ Doyle, Free Will: The Scandal in Philosophy, 70-71.

${ }^{1671}$ Leucippus, Fragment 569, from Fr. 2 Actius I, 25, 4, as cited in Doyle, Free Will: The Scandal in Philosophy, 71.

${ }^{1672}$ Falzon, Philosophy Goes to the Movies: An Introduction to Philosophy, 109. See also, Keith Ward, Religion and Creation (Oxford, UK: Oxford University Press, 2002), 192; Donald A. Crosby, Nature as Sacred Ground: A Metaphysics for Religious Naturalism (Albany, NY: State University of New York Press, 2015), 40, 5760; and Gary Alan Scott and William A. Welton, Erotic Wisdom: Philosophy and Intermediacy in Plato's Symposium (Albany, NY: State University of New York Press, 2008), 143.

${ }^{1673}$ Adrian Pabst, Metaphysics: The Creation of Hierarchy (Grand Rapids, MI: Eerdmans, 2012), 2, 32, 38.
} 
and, with several sophisticated enhancements, this best represents what is the contemporary position of many Roman Catholic theologians. ${ }^{1674}$ In other words, while the issue of freedom was of interest to Plato and Aristotle, "Plato and Aristotle did not yet have a notion of a free will and that it was for this reason that they did not talk of a free will,"1675 at least certainly not as philosophers later would address it. However, Aristotle's views are worthy of a further comment.

Aristotle originated an important possibility that opens up the concept of freedom. As Doyle suggests, "the first major philosopher to argue convincingly for some indeterminism was probably Aristotle."1676 It seems Aristotle was aware of the fact that earlier thinkers had found no place for chance, but while he was aware of the apparent causality chains initiated in nature and logical necessity, he nevertheless argued for "breaks" in the causal chain that would allow "us to feel our actions 'depend on us."'1677 As Aristotle put it, "if we are unable to trace conduct back to any other origins than those within ourselves, then actions of which the origins are within us, themselves depend upon us, and are voluntary."1678 Many have interpreted this as the first clear statement of

\footnotetext{
${ }^{1674}$ This point is important, and will be returned to below as I briefly explore the work of David L. Schindler on the nature of religious freedom. The critical nature of the connection between truth and freedom, in a neoplatonic context, is explained well by Barry Hudock, when he expounds upon the rationale behind the 1965 Catholic statement on religious freedom, Dignitatis Humanae. Hudock quotes Karol Wojtyła, later known as Pope John Paul II, to explain "it is in the truth that the human person achieves his own proper perfection, for the truth corresponds to his rational nature and constitutes the firmest foundation for true freedom." Again, "there is no freedom without truth." This must be seen in contrast to John Courtney Murray, who was "disappointed in this development. He saw it as an unnecessary embellishment and a potential threat to what ought to have been the church's principled commitment to the right to religious freedom. It is a short step, he argued, for a government-be it Catholic or Communist-that sees itself as possessing truth to decide it must impose that truth and repress error for the good of the people," Hudock, “Freedom, Truth, and Human Dignity': The Other Conflict Behind "'Dignitatis Humanae'." For more on this, see Schindler, "Freedom, Truth, and Human Dignity: An Interpretation of Dignitatis Humanae on the Right to Religious Freedom," in Freedom, Truth and Human Dignity: The Second Vatican Council's Declaration on Religious Freedom: A New Translation, Redaction History, and Interpretation of Dignitatis Humanae, 39-210, 129-130. See also, David C. Schindler, The Perfection of Freedom: Schiller, Schelling, and Hegel between the Ancients and the Moderns (Eugene, OR: Cascade Books, 2012).

${ }^{1675}$ Michael Frede, A Free Will: Origins of the Notion in Ancient Thought, ed. A. A. Long (Berkeley, CA: University of California Press, 2011), 2.

${ }^{1676}$ Doyle, Free Will: The Scandal in Philosophy, 71.

1677 Doyle, Free Will: The Scandal in Philosophy, 72.

${ }^{1678}$ Aristotle, The Nicomachean Ethics, tr. Harris Rackham (Hertfordshire, UK: Wordsworth Editions, 1996), 62; 1113a34-b30. See also, Javier Echeñique, Aristotle's Ethics and Moral Responsibility (Cambridge, UK: Cambridge University Press, 2012), 109.
} 
freedom and responsibility. How all this was possible in nature, however, Aristotle did not explain. What's important is that Aristotle did advocate for some sort of "chance."1679

Not long after Aristotle, another philosopher, Epicurus (341-270 B.C.), added the final major ingredient into the free-will and freedom problem in ancient times. Epicurus agreed with Democritus and others that supported the idea that nature consisted of atoms that moved through a void.

However, Epicurus suggested that there were occasions where the atoms would "swerve" from their normal determined pathways, thus initiating new previously unpredictable causal chains. ${ }^{1680}$ It should be noted that Epicurus did not, it seems, believe that human actions were merely the cause of randomness or chance, nor that a single random swerve constituted a "decision" by a human or animal. Indeed, exactly how his insights should be integrated into free-will remains disputed, ${ }^{1681}$ both for his original speculations as well as for modern interpreters evaluating his arguments. ${ }^{1682}$ The major takeaway from Epicurus is, perhaps expectantly, the prescience he had concerning the quantum fluctuations that physicists two thousand years later would discover. As Doyle observes, “Epicurus' intuition of a fundamental randomness was correct,"1683 as contemporary physics appears to demonstrate empirically.

In the centuries that followed, philosophy engaged in a pitched battle over the fate of freedom. The Stoic school of philosophy introduced in wide circulation the idea that natural laws controlled all things, including the mind. ${ }^{1684}$ Although they wished to support the idea that humans possess moral responsibility, the result of their work was the introduction of compatibilism. Overall, while the

${ }^{1679}$ Doyle, Free Will: The Scandal in Philosophy, 71.

${ }^{1680}$ Doyle, Free Will: The Scandal in Philosophy, 72. For more, see also, J. M. Rist, Epicurus: An Introduction (Cambridge, UK: Cambridge University Press, 1972), 42-52; 92-98; and Tim O'Keefe, Epicurus on Freedom (Cambridge, UK: Cambridge University Press, 2005).

${ }^{1681}$ Tim O’Keefe, Epicureanism (New York, NY: Routledge, 2014), 76.

1682 "It matters relatively little whether our choices exploit swerves that are among the many that are constantly occurring anyway, or whether our choices cause swerves of the atoms in our minds.... If all swerves are uncaused on the atomic level, it is difficult to see what it can mean to say that some are caused by choice and others not.... The important point is that Epicurus recognises the swerve as a necessary condition for free choice, even if it is not a sufficient condition and even if the exact relation between choice and swerve remains mysterious. (Whether Epicurus was himself aware of any difficulty here we do not know.)," R. W. Sharples, Stoics, Epicureans and Sceptics: An Introduction to Hellenistic Philosophy (New York, NY: Routledge, 2014), 66.

${ }^{1683}$ Doyle, Free Will: The Scandal in Philosophy, 73.

${ }^{1684}$ Doyle, Free Will: The Scandal in Philosophy, 74. 
Stoics freed man from the fate of the gods, their ideas eventually placed him under the fate of laws, an idea that science would later incorporate into itself that would create the modern problem of determinism. ${ }^{1685}$ The Stoics held no clear concept of freedom or free-will. ${ }^{1686}$ Their struggles to discuss freedom illustrate that the two cultures' battle was already underway. As time would pass, many more philosophers would weigh in on whether or not humans possess freedom, and if so what sort of freedom. In political theory, Cicero the Roman (106-43 B.C.) stands out, ${ }^{1687}$ and, although it is frequently asserted he supported democracy, it likely was not a direct democracy Cicero had in mind ${ }^{1688}$ His discussions are subtle and nuanced, reflecting a struggle to weigh the wishes and rights of all involved.

Overall, the situation surrounding the early Greek discussions about free-will can be summed up as follows. The ancients found themselves "caught between the horns of a dilemma, with determinism on one side and randomness on the other." Within this situation, which remains true and more prominent today, "the standard argument against free will continues to make human freedom an unintelligible mystery." ${ }^{1689}$ In the years that followed, the one major new introduction would be that of Christianity and its formalization of the concept of God. However, the methods and conclusions of how various prominent Christian theologians, such as Augustine and Pelagius, wrestled with the problem of the freedom of the will and God's foreknowledge offered little if anything actually new, except, in the minds of many, to cement into place the "illogical position still held today by most theologians"1690 ${ }^{16}$ werein the idea that God possesses foreknowledge won the day,

1685 "Stoic logic ... strengthened the dogmas of determinism that dominate modern science and philosophy," Doyle, Free Will: The Scandal in Philosophy, 74.

${ }^{1686}$ Susanne Bobzien, Determinism and Freedom in Stoic Philosophy (New York, NY: Oxford University Press, 2004), 343-344.

${ }^{1687}$ For recent works evaluating Cicero's contributions, see Jed W. Atkins, Cicero on Politics and the Limits of Reason: The Republic and Laws (Cambridge, UK: Cambridge University Press, 2013); and Anthony Everitt, Cicero: The Life and Times of Rome's Greatest Politician (New York, NY: Random House, 2003).

${ }^{1688}$ Stuart K. Hayashi, The Freedom of Peaceful Action: On the Origin of Individual Rights (Lanham, MD: Lexington Books, 2014), 177.

${ }^{1689}$ Doyle, Free Will: The Scandal in Philosophy, 75.

${ }^{1690}$ Doyle, Free Will: The Scandal in Philosophy, 76. 
and the human's free will became muted behind the problem of fallen or sinful nature, ${ }^{1691}$ separating out moral and existential freedom from natural and sinful propensities or tendencies, ${ }^{1692}$ a problem most secular scholars ignore or dismiss (by no means all-akrasia, the "weakness of the will," describes the will when it wills contrary to what its agent knows to be best ${ }^{1693}$ ), as the Christian appeal to be "willing to be made willing" and ruled by the Spirit would seem the first step of an indeterminable (and paradoxical) regression. ${ }^{1694}$

Following the rise of Christianity, the situation concerning the tension between freedom and determinism would continue for the next fifteen hundred years virtually unchanged, with the "inertia" of history settling into an uncomfortable tension between the purported freedom of individuals, with limited degrees of free will, underneath the guidance of (often oppressive) ecclesial and kingly political structures. As history has bequeathed us the irony, democracy was conceived early and only lately born to breathe on its own, suffering over 2,000 years in labor. Similarly, the problem of the freedom of the will, or choice, within the individual was identified early, but remained stagnantly quiescent until recent times, including in particular until the arrival of quantum physics.

Yet, prior to concluding this historical review on the origins of freedom, it is worth nothing that it is the rise of modern science (16th-19th centuries), especially in its pre-quantum form, that still

\footnotetext{
${ }^{1691}$ For an excellent illustrative study on how a well known Protestant theologian wrestled with the issues, see Gregory B. Graybill, Evangelical Free Will: Philipp Melanchthon's Doctrinal Journey on the Origins of Faith (Oxford, UK: Oxford University Press, 2010), 177, 202, 245.

${ }^{1692}$ See the brief explanation in, for example, Steven M. Duncan, How Free Will Works: A Dualist Theory of Human Action (Eugene, OR: Wipf \& Stock, 2011), 94. Duncan explains, "although we retain our free will [after Adam and Eve's first sin] and this arguably accounts for all of our actual sins, the 'bentness' of our nature does not permit us freely to choose the good on a consistent basis, acquire virtue, or overcome our sinful condition through our own unaided efforts. Left to our own devices, it is impossible for us substantially to improve the human condition. Our best efforts are worthwhile and can make temporary improvements to human life over time. However, the dream of 'perfecting human nature' through education, social reform, or institutional design, or through trusting in some sort of historical inevitability to save us in spite of ourselves is simply that. Nor can anyone attain true happiness or his/her end as a rational and spiritual being as long as we are burdened with sin. Things will never get much better, and they may get a lot worse, as long as we are left to ourselves.

"The Christian message, however, is that we have not been left to ourselves," ibid.

1693 Callender, Free Will and Responsibility: A Guide for Practitioners, 12. "In akrasia, rational agents act irrationally," ibid.

${ }^{1694}$ Note, for example, how some Christians describe the problem, in Larry Keefauver, Experiencing the Holy Spirit: Transformed by His Presence (Nashville, TN: Thomas Nelson), 14; and Robert E. Marshall, Forgiveness: Journey to the Center of the Hurt (West Jordan, UT: Streams in the Wasteland Christian Ministries, 2012), 34.
} 
defines the contours of most discussions on free will and freedom (or political liberty) today. Newton, along with Galileo, Kepler, Descartes, Laplace, and many others, articulated a powerfully influential worldview, the scientific worldview, within which there was no room for free will, ${ }^{1695}$ or, if there was any freedom, a strict separation of the human's mind and will must exist from the natural world around us, as is well illustrated by both Descartes and Kant. ${ }^{1696}$ This means that all forms of freedom, whether existential or moral, become subject to a specific relationship to time determined by a prior understanding of the nature of time, as later manifested in nature understood deterministically. Importantly, of course, it is the Cartesian/Kantian view that came to dominate the philosophical landscape, including in the present, though now in subtly modified forms.

There is an additional point that must also be noted here, and that is, if nature were understood as fully deterministic, then that would make it, if not ontically timeless (the various chemical states of matter could change, in a manner of speaking), then certainly ontologically timeless. That is, the state of the whole of nature at one moment $\left(\mathrm{t}^{1}\right)$, if fully understood, would be the same as having access to the whole of nature at another "time" in the future $\left(t^{3}\right)$, as the development from $t^{1}$ to $t^{2}$ to $t^{3}$ would be an inevitable chain of cause and effect-to know $\mathrm{t}^{1}$ is the same as to know not just $\mathrm{t}^{2}$, but also $\mathrm{t}^{3}$, or even $\mathrm{t}^{10}$. This would mean that, in essence, Parmenides was right, and there is no real separation between the various parts or "times" of reality. As Karl Popper explained, "by his [Laplace's] doctrine of a fully deterministic and in principle fully predictable world he introduced Parmenides into Newtonian dynamics, and confirmed his status in it (and in Einstein's theory) for over a century. Laplace's whole work in mechanics and mathematics seems motivated by this problem," namely, of reversibility and uncertainty or freedom. ${ }^{1697}$ If nature were wholly deterministic, then it would also

\footnotetext{
${ }^{1695}$ Brian L. Silver, The Ascent of Science (Oxford, UK: Oxford University Press, 1998), 235. See also, Brad Piekkola, Conceptual and Historical Issues in Psychology (Thousand Oaks, CA: SAGE Publications, 2017), 287-288.

${ }^{1696}$ Gardner, The Whys of a Philosophical Scrivener, 413, n. 8. Gardner explains, "Kant's view can be compressed as follows: In the space-time world of your experience, the world investigated by science, causal determinism must be assumed; in this sense the will is not free. But morality is meaningless unless the will is somehow free. For practical reasons, therefore, we must assume that the human soul, considered as a noumenon, a thing in itself, belongs to a transcendent, timeless realm, and in this realm it is truly free. How empirical determinism and noumenal freedom can be reconciled, however, is a mystery utterly beyond our finite minds" in Kant's construal of the issues, ibid.

${ }^{1697}$ Popper, The World of Parmenides: Essays on the Presocratic Enlightenment, 177.
} 
be essentially ontologically timeless as well, providing God with an easy view of all of time if God were simply located outside our space-time continuum. The idea that part of nature might be deterministic, and another part not, seemed then, and still does today for the vast majority of thinkers, to create insurmountable problems that result in a paradoxical dualism.

The above situation requires emphasis and deliberate clarification, as it concerns the popular notions of time, and thus freedom, that we have today. Obviously, most people, even scientists, refer to "time" frequently, and the idea of calendar time certainly promotes the idea of past, present, and future (yesterday, today, and tomorrow). What many non-philosophers and non-philosophers of science are unaware of is that a reversal took place that transposed nature and Parmenidian Being. Originally, it was Being and mathematics that were considered "timeless," and nature was considered, in various developmentally conceptual stages, some combination of transitory, cyclical, and temporal. Eventually, however, this temporality within nature was conceived in a singularly chronologically deterministic way, that is, as essentially “timeless." Ironically, however, a fusion of Newtonian "absolute cosmic" time and "common sense," that is, the calendar, convinced people that they were still utilizing "real time" in their lives. It is precisely this "illusion" of temporality that Heidegger sought to dispel, labeling it vulgar time. Authentic time cannot be defined merely by clocks, calendars, or some cosmic absolute notion of time that resides outside or external to the human mind, including God. There is some sort of subjective individualized temporal time that is what constitutes the human being and his/her intrinsic durancy-that is, interest with re-analyzing the meanings of our past (including causative, but often to use this knowledge to transform beyond what it would naturally cause) and projecting ourselves into various imagined or possible futures. Nothing else in 'nature' does this.

Many "common sense" philosophers prior to Heidegger, such as Thomas Reid, would also object to the climate of scientific determinism that came to have such a profound effect on modern philosophy, and thus introduced language and social issues into the debate over whether humans are 
free or not, ${ }^{1698}$ foreshadowing some of the later developments concerning the relationship between language and philosophy, which includes, of course, Heidegger, and many others, ${ }^{1699}$ such as Richard Rorty, who resuscitated the earlier $19^{\text {th }}$ century American pragmatism again in the middle of the $20^{\text {th }}$ century. ${ }^{1700}$ However, the current state of mainstream philosophy remains one caught in the embrace of an untenable dualism, a legacy of Plato, Kant, and Descartes, and this is reflected in many subtle ways in mainstream society and culture, determining how freedom, and time, are understood and accepted, or, conversely, rejected.

In the contemporary world, all of the historical problems of freedom remained unresolved, and divided by issues at the heart of the two cultures, the sciences and humanities. At the political level in the West, the protection of minority positions in various manifestations of democracy and the debates over how to balance equality versus liberty remain highly contentious. At the personal level, the existence of existential freedom and the reality of moral freedom remain very much disputed. And, even amongst those who support the existence of existential or moral freedom, the meaning of freedom remains intensely debated. What can be said is that many of the disputes concern how freedom relates to time, and that the two cultures, in one way or another, often, or arguably always, underlay the problems. This latter point has been recently clearly affirmed by Sophia McClennen and Alexandra Moore, who describe the many problems facing the humanities, or literary approaches to human rights and freedoms, in today's world. As they see it, "the two cultures ... signals the break between quantitative and qualitative research-a breakdown that would logically affect scholars working on the culture of human rights, since such work must necessarily blend the empirical with the contemplative."1701

\footnotetext{
${ }^{1698}$ Piekkola, Conceptual and Historical Issues in Psychology, 289.

${ }^{1699}$ See, for example, Michael Losonsky, Linguistic Turns in Modern Philosophy (New York, NY: Cambridge University Press, 2006).

${ }^{1700}$ Rorty, Philosophy and the Mirror of Nature: Thirtieth-Anniversary Edition.

${ }^{1701}$ Sophia A. McClennen and Alexandra Schultheis Moore, "Introduction-Aporia and Affirmative Critique: Mapping the Landscape of Literary Approaches to Human Rights Research," in The Routledge Companion to Literature and Human Rights, eds. Sophia A. McClennen and Alexandra Schultheis Moore (New York, NY: Routledge, 2016), 6-7.
} 
Possibly one of the most profound critiques concerning the meaning of freedom along the above vein comes from the Catholic theologian David L. Schindler, which takes on extra significance because he explores it within an inquiry into the meaning of religious freedom in the political sphere. ${ }^{1702}$ For Schindler, and others who have inspired him, such as Joseph Ratzinger (later Pope Benedict XVI) ${ }^{1703}$ and Hans Urs von Balthasar, authentic freedom must escape the shackles of the purported neutrality of the Cartesian-scientific rationality of modernity, otherwise understood as Western/American liberalism in the broad sense. ${ }^{1704}$ Schindler's critique is penetrating, cogently aware of the two cultures, ${ }^{1705}$ and, specifically following Heideggerian and Bohmian premonitions about science and

\footnotetext{
${ }^{1702}$ Schindler, Ordering Love: Liberal Societies and the Memory of God; and Schindler, Heart of the World, Center of the Church: Communio Ecclesiology, Liberalism, and Liberation.

${ }^{1703}$ Pope Benedict XVI, Joseph Ratzinger in Communio Vol. 2: Anthropology and Culture, 188-199. See also, Olsen, On the Road to Emmaus: The Catholic Dialogue with America and Modernity, 125-187; Koyzis, Political Visions \& Illusions: A Survey \& Christian Critique of Contemporary Ideologies, 68-71; Casarella, "Public Reason and Intercultural Dialogue," 51-84; and Barrett, Persons and Liberal Democracy: The Ethical and Political Thought of Karol Wojtyla/Pope John Paul II, 90-93. Note also, Hanby, "Beyond Mechanism: The Cosmological Significance of David L. Schindler's Communio Ontology," 162-192; and O'Regan, "Martin Heidegger and Christian Wisdom," 3758.

${ }^{1704}$ Schindler, Heart of the World, Center of the Church: Communio Ecclesiology, Liberalism, and
} Liberation, 164, 174. "Catholics cannot successfully challenge the mechanistic-subjectivistic worldview implied in modern formal-critical methodological procedures (in the dominant liberal understanding of these) if they challenge this worldview only when it takes an overtly moral or religious form, only when it thus becomes a matter of formal concern within the disciplines of ethics and theology. On the contrary, Catholics must challenge the mechanistic-subjectivistic worldview in all of its analogous forms down through all of the disciplines," ibid., 174. Rather, Schindler insists that it "is not that we should refuse to endorse modern freedom, but only that our endorsement should coincide with an awareness that freedom, even modern freedom, presupposes, willy-nilly, some anthropology (ontology, theology). Any endorsement of modern freedom must therefore coincide with an evaluation of the anthropology which has always-already given that freedom its meaning. In the present context, this means that we must consider carefully the extent to which modern freedom has from its origins been shaped by the liberal disjunction between subjectivity and objectivity, or, again, has been infected by the liberal dualism of will and intelligence, with its corresponding voluntaristic subjectivity and mechanistic objectivity.... Unless we recognize the ambiguity of present-day freedom at its very source, we risk colluding in the development of a culture that can easily, however paradoxically, become the death of freedom. Unless we grasp the ambiguity of modern freedom in its roots, we will not be able to understand how, for example, modernity's achievement of 'rights' can, by virtue of its own dynamic-and precisely coincident with the positive aspects of this achievement-invert into a kind of 'totalitarianism,"' ibid., 182. This is important because, for Schindler, "the Anglo-American" liberalism is already founded upon an anthropology that includes "a metaphysics and a theology-thus (unwittingly) smoothing the way for the triumph of the liberal conception of man" which makes "liberalism particularly dangerous at this momentous time in history," 36, as it denies man his essential freedom as it actually leads into a culture of death. Elsewhere Schindler again reiterates, from the broad perspective, "an economic system itself already embeds, indeed is also, a theology and an anthropology and a culture," D. L. Schindler, "Homelessness' and Market Liberalism," in Wealth, Poverty \& Human Destiny, 349.

${ }^{1705}$ Schindler, Ordering Love: Liberal Societies and the Memory of God, 330. Schindler here addresses, in particular, secularism and religionism, within the context of the Right and Left within America, but his entire critique is premised upon an awareness of the sciences and humanities. 
technology, ${ }^{1706}$ proffers that modern society's obsession with and addiction to deterministic technologies creates a culture of death coincident with an implicit theology ${ }^{1707}$ (or atheology) that denies freedom, especially given how it penetrates even into the disciplines of psychiatry and psychology, let alone politics and religious freedom, the latter of which are Schindler's focus.

The basic point for Schindler is that religious freedom is not possible if we have a deficient understanding of personal freedom and free-will, and that a paradox is entailed here, as the most common framework within which the modern concept of freedom operates, that of scientific progress over time through technology, actually leads to a loss of freedom and a culture of death. Schindler's alternative, interestingly, includes a subtle introduction of religion into society to liberate society's institutions ${ }^{1708}$ through his redefinition, or restoration in his perspective, of the true meaning of freedom, which includes, in particular, an intrinsic relationship to truth. ${ }^{1709}$ For Schindler, authentic freedom is not, following the modernistic Western mind, merely the allowance of a belief in something and autonomy from coercion (a negativized freedom from), but also always a relation to

${ }^{1706}$ Schindler, Ordering Love: Liberal Societies and the Memory of God, 278-279.

${ }^{1707}$ Schindler, Ordering Love: Liberal Societies and the Memory of God, 128. Following alongside the Heideggerian (and Bohmian) suggestion that the modern world is ontotheological through its technological nature, Schindler argues that "the question of metaphysical, and indeed also by implication theological, truth cannot be avoided in statecraft, even in the case of the liberal-juridical state. The would-be deferral of metaphysics attempted in liberal-juridical statecraft is mediated by metaphysical assumptions: those of a technological instrumentalism that leads unwittingly to a paradoxical inversion of liberalism's fundamental goals and purposes," ibid., 128.

${ }^{1708}$ The common American "definition of religious freedom" "insists that it is merely offering a formaljuridical freedom to [or freedom from] all religions, while at the same time it (tacitly) mediates its appeal to freedom via a definite theoretical (if typically unconscious) dualism. The non-triviality of this maneuver becomes especially clear when we note its implications with respect to any non-Western (or nonliberalized) religion-with respect to any country where a traditional (or non-dualistic) worldview still predominates. In countries, for example, where certain forms of Orthodoxy, Islam, Judaism, Native American-Indian, or African religion still prevail, an invitation to adopt the juridical notion of religious freedom amounts to nothing less than an invitation to adopt the theological dualism of liberalism-albeit, again, only in the name of a purely formal commitment to the principle of freedom." However, if the dualistic technologized-rationalized freedom of liberalism actually denies authentic freedom, then what "liberalism does in effect is invite other countries to adopt a religious freedom, not which leaves a traditional religion intact but which on the contrary requires transformation of that religion, requires that it subscribe to an alternative religious truth. Failure to be clear about this implies nothing less than the paradox of imparting a [supposed] truth about freedom unconsciously and blindly-and just so far unfreely," Schindler, Heart of the World, Center of the Church: Communio Ecclesiology, Liberalism, and Liberation, 66-67 (latter addition mine).

${ }^{1709}$ This is explained well by Hudock, “'Freedom, Truth, and Human Dignity': The Other Conflict Behind "'Dignitatis Humanae'." 
truth and the participation in practices and actions (a positivized freedom for), ${ }^{1710}$ which takes on extra significance when one takes into account the ethical/moral/religious freedom that the Catholic Sacramental view advocates, including its unique relationship to space, freedom, and time within a framework that includes the common good and social justice. ${ }^{1711}$ Notably, all of this, however, hinges

${ }^{1710}$ Schindler, "Freedom, Truth, and Human Dignity: An Interpretation of Dignitatis Humanae on the Right to Religious Freedom," 48-49, 87-90, 165 n. 23, 191 n. 136-137, 192 n. 138. See also, Edward, Persons and Liberal Democracy: The Ethical and Political Thought of Karol Wojtyla/Pope John Paul II, 91; Farrow, Desiring a Better Country: Forays in Political Theology, 166 n. 33; Levering, Biblical Natural Law: A Theocentric and Teleological Approach, 1-21; Cavanaugh, Theopolitical Imagination: Christian Practices of Space and Time, 15-21, 57, 68, 87; and the essays in Philpott and Anderson, eds. A Liberalism Safe for Catholicism: Perspectives from 'The Review of Politics'. For the work of an advocate of Schindler's general theo-political philosophy, see Tan, Justice, Unity, and the Hidden Christ: The Theopolitical Complex of the Social Justice Approach to Ecumenism in Vatican II, esp. 10-13, 38-49, 59, and 69-87. Schindler is a critic of both the American religious "Right" and secular "Left," and thus would agree, fundamentally, with Schafly and Neumayr, No Higher Power: Obama's War on Religious Freedom, and Hurd, Beyond Religious Freedom: The New Global Politics of Religion, 13, 52, 60. Hurd insists that, deep down, the liberal definition of religious freedom only includes one's freedom to belief, but not freedom to practice, thus creating a Cartesian dualism, and it is this tension that lies at the heart of many religious conflicts around the world and the challenge of the West's interventions to insert the Western concept of freedom into cultures that have a different understanding of religious freedom.

See also, for a comparable broader critique of how religion and freedom intersect with the political, Raschke, Force of God: Political Theology and the Crisis of Liberal Democracy, 81, 83, 91-92. Raschke observes that "one of the reason[s] the very idea of a political theology, especially a 'global' political theology, makes us uncomfortable is that we are virtually hypnotized these days, particularly in America, to think-politically-solely in terms of an economy of entitlement and resentment, which we mistakenly associated with some vague idea of 'justice.' [The Heideggerian philosopher Giorgio] Agamben has forced us decisively into rethinking our 'economic' and 'ecumenical' models of the new global political as ultimately the 'God' question. We are ... all now political theologians, mainly because all theology is political and all politics is theological," ibid., 83. Raschke continues, "the 'reversal of Platonism' may have happened in [postmodern] epistemology and language theory, but the reversal itself has been dramatically reversed when it comes to the codes and modes of symbolization that matter significantly in our personal lives. Political economy should have gone the way of structural linguistics, but instead it has reverted to Platonism of a very odd sort," ibid., 92. Note also, Schmitt, Political Theology, 36. Schmitt asserts that, "all significant concepts of the modern theory of the state are secularized religious concepts," ibid; Crockett, Radical Political Theology: Religion and Politics After Liberalism, where he shares the "distinction between religious and secular is breaking down, so that it is no longer possible to consistently and rigorously separate and oppose the sacred and the profane ... [and] if religion and secularity cannot be neatly separated, we cannot fully separate or distinguish political philosophy from political theology," ibid., 2; and Robbins, Radical Democracy and Political Theology, 162-165.

${ }^{1711}$ See again, Younker, "From Metaphysics to Templephysics: Situating the Significance of Fernando Canale's Contributions for the 'Christian Philosopher,'” 208-230. Tan writes "it is important to note that securing space in a way that sets the Church as a political community in its own right can only be complete with a liturgical interruption of an often overlooked dimension of modernity, postmodernity and their subsequent cultural manifestations-time. Thus it is important to first consider how eucharistic space challenges the conception of time within the state/society/market complex. What is important to note, first of all, is that time is not the result of scientific distillation but is 'structured through social practices.'” Unfortunately, "modern time-sometimes called 'clock' time-operates as a seamless stream of repeated units of measure that are constantly being replicated in the present, then irrevocably lost to the past. This is the flattened time that sustains both the state and the market as political communities, since both are founded on confining all reality to the [deterministic?] temporal, coupled with the imperative to compress the processes of life into reified commodities whose value can be discerned in a single moment in the present. Eucharistic practice poses a challenge to the status quo because the Eucharist interrupts this flattened time by having eternity 'enter history,' making the liturgy a simultaneously historical and eschatological event that transforms temporal, and indeed political, experience." There is thus a simultaneous looking back and eschatological looking forward that 
upon a definition of what personal freedom really is in relationship to a scientific culture that

continues to tell us we are not free (a point the non-Western world is happy to point out to the West).

To state it plainly, if Schindler is correct in his critique of the faulty theological foundation of Western political philosophy and freedom, ${ }^{1712}$ why should an advocate of a radically militant religion or religious group feel compelled to respect the Western world's view of religious freedom when the ontology grounding the Western world actually denies ${ }^{1713}$ humans have any meaningful freedom at

makes the modern compartmentalization of past, present and future 'lose their fixed character.' The Eucharist thus interrupts 'clock' time because the liturgy presumes a confusion of past, present and future in a single moment." Tan continues, "this is given a sharper focus in the offering of bread and wine. The 'in the now' offering of bread and wine casts the participants' minds back to the events leading up to Jesus' death and Resurrection. This can be a simple memorial of a past event, but remember that the endpoint of the eucharistic liturgy is the reception of the Body of Christ. Recall that these elements to the participant are not merely symbolic and pointing to the past, but are real and present 'in the now.' This reception 'in the now' of a real Body of Christ that is the result from that same single sacrifice took place in the past, denotes a bringing forward of that past event into the present. The liturgical sacrifice both as a memorial of Jesus' bounded historical death and resurrection as well as part of a heavenly liturgy collapses the duality between historical (Kronos) and eternal (Kairos) time. Participants are reminded that the Eucharist is not a replication of a past sacrifice that occurred in a past time, but of one that is continuing outside of time in 'the heavenly Jerusalem ... [with] innumerable angels ... \{and the assembly of the firstborn enrolled in Heaven. This participation in the Kairos, where past, present and future meet, is what brings into the now the seemingly unknown events of the future into a single moment," Tan, Justice, Unity, and the Hidden Christ: The Theopolitical Complex of the Social Justice Approach to Ecumenism in Vatican II, 69-71 (additions mine). Despite the very "Heideggerian" description of time by Tan, in reality, as will be shown later, he is more Bohmian, following Schindler's conceptualization, and thus supports a subtle form of timelessness.

${ }^{1712}$ Whether Schindler is correct about the foundations of American liberalism is, in itself, a disputed issue. The Heideggerian G. B. Madison, for one, would suggest, contra Schindler, that America was not primarily founded upon a mechanistic-subjectivistic worldview, even if elements of it have always existed, and continue to do so. American liberalism is unique for Madison. See Madison, The Logic of Liberty, xi, 1-6.

${ }^{1713}$ Importantly, there are two competing conclusions that the mechanistic-subjectivistic worldview system has generated in the West-one of atomistic liberalism, and another one that denies freedom altogether. For an illustration of Schindler's point concerning the latter scenario in particular, note Sam Harris in The End of Faith: Religion, Terror, and the Future of Reason. Harris, a scientistic atheist and denier of human free will, and a critic of Christianity, additionally asserts that the Western scientific culture is "at war with Islam. It may not serve our immediate foreign policy objectives for our political leaders to openly acknowledge this fact, but it is unambiguously so," ibid., 109. Indeed, Harris would claim that science is at war with all religion, ibid., 20-21. Harris believes that "while moderation in religion may seem a reasonable position to stake out, in light of all that we have (and have not) learned about the universe, it offers no bulwark against religious extremism and religious violence," ibid., 20. For another atheist who thinks similarly, see Silverman, Fighting God: An Atheist Manifesto for a Religious World, 60-69, 91-92; and Leah Marieann Klett, "Richard Dawkins Clarifies Why He Believes Islam Has Replaced Christianity as 'Most Evil Religion'” in The Gospel Herald Society at http://www. gospelherald.com/articles/70936/20170615/richard-dawkins-clarifies-why-believes-islam-replaced-christiani ty-evil-religion.htm (accessed June 15, 2017). Some Muslims strongly disagree with Harris, such as Abdullah Saeed, Islam and Belief: At Home with Religious Freedom (Center for Islam and Religious Freedom, 2014). For further relevant insights from perspectives sympathetic to Islam, see Asma Afsaruddin, Contemporary Issues in Islam (Edinburgh, UK: Edinburgh University Press, 2015); Hichem Djaï, Islamic Culture in Crisis, tr. Janet Fouli (New York, NY: Routledge, 2017); and Ali A. Allawi, The Crisis of Islamic Civilization (London, UK: Yale University Press, 2009), the point here is others recognize the situation as complex; the obvious concerns with militant Islam need not be overstated presently-though, the brief comment that, as Pylkkö explained above, it is possible that Heideggerianized Nazism is equitably comparable to militant or radical Islam-both seek an authentic 'religious' experience rooted in history. Nevertheless, for a survey of the 
all $?^{1714}$ Of course, none of this removes the irony that the Western tradition, Catholicism, and Islam,

contemporary landscape on the issue, see the essays in Madawi Al-Rasheed and Marat Shterin, eds. Dying for Faith: Religiously Motivated Violence in the Contemporary World (New York, NY: Palgrave Macmillan, 2009); William McCants, The ISIS Apocalypse: The History, Strategy, and Doomsday Vision of the Islamic State (New York, NY: St. Martin's Press, 2015); Jessica Stern and J. M. Berger, ISIS: The State of Terror (New York, NY: Harper Collins, 2015); Joby Warrick, Black Flags: The Rise of ISIS (New York, NY: Anchor Books, 2016); Brendan January, ISIS: The Global Face of Terrorism (Minneapolis, MN: Twenty-First Century Books, 2018); Jay Sekulow, Rise of ISIS: A Threat We Can't Ignore (New York, NY: Howard Books, 2014); Fawaz A. Gerges, ISIS: A History (Princeton, NJ: Princeton University Press, 2016); Michael Weiss and Hassan Hassan, ISIS: Inside the Army of Terror, updated ed. (New York, NY: Regan Arts, 2016); Sahaja Carimokam, Muhammad and the People of the Book (Bloomington, IN: Xlibris, 2010); Andrew G. Bostom, Sharia Versus Freedom: The Legacy of Islamic Totalitarianism (Amherst, NY: Prometheus Books, 2012); and Andrew G. Bostom, ed. The Legacy of Jihad: Islamic Holy War and the Fate of Non-Muslims (Amherst, NY: Prometheus Books, 2005). As the $21^{\text {st }}$ century advances, the debates about how Islam is portrayed in the West continue. For some works examining this issue in the academy, see the trio of books by Aaron W. Hughes, Situating Islam: The Past and Future of an Academic Discipline (Oakville, CT: Equinox, 2007); Theorizing Islam: Disciplinary Deconstruction and Reconstruction (Bristol, CT: Acumen, 2014); and Islam and the Tyranny of Authenticity: An Inquiry into Disciplinary Apologetics and Self-Deception (Bristol, CT: Equinox, 2015). From a broader perspective, also note, Carl Raschke, GloboChrist: The Great Commission Takes a Postmodern Turn (Grand Rapids, MI: Baker Academic, 2008), 94-115; and Roy E. Gane, "Methodology for Interpretation of Daniel 11:2-12:3," in Journal of the Adventist Theological Society Vol. 27 \#1-2 (2016), 294-343.

${ }^{1714}$ For an attempted rationale about how all the confusion relating to Islam might have come about concerning the concept of freedom in particular, see especially, Arvind Sharma, Problematizing Religious Freedom (New York, NY: Springer, 2011), 108-109. Sharma explains that for some Muslims, "the concept of religion in Islam is that of a "revealed religion." So, "with the coming of Islam, which is the revealed religion par excellence, religious freedom came to mean the freedom to possess a revealed religion. This is the common implication of disparate facts related to Islam.... There is the claim that early Islam offered to the Arab the choice between Islam or death. The point to be rescued from this dire situation is that this was so because now a revelation had been sent in its fullness to the Arabs, therefore rejection of Islam meant rejection of the revealed religion," and rejection of such a clear revealed religion would imply a rejection of spiritual or religious freedom, and cause one to be worthy of death, ibid., 108. Worthy of observation in this context is that in philosophical circles Islam has struggled over the problem of human free will and divine omniscience as much as Christianity has, and this only exacerbates the problem of how the religious cultures of Christianity and Islam can or should be related to one another philosophically. For more, see Charles Le Gai Eaton, Islam and the Destiny of Man (Albany, NY: State University of New York Press, 1985), 195; Maria De Cillis, Free Will and Predestination in Islamic Thought: Theoretical Compromises in the Works of Avicenna, al-Ghazālī and Ibn 'Arabī (New York, NY: Routledge, 2014); and F. E. Peters, The Monotheists: Jews, Christians, and Muslims in Conflict and Competition: The Words and Will of God Vol. II (Princeton, NJ: Princeton University Press, 2003), 162-165, 223, 232. For more general discussions on the issue of freedom from the perspective of Islamic studies, see also, Erich Kolig, ed. Freedom of Speech and Islam (New York, NY: Routledge, 2014); Richard K. Khuri, Freedom, Modernity, and Islam: Toward a Creative Synthesis (Syracuse, NY: Syracuse University Press, 1998); Jake Neuman, It Is All About Islam (Ingram Book Group, 2013), 199; Peter Riga, The Islamic War on Christians (Bloomington, IN: AuthorHouse, 2012), 13; Maulana Wahiduddin Khan, Spirit of Islam (Goodword Books, 2014), 30; Muhammad Tahir ul-Qadri, Islam and Freedom of Human Will (Lancashire, UK: Minhag Welfare Foundation, 2005); John van Schaik, Christine Gruwez, and Cilia ter Horst, eds. The Impulse of Freedom in Islam (Great Barrington, MA: Lindisfarne Books, 2014); Aaron W. Hughes, Muslim Identities: An Introduction to Islam (Chichester, West Sussex: Columbia University Press, 2013), 188; Ernst von Bunsen, Islam, Or True Christianity: Including a Chapter on Mahomed's Place in the Church (Trübner, 1889), 151-152; and Kim Ghattas, "How the Muslim World Lost the Freedom to Choose," in Foreign Policy (10/20/2017) at http://foreignpolicy.com/2017/ 10/20/how-the-muslim-world-lost-the-freedom-to-choose/ (accessed October 25, 2017).

Concerning the issue of human freedom in particular in relation to Islam and Catholicism, one can only note the ironies of the above situation in Islam, given that Karol Wojtyła (Pope John Paul II) asserted that "there is no freedom without truth" and inserted this perspective into Dignitatis Humanae, the Vatican's statement on religious liberty. However, the American more libertarian-conservative Catholic philosopher John Courtney Murray, the primary target of Schindler's critique, who also contributed to Dignitatis Humanae, was "disappointed in this development. He saw it as an unnecessary embellishment and a potential threat to what 
share much by way of their mutual philosophical dependence upon Greek thought, ${ }^{1715}$ however contentious and complex a heritage. It seems not only the Christian West, but also Islamic East, contains its own history of the "two cultures."1716

ought to have been the church's principled commitment to the right to religious freedom. It is a short step, he argued, for a government-be it Catholic or Communist-that sees itself as possessing truth to decide it must impose that truth and repress error for the good of the people," Hudock, "Freedom, Truth, and Human Dignity': The Other Conflict Behind "'Dignitatis Humanae'." See also, Berny Belvedere, "Two Kingdoms: Christianity and Islam: How Far Should we go in Restricting Freedom in Order to Promote Virtue?," at https://arcdigital.media/ two-kingdoms-christianity-and-islam-193be539476e (accessed June 14, 2017). Again, for more on the general tensions existing between the Islamic world and the Christian west, see Bernard Lewis, Cultures in Conflict: Christians, Muslims, and Jews in the Age of Discovery (Oxford, UK: Oxford University Press, 1995); Bernard Lewis, The Crisis of Islam: Holy War and Unholy Terror (New York, NY: Modern Library, 2003); and Shadi Hamid, Islamic Exceptionalism: How the Struggle Over Islam is Reshaping the World (New York, NY: St. Martin's Press, 2016).

${ }^{1715}$ See, in particular, Reilly, The Closing of the Muslim Mind: How Intellectual Suicide Created the Modern Islamist Crisis; and Peter V. Rabins, The Why of Things: Causality in Science, Medicine, and Life (New York, NY: Columbia University Press, 2013), 22. Reilly's supposition is that mainstream Sunni Islam's late medieval abandonment of Greek philosophy and modern science led to their crisis, including the rise of certain militant groups in recent times. I do not dispute this in the broad sense, but I suggest the links between every variant of Islam and Greek philosophy penetrate more deeply than Reilly has suggested. That is, Islam has experienced the same crisis of "two cultures" that the West has experienced, with similarly polarizing and dramatic results. For evidence of this in recent times, one merely need note the interest by Sufi Muslims in Bohm, and also that there has recently been a "renewed interest [by some, such as Henry Corbin] in Heidegger within Islamic circles: Heidegger, the philosopher who ambiguously collaborated with the Nazi regime," Mona Abaza, Debates on Islam and Knowledge in Malaysia and Egypt: Shifting Worlds (New York, NY: Routledge, 2002), 114. Similarly, "several of the intellectual architects and principal ideologues of the Iranian Revolution were formed by their understanding of Heidegger, drawing on his thought in their diagnosis of the toxicity of Western civilization, the possibility of a future-oriented revolution that would repeat something of a lost Islamic past," Alexander S. Duff, Heidegger and Politics: The Ontology of Radical Discontent (New York, NY: Cambridge University Press, 2015), 7. As Tom Cheetham observes of the well known inter-religious theologian Henry Corbin, "without doubt Heidegger provided [Corbin] the foundation for a bridge between Western philosophy and Islamic theology," Tom Cheetham, "Henry Corbin on Heidegger," at http://henrycorbinproject.blogspot.com/2008/09/onheidegger.html (accessed September 12, 2008). See also, Mohammad Rafi, "Re-Working the Philosophy of Martin Heidegger: Iran's Revolution of 1979 and Its Quest for Cultural Authenticity," at http://www.

telospress.com/re-working-the-philosophy-of-martin-heidegger-irans-revolution-of-1979-and-its-quest-for-cul tural-authenticity/ (accessed Friday, April 19, 2013); S. Parvez Manzoor, "The Unthought of Islamic Science (Part One)," in Studies in the Islam and Science Nexus Vol. 1, ed. Muzaffar Iqbal (New York, NY: Routledge, 2012), 51-66; Ali Mirsepassi and Tadd Graham Fernée, Islam, Democracy, and Cosmopolitanism: At Home and in the World (Cambridge, UK: Cambridge University Press, 2014); Amin Sharifi Isaloo, Power, Legitimacy and the Public Sphere: The Iranian Ta'ziyeh Theatre Ritual (New York, NY: Routledge, 2017), 26-29, 123; Mohammad Azadpur, Reason Unbound: On Spiritual Practice in Islamic Peripatetic Philosophy (Albany, NY: State University of New York Press, 2011), 21-38; Aaron W. Hughes, The Texture of the Divine: Imagination and Medieval Islamic and Jewish Thought (Bloomington, IN: Indiana University Press, 2004), 32-33, 216-225; and Mazyar Lotfalian, Islam, Technoscientific Identities, and the Culture of Curiosity (Lanham, MD: University Press of America, 2004), 15-29.

${ }^{1716}$ Many advocates of Islam deny Snow's critique applies to authentic Islam as true Islam has always maintained an integration of the sciences and humanities. For example, see Osman Bakar, Islamic Civilisation and the Modern World: Thematic Essays (Gadong, Malaysia: Universiti Brunei Darussalam Press, 2014), 55-56, and Imad-ad-Dean Ahmad, Signs in the Heavens: A Muslim Astronomer's Perspective on Religion and Science (Beltsville, MD: Writer's Inc., 1992), 2-3. Nonetheless, many also acknowledge the challenges between the sciences and humanities, and even Bakar acknowledges they have infected contemporary Islam's diversity of expression. For discussions ranging from the practical to philosophical, see H. R. Dalafi and M. H. A. Hassan, eds. Renaissance of Sciences in Islamic Countries (London, UK: World Scientific Publishing, 1994), 253-254; Fathi Hasan Malkawi, Epistemological Integration: Essentials of an Islamic Methodology, tr. Nancy Roberts (London, UK: The International Institute of Islamic Thought, 2014), 1-36; and Mahmoud Dhaouadi, Cultural Sociology 
The "third culture" psychiatrist Callender expresses what is probably the contemporary sentiments of a majority of today's scholars who are immersed within the complex of the sciences when he shares that "the paradox of freedom and deterministic understanding arises only if we assume the existence of libertarian free will." Rather, he continues, "only by understanding our lives in the framework of causal determinism" can a concept of free will "acquire coherence or make sense to us." ${ }^{1717}$ The unanswered question of course, is what kind of determinism? In any case, Callender correctly suggests that "the themes of free will and moral responsibility are ones that bring together" the areas of "moral philosophy, aesthetics, philosophy of mind, social psychology, anthropology, philosophy of law, neuroscience, molecular genetics, clinical psychology, and psychiatry." Furthermore, the integration of all these "more specialized areas of research and scholarship" are necessary if "a complete understanding of what it may mean to be free or responsible" can be found-in other words, "contributions from both science and the humanities" are necessary. ${ }^{1718}$ Importantly, he also notes that "the growing sophistication of neuroscience has thrown into relief venerable debates about free will and responsibility," and he speculates that "in years to come we will see the emergence of ever more powerful and sophisticated capacities to mold and manipulate behavior, feeling, and personality. These developments hold out great promise but will also create unprecedented ethical dilemmas, ${ }^{1719}$ which suggests serious implications for theological and religious reflection, as well. The question will then become, in what way can or should the humanities, especially of a Heideggerian sort, impact upon our understanding of freedom? Of course, the question of the way in which theology, and Scripture, should influence our picture of freedom also naturally follows. These questions are the ones often ignored or neglected by individuals from the sciences, even including those such as Callender (who has a limited view of what constitutes the humanities as he does not engage Heidegger), and those he refers to in the above disciplines.

within Innovative Treatise: Islamic Insights on Human Symbols (Lanham, MD: University Press of America, 2013), 95.

${ }^{1717}$ Callender, Free Will and Responsibility: A Guide for Practitioners, 17.

1718 Callender, Free Will and Responsibility: A Guide for Practitioners, 17.

${ }^{1719}$ Callender, Free Will and Responsibility: A Guide for Practitioners, 17. 


\section{Summary on the Origin of Freedom in Ancient Greece and the West}

Freedom emerged as a topic of discussion very early in Greek history, and typically in the context of political liberty, although the relationship between political liberty and personal freedom (free-will and ethical/religious freedom) are ultimately closely intertwined. Indeed, all of the varieties of freedoms that one can deduce from history appear to coalesce in shared understandings of the problems contained within the meaning of rationality and its relationship to morality. Within this matrix, the primary issues that divided the ancients, and moderns, are the issues of the protection of the minority, and the distinct roles of determinism and chance/randomness as the definitive problems for any meaningful understanding of freedom. Understood this way, freedom becomes a problem of science, which in turn becomes a problem of natural science in the modern context. Importantly, the more focus that is shifted to freedom and a problem of natural science, the more the problem of freedom as a moral or ethical issue becomes subsumed under the same scientific problematic of determinism and chance/randomness.

Put another way, the entirety of the discussion surrounding the virtues of democracy, or political freedom, loses some of its potency if individual humans themselves do not possess free-will. As such, the discussion then turns upon the function of rationality in its relationship to time and various freedoms, including moral freedom. If freedom is understood in a timeless way, then various paradoxes arise when one seeks the attainment of yet greater freedoms in some (common-sense) "temporal" or historical future. The use of (even democratic!) coercion to attain greater "freedom" then becomes the story of modernism's historical struggle, as the 'form' of freedom sought is timeless (objective). The paradox just described is in fact our common situation today, and the common denominator is the "mathematical" core or foundation that grounds our modern discussions about both socio-political freedom and individual free-will. Intriguingly, ethical freedom, caught

uncomfortably between the two previous freedoms, has also become grounded upon a mathematical (timeless) foundation.

Within Christian circles, the above problems were merely repeated. No distinctly "Christian," or even theist, suggested explanation for grounding freedom has gained any serious attention that 
deviates in any significant way from the above fundamental problem that trapped the ancients in the "horns of a dilemma, with determinism on one side and randomness on the other."1720 The only exception would be the Heideggerian stream of thought, which rejects the above dualism, though without, of course, any standard scientific evidence. This is not to discount that one of the distinctly Christian ideas that does exist is that the Holy Spirit is somehow related to the question of freedom-but from a conceptual point of view, this has been the focus of more criticisms than praise, as it only supports, or seems to supports, the idea of an infinite indeterminable explanatory regression concerning how to 'find' freedom in ourselves and our world (and thus into the work of Bohm and Pylkkö), and thus doesn't offer much support to those seeking to ground a persuasive argument against sceptics of free-will.

The purpose of this study's inquiry into the origins of freedom and time was to help expose and explain the context and position within which Bohm and Pylkkö appear today-namely, is the contemporary conflict within the two cultures concerning freedom and time also discernable at the origins of the appearance of reflections about freedom and time? The answer to this question appears affirmative, which supports the supposition that the two cultures represent a very deeply rooted problem for philosophers, one located not only in the West, which has been the focus of this study, but also, anecdotally, in other traditions, as has been noted in passing.

\section{Summary on the Origins of Freedom and Time}

There are three major points to deduce from the above survey of the history and contemporary context of the problems of freedom and time. First, the value and role of theology or religion, as an academic culture or social culture, appears tenuous, as it serves presently to merely replicate a much deeper philosophical divide concerning how we should understand freedom and time that is represented by the two cultures of the sciences and humanities. Second, this division became evident

\footnotetext{
${ }^{1720}$ Doyle, Free Will: The Scandal in Philosophy, 75. Notably, of course, isolating the problem of freedom as one between determinism and randomness risks preclusion from any serious engagement with the idea that reality is more fundamentally temporal or historical, which was been the burden of Heidegger to articulate.
} 
in an examination of the three major mediatory third cultures of psychology and psychiatry, economics, and the socio-political sciences, all of which utilize elements of both the sciences and humanities, and which are divided over how to interpret the concepts of freedom and time. Importantly, adherents of religion use theology to justify their own positions within these three third culture disciplines, and the results indicate that religionists are replicators of the philosophical divide between the sciences and humanities. Third, the above situation raised the question about the origins of the conflict of interpretations about freedom and time, and it was affirmed that the earliest reflections in the Western tradition reveal that the division between the two cultures has existed since the dawn of philosophical reflection in the West, as well as other cultures. Indeed, in what has become the standard interpretation of the pre-Socratics, it appears true that in general "these first people to be called philosophers, lovers of wisdom, addressed themselves, amongst other things, to the problem of establishing the basis of the order that pervades the world."1721 What was understood as 'order' included the issues of freedom and time, and two divergent interpretive thought pathways developed concerning them, with the 'scientific' pathway growing to predominate over the 'mythical' pathway, which has become a public as well as academic crisis in the contemporary world, both inside and outside Christianity and religious cultures. ${ }^{1722}$

${ }^{1721}$ Curnow, Wisdom in the Ancient World, 87.

${ }^{1722}$ How this relates to Scriptural interpretation, and thus Christianity, is clear. The classic article by Langdon B. Gilkey, "Cosmology, Ontology, and the Travail of Biblical Language," in The Journal of Religion Vol. 41 No. 3 (July, 1961), 196-203. clearly represents the contemporary crisis of scientific interpretations predominating over "mythical" interpretations of the theological content of Scripture as it pertains to history. Many Christians, such as Kevin Vanhoozer, have attempted to respond to this crisis by remythologizing theology and Scriptural interpretation. See, for example, Kevin J. Vanhoozer, Remythologizing Theology: Divine Action, Passion, and Authorship (Cambridge, UK: Cambridge University Press, 2012). Of course, there is a deeper layer relevant here concerning the issues of freedom and time in relation to Scripture and science. The point at present is that, as pointed out by the psychologist Jordan Peterson, many believe science itself and its implicit ontology eliminates the subjective experience of freedom and time, and as such, a restoration of "myth ... assumes that the subjective is a precondition of the real. This idea seems exceedingly foreign to modern sensibility, which is predicated upon the historically novel proposition that the objective material in and of itself constitutes the real, and that subjective experience, which in fact provides source material for the concept of the object, is merely an epiphenomenal appendage. However, it is the case that self-referential systems (like that consisting of being as subject and object, simultaneously) are characterized by the emergence of unexpected and qualitatively unique properties. The world as subject (that is, the individual) is an exceedingly complex phenomenon-more complex, by far, than anything else (excepting other subjects). The world as object is hardly less mysterious. It is reasonable to regard the interaction of the two as something even more remarkable. We think: matter first, then subject-and presume that matter, as we understand it, is that which exists in the absence of our understanding. But the 'primal matter' of mythology (a more comprehensive 'substance' than the matter of the modern world) is much more than mere substance: it is the source of everything, objective and subjective 
An additional point of clarity that is important to emphasize is that the above situation truly can be bewildering to many people, both in the general population, as well as various specialists in any given field or discipline. In particular, the reversal that took place transposing nature and Parmenidian Being altered the primary or functionally pragmatic "location" of timelessness. While the abstractions of mathematics and Being were what originally inspired the creation of a "timeless" realm, historically, nature was originally considered transitory/temporal or cyclical. However, a significant change took place as modern science came onto the scene and rose to dominance. The temporality within nature became conceived in an objective and deterministic way, which meant that it was essentially ontologically "timeless," for, considered as a 'temporal' whole, nature could never be anything other than what it is-any temporal changes would be merely changes in the appearance of the timeless whole as it necessarily altered its outer form or shape but not its inner deterministic necessity-the analogy would be that of changing the paint on a car without touching its engine or burning fuel.

That is, what has become the standard interpretation of the pre-Socratics "has been to show how these first people to be called philosophers, lovers of wisdom, addressed themselves, amongst other things, to the problem of establishing the basis of the order that pervades the world." ${ }^{1723}$ This equating of wisdom with world order (natural science) is a form of natural theology. Importantly, the Greeks came to see mathematics as the essence of the superintendent order of the mind-and as such also of theology. This elevation of mathematics became acute with the rise of modern science, placing mathematical order and its apparent objectivity in the supreme position governing both the world and the mind. The Cartesian-Kantian legacy cemented it into place for several centuries. All this must be contrasted with a biblical theology, or any theology of special revelation. Theology does not, strictly, seek order in the world and mind. Theology is concerned, first of all, with matters of morality

(is matter and spirit, united in essence). From this perspective, consciousness is fundamental to the world of experience-as fundamental as 'things' themselves. The matter of mythology therefore seems more than 'superstition, that must be transcended'-seems more than the dead stuff of the modern viewpoint," Jordan B. Peterson, Maps of Meaning: The Architecture of Belief (New York, NY: Routledge, 1999), 290-291; see also, 1-2, 81-88, 139, 216, 329-331.

${ }^{1723}$ Curnow, Wisdom in the Ancient World, 87. 
and ethics, not simply natural order, and the former are not easily or perfectly derivable from the latter.

What makes this especially complex and difficult to understand is that many utopian dreams are founded upon an ethical system that is conceived as "timelessly" absolute (often inspired by our understanding of the divine, of course) or objective, and the efforts of many politicians and leaders engaged in these programs throughout 'history' have followed an "ends justifies the means" approach in which the 'temporal' flow of common sense time is nothing more than a stepping stone or passageway toward some timeless idealistic-platonic social configuration. Importantly, similar sociopolitical orders are envisioned, when freedom is seen as timeless or non-existent. One can see, I hope, that such visions are equally prone to lie on the "Right" or "Left" of the major socio-political impulses throughout history, as described above, and that Christianity, as an historical-cultural phenomena, has created its own variants of these 'theo-ethical' utopias as well-that is, toward conflicting interpretations of how a utopia ought to be constructed based upon divergent understandings of freedom and time. Indeed, concerning freedom and time within Christianity, "whereas calendar dating reflects a chronological conception of time, a measuring of and reckoning with time, the expectation of Christian temporality is oriented to a parousia which is more than a mere event-intime"1724 and thus not fully equitable with time understood in merely a chronological way.

Precisely the point to be inferred from the above is that one's conception of science, time, and freedom, do factor implicitly into these agendas, whether they are explicitly "religiously" grounded or not. Once nature is viewed as 'timelessly' manipulable to a technocracy, it too becomes merely a tool in the hand of theo-ethically grounded utopias. This situation becomes more transparent when today's scientists inform society that humans do not actually have free-will, as they are unable to separate the determinism they see in nature from the human mind, and then draw socio-political implications (which still usually pay lip service to some sort of political liberty based upon a mathematized 'equality') from their philosophical position. As such, it is a theoretical-technical 181.

${ }^{1724}$ Ted Sadler, Heidegger and Aristotle: The Question of Being (Atlantic Highlands, NJ: Athlone, 1996), 
conception of the issues of freedom and time, in philosophy and nature, that grounds the theo-ethical visions and their justifications for any socio-political configuration that works itself out over common sense "vulgar" time on the calendar, as Heidegger would have put it, which few would deny. This is the situation within which Bohm and Pylkkö operate.

At this point, the historical context has been established that demonstrate the emergence of the tensions between the cultures of the sciences and humanities appeared very early in Western history. This corroborates the assertions of both Heidegger and Bohm. This indicates that mediating the conflict between the sciences and humanities concerning their foundational rift about how to correctly define and interpret the concepts and meanings of freedom and time is a complex task, one that can only be done through a more critical engagement with both history, the sciences, and the humanities together, in addition to an inclusive theology which reflects them all. 


\section{BIBLIOGRAPHY}

Abaris, Brother. The Illuminist Army. Raleigh, NC: Lulu Press, 2016.

Abaza, Mona. Debates on Islam and Knowledge in Malaysia and Egypt: Shifting Worlds. New York, NY: Routledge, 2002.

Abdullah, Jinaki. "Bismillah-Message to the Blackman Revisited: Being and Power." In Africana Islamic Studies, eds. James L. Conyers Jr., and Abul Pitre, 59-76. Lanham, MD: Lexington Books, 2016.

Abney, Patrick Lin, Keith, and Ryan Jenkins, eds. Robot Ethics 2.0: From Autonomous Cars to Artificial Intelligence. Oxford, UK: Oxford University Press, 2017.

Accardi, Luigi, Kentaro Imafuku, and Massimo Regoli. "An Introduction to the EPR-Chameleon Experiment." In Fundamental Aspects of Quantum Physics: Proceedings of the Japan-Italy Joint Workshop on Quantum Open Systems, Quantum Chaos and Quantum Measurement, ed. Luigi Accardi and Shuichi Tasaki, 306-322. Singapore: World Scientific Publishing, 2003.

Addinall, Peter. Philosophy and Biblical Interpretation: A Study in Nineteenth-Century Conflict. Cambridge, UK: Cambridge University Press, 1991.

Adler, Mortimer J. The Idea of Freedom. Volumes 1 \& 2. Westport, CT: Greenwood Press, 1976.

Adluri, Vishwa. Parmenides, Plato and Mortal Philosophy: Return from Transcendence. New York, NY: Continuum, 2011.

Advani, Lal Krishna. My Take. New Dalhi, India: Prabhat Prakashan, 2014.

Afsaruddin, Asma. Contemporary Issues in Islam. Edinburgh, UK: Edinburgh University Press, 2015.

Aird, Harnish. Pericles: The Rise and Fall of Athenian Democracy. New York, NY: The Rosen Publishing Group, 2004.

Akhundov, Murad Davudovich. Conceptions of Space and Time. Cambridge, MA: Massachusetts Institute of Technology Press, 1986.

Alackapally, Sebastian. Being and Meaning: Reality and Language in Bhartrhari and Heidegger. Delhi: Motilal Banarsidass, 2002.

Alavezos, Larry. A Primer on Salvation and Bible Prophecy. TEACH Services, 2010.

Albertson, David. Mathematical Theologies: Nicholas of Cusa and the Legacy of Thierry of Chartres. Oxford, UK: Oxford University Press, 2014.

Albertson, David, and Cabell King, eds. Without Nature?: A New Condition for Theology. New York, NY: Fordham University Press, 2010. 
Albright, William Foxwell. From the Stone Age to Christianity: Monotheism and the Historical Process. Garden City, NY: Doubleday Anchor Books, 1957.

Alcorn, Randy. If God is Good: Faith in the Midst of Suffering and Evil. Colorado Springs, CO: Multnomah Books, 2009.

Alexander, Amir. Infinitesimal: How a Dangerous Mathematical Theory Shaped the Modern World. London, UK: Oneworld Publications, 2014.

Ahmad, Imad-ad-Dean. Signs in the Heavens: A Muslim Astronomer's Perspective on Religion and Science. Beltsville, MD: Writer's Inc., 1992.

Ahmed, Durre S. Islam and the West: A Psychological Analysis. Sustainable Development Policy Institute, 1993.

Ali, Zain. Faith, Philosophy and the Reflective Muslim. New York, NY: Palgrave Macmillan, 2013.

Al-Jubouri, I. M. N. History of Islamic Philosophy: With View of Greek Philosophy and Early History of Islam. Herford, UK: Authors OnLine, 2004.

Allawi, Ali A. The Crisis of Islamic Civilization. London, UK: Yale University Press, 2009.

Allday, Jonathan. Quantum Reality: Theory and Philosophy. Boca Raton, FL: CRC Press, 2009. Space-time: An Introduction to Einstein's Theory of Relativity. Boca Raton, FL: CRC Press, 2019.

Allen, Bob. "Critics Say Seminary Professor's Departure Reveals Faculty Rift between Faith and Science." At https://baptistnews.com/article/critics-say-seminary-professors-departure-reveals-faculty-rift -faith-science/ (accessed September 14, 2017).

Allmon, Warren D. "The Structure of Gould: Happenstance, Humanism, History, and the Unity of His View of Life." In Stephen Jay Gould: Reflections on His View of Life, eds. Warren D. Allmon, Patricia H. Kelley, and Robert M. Ross, 3-68. Oxford, UK: Oxford University Press, 2009.

Allori, Valia. "Primitive Ontology and the Structure of Fundamental Physical Theories." In The Wave Function: Essays on the Metaphysics of Quantum Mechanics, eds. Alyssa Ney, and David Z. Albert, 58-75. Oxford, UK: Oxford University Press, 2013.

Al-Rasheed, Madawi, and Marat Shterin, eds. Dying for Faith: Religiously Motivated Violence in the Contemporary World. New York, NY: Palgrave Macmillan, 2009.

Amar, Akhil Reed. The Constitution Today: Timeless Lessons for the Issues of Our Era. New York, NY: Basic Books, 2016.

Ameringer, Charles D. The Socialist Impulse: Latin America in the Twentieth Century. St. Gainseville, FL: University Press of Florida, 2009.

Andreasen, M. L. The Sanctuary Service. Hagerstown, MD: Review and Herald, 2006.

Andrews, David. Keynes and the British Humanist Tradition: The Moral Purpose of the Market. New York, NY: Routledge, 2010. 
Anstey, Peter R. John Locke and Natural Philosophy. Oxford, UK: Oxford University Press, 2011.

Applegate, Kathryn, and J. B. Stump, eds. How I Changed My Mind About Evolution: Evangelicals Reflect on Faith and Science. Oxford, UK: Lion Hudson with BioLogos, 2016.

Aptheker, Herbert. The Nature of Human Democracy, Freedom and Revolution. New York, NY: International Publishers, 1967.

Araújo, Glauber. "Miracles and Natural Law: Are They Compatible?" In Journal of the Adventist Theological Society Vol. 28 \#2 (Autumn, 2017): 120-138.

Arceneaux, Kevin, and Martin Johnson. Changing Minds or Changing Channels?: Partisan News in an Age of Choice. Chicago, IL: The University of Chicago Press, 2013.

Arendt, Hannah. Between Past and Future: Eight Exercises in Political Thought. London, UK: Penguin Books, 2006.

Arida, Ayssar. Quantum City. New York, NY: Routledge, 2002.

Ariotti, P. E. "The Concept of Time in Western Antiquity." In The Study of Time II: Proceedings of the Second Conference of the International Society for the Study of Time, eds. J. T. Fraser and N. Lawrence, 69-80. New York, NY: Springer-Verlag, 1975.

Aristotle. Physics, tr. Richard Hope. Lincoln, NE: University of Nebraska Press, 1961.

The Metaphysics: Books I-IX, tr. Hug Tredennick. Cambridge, MA: Harvard University Press, 1980.

The Nicomachean Ethics, tr. Harris Rackham. Hertfordshire, UK: Wordsworth Editions, 1996.

Arminius, James. The Works of James Arminius, tr. James Nichols and William Nichols. Grand Rapids, MI: Baker Books, 1991.

Armitage, Duane. Heidegger and the Death of God: Between Plato and Nietzsche. Cham, Switzerland: Palgrave Macmillan, 2017.

Armstrong, Richard H. A Compulsion for Antiquity: Freud and the Ancient World. Ithica, NY: Cornell University, 2005.

Aron, Paul. We Hold These Truths. ...: And Other Words that Made America. Williamsburg, VA: Rowman \& Littlefield, 2008.

Aron, Raymond. History, Truth, Liberty: Selected Writings of Raymond Aron, ed. F. Draus. Chicago, IL: The University of Chicago Press, 1965.

Aronowitz, Stanley, and William DiFazio. The Jobless Future: Sci-Tech and the Dogma of Work. Minneapolis, MN: University of Minnesota Press, 1994.

Arrais, Tiago. A Study on the Influence of Philosophical Presuppositions Relating to the Notion of the God-human Relation Upon the Interpretation of Exodus. Berrien Springs, MI: Andrews University. Doctoral dissertation, 2015. 
. "The Influence of Macro-Hermeneutical Assumptions Upon Biblical Interpretation: A Brief Evaluation of the Historical Grammatical Method." In Scripture and Philosophy: Essays Honoring the Work and Vision of Fernando Luis Canale, eds. Tiago Arrais, Kenneth Bergland, and Michael F. Younker, 295-319. Berrien Springs, MI: Adventist Theological Society Publications, 2016.

Arroyo, Ciriaco Morón. The Humanities in the Age of Technology. Washington, D.C.: The Catholic University of America Press, 2002.

Arum, Richard, Josipa Roksa, and Amanda Cook. Improving Quality in American Higher Education: Learning Outcomes and Assessments for the $21^{\text {st }}$ Century. San Francisco, CA: Wiley, 2016.

Askay, Richard, and Jensen Farquhar. Apprehending the Inaccessible: Freudian Psychoanalysis and Existential Phenomenology. Evanston, IL: Northwestern University Press, 2006.

Askew, Mike. Transforming Primary Mathematics. New York, NY: Routledge, 2012.

Aspect, Alain, Philippe Grangier, Gérard Roger. "Experimental Realization of Einstein-Podolsky-Rosen -Bohm Gedankenexperiment: A New Violation of Bell's Inequalities" in Phys. Rev. Lett. 49\#2 (1982): 91-94.

Asseraf, Arthur. "What's So New about News? The Interesting Thing about News Has Never Been its Truth or Falsehood but How it Explodes Our Sense of Onrushing Time." At https://aeon.co/essays/news-has-never-been-pristine-always-entangled-in-time (accessed May $23,2017)$.

Assoun, Paul-Laurent. Freud and Nietzsche, tr. Richard L. Collier, Jr. New York, NY: Continuum, 2000.

Atkins, Jed W. Cicero on Politics and the Limits of Reason: The Republic and Laws. Cambridge, UK: Cambridge University Press, 2013.

Atmanspacher, Harald, and Frederick Kronz. "Many Realisms" in Acta Polytechnica Scandinavica Ma-91 (1998): 31-43.

Atmanspacher, Harald, and Hans Primas. "Introduction." In Recasting Reality: Wolfgang Pauli's Philosophical Ideas and Contemporary Science, ed. Herald Atmanspacher and Hans Primas, 1-10. Germany, Berlin: Springer-Verlag, 2009.

$\mathrm{Au}$, Wilson W. S. Reclaiming Communist Philosophy: Marx, Lenin, Mao, and the Dialectics of Nature. Charlotte, NC: Information Age Publishing, 2017.

Audretsch, Jürgen. Entangled Systems: New Directions In Quantum Physics. Weinheim, Germany: Verlag, 2007.

Auxier, Randall E. Time, Will, and Purpose: Living Ideas from the Philosophy of Josiah Royce. Chicago, IL: Open Court, 2013.

Auyang, Sunny Y. How is Quantum Field Theory Possible? Oxford, UK: Oxford University Press, 1995.

Axtell, James L. "Locke, Newton and the Two Cultures." In John Locke: Problems and Perspectives: A Collection of New Essays, ed. John W. Yolton, 165-182. Cambridge, UK: Cambridge University Press, 1969. 
Ayton, Peter. “Why Does Psychology Need Methodology?” In Laboratory Psychology: A Beginner's Guide, ed. Julia Nunn, 1-14. East Sussex, UK: Psychology Press Ltd., 1998.

Azadpur, Mohammad. Reason Unbound: On Spiritual Practice in Islamic Peripatetic Philosophy Albany, NY: State University of New York Press, 2011.

Azerrad, David. "America Divided: The Republican Party in Theory and Practice." At http://www.heritage.org/conservatism/commentary/america-divided-the-republican-party-th eory-and-practice (accessed October 22, 2017).

"America Divided: Trumpism Emerges Where Left and Right Fall Short." At http://www.heritage.org/conservatism/commentary/the-clash-ideologies-america-divided-tru mpism-emerges-where-left-and-right (accessed October 23, 2017).

Azoulay, Incent. Pericles of Athens, tr. Janet Lloyd. Princeton, NJ: Princeton University Press, 2014.

Baab, Lynne M. Sabbath Keeping: Finding Freedom in the Rhythms of Rest. Downers Grove, IL: InterVarsity Press, 2005.

Baert, P. J. N., ed. Time in Contemporary Intellectual Thought. Amsterdam, The Netherlands: Elsevier Science, 2000.

Baggott, Jim. Beyond Measure: Modern Physics, Philosophy, and the Meaning of Quantum Theory. Oxford, UK: Oxford University Press, 2004.

The Quantum Story: A History in 40 Moments. Oxford, UK: Oxford University Press, 2011.

Bambach, Charles R. Heidegger, Dilthey, and the Crisis of Historicism. Ithaca, NY: Cornell University Press, 1995.

Barak, Aharon. Human Dignity: The Constitutional Value and the Constitutional Right, tr. Daniel Kayros. Cambridge, UK: Cambridge University Press, 2015.

Barbour, Julian B. Absolute or Relative Motion?: The Discovery of Dynamics Vol. 1. New York, NY: Cambridge University Press, 1989.

Bardon, Adrian. A Brief History of the Philosophy of Time. New York, NY: Oxford University Press, 2013.

Bargh, John A. "Automatic Information Processing: Implications for Communication and Affect." In Communication, Social Cognition, and Affect, eds. Lewis Donohew, Howard E. Sypher, and Edward Tory Higgins, 9-32. Hillsdale, NJ: Lawrence Erlbaum, 1988.

Before You Know It: The Unconscious Reasons We Do What We Do. New York, NY: Touchstone, 2017.

Bacchiocchi, Samuele. Divine Rest for Human Restlessness: A Theological Investigation of the Good News of the Sabbath. Berrien Springs, MI: Biblical Perspectives, 1997.

From Sabbath to Sunday: A Historical Investigation of the Rise of Sunday Observance in Early Christianity. Vatican City: Pontifical Gregorian University, 1977.

Bacchiocchi, Silvia Canale. "Luther in the Eucharistic Debates: Sola Scripture or Divination of Man?" In Scripture and Philosophy: Essays Honoring the Work and Vision of Fernando Luis Canale, eds., 
Tiago Arrais, Kenneth Bergland, and Michael F. Younker, 355-381. Berrien Springs, MI: Adventist Theological Society Publications, 2016.

Backhouse, Roger E., and Philippe Fontaine. "Introduction." In The History of the Social Sciences Since 1945, eds. Roger Backhouse and Philippe Fontaine, 1-16. Cambridge, NY: Cambridge University Press, 2010.

Backmann, Marius. Humean Libertarianism: Outline of a Revisionist Account of the Joint Problem of Free Will, Determinism and Laws of Nature. Piscataway, NJ: Rutgers University, 2013.

Bagger, Matthew C. The Uses of Paradox: Religion, Self-Transformation, and the Absurd. Chichester, West Sussex: Columbia University Press, 2007.

Baggini, Julian. Freedom Regained: The Possibility of Free Will. Chicago, IL: The University of Chicago Press, 2015.

Bailey, Andrew, ed. First Philosophy III: God, Mind, and Freedom: Fundamental Problems and Readings in Philosophy. Orchard Park, NY: Broadview Press, 2004.

Baird, Davis. "Navigating Nanotechnology Through Society." In Nanotechnology: Societal Implications II: Individual Perspectives, eds. Mihail C. Roco and William Sims Bainbridge, 75-86. Dordrecht, The Netherlands: Springer, 2007.

Bakar, Osman. Islamic Civilisation and the Modern World: Thematic Essays. Gadong, Malaysia: Universiti Brunei Darussalam Press, 2014.

Bala, Arun. Complementarity Beyond Physics: Niels Bohr's Parallels. New York, NY: Palgrave Macmillan, 2017.

Balaban, Oded. "Epoché: Meaning, Object, and Existence." In Phenomenology World-Wide: Foundations, Expanding Dynamics, Life-Engagements: A Guide for Research and Study, ed. Anna-Teresa Tymieniecka, 103-113. Dordrecht, The Netherlands: Kluwer Academic Publishers, 2002.

Bales, Eugene F. Philosophy in the West: Men, Women, Religion, Science. Bloomington, IN: Xlibris, 2008.

Ball, Tim. The Deliberate Corruption of Climate Science. Mount Vernon, WA: Stairway Press, 2013.

Baldwin, John T., ed. Creation, Catastrophe, \& Calvary: Why a Global Flood is Vital to the Doctrine of Atonement. Hagerstown, MD: Review and Herald, 2000.

"The Geologic Column and Calvary: The Rainbow Connection-Implications for an Evangelical Understanding of the Atonement." In Creation, Catastrophe, \& Calvary: Why a Global Flood is Vital to the Doctrine of Atonement, ed. John T. Baldwin, 108-123. Hagerstown, MD: Review and Herald, 2000.

Balk, Antii P. Saints and Sinners: An Account of Western Civilization. London, UK: Thelema Publications, 2008.

Balkin, Jack M. Living Originalism. London, UK: Belknap Press, 2011.

Bamber, Philip M. Transformative Education Through International Service-Learning: Realising an Ethical Ecology of Learning. New York, NY: Routledge, 2016. 
Bandow, Doug, and David L. Schindler, eds. Wealth, Poverty \& Human Destiny. Wilmington, DE: ISI Books, 2003.

Barash, Jeffrey Andrew. "Historical Meaning in the Fundamental Ontology of Being and Time, from Martin Heidegger and the Problem of Historical Meaning." In Heidegger's Being and Time: Critical Essays, ed. Richard F. H. Polt, 169-188. Oxford, UK: Rowman \& Littlefield Publishers, 2005.

Barbour, Ian G. Religion and Science: Historical and Contemporary Issues. New York, NY: HarperCollins, 1997.

.When Science Meets Religion: Enemies, Strangers, or Partners? New York, NY: HarperCollins, 2000.

Barbour, Julian. The End of Time: The Next Revolution in Physics. Oxford, UK: Oxford University Press, 1999.

Barr, James. Biblical Words for Time 2 ${ }^{\text {nd }}$ ed. Eugene, OR: Wipf \& Stock, 2009, 1962.

Barrett, Edward. Persons and Liberal Democracy: The Ethical and Political Thought of Karol Wojtyla/Pope John Paul II. Lanham, MD: Lexington Books, 2010.

Barrett, Jeffrey A. "On the Nature of Measurement Records in Relativistic Quantum Field Theory." In Ontological Aspects of Quantum Field Theory, eds. Meinard Kuhlmann, Holger Lyre, and Andrew Wayne, 165-180. London, UK: World Scientific, 2002.

. "Quantum Mechanics and Dualism." In Quantum Physics Meets the Philosophy of Mind: New Essays on the Mind-Body Relation in Quantum-Theoretical Perspective, eds. Antonella Corradini and Uwe Meixner, 65-84. Berlin, Germany: Walter de Gruyter, 2014.

Barrett, William, and Daisetz T. Suzuki. Zen Buddhism. New York, NY: Random House, 1996.

Batat, Wided. "An Adolescent-centric Approach to Consumer Vulnerability." In Consumer Vulnerability: Conditions, Contexts and Characteristics, eds. Kathy Hamilton, Susan Dunnett and Maria Piacentini, 103-117. New York, NY: Routledge, 2016.

Bateson, Gregory, and Mary Catherine Bateson. Angels Fear: Towards an Epistemology of the Sacred. New York, NY: Macmillan, 1987.

Bauckham, Richard. God and the Crisis of Freedom: Biblical and Contemporary Perspectives. Louisville, KT: Westminster Jon Knox Press, 2002.

The Bible in the Contemporary World: Hermeneutical Ventures. Grand Rapids, MI: Eerdmans, 2015.

"Using the Bible to do Politics: Freedom." In Third Way (April 1985): 6-7, 31.

Baym, Geoffrey. "Real News/Fake News: Beyond the News/Entertainment Divide." In The Routledge Companion to News and Journalism, ed. Stuart Allan, 374-383. New York, NY: Routledge, 2010.

Baez, John C., and Emory F. Bunn. “The Meaning of Einstein's Equation.” At http://math.ucr.edu/home/baez/einstein/einstein.pdf (accessed July 1, 2014). 
Beahrs, John 0. Limits of Scientific Psychiatry: The Role of Uncertainty in Mental Health. New York, NY: Brunner \& Mazel, 1986.

Becker, Adam. What Is Real?: The Unfinished Quest for the Meaning of Quantum Physics. New York, NY: Basic Books, 2018.

Becker, Tobias. “Chronopolitics: Time of Politics, Politics of Time, Politicized Time." At https://www.hsozkult.de/event/id/termine-39537 (accessed February 26, 2019).

Beg, Moazziz Ali. The Ideological Integration of East and West: An Enquiry Concerning World Peace. New Delhi, India: Global Vision Publishing, 2005.

Begley, Carl E. Afraid to Believe in Free Will: The Human Tendency to Avoid Responsibility for Free Choices. Bloomington, IN: WestBow Press, 2010.

Behe, Michael J. Darwin's Black Box: The Biochemical Challenge to Evolution. New York, NY: Touchstone, 1998.

Behl, Chander. Anatomy of Spirituality: Portrait of the Soul. Victoria, BC: Friesen Press, 2015.

Beilby James, and Paul R. Eddy, eds. The Nature of the Atonement: Four Views. Downers Grove, IL: InterVarsity Press, 2006.

Beistegui, Miguel de. Heidegger and the Political. New York, NY: Routledge, 1998.

The New Heidegger. New York, NY: Continuum, 2005.

Bell, E. T. Men of Mathematics. New York, NY: Simon \& Schuster, 2014.

Bell, John S. "Speakable and Unspeakable in Quantum Mechanics." In J. S. Bell, Collected Papers on Quantum Philosophy: Speakable and Unspeakable in Quantum Mechanics, ed., Simon Capelin. Cambridge, UK: Cambridge University Press, 1987.

Beller, Mara. Quantum Dialogue: The Making of a Revolution. University of Chicago, 1999.

Belvedere, Berny. "Two Kingdoms: Christianity and Islam: How Far Should we go in Restricting Freedom in Order to Promote Virtue?" At https://arcdigital.media/two-kingdoms-christianity-and-islam-193be539476e (accessed June 14, 2017).

Benedict XVI. (Joseph Ratzinger-Pope). Joseph Ratzinger in Communio Vol. 2: Anthropology and Culture, eds. David L. Schindler and Nicholas J. Healy. Grand Rapids, MI: Eerdmans, 2013.

Benestad, J. Brian. Church, State, and Society: An Introduction to Catholic Social Doctrine. Washington, D. C.: The Catholic University of America Press, 2011.

Ben-Menahem, Yemima. "Realism and Quantum Mechanics." In Microphysical Reality and Quantum Formalism Vol. 2, eds., A. Van der Merwe, F. Selleri, and G. Tarozzi, 103-114. Dordrecht, The Netherlands: Kluwer Academic Publishers, 1987.

“Struggling with Causality: Einstein's Case." In Einstein in Context, eds. Mara Beller, Robert S. Cohen, and Jürgen Renn, 291-310. Cambridge, UK: Cambridge University Press, 1993. 
Bequette, John P. Christian Humanism: Creation, Redemption, and Reintegration. Lanham, MD: University Press of America, 2007.

Berg, Eva Désirée van den. Language of the Heart: A Sufi Interpretation of Form and Meaning in Contemporary Society. New York, NY: Blue Dome Press, 2012.

Berger, Louis S. Averting Global Extinction: Our Irrational Society as Therapy Patient. Lanham, MD: Jason Aronson, 2009.

. Human Development, Language and the Future of Mankind: The Madness of Culture. New York, NY: Palgrave Macmillan, 2014. . Humanity's Madness: Consequences of Becoming Literate. Forsyth, GA: Forsyth Books, 2011. Issues in Psychoanalysis and Psychology: Annotated Collected Papers. Victoria, BC: Trafford Publishing, 2002. . Language and the Ineffable: A Developmental Perspective and Its Applications. Lanham, MD: Lexington Books, 2011.

Psychoanalytic Theory and Clinical Relevance. Hillsdale, NJ: The Analytic Press, 1985.

. Psychotherapy as Praxis: Abandoning Misapplied Science. Victoria, B.C.: Trafford Publishing, 2002.

The Unboundaried Self: Putting the Person Back Into the View from Nowhere. Victoria, BC: Trafford Publishing, 2005.

Berkowitz, Peter. Nietzsche: The Ethics of an Immoralist. New York, NY: Harvard University Press, 1996.

Berlinerblau, Jacques. The Secular Bible: Why Nonbelievers Must Take Religion Seriously. New York, NY: Cambridge University Press, 2005.

How to Be Secular: A Call to Arms for Religious Freedom. New York, NY: Houghton Mifflin, 2012.

Berndtson, Arthur. Power, Form, and Mind. Toronto, Canada: Bucknell University Press, 1981.

Bernstein, Richard J. The Pragmatic Turn. Malden, MA: Polity Press, 2010.

Berry, David. Journalism, Ethics, and Society. Burlington, VT: Ashgate Publishing, 2008.

Berry, David M., and Anders Fagerjord. Digital Humanities: Knowledge and Critique in a Digital Age. Cambridge, UK: Polity Press, 2017.

Berryman, Phillip. Liberation Theology: The Essential Facts About the Revolutionary Movement in Latin America-and Beyond. New York, NY: Pantheon Books, 1987.

Bertalanffy, Ludwig von. Problems of Life: An Evaluation of Modern Biological Thought. London: Watts \& Co., 1952.

Berto, Francesco. Existence as a Real Property: The Ontology of Meinongianism. New York, NY: Springer, 2013. 
Best, Steven, and Douglas Kellner. The Postmodern Turn. New York, NY: Guilford Press, 1997.

Betz, Joseph. "Commentary: Understanding Bernie Sanders' Brand of Socialism." At http://www.chicagotribune.com/news/opinion/commentary/ct-bernie-sanders-democratic-so cialism-20160223-story.html (accessed February 23, 2016).

Beukel, Anthony Van Den. The Physicists and God: The New Priests of Religion? North Andover, MA: Genesis Publishing, 1995.

Berquist, Jon L. Controlling Corporeality: The Body and the Household in Ancient Israel. Piscataway, NJ: Rutgers, 2002.

Bhaskar, Roy, and Mervyn Hartwig, ed. Enlightened Common Sense: The Philosophy of Critical Realism. New York, NY: Routledge, 2016.

Bhaskar, Roy, and Mervyn Hartwig. The Formation of Critical Realism: A Personal Perspective. New York, NY: Routledge, 2010.

Bhattacharya, Sutapas. The Oneness/otherness Mystery: The Synthesis of Science and Mysticism. Delhi: Motilal Banarsidass Publishers, 1999.

Bidgoli, Hossein, ed. The Handbook of Technology Management, Supply Chain Management, Marketing and Advertising, and Global Management Vol. 2. Hoboken, NJ: John Wiley \& Sons, 2010.

Bishop, James. "God \& Time: A Relational \& A-Theory View of Time." At https://jamesbishopblog.com/2017/08/06/god-time-a-relational-a-theory-view-of-time/ (accessed August 6, 2017).

Blackledge, Paul. Marxism and Ethics: Freedom, Desire, and Revolution. Albany, NY: State University of New York Press, 2012.

Blackmore, Susan. Conversations on Consciousness: What the Best Minds Think About the Brain, Free Will, and What It Means to Be Human. Oxford, UK: Oxford University Press, 2006.

Blaising, Craig A., and Darrell L. Bock, eds. Dispensationalism, Israel and the Church: The Search for Definition. Grand Rapids, MI: Zondervan, 1992.

Blattner, William D. Heidegger's Temporal Idealism. Cambridge, UK: Cambridge University Press, 1999.

Bloesch, Donald G. A Theology of Word \& Spirit: Authority \& Method in Theology. Downers Grove, IL: InterVarsity Press, 1992.

Blokland, Hans Theodorus. Freedom and Culture in Western Society, tr. Michael O'Loughlin. New York, NY: Routledge, 1997.

Bloom, Harold. Ruin the Sacred Truths: Poetry and Belief from the Bible to the Present. New York, NY: Harvard University Press, 1989.

Blum, Mark E. Continuity, Quantum, Continuum, and Dialectic: The Foundational Logics of Western Historical Thinking. New York, NY: Peter Lang, 2006.

Blumenau, Ralph. Philosophy and Living. Exeter, UK: Imprint Academic, 2005. 
Bobzien, Susanne. Determinism and Freedom in Stoic Philosophy. New York, NY: Oxford University Press, 2004.

Bocking, Stephen. Nature's Experts: Science, Politics, and the Environment. Piscataway, NJ: Rutgers University Press, 2004.

Boddington, Jacqui. "All Together Now?" In The Pedagogy of Compassion at the Heart of Higher Education, ed. Paul Gibbs, 213-228. New York, NY: Springer, 2017.

Boden, Margaret A. Mind as Machine: A History of Cognitive Science Volume 1 \& 2. Oxford, UK: Clarendon Press, 2006.

Boehner, Philotheus. "Introduction." In William Ockham, Philosophical Writings, tr. and ed. Philotheus Boehner, and Stephen F. Brown, ix-li. Indianapolis, IN: Hackett Publishing Company, 1990.

Boer, Karin de. "The Temporality of Thinking: Heidegger's Method, from Thinking in the Light of Time: Heidegger's Encounter with Hegel." In Heidegger's Being and Time: Critical Essays, ed. Richard F. H. Polt, 33-46. Oxford, UK: Rowman \& Littlefield Publishers, 2005.

Boersma, Hans. Heavenly Participation: The Weaving of a Sacramental Tapestry. Grand Rapids, MI: Eerdmans, 2011.

Boff, Leonardo. Ecology \& Liberation: A New Paradigm. Maryknoll, NY: Orbis Books, 1995. Introducing Liberation Theology. Tunbridge Wells, Kent, UK: Burns \& Oates, 1987.

Bohm, David. "A New Theory of the Relationship of Mind and Matter." In Philosophical Psychology Vol. 3, No. 2 (1990): 271-286.

"A Suggested Interpretation of the Quantum Theory in Terms of 'Hidden Variables.'” Physical Review 85 (1952): 166-193.

Causality \& Chance in Modern Physics. New York, NY: Routledge, 1957.

Causality and Chance, Letters to Three Women, ed. Chris Talbot. Cham, Switzerland: Springer, 2017.

"Hidden Variables and the Implicate Order." Zygon 20 (1985): 111-124.

. "Insight, Knowledge, Science, and Human Values." In Toward the Recovery of Wholeness: Knowledge, Education, and Human Values, ed. Douglas Sloan, 8-30. New York NY: Teachers College Press, 1984.

. "Meaning and Information." In The Search for Meaning: The New Spirit in Science and Philosophy, ed. Paavo Pylkkänen, 43-85. Wellingborough, UK: Crucible, 1989.

. On Creativity, ed. Lee Nichol. London, UK: Routledge, 2003.

. On Dialogue, ed. Lee Nichol. London, UK: Routledge, 1996.

. "On Insight and its Significance, for Science, Education, and Values." In Education and Values, ed. Douglas Sloan, 7-22. New York, NY: Teachers College Press, 1980.

Quantum Theory. Englewood Cliffs, NJ: Prentice-Hall, 1951. 
. The Essential David Bohm, ed. Lee Nichol. New York, NY: Routledge, 2005.

. "The Implicate Order: A New Approach to the Nature of Reality." In Beyond Mechanism: The Universe in Recent Physics and Catholic Thought, ed. David L. Schindler, 13-37. Lanham, MD: University Press of America, 1986.

The Special Theory of Relativity. New York, NY: Routledge, 1996.

Thought as a System. New York, NY: Taylor \& Francis e-Library, 2004.

. "Time, The Implicate Order, and Pre-Space." In Physics and the Ultimate Significance of Time: Bohm, Prigogine, and Process Philosophy, ed. David Ray Griffin, 177-208. Albany, NY: State University of New York Press, 1986.

Unfolding Meaning: A Weekend of Dialogue with David Bohm. Gloucestershire, UK: Foundation House, 1985.

Wholeness and the Implicate Order. London, UK: Routledge, 1980.

Bohm, David, with Charles Biederman. Bohm-Biederman Correspondence: Creativity and Science, ed. Paavo Pylkkänen. London, UK: Routledge, 1999.

Bohm, David, and B. J. Hiley. The Undivided Universe: An Ontological Interpretation of Quantum Theory. London, UK: Routledge, 1993.

Bohm, David, with F. David Peat. Science, Order, and Creativity: A Dramatic New Look at the Creative Roots of Science and Life. New York, NY: Taylor \& Francis e-Library, 2011.

Bohm, David, with Mark Edwards. Changing Consciousness: Exploring the Hidden Source of the Social, Political and Environmental Crises Facing our World. San Francisco, CA: Harper, 1991.

Boix, Carles. Political Parties, Growth and Equality: Conservative and Social Democratic Strategies in the World Economy. Cambridge, UK: Cambridge University Press, 1998.

Bolt, Barbara. Heidegger Reframed: Interpreting Key Thinkers for the Arts. New York, NY: I. B. Tauris \& Co., 2011.

Bomann-Larsen, Lene. "Communicative Revisionism." In Moral Responsibility: Beyond Free Will and Determinism, eds. Nicole A. Vincent, Ibo van de Poel, and Jeroen van den Hoven, 141-160. New York, NY: Springer, 2011.

Boni, Rocco. Quantum Christian Realism: How Quantum Mechanics Underwrites and Realizes Classical Christian Theism. Indianapolis, IN: Xlibris, 2016.

Booker, Christopher. The Real Global Warming Disaster: Is the Obsession with 'Climate Change' Turning Out to be the Most Costly Scientific Blunder in History? New York, NY: Continuum, 2009.

Bordon, A. R. Ultimate Thought: Life in a Bicausal Universe. Morrisville, NC: Lulu Press, 2010.

Bork, Robert H. The Tempting of America: The Political Seduction of the Law. New York, NY: Touchstone, 1991. 
Borondo, F. “Dynamical Systems Approach to Bohmian Mechanics.” In Quantum Trajectories: Atoms, Molecules, and Clusters-Structure, Reactivity, and Dynamics, ed. Patrim Kumar Chattaraj, 381-388. Boca Raton, FL: CRC Press, 2011.

Bosserman, B. A. The Trinity and the Vindication of Christian Paradox: An Interpretation and Refinement of the Theological Apologetic of Cornelius Van Til. Cambridge, UK: James Clarke \& Co., 2015.

Bostom, Andrew G. Sharia Versus Freedom: The Legacy of Islamic Totalitarianism. Amherst, NY: Prometheus Books, 2012.

Bostom, Andrew G., ed. The Legacy of Jihad: Islamic Holy War and the Fate of Non-Muslims. Amherst, NY: Prometheus Books, 2005.

Bourdieu, Pierre. Sociology in Question, tr. Richard Nice. London, UK: Sage Publications, 1993.

Bourcier, Simon de. Pynchon and Relativity: Narrative Time in Thomas Pynchon's Later Novels. New York, NY: Continuum, 2012.

Bourne, Craig. A Future for Presentism. Oxford, UK: Oxford University Press, 2006.

Bouton, Christophe. Time and Freedom, tr. Christopher Macaan. Evanston, IL: Northwestern University Press, 2014.

Bouton, Christophe, and Philippe Huneman, eds. Time of Nature and the Nature of Time: Philosophical Perspectives of Time in Natural Sciences. Cham, Switzerland: Springer International Publishing, 2017.

Bovell, Carlos R. Rehabilitating Inerrancy in a Culture of Fear. Eugene, OR: Wipf \& Stock, 2012.

Bowald, Mark Alan. Rendering the Word in Theological Hermeneutics: Mapping Divine and Human Agency. New York, NY: Routledge, 2016.

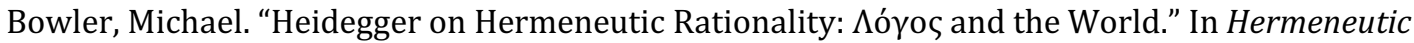
Rationality / La rationalité herméneutique, eds. Maria Luísa Portocarrero, Luis António Umbelino and Andrzej Wierciński, 219-230. Berlin, Germany: Lit Verlag, 2012.

Boyd, Gregory A. God at War: The Bible \& Spiritual Conflict. Downers Grove, IL: InterVarsity Press, 1997.

Boyd, Jay. "The Problem with 'A Personal Relationship with Jesus."' At http://www.hprweb.com/2014/07/the-problem-with-a-personal-relationship-with-jesus/ (accessed May 4, 2017).

Boyer, Paul. When Time Shall Be No More: Prophecy Belief in Modern American Culture. Cambridge, MA: The Belknap Press, 1992.

Boys-Stones, G. R., and J. H. Haubold, eds. Plato and Hesiod. Oxford, UK: Oxford University Press, 2010.

Braaten, Carl E. Principles of Lutheran Theology. Philadelphia, PA: Fortress Press, 1983.

Bradbury, John P. Perpetually Reforming: A Theology of Church Reform and Renewal. New York, NY: Bloomsbury, 2013. 
Bradley, Anthony B. Something Seems Strange: Critical Essays on Christianity, Public Policy, and Contemporary Culture. Eugene, OR: Wipf \& Stock, 2016.

Bradley, D. L. In the Academy of Plato. Raleigh, NC: Lulu Press, 2015.

Bradley, James. "Randomness and God's Nature." In the American Scientific Affiliation: A Fellowship of Christians in Science Vol. 64 \#2 (June 2012). At https://www.asa3.org/ASA/PSCF/2012/PSCF6-12Bradley.pdf (accessed September 30, 2018).

Brady, Bernard V. Essential Catholic Social Thought. Maryknoll, NY: Orbis Books, 2008.

Brahm, Laurence J. Fusion Economics: How Pragmatism is Changing the World. New York, NY: Springer, 2014.

Brand, Leonard, and Arthur Chadwick. Faith, Reason, \& Earth History: A Paradigm of Earth and Biological Origins by Intelligent Design $3^{\text {rd }}$ ed. Berrien Springs, MI: Andrews University Press, 2016.

Brand, Leonard, with David C. Jarnes, Beginnings: Are Science and Scripture Partners in the Search for Origins? Nampa, ID: Pacific Press, 2006.

Brann, Eva. What, Then, Is Time? New York, NY: Rowman \& Littlefield, 1999.

Braver, Lee. Heidegger: Thinking of Being. Cambridge, UK: Polity Press, 2014.

Bregman, Rutger. "A Growing Number of People Think Their Job Is Useless-Time to Rethink the Meaning of Work." At https://www.weforum.org/agenda/2017/04/why-its-time-to-rethink-the-meaning-of-work (accessed September 18, 2018).

Breisach, Ernst. Historiography: Ancient, Medieval, and Modern $3^{\text {rd }}$ ed. Chicago, IL: The University of Chicago Press, 2007.

Brenner, Joseph E. Logic in Reality. Dordrecht, The Netherlands: Springer, 2008.

Brian, Denis. Einstein: A Life. New York, NY: J. Wiley, 1996.

Bricmont, Jean. Making Sense of Quantum Mechanics. New York, NY: Springer, 2016.

Bridle, James. New Dark Age: Technology and the End of the Future. Brooklyn, NY: Verso, 2018.

Brier, Søren. Cybersemiotics: Why Information Is Not Enough. Toronto, Canada: University of Toronto Press, 2008.

Brigandt, Ingo. "Intelligent Design and the Nature of Science: Philosophical and Pedagogical Points." In The Philosophy of Biology: A Companion for Educators, ed. Kostas Kampourakis, 205-238. New York, NY: Springer, 2013.

Brill, Steven. Tailspin: The People and Forces Behind America's Fifty-Year Fall-and Those Fighting to Reverse It. New York, NY: Knopf, 2018.

Broadwater, Billy. Exposing the Fallacies of the Pre-Tribulation Rapture: A Biblical Examination of Christ's Second Coming. Bloomington, IN: WestBow Press, 2014. 
Brockman, David R. Dialectical Democracy Through Christian Thought: Individualism, Relationalism, and American Politics. New York, NY: Palgrave Macmillan, 2013.

Brockman, John, ed. The Third Culture: Beyond the Scientific Revolution. New York, NY: Simon \& Schuster, 1995.

Brogaard, Berit 0. “Mead's Temporal Realism.” In Transactions of the Charles S. Peirce Society Vol. XXXV No. 3 (Summer, 1999): 563-593.

Bronk, Richard. The Romantic Economist: Imagination in Economics. Cambridge, UK: Cambridge University Press, 2009.

Brook, Angus. "The Potentiality of Authenticity in Becoming a Teacher." In Exploring Education Through Phenomenology: Diverse Approaches, ed. Gloria Dall'Alba, 53-65. West Sussex, UK: John Wiley \& Sons, 2009.

Brooks, Arthur C. Love Your Enemies: How Decent People Can Save America from the Culture of Contempt. New York, NY: Broadside Books, 2019.

The Road to Freedom: How to Win the Fight for Free Enterprise. New York, NY: Basic Books, 2012.

Who Really Cares: The Surprising Truth about Compassionate Conservatism. New York, NY: Basic Books, 2006.

Brown, Andrew J. The Days of Creation: A History of Christian Interpretation of Genesis 1:1-2:3. Blandford Forum, UK: Deo Publishing, 2014.

Brown, Brian, Paul Crawford, and Carolyn Hicks. Evidence-Based Research: Dilemmas and Debates in Health Care. Berkshire, UK: Open University Press, 2003.

Brown, Charles S., and Ted Toadvine, eds. Eco-Phenomenology: Back to the Earth Itself. Albany, NY: State University of New York Press, 2003.

Brown, Valerie A., Robert Dyball, Meg Keen, Judy Lambert, and Nicki Mazur. "The Reflective Practitioner: Practising What We Preach." In Social Learning in Environmental Management, eds. Rob Dyball, Valerie A. Brown, and Meg Keen, 224-246. Sterling, VA: Earthscan, 2005.

Brueggemann, Walter. Sabbath as Resistance; Saying No to the Culture of Now. Louisville, KT: Westminster John Knox Press, 2014.

Brush, Stephen G., with Ariel Segal. Making $20^{\text {th }}$ Century Science: How Theories Became Knowledge. Oxford University Press, 2015.

Bruzina, Ronald, and Bruce Wilshire, eds. Phenomenology: Dialogues and Bridges. Albany, NY: State University of New York Press, 1982.

Brynjolfsson, Erick, and Andrew McAfee. Harnessing Our Digital Future: Machine, Platform, Crowd. New York, NY: W. W. Norton \& Company, 2017.

Race Against the Machine: How the Digital Revolution is Accelerating Innovation, Driving Productivity, and Irreversibly Transforming Employment and the Economy. Digital Frontier Press, 2011. 
. The Second Machine Age: Work, Progress, and Prosperity in a Time of Brilliant Technologies with a new introduction. New York, NY: W. W. Norton \& Company, 2016.

Bucholz, Rogene. Reforming Capitalism: The Scientific Worldview and Business. New York, NY: Routledge, 2012.

Buck, Ken, with Bill Blankschaen. Drain the Swamp: How Washington Corruption is Worse than You Think. Washington, D.C.: Regnery Publishing, 2017.

Buckley, James Lane. Freedom at Risk: Reflections on Politics, Liberty, and the State. New York, NY: Encounter Books, 2010.

Buckley, R. Philip. Husserl, Heidegger and the Crisis of Philosophical Responsibility. Dordrecht, The Netherlands: Kluwer, 1992.

Buehler, Arthur F. "Researching Sufism in the Twenty-First Century: Expanding the Context of Inquiry." In The Bloomsbury Companion to Islamic Studies, ed. Clinton Bennett, 93-118. New York, NY: Bloomsbury Academic, 2013.

Bull, Brian S. "Why are Science and Religion Still Fighting?" In Understanding Genesis: Contemporary Adventist Perspectives, eds. Brian Bull, Fritz Guy \& Ervin Taylor, 23-34. Riverside, CA: Adventist Today Foundation, 2006.

Bull, Brian S., and Fritz Guy. "Then A Miracle Occurs." In Understanding Genesis: Contemporary Adventist Perspectives, eds. Brian Bull, Fritz Guy \& Ervin Taylor, 53-69. Riverside, CA: Adventist Today Foundation, 2006.

Bunsen, Ernst von. Islam, Or True Christianity: Including a Chapter on Mahomed's Place in the Church. Trübner, 1889.

Bürdek, Bernhard E. Design: History, Theory and Practice of Product Design rev. ed. Basel, Switzerland: Birkhäuser, 2015.

Burke, Thomas Patrick. The Concept of Justice: Is Social Justice Just? New York, NY: Continuum, 2011. “The Origins of Social Justice: Taparelli d'Azeglio." In Modern Age: A Conservative Review Vol. 52, No. 2 (Spring 2010): 97-106.

Burkert, Walter. Lore and Science in Ancient Pythagoreanism, tr. Edwin L. Minar, Jr. Cambridge, MA: Harvard University Press, 1972.

Burneko, Guy. "It's Child's Play: Contemplative Anthropocosmic Creativity." In World Futures: The Journal of New Paradigm Research Vol. 70:8 (2014): 496-514.

Burnett, Thomas. "What is Scientism?” At https://www.aaas.org/page/what-scientism (accessed February 11, 2018).

Burnham, James, with John O'Sullivan and Roger Kimball. Suicide of the West: An Essay on the Meaning and Destiny of Liberalism. New York, NY: Encounter Books, 2014.

Burris, Beverly H. Technocracy at Work. Albany, NY: State University of New York Press, 1993. 
Burrus, Daniel. “Is Technology Good or Evil?" At

https://www.huffingtonpost.com/daniel-burrus/is-technology- good-or-evi_b_ 1826270.html (accessed August 24, 2012).

Burtt, E. A. The Metaphysical Foundations of Modern Science. Mineola, NY: Dover, 2003.

Butler-Bowdon, Tom. The Literature of Possibility. Nicholas Brealey Publishing, 2013.

Butto, Nader. Unified Integrative Medicine: A New Holistic Model for Personal Growth and Spiritual Evolution. Bloomington, IN: AuthorHouse, 2014.

Bryant, Levi, Nick Srnicek, and Graham Harman. "Towards a Speculative Philosophy." In The Speculative Turn: Continental Materialism and Realism, eds. Levi Bryant, Nick Srnicek, and Graham Harman, 1-18. Melbourne, Australia: RE Press, 2011.

Cadwallader, Eva Hauel. "Guest Preface." In William Henry Werkmeister, Martin Heidegger on the Way, ed. Richard T. Hull, xvii-xxviii. Atlanta, GA: Rodopi, 1996.

Caiazza, John C. The Crisis of Progress: Science, Society, and Values. New York, NY: Transaction Publishers, 2016.

Caldwell, Bruce. "Introduction." In The Collected Works of F. A. Hayek Vol. IX: Contra Keynes and Cambridge-Essays, Correspondence, ed. Bruce Caldwell, 1-48. Chicago, IL: The University of Chicago Press, 1995.

Caldecott, Stratford. "Catholicism and the New Age Movement." In The Catholic Church and World Religions: A Theological and Phenomenological Account, ed. Gavin D'Costa, 178-216. New York, NY: T\&T Clark, 2011.

Calinescu, Matei. “On Postmodernism (1986)." In Modernism: Critical Concepts in Literary and Cultural Studies (Vol. IV 1985-1991), ed. Tim Middleton, 74-112. New York, NY: Routledge, 2003.

Callahan, Gene. Economics for Real People: An Introduction to the Austrian School, $2^{\text {nd }}$ Edition. Auburn, AL: Ludwig von Mises Institute, 2004.

Callataÿ, Godefroid de. Ikhwan al-Safa': A Brotherhood of Idealists on the Fringe of Orthodox Islam. London, UK: Oneworld Publications, 2012.

Callender, John S. Free Will and Responsibility: A Guide for Practitioners. Oxford, UK: Oxford University Press, 2010.

Campagna, Federico. Technic and Magic: The Reconstruction of Reality. London, UK: Bloomsbury, 2018.

Campbell, Colin. "Postmodernism." In The Blackwell Companion to the Study of Religion, ed. Robert A. Segal, 311. Malden, MA: Blackwell Publishing, 2006.

Campbell, George Van Pelt. "A Biblical Theology of the Common Good." In Bibliotheca Sacra 172 (April-June 2015): 139-153.

Campbell, Heidi A., and Heather Looy, eds. A Science and Religion Primer. Grand Rapids, MI: Baker Academic, 2009. 
Campbell, Scott M. The Early Heidegger's Philosophy of Life: Facticity, Being, and Language. Bronx, NY: Fordham University Press, 2012.

Campolo, Tony. Speaking My Mind: The Radical Evangelical Prophet Tackles the Tough Issues Christians are Afraid to Face. Nashville, TN: Thomas Nelson, 2004.

Camus, Albert. Christian Metaphysics and Neoplatonism, tr. Ronald D. Srigley. Columbia, MO: University of Missouri Press, 2007.

Canale, Fernando. "Absolute Theological Truth in Postmodern Times." In Andrews University Seminary Studies Vol. 45 \#1 (Spring 2007): 87-100.

. A Criticism of Theological Reason: Time and Timelessness as Primordial Presuppositions. Berrien Springs, MI: Andrews University Press, 1987.

. Basic Elements of Christian Theology: Scripture Replacing Tradition. Berrien Springs, MI: Andrews University Lithotec, 2005.

Creation, Evolution, and Theology: The Role of Method in Theological Accommodation. Berrien Springs, MI: Andrews University Lithotech, 2005.

"Philosophical Foundations and the Biblical Sanctuary," in Andrews University Seminary Studies Vol. 36 \#2 (Autumn 1998): 183-206.

. Scripture Replacing Tradition. Berrien Springs, MI: Andrews University Lithotech, 2005.

The Cognitive Principle of Christian Theology: A Hermeneutical Study of the Revelation and Inspiration of the Bible. Berrien Springs, MI: Andrews University Lithotech, 2005.

Canales, Jimena. The Physicist \& the Philosopher: Einstein, Bergson, and the Debate That Changed Our Understanding of Time. Princeton, NJ: Princeton University Press, 2015.

Čapek, Milič. "The Unreality and Indeterminacy of the Future in the Light of Contemporary Physics." In Physics and the Ultimate Significance of Time: Bohm, Prigogine, and Process Philosophy, ed. David Ray Griffin, 209-218. Albany, NY: State University of New York Press, 1986.

Capra, Fritjof. The Tao of Physics: An Exploration of the Parallels Between Modern Physics and Eastern Mysticism. Boston, MA: Shambhala, 2010.

Caputo, John D. Demythologizing Heidegger .Bloomington, IN: Indiana University Press, 1993. The Mystical Element in Heidegger's Thought. New York, NY: Fordham University Press, 1990.

Carel, Havi. Life and Death in Freud and Heidegger. Amsterdam, The Netherlands: Rodopi, 2006.

Carimokam, Sahaja. Muhammad and the People of the Book. Bloomington, IN: Xlibris, 2010.

Carlisle, Keith, and Rebecca L. Gruby. "Polycentric Systems of Governance: A Theoretical Model for the Commons." In The Policy Studies Journal Vol. 00, \#00 (2017): 1-26.

Carlson, Richard F., and Tremper Longman III. Science, Creation and the Bible: Reconciling Rival Theories of Origins. Downers Grove, IL: InterVarsity Press, 2010. 
Carman, Taylor. Heidegger's Analytic: Interpretation, Discourse and Authenticity in Being and Time. Cambridge, UK: Cambridge University Press, 2003.

Carrette, Jeremy. William James's Hidden Religious Imagination: A Universe of Relations. New York, NY: Routledge, 2013.

Carson, Ben. America the Beautiful: Rediscovering What Made This Nation Great. Grand Rapids, MI: Zondervan, 2012. . One Nation: What We Can All Do To Save America's Future. New York, NY: Penguin Group, 2014.

Carter, John D. Psychology and Christianity: Integrative Readings. Nashville, TN: Abingdon Press, 1981.

Carter, John D., and Bruce Narramore. The Integration of Psychology and Theology: An Introduction. Grand Rapids, MI: Zondervan, 1979.

Paul Cartledge, Democritus: Democritus and Atomistic Politics. Phoenix, AZ: 1998.

Cartwright, John H., and Brian Baker. Literature and Science: Social Impact and Interaction. Santa Barbara, CA: ABC-CLIO, 2005.

Cartwright, Nancy, and Eric Martin, “Queen Physics: How Much of the Globe is Painted Red?" In God and the Scientist: Exploring the Work of John Polkinghorne, eds. Fraser Watts and Christopher C. Knight, 67-76. New York, NY: Routledge, 2012.

Casarella, Peter. "Public Reason and Intercultural Dialogue." In At the Limits of the Secular: Reflections on Faith and Public Life, ed. William A Barbieri Jr., 51-84. Grand Rapids, MI: Eerdmans, 2014.

Case-Winters, Anna. "Rethinking Divine Presence and Activity in World Process." In Creation Made Free: Open Theology Engaging Science, ed. Thomas Jay Oord, 69-87. Eugene, OR: Pickwick Publications, 2009.

Castles, Francis G. Pressure Groups and Political Culture: A Comparative Study. New York, NY: Routledge, 2009, 1967.

Cataldi, Sue L. Emotion, Depth, and Flesh: A Study of Sensitive Space: Reflections on Merleau-Ponty's Philosophy of Embodiment. Albany, NY: State University of New York Press, 1993.

Cato, Brother. Illuminism Contra Discordianism. Raleigh, NC: Lulu Press, 2016.

Caughill, Patrick. "Artificial Intelligence Is Our Future. But Will It Save Or Destroy Humanity?" At https://futurism.com/artificial-intelligence-is-our-future-but-will-it-save-or-destroy-humanity / (accessed September 29, 2017).

Cavanaugh, William T. Theopolitical Imagination: Christian Practices of Space and Time. New York, NY: T \& T Clark, 2002.

Cayer, Mario. “The Five Dimensions of Bohm's Dialogue." In Dialogue as a Means of Collective Communication, eds. Bele H. Banathy and Patrick M. Jenlink, 161-192. New York, NY: Kluwer, 2005.

Cernuschi, Claude, Barnett Newman and Heideggerian Philosophy. Lanham, MD: Fairleigh Dickinson University Press, 2012. 
Chadderton, Ronald A. Purposeful Engineering Economics. London, UK: Springer, 2015.

Chadwick, Henry. Studies on Ancient Christianity. Burlington, VT: Ashgate, 2006.

Chafer, Lewis Sperry, with John F. Walvoord. Major Bible Themes: 52 Vital Doctrines of the Sacred Scriptures Simplified and Explained. Grand Rapids, MI: Zondervan, 1974.

Chalk, Casey. "The Glorious Mission of Theology." In The Catholic Thing. At https://www.thecatholicthing.org/2018/02/01/the-glorious-mission-of-theology/ accessed February 1, 2018).

Chalmers, David J. "The Hard Problem: Facing Up to the Problem of Consciousness." In Explaining Consciousness: The 'Hard Problem,' ed. Jonathan Shear, 9-32. Cambridge, MA: The MIT Press, 1997.

Chandrankunnel, Mathew. Philosophy of Quantum Mechanics: Quantum Holism to Cosmic Holism: The Physics and Metaphysics of Bohm. New Delhi, India: Global Vision Publishing, 2008.

Chanter, Tina. Time, Death, and the Feminine: Levinas with Heidegger. Stanford, CA: Stanford University Press, 2001.

Chaplin, Jonathan. Herman Dooyeweerd: Christian Philosopher of Civil Society. Notre Dame, IN: University of Notre Dame Press, 2016.

Chappell Dorothy F., and E. David Cook, Not Just Science: Questions Where Christian Faith and Natural Science Intersect. Grand Rapids, MI: Zondervan, 2005.

Chardin, Pierre Teilhard de. The Phenomenon of Man. New York, NY: HarperCollins, 1976.

Charyton, Christine. "Art, Creativity, and Culture: How Art Intersects with Science in the Expression of Artistic Creativity." In Creativity and Innovation Among Science and Art: A Discussion of the Two Cultures, ed. Christine Charyton, 179-204. Dordrecht, The Netherlands: Springer, 2015.

Cheetham, Tom. "Henry Corbin on Heidegger." At http://henrycorbinproject.blogspot.com/2008/09/on-heidegger.html (accessed September 12, 2008).

Chen, Sophia. "Physicists Can't Agree on What the Quantum World Looks Like." At https://www.newscientist.com/article/mg23331074-600-physicists-cant-agree-on-what-the-q uantum-world-looks-like/ (accessed January 4, 2017).

Chia, Robert. "The Shaping of Dominant Modes of Thought: Rediscovering the Foundations of Management Knowledge." In The Foundations of Management Knowledge, ed. Paul Jeffcutt, 169187. New York, NY: Routledge, 2004.

Chiew, Sze Sze. Middle Knowledge and Biblical Interpretation: Luis de Molina, Herman Bavinck, and William Lane Craig. New York, NY: Peter Lang, 2016.

Childs, Brevard. Myth and Reality in the Old Testament. Eugene, OR: Wipf \& Stock, 1962.

Chilton, David. Productive Christians in an Age of Guilt Manipulators: A Biblical Response to Ronald J. Sider. Institute for Christian Economics, 1985. 
Chow, Sheldon Joseph. Zeno's Paradoxes and Problems with Infinity in the Physical World. Canada: Dalhousie University, 2006.

Christidis, Theodoros. "Probabilistic Causality and Irreversibility: Heraclitus and Prigogine." In Between Chance and Choice: Interdisciplinary Perspectives on Determinism, eds. Harald Atmanspacher and Robert Bishop, 165-188. Exeter, UK: Imprint Academic, 2002.

Chua, Amy. Day of Empire: How Hyperpowers Rise to Global Dominance-and Why They Fall. New York, NY: Anchor Books, 2007.

Political Tribes: Group Instinct and the Fate of Nations. New York, NY: Penguin Press, 2018.

World on Fire: How Exporting Free Market Democracy Breeds Ethnic Hatred and Global Instability. New York, NY: Anchor Books, 2004.

Church, Richard P. "Answering the Dispersed Self and Nation: A Response to Jed Rubenfeld's Freedom and Time: A Theory of Constitutional Self Government," in the Journal of Law \& Religion (Vol. XXI, 2006): 349-383.

Cillis, Maria De. Free Will and Predestination in Islamic Thought: Theoretical Compromises in the Works of Avicenna, al-Ghazālī and Ibn 'Arabì. New York, NY: Routledge, 2014.

Ciocchi, David M. "Human Freedom." In Christian Perspectives on Being Human: A Multidisciplinary Approach, eds. J. P. Moreland and David M. Ciocchi, 87-116. Eugene, OR: Wipf and Stock, 1993.

Claeys, Eric R. "The National Regulatory State in Progressive Political Theory and Twentieth-Century Constitutional Law." In Modern America and the Legacy of the Founding, eds. Ronald J. Pestritto and Thomas G. West, 35-74. Lanham, MD: Lexington Books, 2007.

Clark, Gordon H. A Christian View of Men and Things: An Introduction to Philosophy. Jefferson, MD: The Trinity Foundation, 1991.

Logic. Unicoi, TN: Trinity Foundation, 1985.

Thales to Dewey: A History of Philosophy-An Entertaining and Enlightening Survey of the World's Great Thought. Grand Rapids, MI: Baker Book House, 1957.

Clark, Timothy. Martin Heidegger. London, UK: Routledge, 2002.

Clark, Tom. "The Specter of Scientism." At

http://www.naturalism.org/philosophy/new-age/the-specter-of-scientism (accessed February 11, 2018).

Clausen, Ben, and Gerald Wheeler. The Book of Beginnings: Creation and the Promise of Redemption. Hagerstown, MD: Review and Herald, 2006.

Clayton, Philip. Adventures in the Spirit: God, World, Divine Action. Minneapolis, MN: Augsburg Fortress, 2008.

God and Contemporary Science. Edinburgh, Scotland: Edinburgh University Press, 1997.

. Religion and Science: The Basics. New York, NY: Routledge, 2012. 
Cleary, John J., ed. The Perennial Tradition of Neoplatonism. Leuven, Belgium: Leuven University Press, 1997.

Cleve, Felix M. The Giants of Pre-Sophistic Greek Philosophy: An Attempt to Reconstruct Their Thoughts Vol. 2. Dordrecht, The Netherlands: Springer Science, 1969.

Cobern, William W. "Worldview, Science, and the Understanding of Nature." In the Scientific Literacy and Cultural Studies Project (ScholarWorks at WMU, 2005); available at http://scholarworks.wmich.edu /cgi/viewcontent.cgi?article=1021\&context=science_slcsp.

Cochrane, J. H. “How Did Paul Krugman Get It So Wrong?” In Economic Affairs \#31 (2011): 36-40.

Coeckelbergh, Mark. "Drones, Morality, and Vulnerability: Two Arguments Against Automated Killing." In The Future of Drone Use: Opportunities and Threats from Ethical and Legal Perspectives, ed. Bart Custers, 229-240. Berlin, Germany: Springer-Verlag, 2016.

Coffin, Harold G., Robert H. Brown, and L. James Gibson. Origin by Design rev. ed. Hagerstown, MD: Review and Herald, 2005.

Cohen, Daniel J. Equations from God: Pure Mathematics and Victorian Faith. Baltimore, MD: John Hopkins University Press, 2008.

Cohen, Irun R. Tending Adam's Garden: Evolving the Cognitive Immune Self. London, UK: Academic Press, 2000.

Cohen, Michael H. Beyond Complementary Medicine: Legal and Ethical Perspectives on Health Care and Human Evolution. Ann Arbor, MI: The University of Michigan Press, 2000.

Colander, David, and Roland Kupers. Complexity and the Art of Public Policy: Solving Society's Problems from the Bottom Up. Princeton, NJ: Princeton University Press, 2014.

Collier, Andrew. Critical Realism: An Introduction to Roy Bhaskar's Philosophy. New York, NY: Verso, 1994.

Collins, Francis. The Language of God: A Scientist Presents Evidence for Belief. New York, NY: Free Press, 2006.

Collins, C. John. Reading Genesis Well: Navigating History, Poetry, Science, and Truth in Genesis 1-11. Grand Rapids, MI: Zondervan, 2018.

Comblin, José. The Holy Spirit and Liberation. Eugene, OR: Wipf and Stock, 1989.

Commager, Henry Steele. "Is There a 'Philosophy of History?'” In Mind Science and History, eds. Howard Evans Kiefer and Milton Karl Munitz, 300-317. Albany, NY: State University of New York Press,

Compton, John W. The Evangelical Origins of the Living Constitution. Cambridge, MA: Harvard University Press, 2014.

Conard, Edward. The Upside of Inequality: How Good Intentions Undermine the Middle Class. New York, NY: Penguin Random House, 2016. 
Conard, Edward. Unintended Consequences: Why Everything You've Been Told about the Economy is Wrong. New York, NY: Penguin, 2012.

Congdon, David W. The God Who Saves: A Dogmatic Sketch. Eugene, OR: Cascade Books, 2016.

Conley, John J. "Churched Philosophy." At http://www.americamagazine.org/issue/churched-philosophy (accessed October 17, 2016).

Conte, Joseph. Design and Debris: A Chaotics of Postmodern American Fiction. Tuscaloosa, AL: The University of Alabama Press, 2002.

Coogan, Clark. Escape from Planet Lame. Jacksonville, FL: Plain Thinking Publishers, 2005.

Cook, Gary A. George Herbert Mead; The Making of a Social Pragmatist. Chicago, IL: University of Illinois Press, 1993.

Cooke, Austin. An Enduring Vision: Revelation Revealed: An Historic and Prophetic, Verse-by-Verse Exposition of John's Apocalypse. TEACH Services, 2014.

Copan, Paul, Tremper Longman III, Christopher L. Reese, and Michael Strauss, eds. Dictionary of Christianity and Science: The Definitive Reference for the Intersection of Christian Faith and Contemporary Science. Grand Rapids, MI: Zondervan, 2017.

Corey, Michael Anthony. The God Hypothesis: Discovering Design in Our "Just Right" Goldilocks Universe. Lanham, MD: Rowman \& Littlefield Publishers, 2007.

Cornford, Francis MacDonald. From Religion to Philosophy: A Study in the Origins of Western Speculation. New York, NY: Cosimo, 2009; 1912.

Cornman, James W., Keith Lehrer, and George Sotiros Pappas. Philosophical Problems and Arguments: An Introduction $4^{\text {th }}$ ed. Indianapolis, IN: Hackett, 1987.

Cornwell, John. "Pope vs. Pope: How Francis and Benedict's Simmering Conflict Could Split the Catholic Church." At https://www.vanityfair.com/news/2018/10/pope-francis-benedict-conflict-catholic-church (accessed November 2, 2018).

Corredoira, M. Lopez. "Is Ethics in Science an Oxymoron?" In Against the Tide: A Critical Review by Scientists of How Physics \& Astronomy Get Done, eds. Martín López Corredoira and Carlos Castro Perelman, 145-178. Boca Raton, FL: Universal Publishers, 2008.

Cosper, Mike. "Grinding Through the Pleasure Factory: Reading Arendt at Disney World." At https://www.cardus.ca/comment/article/4285/grinding-through-the-pleasure-factory-reading -arendt-at-disney-world/ (accessed May 3, 2017).

Counihan, Christopher R., and Mark J. Miller. "Competing for Global Talent in an Age of Turbulence." In Competing for Global Talent, eds. Christiane Kuptsch and Pang Eng Fong, 259-277. Geneva, Switzerland: International Labour Organization, 2006.

Court, John M. "Introduction." In Biblical Interpretation: The Meanings of Scripture-Past and Present, ed. John M. Court, 1-9. New York, NY: T\&T Clark, 2003. 
Cowan, Steven B., and James S. Spiegel. The Love of Wisdom: A Christian Introduction to Philosophy. Nashville, TN: B\&H Publishing, 2009.

Coyne, Christopher J. "Economics as the Study of Coordination and Exchange." In Handbook on Contemporary Austrian Economics, ed. P. J. Boettke, 14-29. Cheltenham, UK: Edward Elgar Publishing, 2010.

Coyne, Jerry A. Faith Versus Fact: Why Science and Religion are Incompatible. New York, NY: Penguin Books, 2015.

Craig, William Lane. "Doctrine of Man (Part 5) At https://www.reasonablefaith.org/podcasts/defenders-podcast-series-2/s2-doctrine-of-man/d octrine-of-man-part-5/ (accessed December 6, 2017).

Interview at https://www.youtube.com/watch?v=Sd95H_f0mGo (accessed December 21, 2017).

"Doctrine of God Part 15: God's Middle Knowledge," at

https://www.youtube.com/watch?v=882AGGzDJmk (accessed May 8, 2019).

“Ducking Friendly Fire: Davison on the Grounding Objection." In Philosophia Christi 8:1 (2006): 161-166.

. God, Time, and Eternity: The Coherence of Theism II: Eternity. Dordrecht, The Netherlands: Kluwer Academic, 2001.

Reasonable Faith: Christian Truth and Apologetics $3^{\text {rd }}$ ed. Wheaton, IL: 2008.

The Only Wise God: The Compatibility of Divine Foreknowledge and Human Freedom. Eugene, OR: Wipf and Stock, 2000.

The Problem of Divine Foreknowledge and Future Contingents from Aristotle to Suarez. Leiden, The Netherlands: E. J. Brill, 1988.

Time and Eternity: Exploring God's Relationship to Time. Wheaton, IL: Crossway Books, 2001.

Time and the Metaphysics of Relativity. Dordrecht, the Netherlands: Springer, 2001.

Craig, William Lane, and Quentin Smith, eds. Einstein, Relativity and Absolute Simultaneity. New York, NY: Routledge, 2008.

Craigen, Trevor. "Can Deep Time Be Embedded in Genesis?" In Coming to Grips With Genesis: Biblical Authority and the Age of the Earth, eds. Terry Mortenson and Tahne Ury, 193-210. Green Forest, AR: Master Books, 2012.

Creaven, Sean. Against the Spiritual Turn: Marxism, Realism, and Critical Theory. New York, NY: Routledge, 2010.

Crisp, Oliver D. "Calvin on Creation and Providence," in John Calvin and Evangelical Theology: Legacy and Prospect-In Celebration of the Quincentenary of John Calvin, ed. Sung Wook Chung, 43-65. Colorado Springs, CO: Paternoster, 2009. 
Critchley, Simon. Continental Philosophy: A Very Short Introduction. Oxford, UK: Oxford University Press, 2001.

Crockatt, Richard. Einstein and Twentieth-Century Politics: 'A Salutary Moral Influence'. Oxford, UK: Oxford University Press, 2017.

Crockett, Clayton. Deleuze Beyond Badiou: Ontology, Multiplicity, and Event. Chichester, West Sussex: Columbia University Press, 2013. . Radical Political Theology: Religion and Politics After Liberalism. New York, NY: Columbia University Press, 2013.

Crome, Victor J. Zeno's Paradoxes and the Passage of Time. New York, NY: City University of New York, 2007.

Crosby, Donald A. Nature as Sacred Ground: A Metaphysics for Religious Naturalism. Albany, NY: State University of New York Press, 2015.

Crouse, Eric R. The Cross and Reaganomics: Conservative Christians Defending Ronald Reagan. Lanham, MD: Lexington Books, 2013.

Crowe, Benjamin D. Heidegger's Phenomenology of Religion: Realism and Cultural Criticism. Bloomington, IN: Indiana University Press, 2008.

Crull, Elise. "You Thought Quantum Mechanics was Weird: Check out Entangled Time." At https://aeon.co/ideas/you-thought-quantum-mechanics-was-weird-check-out-entangled-time (accessed February 2, 2018).

Cubeddu, Raimondo. The Philosophy of the Austrian School. New York, NY: Routledge, 1993.

Cullmann, Oscar. Christ and Time: The Primitive Christian Conception of Time and History, tr. Floyd V. Filson. London, UK: SCM Press, 1951.

Cummings, Nicholas A., and William T. O'Donohue, eds. Understanding the Behavioral Healthcare Crisis. New York, NY: Routledge, 2011.

Cunningham, Timothy R. How Firm a Foundation?: An Exegetical and Historical Critique of the 'Ethical Perspective of [Christian] Reconstructionism' Presented in Theonomy in Christian Ethics. Eugene, OR: Wipf \& Stock, 2012.

Curnow, Trevor. Wisdom in the Ancient World. London, UK: Bristol Classical Press, 2011.

Curran, Charles E. Catholic Social Teaching, 1891-Present: A Historical, Theological, and Ethical Analysis. Washington, D. C.: Georgetown University Press, 2002.

Currie, Stephen. Sharing Posts: The Spread of Fake News. Referencepoint Press, 2017.

Curry, James A., Richard B. Riley, and Richard M. Battistoni. Constitutional Government: The American Experience $5^{\text {th }}$ ed. Dubuque, IA: Hunt Publishing, 2003.

Curtis, Benjamin L., and Jon Robson. A Critical Introduction to the Metaphysics of Time. New York, NY: Bloomsbury Academic, 2016. 
Cushing, James T. "The Causal Quantum Theory Program," in Bohmian Mechanics and Quantum Theory: An Appraisal, eds. James T. Cushing, Arthur Fine, and Sheldon Goldstein, 1-21. Dordrecht, The Netherlands: Springer, 1996.

Quantum Mechanics: Historical Contingency and the Copenhagen Hegemony. Chicago, IL: The University of Chicago Press, 1994.

Dabrowski, Irene J. “David Bohm's Theory of the Implicate Order: Implications for Holistic Thought Processes." In Issues in Integrative Studies No. 13 (1995): 1-23.

Dag, Esra Akay. Christian and Islamic Theology of Religions: A Critical Appraisal. New York, NY: Routledge, 2017.

Dahlstrom, Daniel 0. Heidegger's Concept of Truth. Cambridge, UK: Cambridge University Press, 2001.

Daiches, David. "Scott's Redgauntlet." In From Jane Austen to Joseph Conrad, eds. Robert C. Rathburn and Martin Steinmann, Jr., 45-59. Minneapolis, MN: University of Minnesota, 1958.

Dalafi, H. R., and M. H. A. Hassan, eds. Renaissance of Sciences in Islamic Countries. London, UK: World Scientific Publishing, 1994.

Dallmayr, Fred. Mindfulness and Letting Be: On Engaged Thinking and Acting. Lanham, MD: Lexington Books, 2014.

Dalsgaard, Inger H. "Science and Technology." In The Cambridge Companion to Thomas Pynchon, eds., Inger H. Dalsgaard, Luc Herman, Brian McHale, 157. Cambridge, UK: Cambridge University Press, 2012.

Daoud, Yousef, and Joe Martin. The Rose and the Lotus: Sufism and Buddhism. Bloomington, IN: Xlibris, 2009.

Das, Kunal K. The Quantum Guide to Life: How the Laws of Physics Explain Our Lives from Laziness to Love. New York, NY: Skyhorse Publishing, 2013.

Davenport, John. "A New Existential Model of God: A Synthesis of Themes from Kierkegaard, Buber, Levinas, and Open Theism." In Models of God and Alternative Ultimate Realities, eds. Jeanine Diller and Asa Kasher, 567-586. London, UK: Springer, 2013.

Davenport, Thomas H., and Julia Kirby. Only Humans Need Apply: Winners and Losers in the Age of Smart Machines. New York, NY: HarperCollins, 2016.

Davidson, Jo Ann. "The Decalogue Predates Mount Sinai: Indicators from the Book of Genesis," in Journal of the Adventist Theological Society Vol. 19 \#1-2 (2008): 61-81.

Davidson, Richard M. A Love Song for the Sabbath. Hagerstown, MD: Review and Herald, 1988. Typology in Scripture: A Study of Hermeneutical Typos Structures. Berrien Springs, MI: Andrews University Press, 1981.

Davies, Oliver, and Rowan Williams. God Within: The Mystical Tradition of Northern Europe. Hyde Park, NY: New City Press, 1988; 2006.

Davies, Paul. God and the New Physics. New York, NY: Simon \& Schuster, 1983. 
"That Mysterious Flow," in Scientific American. At

https://www.scientificamerican.com/article/that-mysterious-flow-2006-02/ (accessed February 1, 2006).

Davis, Bob. Skills Mania: Snake Oil in Our Schools? Toronto, Canada: Between the Lines, 2000.

Davis, Bret W. Heidegger and the Will: On the Way to Gelassenheit. Northwestern University Press, 2007.

Davis, Julian L. Mathematics of Wave Propagation. Princeton, NJ: Princeton University Press, 2000.

Dawkins, Richard, and Steven Pinker. "Is Science Killing the Soul?" In The Guardian-Dillons Debate, Edge 53 (April 8, 1999).

D'Costa, Gavin. Theology in the Public Square: Church, Academy, and Nation. Carlton, Victoria: Australia: Blackwell Publishing, 2005.

Dean, Kathryn. Capitalism and Citizenship: The Impossible Partnership. New York, NY: Routledge, 2003.

DeBenedictis, Albert. Evolution or Creation?: A Comparison of the Arguments, $3^{\text {rd }}$ ed. Bloomington, IN: Xlibris Corporation, 2014.

Dehsen, Christian D. Von, ed. Lives \& Legacies: An Encyclopedia of People Who Changed the World: Philosophers and Religious Leaders. Phoenix, AZ: The Oryx Press, 1999.

Delio, Ilia. Making All Things New: Catholicity, Cosmology, Consciousness. Maryknoll, NY: Orbis Books, 2015.

The Unbearable Wholeness of Being: God, Evolution, and the Power of Love. Maryknoll, NY: Orbis Books, 2013.

The Emergent Christ: Exploring the Meaning of Catholic in an Evolutionary Universe. Maryknoll, NY: Orbis Books, 2011.

Demastes, William W. Staging Consciousness: Theater and the Materialization of Mind. Ann Arbor, MI: The University of Michigan Press, 2002.

Demski, William A. Intelligent Design: The Bridge Between Science \& Theology. Downers Grove, IL: InterVarsity Press, 1999.

Dennett, Daniel C. Freedom Evolves. New York, NY: Penguin Books, 2004.

Depoortere, Frederiek, and Magdalen Lambkin. "Editors' Introduction." In The Question of Theological Truth: Philosophical and Interreligious Perspectives, eds. Frederiek Depoortere and Magdalen Lambkin, 1-30. Amsterdam, The Netherlands: Rodopi, 2012.

Derrida, Jacques. Of Spirit: Heidegger and the Question, tr. Geoffrey Bennington and Rachel Bowlby. Chicago, IL: University of Chicago, 1991.

DeRoo, Neal, and John Panteleimon Manoussakis, ed. Phenomenology and Eschatology: Not Yet in the Now. Burlington, VT: Ashgate, 2009. 
Derrick, Paul Scott. Thinking for a Change: Gravity's Rainbow and Symptoms of the Paradigm Shift in Occidental Culture. València, Spain: Universitat de València, 1994.

.We Stand Before the Secret of the World: Traces Along the Pathway of American Romanticism. Spain: Universitat de València, 2003.

Desmond, William. Philosopher-Kings of Antiquity. New York, NY: Continuum, 2011.

d'Espagnat, Bernard. In Search of Reality. New York, NY: Springer, 1983.

On Physics and Philosophy. Princeton, NJ: Princeton University Press, 2006.

Veiled Reality: An Analysis of Present-day Quantum Mechanical Concepts. Boulder, CO: Westview Press, 2003.

Dessler, Andrew. Introduction to Modern Climate Change, $2^{\text {nd }}$ ed. Cambridge, UK: Cambridge University Press, 2016.

Deusen, Nancy Elizabeth Van. The Medieval West Meets the Rest of the World. Institute of Mediaeval Music, 1995.

Deutsch, Sid. Einstein's Greatest Mistake: Abandonment of the Aether. Bloomington, IN: iUniverse, 2006.

DeWeese, Garrett J. God and the Nature of Time. Burlington, VT: Ashgate, 2004.

DeYoung, Kevin. Freedom and Boundaries: A Pastoral Primer on the Role of Women in the Church. Enumclaw, WA: Pleasant Word, 2006.

Dhaouadi, Mahmoud. Cultural Sociology within Innovative Treatise: Islamic Insights on Human Symbols. Lanham, MD: University Press of America, 2013.

Dickey, Colin. "Two-Way Monologue: How to Get Past Science vs. Religion." At https://lareviewofbooks.org/article/two-way-monologue-how-to-get-past-science-vs-religion\# ! (accessed August 1, 2015).

Dickson, Michael, and Rob Clifton. "Lorentz-Invariance in Modal Interpretations." In The Modal Interpretation of Quantum Mechanics, ed. Dennis Dieks and Pieter E. Vermaas, 9-48. Dordrecht, The Netherlands: Kluwer, 1998.

Dillard, Peter S. Heidegger and Philosophical Atheology: A Neo-Scholastic Critique. New York, NY: Continuum Publishing, 2008. Non-Metaphysical Theology After Heidegger. New York, NY: Palgrave Macmillan, 2016.

Dilman, Illham. Free Will: An Historical and Philosophical Introduction. New York, NY: Routledge, 1999.

Djaït, Hichem. Islamic Culture in Crisis, tr. Janet Fouli. New York, NY: Routledge, 2017.

Djupsjöbacka, Stefan. Dialogue in the Crisis of Representation: Realism and Antirealism in the Context of the Conversation between Theologians and Quantum Physicists in Göttingen 1949-1961. Tavastg, Finland: Åbo Akademi University Press, 2005.

Dobrowolny, Marino. Causality and Time: From Relativity to Quantum Physics. USA: Youcanprint, 2017. 
Dodds, Michael J. Unlocking Divine Action: Contemporary Science \& Thomas Aquinas. Washington, D. C.: The Catholic University of America Press, 2012.

Donato, Christopher John, ed. Perspectives on the Sabbath: Four Views. Nashville, TN: B\&H Academic, 2011.

Dooyeweerd, Herman. A New Critique of Theoretical Thought: The Necessary Presuppositions of Philosophy. Lewiston, NY: Edwin Mellen Press, 1997.

Dorrien, Gary. Social Ethics in the Making: Interpreting an American Tradition. Malden, MA: WileyBlackwell, 2011.

The Obama Question: A Progressive Perspective. Lanham, MD: Rowman \& Littlefield Publishers, 2012.

Double, Richard. Metaphilosophy and Free Will. New York, NY: Oxford University Press, 1996.

Dougherty, Peter J. Who's Afraid of Adam Smith: How the Market Got Its Soul. Hoboken, NJ: John Wiley \& Sons, 2002.

Douglass, E. Jane Dempsey. Women, Freedom, and Calvin. Philadelphia, PA: The Westminster Press, 1985.

Draper, John William. History of the Conflict Between Religion and Science. New York, NY: D. Appleton, $1897,1874$.

Drescher, Gary L. Good and Real: Demystifying Paradoxes from Physics to Ethics. Cambridge, MA: Massachusetts Institute of Technology, 2006.

Driver, Tom. Christ in a Changing World: Toward an Ethical Christology. Hertford, NC: Crossroad, 1981.

Drori, Gili S. "Rationalizing Global Consciousness: Scientized Education as the Foundation of Organization, Citizenship, and Personhood." In Global Culture: Consciousness and Connectivity, eds., Roland Robertson and Didem Buhari-Gulmez, 93-109. New York, NY: Routledge, 2016.

Drozdek, Adam. Greek Philosophers as Theologians: The Divine Arche. New York, NY: Routledge, 2016.

D'Souza, Dinesh. The Big Lie: Exposing the Nazi Roots of the American Left. Washington, D. C.: Regnery Publishing, 2017.

Dudley, Underwood. Numerology: Or, What Pythagoras Wrought. The Mathematical Association of America, 1997.

Duff, Alexander S. Heidegger and Politics: The Ontology of Radical Discontent. New York, NY: Cambridge University Press, 2015.

Duffy, Hugh. Queen of the Sciences: The Special Relationship Between Catholic Theology and Liberal Education. Cork Hill Press, 2004.

Duignan, Brian, ed. Ancient Philosophy: From 600 BCE to 500 CE. Britannica Education Publishing, 2011. 
Duits, Rufus A. Raising the Question of Being: A Unification and Critique of the Philosophy of Martin Heidegger. Boca Raton, FL: Dissertation.com Publishers, 2009.

Dunbar, Robin Ian MacDonald. The Trouble with Science. Harvard, MA: Faber and Faber, 1995.

Dungen, Wim van den. "The Impact of Ancient Egypt on Greek Philosophy against Hellenocentrism, against Afrocentrism in Defence of the Greek Miracle." At http://www.maat.sofiatopia.org/hermes1.htm (accessed January 17, 2017).

Dunn, John. Democracy: A History. New York, NY: Atlantic Monthly Press, 2005.

Dürr, Detlef, Sheldon Goldstein, Roderich Tumulka, and Nino Zanghì. "David Bohm." At http://www.mathematik.uni-muenchen.de/ bohmmech/rt/bohmbio.pdf (accessed February 15, 2017).

Dürr, Detlef, and Stefan Teufel. Bohmian Mechanics: The Physics and Mathematics of Quantum Theory. London, UK: Springer, 2009.

Doyle, Bob. Free Will: The Scandal in Philosophy. Cambridge, MA: I-Phi Press, 2011.

"Suarez." At http://www.informationphilosopher.com/solutions/scientists/suarez/ (accessed August 24, 2017).

Dworkin, Ronald. Freedom's Law: The Moral Reading of the American Constitution. Oxford, UK: Oxford University Press, 2005.

Dy, Jr., Manuel B. Philosophy of Man: Selected Readings $2^{\text {nd }}$ ed. Makati City, Philippines: Goodwill Trading, 2001.

Dyer, Allen R. Ethics and Psychiatry: Toward Professional Definition. American Psychiatric Press, 1988.

Eagles, Munroe. Politics: An Introduction to Modern Democratic Government. Peterborough, Ontario: Broadview Press, 2008.

Easterbrook, James A. The Determinants of Free Will: A Psychological Analysis of Responsible, Adjustive Behavior. San Francisco, CA: Academic Press, 1978.

Eaton, Charles Le Gai. Islam and the Destiny of Man. Albany, NY: State University of New York Press, 1985.

Eatwell, John, and Murray Milgate. The Fall and Rise of Keynesian Economics. Oxford, UK: Oxford University Press, 2011.

Ebenezer, Irpeel. Understanding the Gift of Salvation: And a Concise History of How the Church Through Ignorance and Unbelief Lost the Power of the Holy Spirit. Bloomington, IN: AuthorHouse, 2012.

Echeñique, Javier. Aristotle's Ethics and Moral Responsibility. Cambridge, UK: Cambridge University Press, 2012.

Edel, Abraham. Interpreting Education, Vol. 3. New Brunswick, NJ: Transaction Publishers, 1985. 
Edsall, Thomas B. "How Much Do Our Genes Influence Our Political Beliefs?" At https://www.nytimes.com/2014/07/09/opinion/thomas-edsall-how-much-do-our-genes-influ ence-our-political-beliefs.html (accessed February 16, 2017).

Echeverria, Edward Joseph. Criticism and Commitment: Major Themes in Contemporary 'Post-critical' Philosophy. Amsterdam, The Netherlands: Rodopi, 1981.

Edmonds III, Radcliffe G. Redefining Ancient Orphism: A Study in Greek Religion. Cambridge, UK: Cambridge University Press, 2013.

Egan, Kieran. Getting it Wrong from the Beginning: Our Progressivist Inheritance from Herbert Spencer, John Dewey, and Jean Piaget. London, UK: Yale University Press, 2002.

Eidemüller, Dirk. "Quantum Physics, Philosophy, and Understanding Our World." At http://www.chemistryviews.org/details/ezine/10054971/Quantum_Physics_Philosophy_and_ Understanding_Our_World.html (accessed December 6, 2016).

Einstein, Albert. Document at http://www.einstein-website.de/z_biography/credo.html (accessed September 24, 2017).

. "Introduction," in James Clerk Maxwell, A Dynamical Theory of the Electromagnetic Field, ed. Thomas Torrance. Torrance Collection, Wipf \& Stock, 1996. . Out of My Later Years. New York, NY: Philosophical Library, 1950.

. Relativity: The Special and the General Theory, tr. Robert W. Lawson. New York, NY: Three Rivers Press, 1961, 1916.

Eisendrath, Craig. Beyond Permanence. Bloomington, IN: Xlibris, 2011.

Eldred, Michael. A Question of Time. North Charleston, SC: CreateSpace, 2015.

. Being Time Space: Heidegger's Casting of World. Arte-fact.org, 2014.

Social Ontology: Recasting Political Philosophy Through a Phenomenology of Whoness.

Piscataway, NJ: Rutgers, 2008.

. The Digital Cast of Being: Metaphysics, Mathematics, Cartesianism, Cybernetics, Capitalism,

Communication. Lancaster, UK: Gazelle Books, 2009.

"The Digital Cast of Being Metaphysics, Mathematics, Cartesianism, Cybernetics, Capitalism, Communication." At http://www.arte-fact.org/dgtlon_e.html (accessed January 23, 2017).

Thinking of Music. Charleston, SC: CreateSpace, 2015.

Turing's Cyberworld of Timelessly Copulating Bit-strings. Arte-fact.org, 2014.

Ellenberg, Jordan. How Not to Be Wrong: The Power of Mathematical Thinking. New York, NY: Penguin Books, 2015.

Ellis, George F. R., ed. The Far-Future Universe: Eschatology from a Cosmic Perspective. Radnor, PA: Templeton Foundation Press, 2002. 
Elsbernd, Mary, and Reimund Bieringer. When Love is Not Enough: A Theo-ethic of Justice. Collegeville, MN: The Liturgical Press, 2002.

Engel, Stephen M. American Politicians Confront the Court: Opposition Politics and Changing Responses to Judicial Power. New York, NY: Cambridge University Press, 2011.

Entwistle, David N. Integrative Approaches to Psychology and Christianity: An Introduction to Worldview Issues, Philosophical Foundations, and Models of Integration $2^{\text {nd }}$ ed. Eugene, OR: Cascade Books, 2010.

Epstein, Richard A. How Progressives Rewrote the Constitution. Washington, D. C.: Cato Institute, 2006. The Classical Liberal Constitution. Cambridge, MA: Harvard University Press, 2014.

Erickson, Paul. The World the Game Theorists Made. Chicago, IL: The University of Chicago Press, 2015.

Erwin, Edward. "Freud's Rejection of Free Will." In The Freud Encyclopedia: Theory, Therapy, and Culture, ed. Edward Erwin, 214-217. London, UK: Routledge, 2002.

Eshel, Amir. Futurity: Contemporary Literature and the Quest for the Past. Chicago, IL: The University of Chicago Press, 2013.

Espejo, Paulina Ochoa. The Time of Popular Sovereignty: Process and the Democratic State. University Park, PA: The Pennsylvania State University Press, 2011.

Estola, Matti. Newtonian Microeconomics: A Dynamic Extension to Neoclassical Micro Theory. Cham, Switzerland: Palgrave Macmillan, 2017.

Everitt, Anthony. Cicero: The Life and Times of Rome's Greatest Politician. New York, NY: Random House, 2003.

Eysenck, Hans J. "The Growth of a Unified Scientific Psychology: Ordeal by Quackery." In Annals of Theoretical Psychology Vol. 5, eds. Arthur W. Staats and Leendert P. Mos, 91-116. New York, NY: Plenum Press, 1987.

Ezrahi, Yaron. "Einstein and the Light of Reason." In Albert Einstein, Historical and Cultural Perspectives: The Centennial Symposium in Jerusalem, eds. Gerald Holton and Yehuda Elkana, 253-280. Princeton, NJ: Princeton University Press, 1982.

Fadiman, James, and Robert Frager, eds. Essential Sufism. San Francisco, CA: Harper San Francisco, 1997.

Fagg, Lawrence W. The Becoming of Time: Integrating Physical and Religious Time. Atlanta, GA: Scholars Press, 1995.

Fairfield, Paul. Education After Dewey. New York, NY: Continuum, 2009.

Falk, Dan. "A Debate Over the Physics of Time." Quanta Magazine (July 19, 2016). At https://www.quantamagazine.org/a-debate-over-the-physics-of-time-20160719/ (accessed August 9, 2017). 
In Search of Time: The History, Physics, and Philosophy of Time. New York, NY: St. Martin's Press, 2008.

Fallis, George. Multiversities, Ideas, and Democracy. Toronto, Canada: University of Toronto Press, 2007.

Falzon, Christopher. Philosophy Goes to the Movies: An Introduction to Philosophy $2^{\text {nd }}$ ed. New York, NY: Routledge, 2007.

Fantuzzi, Maria Noussia. Solon the Athenian, the Poetic Fragments. Leiden, The Netherlands: Koninklijke Brill, 2010.

Farías, Víctor. Heidegger and Nazism. Philadelphia, PA: Temple University Press, 1989.

Faries, Dillard W. Amazing Grace of Quantum Physics. Eugene, OR: Pickwick, 2017.

Farrow, Douglas. Desiring a Better Country: Forays in Political Theology. Montreal, Canada: McGillQueen's University Press, 2015.

Faye, Emmanuel. Heidegger, l'introduction du Nazisme dans la Philosophie. Paris, France: Albin Michel S. A., 2005.

Heidegger, The Introduction of Nazism into Philosophy in Light of the Unpublished Seminars of 1933-1935, tr. Michael B. Smith with a foreword by Tom Rockmore. London, UK: Yale University Press, 2009.

Faye, Jan. "Neo-modernisn: A New Approach to the Humanities." In The Object of Study in the Humanities, ed. Julio Jensen, 49-68. Gylling, Denmark: Narayana Press, 2004.

Feffer, Andrew. The Chicago Pragmatists and American Progressivism. Ithaca, NY: Cornell University Press, 1993.

Feinberg, John S. No One Like Him: The Doctrine of God. Wheaton, IL: Crossway Books, 2001.

Felser, Joseph M. The Way Back to Paradise: Restoring the Balance Between Magic and Reason. Charlottesville, VA: Hampton Roads, 2005.

Fenn, Richard K. "Epilogue: Toward a Secular View of the Individual." In The Blackwell Companion to Sociology of Religion, ed. Richard K. Fenn, 445-468. Malden, MA: Blackwell Publishing, 2003.

Ferguson, Harvie. Self-Identity and Everyday Life. New York, NY: Routledge, 2009.

Ferguson, Kitty. The Music of Pythagoras: How an Ancient Brotherhood Cracked the Code of the Universe and Lit the Path from Antiquity to Outer Space. New York, NY: Walker \& Company, 2008.

Ferraro, Rafael. Einstein's Space-Time: An Introduction to Special and General Relativity. New York, NY: Springer, 2007.

Ferry, David. The Copenhagen Conspiracy. Singapore: Pan Stanford Publishing, 2019.

Feynman, Richard. The Character of Physical Law. Cambridge, MA: MIT Press, 1965. 
Fjelland, Ragnar. “The 'Copenhagen Interpretation' of Quantum Mechanics and Phenomenology.” In Hermeneutic Philosophy of Science, Van Gogh's Eyes, and God: Essays in Honor of Patrick A. Heelan, S. J., ed. Babette E. Babich, 53-66. New York, NY: Springer Science, 2002.

Figal, Günter. Martin Heidegger: Phänomenologie der Freiheit, 3rd ed. Weinheim: Beltz Athenäum, 2000.

Figgis, John Neville. The Divine Right of Kings $2^{\text {nd }}$ ed. Cambridge, UK: University Press, 1922.

Filho, Jenner Barretto Bastos. "The Quantum Debate: From Einstein to Bell and Beyond." In Physics Before and After Einstein, ed. Marco Mamone Capria, 205-232. Amsterdam, The Netherlands: IOS Press, 2005.

Finley, Guy. Let Go and Live in the Now: Awaken the Peace, Power, and Happiness in Your Heart. Boston, MA: Red Wheel/Weiser, 2004.

Firestein, Stuart. "Certainly Not! Good Science Requires Cultivating Doubt and Finding Pleasure in Mystery." At http://nautil.us/issue/2/uncertainty/certainly-not (accessed January 4, 2017).

Fiscaletti, Davide. The Timeless Approach: Frontier Perspectives in $21^{\text {st }}$ Century Physics. Toh Tuck Link, Singapore: World Scientific, 2016.

Fischer, John Martin, ed. God, Foreknowledge, and Freedom. Stanford, CA: Stanford University Press, 1989.

Flanagan, Owen J. The Problem of the Soul: Two Visions of Mind and How to Reconcile Them. New York, NY: Basic Books, 2003.

Flank, Lenny. Deception by Design: The Intelligent Design Movement in America. St. Petersburg, FL: Red and Black Publishers, 2007.

Flaschel, Peter, and Alfred Greiner. A Future for Capitalism: Classical, Neoclassical and Keynesian Perspectives. Cheltenham, UK: Edward Elgar, 2011.

Fleming, Tony. Self-Field Theory: A New Mathematical Description of Physics. Boca Raton, FL: CRC Press, 2012.

Fletcher, Andrew. Quantum God, Fractal Jesus: How Isaac Newton Redefined God Without Really Meaning To, And Why We Really Don't Get God. Monument, CO: TOK Seminars, 2012.

Flew, Antony, and Roy Abraham Varghese. There is a God: How the World's Most Notorious Atheist Changed His Mind. New York, NY: HarperCollins, 2007.

Flint, Thomas P. Divine Providence: The Molinist Account. Ithaca, NY: Cornell University Press, 1998.

Flipper, Joseph S. Between Apocalypse and Eschaton: History and Eternity in Henri de Lubac. Minneapolis, MN: Fortress Press, 2015.

Flood, Derek. "A Personal Relationship with God?" At http://www.huffingtonpost.com/derek-flood/personal-relationship-with-god_b_914065.html (accessed May 4, 2017). 
Flores, Mónica Judith Sánchez. Political Philosophy for the Global Age. New York, NY: Palgrave Macmillan, 2005.

Flynn, Daniel J. A Conservative History of the American Left. New York, NY: Random House, 2008.

Fockner, Sven. Reason in Theology: A Comparison of Fernando Canale and Wolfhart Pannenberg. MA Thesis, Andrews University, Berrien Springs, MI, 2008.

Folse, Henry J. The Philosophy of Niels Bohr: The Framework of Complementarity. North-Holland: The Netherlands, 1985.

Foner, Eric. Free Soil, Free Labor, Free Men: The Ideology of the Republican Party Before the Civil War. Oxford, UK: Oxford University Press, 1995.

Ford, Kenneth W. Building the H Bomb: A Personal History. Toh Tuck Link, Singapore: World Scientific Publishing, 2015.

Ford, Lewis S. Transforming Process Theism. Albany, NY: State University of New York Press, 2000.

Ford, Martin. Rise of the Robots: Technology and the Threat of a Jobless Future. New York, NY: Basic Books, 2015.

The Lights in the Tunnel: Automation, Accelerating Technology, and the Economy of the Future. Acculant Publishing, 2009.

Forde, Steven. Locke, Science, and Politics. Cambridge, UK: Cambridge University Press, 2013.

Forrest, Peter. "Relativity, the Passage of Time and the Cosmic Clock." In The Ontology of Spacetime II, ed. Dennis Dieks. Amsterdam, The Netherlands: Elsevier, 2008.

Foster, J. "Competitive Selection, Self-Organization and Joseph A. Schumpeter." In Capitalism and Democracy in the $21^{\text {st }}$ Century: Proceedings of the International Joseph A. Schumpeter Society Conference, Vienna 1998 "Capitalism and Socialism in the 21 $1^{\text {st }}$ Century," eds. Dennis C. Mueller and Uwe Cantner, 317-334. Berlin, Germany: Springer-Verlag, 2001.

Foster, Roger S. Adorno and Philosophical Modernism: The Inside of Things. Lanham, MD: Lexington Books, 2016.

Fowler, Robert M. Let the Reader Understand: Reader-Response Criticism and the Gospel of Mark. Harrisburg, PA: Trinity Press International, 1996.

Fox, Karen C., and Aries Keck. Einstein A to Z. Hoboken, NJ: John Wiley \& Sons, 2004.

Fox, Matthew. A Spirituality Named Compassion: Uniting Mystical Awareness with Social Justice. Rochester, VT: Inner Traditions International, 1999.

Fox, Warwick. Toward a Transpersonal Ecology: Developing New Foundations for Environmentalism. Albany, NY: State University of New York Press, 1995.

Franchi, Stefano, and Güven Güzeldere. "Machinations of the Mind: Cybernetics and Artificial Intelligence from Automata to Cyborgs." In Mechanical Bodies, Computational Minds: Artificial Intelligence from Automata to Cyborgs, eds. Franchi and Güzeldere, 15-152. Cambridge, MA: Massachusetts Institute of Technology, 2005. 
Francis, (Jorge Mario Bergoglio-Pope). Evangelii Gaudium. Rome, Italy: Vatican Press, 2013.

Franck, Georg. "Mental Presence and the Temporal Present." In Brain and Being: At the Boundary Between Science, Philosophy, Language and Arts, eds. Gordon Globus, Karl H. Pribram, and Giuseppe Vitiello, 47-68. Amsterdam, The Netherlands: John Benjamins, 2004.

François, Jaran. "L'ontothéologie dans l'oeuvre de Martin Heidegger: Récit d'une confrontation avec la pensée Occidentale." In Philosophie 91 (2006): 37-62.

Frank, Adam. About Time: From Sun Dials to Quantum Clocks, How the Cosmos Shapes our Lives - and We Shape the Cosmos. London, UK: Oneworld Publications, 2012.

Frank, Walter M. Making Sense of the Constitution: A Primer on the Supreme Court and Its Struggle to Apply Our Fundamental Law. Carbondale, IL: Southern Illinois University Press, 2012.

Fraser, Brian John. The Study of Religion in British Columbia: A State-of-the-Art Review. Waterloo, Ontario: Wilfrid Laurier University Press, 1995.

Fraser, Julius Thomas. Time, Conflict, and Human Values. Chicago, IL: University of Illinois, 1999.

Fraser, J. T., et al., ed. Time, Science, and Society in China and the West: The Study of Time V. Amherst, MA: The University of Massachusetts Press, 1986.

Frede, Michael. A Free Will: Origins of the Notion in Ancient Thought, ed. A. A. Long. Berkeley, CA: University of California Press, 2011.

Freeman, Cameron. Post-metaphysics and the Paradoxical Teachings of Jesus: The Structure of the Real. New York, NY: Peter Lang, 2010.

Freire Jr, Olival. The Quantum Dissidents: Rebuilding the Foundations of Quantum Mechanics (19501990), with a foreword by Silvan S. Schweber. Dordrecht, The Netherlands: Springer, 2015.

French, David. "Beto's Constitutional Folly," in National Review (January 16, 2019). At https://www.nationalreview.com/2019/01/betos-constitutional-folly/ (accessed January 16, 2019).

Frey, Carl Benedikt, and Michael A. Osborne. "The Future of Employment: How Susceptible are Jobs to Computerisation?" At https://www.oxfordmartin.ox.ac.uk/downloads/academic/The_Future_of_Employment. pdf (accessed September 17, 2013).

Frey, Rebecca Joyce. Fundamentalism. New York, NY: Infobase Publishing, 2007.

Fried, Richard M. Nightmare in Red: The McCarthy Era in Perspective. New York, NY: Oxford University Press, 1990.

Frieden, B. R. Probability, Statistical Optics, and Data Testing: A Problem Solving Approach. New York, NY: Springer, 2001.

Friedman, Michael. Kant's Construction of Nature: A Reading of the Metaphysical Foundations of Natural Science. Cambridge, UK: Cambridge University Press, 2013. 
Frierson, Patrick R. Freedom and Anthropology in Kant's Moral Philosophy. Cambridge, UK: Cambridge University Press, 2003.

What is Human Being. New York, NY: Routledge, 2013.

Friesen, J. Glenn. "Current Reformational Philosophy and the '95 Theses on Herman Dooyeweerd."' 911 (2007). At https://jgfriesen.files.wordpress.com/2016/12/reformational.pdf (accessed September 29, 2018).

Frischmann, Brett, and Evan Selinger. Re-Engineering Humanity. Cambridge, UK: Cambridge University Press, 2018.

Froese, Katrin. Nietzsche, Heidegger, and Daoist Thought: Crossing Paths In-Between. Albany, NY: State University of New York, 2006.

Froman, Wayne J. "Hermeneutics in Economics: On the Status of 'As-If' Functions." In Humane Economics: Essays in Honor of Don Lavoie, ed. Jack High, 164-172. Cheltenham, UK: Edward Elgar, 2006.

Fronda, Earl Stanley B. Wittegenstein's (Misunderstood) Religious Thought. Boston, MA: Brill, 2010.

Froom, LeRoy Edwin. The Prophetic Faith of Our Fathers 4 Vols. Washington, D.C.: Review and Herald, 1950.

Fuchs, Wolfgang Walter. Phenomenology and the Metaphysics of Presence: An Essay in the Philosophy of Edmund Husserl. The Hague, The Netherlands: Martinus Nijhoff, 1976.

Fuller, Steve. Kuhn Vs. Popper: The Struggle for the Soul of Science. Chichester, West Sussex: Columbia University Press, 2004.

. The Sociology of Intellectual Life: The Career of the Mind in and Around the Academy. London, UK: SAGE Publications, 2009.

Fulmer, C. Ashley, Brandon Crosby, and Michele J. Gelfand. "Cross-cultural Perspectives on Time." In Time and Work: Vol. 2: How Time Impacts Groups, Organizations, and Methodological Choices, eds. Abbie J. Shipp and Yitzhak Fried, 53-75, New York, NY: Psychology Press, 2014.

Gallos, Erhard H. Katapausis and Sabbatismos in Hebrews 4. Andrews University, Berrien Springs, MI: Doctoral Dissertation, 2011.

Gamwell, Lynn. Mathematics and Art: A Cultural History. Princeton, NJ: Princeton University Press, 2016.

Gane, Nicholas, and David Beer, New Media: The Key Concepts. New York, NY: Berg Publishers, 2008.

Gane, Roy. Altar Call. Berrien Springs, MI: DIADEM, 1999.

. Cult and Character: Purification Offerings, Day of Atonement, and Theodicy. Winona Lake, IN: Eisenbrauns, 2005.

"Methodology for Interpretation of Daniel 11:2-12:3." In Journal of the Adventist Theological Society Vol. 27 \#1-2 (2016): 294-343. 
Who's Afraid of the Judgment?: The Good News about Christ's Work in the Heavenly Sanctuary. Nampa, ID: Pacific Press, 2006.

Gadamer, Hans-Georg. Reason in the Age of Science, tr. Frederick G. Lawrence. Cambridge, MA: The MIT Press, 1982.

Garcia, John David. The Ethical State: An Essay on Political Ethics. Wexford College Press, 2003.

Gardner, Martin. Did Adam and Eve Have Navels?: Debunking Pseudoscience. New York, NY: W. W. Norton \& Company, 2000.

Relativity Simply Explained, illustrated by Anthony Ravielli. Mineola, NY: Dover, 1997. The Whys of a Philosophical Scrivener. New York, NY: St. Martin's Press, 1999.

Gare, Arran. The Philosophical Foundations of Ecological Civilization: A Manifesto for the Future. New York, NY: Routledge, 2017.

Garnett, Robert F. Jr. "Rhetoric and Postmodernism in Economics." In The Elgar Companion to Economics and Philosophy, eds. John Bryan Davis, Alain Marciano, and Jochen Runde, 231-259. Glos, UK: Edward Elgar Publishing, 2004.

Garrett, Brian. What is this Thing Called Metaphysics? New York, NY: Routledge, 2006.

Garrison, Roger. "Foreword." In The Hayek-Keynes Debate: Lessons for Current Business Cycle Research, John P. Cochran and Fred R. Glahe, i-x. Lewiston, NY: Edwin Mellen, 1999.

Gasaway, Brantley W. Progressive Evangelicals and the Pursuit of Social Justice. Chapel Hill, NC: The University of North Carolina Press, 2014.

Gay, Peter. The Enlightenment: The Rise of Modern Paganism. New York NY: W. W. Norton \& Company, 1966.

Gay, Volney. Progress and Values in the Humanities: Comparing Culture and Science. New York, NY: Colombia University Press, 2010.

Gehl, Jennifer T., with Marc S. Micozzi. The Science of Planetary Signatures in Medicine: Restoring the Cosmic Foundations of Healing. New York, NY: Simon and Schuster, 2017.

Gehring, John. The Francis Effect: A Radical Pope's Challenge to the American Catholic Church. Lanham, MD: Rowman \& Littlefield, 2015.

Geisler, Norman, and Frank Turek. Legislating Morality: Is it Wise? Is it Legal? Is it Possible? Eugene, OR: Wipf \& Stock, 1998.

Geldard, Richard G. Remembering Heraclitus. England: Lindisfarne Books, 2000.

Gelles, David. “Sundar Pichai of Google: 'Technology Doesn't Solve Humanity's Problems.'” At https://www.nytimes.com/2018/11/08/business/sundar-pichai-google-corner-office.html? (accessed November 8, 2018). 
Gelli, Frank Julian. "Mystery and Plural Faiths: Religious Diversity as Expression of the Quest for a Deus Absconditus." In Islam and Global Dialogue: Religious Pluralism and the Pursuit of Peace, ed. Roger Boase, 227-243. Burlington, VT: Ashgate, 2010.

Gell-Mann, Murray. The Quark and the Jaguar: Adventures in the Simple and the Complex. New York, NY: Henry Holt and Company, 1994.

Gelpi, Donald L. The Gracing of Human Experience: Rethinking the Relationship between Nature and Grace. Eugene, OR: Wipf \& Stock, 2007.

Geoghegan, Vincent. Socialism and Religion: Roads to Common Wealth. New York, NY: Routledge, 2011.

George, Vensus A. The Experience of Being as Goal of Human Existence: The Heideggerian Approach. Washington D. C.: Council for Research in Values and Philosophy, 2000.

Gerbode, Frank A., and John Durkin. Beyond Psychology: An Introduction to Metapsychology. Loving Healing Press, 2013.

Gerges, Fawaz A. ISIS: A History. Princeton, NJ: Princeton University Press, 2016.

Germain, Gil. Thinking About Technology: How the Technological Mind Misreads Reality. Lanham, MD: Lexington Books, 2017.

Geroulanos, Stefanos. An Atheism That Is Not Humanist Emerges in French Thought. Stanford, CA: Stanford University Press, 2010.

Ghannam, Talal. The Mystery of Numbers: Revealed Through their Digital Root. Charleston, SC: CreateSpace, 2011.

Ghattas, Kim. "How the Muslim World Lost the Freedom to Choose." In Foreign Policy (Oct. 10, 2017). At http://foreignpolicy.com/2017/10/20/how-the-muslim-world-lost-the-freedom-to-choose/ (accessed October 25, 2017).

Gibbs, Paul. Heidegger's Contribution to the Understanding of Work-Based Studies. New York, NY: Springer, 2011.

Giberson, Karl. "Scientific Fundamentalism and Its Cultural Impact." At https://biologos.org/ uploads/projects/Giberson_white_paper.pdf (accessed January 28, 2019).

Giese, Albrecht. "A Particle Model Explaining Mass and Relativity in a Physical Way," in Unified Field Mechanics: Natural Science Beyond the Veil of Spacetime, eds. Richard L. Amoroso, Louis H. Kauffman, and Peter Rowlands, 131-142. Toh Tuck Link, Singapore: World Scientific Publishing, 2016.

Gieser, Suzanne. The Innermost Kernel: Depth Psychology and Quantum Physics: Wolfgang Pauli's Dialogue with C. G. Jung. Berlin, Germany: Springer, 2005.

Giest, Sarah, Michael Howlett, and Ishani Mukherjee. "The Relevance of the Academic Study of Public Policy." In The Relevance of Political Science, ed. Gerry Stoker, B. Guy Peters, and John Pierre, 121-135. London, UK: Palgrave, 2015.

Gilbert, Scott F. "Evolutionary Developmental Biology and Intelligent Design.” In Biological Evolution: Facts and Theories: A Critical Appraisal 150 Years After 'The Origin of Species', eds. Gennaro Auletta, Marc Leclerc, and Rafael A. Martínez, 691-700. Roma: Gregorian \& Biblical Press, 2011. 
Gilder, George. Microcosm: The Quantum Revolution in Economics and Technology. New York, NY: Touchstone, 1990.

Gilder, Louisa. The Age of Entanglement: When Quantum Physics was Reborn. New York, NY: Alfred A. Knopf, 2008.

Gilead, Amihud. Necessity and Truthful Fictions: Panenmentalist Observations. New York, NY: Rodopi, 2009.

Gilkey, Langdon B. "Cosmology, Ontology, and the Travail of Biblical Language." In The Journal of Religion Vol. 41 No. 3 (July, 1961): 196-203.

Gill, Sam. Dancing Culture Religion. Lanham, MD: Lexington Books, 2012.

Gimbel, Steven. Einstein's Jewish Science: Physics at the Intersection of Politics and Religion. Baltimore, MD: The Johns Hopkins University Press, 2012.

Gisin, Nicolas, with a foreword by Alain Aspect. Quantum Chance: Nonlocality, Teleportation and Other Quantum Marvels. Geneve, Switzerland: Springer, 2014.

Glass, Newman Robert. Working Emptiness: Toward a Third Reading of Emptiness in Buddhism and Postmodern Thought. Atlanta, GA: Scholars Press, 1995.

Glazebrook, Trish, and Matt Story. "Heidegger and International Development." In Heidegger in the Twenty-First Century, ed. Tziovanis Georgakis and Paul J. Ennis, 121-140. New York, NY: Springer, 2015.

Glazebrook, Trish. Heidegger's Philosophy of Science. New York, NY: Fordham University Press, 2000. .Zeno Against Mathematical Physics." In Journal of the History of Ideas Vol. 62 No. 2 (April, 2001): 193-210.

Gleiser, Marcelo. "We Have Pushed Physics Too Far." At http://cosmos.nautil.us/short/90/we-have-pushed-physics-too-far> (accessed January 7, 2017).

Globus, Gordon G. Quantum Closures and Disclosures: Thinking-Together Postphenomenology. Amsterdam, The Netherlands: John Benjamins Publishing, 2003. The Postmodern Brain. Amsterdam, The Netherlands: John Benjamins Publishing, 1995.

The Transparent Becoming of World: A Crossing Between Process Philosophy and Quantum Neurophilosophy.Amsterdam, The Netherlands: John Benjamins, 2009.

Glock, Hans-Johann. What is Analytic Philosophy? Cambridge, UK: Cambridge University Press, 2008.

Glum, Julia. "Election 2020: Poll Shows Joe Biden and Bernie Sanders Would Beat Donald Trump," in Newsweek. At http://www.newsweek.com/bernie-sanders-joe-biden-trump-reelection-poll-638432 (Accessed July 18, 2017).

Godwin, Joscelyn. The Golden Thread: The Ageless Wisdom of the Western Mystery Traditions. Wheaton, IL: Theosophical Publishing House, 2007. 
Goertzel, Ben. The Hidden Pattern: A Patternist Philosophy of Mind. Boca Raton, FL: BrownWalker Press, 2006.

Goetz, Stewart. Freedom, Teleology, and Evil. New York, NY: T\&T Clark, 2008.

Goldberg, Jonah. Liberal Fascism: The Secret History of the American Left, From Mussolini to the Politics of Change. New York, NY: Random House, 2007.

"Sorry, I Still Won't Ever Vote for Trump." At

http://www.nationalreview.com/article/435686/donald-trump-republican-nomination-I-stillwont-vote-him (accessed May 21, 2016).

Suicide of the West: How the Rebirth of Tribalism, Populism, Nationalism, and Identity Politics is Destroying American Democracy. Danvers, MA: Crown Forum, 2018.

“The Center Does Not Hold" (August 17, 2018). In National Review, At

https://www.nationalreview.com/2018/08/trump-and-obama-ignore-political-center-amp-upbase/ (accessed August 17, 2018).

Goldfajn, Tal. Word Order and Time in Biblical Hebrew Narrative. Oxford, UK: Clarendon Press, 1998.

Goldford, Dennis J. The American Constitution and the Debate Over Originalism. Cambridge, UK: Cambridge University Press, 2005.

Goldie, Matthew Boyd. The Idea of the Antipodes: Place, People, and Voices. New York, NY: Routledge, 2010.

Goldsmith, Donald, and Marcia Bartusiak, eds. E = Einstein: His Life, His Thought, and His Influence on Our Culture. New York, NY: Sterling Publishing Co., 2006.

Goli, Farzad. "Medical Practice in/with the Semiosphere." In Biosemiotic Medicine: Healing in the World of Meaning, ed. Farzad Goli, 217-240. New York, NY: Springer, 2016.

Gomel, Elana. Postmodern Science Fiction and Temporal Imagination. New York, NY: Continuum, 2010.

Gopalan, K. "Challenges of Higher Education in Science and Technology." In Education in India, Vol. 2, ed. Shubha Tiwari, 6-16. New Delhi, India: Atlantic Publishers, 2006.

Gordon, Greg. "Fake, Misleading Social Media Posts Exploding Globally, Oxford Study Finds.” At https://www.mcclatchydc.com/news/nation-world/national/national-security/article2151889 10.html (accessed July 19, 2018).

Goswami, Amit, Richard E. Reed, and Maggie Goswami. The Self-Aware Universe: How Consciousness Creates the Material World. New York, NY: Penguin Putnam, 1995.

Gott III, J. Richard. Time Travel in Einstein's Universe: The Physical Possibilities of Travel Through Time. New York, NY: Houghton Mifflin, 2002.

Gouesbet, Gérard. "From Theories by Lorenz and Mie to Ontological Underdetermination of Theories by Experiments." In The Mie Theory: Basics and Applications, eds. Wolfram Hergert and Thomas Wriedt, 73-97. New York, NY: Springer, 2012. 
Gouesbet, Gérard, with Jean Bricmont, Hidden Worlds in Quantum Physics. Mineola, NY: Dover Publications, 2013.

Gould, Lewis L. Grand Old Party: A History of the Republicans. Oxford, UK: Oxford University Press, 2003.

Gould, Peter. "Allowing, Forbidding, but not Requiring: A Mathematic for a Human World." In Complexity, Language, and Life: Mathematical Approaches, eds. John L. Casti and Anders Karlqvist, 1-20. Berlin, Germany: Springer-Verlag, 1986.

Gould, Stephen Jay. Rocks of Ages: Science and Religion in the Fullness of Life. New York, NY: Ballantine Publishing Group, 1999.

The Hedgehog, the Fox, and the Magister's Pox: Mending the Gap between Science and the Humanities. New York, NY: Harmony Books, 2003.

Gowers, Timothy, June Barrow-Green, and Imre Leader, eds. The Princeton Companion to Mathematics. Princeton, NJ: Princeton University Press, 2008.

Grafio, Sai. Mysteries: Ancient and Modern. New Delhi: Sterling Publishers, 1999.

Graham, Elaine. "Manifestations of the Posthuman in the Postsecular Imagination." In Perfecting Human Futures: Transhuman Visions and Technological Imaginations, eds., J. Benjamin Hurlbut, and Hava Tirosh-Samuelson, 51-72. New York, NY: Springer VS, 2016.

Graham, Loren, and Jean-Michel Kantor, Naming Infinity: A True Story of Religious Mysticism and Mathematical Creativity. Belknap Press, 2009.

Grandy, David A. The Speed of Light: Constancy + Cosmos. Bloomington, IN: Indiana University Press, 2009.

Grant, Edward. A History of Natural Philosophy: From the Ancient World to the Nineteenth Century. Cambridge, UK: Cambridge University Press, 2007.

Granville, William Anthony. The Fourth Dimension and the Bible. Boston, MA: The Gorham Press, 1922.

Grace, André P., and Tonette S. Rocco. Challenging the Professionalization of Adult Education: John Ohliger and Contradictions in Modern Practice. San Francisco, CA: Jossey-Bass, 2009.

Gracia, Jorge J. E. Metaphysics and Its Task: The Search for the Categorial Foundation of Knowledge. Albany, NY: State University of New York Press, 1999.

Graf, Fritz. Greek Mythology: An Introduction, tr. Thomas Marier. Baltimore, MD: The Johns Hopkins University Press, 1996.

Grasso, Kenneth L., and Robert P. Hunt. "Introduction." In Catholicism and Religious Freedom: Contemporary Reflections on Vatican II's Declaration on Religious Liberty, eds. Kenneth L. Grasso and Robert P. Hunt, ix-xxxiii. Lanham, MD: Rowman \& Littlefield, 2006.

Graybill, Gregory B. Evangelical Free Will: Philipp Melanchthon's Doctrinal Journey on the Origins of Faith. Oxford, UK: Oxford University Press, 2010.

Greaves, Tom. Starting with Heidegger. New York, NY: Continuum, 2010. 
Greca, M., and Olival Freire. "Meeting the Challenge: Quantum Physics in Introductory Physics Courses." In International Handbook of Research in History, Philosophy and Science Teaching, ed. Michael R. Matthews, 183-210. New York, NY: Springer, 2014.

Green, Emma. "Bernie Sanders's Religious Test for Christians in Public Office." At https://www.theatlantic.com/politics/archive/2017/06/bernie-sanders-chris-van-hollen-russ ell-vought/529614/ (accessed June 8, 2017).

Greene, Abner S. Against Obligation: The Multiple Sources of Authority in a Liberal Democracy. Cambridge, MA: Harvard University Press, 2012.

Greenberg, Gary. The Book of Woe: The DSM and the Unmaking of Psychiatry. New York, NY: Penguin Group, 2013.

Greenfield, Adam. Radical Technologies: The Design of Everyday Life. Brooklyn, NY: Verso, 2018.

Greer, John Michael. Dark Age America: Climate Change, Cultural Collapse, and the Hard Future Ahead. Gabriola Island, BC: New Society Publishers, 2016.

Greer, Robert C. Mapping Postmodernism: A Survey of Christian Options. Downers Grove, IL: InterVarsity Press, 2003.

Greggo, Stephen P., and Timothy A. Sisemore, eds. Counseling and Christianity: Five Approaches. Downers Grove, IL: InterVarsity Press, 2012.

Greggs, Tom. "The Order and Movement of Eternity: Karl Barth on the Eternity of God and Creaturely Time." In Eternal God, Eternal Life: Theological Investigations into the Concept of Immortality, ed. Philip G. Ziegler, 1-24. New York, NY: T\&T Clark, 2016.

Greig, Ian. "Quantum Romanticism: The Aesthetics of the Sublime in David Bohm's Philosophy of Physics." In Beyond the Finite: The Sublime in Art and Science, eds. Roald Hoffmann and Iain Boyd Whyte, 106-127. Oxford, UK: Oxford University Press, 2011.

Grenz, Stanley J. The Millennial Maze: Sorting Out Evangelical Options. Downers Grove, IL: IVP Press, 1992.

The Named God and the Question of Being: A Trinitarian Theo-Ontology. Louisville, KY:

Westminster John Knox Press, 2005.

Grey, Thomas C. “The Constitution as Scripture.” In the Stanford Law Review 37 (1984): 1-14.

Gribbin, John. In Search of the Multiverse: Parallel Worlds, Hidden Dimensions, and the Ultimate Quest for the Frontiers of Reality. London, UK: Penguin Books, 2009.

Griffin, David Ray. God and Religion in the Postmodern World: Essays in Postmodern Theology. Albany, NY: State University of New York Press, 1989.

"Introduction." In Physics and the Ultimate Significance of Time: Bohm, Prigogine, and Process Philosophy, ed. David Ray Griffin, 1-50. New York, NY: State University of New York Press, 1986.

Religion and Scientific Naturalism: Overcoming the Conflicts. Albany, NY: State University of New York Press, 2000. 
Griffin, Stephen M. American Constitutionalism: From Theory to Politics. Princeton, NJ: Princeton University Press, 1996.

Grigenti, Fabio. Existence and Machine: The German Philosophy in the Age of Madness (1870-1960). New York, NY: Springer, 2016.

Grigolini, Paolo. Quantum Mechanical Irreversibility and Measurement. Singapore: World Scientific Publishing, 1993.

Gritsch, Eric W., and Robert W. Jenson, Lutheranism: The Theological Movement and Its Confessional Writings. Philadelphia, PA: Fortress Press, 1976.

Grondin, Jean. Introduction to Metaphysics: From Parmenides to Levinas. New York, NY: Columbia University Press, 2012. . Sources of Hermeneutics. Albany, NY: State University of New York Press, 1995.

Grudem, Wayne. Politics According to the Bible: A Comprehensive Resource for Understanding Modern Political Issues in Light of Scripture. Grand Rapids, MI: Zondervan, 2010.

Grunfeld, Isidor. The Sabbath: A Guide to Its Understanding and Observance 4th ed. Jerusalem, Israel: Feldheim Publishers, 2003.

Grzybek, Peter. "On the Science of Language In Light of the Language of Science." In Contributions to the Science of Text and Language: Word Length Studies and Related Issues, ed. Peter Grzybek, 115. Dordrecht, The Netherlands: Springer, 2007.

Guerlac, Suzanne. Thinking in Time: An Introduction to Henri Bergson. Ithaca, NY: Cornell University Press, 2006.

Gunton, Colin E. Revelation and Reason: Prolegomena to Systematic Theology, ed. P. H. Brazier. New York, NY: T\&T Clark, 2008.

The Promise of Trinitarian Theology 2nd ed. New York, NY: T\&T Clark, 1997.

Gupta, Hemant. Joy From Deep Within: True Nature of Your Quantum Self. Bloomington, IN: Xlibris, 2010.

Gushee, David P. The Future of Faith in American Politics: The Public Witness of the Evangelical Center. Waco, TX: Baylor University Press, 2008.

Gutenson, Charles E., with Jim Wallis. Christians and the Common Good: How Faith Intersects with Public Life. Grand Rapids, MI: Brazos Press, 2011.

Guthrie, Richard L. The Rapture: From the Ground Up-A Detailed Study on the Rapture of the Church. Bloomington, IN: WestBow Press, 2014.

Guthrie, Kathy L., and Kathleen Callahan. "Liberal Arts: Leadership Education in the $21^{\text {st }}$ Century." In Reclaiming Higher Education's Purpose in Leadership Development, eds. Kathy L. Guthrie and Laura Osteen, 21-34. San Francisco, CA: Jossey-Bass, 2016.

Guthrie, William K. C. A History of Greek Philosophy: Vol. 1: The Earlier Presocratics and the Pythagoreans. Cambridge, UK: Cambridge University Press, 2000. 
Gutierrez, Cathy. Plato's Ghost: Spiritualism in the American Renaissance. Oxford, UK: Oxford University Press, 2009.

Guy, Fritz. Thinking Theologically: Adventist Christianity and the Interpretation of Faith. Berrien Springs, MI: Andrews University Press, 1999.

Haan, Peter de. From Keynes to Piketty: The Century that Shook Up Economics. London, UK: Palgrave, 2016.

Haaparanta, Leila. "Finnish Studies in Phenomenology and Phenomenological Studies in Finland: Interfaces of Analytic Philosophy and Phenomenology." In Analytic Philosophy in Finland, ed. Leila Haaparanta and Ilkka Niiniluoto, 491-510. Amsterdam, The Netherlands: Rodopi, 2003.

Haas, Andrew. The Irony of Heidegger. New York, NY: Continuum, 2007.

Hack, Roy Kenneth. God in Greek Philosophy to the Time of Socrates. London, UK: Humphrey Milford, 1931.

Hackney Jr., James R. Under Cover of Science: American Legal-Economic Theory and the Quest for Objectivity. London, UK: Duke University Press, 2007.

Hadro, Matt. "How a 'Culture of Distraction' is Keeping Millennials from Marrying." At http://www.catholicnewsagency.com/news/how-a-culture-of-distraction-is-keeping-millennial s-from-marrying-28537/ (accessed September 10, 2017).

Hage, Stephen J. Let There Be Light: Physics, Philosophy \& The Dimensional Structure of Consciousness. USA: Algora, 2013.

Hague, Douglas. “The Fourth Industrial Revolution.” In New Scientist 26 (April 1984): 31-37.

Haidt, Jonathan. The Righteous Mind: Why Good People are Divided by Politics and Religion. New York, NY: Vintage Books, 2013.

Haight, David F., and Marjorie A. Haight, The Scandal of Reason: Or Shadow of God. Lanham, MD: University Press of America, 2004.

Hakken, David. The Knowledge Landscapes of Cyberspace. New York, NY: Routledge, 2003.

Halbrook, Steve C. God is Just: A Defense of the Old Testament Civil Laws: Biblical Theocracy, Justice, and Slavery versus Humanistic Theocracy, 'Justice,' and Slavery $2^{\text {nd }}$ ed. Theonomy Resources Media, 2014.

Haldane, J. B. S. The Marxist Philosophy and the Sciences. New York, NY: Routledge, 2016; 1938.

Hall, Dennis R., and Susan Grove Hall, ed. American Icons: An Encyclopedia of the People, Places, and Things that have Shaped Our Culture. Westport, CT: Greenwood Press, 2006.

Hall, Edward T. The Dance of Life: The Other Dimension of Time. New York, NY: Anchor Books, 1983.

Hall, Everett W. "Of What Use Are Whitehead's Eternal Objects?" In Alfred North Whitehead: Essays on His Philosophy, ed. George L. Kline, 101-116. Lanham, MD: University Press of America, 1989. 
Halliwell, Martin. Therapeutic Revolutions: Medicine, Psychiatry, and American Culture, 1945-1970. London, UK: Rutgers University Press, 2013.

Halpern, Jodi. From Detached Concern to Empathy: Humanizing Medical Practice. Oxford, UK: Oxford University Press, 2001.

Ham, Ken. Six Days: The Age of the Earth and the Decline of the Church. Green Forest, AR: Master Books, 2013.

Ham, Ken, and Bodie Hodge, $A$ Flood of Evidence: 40 Reasons Noah and the Ark Still Matter. Green Forest, AR: Master Books, 2016.

Hamid, Shadi. Islamic Exceptionalism: How the Struggle Over Islam is Reshaping the World. New York, NY: St. Martin's Press, 2016.

Hammond, Mason. City-state and World State in Greek and Roman Political Theory Until Augustus. Biblo and Tannen, 1966.

Hanby, Michael. "Beyond Mechanism: The Cosmological Significance of David L. Schindler's Communio Ontology." In Being Holy in the World: Theology and Culture in the Thought of David L. Schindler, eds. Nicholas J. Healy, Jr., and David C. Schindler, 162-192. Grand Rapids, MI: Eerdmans, 2011.

"The Gospel of Creation and the Technocratic Paradigm: Reflections on a Central Teaching of Laudato Si." In Communio 42 (Winter 2015): 724-747.

Hancock, Stephen. The Romantic Sublime and Middle-Class Subjectivity. New York, NY: Routledge, 2005.

Handa, Jagdish. A Reformulation of Keynesian Economics. Toh Tuck Link, Singapore: World Scientific Publishing, 2015.

Handelman, Don. One God, Two Goddesses, Three Studies of South Indian Cosmology. Leiden, The Netherlands: Brill, 2014.

Hanegraaff, Wouter J. New Age Religion and Western Culture: Esotericism in the Mirror of Secular Thought. Albany, NY: State University of New York Press, 1998.

Haney II, William S. Globalization and the Posthuman. Newcastle upon Tyne, UK: Cambridge Scholars Press, 2009.

Hanna, Martin F. "Science and Theology: Focusing the Complementary Lights of Jesus, Scripture and Nature," in Journal of the Adventist Theological Society Vol. 6 \#2 (Fall 1995): 6-51.

The Cosmic Christ of Scripture: How to Read God's Three Books-Comparing Biblical Perspectives with the Writings of Ellen White. Berrien Springs, MI: Andrews University Lithotech, 2006.

. "The Servant-Master Roles of the Laws of Christ, of Scripture, and of Nature," in Journal of the Adventist Theological Society Vol. 9 \#1-2 (1998): 278-309.

Hansen, Niels Viggo. "Spacetime and Becoming: Overcoming the Contradiction Between Special Relativity and the Passage of Time." In Physics and Whitehead: Quantum, Process, and Experience, eds. Timothy E. Eastman and Hank Keeton, 136-163. Albany, NY: State University of New York Press, 2003. 
Harari, Yuval Noah. Homo Deus: A Brief History of Tomorrow. London, UK: Harvill Secker, 2016.

Harcum, E. Rae. Applied Psychology for Servant Religion: A Religious Behavioral Science Promotes Personal and Social Welfare. New York, NY: Hamilton Books, 2014.

Hardin, Garrett. Living within Limits: Ecology, Economics, and Population Taboos. Oxford, UK: Oxford University Press, 1993.

Harding, Sandra. "Human Well-being and Federal Science-What's the Connection?" In Science, Technology \& Democracy, ed. Daniel Lee Kleinman, 121-138. Albany, NY: State University of New York Press, 2000.

Harman, Graham. Guerrilla Metaphysics: Phenomenology and the Carpentry of Things. Peru, IL: Open Court Publishing, 2005.

Harris, Paul A. “Time.” In Encyclopedia of Literature and Science, ed. Pamela Gossin, 469. Westport, CT: Greenwood Publishing Group, 2002.

Harris, R. Baine, ed. Neoplatonism and Contemporary Thought: Part One. Albany, NY: State University of New York Press, 2002.

Harris, Sam. Free Will. New York, NY: Free Press, 2012.

Letter to a Christian Nation. New York, NY: Vintage Books, 2008.

The End of Faith: Religion, Terror, and the Future of Reason. London, UK: W. W. Norton \& Company Ltd, 2005.

The Moral Landscape: How Science Can Determine Human Values. New York, NY: Free Press, 2010.

Harrison, Peter. "Is Science-Religion Conflict Always a Bad Thing? Some Augustinian Considerations." At https://biologos.org/blogs/archive/is-science-religion-conflict-always-a-bad-thing-some-augus tinian-considerations (accessed March 16, 2015).

The Bible, Protestantism, and the Rise of Natural Science. Cambridge, UK: Cambridge University Press, 1998.

The Territories of Science and Religion. Chicago, IL: The University of Chicago Press, 2015.

Hart, Michael. Hubris: The Troubling Science, Economics, and Politics of Climate Change. Ottawa, Canada: Compleat Desktops Publishing, 2015.

Hasel, Gerhard. “The 'Days' of Creation in Genesis 1: Literal 'Days' or Figurative 'Periods/Epochs' of Time?" Origins 21 (1994): 5-38.

Hasker, William. God, Time, and Knowledge. Ithaca, NY: Cornell University, 1989.

Hassey, Janette. No Time For Silence. CBE, 1986.

Hastings, Stephen L. Whole-Earth Ethics for Holy Ground: The Development and Practice of 'Sacramental' Creation Spirituality. Lanham, MD: Lexington Books, 2017. 
Hathaway, Ronald F. Hierarchy and the Definition of Order in the Letters of Pseudo-Dionysius: A Study in the Form and Meaning of the Pseudo-Dionysian Writings. The Hague, The Netherlands: Martinus Nijhoff, 1969.

Haught, John F. Science and Faith: A New Introduction. Mahwah, NJ: Paulist Press, 2012. Science and Religion: From Conflict to Conversation. Mahwah, NJ: Paulist Press, 1995.

Haven, Emmanuel, and Andrei Khrennikov. Quantum Social Science. Cambridge, UK: Cambridge University Press, 2013.

Hawking, Stephen. A Brief History of Time, upd. 10 ${ }^{\text {th }}$ anniversary ed. New York, NY: Bantam, 1998.

Hawkins, Peter S. Getting Nowhere: Christian Hope \& Utopian Dream. Eugene, OR: Wipf and Stock, 1985.

Hawley, George. Right-Wing Critics of American Conservatism. Lawrence, KS: University of Kansas Press, 2016.

Hayashi, Stuart K. The Freedom of Peaceful Action: On the Origin of Individual Rights. Lanham, MD: Lexington Books, 2014.

Hayek, Friedrich August. A Free-Market Monetary System. Auburn, AL: Ludwig von Mises Institute, 2008, 1974.

Haynes, Patrice. Immanent Transcendence: Reconfiguring Materialism in Continental Philosophy. New York, NY: Bloomsbury Academic, 2012.

Hazlitt, Henry. The Failure of the "New Economics": An Analysis of the Keynesian Fallacies. Whitefish, MT: Kessinger Publishing, 2010.

Heffner, Dennis Knight. Unlimited Progress: The Grand Delusion of the Modern World. Bloomington, IN: iUniverse, 2010.

Hegel, Georg Wilhelm Friedrich. The Science of Logic, tr. George Di Giovanni. Cambridge University Press, 2010.

Heidegger, Martin. Basic Concepts, tr. Gary E. Aylesworth. Bloomington, IN: Indiana University Press, 1993.

Basic Questions of Philosophy: Selected "Problems" of "Logic", tr. Richard Rojcewicz and André Schuwer. Bloomington, IN: Indiana University Press, 1994.

Being and Time, tr. Joan Stambaugh with Dennis J. Schmidt. Albany, NY: State University of New York Press, 2010.

. Being and Truth, tr. Gregory Fried and Richard Polt. Bloomington, IN: Indiana University Press, 2010.

Contributions to Philosophy (of the Event), tr. Richard Rojcewicz and Daniela Vallega-Neu. Bloomington, IN: Indiana University Press, 2012. 
. Four Seminars, tr. Andrew Mitchell and François Raffoul. Bloomington, IN: Indiana University Press, 2003.

. Identity and Difference, tr. Joan Stambaugh. University of Chicago Press, 2002.

Introduction to Metaphysics, tr. Gregory Fried and Richard Polt. New Haven, CT: Yale University Press, 2000.

. Introduction to Philosophy-Thinking and Poetizing, tr. Phillip Jacques Braunstein. Bloomington, IN: Indiana University Press, 2011.

Introduction to Phenomenological Research, tr. Daniel O. Dahlstrom. Bloomington, IN: Indiana University Press, 2005.

"Introduction to 'What is Metaphysics?'," tr. Walter Kaufmann. In Martin Heidegger,

Pathmarks, ed. William McNeill, 277-290. Cambridge, UK: Cambridge University Press, 1998.

. Kant and the Problem of Metaphysics 5th edition, tr. Richard Taft. Bloomington, IN: Indiana

University Press, 1997.

"Kant's Thesis about Being," tr. Ted E. Klein, Jr. and William E. Pohl, in Pathmarks, ed. William McNeill, 337-364. Cambridge, UK: Cambridge University Press, 1998.

"Letter on 'Humanism,'” tr. Frank A. Capuzzi, in Pathmarks, ed. William McNeill, 239-276.

Cambridge, UK: Cambridge University Press, 1998.

Logic as the Question Concerning the Essence of Language. Albany, NY: State University of New York Press, 2009.

Logic: The Question of Truth, tr. Thomas Sheehan. Bloomington, IN: Indiana University Press, 2010.

Mindfulness, tr. Parvis Emad and Thomas Kalary. New York, NY: Continuum, 2006.

Nietzsche Vols. 3 \& 4, ed. David Farrell Krell. San Francisco, CA: Harper \& Row, 1991.

"On the Essence of Trutn," tr. John Sallis, In Martin Heidegger, Pathmarks, ed. William McNeill, 136-154. Cambridge, UK: Cambridge University Press, 1998.

. "On the Question of Being," tr. William McNeill. In Martin Heidegger, Pathmarks, ed. William

McNeill, 291-322. Cambridge, UK: Cambridge University Press, 1998.

On Time and Being, tr. Joan Stambaugh. Chicago, IL: The University of Chicago Press, 2002.

Ontology-The Hermeneutics of Facticity, tr. John van Buren. Bloomington, IN: Indiana University Press, 1999.

Parmenides, tr. André Schuwer and Richard Rojcewicz. Bloomington, IN: Indiana University Press, 1998.

Phenomenological Interpretation of Kant's Critique of Pure Reason, tr. Parvis Emad and Kenneth Maly. Bloomington, IN: Indiana University Press, 1997. 
. Phenomenological Interpretations of Aristotle, tr. Richard Rojcewicz. Bloomington, IN: Indiana University Press, 2001.

. "Phenomenology and Theology," tr. James G. Hart and John C. Maraldo. In Martin Heidegger, Pathmarks, ed. William McNeill, 39-62. Cambridge, UK: Cambridge University Press, 1998.

Ponderings: II-VI, tr. Richard Rojcewicz. Bloomington, IN: Indiana University Press, 2016.

. Schelling's Treatise on the Essence of Human Freedom, tr. Joan Stambaugh. Athens, OH: Ohio University Press, 1985.

The Basic Problems of Phenomenology, tr. Albert Hofstadter. Bloomington, IN: Indiana University Press, 1982.

. The Beginning of Western Philosophy: Interpretation of Anaximander and Parmenides, tr. Richard Rojcewicz. Bloomington, IN: Indiana University Press, 2015.

. The End of Philosophy, tr. Joan Stambaugh. Chicago, IL: University of Chicago Press, 1973.

The Essence of Human Freedom, tr. Ted Sadler. New York, NY: Continuum, 2002.

The Event, tr. Richard Rojcewicz. Bloomington, IN: Indiana University Press, 2013.

. The Fundamental Concepts of Metaphysics: World, Finitude, Solitude, tr. William McNeill and Nicholas Walker. Bloomington, IN: Indiana University Press, 1995.

The History of Beyng, tr. Jeffrey Powell and William McNeill. Bloomington, IN: Indiana University Press, 2015.

. The Metaphysical Foundations of Logic, tr. Michael Heim. Bloomington, IN: Indiana University Press, 1984.

. The Phenomenology of Religious Life, tr. Matthias Fritsch and Jennifer Anna Gosetti-Ferencei. Bloomington, IN: Indiana University Press, 2004.

The Principle of Reason, tr. Reginald Lilly. Bloomington, IN: Indiana University Press, 1991.

"The Question Concerning Technology," tr. William Lovitt, with David Farrell Krell, in Martin Heidegger, Basic Writings, ed. David Krell, 307-342. New York, NY: HarperCollins, 1993.

The Question Concerning Technology and Other Essays, tr. William Lovitt. New York, NY: Harper \& Row, 1977.

Towards the Definition of Philosophy, tr. Ted Sadler. New York, NY: Continuum Press, 2002.

What is a Thing?, tr. W. B. Barton, Jr., and Vera Deutsch. Chicago, IL: Henry Regnery, 1967.

What is Called Thinking?, tr. Fred D. Wieck and J. Glenn Gray. New York, NY: Harper \& Row, 1968.

.Wilhem Dilthey's Research and the Struggle for a Historical Worldview," tr. Charles Bambach. In Supplements: From the Earliest Essays to Being and Time and Beyond, ed. John van Buren, 147-176. Albany, NY: State University of New York Press, 2002. 
. Zollikon Seminars: Protocols-Conversations-Letters, ed. Medard Boss, with tr., Franz Mayr and Richard Askay. Evanston, IL: Northwestern University Press, 2001.

Heidegger, Martin, and Eugen Fink. Heraclitus Seminar, tr. Charles H. Seibert. Evanston, IL: Northwestern University Press, 1993.

Heidegger, Martin, with Theodore J. Kisiel and Thomas Sheehan. Becoming Heidegger: On the Trail of His Early Occasional Writings, 1910-1927. Evanston, IL: Northwestern University Press, 2007.

Heikkilä, Martta. At the Limits of Presentation: Coming-into-Presence and its Aesthetic Relevance in Jean-Luc Nancy's Philosophy. Frankfurt am Main, Germany: Peter Lang, 2008.

Heine, Steven. Existential and Ontological Dimensions of Time in Heidegger and Dōgen. Albany, NY: State University of New York Press, 1985.

Helm, Paul. John Calvin's Ideas. Oxford, UK: Oxford University Press, 2004.

Hempstead, Colin, and William Worthington. "Technology and Ethics." In Enc yclopedia of 20th-Century Technology Vol. 2, eds. C. Hempstead and W. Worthington, 785. New York, NY: Routledge, 2004.

Hendershott, Anne. "Taking the Catholic Out of Catholic Universities." At https://www.city-journal.org/html/taking-catholic-out-catholic-universities-15495.html (accessed November 27, 2017).

Hendricks, Jared. Quantum Physics $2^{\text {nd }}$ ed. Morrisville, NC: Lulu Press, 2015.

Hendrix, Howard V. "Fighting Out of Context: Culture Wars Within and Without Science Fiction, from Snow to Sokal." In Science Fiction and the Two Cultures: Essays on Bridging the Gap Between the Sciences and the Humanities, eds. Gary Westfahl and George Edgar Slusser, 37-48. Jefferson, NC: McFarland \& Company, 2009.

Henle, Robert J. "Science and the Humanities." In Philosophy and Science as Modes of Knowing: Selected Essays, eds. Alden L. Fisher and George B. Murray, 1-21. New York, NY: Appleton-Century-Crofts, 1969.

Henriques, Gregg. A New Unified Theory of Psychology. London, UK: Springer, 2011.

Henry, Carl F. H. God, Revelation and Authority 6 Vols. Grand Rapids, MI: Crossway Books, 1999.

Henry, David Paul. The Early Development of the Hermeneutic of Karl Barth as Evidenced by His Appropriation of Romans 5:12-21. Mercer University Press, 1985.

Herbrechter, Stefan. Posthumanism: A Critical Analysis. New York, NY: Bloomsbury Academic, 2013.

Hergenhahn, B. R. An Introduction to the History of Psychology. Belmont, CA: Wadsworth, 2009.

Hergenhahn, B. R., and Tracy Henley. An Introduction to the History of Psychology, $7^{\text {th }}$ ed. Belmont, CA: Wadsworth, 2014.

Hersh, Reuben. What is Mathematics, Really? Oxford, UK: Oxford University Press, 1997. 
Heschel, Abraham Joshua. The Sabbath: Its Meaning for Modern Man, with Sylvia Heschel. New York, NY: Farrar, Straus and Giroux, 2005.

Hesiod. Hesiod's Calendar: A Version of Hesiod's Theogony and Works and Days, tr. Robert Saxton. Manchester, UK: Carcanet, 2010.

Theogony \& Works and Days, tr. and ed. Stephanie Nelson and Richard Caldwell. Indianapolis, IN: Hackett Publishing, 2009.

. Theogony and Works and Days, tr. and ed. Catherine M. Schlegel and Henry Weinfield. Ann Arbor, MI: The University of Michigan Press, 2006.

.Works and Days and Theogony, tr. Stanley Lombardo, with Robert Lamberton. Indianapolis, IN: Hackett Publishing, 1993.

Hess, David J. Undone Science: Social Movements, Mobilized Politics, and Industrial Transitions. Cambridge, MA: The MIT Press, 2016.

Hester, Jim. Fourth and Long: Making America a Championship Team. Indianapolis, IN: Dog Ear Publishing, 2007.

Heuvel, Gary Van Den. Wealth of Shenanigans: The Tactile Underbelly of Concept. Morrisville, NC: Lulu Press, 2016.

Hibbing, John R., Kevin B. Smith, and John R. Alford. Predisposed: Liberals, Conservatives, and the Biology of Political Differences. New York, NY: Routledge, 2014.

Hieb, Nathan D. Christ Crucified in a Suffering World: The Unity of the Atonement and Liberation. Minneapolis, MN: Fortress Press, 2013.

Higgs, Philip, and Jane Smith. Rethinking Our World. Cape Town, South Africa: Juta \& Co., 2007.

Highfield, Ron. Great Is the Lord: Theology for the Praise of God. Grand Rapids, MI: Eerdmans, 2008.

Hill, Daniel J., and Randal D. Rauser. Christian Philosophy A-Z. Edinburgh, UK: Edinburgh University Press, 2006.

Hobson, Art. Tales of the Quantum: Understanding Physics' Most Fundamental Theory. Oxford, UK: Oxford University Press, 2017.

Hockney, Mike. The Omega Point. Hyperreality Books, 2013.

Hodder, Alfred. The Adversaries of the Sceptic, Or, The Specious Present: A New Inquiry into Human Knowledge. New York, NY: The Macmillan Company, 1901.

Hodge, Ian. Baptized Inflation: A Critique of "Christian" Keynesianism. Institute for Christian Economics, 1986.

Hodge, Steven. Martin Heidegger: Challenge to Education. New York, NY: Springer, 2014.

Hodgson, Peter E. Theology and Modern Physics. Burlington, VT: Ashgate, 2005.

Hoerber, Thomas. Hayek vs Keynes: A Battle of Ideas. London, UK: Reaktion Books, 2017. 
Hoffman, John Charles. Law, Freedom, and Story: The Role of Narrative in Therapy, Society, and Faith. Waterloo, ON: Wilfrid Laurier University Press, 1986.

Hoffmann, Gerhard. From Modernism to Postmodernism: Concepts and Strategies of Postmodern American Fiction. Amsterdam, The Netherlands: Rodopi, 2005.

Hoffmeier, James K., and Dennis R. Magary, eds. Do Historical Matters Matter to Faith?: A Critical Appraisal of Modern and Postmodern Approaches to Scripture. Wheaton, IL: Crossway, 2012.

Højrup, Thomas. State, Culture and Life-Modes: The Foundations of Life-Mode Analysis. Burlington, VT: Ashgate Publishing, 2003.

Holbrook, Frank B. The Atoning Priesthood of Jesus Christ. Berrien Springs, MI: Adventist Theological Society, 1996.

Holland, Peter R. The Quantum Theory of Motion: An Account of the de Broglie-Bohm Causal Interpretation of Quantum Mechanics. Cambridge, UK: Cambridge University Press, 1993.

Holland, Carlisle. Under the Eagle's Wing: Medicine, Mind, Metaphysics. Sebastopol, CA: 2007.

Holland, Richard A. God, Time, and the Incarnation. Eugene, OR: Wipf \& Stock, 2012.

Hollander, Paul. Anti-Americanism: Irrational \& Rational. New Brunswick, NJ: Transaction Publishers, 2003.

Hollinger, David A. "Justification by Verification: The Scientific Challenge to the Moral Authority of Christianity in Modern America." In Religion and Twentieth-Century American Intellectual Life, ed. Michael James Lacey, 116-135. New York, NY: Cambridge University Press, 1989.

Holt, Justin P. The Social Thought of Karl Marx. Singapore: Sage Publications, 2015.

Holt, Richard P. F., and Steven Pressman, "Empirical Analysis and Post Keynesian Economics." In Empirical Post Keynesian Economics: Looking at the Real World, eds. Richard P. F. Holt, Steven Pressman, 3-20. New York, NY: Taylor \& Francis, 2007.

Holton, Gerald, and Stephen G. Brush. Physics-The Human Adventure: From Copernicus to Einstein and Beyond. New Brunswick, NJ: Rutgers University Press, 2004.

Home, Dipankar, and Andrew Whitaker. Einstein's Struggles with Quantum Theory: A Reappraisal. New York, NY: Springer-Science, 2007.

Hood, Marlowe. "Modern Medicine Infected by the Virus of Mistrust." At https://medicalxpress.com/news/2018-01-modern-medicine-infected-virus-mistrust.html (accessed January 26, 2018).

Hooykaas, Reijer. Religion and the Rise of Modern Science. Edinburgh, Scotland: Scottish Academic Press, 1972.

Hopkins, Burt C. The Origin of the Logic of Symbolic Mathematics: Edmund Husserl and Jacob Klein. Bloomington, IN: Indiana University Press, 2011.

Horgan, John. "Psychiatry in Crisis! Mental Health Director Rejects Psychiatric 'Bible' and Replaces With Nothing." In Scientific American (May 4, 2013). At 
http://blogs.scientificamerican.com/cross-check/psychiatry-in-crisis-mental-health-director-re jects-psychiatric-bible-and-replaces-with-nothing/ (accessed July 20, 2015).

The End of Science: Facing the Limits of Knowledge in the Twilight of the Scientific Age. New York, NY: Basic Books, 2015.

Horky, Philip Sidney. Plato and Pythagoreanism. Oxford, UK: Oxford University Press, 2016.

Horn, Gerd-Rainer. Western European Liberation Theology: The First Wave (1924-1959). Oxford, UK: Oxford University Press, 2008.

Horowitz, David. Take No Prisoners: The Battle Plan for Defeating the Left. Washington, D. C.: Regnery Publishing, 2014.

Horowitz, Irving Louis. “Two Cultures of Science: The Limits of Positivism Revisited." In Journal of Policy History Vol. 16 \# 4 (2004): 332-347.

Horrocks, Chris. "Between Relativism and Truth: Jean Baudrillard, the Sokal Affair and the Use of Scientific Terminology Across Cultural Boundaries." In Relative Points of View: Linguistic Representations of Culture, ed. Magda Stroinska, 101-118. Oxford, UK: Berghahn Books, 2001.

Horst, Steven. Laws, Mind, and Free Will. Cambridge, MA: The MIT Press, 2011.

Horstmann, Ulrich. "The Aphorist as Go-Between." In Literature and Philosophy, ed. Herbert Grabes,149-160. Tübingen, Germany: Gunter Narr Verlag, 1997.

Horton, Emily. Contemporary Crisis Fictions: Affect and Ethics in the Modern British Novel. New York, NY: Palgrave Macmillan, 2014.

Hosinski, Thomas E. The Image of the Unseen God: Catholicity, Science, and Our Evolving Understanding of God. Maryknoll, NY: Orbis Books, 2017.

Hottinger, Sara N. Inventing the Mathematician: Gender, Race, and Our Cultural Understanding of Mathematics. Albany, NY: State University of New York Press, 2015.

House, Paul R. Old Testament Theology. Downers Grove, IL: InterVarsity Press, 1998.

Hovind, Chad. Godonomics: How to Save Our Country-and Protect Your Wallet-Through Biblical Principles of Finance. Colorado Springs, CO: Multnomah Books, 2013.

Hoy, David Couzens. The Time of Our Lives: A Critical History of Temporality. Cambridge, MA: The MIT Press, 2009.

Hoy, Ronald C. "Heraclitus and Parmenides." In A Companion to the Philosophy of Time, eds. Adrian Bardon and Heather Dyke, 9-29. West Sussex, UK: John Wiley \& Sons, 2013.

Hu, Danian. China and Albert Einstein: The Reception of the Physicist and His Theory in China, 1917-1979. Cambridge, MA: Harvard University Press, 2005.

Hua, Shiping. Scientism and Humanism: Two Cultures in Post-Mao China (1978-1989). Albany, NY: State University of New York Press, 1995.

Huard, Roger L. Plato's Political Philosophy: The Cave. New York, NY: Algora Publishing, 2007. 
Hudock, Barry. "'Freedom, Truth, and Human Dignity': The Other Conflict Behind "'Dignitatis Humanae'." At https://www.commonwealmagazine.org/freedom-truth-and-human-dignity (accessed February 18, 2016).

Huerta, Robert D. Vermeer and Plato: Painting the Ideal. Cranbury, NJ: Rosemont Publishing, 2005.

Hughes, Aaron W. Islam and the Tyranny of Authenticity: An Inquiry into Disciplinary Apologetics and Self-Deception. Bristol, CT: Equinox, 2015. . Muslim Identities: An Introduction to Islam. Chichester, West Sussex: Columbia University Press, 2013. Situating Islam: The Past and Future of an Academic Discipline. Oakville, CT: Equinox, 2007. Theorizing Islam: Disciplinary Deconstruction and Reconstruction. Bristol, CT: Acumen, 2014.

The Texture of the Divine: Imagination and Medieval Islamic and Jewish Thought. Bloomington, IN: Indiana University Press, 2004.

Hughes, John. The End of Work: Theological Critiques of Capitalism. Malden, MA: Blackwell, 2007.

Hughes, Paul A. Neoplatonist Stew: Or, How Sacramentalism, Mysticism, and Theurgy Corrupted Christian Theology. Liberty, TX: God's Trombone/Lulu Press, 2014.

Hughson, S. J. Connecting Jesus to Social Justice: Classical Christology and Public Theology. Lanham, MD: Rowman \& Littlefield, 2013.

Hulusi, Ahmed. Up to Date Understanding of Islam, tr. Ahmed Baki. Istanbul, Turkey: Kitsan, 1996.

Humphreys, Janelle Robyn. Shadows of Another Dimension: A Bridge Between Mathematician and Artist. University of Wollongong Thesis Collections, 2009.

Hunt III, Arthur W. The Vanishing Word: The Veneration of Visual Imagery in the Postmodern World. Eugene, OR: Wipf \& Stock, 2003.

Hunter, James Davison. Culture Wars; The Struggle to Define America: Making Sense of the Battles over the Family, Art, Education, Law, and Politics. New York, NY: Basic Books, 1991.

Hunter, James Davison, and Paul Nedelisky. Science and the Good: The Tragic Quest for the Foundations of Morality. New Haven, CT: Yale University Press, 2018.

Hurd, Elizabeth Shakman. Beyond Religious Freedom: The New Global Politics of Religion. Princeton, NJ: Princeton University Press, 2015.

Hustvedt, Siri. The Blazing World. New York, NY: Simon \& Schuster, 2014.

Hyland, Laurie Z. Toward a New Money Reality and a Quantum Economy: A Visionary Look at How Money and the Economy Can Become Connecting Forces for a New World. Indianapolis, IN: Xlibris, 2013.

Hyslop-Margison, Emery J., and M. Ayaz Naseem. Scientism and Education: Empirical Research as NeoLiberal Ideology. New York, NY: Springer, 2007. 
Ihde, Don. Postphenomenology: Essays in the Postmodern Context. Evanston, IL: Northwestern University Press, 1995.

Iida, Akira. Theory \& Policy Making: Reconfiguring the Future. North Clarendon, VT: Tuttle Publishing, 2004.

Imamichi, Tomonobu. In Search of Wisdom: One Philosopher's Journey, tr. Mary E. Foster. International House of Japan, 2004.

Ingersoll, Julie J. Building God's Kingdom: Inside the World of Christian Reconstruction. Oxford, UK: Oxford University Press, 2015.

Inglis, David, and Christopher Thorpe, An Invitation to Social Theory. Malden, MA: Polity Press, 2012.

Ingold, Tim. Making: Anthropology, Archaeology, Art and Architecture. New York, NY: Routledge, 2013. Being Alive: Essays on Movement, Knowledge and Description. New York, NY: Routledge, 2011.

Ingraffia, Brian. Postmodern Theory and Biblical Theology. Cambridge, UK: University of Cambridge, 1995.

Inwagen, Peter van. Metaphysics 2nd ed.. Boulder, CO: Westview Press, 2002.

.Metaphysics." At http://plato.stanford.edu/entries/metaphysics/ (accessed June 7, 2011).

Iqbal, Muzaffar. Science and Islam. Westport, CT: Greenwood Press, 2007.

Isaacson, Walter. Einstein: His Life and Universe. New York, NY: Simon \& Schuster, 2007.

Isaloo, Amin Sharifi. Power, Legitimacy and the Public Sphere: The Iranian Ta'ziyeh Theatre Ritual. New York, NY: Routledge, 2017.

Ivereigh, Austen. "Is the Pope the Anti-Trump?" At https://www.nytimes.com/2017/03/04/ opinion/sunday/is-the-pope-the-anti-trump.html (accessed March 4, 2017).

The Great Reformer: Francis and the Making of a Radical Pope. New York, NY: Henry Hold and Company, 2014.

Jaeger, Lydia. "Beyond Emergence: Learning from Dooyeweerdian Anthropology?" In The Future of Creation Order: Vol. 1, Philosophical, Scientific, and Religious Perspectives on Order and Emergence, eds. Gerrit Glas and Jeroen de Ridder, 231-256. Cham, Switzerland: Springer, 2018.

"Cosmic Order and Divine Word." In Spiritual Information: 100 Perspectives on Science and Religion, ed. Charles L. Harper, Jr., 151-154. West Conshohocken, PA: Templeton Foundation Press, 2005.

Einstein, Polanyi, and the Laws of Nature. West Conshohocken, PA: Templeton Press, 2010.

What the Heaven's Declare: Science in the Light of Creation, tr. Jonathan Vaughan. Eugene, OR: Cascade Books, 2012.

Jackson, Maggie. Distracted: The Erosion of Attention and the Coming Dark Age. Amherst, NY:

Prometheus Books, 2008. 
Jacobs, Jane. Dark Age Ahead. New York, NY: Random House, 2004.

Jacobsen, Anja Skaar. Léon Rosenfield: Physics, Philosophy, and Politics in the Twentieth Century. Toh Tuck Link, Singapore: World Scientific Publishing, 2012.

Jacquette, Dale. Ontology. Slough, UK: Acumen Publishing, 2002.

Jagerman, Louis S. The Mathematics of Relativity for the Rest of Us. Victoria, B.C.: Trafford, 2001.

James, John. The Great Field: Soul at Play in a Conscious Universe. USA: Elite Books, 2007.

Jammer, Max. "A Consideration of the Philosophical Implications of the New Physics." In The Structure and Development of Science, eds. Gerard Radnitzky and Gunnar Andersson, 41-62. London, UK: D. Reidel Publishing, 1979.

Einstein and Religion: Physics and Theology. Princeton, NJ: Princeton University Press, 1999.

Janke, Robert W., and Bruce S. Cooper. News Literacy: Helping Students and Teachers Decode Fake News. New York, NY: Rowman \& Littlefield, 2017.

January, Brendan. ISIS: The Global Face of Terrorism. Minneapolis, MN: Twenty-First Century Books, 2018.

Jarosek, Stephen. Transcending Scientism: Mending Broken Culture's Broken Science. Raleigh, NC: Lulu Press, 2016.

Jarvis, Edward A. The Conception of God in the Later Royce. The Hague, Netherlands: Martinus Nijhoff, 1975.

Jáuregui, Miguel Herrero de. Orphism and Christianity in Late Antiquity. Berlin, Germany: Walter de Gruyter, 2010.

Jayapalan, N. Comprehensive Study of Plato. Rajouri Garden, New Delhi: Atlantic Publishers, 2002.

Jennings, Timothy R. Could It Be This Simple? A Biblical Model for Healing the Mind (Hagerstown, MD: Autumn House, 2007.

The God-Shaped Heart: How Correctly Understanding God's Love Transforms Us. Grand Rapids, MI: Baker Books, 2017.

Jensen, Alexander S. Divine Providence and Human Agency: Trinity, Creation and Freedom. New York, NY: Ashgate, 2014.

Jensen, Molly Hadley. “Fleshing' Out an Ethic of Diversity." In Merleau-Ponty and Environmental Philosophy: Dwelling on the Landscapes of Thought, ed. Sue L. Cataldi and William S. Hamrick, 191-202. Albany, NY: State University of New York Press, 2007.

Jeon, Jeong Koo. Calvin and the Federal Vision: Calvin's Covenant Theology in Light of Contemporary Discussion. Eugene, OR: Resource Publications, 2009.

Johansson, Lars-Göran. Interpreting Quantum Mechanics: A Realistic View in Schrödinger's Vein. New York, NY: Routledge, 2016. 
Johns, Oliver. Analytical Mechanics for Relativity and Quantum Mechanics $2^{\text {nd }}$ ed. Oxford, UK: Oxford University Press, 2011.

Johnson, Dale A. Einstein at Prayer, Jesus in the Lab. New Sinai Press, 2006.

Johnson, Eric L. Foundations for Soul Care: A Christian Psychology Proposal. Downers Grove, IL: InterVarsity Press, 2014.

. God and Soul Care: The Therapeutic Resources of the Christian Faith. Downers Grove, IL: InterVarsity Press, 2017.

Johnson, Eric L., ed. Psychology \& Christianity: Five Views. Downers Grove, IL: InterVarsity Press, 2010.

Johnson, Gregory R. "Preface." In Charles M. Sherover, Are We In Time?: And Other Essays on Time and Temporality, ix-xv. Evanston, IL: Northwestern University Press, 2003.

Johnson, Richard E. Existential Man: The Challenge of Psychotherapy. Elmsford, NY: Pergamon Press, 1971.

Johnston, Stephen. Tea Party Culture War: A Clash of Worldviews. Enumclaw, WA: WinePress, 2011.

Johnson, William Stacy. John Calvin: Reformer for the $21^{\text {st }}$ Century. Louisville, KT: Westminster John Knox Press, 2009.

Jones, P. P. Decoding Jesus: A Comparison between John Calvin and Ellen G. White's Views. Houston, TX: Strategic Books Publishing, 2014.

Jones, Richard H. Reductionism: Analysis and the Fullness of Reality. London, UK: Associated University Presses, 2000.

Jones, Stanton L., and Richard E. Butman. Modern Psychotherapies: A Comprehensive Appraisal. Downers Grove, IL: InterVarsity Press, 1991.

Joost-Gaugier, Christiane L. Measuring Heaven: Pythagoras and His Influence on Thought and Art in Antiquity and the Middle Ages. Ithaca, NY: Cornell University Press, 2006.

Josephson, Paul R. Physics and Politics in Revolutionary Russia. Berkeley, CA: University of California Press, 1991.

Justaert, Kristien. Theology After Deleuze. New York, NY: Continuum, 2012.

Kaczynski, Theodore J., with an introduction by David Skrbina. Technological Slavery: The Collected Writings of Theodore J. Kaczynski. Port Townsend, WA: Feral House, 2010.

Kadavil, Mathai. The World as Sacrament: Sacramentality of Creation from the Perspectives of Leonardo Boff, Alexander Schmemann, and Saint Ephrem. Peeters Publishers, 2005.

Kagan, Jerome. Psychology's Ghosts: The Crisis in the Profession and the Way Back. New Haven, CT: Yale University Press, 2012.

Kahn, Charles H. Pythagoras and the Pythagoreans: A Brief History. Indianapolis, IN: Hackett Publishing, 2001. 
Kaiser, Walter C., and Moisés Silva. An Introduction to Biblical Hermeneutics: The Search for Meaning. Grand Rapids, MI: Zondervan, 1994.

Kalaga, Tomasz. Literary Hermeneutics: From Methodology to Ontology. Newcastle upon Tyne, UK: Cambridge Scholars Publishing, 2015.

Kalsi, Marie-Luise Schubert. Meinong's Theory of Knowledge. Boston, MA: Martinus Nijhoff, 1987.

Kane, Robert. "Free Will: The Elusive Ideal." In First Philosophy: Fundamental Problems and Readings in Philosophy: Vol. III: God, Mind, and Freedom, ed. Andrew Bailey, 269-293. Broadview Press, 2004.

The Significance of Free Will. New York, NY: Oxford University Press, 1996.

Kant, Immanuel. Critique of Pure Reason, 2nd ed. tr. Friedrich Max Müller. Macmillan \& Co., 1920. Critick of Pure Reason, tr. Francis Haywood. London, UK: William Pickering, 1848.

Kaplan, Jerry. Humans Need Not Apply: A Guide to Wealth and Work in the Age of Artificial Intelligence. Grand Rapids, MI: Integrated Publishing Solutions, 2015.

Kapoor, S. S. Islam. New Delhi: Hemkunt, 2004.

Kardaras, Nicholas. How Plato and Pythagoras Can Save Your Life: The Ancient Greek Prescription for Health and Happiness. San Francisco, CA: Conari Press, 2011.

Karsten, Luchien. Globalization and Time. New York, NY: Routledge, 2013.

Kauffman, Stuart A. "Foreword: Evolution beyond Newton, Darwin, and Entailing Law." In Beyond Mechanism: Putting Life Back Into Biology, eds. Brian G. Henning and Adam C. Scarfe, 1-24. Lanham, MD: Lexington Books, 2013.

Kaushik, Rajiv. Art, Language and Figure in Merleau-Ponty: Excursions in Hyper-Dialectic. New York, NY: Bloomsbury, 2013.

Kavanaugh, Leslie Jaye. The Architectonic of Philosophy: Plato, Aristotle, Leibniz. Amsterdam, The Netherlands: Amsterdam University Press, 2007.

Keane, Philip S. Catholicism and Health-Care Justice: Problems, Potential and Solutions. Mahwah, NJ: Paulist Press, 2002.

Keefauver, Larry. Experiencing the Holy Spirit: Transformed by His Presence. Nashville, TN: Thomas Nelson.

Keefe, Donald. "Faith, Science and Sacramental Realism." In Institute of Theological Encounter with Science and Technology Vol. 30 \#2 (Spring 1999): 1-11.

Keen, Steve. Debunking Economics: Revised and Expanded Edition: The Naked Emperor Dethroned? New York, NY: Zed Books, 2011.

Kegley, Ann K. Josiah Royce in Focus. Bloomington, IN: Indiana University Press, 2008. 
Keller, Pierre. Husserl and Heidegger on Human Experience. Cambridge, UK: Cambridge University Press, 2004.

Kellert, Stephen H. Borrowed Knowledge: Chaos Theory and the Challenge of Learning Across Disciplines. St. Paul, MN: The University of Chicago Press, 2008.

Kelly, Kevin. "God is the Machine," in Wired (December 1, 2002). At https://www.wired.com/ 2002/12/holytech/ (accessed August 8, 2017).

Kennard, Douglas W. A Critical Realist's Theological Method: Returning the Bible and Biblical Theology to be the Framer for Theology and Science. Eugene, OR: Wipf \& Stock, 2013.

Kennedy, J. B. Space, Time and Einstein: An Introduction. New York, NY: Routledge, 2003.

Kennedy, Leonard A., ed. Images of the Human: The Philosophy of the Human Person in a Religious Context. Chicago, IL: Loyola Press, 1995.

Kenny, Anthony. The God of the Philosophers. Oxford, UK: Clarendon Press, 1987.

Kernohan, R. D. The Realm of Reform: Presbyterianism and Calvinism in Changing Scotland: Reflections. Handsel Press, 1999.

Khan, Hazrat Inayat. The Heart of Sufism: Essential Writings of Hazrat Inayat Khan. Boston, MA: Shambhala Publications, 1999.

Khan, Maulana Wahiduddin. Spirit of Islam. Goodword Books, 2014.

Khan, Muin-ud-Din Ahmad. A Challenging Encounter with the West: Origin and Development of Experimental Science. Dhaka, Bangladesh: Bangladesh Institute of Islamic Thought, 1997.

Khuri, Richard K. Freedom, Modernity, and Islam: Toward a Creative Synthesis. Syracuse, NY: Syracuse University Press, 1998.

Kile, Frederick. Escape from Time: Disconnecting from Culture. Lincoln, NE: iUniverse, 2000.

Kille, J. Dee. Academic Freedom Imperiled: The McCarthy Era at the University of Nevada. Reno, NV: University of Nevada Press, 2004.

Kim, Hee-Jin. Dōgen on Meditation and Thinking: A Reflection on His View of Zen. Albany, NY: State University of New York Press, 2007.

Kim, Yung Sik. Questioning Science in East Asian Contexts: Essays on Science, Confucianism, and the Comparative History of Science. Leiden, The Netherlands: Koninklijke Brill, 2014.

Kim, Younglae. Broken Knowledge: The Sway of the Scientific and Scholarly Ideal at Union Theological Seminary in New York, 1887-1926. Lanham, MD: University Press of America, 1997.

Kimenyi, Alexandre. "Anatomy of Culture." At http://kimenyi.com/anatomy-of-culture.php (accessed May 21, 2014).

King, J. E. A History of Post Keynesian Economics Since 1936. Cheltenham, UK: Edward Elgar, 2002.

King, Margaret S. Unveiling the Messiah in the Dead Sea Scrolls. Indianapolis, IN: Xlibris, 2012. 
King, Paul G., and David O. Woodyard. The Journey Toward Freedom: Economic Structures and Theological Perspectives. East Brunswick, NJ: Associated University Presses, 1982.

Kinnie, Ernest. Modern Science in Crisis: Best to be Aware of the Influences on Scientists that Affect the Validity of Their Work. USA: Pronoun, 2017.

Kirby, Alan. Digimodernism: How New Technologies Dismantle the Postmodern and Reconfigure Our Culture. New York, NY: Continuum, 2009.

Kishko, Anthony. The Decline and Fall of the United States, Part 1. Bloomington, IN: Xlibris, 2012.

Kisiel, Theodore. "Merleau-Ponty on Philosophy and Science." In Phenomenology and the Natural Sciences: Essays and Translations, ed. Joseph J. Kockelmans, 251-273. Evanston, IL: Northwestern University Press, 1970.

. "Scientific Discovery: Logical, Psychological, or Hermeneutical?" In Phenomenology: Critical Concepts in Philosophy Vol. 3: Phenomenology on Science, Art, and Ethics, eds. Dermot Moran and Lester E. Embree, 43-58. New York, NY: Routledge, 2004.

Kittler, Friedrich. “Thinking Colours and/or Machines.” In Theory, Culture \& Society \#23 (2006): 3950.

Klemm, William R. Making a Scientific Case for Conscious Agency and Free Will. Cambridge, MA: Elsevier, 2016.

Klein, Jacob. Greek Mathematical Thought and the Origin of Algebra, tr. Eva Brann. New York, NY: Dover Publications, 1968.

Klett, Leah Marieann. "Richard Dawkins Clarifies Why He Believes Islam Has Replaced Christianity as 'Most Evil Religion'” in The Gospel Herald Society. At http://www.gospelherald.com/articles/70936/20170615/richard-dawkins-clarifies-why-belie ves-islam-replaced-christianity-evil-religion.htm (accessed June 15, 2017).

Knight, George R. A Brief History of the Seventh-day Adventists 2nd ed. Hagerstown, MD: Review and Herald, 2004.

The Apocalyptic Vision and the Neutering of Adventism: Are We Erasing Our Relevancy? Hagerstown, MD: Review and Herald, 2008.

Knight, Jim. High-Impact Instruction: A Framework for Great Teaching. Thousand Oaks, CA: Corwin, 2013.

Koestler, Arthur. The Ghost in the Machine. London, UK: Arkana, 1989.

Koetsier, T., and L. Bergmans, eds. Mathematics and the Divine: A Historical Study. Amsterdam, The Netherlands: Elsevier, 2005.

Kohanski, Alexander Sissel. The Greek Mode of Thought in Western Philosophy. Cranbury, NJ: Associated University Presses, 1984.

Kolig, Erich, ed. Freedom of Speech and Islam. New York, NY: Routledge, 2014. 
Konnikova, Maria. “Humanities Aren't a Science, Stop Treating Them like One.” At http://blogs.scientificamerican.com/literally-psyched/2012/08/10/humanities-arent-a-scienc e-stop- treating-them-like-one/ (accessed August 10, 2012).

Koosed, Jennifer L., ed. The Bible and Posthumanism. Atlanta, GA: Society of Biblical Literature, 2014.

Koperski, Jeffrey. The Physics of Theism: God, Physics, and the Philosophy of Science. West Sussex, UK: John Wiley \& Sons, 2015.

Koppelman, Andrew. Defending American Religious Neutrality. Cambridge, MA: Harvard University Press, 2013.

Koppl, Roger. “Introduction to 'Entangled Political Economy.'” In Entangled Political Economy (Advances in Austrian Economics Vol. 18), eds. Roger Kopl and Steven Horwitz, 1-14. Bingley, UK: Emerald Group Publishing, 2014.

. "Scientific Hermeneutics: A Tale of Two Hayeks." In Explorations in Austrian Economics, ed. Roger Koppl, 99-122. Bingley, UK: JAI Press, 2008.

Koslowski, Peter. Principles of Ethical Economy, tr. David W. Lutz. Dordrecht, The Netherlands: Kluwer, 2001.

Kovacs, George. The Question of God in Heidegger's Phenomenology. Evanston, IL: Northwestern University Press, 1990.

Koyzis, David T. Political Visions \& Illusions: A Survey \& Christian Critique of Contemporary Ideologies. Downers Grove, IL: InterVarsity Press, 2003.

Kozhevnikov, Alexei B. Stalin's Great Science: The Times and Adventures of Soviet Physicists. London, UK: Imperial College Press, 2004.

Kragh, Helge S. Conceptions of Cosmos: From Myths to the Accelerating Universe: A History of Cosmology. Oxford, UK: Oxford University Pres, 2007.

Kramer, Matthew H. The Quality of Freedom. Oxford, UK: Oxford University Press, 2003.

Kramer, Neil. The Unfoldment: The Organic Path to Clarity, Power, and Transformation. Pompton Plains, NJ: The Career Press, 2012.

Krell, David Farrell. "General Introduction: The Question of Being," in Martin Heidegger, Basic Writings, ed. David Farrell Krell, 1-36. London, UK: HarperPerennial, 2008.

Kriel, Jacques. Matter, Mind, and Medicine: Transforming the Clinical Method. Atlanta, GA: Rodopi, 2000.

Krishnamurti, Jiddu, and David Bohm. Limits of Thought: Discussions. London, UK: Routledge, 1999.

Krishnamurti, Jiddu. The Ending of Time. New York, NY: HarperOne, 1985.

The Future of Humanity: Two Dialogues between J. Krishnamurti and David Bohm. The Netherlands: Krishnamurti Foundation, 1986.

Kuhn, Thomas S. The Structure of Scientific Revolutions. Chicago, IL: University of Chicago Press, 1962. 
Kumar, Manjit. Quantum: Einstein, Bohr, and the Great Debate about the Nature of Reality. New York, NY: W. W. Norton \& Company, 2010.

Kurtz, Paul. Skepticism and Humanism: The New Paradigm. Piscataway, NJ: Transaction Publishers, 2001.

Lack, Martin. The Denial of Science: Analysing Climate Change Scepticism in the UK. Bloomington, IN: AuthorHouse, 2013.

Ladkin, Donna. Rethinking Leadership: A New Look at Old Leadership Questions. Cheltenham, UK: Edward Elgar, 2010.

Lafont, Cristina. Heidegger, Language, and World-Disclosure, tr. Graham Harman. Cambridge, UK: Cambridge University Press, 2000.

LaFreniere, Gilbert. The Decline of Nature: Environmental History and the Western Worldview. Corvallis, OR: Oak Savanna Publishing, 2012.

Lamb, Christopher. "Why Pope Francis' Approach to Islam Breaks the Mold of Benedict and Previous Popes." At https://www.americamagazine.org/faith/2017/05/03/why-pope-francis-approach-islam-brea ks-mold-benedict-and-previous-popes (accessed May 3, 2017).

Lambert, Heath. A Theology of Biblical Counseling: The Doctrinal Foundations of Counseling Ministry. Grand Rapids, MI: Zondervan, 2016.

95 Thesis for an Authentically Christian Commitment to Counseling at https://s3-us-west-2.amazonaws.com/acbcdigitalresources/resources/2017\%2C+95+Theses +of+Biblical+Counseling/95+Theses+-+Heath+Lambert.pdf (accessed September 14, 2017). Also available at https://biblicalcounseling.com/ninety-five/ (accessed September 19, 2017).

Landvik, Dag. "At the Speed of Light." In Aspects of Consciousness: Essays on Physics, Death and the Mind, ed. Ingrid Fredriksson, 76-92. Jefferson, NC: McFarland \& Company, 2012.

Lane, Frederick S. The Court and the Cross: The Religious Right's Crusade to Reshape the Supreme Court. Boston, MA: Beacon Press, 2008.

Lange, Marc. Because Without Cause: Non-Causal Explanations in Science and Mathematics. Oxford, UK: Oxford University Press, 2017.

Lanza, Robert, with Bob Berman. Biocentrism: How Life and Consciousness are the Keys to Understanding the True Nature of the Universe. Dallas, TX: Benbella Books, 2009.

LaRondelle, Hans K. The Israel of God in Prophecy: Principles of Prophetic Interpretation. Berrien Springs, MI: Andrews University Press, 1983.

Larson, Kay. Where the Heart Beats; John Cage, Zen Buddhim, and the Inner Life of Artists. London, UK: The Penguin Press, 2012.

Larson-Miller, Lizette. Sacramentality Renewed: Contemporary Conversations in Sacramental Theology. Collegeville, MN: Liturgical Press, 2016. 
Lavastida, José I. Health Care and the Common Good: A Catholic Theory of Justice. Lanham, MD:

University Press of America, 2000.

Leane, Elizabeth. Reading Popular Physics: Disciplinary Skirmishes and Textual Strategies. New York, NY: Routledge, 2016.

Lears, Jackson. "Afterward: One of the Therapeutic Culture's Most Persuasive Critics Considers the Historical Category Anew." In Rethinking Therapeutic Culture, eds. Timothy Aubry and Trysh Travis, 211-216. Chicago, IL: The University of Chicago Press, 2015.

Lecklider, Aaron. Inventing the Egghead: The Battle over Brainpower in American Culture. Philadelphia, PA: University of Pennsylvania Press, 2013.

LeDrew, Stephen. The Evolution of Atheism: The Politics of a Modern Movement. Oxford, UK: Oxford University Press, 2016.

Ledwig, Marion. Common Sense: Its History, Method, and Applicability. New York, NY: Peter Lang, 2007.

"Folk Psychology and Proverb Knowledge as Common Knowledge in Decision-Making." In Cultures: Conflict, Analysis, Dialogue, ed. Christian Kanzian and Edmund Runggaldier. Piscataway, NJ: Transaction Books, 2007.

Leeuwen, Mary Stewart Van. A Sword between the Sexes?: C. S. Lewis and the Gender Debates. Grand Rapids, MI: Brazos Press, 2010.

"Psychology's 'Two Cultures': A Christian Analysis." In Psychology \& Christianity Integration: Seminal Works that Shaped the Movement, ed. Daryl H. Stevenson, Brian E. Eck, and Peter C. Hill, 114-126. Batavia, IL: Christian Association for Psychological Studies, 2007.

Lefavi, Robert. Reasons to Believe: A Journey of Spiritual Awareness in the Modern World. Pasadena, CA: Hope Publishing, 1999.

Leftow, Brian. Time and Eternity. Ithaca, NY: Cornell University, 1991.

Legutko, Ryszard. The Demon in Democracy: Totalitarian Temptations in Free Societies. New York, NY: Encounter Books, 2016.

Lennan, Richard. An Introduction to Catholic Theology. Mahwah, NJ: Paulist Press, 1998.

Lennox, John C. Seven Days That Divide the World: The Beginning According to Genesis and Science. Grand Rapids, MI: Zondervan, 2011.

León-Sánchez, Antonio. Digital Relativity-A Digital Reinterpretation of the Special Theory of Relativity. Madrid, Spain: Bubok, 2013.

Leontief, Wassily, and Faye Duchin. The Future Impact of Automation on Workers. Oxford, UK: Oxford University Press, 1986.

Levin, Daniel Lessard. Representing Popular Sovereignty: The Constitution in American Political Culture. Albany, NY: State University of New York Press, 1999.

Levin, Yuval. Imagining the Future: Science and American Democracy. New York, NY: Encounter Books, 2008. 
Levendusky, Matthew. How Partisan Media Polarize America. Chicago, IL: The University of Chicago Press, 2013.

Levering, Matthew. Biblical Natural Law: A Theocentric and Teleological Approach. New York, NY: Oxford University Press, 2008.

Levi, Albert William, and Ralph A. Smith, Art Education: A Critical Necessity. Chicago, IL: Illini Books, 1991.

Lewis, Bernard. Cultures in Conflict: Christians, Muslims, and Jews in the Age of Discovery. Oxford, UK: Oxford University Press, 1995. The Crisis of Islam: Holy War and Unholy Terror. New York, NY: Modern Library, 2003. The Middle East: A Brief History of the Last 2,000 Years. New York, NY: Scribner, 1995.

Lewis, C. S. That Hideous Strength. New York, NY: Scribner, 1996.

Lewis, John David. Solon the Thinker: Political Thought in Archaic Athens. New York, NY: Bloomsbury Academic, 2006.

Lewis, Paul. "'Our Minds Can be Hijacked': The Tech Insiders Who Fear a Smartphone Dystopia." At https://www.theguardian.com/technology/2017/oct/05/smartphone-addiction-silicon-valleydystopia (accessed October 6, 2017).

Lewis, Peter J. Quantum Ontology: A Guide to the Metaphysics of Quantum Mechanics. Oxford, UK: Oxford University Press, 2016.

Li Li. "On Complementarity Reality." In Realism and Anti-Realism in the Philosophy of Science, eds. Robert S. Cohen, Risto Hilpinen, and Qui Renzong, 343-358. Dordrecht, The Netherlands, Springer, 1996.

Libby, Ronald T. Purging the Republican Party: Tea Party Campaigns and Elections. Lanham, MD: Lexington Books, 2014.

Libertus, Melissa E., Lisa Feigenson, and Justin Halberda. "Preschool Acuity of the Approximate Number System Correlates with School Math Ability." In Developmental Science Vol 14 \# 6 (Nov. 2011): 1292-1300.

Lim, Jie-Hyun, Barbara Walker, and Peter Lambert, eds. Mass Dictatorship and Memory as Ever Present Past. New York, NY: Palgrave Macmillan, 2014.

Lim, Jie-Hyun, and Peter Lambert. "Introduction: Coming to Terms with the Past of Mass Dictatorship," in Mass Dictatorship and Memory as Ever Present Past, eds. Jie-Hyun Lim et al., 116. New York, NY: Palgrave Macmillan, 2014.

Lindenfeld, David F. The Transformation of Positivism: Alexius Meinong and European Thought, 1880-1920. Berkeley, CA: University of California Press, 1980.

Lindley, David. Uncertainty: Einstein, Heisenberg, Bohr, and the Struggle for the Soul of Science. New York, NY: Random House, 2007. 
Linker, Damon. "What Do Conservative Catholics Want from Pope Francis?" At http://theweek.com/articles/451208/ what-conservative-catholics-want-from-pope-francis (accessed February 11, 2014).

Lipari, Lisbeth. Listening, Thinking, Being: Toward an Ethics of Attunement. University Park, PA: The Pennsylvania State University, 2014.

Lipka, Michael, and Conrad Hackett. "Why Muslims are the World's Fastest-growing Religious Group." At http://www.pewresearch.org/fact-tank/2017/04/06/why-muslims-are-the-worlds-fastest-gro wing-religious-group/ (accessed April 6, 2017).

Lipovetsky, Gilles. Hypermodern Times. Cambridge, UK: Polity Press, 2005.

Lipson, Charles. "Why America's Political Crisis is so Profound." At https://www.realclearpolitics.com/articles/2017/05/30/why_americas_political_crisis_is_so_p rofound_134037.html (accessed May 30, 2017).

Lisle, Jason. Discerning Truth: Exposing Errors in Evolutionary Arguments. Green Forest, AR: Master Books, 2010.

Livingstone, David. Black Terror White Soldiers: Islam, Fascism \& the New Age. Sabilillah Publications, 2013.

Lakoff, Sanford A. “The Nth Culture Problem." In Bulletin of the Atomic Scientists (May, 1964): 21-23.

Llewelyn, John. The Rigor of a Certain Inhumanity: Toward a Wider Suffrage. Bloomington, IN: Indiana University Press, 2012.

Lobel, Diana. A Sufi-Jewish Dialogue: Philosophy and Mysticism in Bahya Ibn Paqūda's Duties of the Heart. Philadelphia, PA: University of Pennsylvania Press, 2007.

Lobo, Francisco S. N. "Nature of Time and Causality in Physics." In Psychology of Time, ed. Simon Grondin, 395-422. Bingley, UK: Emerald Group Publishing, 2008.

Locke, Jeremy. The End of All Evil. Www.endofevil.com, 2006.

Loftin, Todd P. "A Mixed Approach to the Science Curriculum." In Journal for the Philosophical Study of Education Vol. 1, 53-80. Bloomington, IN: AuthorHouse, 2012.

Lombard, Lawrence B. “Time for a Change: A Polemic against the Presentism-Eternalism Debate." In Time and Identity, eds. Joseph Keim Campbell, Michael O’Rourke, Harry S. Silverstein, 49-78. Cambridge, MA: The MIT Press, 2010.

Long, Eugene Thomas. "Philosophy of Religion after Postmodernism." In Nature, Truth, and Value: Exploring the Thinking of Frederick Ferré, eds. George Allan and Merle F. Allshouse, 83-100. Lanham, MD: Lexington Books, 2005.

Long, D. Stephen. Speaking of God: Theology, Language, and Truth. Grand Rapids, MI: Eerdmans Publishing, 2009.

Loocke, Philip Van, ed. The Physical Nature of Consciousness. Amsterdam, The Netherlands: John Benjamins, 2000. 
Losonsky, Michael. Linguistic Turns in Modern Philosophy. New York, NY: Cambridge University Press, 2006.

Lotfalian, Mazyar. Islam, Technoscientific Identities, and the Culture of Curiosity. Lanham, MD: University Press of America, 2004.

Lovat, Terence, and Robert Crotty. Reconciling Islam, Christianity, and Judaism: Islam's Special Role in Restoring Convivencia. New York, NY: Springer, 2015.

Ludeke, Steven, Wendy Johnson, and Thomas J. Bouchard Jr. “'Obedience to Traditional Authority:' A Heritable Factor Underlying Authoritarianism, Conservatism and Religiousness." In Personality and Individual Differences Vol. 55, Issue 4 (August, 2013): 375-380.

Ludlow, Peter. Living Words: Meaning Underdetermination and the Dynamic Lexicon. Oxford, UK: Oxford University Press, 2014.

Lovell, David W. From Marx to Lenin: An Evaluation of Marx's Responsibility for Soviet Authoritarianism. Cambridge, UK: Cambridge University Press, 1984.

Luchte, James. Heidegger's Early Philosophy: The Phenomenology of Ecstatic Temporality. New York, NY: Continuum International Publishing, 2008.

Lum, Gerard. Vocational and Professional Capability: An Epistemological and Ontological Study of Occupational Expertise. New York, NY: Continuum, 2009.

Lurçat, Françios. "Understanding Quantum Mechanics with Bohr and Husserl." In Rediscovering Phenomenology: Phenomenological Essays on Mathematical Beings, Physical Reality, Perception and Consciousness, eds., Luciano Boi, Pierre Kerszberg, Frédéric Patras, 229-258. Dordrecht, The Netherlands: Springer, 2007.

Lurquin, Paul F., and Linda Stone. Evolution and Religious Creation Myths: How Scientists Respond. New York, NY: Oxford University Press, 2007.

Luther, Martin. The Bondage of the Will: Written in Answer to the Diatribe of Erasmus on Free-Will, tr. Henry Cole. Fort Worth, TX: RDMc Publishing, 2005.

Lynds, Peter. "Zeno's Paradoxes: A Timely Solution." At http://philsci-archive.pitt.edu/archive/00001197 (Accessed January 20, 2017).

MacAdam, Richard Dennis. Temporality and Ethics in William James. Boston, MA: Boston College, 1976.

MacCarty, Skip. In Granite Or Ingrained?: What the Old and New Covenants Reveal about the Gospel, the Law, and the Sabbath. Berrien Springs, MI: Andrews University Press, 2007.

Machuga, Ric. Three Theological Mistakes: How to Correct Enlightenment Assumptions about God, Miracles, and Free Will. Eugene, OR: Cascade Books, 2015.

Mack, Michael. Philosophy and Literature in Times of Crisis: Challenging our Infatuation with Numbers. New York, NY: Bloomsbury Academic, 2014.

Madison, Gary Brent. On Suffering: Philosophical Reflections on What it Means to be Human. Hamilton, Canada: Les Érables, 2013. 
. "Phenomenology and Economics." In The Elgar Companion to Austrian Economics, ed. Peter J. Boettke, 38-47. Cheltenham, UK: Edward Elgar, 1994.

. The Hermeneutics of Postmodernity: Figures and Themes. Bloomington, IN: Indiana University Press, 1988.

The Political Economy of Civil Society and Human Rights. New York, NY: Routledge, 1998.

Understanding: A Phenomenological-Pragmatic Analysis. Westport, CT: Greenwood Press, 1982.

Maggi, Claudia. "Iamblichus on Mathematical Entities." In Iamblichus and the Foundations of Late Platonism, eds. Eugene Afonasin, John Dillon, and John F. Finamore, 75-90. Leiden, The Netherlands: Koninklijke Brill, 2012.

Mahon, Peter. Posthumanism: A Guide for the Perplexed. New York, NY: Bloomsbury, 2017.

Maier, Gerhard. Biblical Hermeneutics, tr. Robert W. Yarbrough. Wheaton, IL: Crossway Books, 1994.

Maital, Shlomo. "Reclaiming Moral Sentiments: Behavioral Economics and the Ethical Foundations of Capitalism." In the Handbook of Contemporary Behavioral Economics: Foundations and Developments, ed. Morris Altman, 202-217. New York, NY: Routledge, 2015.

Malerba, Larry. Green Medicine: Challenging the Assumptions of Conventional Health Care-A New Synthesis of Ancient and Modern Healing Traditions. Berkeley, CA: North Atlantic Books, 2010.

Malkawi, Fathi Hasan. Epistemological Integration: Essentials of an Islamic Methodology, tr. Nancy Roberts. London, UK: The International Institute of Islamic Thought, 2014.

Malpas, Jeff E. Heidegger's Topology: Being, Place, World. Cambridge, MA: Massachusetts Institute of Technology Press, 2006.

Manea, Mike. "A Better Way to Fight Evolution: Part 1: Science's Naturalistic Bias." At https://thecompassmagazine.com/blog/a-better-way-to-fight-evolution-part-1-sciences-natura listic-bias (October 28, 2015).

Manen, Max van. Pedagogical Tact: Knowing What to Do When You Don't Know What to Do. New York, NY: Routledge, 2016.

Manent, Pierre. A World Beyond Politics?: A Defense of the Nation-state, tr. Marc LePain. Princeton, NJ: Princeton University Press, 2006.

Mann, Michael. The Dark Side of Democracy: Explaining Ethnic Cleansing. Cambridge, UK: Cambridge University Press, 2005.

Manning, Russell Re. "On Revising Natural Theology: John Polkinghorne and the False Modesty of Liberal Theology." In God and the Scientist: Exploring the Work of John Polkinghorne, eds. Fraser Watts and Christopher C. Knight, 197-215. New York, NY: Routledge, 2012.

Mansueto, Anthony E., and Maggie Mansueto. Spirituality and Dialectics. Lanham, MD: Lexington Books, 2005.

Manuel, Frank E., and Fritzie P. Manuel. Utopian Thought in the Western World. Cambridge, MA: The Belknap Press of Harvard University Press, 1979. 
Manzoor, S. Parvez. "The Unthought of Islamic Science (Part One)." In Studies in the Islam and Science Nexus Vol. 1, ed. Muzaffar Iqbal, 51-66. New York, NY: Routledge, 2012.

Marder, Michael. "A Fight for the Right to Read Heidegger." At https://opinionator.blogs.nytimes.com/2014/07/20/a-fight-for-the-right-to-read-heidegger/ (accessed July 20, 2014).

Maritain, Jacques. On the Philosophy of History. South Bend, IN: Aeterna Press, 2015.

Marini, John. "Progressivism, Modern Political Science, and the Transformation of American Constitutionalism." In The Progressive Revolution and Political Science: Transforming the American Regime, eds. John Marini and Ken Masugi, 221-251. Lanham, MD: Rowman \& Littlefield, 2005.

Marion, Jean-Luc. God Without Being, tr. Thomas A. Carlson. Chicago, IL: University of Chicago, 1995. . The Visible and the Revealed, tr. Christina M. Gschwandtner. New York, NY: Fordham University Press, 2008.

Marius, Richard. Martin Luther: The Christian Between God and Death. Cambridge, MA: The Belknap Press of Harvard University Press, 1999.

Markopoulou, Fotini. "Space Does Not Exist, So Time Can.” At http://fqxi.org/data/essay-contest-files/Markopoulou_SpaceDNE.pdf?phpMyAdmin=0c371ccd ae9b5ff3071bae814fb4f9e9 (accessed July 16, 2017).

Marley, David John. Pat Robertson: An American Life. Lanham, MD: Rowman \& Littlefield, 2007.

Marsh, John. The Liberal Delusion: The Roots of Our Current Moral Crisis. La Vergne, TN: Arena Books, 2012.

Marshall, Robert E. Forgiveness: Journey to the Center of the Hurt. West Jordan, UT: Streams in the Wasteland Christian Ministries, 2012.

Martin, Jonathan. Biblical Eschatology. Eugene, OR: Wipf and Stock, 2013.

Martin, Thomas R. Pericles: A Biography in Context. New York, NY: Cambridge University Press, 2016.

Martos, Joseph. Deconstructing Sacramental Theology and Reconstructing Catholic Ritual. Eugene, OR: Wipf and Stock, 2015.

Mason, Jim. An Unnatural Order: The Roots of Our Destruction of Nature: Why We are Destroying the Planet and Each Other. New York, NY: Lantern Books, 2005.

Mason, Phil. Quantum Glory: The Science of Heaven Invading Earth. Maricopa, AZ: XP Publishing, 2010.

Massaro, Thomas. Catholic Social Teaching in Action: Living Justice. New York, NY: Rowman \& Littlefield, 2008.

Masters, Roger D. The Nature of Politics. New Haven, CT: Yale University Press, 1989.

Matthews, Steven. Theology and Science in the Thought of Francis Bacon. Burlington, VT: Ashgate, 2007. 
Maudlin, Tim. Quantum Non-Locality and Relativity: Metaphysical Intimations of Modern Physics 3rd ed. Chichester, UK: John Wiley \& Sons, 2011.

Maxwell, C. Mervyn. God Cares: The Message of Daniel. Nampa, ID: Pacific Press, 1998. God Cares: The Message of Revelation. Nampa, ID: Pacific Press, 1998.

May, Reinhard, and Graham Parkes. Heidegger's Hidden Sources: East Asian Influences on His Work. New York, NY: Routledge, 1996.

May, Rollo. Freedom and Destiny. New York, NY: Norton, 1999.

Mazur, Joseph. Zeno's Paradox: Unraveling the Ancient Mystery Behind the Science of Space and Time. New York, NY: Plume Publishers, 2007.

McCann, Dennis. Realism \& Liberation Theology: Practical Theologies in Creative Conflict. Eugene, OR: Wipf \& Stock, 2001.

McCants, William. The ISIS Apocalypse: The History, Strategy, and Doomsday Vision of the Islamic State. New York, NY: St. Martin's Press, 2015.

McCarson, Derrick. Origins: An In-Depth Study of Genesis 1-11. Bloomington, IN: CrossBooks, 2012.

McCarthy, John Aloysius. Remapping Reality: Chaos and Creativity in Science and Literature-Goethe, Nietzsche, Grass. Amsterdam, The Netherlands: Rodopi, 2006.

McClennen, Sophia A., and Alexandra Schultheis Moore. "Introduction-Aporia and Affirmative Critique: Mapping the Landscape of Literary Approaches to Human Rights Research." In The Routledge Companion to Literature and Human Rights, eds. Sophia A. McClennen and Alexandra Schultheis Moore, 1-20. New York, NY: Routledge, 2016.

McCracken, Vic, ed. Christian Faith and Social Justice: Five Views. New York, NY: Bloomsbury, 2014.

McCumber, John. Time in the Ditch: American Philosophy and the McCarthy Era. Evanston, IL: Northwestern University Press, 2001.

McDermott, Gerald. "Is Pope Francis a Liberal Protestant?" At https://www.firstthings.com/web-exclusives/2017/11/is-pope-francis-a-liberal-protestant (accessed November 15, 2017).

McDonough, Richard M. Martin Heidegger's Being and Time. New York, NY: Peter Lang, 2006.

McDowall, Stewart A. Evolution and the Need of Atonement. Cambridge, UK: Cambridge University Press, 1912, 2011.

McEvilley, Thomas. The Shape of Ancient Thought: Comparative Studies in Greek and Indian Philosophies. New York, NY: Allworth Press, 2012.

McFarlane, Thomas J. "The Non-dual Root of Science and Religion." In The Rose+Croix Journal Vol. 10 (2014), 41-59.

McGovern, Arthur F. Liberation Theology and Its Critics: Toward an Assessment. Eugene, OR: Wipf \& Stock, 2009. 
McGrade, Arthur Stephen. The Political Thought of William Ockham: Personal and Institutional Principles. Cambridge, UK: Cambridge University Press, 1974.

McGrath, Alister E. Scientific Theology: Nature. New York, NY: T\&T Clark, 2006.

McGrath, S. J. The Early Heidegger \& Medieval Philosophy: Phenomenology for the Godforsaken. The Catholic University of America Press, 2006.

McInerney, Peter K. Time and Experience. Philadelphia, PA: Temple University Press, 1991.

McIntosh, Steve. Evolution's Purpose: An Integral Interpretation of the Scientific Story of Our Origins. New York, NY: Select Books, 2012.

McMullin, Irene. Time and the Shared World: Heidegger on Social Relations. Evanston, IL: Northwestern University Press, 2013.

McMullen, Jeffery S. "Perspective Taking and the Heterogeneity of the Entrepreneurial Imagination." In What is so Austrian about Austrian Economics?, eds. Steven Horwitz, Pierre Desrochers, and Roger Koppl, 113-144. Bingley, UK: Emerald Group Publishing, 2010.

McTaggart, J. M. E. “The Unreality of Time.” Mind 17 (1908): 457-474.

McVicar, Michael J. Christian Reconstruction: R. J. Rushdoony and American Religious Conservatism. Chapel Hill, NC: The University of North Carolina Press, 2015.

McWilliams, Nancy. Psychoanalytic Psychotherapy: A Practitioner's Guide. New York, NY: The Guilford Press, 2004.

Mead, George Herbert. The Philosophy of the Present. Amherst, NY: Prometheus Books, 1992.

Meckstroth, Christopher. The Struggle for Democracy: Paradoxes of Progress and the Politics of Change. Oxford, UK: Oxford University Press, 2015.

Médaille, John. Toward a Truly Free Market: A Distributist Perspective on the Role of Government, Taxes, Health Care, Deficits, and More. Wilmington, DE: ISI Books, 2010.

Medawar, P. B. The Art of the Soluble. London, UK: Methuen, 1967.

Meer, Jitse M. Van der. "European Calvinists and the Study of Nature: Some Historical Patterns and Problems." In Calvinism and the Making of the European Mind, eds. Gijsbert van den Brink and Harro Höpfl, 103-130. Leiden, The Netherlands: Koninklijke Brill, 2014.

"Is There a Created Order for Cosmic Evolution in the Philosophy of Herman Dooyeweerd?" In The Future of Creation Order: Vol. 1, Philosophical, Scientific, and Religious Perspectives on Order and Emergence, eds. Gerrit Glas and Jeroen de Ridder, 171-202. Cham, Switzerland: Springer, 2017.

Meek, Esther Lightcap. Contact with Reality: Michael Polanyi's Realism and Why It Matters. Eugene, OR: Cascade Books, 2017.

Meere, Margaret Stephenson. The Child Within the Lotus. Dulwich Hill, Australia: Rockpool Publishing, 2009. 
Megidish, E., A. Halevy, T. Shacham, T. Dvir, L. Dovrat, and H. S. Eisenberg. "Entanglement Swapping between Photons that have Never Coexisted." In Physical Review Letters 110 (22 May 2013). At https://arxiv.org/pdf/1209.4191.pdf.

Mehta, Hemant. "Christian Theologian: I Still Support Donald Trump Because Hillary Clinton is Worse Than Hitler." At http://www.patheos.com/blogs/friendlyatheist/2016/10/11/christian-theologian-i-still-suppo rt-donald-trump-because-hillary-clinton-is-worse-than-hitler/ (accessed March 2, 2017).

Mehlberg, Henry. Time, Causality, and the Quantum Theory: Studies in the Philosophy of Science Vol. 2: Time in a Quantized Universe, ed. Robert S. Cohen. London, UK: D. Reidel, 1980.

Mehra, Jagdish, and Helmut Rechenberg. The Historical Development of Quantum Theory: 6 Vols. New York, NY: Springer-Verlag, 1982-2000.

Melamed, Abraham. "Medieval and Renaissance Jewish Political Philosophy." In History of Jewish Philosophy, ed. Daniel H. Frank and Oliver Leaman, 352-388. New York, NY: Routledge, 1997.

Merleau-Ponty, Maurice. “Einstein and the Crisis of Reason." In Signs, tr. R. C. McCleary. Evanston, IL: Northwestern University Press, 1964.

The Primacy of Perception: And Other Essays on Phenomenological Psychology, tr. Carleton Dallery. Evanston, IL: Northwestern University Press, 1964.

The Visible and the Invisible: Followed by Working Notes, tr. Alphonso Lingis. Evanston, IL: Northwestern University Press, 1968.

Mermin, N. David. "Is the Moon There when Nobody Looks? Reality and the Quantum Theory." In Philosophy of Science: An Anthology, ed. Marc Lange, 619-633. Malden, MA: Blackwell Publishers, 2007.

Merrell, Floyd. Entangling Forms: Within Semiosic Processes. Göttingen, Germany: Walter de Gruyter, 2010. Peirce, Signs, and Meaning. Buffalo, NY: University of Toronto Press, 1997.

Signs Becoming Signs: Our Perfusive, Pervasive Universe. Bloomington, IN: Indiana University Press, 1991.

. Semiosis in the Postmodern Age. West Lafayette, IN: Purdue University Press, 1995.

Sensing Corporeally: Toward a Posthuman Understanding. Toronto, Canada: 2003.

Metevia, Robert. Secure Forever: Once Saved Always Saved. Bloomington, IN: WestBow, 2012.

Meyer, Stephen C. Signature in the Cell: DNA and the Evidence for Intelligent Design. New York, NY: HarperCollins, 2009.

Meyer, William J. Metaphysics and the Future of Theology: The Voice of Theology in Public Life. Eugene, OR: Pickwick Publications, 2010.

Meyerson, Émile. The Relativistic Deduction: Epistemological Implications of the Theory of Relativity. Dordrecht, Holland: D. Reidel, 1985. 
Mickey, Sam. Coexistentialism and the Unbearable Intimacy of Ecological Emergency. Lanham, MD: Lexington Books, 2016.

Milbank, John, and Aaron Riches “Foreword: Neoplatonic Theurgy and Christian Incarnation." In Gregory Shaw, Theurgy and the Soul: The Neoplatonism of Iamblichus $2^{\text {nd }}$ ed., v-xviii. Kettering, OH: Angelico Press, 2014.

Milberg, William, and J. E. King. In Conversations with Post Keynesians, ed. J. E. King, 51-63. London, UK: St. Martin's Press, 1995.

Miles, James B. The Free Will Delusion: How We Settled for the Illusion of Morality. Leicestershire, UK: Matador, 2015.

Miller, Kenneth R. Finding Darwin's God: A Scientist's Search for Common Ground Between God and Evolution. New York, NY: HarperCollins, 1999. . Only a Theory: Evolution and the Battle for America's Soul. London, UK: Penguin Books, 2008.

Miller, Mark C. The View of the Courts from the Hill: Interactions between Congress and the Federal Judiciary. Charlottesville, VA: University of Virginia Press, 2009.

Mills, Charles W. Blackness Visible: Essays on Philosophy and Race. Ithaca, NY: Cornell University, 1998.

Mills, David. Atheist Universe: The Thinking Person's Answer to Christian Fundamentalism. Berkeley, CA: Ulysses Press, 2006.

Mills, Jon, and Janusz A. Polanowski. The Ontology of Prejudice. Atlanta, GA: Rodopi, 1997.

Milton, Richard. Alternative Science: Challenging the Myths of the Scientific Establishment. Rochester, VT: Park Street Press, 1996.

Mini, Piero V. John Maynard Keynes: A Study in the Psychology of Original Work. New York, NY: St. Martin's Press, 1994.

Miravalle, Mark I. Introduction to Mary: The Heart of Marian Doctrine and Devotion. Goleta, CA: Queenship Publishing, 2006.

Mirman, R. Quantum Mechanics, Quantum Field Theory: Geometry, Language, Logic. Lincoln, NE: iUniverse, 2004.

Mirowski, Philip. More Heat Than Light: Economics as Social Physics: Physics as Nature's Economics. Cambridge, UK: Cambridge University Press, 1989.

Mirsepassi, Ali, and Tadd Graham Fernée. Islam, Democracy, and Cosmopolitanism: At Home and in the World. Cambridge, UK: Cambridge University Press, 2014.

Mitchell, Helen Buss. Roots of Wisdom: A Tapestry of Philosophical Traditions. Stamford, CT: Cengage Learning, 2015.

Mitchell, Nathan D. Real Presence: The Work of Eucharist. Chicago, IL: Liturgy Training Publications, 2001. 
Mitchell, W. J. T. What Do Pictures Want?: The Lives and Loves of Images. Chicago, IL: The University of Chicago Press, 2005.

Mitra, Papia. "Artificial Intelligences and Karma: An Evaluation of Information Technology in Light of J. L. Shaw's Concept of Moral Free Will." In Comparative Philosophy and J. L. Shaw, eds. Purushottama Bilimoria and Michael Hemmingsen, 247-262. Dordrecht, The Netherlands, Springer, 2016.

Modell, Arnold H. "Metaphor, Meaning, and the Mind." In Metaphor and Fields: Common Ground, Common Language, and the Future of Psychoanalysis, ed. S. Montana Katz, 59-66. New York, NY: Routledge, 2013.

Mohr, Jakki, Sanjit Sengupta, and Stanley Slater. Marketing of High-Technology Products and Innovations 3rd ed. Upper Saddle River, NJ: Prentice Hall, 2010.

Molina, Luis de. On Divine Foreknowledge: Part IV of the Concordia, tr. Alfred J. Freddoso. Ithaca, NY: Cornell University Press, 1988.

Molnar, Paul D. Faith, Freedom and the Spirit: The Economic Trinity in Barth, Torrance, and Contemporary Theology. Downers Grove, IL: InterVarsity Press, 2015.

Montuori, Alfonso. "Foreword." In Edgar Morin, Vidal and His Family: From Salonica to Paris-The Story of a Sephardic Family in the Twentieth Century, tr. Deborah Cowell, i-ix. Portland, OR: Sussex Academic Press, 2009.

Moo, Douglas J., and Andrew David Naselli. The Problem of the New Testament's Use of the Old Testament" In The Enduring Authority of the Christian Scriptures, ed. D. A. Carson, 702-746. Grand Rapids, MI: Eerdmans, 2016.

Moody, David Edmund. An Uncommon Collaboration: David Bohm and J. Krishnamurti. Ojai, CA: Alpha Centauri Press, 2017.

Mooij, J. J. A. "The Flow and the Map: On the Dynamic and Static Views of Time." In The Two Cultures: Shared Problems, eds. Ernesto Carafoli, Gian Antonio Danieli, Giuseppe 0. Longo, 13-26. Milano, Italy: Springer-Verlag, 2009.

Mooney, Chris. The Republican War on Science, revised. New York, NY: Basic Books, 2007.

. The Republican Brain: The Science of Why They Deny Science-and Reality. Hoboken, NJ: John Wiley \& Sons, 2012.

"Your Genes Tell You How to Vote." At http://www.motherjones.com/mojo/2013/12/genetics-twins-politics-religion (accessed February 16, 2017).

Moore, Andrew. Realism and Christian Faith: God, Grammar and Meaning. Cambridge, UK: Cambridge University Press, 2003.

Moore, Marvin. The Case for the Investigative Judgement: Its Biblical Foundation. Nampa, ID: Pacific Press, 2010. 
Moreland, J. P. "A Defense of a Substance Dualist View of the Soul." In Christian Perspectives on Being Human: A Multidisciplinary Approach to Integration, eds. J. P. Moreland and David M. Ciocchi, 5579. Grand Rapids, MI: Baker, 1993.

."The Soul and Life Everlasting: Introduction." In Philosophy of Religion: A Reader and Guide, ed. William Lane Craig, 429-446. New Brunswick, NJ: Rutgers University Press, 2002.

Moreland, J. P., and William Lane Craig, Philosophical Foundations for a Christian Worldview. Downers Grove, IL: InterVarsity Press, 2003.

Morin, Edgar, with Stéphane Hessel. The Path to Hope, tr. Antony Shugaar. New York, NY: Other Press LLC, 2012.

Morley, Neville. Theories, Models, and Concepts in Ancient History. New York, NY: Routledge, 2004.

Morris, Charles R. The Sages: Warren Buffett, George Soros, Paul Volcker, and the Maelstrom of Markets. New York, NY: PublicAffairs, 2010.

Morris, John D. The Young Earth: The Real History of the Earth-Past, Present, and Future. Green Forest, AR: Master Books, 2007.

Morris, William Sparkes. The Young Jonathan Edwards: A Reconstruction. Carlson Publishers, 1991.

Morrison II, Roy D. “Tillich, Einstein, and Kant: Method, Epistemology, and the Personal God." In Theonomy and Autonomy: Studies in Paul Tillich's Engagement with Modern Culture, ed. John Jesse Carey, 35-67. Macon, GA: Mercer University Press, 1984.

Mpanya, Mutambo. "Scientific Knowledge in the Context of Environmental Justice." In Environmental Crisis or Crisis of Epistemology?: Working for Sustainable Knowledge and Environmental Justice, ed. Bunyan Bryant, 133-168. New York, NY: Morgan James, 2011.

Mueller, Ian. "Geometry and Scepticism." In Science and Speculation, eds. Jonathan Barnes, Jacques Brunschwig, Myles Burnyeat, and Malcolm Schofield, 69-95. Cambridge, UK: Cambridge University Press, 1982.

Mullarkey, Maureed. "In Wake of Manchester, Pope Francis Asserts Equivalence between Islam And Christianity." At http://thefederalist.com/2017/05/30/wake-manchester-pope-francis-asserts-equivalence-isla m-christianity/ (accessed May 30, 2017).

Muller, Wayne. Sabbath: Finding Rest, Renewal, and Delight in Our Busy Lives. New York, NY: Bantam Books, 2000.

Mullin, William J. Quantum Weirdness. Oxford, UK: Oxford University Press, 2017.

Mullins, R. T. The End of the Timeless God. Oxford, UK: Oxford University Press, 2016.

Munitz, Milton K. Cosmic Understanding: Philosophy and Science of the Universe. Princeton, NJ: Princeton University Press, 1986.

Muntersbjorn, Madeline. "Morality and Mathematics." In Mathematical Cultures: The London Meetings 2012-2014, ed. Brendan Larvor, 387-408. Switzerland, Springer Birkhäuser, 2016. 
Murata, Sachiko. The Tao of Islam: A Sourcebook on Gender Relationships in Islamic Thought. Albany, NT: State University of New York Press, 1992.

Murawski, Roman. “Did Leibniz and Newton Discover or Create the Calculus?” In Topics in Logic, Philosophy and Foundations of Mathematics and Computer Science, eds. S. Krajewski et al., 249-256. Amsterdam, The Netherlands: IOS Press, 2007.

Muray, Leslie A. Liberal Protestantism and Science. Westport, CT: Greenwood Press, 2008.

Murchadha, Felix Ó. The Time of Revolution: Kairos and Chronos in Heidegger. New York, NY: Bloomsbury Academic, 2013.

Murphy, James G. “Carnap's Distinction and the God-Question." In Philosophical Thinking and the Religious Context, ed. Brendan Sweetman, 143-155. New York, NY: Bloomsbury, 2013.

Murphy, Nancey. "Divine Action in the Natural Order: Buridan's Ass and Schrödinger's Cat." In Philosophy, Science and Divine Action, eds. F. LeRon Shults, Nancey C. Murphy, and Robert John Russell, 263-283. Leiden, The Netherlands: Brill, 2009.

. "Introduction." In Downward Causation and the Neurobiology of Free Will, eds. Nancey Murphy, George F. R. Ellis, and Timothy O'Connor, 1-30. New York, NY: Springer-Verlag, 2009.

Murphy, Nancey, and George F. R. Ellis. On the Moral Nature of the Universe: Theology, Cosmology, and Ethics. Minneapolis, MN: Fortress, 1996.

Murphy, Jr., William F. “Introduction.” In Martin Rhonheimer, The Common Good of Constitutional Democracy: Essays in Political Philosophy and on Catholic Social Teaching, xxxvi-xxxvii. Washington, D.C.: The Catholic University of America Press, 2013.

Murray, Charles. Coming Apart: The State of White America, 1960-2010. New York, NY: Random House, 2013.

Murray, Michael J. Nature Red in Tooth and Claw: Theism and the Problem of Animal Suffering. New York, NY: Oxford University Press, 2008.

Musser, George. Spooky Action at a Distance: The Phenomenon That Reimagines Space and Time-and What It Means for Black Holes, the Big Bang, and Theories of Everything. New York, NY: Scientific American, 2015.

Musser, George, with Tim O’Brien. “Let's Rethink Space: Does Space Exist Without Objects, or is It Made by Them?" At http://nautil.us/issue/32/space/lets-rethink-space (accessed August 8, 2017).

Myrdal, Gunnar. "How Scientific Are the Social Sciences?” In Bulletin of the Atomic Scientists (Jan, 1973): 31-37.

Myss, Caroline. Entering the Castle: An Inner Path to God and Your Soul. New York, NY: Free Press, 2007.

Nachtomy, Ohad, and Justin E. H. Smith. "Introduction." In The Life Sciences in Early Modern Philosophy, eds. Ohad Nachtomy and Justin E. H. Smith, 1-2. Oxford, UK: Oxford University Press, 2014. 
Nadeau, Robert, and Menas Kafatos. The Non-local Universe: The New Physics and Matters of the Mind. Oxford, UK: Oxford University Press, 1999.

Nadelhoffer, Thomas, and Daniela Goya Tocchetto. "The Potential Dark Side of Believing in Free Will (and Related Concepts)." In Exploring the Illusion of Free Will and Moral Responsibility, ed. Gregg D. Caruso, 121-140. Lanham, MD: Lexington Books, 2013.

Nadesan, Majia. Crisis Communication, Liberal Democracy, and Ecological Sustainability: The Threat of Financial and Energy Complexes in the Twenty-First Century. New York, NY: Lexington Books, 2016.

. "Neofeudalism and the Financial Crisis: Implications for Occupy Wall Street." In Understanding Occupy from Wall Street to Portland, eds. Renee Guarriello Heath, Courtney Vail Fletcher, and Ricardo Munoz, 35-52. Lanham, MD: Lexington Books, 2013.

Nagel, Ernest. The Structure of Science: Problems in the Logic of Scientific Explanation. Harcourt, Brace \& World, 1961.

Nagel, Thomas. Mind and Cosmos: Why the Materialist Neo-Darwinian Conception of Nature is Almost Certainly False. Oxford, UK: Oxford University Press, 2012.

Nash, Ronald H. Is Jesus the Only Savior? Grand Rapids, MI: Zondervan, 2010. . Poverty and Wealth: The Christian Debate Over Capitalism. Westchester, IL: Crossway Books, 1986.

Poverty and Wealth: Why Socialism Doesn't Work. Richardson, TX: Probe Books, 1986.

The Light of the Mind: St. Augustine's Theory of Knowledge. Lima, OH: Academic Renewal Press, 2003.

Nasr, Seyyed Hossein. The Heart of Islam: Enduring Values for Humanity. New York, NY: HarperCollins, 2004.

Natanson, Maurice A. The Social Dynamics of George H. Mead. The Hague, The Netherlands: Martinus Nijhoff, 1973.

Nathanson, Michael. Between Myth \& Mandate: Geopolitics, Pseudohistory \& the Hebrew Bible. Bloomington, IN: AuthorHouse, 2014.

Naveh, Zev. Transdisciplinary Challenges in Landscape Ecology and Restoration Ecology-An Anthology. Dordrecht, The Netherlands: Springer, 2007.

Nayar, Pramod K. Posthumanism. New York, NY: John Wiley \& Sons, 2014.

Neal, Aubrey. How Skeptics Do Ethics: A Brief History of the Late Modern Linguistic Turn. Calgary, Alberta, Canada: University of Calgary Press, 2007.

Nedelcu, Marla A. Samaan. "What Makes Humans Human? Personal Ontology in the Creation Narrative of Day Six (Gen. 1:24-31)." In Scripture and Philosophy: Essays Honoring the Work and Vision of Fernando Luis Canale, eds. Tiago Arrais, Kenneth Bergland, and Michael F. Younker, 382-407. Berrien Springs, MI: Adventist Theological Society Publications, 2016. 
Nelson, David W. Judaism, Physics and God: Searching for Sacred Metaphors in a Post-Einstein World. Woodstock, VT: Jewish Lights Publishing, 2005.

Nelson, Robert H. God? Very Probably: Five Rational Ways to Think about the Question of God. Eugene, OR: Cascade Books, 2015.

Nessan, Craig L. The Vitality of Liberation Theology. Eugene, OR: Pickwick Publications, 2012.

Neuman, Jake. It Is All About Islam. Ingram Book Group, 2013.

Neuman, Yair. Reviving the Living: Meaning Making in Living Systems. Amsterdam, The Netherlands: Elsevier, 2008.

Neumayr, George. The Political Pope: How Pope Francis is Delighting the Liberal Left and Abandoning Conservatives. New York, NY: Hachette Book Group, 2017.

Newlands, George. The Transformative Imagination: Rethinking Intercultural Theology. Burlington, VT: Ashgate, 2006.

Newsome, William T. "Human Freedom and 'Emergence."' In Downward Causation and the Neurobiology of Free Will, eds. Nancey Murphy, George F. R. Ellis, and Timothy O'Connor, 53-62. New York, NY: Springer-Verlag, 2009.

Niaz, Mansoor. Critical Appraisal of Physical Science as a Human Enterprise: Dynamics of Scientific Progress. Dordrecht, The Netherlands: Springer, 2009.

Nichols, Tom. The Death of Expertise: The Campaign Against Established Knowledge and Why it Matters. Oxford, UK: Oxford University Press, 2017.

Nickolaus, Gary. The Physics of God: Quantum Mechanics and All That Is, On Earth As It Is In Heaven. Bloomington, IN: Xlibris, 2012.

Nielsen, Kai. Naturalism and Religion. Amherst, NY: Prometheus Books, 2001.

Ninet, Antoni Abat i. Constitutional Violence: Legitimacy, Democracy and Human Rights. Edinburgh, UK: Edinburgh University Press, 2013.

No Author. "2016 General Election: Trump vs. Sanders." At http://elections.huffingtonpost.com/pollster/2016-general-election-trump-vs-sanders (accessed October 23, 2017).

No Author. "Atheism Doubles Among Generation Z." At https://www.barna.com/research/atheism-doubles-among-generation-z/ (accessed January $24,2018)$.

No Author. Document at http://www.anti-relativity.com/primer3.htm (accessed August 22, 2017).

No Author. Document at https://en.wikipedia.org/wiki/List_of_U.S._presidential_campaign_slogans (accessed May 12, 2017).

No Author. "General Election: Trump vs. Sanders.” At https://www.realclearpolitics.com/epolls/2016/president/us/general_election_trump_vs_sand ers -5565.html (accessed October 23, 2017). 
No Author. The Royal Embassy of Saudi Arabia, "Islam and the Development of Knowledge." In Encountering the World of Islam, ed. Keith E. Swartley, 63-74. Downers Grove, IL: InterVarsity Press, 2005.

No Author. "Majority of World Population Support Globalism." At https://www.straitstimes.com/world/europe/majority-of-world-population-supports-globalis m-survey-finds (accessed January 20, 2019).

No Author. "Not Even Wrong," in Wikipedia: The Free Encyclopedia. At https://en.wikipedia.org/wiki/Not_even_wrong (accessed October 14, 2017).

No Author. "The Most Embarrassing Graph in Modern Physics." At http://www.preposterousuniverse.com/blog/2013/01/17/the-most-embarrassing-graph-in-m odern-physics/ (accessed August 24, 2017).

No Author. The Declaration of Independence \& the Constitution of the United States. New York, NY: Bantam Dell, 2008.

No Author. “Two Cultures Harmonized Under God.” Life Magazine (April 20, 1962).

No author. "We Hold These Truths": The Meaning of the Declaration: The Natural Rights Principles on which the Nation's Government is Based as Formulated in the Declaration of Independence. Culver City, CA: MindSparks, 2008.

Noble, Tim. The Poor in Liberation Theology: Pathway to God Or Ideological Construct? New York, NY: Routledge, 2014.

Nochimson, Martha. David Lynch Swerves: Uncertainty from Lost Highway to Inland Empire. Austin, TX: University of Texas Press, 2013.

Noll, Mark A. The Scandal of the Evangelical Mind. Grand Rapids, MI: Eerdmans, 1994.

Norris, Christopher. Quantum Theory and the Flight from Realism. New York, NY: Routledge, 2000.

Norsen, Travis. Foundations of Quantum Mechanics: An Exploration of the Physical Meaning of Quantum Theory. Cham, Switzerland: Springer, 2017.

Northcott, Michael S. A Political Theology of Climate Change. Grand Rapids, MI: Eerdmans, 2013.

Nosek, B. A., et al. "Estimating the Reproducibility of Psychological Science." In Science 28, Vol 349 No. 6251 (August, 2015): 943-951. At

http://science.sciencemag.org/content/349/6251/aac4716.full (accessed January 10, 2018).

Novak, Michael, and Paul Adams. Social Justice Isn't What You Think It Is. New York, NY: Encounter Books, 2015.

Numbers, Ronald L. "Scientific Creationism and Intelligent Design." In The Cambridge Companion to Science and Religion, ed. Peter Harrison, 127-147. Cambridge, UK: Cambridge University Press, 2010.

Nunez, Paul L. Brain, Mind, and the Structure of Reality. Oxford, UK: Oxford University Press, 2010. 
Oard, Mike. Flood by Design: Receding Water Shapes the Earth's Surface. Green Forest, AR: Master Books, 2011.

Ochs, Peter. Peirce, Pragmatism and the Logic of Scripture. Cambridge, UK: Cambridge University Press, 1998.

O'Connor, Lydia, and Daniel Marans. "Here Are 16 Examples of Donald Trump Being Racist." At http://www.huffingtonpost.com/entry/president-donald-trump-racist-examples_us_584f2ccae 4b0bd9c3dfe5566 (accessed December 13, 2016).

Odifreddi, Piergiorgio. "And the Eternal Zeno Springs to Mind," in The Two Cultures: Shared Problems, eds. Ernesto Carafoli, Gian Antonio Danieli, Giuseppe 0. Longo, 39-50. Milano, Italy: Springer-Verlag, 2009.

Oerton, Richard. The Nonsense of Free Will: Facing Up to a False Belief. Leicestershire, UK: Matador, 2012.

Ogden, W. Russell. The Freedom Book: Choosing Your Future. Bloomington, IN: WestBow Press, 2011.

O'Hare, Terrence D. The Sabbath Complete: And the Ascendency of First-Day Worship. Eugene, OR: Wipf \& Stock, 2015.

Ojewole, Afolarin Olutunde. The Seed in Genesis 3:15: An Exegetical and Intertextual Study. Berrien Springs, MI: Adventist Theological Society Publications, 2002.

O’Keefe, Tim. Epicureanism. New York, NY: Routledge, 2014.

Epicurus on Freedom. Cambridge, UK: Cambridge University Press, 2005.

Olafson, Frederick A. Naturalism and the Human Condition: Against Scientism. New York, NY: Routledge, 2001.

Oliveira, Lauro Ericksen C. De. "A Phenomenological Justification for the Flexibilization of Protection Principle in the Labor Law System by the Argument of Reality's Feasibility Primacy Principle being used on Employers Side." In Prisma Jur. Vol. 12 \#2 (Dec. 2013): 549-577.

Ollenburger, Ben C. "From Timeless Ideas to the Essence of Religion: Method in Old Testament Theology Before 1939." In The Flowering of Old Testament Theology: A Reader in Twentieth-Century Old Testament Theology, 1930-1990, eds., Ben C. Ollenburger, Elmer A. Martens, and Gerhard F. Hasel, 3-19. Winona Lake, IN: Eisenbrauns, 1992.

Olsen, Glenn W. On the Road to Emmaus: The Catholic Dialogue with America and Modernity. Washington, D.C.: The Catholic University of America Press, 2012.

Olson, Lloyd A. Eternal Security: Once Saved Always Saved. Mustang, OK: Tate Publishing, 2007.

Olson, Roger E. Arminian Theology: Myths and Realities. Downers Grove, IL: InterVarsity Press, 2006.

O'Regan, Cyril. "Martin Heidegger and Christian Wisdom." In Christian Wisdom Meets Modernity, ed. Kenneth Oakes, 37-58. New York, NY: Bloomsbury T\&T Clark, 2016.

Oriols, Xavier, and Jordi Mompart, eds., Applied Bohmian Mechanics: From Nanoscale Systems to Cosmology. Singapore: Pan Stanford Publishing, 2012. 
Ornstein, Allan C. Excellence Vs. Equality: Can Society Achieve Both Goals? New York, NY: Routledge, 2016.

O'Rourke, J. J. The Problem of Freedom in Marxist Thought: An Analysis of the Treatment of Human Freedom by Marx, Engels, Lenin and Contemporary Soviet Philosophy. Dordrecht, Holland: D. Reidel Publishing, 1974.

Osborn, Ronald E. Death Before the Fall: Biblical Literalism and the Problem of Animal Suffering. Downers Grove, IL: InterVarsity Press, 2014.

Osborne, Grant R. The Hermeneutical Spiral: A Comprehensive Introduction to Biblical Interpretation. Downers Grove, IL: IVP, 2006.

Osborne, Hannah. "Stephen Hawking AI Warning: Artificial Intelligence Could Destroy Civilization." At http://www.newsweek.com/stephen-hawking-artificial-intelligence-warning-destroy-civilizati on-703630 (accessed November 7, 2017).

Osborne, Roger. Of the People, By the People: A New History of Democracy. London, UK: Random House, 2011.

Ostrowski, James. Progressivism: A Primer on the Idea Destroying America. Buffalo, NY: Cazenovia Books, 2014.

Owens, Ron. Solon of Athens: Poet, Philosopher, Soldier, Statesman. Portland, OR: Sussex Academic Press, 2010.

Ozment, Steven. The Age of Reform 1250-1550: An Intellectual and Religious History of Late Medieval and Reformation Europe. New Haven, CT: Yale University Press, 1980.

Pabst, Adrian. Metaphysics: The Creation of Hierarchy. Grand Rapids, MI: Eerdmans, 2012.

Pagallo, Ugo. "Aliquid Est Sine Ratione: On Some Philosophical Consequences of Chaitin's Quest for $\Omega . "$ In Randomness and Complexity: From Leibniz to Chaitin, eds. Cristian S. Calude and Gregory J. Chaitin, 287-300. Toh Tuk Link, Singapore: World Scientific Publishing, 2007.

Pagden, Anthony. The Enlightenment: And Why it Still Matters. Oxford, UK: Oxford University Press, 2013.

Pagels, Heinz R. The Cosmic Code: Quantum Physics as the Language of Nature. Mineola, NY: Dover Publications, 1982.

Pais, Abraham. J. Robert Oppenheimer: A Life. Oxford, UK: Oxford University Press, 2006. Subtle is the Lord: The Science and Life of Albert Einstein. New York, NY: Oxford University Press, 1982.

. "The Image of Physics." In The Changing Image of the Sciences, eds. Ida H. Stamhuis, Teun Koetsier, Cornelis de Pater and Albert van Helden, 85-104. Dordrecht, The Netherlands: Kluwer Academic Publishers, 2002.

Palmer, Brian. "What Is the Answer to Zeno's Paradox? Why Achilles Actually Can Catch a Tortoise in a Race." At http://www.slate.com/articles/health_and_science/science/2014/03/zeno_s_paradox_how_to_ explain_the_solution_to_achilles_and_the_tortoise.html (Accessed January 27, 2017). 
Palmer, Kent D. "Advanced Systems Theory for Systems Engineers: Introduction to the Anti-thesis." At http://holonomic.net/sd00V01.pdf (accessed September 16, 2018).

"An Approach Toward Being, Existence, and Manifestation: From the Kindness of Being to the Face of the World and Beyond." At http://archonic.net/fe00v01.pdf (accessed September 16, 2018).

"Heidegger's Error: Philosophy without Sophia." At https://www.academia.edu/35704153/Heideggers_Error_Philosophy_without_Sophia (accessed September 16, 2018).

“How Simultaneous Multiple Independent Times Impact Our 'Ways of Being': Dimensional Splintering of Time Modulates the Kinds of Being." At https://www.academia.edu/35853850/How_Simultaneous_Multiple_Independent_Times_Impa ct_Our_Ways_of_Being (accessed September 16, 2018).

"Intertwining of Duality and Nonduality." At

http://www.isss.org/2000meet/papers/20163.pdf (accessed September 16, 2018).

"Questioning the Terminology of Nonduality: An Exploration of the Foundations of Nonduality." At http://nondual.net/nds11a03.pdf (accessed September 16, 2018).

The Fragmentation of Being and the Path Beyond the Void: Speculations in an Emergent Onto-Mythology. Orange, CA: Apeiron Press, 2007.

Paluch, Stefanie. Remote Service Technology Perception and its Impact on Customer-Provider Relationships: An Empirical Exploratory Study in a B-to-B-Setting. Doctoral Thesis, TU Dortmund University, 2011.

Parfit, Derek. On What Matters (two-volume set), ed. Samuel Scheffler. Oxford, UK: Oxford University Press, 2011.

Parris, David Paul. Reading the Bible with the Giants: How 2000 Years of Biblical Interpretation Can Shed New Light on Old Texts. Eugene, OR: Cascade Books, 2015.

Parker, Jan. "Speaking Out in a Digital World: Humanities Values, Humanities Processes." In Humanities in the Twenty-First Century: Beyond Utility and Markets, eds. Eleonora Belfiore and Anna Upchurch, 44-62. Hampshire, UK: Palgrave Macmillan, 2013.

Parkes, Graham. "Introduction.” In Heidegger and Asian Thought, ed. Graham Parkes, 1-14. Honolulu, HI: University of Hawaii Press, 1987.

Parsons, Stephen D. "Hayek and the Limitations of Knowledge; Philosophical Aspects." In Hayek: Economist and Social Philosopher: A Critical Retrospect, ed. Stephen F. Frowen, 63-86. New York, NY: St. Martin's Press, 1997.

Partee, Charles. The Theology of John Calvin. Louisville, KT: Westminster John Knox Press, 2008.

Pate, C. Marvin. From Plato to Jesus: What Does Philosophy Have to Do with Theology? Grand Rapids, MI: Kregel, 2011.

Paterson, Robert. The Philosophy of the Atonement. Glasgow: David Bryce and Son, 1892. 
Patterson, Orlando. Freedom in the Making of Western Culture Vol. 1. New York, NY: BasicBooks, 1991.

Pattison, George. The Later Heidegger. New York, NY: Routledge, 2000.

Patton, Stacey. "MLA President Offers a Sobering Critique of Graduate Education in the Humanities." At http://www.chronicle.com/article/A-Stark-Appraisal-of-Graduate/136171/ (accessed December 6, 2012).

Paul, Ron. The Revolution: A Manifesto. New York, NY: Grand Central Publishing, 2008.

Peacock, Kent A. The Quantum Revolution: A Historical Perspective. Westport, CT: Greenwood Press, 2008.

Pearl, Joel. A Question of Time: Between Philosophy and Psychoanalysis (in Hebrew). Ramat Gan, Israel: Bar-Ilan University Press, 2011. . A Question of Time: Freud in the Light of Heidegger's Temporality. Amsterdam, The Netherlands: Rodopi, 2013.

Pearcey, Nancy R., and Charles B. Thaxton, The Soul of Science: Christian Faith and Natural Philosophy. Wheaton, IL: Crossway Books, 1994.

Peat, F. David. From Certainty to Uncertainty: The Story of Science and Ideas in the Twentieth Century. Washington, D.C.: Joseph Henry Press, 2002.

Infinite Potential: The Life and Times of David Bohm. Jackson, TN: Perseus Books, 1997. Pathways of Chance. Grosseto, Italy: Pari Publishing, 2007.

Pech, Wesley. "Behavioral Economics and the Economics of Keynes." At http://webs.wofford.edu/pechwj/pech_milan_behavioral_keynes_27april09.pdf (accessed October 24, 2017).

Peckham, John C. Canonical Theology: The Biblical Canon, Sola Scriptura, and Theological Method. Grand Rapids, MI: Eerdmans, 2016.

The Love of God: A Canonical Model. Downers Grove, IL: InterVarsity Press, 2015.

Theodicy of Love: Cosmic Conflict and the Problem of Evil. Grand Rapids, MI: Baker, 2018.

Pedersen, Hans. "Approaching the Debate over Tensed and Tenseless Theories of Time from a Heideggerian Perspective." In Being Amongst Others: Phenomenological Reflections on the Life-World, ed. Eric Chelstrom, 12-23. Angerton Gardens, UK: Cambridge Scholars Press, 2006.

Peirce, Charles Sanders. Peirce on Signs, ed. James Hoopes. Chapel Hill, NC: The University of North Carolina Press, 1991.

Pennock, Robert T. Tower of Babel: The Evidence Against the New Creationism. Cambridge, MA: The MIT Press, 1999.

Penrose, Roger. Shadows of the Mind: A Search for the Missing Science of Consciousness. Oxford, UK: Oxford University Press, 1994. 
. The Emperor's New Mind: Concerning Computers, Minds, and the Laws of Physics. Oxford, UK: Oxford University Press, 1999.

. The Road to Reality: A Complete Guide to the Laws of the Universe. New York, NY: Random House, 2011.

Penrose, Roger, and C. J. Isham, ed. Quantum Concepts in Space and Time. Oxford, UK: Clarendon Press, 1986.

Pensgard, David. Existential Temporality as Fore-Ignorance: Implications for Divine Foreknowledge. MARS Thesis, Liberty University B. R. Lakin School of Religion, 2008.

Pepperell, Robert. The Posthuman Condition: Consciousness Beyond the Brain. Bristol, UK: Intellect Books, 2003.

Pereboom, Derk. Free Will, Agency, and the Meaning of Life. Oxford, UK: Oxford University Press, 2014. Living Without Free Will. Cambridge, UK: Cambridge University Press, 2001.

Pérez, Joseph. The Spanish Inquisition: A History, tr. Janet Lloyd. London, UK: Yale University Press, 2005.

Perry, Philip. "Study Contends There Are Twice as Many Atheists in America as Polls Show." At http://bigthink.com/philip-perry/is-atheism-growing-in-america (accessed April 30, 2017).

Person, Jr., Sidney A. Reflections on American Progressivism. New Brunswick, NJ: Transaction Publishers, 2014.

Perumalil, Augustine. Critical Issues in the Philosophy of Science and Religion. Kashmere Gate, Delhi: Indian Society for Promoting Christian Knowledge, 2006.

Peters, Curtis. Kant's Philosophy of Hope. New York, NT: Peter Lang, 1993.

Peters, F. E. The Monotheists: Jews, Christians, and Muslims in Conflict and Competition: The Words and Will of God Vol. II. Princeton, NJ: Princeton University Press, 2003.

Peters, Michael A. Education, Philosophy and Politics: The Selected Works of Michael A. Peters. New York, NY: Routledge, 2012.

Peters, Michael A., ed. Heidegger, Education, and Modernity. Lanham, MD: Rowman \& Littlefield, 2002.

Peters, Ted. “David Bohm, Postmodernism and the Divine.” In Zygon $20 \# 2$ (June 1985): 193-217.

Petersen, A. “The Philosophy of Niels Bohr.” In Bulletin of the Atomic Scientist 19 \#7 (1963): 8-14.

Peterson, Jordan B. Maps of Meaning: The Architecture of Belief. New York, NY: Routledge, 1999.

Peterman, John. On Ancient Philosophy. Belmont, CA: Thomson \& Wadsworth, 2008.

Petkov, Vesselin. Relativity and the Nature of Spacetime. Berlin, Germany: Springer-Verlag, 2009.

Petruccioli, Sandro. Atoms, Metaphors and Paradoxes: Niels Bohr and the Construction of a New Physics. Cambridge, UK: Cambridge University Press, 1993. 
Petto, Andrew J., and Laurie R. Godfrey, eds. Scientists Confront Intelligent Design and Creationism. New York, NY: W. W. Norton \& Company, 2007.

Petzet, Heinrich Wiegand. Encounters and Dialogues with Martin Heidegger, 1929-1976, tr. Parvis Emad and Kenneth Maly. Chicago, IL: The University of Chicago Press, 1993.

Peuquet, Donna J. Representations of Space and Time. New York, NY: The Guilford Press, 2002.

Pfoh, Emanuel. The Emergence of Israel in Ancient Palestine: Historical and Anthropological Perspectives. New York, NY: Routledge, 2009.

Phan, Peter C., and Diana Hayes, eds. Many Faces, One Church: Cultural Diversity and the American Catholic Experience. New York, NY: Sheed \& Ward, 2005.

Philipse, Herman. "Antonin Scalia's Textualism in Philosophy, Theology and Judicial Interpretation of the Constitution." In Holy Writ: Interpretation in Law and Religion, ed. Arie-Jan Kwak, 15-46. New York, NY: Routledge, 2016.

Philpott, Daniel, and Ryan T. Anderson, eds. A Liberalism Safe for Catholicism: Perspectives from 'The Review of Politics'. Notre Dame, IN: Notre Dame University Press, 2017.

Piekkola, Brad. Conceptual and Historical Issues in Psychology. Thousand Oaks, CA: SAGE Publications, 2017.

Pihlström, Sami. Naturalizing the Transcendental: A Pragmatic View. Amherst, NY: Humanity Books, 2003.

. "Pragmatistic Influences in Twentieth Century Finnish Philosophy: From Pre-analytic to Postanalytic Thought." In Analytic Philosophy in Finland, ed. Leila Haaparanta and Ilkka Niiniluoto, 511-536. Amsterdam, The Netherlands: Rodopi, 2003.

Pike, Nelson. God and Timelessness. London, UK: Routledge \& K. Paul, 1970.

Pink, Arthur W. The Attributes of God. Grand Rapids, MI: Baker Books, 2006.

Pinnock, Clark H. A Wideness in God's Mercy: The Finality of Jesus Christ in a World of Religions. Grand Rapids, MI: Zondervan, 1992.

Pippin, Stephen. Once Saved Always Saved: Satan's Greatest Trick. Bloomington, IN: WestBow, 2015.

Pirsig, Robert M. "Subjects, Objects, Data and Values." In Quantum Structures and the Nature of Reality: The Indigo Book of Einstein Meets Magritte: An Interdisciplinary Reflection, eds. Diederik Aerts and Jaroslaw Pykacz, 79-98. Dordrecht, the Netherlands: Kluwer Academic Publishers, 1999.

Plank, William. The Quantum Nietzsche: The Will to Power and the Nature of Dissipative Systems. Lincoln, NE: Writers Club Press, 1998.

Plantinga, Alvin. "Scientism: Who Needs It?" In Scientism: Prospects and Problems, eds. Jeroen de Ridder, Rik Peels, and René van Woudenberg, 220-232. Oxford, UK: Oxford University Press, 2018.

Where the Conflict Really Lies: Science, Religion, \& Naturalism. Oxford, UK: Oxford University Press, 2011. 
Plass, Paul. "Neoplatonism." In Medieval Italy: An Encyclopedia L-Z, Vol. 2, ed. Christopher Kleinhenz, 764-766. New York, NY: Routledge, 2004.

Plato. Timaeus, tr. Peter Kalkavage. Indianapolis, IN: Hackett Publishing, 2016.

Plotnitsky, Arkady. Complementarity: Anti-Epistemology After Bohr and Derrida. Durham, NC: Duke University Press, 1994.

. Epistemology and Probability: Bohr, Heisenberg, Schrödinger, and the Nature of Quantum-Theoretical Thinking. New York, NY: Springer, 2010.

Plumer, Bradford. "The Two-Income Trap." At

http://www.motherjones.com/politics/2004/11/two-income-trap (accessed May 15, 2017).

Plummer, Robert L. 40 Questions about Interpreting the Bible. Grand Rapids, MI: Kregel, 2010.

Poerksen, Bernhard. The Certainty of Uncertainty: Dialogues Introducing Constructivism. Exeter, UK: Imprint Academic, 2004.

Pöggeler, Otto. Der Denkweg Martin Heideggers. Neske, 1990.

"Heidegger, Nietzsche, and Politics." In The Heidegger Case: On Philosophy and Politics, eds. Tom Rockmore \& Joseph Margolis, 114-140. Philadelphia, PA: Temple University Press, 1992.

Polanyi, Michael. The Logic of Liberty. Chicago, IL: The University of Chicago Press, 1951.

Polkinghorne, Donald E. The Case for a Judgment-Based Practice of Care. Albany, NY: State University of New York Press, 2004.

Polkinghorne, John. One World: The Interaction of Science and Theology. West Conshohocken, PA: Templeton Foundation Press, 2007.

. Science and Religion in Quest of Truth. London, UK: Yale University Press, 2011.

Science and the Trinity: The Christian Encounter with Reality. London, UK: Yale University Press, 2004.

Polkinghorne, John, ed. The Trinity and an Entangled World: Relationality in Physical Science and Theology. Grand Rapids, MI: Eerdmans, 2010.

Polt, Richard. Heidegger: An Introduction. London, UK: Routledge, 1999.

Pontifical Council for Justice and Peace. Compendium of the Social Doctrine of the Church. Washington, D. C.: USCCB, 2004.

Popper, Karl. Conjectures and Refutations. London, UK: Routledge \& Kegan Paul, 1963. . Quantum Theory and the Schism in Physics: From the Postscript to the Logic of Scientific Discovery. New York, NY: Routledge, 2000.

The Logic of Scientific Discovery. New York, NY: Routledge, 2002. 
. The World of Parmenides: Essays on the Presocratic Enlightenment, ed. Arne F. Petersen. New York, NY: Routledge, 1998.

Porter, Theodore M. Trust in Numbers: The Pursuit of Objectivity in Science and Public Life. Princeton, NJ: Princeton University Press, 1995.

Posner, Richard A. Law, Pragmatism, and Democracy. New York, NY: Harvard University Press, 2003.

Potkay, Adam. The Story of Joy: From the Bible to Late Romanticism. Cambridge, UK: Cambridge University Press, 2007.

Pottenger, John R. The Political Theory of Liberation Theology: Toward a Reconvergence of Social Values and Social Science. Albany, NY: State University of New York Press, 1989.

Powell, James Lawrence. The Inquisition of Climate Science. New York, NY: Columbia University Press, 2011.

Poythress, Vern S. Redeeming Science: A God-Centered Approach. Wheaton, IL: Crossway Books, 2006.

Preez, Ron du. Feast-Keeping and the Faithful: Should Adventists Observe the Annual Feast Days? Lansing, MI: Omega Media, 2011.

Price, Huw. Time's Arrow and Archimedes' Point: New Directions for the Physics of Time. Oxford, UK: Oxford University Press, 1997.

Prickett, Stephen. Narrative, Religion and Science: Fundamentalism Versus Irony, 1700-1999. New York, NY: Cambridge University Press, 2002.

Priestley, W. M. Calculus: A Historical Approach. New York, NY: Springer-Verlag, 1979.

Prigg, Mark. "Why We Fall Into a 'Facebook Hole': Researchers Say Our Perception of Time is ALTERED When We Go Online." At http://www.dailymail.co.uk/sciencetech/article-4201018/Face-really-alter-perception-time.ht ml (accessed February 7, 2017).

Prosser, Simon. Experiencing Time. Oxford, UK: Oxford University Press, 2016.

Provan, Iain William, V. Philips Long, and Tremper Longman III. A Biblical History of Israel. Louisville, KT: Westminster John Knox Press, 2003.

Prychitko, David L., ed. Why Economists Disagree: An Introduction to the Alternative Schools of Thought. Albany, NY: State University of New York Press, 1998.

Pryor, Adam. Body of Christ Incarnate for You: Conceptualizing God's Desire for the Flesh. Lanham, MD: Lexington Books, 2016.

Przyłębski, Andrzej. “Gadamer's Critique of the Instrumental Philosophy of Language.” In Gadamer's Hermeneutics and the Art of Conversation, ed. Andrzej Wierciński, 231-242. New Brunswick, NJ: Transaction Publishers, 2011.

Sense, Meaning, and Understanding: Towards a Systematic Hermeneutical Philosophy. Zürich, Switzerland: Lit Verlag, 2013. 
Puddefoot, John, and Irène Fernandez. "Mathematics and Theology." In the Encyclopedia of Christian Theology: Vol. 1. A-F., ed. Jean-Yves Lacoste, 1010-1013. New York, NY: Routledge, 2005.

Pugliese, Marc A. The One the Many and the Trinity: Joseph A. Bracken and the Challenge of Process Metaphysics. Washington, D. C.: The Catholic University of America Press, 2011.

Pyle, Andrew. Atomism and Its Critics: From Democritus to Newton. New York, NY: Thoemmes Press, 1997.

Pylkkänen, Paavo. “Can Quantum Analogies Help Us to Understand the Process of Thought?” In Brain and Being: At the Boundary Between Science, Philosophy, Language and Arts, eds. Gordon G. Globus, Karl H. Pribram, and Giuseppe Vitiello, 165-196. Philadelphia, PA: John Benjamins, 2004.

"Consciousness in the Light of Quantum Theory." In Integrating Eastern and Western Perspectives, eds. Prem Saran Satasangi, Stuart Hameroff, Vishal Sani, Pami Dua, 23-34. New Delhi, India: New Age Books, 2016.

"Fundamental Physics and the Mind: Is There a Connection?" In Quantum Interaction, eds. Harald Atmanspacher, Claudia Bergomi, Thomas Filk, and Kirsty Kitto, 3-11. New York, NY: Springer, 2015.

Mind, Matter and the Implicate Order. Berlin, Germany: Springer-Verlag, 2007.

“The Quantum Epoché." In Progress in Biophysics and Molecular Biology Vol. 119, Issue 3 (December 2015): 332-340.

Pylkkö, Leena. "Back to Content: Nelson Goodman as Philosophical Basis for Multiliteracy." Qualitative and Quantitative Methods in Libraries Vol. 4 (2014): 909-916.

Pylkkö, Pauli, with Leena Pylkkö. Ernst Jünger, Marmorijyrkänteillä, tr. Pauli Pylkkö. Kustavi, Finland: Uuni, 2006.

Pylkkö, Pauli. Ajatus ja Kädet. Taivassalo, Finland: Uuni, 2013.

.Dasein Naturalized." In Analecta Husserliana, Vol. XLIX, eds. Marlies Kronegger and AnnaTeresa Tymieniecka, 203-218. Dordrecht, The Netherlands: Kluwer Academic Publishers, 1996.

. "Eliminative Holism as a Solution to Bohr's Puzzle of Two Languages." In Brain, Mind and Physics, eds. Paavo Pylkkänen, Pauli Pylkkö, and Antti Hautamäki, 140-156. Amsterdam, Netherlands: IOS Press, 1997.

“Fysiikkaviikari Filosofian Ihmemaassa: Eli Olisiko Tiedeuskovaisuutta Hoidettava Lääkkeillä Ja Kirurgialla? Kari Enqvistin Kuoleman ja unohtamisen aikakirjat ja muita hänen kirjoituksiaan." At http://www.uunikustannus.fi/fysiikkaviikari.pdf (accessed June 10, 2015).

. "Huomautuksia Arto Tukiaisen esseeseen "Katsokaa taivaan lintuja." At http://www.artotukiainen.net/pylkko.html (accessed April 5, 2011).

"Indeterminacy and Experience." In Current Trends in Connectionism: Proceedings of the 1995 Swedish Conference on Connectionism, eds. Lars F. Niklasson and Mikael B. Bodén, 321-329. Hillsdale, NJ: Lawrence Erlbaum, 1995.

Kielikuva ja Mielikuva-Ja Muita Dialektisia Esseitä. Taivassalo, Finland: Uuni, 2015. 
. “Lemuurien yö-Ernst Jünger ja kansallissosialismi.” In Ernst Jünger-Marmorijyrkänteillä, tr. Pauli Pylkkö, 155-198. Kiel, Finland: Uuni Verlag, 1999.

. Logic, Formal Languages, and Formal Language Identification: Some Logical Properties of the Languages in the Chomsky Hierarchy, and an Interrogative Model of Formal Language Identification. Florida State University doctoral dissertation, 1988.

Luopumisen Dialektiikka. Taivassalo, Finland: Uuni, 2009.

. "Ontological Nihilism, or, the Meaning of the So-called Finnish Passive Construction." In Snow, Forest, Silence: The Finnish Tradition of Semiotics, ed. Eero Tarasti, 54-66. Bloomington, IN: Indiana University Press, 1999.

. Richard Wagner Ajattelijana: Antimodernisti, Luonnonmystikko, Gnostikko. Kiel, Finland: Uuni Verlag GbR, 2005.

. "Schelling ja panteismikiista." In F. W. J. Schelling: Ihmisen Vapaudesta, tr. Pauli Pylkkö, 141222. Kiel, Finland: Uuni Verlag, 2004.

"Suomen kieli on vetäytymässä ja jättämässä meidät rauhaan toisiltamme." In Filosofinen, Niin \& Näin, Aikakauslehti (1/98). At http://www.netn.fi/198/netn_198_pylkko.html (accessed January 18, 2011).

. The Aconceptual Mind: Heideggerian Themes in Holistic Naturalism. Amsterdam, The Netherlands: John Benjamins Publishing, 1998.

Quealy, Kevin. "Your Rabbi? Probably a Democrat. Your Baptist Pastor? Probably a Republican. Your Priest? Who Knows." At https://www.nytimes.com/interactive/2017/06/12/upshot/the-politics-of-americas-religiousleaders.html?src=twr\&_r=0 (accessed June 12, 2017).

Quincey, Christian de. Radical Nature: Rediscovering the Soul of Matter. Montpelier, VT: Invisible Cities Press, 2002.

Rabins, Peter V. The Why of Things: Causality in Science, Medicine, and Life. New York, NY: Columbia University Press, 2013.

Radin, Dean. Minds: Extrasensory Experiences in a Quantum Reality. New York, NY: Pocket Books with Simon \& Schuster, 2006.

Raengo, Alessandra. Critical Race Theory and Bamboozled. New York, NY: Bloomsbury, 2016.

Raffl, Celina E. “The Two Cultures: A Third Look." In Cybernetics and Systems, ed. R. Trappl, 318-323. Vienna, Austria: Austrian Society for Cybernetic Studies, 2006.

Raffnsøe, Sverre. Philosophy of the Anthropocene: The Human Turn. Hampshire, UK: Palgrave Macmillan, 2016.

Mohammad Rafi, “Re-Working the Philosophy of Martin Heidegger: Iran’s Revolution of 1979 and Its Quest for Cultural Authenticity." At

http://www.telospress.com/re-working-the-philosophy-of-martin-heidegger-irans-revolutionof-1979-and-its-quest-for-cultural-authenticity/ (accessed Friday, April 19, 2013). 
Ramirez-Christensen, Esperanza. Emptiness and Temporality: Buddhism and Medieval Japanese Poetry. Stanford, CA: Stanford University Press, 2008.

Raper, Jonathan. Multidimensional Geographic Information Science. New York, NY: Taylor \& Francis, 2005.

Rapolu, Bhoopathi. The Race for Work: Escape Automation, Transform Your Career and Thrive in the Second Machine Age. Charleston, SC: CreateSpace, 2016.

Rapoport, Diego Lucio. "Hyper Klein Bottle Logophysics Ontopoiesis of the Cosmos and Life." In Phenomenology of Space and Time: The Forces of the Cosmos and the Ontopoietic Genesis of Life: Book Two, ed. Anna-Teresa Tymieniecka, 275-350. London, UK: Springer, 2014.

Rapport, Nigel, and Joanna Overing. Social and Cultural Anthropology. New York, NY: Routledge, 2002.

Raschke, Carl A. Force of God: Political Theology and the Crisis of Liberal Democracy. New York, NY: Columbia University Press, 2015. . GloboChrist: The Great Commission Takes a Postmodern Turn. Grand Rapids, MI: Baker Academic, 2008.

The Digital Revolution and the Coming of the Postmodern University. New York, NY: Routledge Falmer, 2003.

The Next Reformation: Why Evangelicals Must Embrace Postmodernity. Grand Rapids, MI: Baker Academic, 2004.

Ratner, Carl. Cultural Psychology: Theory and Methods. New York, NY: Springer, 2002.

Raud, Rein. “The Existential Moment: Re-reading Dōgen's Theory of Time.” In Philosophy East and West Vol. 62, No. 2 (April 2012): 153-173.

Reder, Melvin W. Economics: The Culture of a Controversial Science. Chicago, IL: The University of Chicago Press, 1999.

Redhead, Michael. "The Conventionality of Simultaneity." In Philosophical Problems of the Internal and External Worlds: Essays on the Philosophy of Adolf Grünbaum, eds. John Earman, Allen I. Janis, Gerald J. Massey, and Nicholas Rescher, 114-120. Pittsburgh, PA: University of Pittsburgh Press, 1993.

Redish, Martin H. The Logic of Persecution: Free Expression and the McCarthy Era. Stanford, CA: Stanford University Press, 2005.

Redding, Paul. "Hegel's Lectures on the History of Ancient and Medieval Philosophy." In The Oxford Handbook of Hegel, ed. Dean Moyar, 603-622. Oxford, UK: Oxford University Press, 2017.

Reddish, Tim. Science and Christianity: Foundations and Frameworks for Moving Forward in Faith. Eugene, OR: Wipf \& Stock, 2016.

Redford, Shawn B. Missiological Hermeneutics: Biblical Interpretation for the Global Church. Eugene, OR: Pickwick Publications, 2012. 
Reed, Randall W. A Clash of Ideologies: Marxism, Liberation Theology, and Apocalypticism in New Testament Studies. Eugene, OR: Pickwick, 2010.

Regal, Philip J. The Anatomy of Judgement. Minneapolis, MN: University of Minnesota Press, 1990.

Reich, Warren T. "A Corrective for Bioethical Malaise: Revisiting the Cultural Influences that Shaped the Identity of Bioethics." In The Development of Bioethics in the United States, eds. Jeremy R. Garrett, Fabrice Jotterand, and D. Christopher Ralston, 79-100. New York, NY: Springer, 2013.

Reichenbach, Hans. From Copernicus to Einstein. Read Books Ltd., 2013.

The Rise of Scientific Philosophy. Berkeley, CA: University of California Press, 1951.

Reilly, Robert R. The Closing of the Muslim Mind: How Intellectual Suicide Created the Modern Islamist Crisis. Wilmington, DE: ISI Books, 2010.

Reiner, Edwin W. The Atonement. TEACH Services, 2001.

Rengger, Nicholas J. Retreat from the Modern: Humanism, Postmodernism, and the Flight from Modernist Culture. London, UK: Bowerdean Publishing, 1996.

Rescher, Nicholas. Free Will: An Extensive Bibliography. Piscataway, NJ: Rutgers University Press, 2010.

. Process Metaphysics: An Introduction to Process Philosophy. Albany, NT: State University of New York Press, 1996.

Reyna, Stephen P. Connections: Brain, Mind, and Culture in a Social Anthropology. New York, NY: Routledge, 2002.

Reynolds, Gregory. The Word is Worth a Thousand Pictures: Preaching in the Electronic Age. Eugene, OR: Wipf and Stock, 2001.

Richards, Jay, ed. God and Evolution. Seattle, WA: Discovery Institute, 2010.

Richards, Jay Wesley. The Untamed God: A Philosophical Exploration of Divine Perfection, Immutability, and Simplicity. Downers Grove, IL: InterVarsity Press, 2003.

Richardson, Heather Cox. To Make Men Free: A History of the Republican Party. New York, NY: Basic Books, 2014.

Richardson, William J. “Heidegger's Critique of Science." In Heidegger on Science, ed. Trish Glazebrook, 27-46. Albany, NY: State University of New York, 2012.

Heidegger: Through Phenomenology to Thought. New York, NY: Fordham University Press, 2003.

Rickey, Christopher. Revolutionary Saints: Heidegger, National Socialism, and Antinomian Politics. University Park, PA: The Pennsylvania State University Press, 2002.

Riddell, Peter G., and Peter Cotterell. Islam in Context: Past, Present, and Future. Grand Rapids, MI, Baker, 2003. 
Riedweg, Christoph. Pythagoras: His Life, Teaching, and Influence, tr. Steven Rendall. Ithaca, NY: Cornell University Press, 2005.

Riga, Peter. The Islamic War on Christians. Bloomington, IN: AuthorHouse, 2012.

Rist, J. M. Epicurus: An Introduction. Cambridge, UK: Cambridge University Press, 1972.

Rivot, Sylvie. Keynes and Friedman on Laissez-Faire and Planning: 'Where to Draw the Line?' New York, NY: Routledge, 2013.

Robbins, Jeffrey W. Between Faith and Thought: An Essay on the Ontotheological Condition. Charlottesville, VA: University of Virginia Press, 2003. Radical Democracy and Political Theology. New York, NY: Columbia University Press, 2011. Radical Theology: A Vision for Change. Bloomington, IN: Indiana University Press, 2016.

Robbins, John W. Freedom and Capitalism: Essays on Christian Politics and Economics. Unicoi, TN: The Trinity Foundation, 2006.

Roberts, Neil. "Fanon, Frantz (1925-1961)." In the Encyclopedia of Political Theory, ed. Mark Bevir, 492-494. Thousand Oaks, CA: SAGE Publications, 2010.

Robertson, Michael, and Garry Walter. Ethics and Mental Health: The Patient, Profession and Community. Boca Raton, FL: CRC Press, 2014.

Robinson, Andrew. Einstein: A Hundred Years of Relativity. Princeton, NJ: Princeton University Press, 2015.

Robinson, Howard. "Idealism and Perception: Why Berkeleyan Idealism is Not as Counterintuitive as It Seems." In Idealism and Christian Philosophy: Idealism and Christianity Vol 2, eds. Steven B. Cowan and James S. Spiegel, 71-90. New York, NY: Bloomsbury, 2016.

Robinson, Keith. "Mediating the Divide: Process Philosophy between the Two Cultures." In Applied Process Thought I: Initial Explorations in Theory and Research, eds. Mark Dibben and Thomas Kelly, 137-148. Piscataway, NJ: Rutgers, 2008.

Robinson, Michael D. The Storms of Providence: Navigating the Waters of Calvinism, Arminianism, and Open Theism. Lanham, MD: University Press of America, 2003.

Rodemeyer, Lanei M. Intersubjective Temporality: It's About Time. Dordrecht, The Netherlands, Springer, 2006.

Rodríguez, Ángel M. Spanning the Abyss: How the Atonement Brings Humanity and God Together. Hagerstown, MD: Review and Herald, 2008.

Rodríguez, Ángel Manuel, ed. Toward a Theology of the Remnant: An Adventist Ecclesiological Perspective. Silver Spring, MD: Biblical Research Institute, 2009.

Roeckelein, Jon E. “Early Greek and Later Philosophical Theories of Time.” In Elsevier's Dictionary of Psychological Theories, ed. Jon E. Roeckelein, 176. Boston, MA: Elsevier, 2006. 
. The Concept of Time in Psychology: A Resource Book and Annotated Bibliography. Westport, CT: Greenwood Press, 2000.

Roecklein, Robert J. Plato versus Parmenides: The Debate over Coming-into-Being in Greek Philosophy. Lanham, MD: Lexington Books, 2011.

Roggenhofer, Johannes. "From Science Wars to Science Worries: Some Reflections on the Scientific Conquest of Reality." In Knowledge and the World: Challenges Beyond the Science Wars, eds. Martin Carrier, Johannes Roggenhofer, Günter Küppers, and Philippe Blanchard, 293-306. New York, NY: Springer, 2004.

Rojcewicz, Richard. Gods and Technology: A Reading of Heidegger. Albany, NY: State University of New York Press, 2006.

Romdenh-Romluc, Komarine. Merleau-Ponty and Phenomenology of Perception. New York, NY: Routledge, 2011.

Roosenberg, Tim. Islam \& Christianity in Prophecy revised ed. Emmett, ID: Islam and Christianity in Prophecy Seminars, 2016.

Rorty, Richard. Philosophy and the Mirror of Nature: Thirtieth-Anniversary Edition, with Michael Williams and David Bromwich. Princeton, NJ: Princeton University Press, 2009.

Rosen, Robert. Essays on Life Itself. New York, NY: Columbia University Press, 2000.

Rosen, Steven M. "Bridging the 'Two Cultures': Merleau-Ponty and the Crisis in Modern Physics." In Cosmos and History: The Journal of Natural and Social Philosophy Vol. 9 No. 2 (2013): 1-12.

Dimensions of Apeiron: A Topological Phenomenology of Space, Time, and Individuation. Amsterdam, The Netherlands: Rodopi, 2004.

. Dreams, Death, Rebirth: A Topological Odyssey into Alchemy's Hidden Dimensions. Asheville, NC: Chiron Publications, 2014.

. "Quantum Gravity and Phenomenological Philosophy." In Foundations of Physics Vol. 38 Issue 6 (June 2008): 556-582.

. "Quantum Gravity and Taoist Cosmology: Exploring the Ancient Origins of Phenomenological String Theory." In Progress in Biophysics and Molecular Biology, Vol. 131 (2017): 34-60.

. Science, Paradox, and the Moebius Principle: The Evolution of a 'Transcultural' Approach to Wholeness. Albany, NY: State University of New York Press, 1994.

The Self-Evolving Cosmos: A Phenomenological Approach to Nature's Unity-in-Diversity. Toh Tuck Link, Singapore: World Scientific Publishing, 2008.

. Topologies of the Flesh: A Multidimensional Exploration of the Lifeworld. Athens, OH: Ohio University Press, 2006.

. "Why Natural Science Needs Phenomenological Philosophy." In Progress in Biophysics and Molecular Biology Vol. 119, Issue 3 (December 2015): 257-269. 
Rosenblum, Bruce, and Fred Kuttner. Quantum Enigma: Physics Encounters Consciousness. Oxford, UK: Oxford University Press, 2006.

Rosenau, James N. Distant Proximities: Dynamics Beyond Globalization. Princeton, NJ: Princeton University Press, 2003.

"The Governance of Fragmegration: Neither a World Republic Nor a Global Interstate System." (Modified 2000). At http://aura.u-pec.fr/regimen/_fich/_pdf/pub_002.pdf (accessed September 16, 2018).

Rosenau, Pauline Marie. Post-Modernism and the Social Sciences: Insights, Inroads, and Intrusions. Princeton, NJ: Princeton University Press, 1992.

Rosenberg, Alex. The Atheist's Guide to Reality: Enjoying Life Without Illusions. New York, NY: W. W. Norton \& Company, 2011.

Rosenthal, Vlad Van. From the Big Bang to the Big Crunch: A Simplified Look at a Not-So-Simple Universe. Bloomington, IN: iUniverse, 2011.

Rosner, David J. Conservatism and Crisis: The Anti-modernist Perspective in Twentieth Century German Philosophy. Lanham, MD: Lexington Books, 2012.

Rosenof, Theodore. Economics in the Long Run: New Deal Theorists and Their Legacies. Chapel Hill, NC: The University of North Carolina Press, 1997.

Rosenthal, Sandra B., and Patrick L. Bourgeois. Pragmatism and Phenomenology: A Philosophic Encounter. Amsterdam, The Netherlands: B. R. Grüner, 1980.

Roshwald, Mordecai. Liberty: Its Meaning and Scope. Westport, CT: Greenwood Press, 2000.

Ross, Alf. On Law and Justice. Berkeley, CA: University of California Press, 1959.

Rossi, Ernest Lawrence. Dreams, Consciousness, Spirit: The Quantum Experience of Self-Reflection and Co-Creation, $3^{\text {rd }}$ ed. Phoenix, AZ: Zeig, Tucker \& Theisen, 2000.

Rossinow, Douglas Charles. Visions of Progress: The Left-liberal Tradition in America. Philadelphia, PA: University of Pennsylvania Press, 2008.

Roth, Ariel A. Origins: Linking Science and Scripture. Hagerstown, MD: Review and Herald, 1998. Science Discovers God: Seven Convincing Lines of Evidence for His Existence. Hagerstown, MD: Autumn House with Review \& Herald, 2008.

Roth, Michael S. "Freud's Use and Abuse of the Past." In Rediscovering History: Culture, Politics, and the Psyche, ed. Michael S. Roth, 336-348. Stanford, CA: Stanford University Press, 1994.

Rothbard, Murray N. Keynes the Man. Auburn, AL: Ludwig von Mises Institute, 2010.

Rotman, Brian. Signifying Nothing: The Semiotics of Zeno. London, UK: Macmillan Press, 1987.

Roubekas. Nickolas P. New York, NY: Routledge, 2017.

Rovelli, Carlo. The Order of Time. New York, NY: Riverhead Books, 2018. 
Rowe, Stephen C. Overcoming America / America Overcoming: Can We Survive Modernity? Lanham, MD: Lexington Books, 2012.

Rowlands, Mark. Externalism: Putting Mind and World Back Together Again. New York, NY: Routledge, 2014.

Roy, Louis. Mystical Consciousness: Western Perspectives and Dialogue with Japanese Thinkers. Albany, NY: State University of New York Press, 2003.

Roy, Steven C. How Much Does God Foreknow?: A Comprehensive Biblical Study. Downers Grove, IL: InterVarsity Press, 2006.

Rubenfeld, Jed. Freedom and Time: A Theory of Constitutional Self-Government. New Haven, CT: Yale University Press, 2001.

. "Reading the Constitution as Spoken." In Yale Law Journal 104 (1995): 1119-1185.

. Revolution by Judiciary: The Structure of American Constitutional Law. Cambridge, MA: Harvard University Press, 2005.

Rudavsky, T. M. Time Matters: Time, Creation, and Cosmology in Medieval Jewish Philosophy. Albany, NY: State University of New York Press, 2000.

Rudolph, David J. A Jew to the Jews: Jewish Contours of Pauline Flexibility in 1 Corinthians 9:19-23 $2^{\text {nd }}$ ed. Eugene, OR: Pickwick, 2016.

Runde, Jochen, and Sohei Mizuhara, eds. The Philosophy of Keynes's Economics: Probability, Uncertainty and Convention. New York, NY: Routledge, 2003.

Runes, Dagobert D., ed. The Dictionary of Philosophy. New York, NY: Kissinger Publishing, 2006.

Ruse, Michael. Darwinism As Religion: What Literature Tells Us about Evolution. Oxford, UK: Oxford University Press, 2017.

Rushdoony, Rousas J. The One and the Many. Vallecito, CA: Ross House Books, 1971.

The Roots of Reconstruction. Vallecito, CA: Ross House Books, 1991.

Russ, Andrew R. The Illusion of History: Time and the Radical Political Imagination. Washington, D. C.: The Catholic University of America Press, 2013.

Russell, Bertrand. History of Western Philosophy. New York, NY: Simon \& Schuster, 1945.

Russell, Ellen. New Deal Banking Reforms and Keynesian Welfare State Capitalism. New York, NY: Routledge, 2008.

Russell, Heidi Ann. Quantum Shift: Theological and Pastoral Implications of Contemporary Developments in Science. Collegeville, MN: Liturgical Press, 2015.

The Source of All Love: Catholicity and the Trinity. Maryknoll, NY: Orbis Books, 2017.

Russell, Letty M. Household of Freedom: Authority in Feminist Theology. Philadelphia, PA: The Westminster Press, 1987. 
Russell, Robert John. "A Response to David Bohm's 'Time, the Implicate Order and Pre-Space.' In Physics and the Ultimate Significance of Time: Bohm, Prigogine, and Process Philosophy, ed. David Ray Griffin, 209-218. Albany, NY: State University of New York Press, 1986.

Cosmology: From Alpha to Omega. Minneapolis, MN: Fortress Press, 2008.

Time in Eternity: Pannenberg, Physics, and Eschatology in Creative Mutual Interaction. South Bend, IN: University of Notre Dame Press, 2012.

"The Science of Light and the Light of Science: An Appreciative Theological Reflection on the Life and Work of Charles Hard Townes." In Visions of Discovery: New Light on Physics, Cosmology, and Consciousness, eds. Raymond Y. Chiao, Marvin L. Cohen, Anthony J. Leggett, William D. Phillips, and Charles L. Harper, Jr., 751-769. Cambridge, UK: Cambridge University Press, 2011.

Ryan, Robin. Jesus and Salvation: Soundings in the Christian Tradition and Contemporary Theology. Collegeville, MN: Liturgical Press, 2015.

Rydnik, V. J. ABC's of Quantum Mechanics, tr. George Yankovskey. Honolulu, HI, University Press of the Pacific, 2001.

Sachs, Carl B. Intentionality and the Myths of the Given: Between Pragmatism and Phenomenology. New York, NY: Routledge, 2014.

Sadler, Ted. Heidegger and Aristotle: The Question of Being. Atlantic Highlands, NJ: Athlone, 1996.

Saeed, Abdullah. Islam and Belief: At Home with Religious Freedom. Center for Islam and Religious Freedom, 2014.

Safranski, Rüdiger. Heidegger: Between Good and Evil, tr. Ewald Osers. Cambridge, MA: Harvard University Press, 1999.

Salam, Abdus, and Azim Kidwai. "A Blueprint for Science and Technology in the Developing World." In Worldwide Science and Technology Advice to the Highest Levels of Governments, ed. William T. Golden, 61-79. New York, NY: Pergamon Press, 1991.

Samartha, S. J. One Christ-Many Religions: Toward a Revised Christology. Eugene, OR: Wipf and Stock, 1991.

Sambursky, Samuel. Physics of the Stoics. Princeton, NJ: Princeton University Press, 1959.

Samons II, Loren J. What's Wrong with Democracy?: From Athenian Practice to American Worship. Berkeley, CA: University of California Press, 2004.

Samuels, Robert. "Auto-Modernity after Postmodernism: Autonomy and Automation in Culture, Technology, and Education." In Digital Youth, Innovation, and the Unexpected, ed. Tara McPherson, 219-240. Cambridge, MA: Massachusetts Institute of Technology, 2008.

Sanders, E. P. Jewish Law from Jesus to the Mishnah: Five Studies. Minneapolis, MN: Fortress, Press, 2016.

Sandbothe, Mike. The Temporalization of Time: Basic Tendencies in Modern Debate on Time in Philosophy and Science, tr. Andrew Inkpin. Lanham, MD: Rowman \& Littlefield, 2001. 
Sandelands, Lloyd E. An Anthropological Defense of God. New Brunswick, NJ: Transaction Publishers, 2007.

Sanderson, Rohnn B. and Marc A. Pugliese. Beyond Naïveté: Ethics, Economics, and Values. Lanham, MD: University Press of America, 2012.

Sandywell, Barry. Presocratic Reflexivity: The Construction of Philosophical Discourse C. 600-450 BC. New York, NY: Routledge, 1996.

Sarewitz, Daniel. "Human Well-being and Federal Science-What's the Connection?" In Science, Technology \& Democracy, ed. Daniel Lee Kleinman, 87-102. Albany, NY: State University of New York Press, 2000.

Satell, Greg. Mapping Innovation: A Playbook for Navigating a Disruptive Age. New York, NY: McGraw-Hill, 2017.

Saucy, Robert. The Case for Progressive Dispensationalism: The Interface Between Dispensational and Non-Dispensational Theology. Grand Rapids, MI: Zondervan, 2010.

Saunders, Simon. "How Relativity Contradicts Presentism," in Time, Reality and Experience, ed. Craig Callender, 277-292. New York, NY: Cambridge University Press, 2002.

Saxton, Alexander. "The God Debates and the Materialist Interpretation of History." In Reasonable Perspectives on Religion, ed. Richard Curtis, 17-34. Lanham, MD: Lexington Books, 2010.

Searle, John R. Freedom \& Neurobiology: Reflections on Free Will, Language, and Political Power. New York, NY: Columbia University Press, 2007.

Seely, Paul. "The Subordination of Scripture to Human Reason at Old Princeton." In Interdisciplinary Perspectives on the Authority of Scripture: Historical, Biblical, and Theoretical Perspectives, ed. Carlos R. Bovell, 28-45. Eugene, OR: Pickwick, 2011.

Seidel, Asher. Inhuman Thoughts: Philosophical Explorations of Posthumanity. Lanham, MD: Lexington Books, 2008.

Seigfried, Charlene Haddock. William James's Radical Reconstruction of Philosophy. Albany, NY: State University of New York Press, 1990.

Seligman, Adam B., ed. Religious Education and the Challenge of Pluralism. Oxford, UK: Oxford University Press, 2014.

Scalia, Antonin, and Bryan A. Garner. Reading Law: The Interpretation of Legal Texts. Rochester, New York: Thomson/West, 2012.

Scarborough, Milton. Comparative Theories of Nonduality: The Search for a Middle Way. New York, NY: Continuum, 2009.

Scaruffi, Piero. Thinking about Thought: A Primer on the New Science of Mind. Bloomington, IN: iUniverse, 2003.

Schaefer, Henry F. Science and Christianity: Conflict Or Coherence? Watkinsville, GA: Apollos Trust, 2003.

Schaffner, Kenneth F. Nineteenth-Century Aether Theories. Oxford, UK: Pergamon Press, 1972. 
Schafly, Phyllis, and George Neumayr. No Higher Power: Obama's War on Religious Freedom. Washington, D.C.: Regnery Publishing, 2012.

Schaik, John van, Christine Gruwez, and Cilia ter Horst, eds. The Impulse of Freedom in Islam. Great Barrington, MA: Lindisfarne Books, 2014.

Schalg, Martin, and Juan Andrés Mercado, eds. Free Markets and the Culture of Common Good. New York, NY: Springer, 2012.

Schalow, Frank. Departures: At the Crossroads Between Heidegger and Kant. Germany: Walter de Gruyter, 2013.

. Heidegger and the Quest for the Sacred: From Thought to the Sanctuary of Faith. Dordrecht, The Netherlands: Kluwer, 2001.

Schansberg, D. Eric. Turn Neither to the Right Nor to the Left: A Thinking Christian's Guide to Politics and Public Policy. Greenville, SC: Alertness Ltd, 2003.

Schapiro, Rich, and Erica Pearson. "Americans are Less Christian, More Atheist and Agnostic: Pew Survey." At http://www.nydailynews.com/news/national/americans-christian-atheist-agnostic-survey-arti cle-1.2219229 (accessed May 12, 2015).

Schatzki, Theodore R. The Timespace of Human Activity: On Performance, Society, and History as Indeterminate Teleological Events. Plymouth, UK: Lexington Books, 2010.

Schelling, F. W. J. Philosophical Investigations into the Essence of Human Freedom, tr. Jeff Love and Johannes Schmidt. Albany, NY: State University of New York Press, 2006.

Schermer, Victor L. Meaning, Mind, and Self-Transformation: Psychoanalytic Interpretation and the Interpretation of Psychoanalysis. London, UK: Karnac Books, 2014.

Scheurer, P. B. “The Surprises of Newtonian Determinism." In Newton's Scientific and Philosophical Legacy, eds. P. B. Scheurer and G. Debrock, 135-150. Boston, MA: Kluwer Academic, 1988.

Schilbrack, Kevin. “Metaphysics in Dōgen." Philosophy East \& West, Vol. 50 \#1 (Jan. 2000): 34-55.

Schins, Juleon M. "Quantum Theory: A Pointer to an Independent Reality-A Discussion of Bernard d'Espagnat's 'Veiled Reality."' In Mathematical Undecidability, Quantum Nonlocality and the Question of the Existence of God, eds. Alfred Driessen and Antoine Suarez, 173-182. Dordrecht, The Netherlands: Springer, 1997.

Schindler, David C. Freedom From Reality: The Diabolical Character of Modern Liberty. Notre Dame, IN: University of Notre Dame Press, 2017. . Love and the Postmodern Predicament: Rediscovering the Real in Beauty, Goodness, and Truth. Eugene, OR: Cascade Books, 2018.

"Truth and the Christian Imagination: The Reformation of Causality and the Iconoclasm of the Spirit." In Communio 33 (Winter 2006): 521-539.

The Catholicity of Reason. Grand Rapids, MI: Eerdmans, 2013. 
. The Perfection of Freedom: Schiller, Schelling, and Hegel between the Ancients and the Moderns. Eugene, OR: Cascade Books, 2012.

. "What's the Difference? On the Metaphysics of Participation in a Christian Context." In The Saint Anselm Journal 3.1 (Fall 2005): 1-27.

Schindler, David L. "David Bohm on Contemporary Physics and the Overcoming of Fragmentation." In International Philosophical Quarterly Vol. 22 \# 4 (Dec. 1982): 315-327.

. "Freedom, Truth, and Human Dignity: An Interpretation of Dignitatis Humanae on the Right to Religious Freedom." In Freedom, Truth and Human Dignity: The Second Vatican Council's Declaration on Religious Freedom: A New Translation, Redaction History, and Interpretation of Dignitatis Humanae, eds. David L. Schindler and Nicholas J. Healy, Jr., 39-210. Grand Rapids, MI: Eerdmans, 2015.

. "Habits of Presence and the Generosity of Creation: Ecology in Light of Integral Human Development." In Communio 42 (Winter 2015): 574-593.

. Heart of the World, Center of the Church: Communio Ecclesiology, Liberalism, and Liberation. Grand Rapids, MI: Eerdmans, 1996.

“'Homelessness' and Market Liberalism." In Wealth, Poverty \& Human Destiny, eds. Doug Bandow and David L. Schindler, 347-414. Wilmington, DE: ISI Books, 2003.

"'In the Beginning was the Word': Mercy as a 'Reality Illuminated by Reason."' in Communio 41 (Winter 2014): 751-773.

Ordering Love: Liberal Societies and the Memory of God. Grand Rapids, MI: Eerdmans, 2011.

"The Given as Gift: Creation and Disciplinary Abstraction in Science." In Communio (Vol. 38, Spring 2011): 52-102.

Schindler, David L., ed. Beyond Mechanism: The Universe in Recent Physics and Catholic Thought. Lanham, MD: University Press of America, 1986.

Schlosshauer, Maxmilian A. Decoherence: And the Quantum-To-Classical Tradition. New York, NY: Springer, 2008.

Schmitt, Carl. Political Theology, tr. George Schwab. Chicago, IL: University of Chicago Press, 2006.

Schoen, Douglas E. Hopelessly Divided: The New Crisis in American Politics and What It Means for 2012 and Beyond. Lanham, MD: Rowman and Littlefield, 2012.

Schomberg, René von. "Introduction," in Science, Politics and Morality: Scientific Uncertainty and Decision Making, ed. René von Schomberg, 1-4. Dordrecht, The Netherlands: Springer Science, 1993.

Schroll, Mark A. “Understanding Bohm's Holoflux: Clearing Up a Conceptual Misunderstanding of the Holographic Paradigm and Clarifying its Significance to Transpersonal Studies of Consciousness." In the International Journal of Transpersonal Studies (Vol. 32 \#1, 2013): 140163. 
Schumacher, Ernst Friedrich. Small is Beautiful: Economics as if People Mattered. New York, NY: HarperCollins, 2010.

Schuster, Shlomit C. Philosophy Practice: An Alternative to Counseling and Psychotherapy. Westport, CT: Praeger Publishers, 1999.

Schwab, Klaus. The Fourth Industrial Revolution. New York, NY: Random House, 2017.

Schwartz, Stephen. The Other Islam: Sufism and the Road to Global Harmony. New York, NY: Doubleday, 2008.

The Two Faces of Islam: Saudi Fundamentalism and Its Role in Terrorism. New York, NY: Doubleday, 2003.

Schwinger, Julian. Einstein's Legacy: The Unity of Space and Time. Mineola, NY: Dover, 2002.

Sciabarra, Chris Matthew. Total Freedom: Toward a Dialectical Libertarianism. University Park, PA: The Pennsylvania State University Press, 2000.

Scola, Nancy. "Can Washington Be Automated?: An Algorithmic Lobbyist Sounds like a Joke-But it's Already Here-Here's Who the Robots are Coming for Next." At https://www.politico.com/magazine/story/2018/01/05/washington-automation-congress-pol itics-lobbying-policy-216216 (accessed January 17, 2018).

Scott, Gary Alan, and William A. Welton. Erotic Wisdom: Philosophy and Intermediacy in Plato's Symposium. Albany, NY: State University of New York Press, 2008.

Scruton, Roger. Modern Culture. New York, NY: Continuum, 2005.

Scully, Stephen. Hesiod's Theogony: From Near Eastern Creation Myths to Paradise Lost. Oxford, UK: Oxford University press, 2015.

Sekulow, Jay. Rise of ISIS: A Threat We Can't Ignore. New York, NY: Howard Books, 2014.

Shanks, Niall. God, The Devil, and Darwin: A Critique of Intelligent Design Theory. Oxford, UK: Oxford University Press, 2004.

Shannon, John. Keynesian Economics: The Cancer in America. Bloomington, IN: AuthorHouse, 2012.

Sharma, Arvind. Problematizing Religious Freedom. New York, NY: Springer, 2011.

Sharon, Tamar. Human Nature in an Age of Biotechnology: The Case for Mediated Posthumanism. New York, NY: Springer, 2014.

Shapiro, Stewart, ed. The Oxford Handbook of Philosophy of Mathematics and Logic. New York, NY: Oxford University Press, 2005.

Sharpe, Kevin J. David Bohm's World: New Physics and New Religion. Cranbury, NJ: Associated University Presses, 1993.

Sharples, R. W. Stoics, Epicureans and Sceptics: An Introduction to Hellenistic Philosophy. New York, NY: Routledge, 2014. 
Sharrock, Russell. Spiritual Warfare: A Struggle for Truth. Morrisville, NC: Lulu Press, 2007.

Shaw, Gregory. Theurgy and the Soul: The Neoplatonism of Iamblichus $2^{\text {nd }}$ ed. Kettering, $\mathrm{OH}$ : Angelico Press, 2014.

Shaw, R. Daniel, and Charles E. Van Engen. Communicating God's Word in a Complex World. New York, NY: Rowman \& Littlefield, 2003.

Shea, William H. Daniel: A Reader's Guide. Nampa, ID: Pacific Press, 2005.

Shellnutt, Kate. "The Rise of the Nons: Protestants Keep Ditching Denominations: Nondenominational Identity has Doubled in the US Since 2000, Gallup Finds." At http://www.christianitytoday.com/news/2017/july/rise-of-nons-protestants-denominationsnondenominational.html (accessed July 20, 2017).

Shepherd, Ken. "Theologian Wayne Grudem, Who Briefly Recanted His Endorsement, Back on the Trump Train." At http://www.washingtontimes.com/news/2016/oct/20/theologian-wayne-grudem-who-briefly -recanted-his-e/ (accessed March 2, 2017).

Sherover, Charles M. Are We In Time? And Other Essays on Time and Temporality. Evanston, IL: Northwestern University Press, 2003.

. From Kant and Royce to Heidegger: Essays in Modern Philosophy, ed. Gregory R. Johnson. Washington, D. C.: The Catholic University of American Press, 2003.

Heidegger, Kant, and Time. Bloomington, IN: Indiana University Press, 1971.

Time, Freedom, and the Common Good: An Essay in Public Philosophy. Albany, NY: State University of New York, 1989.

Sherover, Charles M., ed. The Development of the Democratic Idea: Readings from Pericles to the Present. New York, NY: Washington Square Press, 1974.

Sherover, Charles M., ed. The Human Experience of Time: The Development of Its Philosophic Meaning. Evanston, IL: Northwestern University Press, 2001.

Shiang, David A. God Does Not Play Dice: The Fulfillment of Einstein's Quest for Law and Order in Nature. Lexington, MA: Open Sesame, 2011.

Shiffrin, Steven H. The Religious Left and Church-State Relations. Princeton, NJ: Princeton University Press, 2009.

"The Religious Left and Church-State Relations: A Response to Kent Greenawalt and Bernie Meyler." In Cornell Journal of Law and Public Policy Vol. 19 (2010): 761-772.

Shionoya, Yuichi. "Austrian Subjectivism and Hermeneutical Economics." In Subjectivism and Objectivism in the History of Economic Thought, eds. Yagi Kiichiro and Yukihiro Ikeda, 73-90. New York, NY: Routledge, 2012.

Shirley, Greg. Heidegger and Logic: The Place of Lógos in 'Being and Time'. New York, NY: Continuum, 2010. 
Shogimen, Takashi. Ockham and Political Discourse in the Late Middle Ages. Cambridge, UK: Cambridge University Press, 2007.

Shuebrook, Kyle J. "Science and Sufism: A Discussion of David Bohm and Ibn al-Arabi." At https://www.academia.edu/2272891/Science_and_Sufism_A_Discussion_of_ David_Bohm_and_Ibn_al-Arabi (accessed August 24, 2017).

Sider, Ronald J. Rich Christians in an Age of Hunger: Moving from Affluence to Generosity. Nashville, TN: Thomas Nelson, 2015.

Sidharth, B. G. When the Universe Took a U-turn. London, UK: World Scientific, 2010.

Sigmund, Paul E. Liberation Theology at the Crossroads: Democracy or Revolution. New York, NY: Oxford University Press, 1990.

Sikka, Sonia. Forms of Transcendence: Heidegger and Medieval Mystical Theology. Albany, NY: State University of New York Press, 1997.

Heidegger, Morality and Politics: Questioning the Shepherd of Being. Cambridge, UK: Cambridge University Press, 2018.

Silberstein, Michael, W. M. Stuckey, and Michael Cifone. "An Argument for 4D Block World from a Geometric Interpretation of Nonrelativisitic Quantum Mechanics." In Relativity and the Dimensionality of the World, ed. Vesselin Petkov, 197-216. New York, NY: Springer, 2007.

Sills, Stephen. The Basis for Christianity. Los Angeles, CA: Stephen Sills, 2016.

Silver, Brian L. The Ascent of Science. Oxford, UK: Oxford University Press, 1998.

Silverman, David. Fighting God: An Atheist Manifesto for a Religious World. New York, NY: St. Martin's Press, 2015.

Simataa, A. M. The Seventh-day Sabbath and the Christian Doctrine of Redemption. Bloomington, IN: Xlibris, 2015.

Simmons, J. Aaron, and Bruce Ellis Benson, The New Phenomenology: A Philosophical Introduction. New York, NY: Bloomsbury Academic, 2013.

Simon, Roger L. I Know Best: How Moral Narcissism is Destroying Our Republic, If It Hasn't Already. New York, NY: Encounter Books, 2016.

Sire, James W. The Universe Next Door: A Basic Worldview Catalog. Downers Grove, IL: InterVarsity Press, 2009.

Skidelsky, Robert. Keynes: The Return of the Master. New York, NY: PublicAffairs, 2009.

Skilton, Mark, and Felix Hovsepian. The $4^{\text {th }}$ Industrial Revolution: Responding to the Impact of Artificial Intelligence on Business. New York, NY: Palgrave Macmillan, 2018.

Skocz, Dennis. "Environmental Management in the 'Age of the World Picture."' In Heidegger and the Earth: Essays in Environmental Philosophy, eds. Ladelle McWhorter and Gail Stenstad, 123-143. Toronto, Canada: University of Toronto Press, 2009. 
Skousen, Mark. Dissent on Keynes: A Critical Appraisal of Keynesian Economics. Greenwood Publishing Group, 1992.

The Big Three in Economics: Adam Smith, Karl Marx, and John Maynard Keynes. New York, NY: Routledge, 2015.

Vienna \& Chicago: Friends or Foes?: A Tale of Two Schools of Free-Market Economics.

Washington, D.C.: Regnery Publishing, 2005.

Skrbina, David. The Metaphysics of Technology. New York, NY: Routledge, 2015.

Slife, Brent D. Time and Psychological Explanation. Albany, NY: State University of New York Press, 1993.

Sloan, Douglas. Faith and Knowledge: Mainline Protestantism and American Higher Education. Louisville, KT: Westminster John Knox Press, 1994.

. Insight-Imagination: The Emancipation of Thought and the Modern World. Westport, CT: Greenwood Press, 1983.

"Preface: Toward an Education for a Living World." In Education for Peace and Disarmament: Toward a Living World, ed. Douglas Sloan, 1-14. New York, NY: Teachers College Press, 1983.

Smart, Alan, and Josephine Smart. Posthumanism: Anthropological Insights. Toronto, Canada: University of Toronto Press, 2017.

Šmajs, Josef. Evolutionary Ontology: Reclaiming the Value of Nature by Transforming Culture. Amsterdam, The Netherlands: Rodopi, 2008.

Smetham, Graham. The Grand Designer: Discovering the Quantum Mind Matrix of the Universe. Brighton, UK: Shunyata Press, 2011.

. Quantum Buddhism: Dancing in Emptiness-Reality Revealed at the Interface of Quantum Physics \& Philosophy. Sussex, UK: Shunyata Press, 2010.

Smilansky, Saul. Free Will and Illusion. Oxford, UK: Clarendon Press, 2002.

Smith, Cary Stacy, and Li-Ching Hung. "Bible and Time." In Encyclopedia of Time: Science, Philosophy, Theology, \& Culture, ed. H. James Birx, 87-89. Thousand Oaks, CA: SAGE Publications, 2009.

Smith, Christian. The Emergence of Liberation Theology: Radical Religion and Social Movement Theory. Chicago, IL: The University of Chicago Press, 1991.

Smith, Gregory B. Martin Heidegger: Paths Taken, Paths Opened. Lanham, MD: Rowman \& Littlefield, 2007.

Smith, John, and Chris Jenks. Qualitative Complexity: Ecology, Cognitive Processes and the Re-Emergence of Structures in Post-Humanist Social Theory. New York, NY: Routledge, 2006.

Smith, Karl. The Nature of Mathematics 11th ed.. Belmont, CA: Thomson Higher Education, 2007.

Smith, Peter B., Ronald Fischer, Vivian L. Vignoles, and Michael Harris Bond. Understanding Social Psychology Across Cultures: Engaging Others in a Changing World. London, UK: SAGE, 2013. 
Smith, Quentin. Time, Change, and Freedom: An Introduction to Metaphysics, eds., Quentin Smith and L. Nathan Oaklander. New York, NY: Routledge, 1995.

Smith, Uriah. The Prophecies of Daniel and the Revelation. Literary Licensing LLC, 2014.

Smolin, Lee. Einstein's Unfinished Revolution: The Search for What Lies Beyond the Quantum. Toronto, Canada: Alfred A. Knopf, 2019. Three Roads to Quantum Gravity. New York, NY: Basic Books, 2001.

Snobelen, Stephen D. "Isaac Newton: His Science and Religion." In Science, Religion and Society: An Encyclopedia of History, Culture, and Controversy, eds. Arri Eisen and Gary laderman, 355-369. New York, NY: Routledge, 2015.

Snoke, David. A Biblical Case for an Old Earth. Grand Rapids, MI: BakerBooks, 2006.

Snow, Charles P. Science and Government. Cambridge, MA: Harvard University Press, 2013. The Two Cultures. New York, NY: Cambridge University Press, 1998.

Soccio, Douglas J. Archetypes of Wisdom: An Introduction to Philosophy. Boston, MA: Cengage Learning, 2016.

Söderqvist, Thomas. "Introduction: A New Look at the Genre of Scientific Biography." In The History and Poetics of Scientific Biography, ed. Thomas Söderqvist, 1-16. New York, NY: Ashgate Publishing, 2016.

Sokal, Alan, and Jean Bricmont, Fashionable Nonsense: Postmodern Intellectuals' Abuse of Science. New York, NY: Picador, 1998.

Solomon, Frank H. Capitalism: An Analysis and Summary of Adam Smith's Wealth of Nations $2^{\text {nd }}$ ed. Bloomington, IN: Archway Publishing, 2013.

Solomon, Lawrence. The Deniers: The World-renowned Scientists who Stood Up Against Global Warming Hysteria, Political Persecution, and Fraud. USA: Richard Vigilante, 2010.

Solomon, Robert, and Kathleen Higgins, The Big Questions: A Short Introduction to Philosophy. Belmont, CA: Wadsworth, 2010.

Sommers, Tamler, ed. A Very Bad Wizard: Morality Behind the Curtain 2nd ed. New York, NY: Routledge, 2016.

Song, In-Kyu. Divine Foreknowledge and Necessity: An Ockhamist Response to the Dilemma of God's Foreknowledge and Human Freedom. Lanham, MD: University Press of America, 2002.

Soulen, Richard N., and R. Kendall Soulen. Handbook of Biblical Criticism, $3^{\text {rd }}$ ed. Louisville, KT: Westminster John Knox Press, 2001.

Soupios, M. A. The Greeks Who Made Us Who We Are: Eighteen Ancient Philosophers, Scientists, Poets and Others. Jefferson, NC: McFarland \& Company, 2013. 
Souza, Elias Brasil de. The Heavenly Sanctuary/Temple Motif in the Hebrew Bible: Function and Relationship to the Earthly Counterparts. Berrien Springs, MI: Adventist Theological Society Publications, 2005.

Spariosu, Mihai I. Dionysus Reborn: Play and the Aesthetic Dimension in Modern Philosophical and Scientific Discourse. Ithaca, NY: Cornell University, 1986.

Sperry, Paul. "Don't be Fooled by Bernie Sanders-He's a Diehard Communist." At http://nypost.com/2016/01/16/don't-be-fooled-by-bernie-sanders-hes-a-diehard-communist/ (accessed January 16, 2016).

Spinelli, Ernesto. Practising Existential Psychotherapy: The Relational World. Thousand Oaks, CA: SAGE Publications, 2007.

Splane, Lily. Quantum Consciousness: A Philosophy of the Self's Potential Through Quantum Cosmology. San Diego, CA: Anaphase II Publishing, 2004.

Sproul, R. C. Knowing Scripture. Downers Grove, IL: InterVarsity Press, 2009.

Squires, Euan J. The Mystery of the Quantum World. New York, NY: Taylor \& Francis, 1994.

Stace, Walter Terence. Religion and the Modern Mind. New York, NY: J. B. Lippincott, 1952.

Stacey, Marie. The Election of Ideologies: Do You Know Where You Stand? New York, NY: iUniverse, 2008.

Stachel, J. "Development of the Concepts of Space, Time and Space-Time from Newton to Einstein." In 100 Years of Relativity: Space-time Structure: Einstein and Beyond, ed. Abhay Ashtekar, 3-36. Toh Tuck Link, Singapore: World Scientific, 2005.

Stahl, Philip A. Beyond Atheism, Beyond God: The Quest for Transcendent Being. Bloomington, IN: iUniverse, 2013.

Stambaugh, Joan. "Heidegger, Taoism and the Question of Metaphysics." In Journal of Chinese Philosophy 11 (1984): 337-352. Impermanence is Buddha-nature: Dōgen's Understanding of Temporality. Honolulu, HI: University of Hawaii Press, 1990.

. "Introduction." In Martin Heidegger, Identity and Difference, tr. Joan Stambaugh, 1-18. University of Chicago Press, 2002.

Stamatellos, Giannis. Plotinus and the Presocratics: A Philosophical Study of Presocratic Influences in Plotinus' Enneads. Albany, NY: State University of New York Press, 2007.

Standish, Paul. Beyond the Self: Wittgenstein, Heidegger, and the Limits of Language. Aldershot, UK: Avebury, 1992.

Stanford, P. Kyle. Exceeding Our Grasp: Science, History, and the Problem of Unconceived Alternatives. Oxford, UK: Oxford University Press, 2006.

Stanley, Jason. How Propaganda Works. Princeton, NJ: Princeton University Press, 2015. 
Stanley, Timothy. Protestant Metaphysics after Karl Barth and Martin Heidegger. Eugene, OR: Cascade Books, 2010.

Stapp, Henry P. "Light as a Foundation of Being." In Quantum Implications: Essays in Honour of David Bohm, eds. B. J. Hiley and F. David Peat, 255-266. London, UK: Routledge, 1987.

Mindful Universe: Quantum Mechanics and the Participating Observer. Berlin, Germany: Springer, 2007.

Stefan, V. Alexander. Thus Spoke Einstein on Life and Living: Wisdom of Albert Einstein. La Jolla, CA: The Stefan University Press, 2011.

Stefanov, André, Hugo Zbinden, and Nicolas Gisin. "Quantum Correlations with Spacelike Separated Beam Splitters in Motion: Experimental Test of Multisimultaneity." In Physical Review Letters Vol. 88 Num. 12 (March 25, 2002): 1-4.

Steger, Manfred B., and Perle Besserman. Grassroots Zen. Boston, MA: Tuttle Publishing, 2001.

Steinbock, Anthony J. Phenomenology and Mysticism: The Verticality of Religious Experience. Bloomington, IN: Indiana University Press, 2007.

Steiner, Rudolf. Nature's Open Secret: Introductions to Goethe's Scientific Writings. Hillside House, UK: Rudolf Steiner Press, 2000. . The Origins of Natural Science. London, UK: Rudolf Steiner Press, 1985.

Steele, G. R. Keynes and Hayek: The Money Economy. New York, NY: Routledge, 2001.

Stenger, Victor J. Timeless Reality: Symmetry, Simplicity, and Multiple Universes. Amherst, NY: Prometheus Books, 2000.

Stenstad, Gail. Transformations: Thinking After Heidegger. Madison, WI: The University of Wisconsin Press, 2006.

Stephens, Mitchell. Imagine There's No Heaven: How Atheism Helped Created the Modern World. New York, NY: St. Martin's Press, 2014.

Stern, Jessica, and J. M. Berger. ISIS: The State of Terror. New York, NY: Harper Collins, 2015.

Stern, Sacha. Time and Process in Ancient Judaism. Littman Library of Jewish Civilization, 2003.

Stetzer, Ed. "The Rapid Rise of Nondenominational Christianity: My Most Recent Piece at CNN." At http://www.christianitytoday.com/edstetzer/2015/june/rapid-rise-of-non-denominational-ch ristianity-my-most-recen.html (accessed June 30, 2015).

Steyn, Mark, ed. “A Disgrace to the Profession.” Woodsville, NH: Stockade Books, 2015.

Stoddard, Kathryn. The Narrative Voice in the Theogony of Hesiod. Boston, MA: Brill, 2004.

Stone, Gene. Are You Believing the Once Saved Always Saved Lie? Can a Born Again Christian Go to Hell? Maitland, FL: Xulon, 2005.

Strauss, David A. The Living Constitution. Oxford, UK: Oxford University Press, 2010. 
Strawson, Galen. Freedom and Belief. Oxford, UK: Oxford University Press, 2010.

Strong, Carson. "Medicine and Philosophy: The Coming Together of an Odd Couple." In The Development of Bioethics in the United States, ed. Jeremy R. Garrett, Fabrice Jotterand, and D. Christopher Ralston, 117-136. New York, NY: Springer, 2013.

Stroud, Natalie Jomini. Niche News: The Politics of News Choice. Oxford, UK: Oxford University Press, 2011.

Stueber, Karsten R. Rediscovering Empathy: Agency, Folk Psychology, and the Human Sciences. Cambridge, MA: MIT Press, 2006.

Stump, David J. Conceptual Change and the Philosophy of Science: Alternative Interpretations of the A Priori. New York, NY: Routledge, 2015.

Stump, J. B. Science and Christianity: An Introduction to the Issues. Malden, MA: John Wiley \& Sons, 2017.

Styhre, Alexander. The Innovative Bureaucracy: Bureaucracy in an Age of Fluidity. New York, NY: Routledge, 2007.

Su, Ya-hui. "Lifelong Learning as Being: The Heideggerian Perspective." In Adult Education Quarterly Vol. 61 \#1 (2011): 57-72.

“The Constitution of Agency in Developing Lifelong Learning Ability: The 'Being' Mode." In Higher Education Vol. 62 (2011): 399-412.

Suarez, Antoine. "Any Nonlocal Model Assuming 'Local parts' Conflicts with Relativity." At https://arxiv.org/pdf/1304.4801.pdf (accessed September 3, 2017).

"Bohm's 'Quantum Potential' Can be Considered Falsified by Experiment." At https://arxiv.org/pdf/1410.2014.pdf (accessed October 8, 2014).

"Entanglement and Time." At https://arxiv.org/pdf/quant-ph/0311004.pdf (accessed October $4,2018)$.

.Leggett's Inequality, the Before-Before Experiment, and Free Will on the Part of Nature." At https://arxiv.org /pdf/0801.3050.pdf (accessed December 21, 2017).

. "Nonlocal 'Realistic' Leggett Models Can be Considered Refuted by the Before-Before Experiment." At http://www.quantumphil.org/ SuarezFO0P201R2.pdf (accessed May 27, 2008).

"Preface." In Is Science Compatible with Free Will?: Exploring Free Will and Consciousness in the Light of Quantum Physics and Neuroscience, ed. Antoine Suarez and Peter Adams, v-vii. New York, NY: Springer, 2013.

"Quantum Randomness, Free Will and Evolution," Powerpoint Presentation online at www.quantumphil.org (accessed 2010).

"Time and Nonlocal Realism: Consequences of the Before-Before Experiment." At https://arxiv.org/pdf/0708.1997.pdf (accessed August 15, 2007). 
Suarez, Xavier L. The Wealth of a Nation. Bloomington, IN: AuthorHouse, 2014.

Sullivan, Winnifred Fallers. The Impossibility of Religious Freedom. Princeton, NJ: Princeton University Press, 2018.

Suoranta, Juha, and Tere Vadén. Wikiworld. New York, NY: Pluto Press, 2010.

Sweeney, Conor. Sacramental Presence after Heidegger: Onto-theology, Sacraments, and the Mother's Smile. Eugene, OR: Cascade Books, 2015.

Swenson, Jr., Loyd S. The Ethereal Aether: A History of the Michelson-Morley-Miller Aether-Drift Experiments, 1880-1950. Austin, TX: University of Texas Press, 1972.

Swoboda, A. J. Subversive Sabbath: The Surprising Power of Rest in a Nonstop World. Grand Rapids, MI: Brazos Press, 2018.

Szabó, Árpád. The Beginnings of Greek Mathematics, tr. A. M. Ungar. Dordrecht, The Netherlands: Springer Science, 1978.

Szabó, László E. “Lorentzian Theories vs. Einsteinian Special Relativity-a Logico-empiricist Reconstruction." At http://philsci-archive.pitt.edu/5339/1/leszabo-lorein-preprint.pdf (accessed September 10, 2018).

Tabb, William K. Reconstructing Political Economy: The Great Divide in Economic Thought. New York, NY: Routledge, 1999.

Tagliaferre, Lewis. Theofatalism: Theology for Agnostics and Atheists. Bloomington, IN: iUniverse, 2013.

Tahir ul-Qadri, Muhammad. Islam and Freedom of Human Will. Lancashire, UK: Minhag Welfare Foundation, 2005.

Taibbi, Matt. The Divide: American Injustice in the Age of the Wealth Gap. New York, NY: Random House, 2014.

Talbot, Michael. The Holographic Universe. New York, NY: Harper Collins, 1991.

Talbott, Rick Franklin. Sacred Sacrifice: Ritual Paradigms in Vedic Religion and Early Christianity. Eugene, OR: Wipf and Stock, 1995.

Tallis, Frank. Hidden Minds: A History of the Unconscious. New York, NY: Arcade, 2011.

Tampio, Nicholas. Common Core: National Education Standards and the Threat to Democracy. Baltimore, MD: Johns Hopkins University Press, 2018.

Tan, Matthew John Paul. Justice, Unity, and the Hidden Christ: The Theopolitical Complex of the Social Justice Approach to Ecumenism in Vatican II. Eugene, OR: Pickwick, 2014.

Tanzer, Mark Basil. Heidegger: The Freedom of Dasein in the Early Heidegger. Amherst, NY: Humanity Books, 2002.

Tapp, Christian. "Eternity and Infinity." In God, Eternity, and Time, eds. Edmund Runggaldier and Christian Tapp, 99-116. New York, NY: Routledge, 2016. 
Tarozzi, Gino, and Alwyn van der Merwe. "Epilogue." In Open Questions in Quantum Physics: Invited Papers on the Foundations of Microphysics, eds. G. Tarozzi and A. van der Merwe, 391-394. Dordrecht, The Netherlands: D. Reidel Publishing, 1983.

Tausch, Arno. "Global Catholicism in the Age of Mass Immigration and the Rise of Populism: Comparative Analyses, Based on Recent 'World Values Survey' and 'European Social Survey Data."' At https://www.academia.edu/30068865/Global_Catholicism_in_the_age_of_mass_migration_and_ the_rise_of_populism_comparative_analyses_based_on_recent_World_Values_Survey_and_Europ ean_Social_Survey_data (accessed January 17, 2018).

Taylor, Charles. A Secular Age. Cambridge, MA: The Belknap Press of Harvard University Press, 2007.

Taylor, Ervin. "Creation, Evolution, and Theology: The Role of Method in Theological Accommodation [Review]/Fernando Canale." In Andrews University Seminary Studies Vol, 46, \# 1 (2008): 83-90.

Taylor V, John Wesley. "A Christian Critique of the Antimodern Quest: Challenge and Opportunity," in Journal of the Adventist Theological Society Vol. 25 \#2 (2014): 88-103.

Taylor, Mark C. Speed Limits: Where Time Went and Why We Have So Little Left. London, UK: Yale University Press, 2014.

Taylor, Paul C. Race: A Philosophical Introduction $2^{\text {nd }}$ ed. Malden, MA: Polity Press, 2013.

Taylor, Richard. "Can There Be a Science of Human Behavior? (A Response)." In Mind Science and History, eds. Howard Evans Kiefer and Milton Karl Munitz, 34-38. Albany, NY: State University of New York Press, 1970.

Tennent, Timothy C. "Paradigm Shifts in the Global Revitalization of Christianity." In Bibliotheca Sacra 175 \#699 (July-September, 2018): 338-349.

Terreros, Marco T. Theistic Evolution and Its Theological Implications. Medellin, Colombia, Marter Editions, 1994.

Tetlock, Philip E. Expert Political Judgement: How Good Is It? How Can We Know? Princeton, NJ: Princeton University Press, 2005.

Thackrah, John Richard. Politics Made Simple. London, UK: William Heinemann Ltd., 1987.

Thiselton, Anthony C. The Two Horizons: New Testament Hermeneutics and Philosophical Description. Grand Rapids, MI: Eerdmans, 1980.

Thom, René. Prédire n'est pas Expliquer. Paris, France: Flammarion, 1993.

Thomas, Robert L. Evangelical Hermeneutics: The New Versus the Old. Grand Rapids, MI: Kregel, 2002.

Thompson, Alden. Beyond Common Ground: Why Liberals and Conservatives Need Each Other. Nampa, ID: Pacific Press, 2009.

Thompson, Evan. Mind in Life: Biology, Phenomenology, and the Sciences of the Mind. Cambridge, MA: The Belknap Press of Harvard University Press, 2007. 
Thompson, George E. God Is Not Fair, Thank God!: Biblical Paradox in the Life and Worship of the Parish. Eugene, OR: Resource Publications, Wipf and Stock, 2014.

Thomson, Iain D. Heidegger, Art, and Postmodernity. Cambridge, UK: Cambridge University Press, 2011.

Heidegger on Ontotheology: Technology and the Politics of Education. New York, NY: Cambridge University Press, 2005.

. "Ontotheology." In Interpreting Heidegger: Critical Essays, ed. Daniel O. Dahlstrom, 106-132.

Cambridge, UK: Cambridge University Press, 2011.

. "Ontotheology? Understanding Heidegger's Destruktion of Metaphysics." In the International Journal of Philosophical Studies, 8 \#3 (2000): 297-327.

Thompson, Mark. "Trump and the Dark History of Straight Talk." At https://www.nytimes.com/2016/08/28/opinion/sunday/trump-and-the-dark-history-of-strai ght-talk.html (accessed February 9, 2017).

Thompson, Michael Guy. The Truth About Freud's Technique: The Encounter with the Real. New York, NY: New York University Press, 1994.

Thornton, Bruce. "The Dangerous Rise of Scientism." At

https://www.hoover.org/research/dangerous-rise-scientism (accessed June 8, 2016).

Thornton, Tim B. From Economics to Political Economy: The Problems, Promises, and Solutions of Pluralist Economics. New York, NY: Routledge, 2017.

Thrift, Nigel. Knowing Capitalism. London, UK: SAGE Publications, 2005.

Tiessen, Terrance L. Providence and Prayer; How Does God Work in the World? Downers Grove, IL: InterVarsity Press, 2000.

Tilby, Angela. Soul: God, Self and New Cosmology. New York, NY: Knopf Doubleday, 2010.

Timmons, Todd. Makers of Western Science: The Works and Words of 24 Visionaries From Copernicus to Watson and Crick. McFarland, 2012.

Timpe, Kevin, and Jonathan D. Jacobs. "Free Will and Naturalism: How to Be a Libertarian, and a Naturalist Too," in The Blackwell Companion to Naturalism, ed. Kelly James Clark, 319-335. Malden, MA: John Wiley \& Sons, 2016.

Togati, Teodoro Dario. Keynes and the Neoclassical Synthesis: Einsteinian Versus Newtonian Macroeconomics. New York, NY: Routledge, 1998.

Tonner, Philip. "Between Medieval and Modern Beholding: Heidegger, Deleuze and the Duns Scotus Affair." In Heresy and the Making of European Culture: Medieval and Modern Perspectives, eds. Andrew P. Roach and James R. Simpson, 413-428. New York, NY: Ashgate, 2013.

Heidegger, Metaphysics and the Univocity of Being. New York, NY: Continuum, 2010.

Tonning, Erick. Modernism and Christianity. New York, NY: Palgrave Macmillan, 2014. 
Tonstad, Sigve. The Lost Meaning of the Seventh Day. Berrien Springs, MI: Andrews University Press, 2009.

Topper, David. How Einstein Created Relativity out of Physics and Astronomy. New York, NT: Springer, 2013.

Torrance, Thomas. Theological and Natural Science. Eugene, OR: Wipf \& Stock, 2005.

Toulmin, Stephen. Cosmopolis: The Hidden Agenda of Modernity. Chicago, IL: The University of Chicago Press, 1990.

Return to Reason. Cambridge, MA: Harvard University Press, 2003.

Trabbic, Joseph Gerard. Aquinas, God, and Ontotheology. Ann Arbor, MI: ProQuest, 2008.

Tracy, Stephen V. Pericles: A Sourcebook and Reader. Berkeley, CA: University of California Press, 2009.

Trueman, Carl. The Real Scandal of the Evangelical Mind. Chicago, IL: Moody Publishers, 2011.

Trull, Timothy J., and Mitchell J. Prinstein. Clinical Psychology $8^{\text {th }}$ ed. Belmont, CA: Wadsworth, 2013.

Trundle, Robert. From Physics to Politics: The Metaphysical Foundations of Modern Philosophy. New York, NY: Routledge, 1999.

Tukianinen, Arto. “Pylkkö, nurjailija." At http://www.artotukiainen.net/pylkko_eurooppa.pdf (accessed April 5, 2011).

Tunstall, Dwayne A. Yes, But Not Quite: Josiah Royce's Ethico-Religious Insight. Bronx, NY: Fordham University Press, 2009.

Tuszynski, J. A., ed. The Emerging Physics of Consciousness. Berlin, Germany: Springer-Verlag, 2006.

Tymieniecka, Anna-Teresa, ed. Phenomenology World-Wide: Foundations, Expanding Dynamics, Life-Engagements: A Guide for Research and Study. Dordrecht, The Netherlands: Kluwer Academic Publishers, 2002.

Tyson, Paul. De-Fragmenting Modernity: Reintegrating Knowledge with Wisdom, Belief with Truth, and Reality with Being. Eugene, OR: Cascade Books, 2017.

. Returning to Reality: Christian Platonism for our Times. Cambridge, UK: The Lutterworth Press, 2015.

Tzamalikos, Panagiōtēs. Origen: Cosmology and Ontology of Time. Leiden, The Netherlands, Koninklijke Brill, 2006.

Tze-wan, Kwan. "The Human Sciences and Historicality: Heidegger and the Self-positioning of the Western Humanistic Tradition." In Space, Time and Culture, eds. David Carr and Chan-Fai Cheung, 31-56. Dordrecht, The Netherlands: Kluwer Academic, 2004.

Underhill, Evelyn. Mysticism. Stilwell, KS: Digireads.com Publishing, 2005. 
Unger, Roberto Mangabeira, and Lee Smolin. The Singular Universe and the Reality of Time. Cambridge, UK: Cambridge University Press, 2015.

Unno, Mark T. "Buddhism, Christianity, and Physics: An Epistemological Turn." In The Boundaries of Knowledge in Buddhism, Christianity, and Science, ed. Paul David Numrich, 80-104. Göttingen, Germany: Vandenhoeck \& Ruprecht, 2008.

Urminsky, Oleg. "The Role of Psychological Connectedness to the Future Self in Decisions Over Time." In Current Directions in Psychological Science Vol. 26 \#1 (2017): 34-39.

Urry, John. "Speeding Up and Slowing Down." In High-speed Society: Social Acceleration, Power, and Modernity, eds. Hartmut Rosa and William E. Scheurman, 179-200. University Park, PA: The Pennsylvania State University Press, 2009.

Uždavinys, Algis. Orpheus and the Roots of Platonism. London, UK: The Matheson Trust, 2011. . The Golden Chain: An Anthology of Pythagorean and Platonic Philosophy. Bloomington, IN: World Wisdom, 2004.

Vadén, Tere. "Between Žižek and Wagner: Retrieving the Revolutionary Potential of Music." In the International Journal of Žižek Studies Vol. 6 \#3 (2012): 1-12.

"Ethics and Gods: How is Local Ethics Possible." In Continental Philosophy Review 37 (2004): 407-438.

. "What is 'Local Thinking'?" In Re-ethnicizing the Minds?: Cultural Revival in Contemporary Thought, ed. Thorsten Botz-Bornstein and Jürgen Henglebrock, 219-236. Amsterdam, the Netherlands: Rodopi, 2006.

Heidegger, Žižek and Revolution. Rotterdam, The Netherlands: Sense Publishers, 2014.

Valasquez, Manuel. Philosophy: A Text with Readings. Boston, MA: Wadsworth, 2011.

Vallabhajosula, Brigitte. Murder in the Courtroom: The Cognitive Neuroscience of Violence. Oxford, UK: Oxford University Press, 2015.

Vallega-Neu, Daniela. Heidegger's Poietic Writings: From Contributions to Philosophy to The Event. Bloomington, IN: Indiana University Press, 2018.

Vallely, Paul. Pope Francis: The Struggle for the Soul of Catholicism. New York, NY: Bloomsbury, 2015.

Vallicella, William F. A Paradigm Theory of Existence: Onto-Theology Vindicated. New York, NY: Kluwer Academic Publishers, 2002.

Vamvacas, Constantine J. The Founders of Western Thought-The Presocratics: A Diachronic Parallelism between Presocratic Thought and Philosophy and the Natural Sciences, tr. Robert Crist. New York, NY: Springer Science, 2009.

Vanhoozer, Kevin J. Is There a Meaning in This Text? The Bible, the Reader, and the Morality of Literary Knowledge. Grand Rapids, MI: Zondervan, 1998.

Remythologizing Theology: Divine Action, Passion, and Authorship. Cambridge, UK: Cambridge University Press, 2012. 
. The Drama of Doctrine: A Canonical-linguistic Approach to Christian Theology. Louisville, KT: Westminster John Knox Press, 2005.

Vardy, Peter. The Puzzle of Evil. New York, NY: Routledge, 1997.

Varela, Charles. Science for Humanism: The Recovery of Human Agency. New York, NY: Routledge, 2009.

Varkey, Wilson. Role of the Holy Spirit in Protestant Systematic Theology: A Comparative Study of Karl Barth, Jürgen Moltmann, and Wolfhart Pannenberg. Langham Monographs, 2011.

Vaughan, David J. Give Me Liberty: The Uncompromising Statesmanship of Patrick Henry. Elkton, MD: Cumberland House, 1997.

Vaughn, Karen I. Austrian Economics in America: The Migration of a Tradition. Cambridge, NY: Cambridge University Press, 1994.

Vaughan-Lee, Llewellyn. Prayer of the Heart in Christian \& Sufi Mysticism. Point Reyes, CA: The Golden Sufi Center, 2012.

Vedder, Ben. Heidegger's Philosophy of Religion: From God to the Gods. Pittsburgh, PA: Duquesne University Press, 2007.

Velmans, Max. Understanding Consciousness. New York, NY: Routledge, 2009.

Verbeek, Peter-Paul. "Artifacts and Attachment: A Post-Script Philosophy of Mediation." In Inside the Politics of Technology: Agency and Normativity in the Co-Production of Technology and Society, ed. Hans Harbers, 125-146. Amsterdam, The Netherlands: Amsterdam University Press, 2005.

What Things Do: Philosophical Reflections on Technology, Agency, and Design. State College, PA: Pennsylvania State University Press, 2005.

Vermeulen, Timotheus, and Robin van den Akker. "Notes on Metamodernism." In Journal of Aesthetics \& Culture Vol. 2\#1, 5677 (2010): 1-14.

Vesna, Victoria. "Towards a Third Culture or Working in Between." At http://vv.arts.ucla.edu/publications/publications/00-01/ThirdCulture/ThirdCulture.htm (accessed February 15, 2018).

Ville, Jacques de. "The Gift and the Meaning-Giving Subject: A Reading of Given Time." In Prospects of Legal Semiotics, eds. Anne Wagner and Jan M. Broekman, 79-106. New York, NY: Springer, 2010.

Vincent, James. "Former Facebook Exec Says Social Media is Ripping Apart Society." At https://www.theverge.com/2017/12/11/16761016/former-facebook-exec-ripping-apart-socie ty (accessed December 11, 2017.

Vitiello, Giuseppe. My Double Unveiled. Amsterdam, The Netherlands: John Benjamins, 2001.

Vogel, Lawrence. The Fragile "We": Ethical Implications of Heidegger's Being and Time. Evanston, IL: Northwestern University Press, 1994.

Vogel, Winfried. The Cultic Motif in the Book of Daniel. New York, NY: Peter Lang, 2010. 
Vrahimis, Andreas. "Philosophy and Humanistic Education: J. S. Mill's Catastrophic Pedagogy.” In Pedagogies of Disaster, ed. Vincent W. J. Van Gerven Oei, Adam Staley Groves, and Nico Jenkins, 299-330. Brooklyn, NY: Punctum Books, 2013.

Vu, Thuy T., and Gloria Dall'Alba. "Becoming Authentic Professionals: Learning for Authenticity." In 'Becoming' a Professional: An Interdisciplinary Analysis of Professional Learning, ed. Lesley Scanlon, 95-108. New York, NY: Springer, 2011.

Vucinich, Alexander. Einstein and Soviet Ideology. Stanford, CA: Stanford University Press, 2001.

Wade, Jenny. Changes of Mind: A Holonomic Theory of the Evolution of Consciousness. Albany, NY: State University of New York Press, 1996.

Wainwright, William J. "Introduction." In God, Philosophy, and Academic Culture: A Discussion between Scholars in the AAR and the APA, ed. William J. Wainwright, 3-12. Oxford, UK: Oxford University Press, 1996.

Wajcman, Judy. Pressed for Time: The Acceleration of Life in Digital Capitalism. Chicago, IL: The University of Chicago Press, 2015.

Waldron, Jeremy. Political Political Theory: Essays on Institutions. New York, NY: Harvard University Press, 2016.

Walker, Adrian J. “'Constitutive Relations': Toward a Spiritual Reading of Physis." In Being Holy in the World: Theology and Culture in the Thought of David L. Schindler, eds. Nicholas J. Healy, Jr., and David C. Schindler, 123-161. Grand Rapids, MI: Eerdmans, 2011.

Wallace, Ronald S. The Atoning Death of Christ. Eugene, OR: Wipf and Stock, 1997.

Walleczek, Jan, Gerhard Grössing, Paavo Pylkkänen, and Basil Hiley, eds. Emergent Quantum Mechanics: David Bohm Centennial Perspectives. Basel, Switzerland: MDPI, 2019.

Wallerstein, Immanuel. World-Systems Analysis: An Introduction. Durham, NC: Duke University Press, 2004.

Wallis, Jim. Rediscovering Values: On Wall Street, Main Street, and Your Street. New York, NY: Howard Books, 2010.

Walls, Jerry L., and Joseph R. Dongell. Why I Am Not a Calvinist. Downers Grove, IL: InterVarsity Press, 2004.

Walsh, Albert J. D. A Pastoral Proposal for an Evangelical Theology of Freedom: A Respectful Response to the Expressed Hope of Dr. Karl Barth. Eugene, OR: Wipf \& Stock, 2013.

Walters, Nelson. Rapture: Case Closed? Ready for Jesus Publications, 2017.

Walton, John H. The Lost World of Genesis One: Ancient Cosmology and the Origins Debate. Downers Grove, IL: IVP Press, 2009.

Walton, John H., with N. T. Wright. The Lost World of Adam and Eve: Genesis 2-3 and the Human Origins Debate. Downers Grove, IL: InterVarsity Press, 2015. 
Walton, John H., and Tremper Longman III. The Lost World of the Flood: Mythology, Theology, and the Deluge Debate. Downers Grove, IL: InterVarsity Press, 2018.

Walvoord, John F. “Is Moral Progress Possible?” In Bibliotheca Sacra 175 \#699 (July-September, 2018): 259-270.

Walzer, Michael. In God's Shadow: Politics in the Hebrew Bible. London, UK: Yale University Press, 2012.

Wanliss, James. Resisting the Green Dragon: Dominion, Not Death. Burke, VA: Cornwall Alliance, 2010.

Wapshott, Nicholas. Keynes - Hayek: The Clash that Defined Modern Economics. New York, NY: W. W. Norton, 2011.

Ward, Keith. Religion and Creation. Oxford, UK: Oxford University Press, 2002.

Ward, Pete. Gods Behaving Badly: Media, Religion, and Celebrity Culture. Waco, TX: Baylor University Press, 2011.

Ware, Bruce A. An Evangelical Reexamination of the Doctrine of the Immutability of God.Ann Arbor, MI: University Microfilms, 1987; Ph.D. Dissertation, Fuller Theological Seminary, 1984.

Warehime, Nancy. To Be One of Us: Cultural Conflict, Creative Democracy, and Education. Albany, NY: State University of New York Press, 1993.

Warrick, Joby. Black Flags: The Rise of ISIS. New York, NY: Anchor Books, 2016.

Washington, Ellis. The Progressive Revolution: History of Liberal Fascism through the Ages Vo. 5. Lanham, MD: Hamilton Books, 2017.

Waters, Brent. From Human to Posthuman: Christian Theology and Technology in a Postmodern World. New York, NY: Routledge, 2006.

Waters, Larry J. “Paradoxes in the Pauline Epistles.” In Bibliotheca Sacra 167 (October-December 2010): 423-441.

Watkins, Stephen. Jesus Our Jewish Messiah Vol. One: Once in Time. Flagstaff, AZ: Lessons from Heaven Publications, 2009.

Watson, Bradley C. S. Living Constitution, Dying Faith: Progressivism and the New Science of Jurisprudence. Wilmington, DE: ISI Books, 2009.

Watson, James R. "Beyond Ontic-Ontological Relations." In Heidegger on Science, ed. Trish Glazebrook, 47-66. Albany, NY: State University of New York, 2012.

Waugh, Patricia. "Thinking in Literature: Modernism and Contemporary Neuroscience." In The Legacies of Modernism: Historicising Postwar and Contemporary Fiction, ed. David James, 75-95. Cambridge, UK: Cambridge University Press, 2012.

Webel, Charles P. The Politics of Rationality: Reason Through Occidental History. New York, NY: Routledge, 2014. 
Webber, Jeremy. "The Meanings of Consent." In Between Consenting Peoples: Political Community and the Meaning of Consent, eds. Jeremy Webber, Colin M. Macleod, 3-44. Vancouver, BC: The University of British Columbia, 2010.

Webster, Scott, and Ann Ryan. Understanding Curriculum: The Australian Context. Sydney, NSW: Cambridge University Press, 2014.

Wegerif, Rupert. "From Dialectic to Dialogic." In Theories of Learning and Studies of Instructional Practice, ed. Timothy Koschmann, 201-222. New York, NY: Springer Science, 2011.

Wegter-McNelly, Kirk. The Entangled God: Divine Relationality and Quantum Physics. New York, NY: Routledge, 2011.

Weinberg, Steven. "Changing Attitudes and the Standard Model." In The Rise of the Standard Model: Particle Physics in the 1960s and 1970s, eds. Lillian Hoddeson, Laurie Brown, Michael Riordan, and Max Dresden, 36-44. Cambridge, UK: Cambridge University Press, 1997.

“The Trouble with Quantum Mechanics." At http://www.nybooks.com/articles/2017/01/19/trouble-with-quantum-mechanics/ (accessed January 19, 2017).

Weinert, Friedel. The Scientist as Philosopher: Philosophical Consequences of Great Scientific Discoveries. Berlin, Germany: Springer-Verlag, 2005.

Weisheipl, James A. "The Nature, Scope, and Classification of the Sciences." In Science in the Middle Ages, ed. David C. Lindberg. Chicago, IL: The University of Chicago Press, 1978.

Weiss, Charles. The Metaphysical Implications of Modern Physics. New York, NY: New York University, 1931.

Weiss, Michael, and Hassan Hassan. ISIS: Inside the Army of Terror, updated ed. New York, NY: Regan Arts, 2016.

Weizenbaum, Joseph. "Limits in the Use of Computer Technology: Need for a Man-Centered Science." In Toward the Recovery of Wholeness: Knowledge, Education, and Human Values, ed. Douglas Sloan, 149-158. New York NY: Teachers College Press, 1984.

Welker, Michael. Quests for Freedom: Biblical-Historical-Contemporary. Göttingen, Germany: Neukirchener Verlagsgesellschaft, 2015.

Wenders, Wim, and Mary Zournazi. Inventing Peace: A Dialogue on Perception. New York, NY: Palgrave Macmillan, 2013.

Westphal, Merold. "Onto-theology, Metanarrative, Perspectivism, and the Gospel." In Christianity and the Postmodern Turn: Six Views, ed. Myron Penner, 141-156. Grand Rapids, MI: Brazos Press, 2005.

. Overcoming Onto-Theology: Toward a Postmodern Christian Faith. New York, NY: Fordham University Press, 2001.

Wheeler, John Archibald. At Home in the Universe. American Institute of Physics, 1996. 
Whitaker, Andrew. Einstein, Bohr and the Quantum Dilemma: From Quantum Theory to Quantum Information $2^{\text {nd }}$ ed. Cambridge, UK: Cambridge University Press, 2006.

White, Andrew Dickson. History of the Warfare of Science with Theology in Christendom, 2 vols. New York, NY: D. Appleton, 1922, 1896.

White, Curtis. The Science Delusion: Asking the Big Questions in a Culture of Easy Answers. Brooklyn, NY: Melville House, 2013.

White, Ellen. Early Writings. Silver Spring, MD: Ellen G. White Estate, Inc., 1882. . Christ's Object Lessons. Oakland, CA: Pacific Press, 1900. . Education. Silver Spring, MD: Ellen G. White Estate., 1903. . Evangelism (Washington, D.C.: Review and Herald Publishing Association, 1946). . God's Amazing Grace. Hagerstown, MD: Review and Herald, 1973. . Spalding and Magan Collection. Silver Spring, MD: Ellen G. White Estate, Inc., 1985. Selected Messages Book 3. Silver Spring, MD: Ellen G. White Estate, Inc., 1980. . Steps to Christ. Silver Spring, MD: Ellen G. White Estate, Inc., 1892. Testimonies for the Church Vol. 4. Mountain View, CA: Pacific Press, 1948. . Testimonies to Ministers and Gospel Workers. Silver Spring, MD: Ellen G. White Estate, Inc., 1923.

. The Ministry of Healing. Silver Spring, MD: Ellen G. White Estate, Inc., 1905. . The Spirit of Prophecy Volume Four. Silver Spring, MD: Ellen G. White Estate, Inc., 1884. . "The Test of Loyalty." In The Signs of the Times February 13 (1896). "The Work of the Holy Spirit in Conversion." The Signs of the Times March 8 (1910). . "True Worth." In The Review and Herald December 29 (1896). .Man's Obligation to God." In The Signs of the Times April 3 (1884). Manuscript Releases Vol. 14 (1990).

"Ms 69, 1897." At https://egwwritings.org/?ref=en_Ms69-1897.56\&para=6793.66 (accessed January 10, 2017).

."Lt 5, 1898.” At https://egwwritings.org/?ref=en_Lt5-1898.13\&para=5043.19 (accessed January 10, 2017).

White, Lawrence H. The Clash of Economic Ideas: The Great Policy Debates and Experiments of the Last Hundred Years. Cambridge, UK: Cambridge University Press, 2012. 
White, Michael. "The Humanities Are In Crisis - Science Is Not." At http://www.science20.com/adaptive_complexity/humanities_are_crisis_science_not (accessed April 27, 2009).

White, Vernon. Atonement and Incarnation: An Essay in Universalism and Particularity. Cambridge, UK: Cambridge University Press, 1991.

Whitrow, G. J. "Reflections on the History of the Concept of Time." In The Study of Time: Proceedings of the First Conference of the International Society for the Study of Time, eds. J. T. Faser, F. C. Haber, and G. H. Müller, 1-11. New York, NY: Springer-Verlag, 1972.

Whittaker, Sir Edmund. A History of the Theories of Aether and Electricity: Vol. 1 The Classical Theories, and Vol. 2 The Modern Theories (1900-1926) in one volume. Mineola, NY: Dover, 1951.

Wickman, Matthew. "Alba Newton and Alasdair Gray." In Scotland as Science Fiction, ed. Caroline McCracken-Flesher, 171-184. Lanham, MD: Bucknell University Press, 2012.

Widder, Nathan. Reflections on Time and Politics. University Park, PA: The Pennsylvania State University, 2008.

Wight, Colin. "Realism, Science and Emancipation." In Realism, Philosophy and Social Science, eds. Kathryn Dean, Jonathan Joseph, John Michael Roberts, and Colin Wight, 32-64. New York, NY: Palgrave Macmillan, 2006.

Wikipedia, The Free Encyclopedia. “Ontotheology.” At http://en.wikipedia.org/wiki/Ontotheology (accessed January 19, 2011).

Wilber, Ken, ed. Quantum Questions: Mystical Writings of the World's Greatest Physicists. Boston, MA: Shambhala, 2001.

Wilberding, James, and Christoph Horn. Neoplatonism and the Philosophy of Nature. Oxford, UK: Oxford University Press, 2012.

Wilch, John R. Time and Event: An Exegetical Study of the Use of "èth in the Old Testament in Comparison to Other Temporal Expressions in Clarification of the Concept of Time. Leiden, The Netherlands: E. J. Brill, 1969.

Wilczek, Frank. "The Third Culture: Is Quantum Physics, like Science and Literature, in a World of Its Own?" In Nature 424 (August 2003): 997-998.

Williams, John R. Martin Heidegger's Philosophy of Religion. Canadian Corporation for Studies in Religion, 1977.

Williams, Richard N. "Introduction." In Scientism: The New Orthodoxy, eds. Richard N. Williams and Daniel N. Robinson, 1-22. London, UK: Bloomsbury, 2015.

Wilkinson, David. Christian Eschatology and the Physical Universe. New York, NY: T\&T Clark, 2010.

Wilshire, Bruce. The Primal Roots of American Philosophy: Pragmatism, Phenomenology, and Native American Thought. University Park, PA: The Pennsylvania State University Press, 2000. 
Wilson, Fred. "Placing Bergmann." In Ontology and Analysis: Essays and Recollections about Gustav Bergmann, eds. Laird Addis, Greg Jesson, and Erwin Tegtmeier, 185-205. Piscataway, NJ: Rutgers University, 2007.

Wilson, Sean. The Flexible Constitution. Lanham, MD: Lexington Books, 2013.

Windley-Daoust, Jerry. Primary Source Readings in Catholic Social Justice. Winona, MN: Saint Mary's Press, 2007.

Wintgens, Luc J. Legisprudence: Practical Reason in Legislation. New York, NY: Routledge, 2016.

Witham, Larry A. Where Darwin Meets the Bible: Creationists and Evolutionists in America. Oxford, UK: Oxford University Press, 2002.

Witteveen, Hendrikus Johannes. Universal Sufism. Dorset, UK: Element, 1997.

Woessner, Martin. Heidegger in America. New York, NY: Cambridge University Press, 2011.

Wolcher, Louis E. Beyond Transcendence in Law and Philosophy. Abingdon, Oxfordshire, UK: Birkbeck Law Press, 2005.

Law's Task: The Tragic Circle of Law, Justice and Human Suffering. New York, NY: Routledge, 2016.

The Ethics of Justice Without Illusions. New York, NY: Routledge, 2016.

Wolf, Susan. Freedom Within Reason. New York, NY: Oxford University Press, 1990.

Wolfe, Cary. What is Posthumanism? Minneapolis, MN: University of Minnesota Press, 2010.

Wood, David. The Deconstruction of Time. Evanston, IL: Northwestern University Press, 2001.

Thinking After Heidegger. Malden, MA: Blackwell Publishers, 2002.

Wood, Kerry. Fake News; MSM: The Illegitimate Press. DHSG Press, 2017.

Wood, Laurence W. God and History: The Dialectical Tension of Faith and History in Modern Thought. Lexington, KY: Emeth Press, 2005.

Wood, Patrick M. Technocracy Rising: The Trojan Horse of Global Transformation. Mesa, AZ: Coherent Publishing, 2015.

Woods, Thomas E. The Church and the Market: A Catholic Defense of the Free Economy. Oxford, UK: Lexington Books, 2005.

Woody, J. Melvin. Freedom's Embrace. University Park, PA: The Pennsylvania State University Press, 1998.

Wootton, David. "Introduction." In Divine Right and Democracy: An Anthology of Political Writing in Stuart England, ed. David Wootton, 21-90. Indianapolis, IN: Hackett Publishing, 2003. 
. "Hobbes, the Reformation, and the Scientific Revolution." In Modern Political Thought: Readings from Machiavelli to Nietzsche, ed. David Wootton, 93-302. Indianapolis, IN: Hackett Publishing, 1998.

Worthington Jr., Everett L. Coming to Peace with Psychology: What Christians Can Learn from Psychological Science. Downers Grove, IL: InterVarsity Press, 2010.

Wrathall, Mark A. Heidegger and Unconcealment: Truth, Language, and History. Cambridge University Press, 2011.

Wright, G. Ernest. God Who Acts: Biblical Theology as Recital. London, UK: SCM Press, 1952.

Wright, N. T. Evil and the Justice of God. Downers Grove, IL: InterVarsity Press, 2006.

Wright, R. K. McGregor. No Place for Sovereignty: What's Wrong with Freewill Theism. Downers Grove, IL: InterVarsity Press, 1996.

Wright, Rob. We Hold These Truths to be Self Evident..: Where is the Self in Government? Raleigh, NC: 2013.

Yasue, Kunio, Mari Jibu, Tarcisio Della Senta, ed. No Matter, Never Mind. Amsterdam, The Netherlands: John Benjamins, 2002.

Yergin, Daniel, and Joseph Stanislaw. The Commanding Heights: The Battle Between Government and the Marketplace That Is Remaking the Modern World. New York, NY: Simon \& Schuster, 1998.

Yomtov, Jesse. "Would Bernie Sanders have Defeated Donald Trump?" At https://www.usatoday.com/story/news/politics/onpolitics/2016/11/09/bernie-sanders-dona ld-trump/93530352/ (accessed November 9, 2016).

Young, Matt, and Taner Edis, eds. Why Intelligent Design Fails: A Scientific Critique of the New Creationism. New Brunswick, NJ: Rutgers University Press, 2006.

Young, Robert M. "Science and the Humanities in the Understanding of Human Nature." (May 25, 2000). At http://human-nature.com/ rmyoung/papers/pap131h.html (accessed January 30, 2013).

Younker, Michael F. "Adventist Eschatology in Relation to the Religious Left and the Religious Right." In Journal of the Adventist Theological Society Vol. 23 \#2 (Autumn, 2012): 190-242.

."A Dialogue Between Contemporary Perspectives and Ellen White on Divine Action and Quantum Physics." In Journal of the Adventist Theological Society Vol. 23 \#1 (2012):120-154.

"From Metaphysics to Templephysics: Situating the Significance of Fernando Canale's Contributions for the 'Christian Philosopher.'” In Scripture and Philosophy: Essays Honoring the Work and Vision of Fernando Luis Canale, eds. Tiago Arrais, Kenneth Bergland, and Michael F. Younker, 194-259. Berrien Springs, MI: Adventist Theological Society Publications, 2016.

"The American Socio-Political Spider Web and the Rise of Global Christianity." In Journal of the Adventist Theological Society Vol. 25 \#1 (2014): 132-188.

Younker, Randall W., and Richard M. Davidson. "The Myth of the Solid Heavenly Dome: Another Look at the Hebrew Raqia." In Andrews University Seminary Studies \#1 (2011): 125-147. 
Yourgrau, Palle. A World Without Time: The Forgotten Legacy of Gödel and Einstein. Cambridge, MA: Basic Books, 2005.

Zack, Naomi. The Handy Philosophy Answer Book. Canton, MI: Visible Ink Press, 2010.

Zagorin, Perez. Francis Bacon. Princeton, NJ: Princeton University Press, 1998.

Zagzebski, Linda Trinkaus. The Dilemma of Freedom and Foreknowledge. Oxford, UK: Oxford University Press, 1991.

Zakaria, Rafiq. Discovery of God. Tardeo, Mumbai: Popular Prakashan, 2000.

Zakay, Dan, and Dida Fleisig. "Psychological Time, Time Perspective, Culture and Conflict." In Culture and Neural Frames of Cognition and Communication, ed. Shihui Han and Ernst Pöppel, 123-138. New York, NY: Springer, 2011.

Zedania, Giga. "Beyond the Two Cultures: Foreword." In Gigi Tevzadze, Evolution of Social Behavior to Homo and After, tr. P. J. Hillery, xiv-xviii. Tbilisi, Georgia: Ilia State University Press, 2013.

Zeilinger, Anton. "Quantum Physics: Ontology or Epistemology?" In The Trinity and an Entangled World: Relationality in Physical Science and Theology, ed. John C. Polkinghorne, 32-40. Grand Rapids, MI: Eerdmans, 2010.

Zetterberg, Hans L. Sociological Endeavor, eds. Richard Swedberg and Emil Uddhammar. New Brunswick, NJ: Transaction Publishers, 1999.

Zhang, Wei-Bin. American Civilization Portrayed in Ancient Confucianism. New York, NY: Algora Publishing, 2003.

Zimmermann, Jens. Humanism and Religion: A Call for the Renewal of Western Culture. New York, NY: Oxford University Press, 2012.

. Incarnational Humanism: A Philosophy of Culture for the Church in the World. Downers Grove, IL: InterVarsity Press, 2012.

Zimmerman, Michael E. Heidegger's Confrontation with Modernity: Technology, Politics, and Art. Bloomington, IN: Indiana University Press, 1990.

Žižek, Slavoj. The Parallax View. Cambridge, MA: Massachusetts Institute of Technology Press, 2006.

Žižek, Slavoj, with F. W. J. Von Schelling. The Abyss of Freedom: Ages of the World: An Essay, tr. Judith Norman. Grand Rapids, MI: The University of Michigan Press, 1997.

Zizioulas, John. "Relational Ontology: Insights from Patristic Thought." In The Trinity and an Entangled World: Relationality in Physical Science and Theology, ed. John C. Polkinghorne, 146-156. Grand Rapids, MI: Eerdmans, 2010.

Zukav, Gary. The Dancing Wu Li Masters: An Overview of the New Physics. Ebury Publishing, 2012.

Zwick, Mark and Louise. "Pope Wants a Church of the Poor and For the Poor, but a Well-known Catholic Writer Rejects Saint Francis of Assisi.” At http://cjd.org/2013/07/05/pope-wants-a-church-of-the-poor-and-for-the-poor-but-a-well-kno wn-catholic-writer-rejects-saint-francis-of-assisi/ (accessed September 10, 2017). 
Zyga, Lisa. "Scientists Suggest Spacetime has No Time Dimension." At https://phys.org/news/2011-04-scientists-spacetime-dimension.html (accessed August 8, 2017).

.Quantum Mysticism: Gone but Not Forgotten." At https://phys.org/news/2009-06-quantum-mysticism-forgotten.html (accessed June 9, 2017). 